\title{
FRANZ DOFLEIN
}
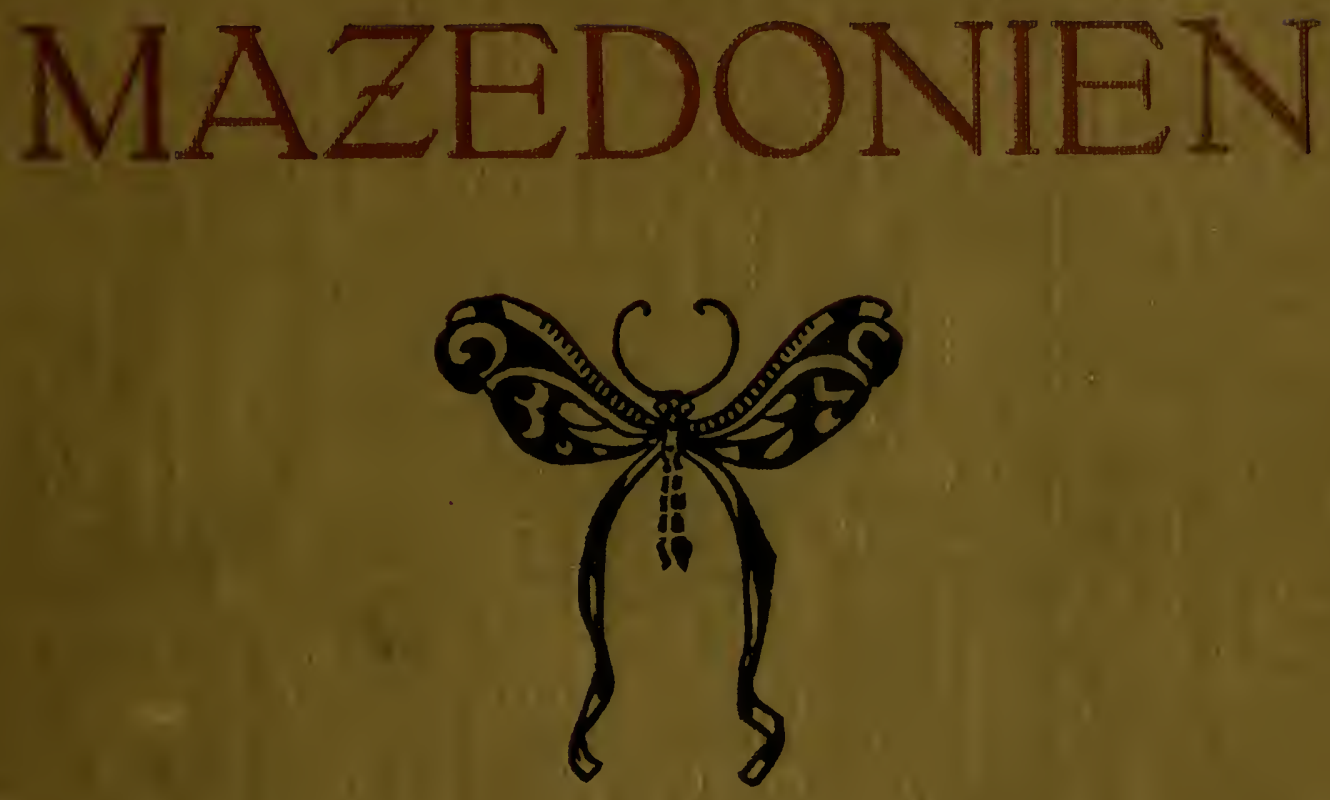

GUSTAV FISCHER - JENA 
This book must not be taken from the Library building.

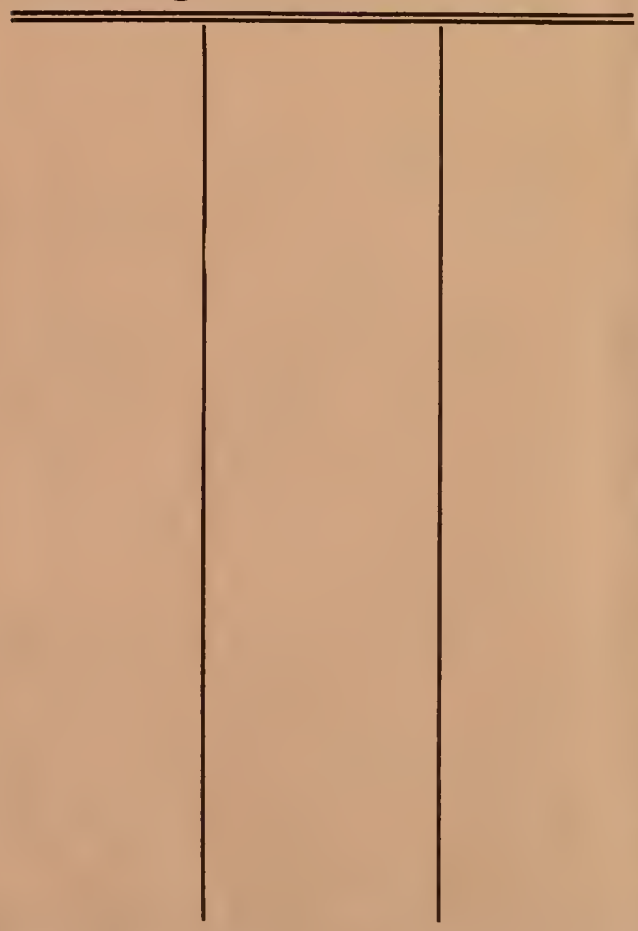






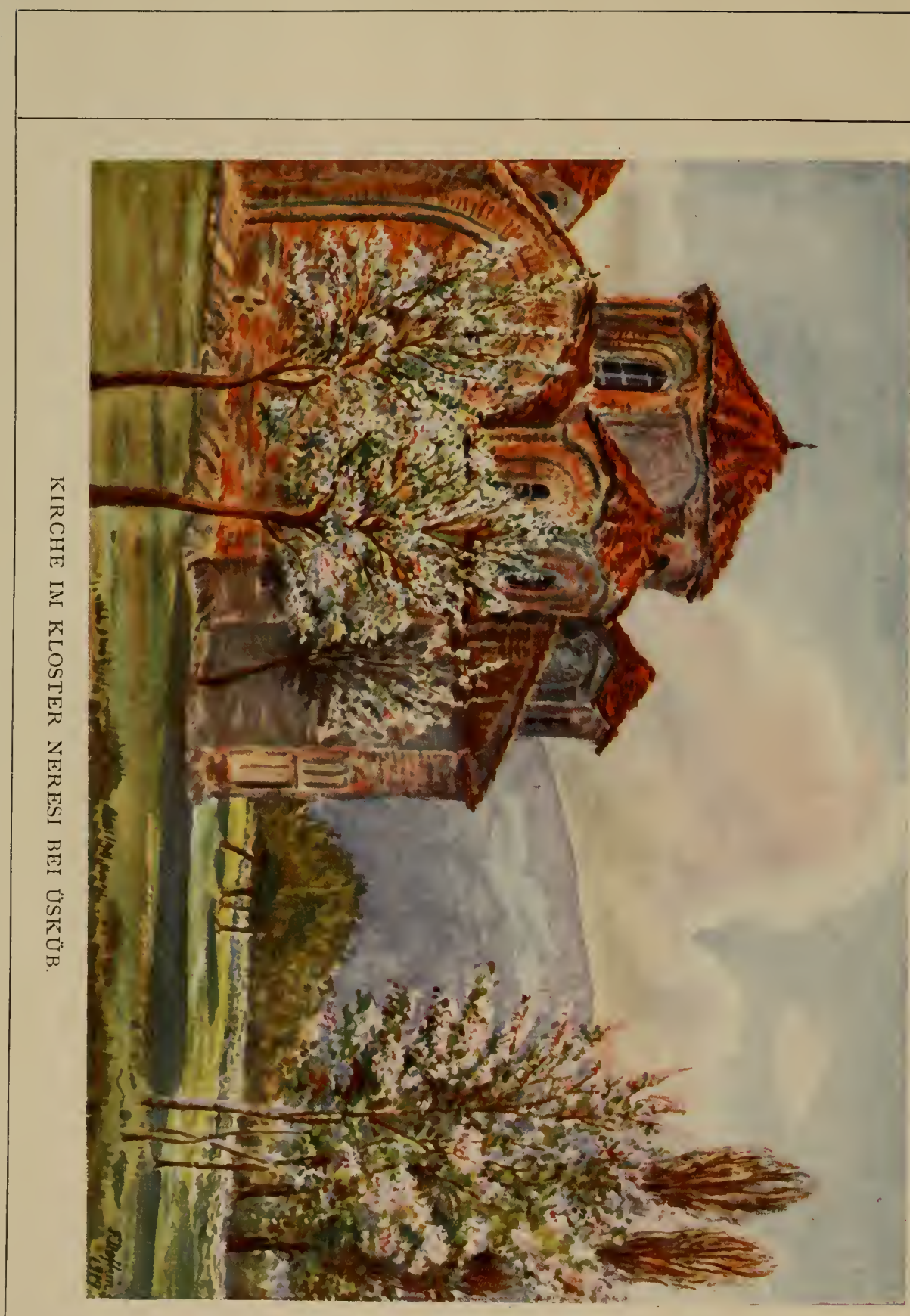




\section{MAZEDONIEN}

ERLEBNISSE UND BEOBACHTUNGEN

EINES NATURFORSCHERS

IM GEFOLGE DES DEUTSCHEN HEERES

VON

Dr. FRANZ DOFLEIN

o. ö. PROFESSOR DER ZOOLOGIE AN DER UNIVERSITÄT BRESLAU

MIT 279 ABBILDUNGEN IM TEXT

UND 4 FARBIGEN UND 12 SCHWARZEN TAFELN

JENA

VERLAG VON GUSTAV FISCHER

1921 
ALLE RECHTE VORBEHALTEN 
DEN MANNSCHAFTEN, ÄRZTEN UND OFFIZIEREN

\section{DES MAZEDONISCHEN HEERES}

\section{GEWIDMET}





\section{VORWORT}

$W^{\text {ie }}$

ie nach meiner amerikanischen und ostasiatischen Reise, war es nach meinem Aufenthait in Mazedonien in den Jahren 1917 und 1918 mir ein seelisches Bedurfnis das, was ich dort erlebt und erfahren hatte, in einem Werk zusammenzufassen. Vielleicht ist es mehr eine künstlerische Neigung, welche sich in dem Drang ausspricht, einem großen, nachhaltigen Erlebnis eine Form zu geben; dem Gelehrten, dem Naturforscher hätte es näher gelegen, die Bearbeitung aller Forschungsresultate abzuwarten, um nach einer Reihe von Jahren die Gesamtergebnisse zusammengefaßt vorzulegen.

Überlegungen zweierlei Art waren es, welche mich veranlaßten, kurz nach meiner Heimkehr an die Ausarbeitung und Darstellung von Mazedonien heranzutreten. Zunächst, wie bei meiner "Ostasienfahrt" der Wunsch, noch unter dem frischen Eindruck meiner Erlebnisse die geeignetste Form der Darstellung zu finden. Während noch die Buntheit der Landschaften, die Bewegtheit der Vorgänge ungealtert in meinem Bewußtsein hafteten, sollten sie Gestaltung finden.

Dazu kam die Verpflichtung gegenüber den einstigen Angehörigen der mazedonischen Armee, die mir draußen soviel geholfen hatten, ihnen ein zusammenfassendes Bild des Landes zu geben, in welchem sie Jahre ihres Lebens in treuer Pflichterfüllung verbracht hatten, in militärischem Dienst, als Ärzte und Beamte. Es gibt keine solche Darstellung in deutscher Sprache; es ist doch eine merkwürdige Tatsache, daß Mazedonien in Europa vor dem Kriege zu den unbekanntesten Teilen der Erde gehörte, und daß es keine zusammenfassende Schilderung dieses Landes gab. Ich habe das Bewußtsein, durch mein Buch ein Stück von Europa, welches bisher nur einem kleinen Kreis von Spezialisten mehr oder minder bekannt war, vor den Augen einer größeren Öffentlichkeit zu entschleiern.

Was die Resultate der Forschungen anlangt, so ist an ihnen während des Krieges eine größere Anzahl von Fachleuten in den verschiedensten Wissenszweigen beteiligt gewesen. Deren Veröffentlichung wird sich auf Jahrzehnte erstrecken. Das konnte 
und wollte ich nicht abwarten. Die zoologischen Ergebnisse konnten sich dank der Mitarbeit zahlreicher Fachmänner soweit sichten lassen, daß ein Überblick über sie in meinem Buch gegeben werden konnte. Auch von den botanischen Forschungen stand mir alles, was für meine Darstellung wesentlich war, durch das kollegiale Entgegenkommen von Prof. Bornmüller zur Verfügung. So war ich in der Lage, in einem Naturforscherbuch ein. Bild des Landes, einen Umriß der Probleme, die dem Biologen das Zentrum der Balkanhalbinsel bietet, zu entwerfen.

Dabei bin ich einer ganzen Reihe von Mitarbeitern zu Dank verpflichtet. Diejenigen, welche draußen mitwirkten, sind in den einzelnen Kapiteln genannt, so auch die verschiedenen Gelehrten, welche mitgebrachtes Material schon so weit bearbeiteten, daß die Resultate angeführt werden konnten.

Für die Durchführung der Expeditionen bin ich außer der Heeresleitung, deren Entgegenkommen an vielen Stellen des Buches hervorgehoben ist, dem badischen Kultusministerium und der Bayerischen Akademie der Wissenschaften für Zuweisung von Geldmitteln zu Dank verpflichtet, welche einige der Gebirgsexpeditionen ermöglichten. Ersterem habe ich ferner die Großzügigkeit bei der Urlaubsgewährung zu danken.

Der reiche Bilderschmuck des Buches besteht meist aus von mir selbst gefertigten photographischen Aufnahmen von Landschaften und Naturgegenständen. Dazu kommen vier farbige Bilder nach meinen Aquarellen. Eine Anzahl Photographien verdanke ich den Kameraden beim Mazedonischen Heer Dr. Laser, Dr. Burmester, Dr. Nachtsheim, Prof. Müller, Dr. Gripp, Dr. Hansen, Dr. Frischholz. Ihnen allen sei an dieser Stelle gedankt. Manche nicht im Text genau nach Urheber bezeichnete Bilder rühren von Soldaten her, deren Namen ich nicht weiß, oder haben andere mir unbekannte Urheber. Das sind aber nur einige wenige. Die Tierbilder sind von den Frls. Gottschalk, Schönfeld und Limprecht, die meisten von dem Maler P. Rose angefertigt.

Meinem Verleger Dr. Gustav Fischer bin ich für sein Entgegenkommen bei der Ausstattung des Werkes, die heutzutage etwas ganz Besonderes darstellt, sehr zu Dank verpflichtet.

Breslau, im November 1920. 


\section{INHALTSVERZEICHNIS.}

Seite

Erstes Kapitel: Im IVardartal. Frübling in Mazedonien . . . . I I

Zweites Kapitel: Kaluckova und das Forscherhaus ........ 10

Drittes Kapitel: Die Ebene ron Hudova . . . . . . . . . 26

Viertes Kapitel: Mravinca und sein Feldlazaret. Mazedonische Schildkröten und Fische . . . . . . . . . . 42

Fünftes Kapitel: Die Plaguša Planina ... . . . . . . 57

Sechstes Kapitel: Das Nikolatal . . . . . . . . . . 78

Siebentes Kapitel: Fabrt ins Gebiet der Mala Rupa . . . . . . . . 96

Achtes Kapitel: Regenwürmer und Ackererde in Mazedonien . . 119

Neuntes Kapitel: Das geliebte Veles . . . . . . . . . . I30

Zehntes Kapitel: Am Doiransee . . . . . . . . . . . . 141

Elftes Kapitel: Dre mazedonischen Ameisen und ihre Bauten . . I 58

Zwölftes Kapitel: Die Schluchten des Balkan . . . . . . . 182

Dreizehntes Kapitel: Im Hain Mamre. Strumiza. Belasiza Planina. Gewgeli ........... . 198

Vierzehntes Kapitel: Die Expedition in den Schardakb . . . . . 116

Fünfzehntes Kapitel: Die Bevölkerung Mazedoniens . . . . . . . 245

Sechzehntes Kapitel: Üsküb als Standquartier . . . . . . . . . 256

Siebzehntes Kapitel: Die Bulgaren in Mazedonien . . . . . . . . 270

Achtzehntes Kapitel: Der Tschifflik von Bardovce. . . . . . . . 284

Neunzehntes Kapitel: Beobachtungen an mazedonischen Spinuen . . . 30r

Zwanzigstes Kapitel: Das Chrombergwerk von Radusche . . . . . . 319

Einundzwanzigstes Kapitel: Der Katlanovosee . . . . . . . . . . . . 324

Zweiundzwanzigstes Kapitel: Besuch bei den Albanern . . . . . . . . . 335

Dreiundzwanzigstes Kapitel: Der Wodno, die Treskaschlucht und das Kloster Markova 34 I

Vierundzwanzigstes Kapitel: Neresi (Über die Kircben, Klöster und Feste der Nazedonier) . . . . . . . . . 354

Fünfundzwanzigstes Kapitel: Bienen Mazedoniens . . . . . . . . . . . 369

Sechsundzwanzigstes Kapitel: Die Erforschung der Golesniza Planina . . . . 380 

Siebenundzwanzigstes Kapitel: Stip und das Orce Polje . . . . . . . . . . 42I

Achtundzwanzigstes Kapitel: Klima und Seuchen in Mazedonien . . . . . . 431

Neunundzwanzigstes Kapitel. Prilep und seine Pässe (Babuna und Pletwarpaß) 448

Dreißigstes Kapitel: Ameisenlöwen . . . . . . . . . . . . 473

Einunddreißigstes Kapitel: Krusevo als Aromunenstadt . . . . . . . . . $4 \mathrm{~S}_{4}$

Zweiunddreißigstes Kapitel: Gopes . . . . . . . . . . . . . . . . . 492

Dreiunddreißigstes Kapitel: Sommer in Mazedonien . . . . . . . . . . . 502

Vierunddreißigstes Kapitel: Der Peristeri. Die mazedonischen Alpen . . . . 516

Fünfunddreißigstes Kapitel: Am Prespasee . . . . . . . . . . . . 530

Sechsunddreißigstes Kapitel: Ritt über den Tomoros . . . . . . . . . . . 336

Siebenunddreißigstes Kapitel: Die Wirbeltiere Mazedoniens . . . . . . . . . 543

Achtunddreißigstes Kapitel: Ochrida . . . . . . . . . . . . . . . . . . 554

Neununddreißigstes Kapitel: Der Ochridasee . . . . . . . . . . . . . 566

Vierzigstes Kapitel: Ende des Feldzuges und der Forschungarbeiten in Mazedonien ............. . . 586

Anmerkungen zu den Kapiteln . . . . . . . . . . . . . . . . . . . 580 


\section{IM WARDARTAL. FRÜHLING IN MAZEDONIEN.}

$T^{n}$ den ersten Tagen des Monats Mai 1917 trug mich der Balkanzug südwärts durch das Moravatal Mazedonien entgegen und damit nahte für mich die Erfüllung eines Herzenswunsches. Ich durfte meine eigene Wissenschaft, meine Arbeitskraft in den Dienst meines Vaterlandes stellen! Als Naturforscher wurde ich von der deutschen Heeresgruppe nach Mazedonien gerufen, um dort ihre Zwecke durch Forschungen in meinen Arbeitsgebieten zu fördern.

Ein kurzer Aufenthalt in $\mathrm{N}$ isch, der alten Hauptstadt Serbiens, führte mich in die Kreise der Etappeninspektion XI ein, deren Kommandeur, Generalleutnant von $\mathrm{Krane}$ mich als frischer Soldat mit starkem Interesse und vollem Verständnis für meine Absichten empfing. In seinem Stab traf ich mit Generaloberarzt Ludolf Brauer, dem beratenden inneren Kliniker der Heeresgruppe, dem Direktor des Eppendorfer Krankenhauses in Hamburg, zusammen. Er war der Geschäftsführer der neu begründeten Mazedonischen Landeskundlichen Kommission beim Oberkommando Scholtz; ich war als eines der ersten Mitglieder auf dem Kriegsschauplatz erschienen und beriet sofort die Organisation unserer Kommission mit ihm. Ich erfuhr, daß ich in voller Freiheit meine Pläne durchführen könne und daß mir nur der Wunsch ausgesprochen würde, ich möge mich durch Forschungen auf zoologischem Gebiet auch an der Bekämpfung der für unser Heer so gefährlichen Seuchen beteiligen.

Ich beschloß, sofort an die Arbeit zu gehen, über Üsküb ins südliche Wardartal zu reisen und mir dort in der für meine Forschungen geeignetsten Gegend als Gast des deutschen Heeres ein Standquartier auszusuchen. Überall, wo ich mit Heeresstellen in Berührung kam, fühlte ich Verständnis und Entgegenkommen heraus, und machte mich mutig auf den Weg.

Schon von Nordserbien aus war es deutsche Militär-Eisenbahn, der ich mit meiner wissenschaftlichen Ausrüstung anvertraut Doflein, Mazedonien.

\section{H. HILL LIBRARY}


war. Die Militär-Eisenbahn-Direktion 7 mit ihrem so pünktlichen und sicheren Verkehr habe ich bei den Reisen der nächsten zwei Jahre bis zum traurigen Abschied von Mazedonien stets gesegnet. Aber jetzt bei der Ausreise südwärts schien nicht alles von vornherein sicher und glatt vor sich gehen zu sollen. Serbische Banden waren tags vorher bei $\mathrm{Ristowac}$ aufgetaucht, gut bewaffnet und von serbischen Offizieren geführt. Sie hatten die Eisenbahnbrücke zerstört und es hatte an der Eisenbahnstation ein regelrechtes Gefecht stattgefunden, welches von dem alten, begeisterten deutschen Bahnhofskommandanten siegreich geführt worden war. Die Serben hatten 20 Mann und einen Offizier von ihren etwa 300 Mann tot am Platze gelassen, während auf unserer Seite auch I 1 Bulgaren und 5 Deutsche gefallen waren. So wurde mir denn gleich zum Bewußtsein gebracht, daß meine Tätigkeit auf einem Kriegsschauplatz sich vollziehen sollte.

Als ich in Ristow ac ankam, war die Brücke schon wiederhergestellt, wir konnten glatt durchfahren. In den Bergen brannten mehrere Dörfer als Folgeerscheinung einer bulgarischen Strafexpedition, bei der ein ganzes Armeekorps gegen die ziemlich zahlreichen serbischen Banden aufgestellt war. Es war eine von unseren Gegnern von Saloniki aus eingeleitete Aufstandsbewegung gröleren Stils, welche zeitweise sogar Nisch bedrohte, von den Bulgaren aber blutig unterdrückt wurde. Im Eisenbahnzug hörte ich von den deutschen Offizieren schon mancherlei Bemerkungen über die grausame Kriegführung der Bulgaren.

Die Reise ging aber durch die Ereignisse unbehindert weiter. lch kam auch im Angesicht der reizvollen Landschaft nicht dazu, mich über die militärischen und politischen Angelegenheiten weiter zu unterrichten. Die Bahn fährt das Moravatal hinauf. Der Fluß führte damals reichlich durch Regengüsse gelbbraun gefärbtes Wasser. In vielen Windungen laufen Fluß und Bahn durch ein sehr reizvolles Tal, dessen Wände von Bergen mittlerer Höhe gebildet sind. Die ausgedehnten Buchenwälder standen in sommerlicher Pracht; die Felder waren gut bepflanzt, das Getreide schon hoch, Weildorn blühte, die Obstbäume waren schon abgewelkt, in Sümpfen standen gelbe Schwertlilien. Im ganzen erinnerte die Landschaft an sommerliches Mitteldeutschland, etwa an Thüringer Flußtäler.

Der Fluß wurde kleiner, die Landschaft immer sommerlicher, höhere Bergketten traten im Süden auf, zum Teil noch mit Schnee 
bedeckt. Schließlich verließ die Bahn das Moravatal, überschritt die Wasserscheide und trat in der Nähe von $\mathrm{Kumanovo}$ in das mazedonische Gebiet ein, was sich in dem ganzen Charakter der Landschaft kundgab. Die Berge waren zurückgetreten, eine weite Ebene breitete sich aus. Wald fehlte hier, während die Felder schon einen vorgeschrittenen Zustand aufwiesen, Gerste und Roggen standen mit fertigen Ähren, einzelne blühende Mohnfelder verrieten den südlicheren Charakter des Landes.

Weite Getreideäcker, Obsthaine und Dörfer mit Lehmhütten füllten die Ebene, die der Zug durchfuhr, um die Stadt Üsküb, slawisch Skopje genannt, zu erreichen. Bei der Einfahrt überraschte der Wardar als breiter Fluß, Minarets, Moscheen und die hochragende Zitadelle gaben der Stadt ein orientalisches Gepräge. Das malerische Bild der Gebäude wurde sehr gehoben durch die Menge stattlicher Pappeln, die sich hinter den Häusermassen erhoben; rings um die Stadt ziehen sich Ketten von schöngeformten Gebirgen, von denen einige jetzt Mitte Mai noch tief beschneit waren. Vor ihnen dehnt sich eine hügelige Ebene voll reicher Pflanzungen aus.

Von dem bunten orientalischen Leben Üskübs, von dem ich in einem späteren Kapitel erzählen werde, rilo ich mich bald los, um $z u$ meinem Standquartier $z u$ gelangen, in welchem ich mich für mehrere Wochen niederlassen wollte. $\mathrm{Zu}$ diesem $\mathrm{Zweck}$ reiste ich wardarabwärts mit der Bahn nach Süden. Diese bleibt immer nahe am Wardar, so daß man bei der Fahrt einen guten Überblick über dessen Lauf gewinnt. Sie führt zuerst durch das weite Becken von Üsküb, in welches der Wardar von Westen eintritt, nachdem seine Wassermasse durch den Zufluß der Treska ganz erheblich vermehrt wurde. Etwa bei Selenikovo tritt der Fluß in die Enge von Veles, die sich bis Krivolac hinzieht. Hier fließt der Wardar durch eine wechselvolle Landschaft mit vielen malerischen Schönheiten. Prachtvolle enge Schluchten mit steilen Felswänden wechseln mit breiteren Talstellen, in denen ein oft üppiger Baumwuchs absticht von der Öde und Kahlheit, die sonst für den vom Norden kommenden Reisenden das auffallendste Merkmal Mazedoniens zu sein scheint. Im Westen sieht man hohe Berge aufragen, auch diese (jetzt Mitte Mai) noch tief im Schnee. Damals schon faßte mich die Sehnsucht, diese wie Alpen sich darstellenden Gebirge zu erforschen, ein Wunsch, den das nächste Jahr mir erfüllen sollte. Auch die eigenartige Pflanzenwelt der Talwände 
lockte schon bei der Durchreise zum Aussteigen. Ich werde von ihr später mancherlei zu erzählen haben.

Kurz vor Veles erweitert sich das Tal und gestattet wieder Ausblicke westwärts auf die Gebirge, über welche die Pässe gegen Prilep und Monastir führen. Schon dicht bei der Stadt Veles wird das Flußbett des Wardar wieder fast zur engen Klamm. Die Stadt klettert in malerischer Schönheit die Felsenhänge hinan; enge Gassen münden in die Seitenschluchten, Minarets erheben sich über die roten Ziegeldächer der untereinander sehr gleichartigen Häuser, in Felsspalten erscheinen weiße Klöster eingebaut. Von all diesen Steinmassen der Berge und Häuser strahlt pralle Hitze ins Tal und läßt auf den kahlen Felsen keine Pflanzenwelt aufkommen. Im Flulb drehen sich schlanke Räder, welche Wasser zur Bewässerung der Felder in die Höhe schöpfen.

Bis Krivolac, wo die Bulgaren den Franzosen im Jahre 1916 eine ordentliche Niederlage beigebracht haben, fährt der Zug vielfach an kahlen Bergen entlang, die einen öden, menschenleeren Eindruck machen. Gradsko, das riesige Lager mit seinen Magazinen, Baracken und Zelten, von Staubwolken verdüstert, machte keinen freundlichen Eindruck.

Am Bahndamm sah man schon in Serbien, wie jetzt an der ganzen Strecke bulgarische Soldaten als Bahnbewachung. Kleine elende Häuschen aus Lehm und Stroh waren von Stacheldraht und seichten Gräben umgeben, die gegen einen Bandenüberfall wohl nur ein mäßiger Schutz gewesen wären. Die bulgarischen Landsturmsoldaten in ihren zerrissenen, schmutzigen Uniformen waren zunächst nicht geeignet, einen günstigen Eindruck von ihrem Volke zu erwecken.

Südlich von Krivolac durchläuft die Eisenbahn mit dem Wardar ein weites Becken, welches von einem Kranze kahler Berge eingeschlossen ist. Nur in weiter Ferne sieht man im Südwesten die schönen Formen schneebedeckter Berge hervorragen. Die näher liegenden Berge zeigen an ihren Hängen alle Zeichen einer weitgehenden Erosion. Steile Abstürze mit den scharfen Schatten der vom Regenwasser gerissenen Schluchten strahlten im Scheine der Nachmittagssonne in den stärksten Farben: ziegelrote, orangegelbe und violette neben braunen und weißen Hängen. Ein geradezu phantastisches Bild: bizarre Formen und eigenartige grelle Farben. Das waren ganz ungewohnte Landschaftsbilder, die mich 
an Gegenden erinnerten, wie ich sie in Mexiko und am Roten Meer gesehen hatte.

Vor den Bergen dehnte sich eine gutbebaute Ebene aus, deren Gerstenfelder schon leise gelblich zu schimmern begannen; die zahlreichen Mohnpflanzungen waren im Verblühen, an manchen Stellen waren die Kapseln schon gut entwickelt.

Zug und Landstraße gingen direkt auf steile hohe Felsenwände zu; das tat auch der Wardar, der sich in diese Felsen eine steilwandige mächtige Schlucht gegraben hat. Es ist Demir$\mathrm{K}$ a $\mathrm{pu}$, das Eiserne Tor von Mazedonien. Durch gelbrote Wände hat der Fluß sich gearbeitet, die so steil aus seinem Wasser auf-

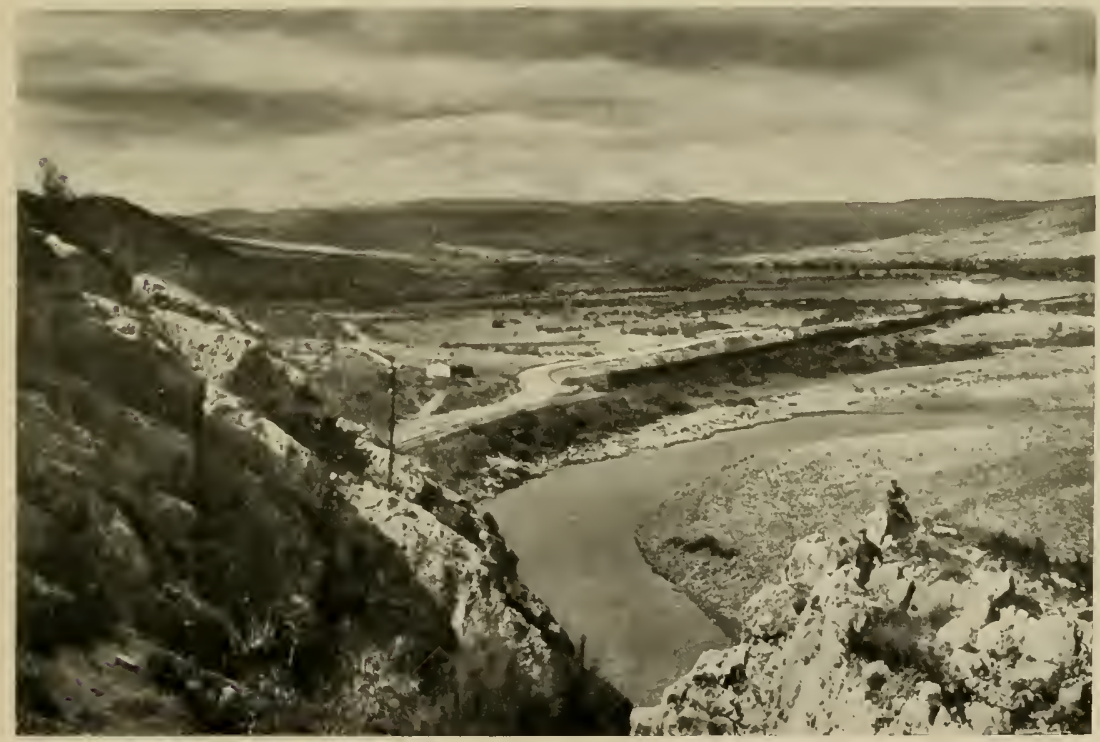

Abb. I. Blick von den Felsen von Demir-Kapu über die Steppe von Krivolac.

ragen, daß Straße und Bahn nur durch Tunnels hier an ihm vorbeigeführt werden können. Wir werden diese eigenartige, grandiose Landschaft des Wardardurchbruchs später noch genauer kennen lernen.

Einige hundert Meter ist diese Flußwildnis lang; hinter ihr treten die Berge nicht stark zurück und zeigen immer noch schöne wildzerissene Steilwände. Täler münden von beiden Seiten ein, die zum Teil in schön bewaldete Mittelgebirge führen. Hier durfte ich als Naturforscher interessante Beobachtungen erwarten. Aber 
schnell führte mich der Zug jetzt an diesen Tälern vorbei, an Dörfern, die im Schatten von Obstbäumen und Pappeln friedlich lagen, an mächtigen Schotterbänken entlang, welche die Bäche aus den Seitentälern zum Wardar geschwemmt hatten und die von der Wucht der in diesem Gebiet herrschenden Naturkräfte zeugten.

In der Ferne sah man das Tal in eine weite Ebene ausmünden, die im Süden sich wieder zu einem Bergpaß schloß. Es war die Ebene von Hudova, die mich jetzt für einige Monate beherbergen sollte. Wir liefen in den Bahnhof von $\mathrm{Hudova}$ ein

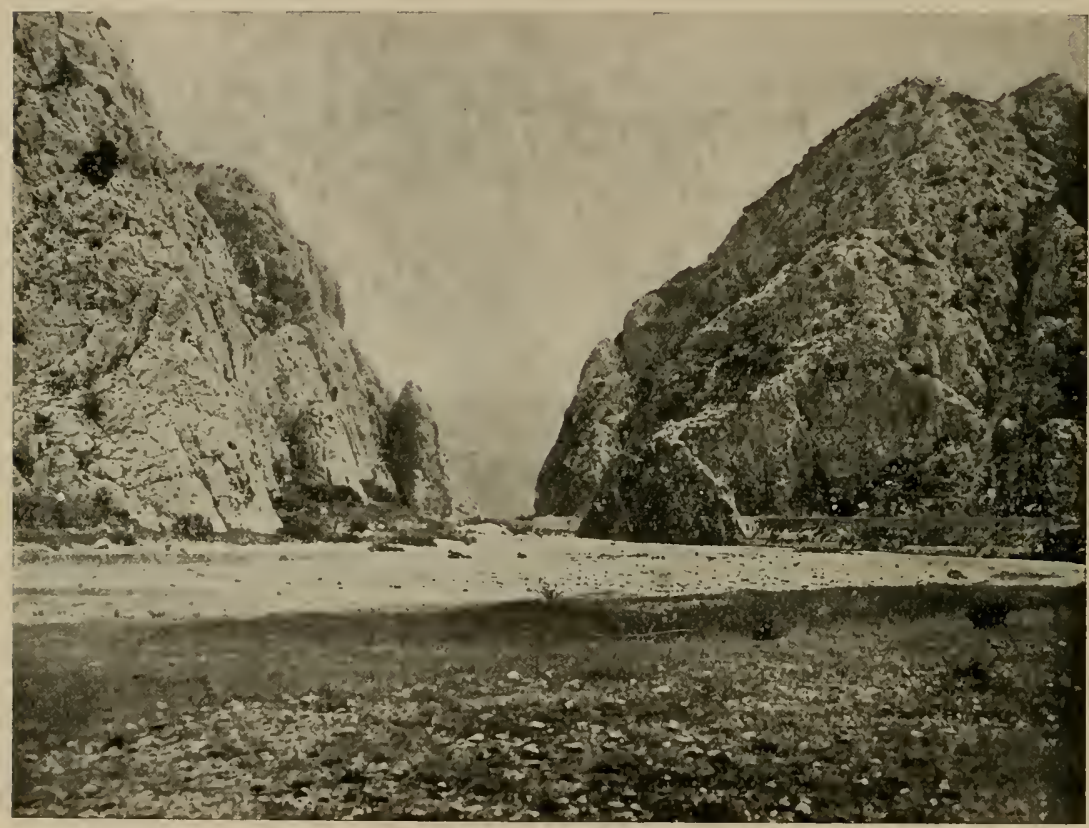

Abb. 2. Demir-Kapu, Eisernes Tor Mazedoniens, Wardardurchbruch von Norden.

den ein ungeheures Barackenlager umgab. Dies war das letzte große Etappenlager vor der Front gegen Saloniki. Etwa $100 \mathrm{~km}$ von Hudova aus gegen Süden und Südosten erstreckt sich noch das Wardartal, bis der Fluß westlich Saloniki ins Ägäische Meer mündet. An die Ebene von Hudova schließt sich noch ein Schluchtgebiet des Wardar an, hier von weniger stattlichen Bergen eingeschlossen. In Friedenszeiten wäre die Bahn bis Saloniki durchgelaufen. Jetzt fand sie in Miletkovo ihren Abschluß; etwas weiter flußabwärts lagen Negorci und Gewgeli; etwa 15 Kilo- 
meter südlich dieser Stadt verlief die feindliche Front, welche meiner Forschungsarbeit eine durchaus nicht natürliche Grenze setzte. An jenem Maiabénd stieg ich aber in $\mathrm{Hudova}$ aus dem Zug; Wagen mit Soldaten holten mich und mein Gepäck ab. Nach wenigen Minuten rollten sie durch mächtige Staubwolken ein Stück südwärts, um dann nach Osten scharf um die Ecke zu biegen, der östlichen Talwand entgegen. Den Staub von Hudova sollte ich in dem nahenden Sommer noch zur Genüge kennen lernen. Jetzt kamen wir bald an den Baracken der Etappenmagazine, an einer Feldwetterwache, einer Feldbäckerei und Fliegerlagern vorbei gegen eines der östlich in die Bergwand eindringenden Tälchen.

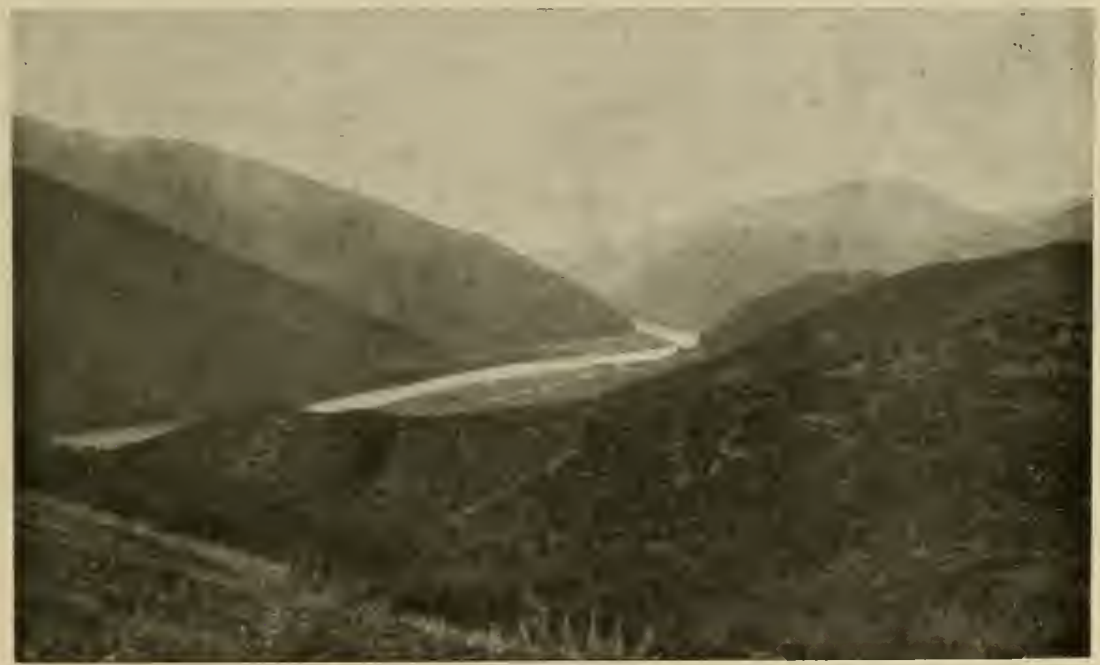

Abb. 3. Wardar oberhalb Hudova.

Vor uns dehnten sich im Tal von Hudova vor allem große Maulbeerpflanzungen aus; zwischen den Bäumen war Getreide gepflanzt. Die Maulbeeren waren zum Teil noch in Blüte. Unser Weg führte zwischen blühenden Rosen-, Brombeer- und Weißdornhecken und war so eng, die Hecken so dicht und üppig, daß bei der flotten Fahrt Zweige und Blüten den Pferden und mir ins Gesicht schlugen. Vom Wegrand dufteten die mannigfaltigsten Blüten, umsummt von einer IIenge von Insekten. Vögel vieler Arten machten auf sie Jagd. Aus den dichten Gebüschen begann der Gesang zahlreicher Nachtigallen sich zu erheben, während allmählich der Abendsonnenschein sich durch das Tal 
ergoß und fern hinter mir auf dem Wardarfluß sich spiegelte. Noch weiter westlich grenzte ein in zarten Farben verschwimmendes Hochgebirge, dessen Gipfel noch breite Schneefelder trugen, in schönen dachsteinähnlichen Formen die Ferne ab.

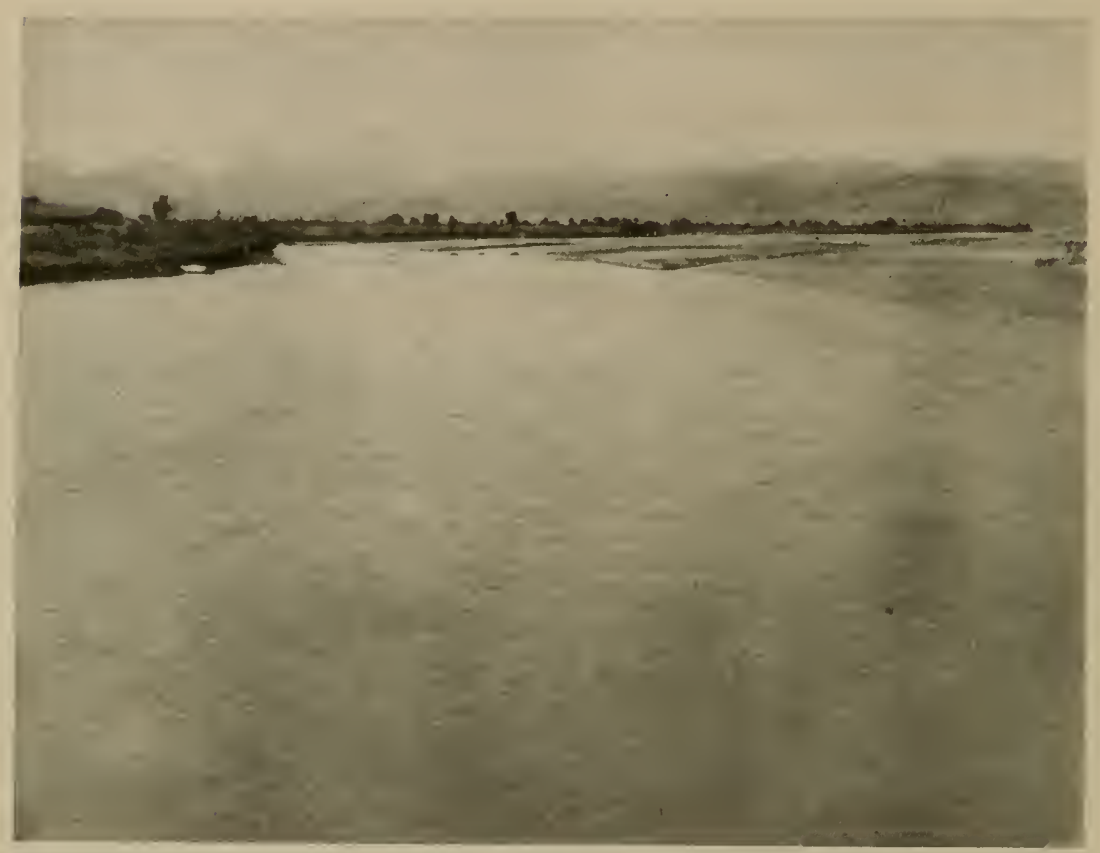

Abb. 4. Blick nordwärts über den Wardar von der Kaiser-Wilhelms-Brücke bei Miletkovo. Hochwasser.

Vor mir im Osten, allmählich sich immer stattlicher erhebend, ragte ein eigenartig herbes Gebirge empor. Eine Bergkette von harten Umrißlinien, mit scharfen Kanten, die von den Gipfeln zu Tale liefen, von zahllosen Schluchten durchfurcht, steinig und dürr, baumlos, nur von Buschwerk an den Flanken bedeckt, so schien es, während ich im Abendschein mich ihm näherte, immer höher vor mir aufzusteigen. Die Beleuchtung ließ es fast wie Alpenberge erscheinen, obwohl es nicht viel über $1000 \mathrm{~m}$ sich erhob. Es war die Plaguša Planina, in deren Schutz ich nun mein Standquartier aufschlagen wollte. Auf deren Gipfeln und in ihren Schluchten wartete manches Erlebnis, manche wissenschaftliche Entdeckung auf mich. 
Über dem weiten Geröll- und Sandbett eines ausgetrockneten Schluchtbaches rollte nun unser Wagen in das Tälchen ein, in dessen Südflanke in einer Mulde das Dorf Kaluckova lag.

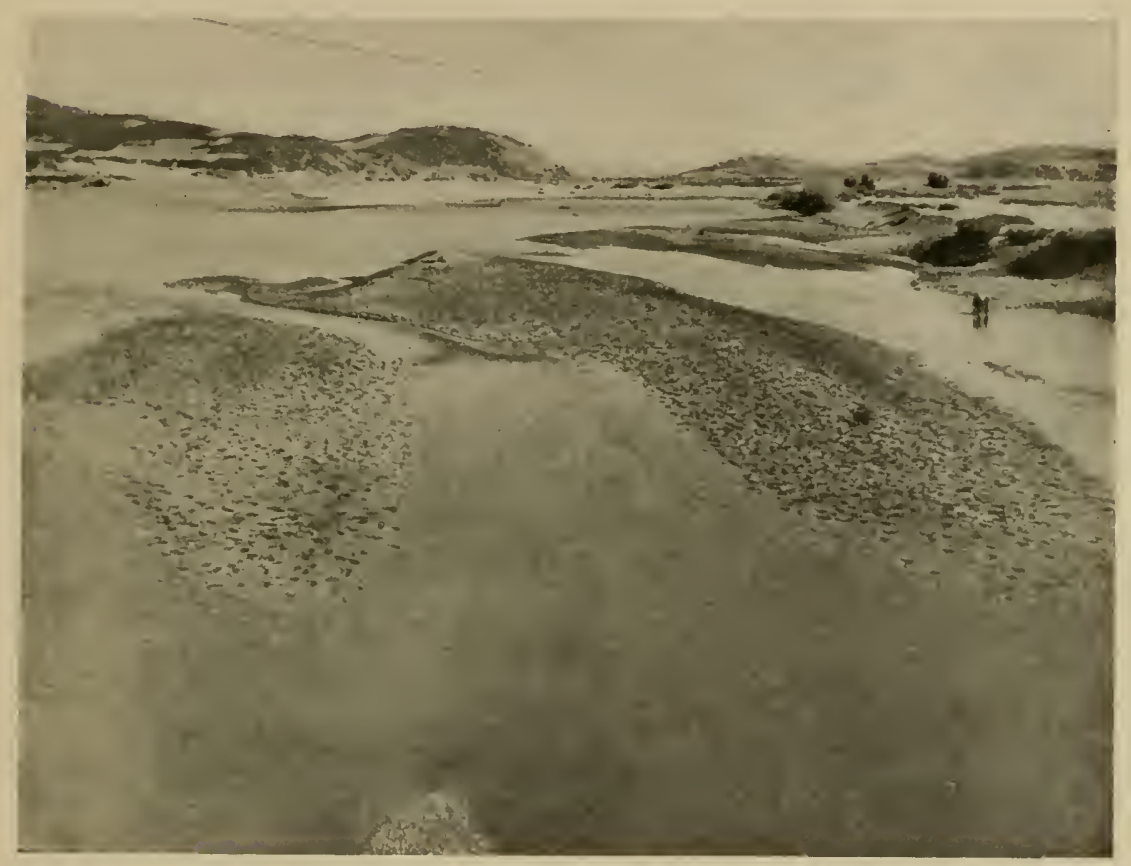

Abb. 5. Blick südlich von der Kaiserwilhelmsbrücke bei Miletkovo. Gegen Gewgeli. Flußbett voll Geröll. 


\section{ZWEITES KAPITEL}

\section{KALUCKOVA UND DAS FORSCHER- HAUS}

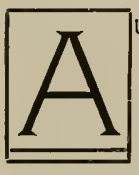

us der Entfernung sah das Dörfchen Kaluckova malerisch und einladend aus. Eine größere Anzahl steinerner Häuser, die einen weiß getüncht, die andern aus dunkelen, rauh behauenen Felsstücken erbaut, lagen am Hügelrand. Die meisten Häuser waren am Südhang gelegen und kletterten ein gut Stïck bergan und in die drei Schluchten hinein, die sich im Dorfe vereinigten. Vor dem Ort breitete sich ein breites Schotterfeld aus, weiße und gelbliche, abgerollte Steine, dazwischen viel Sand und Schlamm, das Ergebnis der Arbeit der drei Schluchtbäche, welche an den Abhängen der Plaguša Planina ihre Quellen hatten. Über diese breite, helle Talsohle, die jetzt ganz trocken lag, führte ein schmaler Steg zu einer kleinen Häusergruppe am Westhang des

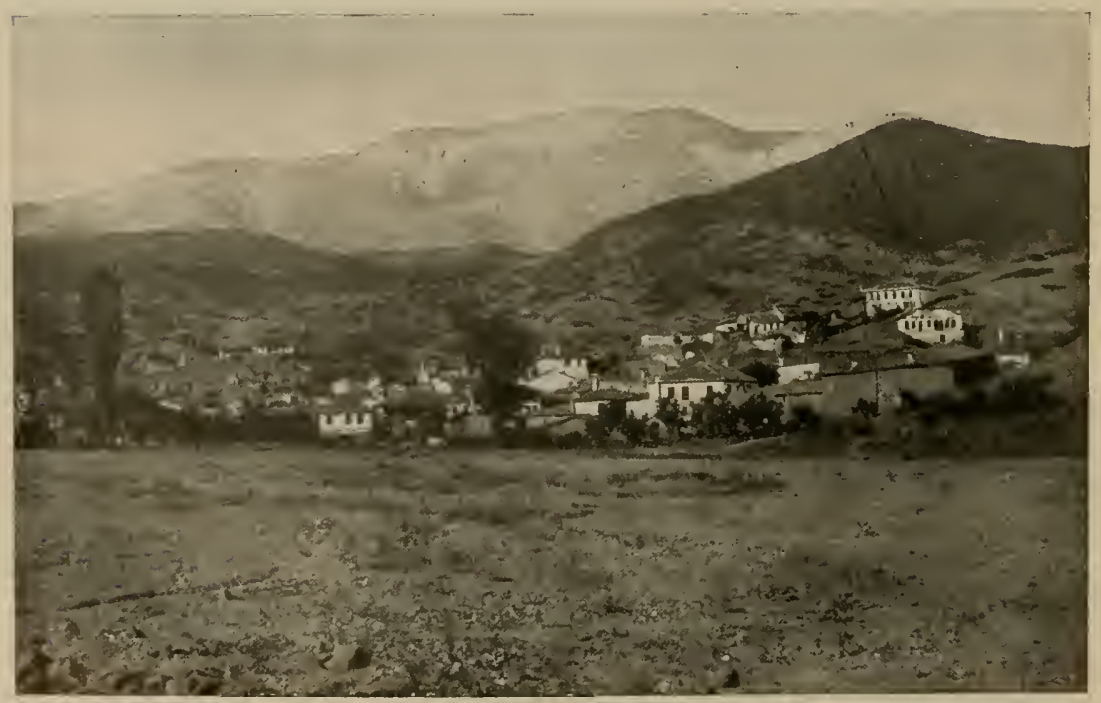

Abb. 6. Kaluckova mit Plaguša Planina in erhaltenem Zustand I9ı6. 
Tälchens. Vor diesen Häusern erhob sich eine riesenhafte, alte Platane, das Wahrzeichen von Kaluckova; sie war mehrere Meter dick, maß etwa $9 \mathrm{~m}$ im Umfang, war ausgehöhlt und breitete ihre Äste über einen großen Platz aus, den sie beschattete (Abb. 7). Hinter ihr ragte eine weiße Moschee mit einem Minaret in die Höhe, seitwärts von ihr stand ein helles, mehrstöckiges Haus, ehemals die Schule des Ortes; ihr schlossen sich noch einige wohlerhaltene Häuser und vor allem der einzige Bauernhof, der noch vollkommen erhalten war, an. Dies war eine Gruppe von Häusern, steil den Berg hinaufgebaut, ganz in Mauern eingeschlossen, wie eine Festung. Tomatenfelder und kleine Äcker schlossen am Talhang die bewohnte Region ab.

Schaute man sich die Häuser auf der südlichen Talseite genauer an, so bemerkte man, daß die meisten von ihnen Ruinen waren. Sie hatten keine Dächer, Türen und Fenster waren herausgerissen und die Wände zerbröckelten. Ein trauriges Ergebnis des Krieges, wie es alle die Dörfer ringsum betroffen hatte. Es waren aber nicht etwa Kampfzerstörungen, die an diesen Dörfern vorübergegangen waren. Im Herbst i 916 waren die damals längst von unseren und den bulgarischen Truppen besetzten Dörfer noch gut instand gewesen (Abb. 6), wenn auch von den meisten Einwohnern verlassen. Im Winter hatten die Häuser als Holzquelle gedient. Vor allem die bulgarischen Soldaten der benachbarten Lager hatten sich die Dachbalken, die Fensterrahmen, die Türen als Brennmaterial geholt und auch unsere Soldaten hatten sich an diesen Zerstörungen beteiligt. In dem holzarmen Lande war während des kalten Winters nichts anders übrig geblieben, als sich hier in der Nähe der Front große Mengen von Soldaten ansammelten, die kochen und warm haben wollten.

So bot denn das Dorf mit seinen halb- und ganz zerstörten Hăusern einen traurigen Anblick dar. Trotzdem mußte es wieder bezogen werden; als ein Seuchenlazarett an dieser Front notwendig wurde, hielt man diesen Ort, der nicht weit der Bahn und Hauptstraßen lag, für besonders geeignet, da in seiner Nähe kein stehendes Gewässer sei. Man hielt es daher für malariafrei. Das stellte sich später als ein schwerer Irrtum heraus, gab mir aber zu besonderen Forschungen Anlaß, von denen in einem späteren Kapitel die Rede sein wird.

Als ich in Kaluckova ankam, hatte man erst gerade begonnen, das Lazarett auszubauen. Einige Baracken waren in dem 
Maulbeerhain am Nordhang des Tals aufgestellt, die Moschee, das Schulhaus und was sonst von Bauten noch brauchbar war, mit Krankenbetten belegt. Nur für die Ärzte, die Pflegeschwestern und die Sanitätsmannschaften war die Unterkunft zunächst sehr mangelhaft. Allmählich wurden aber die Ruinen wieder ausgebaut und so eine Anzahl erträglicher Quartiere eingerichtet, wobei andere der zerfallenen Häuser das Baumaterial lieferten und dabei fast vollständig vom Erdboden verschwanden. So waren ein Schwesternhaus, ein Ärztekasino im Haus des Chefarztes, Ärztequartiere,

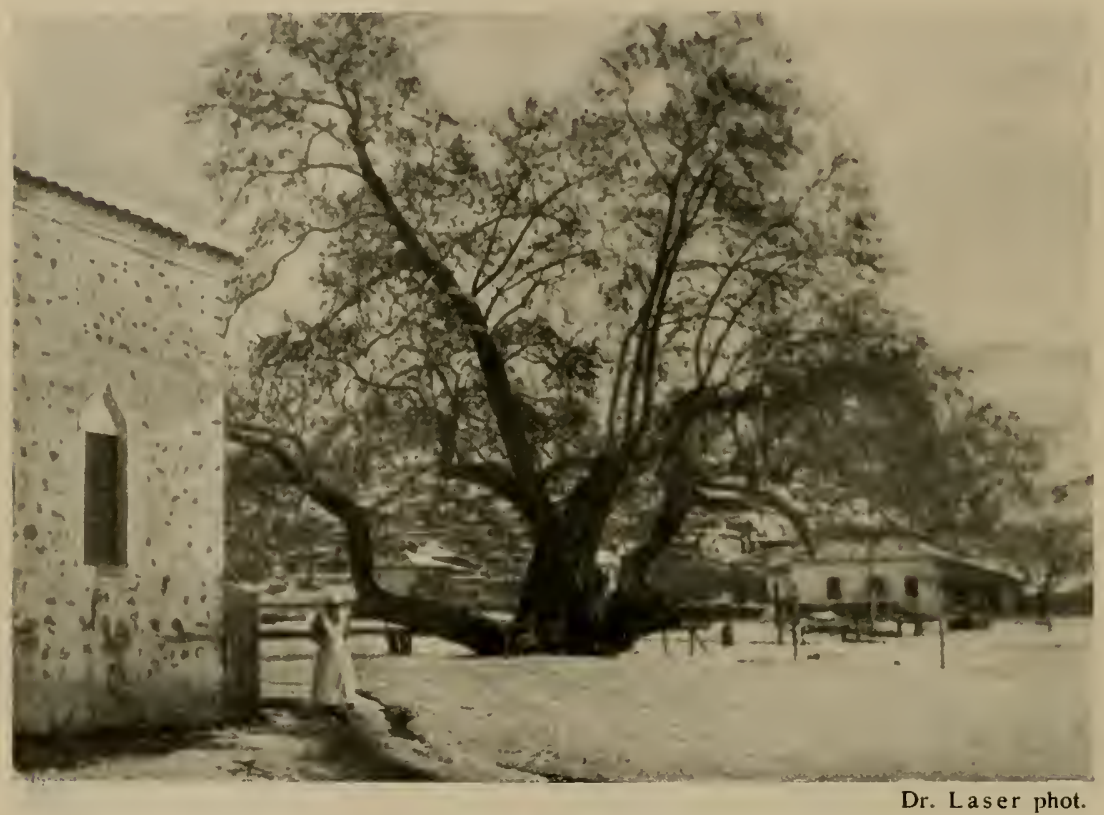

Abb. 7. Die alte Dorfplatane von Kaluckova im Winter.

Räume für Mannschaften, Ställe für Pferde, Lager für Vorräte errichtet worden. Dazu kamen eine Apothekenbaracke und ein ganz brauchbares Laboratorium für Seuchenuntersuchungen.

Als ich am Abend des 19. Mai in Kaluckova eintraf, wurde ich in freundlicher Weise von dem Chefarzt des Seuchenlazaretts, Stabsarzt Halter empfangen. Vorläufig wurde ich mit mehreren Ärzten in einem größeren Schlafraum untergebracht. Bald aber wurde auch für mich ein Haus am Bergende des Dorfes auf luftiger Höhe ausgebaut, dessen Garten ein stattliches Portal mit 
der stolzen Inschrift „Forscherhaus“ erhielt (Abb. 8). Dazu wurde die Hälfte des Laboratoriums mir zur Verfügung gestellt, so daß ich sofort meine Instrumente auspacken und mich zur Arbeit vorbereiten konnte. Eine sehr brauchbare transportable Laboratoriumseinrichtung, das sogenannte Münchner Feldlaboratorium, wurde mir vom Kollegen Brauer, der es von den Beringwerken erhalten hatte, in großzügiger Weise zur Verfügung gestellt; so hatte ich bald ausgezeichnete Arbeitsbedingungen und konnte mich sofort an die Erforschung der Gegend machen, auf die ich äuberst gespannt war.

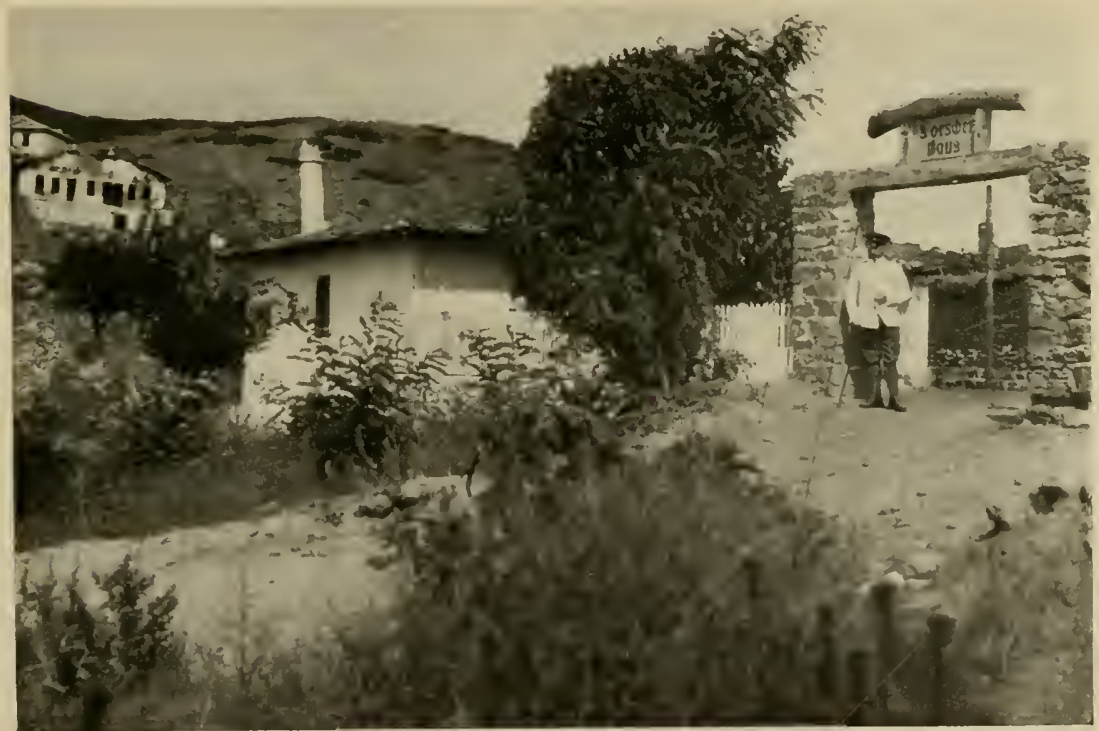

Abb. 8. Mein Wohnhaus in Kaluckova.

Der verständnisvollen Unterstützung, die mir Stabsarzt Halter gewährte, werde ich stets dankbar gedenken. Nun ging eine schöne, eindrucksreiche Zeit in Kaluckova und seiner Umgebung für mich an.

In stillen Forscherhaus habe ich manche ruhige Nacht, aber auch manche unruhige verbracht, zum Glück aber in den Monaten meines Aufenthalts nur einen Tag krank gelegen; in meinem einfachen Zimmer, am Haus und in Garten manche interessante Beobachtung gemacht.

In meinem Zimmer bauten Spinnen ihre Netze; von einer von ihnen habe ich im 19 . Kapitel berichtet; nicht selten flatterten 
junge Vögel zu mir herein. Weidende Rinder brachen in meinen Garten ein, in dem ich vergebens nach Regenwürmern grub. Ameisen bauten im und um das Haus ihre Nester. In der Lehmwand hatten Bienen ihre Nester gebaut, solitäre Bienen aus den Gattungen Anthophora und Halictus. Deren Bauten wurden von den metallisch roten und grünen prachtvollen Goldwespen, Chrysididen, umschwärmt, welche ihre parasitische Nachkommenschaft in die Nester zu den Larven einzuschmuggeln trachteten. Die Dorfschwalbe (Hinundo rustica boissonneauti Temm.) baute

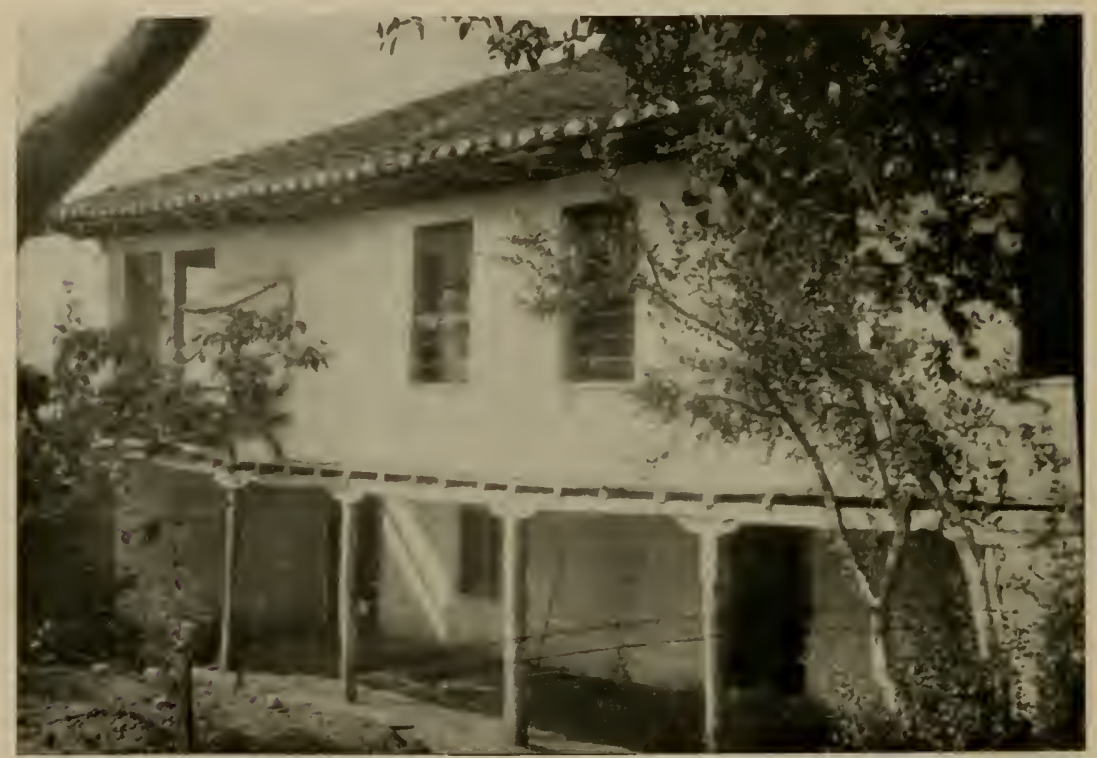

Dr. La s e r phot.

Abb. 9. Das Doktorhaus in Kaluckova mit dem Granatapfelbaum.

und brütete unter meinem Dach, Sperlinge und Goldammern besuchten meinen Hof.

Manche Nacht hörte ich die Malariamücken um mein Moskitonetz summen, während die kleinen $\mathrm{Pappataccimücken}$ durch dessen Maschen zu mir eindrangen und Nacht mit ihren schmerzhaften Stichen schlaflos machten. Dann war es wie eine Erlösung, wenn der Kraftwagen der Flieger aus dem Wardartal vor dem Haus anbrauste und die frischen jungen Männer mich mitten in der Nacht zu einem ihrer improvisierten Feste abholten. 
An einen Haus- und Nachtgast denke ich mit besonderer Sympathie zurück. Es war der einzige Geckonide, eine kleine Eidechse, der im Wardartal vorkam, als südlicher Gast hier eingedrungen. Gymnodactylus kotschyi Stud. hieß das kleine braungraue Tier, das sich in meinem Zimmer eingenistet hatte und mir da das Ungeziefer wegfing. Tagsüber hielt mein Tekkotekko sich verborgen. Nachts aber, sobald ich das Licht gelöscht hatte, begab er sich auf die Wanderung an Wänden und Decke meines Zimmers. Seine Zehen waren für das Laufen an glatten Wänden nicht ganz geschickt ausgestattet und so plumpste er manchmal

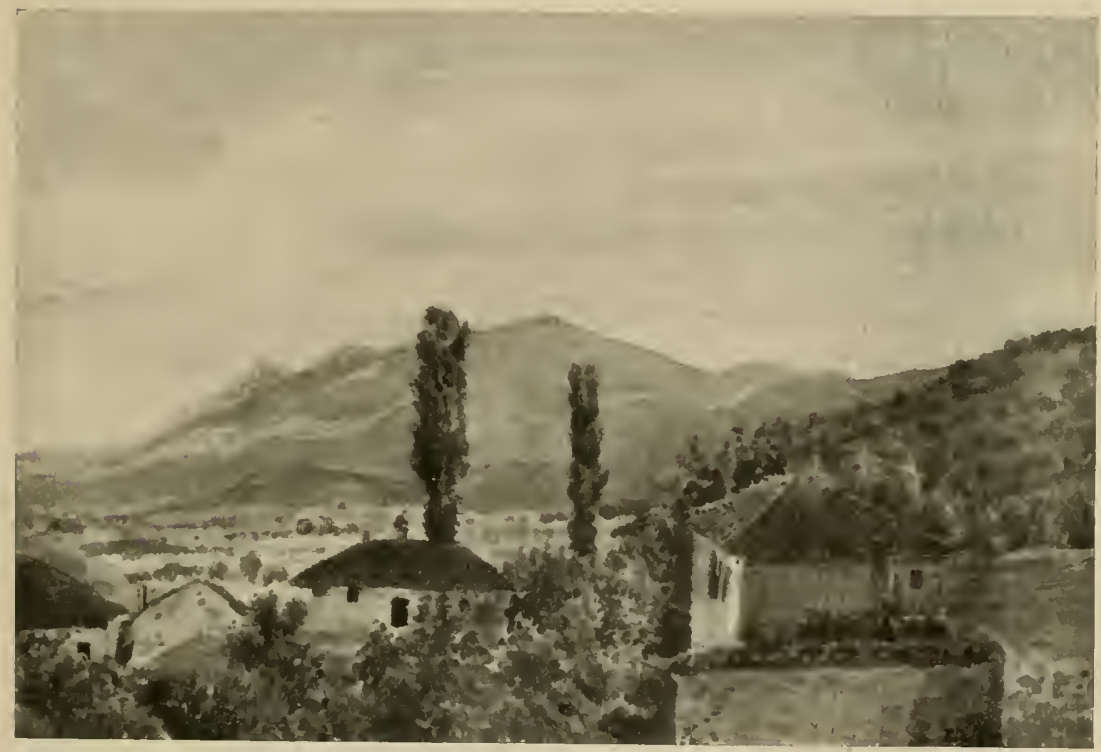

Abb. I0. Mein Standquartier Kaluckova. In Hintergıund Marianska Planina und Mala Rupa.

(Nach Aquarell des Verfassers. Abendstimmung Juli 1917.)

mit lautem Knall auf den Zementboden des Zimmers herunter. Sein leiser, glockenartig tönender Ruf schallte traulich aus den Zimmerecken zu mir. So lielu ich das harmlose Tier leben solange ich das Zimmer bewohnte.

Es war eine ganz seltsame Landschaft, die mich hier umgab, eine Landschaft, wie ich sie noch nicht kennen gelernt hatte. Um den Grund des Baches und seiner Zuflüsse stiegen nach allen Seiten steile Hügel an. Sie reihten sich meist in Ketten den Bachschluchten entlang an, selbst durch Nebenschluchten vonein- 
ander getrennt. So war es ein schwieriges Klettergelände, wollte man seitlich der Schluchten ins Gebirge hinauf. Jeder Hügel überragte seinen Nachbarn in der Kette und war von ihm durch eine tiefe Schlucht getrennt. Und alle diese Hügel sind auf ihrem Rücken von kurzem Buschwerk bedeckt, das meist in Gruppen vereinigt ist, die jeweils durch schmälere und breitere Rasenstrecken voneinander getrennt sind. So waren in dieser Jahreszeit die Hügel ganz grün, der meist hellgrüne Rasen gefleckt mit den dunkelgrünen Büschen. Dazwischen stachen höchst auffällig und grell das Gestein und die Gerölle der Abstürze und der Schluchtenränder mit ihrer rotgelben und dunkelroten Färbung ab. Und in all den Schluchten rauschte und rieselte in dieser Jahreszeit reichliches Wasser, doch immerhin nur soviel, daß es im Schotterbett des Unterlaufs der Bäche vollkommen versickerte.

Hügel über Hügel reihte sich bergan, bis in etwa 500 bis $600 \mathrm{~m}$ Höhe breitere Rücken und Halden sich anschlossen, die schließlich noch durch tiefe Täler von den steilen Felsabstürzen des Plaguša-Gebirges getrennt waren. Letzteres zog sich von Nord nach Süd als eine Kette von schroffen Spitzen dem Wardartal parallel. Im grellen Mittagslicht war das ganze Gebirge durch zahllose, gradlinig begrenzte Schattenflecke gegliedert. Grau und kahl überragte es die grünen Hügel des Vorlandes und einige höhere Zwvischenberge, von denen einer von unseren Soldaten, da er aus dem dürren Lande so auffallend hervorstach, als der Grünber $g$ bezeichnet wurde.

In diesem Gebiet habe ich in den nächsten Monaten und im Frühling 1918 eine Menge von interessanten Beobachtungen an Pflanzen und Tieren gemacht. Es erwies sich als ein biologisches Eldorado und die Wahl des Standquartiers als sehr geeignet.

Die Pflanzenwelt Mazedoniens stellte in ihrem Gesamteindruck wohl für die meisten Deutschen eine große Überraschung dar. Der Deutsche ist gewohnt, wenn er von seiner Heimat südwärts reist, in eine Landschaft von mediterranem Typus etwa in Südtirol, in Oberitalien oder in Südfrankreich zu gelangen. Er erwartet Pinien und Zypressen, sucht Lorbeer und Myrthen, Orangen- und Zitronenbäume.

Nichts davon bekommt man im eigentlichen Mazedonien zu sehen. Die typische Mittelmeerflora mit ihren malerischen Bäumen, mit der Pflanzenwelt der Macchien ist auf dem Balkan nur in Meeresnähe vertreten, also in Dalmatien, in Griechenland und an 
der thrakischen Küste. Die mazedonische Landschaft sieht ganz anders aus; ihr fehlen jene, ebenso wie Ölbäume, Erdbeersträucher und alle anderen Pflanzen, welche der italienischen Landschaft ihren besonderen Reiz verleihen. Wo die Bodenfeuchtigkeit genügt, werden sie durch Pappeln, Ulmen, Eichen ersetzt, Weiden und Erlen, Ahorn, Hainbuchen erinnern mehr an deutsche Gaue.

Auf den trockenen Hügeln, also im Wardartal von Üsküb bis Gewgeli, bei Prilep, Monastir, an den Seen herrscht Buschvegetation vor; manchmal finden sich dichte, fast undurchdringliche Massen, sehr häufig sind lockere Bestände: Gruppen von Büschen sind getrennt durch Flächen, welche mit Gras und Kräutern bedeckt oder ganz vegetationslos sind. Und die Büsche sind meist klein und niedrig, rundlich geformt. An vielen erkennt man bekannte Blätter, wie Brombeeren, Weißdorn, andere muten fremdartig an, wie der stachliche Judendorn (Paliurus aculeatus Lam.) (Abb. I I) und die Stacheleiche (Quercus coccifera I..). Andere sind wir gewohnt als Bäume zu sehen, so weichblätterige Eichen, Feldahorn, Hainbuchen. Dazwischen kommen in manchen Lagen Wachholderbüsche vor.

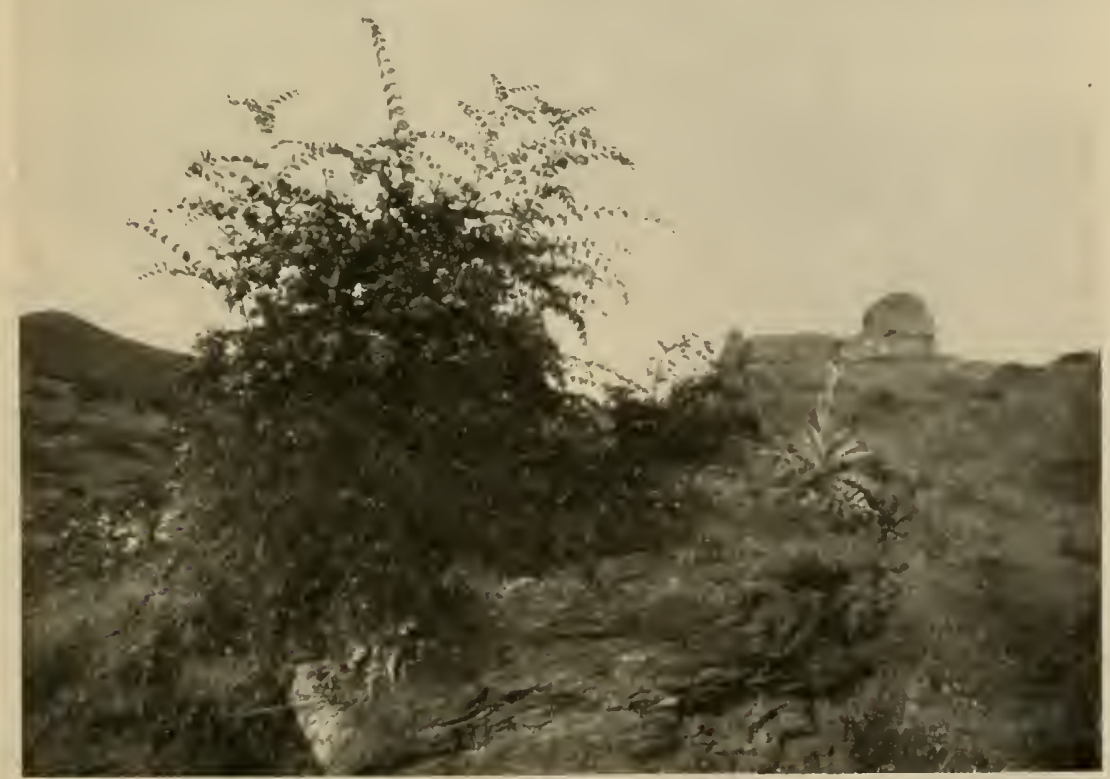

Abb. Ir. Judendorn (Paliurus aculeatus Lam.) bei Kaluckova.

Dr. L a s e r phot. 
Gerade im Frühling war die Fülle der Pflanzen und Tiere auf den Hügeln unermeßlich. Die dunklen Büsche bestanden in der ganzen Gegend fast ausschließlich aus einem dichten Gestrüpp mit harten, stachelichen, glänzenden Blättern. Zunächst glaubte man etwas Ähnliches vor sich zu haben, wie die Stechpalme des heimischen Schwarzwaldes. Sah man genauer $\mathrm{zu}$, so fand man eigenartige Blütenträubchen, manchmal jetzt noch vertrocknet am Busch Früchte, die genau wie unsere Eicheln aussahen, Körbchen und Eicheln lagen zum Teil noch vom Herbst am Boden herum und später im Jahr waren die Büsche reichlich mit Eicheln bedeckt. Es war also eine Eiche, die man wohl die Stacheleic he nennen darf (Quercus coccifera L.), ein Gewächs, das keiner vergessen wird, der einmal in diesem Gebiet gelebt hat (Abb. I 2 und 16).

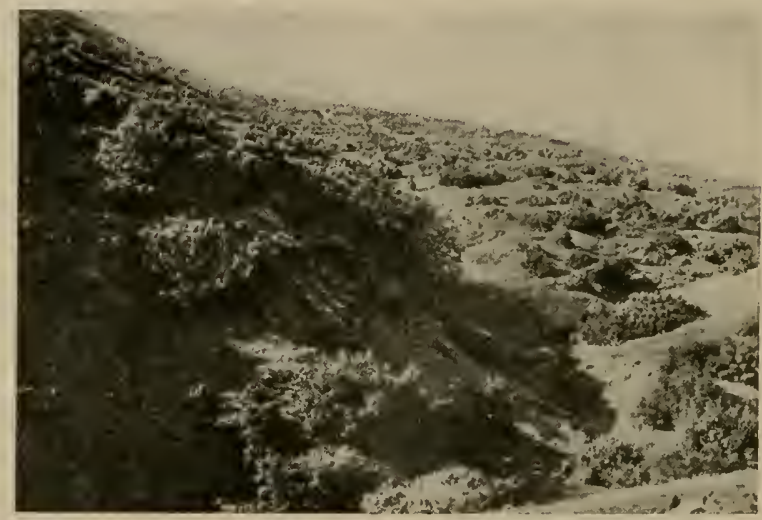

Dr. Frischnolz phot.

Abb. I2. Bebuschte Hügel (hauptsächlich Quercus coccifera) in der glühenden Sommersonne Mazedoniens (bei Gradec).

Jetzt im Frühling sah der Strauch, aus der Nähe betrachtet, sehr reizvoll aus. Die neuen Zweige waren mit hellgrünen, am Rande rötlich schimmernden, zarten Blättern bedeckt. Deren Stacheln waren noch weich, so daß man ruhig mit vollen Händen hineingreifen konnte. Allerdings mußte man dabei im Gebiet der jungen Sprosse bleiben; griff man in die alten hinein, so zerstach man sich an deren scharfen Stacheln die Finger abscheulich.

Zwischen den Büschen stieg ich die steilen Hügel aufwärts, bald am Steilrand einer Schlucht, bald über eine scharfe Felsenkante, dann wieder auf blütenreichem Wiesenpolster; wo Fußpfade 
und Herdenspuren verfolgbar waren, zogen sie sich vielfach geschlängelt durch das Stacheleichengestrüpp.

Mit den Stacheleichen bildeten andere stacheliche, dornige Sträucher die Gebüsche; alle hatten harte, glatte oder dickwollige Blätter. Diese ausdauernden Sträucher waren durch allerhand Schutzmittel gegen tierische Feinde geschützt. Sie alle besaßen Stacheln, Dornen, Behaarung, zum Teil auch lederige Blätter. Trotz dieses Schutzes zeigten sie besonders an dem jungen Zuwachs Anzeichen von Benagung durch Weidetiere. Diese sind hier im Lande die grimmigsten Feinde der ausdauernden Pflanzen. Vor

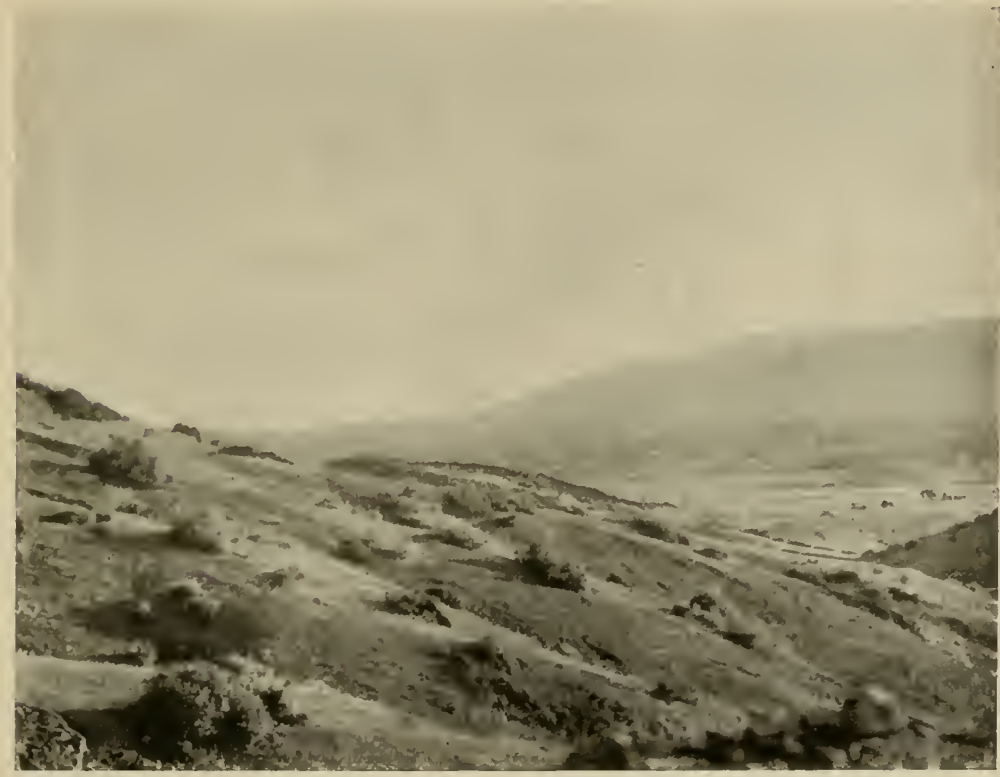

Abb. 13. Hügel bei Kaluckova im Frühling.

allem die so viel gezüchteten Ziegen mit ihrer unersättlichen Gefräßigkeit lassen keinen Baumwuchs, kein höheres Buschwerk aufkommen, es sei denn die Pflanze durch gute Waffen gegen die Zudringlichkeit des Tieres geschützt. Was sie vor Tieren schützt ist vielfach gleichzeitig Schutz vor Austrocknung. Denn viele Feinde bedrohen auf den mazedonischen Hügeln die Pflanzenwelt, und unter ihnen ist neben den Ziegen die Trockenheit der Sommermonate wohl der gefährlichste.

Jetzt schon im Mai war die Erde auf den Hügeln von außerordentlicher Härte und Trockenheit; riß man einen Grasbüschel 
aus, so war die an seinen Wurzeln hängende Masse schon leicht staubig und sehr steinreich. Es war erstaunlich, daß trotzdem eine solche Fülle von Pflanzen im Hügelgelände wuchsen und blühten. Sie mußten besonders gegen Austrocknung geschützt sein; die große Mehrzahl von ihnen waren zudem ganz kurzlebige einjährige Pflanzen.

Viele der Hügelblumen dufteten stark und an den windstillen Maimorgen war die Luft von köstlichen Gerüchen erfüllt, in denen eine mannigfaltige Insektenwelt schwirrte und summte. Thymian und Kamillen bildeten an vielen Stellen große Beete und Polster

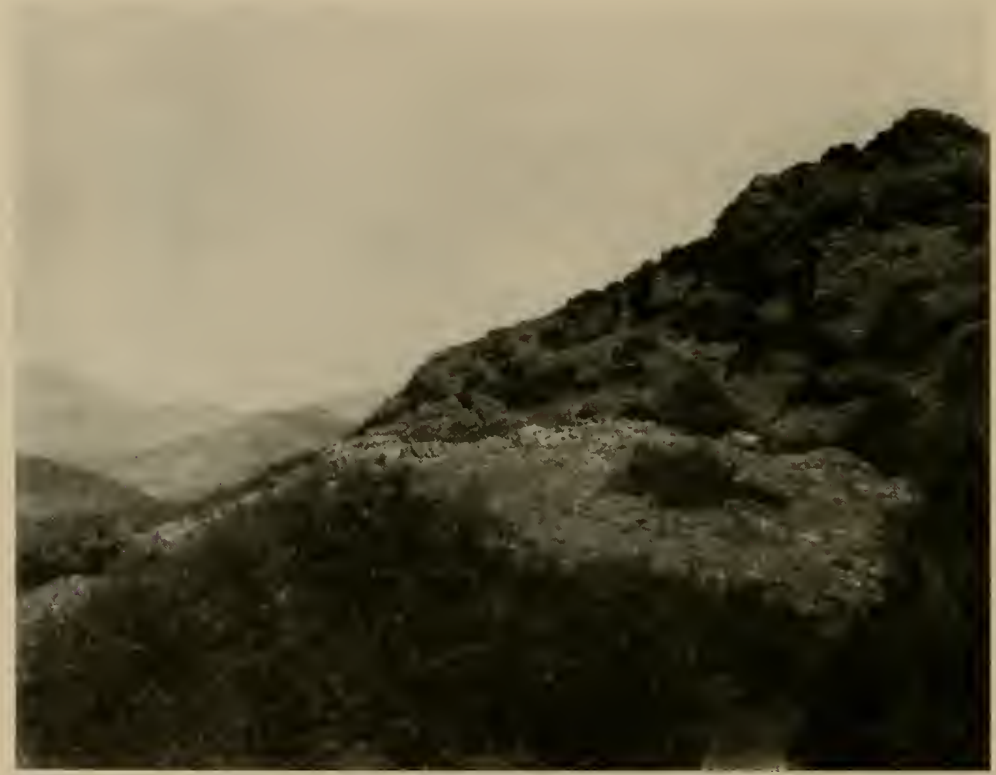

Abb. 14. Buschvegetation der Hügel bei Kaluckova. Sommersanfang.

zwischen Steinen und Gebüsch. Sehr auffallend war eine rosagefärbte, großblütige Cistrose. Strohblumen, Labkräuter, Lichtnelken, Goldklee mischten ihren Duft mit jenen. Verschiedene Kleearten, weiß und rotblühend, waren von zahlreichen Bienen umsummt. Das waren meist solitäre Bienen, welche in der Nähe im Boden bauten. An einzelnen Stellen fand sich ein rundes Loch neben dem anderen im lehmigen Boden; da flogen die Bienen unablässig ein nnd aus. 
Der Artenreichtum der auf den Hügeln jetzt gerade blühenden Pflanzenwelt war außerordentlich groß. Sie bildeten einen bunten Blütenteppich von wunderbarer Pracht. Von einzelnen der Pflanzen fanden sich an einzelnen Stellen große Bestände. So leuchteten an einem Abhang große Flecken einer gelben Schaf-

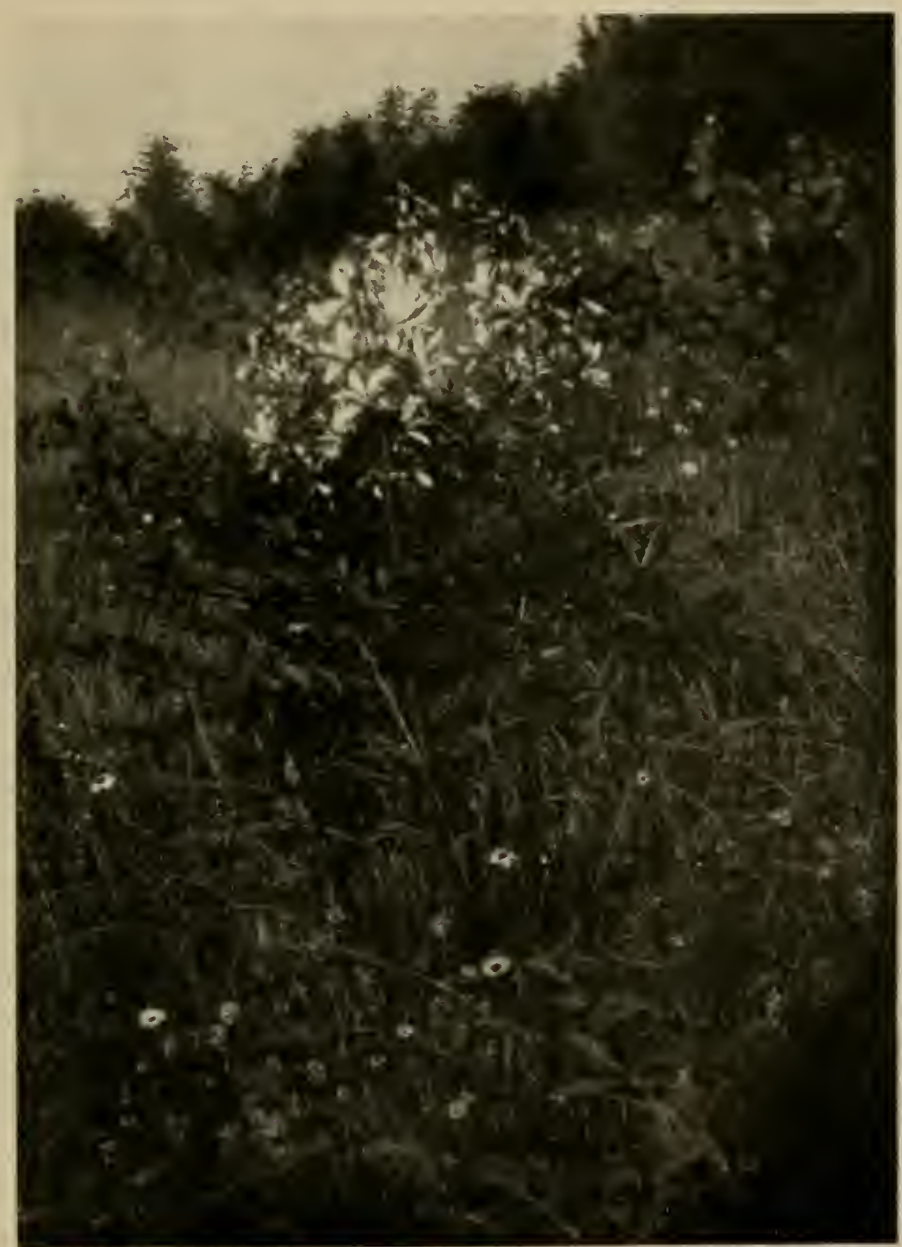

Dr. Laser phot

Abb. 15. Diptam (Dictammes albus L. var. macedonicus Borb.).

garbe, neben ihnen war die Halde mit einer roten Wicke bedeckt. Über diesen Blumen schaukelten im Morgenwind die Ähren eines großen Zittergrases, die mindestens dreimal so groß waren, als bei unseren deutschen Arten. Die großen herzförmigen Ähren 
ließen ein leißes Rascheln ertönen, wenn der Wind sie bewegte. Zarte Lichter wurden von ihrer matten, silberigen Oberfläche gespiegelt.

Als ich die Hügel wieder hinabstieg, blieb mir Zeit, einige Pflanzen genauer zu betrachten, denen ich beim Anstieg bei der Fülle der Erscheinungen weniger Beachtung geschenkt hatte. Zarte phantastische Blumen von rotvioletter Farbe bildeten prachtvolle Sträulue, die einen betäubenden aromatischen Geruch ausströmten. Es war der Diptam (Dictammus albus L. var. macedonicus Borb.) (Abb. 15), bei uns in Deutschland eine große Seltenheit an klimatisch bevorzugten Stellen. Hier standen die Büsche in üppiger Fülle; die großen Sträuße, die man von ihnen ins Quartier mitnahm, wurden durch die Stärke ihres Geruchs bald unangenehm. Versuche auch bei dieser Form, wie es sonst beschrieben wurde, das ausgespritzte ätherische Öl zu entzünden, mißlangen mir bei der hier vorkommenden Art.

Einen eigenartig phantastischen Anblick bot eine Pflanze dar, die unten an den Hügelhängen in großer Menge vorkam. Es war ein riesiger Aronsstab, dessen purpurbraune Blüte in einem Straub hellgrüner Blätter steckte. Die Pflanze ragte meist über einen Meter hoch aus Stacheleichenbüschen hervor, wie das nebenstehende Bild zeigt (Abb. 16). Eigenartig leuchtete der gelbgrüne Stempel auf dem tiefbraunen Grunde des Becherinnern. Ein unangenehmer Aasgeruch entstieg dem Kelch, in dem kleine Fliegen in Menge sich sammelten, um da die Befruchtung zu vermitteln.

Wo man über die Hänge schaute, überall sah man die mächtigen Pflanzen mit ihren Knospen und offenen Blüten emporragen. Fast nie aber standen sie frei zwischen den Büschen, sondern die meisten von ihnen ragten aus stachelichen Büschen hervor, meist aus denen der Stacheleichen. Offenbar waren nur diejenigen Individuen dieser Pflanzenart (Dracunculus vulgaris Schott.) von den weidenden Tieren verschont geblieben, welche innerhalb von Stachelsträuchern ausgekeimt waren. Es mutete direkt wie ein Symbioseverhältnis zwischen den zwei Pflanzen an, wenn man stets die zartblättrigen Aronsstäbe aus den stachelichen Gebüschen herausschauen sah. Auch sonst habe ich nicht selten in Mazedonien zarte Pflanzen in solcher Weise Schutz im Gehege stachelicher Sträucher suchen sehen.

Über den Blumen schwebten zahlreiche Schmetterlinge, vor allem Bläulinge, Weißlinge und Scheckenfalter. Die Arten waren 
den deutschen Formen sehr ähnlich, doch ließen sich stets gewisse Unterschiede erkennen. Ganz außerordentlich zahlreich flogen hier die Bienenarten. Auf den Blüten versammelten sich Käfer, Blattwanzen, Schlupfwespen, Fliegen verschiedener Arten.

Zwischen den Pflanzen waren kahle Stellen, bedeckt mit Steinen, Erde, Sand und Geröll. Dort war alles von einem eigen-

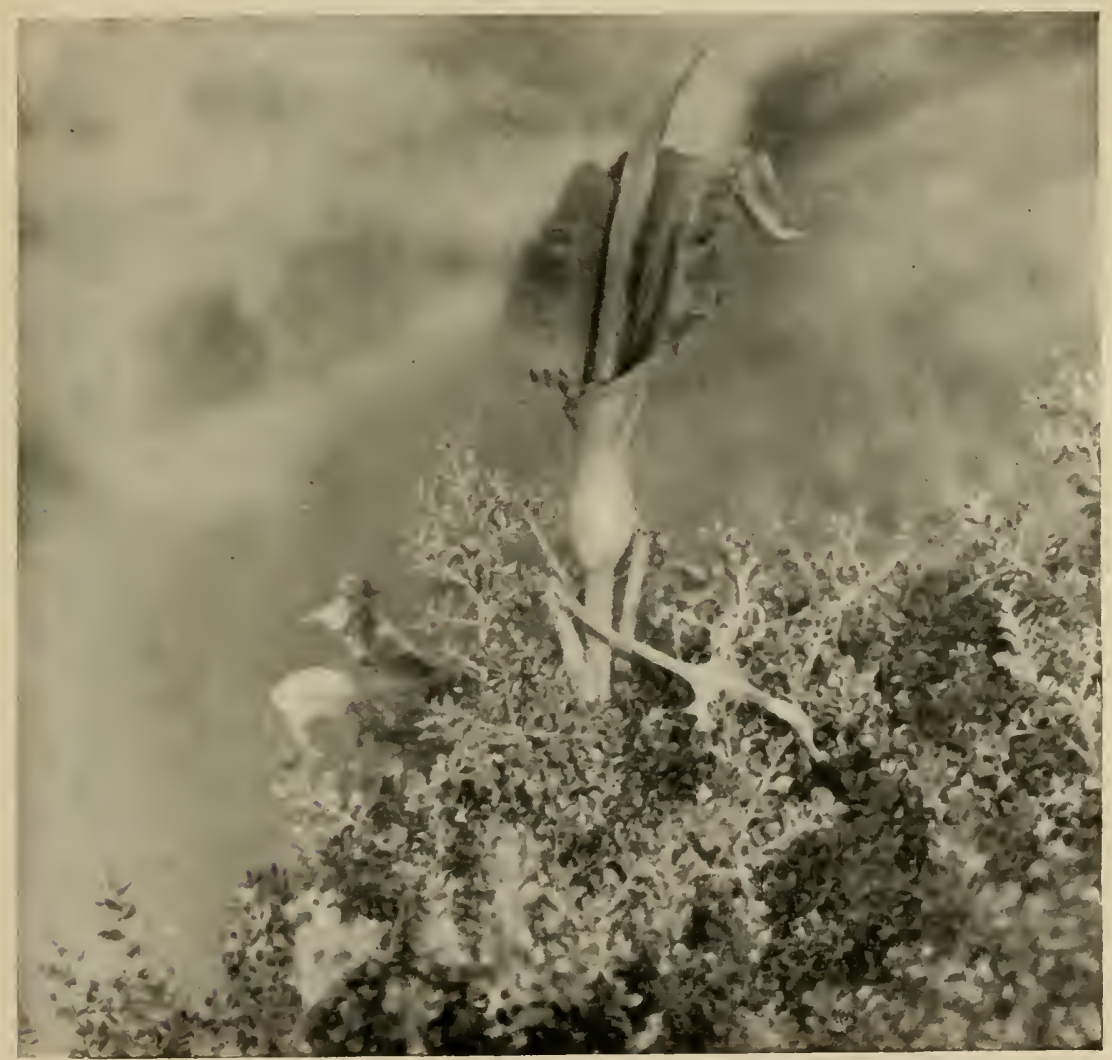

Abb. 16. Aronsstab im Schutz der Stacheleiche (Drxzunculus vulgrris Szhott. is Quercus coccifera L.).

artigen Tierleben erfüllt. Außer Bienen hatten im Lehm zahlreiche Raubwespen ihre Bauten. Ameisen arbeiteten eifrig an ihren Erdbauten und es war auffällig zu beobachten, daß so viele ihrer Arten in der Erde bauten; um die Ausgänge ihrer Nester fand sich bei einer ganzen Anzahl nicht näher untereinander verwandter Arten jeweils ein Ringwall von Bauschutt. Steinchen und 
Sandkörner waren aus der Tiefe herausgeholt und um den Nestausgang angehäuft. Man konnte das gleiche bei Arten von Messor, Tetramorium und Cataglyphis beobachten. Offenbar herrschte bei allen rege Bautätigkeit, denn überall sah man sie aus den Nestern herauskommen und auf ihren Straßen wandern, die schwarzen Körnersammler, die gelben Rasenameisen und merkwürdig bunt gefärbte, in merkwürdiger Haltung sehr flink umherhuschende Cataglyphisarbeiter.

Wo in einer Mulde etwas Sand und Staub zusammengeblasen oder angeschwemmt war, da hatten in dem lockeren Material

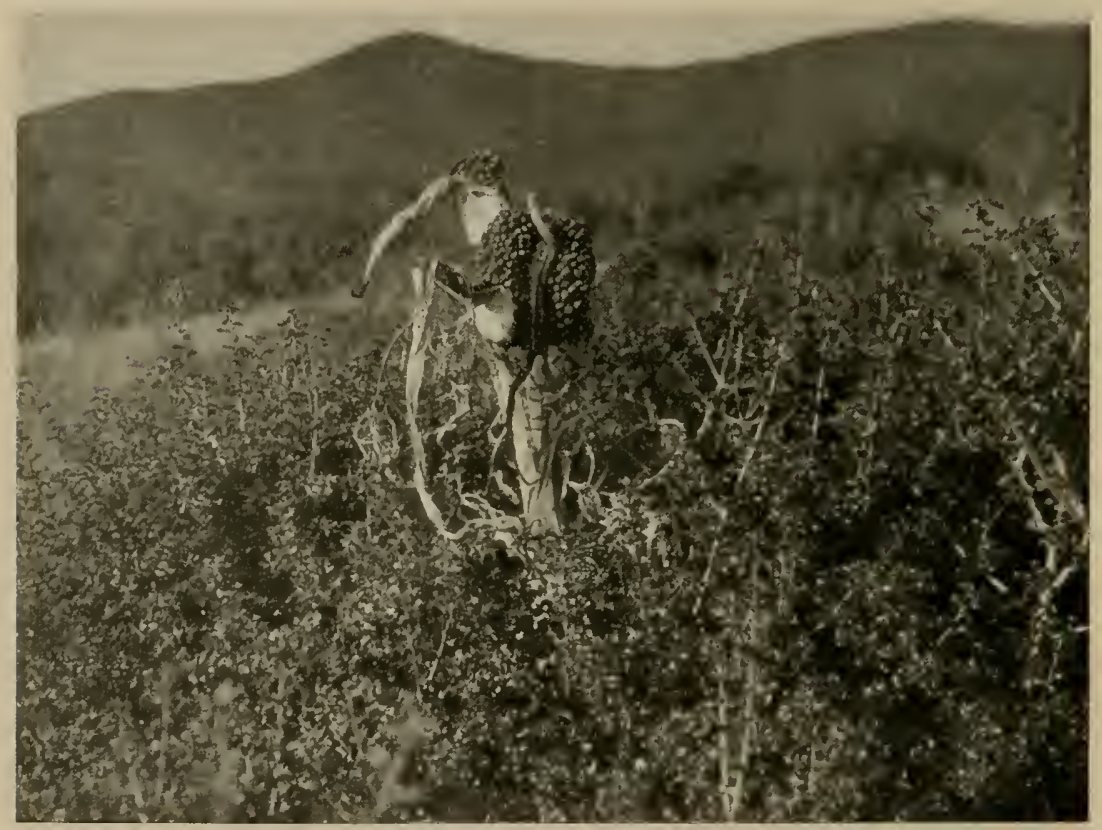

Dr. Laser phot.

Abb I7. Fruchtstände von Dracunculus vulgaris Schott. Der eine normal, der andere abnorm verdoppelt. Im Gebüsch von Quercus coccifera L.

Ameisenlöwen ihre Trichter gebaut. Es waren weite, tiefe Trichter, an deren Grund schon entwickelte große Larven saßen, die emsig Ameisen fingen. Wie ich später feststellen konnte, waren es besondere, von den unserigen abweichende Arten.

Durch die Büsche strichen Buchfinken und Ammern. Würger saßen auf den höchsten Zweigen. Eine Turteltaube stieg vor mir auf, während zwei große Falken durch die Luft strichen. 
Die Mittagssonne zitterte schon über der weiten Ebene bis zum Wardar, als ich zu meinem Quartier wieder abstieg. Bald hatte ich an steilen Felsen zu klettern, bald konnte ich eine Strecke über trockenen Rasen zwischen den Büschen wandern. Vor mir breitete sich das Tal aus, in welches weite Schuttdeltas der Bäche

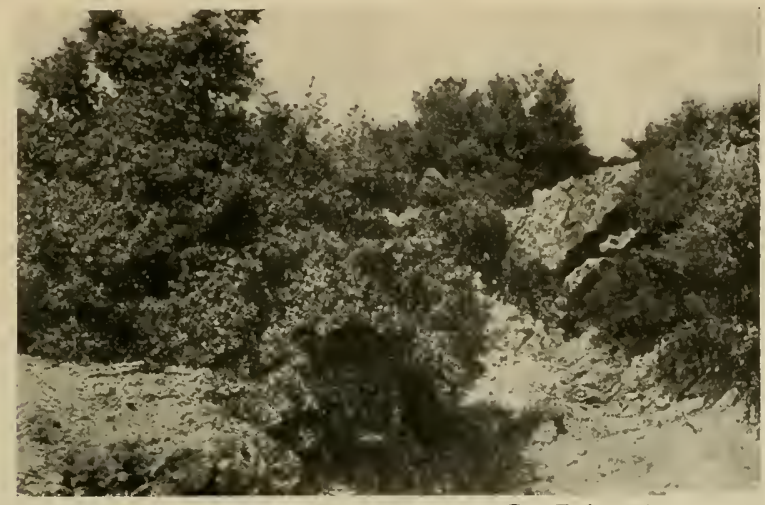

Abb. 18. Sommerliche Schlucht bei Gradec.

sich erstreckten, und wo zwischen den Maulbeerhainen die Zelte und Baracken unserer Truppen hervorlugten. Aus der Gegend des Doiransees hörte man Geschützfeuer. Zwei feindliche Flieger schwebten zu meinen Häupten und erkundeten unsere Stellungen. 


\section{DRITTES KAPITEL}

\section{DIE EBENE VON HUDOVA}

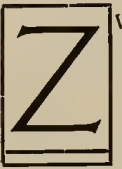

wischen den Vorbergen der Plaguša Planina und dem Wardar dehnt sich eine weite, fruchtbare Ebene aus. Sie ist offensichtlich Schwemmland des Wardar, seiner Nebenflüsse und der Bäche, die ihm von den Randbergen zuströmen. Vollkommen flach erstreckt sie sich auf eine Länge von $10 \mathrm{~km}$ und eine Breite von $6-8 \mathrm{~km}$. Ihre Längenerstreckung geht in der Hauptsache von Nordwesten nach Südosten, so wie der Wardar fließt, der sie südwestlich begrenzt. Jenseits, westlich des Flusses begleitet ihn in kurzem Abstand ein reichgegliedertes Hügelland, hinter welchem die bewaldete Marianska Planina bis $1500 \mathrm{~m}$ ansteigt. Hinter dieser Kette folgt ein malerischer Gebirgsstock, die Mala Rupa und Dudica, die über $2200 \mathrm{~m}$ emporsteigen, und noch im Juni auf der Nord- und Ostseite mit Schnee bedeckt sind. Im Norden und Osten zieht sich die Plaguša Planina mit ihren stark verarbeiteten und zerschnittenen Felsenhöhen von etwa $1000 \mathrm{~m}$ in sehr charakteristischer Umrißlinie gegen Valandova hin; zu diesem Städtchen senkt sich das Gebirge, unterbrochen von einer Reihe allmählich niedrigerer Gipfel hinab. Auf einem der letzten dieser Gipfel erhebt sich als weithin sichtbare Landmarke die Ruine einer Türkenburg. Der letzte Gipfel der Kette ragt als charakteristischer Vorsprung in die Hudovaebene hinein, wegen seiner eigentümlichen Form hieß er bei unseren Truppen die Muhnase. Angeblich sollte er diesen Namen der Ähnlichkeit mit der Nase des Generals der Mu. (Munitionskolonnen) verdanken.

Am Hang der Plaguša Planina zieht sich eine Reihe von Dörfern hin, Kaluckova mit dem Seuchenlazarett, Kalkova mit einem Pferdelazarett, Ahranli, Terzeli, Veseli, Piravo mit einem Offizierserholungsheim. Alle liegen sie in Nischen des Gebirges, beziehen ihr Wasser aus tief eingeschnittenen, hoch zum Gebirge hinaufreichenden Schluchten. So sind sie meist malerisch von Baumgruppen eingehüllt, unter denen schlanke Pappeln besonders weithin sichtbar sind. Aber alle, am wenigsten noch Piravo, 
hatten stark vom Krieg gelitten und die weithin schimmernden Häuser, welche die Dörfer so reizvoll und anziehend erscheinen ließen, waren meist Ruinen wie in Kaluckova.

Die ganze Ebene stand im späten Frühling in grüner Pracht, die aber nur ein schwacher Abglanz von ihrem Zustand im Frieden sein konnte; denn viele der Pflanzungen lagen jetzt brach und waren verwildert.-Vom Rand der Hügel bis weit in die Ebene hinein zogen sich stattliche Weingärten, die reichlich Knospen und aufgehende Blüten trugen. Obgleich an vielen Stellen Spuren von Reblausbefall bemerkbar waren, brachten die Reben im Herbste

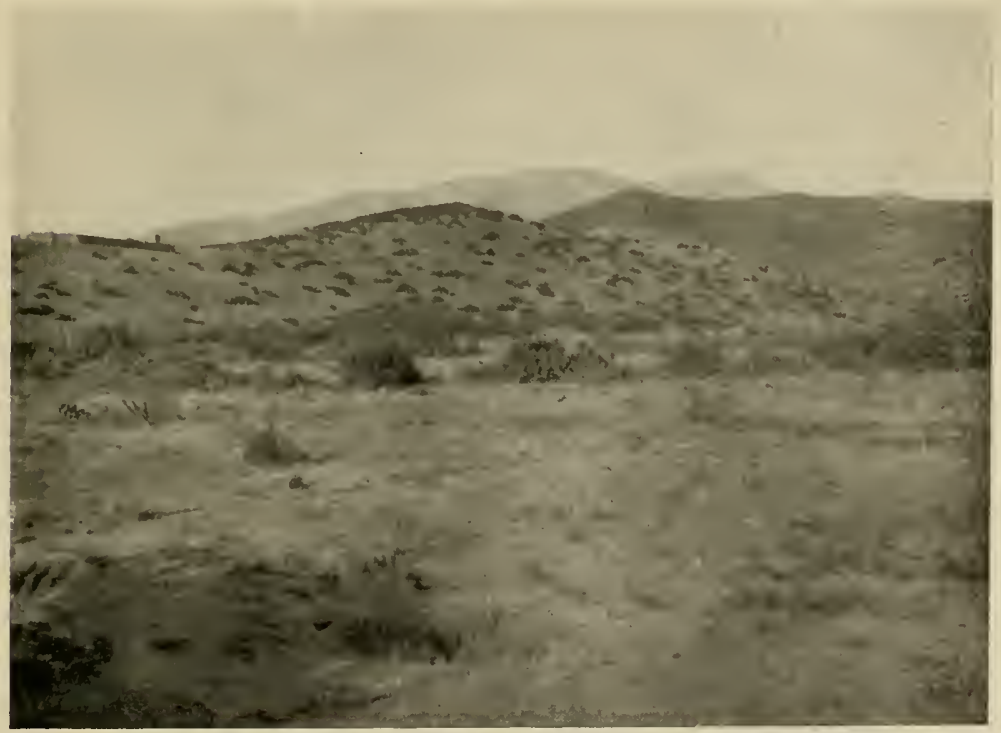

Abb. 19. Ebene von Hudova und erste Hügel mit Buschvegetation im Hochsommer.

reichen Ertrag, der in dem herrenlosen Gebiet den bulgarischen und deutschen Truppen sehr zugute kam. In der Ebene selbst nehmen Pflanzungen von $\mathrm{M}$ a u lbeerbäumen den größten Raum ein. In geraden Reihen durchzogen die Bäume weite Flächen; man sah ihnen noch die frühere, regelmäßige Beschneidung an. Meist war der Stamm in $1 \frac{1}{2} \mathrm{~m}$ Höhe beschnitten und strahlte ähnlich wie unsere Kopfweide von einer keulenförmigen Anschwellung in dieser Höhe einen Büschel von langen Ruten aus. Einzelne der Bäume trugen jetzt schon reife Beeren, die süß und saftig waren und bei den heißen Wanderungen über die Ebene eine angenehme Erquickung boten. 
In der zweiten Maihälfte war es schon recht heiß geworden; am Nachmittag waren regelmäßig schon $22-27^{\circ} \mathrm{C}$ im Schatten zu messen, also Temperaturen, bei denen unsere Schulkinder zuhause schon „Hitzferien" gehabt hätten. Ein wunderbarer blauer Himmel wölbte sich über der Ebene, meist am Nachmittag von großen weißen Wolkenballen durchsegelt, welche mächtige Schatten auf die umgebenden Berge warfen. Seufzend wanderte mein tüchtiger Bursche an meiner Seite, ein braver Bergwerksarbeiter vom Niederrhein namens Saddeler. Das war die erste Hilfe, die mir die Armee zugewiesen hatte. Er versorgte mich gut und faßte sofort Interesse für meine Tätigkeit, wanderte flott und eifrig mit mir durch das Land, wenn auch für seine Bergmannsaugen das Sonnenlicht Mazedoniens eine neue Gewöhnung erforderte. Ich erinnere mich gern an den tüchtigen Mann, der nach einigen Wochen zur Bergwerksarbeit heimgerufen wurde und mir von dort noch öfter Nachricht schickte.

Als ich die Ebene von Hudova durchstreifte, begleitete mich Saddeler zum ersten Mal und war fleißig mit mir auf der Jagd nach Insekten. Stundenlang konnte man durch die Maulbeerpflanzungen wandern, behindert nur manchmal durch die verwilderten Hecken. Hier war es einsam und die fleißigen Arbeiter fehlten, die sonst im Dienste des Seidenbaues emsig tätig gewesen waren. Im unteren Wardartal war ein Zentrum der Seidenkultur des Balkans gewesen. Die Maulbeerbäume lieferten das Laub als Futter für die Raupen des Seidenspinners und wurden von der hier im Gebiet schon stark mit Griechen vermischten Bevölkerung fleilig gepflegt. Die Dörfer am Rande der Ebene, so besonders Piravo, lebten vom Seidenbau und in vereinzelten Häusern konnte man jetzt auch im Kriege noch die Hürden mit Raupen bei der Fütterung und mit den Puppen in ihren Kokons in den Händen der Leute sehen. Aber im großen und ganzen ruhte der Seidenbau und die großen weißen Häuser von Gewgeli, dem Zentrum des Seidenhandels, die man von den Höhen aus fern am Wardar im Süden schimmern sah, waren zerschossen und die ganze Stadt verödet. Zwischen den Maulbeerbäumen der Ebene von Hudova weideten große Herden von Ziegen, Rindern und Pferden, die jetzt am Boden noch reichlich Futter fanden. Später im Jahr jedoch, wenn Gras und Kräuter verdorrt waren, da sah man die Weidetiere an den Maulbeerbäumen sich das letzte Grün holen. Es war ein bizarrer Anblick, wenn magere Rinder und Ziegen, 
selbst Pferde mit den Vorderbeinen in die Bäume stiegen und von den obersten Zweigen die Blätter abrupften.

Teils unter den Maulbeerbäumen, teils zwischen ihnen dehnten sicht prachtvolle Felder von Roggen, Weizen, Gerste und Hafer aus, welche im Jahre 1918 durch die Arbeit unserer Truppen gewaltig zugenommen hatten. Der sandige Schwemm-

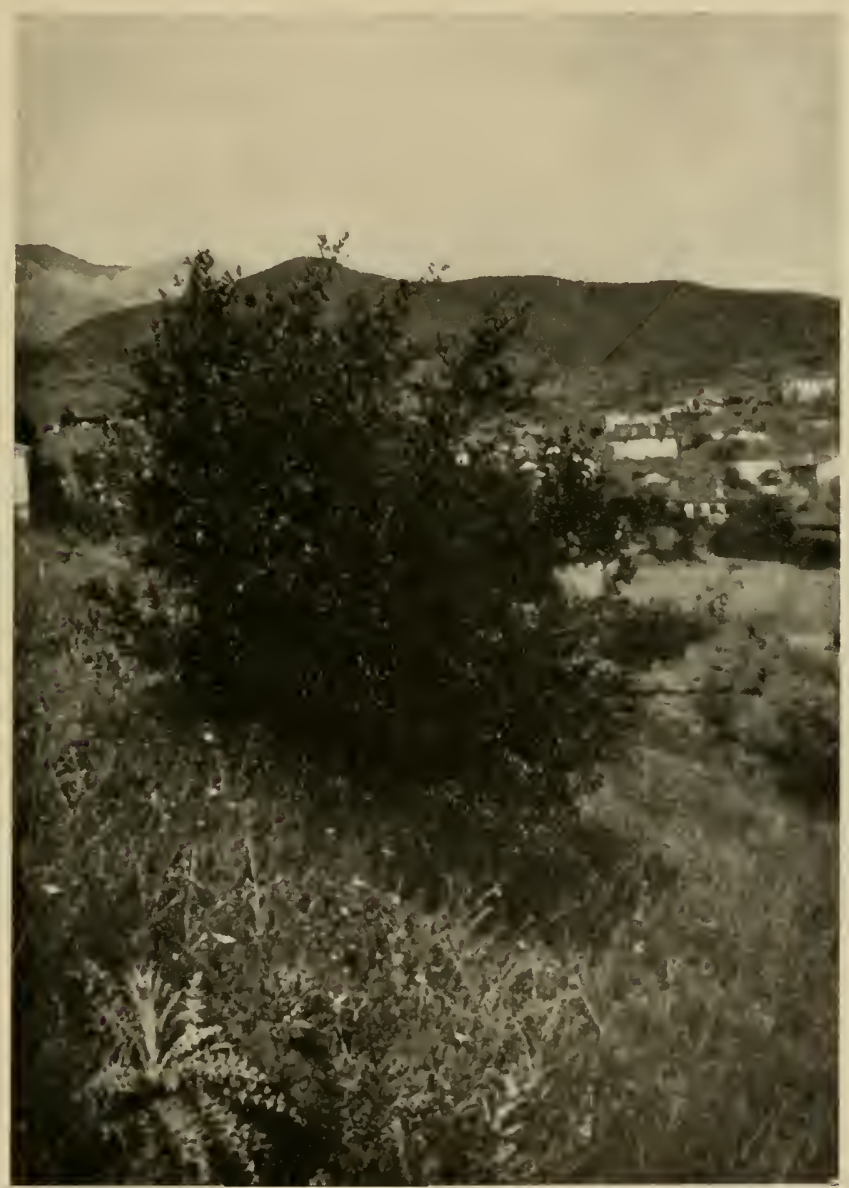

Dr. La s e r phot.

Abb. 20. Frühlingswiese mit Granatapfelbusch bei Kaluckova.

boden des Hudovatals trug reiche Frucht, wenn er gut bearbeitet wurde. Dabei war in vielen Gewannen künstliche Bewässerung notwendig. In der Ausnützung der Schluchtbäche, der Nebenflüsse des Wardar und dieses Flusses selber haben unsere Soldaten viel 
von den Bulgaren gelernt, welche auf diesem Gebiet ausgezeichnete Fachleute sind.

Manche Teile der Ebene glichen einem reichen Garten; da rankten an den Maulbeerbäumen die Reben hinauf und zwischen ihnen waren Tomaten, Zwiebeln, Bohnen angepflanzt. Die Reben wurden hier im Gebiet hauptsächlich zur Rosinenerzeugung gezogen. Wie ein Mittelpunkt des Seidenhandels, so war Gewgeli auch eine Stätte des Rosinenhandels gewesen. Der Wein blühte hier zwischen dem 15. Mai und I. Juni; die Trauben reiften von Ende Juli an und hielten sich bis tief in den Herbst hinein.

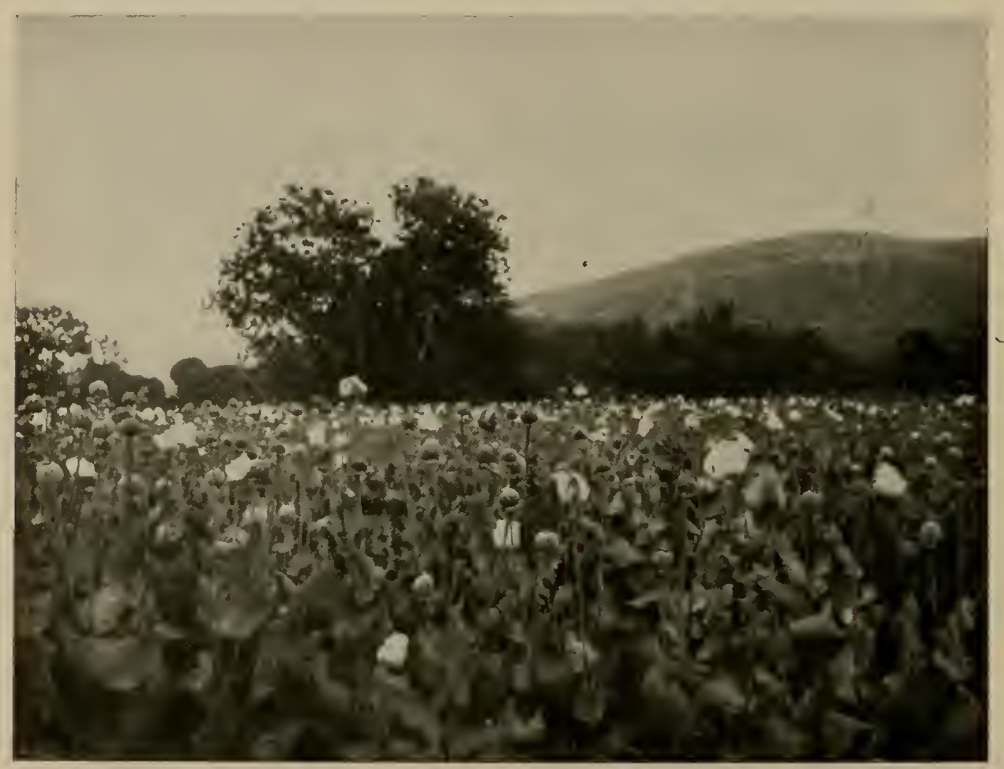

Abb. 21. Blühendes Mohnfeld. Mitte Mai bei Valandova 1918.

Die Bevölkerung des Tals hatte unter den relativ ruhigen Verhältnissen während unserer Besetzung den Anbau immer mehr aufgenommen. So sah man oft Männer, Frauen und Kinder schon in der ersten Morgenfrühe und bis spät in die Nacht auf den Feldern arbeiten.

Besonders auffallend war für unsere deutschen Augen der Anbau von zwei Ackerpflanzen, von Mohn und Baumwolle, die hauptsächlich im südöstlichen Teil der Ebene, gegen Piravo und Valandova hin, viel gepflanzt wurden. Die blühenden Mohnfelder gehörten in der ersten Maihälfte zu den köstlichsten 
landschaftlichen Reizen dieser Gegend (Abb. 21). Unter den zartgrünen, von Weinlaub umrankten Maulbeerbäumen dehnten sich weithin die Felder mit den stattlichen, über I $m$ hohen Mohnpflanzen aus, deren weiße und violette gefüllte Blüten sich gravitätisch im leichten Winde wiegten. Wie schimmerten die Felder silberig mit ihrem milchiggrünen Laub, wie bunt und heiter hoben sie sich von den dunklen Bäumen, die sie umrahmten, und von dem zarten Blau der fernen Berge ab. Welch zarte Abtönung der Farbe zeigten die Blütenblätter mit ihren welligen Rändern.

Ende Mai war der Mohn verblüht und jeder Stengel trug wie

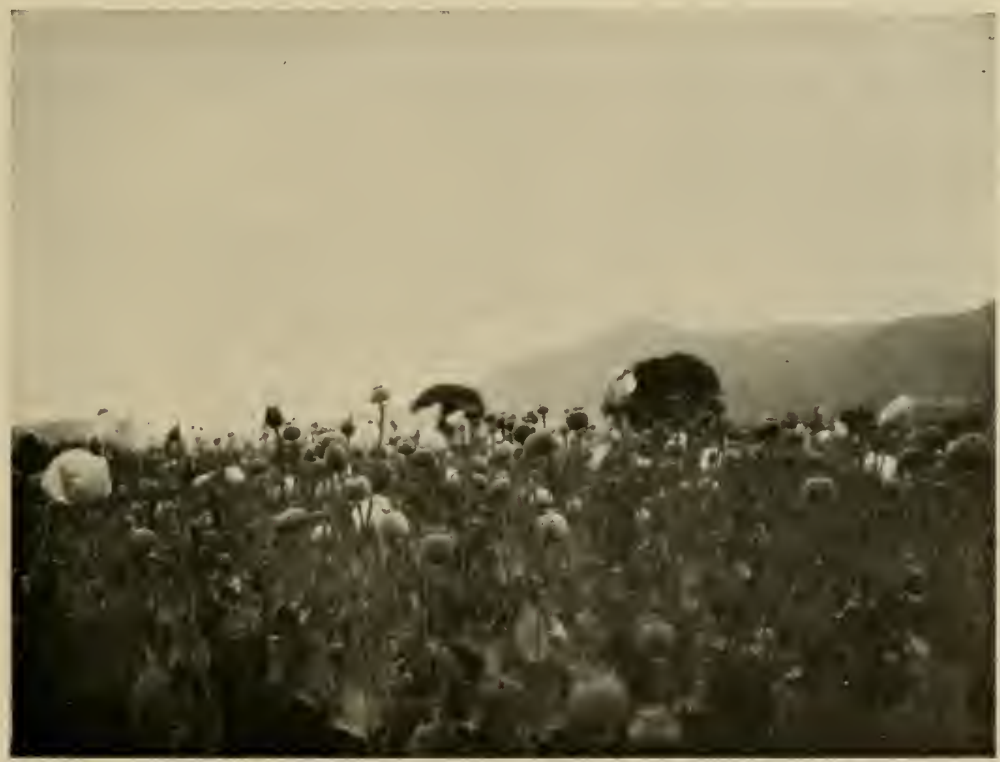

Abb. 22. Mohnfeld mit vielen Kapseln. Bei Valandova Ende Mai.

ein gekröntes Haupt die dicke grüne Kapsel (Abb. 22), welche nun von den fleißigen Bauern, die vorher an den Mohnfeldern durch Hacken und Unkrautbekämpfen schon reichlich Arbeit geleistet hatten, "geringelt" wurden. Das ist eine mühsame Arbeit, die sehr sorgfältig ausgeführt werden muß. Jede Kapsel bekommt einen wagerechten Ringschnitt, der nicht ganz herumgeführt wird. Meist werden mehrere Schnitte gemacht. Aus der Wunde fließt ein milchiger Saft hervor, der harzig gerinnt, meist nach einem Tage abgenommen und zu Klumpen zusammengeballt wird. Diese werden dann zu einer Art Kuchen zusammengeknetet und stellen 
eines der wichtigsten Landesprodukte dar. Aus ihnen werden Opium, Morphium, Morphin und all die wichtigen Arzneimittel hergestellt, die von diesen Substanzen abgeleitet sind. Es war für unsere Kriegsführung von der größten Bedeutung, daß wir ein Opiumland in der Hand hatten. So gefährlich dies Produkt der schönen Pflanze als Gift und Genußmittel ist, so segensreich hat es sich bei Hunderttausenden von Verwundeten als Mittel zur Narkose und Schmerzlinderung erwiesen. Das Rohprodukt wurde nach Deutschland geschafft und in dessen chemischen Fabriken weiterverarbeitet.

Die Fruchtkapseln, welche das Opium geliefert haben, sind noch imstande, Samen zu reifen. So sieht man denn im Juni die Felder gelb und braun werden. Schüttelt man die Kapseln, so rasselt es, als seien Schrotkörner darin. Die kleinen, schwarzen Samen werden geerntet und aus ihnen ein sehr gutes Öl gewonnen, von dem manche Flasche von unseren Soldaten zur Erleichterung der Fettnot nach Deutschland geschickt wurde. So stellt die Mohnpflanze mit ihrer doppelten Ernte ein sehr wichtiges, kostbares Landesprodukt Mazedoniens dar. In der Menge der Produktion wird Mazedonien allerdings von Kleinasien, Indien und China bei weitem übertroffen.

Nicht so wichtig, aber immerhin ein interessantes Erzeugnis der fruchtbaren Erde Mazedoniens ist die Baumwolle. Sie wird hier im Lande in einer einjährigen, krautigen Form gezogen. Im Frühjahr erinnert eine Pflanzung fast an ein Kartoffelfeld, später im Herbst, wenn die Kapseln platzen und der dicke Wattebausch aus den Spalten quillt, dann sieht sie ganz eigenartig und ungewohnt aus, allerdings nicht so schön als in den Tropen; denn im trockenen Land Mazedonien pflegt im Spätsommer alles zu verstauben.

Vor allem im Jahre 1917 gab es $z$ wischen den Feldern noch viele brachliegende Strecken. Da blühten bunte Blumen und um sie wimmelte eine reiche Insektenwelt. Große Büsche von roten Wicken und grelle Flecken einer gelben Wolfsmilchart waren neben Brombeer- und Weißdornbüschen die häufigsten Pflanzen. Bockkäfer und schwarze Blattwespen saßen in dichten Scharen auf der Wolfsmilch. Um die Weißdornbüsche flatterten Schmetterlinge in großen Scharen, die vollkommen unseren einheimischen Formen glichen. Da herrschte, entsprechend seiner Futterpflanze, der Heckenweißling (Aporia crataegi L.) vor, 
von dem ganze weiße Wolken die Hecken umschwebten. Fast ebenso häufig waren die gelbe Acht (Colias croceus Foure) und der Distelfalter. Letzterer (Vanessa cardui L.) ist in dem distelreichen Lande Mazedonien geradezu der Charakterschmetterling. Überall findet man ihn, auf Feldern und Wiesen, an den Flußufern, in den Schluchten, im Gebirge. Hier in der Ebene war er massenhaft vorhanden. In großen Mengen flog auch der Grasfalter Pararge Megaera L.

Auf Brachfeldern wuchsen in üppiger Pracht Kornblumen und roter Mohn, die man hier im Lande oft schon im April blühen sieht. Mit ihnen kommen Doldenpflanzen reichlich vor. Das war der Tummelplatz vieler Blattwespen und Schlupfwespen. Bienen sammelten den Blütenstaub des Mohns oder schnitten dessen rote Blumenblätter. An den Wegen sah man sie ihre Löcher im Boden bauen. Auch andere Formen von Solitären flogen hier (Abb. 22 b). Über ihren Baustätten strichen in brummendem Flug Hummelfliegen aus der Familie der Bombyliden. In raschem Zickzackflug flogen braungraue Wollschweber(Bombylizus fuliginosus $\mathrm{Wd}$. und punctatus $\mathrm{Fb}$.) um die Blüten, mit ihrem langen Rüssel in diese hineinlangend, während Trauerschweber mit düster gefärbten Flügeln über den lehmigen Pfaden hinflogen, die Bienenlöcher aufsuchend, in denen sie ihre Eier an den Bienenlarven ablegen (Anthraxarten, A. fenestrata Fabr., A. polyptermes Mg.

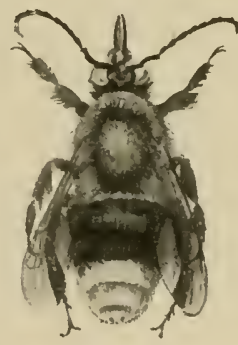

Abb. 22 b.

Halropa tarsata Spm. Solitäre Biene. und andere). Diese Fliegengattungen schmarotzen im Larvenzustand an Schmetterlingsraupen und vor allem an Bienenlarven. Zwischen den Büschen huschte eine wenig scheue, große, gutfliegende Heuschreckenart umher. Auf den Blüten tummelte sich ein reiches Leben von Käfern und Blattwanzen. Zwischen den Gräsern liefen langbeinige Weberknechte in großen Scharen umher. Es waren dies Zachus crista Brüll, eine große Art mit weißem Strich über dem Rücken und hell geringelten Beinen, sonst ganz schwarz, und eine kleinere hellere Form Metaphalangium propinquum (Lucas). Es freute mich, diese Tiere zu erbeuten, denn der Spinnenkenner Dr. Roewer hatte vor der Ausreise mich wissen lassen, daß keine einzige Art von Weberknechten bisher aus Mazedonien bekannt sei.

Im Weißdorn und den Heckenrosen jagten die Würger nach Insekten, rotrückige (Lanius collurio collurio L.) und rotköpfige 
(Lanius senator senator L.) und der große Schwarzstirnwürger (Lanius minor $\mathrm{Gm}$.). Grasmücken sangen im dichten Gebüsch; häufig waren mit ihnen die Nachtigalien. Ganze Schwärme von Sperlingen balgten sich mit Gold- und Grauammern herum. Hier im Süden Mazedoniens trat Ende Mai in Menge ein prachtvoller Vertreter der Ammern, die goldfarbene $\mathrm{K}$ a ppen a mmer mit ihrer dunklen Sammetmütze auf (Emberiza melanocephala Scop.).

Drei Arten von Spatzen traf ich in Mazedonien an, den gemeinen $\mathrm{H}$ aussperling (Passer domesticus domesticus L.), der häufig große, wie Webervogelbauten aussehende Gemeinschaftsnester baute. Noch häufiger war der Feldsperling ( $P$. montanus montanus L.), der vor allem die Dörfer bewohnte. Der Steinsperling jedoch (Petronia petronia macrorrhynchus Brehm) war viel seltener und fand sich vor allem in den großen Felsenschluchten.

Die Nachtigall im Wardartal ist Luscinia megarhynchus $\mathrm{Br}$.

Grasmücken gab es eine ganze Anzahl Arten. Wir konnten in der Umgebung von Kaluckova die Mönchsgrasmücke (Sylvia atricapilla atricapilla L.), die Dorngrasmücke (S. communis communis Lath.), die Zaungrasmücke (S. carruca carucca L.) und die Bartgrasmü cke ( $S$. cantillaus albistriata Brehm) nachweisen. Von Ammern herrschten vor die Zirlammer (Embcriza cirlus L.) und die Zippammer (Emberiza cia cia L.).

Auf den Wegen, am Pferdemist, war eine muntere Tätigkeit der Pillendreher im Gange. Zwei Arten waren es hauptsächlich, die man hier oft nebeneinander fand. Die eine Form war, wie ich im nächsten Jahr feststellte, schon früh im April bei der Arbeit; das war Sisyphus Schaefferi L., der Pillenwälzer, von dem oft Hunderte sich an einem Kuhfladen zu schaffen machten. Erst viel später im Jahre kam der große heilige Pillendreher (Ateuchus sacer L.) und mit ihm Scarabaeus piles Illig, dieses Charaktertier der Mittelmeerländer aus seinem Erdloch hervor. Überall waren sie in Mengen auf den sandigen Straßen, auf denen die Herden der Pferde ihren Kot hatten fallen lassen. Da sah man viele der glänzend schwarzen Käfer ihre großen Pillen aus Pferdekot die Straße entlang seitwärts auf die Wiese rollen und da in ein nicht sehr tiefes Erdloch hineinschaffen.

In der heißen Mittagssonne war ein lebhaftes Treiben um die Kothaufen am Wege. Die kleinen Sisyphus ließen sich leicht vertreiben, flogen dann auf und schwirten mit Gesumme $a b$, um bald wiederzukehren und den ganzen Kothaufen wieder mit ihren 
Leibern zu bedecken. Die großen Pillendreher waren schwerer in Bewegung $z u$ bringen. Aber auch sie kamen oft brummend und summend weither angeflogen, setzten sich an einem Kothaufen nieder und fingen bald an, mit Kopfschild und Vorderbeinen den Kot zusammenzuschaufeln. Sie schafften ihn unter ihren Körper, ballten ihn zusammen und rundeten ihn unter steter Arbeit der zwei hinteren Beinpaare zu einer immer glatter werdenden Kugel ab. Diese rollten sie dann in emsiger Arbeit über den Weg, am liebsten an den Hang des Hügels zwischen die Wiesenpflanzen. Dort gruben sie Löcher in die Erde, in welche sie ihre Kugel schafften, um unter dem Boden in schützender Höhle mit aller Ruhe ihre Beute zu verzehren. Verdient war diese Ruhe wohl, denn welche Arbeit hatten die seltsamen Tiere beim Heranrollen ihrer Mistkugel geleistet, die ihnen oft den Hügel wieder heruntergerollt war, um dort in die Hände eines Mitbewerbers zu fallen, wenn es einem solchen nicht vorher schon gelungen war, sie ihm in scheinbar gemeinsamer Wälzarbeit $z u$ entwenden. Die Bereitung der eigenartigen Brutnahrungsbirne aus Kot, welche der französische Entomologe Fabre beschrieben hat, in deren Nische der Käfer sein Ei ablegt, konnte ich nie beobachten; allerdings hielten mich davon die vielen anderen Tiere mit ihren Problemen ab, die ich studieren wollte.

Tiere, welche man im Frühsommer im ganzen Gebiet häufig antraf, welche auf blühenden Pflanzen und auf Bäumen saßen, die man leicht von Büschen herunterschütteln konnte, waren die bunten Baum- und Blattwanzen. Viele von ihnen waren auch ganz seltsam gestaltet.

Sie gaben zu manchen Beobachtungen Anlaß, und so will ich einiges von ihnen berichten. Ich verdanke die Bestimmungen Herrn Dr. Schumacher. Die Formen sind vielfach tiergeographisch sehr interessant, indem sie wie in anderen Gruppen die Zusammensetzung der mazedonischen Fauna aus südlichen, nördlichen und östlichen Elementen erkennen lassen.

Von Schildwanzen ist eine Form zu erwähnen, welche auf den auf S. 189 Abb. 100 abgebildeten Echiumstauden häufig vorkam. Es ist ein großes braunes Tier mit weißen Punkten an der Oberseite übersät. Bei Berührung läßt es sich sofort fallen und verschwindet vollkommen $z$ wischen den braunen verwelkten Wurzelblättern der Stauden, welche die gleichen weißen Punkte zeigen. Der wissenschaftliche Name der Art ist Psacacta exanthematica Scop. 
Ein interessanter Fund war Leprosomatessa (Leprosoma) carinata Mont., eine flache sandfarbene Art, ein ausgesprochenes Steppentier, das bisher außer in der Walachei und im Banat noch nirgends gefunden worden war. Auf Disteln und Flockenblumen fand sich eine Blumenwanze mit stark vortretenden Seitenecken des Vorderrückens und fünf geschwungenen erhabenen Leisten auf der Oberseite (Ancyrosoma leucogramma Gmel.). In geradezu überwältigenden Mengen lebte auf Kirschbäumen und Pflaumenhecken Apodiphus amygdali Germ., eine vorderasiatische Art. An Mengen wetteiferte mit ihr auf Disteln Carpocoris purpureipennis Deg. und die Beerenwanze Dolycoris baccarum L.

Bemerkenswert war das Vorkommen von Nezara-Arten, welche in den Tropen und Subtropen weit verbreitet sind, so $N$. viridula L. und $N$. (Acrostermum) heegeri Fieb., welch letztere z. B. aus Deutsch-Ostafrika bekannt ist.

Ein wichtiger Fund bei Kaluckova war Opisthotaenia fulvipes Reut., die neu war für den europäischen Kontinent und nur aus Kaukasien und Kleinasien bekannt war.

Habe ich schon oben Formen von Wanzen erwähnt, welche ihrer Ungebung auffallend ähnlich sind, so möchte ich ihnen noch eine Form hinzufügen, Phyllomorpha laciniata Vill., eine Blattwanze, deren Gestalt durch Fortsätze am Rand und deren graubraune Färbung sie einem verschlissenen, verdorrten Blatt ähnlich machte.

An dieser Stelle will ich noch zwei Fälle auffallender Ähnlichkeit von Insekten mit Tieren und Blumen erwähnen, die ich

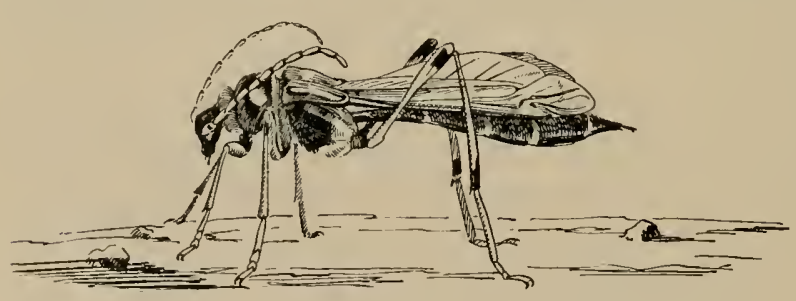

Abb. 22 c. Necydalis panzeri Herold. Wespenähnlicher Käfer. in Mazedonien beobachtete. Die eine betrifft einen Käfer aus der Gattung Necydalis, den ich auf der Plaguśa Planina fing, und welcher einer Wespe mit dünner Taille in Farben und Formen ganz außerordentlich ähnlich sah (Abb. $22 \mathrm{c}$ ).

Noch merkwürdiger war eine Beobachtung am Wardar oberhalb Demirkapu. Dort wuchs an lichten Stellen im Weidengebüsch eine stark behaarte Pflanze mit leuchtend violetten Blüten (Anchusa hybrida Tenn.). 
Auf dieser Pflanze fingen wir eine ganze Anzahl kleiner Schmetterlinge, tagfliegende Eulen (Janthina friwaldszkyi Dup.), welche in Größe und Ton und Charakter der Farbe aufs täuschendste den Blüten der Pflanze glichen. Sie setzten sich stets nach kurzem Flug auf die Pflanze in die Region der Blütenstände, fast stets auf die violetten Blüten selber (Abb. $22 \mathrm{~d}$ ).

Ich bin geneigt, die offenbare Anlockung durch die Blütenfarbe in ähnlicher Weise zu deuten, wie ich sie schon früher bei anderen Tieren in einem allgemeineren Zusammenhang zu erklären suchte. Ich vermute, daß die kleinen Schmetterlinge beim Flug zu den Blüten die Farbe aufsuchen, welche ihr eigener Körper trägt und daß dies der Vereinigung der Geschlechter dient. An anderer Stelle dieses Buches erwähne ich, dalb auch andere Schmetterlinge durch den Duft von Blüten angelockt wer-

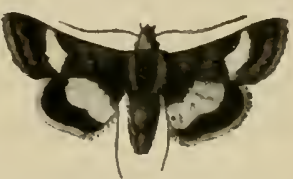

Abb. $22 \mathrm{~d}$. Janthinea frizialdszkyi Dup. Blaue Blumen befliegende Tageule. den, ohne dort Nahrung zu suchen, nur um in beiden Geschlechtern sich dort zur Begattung zu treffen. Und dort erwähne ich auch, daß die Pappatacci-Männchen dem Geruch des Menschen nachfliegen, obwohl sie sein Blut nicht saugen. Sie tun dies nur, um dort ihre Weibchen zu finden, die allnächtlich, um Blut zu saugen, die Menschen aufsuchen.

Im Süden begrenzt die Ebene von $\mathrm{Hudova}$ eine Kette hoher Hügel, welche von kurzem Buschwerk bewachsen und von vielen tiefen Schluchten durchzogen sind. Die Hügelkette zieht sich ziemlich gerade von Osten nach Westen, bis sie gegenüber von Miletkovo mit einem steilen Absturz am Wardar abbricht. Ihr entlang zieht, etwa $\mathrm{I}-2$ Kilometer nördlich von ihr, ein kleiner Nebenfluß durch die Ebene, der sich auch gegenüber Miletkovo mit dem Wardar vereinigt; es ist der unweit Dedeli beim Hain Mamre in einem mächtigen Quell entspringende Kozludere, der nach Aufnahme einer Reihe von Süd und hauptsächlich von Norden ihm zufließender Nebenbäche als Bojimiadere sich in den Wardar ergießt. In der Umgebung seiner Mündung ist die Ebene fruchtbar. Dickichte von Weiden und Erlen umrahmen schöne Durchblicke auf die das Tal umgebenden Gebirge. Einzelne riesengroße, uralte Bäume, vom Talwind alle nach einer Seite gebeugt, waren ganz eigenartige und seltene Erscheinungen in diesem Lande. Es waren teils Eichen, teils Rüster. Ich habe oft ihre charaktervollen Formen bewundert, wenn ich am späten Nach- 
mittag durch die Ebene dem Abendhimmel entgegen wanderte. Solche Glut und Farbenpracht des Sonnenuntergangs wie in diesem Winkel des Tals bei Mravinca, habe ich in meinem Leben nicht oft genossen, obwohl das Schicksal mich nicht selten an schönste Stellen der Erde geführt hat. Mein Ziel bei diesen Wanderungen war neben dem Genuß der schönen Landschaft zoologische Beobachtung. Ich wollte feststellen, welchen Vogelarten die alten Riesen als Schlafbäume dienten. Wo ein großer Baum in Mazedonien aufragt, wird er von Vögeln als Nachtquartier aufgesucht und je einsamer so ein Baum steht, um so eigenartigere Gäste kann man auf ihm vermuten. Steht er am Rande einer Stadt oder in einem Dorf, so ist man in Mazedonien sicher, jeden Abend hunderte, ja tausende von Dohlen in ihm einbrausen zu hören. Der Himmel verdunkelt sich, wenn sie in Scharen ankommen und ihr kreischendes Geschrei die Luft erfüllt. Meist begleiten sie, ebenfalls in großer Anzahl, Saatkrähen und Nebelkrähen, die nicht weniger geräuschvoll sind.

Die Rabenvögel Mazedoniens, welche wir in dieser Gegend feststellten, gehörten zu folgenden Formen: Die Dohle (Coloeus monedula soemmeringi [Fisch.]), die Satkrähe (Corvus frugilegus frugilegus L.), die Nebelkrähe (Corvus cornix pallescens Mad.).

Ist die Gegend etwas einsamer, steht der alte Baum etwa nur neben einem stillen Gehöft, so dient er auch edleren Gästen als nächtliche Ruhestätte. Dann sammeln sich wohl auf seinen höchsten Ästen Bussarde, Habichte, Falken der verschiedenen Arten. Meist hält aber dann jeder einzelne seinen Ast für sich allein besetzt und jagt einen verspäteten Ankömmling erbarmungslos davon. Auf den Baumriesen in der Ebene des Wardar konnte man im Anfang der Besetzung durch die verbündeten Heere oft mächtige Nachtgäste aufbäumen sehen. Da saßen in ihren Kronen die häufigen $\mathrm{K}$ aiseradler und gelegentlich einmal ein Steinadler; vor allem aber seltsam und eindrucksvoll waren die großen Geier, von denen Mönchsgeier und Gänsegeier nicht selten in der Dämmerung in den höchsten Ästen sich niederließen. Es war ein phantastischer Anblick, wenn durch die mächtigen Körper der riesigen Vögel bizarr verändert der Umriß des Baumes yegen den bernsteingelben Abendhimmel sich abhob. Wie Bildsäulen standen die Geierkörper in dem schimmernden Glanz. Von Zeit zu Zeit erhoben sie sich von ihren Sitzen und entfalteten ihre 
mächtigen Flügel, deren gespreizte Schwungfedern als dunkle Silhouetten sich von der goldenen Fläche einzeln abhoben. Senkten sie sich dann wieder auf die Kronen der Bäume nieder, so schienen sie auf die Hälfte der früheren Grölie zusammenzuschrumpfen, wenn sie ihre Flügel zusammenfalteten und den langen mageren Hals einzogen.

Je länger der Krieg clauerte, je öfter von Soldaten und Offizieren auf die großen Vögel gejagt wurde, um so seltener kamen sie in die Wardarebene. Umso schwerer war es, an die freistehenden Bäume anzuschleichen, um sie zu beobachten und zu erlegen. Da nützten die wohlmeinenden Befehle unserer obersten Heeresleitung nicht viel, durch welche der Abschuß der großen Vögel im Interesse des Schutzes der „Naturdenkmäler“ immer wieder unseren Truppen verboten wurde. Die Offiziere verhinderten zwar vielfach ihre Mannschaften am Abschuß der Adler und Geier; aber sie selber und die Ärzte der Lazarette konnten oft dem Jagdeifer nicht widerstehen und schlichen sich abends an die Schlafbäume heran, von denen mancher stolze Adler und stattliche Geier heruntergeschossen wurde. Und alle Schonung durch das deutsche Heer konnte nicht viel nützen, denn gedankenlos wurde von den Bulgaren, in deren Interesse wir sie schonen wollten, alles was auffallend war, weggeknallt.

So waren denn schon im Sommer 1917 die meisten Schlafbäume verlassen; später waren viele von diesen stolzen, schönen Produkten jahrhunderte langen Wachstums der Holznot der Truppen zum Opfer gefallen. Geier und Adler kamen nunmehr selten ins Tal. Aber immer noch konnte man täglich mehrere Paare der mächtigen Tiere, fast immer Männchen und Weibchen gemeinsam, die weite Ebene überfliegen sehen, wenn sie von einem Gebirge zum anderen flogen, in welchem sie ihre Schlupfwinkel hatten, wo sie brüteten und vor Nachstellungen sicher waren. Die Erinnerung an manche mazedonische Landschaft ist mir unzertrennbar verknüpft mit dem Flugbild der stetig und rasch mächtige Weiten durchfliegenden Raubvögel, die in wenigen Stunden von Griechenland bis nördlich der Donau reisten, Kleinasien, die Dardanellen und Albanien besuchten und über all den Kriegsschauplätzen majestätisch hinschwebten, auf denen die Heere der Welt verteilt waren. Dann und wann senkten sie sich nieder, um aus den Armeeschlächtereien, aus den Abfallplätzen der Truppenlager, an Heerstraßen oder auf Schlachtfeldern sich ihre Beute zu holen, 
ein Geschäft, an das in diesem Teil der Welt seit Jahrtausenden jede Generation der Aasvögel sich wieder hatte gewöhnen können.

In dem feuchteren Teil der Ebene, gegen Mravinca zu, sah man oft große Herden von Störchen durch Sumpf und Felder stelzen. Zwanzig bis dreißig waren ihrer häufig und manchmal mochten es selbst ihrer Hunderte sein, die man in einem Abschnitt der Ebene beieinander sah. Es war ein reizvoller Anblick, wenn die großen, schwarz-weißen Vögel mit ihren roten Beinen durch das hohe Gras und Schilf der sumpfigen Strecken stolzierten, bald tief geduckt am Boden suchten, bald den roten Schnabel hoch in die Luft warfen. Dann und wann ging ein

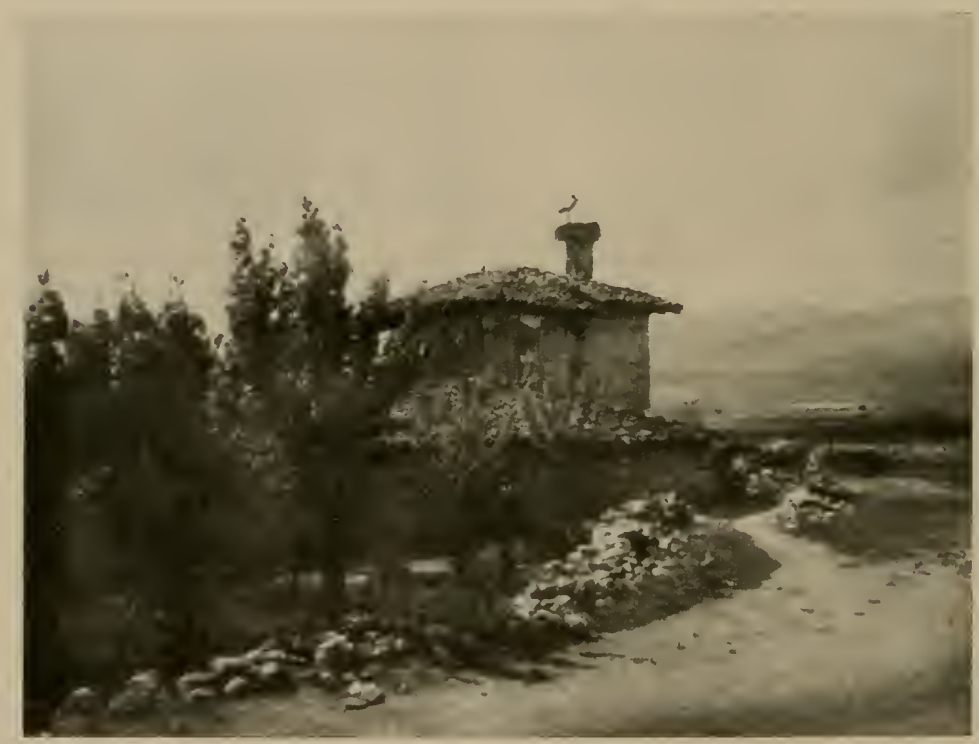

Abb. 23. Haus mit Storchennest in Piravo.

mächtiges Klappern vieler Schnäbel los. Das war die Zeit, wenn sie ihre Jungen aus den Nestern hinausführten, und sie lehrten, ihre Beute $z u$ finden und $z u$ fangen. Rings um die Ebene fanden sich auf Bäumen und auf den Dächern der Häuser viele Storchennester. Nicht nur im Sumpf zwischen Binsen, Schwertlilien und anderen Sumpfpflanzen wateten die Störche umher, auch auf den trockenen Feldern wetteiferten sie an Farbenpracht mit den Kornblumen, dem wilden, roten Mohn und den Kamillenflächen. Dort waren sie eifrig hinter Eidechsen und vor allem Heuschrecken 
her, die mit dem fortschreitenden Sommer heranwuchsen und allmählich eine sehr lohnende Beute darboten.

So viel Frösche die Störche auch fingen, man hatte doch den Eindruck, daß es deren nicht weniger wurden, wenn man nachts durch die Ebene wanderte. Wenn der Vollmond sein Licht durch die Büsche schickte und die fernen Felsengrate der Gebirge silbern aufleuchteten, dann schallte über die Ebene das gewaltige Konzert der Frösche. Ungeheuer viel von diesen Tieren mußte es hier geben, denn es klang wie ein gewaltiges Riesenorchester, was da aus dem Sumpfe erscholl. Die Stimme des häufigsten mazedonischen Frosches klingt anders als die unserer Frösche, obwohl die Rana ridibunida Pall., der mächtig große Frosch dieses Landes, unserem Teichfrosch sehr nahe steht. Aber sein gewaltiges, sonores Lachen und Meckern, das ihm den Namen des Lachfrosches gebracht hat, ist eine eigenartige, volltönende Melodie, die in stiller, einsamer Nacht einen großen Eindruck macht. Mein getreuer Mitarbeiter und Begleiter, der tüchtige Herpetologe Prof. Lorenz Müller, stand seinen Lieblingen und Opfern so nahe, daß er wundervoll und täuschend ihre Stimmen nachmachen konnte. Hatte er unsere Gesellschaft durch sein Gequake in heiterste Stimmung versetzt, so konnten wir alle nicht mehr anders, als mit freundlichen Erinnerungen des mazedonischen Lachfrosches gedenken.

Einen Vogel, der in der Ebene von Hudova durch sein massenhaftes Auftreten einen besonderen Eindruck machte, möchte ich nicht vergessen. Es ist das der Truthahn, der auf dem Balkan sehr viel als Haustier gezüchtet wird. Während man ihn bei uns meist nur in einzelnen Paaren im Bauernhof $\mathrm{zu}$ sehen pflegt, wird er hier im Süden in großen Herden auf die Weide getrieben. 400-500 Truthähne und Truthennen mit ihren Kücken wanderten oft durch die Büsche und Maulbeerhaine. In langen Reihen liefen sie hintereinander und wenige Kinder genügten, um sie zusammen zu halten, auf die Weide hinaus und sicher in die Dörfer nach Hause zu treiben, wo sie mit den Hühnern auf den Bäumen übernachteten. Ein buntes, malerisches Bild war solch eine Putenherde, wenn sie, geleitet von den farbig gekleideten Mazedonierkindern durch das blühende Unkraut, die Kornblumen und den Mohn, geschäftig, den Schnabel am Boden, dahinliefen. Mancher solche Truthahn, um teures Geld gekauft, wanderte mit dem Urlauber in das hungernde Deutschland. 


\section{MRAVINCA UND SEIN FELDLAZARETT. MAZEDONISCHE SCHILDKRÖTEN UND FISCHE.}

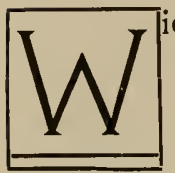

ie viele schöne Erinnerungen, menschliche und wissenschaftliche Eindrücke weckt mir der Name Mravinca. Von Kaluckova waren es etwa zwei Stunden Wagenfahrt über die Ebene südlich nach Mravinca. Von weitem schon, gleich nach der Ausfahrt, sah man über die ganze Ebene hinweg das weiße Schwesternhaus blinken, das hoch am Hügel gelégen, einer kleinen Kapelle glich. Dahinter erhoben sich die rosagrauen Hügel, dürr und unscheinbar, verbranntes, ödes Gelände, das aus der Ferne keine Reize versprach. Kam man näher, so sah man die tiefen Schatten der Schluchten das Gelände zerlegen, davor jetzt Anfang Juni noch grüne Wiesen und Gemüsegärten; hie und da blinkte Wasser des Flüßchens und von Bewässerungskanälen auf, getrennt und beschattet von Gruppen von Weiden, grüne Streifen in der Landschaft mit ihrer Einfassung durch Schilf, Binsen und Schwertlilien bildend. Vor dem Steilabfall des Hügelrandes führte die Landstraße von Valandova nach Miletkovo zwischen den Bauten des Feldlazaretts 358 hindurch, oft bei starkem Verkehr die ganze Gegend mit Staub überschüttend.

Ritt man näher heran, so hatte man zunächst den Eindruck eines großen Zeltlagers. Talwärts von der Landstraße breiteten sich etwa ein Dutzend große braune Segelstoffzelte aus, an denen die deutschen Fahnen lustig im Winde flatterten. Die Krankenzelte waren meist für Verwundete bestimmt; denn das Feldlazarett $35^{8}$ war ein chirurgisches Spital.

Auf den ersten Anblick schien die Anlage höchst ungeeignet als Lazarett. Man dachte, der Staub der Landstraße müsse das Leben dort unleidlich gestalten und die Heilung der Wunden gefährden. Auch schien die Hitze in dem offenen, baumlosen, schattenfreien Gelände wohl unerträglich $z u$ sein und in den ge- 
schlossenen Zelten mußte sie wohl noch gesteigert sein. Aber bei genauerem Zusehen erwies sich das Lazarett als sehr geschickt angelegt. Schatten war im Gebiet nirgends zu haben. Staubentwicklung war hier im feuchtesten Winkel der Hudovaebene immerhin geringer als sonstwo, die Zufahrtsstraßen waren sehr günstig, um den An- und Abtransport der Verwundeten zu beschleunigen.

Zudem waren die Zelte, in denen Kranke lagen, alle mit Berieselungsanlagen versehen, welche eine gewisse Abkühlung ermöglichten. Ein großer Wasserturm, der zu diesem Zweck errichtet war, verriet, daß genügend Wasser vorhanden sein mußte. Dazu kam die Lage des Lagers am Ausgang einer Schlucht, welche abends mit dem Talwind regelmäßig Kühlung brachte.

Ferner war das Lazarett mit den Jahren der Besetzung des Landes immer stabiler geworden. Es war immer mehr zum Musterlazarett des Kriegsschauplatzes geworden. Für mich und meine Leute war es bei der gastlichen Aufnahme, die wir dort stets fanden, nach anstrengenden Märschen und schwerer Arbeit ein richtiges körperliches und geistiges Erholungsheim. Der Chef, Stabsarzt Dr. Weyer, eine frische, tatkräftige Persönlichkeit, empfing mich, nachdem ich ihm meinen ersten Besuch gemacht hatte, stets fröhlich und gastfrei. In seinem Lazarett hielt er auf strenge Ordnung und Sauberkeit. Und er hatte alle Möglichkeiten ausgenützt, um sein Lazarett zu vervollkommnen. Viele glückliche Operationen hatten ihn in freundschaftliche Beziehungen zu bulgarischen Truppen gebracht, die ihm in der Folge durch Lieferung von Steinen und anderem Baumaterial sein Lazarett verbessern halfen. So habe ich im Verlauf meiner Besuche in Mravinca dort zwei lange, luftige Steinhäuser entstehen sehen, in denen die Verwundeten im Sommer kühler, im Winter wärmer lagen, als in den Zelten. So war denn auch zum Schluß ein stattliches, steinernes Operationshaus gebaut worden, das sterile Räume enthielt und viel sicherer zu operieren gestattete, als das alte Operationszelt.

Nicht minder gut war für die Mannschaft und das Pflegeund Sanitätspersonal des Feldlazaretts gesorgt. Eine besondere Wohltat war ein schönes zementiertes Schwimmbassin, in dem ein Dutzend Männer schwimmen und sich im Wasser tummeln konnten. In ihm habe ich manche erquickende Stunde mit den jungen Fliegeroffizieren von $\mathrm{Hudova}$ verbracht; denn Badegäste aus der ganzen Nachbarschaft kamen fast jeden Tag dort an. 
Diese wurden auch oft im Lazarett bewirtet und gastlich beherbergt, wie das mir ja nicht selten widerfuhr. Jenseits der Landstraße war am Abhang der Hügel eine ganze Reihe von „Unterständen“ eingebaut, kleine Hütten mit steilen Dächern, am Felsen angelehnt oder zum Teil in ihn eingefügt. In jedem dieser malerischen, sauberen Häuschen war je einer der Beamten des Lazaretts wohnhaft und jeder hatte es im Laufe der Zeit behaglich ausgestattet und je nach seiner Individualität künstlerisch eingerichtet. Da wohnten der Oberapotheker, die jüngeren Ärzte, die Inspektoren, der Röntgeningenieur. Ganz oben über den anderen Bauten in luftiger Höhe am Berg, erhob sich das weiße Schwesternhaus, das wir schon aus der Ferne erblickt hatten, bewohnt von vier ganz vorzüglichen, sympathischen Operations- und Verwaltungsschwestern. Hoch über den Männern hausten diese einträchtig in dem sauberen, zierlich ausgeschmückten Heim. Es war immer ein fast formeller, feierlicher Besuch, den man in dem feinen Häuschen abstattete. Die vier, nicht ganz jungen, sehr gut zusammen eingearbeiteten, getreuen Schwestern mit ihrer unermüdlichen, aufopfernden Tätigkeit für ihre Verwundeten werde ich nicht so leicht aus dem Gedächtnis verlieren. Ich lernte das Lazarett genau kennen, habe manche Pflege, manche Operation mit erlebt, Sanitätsschule, tägliche Prüfung der Mannschafts- und Krankenkost mitgemacht. Und noch dazu manche schöne, fröhliche Stunde dort erlebt.

Während Mittags die Männer und die Schwestern gesondert rasch zwischen der Arbeit ihre Mahlzeit zu sich nahmen, versammelte man sich abends nach getaner Arbeit gemeinsam in den Kasinos. Im letzten Jahre gab es ein Sommer- und Winterkasino. Ersteres war das interessantere, letzteres das künstlerisch bessere.

Das Sommerkasino war ein ganz kunstloser Käfig; es war aus einem dünnen Gestell aus Balken und Latten gebaut, mit einem festen, dachpappegedeckten Holzdach überwölbt, seine Außenwände bestanden aber nur aus Drahtgaze, so daß es aussah, als sei es durchsichtig. So konnte man bei Tag und was noch wichtiger war im helldurchleuchteten Drahthaus nachts verweilen, ohne von den Malariamücken gefährdet zu sein. Im kühlen Windzug, der von den Bergen kam - das Kasino lag am Ausgang der Schlucht -, konnte man in der heißesten Zeit des Jahres dort tafeln und sich bis tief in die Nacht der getanen Arbeit und seines Lebens freuen. Da saß ich oft an dem großen kreisrunden Tisch mit den tüchtigen, 
freundlichen und fröhlichen Menschen, Männern und Frauen, die hier drei Jahre lang im Dienste des Heeres und des Vaterlandes gemeinsam verdienstvolle Arbeit geleistet haben. Da wurde erzählt, diskutiert und debattiert. Man erfuhr viel von Landessitten, von medizinischer Arbeit, von der Natur des Landes und sprach viel von zukünftigen Absichten in der Heimat im Frieden; denn damals war noch frische, zuversichtliche Stimmung und jedermann dachte an ein starkes, tüchtiges, sicheres Vaterland nach dem Kriege. Da wurde auch manchmal gesungen und mit allerhand Aufführungen ein Fest gefeiert. Jedermann hatte Interesse für meine Arbeit, beobachtete und sammelte mit mir, und jedesmal, wenn ich in längeren Zwischenräumen wieder als Gast eintraf, hatte man mir interessante Funde von Tieren, Nestern und Bauten aufgehoben. So ist es verständlich, daß ich mit meinen ganzen dort so gut aufgehobenen Leuten niederen und höheren Ranges immer wieder gern in Mravinca einkehrte und einige Tage Ruhe und Erfrischung suchte. Nach starker, ermüdender Arbeit konnte man hier unter fleißigen Arbeitsmenschen eine schöne Erholung und Anregung finden. Mravinca nannte ich daher, solange ich in Mazedonien war, mein seelisches Erholungsheim.

Und manche stille beschauliche Stunde habe ich dort auf der Veranda des schönen hochgelegenen Hauses des Chefarztes zugebracht, das er mit verfeinertem Geschmack und einfachen Mitteln der widerspenstigen Natur des Landes abgezwungen hatte. Im Liegestuhl ausgestreckt, nach kühlendem Bad im Schwimmbassin, wartete ich im sinkenden Tag die Zeit ab, zu der all die fleißigen Frauen und Männer mit ihrer Tagesarbeit fertig waren und die Hände zum leckeren Mahle ausstrecken konnten. Da sank dann mir gegenüber die heiße Sonne Mazedoniens allmählich gegen den Rand der Ebene hinab. Links von mir blinkten vom Wardar rote Strahlen zurück, noch über ihm hinaus leuchteten die Berge der Marianska Planina und die schönen, schlanken Gipfel der Mala Rupa in glänzenden Farben auf, daß man meinen konnte, sie beständen aus einer purpurnen und violetten, glühenden Masse. Zur Rechten zog sich die Kette der Plaguša Planina hin, in fahlerem Licht und dennoch mit tiefen Schattenflecken. Gerade mir gegenüber sperrten das Nordende des Tals Ketten von gezackten Felsenbergen, eine hinter der anderen, in den verschiedensten zarten Abtönungen von Blau sich voneinander abhebend. Märchenlandschaften mußten in jenen mattleuchtenden 
Tälern verborgen sein, aus denen feine Nebel aufstiegen und zu den flammenden Wolken wanderten, die sich wie viel gewaltigere Gebirge über jene zarten blauen Berge türmten. Wie vom herrischen Pinsel eines großen Meisters gemalt, war das Gewölbe des Himmels hoch hinauf mit leuchtenden gelben, flammendroten, tiefblauen, grauvioletten, rotbraunen und grünlichen Wolken behängt. Das häufte sich übereinander, bäumte sich auf und zerfloß am obersten Rande in ein ätherisch klares sanftes Blau, das bis zu mir herüber sich wölbte, während über meinem Ruhesitz der erste Stern sein mildes Licht aufstrahlen ließ. Unten in der verdunkelnden, kühl blauenden Ebene, auf der die Schatten der Berge und Wolken sich allmählich immer mehr vorwärtsschoben, tauchte plötzlich eine Staubwolke rotgelb im letzten Scheine der Sonnenscheibe auf. Der helle Hauch erlosch in dem Augenblick, als die Sonne oben zwischen den fernen Schneebergen und den Felsenmassen von Demir Kapu fast im Norden versank. Kühle blaue Töne, zarte Nebelstreifen wanderten weiter den östlichen Bergen zu, über denen im grünblauen, stillen Himmelszelt zartrosa gefärbte, kleinste Wölkchen schwebten.

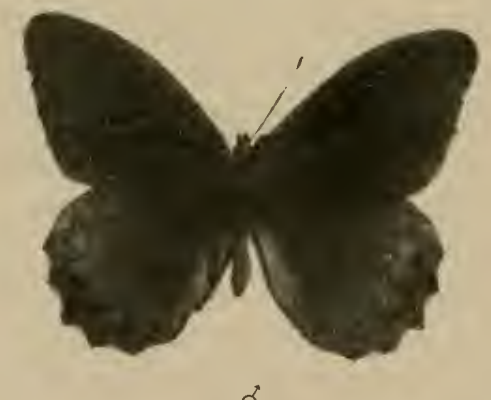

Abb. 24

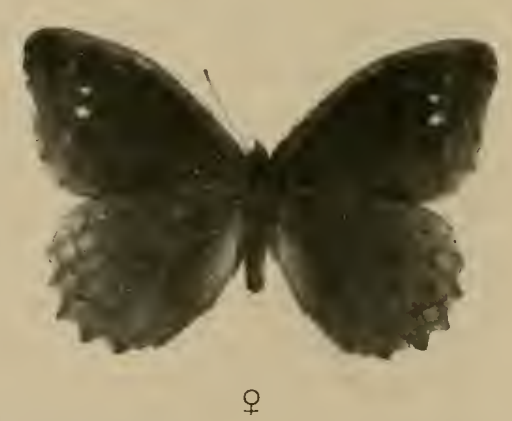

오

Das waren stille, friedliche Ruheabende in Mravinca vor arbeitsreichen Forschungstagen, zu denen jedesnal der frühe Morgen des zweiten Tages nach der Ankunft rief. Dann ging es meist zuerst aufwärts in die dürren Hügel hinter dem Feldlazarett durch steile Schluchten an dem halb verfallenen Dorf Mravinc a vorbei, wo fleißige Bauern schon in der Morgenfrühe bei der Arbeit waren. Ein römischer Sarkophag nahe bei dem Dorf hielt mich kurze Zeit auf, ehe ich auf die Hochebene stieg, wohin mich die Interessen des Naturforschers mächtig lockten. Dort breitete sich 
eine wellige Fläche aus, mit trockenem kurzem Gras bedeckt, in die mit scharfen Kanten aus der Fläche geschnitten, tiefe, steile Schluchten sich senkten. Deren Ränder waren auf beiden Sciten etwa gleich hoch. Man sah in ihre Tiefe erst hinab, wenn man dicht am Steilrand stand. Die Wände waren so steil, die Brüche schienen so frisch, dal3 man glauben konute, sie seien von Menschenhand am Tag vorher gegraben. Es war ein ganz anderer Typus von Schluchten, als ich sie aus dem Felsengebirge in einem der nächsten Kapitel beschreiben werde. Hier sah man, wie die Schluchten entstanden und wuchsen. Man konnte sie von ganz kleinen ersten Anfängen, von zentimetergroßen Vertiefungen bis zur Entwicklung zu hundert Meter tiefen, gewaltigen Schluchten verfolgen. Die größte dieser Schluchten hatte bei unseren Soldaten in der Gegend den

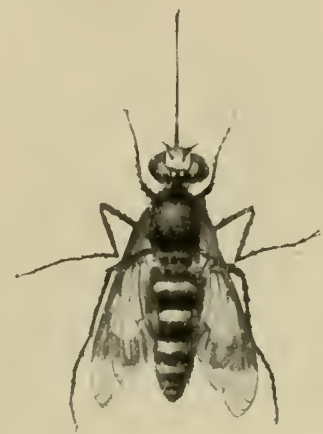

Abb. 25. Hummelfliege (Collostoma fascipenne Sch.) Kaluckova. Namen der Fuchsschlucht nach irgend einem Jagderlebnis erhalten. Auf der trockenen Hochfläche sah man nach verschiedenen Richtungen die Schluchten laufen, die alle am oberen Ende noch in Wachsen begriffen waren und an denen immerfort noch Verzweigungen entstanden. Am unteren Ende, gegen den Wardar hin, riß das Hochwasser nach starken Regengüssen große Massen der lehmigen Erdmassen von den Wänden ab, und schwemmte die fein sich verteilende Masse zum Fluß. So entstand am Wardar eine breite Sandschicht, die deltaähnlich in den Fluß sich erstreckte. IVenn unten Masse weggeschwemmt worden war, stürzte immerfort Masse im oberen Teil der Schlucht nach. Das erfolgte bald an der einen, bald an der anderen Seite der Schlucht. Dieses Nachstürzen war eine spätere Folge der Hochwassertätigkeit und erfolgte in Zeiten, in denen sehr wenig oder gar kein Wasser in der Schlucht floß. Während das Erdreich austrocknete, entstanden Sprünge im Boden und große Stücke lösten sich los und kollerten den Abhang hinunter. Dadurch wurden die Zustände am oberen Rand wieder verändert, neue Sprünge entstanden, neue Blöcke lösten sich ab und stürzten in die Schluchttiefe. Dort füllten sie das Bachbett auf, sperrten auch oft den Wasserlauf.

Die steilen Schluchtwände, rotgelb gefärbt, bestanden meist aus ganz gleichmäßiger feiner Substanz; sie sahen fast wie Lehm 
oder Löß aus. Die Schichten, aus denen die Schluchten gegraben waren, entstammten offenbar den höheren Hügeln und Bergen, aus denen das Wasser sie hinabgeschwemmt und in gleichmäßiger Verteilung an ihrer jetzigen Stätte abgelagert hatte. Hie und da

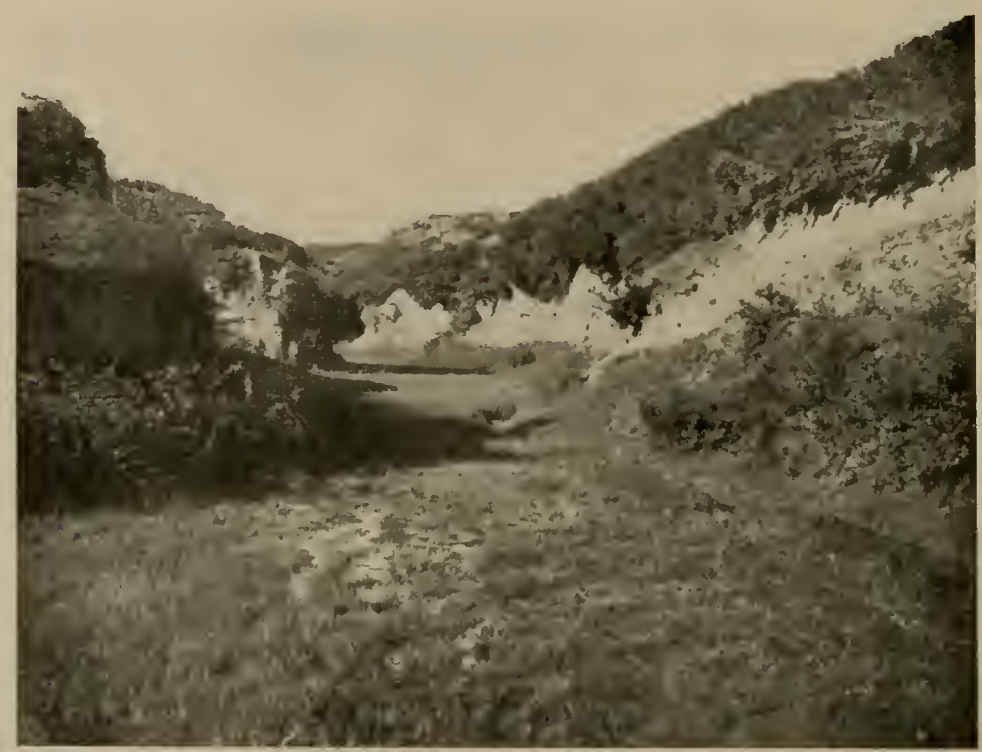

Abb. 26. Unterer Teil der Fuchsschlucht bei Mravinca.

ragten aus der feinkörnigen Masse größere und kleinere weiße Gesteinsbrocken heraus.

Die Wände der Schluchten dienten einer Menge von Tieren zum Nestbau. Außer den Bauten vieler Bienen und Wespen

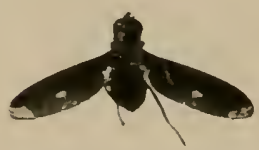

Abb. 27. Hummelfliege Exoprosopa vespertilio Wd. Nat. Gr. waren zahlreiche Vogelnester in die Lehmwände eingebohrt. An manchen Stellen sah man ein großes, dunkles Loch neben dem andern an der sonnenbestrahlten, gelben Schluchtwand. Die Vögel, welche hier in den Löchern brüteten, waren für die Augen des Nordländers auffällige, seltsame Formen. Es waren die farbigsten Vögel Mazedoniens, die hier hausten. Die Blaurake und der Bienenfresser flogen um die Schlucht und letztere vor allem tauchten immer wieder zu den Nestlöchern herunter, dabei ihre eigenartigen Zickzackflüge ausführend. Auch Wiedehopf und $\mathrm{K}$ appenammer trugen zur Buntheit in der Vogelwelt bei. Daß 


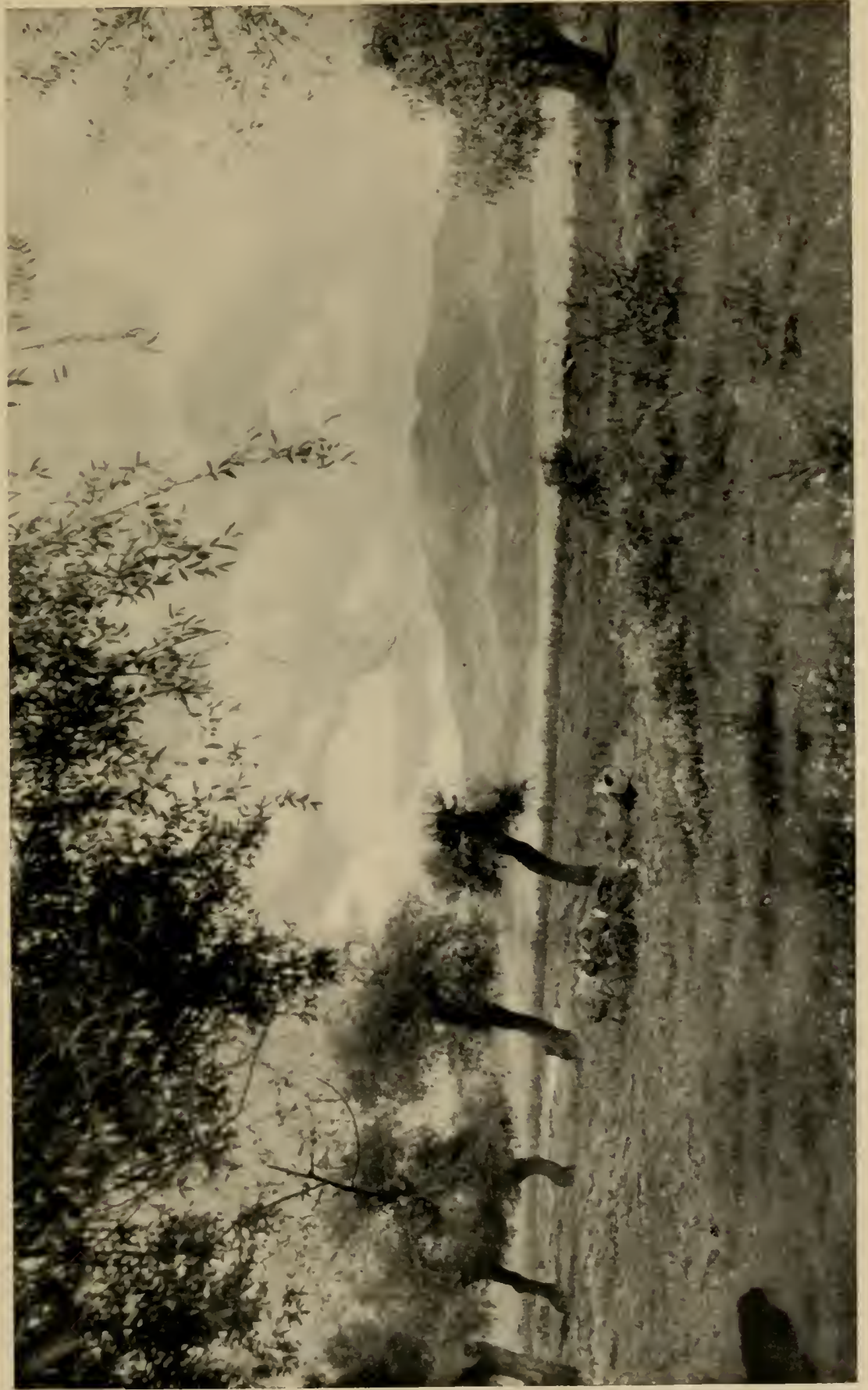



alle diese Formen als Zugvögel meist erst im Mai im Wardartal auftreten, ist unten im 37. Kapitel besprochen.

Jede Wanderung durch die Fuchsschlucht brachte neue Beobachtungen und neue Funde. Um den Bach flogen viele Libellen und machten auf Fliegen, Schmetterlinge, Eintagsfliegen eifrig Jagd. Unter den Zweiflüglern spielten wieder die Bombyliden eine große Rolle. Zwei charakteristische Formen sind (Abb. 25 u. 27) abgebildet. Die Schmetterlinge, Heuschrecken, Käfer und Ameisen entsprachen meist den Formen, die bei Kaluckova und Hudova vorkommen. Aber auch unter ihnen fanden sich manche Besonderheiten.

Am Schluchtbach war ein dichtes Buschwerk von Brombeerbüschen, Schlehdorn, Stacheleichen entwickelt, zwischen denen Sumpfpflanzen verschiedener Art, vor allem viel Wasserminze wuchs. Ende Juni 1917 waren diese Büsche von vielen Hunderttausenden einer Käferart bedeckt (Anomala solida Er.), welche alles kahlfraßen. Man hätte leicht Eimer voll von diesem Käfer sammeln können. Auf den Minzen fanden sich zahlreich die schönen metallisch glänzenden Chry'somela menthastri Suff. Nicht selten war ein Spanner Larentia corollaria H.-S.

Am Ausgang der Schlucht gegen den Wardar waren die Hänge mit reichlich Geröll bedeckt. Hier waren die Fundorte für eine Anzahl südliche und Steppenformen, wie die großen Gliederspinnen (Galeodes graecus C. L. Koch), verschiedene Arten von Skorpionen und riesige Tausendfüßler.

Unten am Wardar selbst und in dem sumpfigen Teil der Ebene, wo der Koslodere in den Strom einmündete, war ein üppiges Gelände von alten Weidenbäumen bestanden. Es waren richtige kleine Weidenwälder. Der Bach durchfloß die Fläche in verschiedenen Windungen, an seinem Ufer wuchsen Schilf, Röhricht, Schwertlilien und viele Wasserpflanzen.

Das war auch ein Gebiet, in welchem zahllose Libellen umherflogen; neben den stahlblauen Wasserjungfern schwebten trägeren Fluges die zarten blauschwarzen, grünschwarzen und goldgelben Arten von Lestes, Agrion und Gomphus, zwischen ihnen sausten gewalttätig die großen roten, grauen, braunen, zum Teil schwarzgefleckten Formen von Libellula und Aeschna. Gerade die letzteren waren schwer zu fangen, und es war eine Freude, waren sie endlich mit metallischem Klirren im Insektennetz gelandet.

Es war schön, im Frühsommer auf den blumenreichen Wiesen stundenlang beobachtend $\mathrm{zu}$ verweilen, wenn die großen Wolken- 
massen am Himmel schwebten und ihre Schatten auf die weite Ebene und das jenseits sich erhebende Gebirge der Plaguša Planina warfen. Da entstanden Bilder von größtem malerischen Reiz, die mir unvergeßlich geblieben sind.

Es konnte aber auch glühend heiß sein; einmal hatte ich den Eifer im Verfolgen der Libellen zu weit getrieben; mehrere Stunden lang hatte ich am schattenlosen Ufer die flinken Tiere verfolgt und war mit reicher Beute heimgekehrt. Nachts überfiel mich aber hohes Fieber und allerhand unangenehme körperliche Erscheinungen zeigten mir, das ich einen Sonnenstich erlitten hatte, von dem ich mich aber in zwei Tagen wieder erholte.

Der Kosloderebach beherbergte in seinem Wasser eine Sumpfschildkröte, die wir - so eifrig mein Begleiter, Professor Lorenz Müller, sich auch nach den Reptilien umschaute - nur hier fanden; sie kommt auch am Doiransee vor. Es ist die kaspische Sumpfschildkröte (Clemmys caspica virulata Val.). Sie kommt offenbar nördlich der Hudovaebene in Mazedonien nicht vor.

Ich nehme Anlaf, bei dieser Gelegenheit einiges von den übrigen mazedonischen Schildkröten zu berichten. Sehr häufig war im ganzen Land in allen möglichen stehenden Gewässern die gewöhnliche europäische Sumpfschildkröte (Emys orbicularis L.). In allen Teichen und Tümpeln, in Bächen, Straßengräben, Reisfeldern tauchten die plumpen schwarzen Tiere gelegentlich auf.

Außer diesen zwei Wasserschildkröten kommen in Mazedonien zwei Landschildkröten, damit also im Land im ganzen vier Schildkrötenarten vor. Diese Landschildkröten waren in den meisten Gegenden des Flachlandes von Mazedonien so häufig, daß man sie nicht übersehen konnte. Mit ihren langsamen, watschelnden Bewegungen, mit dem Gepolter, mit dem sie durch eine steinige Schlucht oder durch ein dichtes Gebüsch hindurchrumpelten, verrieten sie sich auf weite Entfernung und besonders die deutschen Soldaten schenkten ihnen eine weitgehende Beachtung. In vielen Lagern und Quartieren wurden sie lebend gehalten und ich übertreibe nicht, wenn ich erzähle, daß viele Tausende von ihnen als Heimatpakete nach Deutschland geschickt wurden oder mit Urlaubern heimreisten.

Die possierlichen, anspruchslosen Tiere, welche eine Panzerlänge von $30-40 \mathrm{~cm}$ erreichen, ihren Kopf, Schwanz und Füße 
in den Panzer zurückziehen können und so lange zappeln müssen, um sich wieder aufzurichten, wenn man sie auf den Rücken legte, haben unseren Soldaten manche Stunde vertrieben. Auch haben diese sich nicht selten eine Schildkrötensuppe aus ihnen gekocht. $\mathrm{Ob}$ von den vielen heimgebrachten mazedonischen Schildkröten wohl noch eine oder die andere in Jeutschland lebt?

Die beiden mazedonischen Arten von Landschildkröten sind Testudo graeca (L.) und T. ibera Pall. Beide mit ihrem schwarz und gelb oder schwarz und dunkelgrün gefleckten Panzer sehen einander sehr ähnlich und werden vom Laien auch nicht unterschieden. Die griechische Schildkröte ist in ihrer Verbreitung hauptsächlich auf die Balkanhalbinsel und Süditalien beschränkt, während die andere Art auch in ganz Nordafrika und Westasien verbreitet ist.

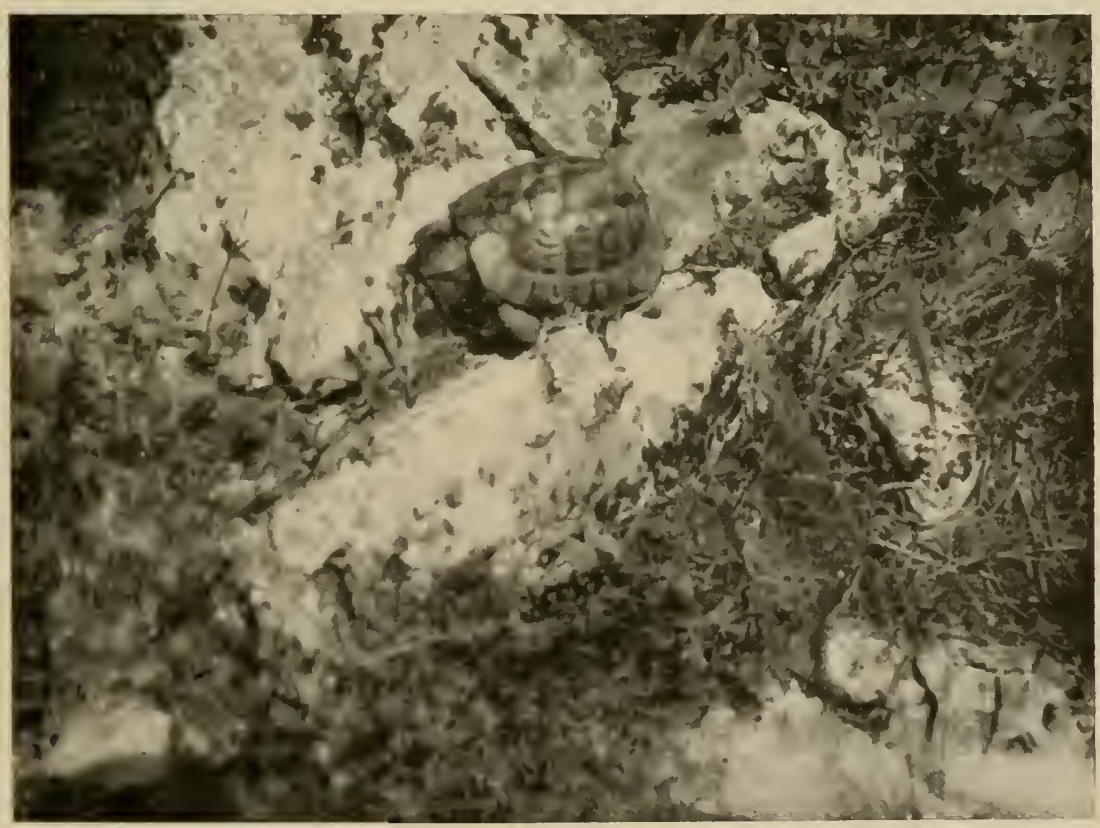

Abb. 28. Landschildkröte (Testudo ibera Pall.) in den Felsen bei Valandova.

Beide Arten waren in der ganzen Hudovaebene und den angrenzenden Hügeln und Gebirgen auch bei Mravinca sehr häufig. Wir fingen sie oft, beobachteten sie viel im Sommer, wie die Männchen die Weibchen verfolgten und unter eigenartigem Grunzen und Anstoßen mit den Panzern zur Begattung schritten. Auch 
ihre Gelege fand ich öfter, mit den hartschaligen Eiern von einem Längsdurchmesser von $3-3 \frac{1}{2} \mathrm{~cm}$. Oft lagen die Eier vereinzelt im Gras und zwischen den Büschen. In Mazedonien lernte ich verstehen, warum die Japaner die Schildkröte als Symbol der Geilheit betrachten. Hier waren die Männchen vom Frühsommer bis in den Spätherbst hinter den Weibchen her und in allen Teilen des Landes konnten ihre Kopulationsgeräusche bei Tag und Nacht aus Büschen und Gräben hervortönen.

In den Weiden am Wasser gab es auch manche besonderen Insekten. So war ein auffallender Rüsselkäfer Chlorophamus axinus Fabr. Auch kam im Sommer 191 7 in der ganzen Gegend der große Bockkäfer Cerambyx scopolii Füssl. vor. Das war ein höchst auffälliges Tier mit seinen langen gebogenen Fühlern, wenn er, diese weit vorstreckend und die Beine abspreizend im heißen Sonnenschein hoch über den Büschen durch die Luft flog. Dann machte er einen ganz unwahrscheinlich großen Eindruck. Ich beobachtete ihn zwischen dem 10. und 20. Juni an vielen Orten Südmazedoniens, außer bei Mravinca bei Kaluckova, Hudova, Davidovo, auf der Fahrt nach der Malarupa bei Negorci und Koinsko, im Nikolatal. Da er in Fühlergestalt und Fühlerlänge in beiden Geschlechtern sehr zu variieren schien, so sammelte ich eine größere Anzahl von Exemplaren, die einmal genauer untersucht werden sollen.

Von Käferbeobachtungen aus der Gegend von Mravinca möchte ich noch die Dorcadion arten erwähnen, Formen mannigfaltiger, schön gefärbter Bockkäfer, die meist unter Steinen saßen und von denen wir im Sommer nur Spuren in Gestalt von Flügeldecken und ihren knotigen, gebogenen Hörnern fanden. Ihnen und anderen Tieren zuliebe kehrte ich einmal im frühen Frühling I918 nach Mravinca zurück, wo ich schöne Exemplare dieser Erdböcke fand, so Nosodorcadion bilineatum Gam. und Dorcadion lineatocolle Kraatz. Von dieser in Südeuropa und den asiatischen Steppen in vielen Arten vertretenen Familie fand ich in Mazedonien noch manche schönen, interessanten Formen der Gattung, so auf dem Wodno Dorcadion equestre Laxm., einen samtschwarzen Käfer mit weißen Längsstreifen auf dem Brustschild und großen weißen Flecken auf der Mitte der Flügeldecken. Eine zart silbergraue Art mit schwarzen Flecken, auf der Golesniza Planina in $2000 \mathrm{~m}$. Höhe gefunden, ist wohl noch nicht beschrieben. 
Mit dem Aufenthalt in Mravinca sind auch Erinnerungen an Fischfang verknüpft. $\mathrm{Zu}$ solchen Zwecken mußte man sich mit Fischern oder mit Pionieren in Verbindnng setzen. Fischer als einheimische Bevölkerung fand man wohl an den Seen und am Wardar, aber sehr wenig; zumal in den besetzten Gegenden fehlten der Bevölkerung Boote vollkommen. Auch ich hatte keine geeigneten Geräte für den Fang größerer Fische bei mir. Somit war hier am unteren Wardar der Pionier mit seinen Booten die notwendige Stütze. Und außerdem mußte $z u$ dem grausamen und dem Naturforscher sehr unsympathischen Hilfsmittel der Handgranaten und anderen Sprengmitteln gegriffen werden.

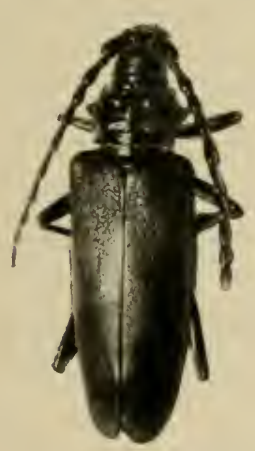

Abb. 29. Bockkäfer mit sehr variabler Ausbildung der Fühler. Nat. Gr. (Ceramby'x scopolii Füssl.)

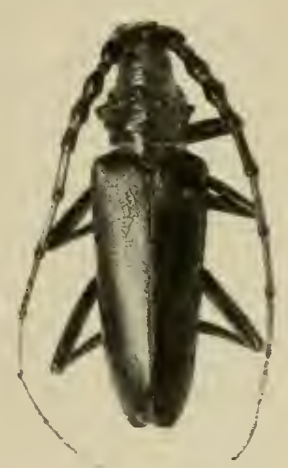


glänzenden Fisches mit grüngrauem Rücken, schwarzgefleckten silberigen Seiten und orangegelb gesäumten Flossen. An der gleichen Stelle wurden die altbekannten Elritzen (Phoximus laevis Ag.) erbeutet, im Wardar selbst Cottus ferrugineus H. u. K., ein Verwandter unserer Groppe.

Reicher und vor allem nahrhafter war die Ausbeute im Wardar selbst, die unter sachgemäßer Leitung des Pionierhauptmanns Frischholz erzielt wurde. Dieser, ein Fachzoologe, früherer Schüler des Münchener zoologischen Instituts, in seiner Zivilstellung Fischereisachverständiger des bayerischen Ministeriums, befehligte das bayerische Pionierlager in Hudova. Mit einem seiner Boote fuhren wir auf den rauschenden, brausenden Wardar bei Gradeč hinaus. Wir suchten die stillen, tiefen Stellen unterhalb der Schnellen auf und warfen da ausrangierte Handgranaten ab. Wenn eine davon noch losging, gab es im Wasser eine starke Detonation, ein Springbrunen von $10-20 \mathrm{~m}$ Höhe sprang in die Höhe. Aus der Tiefe wurden gelähmte Fische emporgerissen und nun hieß es mit dem Boot gut manöverieren, wollte man die auf der Seite treibenden Fische mit dem großen Handnetz erfassen, ehe sie die wilde Strömung über Stromschnellen und kleine Fälle hinabtrieb, an Stellen, wo das Boot entweder gar nicht oder nur unter großer Gefahr nachfolgen konnte. Das waren aufregende Stunden, in wilder Bewegung und toller Lust mit den strammen bayerischen Pionieren, die einst auf der auch nicht viel zahmeren Isar ihre Künste geübt hatten.

Die Ausbeute war dem entsprechend. Wir bekamen einen Eindruck von dem Reichtum an Fischen, den die mazedonischen Flüsse bis zur Zeit vor dem Krieg beherbergt haben müssen. Wir holten vor allem Karpfen und Barben heraus. Die Karpfen (Cyprinus carpio L.) waren Riesen, wie man sie in Mitteleuropa jedenfalls im freien Wasser niemals zu sehen bekommt. Sie maßen im Durchschnitt $1-1 \frac{1}{2} \mathrm{~m}$ in der Länge, hatten einen mächtigen Umfang und wogen dementsprechend $10-20 \mathrm{~kg}$. Auch die Barben (Barbus plebejus Val.) waren mächtige Tiere, bis zu einem Meter lang und auch 6-12 kg. schwer. Es war eine Freude für das ganze Pionierlager in Hudova und noch dazu für das Lazarett Kaluckova, als wir mit unserer Ausbeute heimkamen.

Nicht minder große Welse (Silurus glanis L.) beherbergte der Wardar; da waren die mächtigsten Vertreter im Winter vor- 
her gefangen worden, von Soldaten, welche mir Photographien von ihnen brachten, die hier wiedergegeben sind. Über 220 Pfd. wogen die über $2 \mathrm{~m}$ langen Kolosse, welche an Mächtigkeit nur selten von den Riesenwelsen der oberbayerischen Seen erreicht werden, die gelegentlich als uralte Greise aus den Tiefen des Chiemsees, Königssees, Starnbergersees mit der Grundangel heraufgeholt werden.

Nicht so mächtig waren die Salmoniden desWardar; die Lach se, die wir erbeuteten, waren viel kleiner (Salmo dentex Hek.).

$\mathrm{Da} \beta$ in den mazedonischen Flüssen solche Riesenfische überhaupt in gröleren Mengen vorkommen konnten, erklärt sich wohl durch die primitive Art der

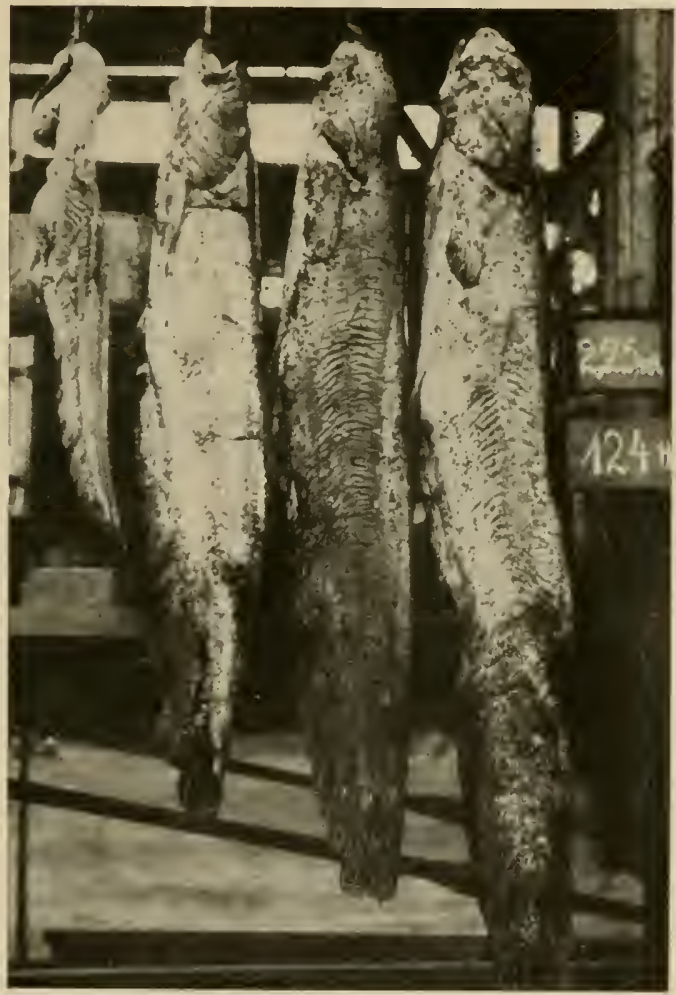

Abb. 30. Riesenwelse aus dem Wardar. (Silurus glanis L.) Soldatenaufnahme.

Fischerei, welche seit Jahrhunderten dort betrieben wurde. War ein Fisch einmal über eine gewisse Größe erwachsen, so entging er leicht den Nachstellungen der Landesbewohner, welche nur mit kleinen Netzen, Angeln und Spießen fischten.

Die Kriegszeit werden aber nicht viele dieser Riesen überlebt haben, denn die Truppen beider Fronten und besonders rücksichtslos unsere Bundesgenossen, die Bulgaren, haben diese Raubfischerei ohne alle Zukunftsgedanken betrieben, diese Raubwirtschaft, die wir auf allen Gebieten als eine besondere Eigentümlichkeit der Balkanvölker kennen lernen werden. Als Wardarfische wären als von uns beobachtete Formen noch an dieser Stelle zu erwähnen: Cottus ferrugineus H. u. K., Chondrostoma genei Bor., 
Alburnus alborella H. u. K., die südliche Laube, A. scaranzoides H. u. K. und Abramis melanops Heck., der mit unserem Brachsen verwandte Seerüstling, der als ein ins Süßwasser übergegangener Meeresfisch betrachtet wird.

Von allen Süßwasserfischen meiner Ausbeute ist nur Alburmus scaranzoides $\mathrm{H}$. u. $\mathrm{K}$. als Sonderform des Balkangebiets zu bezeichnen; er ist aus Montenegro, Albanien und „Rumelien“ bekannt. Alle anderen Arten sind in Küstenflüssen der Adria und des östlichen Mittelmeers, zum Teil in dem Gesamtgebiet von Südund Südosteuropa gefunden worden.

Sonst kam ich in Mazedonien nur am Ochridasee zur Beobachtung von zahlreicheren Fischarten. Sie sind im 39. Kapitel geschildert, wie die vereinzelten einzelnen Formen entsprechend den Orten, an denen sie gefunden wurden. 


\section{FÜNFTES KAPITEL}

\section{DIE PLAGUŠA PLANINA}

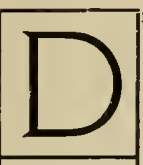

ie Berge, welche sich dicht hinter Kaluckova erheben und als Kette parallel dem Wardartal von Norden nach Süden ziehen, haben den Namen der Plaguša Planina, wohl von dem türkischen Dorf Plauš, welches im Nordteil der Kette gelegen ist. $\mathrm{Zu}$ diesem Dorf führt der Saumpfad, welcher durch Kaluckova und seine Schlucht bergan steigt. Etwas weiter südlich führt ein besser ausgebauter Weg über einen $\mathrm{Pa} \beta$ der Plaguša Planina nach Strumiza. In Friedenszeiten war Hudova die Eisenbahnstation für die Stadt Strumiza, zu der man mit Pferd oder Maultier von dort etwa $20 \mathrm{~km}$ zurückzulegen hatte. Über das Gebirge zog vor dem Krieg die neue Grenze zwischen Serbien und Bulgarien hin. Jetzt war das keine Grenze mehr und der Verkehr in den Bergen viel geringer, als in der Zeit, in welcher ein blühender Schmuggelhandel auf den jetzt vielfach zerfallenen Pfaden sich abspielte. Immerhin kam noch jede Woche eine Kamelkarawane, welche Militärgut von Strumiza zur Bahn nach

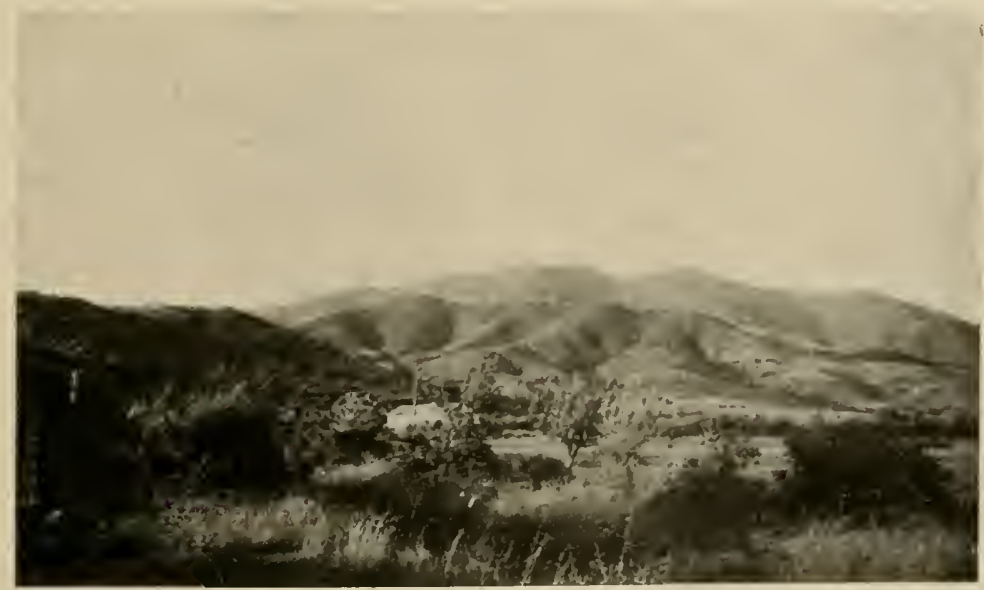

Abb. 31. Plaguša Planina in ganzer Ausdehnung, vor ihr der Grünberg. Aufgenommen vom Fliegerlager. 
Hudova brachte, auf Hin- und Rückweg durch Hudova; von dort ging der Weg über Kalkova auf den Hauptpaßsteig.

Bei Tag war es im Sommer ein heißer anstrengender Weg, an den Wänden der Schlucht entlang sich nach Plauš hinaufzuarbeiten, wo erst die schlimmste Steigung anfing, wollte man die Kammhöhe von I Ioo m erreichen.

So brach ich denn bei den häufigeren Besteigungen des Gebirges regelmäßig vor Tagesanbruch auf, um womöglich, wenn die heißen Stunden des Tages kamen, schon auf der Kammhöhe zu sein. Der Weg führte zunächst durch die altbekannte Schluchtregion auf die ersten Höhen. Von dort genoß ich oft bei Sonnenaufgang den wundervollen Blick ins allmählich aufleuchtende Wardartal, während die ersten Strahlen die Schneehänge der Mala Rupa fern im Westen vergoldeten.

In der Höhe von 700-800 $\mathrm{m}$ nimmt der Anbau zu; man merkt, daß man sich einer menschlichen Ansiedlung nähert. Hier sind den steilen Hängen durch fleißige Arbeit Felder und Gärten abgewonnen, die in Friedenszeiten wohl sicher viel besser bepflanzt waren. An den Halden ziehen sich Weingärten hin, hie und da steht grüner Roggen auf einem steinigen Acker spärlich gewachsen, dazwischen sind Beete mit Bohnen bepflanzt. Es war der 22. Mai, an welchem ich zum erstenmal hier hinaufstieg; so waren die Obstbäume schon verblüht und kleine grüne Kirschen und Mirabellen hingen an den Zweigen.

Eine Quelle, überschattet von alten Weiden, verführte zu einer kurzen Rast. In der Nähe wimmelten auf dem Boden viele Aaskäfer. In den Büschen höre ich den $\mathrm{Kuckuck}$ rufen, der in dieser Gegend jetzt im Mai überall häufig ist. Was aber den Aufenthalt an der Quelle besonders verlockend machte, war der Gesang zahlreicher Nachtigallen, die jetzt am frühen Morgen noch eifrig schlugen. Ihr Gesang war außerordentlich klangvoll und schön.

Auch sonst war die Vogelwelt hier im bebauten Gebiet sehr reich. In den Gärten und auf den Wegen flogen $\mathrm{Hauben-}$ lerchen und Feldlerchen vor uns auf. Der Bergsperling (Passer montanus montanus L.) war in Mengen da. Mit prasselndem Flug stiegen Turteltauben auf und flogen dicht über den Büschen davon (Steptopelia turtur turtur L.). In den Dickichten huschten zahlreiche Zaungrasmücken umher (Sylvia curruca curruca L.). 
Beim Weitersteigen umgingen wir eine Bergkuppe; jenseits von ihr sahen wir vor uns, malerisch sich aufbauend das Dorf Pla us.. In drei Teilen, bedingt durch drei Einschnitte im Gelände, zogen sich die Häuser bergauf in die Schluchten hinein. Im obersten Teil ragte ein weißes Minaret aus einer Gruppe von Bäumen empor und verriet uns, daß wir uns einem türkischen Städtchen näherten. Aus der Ferne machte der Ort einen reizvollen, einladenden Eindruck.

Aber wir waren ihm nur in der Luftlinie nahe; als wir die Bergkuppe umgangen hatten, sahen wir zwischen uns und dem Städtchen eine tiefe Schlucht klaffen. Es war eine Fortsetzung der einen Stadtschlucht, durch welche wir später in den Ort eintraten. Zunächst lief aber unser Pfad nahe an Abgründen entlang, die etwa $200 \mathrm{~m}$ tief sich neben uns öffneten. Die Schlucht war eng, kaum $300 \mathrm{~m}$ breit; ihre beiden Wände stürzten steil in die Tiefe, zu dem rauschenden Bach hinab, der reichlich schäumendes Wasser über mächtige Felsblöcke wälzte. Beide Wände waren kahl und schroff, kaum bewachsen; damals dachte ich, es sei unmöglich zum Bach hinabzugelangen. Später bin ich hinabgestiegen und konnte in der Tiefe am Bach manches interessante Tier beobachten.

Heute lag der Grund der Schlucht noch im tiefen Schatten, kühle Luft wehte zu uns herauf, denen es vom Aufstieg schon recht heiß geworden war. Wo die Schlucht gegen den Ort verlief, wuchsen im Grund stattliche Bäume, deren Kronen unter uns im Schatten der Schluchtwand standen. Es waren Platanen, Eschen, Ebereschen, Eichen, welche nahe dem Ort eine ganze Wildnis von Brennesseln und Disteln umgab, mit allen jenen Pflanzen, welche die Abfälle einer menschlichen Siedelung bedecken.

Auf einer kleinen gewölbten Brücke überschritten wir die Schlucht und kletterten am jenseitigen Rand aufwärts zu den Häusern. Vorher warfen wir von dem Brückchen noch einen Blick die Schlucht hinab. Es war die echte Balkanschlucht. Oberhalb des Orts und der Brücke begann sie als seichte Vertiefung im gewölbten Hang des Berges, von dem aus noch mehrere ähnliche Schluchtanfänge ausgingen. Eine kurze Strecke unterhalb der Brücke stürzte ein Wasserfall eine Stufe hinab, vor welcher die Wände der Schlucht etwas weiter zurücktraten. Unten tobte das Wasser zwischen den donnernden Steinklötzen, die übereinander kugelten und sich aneinander und an den Wänden des Bach- 
bettes rieben. So bekam man ein Bild von den Kräften, die wohl in wenigen Jahrhunderten die jetzige Sohle der Schlucht aus dem Felsen herausgearbeitet hatten. Weit reichte der Blick nicht; denn die Schlucht machte in ihrer Fortsetzung eine starke Wendung nach rechts, so daß die

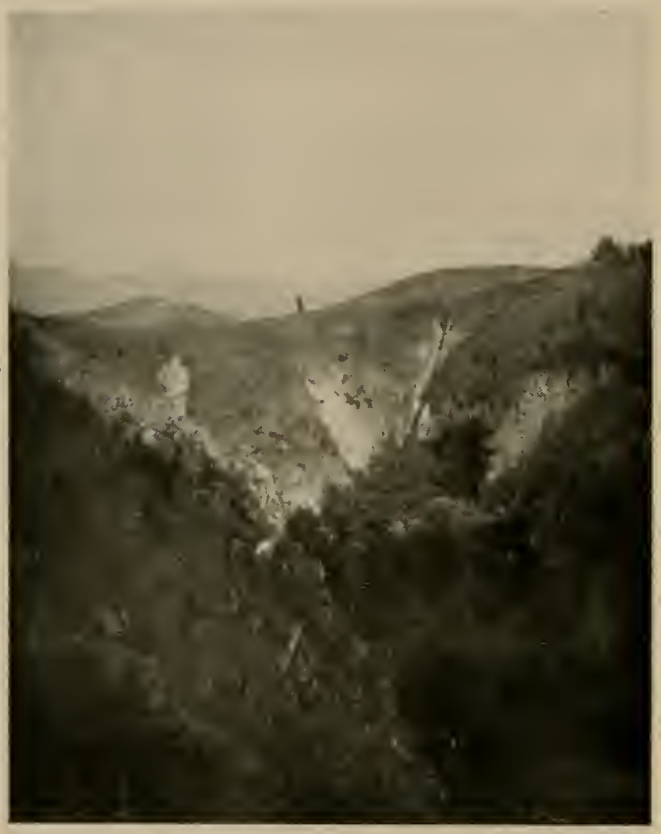

Abb. 32. Schlucht bei Plauš.

Seitenwand sich wie eine Kulisse vorschob. Hinter ihr ragte eine weitere Steilwand in die Höhe; so glaubte man in einen Kessel hineinzublicken. Im Vordergrund erhoben sich stattliche Laubbäume, die von den weißen Kalkfelsen sich scharf abhoben; über dem Schluchtbecken tauchten ferne blaue Berge auf. Es war ein schönes Bild, welches sich da vor uns aufbaute.

Weniger erfreuliche Eindrücke traten uns entgegen, als wir die steilen Gassen des Städtchens durchkletterten. Was uns aus der Ferne so anmutig erschienen war, bot uns jetzt das Bild der Zerstörung. Die meisten Häuser waren Ruinen, dachlos mit halbeingestürzten Mauern. Einsam war es in den Straßen, leer gähnten die Fensterhöhlen, kaum ein Haus hatte noch eine Türe. Hohe Mauern, meist nur stückweise erhalten, hatten einst Höfe und Gärten umschlossen, in denen jetzt nur Unkraut und verwilderte Sträucher wucherten. Nur hie und da stand noch ein Obstbaum aufrecht, in der Schlucht erhoben sich einige stattliche Pappeln. Von hohen Bäumen war die Moschee umstanden, welche in einem etwas besser erhaltenen Teil des Städtchens sich befand.

Bei jedem meiner Besuche in Plauš fielen mir die verödeten Gassen, der Zerfall und die Zerstörung mehr auf; jedesmal waren wieder einige Häuser zerstört, wieder einige Bäume gefällt. Beides war auf das Bedürfnis nach Brennholz zurückzuführen. Verlumpte 
Kinder liefen herum, verschleierte Frauen flüchteten in die Häuser. $\mathrm{Daß}$ ich so wenig Männern begegnete, hatte wohl zum Teil seinen Grund darin, daß sie draußen auf den Feldern bei der Arbeit waren. Aber selbst an einem Feiertag, als ich sie in der Moschee versammelt fand, war es nur eine kleine Zahl.

Die Zerstörung des Ortes rührte wohl in der Hauptsache aus dem Balkankrieg her, wo Bulgaren und Serben hier gekämpft hatten. Und später fanden wir in der Gegend auch Gräben aus dem gegenwärtigen Krieg.

Der Aufenthalt in dem Orte hatte nichts anziehendes und so habe ich mich niemals in ihm länger als eine Stunde aufgehalten.

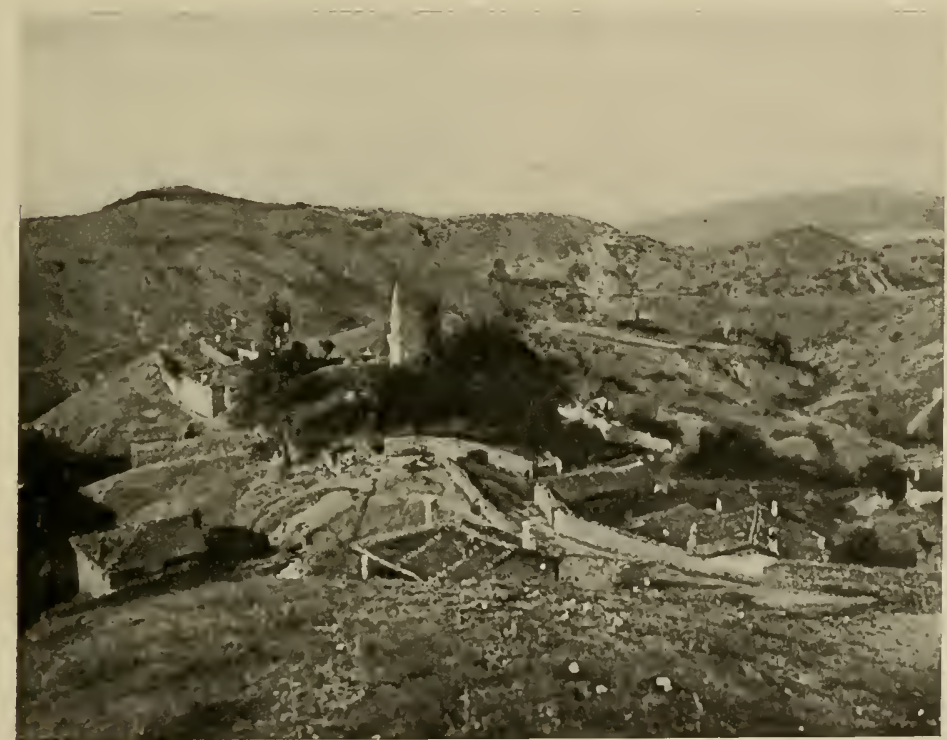

Abb. 33. Dorf Plauš von oben gesehen.

Der gegebene Rastplatz war der Garten der Moschee, wo man im Schatten der Bäume ruhen konnte und ein laufender Brunnen uns den Durst löschte; er war, wie stets, wo Türken wohnen, gut gehalten und sorgfältig gebaut.

Die Moschee war ein schmuckloses, viereckiges Gebäude, niedrig mit schwach geneigtem Dach, kleiner Türe, mit wenig kleinen scheibenlosen Fenstern. Es war aus Hausteinen mit eingelegten roten Ziegellagen gebaut; das Dach war mit Rundziegeln gedeckt, wie die meisten Häuser des Ortes. Von den roten Ziegeln 
der Flächen des Daches, stachen hellgelbe Randziegel freundlich ab. Das Innere der Moschee bestand aus einer Halle mit nacktem Tennenboden, von einigen Balken war das Dach gestützt. Schmutzig und schmucklos war der ganze Raum, nicht einmal ein Teppich war da und die zum Gebet versammelten Männer waren ebenso schmutzig und verlumpt wie ihre Ortschaft. Nach der Zahl, Anlage und Größe der Häuser muß aber Plauš in nicht zu ferner Vorzeit ein blühendes, wohlhabendes Städtchen gewesen sein.

Der Anstieg, der von dem Orte weiter hinauf zum Kamme der Plaguśa Planina führte, war steil und ging über einen

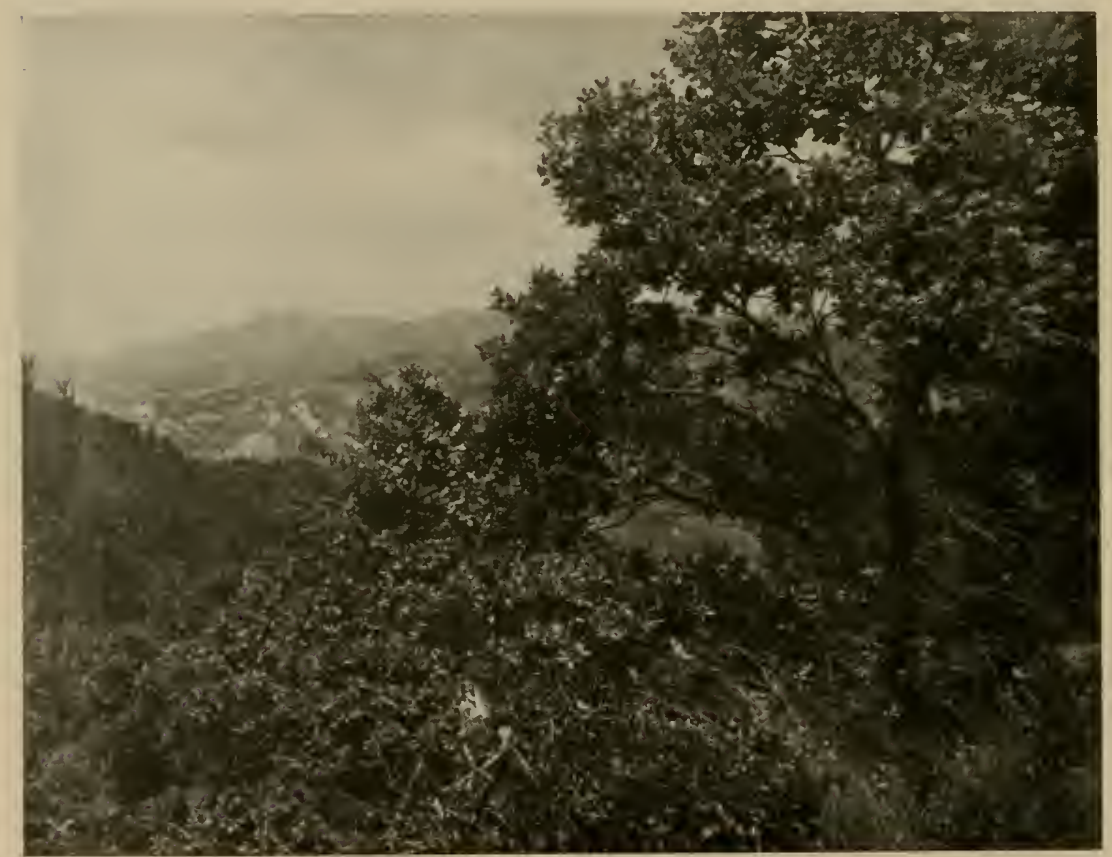

Abb. 34. Eichen im Waldtal der Plaguša Planina (Quercus conferta IV. K.).

kahlen von Wasserrinnen verarbeiteten Rücken zu einem $\mathrm{Paß}$ hinauf Ganz oben in fast $1000 \mathrm{~m}$ Höhe war ein Türke mit seinem primitiven Pflug beim Plügen eines Ackers beschäftigt, den ich im Herbst mit reifem Korn bestanden wiedersah.

Von der Paßhöhe, von der der Pfad nach Strumiza hinüberführte, führte eine Talschlucht nordwestwärts, welche mit einem stattlichen Buchenivald an der Südseite, am Nordhang mit einem lichten Eichenhain bedeckt war. Dieses Waldtal habe ich während 
der beiden Jahre meines Aufenthalts in Mazedonien mehrere Male besucht. Es gehörte wie die ganze Plaguša Planina zu jenen Gebieten, welche ich planmäßig zu allen Jahreszeiten zu besuchen pflegte, um den Wechsel der Fauna und Flora zu beobachten.

Bei diesem Besuch genoß ich mehr das frische Grün des Buchenwalds und seinen lichten Schatten, als daß ich eine reichliche Ausbeute erzielt hätte. Diese stellte sich erst ein, als ich noch etwa $200 \mathrm{~m}$ höher gestiegen, in die Gipfelregion des Gebirges gelangte. Beim Anstieg kamen wir durch Buchengebüsch, dichte Bestände von Hainbuchen und Ebereschen, zwischen denen als mir neue Pflanzen ein kleines dunkelblaues Vergißmeinnicht und schöne Glockenblumen standen. Eine der auffallenden Pflanzen dieses Gebietes war die wilde Pfingstrose (Paeonia decora Anders), deren rote Blüten zwar kleiner waren, als diejenigen der Kulturrassen unserer Gärten, aber doch einen schönen stattlichen Eindruck machten.

Als wir uns dem ersten Gipfel näherten, bot sich uns ein wundervolles, farbenprächtiges Bild dar. Eine blumenreiche Wiese war in der Gipfelregion von einem dichten Gebüsch von Weißdorn bedeckt. Alle diese Büsche waren in voller Blüte und die weilben Blumensträuße, umrahınt von dem sattgrünen Laub, hoben sich scharf und klar von dem tiefblauen Himmel ab. Es war ein wolkenloser Tag und wir genossen die Sonnenwärme, die uns hier bestrahlte. Als wir vor Tagesanbruch um ${ }_{4}$ Uhr im Tal abmarschierten, froren wir bei $9^{\circ} \mathrm{C}$ in unseren dünnen Sommeruniformen; bis 9 Uhr war in $800 \mathrm{~m}$ Höhe die Temperatur schon auf $16^{\circ} \mathrm{C}$ gestiegen. Hier oben maß ich im Schatten mit dem geschwungenen Thermometer $26^{\circ} \mathrm{C}$.

Um die Blüten des Weilodorns flogen zahlreiche weiße Schmetterlinge, eine Art der Gattung Mnemosyne, Verwandte des Apollofalters umher. Auf den Blättern saßen me-

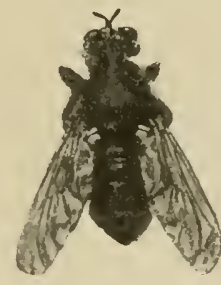

$a$

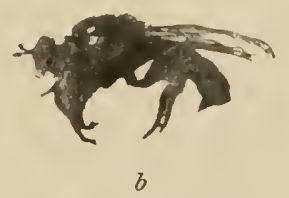

Abb. 35. Große Raubfliege (Pogonosoma maroccanum Fabr.)

$a$ von oben, $b$ von der Seite. tallisch glänzende Käfer aus der Gruppe unseres Rosenkäfers (Cetonia aurata, var. viridiventris Reit.). Bienen und bunte Fliegen umsummten die Blüten.

Bei diesem ersten Ausflug in die Berge war ich noch nicht genügend für die Sammeltätigkeit ausgerüstet, da mein Gepäck in 
Kaluckova noch nicht angelangt war. Um so mehr konnte ich die Schönheit der Landschaft genielben und mich in der mir ganz neuen Gegend orientieren.

Der erste Gipfel, den ich erstiegen hatte, erlaubte einen weiten Überblick nach Osten, Norden und Westen. Im Süden war die nähere Ungebung durch die Fortsetzung der Bergkette, aus der sich noch eine Reihe von Gipfeln erhob, teilweise verdeckt.

Nach Norden setzte sich das von mir bestiegene Gebirge noch in eine Gruppe niedriger Gipfel fort, zwischen denen die Täler tief eingeschnitten waren. Seine Fortsetzung fand es in den Ketten, welche gegen den Wardar bis Demir-Kapu sich hinzogen. An den Abhängen der Berge und in den grünen Winkeln der Täler sah man kleine, türkische Ortschaften eingeschmiegt, als solche zum Teil an den Minarets zu erkennen. Nach der Karte erkannte ich Arazli Menekli, Kara Eliasli, und Baceli-Cesme. Nach Süden sah man der Westkante des Gebirges entlang, welche in schroffen Felswänden mehrere hundert Meter fast senkrecht zum Wardartal abfiel. Über die vor mir liegenden Gipfel hinweg sah ich in der Klarheit des schönen Maitages die Berge der Doiranfront mit allen Einzelheiten vor mir liegen. Eine Menge von Ortschaften konnte man erkennen, ja es waren unsere Stellungen und diejenigen der Feinde dort deutlich zu sehen.

Fern hinter diesem Gebiet blitzten der Spiegel des Doiransees und des Ardzansees auf. Zwischen ihnen ragt ein kegelförmiger Berg auf, der Dub, eine vielumkämpfte Vorstellung unserer Truppen, welche einen vollen Einblick in die feindlichen Stellungen im südlichen Wardartal erlaubte. Dort schwebten zwei Fesselballons am Himmel und kaum waren sie sichtbar geworden, als drüben eine heftige feindliche Beschießung losging. Von den Granateinschlägen an einer Straße entlang, stiegen mächtige schwarze Rauchwolken auf.

Über den Seen und den vorderen Bergen hinweg sah ich im blauen Dunst der Ferne einen hohen Doppelgipfel; es war der Olymp, der Götterberg des alten Hellas, der dort herüberschaute.

Ich überblickte das weite Tal des Wardar, wie es sich aus der Enge bei Hudova öffnete, darüber die mir schon lieb gewordenen Umrisse der Marianska Planina und der Mala Rupa. Durch die grüne Ebene von Hudova flol der breite Strom, zum Teil in Arme zerspalten, zu einem neuen Engpaß, in welchem er 
bei Miletkovo eintrat, um weit nach Süden bis gegen Gewgeli sichtbar zu bleiben.

Quer von Miletkovo herüber sah man eine Hügelkette an Mravinca vorbei gegen Dedeli ziehen und von dort konnte das Auge rückwärts wandernd die Reihe der Dörfer am Fuß der Plaguša Planina verfolgen, vom südlichsten Piravo über Verceli, Aranli, Terzeli und Kalkova nach Kaluckova.

$\mathrm{Da}$ ich für die nächsten Tage mir eine neue Besteigung des Plaguša-Gebirges vorgenommen hatte, so nahm ich jetzt den Abstieg hinter dem Grünberg nach Kalkova, wo ein deutsches Pferdelazarett untergebracht war. Als ich die Region von ungefähr $500 \mathrm{~m}$ Höhe erreicht hatte, traf ich dort in der Nachmittagssonne ein reiches Insektenleben. Vor allem häufig waren zwei Arten von Ameisenlöwen, darunter die zierliche Form mit den bandförmigen Hinterflügeln (Nemoptera simuata Oliv.). Schmetterlinge flogen um die Blüten, auch zahlreiche Bienen und Fliegren. Auf letztere jagten zwei Libellenarten. Auf den Pflanzen und am Boden gab es zahlreiche Käferarten, so Mistkäfer, unter denen die Pillendreher besonders auffielen.

Die gleichen Tiere, in noch vermehrter Menge, konnte ich in derselben Region beobachten, als ich am 27. Mai, am Pfingstsonntag, den gleichen Weg, aber mit weiterem Ziel zurücklegte. Geradezu erstaunlich war die Menge von Mistkäfern, welche auf dem Pfad und an den Hängen herum wimmelten. Sicher ein Anzeichen dafür, daß auf dem jetzt so einsamen Pfädchen der Verkehr früher viel stärker war.

Als ich in der Gipfelregion ankam, wehte hier ein kalter Wind. Große Wolken trieben am Himmel und versprachen weniger gutes Wetter als beim letzten Aufstieg. Am ersten Gipfel flogen wieder die Mnemosynen, d. h. bei der Kälte flogen sie nur in den kurzen Augenblicken des Sonnenscheins. Sonst saßen sie starr auf den Büschen und ließen sich leicht mit der Hand fangen.

Aber die Kälte konnte den Insektenreichtum dieser Region nicht vollkommen unterdrücken. Sowie die Sonne herauskam, erhoben sich die Schmetterlinge aus ihren Schlupfwinkeln und gaukelten um die Blüten. Dabei fiel auf, welch kräftige Farben hier in dieser Region die meisten Arten aufwiesen. In die Augen fallend war vor allem das leuchtende Blau der Bläulinge.

Auch andere Insekten waren reichlich vorhanden. Hummeln und Bienen lockten durch ihr Summen die Aufmerksamkeit aller 
meiner Begleiter auf sich. Cetonien und andere Blumenkäfer ließen sich leicht von den Sträuchern herunterschütteln. Kleine Bockkäfer waren häufig, so Leptura erratica Dalm. und L. fulva de Geer, wie die bunte Strangalia septempunctata Fabr. und die dunkle L. melanura L. Auffallend viele Spanner und Motten flogen umher.

Auf dem Pfad und an seinen Rändern liefen Tigerlaufkäfer (Cicindela campestris L.) herum und überall waren die kreisrunden Löcher im Boden zu sehen, in denen ihre Larven auf Beute lauerten. Auf den Wiesenpflanzen saßen kleine Zikaden mit schwarzrot gefleckten Flügeln (Triecphora mactata Germ.), eine Schaumzikade. Grillengezirpe ertönte von allen Seiten, als eine zeitlang die Sonne wärmer schien.

Das Unwälzen der Steine brachte reiche Ausbeute. Viele Käfer, besonders Laufkäfer saßen unter ihnen. Durch seine krepierenden Bomben aus Sekret der Afterdrüsen fiel der Bombardierkäfer Erachinus immaculicornis Dej. besonders auf. Ganze Scharen von schwarzen und braunen Juliden, jenen walzenförmigen, sich einrollenden Tausendfüßlern, traf ich unter den Steinen an oder fing sie, als sie offen auf den Wegen krochen (Brachyjulus unilineatus hercules Verh.). Fand ich aber einen jener großen, flachen, flinken Tausendfüßler aus der Gattung Scolopendra, so saß das Raubtier sicher einsam und ungesellig unter seinem Stein. Jedesmal gab es eine aufregende Jagd, bis das Tier mit der Pinzette gefaßt, der schmerzliche und unter Umständen gefährliche $\mathrm{Bi} \beta$ vermieden, und trotz aller Gewandtheit und schnellen Bewegungen die Beute im Sammelglas saß.

Unter Steinen fand sich hier, wie auch in der Ebene, sehr häufig eine Wolfsspinne (Lycosa amentata [Clerk]), eine der Formen, welche kein Netz bauen und ihre Spinndrüsen außer zur Anfertigung der Eierkokons nur zum Umspinnen der Beute verwenden. Auch dieses stattliche Tier war infolge der Schnelligkeit seiner Bewegungen nicht leicht zu fangen.

Merkwürdig ist die Tatsache, daß ich hier oben, das einzige Mal in Mazedonien die bei uns häufigste Hausspinne (Tegenaria domestica [Clerck]) im Freien bei etwa $1000 \mathrm{~m}$ Höhe fand, wo sie ihr Netz unter einem Strauch gebaut hatte. In Häusern habe ich diese Spinne und ihr charakteristisches Netz in Mazedonien nie beobachtet, was wohl nicht nur ein Zufall ist. 
Eine Merkwürdigkeit der Region waren die zahlreichen Löcher im Boden, welche der Bautätigkeit von Insekten ihre Entstehung verdankten. Außer den Cicindelenlarven hatten Ameisen und Bienen solche gebaut. Die Löcher dieser beiden Insektenformen unterschieden sich aber sehr von denjenigen der Käferlarven und der Spinnen, die auch nicht selten waren, durch einen kraterähnlichen Wall aus beim Bau ausgeworfenen Erdteilchen, welche in regelmäßigem Kreis das Loch umgaben. Auffallend war oft die gänzlich von der Erde der Oberfläche abweichende rötliche, schwärzliche oder gelbe Farbe, welche dieser aus grölerer Tiefe stammende, auch vielfach noch feuchte Bauschutt besaß.

Die Ameise, welche hier häufig aus solchen Kraternestern kam und die Öffnungen eifrig umschwärmte, war eine Form, die auch unten in der Ebene infolge ihrer Lebhaftigkeit und eigenartigen Körperhaltung kaum übersehen werden konnte. Es war eine große Ameise, in Größe und Gestalt unseren Waldameisen ähnlich sehend, mit rotem Kopf, roter Brust und braunem Hinterleib. Das Tier schoß, wenn es erregt war, mit sehr raschen Bewegungen im Zickzack hin und her und hielt dabei den Kopf und die Vorderbeine steil in die Höhe. Es ist die Art Cataglyphis bicolor F. var. orientalis For., deren Arbeiter sich außerhalb des Nestes so auffallend benehmen.

Hier oben fing ich auch zum erstenmal Exemplare der großen schwarzen, bronzeglänzenden, flügellosen $\mathrm{Heuschrecke} \mathrm{Callimenus}$ oniscus Charp.; diese habe ich später im Nikolatal genauer beobachtet und will daher im Kapitel über jenes Tal näheres über sie berichten und sie dort abbilden.

Unterdessen war trotz des fortschreitenden Tages der Wind kälter geworden. Die Bewölkung nahm zu. Indem sie sich von Zeit zu Zeit in irgendeiner Himmelsrichtung öfnete, ergaben sich engumrahmte Fermblicke von großer Klarheit und von phantastiscker Schönheit. Bald konnten wir nach Westen durch ein Wolkenloch tief ins Wardartal hineinsehen, bald wurde es im Osten klar. Dann blickten wir über den sanfteren Osthang der Plaguša Planina in das Tal von Strumiza, dessen Sohle und Hänge gut angebaut schienen; wohl abgeteilte Äcker und Felder deuteten auf ertragreichen Ackerbau.

Einmal, als die Wolken sich verteilten, öfnete sich der Vorhang vor einem Prospekt von zauberhafter Schönheit. Es zeigte sich, auf den Gipfeln noch schneebedeckt, vor uns im Südosten das 
Belasizagebirge mit seinen einfachen, großen Formen. Weit in der Ferne im Osten ragten aber schimmernde, eis- und schneebekleidete Zinnen in gewaltige Höhen empor. Wir konnten uns kaum entscheiden, daß es das Rhodogegebirge sein müßte, als die Wolken sich wieder schlossen und das vorgezauberte Bild entschwand.

Es war II Uhr vormittags; wir hatten unsern Marsch über den Kamm fortgesetzt, einige der Gipfel erstiegen und waren durch dichtes Buschwerk gekrochen. Nun nahm die Bewölkung zu, an alle Gebirgsketten hingen sich schwarze Gewitterwolken, die schließlich auch die unserige einhüllten. Hagel und Regen prasselten los und hatten rasch unsere dünnen Uniformen durchweicht. Wir suchten Schutz unter den Büschen, indem wir uns auf den Boden hockten. Bald aber kam der Regen durch und wir waren froh auf einen alten Unterstand zu stoßen.

In diesen krochen wir hinein, erlebten aber hier nicht allzuviel Freude. Das Gewitter umtobte uns, grelle Blitze zuckten durch die um uns jagenden Wolken, fast im gleichen Niveau, in dem unsere Höhle lag. Schwere Donnerschläge, den Blitz begleitend, erschütterten den Boden. Erde und Steinchen rieselten herunter und schließlich ergossen sich Ströme von Schlamm und Wasser auf uns von oben herab.

Uns schien es richtiger, diesen etwas bedenklichen Aufenthalt zu verlassen und lieber etwas mehr Nässe zu riskieren. Der ganze Bergkamm war hier von alten Schützengräben, von Befestigungen und Unterständen durchzogen. Überall lagen französische und serbische Patronenhülsen und Rahmen umher. Jeden Augenblick wühlte der Fuß Kugeln aus dem Boden. Hier mußte einmal ein scharfer Kampf getobt haben.

Ein trockenes Plätzchen fand sich aber nicht. Wir suchten Deckung an einer Felsenwand. Tief unter uns im Abgrund brodelte der Nebel und eiskalt fegte der Wind um die Ecken.

Doch ebenso plötzlich wie das Unwetter gekommen war, klarte es wieder auf. Die Sonne brach durch, die Wolken verzogen sich und schmolzen vor ihrer Glut dahin. Nach einer halben Stunde war das Gebirge wieder vollkommen frei, das Gewitter verzog sich nach Nordwesten und in strahlender Klarheit lag das Land vor uns. Nur um ferne Berge hingen Wolkenmassen. Wir kletterten noch ein Stück an den Felsengraten weiter, suchten uns ein gedecktes Plätzchen in den schon trocknenden Felsen. Es war 1 Uhr geworden, so daß es geeignet schien, den Proviant 
auszupacken und während der Mahlzeit die Kleider in der Sonne zu trocknen. Und richtig, zwischen 2 und 3 Uhr waren wir wieder vollkommen trocken und konnten mutig unseren Marsch fortsetzen, der uns noch über die letzten Gipfel der Plaguša-Kette in das Tal bei Dedeli hinunterführen sollte.

Unsere Rast war an günstiger Stelle erfolgt. Wir waren in dem felsigsten, romantischsten Teil des Gebirges. Es war etwas südlich des Passes von Kalkova nach Strumiza. Uns zur Seite stürzte der Felsen fast senkrecht in die Tiefe; an seine

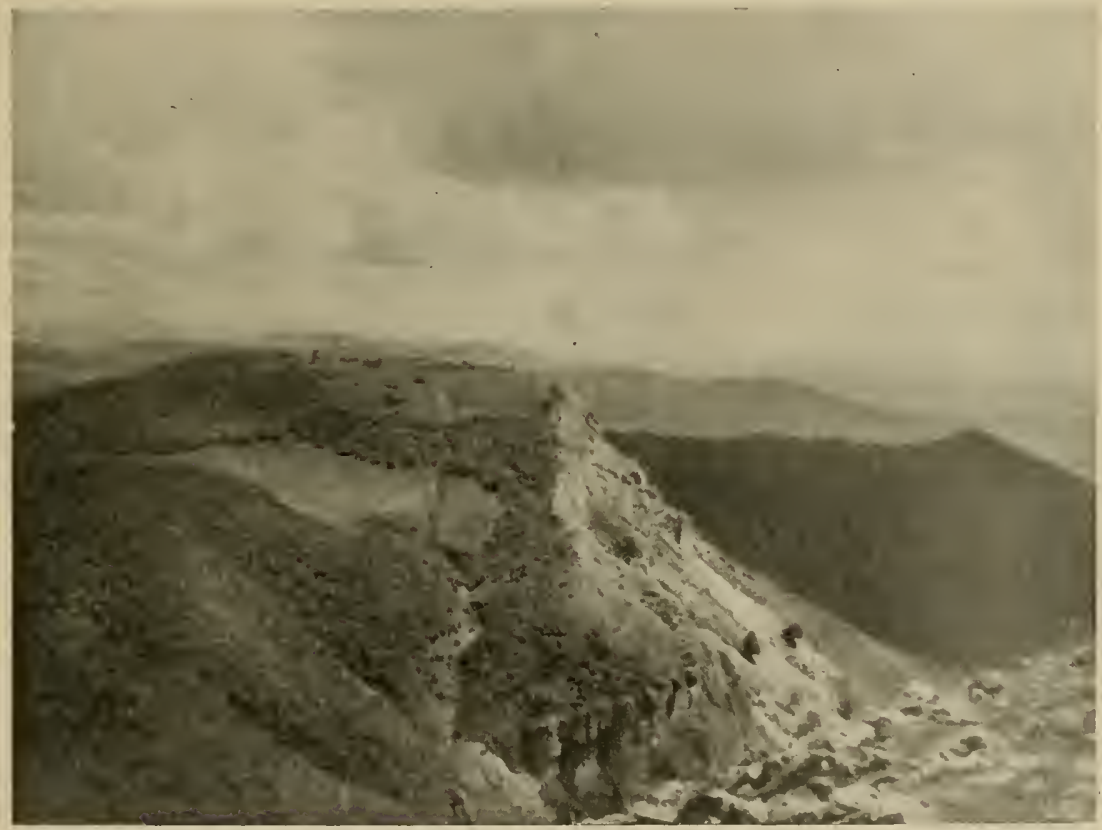

Abb. 36. Fernblick vom Westhang der Plaguša Planina. Blick nach Süden. Richtung Doiransee.

Wand schloß sich unten eine mächtige Schutthalde an. Im allgemeinen war die Farbe des Felsens weißlich grau; er bestand in der Hauptsache aus Kalk; eine ganze große Bergwand war aus Marmorplatten aufgebaut. Hie und da fand man in Spalten und zerbrochenen Geröllstücken Drusen mit Kalkspatkristallen. An manchen Stellen traten auch rötliche Färbungen der Felsen auf. Die Verwitterungsprodukte des Felsens, Erde und Sand, waren an den meisten Stellen rotgelb. Der Regen hatte manche Tiere mobil gemacht. So fand ich hier oben, zum ersten Mal im maze- 
donischen Gebirge R egenwürmer, welche offenbar der eindringende Regen aus ihren Schlupfwinkeln getrieben hatte. Das gab Anlaß, an mehreren Stellen Löcher zu graben, um nach weiteren Exemplaren zu suchen. Auch hier in den Bergen war das Graben in der harten, steinigen Erde sehr schwer. Der Regen war nur wenige Zentimeter tief eingedrungen, der Humus ganz dünn und in geringer Tiefe noch vollkommen trocken. Wir fanden weder Regenwürmer noch irgend ein anderes Tier im Boden.

Dagegen fand ich an den benäßten Pflanzen in größerer Anzahl Schnecken von verschiedenen Arten der Gattungen Helix, Buliminus und Clausilia. Eine ganze Anzahl Tiere waren in der feuchten Luft beweglich und krochen auf Steinen und Pflanzen umher; bei den verschiedenen Arten waren es Individuen von verschiedener Größe. Am Boden lagen viele leere, gebleichte Schalen umher.

Auch die Vögel waren nach dem Regen im hellen Sonnenschein recht munter geworden. Hier oben war ein Vogel sehr häufig, der einen schönen, dem der Drosseln ähnlichen Gesang hören ließ. Er war aber kleiner als eine Drossel, hatte einen blaugrauen Kopf, roten Bauch und roten Schwanz; die Flügeldecken stachen durch ihr dunkles Schwarz stark von diesen Farben ab. Es war der Steinrötel oder die Steindrossel (Monticala saxatilis I..), ein Vogel, den ich später noch oft in den mazedonischen Gebirgen beobachtete. Hier war er erst vor kurzem vom Zug heimgekehrt. Wir sahen ihn auch seinen eigenartigen Balzflug ausführen. Auch Saxicola rubetra (L.) kam hier oben vor. Raubvögel flogen nicht selten über den Bergkamm dahin, unter denen wir Adler und Geier, Bussarde und Falken erkannten, ohne daß wir die Arten genau feststellen konnten, außer bei clen häufigen Rötelfalken.

So hatten wir reichlich Beobachtungen gemacht und Tiere gesammelt, während wir im Kammgebiet südwärts weiter wanderten. Allmählich, nachdem der Weg uns auf und ab über eine Reihe felsiger Gipfel geführt hatte, sahen wir von einer Spitze aus den Kamm sich langsam zum Tal senken. Er blieb dabei ein scharfer Grat, der sich noch mehrmals zu Spitzen erhob.

Hier oben gab es noclı stattliche Bestände von Stacheleichensträuchern; wie die Wolle eines Schafes sieht auf den Photographien dieser Bestand vielfach aus. Hier oben beobachtete ich den seltenen Fall, daß eine Stacheleiche (Quercus coccifera L.) zu 
einem stattlichen Baum mit einem knorrigen Stamm von fast $50 \mathrm{~cm}$ Durchmesser erwachsen war (Abb. 37). Er stand auf einer blumigen Wiese als vollkommener Eigenbrödler ganz allein, dahinter ein Gipfel, der noch vollkommen mit niederen Büschen der gleichen Art bedeckt war. Was mögen es wohl für Bedingungen gewesen sein, welche es diesem Individuum der Art erlaubten, zu einem stattlichen Baum zu werden? Sind es wirklich die Ziegen, welche auch bei dieser Pflanze im Frühjahr die zarten, frischen Triebe abfressen und so im niederen Wuchs erhalten. Und sollte dies

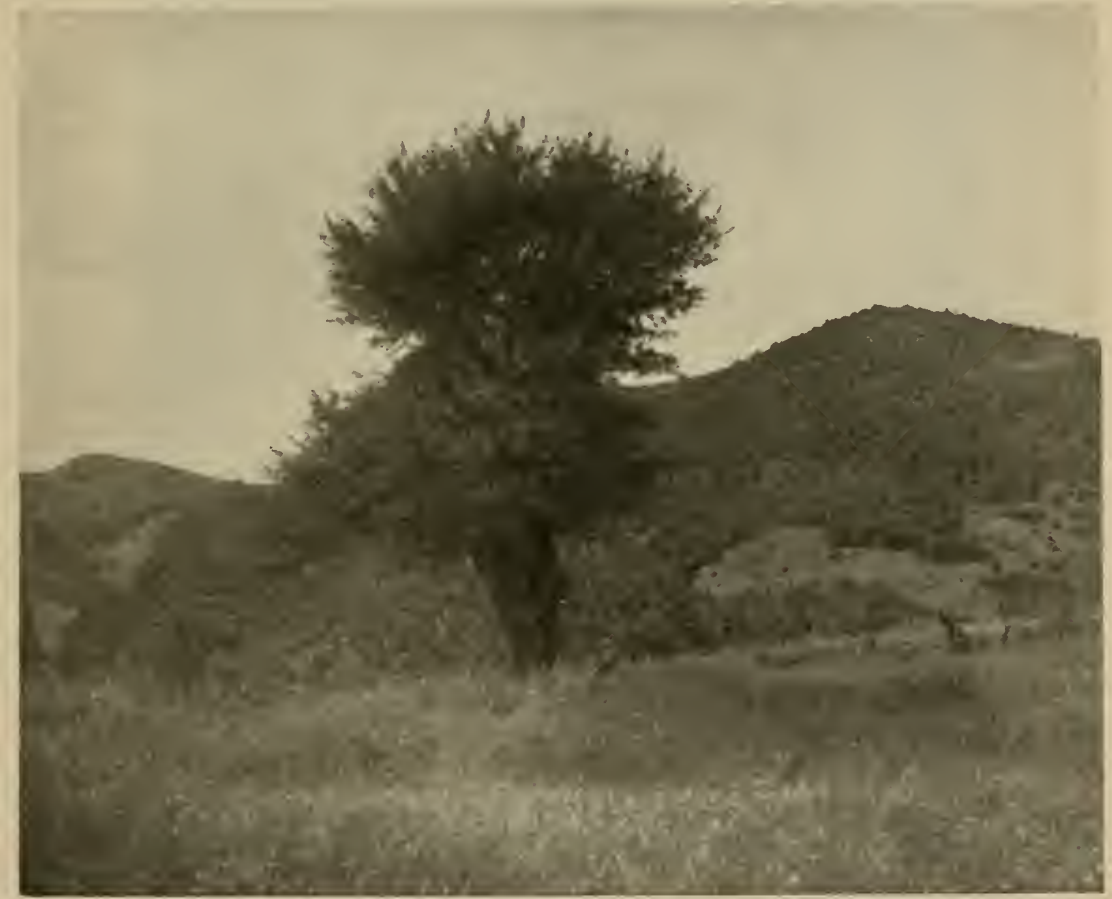

Abb. 37. Hoher Baum der Stacheleiche (Quercus coccifera L.) in der Bergregion der Plaguśa Planina auf blumiger WViese, dahinter das übliche Gebüsch der gleichen Eiche.

eine Individuum einmal einen Trieb so lang entwickelt haben, daß er hoch über den Bereich der gefräßigen Ziegenmäuler ragte und hart und stachlig wurde, ehe sie ihn vertilgt hatten? Noch einige Male sah ich ältere Bäume von Quercus coccifera, die bewiesen, daß auch diese Eiche die Fähigkeit hat, zum stattlichen Baum zu werden.

Auf dem Felsen wuchsen hier schon jene wollblättrigen Pflanzen, die mir später in den Hochgebirgen begegneten. In der 
Plaguša Planina waren es Kompositen der Gattung Hieracium vor allem $H$. pannosum Gris., die nebenan abgebildet sind, wie sie wie weiße Plüschgebilde sich vom Felsgestein abheben.

Der Abstieg wurde zur beschwerlichen Felsenkletterei, als wir nun an einem alten türkischen Turm vorbei den Kamm ver-

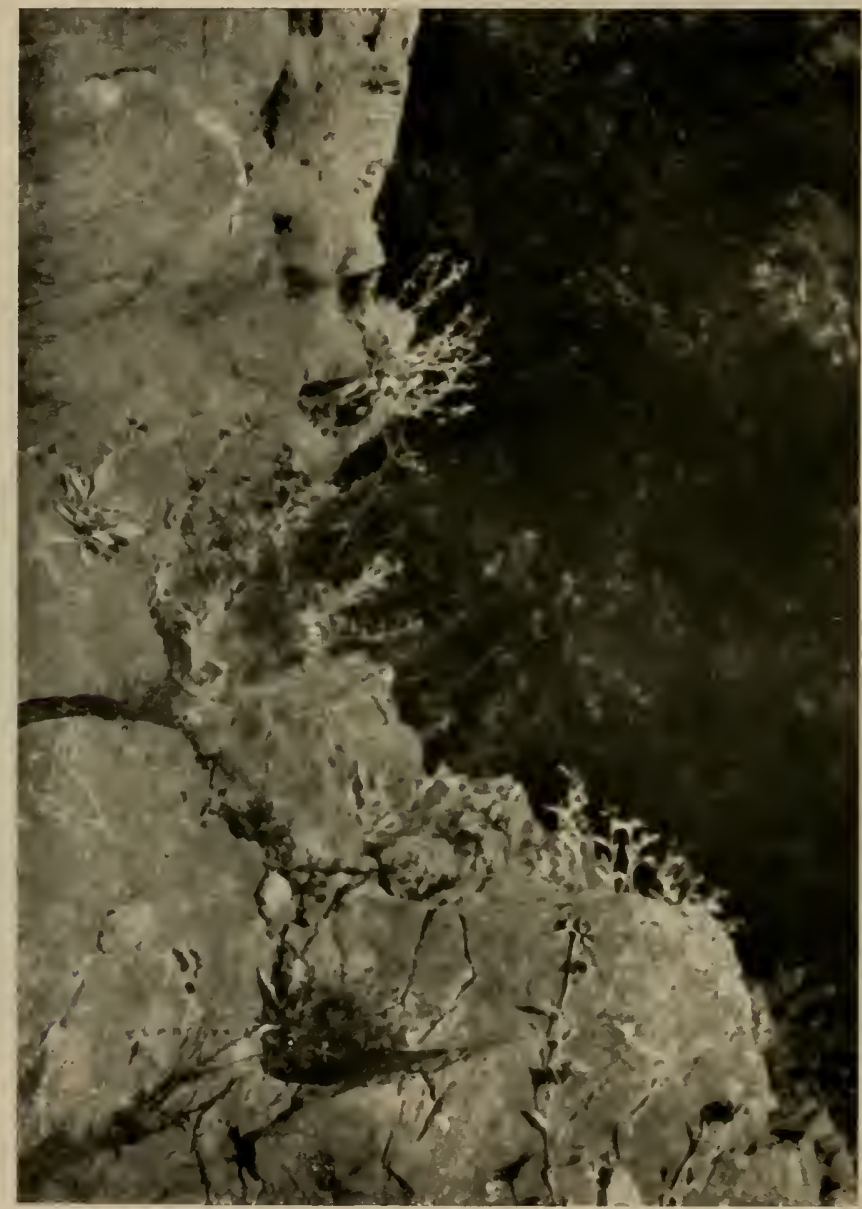

Dr. La s er phot.

Abb. 38. Felsen in der Plagusa Planina bewachsen mit wollblättrigen Kompositen (Hieracium pannoszm Gris.).

folgten. Der Turm, kaum ruiniert, ragte stattlich empor und bot einen schönen Blick auf die reizende Stadt, welche unter uns lag, der Ort mit dem wohllautenden Namen Valandova. Der ganze Kamm, besonders alle Spitzen trugen Spuren türkischen Mauer- 
werkes; der Zugang aus dem Gebirge in die Stadt, und damit einer der Pässe nach Strumiza muß früher stark befestigt gewesen sein

Valandova ist ein stattlicher Ort, wenig zerstört, mit vielen Häusern, deren rote Dächer fast ganz in grüne Bäume eingehüllt sind. Die Kuppel einer Moschee, ein Minarett, eine christliche Kirche ragten über die kleinen Häuser empor. Auch die ganze Talebene um den Ort war in saftiges Grün getaucht, Maienpracht war dort noch über Wiesen und Felder gebreitet. Wundervoll leuchteten zwischen den Maulbeerpflanzungen die weißen und violetten Flächen der blühenden Mohnfelder heraus.

Über Valandova hinaus dehnte sich das Tal weit gegen die Belasiza Planina aus. Vor uns, jenseits Valandova, lagen die Lazarette von Rabrovo mit ihren vielen Zelten und Baracken. Jenseits des Tales mündete die Kleinbahn von Hudova in dem Lager von Dedeli. Zwischen der Endstation der Bahn und dem schattigen „Hain Mamre“ stieg im Zickzack die steile Straße zum Furkapaß hinauf, welche an die Doiranfront führte. Staubwolken, welche von ihr aufwirbelten, zeigten den starken Kolonnenverkehr an, der der wichtigen Doiranfront galt.

Beim Hinuntermarsch nach Valandova galt es wie immer in Mazedonien, auf weiten Bogen die Schluchten zu umgehen, welche auch hier von allen Seiten tief in den Berghang einschnitten. Nur so konnte man ein ermüdendes Auf- und Abklettern an den Schluchtwänden vermeiden; wir hätten 6-8 Schluchten durchklettern müssen, um auf geradem Weg ins Tal zu gelangen, hätten wir nicht ihre oberen Enden geschickt umgangen.

Über der Stadt hoben sich von der dürren Felsenwand des Berges zwei scharf umrissene, dunkle Flecken ab. Es waren dies zwei Haine alter Platanen. Dem einen von ihnen strebten wir zu, denn einer meiner Begleiter, Dr. Laser, kannte den köstlichen Quell, der in seinem Schatten entspringt. Der Abend nahte, wir waren I 4 Stunden auf den Beinen, die Feldflaschen waren leer, Durst und Müdigkeit bei uns allen groß; zudem hatte die Sonne am Nachmittag, je tiefer wir hinabstiegen, immer mehr ihre mazedonische Sommerkraft entfaltet.

Die Gegend von Dedeli und Valandova ist durch ihre starken Quellen berühmt. In friedlichen Zeiten muß dies Gebiet ein fruchtbares Land fast ohne gleichen gewesen sein, und mulb es in Zukunft wieder werden. Valandova war für die Versorgung der Truppen in der Gegend der wichtigste Markt. Hier 
konnte man vielerlei Gemüse einkaufen, Bohnen, Erbsen, Tomaten, Lauch, Zwiebeln und Kohl gediehen üppig auf den gut bewässerten Feldern und in den Gärten.

Der Sommer brachte alle Melonenarten, jetzt gerade reiften die Kirschen, Pfirsich, Aprikosen-, Äpfel- und Birnbäume hatten reichlich Früchte angesetzt. Zwischen den Getreidefeldern waren weite Strecken mit Mohn bepflanzt und die unendlichen Maulbeerhaine verrieten, daß dieser Teil des Wardartales, vor allem Valandova und Piravo in Friedenszeiten ein Zentrum der Zucht des Seidenspinners waren, von dem die Fabriken im nicht fernen Gewgeli einen großen Teil ihres Bedarfs bezogen. Jetzt noch

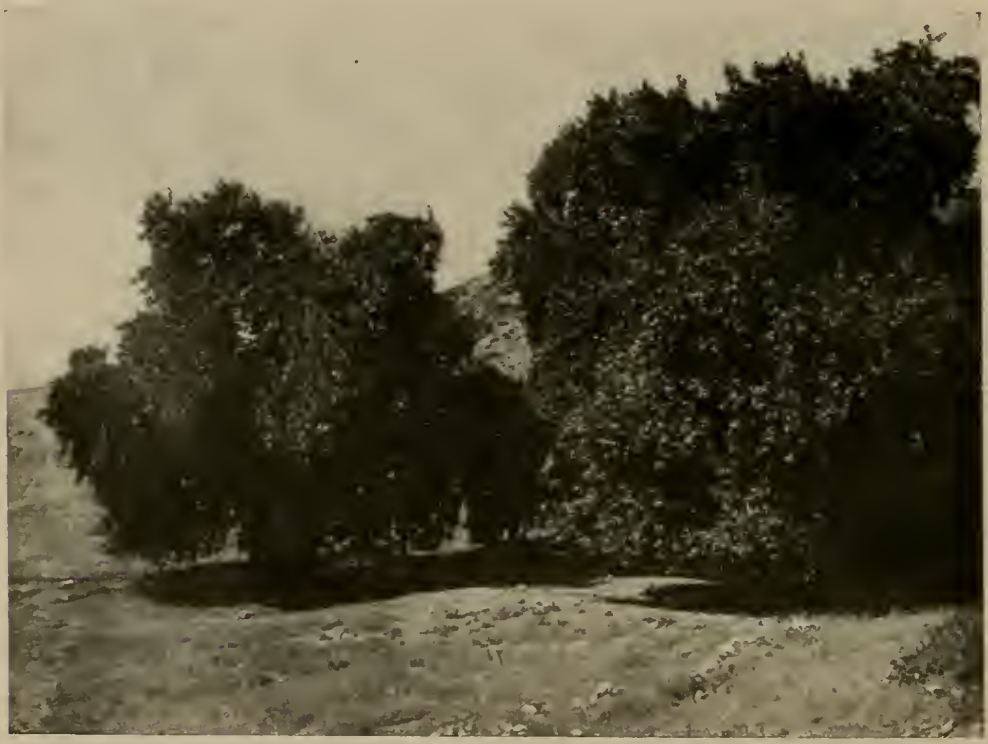

Abb. 39. Der heilige Hain bei Valandova.

sah man in einzelnen Häusern die hier ziemlich primitive Kultur des Seidenwurmes betreiben. Im Tal gab es sogar einige mit Baumwollstauden bepflanzte Gebiete, eine der wenigen Stellen in Europa, wo dies wichtige Gewächs, der Reichtum der Südstaaten von Nordamerika und von Ägypten, gezogen wird.

Während wir uns von diesen Dingen erzählten, erquickte uns der Schatten des Platanenhains und vor allem die mächtige Wasserader, welche aus dieser Quelle des Reichtums der Gegend floß. Eine Gruppe von 4-5 riesigen uralten Platanen war an einen 
senkrecht abfallenden grauen Felsen angelehnt, aus welchem eine Quelle über einen Meter breit einen Wasserstrahl aus seinem Innern herausschoß, der sofort als stattlicher Bach sich in die Schlucht stürzte, die er sich selbst im Laufe der Jahrhunderte gegraben hatte.

Als wir herannahten, erschien uns der Hain mit seiner rauschenden Quelle wahrhaft wie ein segenbringendes Heiligtum. Seit die Wolken sich oben im Gebirge zerteilt hatten, hatte kein Schatten uns mehr berührt. Schwarz standen die Kronen der Bäume über der glühenden Landschaft, als wir den Berg, meist stark mit unserer wissenschaftlichen Ausbeute belastet, hinab-

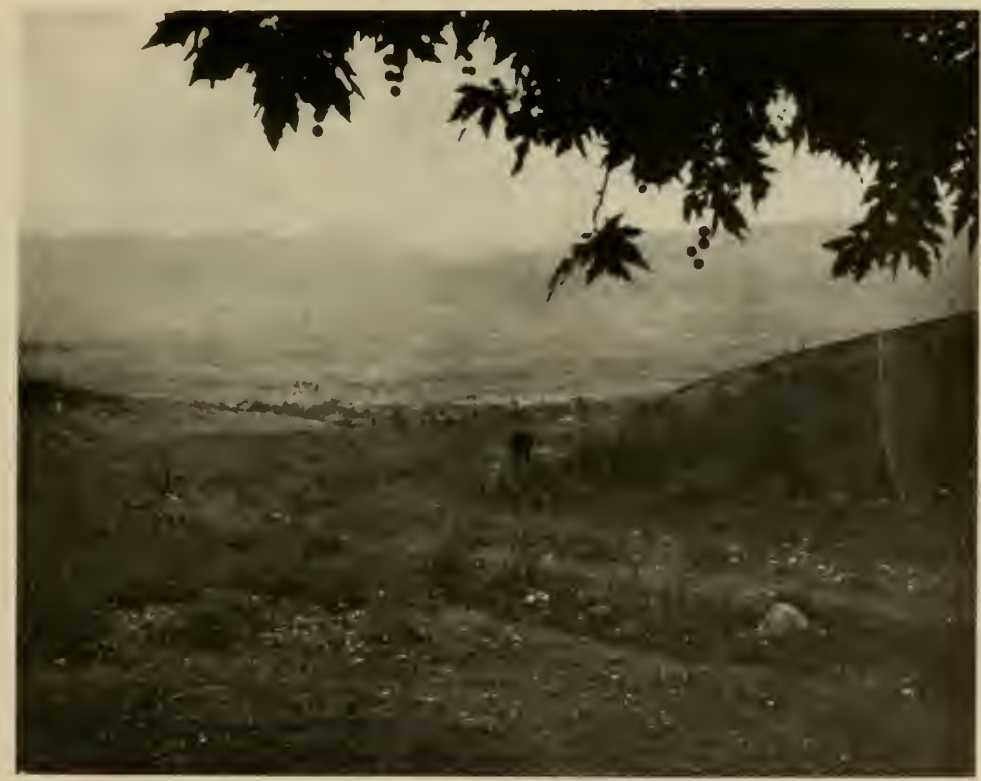

Abb. 40. Blick aus dem heiligen Hain bei Valandova auf Dedeli und den Furkapaß.

keuchten. Schwarz erschienen die knorrigen, meterdicken Stänme der Platanen; fast war es, als träten wir in ein dunkles, kühles Gewölbe ein, als wir den Rand des Schattens erreichten.

Er brachte uns bald Kühlung und Erfrischung, dieser heilige Hain mit seiner Quelle. Bald erholten sich die Augen von der Blendung des Sonnenlichtes und man begann die Schönheit des Ortes ganz aufzunehmen. Graugrün erschienen jetzt die Stämme der Bäume, wie mächtige Säulen das Blättergewölbe stützend, das sich über uns zusammenfügte. Auf den gelbgrauen Felsen kletterten Ziegen. Am kaum entstandenen Bach wuschen Frauen im klaren Wasser. 
Und vor uns öfnete sich ein lieblicher Blick über das Tal und die fernen Berge, wie von einem köstlichen Rahmen umschlossen durch die Stämme der Platanen und die zierlichen Formen ihrer im Abendhimmel schwebenden Blätter.

Der Quellbach stürzte bald brausend in die Schlucht, die wir verfolgen mußten, um in die Stadt zu gelangen. Kaum geboren, mußte der Bach schon die erste Mühle treiben und so deren noch eine ganze Reihe, ehe er unten im Tal, zwischen den Häusern

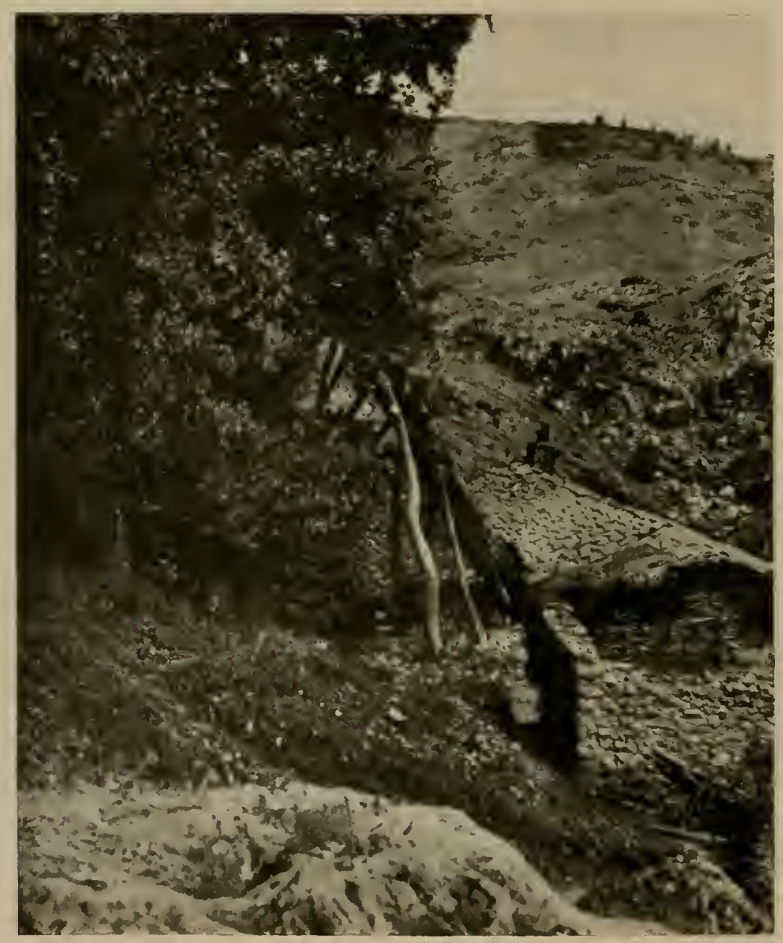

Abb. 4I. Mühle unterhalb des heiligen Hains bei Valandova.

der Stadt seine ganze Burschenkraft verloren hatte und träg über dem Geröll dahinschlich.

Die Mühlen waren kleine, dunkle Steinhäuser, meist ohne Fenster; durch die enge Türe sah man direkt in die Mahlstube hinein, wo der Mühlstein wagerecht sich drehte, so wie unten auch das Mühlrad wagerecht lag und mit seinen Schaufeln das seitlich zufließende Wasser nach Art einer Turbine auffing.

Alte türkische Männer mit vermehlten Haaren und Bärten, umgeben von Knaben, besorgten die geringe Arbeit in den primi- 
tiven Mühlen. Es waren malerische Bilder, welche die Mühlen, zum Teil von Schlingpflanzen überwachsen, mit ihren hölzernen, halbvermoderten Zuleitungsröhren, hohlen Baumstämmen, eingeschmiegt in der Wand der Schlucht darboten. Grell beschien sie noch die Abendsonne, dunkle Schatten fielen von ihren Wänden auf die Hänge der Schlucht. Das Wasser toste und brauste durch Röhren, Kanäle, an den Rädern vorbei, der Tiefe der Schlucht $\mathrm{zu}$, die wir betraten, um unter einer alten, überwachsenen Brücke den Ort zu erreichen.

Dort herrschte auf den Straßen das geräuschvolle Leben der deutschen Soldaten. Zahlreiche Kolonnen waren hier einquartiert.

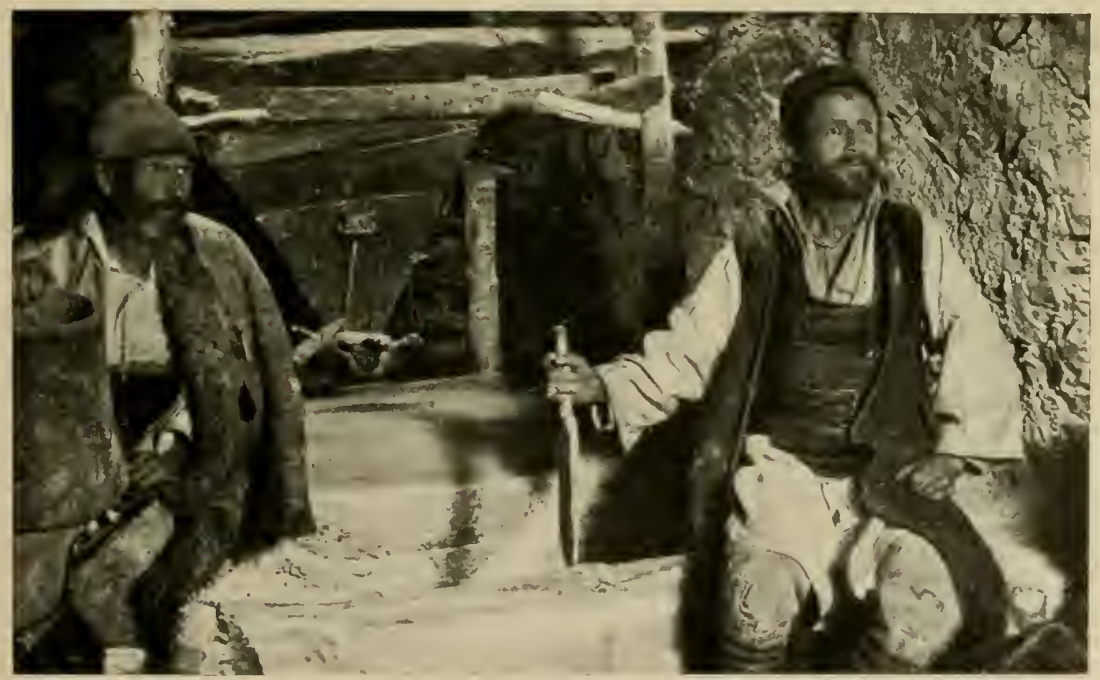

Abb. 42. Die Müller und das Innere ihrer Mühle mit dem wagrecht laufenden Mühlstein und dem Getreidetrichter.

Vor der Marketenderei und einer Feldbuchhandlung stauten sich die Mannschaften. Aus den Höfen tönte das Lachen und Singen türkischer Kinder. Abendfrieden und goldener Sonnenschein lagen über dem Städtchen, als wir unseren Wagen, der uns vor der Moschee erwartete, bestiegen.

In der kühlen Abendluft fuhren wir durch das Wardartal nordwärts „heim“, wie man schon zu sagen begann. „Heim“ zu den Briefen aus der richtigen Heimat, die ich an diesem Abend noch vorfand, als ich voll von den Eindrücken des reichen Tages im Standquartier wieder eintraf. 


\section{DAS NIKOLATAL}

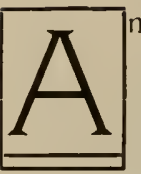

m Morgen des I. Juni brauste ein Kraftwagen vor der Türe meines Laboratoriums an und mit ähnlichem Gebrause drang ein kleiner, ältlicher, lebhafter Mann in mein Zimmer ein. Er stellte sich als Hauptmann Jungmann vor: er habe gehört, ein Naturforscher sei hier angelangt, das interessiere ihn brennend, ob er mir etwas nützen könne, er sei begeisterter Naturfreund. Hier im Lande könne und müsse etwas geschehen.

Dieser Mann hat in der Folge mir und der Erforschung von Mazedonien viel genützt. Mit seinem impulsiven Temperament brachte er Dinge zur Erfüllung, an welchen andere sich lange herumquälten; um ihn herrschte stets Bewegung und Leben. Er war Nürnberger Fabrikant, tat hier im fernen Land seinen Kriegsdienst als Hauptmann und Kommandeur eines Arbeiterbataillons und suchte seine Zeit durch Vertiefung in die Kenntnis des Landes und durch hilfreiche Unterstützung aller Forscher nutzbar anzuwenden. Ich habe viel von ihm gehabt und werde in diesem Buch seinen Namen oft zu erwähnen haben.

Am I. Juni lud er mich sofort in sein Auto und fuhr mich am Wardar entlang in ein schönes Tal, in dem es viele Käfer und andere Insekten gäbe, wo ein richtiger Wald vorhanden sei und eine unendliche Blütenfülle prange und dufte. Er hatte mir nicht $\mathrm{zu}$ viel versprochen; das Nikolatal erwies sich als eine zoologische Fundgrube. Es wurde eine der Stätten, welche ich in allen Jahreszeiten regelmäßig besuchte, und in welchem ich eine Reihe interessanter Beobachtungen machen durfte.

Jetzt fuhr er mich in flottem Tempo den Wardar aufwärts, an dessen rechtem Ufer auf der Straße, welche er im Jahre vorher mit seinem Bataillon gebaut hatte. Hohe mit Buschwald bewachsene Berge faßten das malerische Tal ein, in welchem der hochgeschwollene Wardar seine gelben Fluten majestätisch daher wälzte. Die Wände des Tales zeigten die charakteristischen Erosionswirkungen; zahlreiche Seitentäler führten brausende Bäche zum 
Fluß. Die Hügel waren von Buschwald bewachsen, aus dem jetzt in der schönsten Zeit des Jahres viele bunte Blumen herausleuchteten.

Stattliche Pappeln standen hie und da am Ufer, alte knorrige Weiden und Platanen beugten ihre Äste über das Wasser. Die Straße stieg bald steil über dem Fluß empor, um dann sich wieder fast zu seinem Spiegel zu senken. Eine Bucht in der Talwand öfnete sich nach rechts, durch einen seichten, an der Mündung verbreiterten Bach bogen wir in das Nikolatal ein. Es war zur Zeit ein wasserreiches, grünes, reich bewachsenes Tal. Längs der Talsohle standen zahlreiche mächtige Platanen; aber ihre weiß-

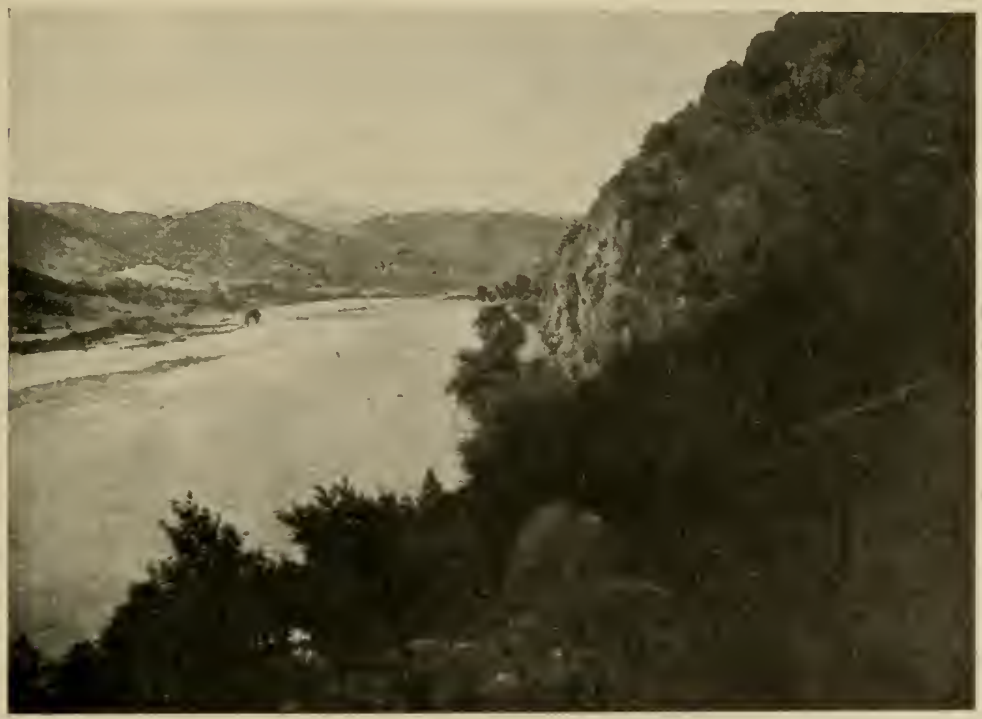

Abb. 43. Aussicht ins Wardartal von Nikola gegen Gradec.

grauen Stämme waren zumeist grausam verstümmelt. Hier hatten die bulgarischen Soldaten auf der Holzsuche bös gehaust. Die großen Äste waren meist abgesägt und die uralten Stämme standen traurig da, hohl und vielfach im Innern ausgebrannt. Fledermäuse flatterten auf, wenn wir an die Stämme klopften.

Steil stiegen zu beiden Seiten die dicht bewachsenen Berghänge hinan, von Schluchten zerrissen, in der Höhe zum Teil von Felsen überragt. Große Eichen und Eschen bildeten einen beträchtlichen Teil des Bestandes. An freieren Stellen erhoben sich viele meterhohe Sträucher von Buchsbaum. Trotz der inten- 
siven Ausbeutung durch Deutsche und Bulgaren dehnten sich noch üppige Baumbestände die Hänge hinan. Wo die Stämme schwer wegzuschaffen waren, da hatten die Bäume sich erhalten. Und wirklich, wie der Hauptmann mir versichert hatte, eine reiche Tierwelt belebte das Tal, kaum berührt von menschlicher Kultur.

Schon der kurze Ausflug dieses Tages brachte eine Anzahl interessante Beobachtungen. Und schon am I2. Juni wiederholte ich den Besuch im Nikolatal, diesmal gut ausgerüstet und auf längeren Aufenthalt vorbereitet. Ein schwerer, bremsenloser Bauernwagen fuhr uns die Wardarstraße zum Taleingang. Die Fahrt war nicht so gefahrlos, wie neulich die Beförderung im Auto. Auch war sie zeitraubender. Denn ich mit meinen vier Begleitern mußten uns jedesmal, wenn es bergab ging, mit allen Kräften an den Hinterteil des bremsenlosen Wagens hängen, damit er uns nicht mit den Pferden in den Wardar rutschte.

Aber schließlich kamen wir gut in das Nikolatal und fuhren dort aufwärts bis zu einer frischen Quelle mit kalkhaltigem Wasser, auf welche mich beim ersten Besuch schon Hauptmann Jungmann aufmerksam gemacht hatte. Hier wurden die Pferde ausgespannt und auf die Weide geführt, einer der Burschen erhielt den Auftrag die Zelte aufzuschlagen und das Lager zu bewachen, während ich mit zwei Begleitern mich aufmachte, um die Berge und die Fortsetzung des Tales zu durchforschen.

Auf den Karten ist südlich vom Ausgang des Tales ein Kloster Sv. Nikola verzeichnet, welches wir schon beim ersten Besuch vergeblich gesucht hatten. Auch diesmal fanden wir keinen Stein von ihm. Aber als Anzeichen früherer stärkerer Besiedlung des Tales durfte ich wohl die zahlreichen Nußbäume deuten, die in großen Mengen an den Hängen wuchsen. Allerdings die mächtigsten und prachtvollsten unter ihnen hatte Hauptmann Jungmann auf dem Gewissen, dessen Bataillon sie für die deutschen Gewehrfabriken gefällt hatte. Nicht minder als diese, deuteten auf frühere menschliche Bewohner die vielen Reben, welche über die Bäume und Büsche rankten und hier ein verwildertes Dasein führten. Es ist ja wohl noch fraglich, ob der edle Wein auf dem Balkan ursprünglich als Wildpflanze vorkommt.

Zunächst wollte ich die Wälder besuchen; denn solche hatte ich bis dahin außer im Gebirge in größeren Höhen noch nicht in Mazedonien angetroffen. Es war keine leichte Arbeit hier zu ihnen zu gelangen. Der Abhang war mit kantigem Geröll bedeckt, in 
welchem das Klettern sehr mühsam war. Dazwischen war ein dichtes Dorngebüsch aufgeschossen, durch welches man nur mit viel Zeit und Arbeit hindurchdringen konnte. Brombeeren und Himbeeren, auch Schlehdorn standen zwischen Judendorn und einer Menge anderer stachlicher Sträucher.

So war ich schon schweißbedeckt und ermüdet, als ich an den Rand des Waldes gelangte. Der war nun nicht sehr reizvoll. Der Boden war trocken, steinig und entbehrte fast ganz des Wachstums von Niederholz oder Kräutern. Knorrige Wurzeln durchzogen nach allen Seiten die Furchen und Spalten, von denen er stark zerklüftet war. Umso eigenartiger war die Zusammensetzung des Gehölzes. Neben schönen hochstämmigen Eichen bestand er am unteren Rand aus Haselnußbäumen. Es waren wirkliche starke Bäume mit knorrigen Stämmen und starken Ästen. Sie hatten dieselbe streifige, braune Rinde und hatten ganz ähnliche Nüsse angesetzt wie unsere Haselsträucher. Es war der türkische Haselbaum (Corylus colurna L.). Weiter nach oben zog sich ein stattlicher Wald von Silberlinden hin. Die Silberlinde ist ein sehr charakteristischer Waldbaum des Balkans (Tilia tomentosa Monsch). Hier oben konnten wir eine lange Strecke in ihrem Schatten wandern; aber auch hier war es kein behagliches Gehen, sondern mehr ein Klettern.

Reizvoller bot sich der Wald der Silberlinden aus der Ferne dar. Am Nachmittag sahen wir ihn von den Nordbergen über das Tal im Schein der tieferstehenden Sonne zu uns herüberblinken. Besonders schön erschien er mir, wenn der Wind über die Lindenkronen strich und nun Lichtund Schattenwellen über die Oberfläche des Waldes hinzogen und den feinen Silberglanz der Blätter aufblinken ließen.

Am Kamm der Berge war der dichte Wald von Waldwiesen

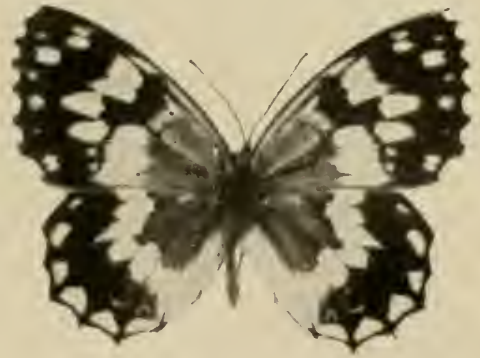

Abb. 44. Melanargia larissa vic. taurica. unterbrochen; goldener Sonnenschein lag auf diesen Lichtungen, die sich immer wieder im Dickicht verloren. Auf ihnen wuchsen Salbei (Salvia sclarea L.), eine Form mit violetten Hochblättern und sonstige Lippenblütler, Wicken und andere farbige Blumen, welche zahlreiche Insekten anlockten. Hier flog in großen Mengen 
ein schwarz-weißer Schmetterling, verwandt mit unserem Dambrett aus der Gattung Melanargia (Melanargia larissa, ähnlich der kleinen asiatischen taurica). Viele Bienen summten umher, Fliegen und Käfer gab es in Mengen, von letzteren hauptsächlich Bockkäfer und große silbergraue Rüsselkäfer. Unter ersteren war Argalia punctata L., ein silberiger Käfer mit dunklen Flecken, Agapanthia cynare Germ., ein olivgrüner Bock mit gestreifter Brust und weiß-schwarz geringelten Fühlern besonders auffällig, ferner der große graue Morimus funereus Muls. mit seinen vier schwarzen Flügelflecken. Auch ein großer Hirschkäfer (Lucanus cervus turcicus Sturm) fand sich hier.

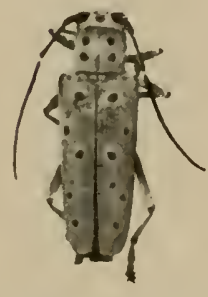

Abb. 45. Bockkäfer Argalia punctata L. Kaluckova. Nat. Gr.

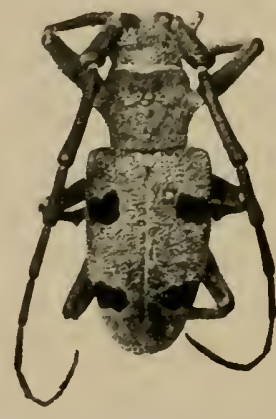

Abb. 46. Morimus funereus Muls. Tomeros. Nat. Gr.

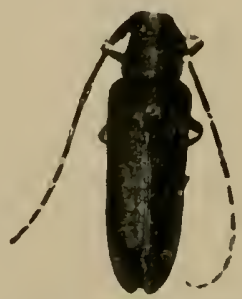

Abb. 47. Agapanthia cynare Germ. Nikolatal. Nat. Gr.

Hauptmann Jungmann hatte uns allerhand von Rehen und Wildschweinen versprochen, die wir hier oben antreffen sollten. Wir fanden tatsächlich ein Suhlbett, wo Säue gewühlt hatten und auch auf einen Rehwechsel stießen wir. So müssen damals tatsächlich solche jagdbaren Tiere im Gebiet vorhanden gewesen sein. In jenen Tagen war ich für eine Jagd nicht ausgerüstet und verfolgte andere Absichten. Als ich im nächsten Jahre (Juni 1918) mit waidgerechten Freunden eine richtige Jagdexpedition in das Nikolatal unternahm, war es zu spät. Das Wild war durch zielloses Jagen von Bulgaren und anderen Soldaten vergrämt und wohl auch erlegt. Im Jahre 1918 konnte ich im ganzen Gebiete weder Wechsel noch Losung einer Wildart entdecken. Von Säugetieren traf ich bei allen Besuchen im Nikolatal nur Mäuse und Fledermäuse an.

Durch den Wald huschten Schwarzamseln, verschiedene Ammern waren zu bemerken, NuBhäher flogen vor unseren Schritten auf, auch Buchfinken waren nicht selten. Raubvögel, die hier in den Wardarfelsen sehr viel horsten, zogen oft ihre 
Kreise über uns, in einigen erkannten wir mit Sicherheit Adler Ja, wohl zu einem solchen gehörte ein Horst, den wir am Südhang. an einem unersteigbaren Felsen befliegen sahen. Bussarde waren nicht selten, ein solcher durch Abschuß als Mäusebussard erwiesen.

Besonders eigenartig war ein Tier, welches ich hier auf der Südseite in großer Anzahl antraf. Es war ein großes grillenähnlich aus-

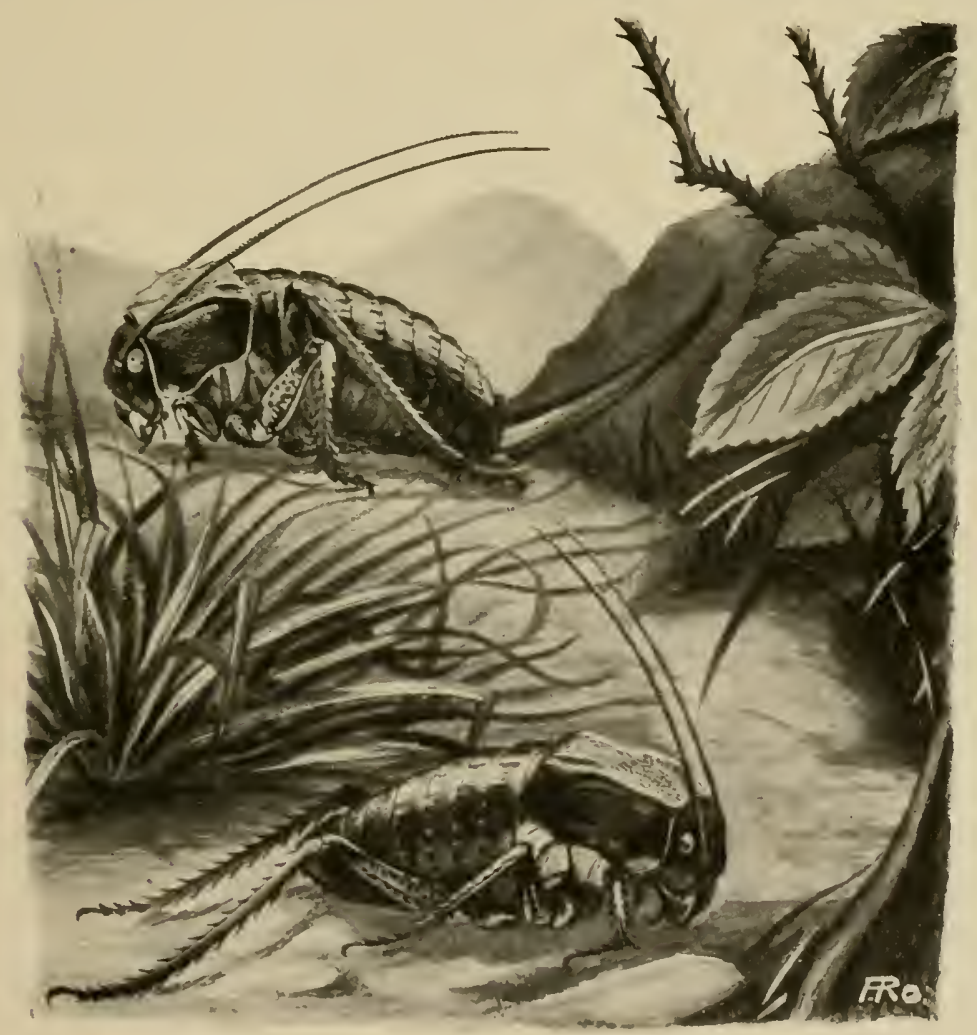

Abb. 48. Große Bronzeheuschrecke (Dinarchus dasypus Illig). Männchen (unten) und Weibchen (oben).

sehendes Tier von etwa $6-8 \mathrm{~cm}$ Länge, so groß wirkend wie eine Maus. Es stellte sich später als eine eigenartige Heuschreckenart heraus. Zwei einander sehr ähnliche Arten kamen im Lande vor; sie gehören zu zwei Gattungen und führen die wissenschaftlichen Namen Callimenus oniscus Charp. und Dinarchus dasypus Illig. Beide wären geeignete Vorbilder für einen Kunstgewerbler vom 
Talent und den Neigungen eines Japaners. Sie sehen schon im Leben aus, als wären sie aus Bronze gebildet. Beide Gattungen gleichen sich sehr mit ihrem kantigen Brustschild und ihren langen dünnen Fühlern. Meist sind sie schwarz oder dunkelbraun gefärbt, manchmal ist ein grünlicher Ton auf ihrer Oberfläche ausgebreitet. Stets glänzen sie eigenartig metallisch.

Beide Arten hüpfen trotz ihrer langer Hinterbeine nicht, sondern sind außerordentlich träg in ihren Bewegungen. Bei der einen von ihnen dient eine auch sonst bei Insekten häufige Eigentümlichkeit als wirksame Verteidigungswaffe. Faßt man diese Heuschrecken an, so lassen sie an verschiedenen Gelenken ihres Körpers eine gelbe, klebrige Flüssigkeit in solcher Masse austreten, daß einem die ganzen Hände damit verschmiert werden, und daß sie in großen Tropfen über diese und von ihnen hinabfließt. Diese Flüssigkeit ist ihr Blut, welches durch Poren austritt und auf Feinde eine abwehrende, vielleicht auch ätzende Wirkung hat. Es wird angegeben, daß diese Ausscheidung nur bei der Gactung Callimenus vorkommt, nicht bei Dinarchus und zwar bei jener aus den Zwischenräumen zwischen dem ersten und zweiten Dorsalsegment des Abdomens. Ich glaube sie bei allen Individuen der Arten, die ich fing, beobachtet zu haben und zwar an verschiedenen Stellen des Körpers. Doch achtete ich in Mazedonien nicht genügend auf die Verschiedenheit der zwei Arten, die ich erst in der Heimat feststellte.

Beim Abstieg vom Nordkamm geriet ich mit meinen Begleitern wieder in dichtes Dorngebüsch, durch welches wir uns nur mit dem Seitengewehr einen Pfad hauen konnten. So verirrten wir uns und kamen erst nach vielen Stunden erschöpft bei den Zelten an, wo schon die Kochtöpfe über dem Lagerfeuer dampften.

Für die Nachmittagsstunden war nicht viel Kraft übrig; so wurden an diesem Tage keine Berge mehr bestiegen, sondern der Bach und seine Ufer untersucht. Plätschernd floß das Gewässer über die Steine, hie und da einen breiten, tiefen Tümpel bildend, wo etwa ein vom Hang herabgerollter Felsblock oder ein gebrochener Baumstamm es gestaut hatte. Solche Tümpel bildeten höchst geeignete Badewannen, in denen jeder von uns nachmittags ein erfrischendes Bad nahm.

Das durfte aber erst geschehen, nachdem der Bach sorgfältig auf seine Tierwelt untersucht war. Sand und Steine bedeckten seinen Grund, das Wasser war von durchsichtiger Klarheit. So 
sah man zwischen den Steinen kleine Fische lebhaft herumschießen, welche sich als jugendliche Individuen derselben Barbenart herausstellten, die ich später in riesigen Exemplaren im Wardar fing. Hier in den kleinen Bächen hielten sich also vor allem die Jugendstadien auf, die großen Barben hätten in diesen kleinen Gewässern gar nicht Platz.

Unter Holzstücken und Steinen fanden sich zahlreiche Flußkrebse in allen Größenstadien, von kleinen einjährigen bis zu großen ausgewachsenen Exemplaren. Es waren zwei Arten hier im Bach vertreten, Astacus fluviatilis L. und A. torrentium Schrank.

Auf dem Wasserspiegel im Schatten der Bäume schwirrten stahlblau schimmernde Taumelkäfer im Kreis herum. Sie gehörten zwei Arten an (Aulonogyrus concinnus Klug und Gyrinus caspius Mén.). Wasserläufer schossen von Ufer zu Ufer auf der Oberfläche der Tümpel. Unten am Boden lagen die Larven der Libellenarten, welche blau, rot, grün gefärbt, in vielen Formen unter den Bäumen, im Röhricht umherhuschten. Vor allem an Stellen, wo der Bach sein Kiesbett in viele Arme geteilt durchströmte, wo Binsen, kleine Weidenbüsche und Minzen wuchsen, waren viele Arten von Libellen versammelt, welche auf all die kleineren Insekten jagten, die über den Blüten der Sumpfpflanzen gaukelten.

Trotz der Feuchtigkeit und des reichen Pflanzenwuchses fiel mir bei jedem Besuch des Nikolatales wieder die Armut der Schneckenfauna auf. Zwar eine Art mit dunkler, schwarzbrauner Schale, von der Größe unserer Helix pomatia L. kam in vielen Individuen vor. Aber sonst fanden sich nur wenig Schneckenarten in geringer Individuenzahl. Jene große braune Art fanden wir auch an jenem Abend in größerer Anzahl in der Nähe des Baches.

Über all diesen Beobachtungen sank die Nacht herab. Meine Leute versammelten sich am Lagerfeuer, während das Abendrot am Himmel verglomm. Als es dunkel wurde, das Feuer zusammensickerte, zogen wir uns alle müde in unsere kleinen Zelte zurück. Mein Bursche hatte mir Gräser und Blüten unter meine Decke gesammelt, so daß ich recht wohlig auf dem Sandbett eines ausgetrockneten Baches mich ausstreckte, ermüdet von dem anstrengenden, früh begonnenen Tag.

Ehe ich mich niederlegte, beugte ich mich noch einmal aus dem Zelt heraus und blickte aufwärts, wo über dem tiefschattenden 
Gewölbe der Platanen die Sterne in klarer Pracht aufblitzten. Nun begann es auch auf der Erde zu gleißen und zu blinken. Hunderte von Leuchtkäfern hatten mit ihrem Lichtspiel begonnen; im Gras saßen die Weibchen und antworteten mit ihrem Lichtsignal auf den Lichtblitz eines vorüberfliegenden Männchens. Es war eine Art, welche abwechselnd ihr Licht erscheinen und wieder verschwinden ließ. Es war äußerst reizvoll, das Frage- und Antwortspiel der einzelnen Paare $z u$ beobachten, welche sich allmählich zueinander blinkten und unsere Soldaten fingen sofort an, die Tiere mit unseren Blinkern zu vergleichen.

Rasch ging es noch einmal zum Zelt heraus, um eine Anzahl Belegexemplare der Art, es war Luciola husitanica Charp., zu sichern. Es war wohl der Mühe wert gewesen, das Zelt noch einmal zu verlassen, denn es zeigte sich, daß das Geblinke der Leuchtkäfer in Büschen und Bäumen an der ganzen Talwand und rings um den Bach sich tausendfach wiederholte. Unendliche Mengen der Tierchen waren in dieser Nacht unterwegs; unter den Wölbungen der Bäume verbreitete ihr Licht einen zarten geheimnisvollen Schimmer und an der Talwand wiederholten sie die Sternbilder, welche an Himmelsdom strahlender zu glänzen schienen, als je.

Trotz aller Müdigkeit war es ein schwerer Entschlụ sich ins Zelt zurückzuziehen. Während die Augen langsam zufielen, ertönte über der Zeltbahn, aus allen Bäumen und Büschen der Umgebung das klangvolle Lied der Nachtigallen, deren es große Mengen im Nikolatal gab. Mit ihren schönen Stimmen vereinigte sich das Orchester der zahllosen Frösche, die feinen Glockentöne der Unken am ganzen Bach entlang. Während ich einschlief, störte mich das feine Summen der Schnaken nicht, die ich am nächsten Morgen als Culex und Anopheles, also als harmlose Stechmücken und Malariaüberträger erkannte. Aber hier in menschenloser Gegend konnten wir die Stiche von ihnen beiden als harmlos betrachten.

Lange, ehe die Sonnenstrahlen ins Tal hineinlangten, waren wir am nächsten Morgen wieder marschbereit. Heute galt es den Nordhängen des Nikolatales, welche schon von unten her ein besonders malerisches Bild darboten. Ich stieg durch ein flaches Nebental hinan, in welchem zwischem den hohen Buchsbaumstauden schöne, weiße Lilien (Lilium candidum L.) standen. Ihr süßer Duft wurde vom Morgenwind talwärts uns entgegen getragen. Meine Soldaten sprachen sofort von Engels- und Madonnenhänden, in welche diese frommen Blumen gehörten und beschlossen sofort 
am Abend den Schwestern unseres Lazaretts einen großen Strauß mitzubringen, was auch geschah.

Auch in dem Naturforscher weckten die steifen, sanften Blüten Erinnerungen an Bilder alter Meister. Und doch konnte ich nicht übersehen, daß in ihren Kelchen vielfach Käfer einer eigenartigen roten Form saßen, welche durch irgend etwas sich $z u$ den Lilien angezogen fühlten. Es war Lilioceris lilii Scop.

Durch einen feinen, von hellen Felstrümmern besäten Rasen ging die Kletterei aufwärts, bis die Steigung sanfter wurde und sich wie auf den Wiesen eines Parkes auffallend schön geformte, dunkelbelaubte Bäume vor mir erhoben.

Wieder fanden sich hier Buchsbäume, Eichen, Eschen und Hainbuchen, teils einzeln stehend, teils in Gruppen miteinander vereinigt. Was sie aber alle

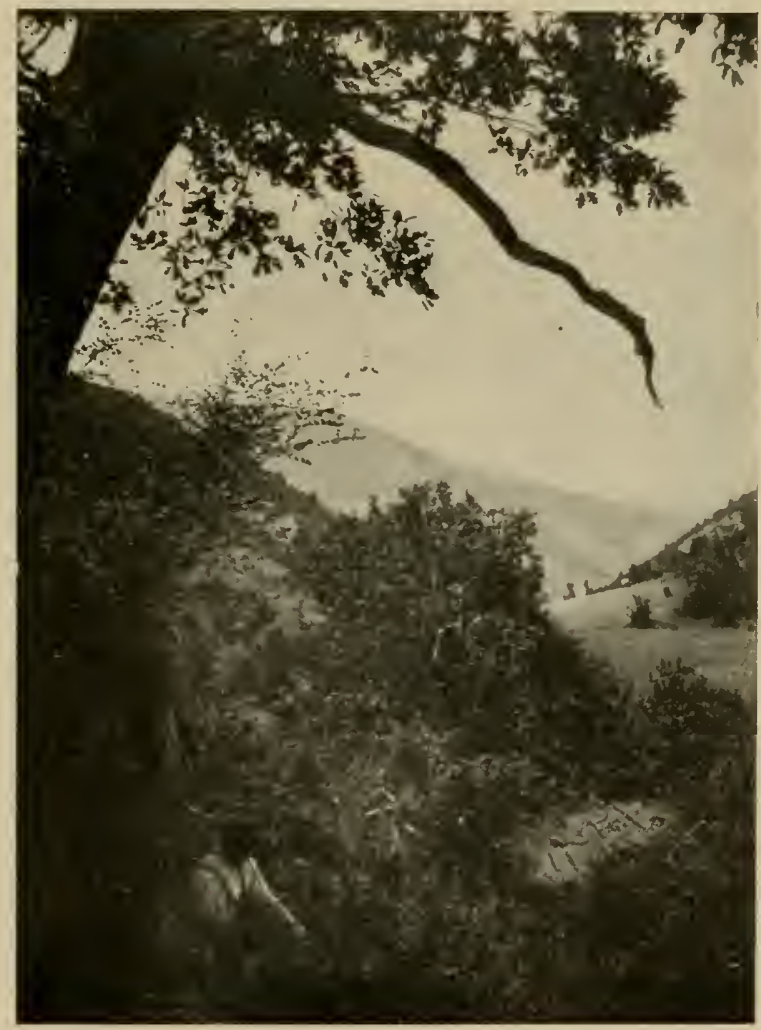

Abb. 49. Vegetationsbild aus dem Nicolatal (Quercus lanuginosa Lam.). auszeichnete, waren die gedrungenen Formen ihrer Stämme, die schönen Umrisse ihrer Kronen. Besonders trat unter ihnen der Feldahorn (Acer campestre L.) mit seinen zierlichen Blättern hervor. Die Formen aller dieser Bäume entzückten mich durch ihre malerische Schönheit. Man hätte sich hinsetzen und eine der Gruppen nach der anderen malen können; jede hätte ein eigenartiges, reizvolles Bild ergeben auf dem blumenbedeckten Rasen mit den weißen Felsen dahinter, 
über dem sich ein dunkelblauer Himmel, von großen weißen Wolken durchschwebt, ausspannte.

Es waren Wetterbäume, die hier in trockenem Fels unter dem Einfluß regelmäßiger Windströmungen langsam durch viele Jahrzehnte gewachsen waren, bedächtig Zweig neben Zweig setzend, aber so bei jeder Ast- und Stammverdickung jeden Millimeter ihrer Umgebung abringend. So glichen sie jenen japanischen Zwergbäumchen, welche unter dem Zwang des Menschen ähnliche Formen aber noch viel geringere Dimensionen annehmen. Neben dem Feldahorn waren die Eichen und Hainbuchen (Carpinus duinensis Scop.) besonders schön gewachsen. Letztere und der Feldahorn waren mit reifenden Früchten dicht bedeckt.

Um die Gebüsche und unter den Kronen der Bäume dehnte sich ein fast haideähnliches Pflanzenpolster aus. Da blühten dunkelrote Skabiosen (Knautia macedonica Grieseb.), weiße und gelbe Schafgarben, große und kleiublütige Johanniskräuter (Hypericum olympicum L.), viele Gräser waren in Blüte. Das Seltsame der Landschaft wurde noch stark betont durch eine Anzahl Knabenkräuter mit hohen dunkelrot und braungefärbten Blütenrispen, deren Blüten sich in eine lange, schmale Unterlippe fortsetzten. Phantastisch wiegten diese eigenartigen Blüten sich im leichten Bergwind. Es war eine Art der Gattung Himantoglossum (H. caprinum (M. B.)).

Weiter oben wurde die Wiese wieder üppiger, dort stand auch der Sanddorn (Hippophae rhamnoides L.) in mächtigen Büschen, die zum Teil baumartig aufgewachsen waren. Als eigenartiger Befund ließen sich kleine Bäumchen des Lebensbaumes (Thuia orientalis L.) nachweisen, die wohl von der alten Besiedelung herrührten.

Vor allem war aber hier die Wiese reich an bunten, duftenden Blüten. Eine farbenprächtige Kronenwicke (Coronilla varia L.), zahlreiche verschiedenfarbige Wicken, Tragantharten, eine kleine rosablühende und eine große Winde mit mächtigen, weißen Trichtern, viele Lippenblütler, eine Anzahl Doldenpflanzen bildeten mit ihren gelben, roten, blauen und violetten Blumen einen farbenreichen Teppich. Bemerkenswert war viel Hafer, der wild zwischen den anderen Gräsern stand und gerade blühte.

Zwischen den Felsblöcken ragten stattliche Königskerzen (Verbascum pulverulentum MB.) empor, die meist erst gerade $\mathrm{zu}$ 
blühen anfingen; neben ihnen erhoben sich üppige Disteln mit weißen und roten Blüten, welche nach Art von Kompaßpflanzen ihre Blätter senkrecht aufgerichtet hielten, so daß ihre Oberflächen alle in einer Ebene, der Ebene des Meridians, lagen. Somit standen die Kanten der Blätter nach Osten und Westen, die Flächen nach Süden und Norden. Wie Stahl bei unserem gewöhnlichen Lattich (Lactuca scariola) gezeigt hat, wird durch diese Stellung der Blätter bei Pflanzen in sonnigem Klima und besonders auf trockenem Standort ein geringerer Wasserverlust durch Transpiration und eine Milderung der Schädigung durch zu intensives Sonnenlicht herbei-

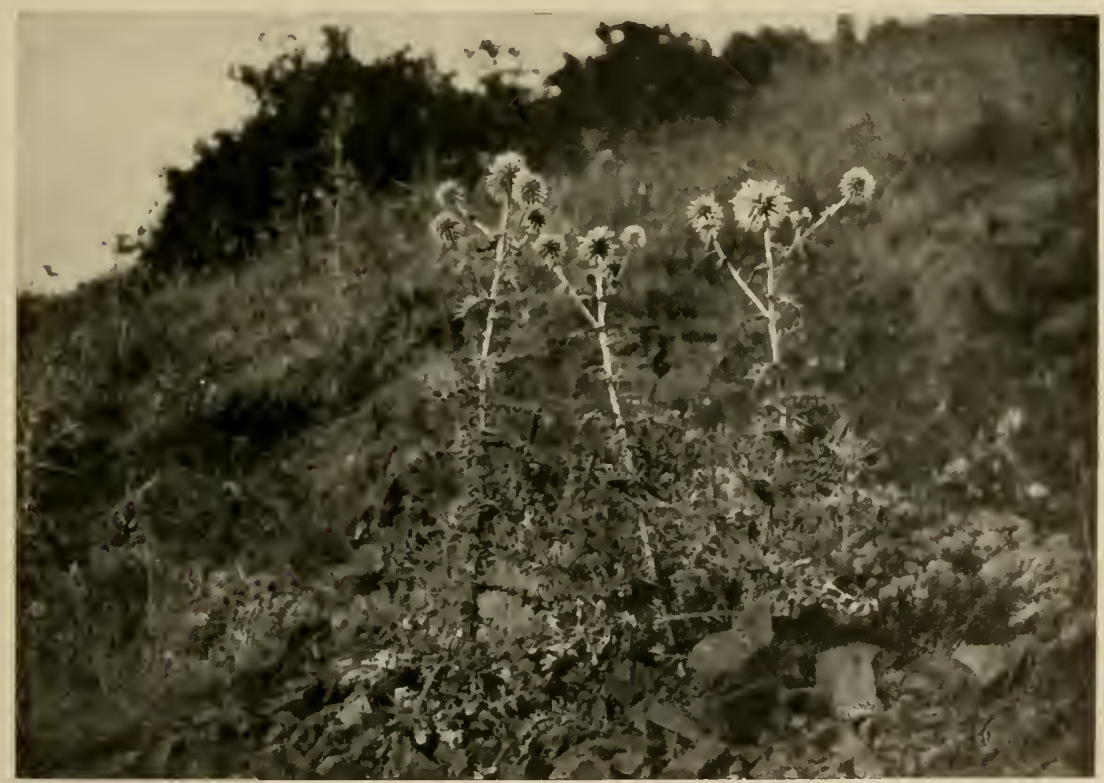

Dr. L a s er phot.

Abb. 50. Cirzium sp. bei Kaluckova.

geführt. Es ist nicht verwunderlich, daß in einem Lande mit so sonnigem trockenen Sommer, wie ihn Mazedonien hat, zahlreiche solche Kompaßpflanzen vorkommen, die ich denn auch an vielen anderen Orten beobachtete. Die Hauptarten waren Carduzs leiophyllus Petr. und Silybum marianum L.

Schon nach dem Anblick von unten hatte ich hier oben eine reiche Insektenwelt erwartet. Ich wurde nicht enttäuscht. Als erster Fund trat uns ein großer schwarzer Schmetterling mit weißen 
Flecken entgegen, der hier auf dem Nordkamm ebenso dominierte, wie drüben auf dem Südkamm gestern das Dambrett. Schon an seinem schönen stolzen Flug erkannte ich ihn als einen Satyrus ( $S$. circe Fab., dort auch $S$. anthelea amalthea Friw.). Männchen und Weibchen flogen in großer Zahl hintereinander her, wirbelten sich hoch in die Luft, um dann tief hinabtauchend in das Gras, selbst zwischen die Halme zu fliegen. Oft konnte man die Tiere sich begatten sehen. Es war wohl großer Hochzeitstag. Die Weibchen sah man immer wieder tief ins Gras fliegen, un da als echte Grasfalter die Eier abzulegen. Von Schmetterlingen waren hier auch Hesperiden sehr häufig, so Hesperia orbifer Hub. und $H$. cinare Rbr. und $H$. malvoides Elw. und Edw.

Nicht unerwähnt soll ein damals erbeuteter Perlmutterfalter der Art Argynnis niobe L. sein, der durch seine riesenhafte Größe auffiel und an asiatische Formen erinnert. Er dürfte wohl eine neue Form sein.

In diesen Wochen, Mitte Juni, machte es mir immer wieder einen starken Eindruck, wie jeweils eine Insektenart in großer Individuenzahl einige Tage stark vorherrschte, um dann nach wenig Tagen fast ganz zu verschwinden. Libellen, Ameisenlöwen, Käfer, einige Fliegenarten und vor allem Tagschmetterlinge sind solche Eintagstiere. Ihr Leben, ohnehin kurz angesetzt, wird in der Tropenglut mazedonischer Sommertage rasch aufgezehrt. Indem in einem Jahre die meisten Individuen in denselben Tagen zur Eiablage schritten, gelangen ihre Nachkommen zur gleichen Zeit zum Ausschlüpfen, so daß dies periodische Erscheinen besonders auffällig wird.

Eine besondere Freude machte meinem Insektensammler Rangnow der Fang einer ganzen Anzahl von. Sesien, jenen eigenartigen Schmetterlingen mit glasartig durchsichtigen Flügeln, die wir auf den Doldenpflanzen fanden; hier gab es auch eine Form mit undurchsichtigen Flügeln (Microsphecia myrmosaeformis $\mathrm{H}$. S.). Libellen, zahlreiche solitäre Bienen, Blatt- und Schlupfwespen und Fliegenarten brachten reiche Ausbeute. Auch Käfer, besonders Vertreter der prachtvoll metallisch glänzenden Rosenkäfer (Cetonia aeruginosa Drury), die brummend durch die Luft flogen, vermehrten die Ausbeute.

Einen besonders interessanten Beitrag zum Problem der Eintagsinsekten brachten hier die Ameisenlöwen. Mit ihnen werden 
wir uns in einem besonderen Kapitel beschäftigen. Hier sei nur hervorgehoben, daß wir diesmal vom Nikolatal vier Arten dieser eigenartigen Tiere mitbrachten. Wie Zwischenformen zwischen Libellen und Schmetterlingen erscheinen sie mit ihren genetzten aber doch buntgefärbten Flügeln, wenn sie langsamen Fluges über die Blumen gaukeln. In großen Mengen trat die Form mit den bandförmigen Hinterflügeln auf (Nemoptera sinuata Oliv.), welche auf der Plaguša Planina vor einigen Tagen aufgetreten war, in wenigen Exemplaren dagegen, zum Teil ganz frisch ausgeschlüpft, flatterten langsamen Fluges die auffallend großen Planares mit ihren braungefleckten Flügeln umher, nicht häufig waren Vertreter einer dritten Form echter Ameisenlöwen, während ein Ascalaphus, ein schön schwarz-gelb geflecktes Tier, häufiger vorkam.

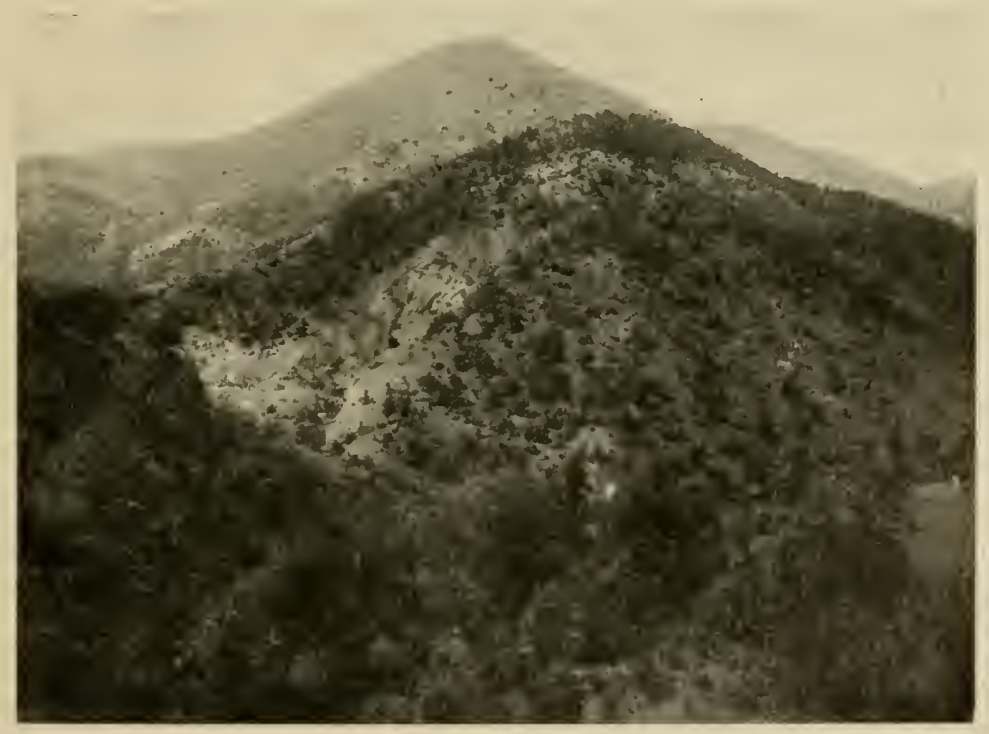

Abb. 51. Buschwald und Talbildung im Nikolatal.

Sehr auffallende Schildw an zen fanden sich auf den Doldenblüten; es waren lebhaft rot und schwarz gebänderte Tiere der Arten Graphosoma semipunctatum F. und italicum Müll. Vor allem fiel aber die größte Landwanze Europas Mustha spinulosa auf, die in Scharen an den Baumstämmen herumlief. Es ist ein vorderasiatisches Tier, das im Balkan, vor allem in dessen Osten vorkommt. 
Rot und schwarz gezeichnet waren auch Lang w anzen der Arten Spilostethus saxatilis Scop. pandurus Scop. und equestris L.., welche auch in großer Anzahl auf dem Schwalbenwurz sich aufhielten. Auf den Salbeiarten der Felshalden fand sich Calocoris cinctipes Costa, ein typisch mediterranes Tier. Auf verschiedenen Pflanzen jagden auf Blattläuse schwarz- und rotgewürfelte Krautwanzen Doraeocoris Schach., eine Art von ähnlicher Verbreitung wie die vorige.

Ein Tier, dessen Stich sehr unangenehm war, fand sich wie bei Kaluckova und in der Plaguša Planina auch hier im Nikolatal, die große, bunte Raubwanze Rhinocoris iracunda Poda; sie schwärmte an Büschen und blühenden Pflanzen im Sonnenschein umher und verführte gelegentlich zum Fang mit der Hand, was sich empfindlich bestrafte.

Auch sogenannte Leuchtzikaden gab es im Nikolatal, jene Tiere mit fast schnabelförmig verlängertem Vorderkopf, bei denen man früher in diesem ein Leuchtorgan suchte, welches aber nie nachgewiesen wurde, da es gar nicht existiert. Trotzdem haben die Tiere den Namen Leuchtzirpen behalten. Sie sind deswegen nicht weniger interessant mit ihrer Wachsproduktion am Hinterende, welche bei manchen exotischen Arten ganz enorm ist. Im Nikolatal kamen zwei flink springende Arten mit grün geäderten Flügeln vor (Dictyophora europaea L.), der europäische Laternenträger und Chanithus longirostris Walck.

Unter diesen Fängen und Beobachtungen waren wir am Kamm angelangt, wo ein frischer Wind blies und wir mit Behagen uns unter einem Baum niederließen, um den Ausblick zu genießen, der vor allem nach Norden sich reizvoll vor uns öffnete. Wir blickten in die Felsenberge gegen Demir Kapu; dicht vor uns öffnete sich ein weites zirkusähnliches Tal, am jenseitigen Rand von einem weilen, rosa angehauchten Kalkgrat abgeschlossen. Die Wardarschlucht, nach Norden sich verengend, lag tief unter uns. Nach Süden konnten wir den Fluß in vielen Windungen durch das felsige Land verfolgen, das dürr und kahl aussah, bis auf die Talmulde bei Gradeč, von wo das angebaute und Gartenland grün herüberschimmerte.

Nach kurzer Rast stiegen wir diesmal vorsichtiger auf wohlüberlegten Pfaden rasch zur Talsohle ab. Dann wurde gegessen, die Zelte abgebaut, der Wagen beladen und bespannt, worauf die 


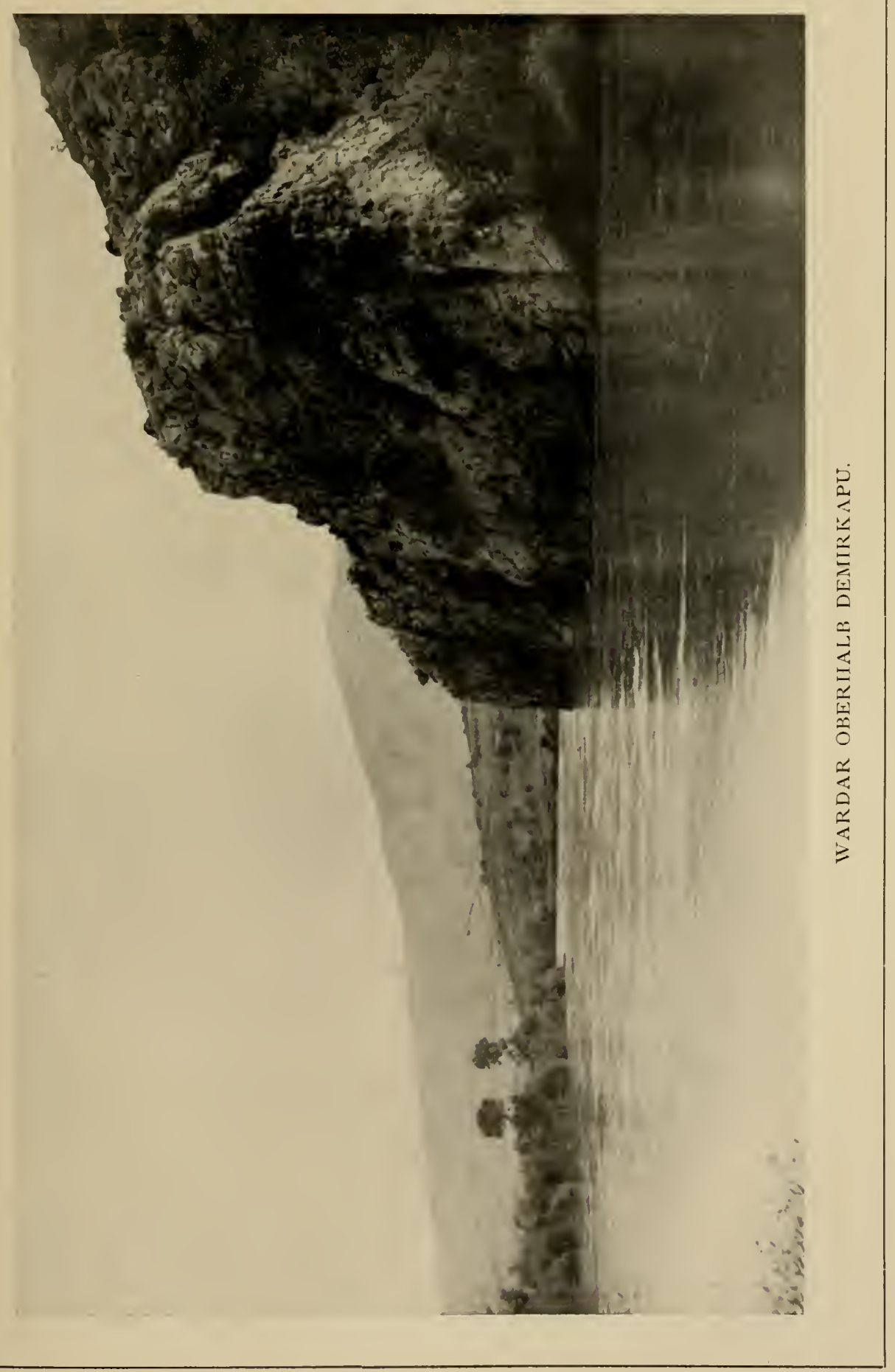



Heimreise nach Kaluckova angetreten wurde. Im Nikolatal war die Umgebung des Baches, im Tal des Wardars, dessen Ufer umflogen von vielen Hunderten von Libellen, welche in diesen Tagen wesentlich zum Charakter der Landschaft beitrugen.

Am Abend, beim Übergang über den Wardar bei Hudova, spiegelte der Fluß einen unvergeßlich schönen Sonnenuntergang wieder, in welchem die Felsenberge der Schlucht wie flüssiges Metall glühten, das sich über den Spiegel des Wassers zu ergießen schien, blaue und grüne Schatten in den Wogen erzeugend.

Am 31. Juli erfolgte ein weiterer Besuch des Nikolatales. Wie im Wardartal, so trat uns auch in den engen Tälchen die Macht der verdorrenden Sommersonne Mazedoniens augenfällig entgegen. Sie hatte uns schon auf dem Weg überfallen. Kaum hatten wir die Wardarbrücke bei Hudova passiert, so brach unser leichter, von den Fliegern geliehener Wagen zusammen. Ein Hinterrad zerkrachte hoch oben am Steilufer des Wardar und es fehlte nicht viel, daß Wagen, Pferde und Menschen in die brausende Flut hinuntergekollert wären. Jedenfalls mußten wir den Wagen zurückschicken; da ich aber den Plan nicht aufgeben wollte, so galt es auf der Landstraße zu marschieren, was bei den deutschen Soldaten in Mazedonien nicht sehr beliebt war. Mit frischem Marschgesang war die staubige Strecke bald überwunden.

$\mathrm{Zu}$ meinem Erstaunen fand ich aber den Bach des Nikolatales in seinem Unterlauf schon vollkommen ausgetrocknet. An den Hängen des Tales war es fast schon so verdorrt und verstaubt, wie draußen bei Hudova. Alle die blühenden Frühlings- und Frühsommerpflanzen waren verschwunden. Kaum einige verdorrte Stengel zeugten noch von der Lilienpracht; nichts mehr war von Orchideen, von Salbei oder Fingerhut zu sehen. Die Bäume waren verstaubt und von den an ihnen kletternden Weinreben hingen schwere Trauben herab. Hie und da ragte eine schon oben früchtetragende, am unteren Teil des Stieles noch kümmerlich blühende Königskerze, eine mit dicken Schöpfen beladene Distel, empor.

Im trockenen Teil des Baches waren die Steine mit einer kalkigen, aus dem verdunsteten Wasser ausgesickerten Masse überzogen. Die Krebse und die Barben befanden sich an feuchten Stellen oder unter dem Boden im Sommerschlaf. Hie und da lag auch von beiden Formen ein totes, vertrocknetes Exemplar, da wo es das zurückweichende oder verdunstende Wasser zurückgelassen 
hatte. Nur die Büsche und Bäume zeigten noch Grün, ebenso der weite Flächen bedeckende Adlerfarn, der jetzt mit seinem dunkelen Grün vielmehr auffiel, als zwischen der Üppigkeit des Juni. Das Insektenleben war viel geringer geworden, die Vögel still. An ihrer Stelle hatte das Konzert der Heuschrecken zugenommen. Von glühend von der Sonne bestrahlten Büschen erscholl der schrille Gesang von Zikaden (Cicada plebeja Scop.. Tettigia omi L. u. A.).

Die Vögel waren viel stiller als im Frühling und'Frühsommer und nur in den Morgen- und Abendstunden lebhafter. Amseln, Ammern, Finken und Nußhäher wurden beobachtet.

Von Schmetterlingen flogen noch reichlich Segelfalter in zweiter Generation, viele Bläulinge und Weißlinge. Sonst waren Insekten in allgemeineı spärlicher. In größeren Mengen waren sie noch am Bach versammelt. Im Schatten der Bäume und vor allem im dichten Gebüsch, wo noch Minze und Doldenpflanzen blühten, da hatten Schmetterlinge, viele Dipteren, besonders Syrphiden, Stratiomyiden, Anthomyiden Schatten und Kühle, aber auch die wenigen noch blühenden Pflanzen aufgesucht. Auch Bienen, solitäre Formen in zweiter Generation, Hummeln, von Wespen verschiedene Arten, darunter die großen Scoliaarten, waren noch da. Vor allem war aber hier der Tummelplatz vieler Libellen in einer ganzen Anzahl von Arten. Die Wasserrhynchoten, Wasserwanzen und Wasserläufer waren jetzt alle geflügelt und bei der Fortpflanzung.

Besonders auffällig waren jetzt die Reptilien von denen Lacerta muralis Laur. und viridis Laur. viel beobachtet, Coluber leopardinus Bon., die Leopardnatter und Tropidonotus tesselatus Laur., die Würfelnatter in mehreren Exemplaren gefangen wurden. Auch Schildkröten, die zwei verschiedenen Arten von Landschildkröten, begegneten uns.

Von späteren Besuchen der Gegend sei einer im Herbst erwähnt, Anfang Oktober, zu einer Zeit, in welcher der ganze Boden von duftenden Cyclamen (Alpenveilchen) (C. neapolitanum Ten.) bedeckt war. Noch schöner und auffälliger waren die großen Flächen, ivelche dicht mit den leuchtend bläulichrosa gefärbten Sträußen der mazedonischen Herbstzeitlose (Colchicum byzantinum Ker. Gawl.) überzogen waren. Viele Kräuter und Sträucher, selbst die großen Disteln, hatten unter dem Einfluß der ersten Herbstregen neue Triebe gebildet und bereiteten einen kurzen 
Ersatzfrühling nach der Dürre des Sommers vor. $\mathrm{Zu}$ dieser Zeit ist im Wardartal das Phänomen des Herbstzuges der nördlichen Vögel oft prachtvoll zu beobachten.

Der schöne Spätherbst mit reichlichen Regengüssen kann bis in den Dezember hinein dauern, ehe der mazedonische Winter mit Eis und Schnee einzieht. Zu dieser Zeit kam ich nur am Ausgang des Nikolatales vorbei. Die Hänge lagen voll Schnee, der Bach hatte eine leichte Eisdecke. Mit einem alten Kolkraben balgte sich eine Schar Dohlen, Elstern und Krähen um das Aas eines gefallenen Tieres und bildeten so eine malerische Silhouette auf dem weißen Hintergrund der Straße zum unvergeßlichen Nikolatal. 


\section{SIEBENTES KAPITEL}

\section{FAHRT INS GEBIET DER MALA RUPA.}

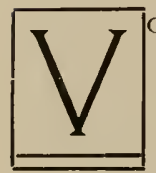

on meinem Standquartier $\mathrm{K}$ aluckova aus hatte ich oft meine Blicke sehnsüchtig nach den blauen Bergen schweifen lassen, die westlich über dem Wardar in weiter Ferne zart und duftig aufragten. Vor allem im Monat Mai boten ihre schneebedeckten Gipfel einen eigenartigen Kontrast zur farbigen Üppigkeit des Vordergrundes dar. Grün leuchtete die Wardarebene vor den Hïgeln, die Kaluckova umgaben, die Bäume blühten, bunte Blumen bedeckten die Wiesen. Jenseits des Wardar erhoben sich bebuschte Hügel, die allmählich in höhere bewaldete Berge übergingen, welche von der Bevölkerung als Marianska Planina bezeichnet wurden. Mehrere Ketten zogen hintereinander, immer höher aufsteigend und entwickelten vor allem in der Zeit des Sonnenuntergangs alle Abstufungen blauer und violetter Töne. Hinter ihnen erhoben sich in phantastischer Klarheit die höchsten, schön geformten Pyramiden der Schneeberge mit ihren weißen Flanken und dem strahlenden Blau der Schatten ihrer Schluchten.

Der Schnee war schon bis auf kleine Reste weggeschmolzen, als es endlich gelang, die Fahrt ins Gebirge zu unternehmen. Auf der Karte war der Gebirgsstock als Dudica bezeichnet und von unseren Truppen wurde besonders die Berggruppe der $\mathrm{Mala}$ Rupa oft genannt, auf der sich Stellungen befanden. Allerhand merkwürdiges wurde von diesen Bergen berichtet und so waren meine Erwartungen aufs höchste gespannt.

Bei den bescheidenen Hilfsmitteln, welche mir damals in den ersten Monaten meines mazedonischen Aufenthaltes zur Verfügung standen, konnte keine größere Expedition geplant werden. Ich mußte sehen, wie ich mit meinen beiden Begleitern, Prof. Müller und Sammler Rangnow irgendwie an die Berge herankam. Das Weitere würde sich dann schon finden.

Da bot die Freundschaft des Fliegerhauptmanns Arndt eine besonders günstige Möglichkeit. Er stellte mir für einige Tage seinen Kraftwagen mit den Fahrern zur Verfügung und so konnte 
ich mir vornehmen, in einem halben Tag nach dem Dorf Koinsko zu gelangen, welches am Fuße der Mala Rupa liegt. Dort hielt sich in militärischer Dienststellung um jene Zeit Prof. Leonhard Schultze-Jena auf, der bekannte Geograph, der mir bei meinen Plänen behilflich sein wollte.

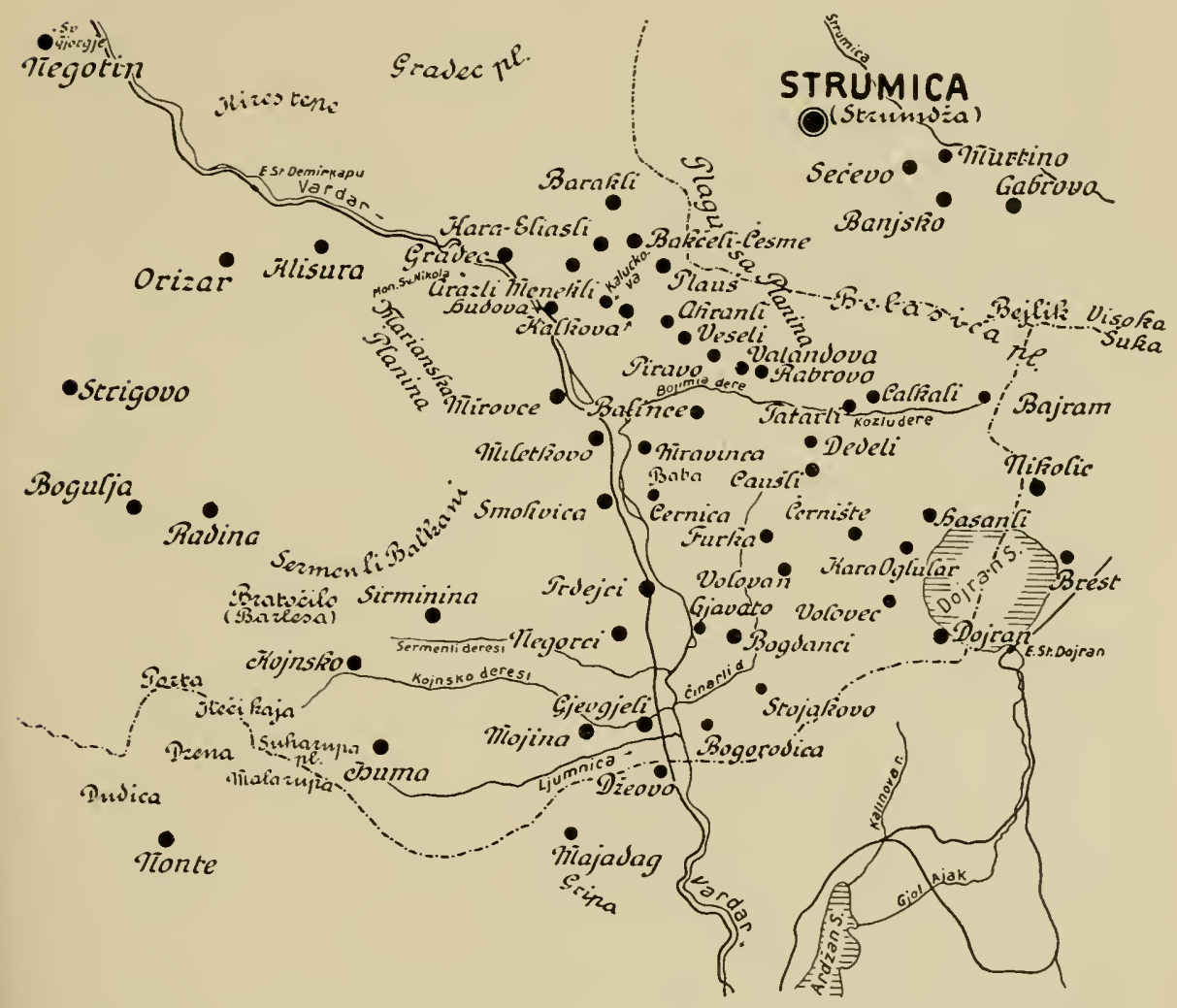

Abb. 52. Kartenskizze von Südostmazedonien. Südliches Wardartal, Ebene von Hudova, Dorransee.

Manches kam anders als ich gedacht hatte. Um $1 / 24 \mathrm{Uhr}$ nachmittags, am 17. Juli 1917, fuhren wir nach manchen Verzögerungen im Auto in flottem Tempo von Kaluckova ab. Wir bogen südwärts ins Wardartal ein; kaum hatten wir einige Kilometer zurückgelegt, als mit lautem Knall ein Reif platzte; die erste Panne! Nach kurzem Aufenthalt ging die Fahrt weiter. 
Die zweite Panne kam im Wardartal bei Smokwiza, die dritte und ernsthafteste im Mühlbachtal bei Negorci.

Immerhin gingen die Aufenthalte nicht ungenützt vorbei. Wir fuhren zuerst durch die Hudovaebene auf dem linken Wardarufer, kamen dicht bei dem Lazarett Mravinca vorbei und überschritten auf der Kaiser Wilhelmsbrücke bei Miletkovo den Wardar. Dann ging es in gutem Tempo am rechten Wardarufer über Smokwiza bis Negorci, wo wir das Tal verließen und westwärts einbogen, dem Gebirge entgegen. Wie hatte sich in den letzten Wochen das Wardartal verändert! Vom Frühlingsgrün war nichts mehr zu entdecken. Alles war verbrannt und verdorrt von der Sonnenglut. Wo vor wenigen Wochen zwischen den Stecheichenund Judendornsträuchern die bunte Pracht der Blüten prangte, da gab es jetzt nur feinen gelben oder grauen Staub. Kaum fand sich hie und da noch eine Spur von verdorrtem Gras. Am traurigsten sah es natürlich in der unmittelbaren Nachbarschaft der belebten Landstraße aus, auf der hier zur Front nachts und frühmorgens viele Kolonnen verkehrten, wo Truppen marschierten und der Nachschub vorgebracht wurde. Denn in diesem Teil des Wardartales bis südlich zur Front bei Gewgeli verkehrte die Bahn nicht, da die ganze Strecke unter dem Feuer der weittragenden Geschütze des Feindes stand. So fuhr nur ein Schienenautomobil nachts südwärts, um wichtige Transporte zu vermitteln. Längs der Straße war alles, Steine, Felsen, Büsche, Häuser, alles, alles von feinem Staub eingepudert und keine andere Farbe als fahles Grau war zu sehen, noch dazu verschleiert durch die Staubwolken, die jeder Mensch, jedes Fahrzeug, jedes Tier, das sich auf der Straße bewegte, aufwirbelte.

Daß die Straße vom Feinde eingesehen wurde und beschossen werden konnte, machte unsere Autopannen nicht allzu behaglich. Immerhin kamen wir gut durch und benutzten den unfreiwilligen Aufenthalt uns jeweils in der Gegend umzusehen. Von der Staubwüste längs der Straße stach die Umgebung der Dörfer freundlich ab, besonders da, wo durch Schöpfräder Wasser aus dem Wardar zugeleitet oder den vom Gebirge dem Fluß zustrebenden Bächen zur Bewässerung der Gärten und Felder entnommen wurde. Obstbäume beschatteten die Häuser; in den Gärten grünte das Gemüse, Tomaten prangten und wetteiferten mit den an den Fenstern hängenden Bündeln von Paprikaschoten in grellstem Rot, Maisfelder waren in voller Üppigkeit, während die anderen Getreide 
alle schon geerntet waren. Weite Melonenfelder mit den grünen, gelben, roten mächtigen Früchten brachten einen ganz eigenartigen Charakter in die Landschaft. Wie seltsam mußte sich das Leben der wenigen Landeseinwohner in dieser Gegend abspielen in den halbzerstörten Dörfern. Sie hatten unter dem Donner der Geschütze gepflügt und gesät, nun kam auch in diesem Jahre die Ernte, ohne daß der Krieg aufgehört hatte.

IVir fanden trotz des Staubes, besonders am Ufer kleiner Bäche, noch reichlich tierisches Leben. Über dem Wasser schwirrten große Schwärme von Libellen, Bienen und Hummeln kamen zum Trinken und besuchten die Blüten der am Wasser noch gedeihenden Pflanzen. Eidechsen lauerten auf den Steinen auf Beute.

Besonders reich war das Tierleben am Ort unseres letzten Unglücks, das wir mit unserem Auto hatten. Als wir dicht hinter den Stellungen durch das von unseren Soldaten so benannte Müh1bachtal fuhren, brach das Auto vollkommen zusammen. Es stand in der grellen Sonne auf einer Stelle der Straße, die, wie die Granattrichter in der Umgebung verrieten, nicht selten beschossen wurde. Während die Fahrer sich quälten, das Fahrzeug wieder in Gang zu bringen, flüchteten wir, die nichts dabei nützen konnten, aus der immer noch glühenden Sonne in den Schatten des einzigen Baumes der Gegend. Es war eine Weide, die von einem kleinen Weidengebüsch umgeben, am Bach sich erhob, neben einer Brücke.

Die Gegend war recht eigenartig. Das ziemlich breite Tal zog an einer Hügelkette entlang, auf welcher die Stellungen unserer Truppen und der Bulgaren eingebaut waren. Unten am Rand der Hügel, dicht am Bach waren teils in den Berg eingefügt, teils an ihm angelehnt die Quartiere der Truppen, die Ställe der Pferde, die Magazine für Proviant und Munition. Im Bach, an erweiterten Stellen, badeten deutsche Soldaten, etwas weiter oben waren Pferde in der Schwemme.

Der Abend sank herab und das Auto war noch nicht wieder heil; ja es war klar, daß es so schnell nicht zu flicken war. Wir mußten nach einer Stelle suchen, von der wir telefonisch um Hilfe rufen, und wo wir die Nacht verbringen konnten. Eine solche war bald gefunden. Nicht weit von der Brücke sahen wir Bauten, welche auf eine deutsche Abteilung schließen ließen, während sonst alles ringsumher sehr bulgarisch aussah.

An den Hängen der Hügelreihe waren tatsächlich die rückwärtigen Stellungen unserer Front eingebaut. Zwischen den Bauten 
sah man überall Stollen und Unterstände, ein Zeichen, daß man hier vor Beschießung nicht vollkommen sicher war. Alle größeren Bauten waren sehr geschickt dem Gelände eingeschmiegt. So sah man ganz oben am Berg, an dessen Rückwand ein villenähnliches Holzhaus, wie wir später erfuhren, die Wohnung des bulgarischen Artilleriekommandeurs.

Wir suchten die deutsche Stellung auf; es war eine Abteilung schwerer Artillerie, deren Offiziere uns sehr freundlich aufnahmen, bewirteten und beherbergten. Unter anregenden Gesprächen verlief der Abend, nachdem telefonisch mir die Nachsendung eines zweiten Autos zugesichert worden war. Es traf noch nachts ein; aber wir mußten den Morgen abwarten, um die Fahrt auf der sehr kühn angelegten, nicht auf Kraftwagenverkehr berechneten Bergstraße riskieren zu können.

Frühmorgens ging es los. Es war die Straße nach Huma, die wir zunächst verfolgten. Sie führte zuerst noch durch das Bachtal, dessen felsiger Südhang weithin noch von den Quartieren bulgarischer Truppen eingenommen war. Es ist eine eigenartige Erinnerung, die ich an diese Fahrt dicht hinter der Front mitgenommen habe. Wie war die ganze Landschaft verändert durch die Bauten des Heeres. Seit 16 Monaten war in jener Zeit die Front in dieser Gegend nicht verschoben worden. So blieb es auch noch ein ganzes Jahr. Wie wurde in dieser Zeit die ganze Erde der Hügel von unseren Truppen durchwühlt; ich wurde unwillkürlich zu einem Vergleich mit den unterirdischen Nestern der Ameisen gedrängt, welche in Massen die gleichen Hänge besiedelten. Überall hatten die Soldaten Felder bestellt, Gärten mit Blumen und Gemüsen bepflanzt, Bewässerungsgräben gezogen. Welche Massen von Brettern und Balken waren in das holzarme Land gebracht worden, um all die Bauten aufzuführen. Es war, als sei ein Volk von lauter Männern im Lande eingewandert, das hier für alle Zeiten zu bleiben glaubte.

Der Weg, eine schmale Straße, auf der das Ausweichen nicht leicht war, führte den klaren Bach entlang, dessen Wasser über Felsen brauste, bald größere, bald kleinere Tümpel bildend, die in ihrem hellen Grün seltsam vom gelbroten Felsen abstachen. Durch tiefe Schluchten mit steilen Felswänden strömten Seitenbäche dem Humabach zu. Das waren wieder die typischen Balkanschluchten, mit ihren malerischen Wirkungen von Licht und Schatten, 
mit der jetzt im Hochsommer noch üppigen Pflanzenwelt in ihren schattigen Gründen.

Die Straße fing an in Riesenwindungen die Berge hinanzuklimmen, um scharfe Kurven fauchte das Auto bergauf. Von der Straße, die allmählich von dem Wardartal mit weniger als $100 \mathrm{~m}$ Meereshöhe auf über $800 \mathrm{~m}$ hinanstieg, eröffneten sich reizvolle Blicke auf ein welliges Bergland und tief eingeschnittene Täler, die alle noch von einer schön grünen Vegetation überzogen waren. Von der Paßhöhe sausten wir auf einer nicht minder halsbrecherischen Straße neben tiefen Abgründen durch oft ganz

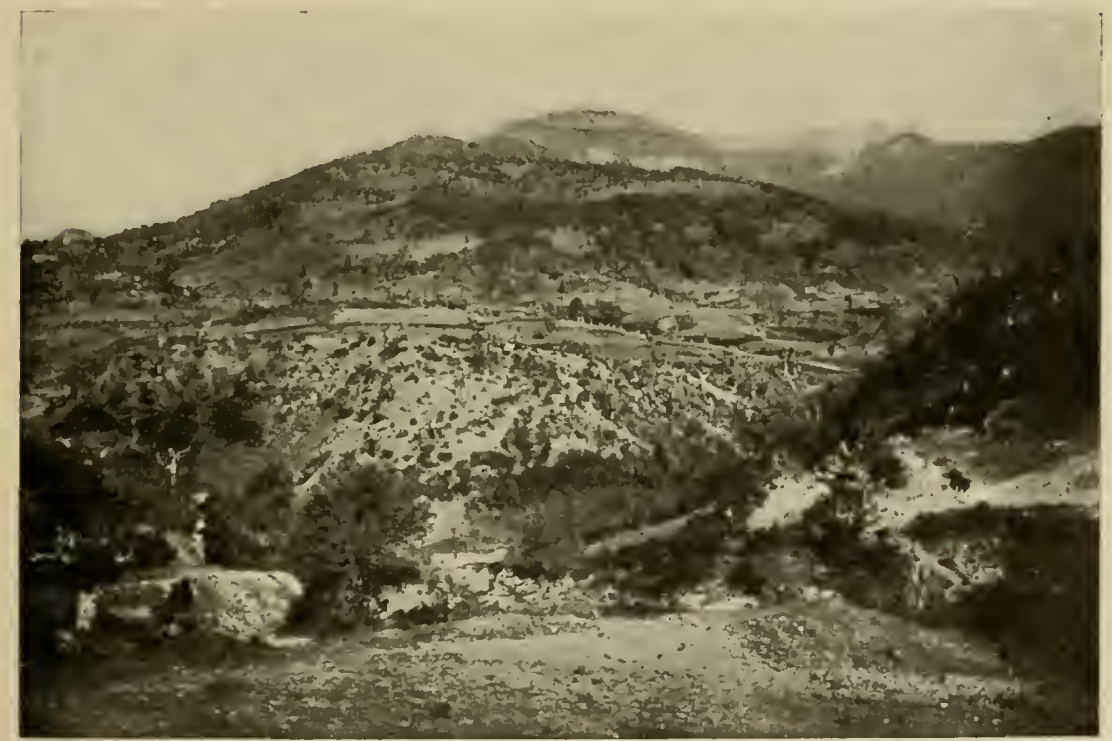

Burmester phot.

Abb. 53. Gesamtansicht des Mala Rupagebirges aus der Gegend zwischen Huma und Koinsko.

knappe Kurven wieder bergab. Der Blick nach Südwesten, das war die Hauptrichtung unserer Fahrt, nachdem wir die Hauptstraße nach Huma verlassen und die Nebenstraße nach Koinsko eingeschlagen hatten, wurde immer reizvoller.

Nun tauchten die hellen Felszacken der Mala Rupagruppe auf; die bläulich-weißen Felsmassen hoben sich prachtvoll von den dunklen Flächen der Wälder $a b$, die wir da oben ahnen durften. Eine gedrängte Gruppe von hohen Gipfeln, die 2000 bis $2400 \mathrm{~m}$ erreichen, baute sich immer mächtiger vor uns auf. Es waren große, scharfe Bergformen von schönen Unrissen, die 
im Charakter an Voralpen, zum Teil in den Felsenbildungen an Jura erinnerten. Der feine blaue Duft, der die Berge einhüllte, gab einen wirkungsvollen Gegensatz zu dem grünen Vordergrund, durch den unser Wagen sich bewegte.

Je näher wir kamen, umso höher schienen die Berge zu werden, umso deutlicher wurden die hellen Felsen, die sie aufbauten. Man erkannte pyranidenförmige Bergspitzen, die sich immer klarer von ihren Nachbarn abhoben, sah schimmernde Felsenbänder von großer wagerechter Ausdehnung, Felsenabstürze und Klüfte. All das war schön gegliedert durch dunklere Flächen, die sich später in den oberen Zonen als grasbedeckte Matten, in der Mitte als hochstämmige Laubwälder herausstellten.

Wir blieben dauernd in einer beträchtlichen Höhenlage zwischen 600 und $800 \mathrm{~m}$, Koinsko, unser Ziel liegt etwa $600 \mathrm{~m}$ hoch. So sahen wir auf unserem Weg die Charakterpflanzen der Ebene mehr und mehr verschwinden. Judendorn (Paliurus) und Stacheleiche wurden immer spärlicher, an ihre Stelle traten Wachholder, Hainbuchen und weichblätterige Eichen. Hier zeigten sich Spuren eines reichen Insektenlebens. Grole Bockkäfer (Cerambyx scopolii Füssl.) flogen durch die Luft, die von dem Getöse der Zikaden und Heuschrecken erfüllt war.

Wir näherten uns Koinsko, das reizvoll in einem Talkessel liegt, dessen baumreiche Fluren von einem starken Bach durchflossen sind. Einen wunderbaren Rahmen um das Tal bilden die hohen Berge, die es auf drei Seiten umschließen. Nun mehrten sich Getreidefelder und Gärten mit Obstbäumen. Die Ernte war hier, in $600 \mathrm{~m}$ Meereshöhe noch in vollem Gange, die Haferfelder standen noch halbgrün. Das Städtchen war in Grün gebettet, von dem sich die dunklen Dächer malerisch abhoben.

Es war nicht leicht mit dem großen Personenwagen in die engen Straßen des Ortes einzufahren. Der Eindruck des Städtchens war höchst reizvoll. Die Häuser sind aus Steinen gebaut mit viel Holzwerk, die Dächer mit Schindeln gedeckt, Veranden und andere Vorbauten aus Balken und Brettern, vom Alter gebeugt, gaben eigenartige farbige Bilder. So wanden wir uns durch enge Gassen und Durchschlüpfe, die überall von Reben umrankt und überdacht waren. Reben gab es überall. Sie zogen sich laubenähnlich an Querbalken rankend über Höfe und Gassen und überzogen die Wände der Häuser. Während wir durch die Höfe wanderten, hingen schwere Trauben, allerdings noch nicht reif, 
überall über unseren Köpfen herunter. So hat der Ort einen ganz eigenartigen Reiz, erinnert etwa an oberitalienische Dörfer.

Noch am gleichen Nachmittag begannen wir die nähere Umgebung des Ortes zu erkunden. Koinsko liegt am Berghang, so daß man eine Strecke steil zum Bach hinabsteigen muß. Wie genossen wir nach der Sommerglut des Wardartales die frische Luft, die hier die Nähe des Gebirges verkündete. Der wasserreiche Bach, der über Felsen und Steine dahinrauschte, war von dichtem Weidengebüsch umgeben. Dieses durchstreiften wir und fanden hier eine reiche Insektenwelt. Kleine Fliegen umschwirrten

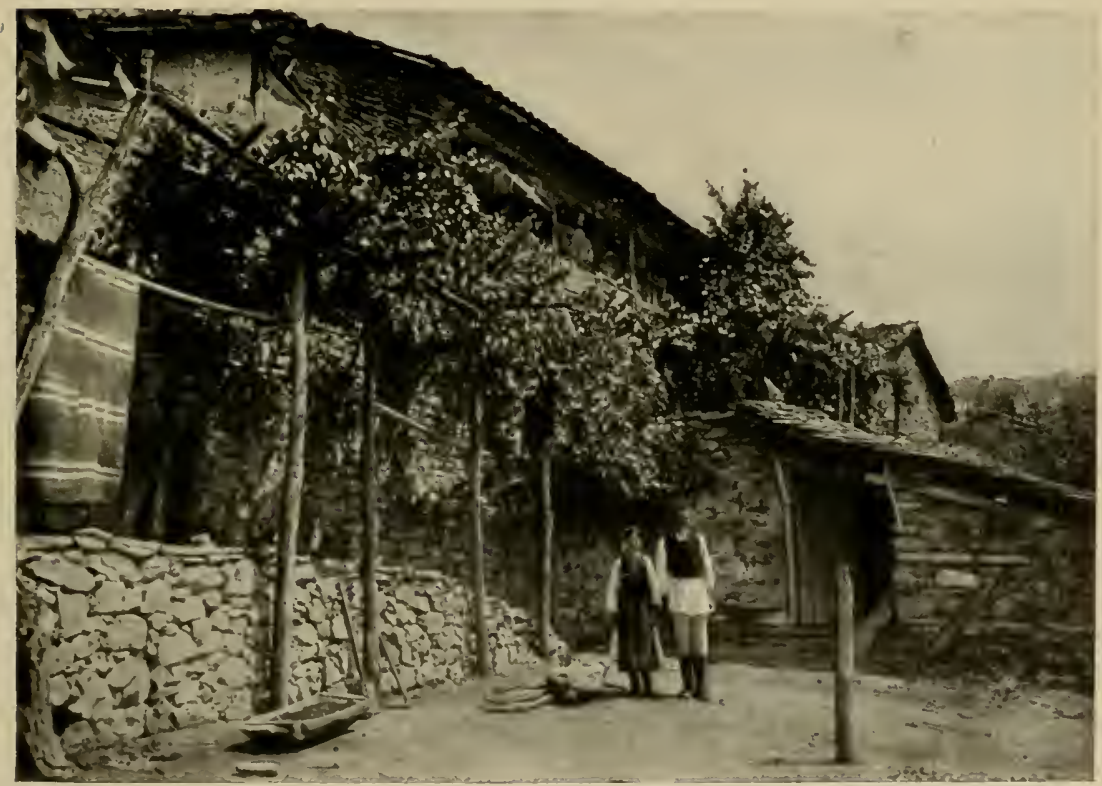

Prof. Schultze-Jena, phot.

Abb. 54. Bamernhaus mit Rebenlauben in Koinsko.

uns in Menge, das Goldauge (Chry'sopa) kam häufig vor, zahllose Hymenopteren, vor allem Hummeln, besuchten die Blüten der Brombeersträucher, der Königskerzen, von allerhand Lippenblütlern, die hier einen reichen Flor bildeten.

Durch Erlengebüsch stieg ich am Bachufer hinauf, kam durch eine Fläche, die mit hohem Adlerfarn bedeckt war, dieser weltweit verbreiteten Pflanze, und gelangte nach kurzem Steigen in einen Hain stattlicher Bäume. Es waren große, hohe Buchen, 
deren silbergraue Stämme uns freundlich anheimelten. Welcher Gegensatz gegen die Gluthölle der Wardarebene.

Am Rande des Buchenhains standen wieder Erlen und Weiden, weichblätterige Eichenbüsche und prachtvolle, alte Nußbäume. Daneben erstreckte sich eine frische grüne Wiese mit vielen blühenden Pflanzen, salbeiähnlichen Lippenblütlern, einem Tausendgüldenkraut (Erythraea centaureum Pers.), Hornkräutern (Stellaria holostea L.) u. dgl. Von Riedgräsern eingefaßt breitete sich am Rand des Gebüsches ein kleiner Sumpf aus. Der Frosch, den wir dort fanden, war Rana agilis Thom. Hier oben flogen viele Libellen, Hummeln und bunte Fliegen, Syrphiden und Stratiomyiden (Rhynchomyia impavida Rossi und R. speciosa L.w.); von Schmetterlingen schöne Vertreter der Gattung Coenonympha ( $C$. arcania $\mathrm{H}$. S.).

An dem trockneren Hang standen hohe Disteln mit roten Blüten, Königskerzen mit ihren duftenden gelben Blütenständen ragten hoch empor; der Sanddorn war in mächtigen, baumähnlichen Sträuchern reichlich vertreten.

Vor allem schön und malerisch stellten sich aber mächtige Buchen dar, welche von Reben umschlungen und überwachsen waren. Wie wunderbar umrahmten ihre Ranken und die grauen Stämme der Buchen die Ausblicke auf die im Glanz der Nachmittagssonne liegenden Berge.

Der Bach kam durch eine tiefeingeschnittene Talschlucht von den Bergen herab. Seine felsigen Ufer trugen ebenfalls prachtvolle Buchen, die hier schon einen schattigen Wald bildeten. Am Bachufer mündete eine Mineralquelle aus, wie sie in Mazedonien so häufig sind. Das Wasser, welches Kohlensäure und Eisen und etwas Schwefel enthält, schmeckt recht erfrischend. Im Wald tummelte sich eine reiche Vogelwelt. Mit Vergnügen begrüßten wir unsere einheimischen Formen Buchfink und Amsel, Kleiber, Meisen und den stattlichen Pirol.

Ein erfrischendes Bad im kühlen Wasser des Bachs schloß den Nachmittagsspaziergang ab. Den Abend verbrachten wir im Kreise der deutschen Offiziere; nachts teilte ich das Quartier mit Prof. Schultze-Jena. Obwohl der Abmarsch auf 4 Uhr früh angesetzt war, verplauderten wir in alten Erinnerungen bei einer guten Flasche Burgunder, die sein Vater, der altberühmte Jenenser Gynäkologe ihm ins Feld gesandt hatte, fast die ganze Nacht und lauschten auf das beständige leise Rauschen, welches von den vielen 
tausenden von Holzwürmern (Käferlarven) erzeugt wurde, die ihre Gänge durch das Holzwerk des Hauses fraßen. Ein solches Massenvorkommen von Holzwürmern in einem bewohnten Hause war mir noch nie begegnet und man mußte sich wirklich fragen, wie lange Dach und Fußböden dieses Hauses noch halten könnten, wenn die Tiere unablässig an seinen Stützen nagten.

Nach kurzem, tiefem Schlaf fuhr uns im Dunkeln das Auto zum geeignetsten Anstieg, den wir noch in der Dämmerung begannen. Als die Sonne aufging, waren wir schon in schönem Buchenwald. Wir stiegen einen Kamm entlang, an Batterien vor-

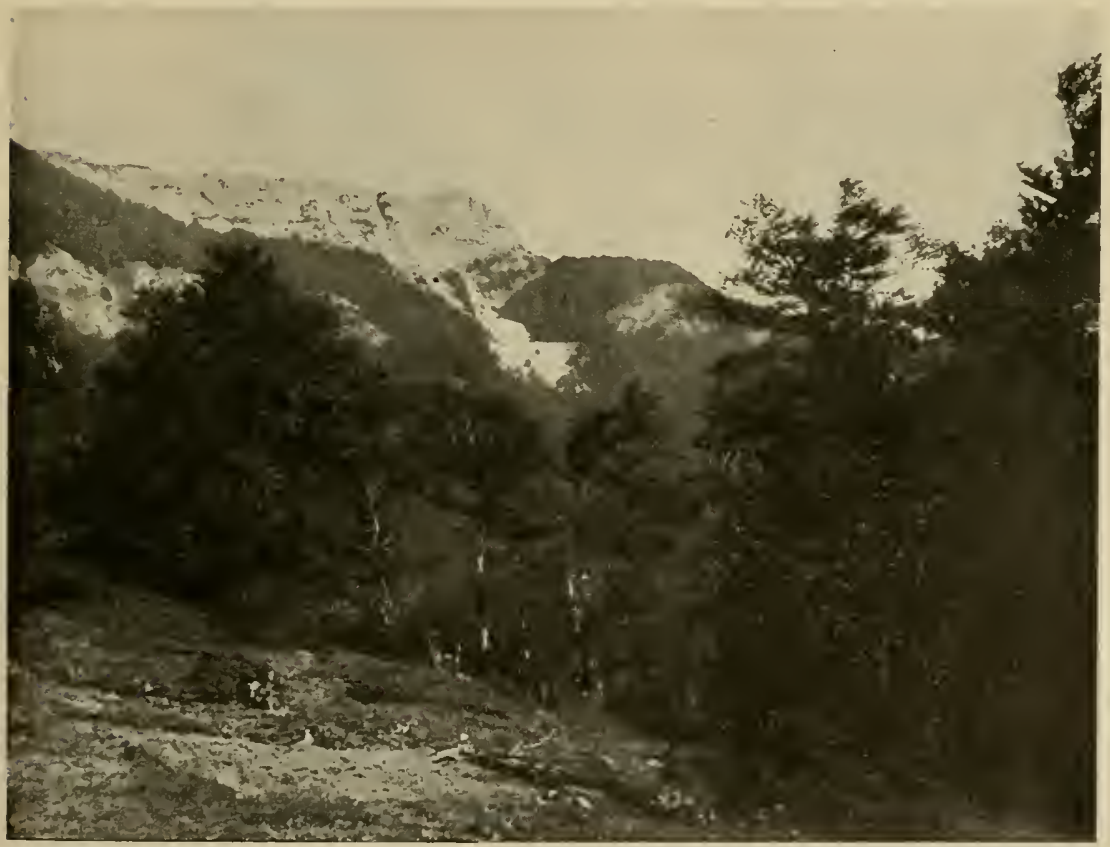

Abb. 55. Buchenwald auf der Mala Rupa. Im Hintergrund Kalkberge.

bei, passierten einen Sumpf, in welchem schöne rote Orchideen blühten. Der Buchenwald war hier noch licht, von Waldwiesen unterbrochen, welche mit Salvien, Königskerzen, Brombeersträuchern nnd Disteln bestanden waren. An den Blüten fingen wir Lepturen und andere Bockkäfer, Hummeln, Bienen und Schmetterlinge. Weiter oben wurde der Wald so dicht, daß es sich köstlich in seinem kühlen Schatten wanderte. Zudem war der IValdboden mit unzähligen reifen süßen Walderdbeeren bedeckt. Diese fand 
ich noch oft in den mazedonischen Bergwäldern. Indem man sie schmauste, fühlte man sich in die Heimatswälder versetzt, von denen sich der von uns durchwanderte Forst in nichts unterschied.

In etwa $1000 \mathrm{~m}$ Meereshöhe gelangten wir an eine offene feuchte Stelle, wo sich ein schöner Birkenbestand befand. Wie schön hoben sich die zierlichen weißen Stämme und die zarten hellgrünen Blätter der Birken (Betula pubescens L.) von dem blauen Himmel ab, an dem große weiße Wolken dahinzogen. Welch köstliche Durchblicke eröffneten sich zwischen den Zweigen auf die schroffen Felsen, denen wir jetzt immer näher kamen. Die weißen Bänder, welche

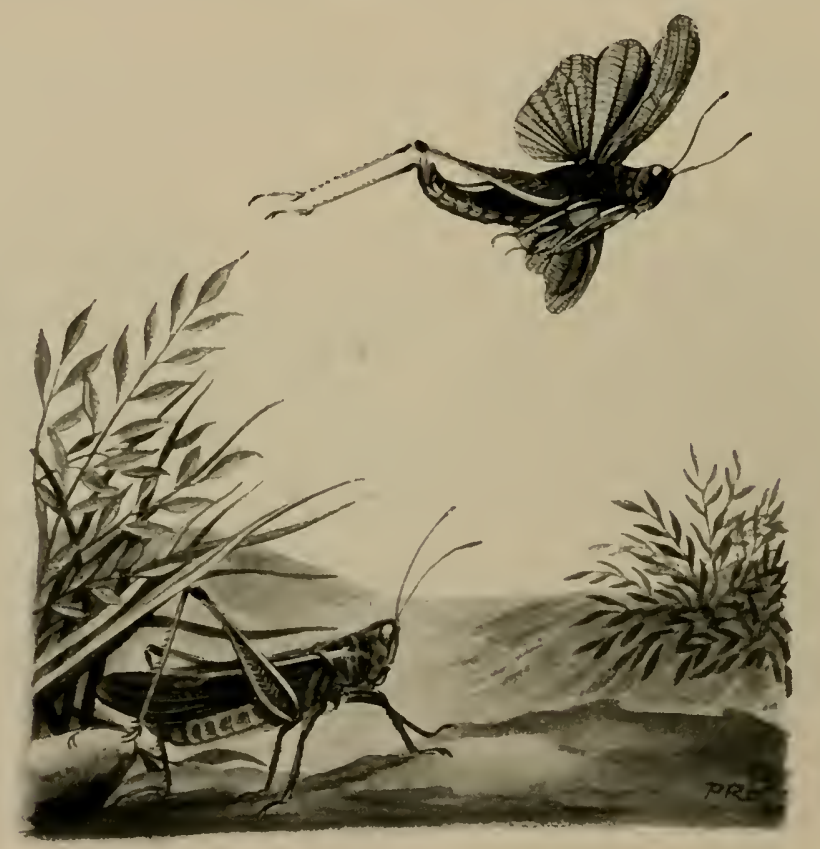

Abb. 56. Bergheuschrecke beim Balzflug. (Stenobothrus miniatus Charp.) (Mala Rupa, Kobeliza, Peristeri).

die Matten durchzogen, bestanden aus Kalk, der oft Formen annahm, die an Jura erinnerten. Vielfach war er geschichtet und in Platten gebrochen. Doch stießen wir im Gebirge auch auf Gneis und Granit.

Weiter oben, zwischen 1000 und $1500 \mathrm{~m}$ wird der Buchenwald immer dichter und hochstämmiger: oft glich er einem großen Saal voller Säulen, in seinem Schatten flimmerten allerorts die Sonnenflecken. Hier beginnen zwischen dem Wald sich Wiesen- 
flächen einzuschalten, auf denen einzelne Buckel ganz von einem zarten, niederliegenden, bläulich schimmernden Wachholder bedeckt sind, der von dem feinen, grünen Gras dunkel sich abhebt (Juniperus nana Willd.).

In dieser Region fand sich in Massen eine kleine Schnarrheuschrecke, deren Musik die Luft erfüllte. Die kleine, etwa $5 \mathrm{~cm}$ lange Heuschrecke (Stenobothrus miniatus Charp.) zeigte eine merkwürdige Gewohnheit, die man sonst bei Heuschrecken nicht beobachtet. Das Tierchen hat schwarze Flügeldecken, rote Beine und roten Leib. Diese traten leuchtend hervor, wenn das Tier mit ausgebreiteten Flügeldecken sich etwa I $m$ hoch laut

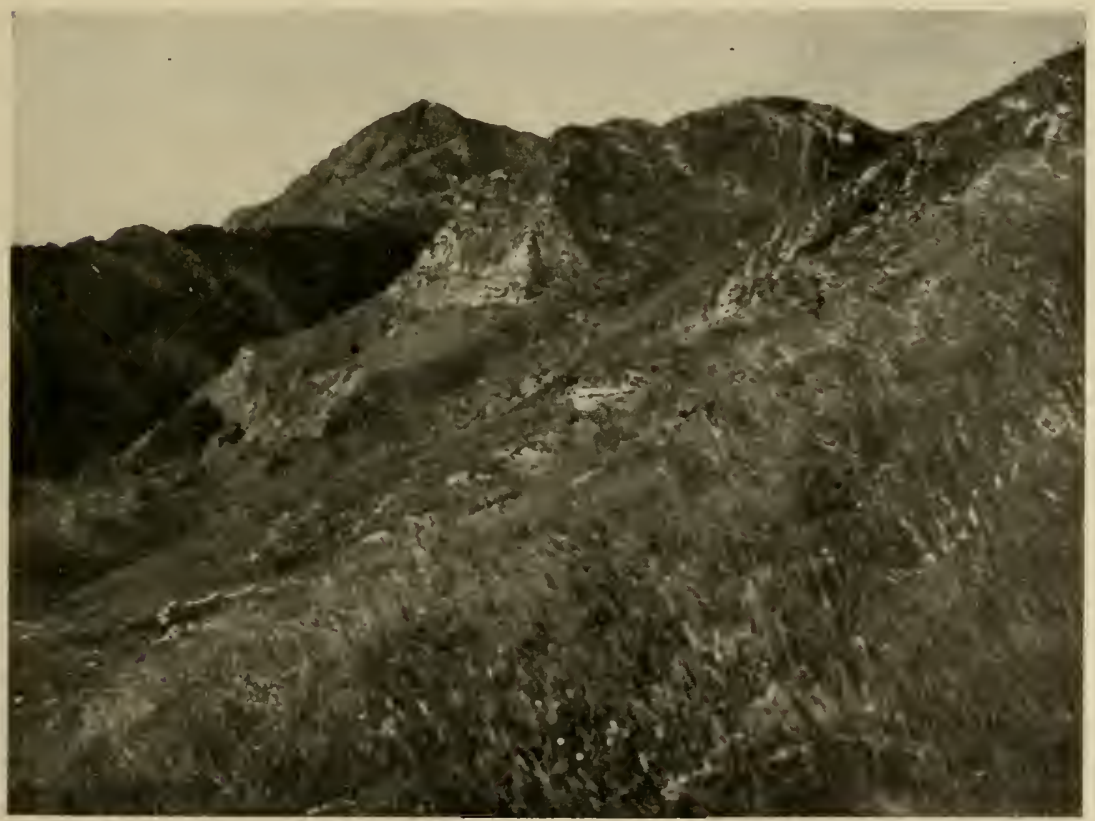

Abb. 57. Mala Rupa. Alpenmatte in fast $2000 \mathrm{~m}$. Blick gegen die Porta. Juni 1917.

schnurrend in die Luft erhob, da anders als andere Heuschrecken einige Sekunden schwirrend schwebte, um dann langsam auf den Boden $z u$ sinken und $z u$ schweigen. Es ist eine Art von Balzflug, welchen das Tierchen ausführt. Ich habe die Art auch sonst in den mazedonischen Gebirgen beobachtet, stets aber nur in größeren Höhen, von $1200-1800 \mathrm{~m}$. 
Noch etwas weiter oben breitet sich auf den Wiesenflächen, die in ihrer reichen, äußerst mannigfaltigen Pflanzenwelt einen heideartigen Charakter annehmen, eine zarte, sehr reizende Erika aus. Mit ihren rosenroten Blüten und ihrem feinen Duft war sie ein köstlicher Schmuck dieser Halden (Bruckenthalia spiculifolia Salisb).

Je höher ich kam, desto schöner wurden die Buchenwälder, die hohen Bäume bildeten ein dichtes Blätterdach, das tiefen Schatten auf den in dieser Region unbewachsenen, von braunen Blättern bedeckten Waldboden warf. Um so reicher war die Vegetation an den Waldrändern, die entzückende Blicke auf die Felsgipfel der Berge gewährten. Hier gingen die Buchen in Buschwerk über, zwischen denen einzelne Birken und stattliche Edeltannen sich erhoben. Der Tannenduft rief Heimatserinnerungen wach. Zwischen dem niederen Wachholder blühten hier die Gräser und standen stolz und steif die dunkelroten Blüten einer Form des Türkenbunds (Lilium martagon L.).

Im Buchenwald fanden wir auf der Rinde der Stämme stattliche graue Bockkäfer. Ein kurzer Anstieg durch den Wald brachte uns in etwa $1700 \mathrm{~m}$ Höhe zu einer kleinen Hütte, der Bergstation der Vermessungsabteilung 7. Wir fanden hier gastliche Aufnahme und Nachtquartier. Die Abteilung hatte hier wichtige Aufgaben zu erfüllen. Zunächst wurde die kartographische Aufnahme dieses wichtigen Frontgebietes durchgeführt.

Die Männer, die hier oben in primitivster Weise hausten, leisteten eine auch für die Wissenschaft wichtige Arbeit. Die Kartenaufnahme erfolgte mit den von dem Jenenser Pulfrich erfundenen photogrammetrischen Methoden. Die Arbeit wurde in der Hauptsache ausgeführt von einem Dr. Burmester, einem Assistenten Prof. Finsterwalders in München, in dem ich einen Münchner Bekannten fand. Ihm stand dabei zur Seite ein junger Mann, namens Pulfrich, ein Sohn jenes Gelehrten, der hier mit den Methoden seines Vaters als Soldat dem Vaterland diente.

Aulberdem traf ich dort oben zwei Marinesoldaten, welche mit einem riesigen Zeiss'schen Doppelfernrohr den Hafen von Saloniki überwachten. Sie konnten den wachsenden oder ruhenden Verkehr in diesem für unsere Feinde so wichtigen Hafen kontrollieren. Eine $4 \mathrm{~m}$ lange photographische Kamera mit sehr lichtstarkem Objektiv diente dazu, genaue Fernaufnahmen des Hafens mit den ankernden Schiffen zu machen. Besondere Listen der englischen 
Kriegs- und Handelsschiffe ermöglichten, deren Art und Namen festzustellen und so wichtige Schlüsse auf die Vorgänge in der Hafenstadt und an der feindlichen Front zu ziehen.

Selten allerdings lag Saloniki und das Meer so klar in der Ferne, daß gute Aufnahmen gelingen konnten. Auch während unseres kurzen Aufenthaltes hier oben bekamen wir die Stadt und den Hafen nicht klar zu sehen. Immerhin wurde uns ein Blick auf das blaue Ägäische Meer zuteil und am nächsten Morgen kam auch der Olymp auf kurze Zeit aus dem Dunst der Ferne heraus.

Wir waren ja hier ganz nahe der Grenze Griechenlands. Jenseits des Berges, von oben nicht zu sehen, lag die kleine griechische Stadt Nonte. Klar und deutlich erkannte man aber von unserem Aussichtspunkt die weißen großen Gebäude in der Stadt Gewgeli. Die Stadt sah ganz wohlerhalten aus; aber tatsächlich war sie sehr zerstört und von ihren Bewohnern verlassen, wie ich bei einem späteren Besuch beobachten konnte.

War auch die Ferne nicht so klar, als ich es erhofft hatte, der schöne Blick in die näher gelegenen Täler und Berge entschädigte mich in vollkommenster Weise. Es war eine Landschaft von großer Schönheit, die sich un das Gebirge ausbreitete.

Rückwärts lag unten im Tal Koinsko, im Grün so verborgen, daß es schwer war, die Häuser und Dächer mit dem Fernglas aufzufinden. Zum Ort hin zog sich ein Taleinschnitt, aus dem die in vielen Windungen verlaufende Straße nach $\mathrm{Huma}$ hervorkam, die man als helles Band weithin verfolgen knnnte. Unter uns lag ein schmales tiefes Tal, durch welches man deutlich die Schützengräben unserer und der feindlichen Front in kurzem Abstand voneinander hinziehen sah. Sie stiegen vom Südhang unseres Berges hinunter ins Tal, durchquerten dieses, um jenseits sich wieder an ein Gebirge anzulehnen, das ostwärts gegen den Wardar veilief. Diese niedrigen Berge waren kahl und vegetationslos, ganz anders als die üppige Natur, aus der ich hinunterblickte. Sie glichen mehr den Bergzügen, die wir auf dem Weg nach Koinsko durchfahren hatten.

Direkt unter uns lag, noch in unseren Linien, ein kleines, wohlerhaltenes Städtchen, Borislaw. Davor in der Ebene sah man mehr der feindlichen Front genähert, die Gebäude eines Klosters, Sv. Archangeli. Von diesem erzählten unsere Soldaten eine nette Geschichte. Der Abt dieses Klosters, dessen Lage ja dazu herausforderte, spionierte für den Feind. Man war ihm auf 
die Spur gekommen und so ritten eines schönen Morgens einige von unseren Ulanen hinüber und, ,holten ihn ab". Sie sollen ihn ohne allzugroße Sanftheit aus dem Bett geholt haben.

Während wir die Gegend überblickten, begannen die feindlichen Batterien unsere Gräben tief unten im Tal zu beschießen. Man sah die Einschläge der Granaten, die hohen Rauch- und Staubwolken in der stillen Luft senkrecht aufsteigen. Deutlich sahen wir die bulgarischen Soldaten rückwärts sich verziehen. Sie verließen die Gräben und zogen sich in die Unterstände zurück.

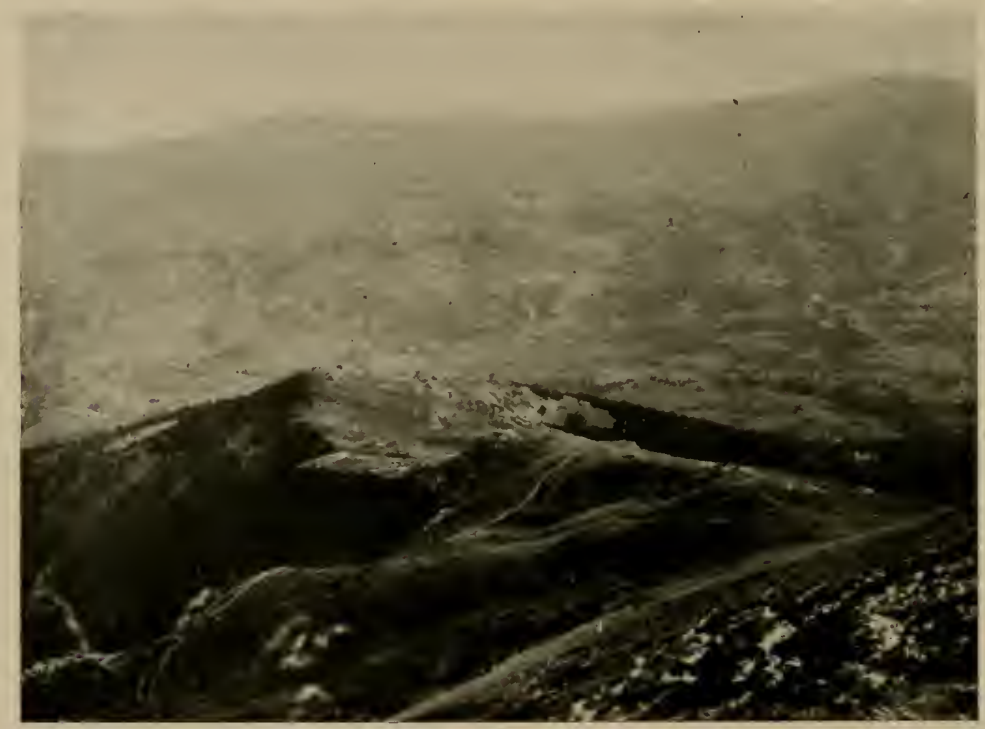

Dr. Burmeste r phot.

Abb. 58. Fernsicht von Mala Rupa Ball.

Wir sahen bald, daß die Beschießung keinen großen Erfolg hatte und so wandten wir uns beruhigt unserer Arbeit zu. Wir waren rasch gestiegen, so daß wir noch einige Vormittagsstunden zum Sammeln und zu Beobachtungen vor uns hatten. Diese konnten wir gut ausnützen. In leichter Steigung führte uns ein Pfad durch den stattlichen Buchenwald, der etwa die obere Waldgrenze darstellte. Wir durchwanderten einige Schluchten, in denen Bäche abwärts flossen. In einer dieser Schluchten wurde später der gefleckte Salamander (Salamandra maculosa L.) beobachtet, der scheinbar in Mazedonien meist in Höhen von über $1000 \mathrm{~m}$ vorkommt. 
Über dem Wald zogen sich weiße Kalkfelsen hin, jenseits von denen grüne Matten begannen. Es war ein herrliches, farbenprächtiges Bild, das wir durch die grauen Stämme der Buchen und ihr helles Laub eingerahmt vor uns sahen, wenn wir die Blicke bergauf richteten. Und über all dieser irdischen Pracht wölbte sich ein leuchtend blauer Himmel in dem Glanz und der Tiefe des Hochgebirgshimmels. Große weiße Wolken, sich ballend, aufblähend und verschwimmend schwebten am Gewölbe des Himmels, als seien es zarte Wollflocken, die langsam und majestätisch von Osten nach Westen wanderten.

Vom Waldrand erstreckte sich eine Schlucht bergab, die ein Bach durchfloß; unten, einige hundert Meter unter mir, zog sich ein weißes Band von Schotter und Gesteinstrümmern durch eine reiche Pflanzenwelt. Kurz oberhalb des Waldes weitete sich die Schlucht zu einer breiten Mulde aus. Dort war eine üppige Vegetation aufgewachsen, so hoch, daß sie mir unter die Schultern reichte. Es standen hier zahlreiche Brennesseln, Disteln in Blüte, weiße Umbelliferen, stattliche Königskerzen, dazwischen Wachholder- und Brombeersträucher.

Die Mulde war nach oben abgeschlossen durch ein weißes Felsenband, das aus würfel- und plattenförmigen Kalkmassen gebildet war. Hier, in den Spalten zwischen den Steinen und auf all den kleinen Balustraden, die sie bildeten, leuchtete und duftete es von einer Menge von Pflanzen von Hochgebirgscharakter. Es war fast, als wäre da künstlich ein Alpengarten angelegt; die ganze Farbenpracht alpiner Blumen war hier auf engem Raum zusammengedrängt. Dunkelblaue Glockenblumen bildeten dichte Polster neben roten und weißen Nelken (Dianthus silvestris Walb.) und Lichtnelken, Steinbrech in mehreren Arten, Fettkraut, Sempervivum batens Gris., farbige Stiefmütterchen (Viola orphanites Boas), Vergißmeinnicht, alles war da dicht beieinander gewachsen und bildete Rasen und Polster zwischen den Steinen.

Über den Blüten summte und bewegte sich eine reiche Insektenwelt. Hummeln brumnten von Blume zu Blume, Bienen der verschiedensten Arten wetteiferten mit ihnen und über allem zogen edle Falter ihre Kreise. Ich hatte sicher erwartet in diesem Gebiet und in dieser Jahreszeit einen Schmetterling aus der schönen Gruppe der Apollofalter anzutreffen. Wir waren gespannt, ihn hier zu finden und kaum waren wir eine Viertelstunde im Gebiet, 
so erscholl der triumphierende Ruf von Prof. Müller: „Da ist er schon!"

In stolzem Flug über allen anderen Insekten zog der große, weiße Schmetterling seine Kreise. Bald waren einige Exemplare gefangen und voll Freude betrachteten wir die schönen Tiere mit den schwarz-roten Augenflecken. Es war nicht leicht in dem gefährlichen Gelände die raschen Falter zu erhaschen. Kaum gesehen, schwangen sie sich in hohem Bogen über die Felswand empor und entflatterten über den grünen Matten. Außerdem waren es ihrer nicht viele; die Flugzeit hatte offenbar erst gerade begonnen, was sich auch darin aussprach, dal3 die Männchen weit über die Weibchen überwogen. Bald hatten wir sechs Männchen,

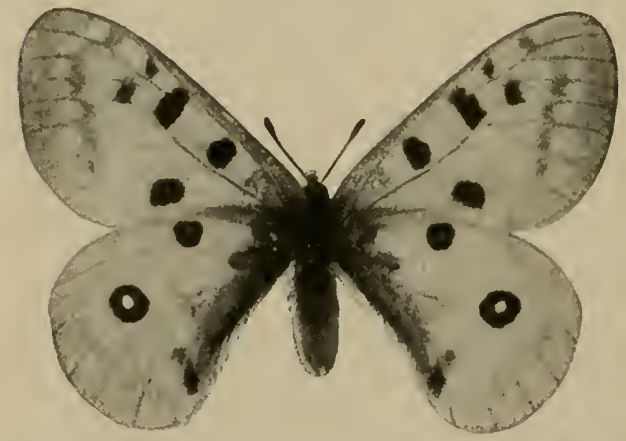

Abb. 59. Parnassizes Apollo. Form von der Mala Rupa. aber nur ein Weibchen gefangen. Das hatte aber alle Geschicklichkeit und Gewandtheit erfordert, in dem steinigen Gebiet mit der dichten Vegetation und den vielen tiefen Löchern, die sie verdeckte, nicht Arm und Bein zu brechen. In Beachtung der Flugart großer Schmetterlinge, die gewöhnlich in großen Kreisen ein ziemlich umgrenztes Gebiet abfliegen, verteilten wir drei Männer uns auf Felsenband, Mulde und Waldrand, und so gelang es nach einiger Zeit, vor allem durch die Anstrengungen des gewandten $\mathrm{R}$ angnow, eine befriedigende Ausbeute zu erzielen. Über den Apollos vergaßen wir aber die anderen Insekten nicht, die hier in der warmen Sonne sich tummelten. Von Schmetterlingen gab es zahlreiche Bläulinge, Perlmutterfalter, unter diesen Argynnis pales balcanica Rbl., und vor allem dunkle Erebien mit schönen blauen Augenflecken auf den Flügeln. In der Schlucht, die wir die "Apolloschlucht" benannten, fanden sich, vor allem auf den Doldenpflanzen, viele schöne Käfer. Wie Edelsteine blinkten Chrysomeliden, bunt gefleckte Trichia (T. fasciata L.) und Bockkäferarten wimmelten auf den Dolden mit vielen Bienen, Hummeln, auffallend gefärbten Fliegen, eigenartigen Spinnen usw. Die prachtvollen Chrysomeliden waren die schön metallisch rot-grün-blau- 
gestreiften Orina variabilis Wsc. var. balcanica, Cryptococcus aureolus ab. cocrulescens Schil und Cryptocephalus aureohus Suffr.

Am Waldrand fanden sich unter Steinen Skorpione und seltsame Tausendfüßler. Wir hatten schon reiche Beute eingeheimst, als wir zur Hütte zurückkehrten, um dort im Schatten die heißesten Stunden zu verbringen.

Wir lebten aus unseren Rucksäcken, denn hier an der Front waren Offiziere und Soldaten meist so knapp verpflegt, daß Gäste nicht allzuwillkommen waren. Das machte einen eigenartigen Eindruck, daß die wichtigsten Bestandteile des Heeres, die Front,

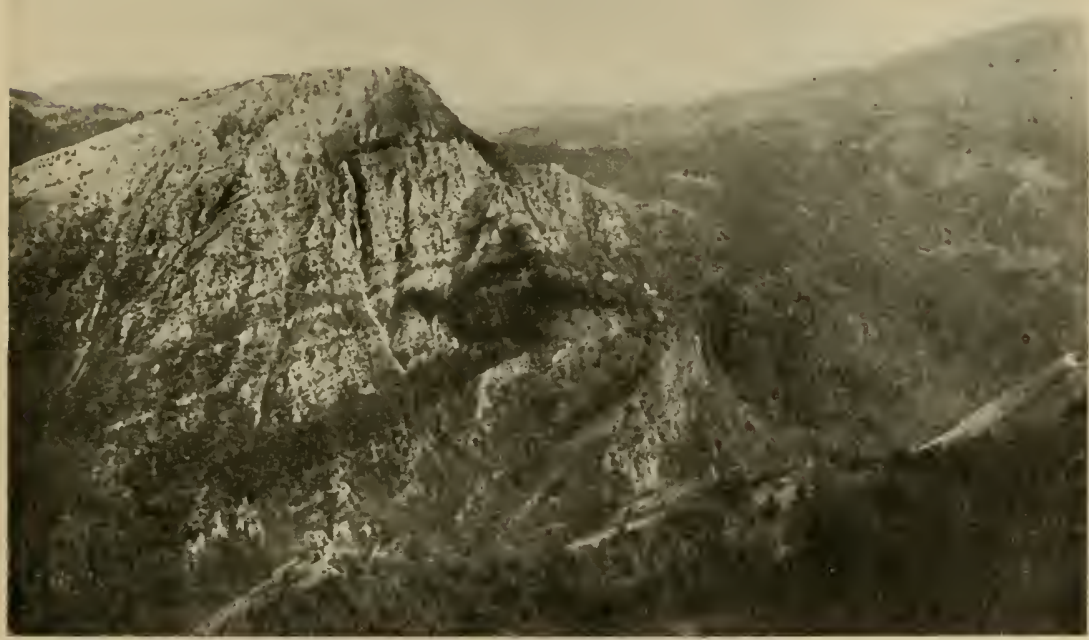

Dr. Burmest e r plot.

Abb. 60. Felsenkessel zwischen Mala Rupa und Asanť́asma.

so viel weniger gut versorgt wurden, als die fette Etappe. Mit gutem Hunger verzehrten wir das Stück Speck zu unserem Kommißbrot, das wir mitgebracht hatten und stillten unseren gewaltigen Durst an dem köstlichen Wasser der Bergquelle.

Zum Ausruhen gab es mittags nicht viel Zeit; wir mußten die kurze Frist, die uns gewährt war, nach Möglichkeit ausnützen. So begaben wir uns bald an den Aufstieg zur Gipfelregion des Mala Rupa-Gebirges. Zwischen Felsen und über blumenreiche Matten ging der Weg steil aufwärts. Die Matten bedeckte ein 
hohes, sehr feines, dunkelgrünes Gras, das vielfach von den Truppen gemäht wurde und ein zartes, blaugrünes Heu lieferte.

Zwischen dem Gras gab es eine Menge verschiedenartiger blühender Pflanzen. Sehr häufig war ein kleinblütiger weißer Klee; dazwischen standen grellrote Nelken und eine rotblühende Iichtnelke mit weißlichen Blättern. Blaue Flecken wurden von zahlreichen Glockenblumen gebildet, Thymian erfüllte die Luft mit seinem starken Dufte. Zwischen den Steinen war ein kleines Hornkraut mit zarten weißen Blüten sehr häufig. Sauerampfer und viele Doldenpflanzen standen an den feuchteren Stellen.

Über den Matten gaukelten Schmetterlinge, vor allem glänzend gefärbte Bläulinge und eine tiefschwarze Erebia mit leuchtend blauen Augenflecken. Es war dies

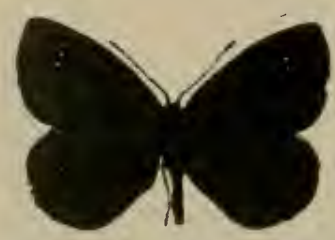

Abb. 61. Erebia tyndarus balcanicus Rbl. Mala Rupa. Nat. Gr. Erebia melas herzegowinensis Schar. Eine zweite Erebia der Höhenzone bilde ich nebenan ab; es ist dies Erebia tyndarus balcanicus Rbl.

Im allgemeinen war die Fauna der Gipfelregion nicht sehr reich. Das hing wohl 'auch mit der Tageszeit zusammen. Es war schon später Nachmittag; am Morgen hätten wir nach den späteren Erfahrungen an Berggipfeln reichere Beute gemacht. Über die grünen Matten kamen wir in $1860 \mathrm{~m} \mathrm{zu}$ einem ersten Gipfel, der als Mala Rupa-Ball bezeichnet war (Abb. 58). Von da kletterten wir noch einige hundert Meter aufwärts und erreichten wohl auf der nächsten Kuppe eine Höhe von etwa $2100 \mathrm{~m}$.

Von oben hatten wir einen weiten Überblick über das Gebirge mit seinen zahlreichen steilen Gipfeln und seinen weißschimmernden Berghalden. Vor allen Dingen schön war der Blick auf die mittleren Höhen, wo die dunklen Laubwälder einen wundervollen Kontrast zu den hell aufleuchtenden Felsen bildeten. Im Glanze der Nachmittagssonne waren die Gipfel alle klar und deutlich zu übersehen. Der stattliche höchste Gipfel wurde als Porta, ein zweiter Kičikaia benannt. Ein spitzer Kegelberg führte den Namen Drena, daneben der Gipfel Asančasma. Von der Iberiza zog sich ein langer Kamm talwärts, der einen scharfen Schatten auf die Matten warf. Nach Norden sahen wir ins Tal hinab und zu den Bergen, die ich immer von Kaluckova bewundert hatte und die ich jetzt von der anderen Seite vor mir sah. Gegen 
Sermenli zu erstreckte sich als langer Rücken der $\mathrm{Z}$ weiohrenberg (Abb. 62) und hinter ihm, von hier aus klein und unscheinbar, die Marianska Planina.

Wundervoll und eindrucksreich war der Blick in die weite Ebene nördlich von Saloniki, über welche hinaus das Meer aufblinkte. In der Ebene erhob sich der Gandač, eine steile Bergmasse mit feindlichen Stellungen. Vor uns fielen die steilen Halden in tiefe Schluchten ab, Matten dehnten sich weit bis zu den großen Wäldern hin. Hier und da stieg in der Ferne der Rauch von Lagerfeuern auf.

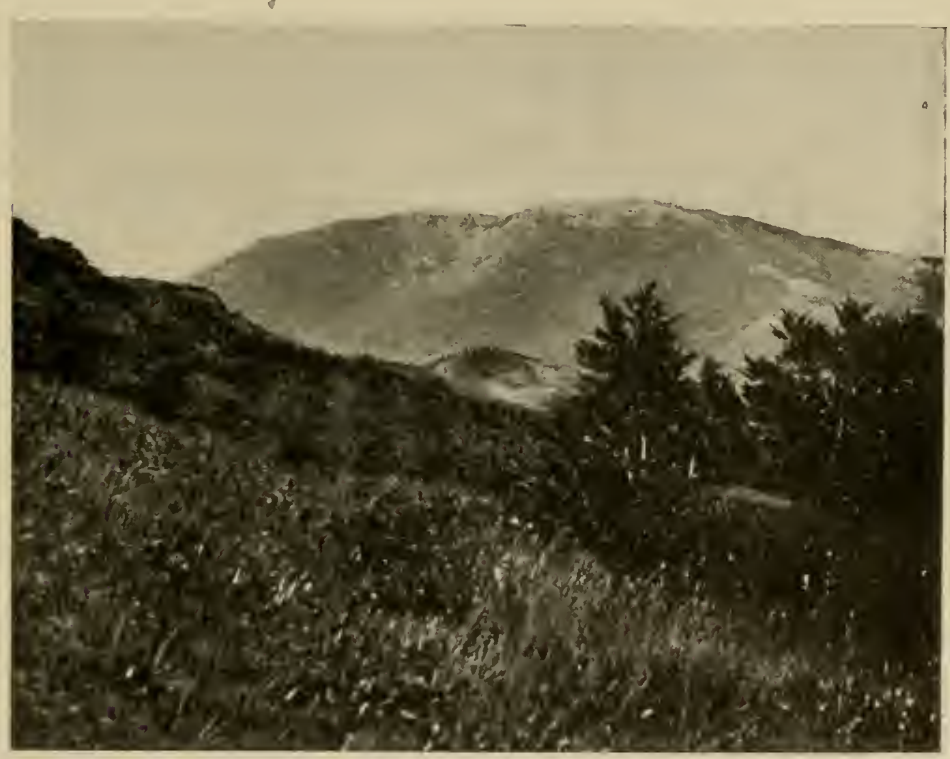

Abb. 62. Wiese an der Baumgrenze. Mala Rupa. Im Hintergrund Zweiohrenberg.

Wir durften nicht lange oben verweilen, wollten wir vor der Nacht im unbekannten Gelände die Hütte erreichen. Beim Abstieg konnte ich der reichen Flora der unteren Matten noch etwas Aufmerksamkeit schenken; deren Pflanzenreichtum war noch viel größer als der der höheren Zone. Hier war sehr auffallend ein leuchtend gelber Goldklee; neben dem gleichen Thymus, der oben häufig war, stand hier eine zweite, auffallend großblütige Form mit dem gleichen starken Geruch. Ein Stiefmütterchen, ähnlich Viola tricolor (Viola orphanites Boas), bildete große Rasen, ebenso die unten schon beobachtete Erika; an geschützten Orten standen 
höher wachsende Pflanzen, welche stark an Frühlingsblumen der Heimat erinnerten. Da glaubte ich den kriechenden $\mathrm{Günsel}$ (Ajuga genevensis L.) und den Gundermann (Glechoma hirsuta Uk.) zu erkennen, ein weißes Galium (Galium mollugo L.) blühte in großen Garben, eine Schafgarbe, vollkommen der unserigen gleich in den Blüten und den feinverteilten Blättern und die tatsächlich die gleiche war. Dazwischen merkte ich mir von auffallenden Planzen Taubenkropf (Silene venosa Asch.), eine weiße Kornblume (Cyanea mollugo L.), eine Pflanze, die genau wie roter Bienensaug (Lamium striatum L. S.) aussah. Büsche von blühendem Ginster (Cytisus) zauberten goldene Flecke in die Landschaft. Viele gelbblühende Kompositen mit Wollblättern standen zwischen den Steinen, vor allem fiel mir ein großblütiges Habichtskraut auf, dessen Blattrosetten aussahen, als beständen sie aus weißem Samt (Hieracium pannosum Gris.). Besonders in der Erinnerung geblieben sind mir kleine Sträucher einer süßduftenden, dunkelroten Wildrose (Rosa orientalis).

Ich hatte vollkommen den Eindruck einer Bergmatte in den bayerischen Alpen, wie sie im Frühsommer ihre volle Pracht, ihren überquellenden Reichtum entfaltet. Beim Abstieg mischten sich immer mehr die mächtigen Stauden von Disteln und Königskerzen in die Alpenflora.

In Abendschein langte ich in der Nähe der Hütte an. Ein kurzes Gewitter hatte heftigen Blitz und Donner losgelassen, aber nur wenige Regentropfen bis zur Erde hinabgesandt, wo sie auf Steinen und Pflanzen sofort verdunsteten. Wunderbare große Wolken segelten über die Berge der Ebene entgegen. Sie fingen auf ihren gewaltigen Wölbungen die roten und gelben Strahlen der scheidenden Sonne auf, die auch die Felsen rot aufleuchten ließren.

Die Nacht fand uns mit den Soldaten in der Hütte versammelt. Es war nicht leicht mit den 1 I Schlafgenossen in dem engen Raum, auf harten Brettern, den Rucksack unter dem Kopf Schlaf $z u$ finden, der noch dazu durch das Schnarchen mancher Kameraden erheblich gestört wurde.

Immerhin erfrischt erhoben wir uns mit der Sonne, um die wenigen Stunden, die uns in der Berghöhe vergönnt blieben, nach Kräften auszunützen. Als wir auf die Wiesen hinaustraten, waren alle Pflanzen vom Tau stark benetzt. Wir eilten noch einmal zur 
Apolloschlucht, um die Sammlungen dort zu ergänzen. Wir fanden dort noch nicht gesammelte Insekten, darunter schwarze Käfer aus der Verwandtschaft von Leptura.

Unsere Arbeit wurde etwas dadurch gestört, daß über uns ein Geschwader feindlicher Flieger erschien. Das war mir, der ich damals noch Freiburger Universitätsprofessor war, nichts Ungewohntes. Immerhin hatte ich es noch nicht allzuoft in freier Natur, fern jeder Deckung erlebt. Sechs französische Flieger erschienen über uns und wurden heftig beschossen, so daß die Sprengstücke um uns niederprasselten. Bald erschien ein einzelnes deutsches Kampfflugzeug, worauf die Feinde sich verzogen.

Wir konnten unsere Arbeit ungestört fortsetzen, bis die vorgeschrittene Zeit uns zwang, den Abstieg anzutreten. Wir durchwanderten etwa dieselbe Gegend wie am vorigen Morgen. Als wir wieder in die Tiefe kamen, machte mir die Gegend einen reizloseren, verstaubteren und verdorrteren Eindruck als sie im Halbdunkel des Frühmorgen am Tag vorher mir erschienen war. Es war schon Gluthitze der Mittagszeit eingetreten als wir unser Auto erreichten. In flotter Fahrt ging es zurück nach Koinsko, wo wir mit den Offizieren ein für uns verspätetes Mittagsmahl einnahmen. Nach herzlichem Abschied von Prof. Schultze-Jena traten wir die Fahrt rückwärts ins Wardartal auf demselben Weg an, den wir zur Hinfart benützt hatten.

Während wir wieder durch das Tiefland fuhren, ertönte hier überall aus den Büschen das berauschte Liebeslied der Zikaden lauter als je. Welch schöne, starke Eindrücke hatte der kurze Aufenthalt im Gebirge mir gebracht. Die Kontraste zwischen Ebene und Bergeshöhe, mir aus der Heimat, vor allem den bayerischen Alpen, so wohl vertraut, waren mir hier noch ausgesprochener entgegengetreten. Hier im Gebirge entsprach die Natur vollkommen in Pflanzen- und Tierwelt derjenigen im Flachland des gemäßigten Mitteleuropa. Auf der Breite des südlichsten Italien genügte Gebirgshöhe von 1000-2000 Metern, um die Natur der Heimat herbeizuzaubern. Ja, das Klima erinnerte sogar an Vorgebirge der Heimat. So hatten wir die Tannen auf der Mala Rupa jetzt im Juli im Schmuck der hellgrünen Triebspitzen angetroffen, ein Stadium, das im Schwarzwald schon seit einigen Wochen vorbei sein mußte.

Neben den Bäumen, also Weißtanne, Buche, Birke und den Blüten der Mattenregion hatte vor allem die Vogelwelt beigetragen, 
den heimatlichen Eindruck zu verstärken. Buchfink, Kleiber, Sumpfmeise schienen sich kaum von den heimischen Formen zu unterscheiden. Amsel und Drossel sangen die altbekannten Lieder, Pirol und Häher belebten die Baumkronen des schattigen Buchenwaldes, in dem wir die Erdbeeren gepflückt hatten. Von dem Vorkommen von Hirsch und Reh hatten wir gesicherte Nachricht bekommen, vom Hirsch sogar eine Haut erworben. Von Schlangen hatten wir Äskulapschlange und glatte $\mathrm{Natter}$ beobachtet, von Eidechsen allerdings die südlichen Arten Lacerta viridis und muralis, von Fröschen die uns so vertraute Rana ridibunda und dazu R. agilis. Die zahlreichen Adler und Geier, die Falken und Bussarde, Kolkraben und Felsenhühner, die wir auftrieben, paßten besser in das Land, in dem wir nun lebten.

Zufrieden, in der kurzen Zeit so viel Interessantes erlebt und beobachtet zu haben, kehrte ich in mein Standquartier Kaluckova zurück mit dem festen Vorsatz, die mazedonischen Gebirge öfter zu besuchen, und zu durchforschen. Daß dieser Vorsatz Erfüllung fand, werden weitere Kapitel dieses Buches zeigen. 


\section{REGENWÜRMER UND ACKERERDE IN MAZEDONIEN}

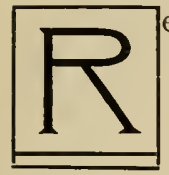

egenwürmer sind Tiere, welche keine großen Wanderungen ausführen können; auch ihre Eier und Entwicklungsstadien sind nicht zu weiter Verbreitung geeignet. So werden sie auch niemals weithin durch andere Tiere verschleppt, was bei manchen Tierarten eine wichtige Form passiver Wanderungen darstellt. Erst im Zeitalter des Welthandels wurden sie mit Pflanzen auf dem Weg über Baumpflanzungen, Ackerbetrieb, Gärtnereien in einer unnatürlichen Weise verbreitet, indem sie mit den heimatlichen Pflanzen in fremde Gegenden verpflanzt, sich dort weiterentwickelten und einbürgerten. Auf diese Weise wurden wohl schon seit den Zeiten des römischen Weltreiches Regenwürmer weithin verschleppt. Michaelsen, wohl der beste Kenner dieser Tiergruppe und ihrer Verbreitung, ist sogar der Meinung, daß die Verschleppung schon in prähistorischer Zeit begann.

In weniger kultivierten Ländern müssen aber Regenwürmer einen sehr seßhaften Bestandteil der Fauna darstellen. Aus ihrem Vorkommen kann man vielfach wichtige tiergeographische Schlüsse ziehen. So hatte ich mir denn bei der Ausreise nach Mazedonien gleich vorgenommen, dort aufmerksam auf die vorkommenden Regenwurmarten zu achten.

Sogleich bei Beginn meiner Forschungen suchte ich 11ach Regenwürmern, zunächst in der Nachbarschaft von Kaluckova, dann im Wardartal, später auf allen Reisen in den Gebirgen, den fruchtbaren Tälern und Ebenen, kurz überall, wohin ich kam. Bald merkte ich, daß jedenfalls im Sommer Regenwürmer in Mazedonien etwas außerordentlich seltenes sein mußten.

Es dauerte längere Zeit, bis ich die ersten Vertreter dieser bei uns in Deutschland so häufigen Tiere fand. Das lag zunächst sicher an den besonderen Verhältnissen des südlichen Wardartales, 
in dem ich damals mein Standquartier hatte. Dort in den felsigen Hügeln war es wohl von vornherein vergebliche Mühe nach Regenwürmern zu suchen. Dazu war der Boden, soweit er nicht aus Felsen und grobem Gerölle bestand, im Sommer zu hart und ausgetrocknet, als daß diese Feuchtigkeit liebenden Tiere hier hätten existieren können. Manche Grabungen, die ich zu verschiedenen Zwecken, z. B. bei der Untersuchung von Ameisenbauten in den Hügeln durchführen ließ, zeigten mir, wie hart und trocken der Boden bis tief hinab war. Nur an wenigen Stellen konnte man $1-1 \frac{1}{2} \mathrm{~m}$ in die Tiefe graben, ohne auf gewachsenen Felsen $z u$ stoßen. Meist lag dieser schon unter einer Erdkrume von wenig Zentimetern Dicke. Auch in den Gärten und in den Maulbeerpflanzungen nahe bei Kaluckova wurden mehrfach tiefe Löcher gegraben, ohne daß ich jemals auf einen Regenwurm stieß. Nur in unmittelbarer Nachbarschaft von Wasser gelang es hie und da solche aufzufinden, so an den Nebenflüssen des Wardar, in den Schluchten der Plaguša Planina und vor allem hoch oben in den Bergen.

Eines Tages, im August 1917, entdeckte ich Regenwürmer in großer Zahl unter dem Wasserfaß des Lazaretts, also dicht bei meinem Quartier. In der durchnäßten Erde hatten sich hier die Tiere massenhaft angesammelt. Der Fund war aber nicht allzu interessant, da die Art sich als die kosmopolitische Form Helodrilus (Allobophora) caliginosus Sav. herausstellte, welche in ganz Europa sehr gemein ist, aber auch in Asien, Afrika, Nord- und Südamerika, Australien, also in der ganzen Welt verbreitet ist. Es handelt sich offenbar um eine europäische Form, die allmählich durch den Menschen in die anderen Erdteile verschleppt wurde. Die gleiche Art fand ich dann noch öfter, aber immer an feuchten Stellen, so bei Dedeli und in den Rasenpolstern der Schluchten bei Kaluckova. Merkwürdiger als diese Funde war das Vorkommen in dem Wasser eines Quellbaches an der Kobeliza im Schardakh in der Höhe von etwa $2000 \mathrm{~m}$. Dieses Vorkommen könnte darauf hindeuten, daß die Art doch seit jeher in Mazedonien einheimisch ist. Eine Verschleppung in die Bergeinsamkeit ist kaum anzunehmen.

Andere, wahrscheinlich verschleppte Formen, welche ich in Mazedonien fand, waren die amphibische Eiseniella tetraedra (typica) Sav., welche in der Schlucht bei Plauš in der Plaguša Planina, in der Topolkaschlucht unter Steinen, bei Rabrovo und schließlich im Nikolatal in einem faulenden Baum am Bach- 
ufer vorkam; Eiscnia rosea (Sav.), am Wodno, in der Gipfelregion bei $1000 \mathrm{~m}$ Höhe, im Schlamm am Rand eines Gewässers, ist sogar eine der nachweislich verschleppten Arten; Octalasium lacteım (Örley) von der Plaguša Planina ist offenbar auch eine nicht ursprünglich einheimische Form, welche auch sonst in Mitteleuropa vorkommt, in Ungarn, Südrußland und Rumänien schon beobachtet worden ist, aber auch schon in Spanien, auf den Azoren, in Algier, Nord- und Südamerika gefunden wurde.

Eine Form, deren natürliches Verbreitungsgebiet offenbar Mazedonien umfaßt, ist wohl Lumbricus rubellus Hoffmstr., die weit in Europa verbreitet ist. Sie ist neu für Mazedonien, während Eisenia rosea var. macedonica (Rosa), welche am Pepelaksee in der Golesniza Planina in $2000 \mathrm{~m}$ Meereshöhe gefunden wurde, wahrscheinlich eine typisch mazedonische Form ist. Zum ersten Male in Mazedonien fand ich an verschiedenen Stellen Helodrilus (Dendrobaena) byblicus (Rosa), der bisher nur in Syrien und Palästina und in Kreta beobachtet worden war. Ich fand ihn in einem Schluchtbach hinter Kaluckova in einem Moospolster, im Bach des Nikolatales und merkwürdigerweise auch in einem Quellbach auf der Kobeliza in $2000 \mathrm{~m}$ Meereshöhe. Schließlich entdeckte ich noch Helodrilus caliginosus trapezoides (Ant. Deg.), in einem austrocknenden Tümpel bei Strumiza und bei Dedeli; diese Form war bisher aus dem Mittelmeergebiet und Nordamerika bekannt.

Dazu enthielt meine Sammlung noch drei neue Arten. Criodrilus macedonicus Ude, welche dem Criodrilus lacuum nahe steht, wurde in Wiesenbächen südlich von Valandova gefunden. Dazu kommen Helodrilis (Allobophora) dofleini Ude aus der Gegend von Üsküb, aus der Gipfelregion des Wodno und von einem Hügel beim Spital und Helodrilus (Eophila) bellicosus Ude von einem Nebenfluß des Wardar bei Miletkovo.

Diese I 2 Arten sind kein sehr beträchtliches Ergebnis in einem Land wie Mazedonien, wenn man bedenkt, daß in dem Band des Tierreiches, den Michaelsen 1900 veröffentlicht, für die ganze Erde mehrere Hundert (870) Arten beschrieben sind. Immerhin sind fast alle genannten Arten neu für Mazedonien. Aus diesem Land sind überhaupt nur ganz wenig Oligochäten bekannt. Auch die Limicolen, die wasserbewohnenden Formen, sind selten. Ich fand vielfach eine Form in den Schluchtbächen, in Bergseen, 
Gräben und Kanälen. Es war wohl sicher immer der kosmopolitische Tubifex tubifex $\mathrm{L}$.

Unter den Regenwürmern ist sicher eine ganze Anzahl typisch verschleppter Formen; dabei ist aber zu bedenken, daß Mazedonien zu jenem Gebiet endemischer Formen gehört, das sich von Portugal, Spanien und Südfrankreich, die Alpen bis Kleinasien, Persien und ostwärts bis Japan erstreckt.

$\mathrm{Da} B$ bisher aus Mazedonien so selten Vertreter dieser Gruppe beschrieben wurden, und daß ich so wenig Regenwürmer gerade in diesem Lande auffinden konnte, obwohl ich auf ihr Vorkommen besonders achtete, konnte kein Zufall sein. Das hing sicher mit dem heißen und trockenen Sommer und mit der Bodenbeschaffenheit zusammen.

Darwin hat ein sehr interessantes Buch über die Regenwürmer verfaßt, welches den Titel führt: Die Bildung der A ckererde durch die Tätigkeit der Würmer. In diesem Buch schildert er die Lebensweise der Regenwürmer und die früher nicht geahnte Wirkung, welche diese Tiere auf die Gestaltung der Erdoberfläche haben. Er zeigte, wie sie den Erdboden bearbeiten, indem sie beim Bau ihrer unterirdischen Gänge Erde durch ihren Darm hindurchgehen lassen und immer wieder Massen aus tiefen Schichten in die Höhe tragen und in ihren Kothaufen an der Oberfläche ablagern. So durchwühlen sie den Boden, verlagern seine Bestandteile und lockern seine Zusammensetzung. Auch in anderer Beziehung wirken sie mechanisch auf seine Bestandteile ein, indem in ihrem Kaumagen Steinchen aneinandergerieben, geglättet und verkleinert werden.

Sogar auf die chemische Zusammensetzung des Bodens haben die Regenwürmer einen starken Einfluß, einmal indem sie Blätter und sonstige Pflanzenteile, welche ihnen zur Nahrung dienen, in ihrem Darm chemisch verändern, dann aber auch indem sie alle möglichen anorganischen und organischen Bestandteile des Bodens verarbeiten. So sind ihre eigenartigen Kothäufchen ein guter Dünger für die oberflächlichen Schichten des Erdbodens, denen so immerfort neue Stoffe zugetragen werden.

Sie bewirken, wo sie in großer Menge vorkommen, eine beständige Umarbeitung des Bodens bis in eine beträchtliche Tiefe. Sie sind die Hauptursache der Bildung der schwarzen Erde, welche besonders feinkörnig und fruchtbar ist, wo sie von vielen Regenwürmern ständig durchwühlt wird. 
Tatsächlich sind es in England und in Deutschland, wo fast gleichzeitig mit Darwin Hensen ähnliche Untersuchungen durchgeführt hat, erstaunliche Mengen von Würmern, welche in Gartenerde, in Ackerboden, in den Wäldern ihre unterirdische Arbeit leisten. Hensen wies nach, dal3 in einem Hektar Gartenland sich 133000 Regenwürmer fanden, deren Gesamtmasse fast 10 Zentner wiegt. Etwa die Hälfte davon finden sich nach Darwin in Ackerland, auf Heiden und im Wald. Die Erdmasse, welche diese Tiere in einem Jahr an die Oberfläche befördern, erreicht nach den Untersuchungen dieser Forscher und ihrer Mitarbeiter im Jahr auf den Morgen 8-20 Tonnen, so daß in ro Jahren eine Schicht von $1-5 \mathrm{~cm}$ Dicke über die alte Oberfläche geschichtet werden kann.

Das sind gewaltige Leistungen und es ist nicht verwunderlich, wenn Darwin nachweisen konnte, daß durch diese Arbeit der Regenwürmer Steine und andere Gegenstände langsam im Boden versinken, indem die Regenwürmer den Boden unter ihnen wegfressen, ihn aber nur an ihren Rändern an der Oberfläche ablagern können. So führte Darwin das Einsinken antiker Straßenpflaster, von Mosaikfußböden und Häuserteilen auf die Tätigkeit der Regenwürmer zurück.

Dal3 eine solche intensive Arbeit der Regenwürmer in Ländern unserer Breiten tatsächlich eine große Bedeutung hat, ist in Europa und Amerika vielfach beobachtet worden. Darwin selbst betonte, daß bei der weiten Verbreitung der Regenwürmer, welche auf der ganzen Erde, von den polaren Gegenden bis zum Äquator, in den höchsten Gebirgen und auf den einsamsten ozeanischen Inseln vorkommen, sie wohl eine ähnliche Einwirkung auf den Erdboden in allen feuchten, selbst mäßig feuchten Gegenden haben müßten.

Er selbst sammelte Erfahrungen anderer aus den Tropen, von der Riviera und aus anderen Gegenden. Ich konnte früher mich in Italien, Südfrankreich, in Istrien und in den Tropen an vielen Stellen von dem reichlichen Vorkommen von Regenwürmern und von ihrer Arbeit überzeugen.

Darwin selbst muß aber vermutet haben, daß in trockenen Ländern die Verhältnisse ganz anders liegen müssen; denn in seinem Buch äußert er sein Erstaunen darüber, daß $\mathrm{ihm}$ aus einem so trockenen Land wie Neu-Südwales in Australien von massenhaftem Vorkommen von Regenwürmern berichtet wurde.

Er bringt aber keine positiven Angaben über das Vorkommen von Regenwürmern in ganz trockenen Gebieten und 
auch seither sind darüber keine Beobachtungen gemacht worden, die mir bekannt geworden wären. Sicherlich gibt es in den Wüsten keine Regenwürmer, aber wo Oasen entstehen können, da mulo es auch Regenwürmer geben.

$\mathrm{Da}$ es in Sommer schwer war, in Mazedonien Regenwürmer $\mathrm{zu}$ beobachten, wird man nach den Schilderungen von sommerlicher Hitze und Dürre, die ich in anderen Kapiteln gegeben habe, verstehen. Der Boden der oberflächlichen Schichten erhitzt. sich in Mazedonien während des Tages im Sommer zu Temperaturen, welche nicht nur Regenwürmern, sondern auch anderen Tieren

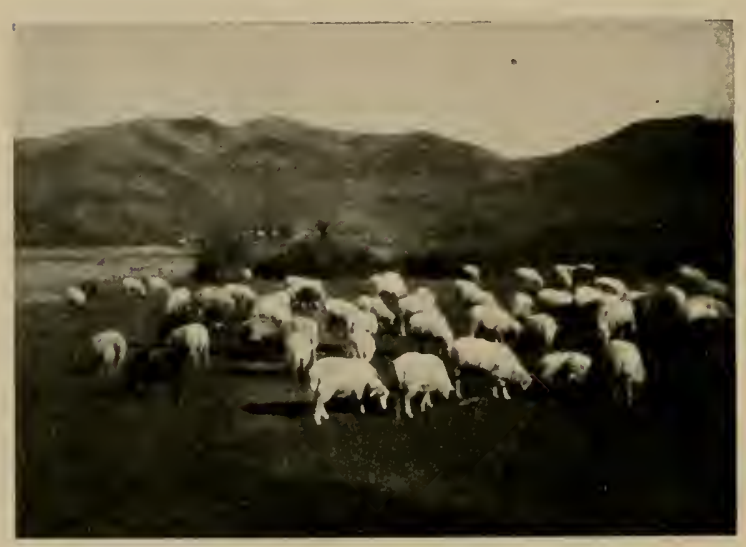

Dr. Laser phot.

Abb. 63. Schafherde bei Kaluckova. den Aufenthalt in ihm unmöglich machen. Temperaturen von $60-70^{\circ} \mathrm{C}$ sind in den Monaten Juli bis September im Boden nicht selten $z u$ messen. In der verstaubten und vertrockneten Oberfläche des Landes waren in den Sommermonaten keine Regenwürmer zu erwarten. Diese

Tiere sind ja außerordentlich empfindlich gegen trockene Hitze. Ich habe nicht selten in Deutschland Regenwürmer, welche auf eine verstaubte Landstraße geraten waren, elend umkommen gesehen. Immerhin habe ich auch in den Sommermonaten in Mazedonien nach ihnen gesucht, aber niemals im Tiefland fern vom Wasser Spuren von ihnen gefunden. Ich habe viele dichte Gebüsche, deren Boden ziemlich schattig war, manche Wälder, Parkanlagen und Friedhöfe untersucht, aber nie jene Mengen von Kothäufchen der Würmer gefunden, welche man in unserem Lande jederzeit an solchen Orten finden würde.

Es lag also nahe, anzunehmen, daß die Regenwürmer, wie manche andere Tiere Mazedoniens, von denen in einem anderen Kapitel die Rede ist, eine Sommerruhe halten. Schon Darwin gibt an, daß die riesenhaften Exkrementhaufen indischer Würmer, die er beschreibt und abbildet, in jenem Tropenland nur während 
der Regenzeit ausgeworfen werden. So mußte ich denn vermuten, daß auch in Mazedonien die Regenwürmer während der großen Hitze in der Tiefe der Erde einem Sommerschlaf verfallen sind. $\mathrm{Da} \beta$ sie etwa tief unten im Boden ihr normales Leben fortsetzen könnten, ist in einem Land wie Mazedonien an den meisten Orten ausgeschlossen. In Tiefen von mehr als $50 \mathrm{~cm}$ finden sie hier keine Nahrung. Eine richtige Humusschicht gibt es in diesem Lande nur in den Flußtälern, in den bewässerten Ebenen, in den Wäldern und auf den Matten der Gebirge. Sonst deckt überall nur eine ganz dünne lockere Erdschicht die felsige Unterlage, welche das Land überzieht. Und dieser dünne Überzug entbehrt vielfach vollkommen oder fast vollkommen der organischen Bestandteile, welche die „schwarze Erde“ anderer Gebiete zu den Kornkammern der Welt gemacht hat.

Das Grundwasser liegt in den Gebieten, die ich genauer kennen lernte, meist so tief, daß es weit unter dem Boden sich findet, in welchem Regenwürmer leben und sich ernähren könnten.

Ich habe während meines Aufenthaltes in Mazedonien jede Gelegenheit benutzt, welche mich über das Vorkommen der gesuchten Tiere hätte unterrichten können. Wenn in Frühling oder Herbst Äcker gepflügt, wenn die Fundamentgrube für ein Haus ausgegraben, von unseren Soldaten Schützengräben oder Unterstände ausgehoben, Bäume oder Sträucher gepflanzt wurden, untersuchte ich die Löcher und die ausgehobene Erde und fand trotz aller Bemühungen fast niemals Würmer. Nur in direkter Berührung mit Wasser kamen sie vor.

Während diese Fragen mich beschäftigten, wurde in Üsküb ein großes Experiment durchgeführt, welches meinen Zwecken vorzüglich entgegenkam und in mancher Beziehung so interessant ist, daß es sich lohnt, an dieser Stelle davon zu erzählen.

Während die Bulgaren glaubten, Mazedonien, das Land, das ihre Väter besaßen, durch unsere gemeinsamen kriegerischen Erfolge dauernd in Besitz behalten zu können, arbeiteten sie in Mazedonien in mancher Hinsicht für die Zukunft. So kamen sie auch auf die Idee, die Umgebung der Stadt Üsküb wieder mit Bäumen zu schmücken, um dieser schön gelegenen Stadt eine sympathische Umgebung, den Bewohnern Erquickung in schattigen Anlagen zu verschaffen. Und so wurde sehr idealistisch für eine Bepflanzung, speziell des Zitadellenhügels, auf dem ich mein Standquartier damals hatte, agitiert. Die Sache fand Anklang, die 
Stadtverwaltung von Üsküb wandte große Mittel auf, um Tausende von Bäumen als Alleen an den Landstraßen, als Haine auf Hügeln, als Wälder an den Abhängen des Berges anzupflanzen. Und es übernahmen Vereine und Schulklassen die Verpflichtung, einzelne Lose zu bepflanzen und zu pflegen. Die Sache wurde mit großem Schwung und Idealismus unternommen; Schulklassen zogen mit bulgarischen Fähnchen aus, um kleine Bäumchen zu pflanzen, ganze Bataillone von rumänischen Kriegsgefangenen hoben tiefe Gruben aus, um viele Tausende von Bäumen einzusetzen.

Alle diese Gräben und Gruben boten mir Gelegenheit, nach den gesuchten Würmern zu forschen. Aber, obwohl es feuchter Frühling und Frühsommer war, ich bekam bei dieser Gelegenheit keinen einzigen Regenwurm in die Hand. Auch sonst ging die Sache traurig aus. Die ganze große Unternehmung war offenbar ohne fachmännische Beratung unternommen. Man hatte Tannen aus dem Gebirge ins Wardartal gepflanzt und nicht auf Bodenart und Bewässerung weder bei diesen, noch bei den Obstbäumen, Pappeln usw. geachtet, die man wahllos an den Berghang gepflanzt hatte. In den ersten Wochen wurden dann und wann die Bäumchen von opferwilligen Schulkindern begossen. Aber als die große Sommerhitze kam, als Menschen und Pflanzen dursteten, da schmolz auch Wille und Idealismus bei diesen Orientalen, die die Üsküber trotz allem sind, dahin und ein Bäumchen nach dem andern verdorrte. Jetzt ist das Land wieder serbisch; die Zigeunerstadt hat wohl die letzten verdorrten Bäumchen im kalten Winter verheizt und die letzte Spur des aufflackernden Idealismus in Mazedonien ist wohl längst verwischt und verschwunden. So war denn all die große Arbeit nutzlos geschehen und keiner der Beteiligten mag je erfahren, daß einem Naturforscher dadurch ein großer Dienst erwiesen wurde.

Bei dieser Gelegenheit konnte ich an vielen Stellen die geringe Dicke des fruchtbaren Bodens messen, sie erreichte selten mehr als $5-10 \mathrm{~cm}$. Darunter kamen sofort Steine und Detritus von Gestein, welches Würmer nicht ernähren konnte. Löcher und Höhlen gab es zwar genug im Erdboden; sie waren aber meist das Werk von Ameisen, welche in Mazedonien bei der Umarbeitung des Bodens sicher viel mehr leisten als die Regenwürmer. Selbst starke Regengüsse in jenen Wochen zauberten keine Würmer aus dem sterilen Boden hervor. So ist denn wohl sicher anzunehmen, daß Mazedonien im Flachland und in den Hügel- 
gebieten ein sehr regenwurmarmes Land ist. Die Waldarmut des Landes ist sicher die Ursache dieser Erscheinung. Mit dem Wald schwand die Humusbedeckung der Hügel und Täler, wie wir in einem anderen Kapitel besprechen werden.

Nur wo genug Wasser vorhanden ist, um den Boden feucht zu erhalten, gedeihen in diesem Lande Regenwürmer. So fand ich sie nicht selten an Brunnen und Zisternen, auf gut bewässerten Feldern und Wiesen, an Wasserleitungen, an und in Bächen, an Ufern von Seen und Flüssen. Am Wardar bei Hudova z. B. war der Überschwemmungsstrand des Wardar weithin von den Spuren und Löchern einer Wurmart wie mit Zeichnungen bedeckt.

In den hohen Bergen und dort auch in den Wäldern fand ich stets Vertreter dieser im Land sonst so seltenen Tiere.

$\mathrm{Da} \beta$ sie trockene Zeiten im Boden verborgen in einem $\mathrm{Zu}$ stand herabgesetzten Stoffwechsels verbringen müssen, auch an manchen Stellen, an denen man sie sonst vermißt und nicht einmal durch ihre Spuren nachweisen kann, bewiesen mir mehrere Fälle, in denen ich Würmer - meist in den Bergen - nach kurzen heftigen Regengüssen frei herumkriechen sah, wohl durch das Wasser aus ihrem Versteck vertrieben. Die kurze Zeit, welche seit dem Regenfall vergangen war, verriet in jedem Fall, daß die Verstecke der Würmer nicht tief im Boden gewesen sein konnten.

Auch habe ich nicht selten nach heftigem, oft tagelangem Sommerregen die Erde aufgegraben, um festzustellen, wie tief das Wasser in eine sehr feste, zusammengetrocknete Erde eindringen kann. Ich stieß in den meisten Fällen schon in der Tiefe von $2-3 \mathrm{~cm}$ auf vollkommen trockenen Boden.

In einem solchen Land muß der Einfluß der Regenwürmer auf Bodenbeschaffenheit, Pflanzenwuchs und Ackerbau sehr gering sein. Die Ackererde in weiten Gebieten von Mazedonien hat nichts von dem großen Einfluß der Regenwürmer auf ihre Beschaffenheit zu verspüren, den wir seit den Forschungen von Hensen und Darwin für unsere Gegenden sehr hoch einzuschätzen wissen.

Die von mir beobachteten Verhältnisse haben mich viel beschäftigt und mich veranlaßt, mir Vorstellungen über die Abhängigkeit des Ackerbaues von der Bodenbeschaffenheit in einem Land vom Charakter Mazedoniens zu bilden. Was ist das ein ganz anderer Anblick, wenn bei uns der Pflug dezimetertief in den Ackerboden sich einwühlt, als wenn der mazedonische Bauer 
mit dem kurzen Eisenhaken seines urweltlichen, primitiven Pflugs den Boden nur oberflächlich ankratzt. Was ist das gar für ein Unterschied gegenüber den Ackerböden in Rumänien, wo ich einmal von Bukarest aus einen Ausflug mit einem Agrikulturbotaniker machte, um dort den äußersten Kontrast zu den mazedonischen Verhältnissen kennen zu lernen. In einem Krongut im Gebiet der „schwarzen Erde" maßen wir in einem Acker eine Decke von fruchtbarem Boden von einer Dicke von $1,10 \mathrm{~m}$. Was ist das für ein Unterschied gegen die $3-5 \mathrm{~cm}$ in Mazedonien. Und wie war dort an Farbe und Geruch der Erde der Gehalt an organischer Materie zu erkennen, wie war der Boden in seiner Feinkörnigkeit und Luftigkeit Zeuge von der Arbeit der Regenwürmer.

Wie ist es aber möglich, daß auf dem scheinbar so sterilen Boden Mazedoniens trotzdem schöne große Ernten zustande kamen, daß im Frühsommer oft die Landschaft dort von Gersten-, Roggenund Weizenfeldern bedeckt, den Eindruck paradisischer Fruchtbarkeit erweckt?

Offenbar beruht in Mazedonien die Fruchtbarkeit auf einer ganz anderen Grundlage als in feuchteren Gegenden. Auf dem felsigen Boden bildet sich jeweils in einigen Jahren eine Schicht von verwittertem Gestein, an dessen Verarbeitung Sonne und Regen, Eis und Schnee, Wind und Sturm beteiligt sind. Diese Schicht bildet eine Erde, die einige wenige Ernten gestattet, wenn Wasser genug geboten ist, wenn also der Acker in Flußnähe liegt oder sonstwie künstlich bewässert werden kann. Fast wie in einer Nährlösung gedeihen auf solchen Feldern die Pflanzen. Bald sind diese Äcker aber erschöpft und sie müssen wieder Jahre brach liegen, bis wieder neue Verwitterungskrume gebildet ist. Ohne Dünger können solche Äcker nur kurze Zeit tragen. Drum sah man in Mazedonien oft halbkahle, erschöpfte Felder.

Die flache Ackerkrume ist auch die Ursache, welche die Dürre in diesem Land für die Ernte so gefährlich macht. Kann ein Acker nicht bewässert werden, so geht in einem heißen, trockenen Sommer die Ernte mit Sicherheit zugrunde.

Tatsächlich muß es genügen, einen solchen Ackerboden mit dem Pflug nur gerade anzukratzen, damit man den Samen in ihn betten kann. Dazu genügt der Pflug des Altertums. Pflügte man tiefer, so wühlte man nur Steine und sterile Massen auf, welche noch nicht verwittert waren, noch nicht so weit aufgeschlossen waren, daß sie dem Getreide Nährstoffe bieten konnten. 
So haben unsere Truppen, auch gute Landwirte und Ansiedler in Mazedonien im Anfang Mißernten erzielt, als sie hochmütig lächelnd die primitive Bearbeitungsweise der mazedonischen Bauern verachteten und tief, oft gar mit Dampfpflügen den Boden aufwühlten. Die fruchtbare, dünne oberste Schicht wurde dabei in die Tiefe versenkt, das Felsengestein und seine Trümmer wurden emporgeholt. Ohne starke Düngung konnte solch ein Feld nichts tragen, ohne einige Jahre den Mächten der Atmosphäre ausgesetzt gewesen zu sein.

Da wäre jahrelange Arbeit des Menschen, oder noch viel längere Tätigkeit der Regenwürmer nötig gewesen, um aus einer Steinwüste fruchtbare Felder hervorzuzaubern. 


\section{NEUNTES KAPITEL}

\section{DAS GELIEBTE VELES}

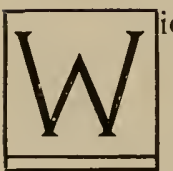

ie verhaßt war Veles bei vielen in unserer Armee, welche dort längere Zeit hatten liegen müssen und wie sehr geliebt war es von anderen, welche mit für die Schönheit geöffneten Augen diese malerischste Stadt Mazedoniens nur als Gäste besucht hatten. Koprülü, die Brückenstadt, war der türkische Name dieser Stadt, deren Häuser steil an beiden Ufern des Wardar die Berge hoch hinauf bedeckten. Es war wohl eine Plage, in der glühenden Hitze eines Sommertages oder auch in einer schwülen dunklen Nacht die engen, steilen Gassen mit ihrem Pflaster, das aus Kanonenkugeln zusammengesetzt zu sein schien, emporzuklettern. Eng schlossen die Häuser zusammen, ein schmaler Streifen dunkelblauen Himmels strahlte von oben herab, grell eingefaßt von den blendenden Mauern. Aus den Fenstern neigten sich Blütenbüsche und die unvermeidlichen Paprikaschoten herab. Einige hundert Meter über dem Fluß war man hinaufgestiegen, bis man in einer der obersten Straßen bei seinem Quartier anlangte.

Oben aber öffneten sich Ausblicke von überraschender Schönheit; hier hatte man den türkischen Orient mit seinen grellen Kontrasten, mit allem seinem Reiz für die Phantasie des Nordländers vor sich. Ein steiler Weg führte zur alten hölzernen Brücke hinunter, über welche ein starker Verkehr zwischen beiden Ufern wechselte. Neben der Brücke erhoben sich hoch über den Fluten des Wardar stattliche Gebäude, welche zum Teil mit einigen Stockwerken auf schiefen Streben über den Fluß hinausragten. Diese vorgebauten Häuserteile faßten Nischen mit Veranden zwischen sich, welche ebenso lauschig aussahen, wie Säulengalerien unter dem Dach dahinter gelegener Häuser. Die schön geschnitzte, dichte Holzvergitterung der Fenster verriet, daß es sich um Haremliks handelte. Die eingesperrten Frauen hatten hier wenigstens einen schönen Blick auf den Fluß und sein Tal vor sich.

In allen Teilen der Stadt ragten Minarets empor und auch während meiner Besuche hörte man abends regelmäßig von ihren 
Galerien den Gesang der Muezzins. In den Straßen von Veles sah man viele Männer in Turban und Fez, die Frauen, meist schwarz gekleidet, gingen verschleiert. So war der starke türkische Einschlag in der Bevölkerung unverkennbar. Aber in den ärmeren Vierteln gab es nicht wenig Bulgaren und wohl auch Serben; die letzteren bekannten sich aber nur in den seltensten Fällen zu ihrer Nation.

Das eine Mal wohnte ich auf dem linken Wardarufer hoch an Berg; mein Quartier war in einem Block von Häusern, welche ganz eng zusammengebaut waren und sich freie Luft nur auf vorgebauten Holzveranden und Balkonen gesichert hatten, von denen

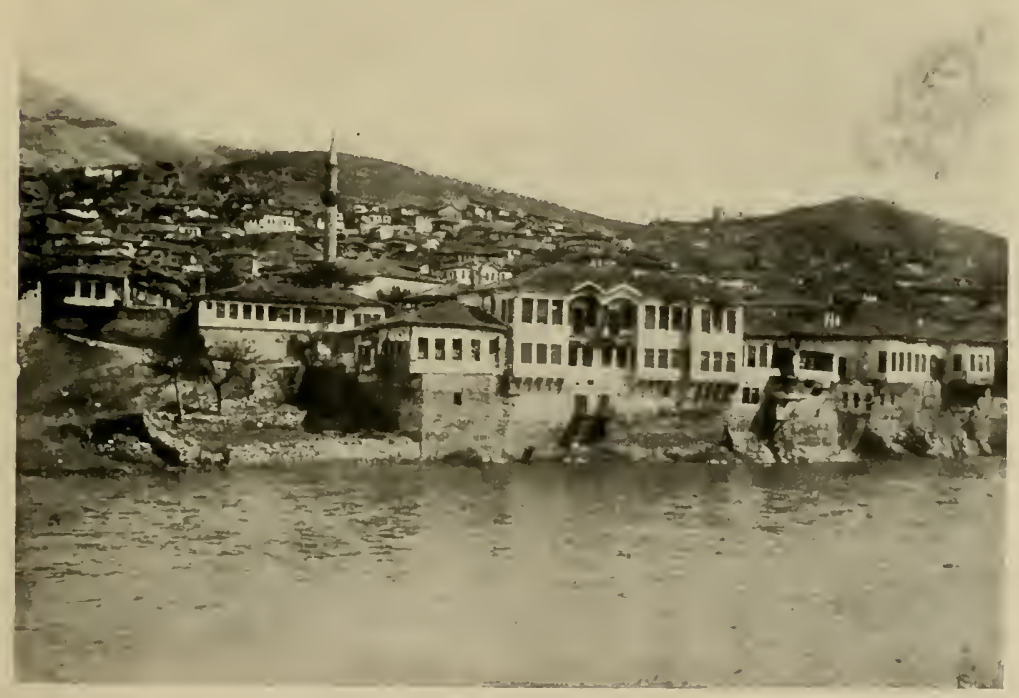

Abb. 64. Veles, Ostufer des Wardar mit Haremshäusern.

man einen weiten Überblick über Stadt und Flußtal hatte. Das tröstete einen über die düsteren, fensterlosen Stuben, in denen die Möbel kaum Platz hatten. Viele staubige Vorhänge, Divans im Staatszinmer und Einrichtungsgegenstände deuteten auf türkische Herkunft, obwohl die Quartiergeber bulgarisch sprachen.

Die Zimmer waren stets reich an Ungeziefer; ein wanzenfreies Quartier galt für eine große Auszeichnung vom Quartieramt. Schließlich sah man sich hier, wie überall in Mazedonien, genötigt, wanzenfreie Soldaten- und Offiziersheime und Verpflegungsanstalten 
zu schaffen. Dann war man allerdings in weniger romantischer Umgebung; aber auf solche legte der Durchschnittssoldat weniger Wert. Auch unter den Offizieren zeigte sich erstaunlich wenig Anpassungsfähigkeit an Fremdes und ein Kleben an Traditionellem, welches es manchem unmöglich machte, die Vorteile und Besonderheiten des Aufenthalts im fremden Land in der richtigen Weise auszunützen.

Daß Veles seinen alten Bestand an slavischen, christlichen Bewohnern hatte, bewiesen schon die stattlichen Kirchen und Klöster, die im Süden der Stadt meist hoch am Berg lagen. Auf

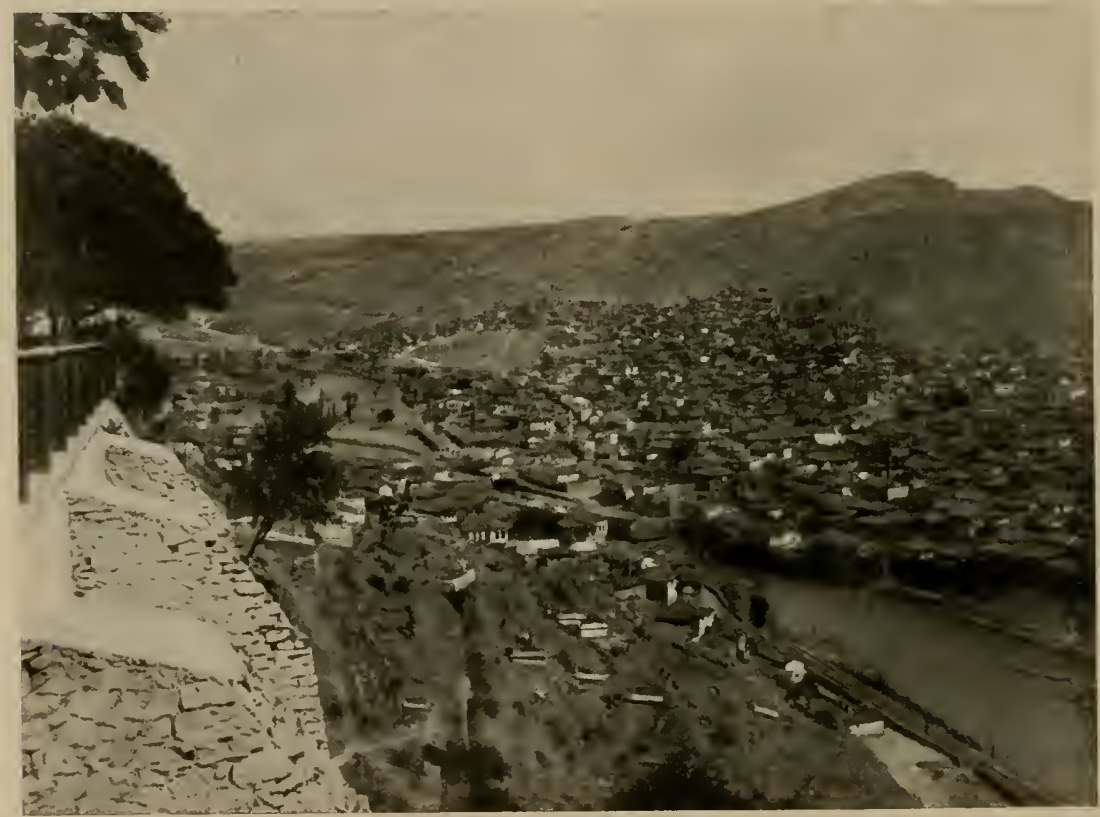

Abb. 65. Veles und der Wardar vom Kloster Sveti Panteleimon.

dem Ostufer ragte, von Bäumen umgeben, weiß leuchtend aus der grünen Umgebung Sveti Spas mit einem serbischen Friedhof, gegenüber, malerisch in die Felsen eingebaut, das große bulgarische Kloster Sveti Panteleimon. Von dessen Terrasse aus hatte man durch Bäume hindurch einen prachtvollen Blick auf das Häusermeer der Stadt, das sich eigentümlich in alle Falten und Schluchten der Berge einfügte, so daß man kaum merkte, wo Stadt aufhörte und Felsen anfingen. Das hatte zum Teil seinen Grund darin, claß die Bausteine den Felsen entstammten, an die sich die Häuser 


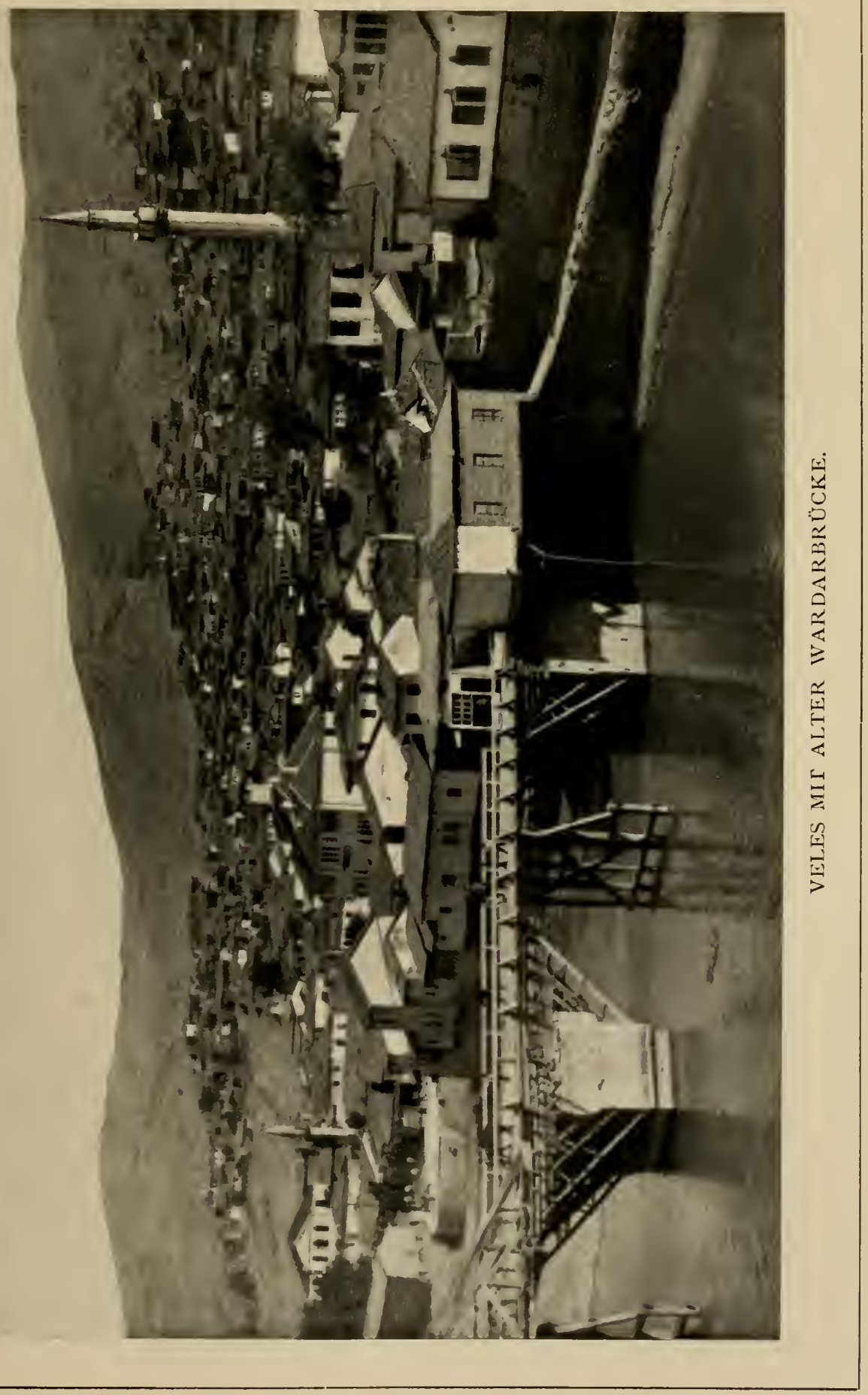



anlehnten. So waren es vornehmlich die dunkelroten Ziegeldächer, welche den Umriß der Stadt hervorhoben.

So dürr und verstaubt die Stadt mit ihren engen Gassen, ihren ausgetrockneten Bächen im Sommer aussah, so waren dennoch die stattlichen Bäume bei den Klöstern nicht die einzigen im Stadtbild von Veles. Wo der Boden es hergab, wurde an Bäumen erhalten, was gewachsen war. An den Stadtausgängen standen mächtige Pappeln, Brunnen waren von Eschen und Platanen beschattet und halfen die reizvollsten Straßenbilder herstellen.

Eine riesige alte Platane am rechten Wardarufer wird jedem Besucher der Stadt in Erinnerung geblieben sein; sie beschattete den Treffpunkt der Lastwagen. Dort waren immer die Töpfereien zum Verkauf ausgestellt, welche ein wichtiges Erzeugnis von Veles und seiner Umgebung waren. Besonders wichtig unter ihnen waren die roten, porösen Tonkrüge, welche als Wassergefäße dienten. Der durch ihre Wand durchgeschwitzte feuchte Überzug ihrer Außenseite hielt im heißen Sommer das Wasser in ihrem Innern durch Verdunstungsabkühlung frisch. Sowie der Sommer nahte, tauchten in Mazedonien diese Tonkrüge in Mengen auf und brachten einen neuen Farbton in das Straßenbild und eine Erinnerung an die Tropen.

Die alte Platane ist uns Zoologen in guter Erinnerung geblieben durch einen mächtigen $\mathrm{Uhu}$, der sich eines Abends auf ihr niederließ und nach aufregender Jagd erlegt wurde. Es war die typische Form, welche jetzt in der Wissenschaft den tönenden Namen Bubo bubo bubo L. führt.

In früheren Zeiten war ein Produkt des Gewerbefleißes von Veles das rote Safianleder, aus dem die türkischen Pantoffeln und feinen Schuhchen der Haremsdamen angefertigt wurden. Man sieht noch die Gerbereien, in denen das dünne Leder gegerbt wurde, wenn auch in ihnen während des Krieges kaum Leder und kaum Betrieb war. Ging man über die alte Brücke und am trocken liegenden Bach die Schlucht hinauf, gegen den Berg am Ostufer des Flusses, so kam man vor einigen hohen Pappeln zu Häusern, um welche herum die Gerbereibetriebe lagen. Auf der einen Seite war die Weißgerberei, auf der anderen die Rotgerberei, welch letztere hier noch weniger wohlriechend war, als in unseren Städten. Eigenartig waren die Einrichtungen der Weißgerberei. Eine Anzahl ovaler Steinbottiche standen am Rand der Straße, halb im Boden eingegraben (Abb.66); dieser war wie sie an dieser Seite vom Alaun 
schneeweiß, während die übelriechende Region der Lohgerberei rotbraun gefärbt war. Hier war also einst viel von dem feinen roten Leder erst weilogegerbt worden, ehe es in anderen Teilen der Stadt gefärbt und zu den zarten Schuhen umgearbeitet wurde, die bestimmt waren, feine Frauenfüße zu umkleiden.

Die Gegend um Veles war, soweit Berg und Felsen dies gestatteten, gut angebaut. Dazu half das Wardarwasser. Zu beiden Seiten der Stadt erweiterte sich

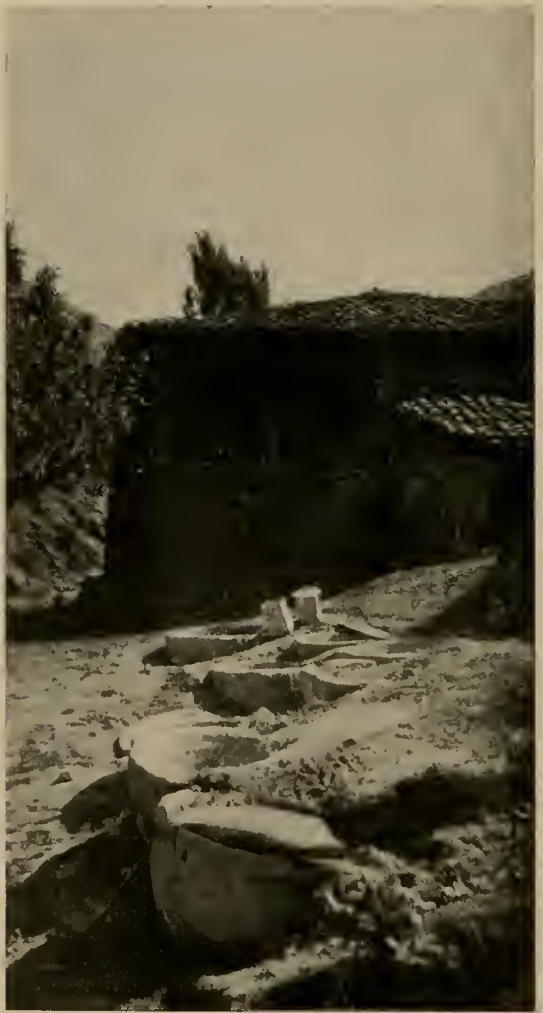

Abb. 66. Anlagen der Weißgerberei in
Veles. das enge Schluchttal des Flusses zu kleinen Ebenen, welche zum Teil in Flußtäler übergingen. Hier waren üppige Felder, die alles trugen, was sonst in Mazedonien gedieh, an manchen Stellen sogar Reisanbau gestatteten. Ein äußerst malerisches Bild boten die hohen, schlanken Schöpfräder, die am Ufer aufgestellt, mit kleinen Bechern beim Eintauchen Wasser aus dem Wardar bis zum obersten Punkt, den ihr Umfang erreichte, heraufhoben, um dort das Wasser in schief zum Lande geneigte Rinnen zu gießen, die es an Gräben weitergaben. Diese wiederum führten das befruchtende Wasser in die Gärten und Felder (Abb. 67). Die meisten Bäche und Flüsse traten in der Nähe Veles nicht durch weite Täler an den Wardar heran, sondern hatten vorher eine Bergkette zu durchbrechen, was sie in gewaltigen Schluchten taten. Zwei Flüßchen, welche kurz unterhalb Veles mündeten, waren durch ihre Durchbruchsschluchten berühmt, die Topolka und die Babuna. Am südlichen Ende der Stadt mündete die kleinere Topolka, ein im Frühling und Herbst starker Bach. Die Babuna war ein Flüßchen, das hoch aus dem Gebirge kam, entsprechend wasserreicher war, 
und demgemäß auch eine gewaltigere Arbeit an den Felsen geleistet hatte.

Beide Schluchten boten für Naturforscher viel Interessantes und wurden daher von mir und meinen Mitarbeitern zu wiederholten Malen besucht. Jedesmal nahmen wir große Natureindrücke und interessante wissenschaftliche Beobachtungen mit.

Die Topolkaschlucht ist von beiden Enden zugänglich. Wir wollen sie von ihrem oberen Ende verfolgen, das man von der Straße nach Prilep über den Babunapaß durch eine kurze Wanderung erreichen kann. Im späten Frühling war die Topolka ein schöner tiefer Bach, dessen rasch dahineilendes Wasser schon oberhalb der Schlucht Mühlen trieb. Die Mühlen bei Veles hatten alle Turbinenräder, an dessen senkrechten Achsen sich oben der Mühlstein drehte. Übermäßig sauber ging es in diesen Mühlen nicht $\mathrm{zu}$ und manchem deutschen Soldaten und seinen Angehörigen zuhause haben im wahrsten

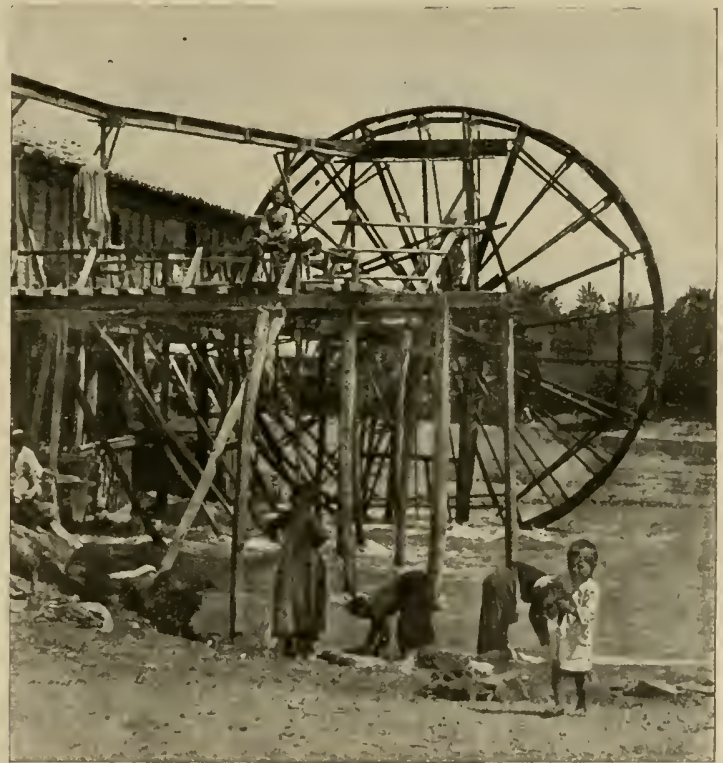

Prof. M ü 11 er phot

Abb. 67. Wasserschöpfrad am Wardar bei Veles. Sinne des Wortes die Zähne geknirscht, wenn sie in dem dunklen Brot aus mazedonischem Mehl auf die Steinchen stießen, die vielleicht schon beim Dreschen zwischen die Körner geraten waren und seither sich eher vermehrt hatten.

Kaum war man von oben in die Schlucht eingetreten, als man erstaunt in fast geschlossenem Raum sich umblickte. Hinter einem ragte ein mächtiger Kalkfelsen wie ein Denkmal mehrere hundert Meter hoch empor. Geröllhalden, von spärlicher Pflanzenwelt bewachsen, zeigten, wie das Wasser gearbeitet hatte, um diese Felsen zu modellieren. Schwer war es gewesen, einen Pfad durch die Schlucht zu schaffen. Aber als Zugang zu den 6-8 Mühlen, 
die in ihr liegen, war er nach allen Zerstörungen durch Hochwasser immer wieder erhalten worden. Wir freuten uns, auf ihm bald dicht an dunkelgrünen Becken tiefen, gurgelnden Wassers dicht entlang zu gehen, bald über hundert Meter emporklimmen zu müssen, um einen brausenden Fall zu umgehen, der weißschäumenden Gischt über rotgelbe Felsen in die Tiefe schleuderte. Die wechselnden, bald grellroten und gelben, braunen und weißen Färbungen der Kalkwände, $z$ wischen denen blaugraue Hänge folgten, gaben der Schlucht einen eigenen Reiz, der mich nie vergessen ließ, daß ich in Mazedonien war. Wie seltsam waren die Gegensätze zwischen einem grellbeleuchteten Felsen, dessen fast wie Metall schimmernden Flanken in unendlichen Zwischentönen flimmerten und dem blauvioletten Schatten eines senkrechten Absturzes, der, ihn einrahmenend, in klares, grünes Wasser sich senkte. Und dessen Oberfläche wieder war reich gegliedert durch die Schaumkronen der Wellen und die vielfachen Reflexe des Himmels auf seinem Spiegel. Und nun gar aus dem Wasser leuchteten die vielfachen Farben der Gesteinstrümmer auf, gebrochen und noch vervielfältigt und mitgenommen durch das strömende Wasser, das in verschiedenen Tiefen über ihnen dahinging.

Wie oft zogen wir hier aus dem Wasser eine der dunkelen Nattern (Tropidonotus natrix persa Pall.), oder die Würfelnatter (T. tesselatus Laur.), die hier so häufig auf die kleinen Fische jagten, welche im ruhigerem Wasser bei den Mühlen oft in Scharen von Hunderten standen.

In vielen Windungen zog sich die Schlucht zum Wardar, ein prachtvolles Bild von großartiger Romantik nach dem anderen bietend, bis sie sich zum Flußtal öffnete, wo gegenüber auf grünem Rasen von Bäumen beschattet das Kloster Sveti Spas, einen friedlichen Gegensatz zu der wilden Felseneinsamkeit bildete; das leise Strömen des Wardar wirkte wie tiefes Schweigen nach dem tollen Brausen und Tosen des Wassers in der Schlucht.

Fast noch großartiger waren die Verhältnisse der Babunaschlucht, welche einige Kilometer südlich von Veles den Wardar erreichte. Sie mußte ich jedesmal von unten durchwandern; denn den oberen Teil bildete eine Klamm, welche man nur bei niederstem Wasserstand durchwaten konnte; ein Weg führte nicht hindurch, da die Felswände senkrecht zum Fluß abfielen. Gerade dort war die eigenartigste Landschaft des Gebietes. 300-400 m stiegen die Felswände fast senkrecht in die Höhe, unten nur von 


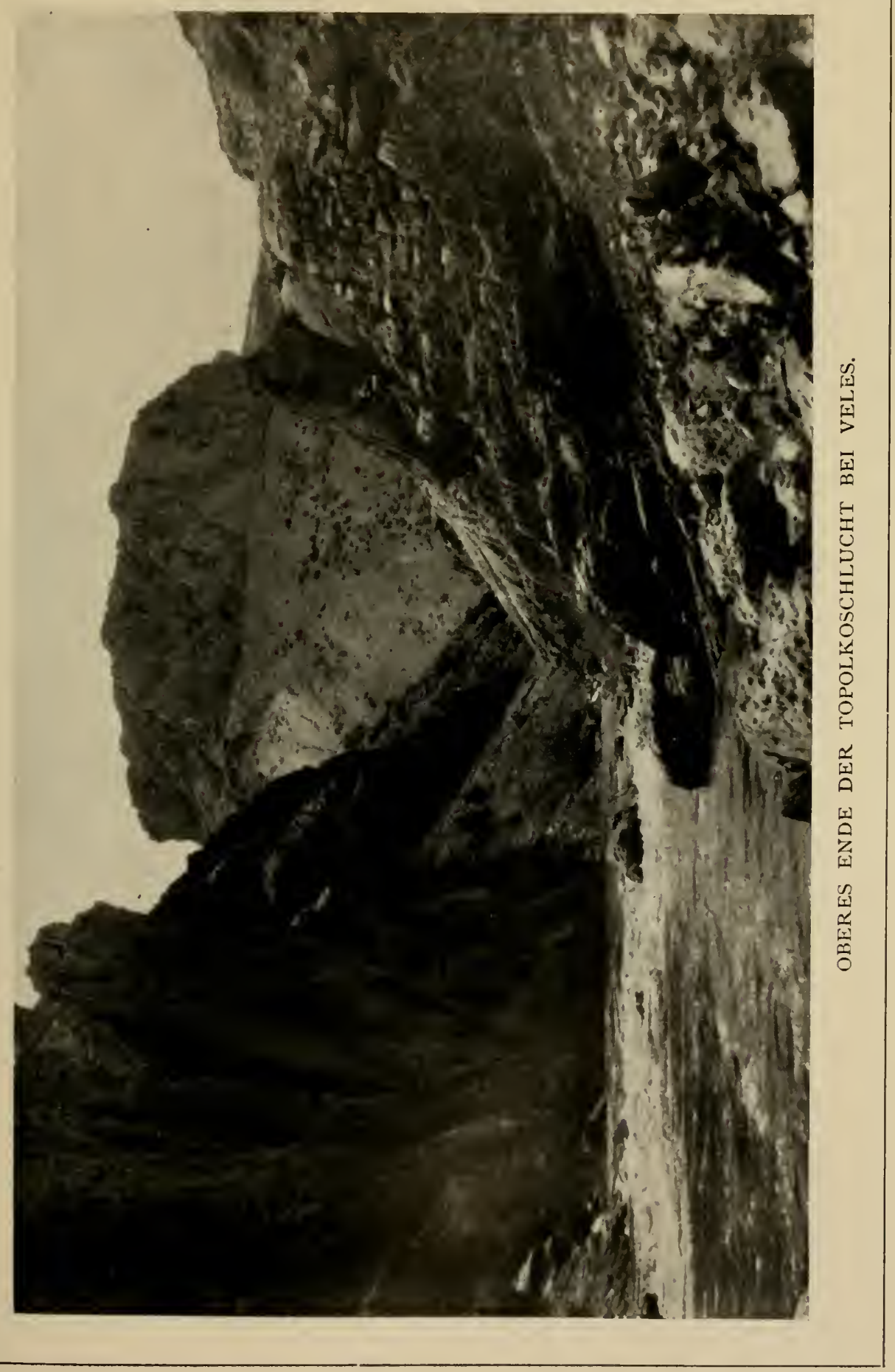



mäßigen Geröllhalden begleitet, welche der Fluß bei Hochwasser stets überflutete.

Auf dem Weg zur Babunamündung kam man am Wardar entlang wandernd an einer kleinen Kapellenruine vorbei, welche im Fluß auf einem vom Wasser umrauschten Felsen stand. Sie bot ein höchst malerisches Bild, mit ihren rötlichen Mauern, besonders im Sommer, wenn sie mit ihrem Felsen von dem grünen Wasser der Wardar umschlossen war.

Zoologisch war der obere Teil der Babunaschlucht besonders interessant. Ehe man die hohen Felsen erreichte, durchwanderte

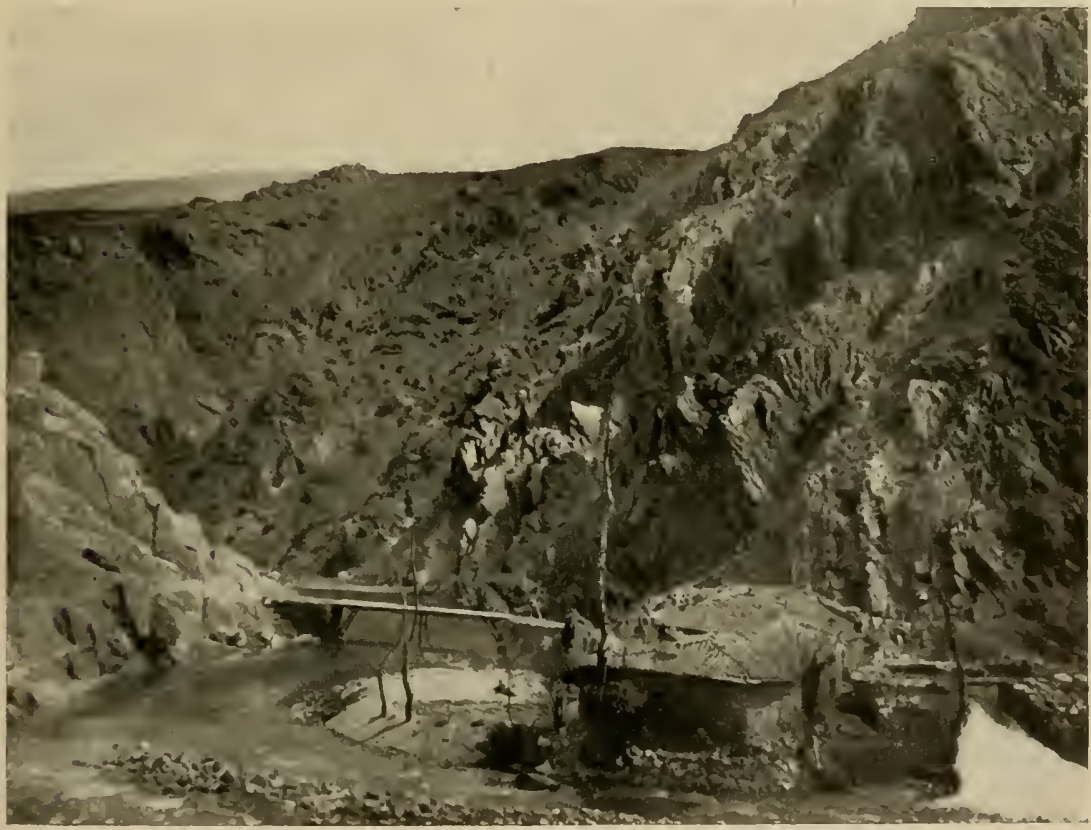

Abb. 68. Mühle in der Topolkaschlucht bei Veles.

man einen Kessel, der fast ringsum abgeschlossen, durch Kalkberge von der Sommersonne zu einer Höllenglut erhitzt werden konnte. I.egte man die Hand an die Felsenwand, so zog man sie erschrocken zurück und glaubte sie verbrannt zu haben. In diesem heißen Gebiet fanden sich unter den Steinen zahlreiche Skorpione und riesige Tausendfüßler. Die Skorpione waren Euscorpius carpathicus L. und Buthus occitamus Amoreux. Hier fingen wir die Giftschlange Vipera ammodytes (L.), die Sandotter, hier lagen auf den 
Felsen große grüne Eidechsen mit blauen Bäuchen (Lacerta major Blgr.), und die flinken Mauereidechsen (Lacerta muralis muralis Laur.) huschten zu Dutzenden umher, auf der Jagd nach der Insektenwelt, die in dem zur Zeit fast pflanzenlosen Gebiet unerklärlich reich erschien. Ein besonders interessanter Fang war dort eine Fliege

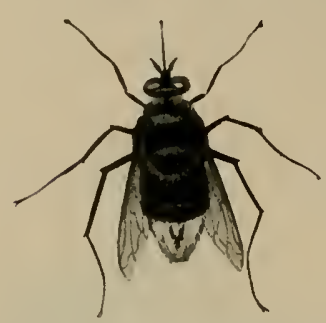

Abb. 69. Hummelfliege. Bombylius analis $\mathrm{Fb}$. (Babunaschlucht). aus der Familie der Bombyliden, die abgebildete Bombylius analis .Eb. mit ihrem schneeweißen Hinterende, das vom tiefschwarzen Körper eigenartig absticht. Sehr geplagt wurde man von Bremsen, besonders dem Tabanus ater Rossi.

In ganz unglaublichen Mengen kam ein kleiner Käfer mit eigenartiger orangegelber Behaarung (Amphicoma vulpes Fabr.) vor. Von Schmetterlingen fielen bei den verschiedenen Besuchen Euchloë groni H. S., ein Verwandter unseres Aurorafalters auf, dessen Männchen am Vorderflügel orange-, am Hinterflügel hellgelb gefärbt ist, während das Weibchen schwarzweiß ist. Übrigens flog dort auch der gewöhnliche Aurorafalter Euchloë cardamines L. Von Bläulingen gab es Lycaena cyllarıs, von Perlmutterfaltern Argynnis pandora Schiff und von den dickköpfigen Hesperiden Allopea lineola Ochs.

Das Überraschendste war aber der Vogelreichtum in den Felswänden; Löcher im Gestein boten reiche Nistgelegenheit, welche vor allem von Felsentauben (Columba livia livia $\mathrm{Gm}$.) ausgenützt wurden. Diese Stammmutter unserer Haustauben brütete dort in Dutzenden von Paaren. Ein Schul trieb Hunderte der Vögel auf, welche einen solchen Schwarm bildeten, daß sie einen deutlichen Schatten auf den Talboden warfen, als sie erschreckt aufflogen. Weiter oben hatte der Schuß stattlichere Gäste zur Erscheinung gebracht. Ein Paar Gänsegeier, dazu mehrere $K$ aiseradler kreisten um die Felsen und die Annahme, daß auch diese da oben brüteten, lag nahe.

Beim Rückmarsch durch das Tal konnte man die in ganz Mazedonien in steinigen Gebieten häufigen Felsenkleiber (Sitta neumayeri neumayeri Michah.) beobachten. Mit seinem blaugrauen Rücken und der weißlichen, rostrot überhauchten Brust ist dieser unruhig auf den Felsen herumlaufende Vogel eine belebende Erscheinung in den Felsenwüsten. Noch eigenartiger ist der Alpen- 
mauerläufer (Tichodroma muraria L.), der mit den hochroten Fahnen seiner Flügelfedern, dem sonst aschgrauen, zerstreut braun-, schwarz- und weißgefleckten Gefieder und seinem eigenartigen Flügelschlag, wenn er an der Felsenwand flattert, einen ganz fremdartigen Eindruck macht.

Weiter unten gegen den Wardar, wo das Tal breiter wird, traten noch Rostschwalben und der am Wasser über die Steine huschende Wasserstar hinzu.

Müde von der Felsenkletterei kehrte man gern in das gastliche Lager des Hauptmanns Jungmann zurück, welches einen weiteren Anziehungspunkt in Veles bedeutete. Draußen, oberhalb der Stadt am Wardar befand sich ein großes Etappenlager als Basis

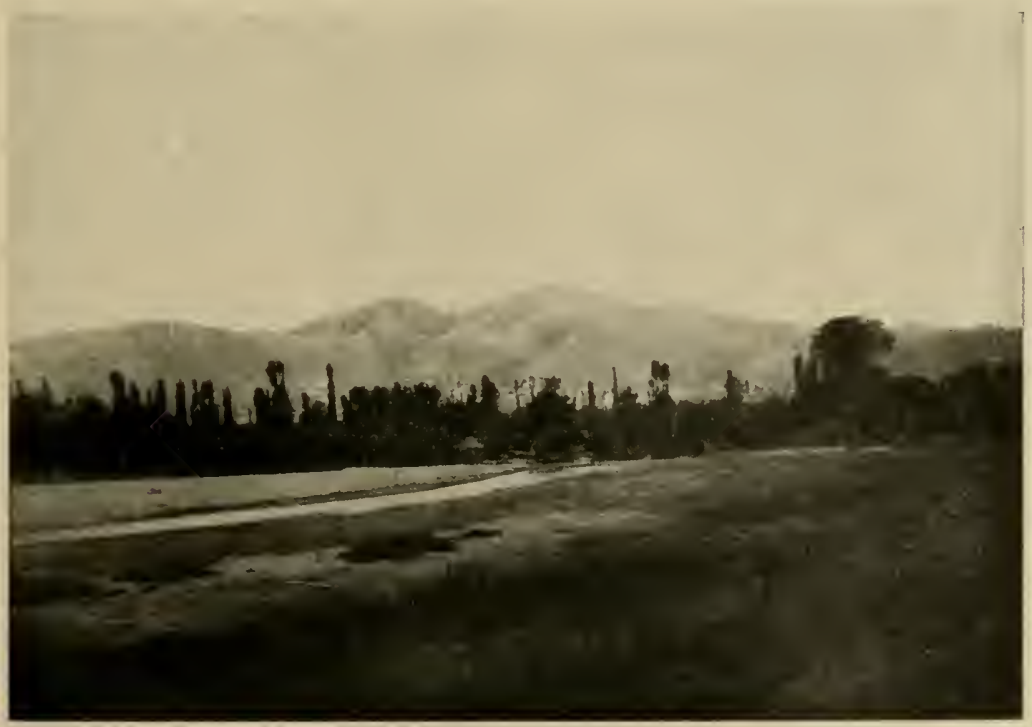

Abb. 70. Pappelhain am Wardar. Im Hintergrund Veles und seine Felsenberge.

für die Babunastraße. Dort hatte der Hauptmann eine kleine Hütte, in der man gastliche Aufnahme fand. Vor dieser Hütte war ein behaglicher Platz zum Sitzen, von dem aus man einen ganz eigenartigen, besonderen Blick auf die Stadt Veles genoß.

Vorn wälzte der Wardar an einem solchen Abend seine hochgeschwellten, trüben Fluten dahin. Von dem gelben Wasser hob sich jenseits ein Wald von Pappeln, Erlen und alten Ulmen ab. Es war eine Wildnis, die sich da längs des Flusses ausdehnte. Vor dem Dunkel der Bäume hoben sich zierlich die hohen Wasser. 
schöpfräder ab. Als es zu dämmern begann, bildete der Baumbestand eine fein umrissene dunkele Silhouette vor den Häusermassen der Stadt, die im Glanz der Abendsonne aufglühten. Klar und scharf standen dahinter die kahlen, dürren Berge mit ihrer schönen Umrißlinie. An ihren Flanken sah man die Stadt sich hinschmiegen. Tiefe Schatten fielen auf die Wände der Schluchten, ihre von Wind und Wetter verarbeiteten Formen traten in wundervoller Klarheit hervor. Von Süden zog eine Gewitterwolke heran, die den hellen Himmel allmählich verdunkelte. Die Stadt selbst glühte immer mehr auf in den Strahlen der scheidenden Sonne, welche unter der Wolkenbank sie erreichten. Einzelne Fenster sandten feurige Blitze herüber. Die aus den Wolken fallenden Regentropfen, welche in ihrer Spärlichkeit den dürstenden Boden nicht erreichten, genügten doch, um einen strahlenden Regenbogen zu erzeugen, der sich wie ein festlicher Schmuck in hohem Bogen über die leuchtende Stadt und die dämmernden Berge schwang. In diesem köstlichen Rahmen steigt wie eine Traumvision noch manchmal das Bild der Stadt Veles in meiner Erinnerung auf. 


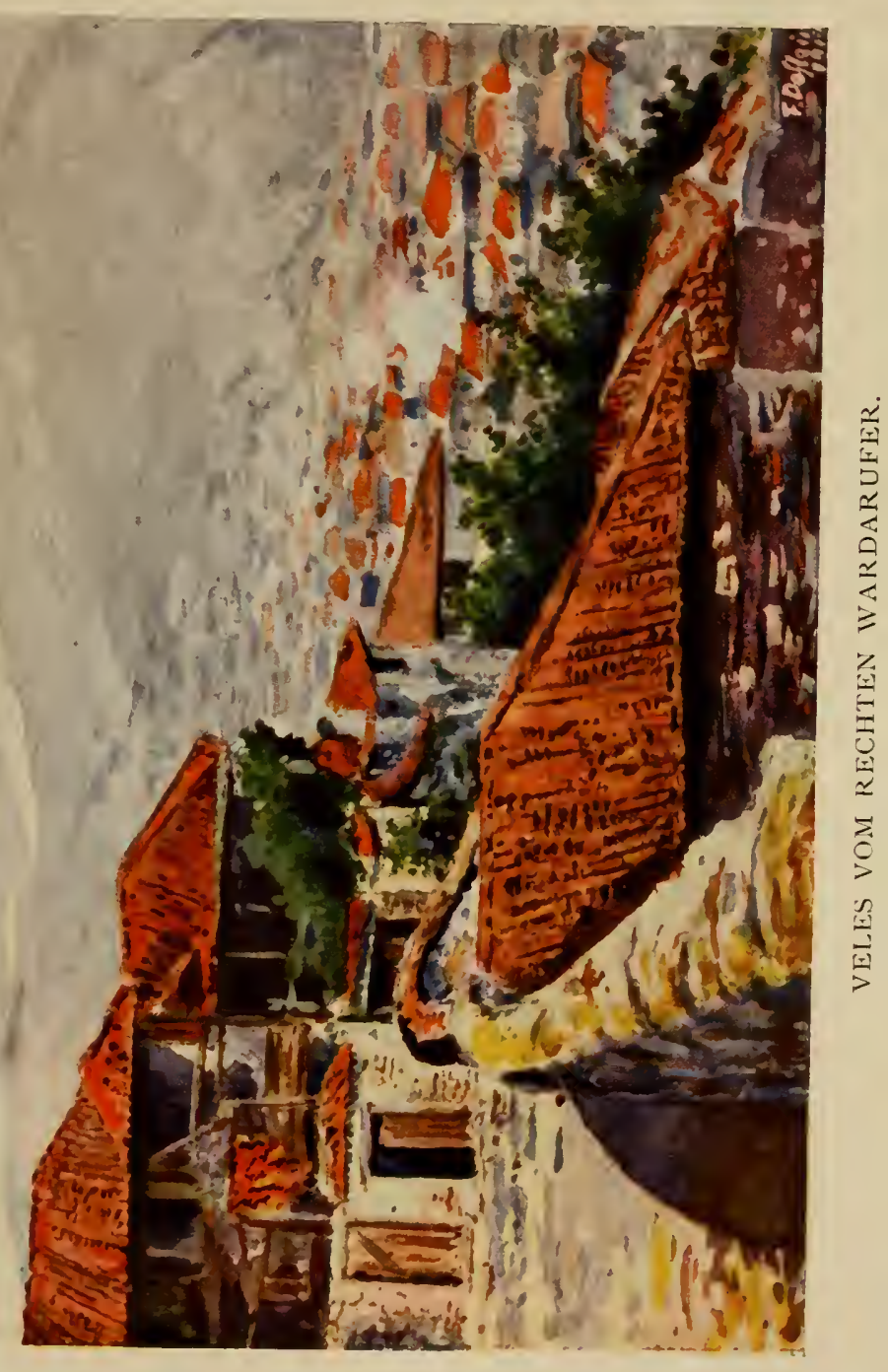





\section{ÀM DOIRANSEE}

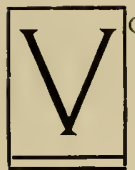

om Doiransee wurde beim mazedonischen Heer viel erzählt. An seinen Ufern wurde im Frühjahr I 917 hart gekämpft. Sein blauer Spiegel sei wundersam von der braungelben Landschaft eingerahmt; reizvoll spiegle sich die weiße Stadt Do ir a n in seinem Wasser. So faßte mich denn Sehnsucht, den schönen See zu sehen. Auch für den Naturforscher mußte er Interessantes versprechen. Ein großer See im Binnenland, der kaum erforscht war, mußte eine eigenartige Tierwelt beherbergen.

Ich plante eine Expedition zum See, stieß aber sogleich auf viele Schwierigkeiten. Es war ja Krieg, und wie bei den anderen großen mazedonischen Seen, so ging auch hier die Front mitten durch den See. Die Ufer wurden viel beschossen und jedes Schiff, welches sich hinauswagte, wurde mit Schrapnells und Granaten bedeckt. Aber so gut unsere Soldaten es am See jetzt seit Jahren aushielten, so gut mußte es für den Naturforscher möglich sein, dort seine Arbeit zu tun.

Der Plan wurde ausgearbeitet und fand bei den militärischen Behörden Verständnis und tatkräftige Unterstützung. Da bei Tag jedes Boot von den gut eingeschossenen englischen Batterien unter Feuer genommen wurde, konnte ein Versuch nur nachts unternommen werden. Militärische Hilfe war notwendig, alle deutschen und bulgarischen Posten und Batterien mußten verständigt werden, damit nicht das Feuer unserer Truppen sich auf uns richtete.

Unsere Fahrt war in allen Einzelheiten aufs sorgfältigste vorbereitet und alles klappte prachtvoll. Am Abend des 8. Juli 1917 kam es zum ersten Besuche des Doiransees. Zwei Tage vorher waren meine Netze, Planktonapparate, Thermometer und sonstigen Instrumente aus Deutschland angekommen. Gute Hilfe leisteten mir wissenschaftliche Kollegen, welche als Offiziere bei den deutschen Truppen der 1. Bulgarischen Armee standen. Einer von ihnen, einer meiner alten Schüler, Hauptmann Frischholz, befehligte einen Pionierpark im Wardartal. Von ihm hatte ich schon manche 
Hilfe erfahren. Er begleitete mich auf der Doiranfahrt und übernahm die militärische Führung. Angeschlossen hatte sich noch der Münchener Geologe Dr. Leuchs, der als Kriegsgeologe im Gebiet tätig war.

Abends nahm uns am Bahnhof in Dedeli ein Auto des A.O.K. auf und brachte uns rasch über den Furkapaß durch das Tal von Cerniste in die Nähe des Sees. Ein rotgoldener Abendhimmel überstrahlte das westlich vom See gelegene Gebiet des Dub und der angrenzenden Berge, als wir uns in ihrem Schatten dem See näherten. Vorsichtig mußten wir die im Schußbereich der feindlichen Artillerie liegende Straße benützen. Vorsicht hieß rasch fahren und etwas riskieren. Es dunkelte schon, als ein Reiter uns empfing und uns durch die Granattrichter die Straße entlang soweit geleitete, als Fahren möglich und erlaubt war. Der Spiegel des Sees blinkte auf, als wir aus dem Wagen stiegen, um zu Fuß in einer Wanderung von wenig Kilometern das Boot zu erreichen. Viel konnte man hier vom See nicht erkennen. Denn das ganze Nordufer und ein großer Teil des Westufers sind flach; ein breiter Schilfgürtel faßt hier den See ein. Der Abendwind rauschte in den Binsen, leise plätscherten die Wellen, während wir bei steigender Dunkelheit nach dem Boot suchten. Es lag versteckt im Schilf nahe bei der Stadt Doiran.

Schon war es vollkommen dunkel, als wir den auf uns wartenden Pionierponton fanden; in der Finsternis leiteten uns das leise Rasseln der Ketten und die Stöße der Ruder am metallenen Rumpf des Bootes. Deutsche Pioniere nahmen uns auf und ruderten langsam seewärts. Es war nicht einfach, in der dunklen Nacht durch den mehrere hundert Meter breiten Schilfwald den Weg zu finden. Aber unsere Soldaten - sie waren meist von Beruf Fischer und Seeleute - kannten sich im Gebiet gut aus und brachten uns bald aufs freie Wasser hinaus.

Dunkelheit umfing uns, als wir aus dem krachenden Schilf auf die Fläche des Sees hinausglitten. Leise mußten die Ruder eingetaucht werden; denn weit tönte der Schall über das Wasser. Wir machten unsere Apparate bereit, brachten die Seile und Schnüre in Ordnung. Hauptmann Frischholz warnte vor Benutzung der Taschenlaternen, um den Feind nicht auf uns aufmerksam zu machen. Am dunklen Himmel strahlten die Sterne stark und schön in der warmen Julinacht; manche warfen einen blinkenden Streifen über die Wellen. Drüben am feindlichen Ufer 
blitzten Lichter auf, roter Rauch von Lagerfeuern stieg in die Höhe. Leise fuhr unser Boot über dem schwarzen, leise gurgelnden Wasser. Es war eine eigenartige Empfindung, so einsam, fern von allen Menschen, als Einzige auf dem dunklen See zu treiben.

Wir hatten nicht Zeit uns lange Stimmungen hinzugeben. Wir mußten rasch unsere Arbeiten erledigen, um nicht das Leben deutscher Soldaten zwecklos zu gefährden. Unsere Thermometer wurden in verschiedene Tiefen gesenkt, die Temperaturen gemessen. Währenddessen wurde gelotet und unsere Planktonnetze schwebten im klaren Wasser. Unter dem Kommando Frischholz' bewegte sich das Boot gewandt und zweckentsprechend. In kurzer Zeit konnte ich alle gewünschten Untersuchungen durchführen. In den Glasgefäßen hatte sich wohl eine vielgestaltige Welt von Planktontieren angesammelt, die wir nur ahnten, noch nicht feststellen konnten. Denn der Hauptmann gestattete nur sekundenlange Lichtblitze aus den Taschenlampen zum Ablesen der Uhren, zur Überwachung der Apparate, der Netze, der Seile und Drähte.

Unter langsamen Ruderschlägen hatte das Boot mehrere Kreise in der Mitte des Sees gefahren. Währenddessen hatten wir die vorgenommenen Untersuchungen erledigt und der Hauptmann mahnte in seiner großen Gewissenhaftigkeit zur Rückkehr zum Ufer.

Mittlerweile waren die Berge am jenseitigen östlichen Ufer allmählich deutlicher geworden. Ein zarter goldner Schein begann am ,Himmel hinter ihnen emporzusteigen und ließ ihre Umrisse scharf hervortreten. Der Mond nahte hinter ihnen und mußte bald seine Strahlen über die Fläche des Sees werfen.

Wir wandten uns zum Ufer und die Pioniere zogen die Riemen kräftig an. Mit dumpfem Gerumpel drehte sich das Boot. Hatte dies Geräusch zu stark über den See geschallt oder war doch vorher unser Lichtblinken beobachtet worden, plötzlich blitzten die beiden englischen Scheinwerfer am jenseitigen Ufer auf und warfen breite Lichtbahnen über den See. Einige Schüsse krachten, Maschinengewehrfeuer, weckte das Echo der Berge.

Dann war es wieder dunkel. Die Pioniere legten sich fest in die Ruder, unser schweres Boot rollte gurgelnd über den Wellen und bald strich es prasselnd durch einzelne Schilfgruppen, die vor dem eigentlichen Schilfwald aufragten. Wir suchten in der Dunkelheit lange nach den Gassen, die den Schiffern vertraut waren. Es war nicht leicht, in der Nacht in der gleichmäßigen Schilfwand 
die richtige Einfahrt aufzufinden. Schließlich fuhren wir in eine Gasse ein und hielten aufs Ufer zu. Bald schloß sich aber der Weg, wir gerieten in dichtes Schilf, das rauschend und knisternd vor unserem Boot sich bog und brach und sich schließlich so verfilzte, daß unser Boot umklammert und festgehalten wurde. Wir steckten fest im Schilf und es kostete starke Arbeit bis wir uns wieder freigemacht hatten. Nun fuhren wir weiter durch das dicke Schilf, in dem es keinen Durchblick und keinen Überblick gab. Hoch ragten die Schilfhalme, etwa $3 \mathrm{~m}$ lang, über unsere Köpfe, selbst wenn wir uns auf Kisten und. Eimer stellten und hoch emporreckteu. Wir kamen durch mehrere offene Stellen im Schilf, die wie stille Weiher aussahen. Sie waren aber selbst wieder vom Schilfwald umgeben, in den wir immer wieder eindrangen, um noch mehrmals hängen zu bleiben. Plötzlich saßen wir auf einer Sandbank fest.

Un uns immer das eintönige Rascheln des Schilfes, das Säuseln des Nachtwindes in seinen Halmen. Es wurde etwas unheimlich in der dunklen Nacht in dieser Wirrnis der Pflanzen. Hatten wir auch nicht die Richtung verloren, gerieten wir nicht in das Gebiet der Engländer?

Mit kräftigem Entschluß befahl schließlich der Hauptmann wieder aus dem Schilfwald herauszurudern. Wir kamen durch, bohrten uns bis an seinen Rand zum offenen Wasser und ruderten nun am Schilf entlang bis zu einer neuen Straße, die durch einen verfallenen Pfahlbau gekennzeichnet, unsere Schiffer zu einem bekannten Landungsplatz führte. Wir waren etwas weiter nach Norden, also weg von den Engländern ans Land gekommen.

Wir kletterten am Ufer hinauf; vorsichtig luden wir Instrumente und Netze sowie die Gläser mit der kostbaren Ausbeute aus. Wir standen im tiefen Dunkel, in für uns alle unbekanntem Land, als das Rauschen im Schilf wieder anhob und uns verriet, daß unsere getreue Schiffmannschaft ohne Abschied, ohne unseren Dank abzuwarten, in der Nacht verschwunden war.

Wir fanden aber bald die uns bekannte, am See entlang laufende Landstraße, die uns orientierte. Nun hätten wir in mehrstündigem Marsch zu Quartieren gelangen hönnen, um dort den Rest der Nacht zu verbringen. Ich hatte aber die Absicht, den nächsten Tag noch am Ufer des Doriansees zu verbringen und weitere Untersuchungen $\mathrm{zu}$ machen. So stiegen wir seitlich vom See einen Hügel hinan, um in einiger Entfernung von der Straße 
uns zwischen Büschen ein Nachtlager zu suchen. Wir hatten außer unseren Apparaten keinerlei Gepäck bei uns. In der lauen Julinacht konnten wir ohne Scheu am Boden im Gras schlafen. Wir wanderten aber einige hundert Meter über die Straße bergauf, weil wir wußten, daß jene nachts regelmäßig mit schwerem Geschütz beschossen wurde, da sie die einzige Etappenverbindung für unsere Truppen in der Doiranstellung darstellte.

Unterhalb Kara Oglular fanden wir eine mit Büschen der Stacheleiche bedeckte Mulde, die wir uns als Nachtquartier erwählten. Kaum waren wir angelangt, so wurden beim Schein der Taschenlampen die Planktonfänge geprüft, die nötigen Konservierungen vorgenommen und der mitgebrachte Proviant verzehrt.

In den Gläsern fand sich ein Gewimmel von durchsichtigen glitzernden Planktontieren. Beim unsicheren Licht der Taschenlampen konnte man gerade noch erkennen, dal Copepoden und Daphniden im Wasser schwirrten, ja ich glaubte schon, einen größeren Planktonkrebs zu sehen, der sich dann später tatsächlich als eine interessante Form, als eine Verwandte der Leptodora des Bodensees erweisen ließ.

Müde legten wir uns dann am Boden nieder, um einige Stunden zu schlafen. Leuchtkäfer leuchteten zwischen den Gräsern und schwirten durch die Luft, als wir in Gruben uns schmiegten, um uns vor dem aufkommenden Seewind zu decken. Wir kamen aber nicht zum Schlafen, denn wir wurden alsbald von Mückenschwärmen umsummt, die sich in Massen auf unsere Gesichter und Hände niederließen. Das mußte uns beunruhigen, denn wir alle wußten, daß die Ufer des Doiransees zu den schlimmsten Malariagegenden des Kriegsschauplatzes gehörten. Natürlich glaubten wir, von den gefährlichen Malariamücken, den Anopheles, umschwärmt zu sein.

Am Morgen konnte ich feststellen, daß unsere Sorge umsonst war. Denn ich fand, als es hell wurde, daß die dichten Mückenschwärme von einer harmlosen nicht stechenden Federmücke aus der Gattung Chironomus gebildet wurden. Ihre Larven erfüllten in Massen das Uferwasser des Doiransees und selbst im nachts gefischten Plankton aus der Mitte des Sees waren sie zahlreich vertreten.

Wir nahmen nun alle pflichtgemäß unsere bis dahin unter den starken Eindrücken vergessene Chinindosis und bewegten uns etwas weiter bergauf. Und das hatten wir nicht zu bereuen; mittlerweile war der Mond aufgegangen und beleuchtete den See 
und die umgebenden Berge mit seinem silbernen Licht. Er kam spät herauf, da er im Abnehmen begriffen war. Dem hatten wir unsere ungestörte Kreuzfahrt im Dunkeln zu verdanken. Jetzt aber genoß ich mit meinen Begleitern das wundervolle Landschaftsbild, welches das Licht des Mondes vor unseren Augen enthüllte.

Von unserem Standpunkt hatten wir den ganzen ovalen See vor uns ausgebreitet; nur zur Rechten verdeckten die Berge die Stadt Doiran und einen Teil des Südendes des Strandes. Auf dem leichtbewegten Spiegel des Sees blinkelten die Silberreflexe des Mondes, eine breite Bahn von den Feinden zu uns herüberziehend. Die schöngeformten Berge jenseits waren von einem feinen blauen Licht durchleuchtet; leichte Nebel hoben sich über dem sumpfigen Nordrande des Sees.

Am Abhang liegend, freuten wir uns des schönen Bildes; aber Ruhe zum Schlafen bekamen wir nicht. Mit dem steigenden Mond hatte sich auch eine starke Beschiefung mit schweren Kalibern von feindlichen Geschützen erhoben, welche der Seestraße galt. Wir waren ganz froh, daß wir unsere Schlafgruben, von den Mücken verjagt, im Stich gelassen hatten, denn im Mondschein erkannten wir sie als Granattrichter von früheren Beschießungen, sahen auch nahe die spärlichen Reste eines zusammengeschossenen Dorfes.

Bald nahmen die deutschen schweren Batterien das Duell auf und hoch über uns brummten und schwirrten die schweren Granaten herüber und hinüber, während wir in Ruhe den schimmernden See bewunderten.

So kamen wir kaum zum Schlaf und setzten uns im dämmernden Morgen gegen 4 Uhr in Bewegung, um den Nordrand des Sees zu umwandern. Dabei waren wir immer noch von dichten Schwärmen der Federmücken umgeben, die auf unsere Uniformen niederfielen, in die Ärmel und den Hals rutschten und uns unangenehm belästigten. Viele Millionen der Tiere schwirrten in der Luft, und mehr noch schwammen als Larven und Puppen im Wasser des Sees.

Es war ein dunstiger Morgen, während wir durch ein flaches Buschland wanderten, hinter welchem niedere stark zerrissene, dürre Hügel emporstiegen; als wir weiter nach Osten am Nordrand des Sees hinwanderten, stiegen im Norden blaue Berge vor uns auf, die wenig charakteristischen Gipfel der Belasiza Planina. Wir liefen soweit nach Osten, bis wir in einem tiefeingeschnittenen 
Tal, das ostwärts zog, die Gräben bei dem Ort Brest erkannten. Hier reichte die feindliche Front weit nach Norden, während sie am Westufer des Sees nur dessen südlichen Rand erreichte. Da sahen wir wirklich weißleuchtend die Stadt Doiran am Strand sich erheben und im blauen Wasser des Sees sich spiegeln. Man konnte meinen, große Paläste und zierliche Villen dort stehen zu sehen. Leider aber wußten wir, daß die Stadt ganz zerschossen und von der Bevölkerung verlassen war. Eine reizvolle und malerische Stadt mul3 es einst gewesen sein; das beweisen die Photographien aus der Stadt, die ich von befreundeter Seite erhielt.

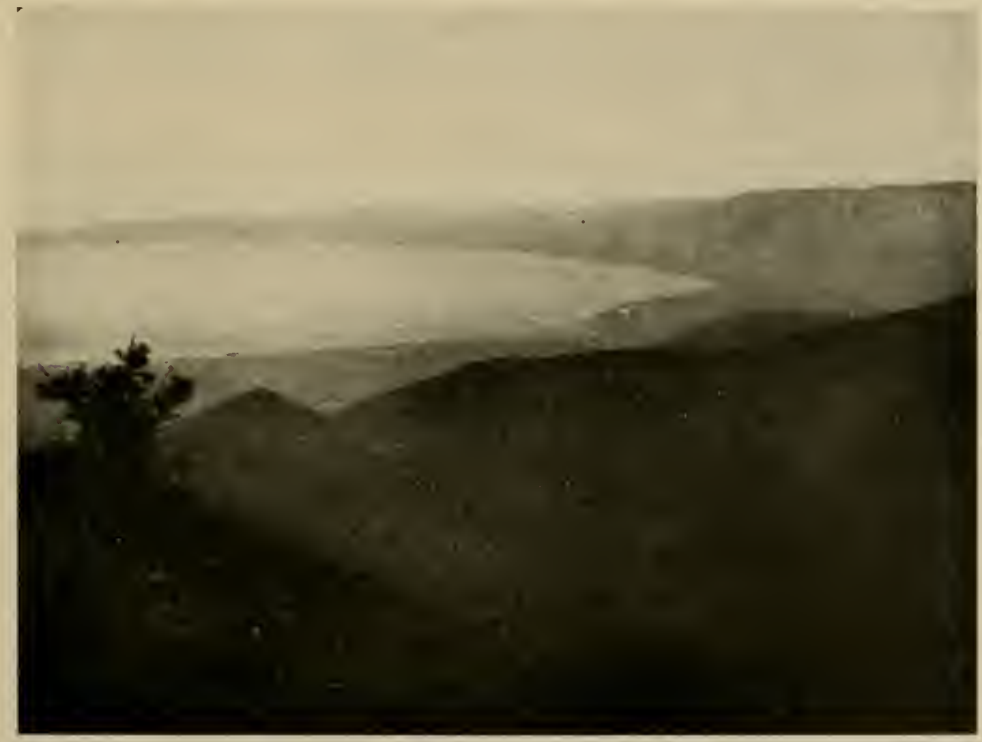

Abb. 7 ז. Doiransee aus der Artilleriestellung in der Belasiza Planina.

Nördlich der Stadt fallen Felsenufer steil zum See ab, während sonst die Ufer am ganzen See ziemlich flach sind.

In den ersten Morgenstunden, solange Dunst und Nebel die Fernsicht behinderten, durchstreifte ich mit dem Insektensammler Rangnow die Fläche, die sich zwischen dem See und den Hügeln ausdehnt. Es ist ein dürres Gelände, zum Teil Schwemnland und ist von einem kleinen Bach durchströmt, der in den Doiransee mündet. Die Umgebung war enttäuschend kahl und reizlos. Fast nur Stacheleichen und der gefürchtete Judendorn bildeten Buschgruppen, die zerstreut auf dem gelben zerissenen 
Boden wuchsen. Dazwischen ragten mächtige Disteln mit purpurroten Blüten empor. Niederes Brombeergestrüpp hinderte überall das Weiterkommen. Größere Bäume, meist Ulmen, erhoben sich nur am Bachufer und vereinzelt in dem Sumpf, der an den See grenzte. Es waren dies auffallend stattliche alte Baumriesen.

Eigenartig wirkte der breite saftgrüne Sumpfstreifen vor dem leuchtend blauen See; die beiden grellen Farbflecken waren harmonisch verbunden durch den grauen Schilf, der zwischen ihnen sich weit in den Sumpf erstreckte; am äußeren Rand vermischten sich graugrün und blau, indem der Schilfbestand wie eine feine Tüpfelung sich im blauen Wasser auflöste. Man konnte durch den Schilf nicht ans Wasser gelangen und unsere schönen Pläne, im See ein erfrischendes Bad zu nehmen, konnten nicht zur Ausführung kommen.

Die Sonne stieg höher, die Ferne wurde klarer. Hauptmann Frischholz wünschte, daß wir uns nicht mehr am Seeufer zeigten, da erfahrungsgemäß selbst kleine Menschengruppen Beschießung auf sich zogen. Ich war gerne bereit auf die Hügel zu steigen, da das Seeufer wenig zoologische Ausbeute versprach. Am Bach hatte ich große Flüge von Libellen beobachtet, die auch über dem Schilf flogen und eifrig die Federmücken fingen. Heuschrecken in verschiedenen Larvenstadien hüpften in Sumpfgras.

Als wir den Hügeln zuwanderten, bemerkte ich hunderte von Schnecken, Vertreter einer Helix-Art, welche in gedeckeltem Zustand an den dürren Gräsern hingen, schon im Sommerschlaf versenkt. Wir marschierten in glühender Hitze vom See weg, setzten uns am Hügelrand in den Schatten eines einsamen Baumes und ließen uns von unserem Geologen erzählen, was er sich von der Entstehung dieses Seebeckens dachte.

Der See lag blinkend in der glühenden Mittagssonne vor uns. Tiefblaue Streifen wechselten mit breiten, wie Quecksilber schimmernden Bändern. Besonders im Süden zeigten die Berge einen rötlichen Schimmer.

Herr Dr. Leuchs war der Meinung, der Doiransee sei früher viel größer gewesen; er vermutete einen früheren Abfluß nach Osten über das flache Tal bei Brest und eine Verbindung mit der Struma. Diese Verbindung sei später gesperrt worden, indem Gerölle von der Belasiza Planina das Tal auffüllten. Der See habe einen neuen Abfluß nach Süden gewonnen, der jetzt bei dem Bahnhof Doiran austritt und eine Verbindung mit dem Ardzansee 
herstellt. Er meinte, der See sei früher ein viel grölueres Becken gewesen, habe sich weit in das Tal von Cerniste gegen Nordwesten erstreckt und sei wohl, den südlichen Seen vergleichbar, eine Lagune, wenn nicht ein Meeresabschnitt gewesen.

Unsere zoologischen Beobachtungen an der Seefauna ergaben keine Belege für eine solche Annahme einstigen Zusammenhangs mit dem Meere.

Wir mußten nachmittags die Gegend des Sees verlassen, um den Treffpunkt zu erreichen, an welchem das Auto uns abends wieder abholen sollte. Es war ein glühend heißer Tag geworden und der Marsch, bei welchem wir die Instrumente und Netze tragen mußten, war sehr anstrengend. Es war einer der Tage, an denen die Schattentemperatur auf $40^{\circ} \mathrm{C}$ stieg.

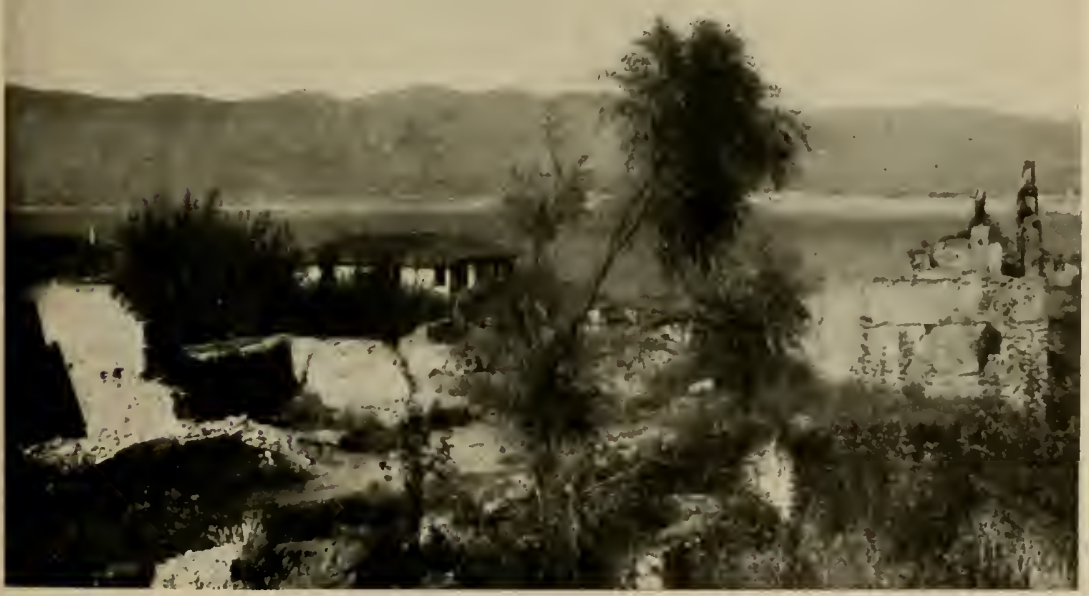

Flieger-Abr. 34 phot.

Abb. 72. Blick aus der Stadt Doiran auf den See.

Während wir am Nordrande des Sees entlang marschierten, begann eine starke Beschielung der Stadt Doiran und unserer südlich von hier sich hinziehenden Stellungen. Dort lagen bulgarische Truppen der I. Armee, welche sich sehr gut schlugen und deren tapfere Verteidigung der Doiranfront immer sehr anerkannt wurde. Schweres Geschütz der Engländer begann ein regelmäßiges Feuer 
auf die Stadt Doiran und die Stellungen. Mächtige Rauchsäulen stiegen in regelmäßigen Abständen auf und verrieten die Einschlagstellen. Bei der geringeı Entfernung -- der Nord-Süd-Durchmesser des Sees mißt $8 \mathrm{~km}$ - konnte man die Beschießung gut über den See hinweg verfolgen.

Wir sahen die weiße Stadt über dem dunkelblauen Wasser aufragen, den gelbgrauen Berg hinansteigend, seinen Falten angeschmiegt. Wir konnten in die Straßen hineinblicken, erkannten am Strand große Lagerhäuser, grüne Baumgruppen dahinter und aus dem Gewirre der Mauern tauchten zwei Minarets und der Turm einer christlichen Kirche auf. Was wir aber aus der Ferne

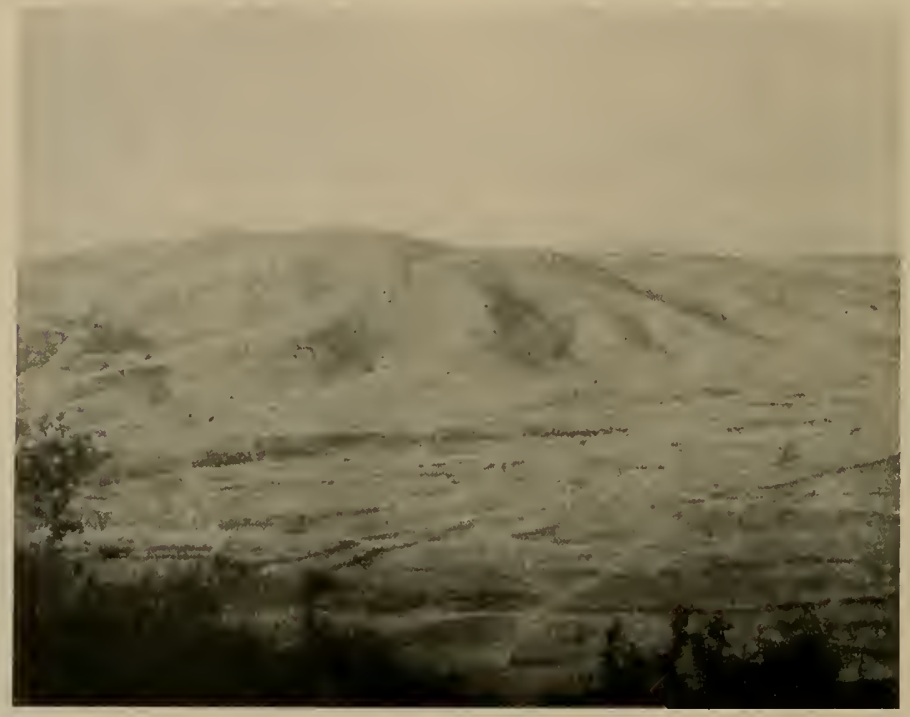

Abb. 73. Hügel bei Cerniste mit typischen Erosionsschluchten.

nicht sehen konnten, waren die fürchterlichen Zerstörungen des Krieges, welche die Stadt, die uns so wohlerhalten schien, zu einem Trümmerhaufen machten.

Granate auf Granate fiel ein; es war ein großer Tag am Doiransee. Rauch- und Staubsäulen fuhren hoch in die Lüfte und hielten sich bei der mittäglichen Windstille lange in der Höhe, so daß man den Zug der Schützengräben und Verhaue aus ihnen entnehmen konnte.

Während dieses Schlachtgetöses marschierten wir schwitzend und seufzend mit unseren Lasten durch die Gluthitze des Julitages 
am Nordrand des Sees entlang. Unsern Marsch richteten wir, wenn es irgendwie möglich war, auf einen der wenigen Bäume, die in der kahlen Landschaft noch aufragten. In dem kargen Schatten dieser Bäume rasteten wir mehrmals. Wir kamen durch die geringen Reste eines ehemaligen Ortes Hasanli, der einer Bewegung der Front einmal zum Opfer gefallen war. Wie ein Fabrikschornstein ragte der Rest eines Minarets aus dem Trümmerhaufen empor. Einige Kilometer weiter fanden wir den letzten Schattenbaum auf dieser Strecke und lagerten unter ihm und wollten dort ruhen bis gegen Abend, da wir nicht mehr allzuweit vom Treffpunkt für das Auto entfernt waren. Wir hatten uns vom See entfernt, Hügel hatten sich zwischen uns und ihn gelegt. Dreieckig abgeschnitten sahen wir seine blaue Fläche aus dem dürren, gelbbraunen Lande aufleuchten.

Zur Ruhe sollten wir aber im Schatten des Baumes nicht kommen. Fliegergeschwader erschienen in der Luft und kämpften miteinander. Abwehrbatterien feuerten von verschiedenen Bergsätteln. Der blaue Himmel war mit zahllosen Schrapnellwölkchen gefleckt. Es war ein großer Kampftag in Mazedonien.

Die schweren Geschütze begannen ein Duell. Die Engländer schossen mit ihren Langrohren über den ganzen See hinüber. Heulend flogen die schweren Granaten hoch oben durch die Bläue des Himmels über Wasser und Berge und schlugen uns gegenüber an den Hängen des Kala Tepe $(608 \mathrm{~m})$ und des Dub (695 m) ein. Diese kahlen Berge trugen deutsche und bulgarische Stellungen. Wir konnten von unserem Rastplatz von hinten in sie hineinsehen.

Von dort antwortete eine unserer schweren Batterien, welche im Steilfeuer mächtige Granaten über den See zu den Engländern warfen. Auf diese Batterien hatten es offenbar die Engländer abgesehen. Immer wieder strichen ihre Flieger über sie hin. Immer wieder suchten die Einschläge der Granaten sie ab. Für uns war es ein behagliches Gefühl zu beobachten, wie die Engländer immer um einige hundert Meter zu kurz schossen.

Ich achtete aber bald nicht mehr auf diesen Kampf der Menschen; ich hörte bald das Schießen der Kanonen nicht mehr vor einem anderen Getön, das die Luft erfüllte und sie in eigentümlicher Weise erschütterte. Das Brausen und Summen rührte von einer riesigen Menge von Zikaden her, welche heute ihren 
Hochzeitstag hatten. Es war eine große, silbergraue Zikadenart (Cicada plebeja Scop.), von denen viele Tausende an diesem heißen Julitag um den Doiransee versammelt waren. In allen Büschen, an allen Pfählen und Stämmen saßen sie und ließen ihren eigenartigen Gesang erschallen. Schon in den Tropen, in Japan, in Italien hatte ich den Gesang der Zikaden genossen und bestaunt. In der Tropennacht mischte sich die Stimme der Zikaden mit mancherlei anderen Tönen, dort auch zu einer eigenartigen und höchst reizvollen Symphonie ihren Beitrag liefernd.

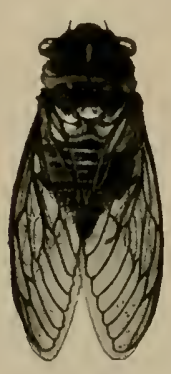

$a$
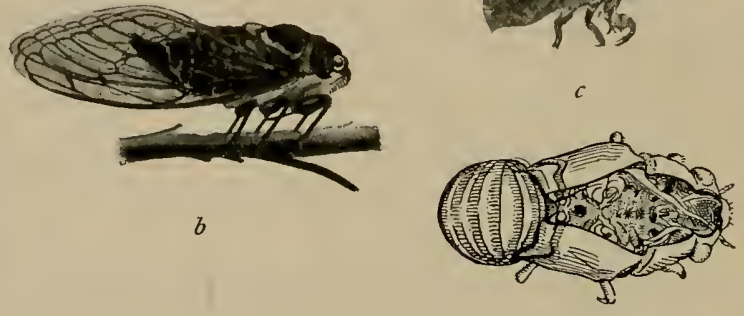

$d$

Abb. $74 a-d$. Cicada plebeja Scop. Große graue Zikade. $a$ von oben, $b$ von der Seite, $c$ Larve, $d$ Nymphenhaut, aus der das fertige Insekt durch den Rückenschlitz ausgeschlüpft ist. Verkl. $3 / 5$.

Aber so wie hier im heißen Sonnenlicht des mazedonischen Nachmittags hatte der Zikadengesang niemals auf mich gewirkt. Hier wetteiferte er nur mit dem Getöse der Geschütze. Und er siegte über ihn. Wie ein gewaltiger Orgelton quoll das Unisono von tausenden von Zikadenpaaren in die heiße zitternde Luft, hob sich in die Höhe und flog in Wellen mir ins Ohr.

Der Gesang der Einzelzikade ist ein grelles Titititititi; oft klingt es wie das Trillern einer Zugführerpfeife. Es gibt aber unendliche Nüancen der Tonhöhe, des Tempos, der Stärke. So entsteht ein polyphones Gebrause, wie von einem mächtigen modernen Orchester, wirkt auf den Menschen ein und erregt seine Nerven. Das Zirpen der einzelnen Zikade mag grell und unschön klingen. Hier im ungeheuer großen Chor vereinigte es sich zu einem Brausen wie Orgelklang, das schön und eigenartig musikalisch wirkte. Es mag sein, daß der rasche Wechsel sehr wenig voneinander verschiedener Töne, die in unendlicher Mannigfaltigkeit auf das Gehörorgan einbrausen, eine ähnliche Wirkung ausübt, wie im großen modernen Orchester. 
Mag das sein wie es will; mag dies Tongewimmel auf den einen Menschen so wirken, auf den anderen anders, die Wirkung auf die Zikaden selbst, die das Konzert erzeugten, war ganz einheitlich. Es war das Liebesfest, der Hochzeitstag der Zikaden; es waren ihre Saturnalien, darum das tolle Gebrause. Sie störte an diesem Tag auch der Donner der Kanonen nicht. So lange die heiße Luft des Julitages sie umhauchte, so lange sangen sie im großen Chor.

Auf all den Büschen und Bäumen der Gegend saßen Dutzende von Paaren, vor allem gern auf der heißen Rinde der in der Gegend so seltenen Ulmen und Eschen. Da sah man sie meist dem Ast dicht angedrückt, die glatten, glasigen, glänzenden Flügel wie ein Dach über den Rücken gefaltet. Ihre großen Augen glänzten in vielen Farben, während das heiße Licht der Sonne sie bestrahlte. Ihr Körper war in einem heftigen Zittern begriffen, die Teile des Leibes bewegten sich gegeneinander, als atmeten sie heftig. Männchen und Veibchen fliegen zueinander und vereinigen sich in Copula, wenn der Chorgesang sie so gereizt hat, der Spannungszustand des Körpers so gestiegen ist, daß sie bereit sind zur Begattung.

Bald trennen sich die Gatten wieder. Das Männchen versteckt sich zum frühen Tod, während das Weibchen noch eine Weile zu leben hat, bis es seine Eier abgelegt und versorgt hat.

Das Hochzeitsfest dauert für die Art nur wenige Tage, wie für das einzelne Individuum nur wenige Stunden. Einige Tage nach dem 8. Juli wurden die Zikaden selten. Nur während der heißesten Sommertage ließen sie ihren Chorgesang ertönen. Früher und später im Jahre hört man nur einzelne Tiere, meist jedes von seinem Baum sein Trillern entsenden.

Das Weibchen legt seine Eier an den Wurzeln von Pflanzen, so von Eschen und anderen Bäumen ab. Die entstehende Larve saugt sich mit ihrem Rüssel an der Wurzel fest und nährt sich von deren Saft. So lebt sie mehrere Jahre unter der Erde, um dann im letzten Larvenstadium emporzusteigen und das fertige Insekt aus sich hervorgehen $7 . u$ lassen. Dabei reißt die derbe Larvenhaut in einem Längsspalt in der Rückenmitte auf; das fertige Insekt schlüpft in ganz weichem, verletzlichen Zustand aus diesem Schlitz heraus und bleibt auf der Larvenhaut oder in deren Nähe sitzen, bis seine Oberfläche verhärtet ist. Daın breitet es seine Flügel aus, schwirrt in den Sonnenschein an den nächsten Baum 
und beginnt sein Lied zu singen. Nach dem langen Larvendasein unter der Erde lebt es eine kurze Zeit in Licht und Sonne, um nach Begattung und Eiablage eines raschen Todes zu sterben.

Ich beobachtete die grauschimmernden Zikaden den ganzen Nachmittag, bis der Abend herabsank. Als kühle Luft vom See herüberwehte, verstummten sie, das Konzert war zu Ende.

Erst jetzt achtete ich darauf, daß das Geschützfeuer auch ein Ende gefunden hatte. Tiefe Stille herrschte in der Natur, als der Abend kam. Wir wanderten in der Dämmerung die kurze Strecke zu der Wegkreuzung, wo der Wagen auf uns wartete, der in schneller Fahrt mich zu meinem Standquartier zurückbrachte.

Es war kein endgültiger Abschied vom Doiransee. Im Mai des Jahres 1918 wurde eine zweite nächtliche Forschungsfahrt auf dem See unternommen, die mit ähnlichem Erfolg endete.

Schöner als von seinen Ufern aus erscheint der Doiransee von den ihn umgebenden Gebirgen aus gesehen. Von den Bergen des Furkapasses, vom Dub und gar von der Belasiza Planina aus gewährt er manch äußerst reizvollen Anblick.

Welch schönes malerisches Bild bot er von den Gipfeln des Gebirges aus dar, wenn man etwa aus den Buchenwäldern der Visoka Čuka, umrahmt von Baumzweigen, tief unter sich den blauen See schimmern sah, umgeben von den zahlreichen Ketten der ihn umgrenzenden Gebirge, und den Blick schweifen ließ in Fernen, wo das Ägäische Meer aufleuchtete, wo die Berge der Chalkidike und der ferne Olymp blau schimmerten und die Gedanken in weite Fernen verführten.

Über unsere Forschungen am Doiransee, bei denen mich im Jahre 19I8 Dr. Nachtsheim unterstützte, kann vorläufig folgendes berichtet werden. Der See ist, nächst dem Kaltanowosee, der kleinste der von mir untersuchten mazedonischen Seen. Er liegt auch viel tiefer als die anderen, nämlich $148 \mathrm{~m}$ über dem Meer. Er umfaßit ein Areal von nur 42,6 qkm. Seine größte Tiefe ist $9,9 \mathrm{~m}$, also nur fast $10 \mathrm{~m}$. Man versteht daher die weitgehende Verschlammung seiner Ufer und den breiten Schilfrand, der ihn umgibt.

Wie bei dem allerdings beträchtlich tieferen Prespasee ist auch sein Plankton reich an pflanzlichen Bestandteilen. Bei dem Fang im Juli I 9 I 7 fanden sich zahllose Blaualgen in den Oberflächenschichten, auch reichlich Ceratien, Chrysomonadinen und andere pflanzliche Organismen. Ähnlich pflanzenreich waren 
auch die Fänge im Mai 1918. Diese enthielten dazu zahlreiche Daphniclen (Daphnia cucullata) und Copepoden, kleine Cyklopiden (Cyclops stremuns). In diesen Frühlingsfängen kamen junge Flohkrebse (Gammariden) in beschränkter Zahl vor. In 8 und $10 \mathrm{~m}$ Tiefe, also dicht über dem Boden, fanden sich auffallend viele Nauplius-Stadien von Copepoden. Das Netz muß hier fast auf dem Boden geschleift sein; in ihm hatten sich einige Muschelkrebse (Ostracoden) und eine Anzahl Wassermilben gefangen.

In den Julifängen fällt besonders eine stattliche Cladocerc, eine Art der Gattung Leptodora, auf. Dieses schöne durchsichtige Tier, aus unseren süddeutschen Seen bekannt und von Weismann

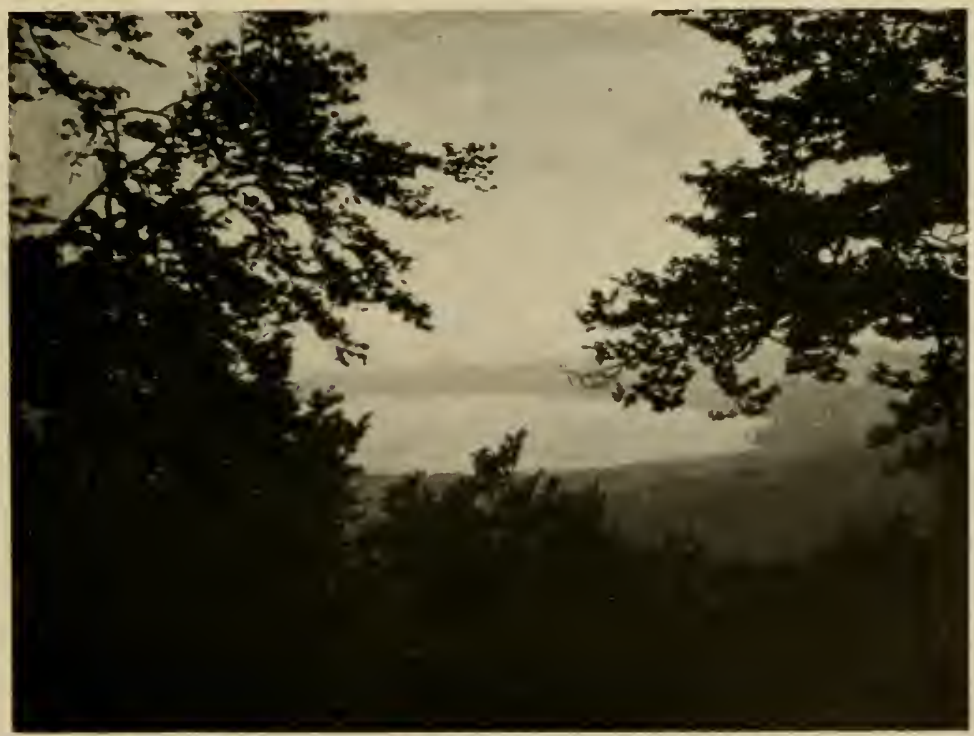

Abb. 75. Blick von der Visoka Čuka auf den Doiransee.

vor vielen Jahren im Bodensee genau studiert, kommt in vielen Varietäten und Arten in süd- und osteuropäischen Seen vor. In den Julifängen war die Art des Doiransees sehr reichlich in Männchen und Weibchen, jugendlichen und erwachsenen Exemplaren vertreten, viel reichlicher als in den Maifängen des Jahres 1918. Der Höhepunkt der Entwicklung scheint also im Hochsommer zu liegen. Im Juli war auch der Reichtum an Rädejitierchen (Asplanchniden) bemerkenswert, sowie das Vorkommen einer Bosmina-Art, einer Daphnide, die beide im Mai fehlten. Selbst weit 
draußen im See schwammen zwischen den zarten Planktontieren die plumperen Larven der Federmücken.

Im Doiransee kommt auch der Flußk kebs (Astacus fluvıatilis L.) vor, und zwar erreicht er dort eine beträchtliche Größe. Die Doirankrebse waren in der Armee sehr berühmt und beliebt.

Leider war es mir unmöglich, Fische aus dem Doiransee zu erhalten. Nur kleine Fischlarven waren in den Planktonfängen enthalten.

Außer den früher erwähnten Insekten möchte ich aus der Schilfregion des Doiransees den Reichtum an schönen, auf-

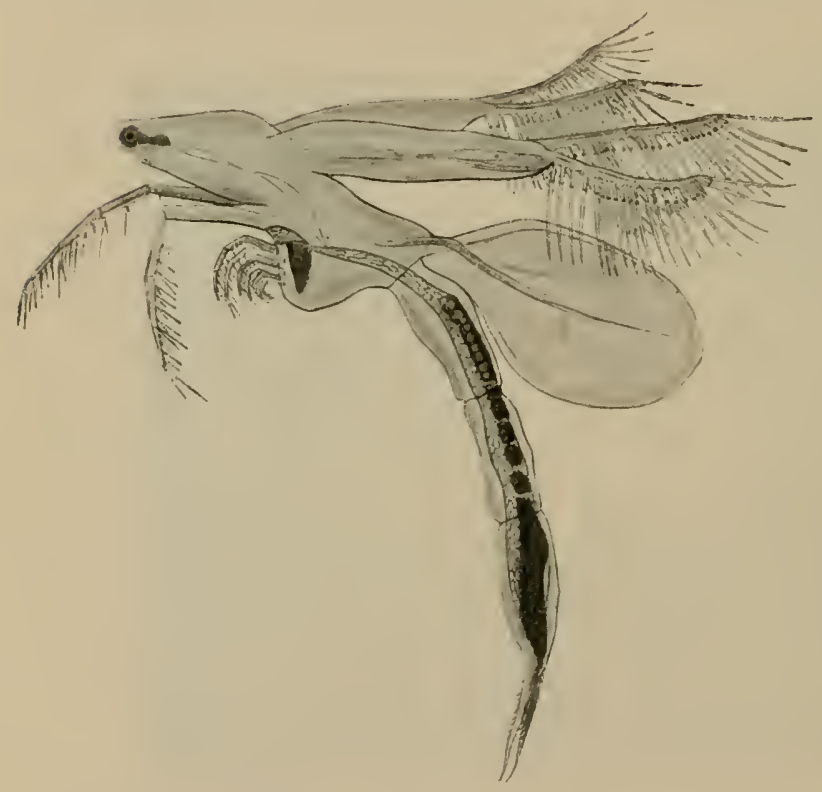

Abb. 76. Leptodora sp. Großer durchsichtiger Plankton. krebs aus Doiran- und Prespasee. Vergr. Io. fallend gefärbten Stratiomyiden, den Waffenfliegen, erwähnen, welche in verschiedenen Arten vertreten waren, so Lasiopa tenuirostris L.w., Rhynchomyia imparida Rossi, Rh. speciosa Lw., Stratiomyia erythrocera Egger und Str. chanaeleon L. - Unangenehm machte sich an dem heißen Julitag die Bremse Tabanus umbrinus $\mathrm{Mg}$. bemerkbar.

Von Käfern fand ich als auffallende Form an den Baumstämmen einen kleinen braunen, goldglänzen. den Borkenkäfer (Capnosa tenebriosa Fal.). Im Juli kamen wir für die Rohrkäfer (Donacien) zu spät und bei dem Besuch im Mai konnten wir nur nachts uns am See aufhalten.

Von Spinnen fing ich Oxyopes ramosus Panz., Thanatus arenarius Thor., Epeira redii Leop., E. patagiata Clerck, Agalena labyrinthica Clerck und Pythonissa exornata C. L. Koch.

Wie schon die Gegend von Mravinca und Dedeli, so trug die Umgebung des Doiransees in ihrer Tierwelt einen südlichen 
Charakter. Es wäre zu wünschen gewesen, daß wir mehr Gelegenheit zu Arbeit und längerem Aufenthalt in diesem Gebiet gehabt hätten. Immerhin wurden unsere Forschungen ergänzt durch die Sammlungen, welche Prof. Burgeff, Botaniker an der Münchener Universität, der als Soldat längere Zeit an der Doiranfront stand, dort anlegte. Unter ihnen sind die Reptilien besonders interessant, so die Wasserschildkröte (Clemmys caspica rizulata Val.); der kleine Gecko, dessen Wohnen in meinem Schlafzimmer ich im zweiten Kapitel beschrieb (Gymnodactylus kotchyi Stud.) ist auch eine ausgesprochen südliche Form. Östliche und südliche Beziehungen zeigt eine mit den Riesenschlangen verwandte kleine Schlange (Eryx juculus L.), die Sandschlange. Ein ähnlich interessanter Fund war Typhlops vermicularis Merr., die im Boden lebende Blindschlange. Auch der seltsame Scheltopusik (Ophisaurus apus Pall.), wie die Blindschleiche einer Schlange gleichend und doch so ganz anders plump gebaut als diese, erscheint als fremdartiges Element in diesem Land, das in seinem Charakter eine so starke Durchmischung südlicher und nördlicher, östlicher und westlicher Bestandteile zeigt.

Die Doiranseegegend bildet offenbar in vielen Beziehungen einen Übergang zu dem südlichsten Teil der Balkanhalbinsel. Hier geht die Landschaft allmählich über ins flache Land bei Saloniki. Hier zeigt sich schon der beginnende Einfluß des Meeres und damit eine Annäherung an die Verhältnisse Griechenlands und an die adriatische Küste des Balkans. 


\section{DIE MAZEDONISCHEN AMEISEN UND IHRE BAUTEN}

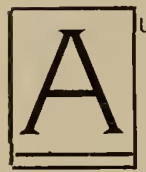

uch die Ameisen sind in Mazedonien Tiere, welche man nicht übersehen kann. Sie kommen in allen Teilen des Landes in großen Mengen vor. So konnte ich während der 2 Jahre meiner Forschung in diesem Lande 36 Arten und Unterarten auffinden, wie aus den Bestimmungen von Herrn H. Viehmayer in Dresden, der meiner Sammlungen sich freundlich angenommen hat, hervorgeht. Diese von mir aufgefundene Zahl von Arten ist nicht allzugroß, es gibt ihrer in Mazedonien sicher noch mehr. Aber da ich meine Forschungen nicht speziell auf Ameisen beschränkte, so ist es immerhin eine beträchtliche Zahl.

Mit ihrer Bautätigkeit bearbeiteten die Ameisen den Boden in einer ganz erstaunlichen Weise, und wir werden später sehen, daß sie gerade in Mazedonien damit eine besondere Rolle spielen, ganz zum Unterschied von anderen Ländern, wo andere Tierarten die Hauptarbeit an der Umarbeitung des Bodens leisten.

Wie bei der übrigen Tierwelt und bei der Pflanzenwelt zeigt sich in der Ameisenfauna Mazedoniens eine Mischung von Arten, welche teils südlichen und östlichen Charakter haben, teils nordischen Arten entsprechen. Vor allem im Süden des Landes und im Tiefland treten die südlichen Arten von Ameisen hervor. Sie fallen dem Deutschen vor allen Dingen auf, weil sie in Aussehen und Lebensverhältnissen von unseren Ameisen abweichen. Ganz besonders machte sich in den heißen Teilen Mazedoniens eine Ameisengattung bemerkbar, die Gattung Messor, welche in ganzen Armeen beobachtet werden konnte, und deren Nester sehr häufig waren. In der gleichen Gegend kamen kleine gelbe Ameisen vor, bei denen neben den winzigen Arbeitern sogenannte Soldaten mit mächtig dicken Köpfen herumliefen. Es ist dies die Gattung Pheidole, die einzige europäische Ameise mit echten Soldaten. Außerdem gab es Vertreter der Gattungen Cataglyphis und Cremastogaster, welche durch ihre große Lebhaftigkeit auffielen. 
Alles das sind südliche Ameisenformen, die in Steppen und Wüsten vorkommen und zum Teil bis Nordafrika verbreitet sind.

Ganz andere Ameisen leben im Gebirge. Kam man in die Wälder in Höhen von $1500-2000 \mathrm{~m}$, so stieß man auf Ameiserarten, welche unseren einheimischen außerordentlich ähnlich waren und sich auch als die nämlichen herausstellten. Es waren dies Arten der Gattung Formica; diese fand ich niemals in Höhen von weniger als $1500 \mathrm{~m}$. Dort gab es auch die Formicina-Arten, die man früher als Lasizis bezeichnete, und die Holzameisen aus der Gattung Camponotus. Die beiden letzteren Gattungen fand man auch im Flachland, allerdings dort nicht so häufig als in den Bergen, während die Formica-Arten in Mazedonien mir unten niemals begegneten.

Es ist zu verstehen, daß ich die meisten Ameisenarten in der Umgebung derjenigen Orte fand, welche längere Zeit mein Standquartier waren. So fand ich in der Gegend von Kaluckova I4, bei Üsküb 12 und bei Dedeli ebenfalls I 2 Ameisenarten.

In Mazedonien ist wie überhaupt in Südeuropa diejenige Form die typische $\mathrm{H}$ ausameise, welche man bei uns die Rasenameise nennt (Tetramorium caespitum L.). Diese kleine braune Ameise drang viel in die Quartiere ein, sie war im ganzen Land bis $1600 \mathrm{~m}$ Höhe verbreitet und konnte sehr lästig werden. So war sie es besonders für den Naturforscher, dem sie gelegentlich seine genadelten Insekten und die schon verpackten Schätze überfiel und auffraß, so daß nur wenige Beine und Flügel übrig blieben. Mit Naphthalin konnte man sie schnell und sicher vertreiben. Es tötet sie rasch und sein Geruch hält sie von den Sammlungen ab.

In den Maulbeerpflanzungen um Kaluckova gab es viele Holzameisen aus der Gattung Camponotus. Vor allen Dingen in alten Bäumen hatten sie vielfach ihre Gänge genagt. In solchen lebten auch Ameisenarten, welche in den hohlen Stämmen feingegitterte Nester aus einer Kartonmasse gebaut hatten. Sie ließen sich als die Arten Liometopum microcephalum Panz. und Cremastogaster scutellaris schmidti Mayr. bestimmen.

Noch mehr Ameisen gab es aber auf den bebuschten Hügeln in der ganzen Gegend um Kaluckova. Da herrschten die MessorArten vor. Deren Löcher waren überall zu sehen und ihre Straßen durchzogen die ganze Gegend. Von ihrer Lebensweise werden wir später ausführlich hören. 
Großes Interesse erregt durch ihre Bewegungen eine große schwarz und rot gefärbte Ameise. Wie die Messor-Arten kam sie aus Bodenlöchern und jagte in der ganzen Gegend nach Insekten. Kam man dieser Ameise nahe, so hob sie den rotgefärbten Kopf und den Brustteil nebst den Vorderbeinen hoch in die Höhe, sperrte die Kiefer weit auseinander und war bereit, sofort zuzubeißen. Mit einer seltsamen Hast rannte sie in dieser Stellung hin und her und packte an, was ihr in den Weg kam. Es war Cataglyphis bicolor F. var, orientalis For. Sie gleicht in ihren bizarren Bewegungen und in ihrer eifrigen Jagd auf allerhand Insekten den zahlreichen Formen ihrer Gattung, welche in den Wüsten Nordafrikas leben.

Reiche Ausbeute an fliegenden Geschlechtstieren von Ameisen lieferte das hellbeleuchtete Kasino des Lazaretts Kaluckova an den schönen warmen Sommerabenden. Da flogen manche Formen an, deren Nester ich nicht in der Umgebung gefunden hatte. Der Aufenthalt in Üsküb und bei Dedeli, sowie die Reisen in die Gebirge Mazedoniens brachten mir eine ganze Menge von Ameisenarten, von denen ich aber hier nicht weiter sprechen will.

Ameisen bekam ich also während meines Aufenthaltes in Mazedonien in Menge zu sehen. Aber etwas vermilte ich in den ersten Monaten meines Aufenthaltes in diesem interessanten Lande, was wir bei uns gewöhnt sind, mit Ameisen und Ameisenleben stets verbunden zu denken. Ich bekam keinen einzigen Ameisenhaufen zu sehen. Als mir das aufgefallen war, begann ich aufmerksam darauf zu achten, und ich merkte bald, daß hier alle Ameisen, die nicht etwa wie die Holzameisen in Bäumen bauen, sich unter die Erde zurückgezogen hatten. Viele von ihnen hausten unter Steinen. Unter diesen begannen ihre Gänge, die in den Boden hineinführten, auch hatten sie vielfach in dem Hohlraum, der sich etwa unter dem Stein befand, Wände errichtet, so daß Kammern und Gänge entstanden waren. So fand ich die Arten von Tetramorium, Pheidole, Cataglyphis, Plagiolepis, Solenopsis, Tapinoma, Myrmica und Cremastogaster entweder immer oder gelegentlich unter.Steinen; sogar eine Art von Formica und zwei solche von Camponotus fand ich im Boden unter Steinen hausend.

Was sonst von Ameisen in der Gegend lebte, lebte auch im Boden, wenn auch nicht unter Steinen. Die Löcher dieser anderen Arten traten aber frei an die Oberfläche und waren im Frühjahr von eigenartigen Ringwällen umgeben. Diese Ringwälle be- 
standen aus dem Bauschutt, der bei dem Ausgraben der Gänge aus der Erde herausgeschafft worden war. Solche Nester bezeichnet man als Kraternester, weil der Ringwall sich wie der Krater eines Vulkans zu dem Ausgangsloch des Ameisennestes herabsenkt. Die Kraternester waren charakteristisch für eine ganze Anzahl Ameisenarten in den Hügeln bei Kaluckova. Es waren dies vor allem die dort vorkommenden drei Arten der Gattung Messor. Ich will gleich ihre Namen nennen und ihr Aussehen kurz beschreiben. Die häufigste Form war Messor barbarus meridionalis E. André, eine sehr dunkelgefärbte Art; ihr Kopf und fast der

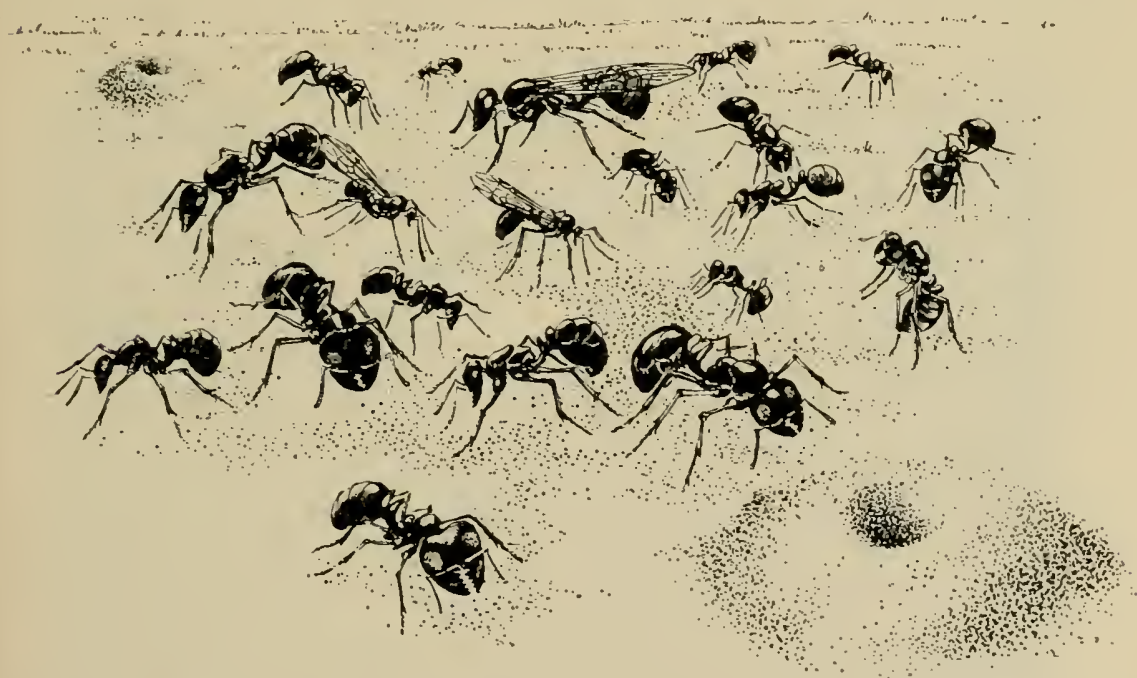

Abb. 77. Messor barbarus meridionalis. Geschlechtstiere und alle Arbeiterformen um die Nestkrater sich bewegend.

ganze übrige Teil des Körpers sind schwarz. Nur der Brustteil, die Knötchen und die Gelenke der Beine zeigen hellbraune Färbung. Die zweite Form Messor oertzeni For. var. amphigea For. ist auch nicht selten, sie fällt durch einen rotbraunen Kopf und Vorderkörper auf, auch ihre Beine haben dieselbe Färbung, während der Hinterleib schwarz ist. Etwas weniger häufig war eine dritte Form Messor barbarus structor Lar, var. mutica Nyl.; sie war ähnlich gefärbt wie die erste, fast noch dunkler am ganzen Körper mit helleren Beinenden.

Außer bei diesen drei Arten fand ich ähnliche Kraternester bei Tetramorium caespitum I.., Cataglyphis bicolor F. var. orientalis 
For. und einer gelben Formicina-Art. Es war eine sehr auffällige Beobachtung, daß hier alle Ameisen, die nicht in Bäumen hausten, in der Erde wohnten, und daß keine einzige einen Ameisenha uf en baute.

Den ersten Ameisenhaufen entdeckte ich, als ich Expeditionen in die Hochgebirge Mazedoniens unternahm. Da fand ich im August 1917 im Schardakh, also im albanischen Grenzgebirge, in der Gipfelregion der Kobeliza, von etwa $1800 \mathrm{~m}$ Meereshöhe $a b$, regelrechte Ameisenhaufen, wie wir sie in unseren Wäldern zu sehen gewohnt sind. Das waren die großen, aus Tannennadeln, Holzstückchen, Erde und allerhand anderem Material

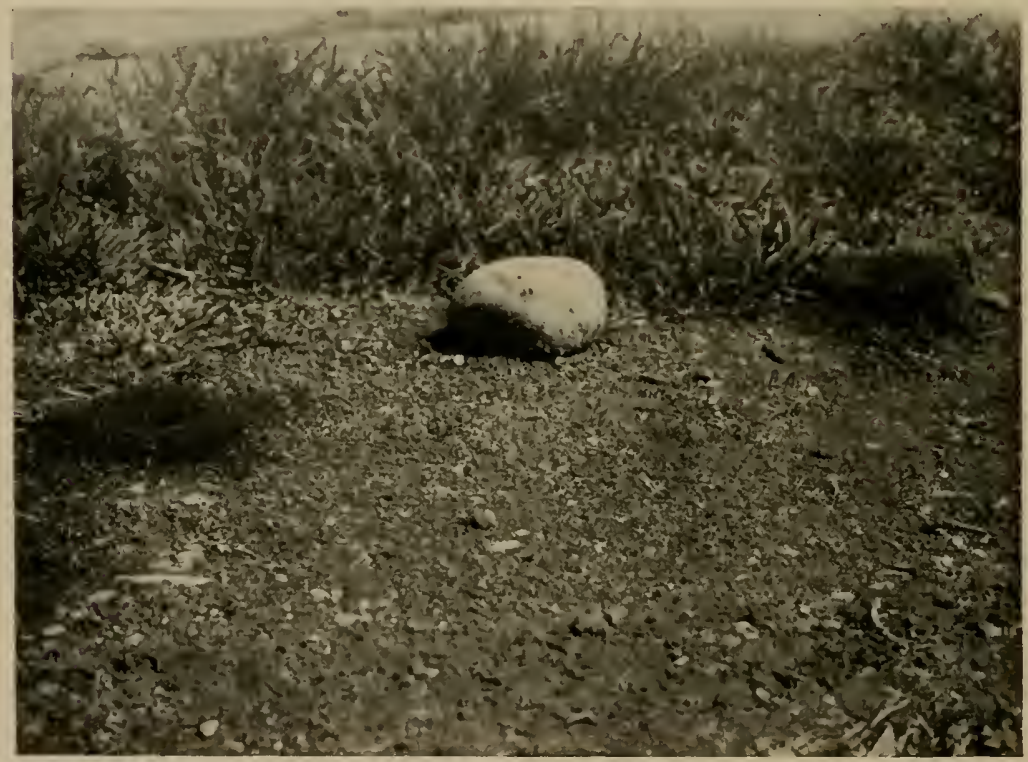

Abb. 78. Ringwälle (Kraternester) von Messor barbarus meridionalis E. André, bei Ưsküb.

aufgebauten Haufen, welche man als die gemischten Nester der Ameisen zu bezeichnen pflegt. Von da an achtete ich bei allen meinen Gebirgsfahrten auf die Ameisenhaufen und fand solche in allen Gebirgen, und zwar jeweils in der Waldregion und niemals in Höhen von unter $\mathrm{I} 500 \mathrm{~m}$. Eine richtige Entwicklung von Ameisenhaufen war stets erst bei etwa $1800 \mathrm{~m}$ Meereshöhe zu beobachten. Als ich diese Haufen untersuchte, fand ich in ihnen die typischen deutschen Waldameisen aus der Gattung Formica, dieselben Arten, welche ich in den Bayrischen Alpen und im 
Schwarzwald viel gesehen hatte. Es waren Nester von Formica (Rhaphi-formica) sanguinea Latr., Formica rufa L., Formica (Serviformica) fusca L., F. exsecta Nyl. und Varietäten von ihneı.

Diese Beobachtungen machten mir manches klar. Mit den Wäldern hatten diese Waldameisen sich in die Berge zurückgezogen. Ich habe nie einen Vertreter einer Formica-Art im Flachlande Mazedoniens gefunden. Eine einfache Überlegung zeigt, daß hügelbauende Formen in dem trocknen, heißen Tiefland Mazedoniens gar nicht existieren könnten; in der Hitze des Sommers würde das ganze Material des Haufens in Kürze ausgetrocknet und würde von den lokalen Winden nach allen Seiten zerstreut.

Nun fielen mir die feinen Beobachtungen wieder ein, welche Forel an den Ameisenhaufen der schweizer Ameisen gemacht hat, und die interessanten Erwägungen, die er an seine Beobachtungen anknüpfte. Unsere mitteleuropäischen Ameisen brauchen ihre Haufen, darum kann man auf jeder Wiese, an jedem Ackerrand die um Gras und Kräuter aufgebauten Erdkuppeln und in jedem Wald die aus gemischtem Material errichteten kleinen und großen Haufen finden. Sie alle stellen für die Ameisen Wärmesammler dar. In den Erdkuppeln sind es die Sonnenstrahlen, welche den verschiedenen Kanımern eine verschiedene Wärme zuführen. In den Haufen der Waldameise wird eine ganz andere Wärmequelle ausgenützt; es ist die Gärungswärme, welche in dem feuchten Pflanzenmaterial dieser Haufen ähnlich wie in zu feucht eingetragenem Heu sich entwickelt. Man weiß ja, daß durch Bakteriengärung im Heu gelegentlich eine solche Hitze hervorgerufen wird, daß Selbstentzündung dadurch bewirkt wird. Ähnliche Gärungserscheinungen erzeugen im Ameisenhaufen Temperaturen, welche oft bis $z u 0^{\circ} \mathrm{C}$ über der Lufttemperatur in der Umgebung erreichen. Ich habe mich selbst durch Messungen von dieser Temperaturerhöhung überzeugt. Diese im Haufen entstehenden, in dessen verschiedenen Zonen verschiedenen Temperaturen, zugleich mit der verschiedenen Feuchtigkeit seiner Schichten nützen die Ameisen bei der Pflege ihrer Entwicklungsstadien aus. Sie heben die Eier in den feuchtesten Regionen, die Larven in den mittleren, die Puppen in den heißesten und trockensten Räumen ihres Haufens auf. Und je nach der Entwicklungsstufe werden die Stadien in die geeigneten Räume gebracht. 
Es leuchtete mir ein, daß solche Wärmesammler in dem heißen Klima Mazedoniens unnötig waren und bei der Trockenheit des Sommers gar nicht bestehen konnten; und so war es wohl zu verstehen, daß sie in Mazedonien nur in den regenreicheren Gebirgszonen mit milderem Sommerklima vorkamen.

So war es denn eine große Überraschung für mich, als ich im Sommer 1917 in dem mir so gut bekannten Gelände der Umgebung von $\mathrm{Ka}$ luckova Haufen von Pflanzenteilen bemerkte, welche insofern anAmeisenhaufen erinnerten, als viele Ameisen sich daran zu schaffen machten. Ich erkannte sofort in diesen die in der Gegend häufigsten Ameisen, die Messor-Arten. Eine Untersuchung der Haufen zeigte mir, daß es sich nicht um bewohnte Bauten der Ameisen handelte. Sie bestanden aus allerhand locker angehäuften Pflanzenteilen und ich konnte sehen, daß die Ameisen noch an der Vergröße-

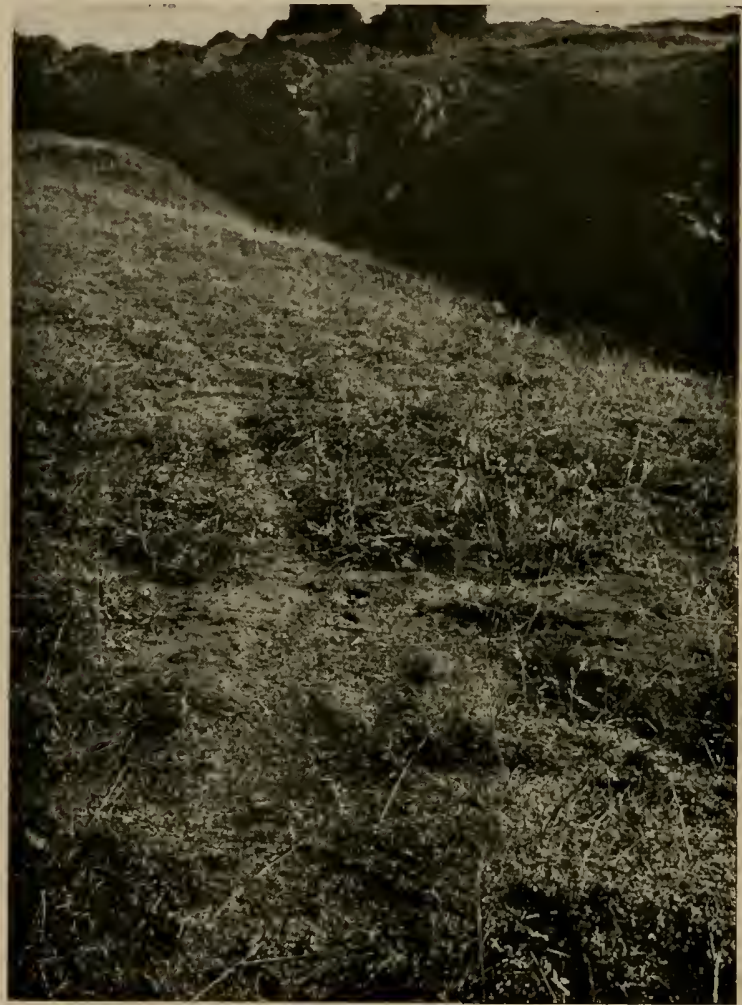

Abb. 79. Nestausgänge, Abfallhaufen und Straßenbau bei Messor barbarus meridionalis E. André. Kaluckova August 1917.

rung der Haufen arbeiteten. Es war eine stark belebte Straße, welche $z u$ dem Haufen führte, und sie kam direkt vom Ausgang eines Nestes her. Wie oft hatte ich in den letzten Wochen gerade diese Ameisen beobachtet, welche in Zügen von vielen Tausenden auf ihren wohlgebahnten Straßen emsig hin und her liefen. Diese Züge bestanden aus ganz verschieden großen Tieren, 
offenbar verschiedenen Formen der gleichen Art. Die einen davon waren auffallend gro $\beta$ und hatten als auffallendstes Merkmal dicke Köpfe mit mächtigen Kiefern. Die kleinsten waren kaum ein Drittel so groß wie sie, hatten viel kleinere Mundgliedmaßen. Und zwischen ihnen liefen Individuen, die in Größe und Gestalt alle Übergangsformen zwischen diesen Extremen darstellten. Wie schon längst bekannt ist, sind die Messor-Arten Ameisen mit unvollständigem Dimorphismus. Die Dickköpfe sehen aus wie die Soldaten, welche bei den Ameisenarten mit vollkommenem Dimorphismus als besondere Formen vorkommen. Hier auf den Straßen sah man sie sich aber genau wie gewöhnliche Arbeiter

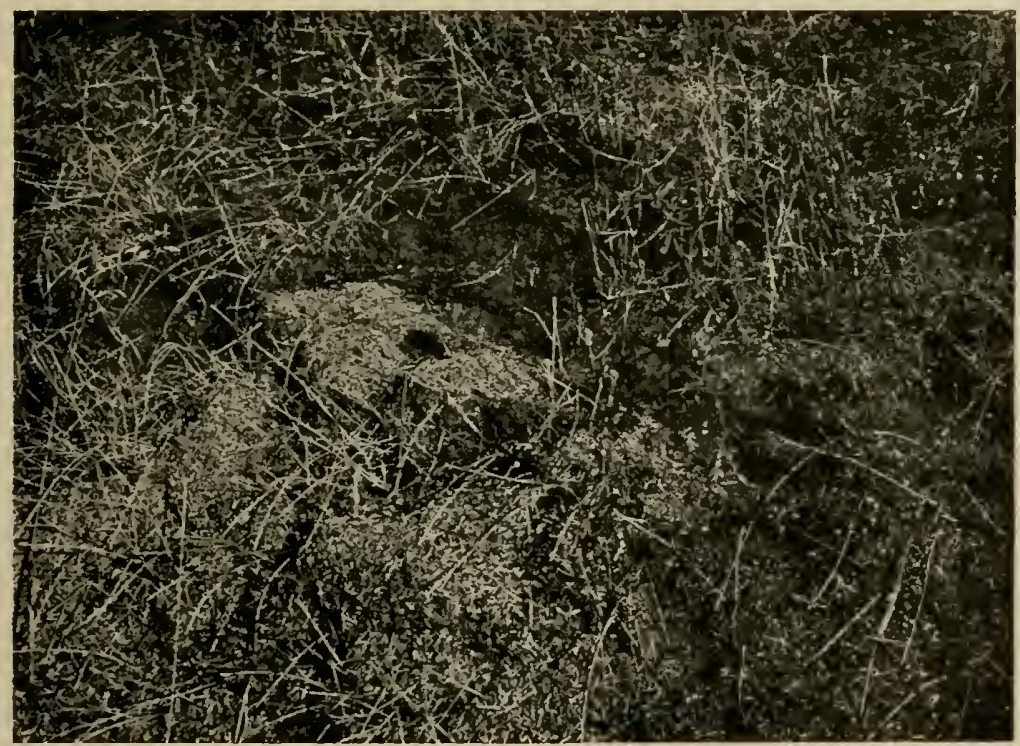

Abb. 8o. Besonders großer Abfallhaufen bei Messor barbarus meridionalis E. André. Kaluckova 26. Aug. 1917.

benehmen. Sie trugen und schleppten Pflanzenteile aus dem Nestloch auf den Haufen und dabei wurden sie von ihren Kameraden aller Größen mit demselben Eifer unterstützt. Wie in Größe und Gestalt keine scharfen Gegensätze sich zeigten, so waren auch Funktionen und I.eistungen bei allen Individuen annähernd die gleichen.

Mit Freuden sah ich, daß ich Körnerameisen vor mir hatte, eine Art jener Körnersammler, die schon seit dem Altertum die Phantasie der Völker beschäftigt haben. Ich beschloß sofort 
diesen Tieren besondere Aufmerksamkeit $z u$ schenken und ihre Lebensweise möglichst genau zu untersuchen auf die Gefahr hin, $\mathrm{da} \beta$ ich nur längst bekannte Beobachtungen bestätigen könnte Im Verlauf meiner Forschungen konnte ich auch manche Dinge feststellen, die noch unbekannt waren.

Während der Jahre 1917 und 18 habe ich ihr Leben während aller Jahreszeiten verfolgt. Im Winter allerdings waren sie verschwunden und hielten ihren Winterschlaf unter der Erde. Ich konnte feststellen, daß der Boden in den Tiefen, in denen sie lebten, gefroren war; die ganzen Ameisenvölker befanden sich in den kalten Wintermonaten Dezember und Januar in einem Zustand der Winterstarre. Diese hielt durchaus nicht den ganzen Winter hindurch gleichmäßig an, sondern sowie wärmeres Wetter eintrat, sobald die Sonne hei $\beta$ auf die von ihnen bewohnten Hänge schien, wagten die Ameisen sich heraus. Aber es war Zufall, wenn man sie dann bemerkte; denn während des Winters sah man keine Spur von ihren Bauten, Wind und Regen hatten die Eingänge der Nester zugeschwemmt. Auf der Spitalıiese in Üsküb, unter deren Boden sich eine Menge von Nester befanden, war im Winter keine Spur von diesen zu bemerken. Die ganze Oberfläche bestand je nach der Witterung aus Staub oder Schlamm. Mehrere Wochen lang war die Wiese sogar mit einer hohen Schneeschicht bedeckt.

Aber schon Anfang Februar konnte ich beobachten, dal3 an einem sonnigen Hügel bei Üsküb an einigen Stellen die Körnerameisen den Eingang ihres Nestes wieder geöffnet hatten. In diesem in Mazedonien meist noch sehr winterlichen Monat trugen sie bereits Schutt aus ihrem Nest heraus, häuften ihn um den Ausgang an, glätteten diesen und begannen ihre Ausflüge in die nächste Umgebung. Da setzte ein gewaltiger Wetterrückschlag ein, die Ameisen wurden in ihre Bauten zurückgetrieben und ruhten noch einmal fast 2 Monate unter $20 \mathrm{~cm}$ tiefem Schnee. Anfang April kam endlich ihr Leben von neuem in Gang. Das galt im Jahre 1918 für das nördliche Mazedonien. Im Süden, also bei $\mathrm{Dedeli}$ und Gewgeli, waren sie schon einige Wochen früher munter.

Gerade grünte das Gras wieder auf der Spitalwiese, die Krokusblüten waren schon beim Welken, da kamen die ersten Arbeiter der Körnerameisen aus dem Boden. Durch feine Spalten wühlten sie sich empor und begannen sofort ihren Körper zu putzen. Vorsichtig und langsam liefen sie in der Nähe des Nestausgangs umher, schlüpften aber bald wieder in die Tiefe. Nach kurzer Zeit 
war aber schon viel Bewegung um den Nestausgang. Dieser hatte schon etwa $1 \mathrm{~cm}$ Durchmesser und man konnte von ihm aus in den Gang hineinsehen, welcher fast senkrecht aus der Tiefe emporführte. An seinen Wänden stiegen nun Mengen von Ameisen empor und jede von ihnen trug Erdkrümchen und kleine Steinchen zwischen ihren Kiefern. Kaum waren sie oben, als sie mit einem eigentümlichen Nicken ihre Last abwarfen, sofort Kehrt machten, um wieder in die Tiefe $\mathrm{zu}$ steigen und bald mit neuer Last zurückzukehren. Dadurch entstand sehr bald um den Ausgang des Nestes ein Ring wall aus diesem Bauschutt, den die Tiere aus ihrem Nest ausräumten. Offenbar hatten sie angefangen die Gänge und Kammern zu reparieren und vielleicht auch schon Neubauten auszuführen. Es war ein ganz eigenartiger Anblick, wie auf der ganzen Wiese und im Lande ringsumher auf allen Hügeln diese Ringwälle zu Hunderten und Tausenden auftraten. Es waren trockene Tage und die Erde

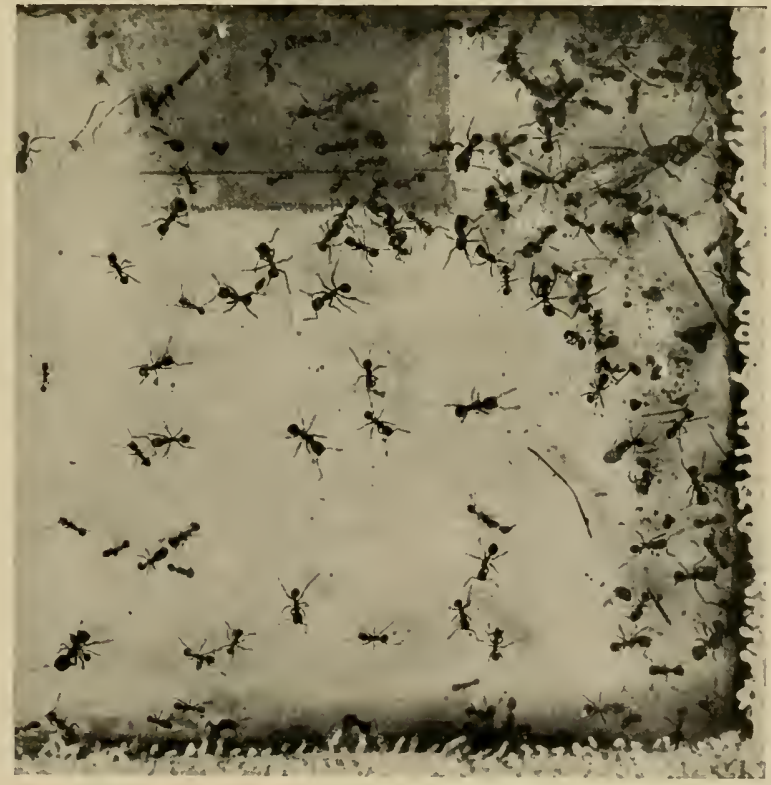

Abb, 81. Geflügelte Königin mit verschiedenen Arbeiterformen im Fieldenest (Messor barbarus meridionalis E. André). an der Oberfläche schon hart und staubig. Unten mußte sie aber noch feucht sein, und so hoben sich denn alle diese Ringwälle mit lebhafter Farbe von der Bodenoberfläche ab; bald waren sie rot, bald leuchtend gelb, bald schwarz oder braun, je nach dem Charakter des Untergrunds. Ich habe schon oben erwähnt, daß nicht nur die Messor-Arten, sondern auch verschiedene andere mazedonische Ameisen solche $\mathrm{K}$ raternester bauen.

Je nach dem Feuchtigkeitsgrad und der Gesteinszusammensetzung waren die Ringwälle flacher und niedriger oder steiler 
und höher. Bei Dedeli sah ich im Mai 1918 Wälle, die mit steilen Wänden eine Höhe von $3-4 \mathrm{~cm}$ erreichten und dabei einen ganz kleinen Kreis umschlossen.

Bei trockenem und windigem Wetter wurden sie oft schon nach kurzer Zeit weggeblasen, bei Regen weggeschwemmt, wobei nicht selten der Eingang des Nestes verstopft wurde und den Ameisen neue Arbeit erwuchs. Selten buken die Erdteilchen fester zusammen, so daß geradezu Mäuerchen entstanden, welche dann etwas dauerhafter waren. Das war besonders bei lehmigem Untergrund der Fall. Trotzdem glaube ich nicht, daß mit diesen Ringwällen ständige Bauten beabsichtigt sind, die einen besonderen Zweck verfolgen. Das wurde von einem Beobachter (Diehl) vermutet, als er sah, dals bei Nestern von Messor arenarius halbkreisförmige Wälle die Regel waren, welche mit ihrer geschlossenen Seite nach der häufigsten Windrichtung gerichtet waren. Solche einseitigen Wälle habe ich auch an manchen Stellen beobachtet; es war dies aber nur dann der Fall, wenn der Gang zur Öffnung des Nestes aus dem Boden schief an die Oberfläche stieg. Dann entstanden besonders am Abhang von Hügeln einseitige Teilwälle, welche wie die Schutthalden eines Bergwerkes aussahen.

Erinnern wir uns an die Art, wie die am Ringwall bauenden Ameisen ihre Sandkörner oder Erdklümpchen jedesmal gerade an der Stelle abwerfen, vor der sie aufrecht aus dem Nestloch hervortreten, so verstehen wir, daß sie, am Boden des schiefen Aufgangs laufend, die Körner stets nach einer Seite abwerfen mußten. In den senkrechten Gängen dagegen hatten sie beim Klettern alle Seiten des Ganges zur Verfügung, alle waren für sie gleich steil und gleich mühsam zu ersteigen; und so warfen sie eben ihre Last nach allen Richtungen ab. So werden wohl in dem einen Fall die vollen Kreise, im anderen Fall die Halbkreise entstehen. Später habe ich in dem Buche von Passarge über die Kalahariwüste gelesen, dalb dieser Forscher in diesem ähnlichen Klima eine entsprechende; Bautätigkeit bei den dort lebenden Ameisen beobachtete und zu derselben Annahme über die Entstehung der verschiedenen Wälle kam. Noch dazu erhielt ich eine unerwartete Bestätigung durch meinen Assistenten Dr. Koehler, als er aus ägyptischer Kriegsgefangenschaft zurückkehrte. Er und seine Kameraden hatten dort oft genug Gelegenheit, durch den Stacheldraht ihres Gefangenenlagers die Ameisen zu beobachten, wie sie vorn am Nestloch ihr Klümpchen zusammengeklebten Sandes von 
sich warfen, wenn sie im Nestgang schief aufsteigend etwa in der Mitte des Lochs herauskamen. Oft bogen sie schief zur Seite und warfen ihre Last seitlich ab, so daß auf diese Weise der halbmondförmige Wall entstand.

Wenn die Ringwälle im Frühjahr in Mazedonien in so großen Mengen auftreten und so rasch wachsen, dann herrscht in den Nestern regste Bautätigkeit. Es werden Kammern gebaut, Verbindungsgänge angelegt und alles für die große Fortpflanzungszeit im Sommer vorbereitet.

Anfang April 1918 erlebte ich den Hochzeitstag der Messor-Völker in Nordmazedonien. Da gab es viel Leben um die Ringwälle herum; in allen Nestern herrschte große Erregung. An einem Tage (am ro. April) frühmorgens sah ich aus zahlreichen Kratern in der Nähe meines Quartiers in Üsküb geflügelte Ameisen hervorkommen, und zwar waren es gleichzeitig die mächtigen dickleibigen Weibchen und die viel kleineren, schlankeren Männchen. Im hellen Sonnenschein des frühen Morgens begann der Hochzeitsflug, welcher die Tiere nicht sehr weit führte. Bei diesen Arten gibt es keine weite Hochzeitsreise auf einen Berggipfel oder zu sonst einem hochragenden Gegenstand, wie sie bei vielen unserer Ameisen die Regel ist. Hier findet die Begattung ganz in der Nähe des Nestes statt. Die Geschlechtstiere finden und begatten sich in der Luft. So sinken sie denn bald nicht weit von ihrem Nest wieder zum

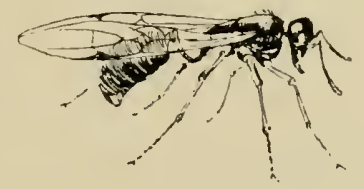
Boden nieder. Da sah man in den nächsten Stunden viele der Männchen sterbend am Boden liegen; denn nach den Begattungsakt ist ihr kurzes Leben in Freiheit, Licht und Sonne beendet.

Die Weibchen dagegen verlieren am Boden, manchmal sogar noch während des Niederschwebens ihre Flügel; man sieht sie am Boden oft schon flügellos anlangen oder dort mit einem oder gar noch beiden Flügeln herumlaufen, um sie dann bald zu verlieren.

Nun ist die Königin befruchtet und bereit, einen neuen Staat zu gründen. Nach meinen Beobachtungen ist es möglich, daß befruchtete Königinnen bei den Körnerameisen wieder zu ihrem eigenen Volk zurückkehren oder bei einem fremden Volk auf- 
genommen werden. Ich sah wenigstens am Hochzeitstage selbst flügellose Königinnen in Nesteingänge eindringen, ohne daß die Insassen sie abwehrten oder irgendwie feindlich behandelten.

Meine Beobachtungen, die ich an Königinnen in künstlichen Nestern machte, lassen es wahrscheinlich erscheinen, dafo bei den Körnerameisen etwas Derartiges möglich ist. Ich erzielte bei keiner isolierten Königin eine selbständige Staatengründung, wohl aber nahm diese einen hoffnungsvollen Anfang, wenn ich eine Königin mit mehreren Arbeitern eines fremden Volkes zusammen einsperrte.

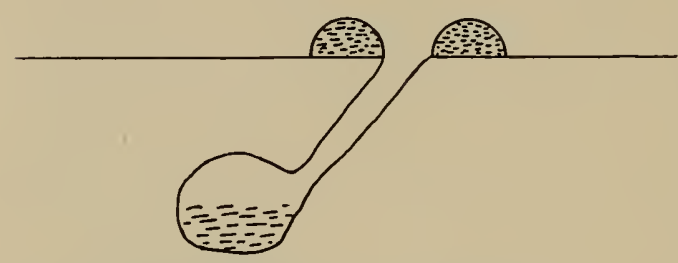

Abb. 83. Kleines Nest mit Erstlingskammer von Messor barbarus meridionalis.

Vereinigte ich mehrere Königinnen ohne Arbeiterhilfe, so nahm die Fortpflanzung keinen regelrechten Fortgang und es kam nicht zu einer rechtzeitigen Entwicklung hilfreicher Arbeiter, um die Entstehung des Staates zu sichern. Dieser Mißerfolg dürfte aber nach späteren Erfahrungen an deutschen Ameisenarten darauf zurückzuführen sein, daß ich zu große Nester anwandte. Die Vorräte an Reservesubstanzen im Körper der Messor-Königinnen lassen doch annehmen, daß

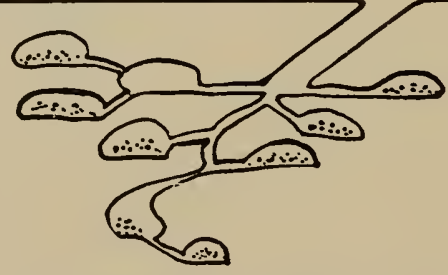

Abb. 84. Nest von kleinem Volk von Messor barbarus meridionalis. auch diese fähig sind, allein einen neuen Staat zu gründen.

Ist das große Hochzeitsfest vorbei, so findet man in den Bauten der Körnerameisen nur mehr befruchtete Weibchen

und alle verschiedenen Formen von Arbeitern. Männchen und geflügelte Weibchen sind dann nicht mehr da und fehlen bis zum Ende des Sommers, wo sie wenigstens als Puppen wieder auftreten.

Vom April an beginnt die Zeit intensiver Vermehrung im Bau der Körnerameisen. Eifrig wird für die Versorgung der hungrigen Larven vorgesorgt, die im Neste entstehen sollen. Schon in den ersten Tagen nach der Öffnung des Nestes haben die Arbeiter begonnen von ihren Ausflügen allerhand mitzubringen; 
und zwar waren das stets entweder getötete Insekten und andere Tiere, oder es waren Pflanzenteile. Die Körnerameisen sind äußerst räuberische Tiere; sie lieben Fleischkost sehr und wenn sie ein Tier überwältigen können, so benützen sie es als bevorzugte Nahrung. Im Frühling in Mazedonien fehlt es ihnen nicht an Beute; bis in den Sommer hinein gibt es genug Insekten von

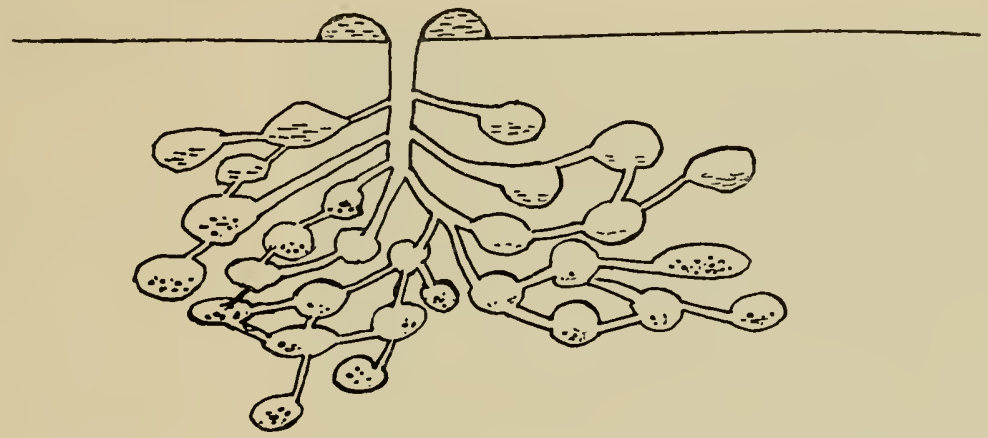

Abb. 85. Plan eines großen Baues von Messor bartarus meridionalis.

einer Größe und von Körperkräften, welche sie überwinden können. So finden sie denn für sich selbst den Tisch reichlich gedeckt.

Trotzdem sieht man sie schon in den ersten Frühlingstagen ihrem eigentümlichen Sammelinstinkt folgen. Sie schleppen allerhand Dinge in ihren Bau hinein. Es war höchst erstaunlich zu beobachten, wie sie an frisch aufgeblühten Graspflänzchen am Halm hinaufkletterten und oben Blüten und unreife Samen abpflückten und geschäftig zum Neste schleppten. Auch Teile derGrasblätter und Grashalme, die sie vorher zerschnit-

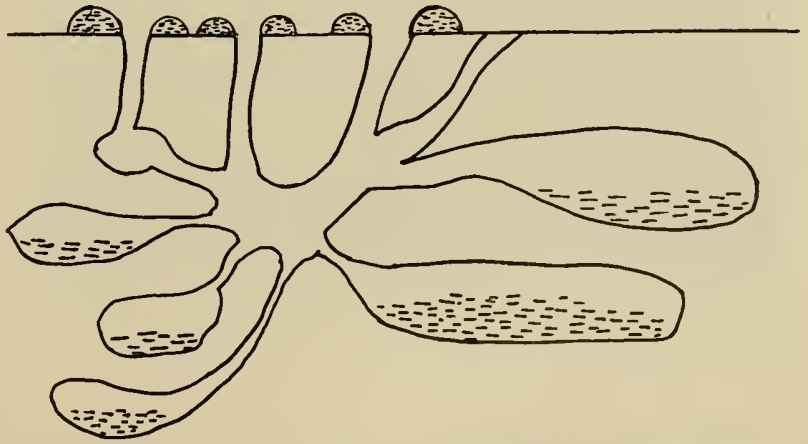

Abb. 86. Schema eines Nestes von Messor barbarus meridionalis mit mehreren senkrechten Ausgangsröhren und großen Vorratskammern. ten hatten, trugen sie zum Nest. Ja hier und da sah man einen Arbeiter sich mit einem halbverfaulten vorjährigen Samen oder irgendeinem anderen unbrauchbaren Gegenstand sich abquälen. 
Allmählich, wie das Frühjahr fortschritt, verblühten immer mehr einjährige Pflanzen und trugen Samen. Nun ging die große Erntezeit für die Ameisen los. In der ganzen Umgebung des Nestes wurden wohlgebahnte Straßen angelegt, in ihnen waren die Pflanzen ausgerodet und um alle Hindernisse gingen sie im Bogen herum. Bei dem Straßenbau waren Arbeiter aller Größen beteiligt. Immerhin waren es vor allem die Mittelgroßen, welche

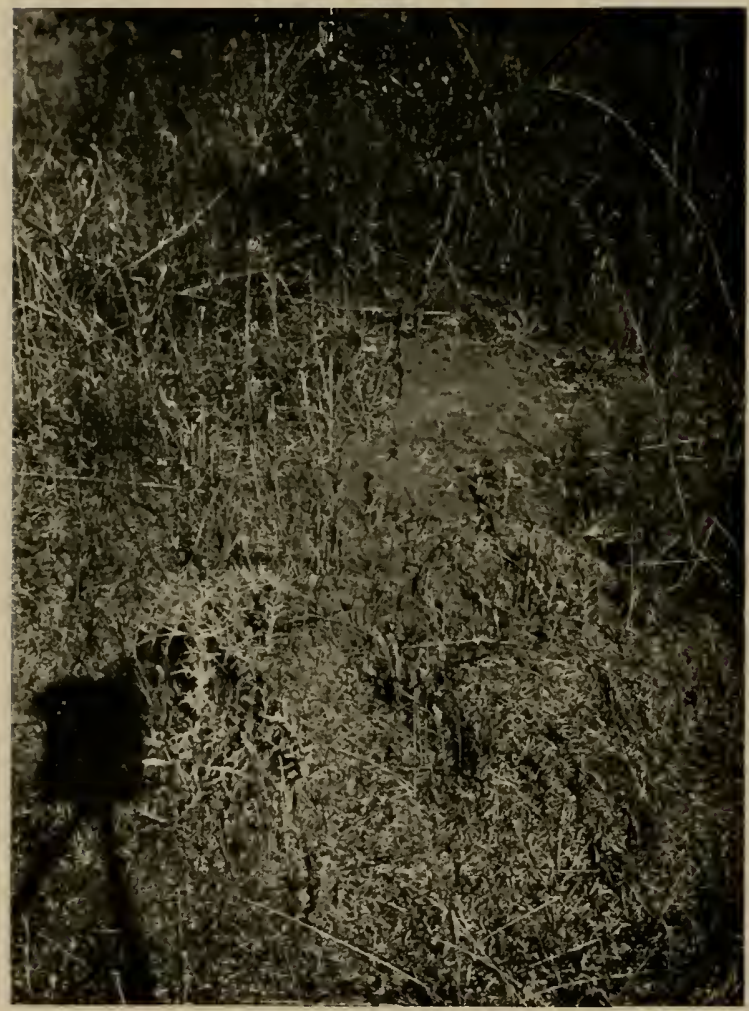

Abb. 87. Freie Stelle am Nestausgang. Darunter Abfallhaufen. Nest von Messor barbarus meridionalis E. André. Kaluckova 26. Aug. I917. bei dieser Arbeit vorherrschten. Auf den Straßen entfaltete sich nun bald ein lebhaftes Treibell. In großen Zügen wanderten die Ameisen vom frühen Morgen an in die Umgebung hinaus und bald schon begegneten ihnen schwer beladene Nestgenossen, welche Beute eintrugen. An alle Pflanzen der Umgebung machten sie sich heran, pflückten die Samen, die Schoten, die Ähren und Blütenstände $\mathrm{ab}$ und warfen sie auf die Erde herunter. Und unten warteten schon andere Messor-Arbeiter aller Größen, zerschnitten die Pflanzenteile, beluden sich mit ihnen und wanderten zum Nest zurück. Oft sah man einen kleinen Arbeiter sich mit. einer ganzen Grasähre abschleppen, andere trugen Schoten, Kapseln, Doldenteile und die verschiedensten Sorten von Früchten. Je heißer der Tag wurde, desto schneller und eifriger ging die Arbeit vor sich und im Frühsommer sah man sie in den heißen Mittags- 
stunden die Straßen entlang geradezu hasten. Hier und da schleppten Gruppen von Ameisen einen langen Grashalm; dabei wie bei dem ganzen Erntegeschäft waren Tiere aller Größenordnungen beteiligt. Schon frühere Beobachter haben festgestellt, daß die Körnerameisen die Samen aller in der Umgebung wachsenden Pflanzen eintragen, und daß man nicht selten $30-40$ Arten von Pflanzensamen im Neste nachweisen kann.

- Hat man am frühē "Norgen zu beobachten angefangen, so sieht man nach einiger Zeit das Bild sich ändern. Nun sind auch die aus dem Nest kommenden Ameisen schwer beladen, aber sie haben keinen so weiten Weg als die mit der Ernte einziehenden. Sie legen ihre Last in der Entfernung von 50 $\mathrm{cm}$ bis höchstens einem Meter vom Nesteingang ab. Und ebenso schnell wie beim Bauen der Ringwälle kehren sie um, nachdem sie, was sie trugen, schnell abgeworfen haben und rennen

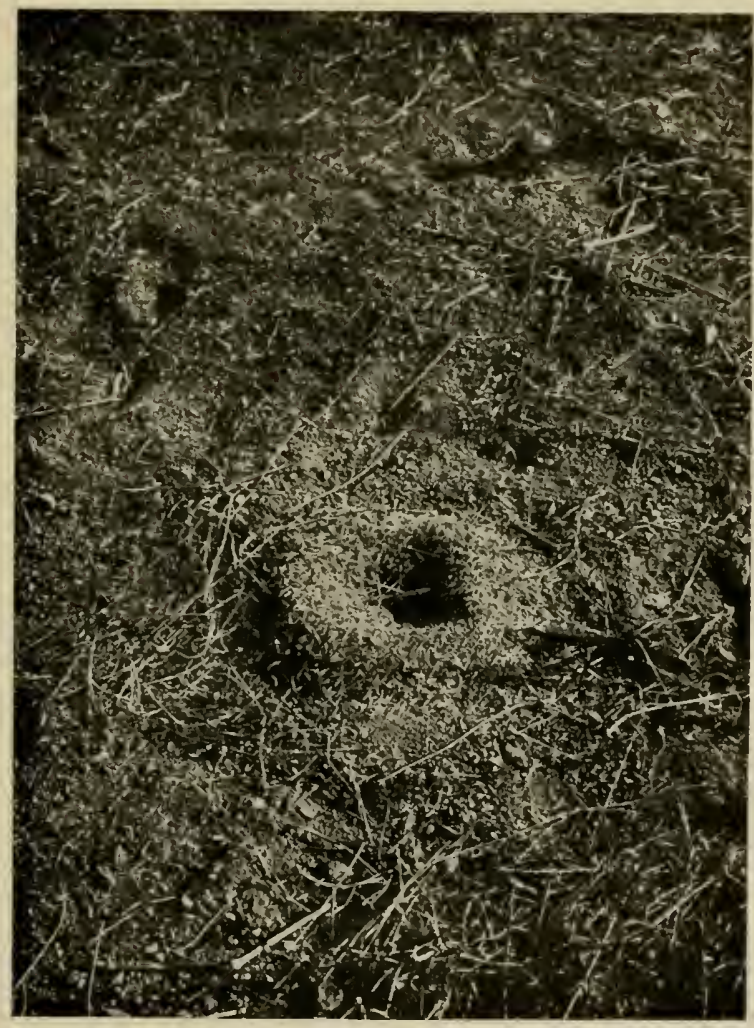

Abb. 88. Ringförmiger Abfallhaufen um den Nestausgang eines Nestes von Messor barbarus meridionalis E. André. Kaluckova 26. Aug. 1917. zum Nest zurück, um neue Last zu holen. Was sie hinausschleppen, das ist A bfall; die leeren Schalen, Schoten, Kapseln der vorher eingetragenen Samen, es sind die Grannen und Spelzen von den Grasähren, dazu kommt allerhand Unnützes, was sie mitgenommen hatten. Denn es kommt häufig vor, daß die Körnerameisen im Eifer alle möglichen Dinge in ihr Nest tragen, die sie dort nicht brauchen können. So hat man in anderen Ländern gesehen, daß sie Beine 
und Flügel von Käfern, Schneckenschalen, Kuhmist in die Nester schleppen; und ich habe ja oben schon beschrieben, daß sie im Frühjahr auch unreife Samen, selbst Blütenteile, Blattstücke u. dgl. eintragen. Es sind das wohl psychologisch sehr interessante Schwankungen und Irrungen des Sammelinstinkts.

Die Sortierung des Unnützen von dem Wichtigen findet erst im Nest statt; was unbrauchbar und irrtümlich eingetragen war, wird in den Kammern aussortiert und aus dem Nest wieder beseitigt.

Nun wußte ich also, was die vermeintlichen A meisenhaufen waren, die mich ursprünglich so überrascht hatten. Es waren die Abfallhaufen der Körnerameisen; diese erreichten oft eine Höhe von 30 , 50 selbst $80 \mathrm{~cm}$ Höhe, sie waren ein Zeichen der Arbeitsleistung, die von den Insassen eines Nestes vollbracht worden war. Die Pflanzenteile trocknen auf den Abfallhaufen sehr bald aus, und werden dann wie feingeschnittes Heu leicht vom Wind fortgeblasen. Die Haufen sind kein wesentlicher Bestandteil der Bautätigkeit der Ameisen, sie entstehen und vergehen, ohne daß die Ameisen sich weiter um sie kümmern. Diese laufen ja nur auf der Oberfläche herum und kaum jemals dringt eine von ihnen freiwillig in das Innere des Haufens ein. Meistens liegen die Abfallmassen in der Nähe des Nestes; liegt dieses am Abhang, dann befinden sie sich abwärts von ihm. Während der eifrigsten Arbeitszeit entsteht auch manchmal ein Ring wall aus den Abfallmassen, ähnlich wie bei den Erdbauten, auch da kommt es vor, daß ein solcher Wall halbmondförmig ausfällt, wenn das Nest am Abhang liegt und die Tiere unmittelbar neben dem Loch den Abfall abwerfen. Dann müssen sie allerdings später wieder aufräumen, um ihre Straßen frei zu bekommen.

Um festzustellen, was die Ameisen im Nest mit dem Resultat ihrer Sammeltätigkeit anfingen, mußte ein Nest aufgegraben werden. Das geschah unter meiner Aufsicht viele Male zu den verschiedenen Jahreszeiten, um die verschiedenen Geschehnisse im Nest verfolgen zu können. Es war keine einfache Arbeit, besonders im Sommer, in die ausgetrocknete harte mazedonische Erde einzudringen. Mit Hacke und Schaufel hatte man zu arbeiten, obwohl die Nester nicht sehr tief im Boden lagen, $\mathrm{I}-\mathrm{I} 1 / 2 \mathrm{~m}$ erstreckten sich die Gänge und Kammern in die Tiefe. Von der Ausgangsöffnung ging ein ungefähr $2 \mathrm{~cm}$ weiter Gang etwa $30 \mathrm{~cm}$ fast senkrecht hinunter. Seine Wände waren schön geglättet; er hatte einen 
176

des Getreides tätig. Hier wurde also sozusagen gedroschen. Es war ein entzückender Anblick, den Tieren zuzusehen, wie sie die Körner aus den Ähren herausnahmen, wie sie die Schalen abschälten, die Kapseln öfneten und die sauberen Samen aus den Schoten herausholten. Diese Arbeit wurde mit ihren Kiefern ausgeführt. Mit diesen zerknackten sie die Schalen, bogen und brachen Teile ab, griffen die Samen und legten sie zur Seite.

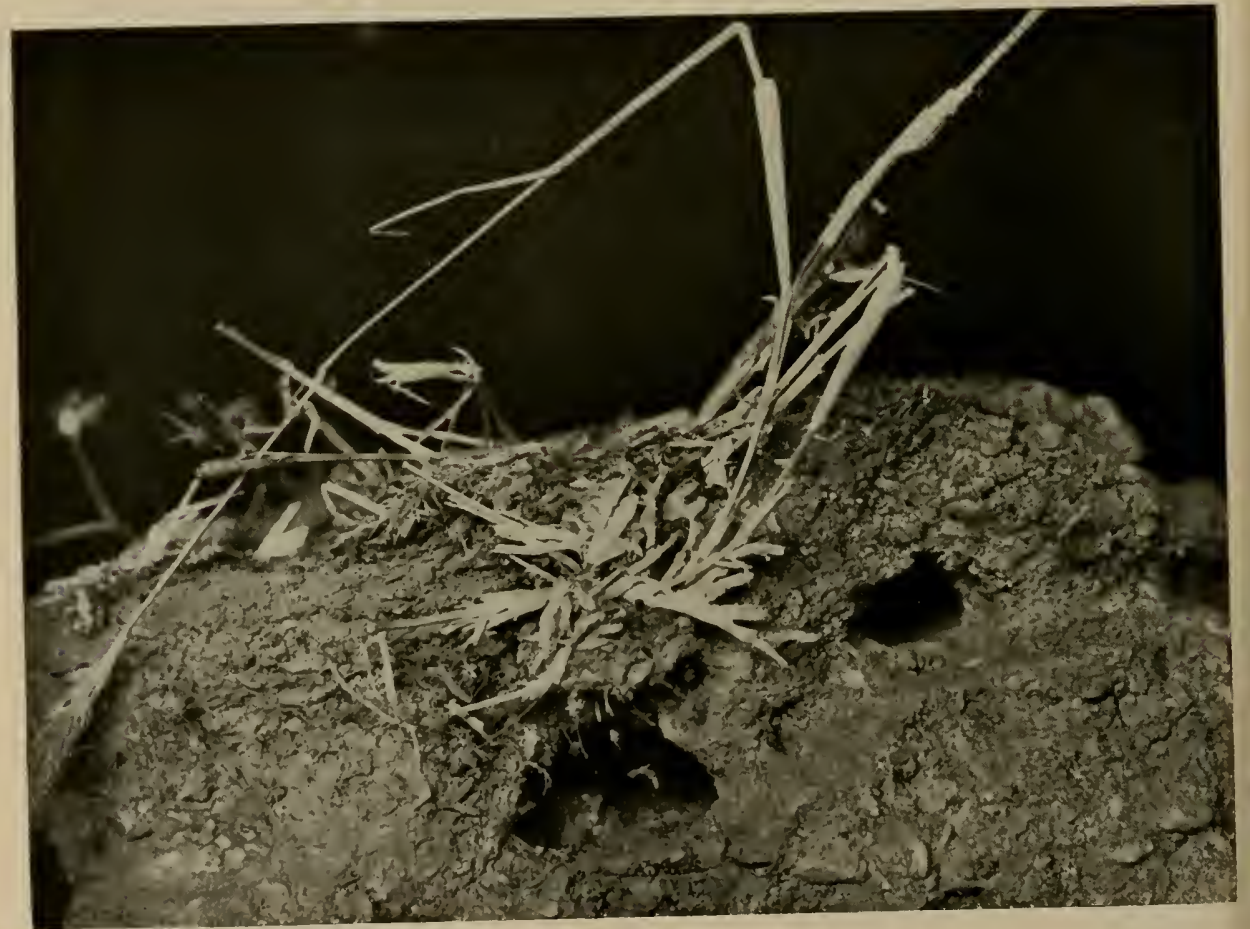

Abb. 90. Nestkammern von Messor barbarus meridionalis E. André. Kaluckova August 1917.

In den Scheunen waren wieder Arbeiter aller Größen tätig. Allerdings überwogen etwas die kleinen und kleinsten Typen; letztere waren es vor allem, welche die sauber geputzten Körner aus den Scheunen in die tiefer gelegenen Getreidespeicher schleppten. Unterdessen war ein Menge anderer Arbeiter schon dabei, die Abfallstücke durch die Gänge aufwärts, aus dem Nest heraus und auf den Abfallhaufen zu schaffen.

Dabei war es nun sehr merkwürdig, daß hier im Innern des Nestes zwischen Nützlichem und Unnützen sehr gut unterschieden 
wurde. Unreife Samen, Blumenblätter, Schneckenschalen, Stücke von Insektenkörpern wurden ausgesondert und auf den Abfallhaufen getragen. Hier fand also eine viel feinere Unterscheidung statt, als draußen unter dem Einfluß des Sammelinstinkts.

Hatten die Ameisen in der Nähe ein geeignetes Erntefeld mit einheitlichem Wachstum gefunden, so fanden sich oft in den Kammern sauber aussortiert die Samen nur einer Pflanze. So entdeckte ich z. B. einmal Wickensamen, ein andermal Grassamen in fast allen Kammern eines Nestes als einziges Ernteresultat. Und vor allem konnten andere Beobachter eine solche Einheitlichkeit der Vorräte feststellen, wenn das Ameisennest in der Nähe eines Getreidefeldes sich befand. Dann waren oft große Massen von Weizen-, Gerste- oder Roggenkörnern schön reinlich in den Kammern aufgeschichtet.

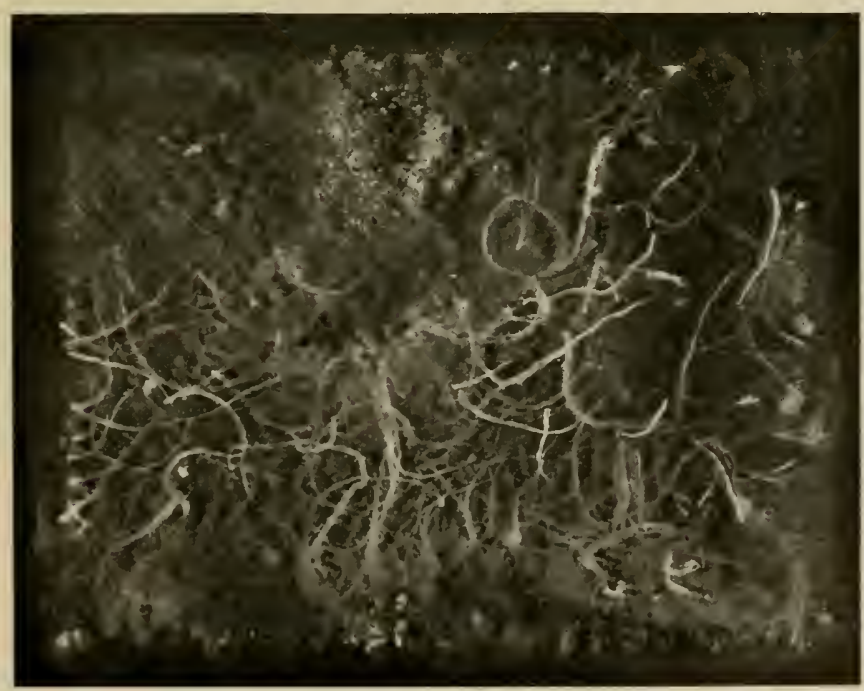

Abb. 91. Zukleben des Glasdeckels eines Fieldenestes mit Drüsensekretstreifen.

Diese eigentümlichen Gewohnheiten der Körnerameisen kannten schon die Völker, welche im Altertum um das Mittelmeer herum wohnten. Nicht nur spricht Salomo in seinen Psalmen von den Ameisen, welche in die Scheunen sammeln, sondern es gibt sogar jüdische Gesetze, welche bestimmten, wer der rechtmäßige Eigentümer der von den Ameisen gesammelten Getreidevorräte ist.

In vielen Fällen konnte ich mich überzeugen, daß die Körner in den Vorratskammern ganz trocken lagen, und daß sie trotz 
monatelangen Liegens nicht zum Keimen gekommen waren. Es war auffallend, daß die Kammern, in denen die Körner lagen, mit einer eigentümlichen hellgrauen Masse gleichsam auszementiert waren. Später konnte ich in künstlichen Nestern feststellen (Abb. 91), dalb diese eine schwer benetzbare wachsähnlich aussehende Substanz ist, welche wahrscheinlich aus den Analdrüsen der Ameisen stammt. Sie schmierten diese auf die Glasdeckel der künstlichen Nester, in welchen ich sie hielt, offenbar dabei einem besonderen Instinkt folgend. Diese Abdichtung der Kammerwände spielt wohl eine nicht unwesentliche Rolle bei der Verhütung der Keimung der Samen. Im Lauf des Sommers nahmen die Vorräte in den Messor-

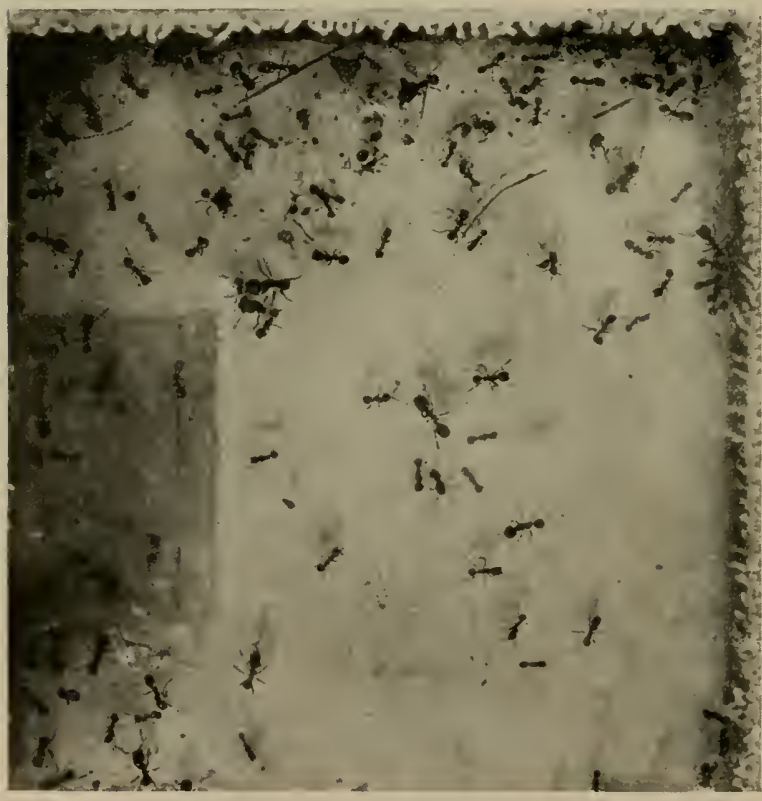

Abb. 92. Verschiedene Arbeiterformen von Messor bar. barus E. André im Fieldenest.

Nestern immer mehr zu. Von Woche zu Woche füllten sich die Kammern mit sauber geputzten Körnern und allmählich wurden die Scheunen leerer und rückten immer mehr zu Speichern auf. Aber noch langein den Herbst hinein wurde noch gesammelt; immerhin hatte der Eifer der Sammler in dieser Zeit etwas nachgelassen. Am stärksten war die Sammeltätigkeit

im Frühsommer, als die meisten Samen reiften. Interessant war die Beobachtung, daß während der größten Hitze, im Juli und August, die Körnerameisen die gleiche Mittagspause machten wie alle Tiere und Menschen im Lande. In den heißesten Stunden des Tages waren ihre Straßen leer. Dafür arbeiteten sie wie die mazedonischen Bauern vom frühesten Morgen bis tief in den Abend hinein, ja in hellen Mondnächten oft bis gegen den frühen Morgen.

Wir haben oben festgestellt, daß der Hochzeitsflug der Körner- 
ameisen im April stattfindet. Es muß wohl auch die Zeit sein, in welcher die alten Königinnen eifrig beim Eierlegen sind. Denn im Juli finden sich in den Messor-Nestern in großen Mengen Larven aller Stadien und auch schon Puppen. Später im Sommer findet man auch die großen Puppen der Geschlechtsformen.

In der zweiten Hälfte des Sommers wurden die Nester immer volkreicher. Dann wimmelt es in Mazedonien geradezu von den Körnerameisen. Offenbar muß in dieser Zeit für die Larven und das vermehrte Volk im Neste Platz geschaffen werden, denn nicht selten sieht man dann frische Ringivälle um die Nestausgänge sich bilden. $\mathrm{Zu}$ dieser Zeit sind im Innern neue Kammern gebaut worden. Die Larven und Eier finden sich in der Regel in den untersten Kammern, hier und da bemerkte ich in solchen auch geringe Spuren von Bodenfeuchtigkeit.

Die Zeit, in welcher viele Larven gefüttert werden müssen, ist offenbar diejenige, in welcher die Samenvorräte zur Verwendung kommen. Wir haben ja oben gesehen, daß die Messor-Arbeiter selbst gern und viel Insekten fressen. Die Messor-Arten sind nahe verwandt mit

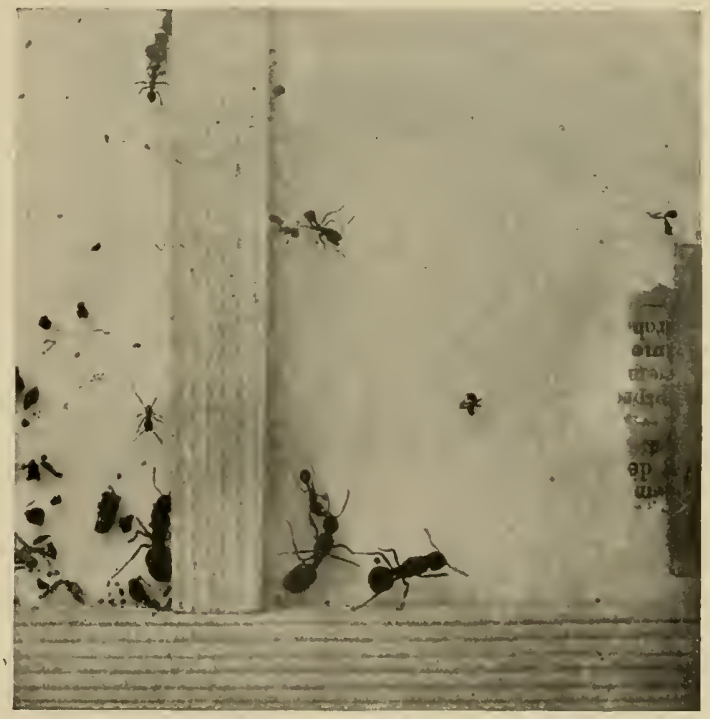

Abb. 93. Drei Königinnen mit Arbeitern im Fieldenest. Messor barbarus meridionalis E. André. Mittlerer Arbeiter füttert Königin. Üsküb Zitadellenberg. Phot. 12. April 1918.

Ameisen, welche sich fast ausschließlich von Insekten ernähren. Aber offenbar reicht mit dem fortschreitenden Sommer und der zunehmenden Zahl der Erwachsenen und Jugendstadien im Nest die Menge der Insekten in der Umgebung nicht aus; und so ist jetzt die Zeit, wo, vor allem für die Larvenernährung, auf die Samenvorräte zurückgegriffen wird. Manche Samen können die Ameisen wohl ohne weiteres benagen und nach den Untersuchungen von Emery ist festgesellt, daß sie im Samen den 
eiweißreichsten Teil, nämlich den Embryo, bevorzugen. Offenbar reichen sie solche Bestandteile der Samen in zerbissenem.Zustand mit Speichel vermischt auch ihren Larven als Nahrung.

Aber noch mehr leisten sie, um die Samen richtig verwerten zu können. Wenn im Sommer Regengüsse fallen, dann sieht man die Körnerameisen eine sehr merkwürdige Tätigkeit ausführen. Jetzt schleppen sie von ihren Körnervorräten aus dem Nest heraus und legen die Körner in den Regen. Ich habe dies in Mazedonien vielfach beobachten können. In den warmen Stunden nach dem Regen keimen die Samen sehr bald und werden wieder in das Nest hineingetragen. Das kleine Stückchen, welches herausgekeimt ist, stellt offenbar eine weiche, gut, besonders für die Larven verwertbare Nahrung dar. Sind Keime zu weit entwickelt, so werden sie entweder von vornherein draußen gelassen, oder wenn sie ins Nest getragen worden sind, drinnen als ungeeignet aussortiert und auf den Abfallhaufen geschafft, wo sie bald vertrocknen. So benützen die mazedonischen Körnerameisen ihre Vorräte zu der Zeit, wo sie sie am nötigsten brauchen. Es sind nicht etwa Wintervorräte bei ihnen, sondern im wesentlichen Reserven für die dürrste und insektenärmste Zeit des Jahres. Anders verhält es sich bei den Körnerameisen in Südfrankreich, die offenbar für den dort milden Winter sammeln und für die Formen der Wüste Nordafrikas, deren knappste Zeit offenbar der heiße, trockene Wüstensommer ist.

Der italienische Forscher Emery hat gezeigt, daß die Körnerameisen sogar Makkaroni gern fressen und als Futter für ihre Larven verwenden. So sind sie denn tatsächlich in einem gewissen Teil des Jahres Vegetarianer und finden in den Samen eine für ihre Ernährung wichtige Kohlehydratquelle. Auch ich konnte in Mazedonien bestätigen, daß die Messor-Arten niemals Blattläuse aufsuchten oder in ihre Nester schleppten. Diese Zuckerquelle, welche sonst bei Ameisen so beliebt ist, benützten in nächster Nachbarschaft der Messor-Nester andere Ameisenarten auch in Mazedonien in ausgiebiger Weise. Jene aber rührten die Blattläuse nicht an.

Sowohl in Mazedonien als auch in der Heimat hielt ich K ö rner ameise $\mathrm{n}$ in künstlichen sog. Fieldenestern und konnte an ihnen eine ganze Reihe interessanter Beobachtungen machen, welche zum Teil die Feststellungen im Freien bestätigten, zum Teil neues lehrten. Wie merkwürdig und eigenartig sind doch die Instinkte dieser Tiere ausgebildet. Wie energisch äubert sich bei ihnen der 
Sammeltrieb und führt sie zur Anlage von Scheunen und Getreidekammern. Aber wie merkwürdig schwankend zeigt sich dieser Instinkt im Freien bei der Unterscheidung des Nützlichen und Nutzlosen. Wie sicher ist er dagegen bei der Aussortierung der gesammelten Vorräte, wenn diese im Nest sich befinden. Was mögen da für Gesetzmäloigkeiten vorliegen, wie mag die ganze eigenartige Biologie dieser Formen $z u$ erklären sein? Sie bieten sicher noch interessante Probleme, die manchen Forscher locken dürften.

Das gleiche gilt auch für die gelben Ameisen der Art Pheidole pallidula Nyl., die ich vor allem im südlichen Wardartal und im Gebiet des Doiransees fand. Das ist jene oben erwähnte einzige europäische Ameisenart mit echten Soldaten. Auch diese habe ich viel im Freien beobachtet und in künstlichen Nestern gehalten.

Dabei zeigte sich, daß bei ihnen die Soldaten viel einseitiger in ihren körperlichen Leistungen und in ihren Fähigkeiten sind als die Dickköpfe der Messor-Arten.

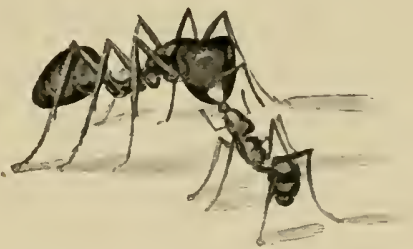

Abb. 94. Soldat von Pheidole pallidula von Arbeiter gefüttert.

Die Pherdole-Soldaten sind viel unbeholfener bei der eigenen Ernährung als ihre Arbeiter, von denen sie sich oft füttern lassen. Sie nehmen auch kaum an den Bauarbeiten im Staat und an dem Eintragen der Nahrung teil. Ein Volk, welches nur aus Soldaten besteht, deren Arbeiter verloren gegangen sind, stirbt bald aus; denn erstere beteiligen sich nicht an der Pflege der Königin und an der Aufzucht der Larven. Allerdings bei der Verteidigung des Staats und seiner Insassen zeigen sie sich besonders energisch.

$\mathrm{Zu}$ welchen interessanten Vergleichen mit dem Menschenleben fordern diese eigenartigen sozialen Tiere heraus. 


\section{DIE SCHLUCHTEN DES BALKAN}

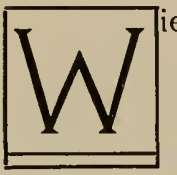

ie anders muß Mazedonien in den Zeiten vor der griechischen Kultur ausgesehen haben, aîs es heute sich darstellt. Es ist früher, soweit wir unterrichtet sind, ein waldbedecktes Land gewesen mit ganz anderem Klima. Auch die Oberflächengestaltung muß sehr abweichend gewesen sein, als thrakische Stämme das Land bewohnten. Die Berge hatten noch kaum ihre zerrissenen Formen, die Nacktheit der Landschaft trat nicht so schroff hervor, das Land muß viel weniger farbig gewesen sein und vor allem die Menge von Schluchten muß gefehlt haben, welche jetzt so charakteristisch für die Landschaft Mazedoniens sind.

Wie auch sonst in den Mittelmeerländern ist an der Oberflächengestaltung des Landes, wie sie uns heute entgegentritt, vor allem die Raubwirtschaft schuld, welche seine Bewohner mit dem Wald getrieben haben. Waldwirtschaft und Waldschonung sind Errungenschaften der neuesten Zeit. Zwar in Deutschland zeigen sich Ansätze dazu schon seit dem Mittelalter; Ehrfurcht vor und Pflege von Bäumen war den Germanen frühe Gewöhnung. Aber erst seit etwa zwei Jahrhunderten hat sich Schritt für Schritt eine geordnete Forstwirtschaft auch bei uns entwickelt. Daß gerade in Mazedonien mit dem Wald so barbarisch gehaust wurde, so daß er jetzt in diesem Land nur noch da existiert, wo die Menschen nicht an ihn heran können, ist zum Teil auch durch die Geschichte dieses Teils von Europa bedingt.

Bei den ungeordneten Zuständen, welche seit Jahrhunderten auf dem Balkan herrschten, dachte niemand daran, für die Zukunft vorzusorgen. Die unterworfenen Völker hatten keine Veranlassung, Naturschätze fur die künftigen Generationen ihrer Beherrscher zu erhalten. Und die Türken gar mit ihrem Fatalismus waren schwer zu weitausschauenden Plänen zu haben. So kam in diesem Land, wo die durch den Ruin der Wälder erzeugten Schäden jedem vor Augen standen, niemand darauf, über die Zusammenhänge nachzudenken und an Maßregeln zur Abhilfe heranzutreten. 
Sicher fanden die Byzantiner schon ein sehr entwaldetes Gebiet vor, und die Waldbestände, welche sie den Türken hinterließen, mögen in den Niederungen auch nicht mehr beträchtlich gewesen sein. Nun begann sich wohl der Raubbau auch auf die Gebirge auszudehnen und das Bild sich auch im Innern der Balkanhalbinsel auszubreiten, welches wohl schon die antiken Völker fast im ganzen Mittelmeergebiet hinterlassen hatten.

Nur wo das Klima mitwirkte, kam der Wald nicht wieder auf; im zentralen Balkan, wurde er nie ganz vernichtet. Die geologischen Verhältnisse mögen auch vielfach dazu beigetragen haben, seine Neuentstehung zu erschweren. Und vor allem waren es die weidenden Haustiere, welche durch Abfressen von jungen Baumindividuen, durch Benagen der frischen Sprosse die Baumarten entweder ausrotteten oder, wenn sie einigermaßen widerstandsfähig waren, zum $Z$ wergw uchs $z$ wangen. Noch jetzt kann man die verderbliche Wirkung der ungestört weidenden $\mathrm{Ziegen}$ - diese sind es vor allem, welche als Waldfeinde in Frage kommen - überall in den Mittelmeerländern beobachten.

Heute findet man in Mazedonien nur mehr im Gebirge ausgedehntere Laub- und Nadelwälder. Auf meinen Gebirgsreisen habe ich solche kennen gelernt und in den entsprechenden Kapiteln geschildert. Die Balkankriege und gar noch der Weltkrieg haben eine weitere empfindliche Lücke in den Baumbestand des Balkan geschlagen. Bei Freund und Feind war für Bauten zu militärischen Zwecken und zum Heizen im Winter ein ganz enormer Verbrauch unvermeidlich, dessen Folgen einem überall in traurigen Bildern entgegentraten. Noch 1917 hatte ich manche Baumgruppen und riesenhafte Exemplare von Ulmen, Eichen, Kastanien, Pappeln bewundert, die im nächsten Jahre schon verschwunden waren. Die Truppen mußten ja doch kochen und heizen; Import von Holz konnte nicht im nötigen Maßstab durchgeführt werden und die Kohlen waren noch viel schwerer heranzubringen.

Schon im Jahre 1917 fiel mir auf, daß Wälder in Höhen unter $1200-1500 \mathrm{~m}$ selbst im Gebirge nur da erhalten waren, wo der Mensch keine Zufahrtsstraßen hatte, um größere Massen von Holz an die Verbrauchsstätten zu bringen. War auch nur ein Saumpfad vorhanden und anlegbar, der für Maultiere gangbar war, so hatte sicher in jedem kleinen Waldbestand mindestens der Köhler sein Zerstörungswerk begonnen. Der rauchende Meiler zeigte an, wo und wie der Wald gemordet wurde. 
Auch hatte ich oft Gelegenheit, zu beobachten, daß keines der Balkanvölker Talent und Neigung hat, den Wald zu pflegen und an die Zukunft zu denken. Ich habe an anderen Stellen geschildert, wie die gefällten Bäume ganz unvollkommen ausgenützt und rücksichtslos zerstört wurden. Alle die einander hassenden Völker und Rassen kamen nie auf den Gedanken, daß noch einer nach ihnen kommen könne, der etwas von dem Wald haben wollte, und daß sie ihm das gönnen würden.

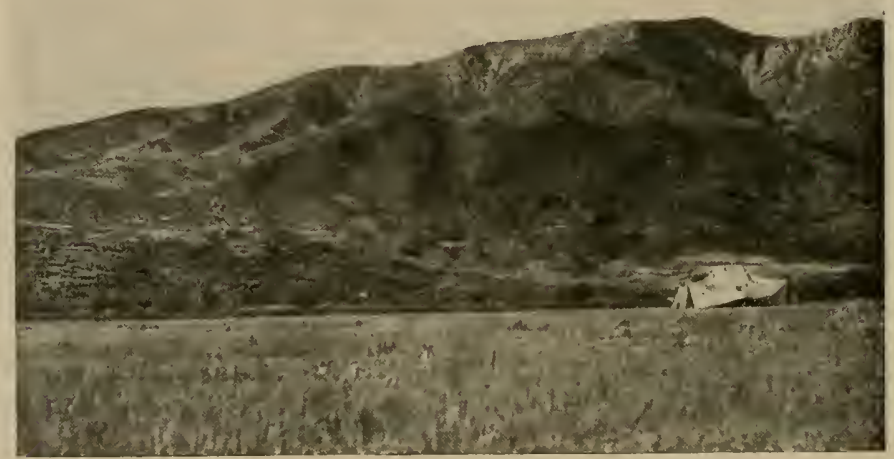

Abb. 95. Nordende der Plaguša Planina. Davor der Grünberg.

Sobald große Strecken entwaldet waren, konnten die Kräfte der Erosion ihre Arbeit beginnen und anfangen, die Berge zu zerstören. Ein Weg zu diesem Ende ist die Bildung von Schluchten. Wo der Waldboden nicht zwischen den Wurzeln der Bäume festgehalten wird, da saugt er das Wasser nicht fest und tief in sich hinein; wo nicht der Schatten der Bäume den Boden vor den ausdörrenden Strahlen der Sonne bewahrt, können keine dauerhaften Quellen sich ansammeln.

Überall in Mazedonien sehen wir heutzutage an jedem Berg, an jedem Hügel die zerstörenden Kräfte der Atmosphäre tätig. Nach jedem starken Regengul entstehen neue Rinnsale an den Abhängen. Das Wasser, vom harten, schon steinig gewordenen Boden nicht aufgesaugt, sammelt sich an dessen Oberfläche schnell in Massen an, welche tosend $z u$ Tale stürzend, den Boden aufwühlen und die spärliche Erdkrume mit sich reißen. So sieht man nach jedem Gewitterregen des Sommers, nach den schweren Güssen 
des Herbstes in Mazedonien hunderte und tausende von jugendlichen Schluchten sich bilden, deren weitere Entwicklungsgeschichte man überall an früher entstandenen verfolgen kann.

Je weiter das Wasser zu Tal fließt, um so mehr wird es, um so gewaltiger wird seine Kraft. Viele kleine Rinnsale vereinigen sich zu einem Wildbach, dieser schließlich zu einem Flüßchen, dessen Wasser schon große Steine, ja Felsenmassen loslösen und auf seinem Weg zu Tal reißen kann. Mächtige Halden bilden sich auf diese Weise an den Abhängen der Berge.

Im Winter gefriert das in die Spalten eingedrungene Wasser und es beginnt die Arbeit des Frostes und des Tauwetters. Die Regengüsse des neuen Jahres finden neue Beute. Die herabgeschwemnten Felsblöcke zerschlagen die Felsen, über welche sie rollen, und schleifen sie und sich gegeneinander ab. So sind es immer kleinere Steine, die unten im Tal anlangen, um so kleiner, je länger der Weg ist, den sie vom Berg zurücklegen müssen, je größer die

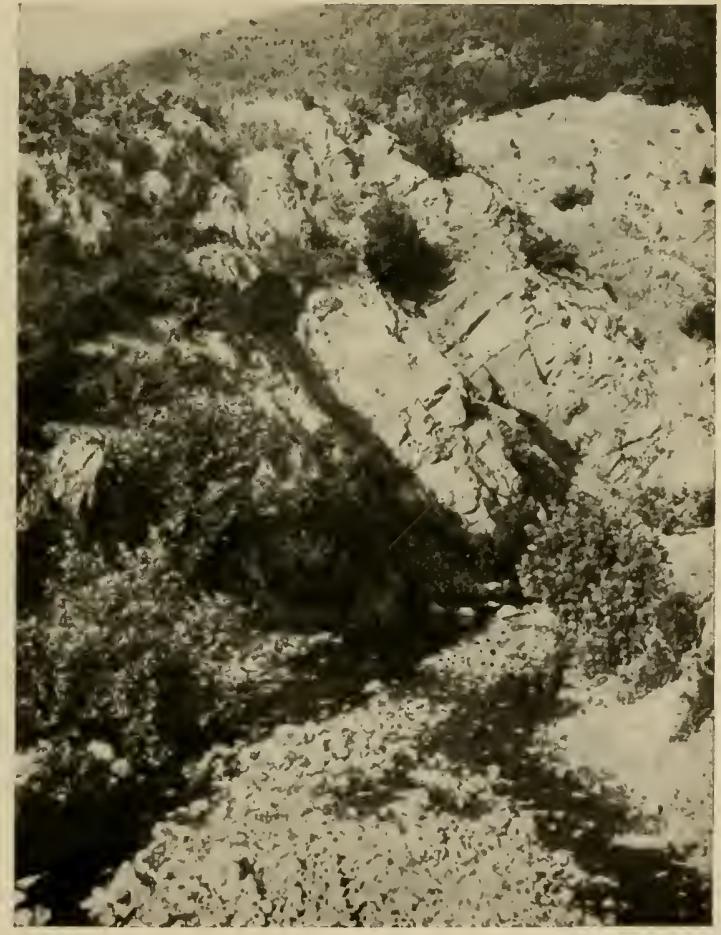

Abb. 96. Schluchtende einer Felsenschlucht bei Negorci mit geröllreichem Bach. Gewalt des Wassers ist, das sie mitriß.

Die Schlucht wird von Jahr zu Jahr tiefer; ihre Wände können schließlich steil $100 \mathrm{~m}$ und höher hinansteigen und die ganze tiefe Schlucht ist das Werk von vielhundertjähriger Arbeit des Wassers und der Steine. Überall in Mazedonien sieht man Schluchten in allen Entwicklungsstadien: ganz junge, die noch sehr harmlos aussehen, mittlere Stadien, welche schon tiefe Falten ins Antlitz des Berges gerissen haben, ältere, welche das Gebirge 
durchbrochen haben und Ströme zu Tal wälzen. Und den traurigsten Eindruck machen die ganz alten, welche ihre Felsblöcke schon zu Kieseln, zu Sand, ja zu feinem Schlamm zermahlen haben, den sie in das Tal über die fruchtbaren Felder schwemmen, so daß vom Ausgang der Schlucht eine lange Zunge von Geröll in die Ebene sich hinausstreckt, welche an das Delta eines Flusses erinnert. Sie ist ja gleichen Ursprungs mit einem solchen; ihr Wasser hat aber die Zerstörung und den Aufbau auf einer Strecke ausgeführt, welche es in Minuten, höchstens einer halben Stunde durchbrauste, während

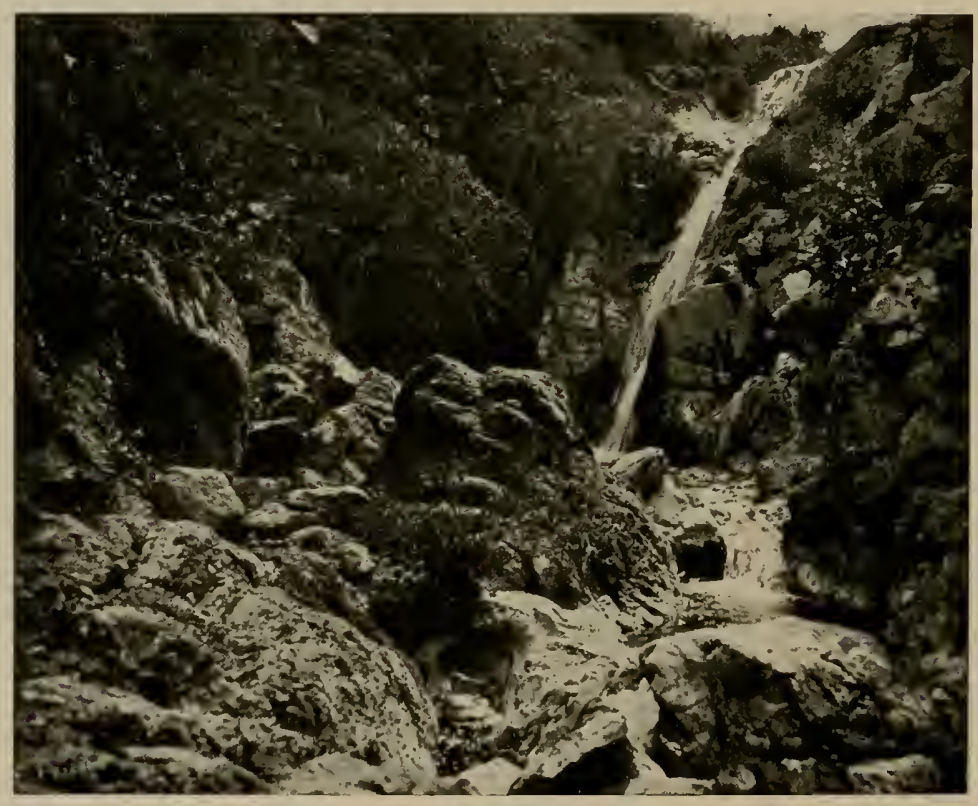

Abb. 97. Schlucht mit Wasserfall bei Davidoro.

der Nil in stiller Arbeit hunderte Kilometer zurücklegte, überall auf seinem Weg Segen austeilend.

Solche Schluchten habe ich während meines Aufenthalts in Mazedonien hunderte durchwandert. Bald dienten sie zum Anstieg ins Gebirge, bald mußte man, an der Flanke des Berges entlang wandernd, in ein Dutzend Schluchten an einer Seite hinab, an der anderen Seite hinaufsteigen, um seinen Weg zu finden, wollte man nicht den ganzen Berg umgehen.

Kaluckova liegt, wie ich früher schon schilderte, am Ausgang einer solchen Schlucht, die mir Anlaß gab, manche Beob- 
achtung über das Wesen der Schluchten, ihre Pflanzen- und Tierwelt zu machen. Ging man in die Schlucht hinein, so wanderte man zunächst auf dem weichen Sandboden eines Tälchens, in welches drei Schluchten einmündeten. Deren Boden war von grobem Gerölle bedeckt. Weiter oben kam man in eine immer enger werdende Schlucht, deren Boden aus anstehendem Felsen bestand. Auf ihm lagen größere und kleinere Felsblöcke herum. Durch diese wurde das Wasser des Baches oft zu kleineren und größeren Tümpeln gestaut. Dazwischen fanden sich Talmulden

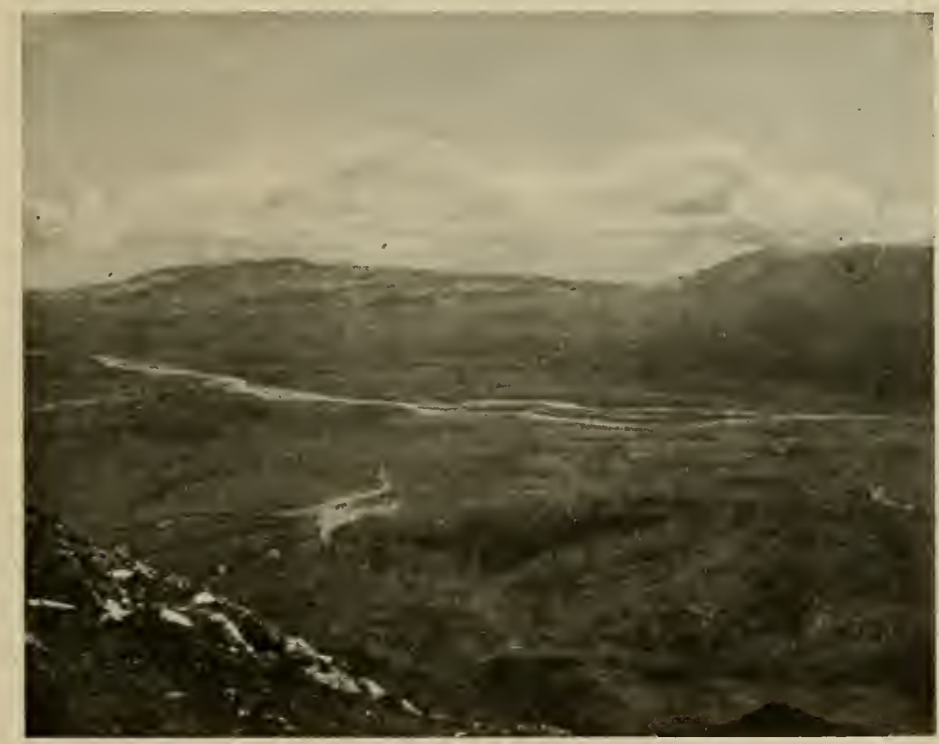

Abb. 98. Einblick in das System der dem Wardar zufließenden Bäche in der Hudovaebene von der Höhe der Plaguša Planina.

von verschiedenem Umfang, wo der Bach langsam floß und sich Gerölle, Sand oder Schlamm angesammelt hatte. Hier war oft eine reiche Pflanzenwelt entwickelt. Gräser, Riedgräser und Binsen, manchmal auch Kolbenschilf, bildeten da einen üppigen Rasen, zwischen dem Minzen, Doldenpflanzen, Glockenblumen blühten. Allerhand Pflanzen, welche draußen auf dem Hügel schon längst verdorrt waren, führten hier noch ein fröhliches Leben bis in den Juli und August hinein. Da blühten noch Orchideen, Wicken, Salbei, Königskerzen und viele andere.

In den Mulden zwischen den Hügeln wuchsen Kräuter heran, welche durch beträchtliche Größenverhältnisse auffielen. Es waren 
dies mächtige Exemplare von $\mathrm{K}$ önigskerzen, Disteln (Abb. 99) und dem Natternkopf. Besonders letzterer übertraf an Größe die bei uns einheimische Art ganz gewaltig. Die blauen Blütenstände, von Bienen und Hummeln umsummt, waren hier noch

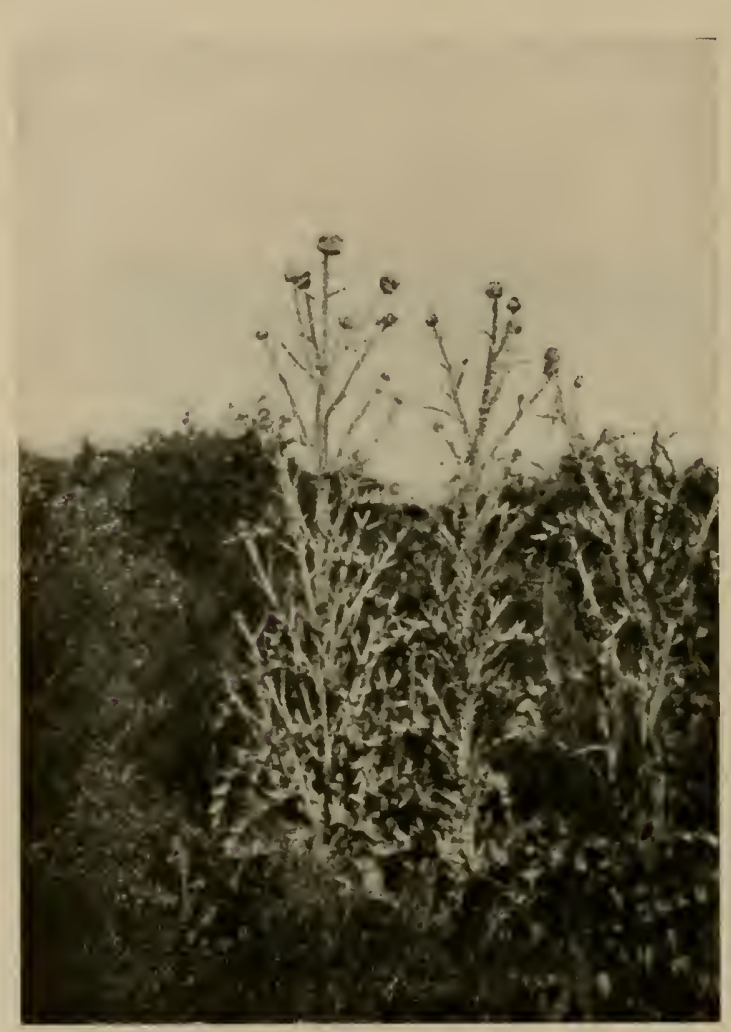

Dr. Laser phot.

Abb. 99. Cirsium candelabrum Gris. Hohe Distel bei Kaluckova, größer und in ihrem Blütenreichtum wirkungsvoller als die Exemplare an den Hügelhängen von Kaluckova und in den Maulbeerhainen bei Hudova. Die hier vorkommende Art war Echium italicum L. (Abb. 100).

Sie waren von vielen Schmetterlingen, Bienen, Fliegen besucht. Von der Tierwelt werden wir noch mehr zu berichten haben. Von Pflanzen fanden sich vielfach die gleichen stachlichen und dornigen Büsche, wie oben auf dem Hügel. Hier wuchsen vor allem Brombeersträucher, die einem nicht selten das Vorwärtskommen sehr erschwerten. Noch mehr war man aber beim Aufstieg behindert, wenn von einer Felsenstufe ein Wasserfall herabbrauste (Abb. 97). Oft mußte man eine weite Ungehungskletterei durchführen, wollte man seine Absicht durchsetzen, die ganze Schlucht kennen zu lernen. Oberhalb und unterhalb solcher Wasserfälle war das Wasser nicht selten zu stattlichen Gumpen angesammelt, deren grünes Wasser zum Bade verlockte. Oft habe ich mit meinen Gefährten die Gelegenheit ausgenützt und nach anstrengender Kletterei in einer solchen Naturbadewanne Erfrischung gesucht. War man gegen den oberen Schluß der Schlucht vorgedrungen, so 
wurde sie oft immer flacher; man war an manchen Zweigschluchten vorbeigekommen, welche dem Schluchtbach Wasser zugeführt hatten. So war er selbst immer dünner und schwächer geworden, bis er schließlich in einer Mulde in einem Grasbüschel zwischen Sand verschwand. Damit hatte man seine Quelle vor den Augen.

Im Laufe des Jahres ging mancherlei in den Schluchten vor sich. Im Winter hingen manchmal die Felsen voll Eiszapfen und ihr Grund wurde gelegentlich voll Schnee geweht. Aber vor allem in der Gegend von Kaluckova hielt das nicht lange an. Viel unangenehmer waren die anhaltenden schweren Regengüsse des Spätherbstes und Winters; dann sammelte sich in den Schluchten oft in wenigen

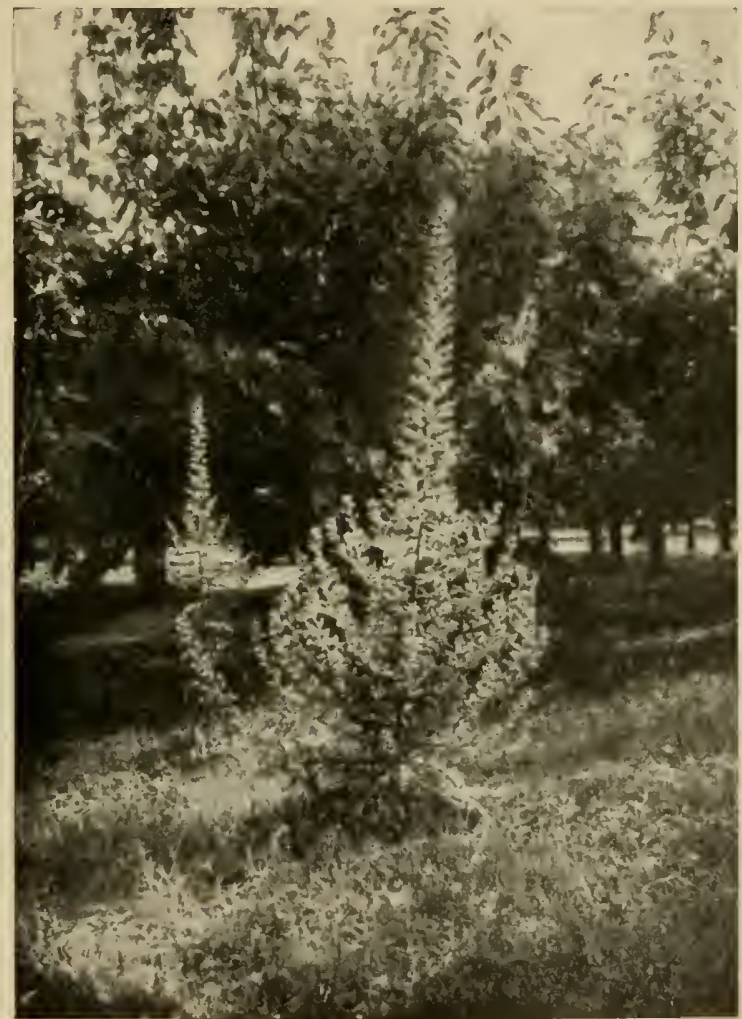

Dr. Laser phot.

Abb. 100. Großer, blaub)ühender Natternkopf (Echium italicum L.).

Stunden eine solche Wassermasse an, daß sie plötzlich durch das Schluchtende in das Dorf einbrach und das Tal in einen See voll schlammigen Wassers verwandelte. Dann war Not in Kaluckova (Abb. I o I). Da kamen die Stege zur Geltung, auf denen man laufen mußte, wollte man von einer Talseite auf die andere. Oft wurden die locker gebauten Brücken auch weggerissen und es erforderte Heldenmut, wollte der Arzt von den Häusern am Hügel zu seinen Kranken, die in Baracken an der anderen Talseite lagen. Meist verlief sich das Wasser in wenig Stunden und von dem stolzen gewalttätigen Fluß war nur ein dünner Wasserfaden 
übrig. Schlamm und Geröll hatte er aber in Massen hinterlassen, welche alle Wege verschüttet und in Gärten und eventuell auch an den Häusern Schaden getan hatten.

Der Bach in der Kaluckovaschlucht erreichte nur in solchen großen Momenten das Tal, aber auch dann wohl niemals den Wardar. Vorher war sein Wasser längst in den Geröllmassen versickert. Das ist ganz typisch für solche mazedonischen Schluchtbäche. Im Frühjahr beginnt der Bach schon seinen Rückzug bergauf, der nur nach einem starken Regen eine Unterbrechung erfährt. Immer weiter muß man hinaufsteigen, will man an fließendes Wasser gelangen. Nach der Trockenzeit des August und September sind manche Schluchten in ihrem ganzen Verlauf trocken.

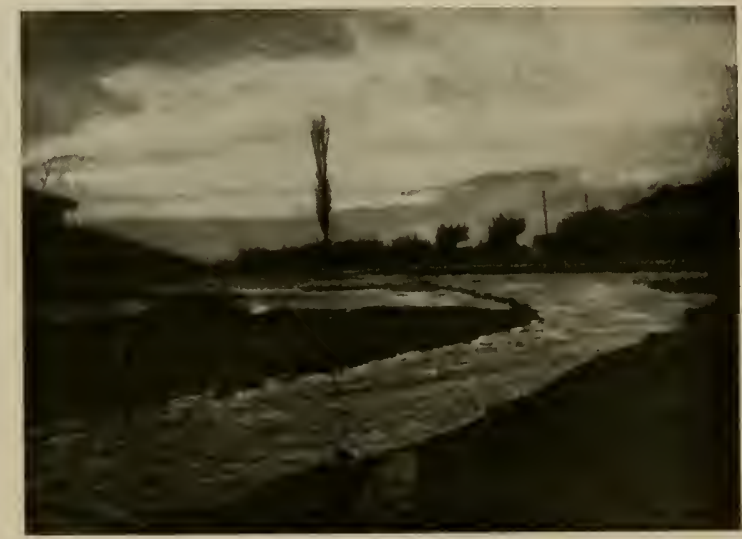

Dr. Las e r phot.

Abb. IOI. Kaluckovabach nach starkem Regen.

Dieser Prozeß verläuft ganz regelmäßig so, daß jeweils im Unterlauf in den Gruben und Vertiefungen größere oder kleinere Tümpel zurückbleiben, die allmählich eintrocknen, so daß man auch ihnen immer höher hinauf nachsteigen muß.

Das tut der Naturforscher gern und oft; denn in den Schluchten ist der Zufluchtsort für eine mannigfaltige Tierwelt, welche schon zu gewöhnlicher Zeit dort Schlupfwinkel und Höhlen leichter und mehr findet, als draußen auf dem kahlen Hügel. Dazu ist es hier auch im heißen Sommer immer feucht und kühl und wie die Pflanzen, so flüchten sich auch viele Tiere aus dem grellen Sonnenbrand in den kühlen Schatten der Schluchten. Wie ich das schon vom Buchenwald auf der Plaguša Planina beschrieb, so stellen auch die Schluchten einen Zufluchtsort für viele Tiere dar. 
Man treibt beim Klettern in den Schluchten nicht nur Ratten und Mäuse, sondern auch Marder, Füchse, Dachse und den großen mazedonischen Hasen auf. Ratternd fliegen Steinhühner (Alectoruis graeca graeca Meicen.) vor unseren Schritten davon. Ammern, Nachtigallen, allerhand kleine Vögel beleben die Büsche der Schluchten. Schlangen und Eidechsen sind an den Schluchtwänden häufig. Nicht selten halten sich hier die Landschildkröten Testudo graeca L. und T. ibera Pall. auf.

Viele Tiere kommen an die Tümpel zum Trinken. Das kann man vor allem in den frühen Morgenstunden und gegen Abend beobachten. Für manche Insekten, so für Schmetterlinge, mag auch die Windstille in der Tiefe der Schluchten verlockend sein.

Vor allen Dingen interessant ist aber die Tierwelt des Baches, welche hauptsächlich seine Becken und Tümpel bewohnt. An ihr ist manche interessante Beobachtung zu machen, und es hatte einen großen Reiz, sie im Verlauf eines Jahres zu verfolgen. Darum gehörten die Schluchten bei Kaluckova zu den Gegenden, welche ich in Abständen regelmäßig während aller Jahreszeiten besuchte, um die Schicksale ihrer Tierwelt zu verfolgen.

Im Winter zur wirklich kalten Zeit war sie nicht allzu reich. Die Wassertiere wurden gar zu leicht mit den Wasserstürzen nach Regengüssen hinabgerissen und kamen um, irgendwo auf Sand und Geröll vom abfließenden Wasser zurückgelassen. So kamen denn Fische in den Schluchtbächen selten vor und dann nur in den großen Gumpen, die nicht ganz ausgeschwemmt werden konnten. Selten fand ich da einmal kleine Barben (Barbus plebejus Val.); in der Kaluckovaschlucht habe ich allerdings niemals Fische gesehen.

Um so zahlreicher waren die Amphibien vertreten, von denen mehrere Formen in den Schluchten lebten und in den Tümpeln laichten.

Der kleine graue Frosch (L) Rana graeca Blgr. mit seinem braungefleckten, hellen Bauch war schon früh beim Laichen. Auch der große Frosch Mazedoniens (Rana ridibunda Pall.) legte im Schluchtbach seine Eier ab, aber erst im Mai, während der erstere dann schon in stattlichen Larven vertreten war. Noch später war die sehr häufige Unke (Bombinator pachypus Blgr.) mit der Fortpflanzung dran; sie laichte erst im Juli. Noch Mitte Juli fand ich Unken bei Kaluckova beim Eierlegen. 
Ganz außerordentlich reich war in den Schluchten die Insektenwelt. Sie bestand zum Teil aus Formen, welche hier die Blüten aufsuchten, während draußen auf den Hügeln alles schon verdorrt war. So schwebten zahlreiche Schmetterlinge über den Stellen der Schlucht, wo die oben gekennzeichnete üppige Vegetation sich entwickelt hatte. Hier war es vor allem, daß man, wie in der Nähe der Dörfer, die gewöhnlichsten deutschen Schmetterlinge antraf, den großen und kleinen Fuchs, das Tagpfauena uge, das weiße C, dazu die Weißlinge; unter den 4-5 mitteleuropäischen Arten allerdings manchmal etwas Besonderes, so Pieris manni Mayr.; daß der Distelfalter, der häufigste Tagschmetterling Mazedoniens, nicht fehlte, braucht kaum betont $\mathrm{zu}$ werden. Von vielen Formen sah man im Verlauf des Sommers zwei Generationen, die als Frühlings- und Sommergeneration nach Farbe und Größe zu unterscheiden waren, so z. B. von Colias croceus Faure, der dort fliegenden Form der goldenen Acht.

Von den drei Arten von Scheckenfaltern (Melitaea phoebe. M. trivia und $M$. didyma) war das Vorkommen des letzteren besonders interessant, da er hier in der südlichen Form flog, während im Gebirge bei Gopes die nördliche Form lebte. Aulerdem ist die Tatsache bemerkenswert, daß von Melitaea trivia und didyma die zweite Generation auffallend klein ist. Unter den $A$ u ge $n$ fal t e r $n$ der Gattung Satyrus fiel $S$. statilimus Hafn. auf, noch mehr $S$. fatua Frg., die erst vor kurzem in Europa aufgefunden wurde (Abb. 24, S. 46). Von den zahlreichen Bläulingen hebe ich Cyaniris argiolus $\mathrm{L}$. hervor. Im Hochsommer drangen um die Blumen die Taubenschwänzchen (Macroglossa croatica) und die auch bei uns so häufige Macroglossa stellatarum. Beide flogen im Herbst massenhaft in die Häuser. Ich habe hier etwas mehr von Schmetterlingen berichtet, da sie auf interessante Gesetzmäßigkeiten der Tiergeographie aufmerksam machen.

Auch an Käfern waren die Schluchten sehr reich. Schöne Böcke saßen auf den Doldenpflanzen, so der metallischglänzende Moschusbock (Aromia moschata L.), die kleine, rotschwarz gefleckte Leptura cordigera Finly, die zierlichen Widderböcke (Clytus ornatus Hbst., Cl. rhamni Germ., Cl. floralis Pall.). Von den großen Bockkäfern waren besonders auffallend Aulacopus sericollis Motsch und Prionus persicus Recht. Ein eigenartig gelblich behaarter Käfer mit weißen Flecken, der massenhaft vorkam, nennt sich Epicometes hirtella L. Auch hier wie überall am 
Wasser gab es die schönen, wie Edelsteine glänzenden Blattkäfer (Chrysomeliden). Dazu Melosoma populi (L.) Clythra elata Fabr. und $\mathrm{Cl}$. traphaxides Pall. Von Rüsselkäfern möchte ich nur die rotfleckigen Rhynchita hungarica Hel. und den schimmerden Rhynchites auratıs Les. erwähnen. An den Kräutern fand sich im Mai vielfach ein speichelähnlicher Schaum, wie er bei uns als „Kuckucksspeichel" bekannt ist; auch hier fand sich in ihm die Larve einer Zikade aus der Gruppe der Schaumzikaden, ähnlich unserer Aphrophora spumaria L.

Damit gebe ich nur eine kleine Auslese aus der Insektenwelt der Balkanschluchten. Schwebfliegen, solitäre Bienen, bunte Wanzen, Heuschrecken, wären noch anzuführen. Eine große Rolle spielten die Libellen, deren es zahlreiche Arten gab. Ganze Schwärme von Eintagsfliegen tauchten gelegentlich auf.

Sehr reich und charakteristisch war die niedere Tierwelt im Wasser. Auf den stillen Tümpeln blinkten die Taumelkäfer, ihre raschen Kreise ziehend. Zwischen ihnen bewegten sich langbeinige Wasserläufer und flinke Rückenschwimmer. Unter dem Wasser war das Leben nicht weniger reich. Da schwammen allerhand Wasserkäfer, große und kleine, Verwandte unseres Gelbrands, auch Kolbenwasserkäfer und jagten auf allerhand Beute. Auch die war reichlich vorhanden, nicht nur in Kaulquappen, sondern auch in den Larven von Insekten, deren fertige Zustände über dem Bach in der Luft flogen. Larven von Libellen und Eintagsfliegen, solche der Köcherfliegen gab es in Menge. Von letzteren hatte eine Form Gehäuse aus kleinen Steinen gebaut, welche am Grund mit der Öffnung bachaufwärts angeklebt waren. An den Steinen festgewachsen oder in großen grünen Algenpolstern fanden sich die eigentümlichen Larven der Kriebelmücken (Simuliiden) und solche von Chironomiden.

Für mich erwies sich als besonders interessant, daß in dem fließenden Wasser der Schluchtbäche sich Larven einer der Malariamücken fanden; bisher hatte man angenommen, daß diese niemals in fließendem Wasser vorkommen. Ich fand aber hier in Mengen die Larven von Anopheles superpictus Gr.; auch sonst gab es in den Schluchtbächen reichlich Stechmückenlarven von Culex und Anopheles-Arten, diese allerdings nur in den Tümpeln mit stehendem Wasser. Über diese und ihre Bedeutung für den Menschen ist näheres in einem späteren Kapitel über Klima und Seuchen zu finden (Kap. 28). 
Ein Bewohner der Schluchten im südlichen Mazedonien erregte mein besonderes Interesse, und so will ich über dies Tier einiges berichten. Es war eine $S$ ü $\beta w$ asserkrabbe, die den Namen Potamon fluviatilis var. edule Latr. führt; in der älteren Literatur war sie Telphusa fluviatilis benannt. Dieser Taschenkrebs kam in vielen Exemplaren von sehr verschiedener Größe, vor allem in den tieferen Tümpeln der Schluchtbäche vor. Selten fand ich ihn im selben Bach mit Flußkrebsen; doch kommt so etwas gelegentlich vor.

In Anfang des Jahres traf ich nur große und mittelgroße Individuen an; diese mußten 2-4 Jahre alt sein. Ihr schildförmiger Rücken maß an der breitesten Stelle $5 \mathrm{~cm}$. Die Grundfarbe des Körpers war ein fahles Gelb, welches durch rotbraune Flecken in

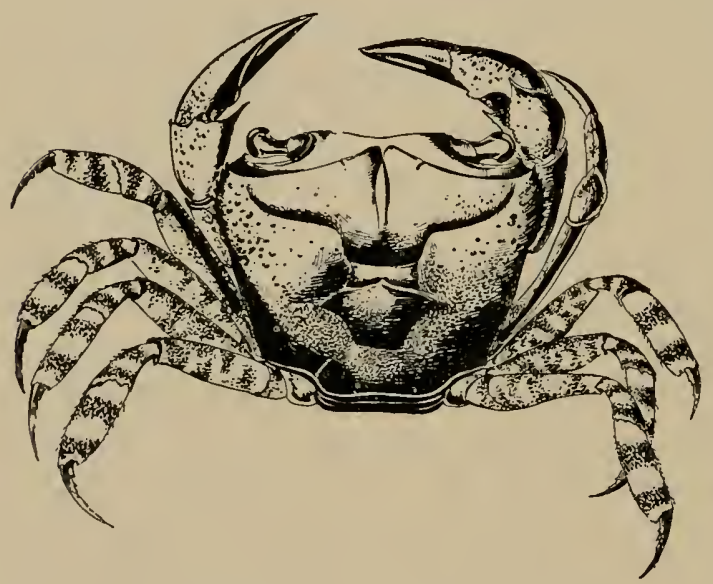

Abb. I02. Süßwasserkrabbe (Potamon fluriatilis var. edule Latr.) von oben gesehen. Nat. Gr. den meisten Regionen des Körpers überdeckt war.

Auffallend war das Überwiegen der Männchen; auf ein Weibchen mit breitem Hinterleib kamen jedesmal mehrere Männchen, die leicht an ihrem schmalen, dreieckigen Hinterleib zu erkennen waren. Ende Mai waren bei den Weibchen die Eier in den Eierstöcken noch nicht zur vollen

Größe herangewachsen. Anfang Juni sah man Männchen und Weibchen sich aneinander klammern. Da fand offenbar die Begattung statt. Am 20. Juli fand ich ein Weibchen mit einigen Eiern am Hinterleib, andere mit etwa 1 oo Eiern. In diesen Tagen waren auch solche mit den verschiedensten Entwicklungsstadien der Jungen $\mathrm{zu}$ finden.

Bei den Weibchen mit reichlich Eiern steht der breite Hinterleib vom Körper ab und der $Z$ wischenraum ist durch stark verbreiterte Hinterleibsfüße ausgefülit. So ist eine umfangreiche Bruthöhle gebildet. Die etwa $2 \mathrm{~mm}$ im Durchmesser erreichenden Eier hängen in ihr an Haaren der Abdominalfüße. In der Brut- 
höhle unter dem Körper machen die jungen Süßwasserkrabben ihre ganze Entwicklung bis zum fertigen kleinen Tier durch.

Ich hielt eine ganze Anzahl der Krabben in Eimern in Laboratorium, um sie zu beobachten. Wie im Freien saßen sie auch hier gern im dunkelsten Winkel ihres Behälters. In den Tümpeln hielten sie sich besonders unter überhängenden Steinen auf, wobei sie stets sich mit dem Hinterrand ihres Panzers anlehnten. Es scheint dies auf einer thigmotaktischen Reizbarkeit zu beruhen; in den Gefäßen, in denen ich sie hielt, saßen sie immer am Boden und drückten sich an die Wand; waren viele in einem Eimer, so saßen sie im Kreis herum, mit dem Vorderrande und den Scheren nach innen gerichtet, was ein sehr possierlicher Anblick war.

Eigenartig sehen diese Tiere aus, wenn sie mit ihren 10 Beinen sich bewegen. Das vorderste Beinpaar trägt die Scheren, welche breit und kräftig sind und sehr schmerzhaft kneifen können. Sie sind die Verteidigungswaffen der Taschenkrebse. Sie stützen sich nur selten bei Bewegungen auf sie. Meist strecken sie sie vor sich. Naht irgendwie eine Gefahr, so nehmen die Tiere eine Bereitschaftsstellung ein, bei der sie die vier hinteren Beinpaare spreizen, den Körper nach vorn aufrichten und die Scheren nach vorn und in die Höhe recken und öffnen. Kommt man ihnen näher, so kneifen sie heftig zu. Mit den Scheren fassen sie auch ihre Nahrung und führen sie zum Munde. Allen möglichen Tieren in ihrem Wohngebiet sind sie gefährlich. Oft sah ich sie Insektenlarven fressen. Auch tote Tiere nehmen sie gern an und an die Leichen ihrer Kameraden machten sie sich ohne weiteres. In der Freiheit sah man sie blitzschnell im Seitwärtsgang auf dem Boden des Wassers herumhuschen. Gelegentlich liefen sie auch auf den Felsen auf dem Trocknen.

Beim Seitwärtslaufen heben sie die vorausgehende Schere hoch und setzen die Beine der beiden Seiten gleichzeitig vor, wobei ganz regelmäßig das zweite Bein mit der Bewegung anfängt, dann das dritte, vierte und fünfte in der Reihenfolge sich anschließen. Im Wasser sind sie bei ihrer Flinkheit gar nicht leicht zu fangen, gern schlüpfen sie in Spalten und Löcher, in denen sie sich fest an die Wände anschmiegen.

Wenn die Jungen aus den Eihüllen ausgekrochen sind, hängen sie noch lange am Hinterleib der Mutter. Sie wachsen zu Ebenbildern ihrer Eltern heran, sind aber zunächst noch wenig pigmentiert und sehen dann ganz hell, blaßgelb aus. Allmählich 
werden sie dunkler und lösen sich dann von den Hinterleibsfüßen der Mutter los und laufen auf deren ganzen Körper umher. Anfangs haben sie aber die Neigung, immer wieder in den Schutz der Bruthöhle zurückzukehren. Da klammern sie sich mit den Hinterbeinen am Körper der Mutter und aneinander fest.

Nimmt man sie im hellgelben Zustand aus der Bruthöhle heraus und setzt sie zur Beobachtung in eine Glasschale, so nehmen sie gleich schon Nahrung an; auch gehen sie prompt zur Bereitschaftsstellung über, kneifen mit den Scheren und benehmen sich wie Erwachsene.

Diese kleinen Tiere wurden allmählich dunkler, die Pigmentierung fand also auch im Versuchsgefäß statt. Fressen tun sie, was von Tierkörpern man ihnen anbietet; auch ihre eigenen toten Brüder.

Draußen in den Schluchten wimmelte es zu dieser Zeit von der kleinen Krabbenbrut. Im Hochsommer verschwanden Alte und Junge, auch im Winter konnte ich sie nicht auffinden. In diesen ungüstigen Zeiten sind sie wohl in einem Ruhezustand in Spalten der Felsen oder unter Steinen.

Von niederen Tieren fand ich in den Schluchttümpeln Strudelwürmer (Planarien) von interessantem Bau und Blutegel. Im Boden der kleinen Wiesen und Rasen die seltenen Regenwürmer. Über diePlanarien berichtet mirDr.Steinmann, der ihre Bearbeitung übernommen hat, daß bei der Ausbeute sich eine ganze Anzahl der merkwürdigen polypharyngealen Strudelwürmer befindet, der Formen mit mehreren Mundöffnungen und Schlünden. Man rechnet sie meist zu der Art Planaria montenegrina Mrazek. Deren Vorkommen in Mazedonien wäre damit festgestellt. Doch glaubt Dr. Steinmann, daß es sich bei diesen südlichen Formen um Varitäten der Planaria alpina handelt. Diese und wahrscheinlich neue Arten aus meiner Ausbeute sollen in der definitiven Bearbeitung zur Darstellung kommen.

Bemerkenswert ist die Beobachtung, daß ich diese polypharyngealen Planarien in Mineralquellen fand, so in dem Bach, welcher im Bereich des Lazaretts Rabrovo entsprang, dicht hinter der Quelle. Das Wasser dieses Baches enthielt Kohlensäure, Eisen und wohl etwas Schwefel und zeigte während des ganzen Jahres eine konstante Temperatur von $20^{\circ} \mathrm{C}$.

So stellen die Balkanschluchten biologisch eine eigenartige Lebensgemeinschaft von Pflanzen- und Tierarten dar, deren Ver- 
kettung miteinander und Abhängigkeit voneinander eine eingehendere Untersuchung verdiente.

Steigt man aus dem Schatten der Schlucht an den Abhang des Berges hinauf, in dessen Flanke sie sich eingewühlt hat, so überblickt man rings in der Landschaft die Wirkungen der Kräfte, welche die Entstehung der Schluchten bedingten. Überall kahle, zerrissene Hügel und Berge, waldlos und steinig. Typisch und charakteristisch sind die welligen Hänge von fast einander parallel verlaufenden Schluchten modelliert, Lehrbuchbilder der Erosionswirkung. Unwillkürlich steigt einem der Gedanke auf: Wie ganz anders würde der Balkan aussehen, existierten die Schluchten nicht und mit ihnen die Bedingungen, welche ihr Werden verschuldeten.

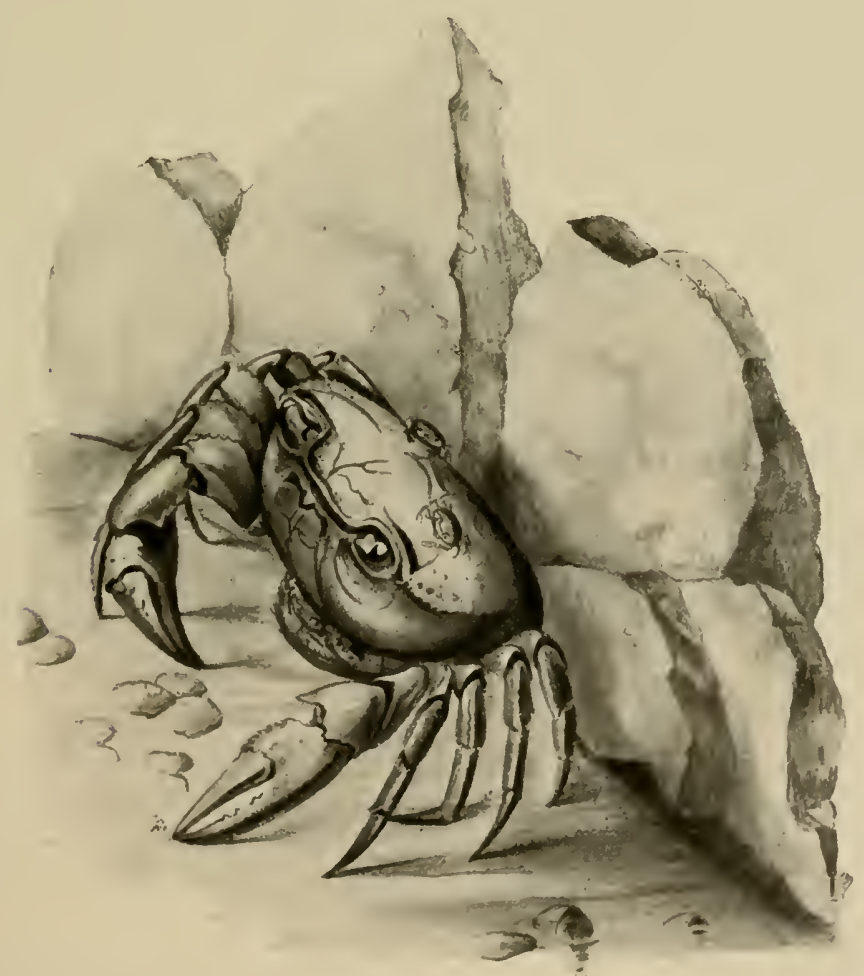

Abb. 103. Süßwasserkrabbe (Potamon fluviatilis var. edule Latr.). Weibchen mit Jungen unter dem Hinterleib und auf dem Rücken. 


\section{DREIZEHNTES KAPITEL}

\section{IM HAIN MAMRE}

\section{STRUMIZA. BELASIZA PLANINA. GEWGELI.}

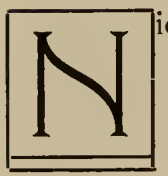

icht weit von Dedeli, dem Endpunkt der von unseren Truppen gebauten Seitenstrecke der Wardarbahn, lag in einem schönen Hain aus Ulmen und Eichen das Oberkommando der I. Bulgarischen Armee. Im Heere nannte man dies Wäldchen den Hain Mamre; wie dieser Name entstanden ist, war nicht herauszubringen. Zum Oberkommando gehörte der deutsche Führer der Spezialwaffen, Generalleutnant Posseldt. Dieser hatte mich bei Gelegenheit eines Ausflugs, den ich mit den Kollegen beim Hochschulkurs in Üsküb zu ihm gemacht hatte, eingeladen, meine Arbeitsstätte für einige Zeit bei ihm aufzuschlagen.

So war ich Ende April 1918 im Hain Mamre eingezogen, wo ein reizendes Quartier für mich bereit stand; meine Hilfskräfte waren bei einer benachbarten Abteilung untergebracht. Es war eine ergebnisreiche, schöne Zeit, die ich in den nächsten 5 Wochen dort verbrachte.

Der Hain Mamre stellte im baumarmen Südmazedonien eine richtige Oase dar. In dem kühlen Schatten der uralten Bäume war auch im Sommer gut arbeiten. Auch die Umgebung hatte ihre Reize; wenige Kilometer vom Hain talaufwärts entsprang der Kosludere als kräftiger Bach einer Felsenwand. Sein Wasser verhalf dem ganzen Tal zu einer reichen Vegetation und ermöglichte einen gute Ernten bringenden Anbau. Ein Bild von diesem reichen schönen Tal gab ich schon im fünften Kapitel.

Was den Aufenthalt im Hain Mamre für mich so erfolgreich und genufreich machte, war vor allem die Persönlichkeit des Generals Posseldt. Unter den ehrwürdigen Bäumen des Hains dehnte sich ein Dorf von Baracken aus; nein, eher einer Villenvorstadt könnte man das Bild vergleichen, das die kleinen, in geschmackvollen Verhältnissen gebauten Häuschen darboten, welche 
die Wohnungen und Kasinos für Offiziere, Schreibstuben, Zeichensäle, Kartenräume, photographische Abteilungen, Werkstätten, Küchen usw. des Armeeoberkommandos beherbergten. Alles stand im gehörigen Abstand voneinander, so daß dazwischen Raum blieb für allmählich im Laufe der Zeit entstandene wohlgepflegte Rasenflächen und Blumenbeete. Manche der Häuser glichen kleinen Villen in einer Sommerfrische.

Im Hain sah es zu allen Zeiten nett und behaglich aus; im Sommer war der Aufenthalt in ihm direkt eine Erholung. Aber auch im Winter, wenn die Bäume im Schneegewand oder von Rauhreif bedeckt prangten, waren die gut geheizten Baracken ein

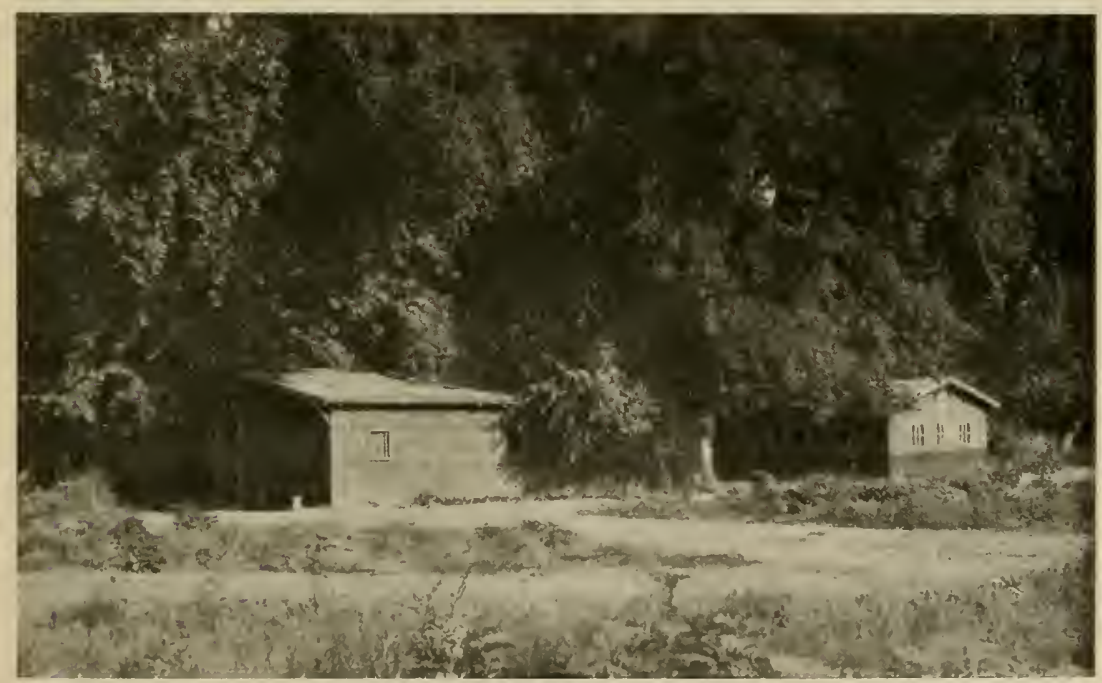

Abb. 104. Hain Mamre im Sommer.

Vermessung 7 phot.

angenehmer Aufenthalt. Es gereicht dem Armeeoberkommando zur Ehre, daß die schönen alten Bäume in unbeschädigtem Zustand beim Rückzug zurückgelassen wurden und so auch in Zukunft eine einzigartige Erscheinung in Südmazedonien bleiben können.

Im Schatten der Bäume lagen die Häuschen zerstreut; im allgemeinen hausten die Deutschen in der nördlichen, die Bulgaren in der südlichen Hälfte. Die Wirtschaftsräume lagen am Rande. Zwischen den Offizieren und Mannschaften beider Völker herrschte meist ein gutes Verhältnis. Die I. Bulgarische Armee wurde stets wegen ihrer guten Haltung und Tapferkeit besonders gerühmt und hatte manche Erfolge zu verzeichnen. An der Doiran- und Wardar- 
front, welche diesem Oberkommando unterstanden, war ja oft etwas los.

General Posseldt war eine energische, frische Persönlichkeit, typischer preußischer Offizier mit vielen der guten Eigenschaften eines solchen. Die Frische und geistige Lebhaftigkeit seines Wesens wünschte er bei seinen Offizieren und suchte sie bei ihnen zu erhalten oder hervorzulocken. Es war ein Kreis von jungen Leuten um ihn gesammelt, die offenbar nach Charakter, geistigen Qualitäten und Bildung ausgesucht waren. Jeder war in irgend einem militärischen Sonderdienst Spezialist.

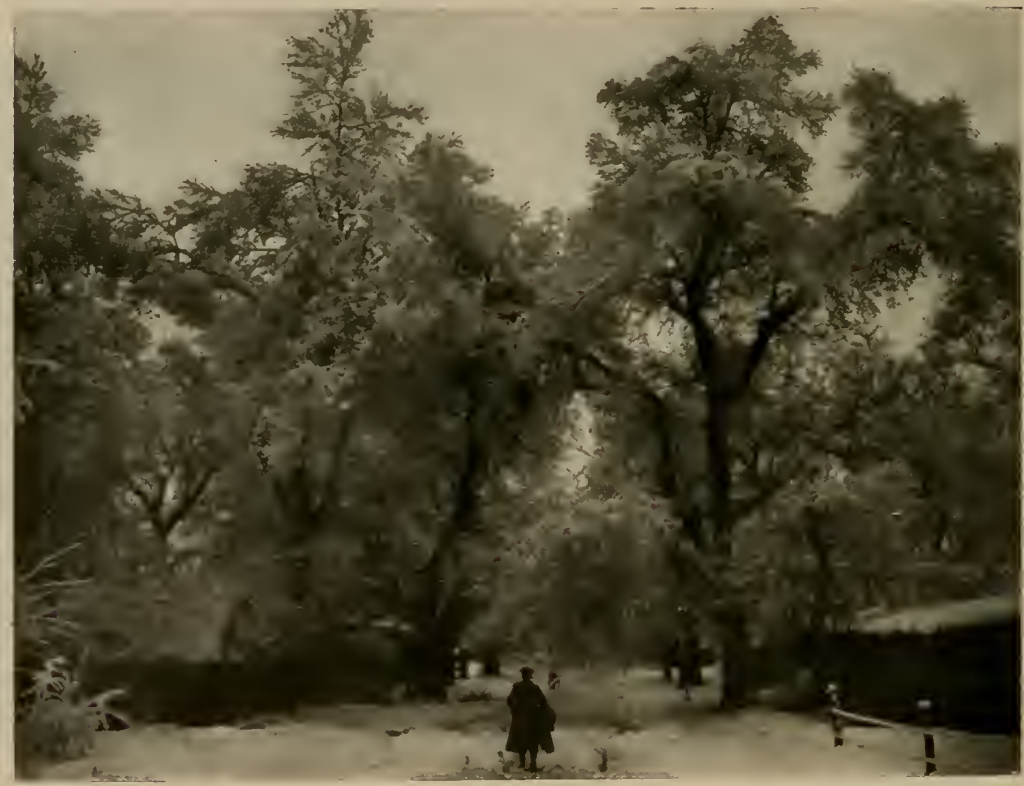

Abb. 105. Hain Mamre in Winter.

Vermessung 7 phot.

Unter den jungen Männern herrschte ein flotter, kameradschaftlicher Ton; sie vertrugen sich meist gut miteinander. Die natürliche Eifersucht zwischen Gleichstrebenden nahm während meines Aufenthaltes nie unsympathische Formen an. Der General suchte den Ton der Tischgespräche stets auf einem hohen Niveau zu erhalten und veranlaßte jeden des Kreises, abends den anderen zu erzählen oder vorzulesen, was ihm bei seiner Privatlektüre Allgemeininteressierendes aufgefallen war. Auch ich war gebeten, die Beobachtungen des Tages, interessante Entdeckungen dem Kreis zugänglich zu machen. Da zudem ein tüchtiger Arbeits- 
geist in dem Stabe herrschte, so wird man verstehen, daß ich eine sehr freundliche Erinnerung an die Wochen in dieser Gesellschaft und an manche Abendgespräche mitnahm.

Zur I. Armee gehörte die Front von der Belasiza Planina und dem Doiransee bis in die hohen Gebirge westlich des Wardar. So war der Hain Mamre ein geeigneter Ausgangspunkt für meine Forschungen in diesen Gebieten. Mehrere der jungen Offiziere hatten starkes Interesse für meine Arbeiten, sammelten Tiere für mich, begleiteten mich auf Exkursionen oder forderten mich auf, ihre Fahrzeuge oder Pferde bei Dienstreisen an die Front mit zu benützen. Und so habe ich mit ihnen manchen Ritt und manche Fahrt gemacht, die mich in Gebiete brachten, welche mir sonst unzugänglich gewesen wären.

Zunächst bot der Hain selbst und seine nähere Umgebung Gelegenheit zu vielen Beobachtungen. Mit der reicheren Pflanzenwelt war hier auch eine große Mannigfaltigkeit in der Tierwelt entwickelt. Wieder bestätigte sich die Erfahrung des vorigen Jahres, daß hier im Süd-Wardargebiet die nördlichen Elemente der Fauna zurücktraten und dafür die südöstlichen Formen mehr und mehr überwogen. Das machte sich in allen Gruppen bemerkbar, bei Reptilien und Vögeln wie bei Insekten besonders auffällig. Ich will einige Beispiele davon geben, indem ich meine Erfahrungen in dem ganzen Gebiet zwischen Doiransee und Wardar südlich bis Gewgeli zusammenfasse; dabei zeigt sich eine nördliche Grenze etwa zwischen Mravinca und Valandova, über welche hinaus merkwürdigerweise manche Formen nicht beobachtet wurden.

Sehr reich war die Vogelwelt an auffallenden und interessanten Formen; nachdem einmal die Offiziere darauf aufmerksam gemacht waren, bemühten sie sich, unsere ornithologischen Sammlungen $\mathrm{zu}$ bereichern. Wie im vorigen Jahre waren die Blauraken (Coracias garrulus garrulus L.) häufig und wetteiferten mit ihrem blauen Glanz mit den Bienenfressern (Merops apiaster L.), welche erst Ende Mai vom Zug heimkehrten, sofort aber durch ihre Prachtfärbung und ihren eigenartigen Flug auffielen. Ein grofer Schwarm hatte sich nahe dem Hain niedergelassen und erfreute uns täglich beim Morgenritt mit seinem raschen Flug, der ihn in wenig Minuten über das ganze Tal hinwegtrug. Wie überall in Mazedonien war auch hier der bunte Wiedehopf (Upupa epops epops L.) ein häufiger Vogel. Bei seiner geringen Scheu war er nicht zu übersehen. Ein später Ankömmling war auch die 


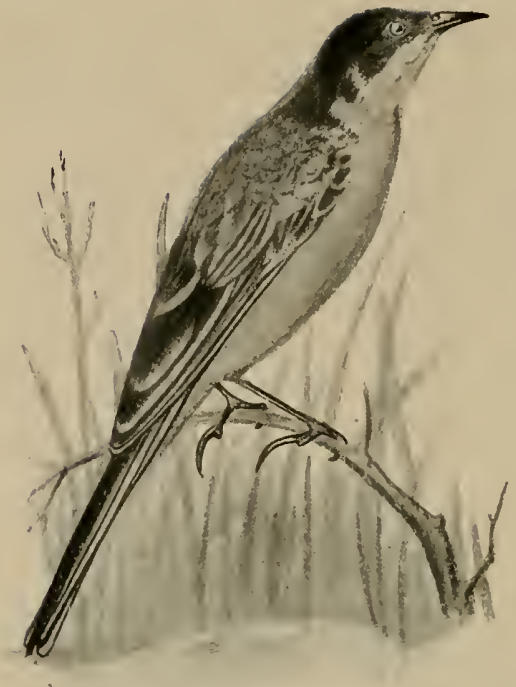

Abb. 106. Kappenammer ơ (Emberiza melanocephala Scop.). Verkl. 1/2.

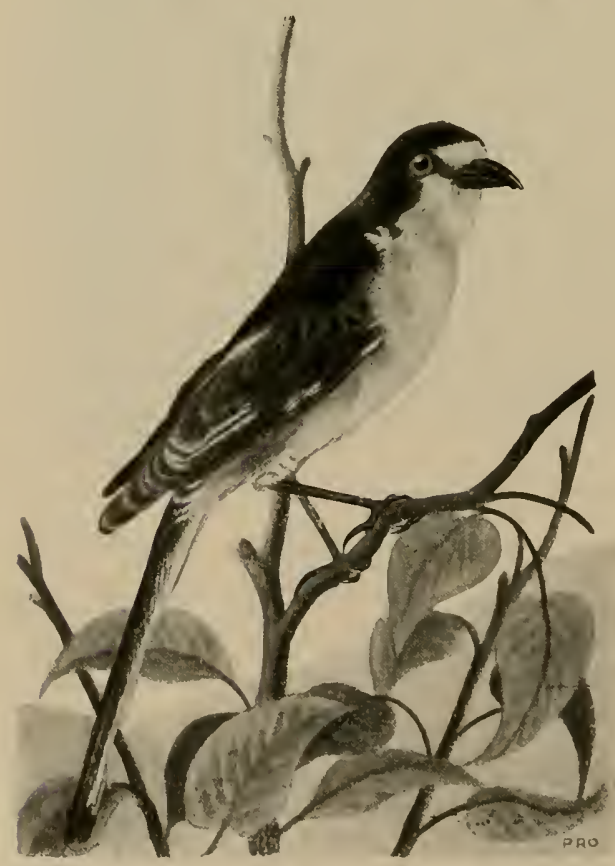

Abb. 107. Lanizs nubicus Licht. Der Maskenwürger. Verkl, 1/2.
Kappenammer (Emberiza melanocephala Scop.), die plötzlich in großer Zahl auftrat und bald am Nestbauen war. Es war ein reizendes Bild, wenn die leuchtend gefärbten Männchen mit ihren schwarzen Mützchen hoch auf den Gipfeln von Büschen und Obstbäumen saßen (Abb. 106). Girlitz (Serinuscanaria serinus L.), Gr ü nling (Chloris chloris mühlen Parrot), und besonders der Ortolan (Emberiza hortulana L.) waren ziemlich häufig in der unmittelbaren Umgebung des Hains. Kopfzerbrechen machte uns ein $\mathrm{Br}$ a chpieper (Anthus mosellamus vierthaleri Brehm), den wir bei Dedeli fanden. Um den Hain herum war die $\mathrm{Hau-}$ benlerche, wie überall in Mazedonien, sehr häufig (Galerida cristata meridionalis $\mathrm{Br}$.$) . Ein interessanter$ Fund war eine Form der Kurzzehenlerche (Calandrella brachydactyla moreatica Mühlb.) auf dem trokkenen Gelände der Hügel.

Dieselben Wür ge r, welche im vorigen Jahr in der Ebene von Hudova so häufig gewesen waren, waren auch hier in Mengen vertreten. Auf jedem Strauch, der etwas über seine Umgebung hervorragte, sah man ihre herausfordernde Silhouette auf der höchsten Spitze. Überall hörte man ihren grellen 
Schrei und an den Dornbüschen, ja selbst an den Stacheldrälıten militärischer Anlagen sah man vielfach ihre Insektensammlungen aufgespießt. Zu ihnen gesellte sich als noch auffallendere Erscheinung Lanius mubicus Licht., der Mask en w ü rger, ein Vogel von dunkler Farbe mit eigentümlichem Schnabel, ein weiteres südliches Element der Ornis (Abb. 107). Da wo die Mohnfelder blühten und die Baumwolle gedieh, traten Ende Mai große Flüge des rosenroten Rosenstars (Pastor roseus L.) auf. Hier wanderte der osteuropäische Vogel ebenso unstät umher, wie er gelegentlich auch in Deutschland auftaucht. Brüten sahen wir ihn nicht.

Im Park selbst war eine große Meise, die Trauermeise (Parus lugubris hugubris Temm.), ein Bewohner der hohen Bäume. Hier zeigte sich auch der Fliegenschnäpper (Muscicapa striata striata Pall.), der Berglaubvogel (Phylloscopus bonelli orientalis Brehm), die Baumnachtigall (Agrobates galactodes syriaca Hempr.u. Ehrenbg.) und Aëdon megarhynchus megarhynchus Brehm. Das war eine eigenartige Gesellschaft, die wir nicht ohne weiteres hier erwartet hätten.

Weniger erstaunlich war es, daß gelegentlich ein großer Buntspecht (Dryobates major balcanicus Gengl. u. Stres.) an den Bäumen des Hains sich zu schaffen machte.

Anders stellte sich die Vogelwelt in dem sumpfigen Gebiet des Kosludere und im Gebiet der Wardarebene bei Mravinca dar. Da gab es viel Wasser und damit viele Bachstelzen und die gelbfederigen Schafstelzen (Budytes flavus flavus L. und B. flavus feldeggi Michah.). Ein FluBregen pfeif er (Charadrius dubius curonicues Gm.) und ein T e ichhuhn (Gallinula chloropus L.) wurden dort erbeutet. Dort gab es auf den Feldern Wachteln (Coturnix coturnix L.). Auch ein Fischadler (Pandion haliaëtus L..) fiel uns dort in die Hände.

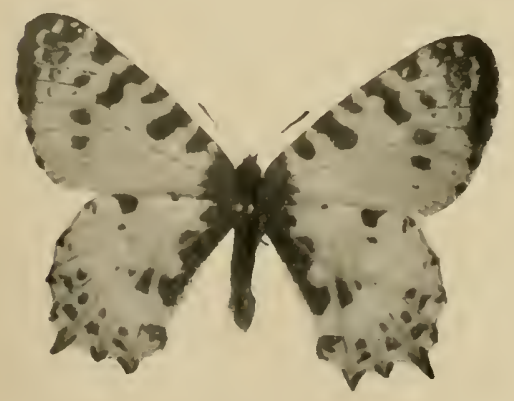

o

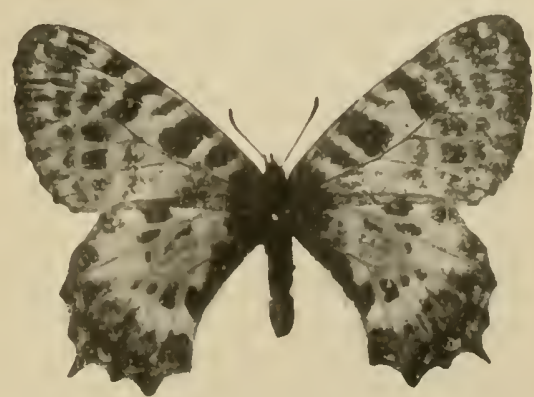

q

Abb. 108. Thais cerisi ferdinandi Stichel. Nat, Gr. 
Nicht weniger von südlichen und östlichen Bestandteilen durchsetzt war die sonstige Tierwelt. Anfang und Mitte Mai trat ein schöner auffallender Schmetterling in großen Mengen auf. Es war Thais cerisi ferdinandi Stich., ein bunter Falter, mit dem Apollo verwandt, der in der ganzen Wardargegend, vor allem in den Felsschluchten, plötzlich erschien, um nach 8-1o Tagen ebenso plötzlich wieder zu verschwinden (Abb. 108). Besonders bei Demir $\mathrm{kapu}$ flog dieser Schmetterling in der sonnendurchstrahlten Schlucht in Wolken von hunderten von Exemplaren. Auch die verwandte Form Thais polyxenor Schiff. fanden wir in der Gegend.

Auf Ameisen achtete ich hier besonders aufmerksam und fand eine Anzahl interessanter Arten. Alle drei Formen der Körnerameisen aus der Gattung Messor kamen hier vor und viele der Beobachtungen, die im elften Kapitel niedergelegt sind, wurden im Hain Mamre gemacht.

Überall am Rande des Hains fanden sich die Kraternester und die Straßen dieser auffälligen Ameisen. Auf den Hügeln der Umgebung, besonders am Zwieselberg, gab es viele Nester der goldgelben Ameise Pheidole pallidula Nyl., der einzigen europäischen Form, welche echte Soldaten als besondere Kaste besitzt. Dort gab es unter Steinen auch Nester von Tapinoma erraticum Först. und Cremastogaster sordidula Nyl. var. Aachi For. Einmal fand ich eine Kolonie der letzteren Art unter einem Stein neben einer solchen von Tetramorium caespitum L. Sie lebten ganz friedlich nebeneinander, und als ich sie zusammen in ein künstliches Nest brachte, begannen sie ein gemeinsames Leben, als hätten sie immer zusammengehört.

Tetramorium caespitum L. kam als Hausameise im Hain selbst viel vor und drang auch in die Baracken ein. In unseren und den anderen Hainen der Gegend gab es viele Baumameisen aus der Gattung Camponotus. Die alten Stämme waren zum Teil morsch und von den Bauten der Ameisen durchsetzt. Oft aber hausten sie auch in ganz gesunden Stämmen und hatten ihre Nester in irgendeinem Ast der Krone. So beobachtete ich einmal eine stark begangene Straße der schwarzrot gefärbten, großen Campo. notus (Orthonotomyrmex) lateralis Oliv., welche zu einer hohen alten Ulme führte. Die Straße setzte sich auf den Stamm der Ulme fort und führte bis in die Krone, wo das Nest sich befinden mußte; denn die Ameisen stiegen beladen hinauf und kamen leer herunter. Beim Anstieg trugen sie Erdklümpchen, die offenbar oben zum 
Bau dienten. Viele von ihnen hatten auch Blattläuse zwischen den Kiefern, die oben wohl weiter gezüchtet werden sollten.

Eine besonders interessante Entdeckung durfte ich in der Umgebung machen. Schon im Jahre 1917 hatte ich eifrig auf meinen Reisen nach Termiten gesucht. Diese sogenannten weißen Ameisen der Tropen kommen in Südeuropa in zwei Arten vor, welche ich schon aus Italien kannte. In Mazedonien waren sie noch nicht nachgewiesen.

So erregte es denn mein höchstes Interesse, als ein junger Offizier, der beim Stab eingeladen war, mir eines Abends erzählte, dicht bei seinem Quartier seien vor einigen Tagen aus einem Erdloch zahlreiche Insekten mit vier zartgeäderten Flügeln, die wie kleine Libellen aussahen, herausgekrochen. Als er sie mir zeigte, waren es Geschlechtstiere einer Termitenart.

Ich verabredete einen Besuch bei ihm und fuhr $\mathrm{zu}$ ihm auf den Furkapaß hinauf. Das war die mir schon von den Fahrten zum Doiransee bekannte Paßstraße, welche in Dedeli begann. Auf dieser Straße war immer ein ungeheurer Verkehr, bei trocknem Wetter schwebte eine dichte Staubwolke über ihr. Lastautos, Geschütze, Munitionskolonnen rollten unablässig über sie zum Doiransee, nach Cerniste und Bogdanci. Wagen folgte hinter Wagen, meist Ochsen- und Büffelgespanne. Bulgarische Soldaten marschierten schweißtriefend und staubbedeckt an meinem Wagen vorbei. Große Herden freilaufender Pferde, Esel, Maultiere, Ochsen und Büffel wurden auf der Straße getrieben. Es war eine Erlösung, als ich seitlich zu dem Quartier abbiegen konnte, welches ich besuchen wollte. Es lag am Berg an einer der kleinen Bachschluchten, welche auch hier in großen Mengen das Gelände durchzogen. Hier herrschten merkwürdig bunte Gesteine vor, so daß die Landschaft einen ganz eigenartigen Charakter besaß. Die obersten Schichten waren spangrüner Serpentin, darunter lag gelber und grauer Diabas; noch tiefer kam dunkelroter Sandstein, der besonders in den feuchten Schluchten fast schwarzrot erschien. Zwischen dem Sandstein zogen sich weiße, schmale Kalkbänder hin.

Weiter oben am $\mathrm{Pa}$, nicht weit vom Dorf Furka, boten lehmige Schichten charakteristische Erosionsbilder. Das geschichtete Gestein war durch eine Menge von Miniaturschluchten gleichmäßig durchfurcht. Man konnte die Arbeit der atmosphärischen Kräfte in allen ihren Phasen verfolgen. Und dabei waren Gebilde entstanden, welche auffallend den berühmten Erdpyramiden bie 
Bozen glichen und ähnlichen Vorgängen wie dort ihre Entstehung verdanken. Die hier eingefügte Abbildung zeigt das eigenartige Bild, das diese Formation darbot (Abb. 109).

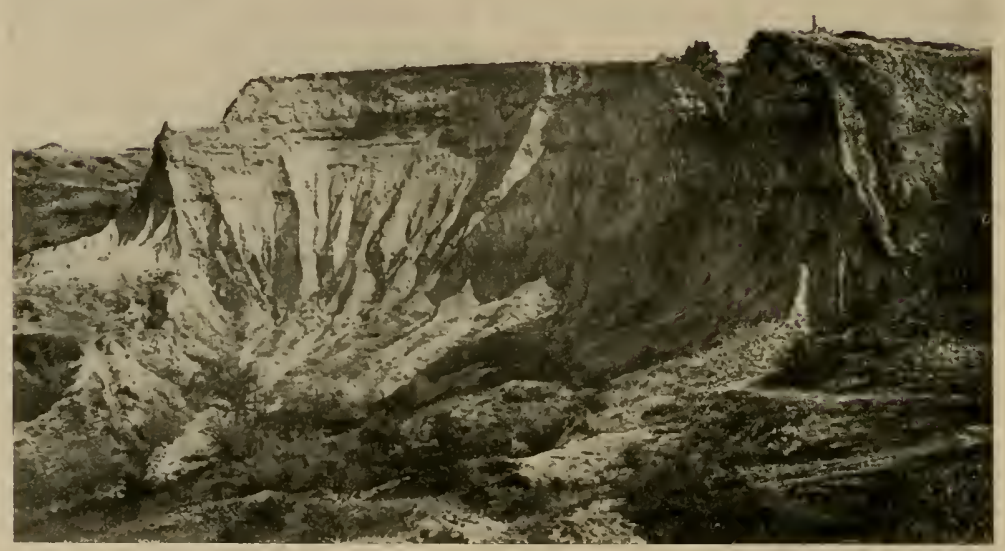

Abb. 109. Erosion mit Pyramidenbildung am Furkapaß. Doiranfront.

Es ist geeignet, die Gesetzmäßigkeiten zu erläutern, welche im vorigen Kapitel dargestellt wurden. In besonders eindringlicher Weise macht es ein für Mazedonien typisches Landschaftsbild verständlich.

Die Schlucht, an der das Quartier des Leutnants Förster lag, war tief und eng. Einige Bäume standen an ihren Hängen, reichliches Buschwerk wuchs dazwischen. An den Wurzeln einer Esche fanden wir nach langem, vergeblichen Graben endlich das erwartete Termitennest. Es war die eine der südeuropäischen Termitenarten, welche hier wohnte (Calotermes flavicollis Fabr.). Wir gruben lang und tief, ohne Geschlechtstiere zu finden. Es war eine relativ große Kolonie und sie mußte Geschlechtstiere enthalten. Sie lebte in den morschen Wurzeln des Baumes, in diesen ihre Gänge bauend. Die Wurzeln erstreckten sich tief in die Wand der Schlucht und wir mußten schließlich das Graben aufgeben, als die ganze Wand der Schlucht nachzustürzen drohte. 
Immerhin hatte ich eine größere Anzahl Tiere in meinen Fanggläsern; es waren darunter auch junge Larven, und so konnte ich hoffen, alle Stadien zu züchten. Zur Zeit, da ich dies niederschreibe, im März 1920, also fast 2 Jahre, nachdem ich die Tiere am Furkapaß mitnahm, ist dies gelungen. Die Kolonie lebt noch in meinem Institut in Breslau fern ihrer Heimat, und ich hoffe manches interessante Resultat durch ihre Beobachtung zu erzielen. Hier ist nicht der Ort, davon eingehender zu berichten.
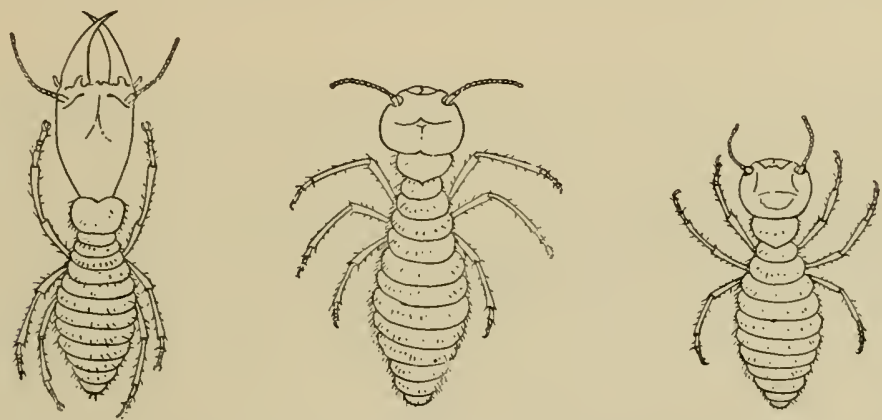

Abb. I 10 . Soldat und Arbeiterstadien von Calotermes flavicornis Fabr.

Auch von den Spinnen gilt das, was ich für andere Tiergruppen über das Vorkommen besonderer Arten schrieb. Eine ganze Anzahl der Spinnenformen, welche im 19. Kapitel beschrieben sind, fand ich in der Gegend des Hains Mamre. So vor allem die abenteuerliche Walzenspinne Galeodes graecus C. L. Koch.

In die Zeit meines Aufenthalts im Hain Mamre fielen auch eine Fahrt nach Strumiza und zwei Ausflüge in das Gebirge nördlich des Doiransees, die Belasiza Planina. Strumiza liegt jenseits der Plaguša Planina im Tal des Flüßchens Strumiza, welches der Struma zuflielat. Die Fahrt führt über mehrere Pässe und bot mir Gelegenheit, nicht fern von der Stadt Strumiza einen Kiefernwald kennen zu lernen. Einige Hügel und ein tief eingeschnittenes, Mitte Mai trocken liegendes Tal waren der Standort dieses lichten WValds. Die Kiefern (Pinus nigra Arn.) waren nur $10-15 \mathrm{~m}$ hoch, knorrige, dunkle Stämme mit sehr dunkelgrünen Nadeln (Abb. I I 1). In diesem Wald fand ich eine ganze Anzahl Ameisenarten, vor allen der Gattung Camponotus und allerhand interessante Spinnen. Es war ein trüber Tag, so daß sonst wenig Insekten unterwegs waren. 
Die Stadt Strumiza liegt eigenartig in einem felsigen Gelände; sie ist von den Ruinen einer Feste überragt. Auch im Stadtgebiet gibt es viele zerstörte Häuser. Steil und kahl steigt der Berg hinter der Stadt auf; geringes Buschwerk steht zerstreut an seinem steinigen Hang. Nur in der Schlucht ist etwas mehr Grün zu entdecken. Von diesem fahlen Hintergrund heben sich die leuchtende Kuppel einer Moschee und zwei grell weiße christliche Kirchen seltsam ab. Sehr eigenartig wirkt der blaue, rote und gelbe Anstrich mancher Häuser. Die Straßen der Stadt sind nicht reizlos mit der großen Mannigfaltigkeit der Bauart der Häuser, deren

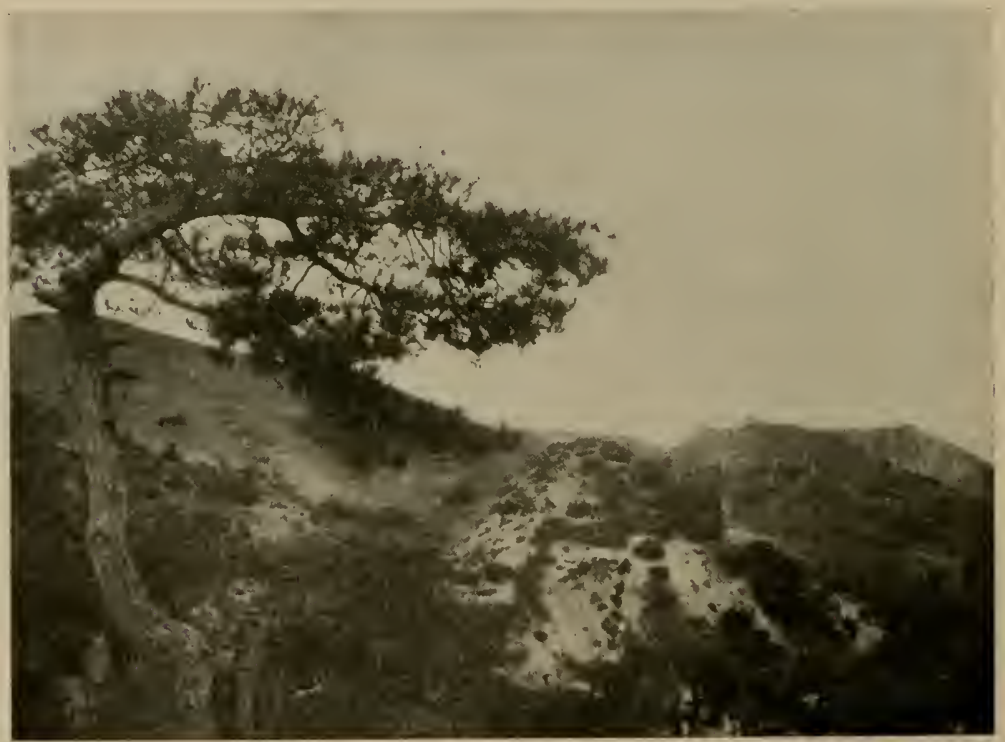

Abb. III. Blick aus dem Kiefernwald auf die Burg von Strumiza (Pinus nigra Arn.).

vorgebaute obere Stockwerke schöne Veranden, säulengetragene Loggien enthalten und oft durch große Bogenfenster fein gegliedert sind. In der Stadt selbst sind Bäume und Büsche nicht selten und über die Hauptgeschäftsstraße wölbt sich ein mächtiger alter Weinstock wie ein Torbogen.

Vor Strumiza war ich über die Grenze zwischen Bulgarien und Serbien gekommen, wie sie vor dem Krieg bestand, und damit in einen Teil Altbulgariens gelangt. Die Bevölkerung von Strumiza ist hauptsächlich bulgarisch, wenn auch nicht wenig Türken und bulgarische Muhamedaner, Pomaken, dort wohnen. 
Es war mir interessant, noch ein Stück in das Strumizatal hineinzufahren. Wie die Plaguša Planina von Osten einen weniger stattlichen Eindruck als von Westen macht, so macht auch das Belasizagebirge von dem Strumizatal aus einen bescheideneren Eindruck. Das gut bewässerte Tal ist reich bebaut. Getreidefelder breiteten sich rings um uns aus, als wir in flotter Fahrt das Tal ein gut Stück südostwärts verfolgten. Alle Dörfer waren von einem Wald von Obstbäumen umgeben. Die Üppigkeit des Grüns ließ einen fast vergessen, daß man im Flachland Mazedoniens sich befand. Ich streifte durch die Felder, zwischen denen wasserreiche

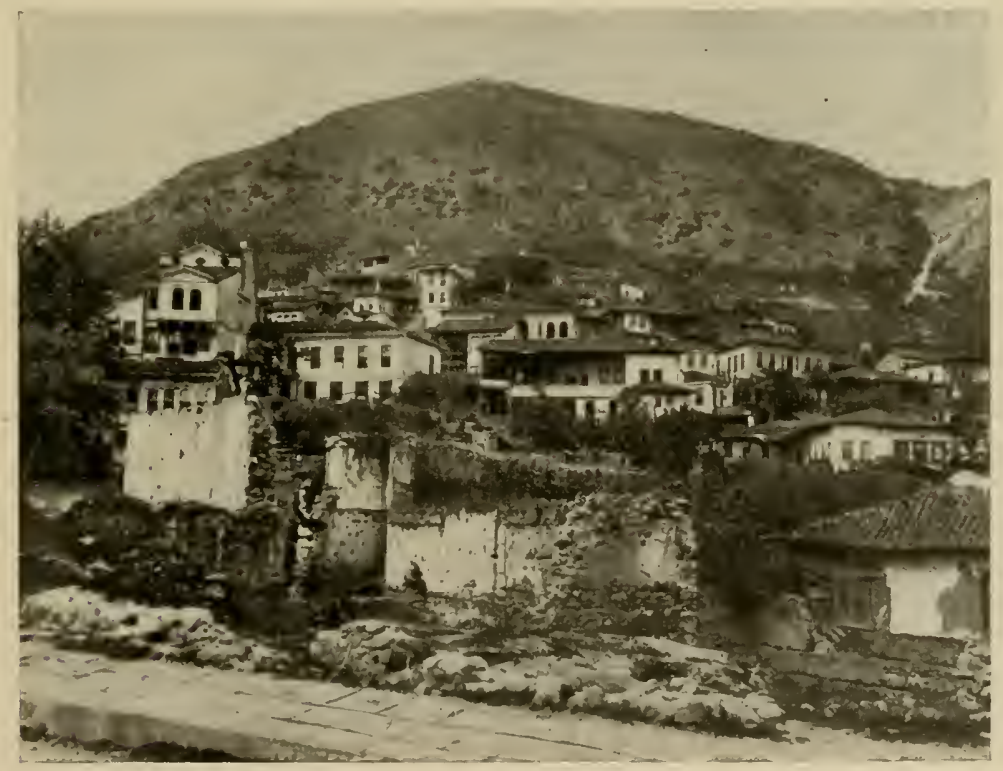

Abb. 112. Strumiza.

Gräben verliefen, die von Weiden umgeben und von Kolbenschilf bewachsen waren. Von einem solchen Gewässer flog vor mir eine prachtvolle Stockente, eine Anas platyrhynchos L., ein alter Erpel, auf und es gelang, mir das Exemplar herunterzuholen.

Als wir in das Dörfchen kamen, in welchem mein Begleiter dienstlich zu tun hatte, erlebte ich eine merkwürdige Überraschung. Der kleine Ort Martino war fast ganz von protestantischen Bulgaren bewohnt, welche vor vielen Jahren von einem amerikanischen Missionar bekehrt worden waren und treu seither an ihrer neuen Religion hielten. Ihr Priester sprach noch etwas englisch Doflein, Mazedonien. 
und hatte seine Holy Bible und methodistische Gebetbücher. Trotz ihrer halbtürkischen Tracht machten die Bewohner einen anderen Eindruck als die Bewohner der Nachbardörfer. Es war ein eigenartiges Schauspiel, als die sauberen, wohlgepflegten Kinder der Gemeinde uns evangelische Kirchenlieder vorsangen. Sie hatten gute Stimmen und waren gut eingeübt. Ich wohnte einer Schulstunde in dem kleinen niedrigen Schulzimmer bei und schied als guter Freund von der netten Gesellschaft.

Die beiden Ausflüge in die Belasiza Planina erfolgten bei Dienstreisen von Offizieren. So waren es flüchtige Besuche dieses

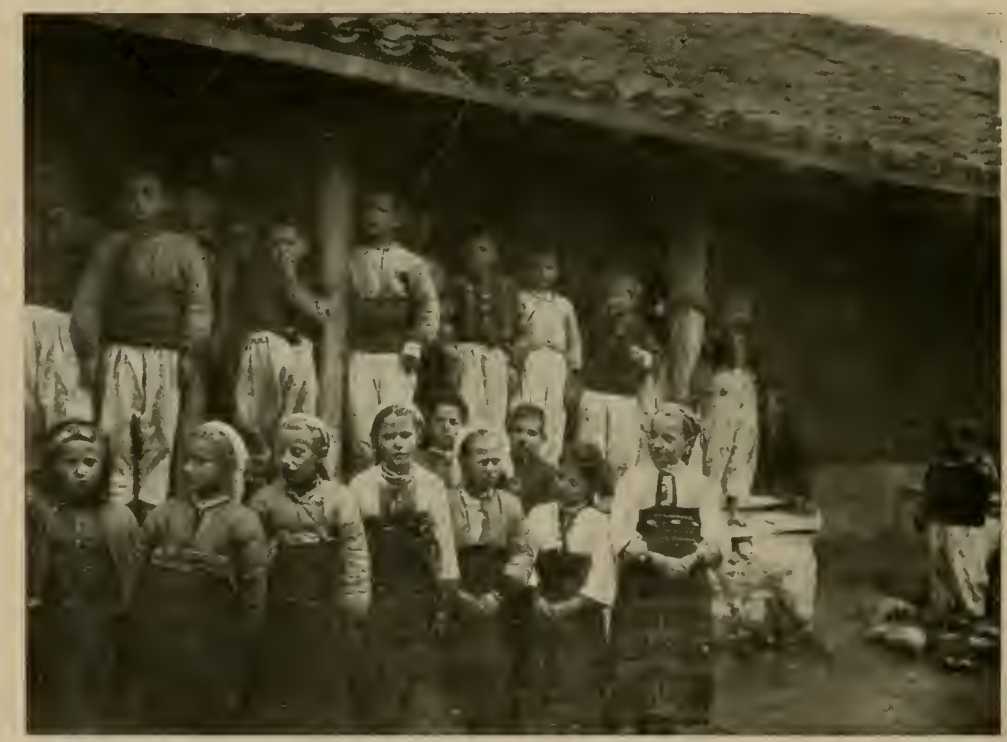

Abb. 113. Die christlichen Schulkinder in dem Dorf Martino.

Gebirges; sie gaben mir immerhin eine Vorstellung von dem Gebiet. Auch die Belasiza steigt steil nördlich des Doiransees auf. Ihre von der Erosion stark verarbeiteten schluchtenreichen Hänge sind in den unteren Regionen nur von Buschvegetation bedeckt, diese geht etwa bei $600-700 \mathrm{~m}$ Höhe in lichtes Buchengebüsch über, das hier und da zu Waldungen wird, die in $900-1000 \mathrm{~m}$ Höhe zu überwiegen pflegen. Das war etwa die Höhe des Bejlik, des ersten Berges, den ich erstieg. Aber schon dieser Gipfel mit $1063 \mathrm{~m}$ trug über dem Wald eine Mattenregion, aus der vereinzelte Felsen herausragten. In dem lichten Wald 
fand sich typische Gebirgsfauna. Von Schmetterlingen flogen Mnemosyne und Erebia-Arten. Auch die Ameisen waren Gebirgsformen der Gattung Formica. Sie bauten Haufen, welche allerdings ziemlich klein waren. Die Art war Formica rufa L., die auch bei uns oft keine Hügel baut. In einem Teich fanden sich in etwa $700 \mathrm{~m}$ Höhe Molche, welche jetzt noch im Wasser saßen und scheinbar noch nicht abgelaicht hatten (Molge vulgaris graeca Wolt.).

Ähnlich stellte sich der etwa $1500 \mathrm{~m}$ hohe Gipfel der Visoka Čuka dar; dieser Berg trug eine Beobachtungsstation unserer Marine, von der aus vor allem der Doiransee und ein großer Teil der Doiranfront überblickt werden konnte. Die Besteigung dieses Berges bot landschaftlich viel größere Reize, als diejenige des Bejlik. An vielen Stellen eröffneten sich Blicke auf den blauen Doiransee, welche sehr eigenartig waren. Hier stiegen die Buchenbäume bis fast $1200 \mathrm{~m}$ hoch am Berg hinauf; auch hier schlol sich an sie eine Mattenregion, welche in der Umgebung der Beobachtungsstation von mächtigen Felsblöcken mit zum Teil bizarren Formen übersät war. Leider konnten wir nicht bis zum höchsten Gipfel vordringen, der nach Mitteilungen von Offizieren eine formenreiche alpine Flora beherbergt.

Von der Beobachtungsstation aus war noch eine ganze Reihe höherer Gipfel zu übersehen, auf denen Mitte Mai noch Schnee lag. Eigenartig zogen sich über die Hänge des Gebirges gegen den Doiransee die Stellungen unserer und der bulgarischen Truppen; Schützengräben und Artilleriestellungen bedeckten alle Höhen und wohlgepflegte Zufahrtsstraßen sicherten den Nachschub. Sehr malerisch war der Blick von dem erreichten Vorgipfel der Visoka Č u a nach dem Doiransee hinunter. An dem dunstigen Tag lag der See lichtblau in der Tiefe; seine Uferberge umgaben ihn mit einem hellvioletten Rahmen, einzelne Bergflanken leuchteten rötlich auf. Vor uns aber bildeten die Buchen mit ihrem frischen Frühlingsurün und den silbergrauen Stämmen einen eigenartigen Gegensatz. Sie waren nahe Wirklichkeit, während der ferne See wie eine Vision aus fernen Zonen den Sinnen entrückt schien (Abb. 75, S. 155).

Eigenartige Erinnerungen sind mir von einer Fahrt an die Wardarfront hei Gewgeli im Gedächtnis geblieben. Über den Furkapaß ging es am Dub vorbei gegen die Ebene des Wardar. Weit und flach lag diese vor mir, als ich vom Gebirge herunter in die kampfreiche Gegend von Bogrdanci kam. Südwärts sah 
man nur mehr niedere Hügel und sonst nur Ebene, die sich gegen das Meer hin dehnte, und durch welche der Fluß seinen Weg zur Aegeis suchte.

Im Dorfe Bogdanci hielten wir uns nur kurz auf; wir waren jetzt in Kampfgebiet und überall verrieten tiefe Trichter, daß wir im Bereich der feindlichen Geschütze waren. Das Dorf selbst bestand fast nur aus Ruinen, zwischen denen die Soldaten sich Unterstände eingebaut hatten. Mit ihnen hausten eine Unmenge von Falken in den Trümmern, welche durch alles Schießen sich nicht hatten vertreiben lassen und in Mauerlöchern horsteten. Es waren mehrere verschiedene Arten, die in vielen Exemplaren schreiend um die Ruinen flogen, immer wieder in die Ebene hinausflogen, dort auf Beute hinabstießen und mit ihr zum Nest heimkehrten. Es waren vor allem Rötelfalken (Falco naumanni naumanni Fleisch.), doch auch Turmfalken darunter (F. tinunculus tinunculus L.).

Die Fahrt zum Wardar wurde nun genau überlegt, denn hier war die ganze Ebene weithin vom Feind eingesehen und selbst einzelne Reiter und Wagen wurden oft mit Granaten beschossen. Der Wagen sauste in gutem Tempo quer durch die Fläche zu einem eigentümlich geformten Hügel, der noch diesseits des Wardar, dicht vor dem Fluß aufragte und in der Armee der Tafelberg hieß. Dicht hinter ihm begannen die feindlichen Stellungen, die hier von Engländern besetzt waren.

Es wehte eine frische, kühle Luft über die Ebene, wir fuhren meist im Gras und selten nur wirbelte unser Auto eine Staubwolke auf. Lerchen, Haubenlerchen, Ammern, hier und da ein Falke flogen vor uns auf. Wundervoll klar war die Fernsicht auf die Bergketten im Osten und vor allem auf die schöngeformten Gebirge im Westen. In der Ferne erkannte man Majadak mit den feindlichen Höhenstellungen. Nach ungefährdeter Fahrt kamen wir in die Deckung des Tafelberges, wo unser Wagen sicher warten konnte, bis er zu einem verabredeten Treffpunkt an der anderen Wardarseite sich in Bewegung setzte. Er mußte eine unbeschossene Wardarbrücke weiter oben am Fluß zur Überfahrt benutzen.

In die Steilwand des Tafelberges waren Unterstände mit Türen und Fenstern in den Felsen eingebaut. Der mich begleitende Hauptmann hatte alle Posten des Nachrichtendienstes zu kontrollieren. Während er dies besorgte, streifte ich in der Umgebung umher. 
Sie war wasserreich, ein starker Bach strebte dem nahen Wardar zu. Seine Ufer waren von Weidenbüschen eingefaßt, und im Wasser stand ein Dickicht von Schwertlinien (Iris pseudacorus L.) von gelber und blauer Farbe. Kleine Vögel huschten durch das hohe Gras jenseits des Wassers. Zahlreiche Libellen sausten über dem Spiegel des Bachs hin und her auf der Jagd nach Eintagsfliegen und Mücken, die geruhsam in der heißen Luft schwebten.

Es war Mittag geworden und vom wolkenlosen Himmel strahlte die brave mazedonische Sonne herab, als wir uns zu einem Fußmarsch auf der Landstraße in Bewegung setzten. Dicht vor dem Tafelberg ging eine stark zerschossene eiserne Eisenbahnbrücke über den Wardar. Ihr mittlerer Teil lag im Flußbett und das Wasser des hier wohl i $50 \mathrm{~m}$ breiten Flusses brauste über ihn hin; er war durch einen Holzbau der Pioniere ersetzt, der oft erneuert werden mußte. Im Abstand von mehreren Minuten mußten wir einzeln die Brücke überschreiten, da man sonst vom Feind beschossen wurde und auch drüben auf der nackten Landstraße mußten wir in gehöriger Entfernung voneinander marschieren, bis wir zwischen die zerschossenen Häuser der Stadt Gewgeli kamen.

Der Besuch in Gewgeli gehört zu meinen eigenartigsten Erinnerungen während meiner Kriegs- und Forscherjahre in Mazedonien. So wollte ich nicht unterlassen, ihn in diesem Buch zu schildern. Die Straßen einer großen Stadt waren es, in welche wir drei Männer eintraten; stattliche weiße Häuser faßten sie ein; zierliche Villen standen dazwischen. Die breiten Straßen waren von Alleen von Platanen und ausländischen Bäumen, so der japanischen Pawlownia imperialis, eingefaßt. Gärten lagen zwischen den Häusern, Kirchen und Kapellen ragten auf. Aber wir drei Männer waren die einzigen lebenden Wesen auf den hellen, breiten Straßen. Kein Wagen, kein Tier, kein Mensch bewegte sich zwischen den leeren Häusern. Die Fensterhöhlen gähnten ohne Scheiben, Türen hingen schief in den Angeln, der blaue Himmel lachte fröhlich zwischen die dachlosen Mauern herein. Granattrichter unterbrachen hier und da die glatte Straßenfläche. Ein zottiger Hund schlüpfte mit mißtrauischem Blick in ein Kellerloch.

Tiefe Stille lag über der großen Stadt, in der früher ein starker Verkehr, Handel und Wandel geherrscht haben müssen. Große Warenlager, Fabrikgebäude zeugen davon, daß hier früher ein Mittelpunkt des Seiden-, Opium-, Wein- und Getreidehandels von Südmazedonien war. Eingeborene Familien waren nicht mehr 
da, die ganze Bevölkerung hatte die mitten in der Front liegende Stadt verlassen. Selten begegnete uns ein scheuer, zerlumpter Zivilist, der vielleicht nach den Trümmern seines Hauses gesehen hatte und nun fürchten mulite, als Spion verdächtigt zu werden. Ich konnte keine Erfahrungen über die griechische Sprache der Gewgelier machen.

Die Schaufenster der Läden waren zertrümmert; war ein Haus noch erhalten, so waren Fenster und Türen mit Brettern vernagelt. Wir gingen auf Schleichwegen durch Höfe und gedeckte Gänge, durch deckenlose Zimmer, deren Böden von Gras bewachsen waren, zu den tief eingegrabenen Unterständen der Abteilungen, welche im Bereich der Stadt lagen. Quartiere waren hier zu gefährlich.

Als der Dienst meines Begleiters erledigt war, verließen wir die Ruinen der Stadt, um die Horchposten an der Front zu besuchen. Ich begleitete die beiden Offiziere, weil ich damit den südlichsten erreichbaren Ort von Mazedonien kennen lernen konnte. Gleich beim Heraustreten aus der Stadt mulbte man sich trennen und sorgsam Deckung suchen, um den Weg durch das Bett der Ljumnitza zu nehmen, welches jetzt fast trocken lag, so daß man durchwaten konnte. Hier mußte man schon Abstände von 5-10 Minuten voneinander nehmen, um heil durchzukommen.

Nach einigen Kilometern Marsch ging die Ebene in niedrige Hügel über. Hier kamen wir über die griechische Grenze; jenseits lag in Maulbeergärten das Dörfchen Dzeovo. Vor diesem erhob sich eine Kette von lehmigen Hügeln, in denen unsere vordersten Gräben eingebaut waren. Über diese hinaus reichten die Erdbauten mit den Horchposten, welche mit feinen Apparaten die Telephon- und sonstigen Gespräche der Feinde abhörten. Während ich mich dort in den Unterkünften der Mannschaften nach Malariaund Pappataccimücken umschaute, nahm ich auch einmal ein Hörrohr in die Hand und hörte fern von mir drüben die Stimme eines Franzosen sich herzhaft über einen „bon vin rouge“ äußern.

Nach kurzem Aufenthalt und frugalem Mittagessen wurde der Rückmarsch angetreten, der wieder über die Ljumnitza, aber diesmal über eine Brücke vor ihrer Mündung in den Wardar führte. Mit der gleichen Vorsicht wie am Vormittag wurden die gefährlichen Strecken zurückgelegt, die Stadt Gewgeli durchwandert, und dann begann ein schlimmer Marsch auf schattenloser, staubiger Landstraße nordwärts. Es war sehr heiß geworden, der Weg war 
lang und sehr ermüdend. Welche schönen Erinnerungen weckte der Übergang über den Koinskobach, der, von der Mala Rupa kommend, hier dem nahen Wardar zuflol. Frische Gebirgsluft blies über seinem Wasser die Phantasie mir zu.

So marschierten wir mutig einige Stunden lang weiter. Auch hier war es nicht gefahrlos; viele Trichter verrieten uns, daß vor kurzem reichlich Granaten eingeschlagen hatten. Wir hatten Glück, denn wir hörten, daß am Tage vorher 600 Granaten der Feinde hier beim Artillerieberg eingefallen waren. Man hatte mir schon vorher anvertraut gehabt, mein Nachrichtenhauptmann habe stets in solchen Dingen besonderen Dusel.

Es wurde schon abendlich, als wir in der Ferne unser Auto auf der Landstraße stehen sahen, dessen nicht sehr tapferer Fahrer sich nicht weiter in die gefährliche Zone gewagt hatte. Aber er hatte keinen schlechten Platz zum Warten gewählt. Neben der landstraße stand ein kleines Haus, in welchem ein altes türkisches Bad von der Heeresverwaltung reinlich ausgebaut war. In einem Bassin sprudelte das Wasser einer heißen, schwach schwefelhaltigen Mineralquelle.

Das war nach dem anstrengenden Marsch die erwünschteste Erquickung. Das heiße Wasser frischte uns auf, der kühle Abendwind trocknete uns auf der Wiese. Als wir wieder angekleidet in unserem Wagen über Negorci, Predeci, Smokwiza dem Hain Mamre in der Nacht zusausten, fühlten wir uns vollkommen erholt und genossen in Gedanken die Eindrücke des Tages.

Bald nach diesem Ausflug kehrte ich vom Hain Mamre nach Üsküb zurück, wo neue Aufgaben meiner warteten. Ich schied mit dankbarer Gesinnung von dem trefflichen Kreis, mit dem festen Vorsatz, in Hochsommer zurückzukehren und noch eine Expedition ins Gebiet der Mala Rupa von dort aus zu unternehmen. Persönliche Erlebnisse und die Vorgänge auf den Kriegsschauplätzen, speziell gerade an dieser Front, verhinderten die Erfüllung dieses meines Wunsches. 


\section{DIE EXPEDITION IN DENSCHARDAKH}

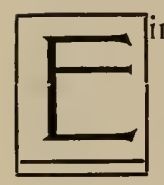

ine brütende Hitze lag Anfang August 1917 über der Stadt Üsküb, als ich dort verweilte, um von da aus eine Forscherfahrt in die albanischen Randgebirge ins Werk zu setzen. Im Frühling sieht man aus der Gegend von Üsküb, wenn der Schnee von den umgebenden Bergen weggetaut ist, zwei Bergketten, die noch tief in den Sommer hinein schneebedeckt sind. Die eine liegt südlich der Stadt, man kann sie nur von den Höhen aus erkennen. Bei jedem Spaziergang außerhalb der Stadt eröffnen sich aber Blicke gegen die westliche Bergkette, die oft im Abendschein violett aufglüht und mit ihren schönen Bergformen jedem Landschaftsbild einen schönen Hintergrund gibt.

Das ist das albanische Randgebirge des Schardakh, welches man von Üsküb stets in zwei Hälften geteilt sieht. Im Nordwesten zieht sich eine lange Kette bis $\mathrm{zu}$ den Vordergrundsbergen, in denen das Chrombergwerk von Radusche liegt. Diese Nordwestkette hat ihre höchste Erhebung im Ljubotren, dem Liebesdorn der Bulgaren. Er erscheint vom Wardartal aus als stattliche Pyramide mit schönen Umrissen. Um ihn herum gliedern sich erheblich niedrigere Berge, so daß er einen sehr stattlichen Eindruck macht mit seinen etwa $2400 \mathrm{~m}$ Höhe. Er ist oft bestiegen worden, auch von Naturforschern, und auch die Offiziere und Ärzte Üskübs hatten ihn öfter besucht. So erschien er mir für eine Forschungsfahrt weniger verlockend, als die südwestliche Gruppe des Gebirges, die nicht so ausgesprochen kettenförmig zu sc: . schien. Dort sah man im Glanz des Abends oft eine Gruppe von mehreren hohen Gipfeln herüberschimmern, die vor allem im frühen Frühjahr ein prachtvolles Bild darboten. Unter ihnen wurde uns der höchste als Kobeliza, der Kürbis, bezeichnet. Wenn das auch nicht eine wilde Romantik verhieß, so erschien uns doch diese Südgruppe des Schardakh manches zu versprechen. Sie war auch bisher selten von Nordeuropäern besucht worden. So entschied ich mich bald für diese südliche Gipfelgruppe, die mir höher 
aufzuragen schien als der Ljubotren, als Ziel unserer ersten größeren Expedition in Mazedonien.

In jener Zeit bestand das beste Einverständnis mit der bulgarischen Regierung und Heeresleitung. So konnte ich denn auf eine verständnisvolle Unterstützung meines Planes rechnen. Unser Verbindungsoffizier Hauptmann Lessing brachte mich zu dem Oberstleutnant Jostoff, einem Namensvetter des bekannten Generals, der bei den Bulgaren dieselbe Funktion vertrat. Dieser liebenswürdige Offizier vermittelte die Beziehungen zu den bulgarischen Zivilbehörden und vor allem zum Stab der neubegründeten

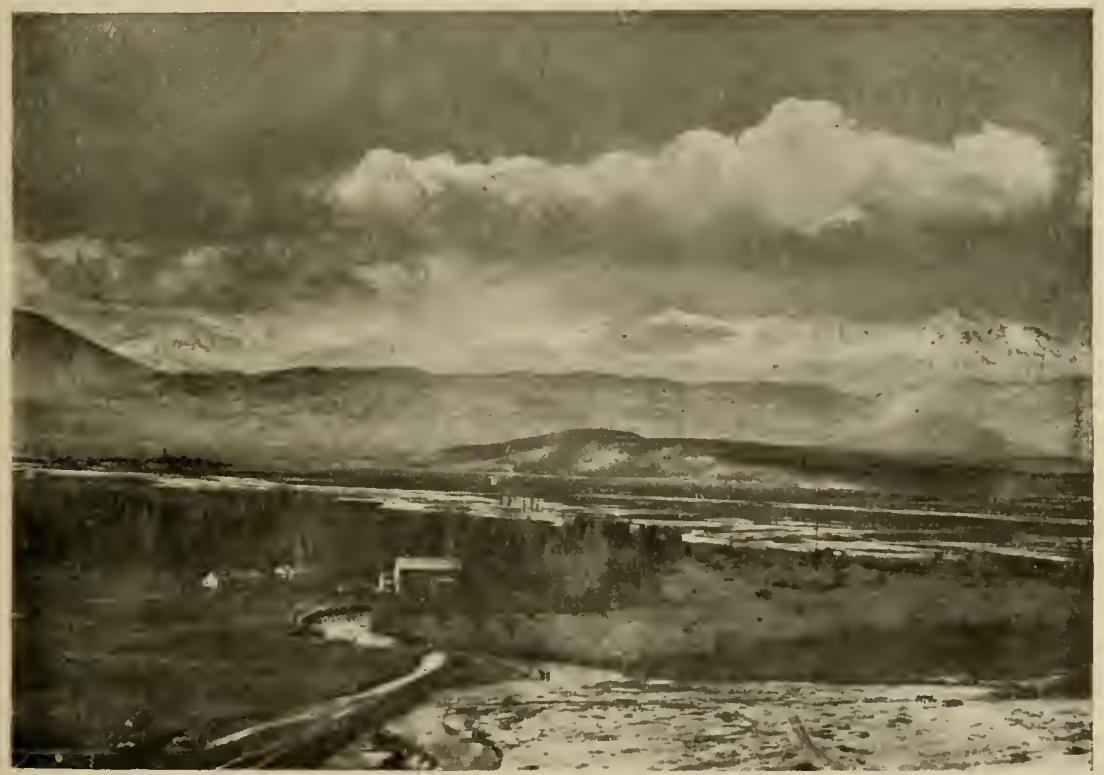

Abb. 114. Westliche Schneeberge über dem oberen Wardartal im Frühling. Links Kobelizagruppe, rechts Ljubotren.

bulgarischen Gebirgsdivision, von der wir mit Reit- und Tragpferden und Bedeckungsmannschaften versorgt werden sollten.

So konnten wir denn am Freitag, den 10. August nachmittags, uns mit der Kleinbahn vom Bahnhof Jostoff in Bervegung setzen. Unser Ziel war die Grenzstadt Kalkandelen. So hieß sie in türkischer Zeit. Ihr bulgarischer Namen war Tetowo. Es war eine der richtigen Durchgangsstädte gegen Albanien. Von Kalkandelen aus führt ein $\mathrm{Pa}$ nach Prizren. 
Auf dieser Reise begleiteten mich zum erstenmal Botaniker. Prof. Bornmüller und Prof. Fleischer schlossen sich mir an. Meine anderen Begleiter waren Prof. Müller, Dr. Wülker, der

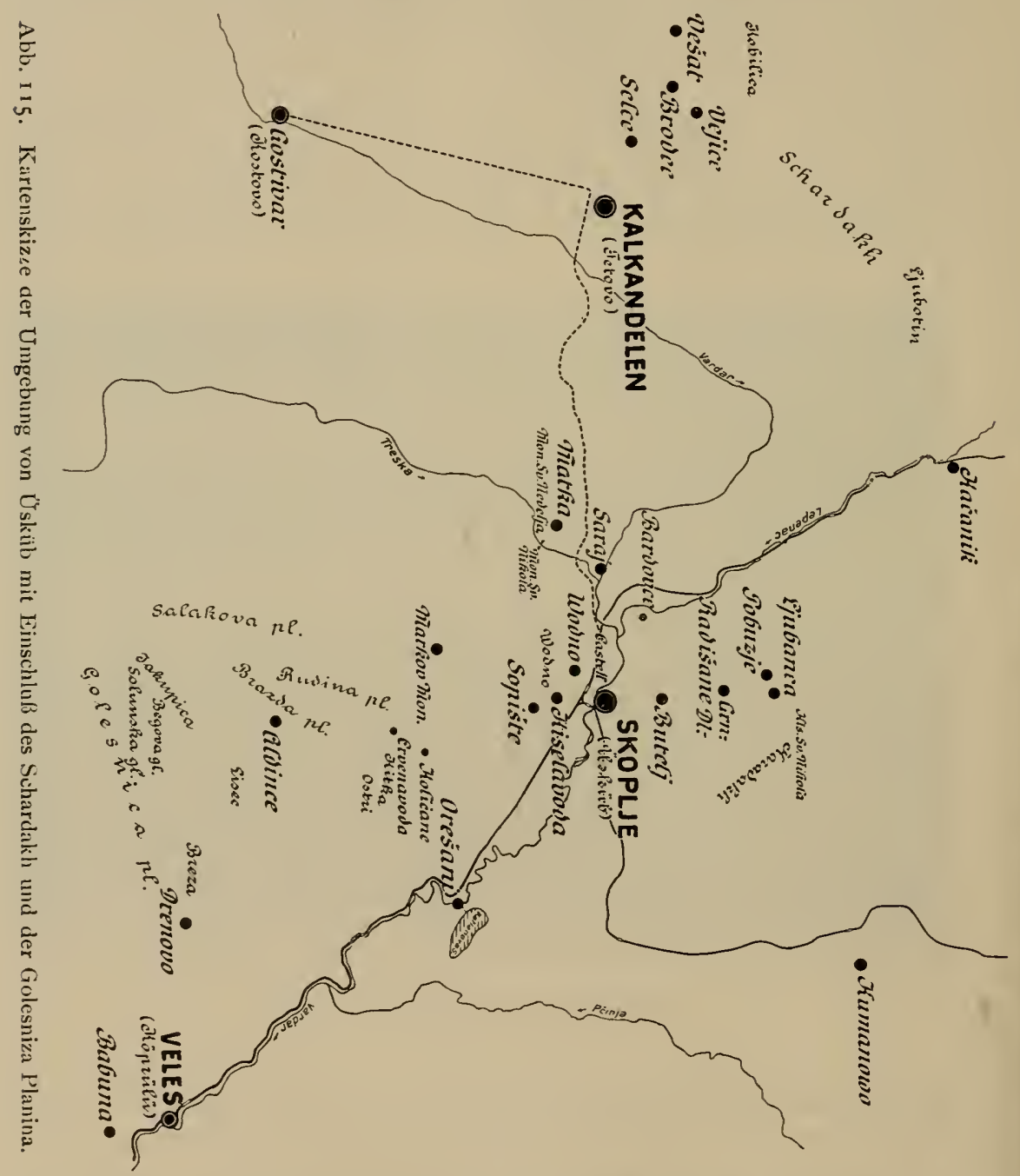

Insektensammler Rangnow und unser gemeinsamer Bursche, ein ungarischer Schwabe namens Michael Schucha.

Die Bahn führte wardaraufwärts, und zwar lernten wir bei der Fahrt die ganze Strecke kennen, welche der Fluß von West nach Osten fließt. Der Wardar hat ja einen eigenartigen Lauf. Er 
entspringt südlich von Kalkandelen, fließt etwa nordöstlich bis zu dieser Stadt, um dann in großem Bogen bis Üsküb sich nach Osten zu wenden. Von dieser Stadt aus strömt er mit der Hauptrichtung nach Südosten dem Meere zu, um westlich von Saloniki zwischen der Chalkidike und Thessalien in eine große Bucht des Ägäischen Meeres zu münden.

Bei $\mathrm{Kalk}$ andelen durchfließt er ein weites Tal, das südlich von der Karaschiza, nördlich von der Südgruppe des Schardakh begrenzt wird. An letzterem angelehnt liegt malerisch die Stadt Kalkandelen.

Im letzten Teil der Bahnfahrt zeigte sich zur Rechten eine hohe Bergkette, deren Abschluß, die Kobeliza, das Ziel unserer Expedition, mächtig vor uns aufragte. Das Tal ringsum war gut angebaut und bewässert. Die Stadt lag, weitläufig angelegt, in Pflanzungen eingebettet. An die Berge geschmiegt, machte sie einen sehr einladenden Eindruck. Das Gebirge selbst bot uns seine waldlose Seite dar, kahle schroffe Felsen schienen vorzuherrschen.

Am Bahnhof wurden wir von einem vom Stab der Gebirgsdivision gesandten Dolmetscher abgeholt. Wagen standen bereit, unser Gepäck zu transportieren. Wir stiegen in einen stattlichen, sauberen Landauer ein, dessen Kutscher uns in rasendem Galopp zur Stadt fuhr, von der der Bahnhof etwas abgelegen war. Für Mazedonien klappte alles auffällig gut.

Rasselnd, unter Peitschenknall, in fast zu flottem 'Tempo über hartes Steinpflaster klappernd, führte uns der Wagen durch die Straßen der Stadt, über einen freien Platz, schließlich durch eine steile enge Gasse bergauf zum Offizierskasino. Hier sollten wir Gäste des Offizierkorps bei den Mahlzeiten sein, während wir für die Nächte auf Bürgerquatiere in der Stadt verteilt wurden.

$\mathrm{Kalk}$ a n dele $\mathrm{n}$ macht einen recht sauberen und sympathischen Eindruck. Vor allem als Gegensatz zu dem verstaubten und verkommenen Üsküb wirkte er sehr freundlich auf mich. Hier hatte der Krieg keine so furchtbaren Spuren hinterlassen als an den großen Heerstraßen Mazedoniens. Keinerlei Zerstörungen waren an den Häusern der Stadt zu sehen, keine verlassenen Gehöfte, nichts von dem Verfall und der Vernachlässigung; wie ich sie in den bisher besuchten Gegenden, im Wardartal und an der Front überall angetroffen hatte. Hier hatte der Krieg nicht getobt, wenn er natürlich auch für diese entlegene Stadt seine Folgen gehabt hatte. Hier hielten die Leute noch etwas auf sich selbst, auf ihren 
Besitz, ihre Häuser und Höfe. Sie gingen gut gekleidet und sahen einem offen und freundlich ins Gesicht, nicht mit dem gedrückten und scheuen Blick der Frontbewohner. Man hörte Frauenstimmen singen, sah jubelnde und spielende Kinder. Das waren für mich neue Eindrücke.

Ich freute mich, hübschere Mädchen auf den Straßen oder abends mit den großen Kupferkannen zum Brunnen zu gehen, mit munterem Geplapper an den Straßenecken stehen zu sehen.

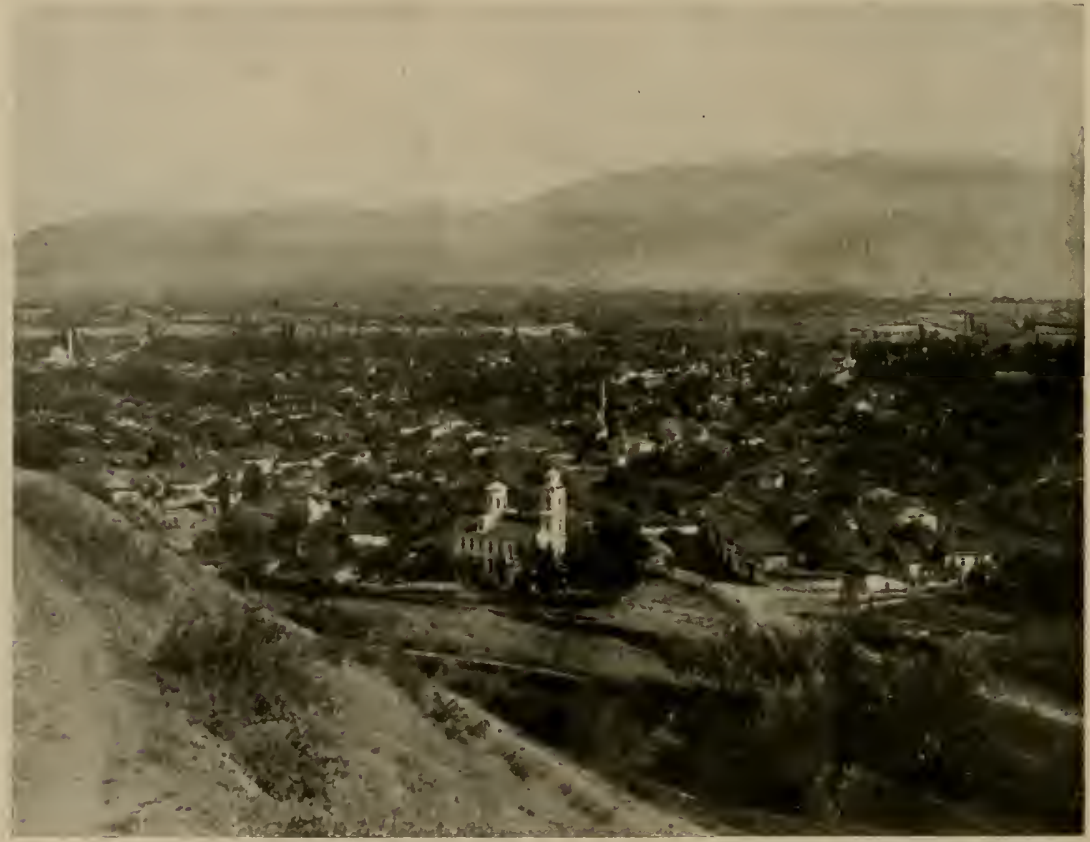

Abb. I 6 . Kalkandelen (Tetowo) gesehen vom Hang jenseits der Sarska.

Im Quartier wurde man freundlich aufgenommen. Die Häuser waren hier durchweg die typischen türkischen Stadthäuser, wenn auch die vornehmeren Familien, bei denen wir als Ehrengäste einquartiert wurden, alle bulgarisch waren. Meist stand das Haus im Hintergrund eines großen viereckigen Hofes. An dessen beiden Seiten oder meist nur an einer von ihnen zogen sich niedrige Wirtschaftsgebäude und Dienstbotenwohnungen hin. Das Wohnhaus war meist zweistöckig, im unteren Stockwerk befanden sich die Räume, in denen Gäste empfangen wurden, und in welchen die erwachsenen Familienmitglieder sich tagsüber aufhielten. Im oberen 
Stockwerk waren die Schlaf- und Wohnzimmer. Das Zimmer, welches mir überlassen war, offenbar das Staatszimmer des Hauses, besaß an zwei Seiten je drei Fenster, war daher hell und luftig.

$\mathrm{Un}$ alle Wände herum liefen Diwans; diese waren mit handgefertigten Spitzen und Häkelarbeiten, die mit rotem Stoff unterlegt waren, überzogen. An einer Wand stand eine Kommode, an einer anderen ein Glasschränkchen. In diesem waren die Kostbarkeiten der Familie aufgestellt. Eine Standuhr auf der Kommode ging nicht. Daneben standen Gefäße aus Glas und Kupfer, selten ein emailliertes Kästchen oder dgl. Dazu nur primitive Photographien, hier und da einmal ein Stich mit Kriegserinnerungen, historischen Szenen,Landschaften oder ein blinder Spiegel. Alles etwas verstaubt und vernachlässigt. Die Schlösser der Türen schlossen nicht, die Fenster ebensowenig, Scheiben fehlten. Aber das ganze Zimmer war sehr sauber gehalten. Das Bett, welches in einer Ecke für mich aufgestellt

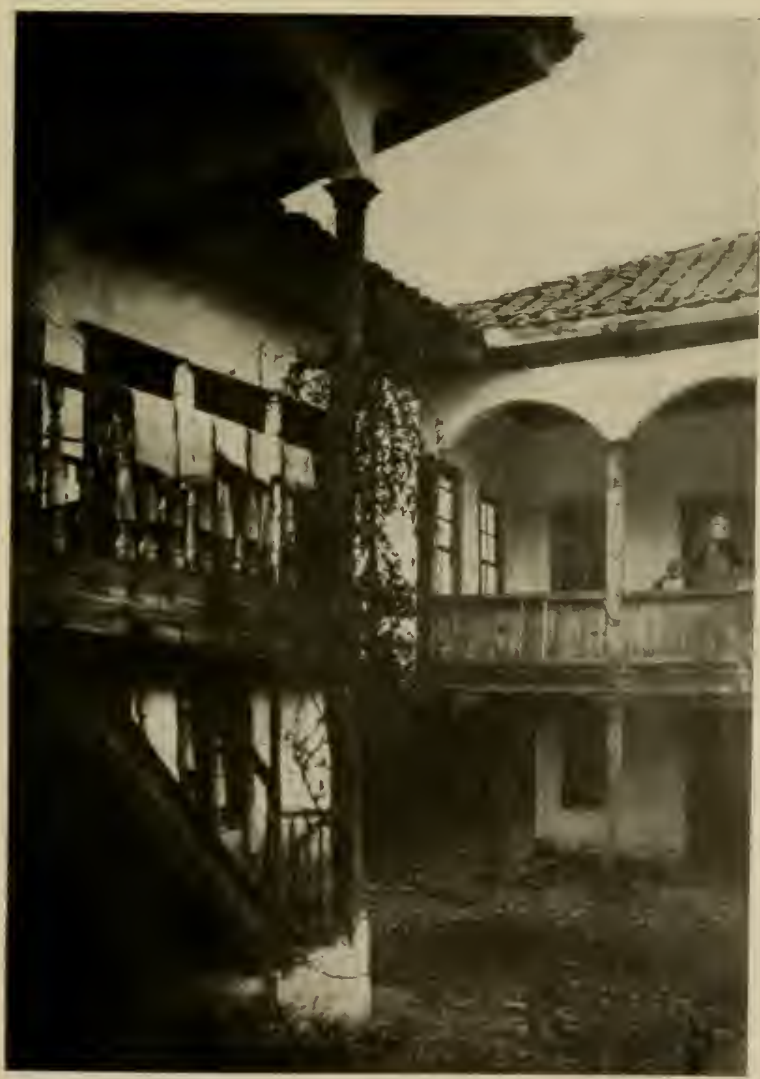

Vermessungsabt. 21 phot.

Abb. 117. Hof eines mazedonischen Bürgerhauses.

war, mitteleuropäisch ausgestattet, mit weißer, blitzblank reiner Wäsche und warmer Steppdecke. Die Kissen mit schön gestickten Überzügen waren offenbar die beste Bettwäsche der Familie.

Morgens früh brachte ein kleines Mädchen, wohl die Tochter 
eines der Dienstleute, mir in kleiner Porzellantasse auf silbernem Tablett heißen türkischen Kaffee. Das Waschgeschirr bestand aus einer ziemlich flachen Messingschale, zu der eine ebenso schön getriebene Messingkanne gehörte. Die übliche Waschprozedur war recht einfach. Man läßt sich über der Waschschale das Wasser über die Hände gießen, wäscht diese und reibt sich mit ihnen das Gesicht ah) und die ganze Reinigung ist erledigt. Also im ganzen orientalisch-türkische Sitte, von den Bulgaren, wie die Hauseinrichtung ohne viel Änderung übernommen. Der Hof war auch hier nach türkischer Sitte zum Teil bepflanzt. Rebenlauben überdachten manche Teile, Oleander, Lorbeer und Granatapfelbäume standen in Kübeln umher, auch schattenspendende Bäume und Blumenbeete waren angepflanzt. Meist plätscherte ein Brunnen inmitten des Hofes; vor allem nachts war dies das einzige Geräusch, welches in das wohlgeborgene Haus drang. Bei Tag ertönte oft fröhlicher Kindergesang von einer munteren Schar, die unter dem Rebdach saß und spielte und den Fremdling freundlich begrülbte.

Abends saßen wir mit den Offizieren im Kasino und besprachen unsere Pläne. Es waren meist Herren von der Intendantur. Die Truppen der Division lagen in der Umgegend, der Stab in einem berühmten Kloster eine Stunde entfernt von Kalkandelen.

Am ersten Morgen fand der übliche feierliche Empfang in der Präfektur statt. In einem großen Saal mit Teppichen und Fahnen an den Wänden wurden wir durch eine längere Ansprache des Präfekten geehrt, auf die ich antworten mußte. Der Präfekt, in Friedenszeiten Gymnasiallehrer für Chemie in Sofia, zeigte volles Verständnis für unsere Pläne und versprach uns die Hilfe der Zivilbehörde als Ergänzung der militärischen Unterstützung, die uns in Aussicht gestellt war.

Nachmittags $3 \frac{1}{2}$ Uhr sollte der Abmarsch erfolgen, um die kühlen Abendstunden zum Anstieg bis auf eine gewisse Höhe auszunützen. In der engen Straße beim Kasino bildete sich alsbald eine höchst malerische Kolonne. Wir waren 7 Deutsche, zu denen I 1 bulgarische Soldaten kamen, welche als Pferdeknechte und Bedeckungsmannschaften uns begleiten sollten. Die meisten der Soldaten, ebenso ihr Unteroffizier, der Tschausch, waren Mohammedaner. Die meisten sprachen nur türkisch. Dolmetscher hatten wir keinen, so war die Verständigung unterivegs vielfach nicht einfach, da nur unser ungarischer Bursche einigermaßen bulgarisch sprach. Wir kamen aber mit den gutmütigen Leuten recht gut aus. 
Sechs gut gesattelte Reitpferde standen für uns Deutsche bereit, die Soldaten waren ebenfalls alle beritten. Dazu kamen 10 Saumpferde, welche unsere Zelte, Decken, Kisten, den Proviant und die ganze Ausrüstung zu tragen hatten.

Jeder von uns suchte sich ein geeignetes Reitpferd aus, wobei diejenigen, welche keine Reiter waren, etwas ängstliche Gesichter machten. Die Botaniker, die schon viele Reisen in Kleinasien, Persien und sonst im Orient hinter sich hatten, hatten schnell gewählt. Auch ich erfaßte die Zügel eines großen, schlanken Pferdes, welches mit ganz neuem Zaumzeug sehr gut ausgestattet war. Ich prüfte die Gurten, paßte die Zügel und Bügel an und als ich die Satteltaschen öfnete, um photographischen Apparat und Sammelgeräte in ihnen unterzubringen, entdeckte ich zu meinem Erstaunen am Sattelzeug dieses bulgarischen Armeepferdes einen deutschen Firmenstempel, und wie überrascht war ich, als ich da las: Handelskammer Freiburg i. Br. Also die Stadt, in der meine Universität sich befand, in der meine Lieben damals weilten, die hatte mein Sattelzeug geliefert. Ich sah dies als ein gutes Omen an, als ich mich zum Abritt mit unserem Führer an die Spitze der Karawane begab.

Bald saßen alle im Sattel; klappernd und hufeklirrend bewegte sich der lange Zug durch die engen Gassen zum Berghang. Wir blieben auf dem linken Ufer des brausenden Flüßchens, das vom Schardakh herunter kam und in wilder Felsenschlucht tief unter uns über die Steine brauste.

Es war die Sarska, deren Tal wir beim Ritt dieses Nachmittags einige Stunden verfolgen mußten. Hoch über dem rauschenden Flüßchen kletterte der Saumpfad den Berghang hinauf. Mit vorsichtigem Schritte suchten die Pferde ihren Weg über die glatten Steine und brachten uns flink vorwärts. Bald klomm der Pfad hoch am Hang in die Höhe, um dann wieder bis zum Wasser des Baches niederzusteigen.

Der Rückblick auf das malerische, in Grün gebettete und von Grün umgebene Kalkandelen war prachtvoll; aus dem Gewirr der Häuser erhoben sich Minarets und Kirchtürme. Als wir etwa 7-80o m Meereshöhe erreicht hatten, wurde die Paßstraße breiter, schöne Wiesen, auf denen Heu lag, Haferfelder breiteten sich aus. Was aber der Gebirgslandschaft einen besonderen Reiz verlieh, waren die mächtigen, alten Bäume, die mit ihren dunklen Stämmen immer neue, wechselnde Umrahmungen der Gebirgs- 
landschaft bildeten. Vor allem fielen die alten, gewaltigen Edelkastanien auf, welche mit ihren gerundeten, üppigen Kronen eigenartig von den schroffen Felsen sich abheben. Sie sind in Mazedonien nicht häufig und außer hier im Sarskatal habe ich sie nur auf dem Wodno bei Üsküb angetroffen.

Auch andere stattliche Bäume vervollständigten den üppigen Eindruck dieser Oase im Felsenland. Eichen und Nußbäume erhoben sich neben allerhand Obstbäumen, an denen noch reichlich Früchte hingen. Um saftige Wiesen dehnte sich üppiges Buschwerk von Haselnuß- und Erlensträuchern aus. Bei einer starken,

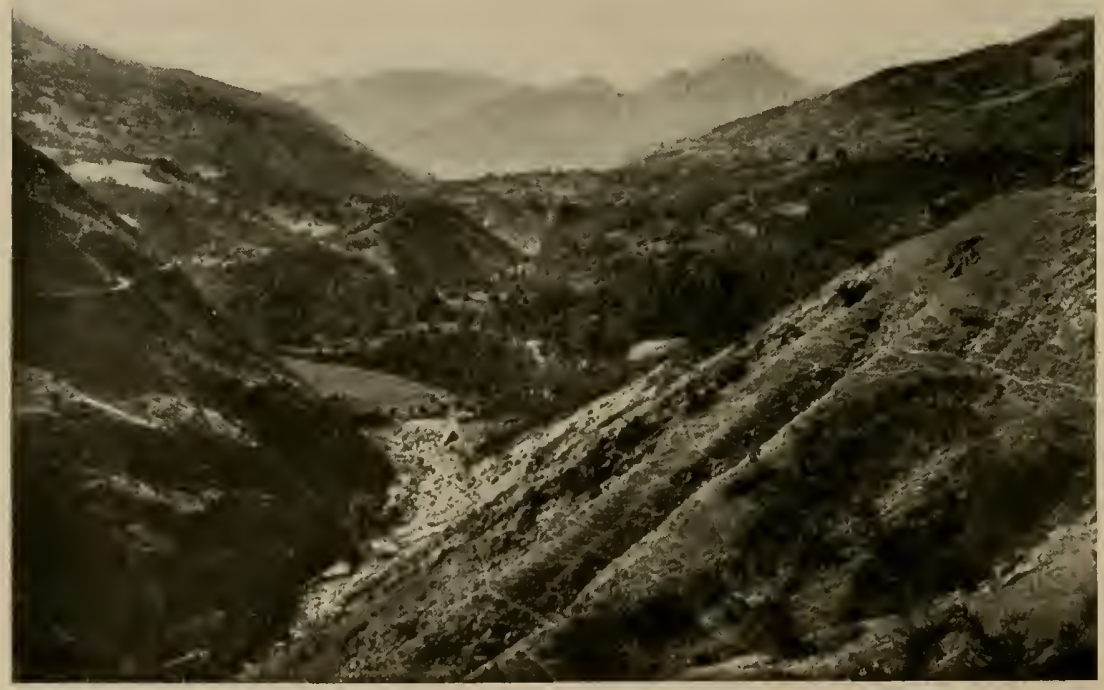

Abb. I I 8. Sarskatal, im Hintergrund Kobeliza.

zum Fluß hinabplätschernden Quelle breitete sich ein grüner Rasen aus, umgeben von knorrigen Weiden. Auf der Wiese blühten dunkelrote Skabiosen, am Wasser weiße Doldenpflanzen und duftende Minze. Un die Blüten schwirrten Hummeln und Bienen, auf ihnen saßen Käfer, vor allem wie Edelsteine glänzende Chrysomelen (Chrysomela menthastri Suffr.).

Durch die Kronen der Bäume öffneten sich jetzt Blicke auf die Kobeliza und die umgebenden Bergmassen mit ihren steilen Felsenhalden, Waldbeständen und schimmernden Matten. 
Sicher und brav stiegen unsere Pferdchen weiter den Pfad hinan, der jetzt schmal und verwegen hoch über der Schlucht am Felsen entlang führte. An einer breiteren Stelle des Tales lag über dem Bach uns gegenüber in etwa $900 \mathrm{~m}$ Höhe das Dorf Brodeč. Die albanischen Bergdörfer mit ihren braunen Häuschen und den grauen Dächern, von Bäumen beschattet, am Berghang angelehnt, boten höchst malerische Bilder, in der feinen Nachnittagsstimmung in silbergrauem Schimmer Erinnerungen an japanische Dörfer wachrufend.

Der Ritt verlief nicht ohne Abenteuer. Als der Pfad steil zum Bach abstieg, rutschte Herr Müller plötzlich samt dem ganzen Sattelzeug über Hals und Kopf seines steil abwärts schreitenden Pferdes hinunter und schlug nahe am Abgrund einen Purzelbaum auf dem Saumpfad. Als wir erschreckt heranritten, schnupperte sein Pferd ganz behaglich an ihm und er stand lachend, zum Glück unbeschädigt, auf, um bald auf das wieder gesattelte Pferd zu klettern. Ähnliche Abenteuer passierten jedem der Teilnehmer der Expedition, da unsere Bulgaren mit den Pferden nicht so sorgfältig umgingen wie deutsche Soldaten und unsere Leute nicht viel von Pferden verstanden. So mußte jeder von uns regelmäßig sein Pferd sorgfältig nachsatteln. Doch verlief die Reise in den Schardakh ohne wesentlichen Unfall.

Abwärts in die Schlucht führte der Pfad über den jetzt schon viel kleineren Bach, jenseits schon am Hang der Kobeliza hinauf und dann steil abwärts zu dem hochgelegenen Dorf Vešal. Durch eine Schlucht gelangten wir in das $1150 \mathrm{~m}$ hoch gelegene Dorf, welches im Verlauf des Balkankrieges verlassen worden war und dessen meiste Häuser nun halb oder ganz zerstört waren. Ein noch ziemlich erhaltenes großes Haus sollte uns als Herberge dienen; es war zu solchem Zweck vorbereitet und mit einem Hängeschloß versperrt, zu welchem wir den Schlüssel mitbrachten. Ein großer Raum war am Boden mit Teppichen belegt. In diesem schlugen wir unser Quartier auf. Wir waren mit Decken wohl versehen; die konnten wir gut gebrauchen, denn in dieser Höhe war auch Mitte August die Nacht recht frisch.

In einem anderen Raum wurde abgekocht und müde nach den anstrengenden Vorbereitungstagen sanken wir auf die Teppiche nieder, um einen erquickenden Schlaf zu halten.

Es war etwas ungewohnt auf dem Boden, auf den nicht ganz sauberen Teppichen zu schlafen, von denen wir nicht wulbten, 
wer sie vorher benutzt hatte. Zudem hatte man uns vorher gewarnt, die albanischen Dörfer seien sehr verlaust und von Fleckfieber verseucht. Aber wir blieben von Ungeziefer verschont. Später habe ich mich an diese Art von Quartier gewöhnt und nicht selten in solchen Räumen geschlafen.

Abends hörten wir noch von uns besuchenden Einwohnern, daß in den benachbarten Bergen Gemsen lebten und sie versprachen uns solche zu jagen.

Der nächste Morgen, Sonntag, den 12. August, fand uns schon früh auf den Pferden, schief am Berghang aufwärts reitend. Wir waren jetzt in einer prachtvollen Gebirgslandschaft. Die steilen, felsigen albanischen Berge erhoben sich ringsum zu beträchtlichen Höhen. Hier und da glänzten Schneefelder zu uns herüber. Steile Felsen warfen blaue Schatten auf weite Matten und stattliche Wälder erhoben sich an den Hängen.

Wir durchritten ein Bachtal, dessen einer Hang von steilen Felsen gebildet war, während die Höhen der anderen Seite über der Steilwand einen Buchenwald trugen, über denen Coniferen, offenbar Weißtannen, sich erhoben. Ein halb ausgetrockneter Bach kam das Tal herab, welches weiter oben üppige Vegetation zeigte, dazwischen Buchengebüsch, in welchem prachtvolle Exemplare einer Fingerhutart mit gelben, rostbraun gefleckten Blüten standen (Digitalis ferruginea Gris).

Etwas weiter oben, bei 1675 m Höhe, beobachteten wir die ersten Appollofalter. Außerdem umflogen die Blüten viele Hummeln und kleine Bienenarten.

Herr Müller fing hier Exemplare des Taufrosches (Rana temporaria L.), ein interessanter Fund, da sein Vorkommen hier im Gebiet noch nicht bekannt war. Die Botaniker machten gute Ausbeute, vor allem als wir steilansteigend bei etwa $2000 \mathrm{~m}$ Höhe an einer steilen Felsenwand entlang einen Sattel überschritten, von wo wir wieder auf $1600 \mathrm{~m}$ herabstiegen, wo ein geeigneter Lagerplatz mit reichlich Wasser sich fand. Wir lagerten an einem Steinhang vor einer großen Rasenfläche, auf der eine kleine, strohgedeckte Hütte lag, die von Schafhürden umgeben war. Hier sollten wir auf Anordnung der Behörden von Kalkandelen mit Sennereiprodukten versorgt werden. Das war also ein sehr geeigneter Standort für unsere Unternehmungen an der Kobeliza.

Zunächst fielen uns wütend ein paar mächtige Hunde an, jene prächtigen mazedonischen Hunde, welche ich stets bei den 
Hirten im Gebirge antraf. Sie beruhigten sich, als wir in der Entfernung von $1 / 2 \mathrm{~km}$ unsere sechs Zelte aufschlugen. Ein lebhaftes Lagerleben entfaltete sich, während die Pferde abgesatteit und auf die Weide getrieben wurden, die Zelte allmählich erstanden und Lagerfeuer aufflammten, an denen unser Essen zubereitet wurde.

Als die Dämmerung herabsank, die Sonne noch in unserem Rücken die spitzen Gipfel der Kobeliza umstrahlte, kamen die Herden zur Sennhütte, die man hier Mandra nennt, von den höher gelegenen Weiden zurück. Es waren hauptsächlich Schafe, von denen viele Hundert herangetrieben und in den Hürden für die Nacht zusammengedrängt wurden. Die Hirten kamen uns zu besuchen und brachten uns vorzüglichen Yogurth, Milch und Käse. So konnten wir getrost den kommenden Tagen entgegensehen.

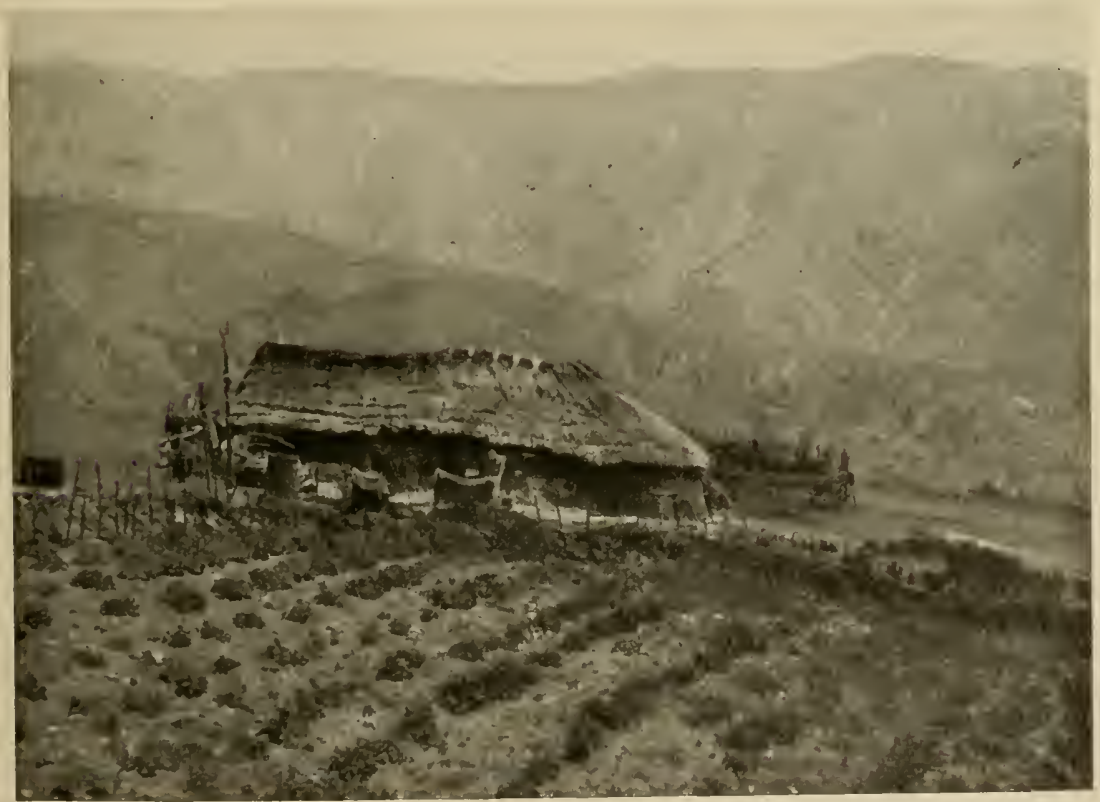

Abb. I19. Mandra (Sennhütte) auf dem Kobelizaanger 1700 m.

Die Nacht sank herab und ein klarer Sternhimmel spannte sich über uns aus. Wie durchsichtig war die Luft in dieser Höhe; wie zog man genießend die frische Bergluft in die Lungen ein und ruhte sich von Staub und Gluthitze aus, aus denen man für einige Tage erlöst war. 
Wir hatten einen sehr geeigneten Platz ausgesucht, um das umliegende Gebiet zu erforschen. Unmittelbar hinter unserem Lager stieg der Gipfel der Kobeliza kegelförmig an, zunächst felsig, nach oben aber in Matten übergehend. Sie ist ein typischer Grasberg, vor allem zogen sich von unserer, der Ostseite, die Matten bis zum Gipfel, während nach Süden schroffe Kalkfelsen steil abfielen.

Schon früh am nächsten Morgen brach ich auf, um zunächst den Gipfel der Kobeliza zu ersteigen. Ich kletterte zuerst durch steile weiße Kalkfelsen, welche sich malerisch hinter unserem Lager erhoben. Über den Hängen flogen Steinrötel (Monticola saxatilis L.) dahin. Die Matten zwischen den Felsen trugen eine reiche Pflanzenwelt. In der unteren Zone gab es noch einzelne Buchenbüsche, dazwischen Wachholder, eine Art hoch, buschig wachsend, eine zweite Form die gleiche, welche ich auf der Mala Rupa beobachtet hatte, am Boden hinkriechend, ein zartes Polster bildend (Juniperus nana Willd.). Zwischen 1600 und $1700 \mathrm{~m}$ Höhe wuchsen Himbeeren und Erdbeeren, allerdings jetzt ohne Blüten und Früchte, dazwischen ein Gänseblümchen, reichlich Fingerhut (Digitalis ferruginea Gris.), zwei Stiefmütterchenarten. Sehr charakteristisch für diese Region waren die zahlreichen Eberdisteln, deren weiße, starre Kronen, überall dicht an den Boden gedrückt, aufleuchteten (Carlina acaulis L.). Silene-Arten blühten zwischen den Steinen und vor allem freute mich, heimatliche Erinnerungen an die bayerischen Berge weckend, ein weißes Studentenröschen (Parnassia palustris L.), welches an feuchteren Stellen stand. In Mulden an geschützten Plätzen erhoben sich stattlichere Pflanzen, Veratrum album, verschiedene hohe Königskerzen (Verbascum longifolium Ten.) und eine Anzahl mächtiger Distelarten bildeten da große Bestände. Zwischen den Steinen standen viele Exemplare einer Wolfsmilchart. Die Distel $\mathrm{n}$ waren Cirsium candelabrum Gris. und $C$. appendiculatum Gris.

Der Aufstieg ging steil über offenes Gelände weiter; vor mir erstreckte sich ein unendlich erscheinender grasiger Abhang, südwärts ragten steile weiße Felsen auf. Als ich etwa die gestern überschrittene Paßhöhe mit $1900 \mathrm{~m}$ erreicht hatte, begann die Pflanzenwelt allmählich alpinen Charakter anzunehmen. Hohe Stöcke von Geum montanum L. mit den tiefgelben Blüten, eine Art von Euphrasia, eine stattliche Primel (Primula columnae Ten.), Glockenblumen (Campanula pusilla), Steinbrecharten, eine schöne 
Storchschnabelart mit großen roten Blüten (Geranium subcaulescens L'Hér.) wuchsen hier nebeneinander und boten, da viele von ihnen noch in Blüte standen, einen bunten reizvollen Anblick dar.

An einem Einschnitt floß das Wasser einer kleinen Quelle rauschend die Wiese hinab. Es war in einer Höhe von $2000 \mathrm{~m}$. Am Rande des Bächleins und unter den Steinen gab es hier Regenwürmer, große Laufkäfer (Pachystus cavernosus E., Carabus violaceus rilvensis Kolbe), und die üblichen Flohkrebse (Gattung Gammarus), welche man hierzulande in fast jedem Brunnen findet. In der Nähe des Wassers fanden sich Ameisen unter Steinen, so die überall so häufige Rasenameise (Tetramorium caespitum L. und Formicina mixta Nil. var. mixto-umbrata For.).

Nun stieg ich steil weiter über einen eigenartig gleichmäßigen Rasen eines dunkelgrünen Grases. Einzelne Blüten der unten gefundenen Pflanzen lockten Schmetterlinge von dunkler Farbe mit blauen Flecken (Erebia sp.) und Bläulinge an.

Ebenso wie die Pflanzenformen, so wurden in der Höhenregion zwischen 2200 und $2500 \mathrm{~m}$ die Insekten ausgesprochen alpin. Es zeigte sich ein charakteristischer Unterschied gegenüber den Erfahrungen auf der einige hundert Meter niedrigeren und um einige Grade südlicher gelegeneren Mala Rupa. Vor allem waren hier oben die ausgesprochenen Hochgebirgsschmetterlinge vertreten, die zum Teil den Formen unserer Hochalpen nahestanden. Dort waren wir auch einer Gebirgsfauna begegnet, der aber die ganz typischen Hochgebirgstiere fehlten. So möchte ich als besonders wichtigen Fund Erebia tyndarus macedonica Buresch erwähnen, der auf der Mala Rupa durch E. t. balcanica Rbl. vertreten war. Die hier fliegende Form steht unserer Hochalpenform von $E$. ty'ndarus viel näher.

Von anderen Arten dieser schönen dunkelbraunen oder tiefschwarzen Falter mit den leuchtend blauen Augenflecken, die reichlich in der Höhenzone der Kobeliza vertreten waren, seien genannt Erebia lygaea L., E. epiphron orientalis Elw., E. rhodopensis Bur. und E. pronoë Esp., eine ganz stattliche Zahl von Arten.

Andere interessante Schmetterlinge waren Epincphele lycaon Rott., Coenony'mpha tiphon forma rhodopensis Elw., ein stattlicher Bläuling (Lycacna corydon Poda), der in Mitteleuropa in der Tiefe, hier als alpiner Schmetterling lebt. Eine Höhenform ist schließlich die Hesperide Angiades comma. 
Bemerkenswert für die Höhenregion der Kobeliza ist das Vorkommen von Hummeln von nordischem bzw. hochalpinem Typus. In der unteren Grenze dieses Gebiets bei I $400-1600 \mathrm{~m}$ flog Bombus lapponicus var. pratincola Nyl., weiter oben die var. alpestris Friese, var. helveticus Friese und var. balcanicus Friese, letztere ganz hoch oben auf den Matten über $2000 \mathrm{~m}$.

Die einzigen Spinnentiere, die ich in dieser Region fand, waren Weberknechte; es fanden sich zwischen 1500 und $2000 \mathrm{~m}$ unter Steinen ziemlich häufig Phalangium cornutum $\mathrm{T}$., seltener Egaenus convexus C. L. Koch, dieser letztere hier das einzige Mal in Mazedonien.

Prof. M üller, der, vom nördlichen Abhang kommend, hier zu mir stieß, gelang in diesem Gras ein interessanter Fang. Er fand hier eine eigenartige Kreuzotternart, die Großaugenviper (Vipera macrops Méhély), welche bisher nur aus Bosnien und der Herzegowina bekannt war. Die Art gleicht unserer Kreuzotter in der dunkeln Färbung und dem Zickzackband des Rückens, frilßt aber nicht Mäuse wie diese, sondern vorwiegend Heuschrecken.

Von hier aus begann der Aufstieg sehr ermüdend zu werden; abwechselnd ging es über Rasen und Felder von Steintrümmern. Immer wieder täuschte ein aufragender Buckel uns den Gipfel vor. Endlich verriet uns ein Steinmanderl, das wer weiß wer hier oben errichtet hatte, den Gipfel.

Hier überraschte mich ein so überwältigend großartiger Rundblick, daß ich beschloß, lange Zeit' auf dem ganz kleinen Raume des Gipfels zu verweilen, hier oben in der Sonne zu liegen und das umliegende Gebirge genau zu studieren. Tatsächlich blieb ich mehrere Stunden lang in dieser wundervollen Höhe, da allmählich von verschiedenen Seiten ansteigend alle Teilnehmer der Expedition sich auf dem Gipfel versammelten.

Die Ausbeute war für uns alle hier oben nicht allzu groß. Solche Grasberge pflegen weder faunistisch noch floristisch große Ausbeute zu liefern. Zumal war es jetzt Mitte August, somit für den Botaniker etwas spät im Jahre für diese Höhenzone. Ich bestimmte die Gipfelhöhe auf etwas über $2500 \mathrm{~m}$. Offenbar war es der höchste Gipfel des Gebirgsstocks.

Die meisten Alpenplanzen waren schon verblüht. Immerhin machten unsere Botaniker auch hier einige interessante Funde, meist an schon samentragenden Pflanzen. Jetzt blühten noch einige Steinbrecharten, Nelken, Silenen und überall lugten zwischen Moos 
und niederem Gras die blauen Sternchen der Alpenaster (Aster alpinus L.) hervor. Etwas weiter unten blühte eine Glockenblume (Hedracanthus kitaibelii DC.), hier oben stand das zierliche Sandglöckchen (Jasione supina Sieper.) und mit Freuden entdeckte unser Botaniker Bornmüller die ersehnte Bal$\mathrm{k}$ and rot tel blume (Soldanella pindicola Hauska.).

Wie immer versammelten sich hier in der Gipfelregion allerlei fliegende Insekten, vor allem Fliegen aus der Familie der Oestriden, von

Schmetterlingen einige dunkle Erebien. Herr Müller erbeutete hier die auch bei uns vorkommende Gebirgseidechse (Lacerta vivipara Jaen.), auch ein wissenschaftlich bedeutungsvoller Fund.

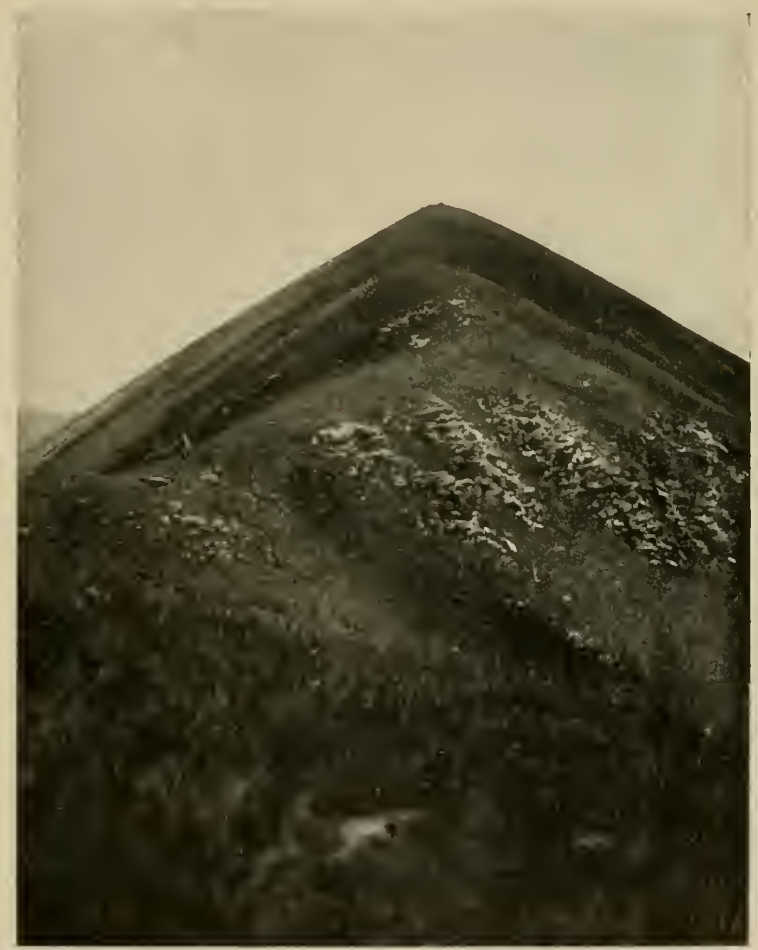

Abb. 120. Gipfel der Kobeliza $2500 \mathrm{~m}$.

Aber mehr als diese wissenschaftlichen Beobachtungen bedeutete mir die wundervolle Landschaft, welche vom Gipfel aus nach allen Seiten sich um mich ausbreitete. Ich wußte nicht, in welche Himmelsrichtung ich zuerst blicken sollte. Ich wandte mich von einer Seite zur anderen, meine Augen tranken voll Wonne all die Schönheit in sich und die ganzen Stunden lang erfüllte mich ein Gefühl des Glückes in dieser menschenfernen Einsamkeit. Hier war ich einmal wirklich fern dem Krieg und den sich hassenden Menschen. Hier tönte der Lärm der Kämpfe nicht herauf und nur die Uniformen, mit denen wir bekleidet waren, erinnerten daran, in welcher Zeit all die Vertreter friedfertiger Berufe sich hier versammelt hatten. 
Es war ein schöner Sommertag; am dunkelblauen Himmel schwebten mächtige weife Wolkenballen hoch über den Bergen und warfen ihre wandernden Schatten auf deren Hänge. Vor allem großartig war der Blick nach Süden; über den Rasenhang vor uns senkte sich der Berg steil zu einem grasbewachsenen Vorberg hinab, den ein dunkler Wolkenschatten scharf vom Hintergrund abhob. Von seinem kahlen Rand mußte es schroff sich zum Tal und zur Paßstraße nach Prizrend hinabsenken; denn blau und zart hoben sich jenseits schon die nächsten Berge von ihm ab. Lange Hochtäler zogen südwärts bergan, von Bergketten eingefaßt, deren beide Flanken man von unserer Höhe viele Kilometer weit nach Süden überblicken konnte, bis sie dort in hohe Gipfel übergingen, deren Nordhänge Schneefelder bedeckten. Silbern blinkte aus jedem Tal der Bach herauf, dessen Zickzackband auf beiden Seiten vom Bergkamm gleichsam nachgeahmt wurde. Eine ungezählte Menge von Tälern und Schluchten modellierten die Seiten der Bergketten, zwischen denen hier und da ein grüner Rasen, eine dunkle Waldgruppe auftauchten.

Steile Felshänge und mächtige Schutthalden verrieten auch hier die Arbeit von Wasser, Eis und Wind, welche diese grandiosen Formen gestaltet hatten. Fast stahlblaue Flecken wurden von den Wolkenschatten über weite Gebiete gebreitet. So wie mit der Wolke ihr Schatten weiter wanderte, traten im Licht der Sonne alle Einzelheiten der Landschaft scharf hervor, jede kleine Kuppe, jede Schrunde, jeder Felsen und Sturzbach kam dem Auge gleichsam entgegen geeilt. Im Hindergrund der Täler, wo sie allmählich in den Wänden der hohen Berge verstrichen, lag in der Tiefe leichter Dunst.

Darüber aber hoben sich in kristallener Klarheit die gewaltigen Kegel mächtiger Hochgipfel; prachtvolle, edle Formen zeigten diese albanischen Berge mit ihren kühnen Umrißlinien.

In allen Abstufungen reiner blauer Töne modellierten sich ihre steilen Abstürze und breiten Flanken. Feine violette Schatten mischten sich am Nachmittag dazu, prachtvoll die zahlreichen Schneefelder aufblinken lassend, die uns anzeigten, daß dort die Gipfel annähernd so hoch wie unser Standort oder noch höher waren.

Zart verschwamm Kette hinter Kette in von der Sonne durchgoldetem Blau. Ganz im Süden, fern von uns schimmerten die gewaltigen Zinnen eines Bergstocks von beträchtlicher Höhe. Wie 


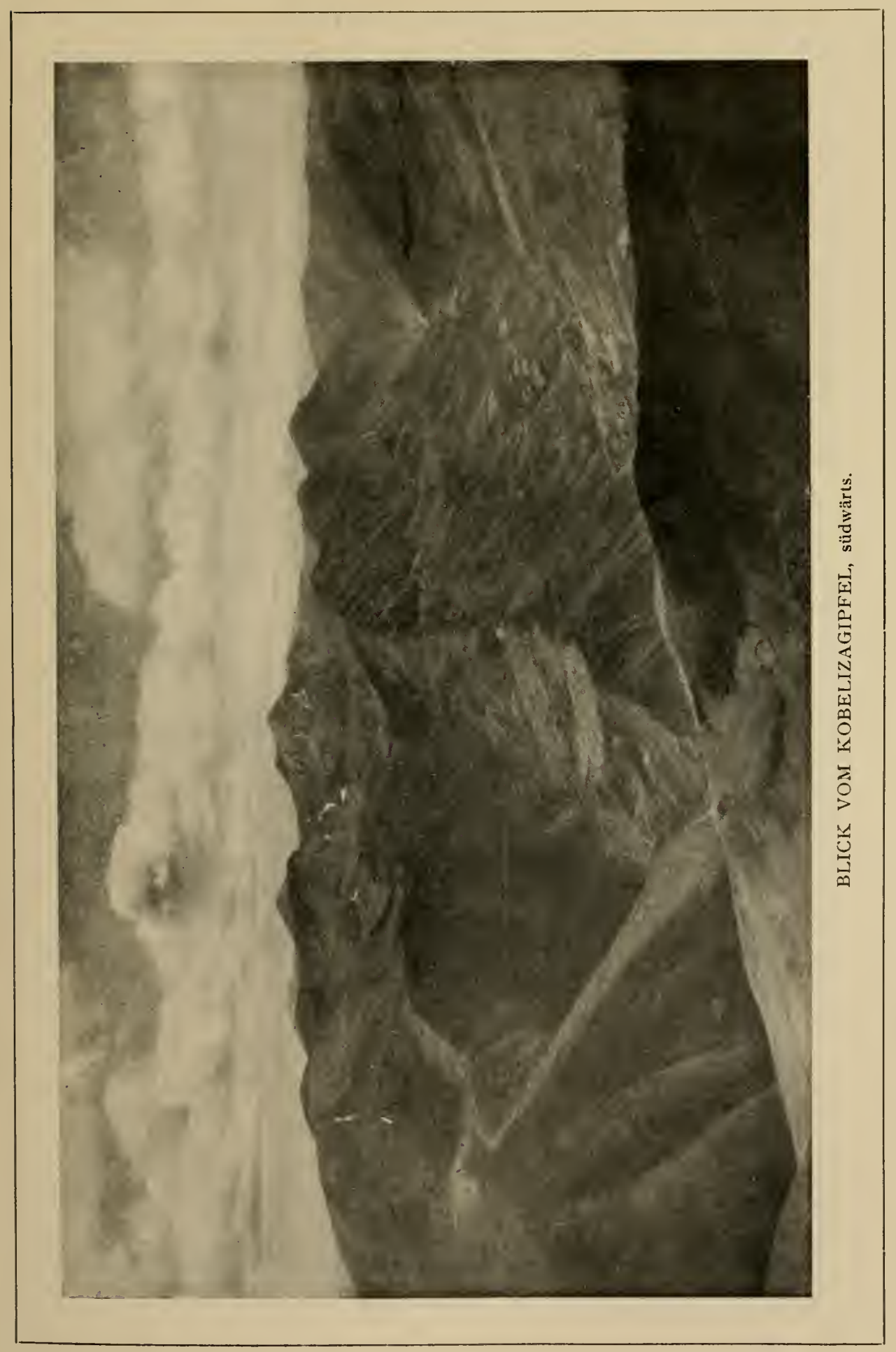



ein Feenpalast erhob dies Massiv seine eis- und schneebedeckten Massen über den kleineren Gebirgen vor ihm. Glitzernd wurden die Strahlen der Sonne von seinem Nordhang uns zugeworfen. Wir erkannten in ihm den Korab, ein Gebirge mit Gipfeln von etwa $3000 \mathrm{~m}$ Höhe, welches nordwestlich vom Ochridasee gelegen ist.

Ganz anders geartet war der Blick nach Norden, da zog die Kette des Schardakh in düsterer Nacktheit gegen den Ljubotren hin. Schroffe, kahle Felsenberge bildeten eine lange Kette, deren hintere Berge den Gipfel des Ljubotren offenbar verdeckten, denn wir konnten diesen nicht mit Sicherheit erkennen. Steil fiel der Abhang von uns hinab in die Mattenregion, welche sich um den Gipfel der Kobeliza ostwärts bis zur Gegend unseres Lagers hinzog. Direkt uns gegenüber stiegen steile Felsenwände senkrecht mehrere hundert Meter hinan zu einem scharfen Kamm. Etwas östlich führten in sanfter Neigung von der Mattenregion Rasenflächen zu einem breiten Buckel, der sich an den Felskamm anlehnte, vor uns aber ihm gegenüber mit steiler Felswand eine Schlucht begrenzt.

Auf dem Rasen des Buckels weideten tausende von Schafen, von oben herab sah jedes wie ein heller oder dunkler Punkt aus. Die Hunde, welche um die Herden herumtobten, trieben sie immer wieder zu dichten Haufen zusammen, welche wie Wölkchen aussahen, die immerfort ihre Gestalt änderten. Ganz seltsam wurde das Bild, als plötzlich zwischen uns und den Herden ein Adler seine Kreise zog. Da drängten sich alle Schafe zu einem mächtigen Haufen zusammen und liefen erst wieder auseinander, als der große Vogel mit majestätischem Schwung über die Felswände emporstieg.

Westwärts begann unterhalb des kegelförmigen Rasengipfels der Kobeliza ein steiler Grat, der vor allem nach Süden schroff abfiel. Auch nach Westen trennte uns ein Steilabfall von der anschließenden Kette albanischer Berge. Eigenartig hob sich der weiße Kalkstein der Gipfelregion von dem in dieser Höhe noch recht frisch grünen Rasen $a b$, in welchem die blauen Sternchen der Alpenaster an vielen Stellen aufleuchteten.

Dunkle Wolkenschatten lagen auf den jenseitigen Bergen, welche unsere albanischen Begleiter die Hasanitza nannten. Wir stritten uns lebhaft, ob ein dort zu Tal prasselnder Steinschlag von einem Rudel Gemsen losgelöst sei, oder ob so hoch oben Vieh weiden könne. Die Leute erzählten uns viel von den Gemsen die tatsächlich in diesem Gebiet nicht selten sein müssen. Unsere 
Versuche, an solche heranzukommen oder während unseres Aufenthalts sie von den albanischen Jägern erlegt zu bekommen, scheiterten an der Kürze des Aufenthalts, der uns hier oben vergönnt war. $\mathrm{Da}$ b wirklich Gemsen hier vorkommen, das wurde mir sicher, als mir beim Abstieg der Bürgermeister des Dorfes Selče eine prächtiges braunes Gemsenfell, eine schöne dicke Winterdecke, zeigte und mir ein paar Krickeln schenkte. Besonders schön und eigenartig war die Aussicht nach Westen; in dieser Richtung waren die Gebirge niedriger, so daß der Blick sich in unendliche Fernen erstrecken konnte. Zahlreiche Gebirgsketten zogen hinter-

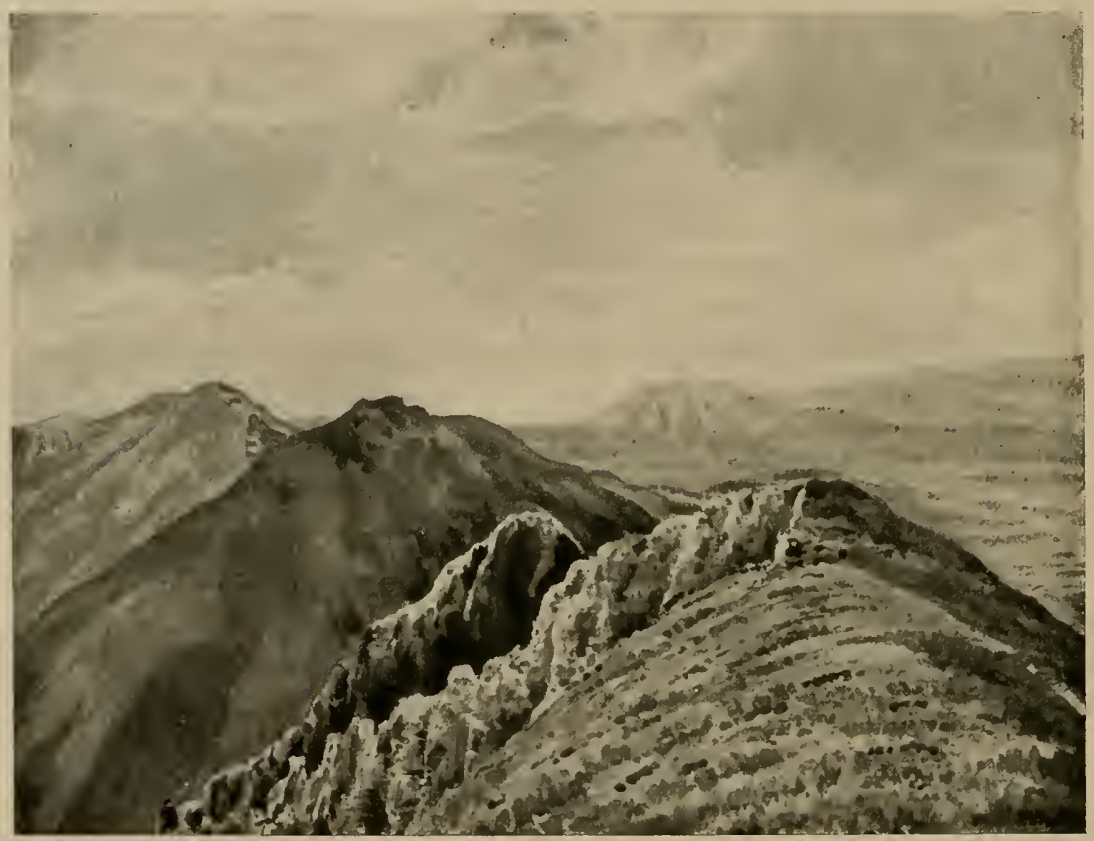

Abb. I21. Blick vom Gipfel der Kobeliza $2500 \mathrm{~m}$ nach Westen. Nach einem Aquarell des Verf.

einander von Süden nach Norden, manche von ihnen in klaren, eigenartigen Formen greifbar nahe vor uns liegend. Wir konnten die Senke erkennen, in der das Amselfeld sich ausbreitet und die Berggruppe, welche im Nordwesten auftauchte, mußte schon zu Montenegro gehören.

Entsprechend der nord-südlichen Ausdehnung des von uns bestiegenen Kettengebirges war auch der Blick nach Osten weit und frei. Von rechts und links traten Berghänge, deren Konturen 
sich gegenseitig überkreuzten, in das Sarskatal, welches man bis zur Ebene vor Kalkandelen verfolgen konnte. Fern vor dem Gebirge der Karaschiza blitzte der Spiegel des Wardar auf. Das waldarme Gebirge ließ seine charakteristische Modellierung, die reiche Verarbeitung seiner Hänge durch die Arbeit der Erosionskräfte mit aller Deutlichkeit erkennen, obwohl es in zarten Farben duftig vor mir lag. Jenseits der $\mathrm{K}$ araschiza sah man wieder eine Bergkette hinter der anderen sich in nord-südlicher Richtung hinziehen.

Voll von den großen Eindrücken traten wir erst am späten Nachmittag den Abstieg zu unserem Lager an. Dabei zerstreuten wir uns wieder alle im Gelände, ohne uns in dieser einsamen Landschaft viel Sorgen wegen unserer Sicherheit $\mathrm{zu}$ machen. Unsere Bedeckungsmannschaften waren viel ängstlicher und fürchteten sich sehr vor den Arnauten. Ich begegnete wiederholt solchen, die bis an die Zähne bewaffnet waren. Obwohl man sich nicht mit ihnen verständigen konnte, waren sie nicht unfreundlich und nahmen mit strahlendem Lächeln die gespendeten Zigaretten an.

Während der nächsten Tage verfolgte jeder der wissenschaftlichen Teilnehmer der Expedition seine Sonderzwecke. So wurden die umliegenden Höhen bestiegen, die Bäche und Tümpel, Quellen und Schluchten untersucht und vor allem die Waldgrenze erforscht.

Es war besonders eine schön bewaldete Kuppe, welche als Vorberg weit in das Tal der Sarsk a hineinragte, welche mancherlei interessante Ausbeute lieferte. Sie war von einem lichten Wald aus stattlichen Buchen und Weißtannen bedeckt. Vor diesem Hain war der felsige Hang von Wachholdersträuchern bedeckt, zwischen denen ein kurzer Rasen wuchs.

Die Höhe mit ihren edlen 'Tannen, zwischen denen die prachtvollsten Durchblicke auf das Hochgebirge sich eröfneten, hat sich ganz in mein Gedächtnis eingegraben. Ich werde nie die Stunden vergessen, die ich am Rande des schattenden Waldes an ihren Abhängen verbrachte. Im Gedenken an schöne Schwarzwalderinnerungen ist sie in meinem Tagebuch als Weißtannenhöhe verzeichnet. Der Aufstieg zu ihr von unserem Lager führte an einem Teich vorbei, den wir den Unkenteich nannten, da zahlreiche dieser Tiere ihn belebten und die Luft mit ihren Glockentönen erfüllten. Im Teich gab es außerdem viele Wasserkäfer (Gaurodytes bipustulatus L. und Colymbus luseus L.) und eine Unmenge der kleinen Muscheln aus der Gattung Pisidium. Von 
dem Wasser aus wurde der Anstieg steiler, der Hang bedeckte sich mit liegendem Wachholder (Juniperus nana Wild.). Zwischen dem zarten Gras blühte ein zierliches Haidekraut. Weiter oben mehrte sich allmählich Buchengebüsch, an welchem eine Anzahl von Spinnen ihre Netze gebaut hatten. Wenn die Tiere und ihre Bauten an Formen der Heimat erinnerten, so war es doch von Interesse festzustellen, welche Arten hier in der Höhe leben und ob sie auch hier ebenso bauen, wie an den Orten, an denen sie schon lange bekannt sind.

An den Buchen fand sich eine Spinne, die zwischen Ästchen und Blättern ein stattliches Segelnetz gebaut hatte, das mit einer zylinderischen Wohnröhre endete, in der die Spinne saß. Die Fäden des Netzes waren nicht kleberig aber auffallend mit Staub bedeckt, obwohl das Netz bewohnt war. An den Buchenbüschen fand sich eine zweite Form, welche ein Wirrnetz baute und ihren Zufluchtsort in einem Nestchen hatte, das aus Knospenschuppen der Buche bestand, welche durch Gespinst zusammengeheftet waren. Zwischen den Stämmen und Zweigen, vor allem der Tannen, waren große Radnetze wieder von anderen Spinnen ausgespannt. Es waren dies Epeira diademata Clerck und E. marmorea Clerck; erstere ist unsere Kreuzspinne, die ich im Flachland nie gefunden hatte und welche, wie so manche anderen mitteleuropäischen Tiere, hier im Lande das Hochgebirge aufgesucht hatte.

In Buchendickicht fand ich damals zum erstenmal in Mazedonien Ameisenhaufen; es waren höchstens $20 \mathrm{~cm}$ hohe Hügel, welche im Durchmesser kaum I5-30 cm erreichten. Obwohl es nicht weit zu den Tannen war, bestanden die Haufen hauptsächlich aus den Nadeln der in der Nähe wachsenden Wachholdersträucher. Dazwischen fand sich Erde, Stengel und Ästchen von mancherlei Pflanzen, so von Heidekraut. Wie alle Haufen, die ich später in Mazedonien fand, waren diese von einer Formica-Art bewohnt und zwar von Formica (Rhaphiformica) sanguinea Latr., einer Art, welche auch bei uns selten Haufen baut. Genauere Angaben finden sich im Ameisenkapitel (S. 159). Hier oben fanden sich im Holz der Tannen die Gänge einer Camponotus-Art (C.herculeanus ligniperda Latr.), also nicht anders als in unseren Wäldern die typische Baumameise.

Um auf den Gipfel der Weißtannenhöhe zu gelangen, mußte ich durch den Tannenwald, der sich hauptsächlich am Westhang gegen das kleine Tälchen hinzog, welches ich am Nach- 


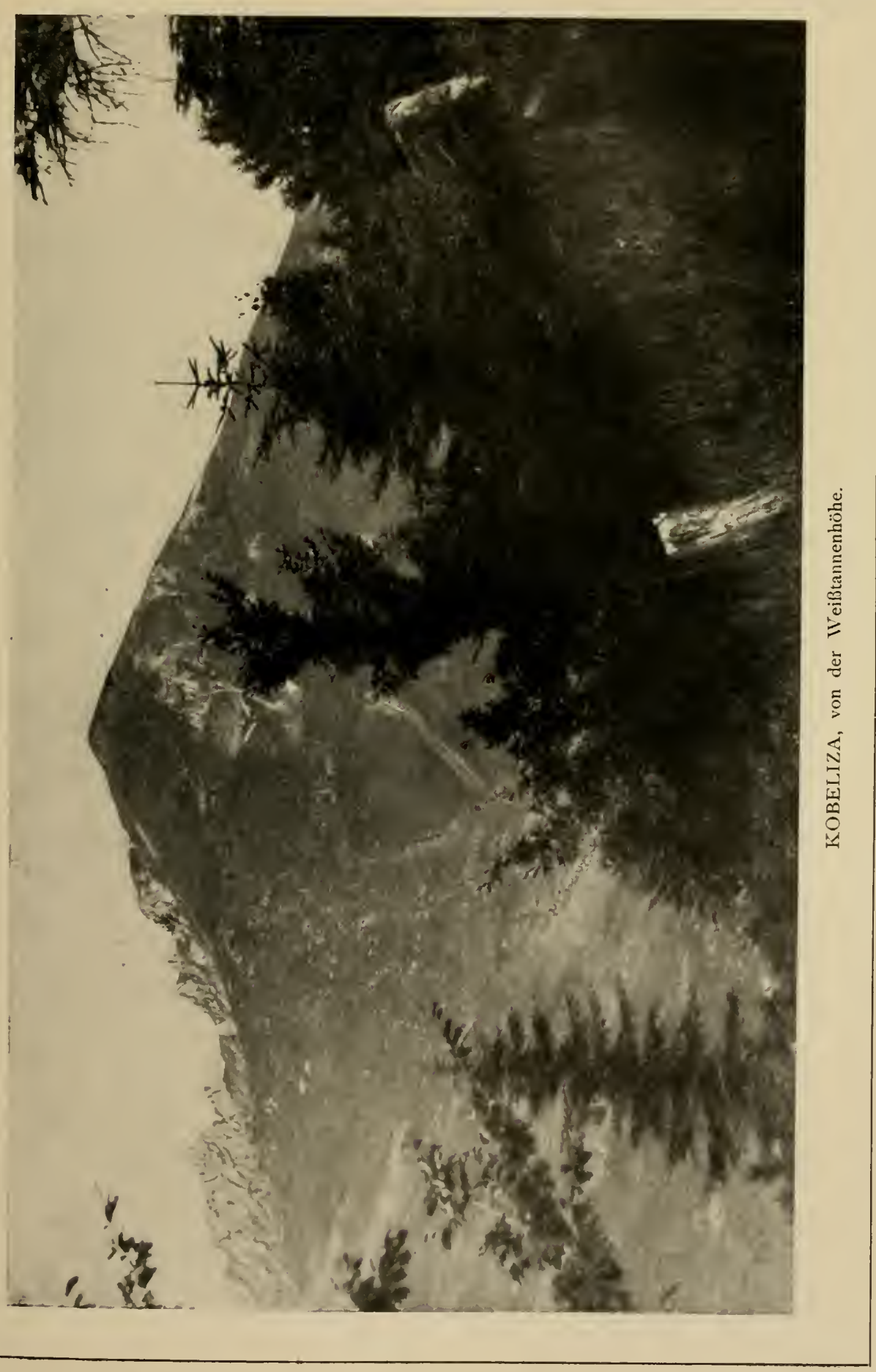



mittag des gleichen Tages besuchte und das an den Felslıängen gegen das Sarskatal weit hinabreichte. Es war ein wilder dichter Wald, nur an einzelnen Stellen rein aus Tannen bestehend, sonst vielfach mit Buchen vermischt. Ein tiefer kühler Schatten herrschte unter den hohen Bäumen, durch deren Kronen ein starker Wind rauschte. Die silbergrauen Buchenstämme hoben sich zart und duftig von dem dunklen Grün des dichten Tannenbestandes ab; wenn der Wind die Tannen beugte, so blinkte silberig die Unterseite ihrer Nadeln auf. Am Hang standen zerzauste und windgebrochene Wettertannen und gar mancher der Riesen lag zerschmettert am Boden neben seinem zerborstenen Stumpf, der kläglich aus dem grasigen Boden in die Höhe ragte. Es war eine echte Weißtanne, die hier noch einen ausgedehnten Wald bildete (Abies alba Mill.), welche nicht von der Schwarzwaldtanne zu unterscheiden ist.

In dem Hang des Waldes, welcher nach Süden abfiel, umrahmten die Tannen ernste, grandiose Gebirgslandschaften. Hier öffnete sich der Blick an vielen Stellen auf die steilen albanischen Berge um die Hasaniza. Tief im Schatten lagen über dem Tal drüben die schroffen Felsen hochansteigender Berge, welche unterhalb auch dichten Wald trugen. Darüber hoben sich klarer als am vorigen Tage die Hochgipfel mit ihren leuchtenden Schneefeldern.

Nordwestlich hoch aufragend bot die Kobeliza von der Weißtannenhöhe ihren reizvollsten Anblick dar. Als mächtige Pyramide mit sanft ansteigendem Nordhang erhob sich der Berg majestätisch aus dem tiefen, dämmernden Talschlund; der Südhang dagegen mit unruhiger Zackenlinie der schroffen Kalkfelsen, an deren Rand ich am Tage vorher gestanden hatte, bildete einen wuchtigen Gegensatz zu den weiten Grashalden, welche die uns zugekehrte Ostseite des Berges bedeckten. Diese war vor allem im Süden und in der Mitte durch Erosionsschluchten und helle Felsen malerisch gegliedert.

Die Fülle blauer und violetter Töne an der breiten Wand der Felsen ließen den Berg wie eine Traumerscheinung weit hinter dem Tal zurücktreten, während das starke Grün der mich umgebenden Bäume mich in der schönen Wirklichkeit festhielt, in der ich verweilen durfte.

Hinter dem Wald überzog eine jetzt noch blumenreiche Wiese den östlichen Teil des Gipfels der Weißtannenhöhe. Verblühte 
Gräser und ein stark duftendes gelbes Labkraut waren von einem Bestand des liegenden Wachholders (Juniperus nana Willd.) eingefaßt, der sich bis hier heraufzog. An geschützten Stellen standen einige jetzt noch blühende Disteln und Königskerzen.

Hier fand sich auch eine reiche Tierwelt. Unter den Steinen fing ich Skorpione und kleine Tausendfüßler. Um die Blumen flogen Schmetterlinge, zahlreiche Bläulinge, dunkle Erebien, eine Anzahl Hesperiden fielen auf. Reich war die Ausbeute an Fliegen und Bienen. Hier begegnete mir wieder die dunkle Heuschrecke mit dem grellroten Hinterleib und den roten Beinen, welche ich schon auf der Mala Rupa bei ihrem Balzflug beobachtet hatte. Auch hier stieg sie schnarrend in den grellen Sonnenschein auf, um schwebend zu lärmen und langsam zu Boden zu sinken (Stenobothrus miniatus Charp.).

An 2 Tagen hielt ich mich vom frühen Morgen bis mittags auf der Weißtannenhöhe auf, um jedesmal am Nachmittag das Buchental zu durchstreifen, welches an den steilen Felsen der Weißtannenhöhe entlang südwärts sich ersteckte. Zum Teil waren seine Hänge von Buchen bewachsen, welche einen halbtrockenen Bach beschatteten. An diesem Bach standen allerhand blühende Pflanzen, im Wald reiften wohlschmeckende Himbeeren und Erdbeeren. Hier gab es wieder viele Insekten, darunter Schwärme kleiner Mücken, viele Spinnen, wieder unter den Steinen Skorpione.

Wo das Tal am Berghang sich öfnete, floß der Bach in ein Sumpfgelände, in welchem zahlreiche hohe Disteln, Doldenpflanzen, Schilf und Binsen, meist verblüht und zum Teil verdorrt standen. Hier entsprang am Hang auch eine kleine Quelle, in deren Wasser unter Steinen sich Blutegel und kleine Flohkrebse fanden, wie sie fast in jeder Quelle und an jedem Brunnen vorkamen.

Über den Sumpf stiegen steile Felsterrassen an der Wand der Weißtannenhöhe aufwärts. Mehrmals wechselte ein senkrechtes Felsenband mit einer sanfter geneigten Halde ab, welche mit Gras und Kräutern und dazwischen den dunklen Wachholdersträuchern (Juniperus excelsa M. B.) bedeckt waren.

Hier und über dem Sumpf flogen die Apollofalter, die wir schon beim Aufstieg bemerkt hatten. Auch hier hatten wir wie in der Mala Rupa kein leichtes Gelände, um die stolzen Schmetterlinge zu fangen. Im Sumpf versank man bis zum Knie im Schlamm, und das Wettrennen am Steilhang, abwechselnd auf dem glatten 
Rasen zwischen dem Wachholder und an den Felsenbändern, kostete trotz der frischen Bergluft manchen Schweißtropfen.

Weder mein braver Rangnow noch ich ließen es uns verdrießen und unsere Mühe wurde durch eine reiche Ausbeute belohnt. Während wir auf der Mala Rupa für den Apollofalter Mitte Juli etwas $z u$ früh daran gewesen waren, und somit nur wenige frische Exemplare antrafen, waren wir hier Mitte August offenbar schon in das Ende der Flugzeit des schönen alpinen Schmetterlings geraten. Wir fingen noch eine Anzahl Exemplare, aber die meisten waren schon recht abgeflattert. Ja einige Exemplare fand ich im Sumpf auf den Disteln sterbend oder schon tot.

Auch sonst flogen hier in der warmen Sonne des Nachmittags zahlreiche Schmetterlinge umher, Lycaeniden, Erebien und Coenonymphen in verschiedenen Arten. Bemerkenswert war hier eine den Perlmutterfaltern zugehörige Form von Argynnis pales, die sich deutlich von der auf der Mala $\mathrm{Rupa}$ aufgefundenen Argynnis pales balcanica Rbl. unterscheidet und wahrscheinlich eine unserer alpinen $A$. pales pales sehr nahestehende neue Form ist. Damit war wieder der ausgesprochene alpine Typus der Tierwelt hier im Schardakh, gegenüber der etwas niedriger und südlicher gelegenen Mala R upa bestätigt. Von den Bläulingen erwähne ich Lycaeaa damon Schiff.

Schöne Schwebfliegen hielten sich auch in der Sumpfregion auf; ich erwähne Chry'sotoxum bicinctum L. und die alpine Ch. cantum Harries.

Reichlich waren in der Nähe des Sumpfes auch Spinnen vertreten, so Oxyopes ramosus Panz., Pirata piscatoria Clerck., Heriaenes hirsutus Walck. und Thanatus arenarius Thor.

Sehr schön war von den Felsen der Blick hinab, steil die Hänge hinunter in das tief eingeschnittene Tal und über dieses hinaus gegen die Wardarebene und auf die Karaschiza.

Wir saßen müde vor unseren Zelten, als die Nacht niedersank und Stern auf Stern am Himmelsgewölbe aufblinkte. Unsere Mannschaften, Deutsche, Bulgaren und Albaner saßen und standen um die Lagerfeuer, deren roter Schein auf die Felsen hinter unserem Lager fiel und riesige Schatten der Menschen über die Wiese warf. Drüben in der Sennhütte bellten und heulten die Hunde und aus den Hürden ertönte das dumpfe Blöken und Meckern der zusammengedrängten Herden. Bei der Rückkehr 
hatten wir diese, in große Staubwolken gehüllt, von den Hochweiden niedersteigen sehen.

Die Lagerfeuer waren allmählich niedergebrannt, manche unserer Leute schliefen schon. Nur von Zeit zu Zeit flackerte ein Feuer noch einmal knisternd auf, warf prasselnd eine Garbe von Funken in die Höhe. Trotzdem kein Mond am Himmel stand, genügte das Licht der Sterne, um uns die Umrisse der Berge, den Taleinschnitt gegen Kalkandelen, drunten die Talebene und jenseits die lange gleichmäßige Kette der Karaschiza erkennen zu lassen.

Während wir die Sternbilder am Himmelszelt aufsuchten, die uns hier in $1600 \mathrm{~m}$ Meereshöhe klarer und sternreicher erschienen als unten im Tal, glaubten wir plötzlich nahe dem Horizont in der Richtung über Kalkandelen neue Sterne aufblitzen zu sehen. Nein, das waren Leuchtkugeln und Raketen, welche dort unten in die Luft stiegen und von unserer Höhe aus einen phantastischen Eindruck machten. Farbige Sterne stiegen auf und verschwanden, Scheinwerfer warfen ihre Strahlenkegel auf die Berge der Umgebung oder ließen sie im endlosen Raum umherirren und verblassen. Und dies seltsame Schauspiel vollzog sich ohne Lärm und Krachen, das wir unwillkürlich erwarteten; die tiefe Bergeinsamkeit umgab uns und das Getöse, das die Menschen da unten verursachten, um sich an irgendwas $\mathrm{zu}$ freuen, drang nicht in unsere köstliche Stille.

Wir hofften auf einen Sieg, unsere Bulgaren träumten von Frieden, bis jemand sich daran erinnerte, daß der I5. August das Regierungsjubiläum des Königs von Bulgarien sei, und daß dies wohl da unten gefeiert werde.

Früh am nächsten Morgen wurden die Zelte abgebrochen; die Tragtiere wurden gesattelt und bepackt. Der Aufbruch war beschlossen, der Proviant für soviel Menschen und Pferde war erschöpft, schweren Herzens trennten wir uns von den Bergeshöhen und begannen den Ritt in die Tiefe.

Der Saumpfad, den wir aufsuchten, führte bald sehr steil abwärts, zunächst über Matten, dann an schönen Buchengruppen vorbei, schließlich tief in eine Schlucht hinunter. Nun kam es wieder zu allerhand Reitabenteuern. Unsere Pferde hatten sich oben von dem saftigen Gras der Matten dick vollgefressen; beim anstrengenden Abstieg schrumpften ihre Bäuche sichtlich zusammen. Die Sattelgurte saßen nicht mehr stramm und da niemand unserer Begleiter acht gab, wir aber alle genug mit Umschauen und 
Beobachten zu tun hatten, so kam es dazu, daß einer nach dem anderen von uns mit seinem Sattelzeug beim Abwärtsreiten üher den Hals seines Pferdes rutschte und einen Purzelbaum bergab machte. Es waltete aber dennoch ein guter Stern über unserer

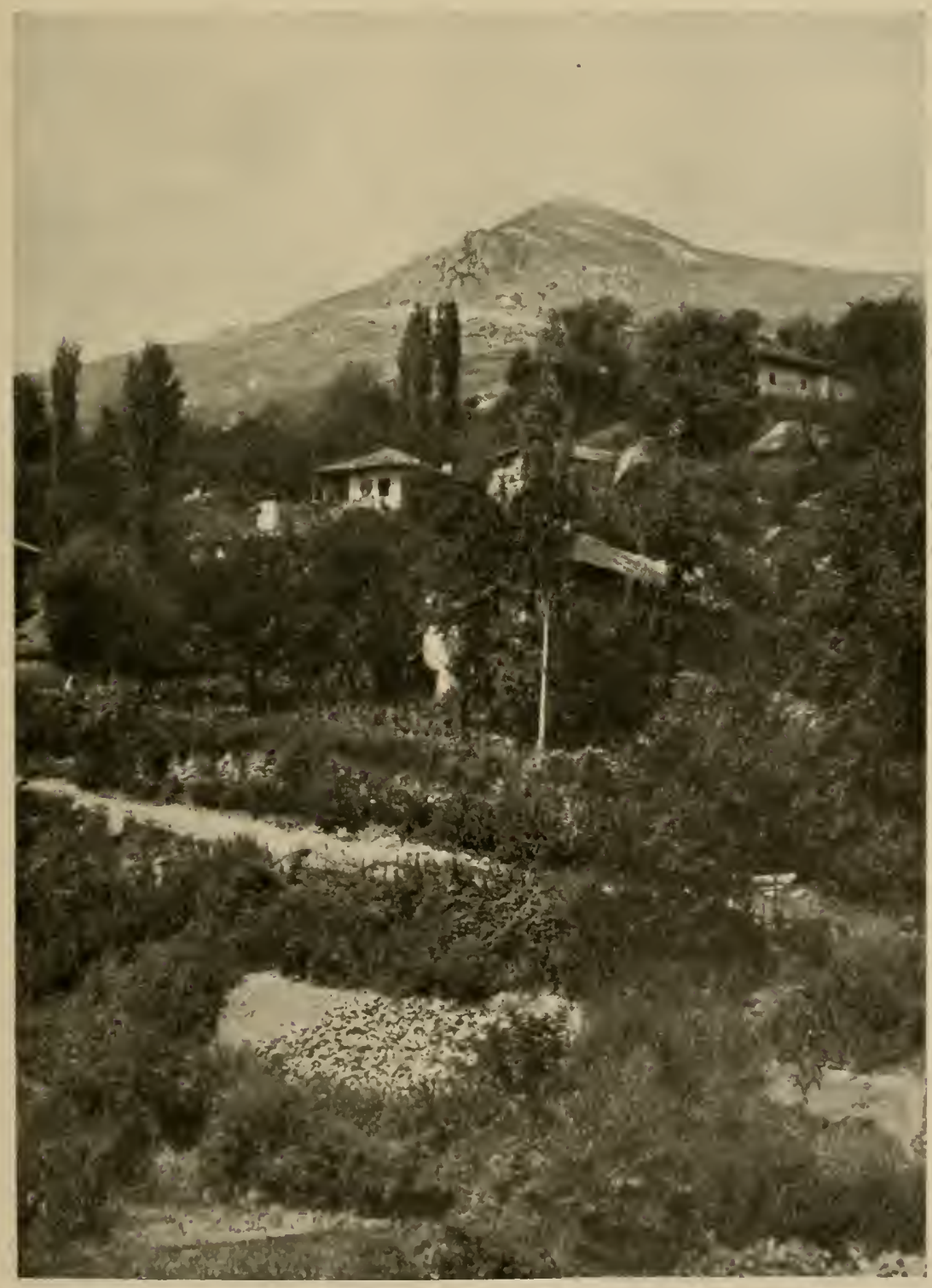

Abb. I 22. Dorf Vejěe im Scbardakh. Dahinter Gipfel der Kobeliza. August I917. Doflein, Mazedonien. 
Kavalkade und keinem von uns widerfuhr mehr Schaden als einige blaue Flecke.

Jenseits der Schlucht kamen wir auf einen Weg am Berghang, den man als feinen hellen Strich in der Landschaft schon von unserem Lager gesehen hatte und den man uns als den richtigen Weg nach Kalkandelen bezeichnete, auf dem wir die Stadt diesmal auf dem linken Ufer der Sarska erreichen sollten. An der Steillehne des jenseitigen Berges entlang kamen wir nach scharfer Biegung zu dem schön gelegenen Dorf Vejče (Abb. 122).

Über das tief eingeschnittene Tal eines brausenden Baches, welcher der Sarska zuströmt, sahen wir das Dorf im Grünen vor uns liegen. Hinter den Häusern stiegen die Berghalden steil hinauf gegen die Abhänge der Kobeliza. Vejče erstreckte sich mit einem Zipfel noch in eine von den Bergen niederziehende Bachschlucht hinein.

Wie reizend war wieder der Eindruck dieses mazedonischalbanischen Bergdorfes. Die meist viereckigen Häuser sind fast alle gleich groß, nur selten schaut hier und da eine breitere Front, ein höheres Dach heraus. Die Wände zeigen die graue Steinfarbe oder sind weiß getüncht. Viele haben schönes braunes Holzwerk, sehr viele Vorbauten oder Veranden mit Holzsäulen. Die kleinen Fenster sind meist auf die oberen Stockwerke beschränkt, die auch hier über die unteren vorragen. Breite, dunkle Schatten werfen die weitausladenden Dächer auf die weißen Wände. Auch die Schornsteine sind meist weil getüncht und ragen mit ihrem flachen Dächlein wie kleine Türme über das Haus empor.

Die Dächer sind mit Stroh oder mit großen Steinplatten bedeckt, die weilggrau gefärbt, wie Solenhofer Schiefer aussehen und einen sehr sauberen, stattlichen Eindruck machen. Und alle die Häuser sind von Gärten und Höfen umgeben, sind in Grün gebettet. Üppige Obstbäume beschatten die Häuser. Zwischen den Wohnhäusern stehen kleinere, meist strohgedeckte Hütten, welche als Scheunen und Vorratsräume dienen.

Um das Dorf herum, unterhalb der Häuser am Bach, aber auch über dem Dorf einige hundert Meter den Berg hinauf ziehen sich frischgrüne Wiesen und wohlbestellte Getreidefelder. Erstere sind frisch gemäht, Heu lagert noch zum Teil auf ihnen. Auch das Getreide ist meist eingetan. Nur Hafer steht noch hier und da auf dem Feld. Fast zu jedem Haus gehört ein Hof, eine Tenne, 
auf der das Pferd oder der Ochs dreschend in Kreise läuft. Überall ist Leben und Bewegung im Dorf.

Wieder steigt mir die Erinnerung an japanische Dörfer auf, wenn ich das feine Silbergrau der Häuser so zart zu dem üppigen Grün der Bäume stimmen sehe, wenn ich die gleichmäßige Besiedelung, die guten Verhältnisse der Bauten und die reiche Pflanzenwelt überblicke. Zwischen den Obstbäumen erheben sich einzelne Pappeln, am Bach Weiden und Espen.

Schöne, schlanke Menschen begegnen uns auf den Feldern und am Rande des Dorfes. Die Bevölkerung ist offenbar mohammedanisch, denn die Frauen sind zumeist verschleiert, drehen sich scheu vor dem fremden Mann um und laufen davon, wenn er naht.

Der Weg führt nun weiter vorbei an dem Dorf, am Hang entlang. Später, weiter abwärts, wird der Boden trockner und felsiger. Die Straße fängt hier und da wieder an zu stauben. Aber noch begleitet uns überall sehr schöner stattlicher Baumwuchs. Edelkastanien treten wieder auf und ein südlicherer Charakter löst damit den Voralpentypus ab. Zahlreiche Obstbäume, zum Teil noch tragend, machen sich bemerkbar, es sind Apfel-, Birn-, Zwetschen- und Nußbäume. Hier beginnen auch wieder Schmetterlinge des Tieflandes zu fliegen, auf den mächtigen Felsblöcken eines Bergsturzes eilen Eidechsen Lacerta viridis und taurica umher.

Eine Zeitlang führt der Weg neben einem brausenden Bach entlang; ein dichter Hain von Bäumen zeigt uns die Nähe einer Ortschaft an. Es ist Selče, ein Dorf, welches steil am Berg gebaut ist und durch dessen steinige Gassen unsere ermüdeten Pferde stolpernd steigen.

Ich werde gebeten, den Bürgermeister zu besuchen und werde von diesem, einem dicken Mann mit einem schlanken Gehilfen, feierlich empfangen und freundlich mit Kaffee bewirtet. Der noch recht gute türkische Kaffee erfrischte ausgezeichnet nach dem ermüdenden Ritt und Marsch. Hier war es, wo der Bürgermeister auf dem schön gegerbten Winterfell einer Gemse saß und mir die Gamskrickeln schenkte.

Das Volk, das sich unterdessen vor seiner Türe drängte, war nicht aus Neugier hier zusammengekommen um uns zu sehen, sondern es hatte dem bulgarischen Beamten Steuern zu bezahlen. Das vollzog sich prompt und rasch und man bekam das Gefühl, daß eine harte Hand auf dem Lande lag. 
Von Selče war es kaum mehr als eine Stunde hinunter nach Kalkandelen. Bald lag die Stadt vor uns mit ihrem Meer von dunklen Dächern, fast so sehr von Bäumen durchgrünt, wie die Gebirgsdörfer. Drunten brauste die Sarska, die mich bald, nachdem abgesattelt und Quartier bezogen war, durch ein kühles Bad erfrischte.

Nach tiefem Schlaf im alten Quartier, Dankerstattung bei den bulgarischen Behörden und Gastfreunden nahmen wir Abschied vom freundlichen Tetowo und seinen schönen Mädchen und Frauen. Gegen Abend des nächsten Tages lud uns die Kleinbahn wieder in Üsküb ab. 


\section{FÜNFZEHNTES KAPITEL}

\section{DIE BEVÖLKERUNG MAZEDONIENS}

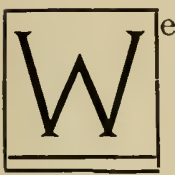

enn man auf der Balkanhalbinsel reist, bekommt man den Eindruck von einer geradezu ungeheuerlichen Durcheinanderwürfelung ganz verschiedenartiger Volkssplitter. Stämme und Rassen, die sich erheblich voneinander unterscheiden, sind in kleinen Gruppen in einer Weise durcheinander geschoben, wie man es wohl selten auf der Erde auf so engem Raum wieder findet.

Einen starken Eindruck von diesem Völkergemisch bekommt man, wenn man durch die Straßen Üskübs, dieser zentralen und größten Stadt Mazedoniens wandert, oder wenn man gar den Dienstagmarkt besucht, auf welchem die Bevölkerung der weiteren Umgebung Üskübs sich mit den Berwohnern aller Quartiere der Stadt vermischt.

Da sieht man ein buntes Gewimmel von Männern und Frauen in bunten Trachten, die sich malerisch von all den nicht minder bunten Waren abheben, welche dort feilgeboten werden. Vor allem sind es slawische Bauern und Bauersfrauen, die mit Landesprodukten aus den Dörfern der Umgegend in die Stadt hereingeströmt sind. Der erfahrene Kenner weiß nach den Gewändern, vor allem denen der Frauen, uns zu sagen, aus welchen Dörfern die Leute kommen. Diejenigen mit den vorwiegend schwarzweißen Kleidern stammen aus dem nördlich gelegenen Karadakh, die mit viel Rot in Röcken und Kitteln kommen von den südlich gelegenen Gehöften und Ortschaften zu beiden Seiten des Treskatales und vom Wodno. Und so gibt es unendlich viel Varianten in diesen von Farben leuchtenden Trachten.

Alle, welche die bunten Bauernkleider tragen, sprechen eine slavische Sprache, die dem Bulgarischen am meisten ähnelt; soweit sie schreiben können, schreiben sie bulgarische Schrift und somit ist man geneigt, den bulgarischen Freunden zu glauben, welche sie als echte Bulgaren ansprechen, die nur einen Dialekt ihrer Sprache verwenden. Ist man in den Dörfern etwas weiter 
nördlich von Üsküb, so wird die Verständigung mit den wenigen Brocken der bulgarischen Sprache, über welche Deutsche meist nur verfügen, immer schwieriger. Und es wird immer wahrscheinlicher, auf Serben zu stoßen. In Üsküb wohnen auch zahlreiche Serben, was ja in einem Serbien so nahen Verkehrszentrum nicht verwunderlich ist.

Einerlei, welchem der beiden feindlichen Brudervölker sie sich zurechnen, man sieht unter ihnen wenig schöne, reizvolle Erscheinungen. Weder Frauen noch Männer haben schöne Gestalten oder Gesichter, wenn auch jugendliche Vertreter beider Geschlechter eines gewissen Reizes nicht entbehren. Noch dazu verdirbt die Tracht die Gestalt ganz außerordentlich. Die Taille wird niemals hervorgehoben, Jäckchen wie Rock, und besonders die bunten Schürzen, welche wie Bretter steif herabhängen,

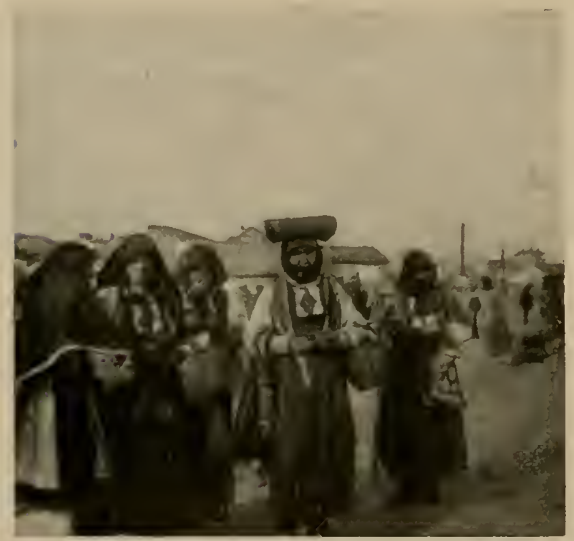

Abb. 123. Mazedonische Fraten auf dem Markt in Üsküb. alles trägt dazu bei, die Erscheinung der Frau zu vergröbern und in die Breite zu ziehen.

Schlankheit und Beweglichkeit der Frau scheint nicht dem Schönheitsideal dieser slavischen Bauern zu entsprechen. Schönere Gestalten, schlank und gut gewachsen, findet man nicht selten unter den jungen Männern, die auch flott und rasch dahin zu marschieren vermögen, während die Frauen mit ihren kurzen

Beinen einen plumpen, watschelnden Gang haben. Damit ist nicht gesagt, daß sie beim Gehen nicht rasch vorwärts kämen. Es ist ganz erstaunlich, zu welchen Marschleistungen die Frauen mazedonischer Bauern vielfach fähig sind.

Ein eigenartiges Bild bieten die Gruppen von mazedonischen Bauern, welche gemeinsam zum Markt in die Stadt kommen. Für die Kulturstufe, auf der sie stehen, ist es charakteristisch, daß auf dem mitgeführten Maultier oder Lastpferdchen, auch wenn es mit Lasten schwer bepackt ist, stets nur den Mann sitzt, während Frau und Kinder nebenher laufen. 
Sieht man auf dem Markt eine hohe, stattliche Gestalt von schlankem Wuchs, so ist es sicher ein Albaner. Diese befinden sich in Mazedonien offenbar immer noch im Vordringen nach Osten, welches seit längerer Zeit im Gang und jetzt etwa im Wardartal zu einem gewissen Stillstand gekommen ist. Der Albaner sieht mit seinem dunklen, meist schwarzen Wollgewand, mit den engen Hosen und den Wickelgamaschen meist flott und energisch aus. Die Gesichter sind meist schmal, die Nasen gut gebaut, leicht gekrümmt, auf dem kurz geschorenen Haar sitzt ein halbkugelförmiges weißes Filzkäppchen, wel-

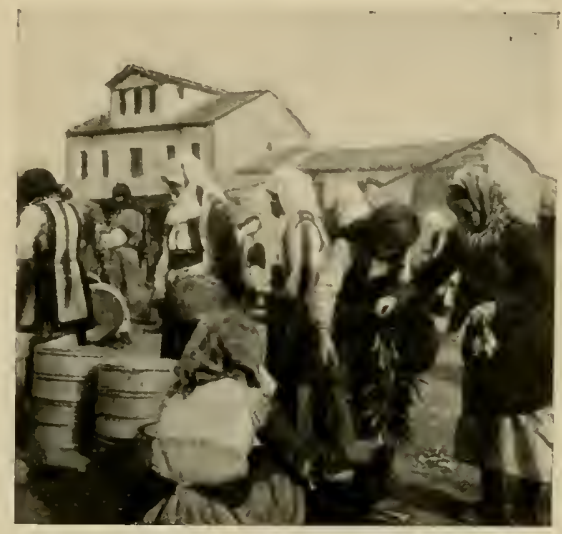

Abb. I24. Marktszene in Üsküb. Paprikaverkauf. ches den Kurzkopf etwas länger erscheinen läß3t als er in Wirklichkeit ist. In der Tracht der Männer ist es hier offenbar auf Schlankheit abgesehen. In den Bergen, wenn sie mit langen Schritten bergan steigen, erinnern mich die Albaner stets an unsere schlanken Bergbewohner in Oberbayern.

Albanische Frauen sieht man auf dem Markte in Üsküb ebensowenig wie Türkinnen. Die letzteren zeigen sich ja als Mohammedanerinnen so wenig wie möglich öffentlich. Aber auch bei den christlichen Stämmen der Albaner tritt die Frau viel mehr in den Hintergrund als bei slavischen Völkern.

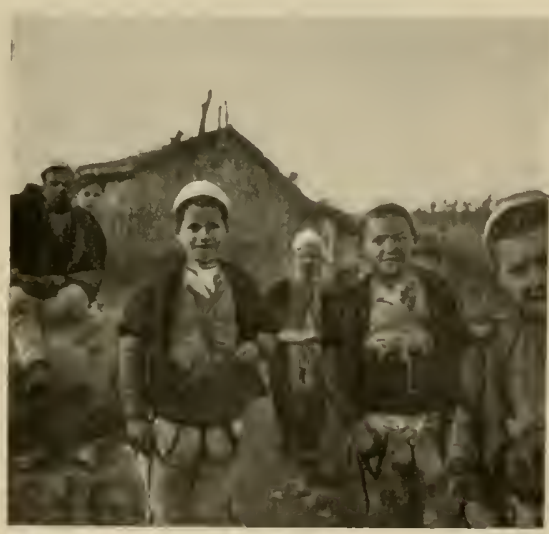

Abb. I 25. Albanische Jugend.

Von den Bewohnern Mazedoniens haben dem Lande die Türken am stärksten ihr Gepräge aufgedrückt. Das merkt man vor allem an den Städten, die alle von Kuppeln von Moscheen und von Minarets überragt sind. Üsküb (bulgarisch Skopje) bietet das malerische 
Bild einer richtigen Türkenstadt. Das gilt vor allem von der Hälfte der Stadt, die auf dem linken Wardarufer liegt. Aber auch die Vorstädte auf dem rechten Ufer des Flusses mit ihren hohen Gartenmauern, innerhalb deren Haus und Hof von der Außenwelt abgesperrt liegen, zeigen echt türkischen Charakter, wenn auch jetzt die Häuser, einst von Türken für Türken gebaut, meist von Bulgaren, Albanern, Juden und Mitteleuropäern bewohnt sind, nur selten mehr von Türken.

Das ganze Stadtviertel auf dem rechten Wardarufer hat einen mehr oder minder südeuropäischen, aber sehr charakterlosen Typus. Es ist schmutzig und verkommen, hat vernachlässigte Straßen, halbzerfallene Häuser, alles ist erfüllt von Staub und Gestank im Sommer, von Schlamm und Unrat im Winter. In den Straßen, die vom Bahnhof gegen die Wardarbrücke führen, liegen einige sogenannte Hotels, schmutzige Buden. Einige von ihnen, vom deutschen Militär in die Hand genommen, boten erträgliches Quartier mit sauberen Betten unter Aufsicht deutscher Feldwebel. Dort fand man ruhige Nächte, wenn man das Haus von Dämpfen schwefeliger Säure erfüllt fand, zum Zeichen, daß gerade eine große Wanzenbekämpfung durchgeführt worden war. Von diesen Plagegeistern wird an einer anderen Stelle die Rede sein.

Nur die von den deutschen Truppen errichteten oder ausgebauten Häuser machten einen erträglichen Eindruck. Das Soldatenheim am Bahnhof, die Offizierkasinos, einige als Sitz der Stäbe und als Wohnungen der höheren Offiziere hergerichtete Bauten, sahen sehr erfreulich und einladend aus. Manche von ihnen waren mit einfachsten Mitteln künstlerisch schön und wohnlich umgewandelt. So boten sie den Deutschen, welche Jahre lang hier hausen mußten, einen Aufenthaltsort, der sie in die Heimat zurückversetzte, während draußen an die geschlossenen Fenster und Türen der Orient anbrandete.

Ging man aber über die Wardarbrücke hinüber, so erhob sich vor einem malerisch und bunt die Türkenstadt. Hier war der Bazar, hier brauste das Leben durch die steilen engen Gassen, hier drängte sich das Volk und klapperte über das holperige Pflaster und man hatte Mühe auszuweichen, wenn irgend ein Wagen in rasendem Galopp, mit Geschrei und Peitschenknallen des Fahrers, die Menge zerteilte.

Hoch über den Gassen hob sich die türkische $\mathrm{Zitadelle}$ mit ihren Mauern und Zinnen, Basteien und Türmen empor. Von 
der Brücke aus bot sie, steil vom Fluß ansteigend, umwachsen von Pappeln, ein schönes Bild. In gelblichen und rötlichen Tönen hob sich das Mauerwerk über grauen Felsen ab; im Frühling leuchteten grüne Rasenflecken und blühende Obstbäume zwischen dem alten Gemäuer hervor. Das da oben also war die Zwingburg, von der aus das ganze Land mit seiner slavischen Bevölkerung hunderte von Jahren unter dem türkischen Joch gehalten worden war.

Kletterte und glitt man über die glatten, knolligen Pflastersteine die Berggassen hinauf, so öffnete sich jeden Moment ein eigenartiges Bild vor einem. In den offenen Vorderräumen der

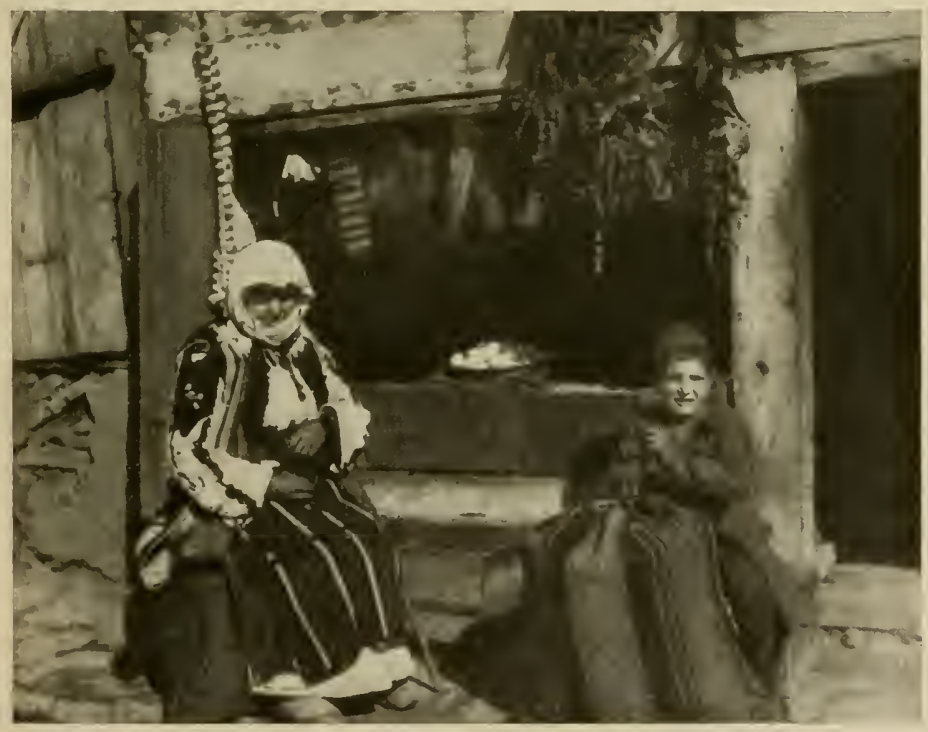

Abb. I 26. Eßwarengeschäft in Ưsküb.

kleinen einstöckigen Häuser spielte Handel und Wandel in voller Öffentlichkeit sich ab, das übliche Bild, welches jede Stadt des Orients von Marokko durch den nahen und fernen Osten bis nach China und Japan hin bietet.

Auch hier fand sich gassen- und viertelweise je ein Handwerk beieinander. Die Schreiner und Schlosser, die Kupferschm iede, die Schuster, die Schneider saßen Haus neben Haus, hier die Konkurrenz dicht beieinander. Es war schön von der grellbesonnten Straße in das Dämmerlicht des Raumes zu schauen, wo im Hintergrund der Schmied mit nacktem Oberkörper den Hammer schwang, daß die Funken bis auf die Gasse hinausstoben 
Stoffe und Teppiche hingen auf die Straße hinaus und wehten im Wind wie Flaggen über die Menschen hinweg, die vorübergingen.

Wo feineres Gewerbe hauste, waren die Öffnungen verglast, hinter den Scheiben sah man manchen feinen Greisenkopf über zierlicher Gold- und Silberarbeit geneigt. Dort wurden Bronze- und Messinggefäße gehämmert, hier duftende Kästchen und Platten aus Sandelholz gefertigt und mit zarten Ornamenten aus Silber eingelegt.

Dazwischen tauchten nüchterne Läden mit europäischem Tand, mit Kolonialwaren, mit Emailgeschirr oder Porzellan, Glas und Blech auf. Der Friseur und der Apotheker fehlten nicht, beide Gruppen von Männern versammelnd, die schwatzten und Zigaretten rauchten. Auch das Kaffeehaus fehlte nicht mit seinen wackeligen Tischen, lahmen Stühlen, dem bespuckten Boden und dem meist noch in der Zeit der Not erträglichen Kaffee. Es sei übrigens zugestanden, daß am Wardar ein stattliches, anständiges Kaffeehaus mit einem Terrassengarten am Flub sich befand, in welchem die Deutschen meist ihre Festlichkeiten abhielten.

Die Türken, besonders die alten Männer, gingen oft noch in wallenden Gewändern mit Turban oder Fez. Die slavischen Stadtbewohner jedoch waren alle mitteleuropäisch gekleidet, oft recht gut, meist aber mit der schäbigen Eleganz der Kleinstadt. Sehr auffallend waren in der Türkenstadt zwei weitere Typen der Bevölkerung, die Juden und die Zigeuner. Unter den Juden, von denen viele Handwerker, oft Feinarbeiter, so Juweliere und Uhrmacher waren, gab es prächtige, würdige alte Köpfe.

Die $\mathrm{Z}$ igeuner dagegen waren ein schmutziges Gesindel. Oben auf dem Berg hinter der Zitadelle auf dem Weg zu meinem Üsküber Standquartier im Ortsspital I der Bulgaren kam ich täglich durch das Zigeunerviertel. Es bestand aus verlotterten, zum Teil halb- und dreiviertel zerfallenen Häusern und Hütten. Diese bildeten ein wirres Durcheinander, mehr wie ein Lager von Nomaden, als wie eine Stadt oder ein Dorf aussehend. Im Eingang zu den Hütten oder vor ihnen auf dem Boden saßen und lagen die Männer, Weiber und Kinder am Boden herum; im Sommer gähnend und schlafend, im Winter und auch sonst am Abend sah man sie ein offenes Feuer mühsam unterhalten, irgendwo in einer Ecke, einerlei ob im Haus, vor diesem oder auf der Straße.

Die Kinder waren kaum bekleidet oder ganz nackt und liefen bettelnd auf die Straße herüber, wenn ein $\mathrm{W}$ agen vorbeifuhr oder ein besser gekleideter Fußgänger vorbeiging, besonders wenn es 
gar ein Offizier war. Die alten Weiber, scheußliche Vetteln, die so aussahen, wie wir uns als Kinder Hexen vorgestellt haben, waren nicht selten auch kaum bekleidet, trugen oft den Oberkörper unverhüllt.

Und wie gar die Haare bei Männern und Frauen aussahen, wirr und ungepflegt! Alle waren verlaust und wenn sie in der

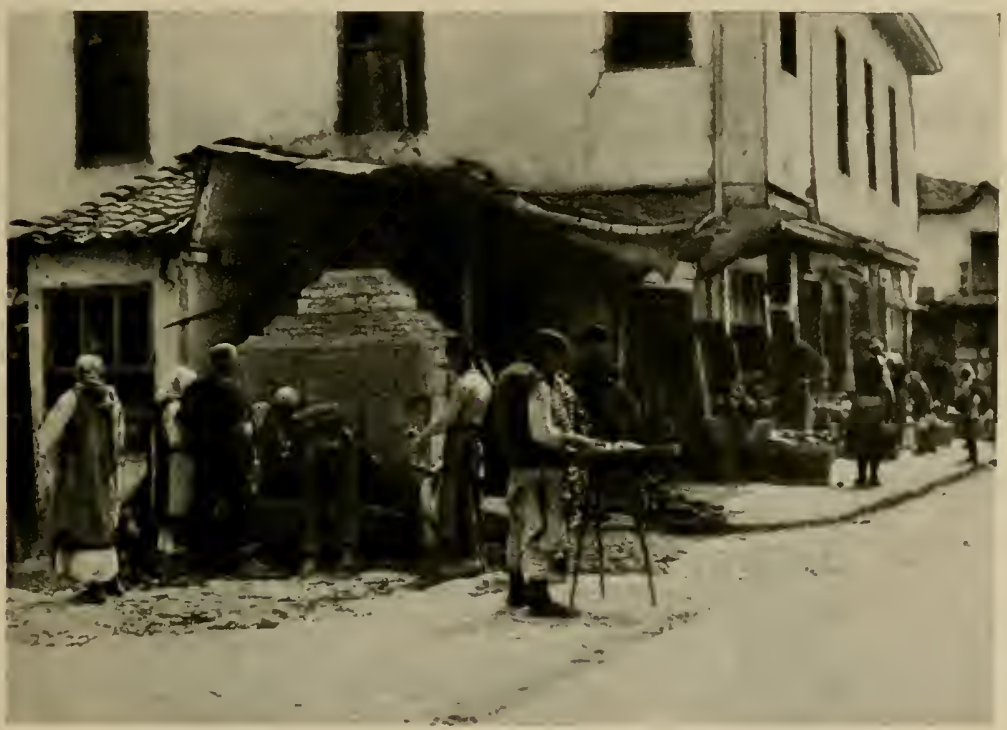

Abb. 12\%. Bazar in Üsküb.

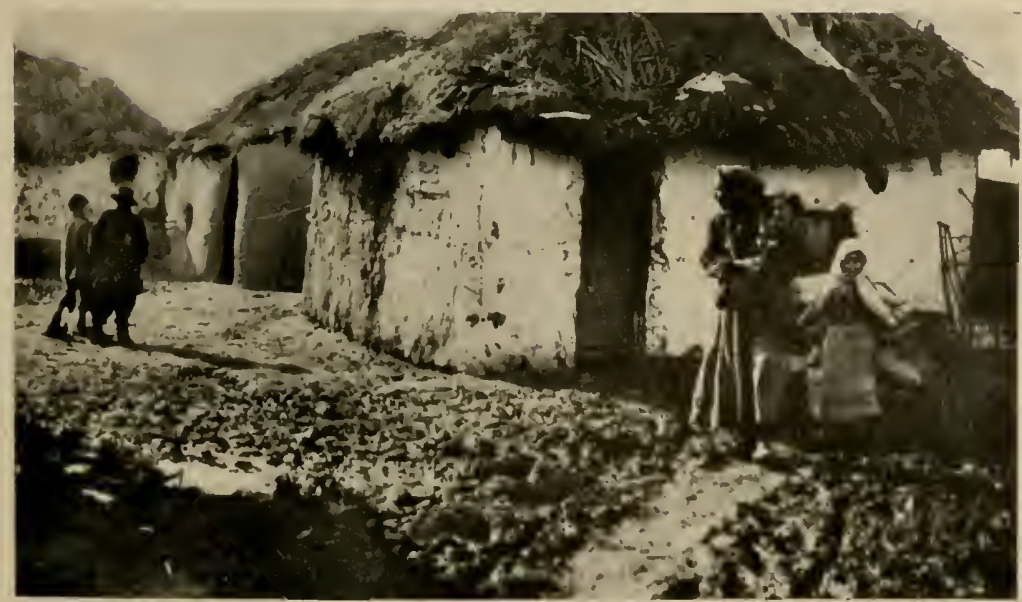

Abb. I 28. Im Zigeunerdorf. 
Sonne saßen, so waren sie meist beim Lausen des eigenen Kopfes und Körpers oder besorgten sich das Geschäft gegenseitig. Vor allem sah man die Mütter die Köpfe ihrer Kinder behandeln, aber auch Männer besorgten sich gegenseitig diesen Freundschaftsdienst; und wenn eine Frau die Haare ihres Mannes abjagte und seinen Kopf kratzte, so schien das ganz geschäftsmäßig vor sich $\mathrm{zu}$ gehen und nicht ein Liebesdienst zu sein.

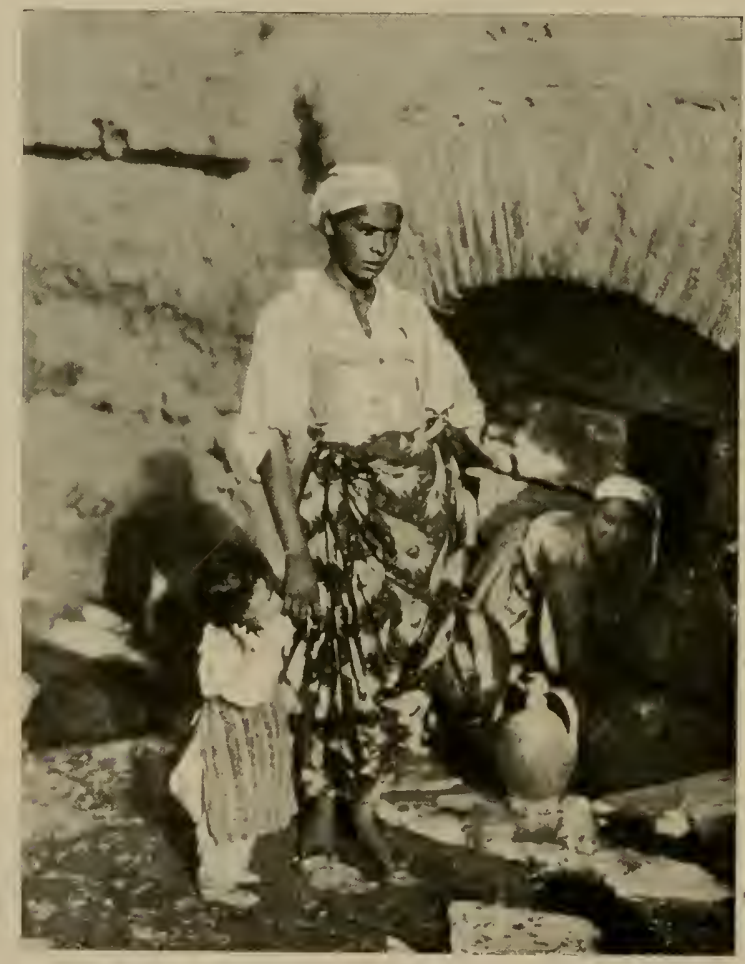

Abb. I 29. Zigeunerin mit Kindern am Brunnen.

$\mathrm{Da}$ unter diesen Umständen die Zigeunerstadt ein verrufenes Viertel war, ist nicht erstaunlich. Immer war es verseucht, Typhusepidemien waren an der Tagesordnung, und immer wieder flackerte dort das Fleckfieber auf. Hautkrankheiten waren verbreitet und man konnte durch sie auf das scheußlichste entstellte Menschen sehen, um welche man einen weiten Bogen herum machte. Geschlechtskrankheiten sind unter den Zigeunern sehr verbreitet und so unwahrscheinlich es klingt, nicht wenige unserer Soldaten, ja Offiziere haben sich in diesem Viertel böse Infektionen geholt. 
Kam man öfter durch das Viertel, so konnte man die Anziehungskraft der Zigeunerinnen besser begreifen. Eine jugendliche Zigeunerin hat meist eine entzückende Haltung und einen schönen, schwebenden Gang. Sie stachen ganz außerordentlich durch ihre natürliche Grazie von den plumpen schwerfälligen Mazedonierinnen ab. Während ich sonst in Üsküb unter den einheimischen Mazedonierinnen keine Frau und kein junges Mädchen gesehen habe, welches ich für schön oder nur reizvoll hätte erklären können, unter den Zigeunerinnen konnte man manchmal große Schönheiten sehen, die jeden Künstler begeistert hätten mit ihren schönen Formen, den edlen Gesichtern, den graziösen Bewegungen ihrer kaum verhüllten Formen.

Eine Zigeunerin, welche zur Zeit der Besetzung ein gewisse Rolle als Dirne spielte, wurde viel photographiert und ist in manchem Album aus Mazedonien als Typus der Zigeunerin abgebildet.

Daß in diesem Viertel ein Spaziergang zur Nachtzeit nicht ohne Gefahr war, konnte man aus den vielen Verbrechen erschließen, die dort vorkamen. Immer wieder hörte man von Mord und Raub, aber auch von füchterlichen Eifersuchts- und Eheszenen, die im Zigeunerdorf vorgefallen waren.

Wenig auffallend waren die wenigen Spaniolen, die man gelegentlich in Üsküb traf; sie hatten dort wie in allen Städten des Balkan als Handelsleute und Makler ihre Rolle gespielt. Diese Abkömmlinge spanischer Juden, die vor Jahrhunderten sich in der Türkei angesiedelt hatten, bilden bekanntlich einen wesentlichen Teil der Bevölkerung voṇ Saloniki. Jetzt in der Kriegszeit waren sie hier im mittleren Mazedonien verschwunden und nur einige wenige dieser sprachgewandten, gebildeten Leute waren als Dolmetscher bei Deutschen und Bulgaren verwandt. Ein solcher begleitete mich auf einer Gebirgsexpedition im Juni 1918 und bewährte sich dabei sehr.

Ebenso traf man im besetzten Gebiet selten Griechen, die ja sonst auf dem ganzen Balkan ein wichtiges Element darstellten. Sie konnten sich natürlich als Feinde nicht dieseits der Front aufhalten. Auf manchen Reisen habe ich allerdings griechische Siedelungen, besonders im Frontgebiet im Süden, angetroffen. Von ihnen wird im gegebenen Zusammenhang die Rede sein.

Ebenso sah man in Üsküb von einem in Mazedonien zerstreuten Volk selten einen Vertreter, und wenn man ihn sah, dann wie den Spaniolen oder Griechen, nicht ohne weiteres als solchen 
erkennbar in irgendeiner bürgerlichen Tätigkeit. Es sind das die A romunen oder Kutzowallachen, ein Volk, von dem ich bei der Schilderung des Besuches seiner eigenartigen Gebirgsstädte Krusevo und Gopes manches zu berichten haben werde.

Wenn man sich nun vorstellt, daß zu diesen normalen Bewohnern Mazedoniens und Üskübs während des Krieges als Soldaten der Heeresgruppe und als Kriegsgefangene Deutsche aus allen Gauen, Österreicher, Ungarn, Tschechen, Kroaten, Bosnier, Dalmatiner, Russen, Polen, Rumänen, schwarze und weile Franzosen, Engländer und Italiener kamen, so kann man sich eine Vorstellung von dem Völkergewimmel machen, welches auf einmal dies sonst von der Welt so abgeschlossene Land überfalien hatte.

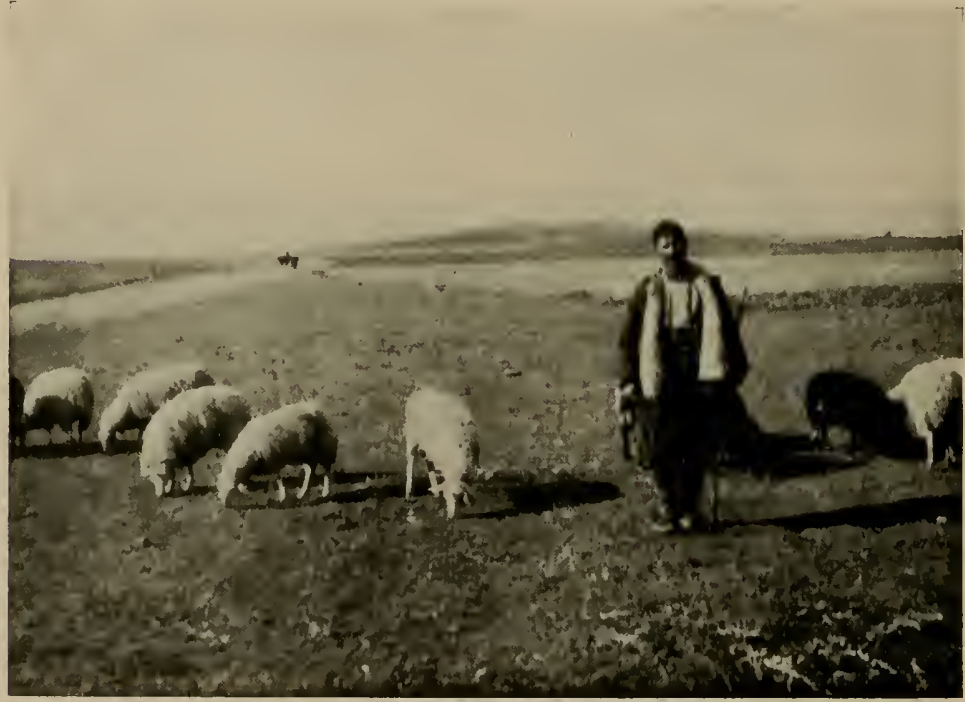

Abb. I30. Türkischer Schafhirt bei Üsküb.

Ich habe mich nun in keiner Weise in völkerkundliche oder anthropologische Studien während meines Aufenthalts in Mazedonien versenkt. Dazu fehlte mir die Zeit, welche durch meine Forschungen als Zoologe vollkommen in Anspruch genommen wurde. Aber ich hielt meine Augen offen für alles, was die Völker Mazedoniens mir Interessantes gelegentlich meiner Reisen zeigten. Das mag als Material für Kenner dieser Gebiete dienen.

Vor allem möchte ich aber Beobachtungen an und Erlebnisse mit meinen Freunden, den Bulgaren, aufzeichnen, die geeignet sein 
können, ein richtiges Urteil über dies Volk bei uns zu befestigen, das mit uns nun einmal durch Schicksal zusammengebracht worden ist.

Elemente der hier angeführten Völker kann man in ganz Mazedonien antreffen. Dabei wiegt in manchen Bezirken die eine oder die andere Nationalität vor. Im äußersten Westen überwogen die Albaner, im Südwesten und Zentrum die Bulgaren, an der Südgrenze die Griechen, im Norden die Serben. In vielen Gegenden hatte die Zahl der vor wenig Jahren noch überall verbreiteten Türken abgenommen, da viele von ihnen ausgewandert waren. Überall war es schwer, bei kurzem Aufenthalt ein klares Bild zu erhalten, welcher Volksteil vorherrsche. 


\section{SECHZEHNTES KAPITEL}

\section{ÜSKÜB ALS STANDQUARTIER}

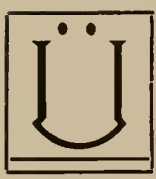

sküb, mit dem bulgarischen Namen Skopje, bot als Standquartier viele Vorteile. Zunächst lag es zentral und hatte Bahnen und Verbindungswege nach allen Seiten. Dazu war es der Sitz des Oberkommandos der Heeresgruppe, welche eine deutsche, zwei bulgarische Armeen und eine Anzahl österreichische und türkische Truppen umfaßte. Hier hatte nach der Eroberung des Landes v. Mackensen sein Hauptquartier gehabt, nach ihm v. Gallwitz und jetzt befehligte v. Scholtz die Heeresgruppe. So konnte ich hier mehr Hilfe und Unterstützung erwarten, als in dem kleinen, abgelegenen Kaluckova mit den bescheidenen Hilfsmitteln eines Lazaretts.

Vor allem aber lockte mich eine Einladung eines bulgarischen Freundes, welcher jenseits der Zitadelle in der sogenannten englischen Mission als Chefbakteriologe der I. Bulgarischen Armee saß. Es war dies Prof. Popoff, ein ehemaliger Schüler des zoo-

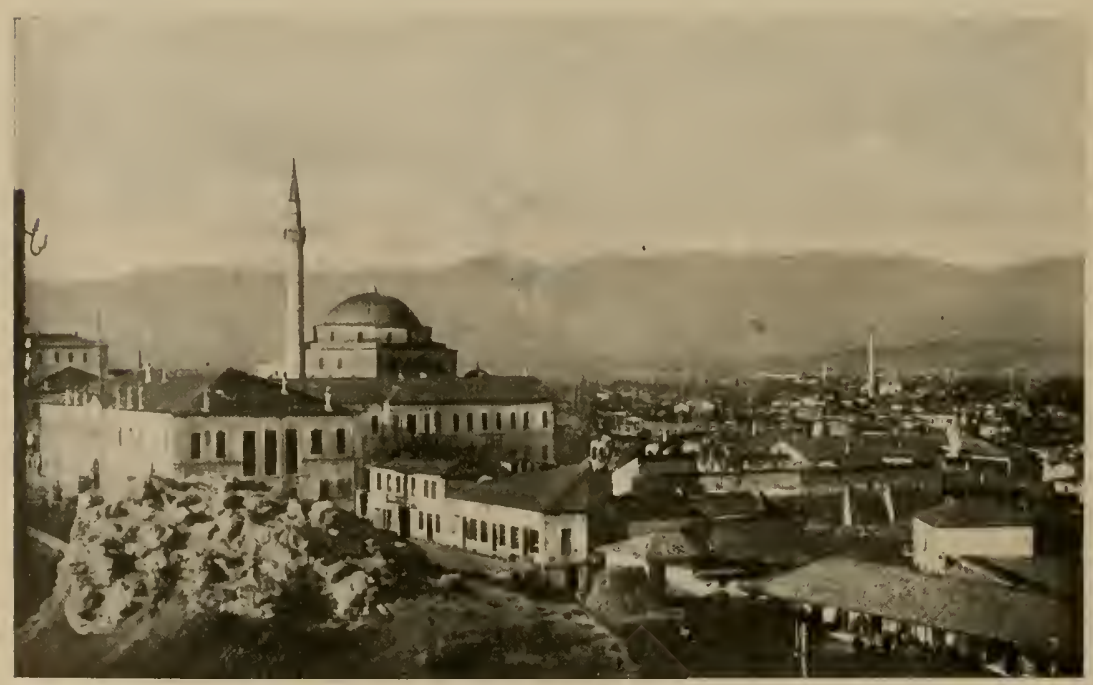

Abb. 131. Blick über die Türkenstadt von Üsküb. 
logischen Instituts in München, damals auch mein Schüler, ein anhänglicher, treuer Freund deutscher Kultur und Wissenschaft. Er stellte mir einen Teil seines bakteriologischen Laboratoriums zur Verfügung und die Möglichkeit mit meinen Tischen, Schränken und Apparaten bei ihm Unterkunft zu finden. Der Chefarzt des großen Spitals, dem Popoffs Laboratorium angegliedert war, Dr. Molloff, ein guter Internist, der später Vertreter dieses Faches an der Unirersität Sofia wurde, bot mir Quartier und Gastfreundschaft im Ärztekasino des Ortsspitales an. Das war eine schöne Gelegenheit, mit hochgebildeten Bulgaren zusammenzuleben, ron ihnen manches über ihr Volk, ihre Ziele, ihre Kultur zu erfahren und manche meiner wissenschaftlichen Unternehmungen erleichtert zu bekommen.

Meine Hoffnung wurde nicht enttäuscht. Als ich nach 9 Monaten mich von den Bulgaren trennte, hatte ich nicht nur in Popoff, dem Dr. Molloff und dem Dermatologen Stefan off gute Freunde, sondern auch manchen tiefen Einblick in bulgarisches Wesen und Volkstum gewonnen.

Die Umgebung von Üsküb, das Wardartal und die angrenzenden Gebirge boten mir manche Gelegenheit zu wissenschaftlichen Beobachtungen, die ich in dem Laboratorium Prof. Popoffs regelrecht verarbeiten konnte.

Anfang Februar 1918 zog ich auf dem Zitadellenberg über Üsküb ein und schlug meine Wohnstätte in dem stattlichen Steinbau des Hospitals, meine Arbeitsstätte in dem geräumigen Laboratorium Prof. Popoffs auf. Die schönen Tage ersten Vorfrühlings gaben mir schon Gelegenheit zu manchen Beobachtungen im Freien, als ein Wetterrückschlag wieder tiefen Winter über die Landschaft legte. So lernte ich noch bitteren mazedonischen Winter kennen mit tiefem Schnee im Tal und Kältegraden von 5-10 unter Null. Zum Glück war mein Zimmer gut heizbar, so daß man nach den Schneespaziergängen sich wärmen konnte.

Die Wanderungen durch die Türkenstadt brachten manchen seltsamen Eindruck. Schwere Schneemassen lagen auf Dächern und Mauern und kaum konnte man sich durch die engen Gassen einen Weg bahnen. Es war ein unerwarteter Anblick, die Minarets und Kuppeln der Moscheen unter dicken Schneehauben zu sehen. Allen Schmutz und alle Zerstörung deckte die weiße Decke zu; so sauber hatte man Üsküb noch niemals erblickt, als unmittelbar nach dem Schneefall. 
Ganz eigenartig war der Anblick des byzantinischen oder alttürkischen Äquadukts, der nahe beim Ortsspital oben auf dem Hügel hinzog in der Winterlandschaft, hinter der der beschneite Wodno sich erhob. Seine charakteristische Modellierung wurde durch die Schneebedeckung scharf hervorgehoben (Abb. 133).

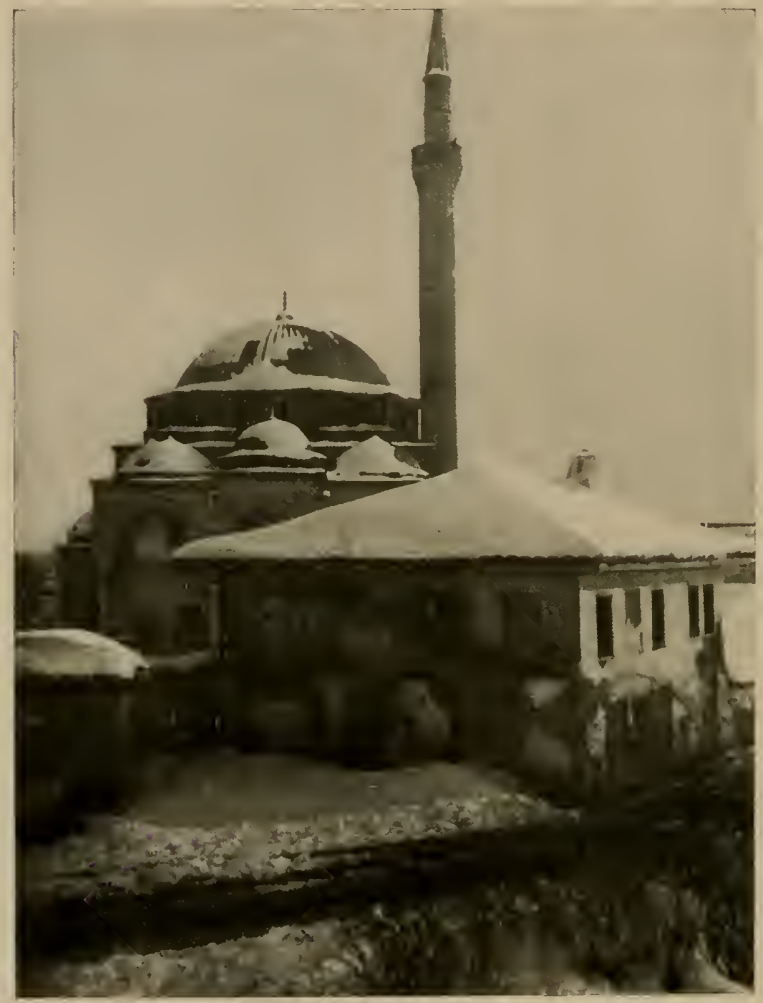

Abb. 132. Zitadellenmoschee in Üsküb im Schnee (März 1918).

Die Formen der großen Bauten traten glanzvoll hervor und vor allem der Blick über die Stadt mit ihren unzähligen Dächern bot im Schneegewand einen phantastischen Eindruck.

Um so schlimmer war es bei der Schneeschmelze; da waren die Straßen von einem unergründlichen Schmutz bedeckt und wer nicht in die Stadt mußte, durfte sich dessen freuen. Es wurde Ende März, bis der Frühling mit Macht hervorbrach. Die Hänge der Hügel bedeckten sich mit weilßen und gelben Crocus, süß- 
duftende Veilchen sproßten in den Hecken und bald begannen die Obstbäume zu blühen.

Im April und Anfang Mai war es in Üsküb schön, überall wo man hinkam. Wäre die Stadt leichter zugänglich und gäbe es dort eine bessere Unterkunft, so könnte sie zu den berühmten

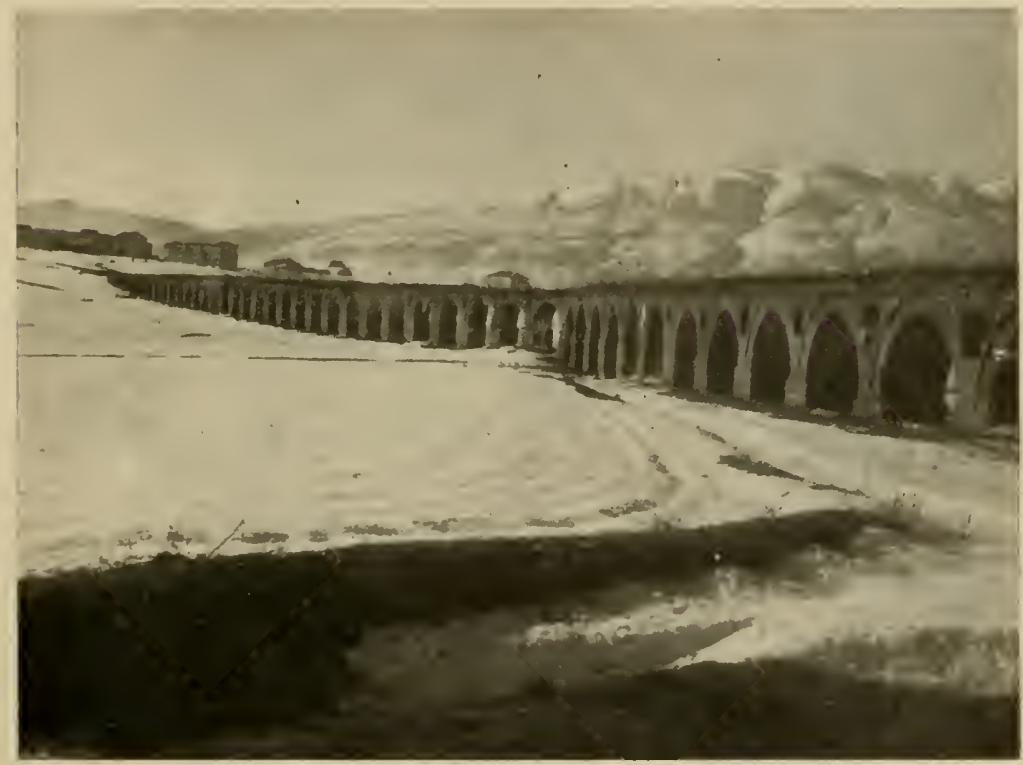

Abb. 133. Byzantinische Wasserleitung bei Üsüb im Winter 1918.

Stätten Europas gehören. Über die Mauern der Gärten beugten sich die blühenden Zweige der Bäume, das Verfallene und Ruinenhafte erschien nur romantisch unter der Fülle der Pflanzenwelt, die für eine kurze Zeit der Pracht mit gewaltiger Macht hervorbrach.

Wo man zwischen den Bäumen und Büschen hindurchsah, öffneten sich überraschende Blicke, ob man nun nach Osten oder Westen ins Tal des Wardar, oder nach Norden und Süden auf die Gebirge blickte. Im Norden erhob sich die Kette des Karadakh noch mit Schnee bedeckt, trotzdem schon dunkel, durch seine schon freigeschmolzenen waldigen Hänge. Kara ist das türkische Wort für schwarz; der Name bedeutet also schwarze Berge. Im Westen grenzte der Schardakh mit der schönen Pyramide des Ljubotren das weite Wardartal ab. Südlich stiegen die mit blühendem Schlehdorn und Obstbäumen bestandenen Hänge des Wodno hinan. Nach Osten dehnte sich eine breite Talfläche, 
die nun grün zu werden begann und deren besondere Schönheit Gruppen mächtiger Pappeln bildeten.

Im Gesamtbild von Üsküb spielen überhaupt die Pappeln eine beherrschende Rolle. Überblickte man die Stadt von der Zitadelle aus, so sah man vor sich hauptsächlich die Südstadt liegen, die mit ihren gleichmäßigen Häusern in der Flußebene ausgebreitet

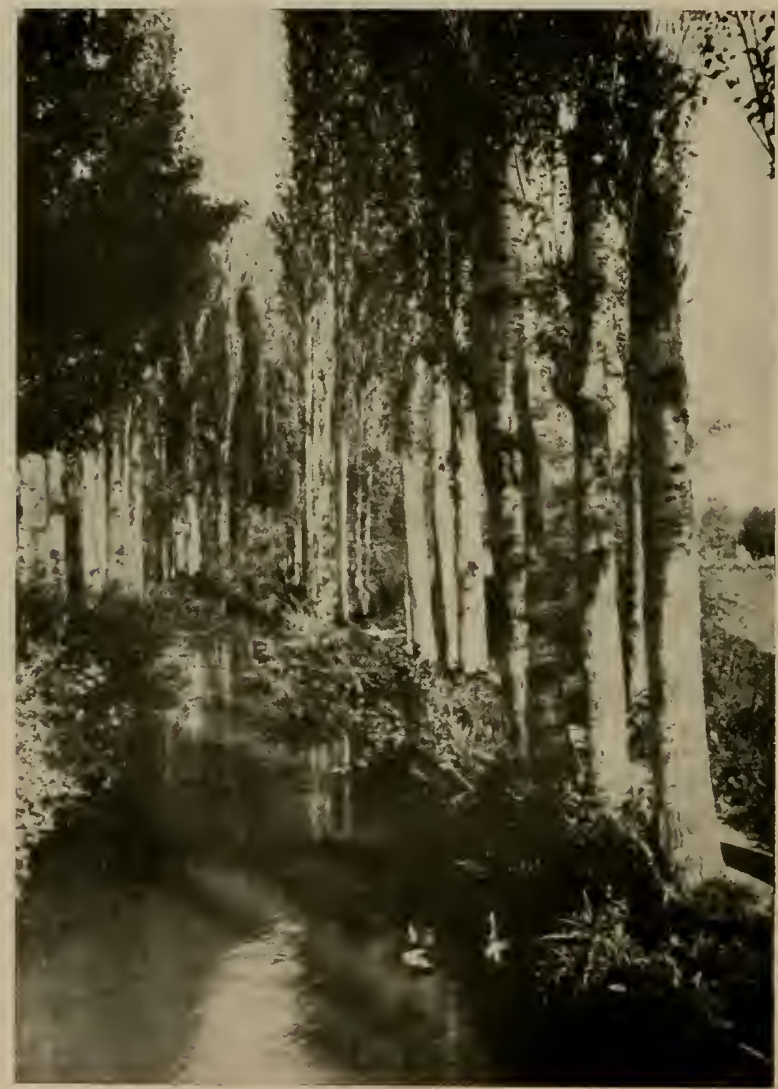

Abb. I34. Kanal mit Pappelallee in Üsküb.

reizlos gewesen wäre, hätte nicht eine mächtige Pappelallee sie malerisch gegliedert, so daß sie sich schön von dem eigenartigen Umriß des Wodno abhob, des Berges, der südlich der Stadt auf I $100 \mathrm{~m}$ Höhe ansteigt. Diese Allee begleitete nicht eine Straße, sondern einen breiten Bewässerungskanal, der längs eines großen Teiles der Stadt hinzog. Wer ins Kriegslazarett in der türkischen 
Kaserne hinaus wollte, der vermied gern die staubige Landstraße und turnte lieber auf den Dämmen des Kanals entlang, die frischere Luft und eine Augenweide darboten. Die silberweißen Stämme mit ihren dunkelen Ringflecken spiegelten sich auf dem stillen, dunkelgrünen Wasser des Kanals, zu welchem sich von den Ufern üppige Kräuter und Büsche hinabneigten. Bunte Enten plätscherten schnatternd im Kanal. Zwischen den säulenähnlichen Stämmen der Pappeln blickte man nach Süden auf die vom Kanal bewässerten, reichen Gemüsegärten, in denen Salate, Kohl und Kräuter, Tomaten, Melonen und schwarzblaue Auberginen zwischen Obstbäumen herrlich gediehen. Nordwärts schweifte der Blick über die im grellen Sonnenschein glühenden farbigen Häusermassen der Türkenstadt mit ihren Moscheen und Minarets, welche den Berghang drüben bedeckten.

Es waren vor allem die Abendstunden, welche $z u$ einem Spaziergang in der Türkenstadt verlockten. Die Moscheen und Kirchen lagen meist hoch am Berg, so daß man von ihnen aus wundervolle Aussichten über Teile der Stadt, über das Wardartal und das weite Land genoß. Im Frühling schwebten meist große Wolkenballen am Himmel, wenn die Sonne hinter dem Schardakh hinabsank und nicht nur jene vergoldete, sondern auch tief in die Gassen der Stadt ihre verklärenden Strahlen auf die roten, gelben oder grell weißen Wände der Häuser, Moscheen und Türme warf. Dann war es außerordentlich reizvoll, die engen Gassen zu durchwandern und die eigenartigen Bauwerke zu besuchen, welche zum Teil recht sehenswert waren.

Unter ihnen sind besonders malerisch die ruinenähnlich aussehenden, runden, kuppelbedeckten Teile eines alten türkischen Bades. Wie eine Gruppe von kleinen, breiten Türmen nimmt sich das ganze Bauwerk aus, dessen Mörtelbewurf zum Teil abgefallen ist. So treten die Reihen von roten Backsteinen und graugelben Hausteinen bunt hervor, aus denen schichtenweise die Wände erbaut sind. Die halbkugeligen Kuppeln, recht baufällig, sind mit Gras und Büschen bewachsen, so daß man zunächst nicht recht weiß, ob es sich um Werke des Menschen oder um Erzeugnisse der Natur handelt. Aber ein farbiges Bild bieten sie dar, im Schein der Abendsonne (Abb. 135).

Ähnlich sahen die Kuppeln einiger zerfallender Moscheen aus, die man in den verschiedenen Stadtteilen antrifft. Noch eigentümlicher mutet eine alte $\mathrm{K}$ arawanserei an, welche auf die 
Zeit des Serbenzaren Stephan Duschan, das 14. Jahrhundert, zurückgeführt wird. Kurschumli-Han, d. h. Blei-Han, wird das Gebäude genannt, wegen der kleinen Bleikuppeln, welche Gemächer des oberen Stockwerks überwölben. Ein $\mathrm{Han}$ ist eine Karawanserei, ein Absteigequartier des Reisenden, vor allem des Kaufmanns, der mit seinen Tragtieren, Dienern, Führern und Gepäck hier in alten Zeiten Unterkunft fand. Solche Hans sind charakteristisch für den ganzen Orient.

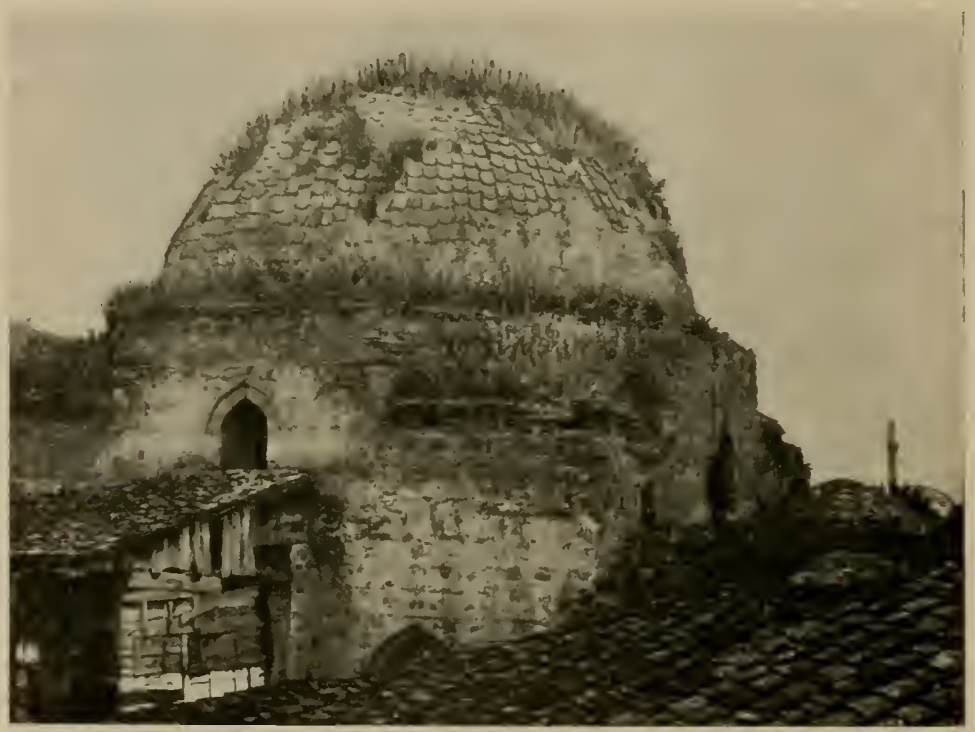

Abb. 135. Altes türkisches Bad in Üsküb.

Der Kurschumli-Han (Abb. 136) in Üsküb ist wirklich eine Sehenswürdigkeit. Es ist ein stattliches, fast burgähnliches Gebäude von guten Verhältnissen. Durch eine weite Torhalle tritt man in einen säulenumgebenen Hof von eigenartigem Reiz. Mitten auf dem gepflasterten Boden des Lichthofes befindet sich von Marmorplatten umfaßt, ein vertieftes Brunnenbecken, in dessen Mitte auf kurzer Säule sich eine skulptierte Schale erhebt. Den Hof umgeben zwei Stockwerke säulengetragener Bogen. In der Hinterwand dieser Loggien führen Rundbogentüren in die Räume, in denen die Reisenden mit ihrem Gepäck Unterkunft fanden, während im Hofraum ihre Reit- und Tragtiere lagerten und gefüttert und am Brunnen getränkt wurden. Zur Zeit meines Besuches war allerdings der Brunnen trocken. 
Das Eigenartigste war aber die Farbe des Bauwerks die; Säulen und Bogenwände trugen ein strahlendes Blau, während die Hinterwände mit einem Rot gestrichen waren, welches an Wände in Pompeji erinnerte. In dem starken Licht des mazedonischen Tages bot der Hof ein prachtvolles Bild dar. Was mag da oft ein buntes Leben sich abgespielt haben, als der Han noch seinem eigentlichen Zweck diente. Jetzt während des Krieges wurde er als bulgarisches Proviantmagazin benutzt. Wenn die gewaltigen Tore des Gebäudes mit den schweren Eisenbalken geschlossen

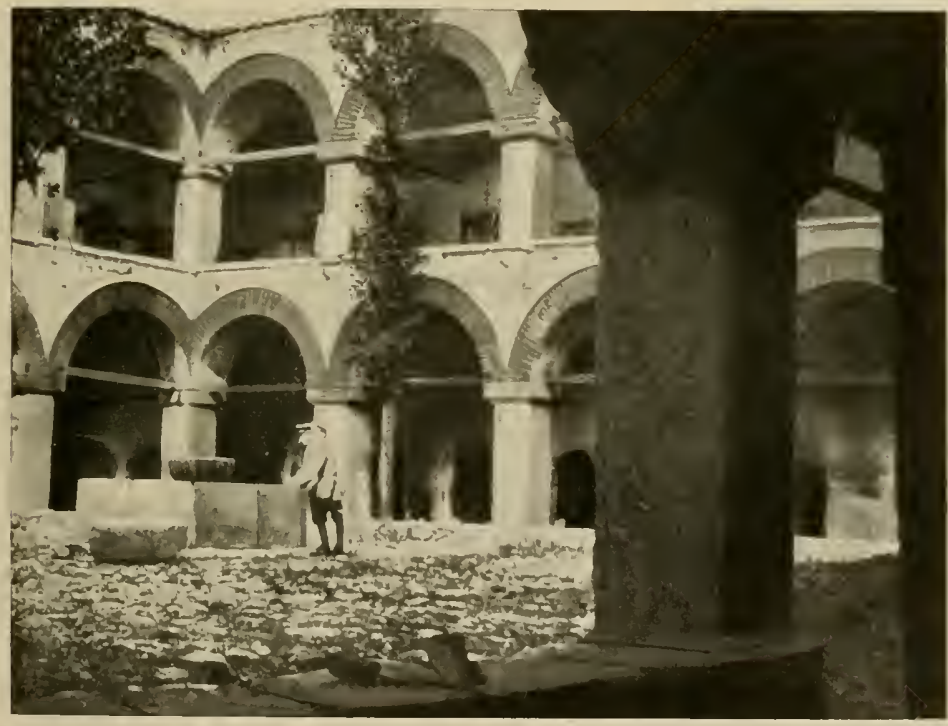

Abb. 136. Kurschumli-Han. Innenhof.

waren, danı mochten sich die Reisenden und die Kaufleute mit ihren Waren hier sicher fühlen vor dem Gesindel der einstigen Großstadt.

Ebenfalls auf die Serbenzeit und sogar auf den Zaren Stepha'n Duschan selbst wird die eigenartige Kirche Sv. Spas zurückgeführt, die klein am Berghang verborgen zwischen Häusern lieg't, ohne Turm und auffallende Fassade. Ihre Fundamente mögen auf alte Zeiten zurückgehen, aber die Malereien und Schnitzereien im Innern sind sicher viel späteren Datums; letztere sind zum Teil mit 1840 datiert.

Es war ein schöner Augenblick, wenn man aus dem Gewimmel der Gasse auf den stillen, kleinen Kirchenhof trat, dessen 
Boden von Grabplatten bedeckt war. Zwischen deren Spalten sproßten Pflanzen hervor und so war im Frühsommer der ganze Raum von Blütenflor bedeckt, von Blumenduft erfüllt. Durch eine niedere Türe führte es einige Stufen hinab in das Kircheninnere, welches von dem auf die Sinne wirkenden, zunächst verwirrenden Glanz der slavischen Kirche erfüllt war. Dunkle Holzschnitzerei füllte den niedrigen Raum bis zur Decke aus, in den Einzelheiten ein merkwürdiges Stilgemisch zeigend, aber doch sehr wirkungsvoll als Einrahmung der Altarbilder mit den reichen Gold

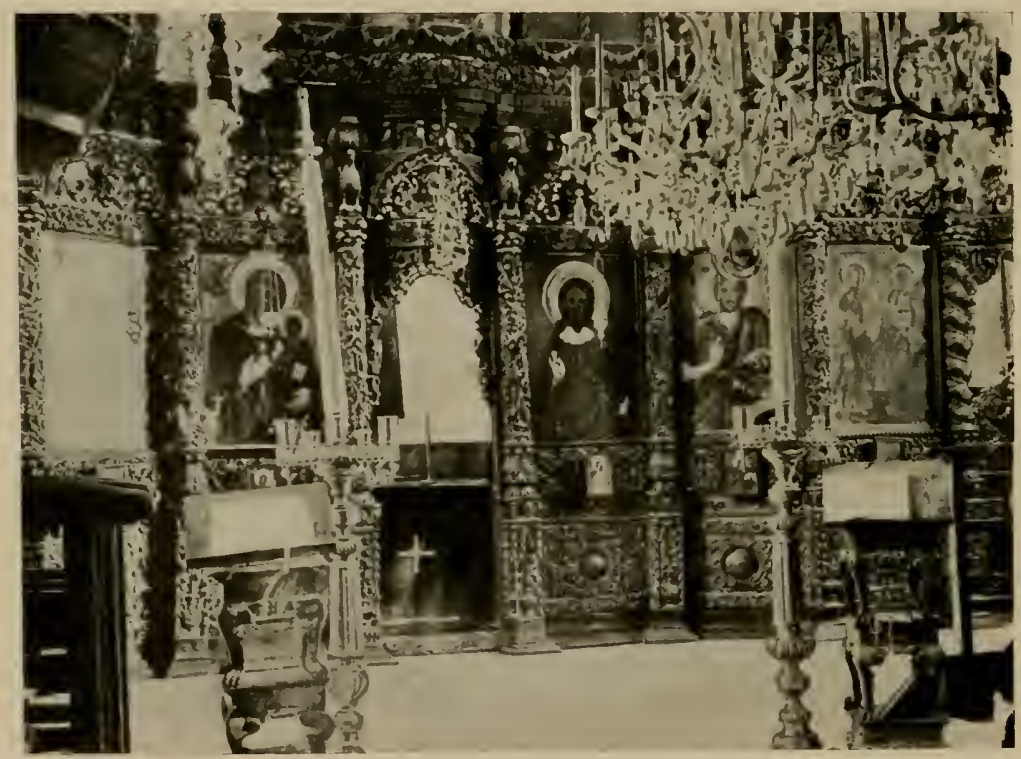

Abb. 137. Ikonostas der Markuskirche in Üsküb.

der Heiligengewänder und Heiligenscheine, als Wände der Beichtstühle, als Stützen der Gestühle und Schranken. Wie stets in der griechischen Kirche, ist das Allerheiligste vom Laienpublikum durch Schranken (Ikonostas) abgeschieden. Die Heiligenbilder sind nicht bedeutende Malereien, in ihrem charakteristischen Stil verfehlen sie ihre Wirkung nicht.

Hier wie in manchen slavischen Kirchen des Balkans habe ich öfters den recht eindrucksvollen griechischen Gottesdienst mitgemacht. Besonders schön pflegen die Gesänge der Kirchenchöre zu sein, bei denen mir oft prachtvolle Männerstimmen, besonders Bässe, auffielen. Die slavischen Kirchengesänge zeichnen sich 
durch großen Melodienreichtum aus. Ich habe gelegentlich in Serbien, Bulgarien, Mazedonien und Rumänien Gottesdiensten beigewohnt, einfachen Feldgottesdiensten wie pompösen Repräsentationen. Ich hatte meist den Eindruck einer leeren, nicht sehr tief wirkenden Handlung. Dazu trug meist das Geringe der Persönlichkeit der Priester bei.

Auch in Üsküb begegnet man oft auf der Straße den schwarzen Gestalten der Popen. Mit ihren großjen Bärten, ihren mächtigen Kopfbedeckungen und wallenden Kaftanen sahen sie manchmal pompös aus. Kam man ihnen näher, so verschwand sehr bald der Nimbus. Viele von ihnen waren schäbig gekleidet, wenig an Körper und Kleidern gepflegt. Andere waren geschniegelt und gut angezogen, je nach Stellung und sonstiger Art. Merkwürdig war die geringe Achtung, welche ihnen im allgemeinen die Soldaten und Offiziere entgegenbrachten. Meine bulgarischen Freunde sagten mir, die meisten unter ihnen seien wenig gebildet, hätten schlechte Manieren, geringes Wissen. Doch gebe es unter ihnen auch tüchtige und feine Menschen.

Ich habe gelegentlich auch höher stehende Popen getroffen, so bei den Armeestäben, aber kaum einen, der eine fremde Sprache beherrschte. Somit habe ich keine eigenen Erfahrungen über diese slavischen Geistlichen. Doch hatte ich Gelegenheit, bei manchem eine prachtvolle Singstimme zu be-

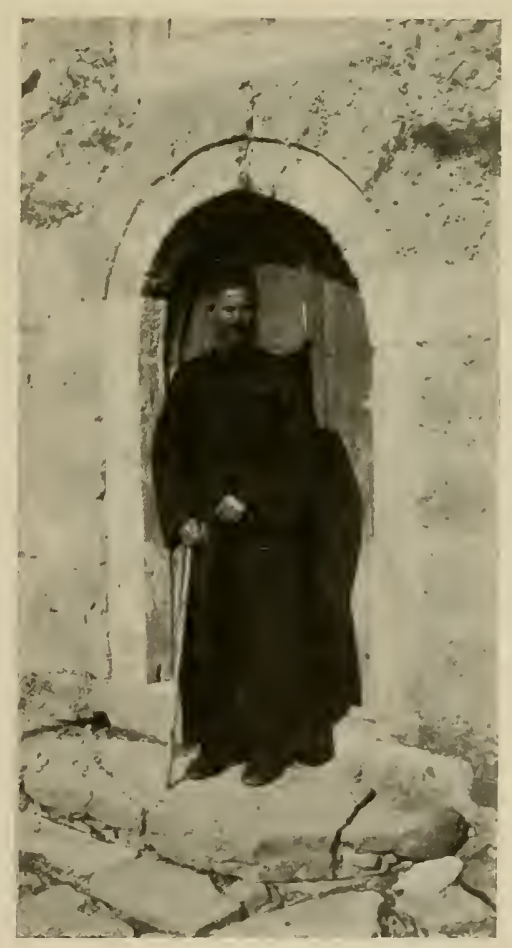

Abb. 138. Bulgarischer Pope aus der Kirchentüre des Klosters bei Pubjance tretend. wundern. Einer eigenartigen Feier wohnte ich in der Kathedrale in Bukarest bei; in Rumänien besteht ja die gleiche orthodoxe griechische Kirche, und so war der Ritus derselbe wie in den bulgarischen Kirchen. In Bukarest zelebrierte der dortige Metropolit selbst die Messe in einer Schar glänzend geschmückter Priester. Es wurden Verse in altslavischer 
Sprache gesungen, denen Chöre antworteten. Diese machten mir damals einen sehr schönen Eindruck, da sowohl die Stimmen der Priester, als auch die in den Chören vortrefflich waren und die sehr schönen Gesänge sehr rein und ausdrucksvoll gesungen wurden. In Üsküb trat allerdings das Christentum jedenfalls in den Gebäuden nicht hervor und im allgemeinen war es auch reizvoller und interessanter, sich mit dem, was aus der Türkenzeit von mohammedanischem Wesen übrig geblieben war, zu beschäftigen.

Von Moscheen besuchte ich eine ganze Anzahl, deren Gittertore, Vorhallen, Gewölbe und Teppiche vielfach sehr schön waren. Auch die um einige von ihnen gelegenen Gräber mohammedanischer Vornehmen waren zum Teil sehr eigenartig und gute Leistungen von Kunstschmieden. Stattlich ist besonders die Murad-Moschee, in welcher schöne Teppiche zu sehen waren. Neben ihr steht der rote Uhrturm, ein Wahrzeichen Üskübs. Im Stadtteil um die Zitadelle, nicht weit des Kurschumli-Han, befinden sich die ältesten Moscheen. Besonders hervorragende Architekturen gibt es in Üsküb nicht, immerhin ist es ein anständiges Niveau, welches die dortigen Moscheen repräsentieren, und was die Türken von Bauwerken hinterlassen haben, flößt einem doch Respekt vor der Kultur ein, welche sie in diesem Lande vertraten.

Einen merkwürdigen Ausdruck mohammedanischer Religiosität lernte ich in den Ekstasen sogenannter tanzender und heulender Derwische kennen. Jeder, der eine Stadt des Orients besucht, hat Gelegenheit, dergleichen kennen zu lernen. Vor allem aus Ägypten oder Algier gibt es viele Darstellungen dieser seltsamen Exzesse. Das, was ich davon in Üsküb sah, verdient wegen seiner Besonderheit Erwähnung. Hier handelte es sich nicht um eine öffentliche Schaustellung in einem großen Raum, sondern wir durften fast heimlich die religiöse Handlung bei einer Sekte, die sich aus armen, einfachen Leuten zusammensetzte, in einem kleinen Haus eines entlegenen Stadteiles ansehen.

Das Ganze war mit einem gewissen Mantel des Geheimnisses umgeben; ein Führer begleitete uns gegen Mitternacht durch dunkle Gassen in ein fernes Quartier am Rand der Türkenstadt. Nur mit der Laterne fanden wir unseren Weg durch enges Gewinkel. Zuletzt bogen wir in einen mauerumfaßten Hof und traten in ein niederes kleines Haus ein, welches nur dürftig mit einigen qualmenden Lampen erhellt war. Ein etwas größerer Raum war für die sogenannten Derwische frei gemacht. Die Nebenräume 


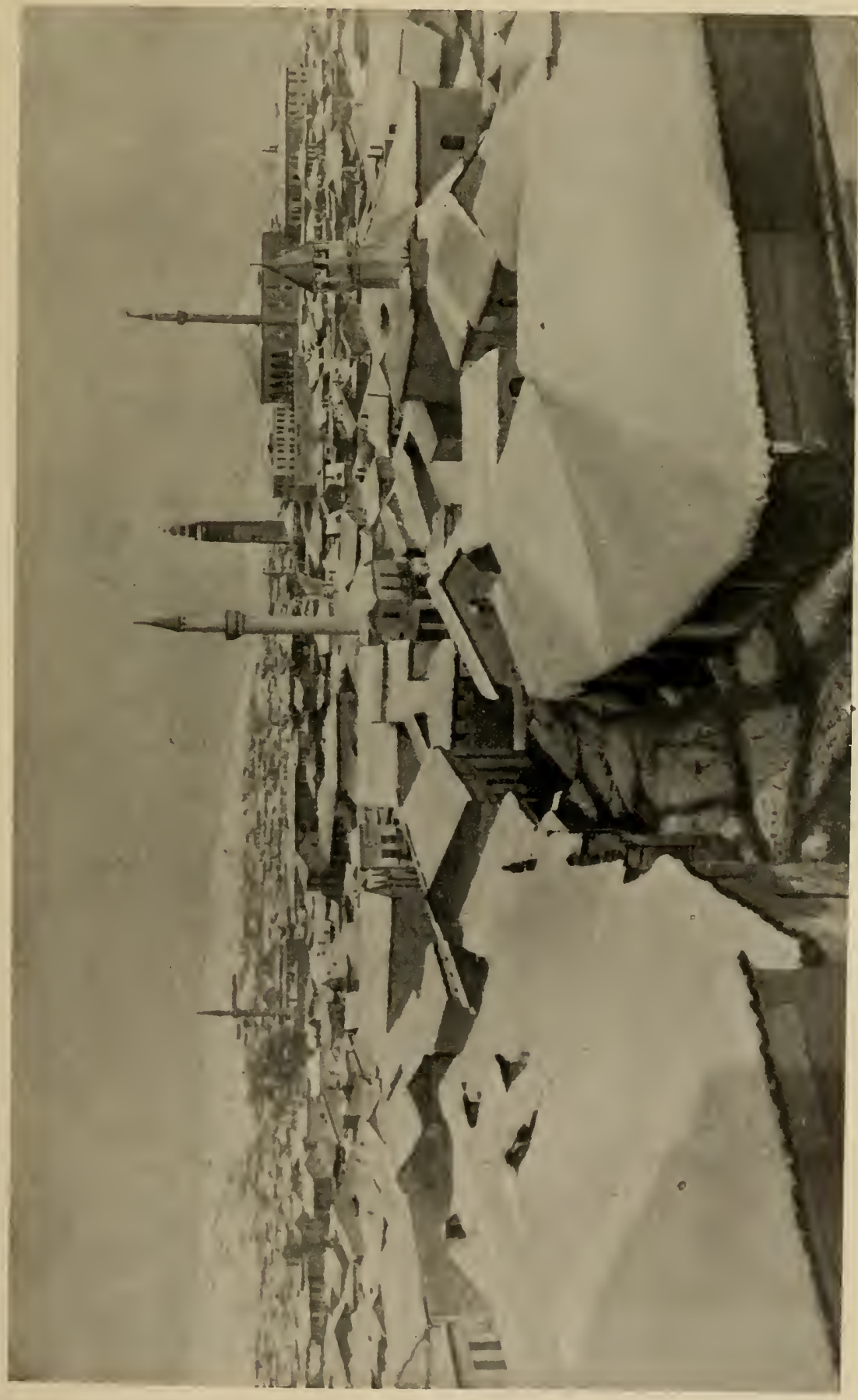

弪 

füllten sich allmählich mit einer Menge einfacher Männer aus dem umgebenden Viertel. Alles flüsterte nur und bewegte sich mit großer Geschäftigkeit schlürfend durch die Räume. Wir als Offiziere wurden mit einer gewissen Auszeichnung behandelt, die in wesentlichen darin bestand, daß man uns Polster darbot, auf denen wir uns niederhocken konnten.

Dann kamen einige einfache Männer in den mittleren Raum, entkleideten sich den Oberkörper und verhielten sich zunächst still und schweigsam. Es waren alles Männer aus dem Volk, Arbeiter, Handwerker, Gärtner, Diener, Knechte, Lastträger, die zu dieser eigenartigen Sekte gehören. Es ist bemerkenswert, daß auch die mohanmedanische Religion Sekten gebildet hat, deren Lehren nicht nur die Theologen ergreifen, sondern einen starken Einfluß auf das Volk haben.

Ein etıvas älterer Mann, den sie ihren Scheik nannten, ordnete die Männer in Reihen mit befehlendem Blick und energischen Handbewegungen, den einen hierhin-, den anderen dorthinweisend. Tiefe Stille trat ein, als er jedem seinen Platz anwies und jeden fast eine Minute lang scharf fixierte. Der Scheik leitete die ganze Handlung, die stundenlang dauerte und hatte offenbar die Leute alle vollkommen in der Hand.

Zunächst hockten sich die Männer hin und begannen langsam und rhythmisch „Allah“, „Allah", „Allah" zu rufen. Laut und sonor klangen die Stimmen, immer lauter werdend. Dann begannen alle gleichmäßig den Oberkörper hin und her zu bewegen, wobei sie die Arme über der Brust gekreuzt hielten. Der Rhythmus des Rufs und der Bewegung wurde beständig von dem Scheik geleitet, der dabei die einzelnen oft sehr grob anherrschte.

Waren die Leute ermüdet, so pausierten sie für einige Minuten und fingen dann wieder mit ihren Ausrufen und Bewegungen an. Der Rhythmus der Bewegung wurde immer schneller und die Rufe immer lauter gegen Ende eines solchen Satzes. Die Leute strengten sich immer mehr an, es war ein ganz seltsamer Anblick, wie ihre Bewegungen immer mechanischer, ihre Blicke immer stierer wurden.

Nach Mitternacht waren Sang und Tanz zu einer hysterischen Ekstase gesteigert. Die Männer waren zum Teil aufgestanden und machten die Bewegungen nun mit dem ganzen Körper. Alle brüllten und schrien Allah, Allah, während einige einen seltsamen rhythmischen Gesang ausführten. Erlahmte einer, wurde 
seine Stimme heiser, seine Bewegungen langsamer, so brüllte ihn der Scheik an. Half das nichts, so stellte er ihn an einen anderen Platz, ihn langsam führend und dabei seine Blicke in seine Augen bohrend.

So wurde es von Sang zu Sang, von Tanz zu Tanz immer toller und wilder, die Bewegungen immer schneller, die Schreie immer greller, wobei der Scheik immer vormachte, immer aneiferte. Die Körper der Männer wurden naß vor Schweiß, in Strömen tropfte er auf den staubigen Boden. Die Bewegungen wurden immer verrenkter, die Stimmen heulten und ächzten. Schlieflich warfen sich einzelne auf den Boden; der Scheik richtete sie sofort wieder auf und wußte sie sofort in den Gesamtrhythmus der Bewegungen und der Töne einzureihen.

Schließlich standen manche ganz starr und regungslos da, sie waren offenbar in einem hypnotischen Zustand. Da ließ sich nun der Scheik lange spitze Nadeln reichen und stach sie den einzelnen durch die Backen, durch die Ohren; durch Oberarm und Wade, ohne dafo die Leute nur zuckten und einen Laut von sich gaben. Immer wieder fing das Geheul und Gewackel an, und immer mehr der Leute ließen sich zu den Nadelexperimenten herbei.

Welch seltsame Form der Gottesverehrung mußte ich da mit ansehen! Wie merkwürdig war die Hingabe der Männer an die Sache, wie folgten sie dem Blick und Wort ihres Scheiks. Seltsam, die ganze Situation stand wieder vor mir auf, als ich im Winter nach der Revolution in Breslau in einem großen Saal die Vorführungen eines Hypnotiseurs und Gedankenlesers sah, der dort das Publikum der Grobstadt ebenso in seiner Gewalt hatte, wie hier der Scheik seine armen Üsküber Vorstädter. Hier wie dort waren es meist blasse, verhungerte Gestalten, besondere Menschentypen, welche sich der Macht des Hypnotiseurs beugten. Allerdings in Mazedonien waren es nur Männer, die teilnehmen durften, in Deutschland waren es ebensoviele Frauen als Männer, die man so ganz den eigenen Willen verlieren sah.

Der Unterschied war groß genug zwischen den beiden Situationen. Wie seltsam berührten mich doch jene religiösen Ekstasen der einfachen Leute in dem halb dunkelen Raum, der schließlich von einer heißen, stinkenden Luft erfüllt war, gemischt aus dem Rauch der Lampen, dem Schweißgeruch und dem versagenden Atem der tollen Menge. 
Draußen winkte die Kühle der Nacht; an die vergitterten Fenster des Hauses drängten sich kleine Kinder und alte Weiber, die etwas von dem seltsamen Schauspiel erhaschen wollten. Halbnackte Zigeunerinnen blickten mit lüsternen Blicken herein.

Es ging schon gegen Morgen, als mein Begleiter und ich den Raum verließen, leise erschauernd im kühlen Wind. Wir atmeten auf, als die Stille der nächtlichen Gassen uns umfing und waren in Gedanken versunken, während wir über den Hügel in unser Quartier zurückkehrten. Nach all dem Getümmel und Lärm ruhten unsere Sinne aus und die Augen erholten sich, als sie im Schein des untergehenden Halbmondes noch über die Dächer der Stadt, die Kuppeln der Moscheen, die Minarets blickten, zwischen denen der Spiegel des Wardar aufblinkte, der leise in der Tiefe rauschte. Welch phantastischen Eindruck hatten wir mitgenommen von den Wurzeln, welche der Mohammedanismus im Boden dieses unglücklichen Landes gefaßt hat. 


\section{DIE BULGAREN IN MAZEDONIEN}

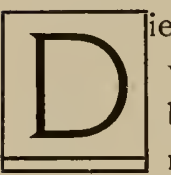

ie Bulgaren sind nun einmal durch Schicksal mit uns verbunden. Das gleiche Unglück wie uns hat sie betroffen. Sie fühlen sich als Schicksalsgenossen und nicht wenige unter ihnen sehen immer noch mit Bewunderung auf uns und hängen an uns. So haben wir die Pflicht, sie nicht $z u$ vergessen, uns mit ihnen $z u$ beschäftigen, sie nicht im Stich zu lassen. Es ist eines der wenigen Völker, das noch etwas von uns hält und zu uns hält. So sollten wir uns bemühen, sie nach Möglichkeit zu verstehen und ihrem Wesen näher zu kommen.

Vor dem Krieg glaubten wir fast alle fremden Völker zu verstehen und sie $\mathrm{zu}$ durchschauen. Wie oberflächlich war in Wirklichkeit die Kenntnis fremder Völker und das Verständnis für ihre Besonderheiten in weiten Kreisen unseres Volkes. Um so mehr bleibt uns jetzt nach dem Kriege in dieser Beziehung zu tun übrig. Wer Gelegenheit hatte, in Kreise und Individuen aus einem Volk, wie die Bulgaren, etwas tiefere Einblicke zu tun, der ist verpflichtet, seine Erfahrungen der Allgemeinheit zugänglich zu machen, um uns für die Zukunft vor so verderblichen Vorurteilen zu bewahren, wie sie während des Weltkrieges zu unserem Schaden viele Deutsche beherrschten.

Mit wie wenig Takt und Verständnis traten unsere Landsleute in den meisten Fällen unseren Bundesgenossen gegenüber. Wie oft war ich peinlich berührt von der unberechtigten Überhebung, mit der unsere Soldaten auf die armen, dummen Bulgaren herabsahen, von der Art, mit der unsere Offiziere von ihren bulgarischen Kameraden sprachen. Gewiß gab es manche Ausnahmen. Es gab Verständnis, es gab rechte Kameradschaft', und wo die Verhältnisse Mănner beider Völker für Monate oder gar Jahre zusammenketteten, kam es auch zu guter, treuer Freundschaft.

Eine große Schwierigkeit bot für die Verständigung die Sprache. Der Eifer zum Erlernen des Deutschen war bei den Bulgaren bedeutend größer als der Deutschen Streben zum Bul- 
garischen. Erschwerend war die fremde Schrift und der Zweifel, ob man mit dieser Sprache später werde viel anfangen können; dazu kam der Mangel an fesselnder Literatur. Auch Grammatiken und Wörterbücher fehlten anfangs und wurden erst allmählich in genügender Menge beschafft. Es war unter den Deutschen die Kenntnis des Bulgarischen vor dem Kriege eine sehr große Seltenheit. Diese Kluft wäre aber zu überbrücken gewesen, wobei der rührende Eifer vieler Bulgaren zum Deutschlernen sehr hätte helfen können. All das hätte im Interesse besserer Beziehungen zwischen beiden Völkern ganz anders ausgenutzt werden können als es geschah.

Sah man sich in einer Gesellschaft bulgarischer Offiziere oder Ärzte um, ging man aufmerksamen Auges an einer marschierenden Truppe vorbei oder bummelte man durch die Straßen einer bulgarischen Stadt, Sofia, Tirnowo oder Rustschuk, so fiel einem stets die Vielheit der Typen auf. Die Menschen sahen ganz außerordentlich verschieden aus. Man erkennt sie nicht ohne weiteres als Bulgaren, wie man etwa Italiener oder Engländer als solche erkennt. In einer größeren Menge herrschte stets ein dunkler Typus vor mit dunkelbraunem Haar, braunen Augen, dunkler Haut. Das war in Bulgarien selbst fast stets der Fall; so sah ich in Tirnowo kaum einen hellhaarigen Menschen. Auch in der Armee wog der brünette Typus vollkommen vor. Es waren fast stets mittelgroße Gestalten mit Kurzköpfen, die oft einem Mitteltypus sich näherten, und länglichen Gesichtern. Sehr viel schöne Erscheinungen sind mir unter den bulgarischen Männern nicht begegnet. Noch weniger allerdings unter den bulgarischen Frauen. Allerdings muß ich gestehen, daß ich in der Kriegszeit gegenüber den vielen Männern nur eine verschwindende $Z a h l$ von Frauen zu Gesicht bekam. In Mazedonien waren ja fast nur Männer aus Altbulgarien; von den mazedonischen Bulgarinnen ist an anderer Stelle die Rede.

Zwischen den brünetten Bulgaren fanden sich aber immer wieder Mischtypen, also blaue Augen kombiniert mit dunkelm Haar, blonde Haare mit braunen Augen. Es gab alle möglichen Kombinationen. Selten waren Langköpfe mit blonden Haaren und blauen Augen in Bulgarien selbst, etwas häufiger in der Armee. Auffallend häufig waren sie im westlichen Mazedonien, so z. B. in Prilep und am Ochridasee. In den Straßen von Prilep tummelten sich spielende Kinder, die man hätte mit deutschen Kindern ver- 
wechseln können, mit ihren noch dazu sonnengebleichten, flachsfarbenen Haaren und leuchtend blauen Augen. Auf die Dauer war eine solche Verwechslung allerdings nicht möglich; denn so verlumpte, verschmutzte, verwahrloste Kinder gab es in Deutschland nirgends.

Die gleiche Vermischung von Typen, welche auf alle möglichen Rassen linweisen, zeigen wie die Bulgaren fast alle Balkanvölker. Das ist die Folge der bewegten Vergangenheit des Balkans, in welchem Völkerwanderungen, Volksverschiebungen, Herrschafts-

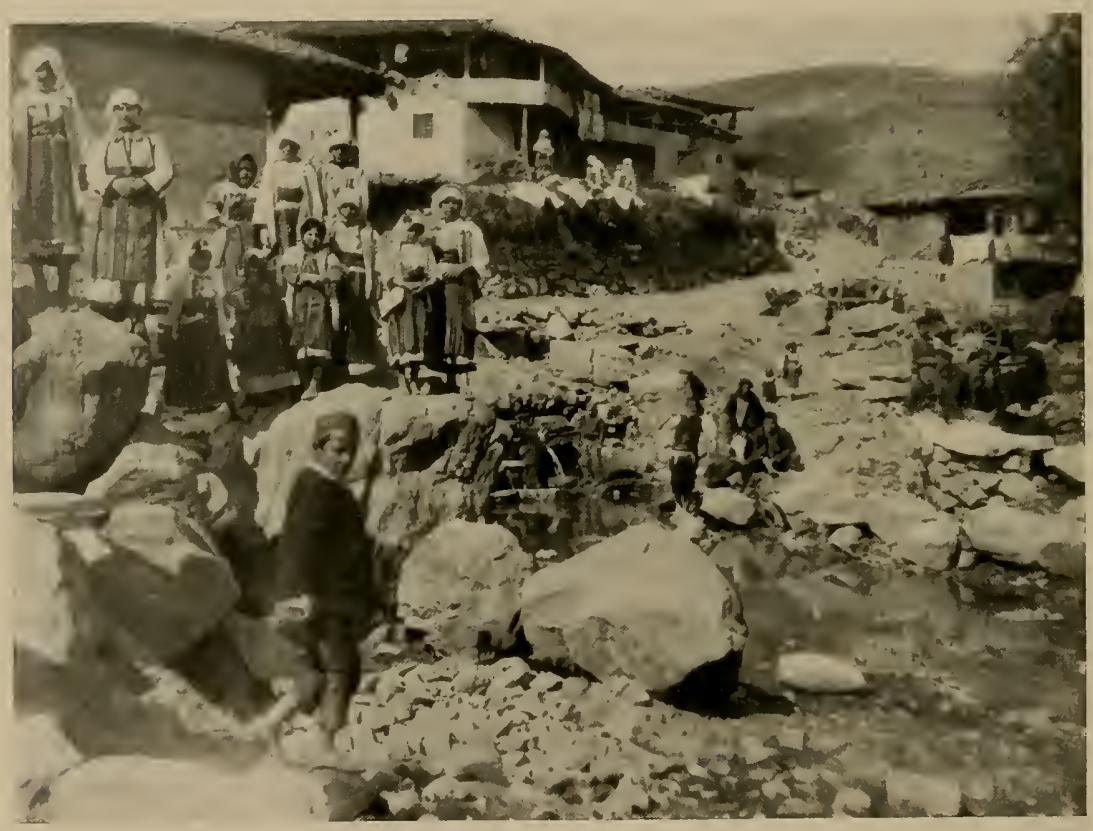

Abb. 139. Sonntag am Brunnen im Dorf Pubjance Juli 1918.

ausdehnungen sich seit zwei Jahrtausenden unablässig folgten. Soviel eingewandert und ausgewandert, verschoben und ausgerottet wurde wohl in keinem Teil Europas in historischer Zeit.

In die von Thrakern, Mazedoniern und Griechen bewohnten Teile des Balkan brachen nacheinander Germanen, vor allem Westund Ostgothen, dann Hunnen, Avaren, schließlich ural-altaische Völker und Slaven ein. Das begann schon, als das Gebiet durch die römische Herrschaft noch kaum oberflächlich latinisiert war. Immerhin waren auch durch die Kolonisation der Römer, vor allem 
durch Ansiedelung von Legionären manche fremde Elemente und mit ihnen lateinische Sprache eingeführt worden. Diese hatte nach der Abtrennung von Ostrom und der Begründung des byzantinischen Reiches immer mehr mit der sich ausbreitenden griechischen Sprache, die von der griechischen Kirche getragen wurde, zu kämpfen.

Es war schon ein rechtes Völkergemisch, welches die Bulgaren antrafen, als sie im siebenten Jahrhundert über die Donau auf dem Balkan einwanderten. Den Namen der Bulgaren brachte ein uralaltaisches Volk mit, welches in nicht allzugroßer Volkszahl über die Donau einbrach, wohl aus Südrußland kommend und südlich der Donau die dort ansässigen slavischen Stämme unterwerfend. Hier fanden sie schon in deren Gebiet keine einheitliche Bevölkerung vor. Aber es saß im Lande eine Bevölkerung mit nicht ganz geringer Kultur und slavischer Sprache. Die kriegerischen, organisatorisch immerhin mehr als jene begabten Bulgaren gaben in dem fruchtbaren Lande ihr Nomadenleben auf, wurden ansässig, vermischten sich mit der eingeborenen Bevölkerung und nahmen mit den Sitten auch ihre Sprache an, die durch die Jahrhunderte zur jetzigen bulgarischen Sprache wurde und dieser Entstehung ihre altslavischen Elemente verdankt. Sie wurde die Staats- und Kirchensprache eines entstehenden Staates, dessen Bevölkerung sich in der Hauptsache aus vorher romanisierten Thrakern, Slaven und den tatarischen Bulgaren zusammensetzte. Dazu kommen noch all die Elemente, welche aus Ureinwohnern und römischen Legionären herzuleiten waren.

Noch sieht man heute unter den Bulgaren nicht selten eine kleine, eckige, schlitzäugige Tatarengestalt und ganz selten glaubt man in einem auffallend edlen Profil einen Tropfen Römer- oder Asiatenblut ahnen zu dürfen. Die Hauptmenge der modernen Bulgaren zeigt slavischen Typus, wobei vielleicht der reinste in Westmazedonien, in der Gegend zwischen Prilep und dem Ochridasee, in den blonden Langköpfen uns entgegentritt.

In dem Reich der Bulgaren erstand bald ein gefährlicher Feind für Byzanz. Es zeigte sich in dem neuentstehenden Volke ein gewisser Sinn für Organisation und die kriegerische Tüchtigkeit war wohl von den Steppenvölkern auf die Mischrasse übergegangen. Nun kamen die Jahrhunderte bald erfolgreicher, bald mit mehr oder weniger vollkommenem Zusammenbruch endenden Kriege der Bulgaren mit Byzanz. Noch in diesen Zeiten floß neues Blut dem Volk der Bulgaren zu. Bei den vielen Grenzverschiebungen strömte byzantinische Bevölkerung verschiedener Herkunft immer wieder in das 
Gebiet der Bulgaren ein. Zum Teil wurden sie von Byzanz zwangsweise unter den Bulgaren und an deren Grenzen angesiedelt. Dieser Zuwachs war zum Teil asiatischer Herkunft.

Und dann kam die große Tragik bulgarischer Geschichte, die sich bis in die Gegenwart fortsetzt. Nie gelingt es diesem Volke, seine großen politischen und völkischen Ziele zu erreichen. Wie oft standen die Bulgaren vor Byzanz, nie gelang es ihnen, diese Stadt einzunehmen und damit den erstrebten Einheitsstaat auf dem Balkan zu begründen. Immer wieder brachen sie im letzten Moment zusammen, verloren den Mut und zogen sich freiwillig oder gezwungen zurück. Muß man nicht unwillkürlich an ihren letzten Versuch im ersten Balkankrieg denken, als sie $191 \mathrm{I}$ an der Tschataldschalinie verbluteten, der Cholera erlagen und alle Erfolge ihrer Siege wieder einbüßen mußten!

Im Mittelalter war es wie heute die Eifersucht zwischen slavischen Brudervölkern, welche die Begründung eines einheitlichen Slavenreiches auf dem Balkan immer wieder verhinderte und die Übermacht erst der Byzantiner, später der Türken sicherte. Sieben Jahrhunderte lang kämpften die Bulgaren vergeblich um die Vormacht auf dem Balkan, ehe sie in die fürchterlichste Knechtschaft versanken, welche die Türken ihnen bereiteten. Schon im achten Jahrhundert begann die Feindschaft der Bulgaren mit den Serben, die ja heute unversöhnlicher ist als jemals. Die vielen Kriege der beiden slavischen Völker miteinander mit immer sich folgenden Grenzverschiebungen, brachten immer wieder Bulgaren und Serben bald als Beherrschte, bald als Herrscher in Beziehungen zueinander. Das gab wieder Veranlassung zu mehr oder minder lokalen Abwanderungen und steigerte den Durcheinander der Siedelungen auf dem Balkan.

Bis in diese Zeiten gehen die Verschiebungen der Grenzen der Sprachgebiete $z$ wischen serbisch und bulgarisch auf dem Balkan, speziell in Mazedonien. Sie machen es so schwer zu sagen, ob im Norden an der Donaugrenze es ein serbisch gefärbter bulgarischer Dialekt ist, der in einem Dorf, etwa bei Pirot, gesprochen wird oder ein bulgarisch gefärbter serbischer. Ähnlich ist in Nordmazedonien die Grenze unklar und verwischt.

Neues Blut wurde schließlich durch die Türkenherrschaft in das bulgarische Volk gebracht. Die Vermischung mit Türken selbst braucht man nicht zu überschätzen, obwohl sie in manchen Gegenden nicht allzu gering gewesen sein wird. Als nach der 
Schlacht auf dem Amselfeld auch das serbische Reich vernichtet, der ganze Balkan osmanisch war, bekamen die Türken ein verwüstetes und entvölkertes Land in die Hand. Vor allem unendlich viele Bulgaren hatten das Leben verloren, ihre Dörfer und Städte waren zerstört. Und die Aufstände gegen die Türkenherrschaft kosteten immer mehr Leben, brachten immer weitere Zerstörungen. Viele Bulgaren wanderten aus, andere - besonders Aufrührer wurden gewaltsam nach Kleinasien oder sonstwohin umgesiedelt.

Eisern lag die Hand der Türken auf dem Land. Große Mengen von Türken wurden in den verödeten Ländern angesiedelt, besonders in Thrakien. Viele Bulgaren traten zum Mohammedanismus über, um bessere Zustände $\mathrm{zu}$ erreichen. Wenn sie auch ihre Sprache behielten, mit türkischen Sitten und türkischer Kleidung steigerte sich natürlich bei diesen ,Pomaken“, wie sie jetzt noch in Mazedonien, Thrakien und Bulgarien heißen, die Möglichkeit der Vermischung mit Türken und all den von diesen auf dem Balkan angesiedelten Asiaten.

Viele Bulgaren zogen sich in die unwegsamen Gebirge ihres Landes zurück; in diesen ärmlichen Gebieten wuchs zwar ein rauhes, kräftiges Volk heran, aber es mußte notwendig verbauern; es verlor ein gut Teil seiner eigenen Kultur, welche mühsam im Zusammenhang mit der Kirche, von einzelnen Klöstern gepflegt, sich in Spuren erhielt.

Schwer lastete das Joch der Türken nun fast 500 Jahre, von 1400 bis fast 1900 , auf den Bulgaren. Man muß verstehen, was das für ein Volk bedeutet, das große Reiche gegründet, welches mit Byzanz um die Vorherrschaft gerungen, eine eigene nicht unerhebliche Kultur entwickelt hatte. Will man die heutigen Bulgaren richtig beurteilen, so mul3 man wissen, was dies Volk in diesen Jahrhunderten gelitten hat, wie ihm das Rückgrat systematisch gebrochen wurde.

Was bedeutet es andererseits, wenn ein Volk von dem durch Gewalt erzwungenen Tiefstand in wenig Jahrzehnten auf die Stufe sich aufschwang, auf der wir es während des Kriegs antrafen, als wir es zum ersten Male richtig kennen lernten. Durch das, was ich in Mazedonien sah und erfuhr, habe ich einiges von den seelischen Leiden verstehen gelernt, die während Jahrhunderten auf diesem unglücklichen Volk lasteten und ihm an Mark und Nerven zehrten. 
Während es unter den gebildeten Bulgaren viele feine, sehr kultivierte Menschen gibt, ist der Eindruck, den die Mehrzahl der Bulgaren in Mazedonien auf Deutsche und Österreicher machte, der eines herben, groben Volks. Und zivar machten nicht nur die Mannschaften, sondern auch vielfach die Offiziere diesen Eindruck. Auch in den Kreisen der Ärzte, mit denen ich viel verkehrte, fand man große Gegensätze. Während die einen sehr gute Manieren zeigten und sich in keiner Weise von kultivierten Mitteleuropäern unterschieden, hatten manche Männer bei guter wissenschaftlicher Ausbildung auperordentlich schlechte, nachlässige Gewohnheiten. Man war vielleicht geneigt, etwas zu sehr auf diese Äußerlichkeiten $\mathrm{zu}$ achten, weil man auch bei unseren Offizieren und Ärzten gegen die hier seltenen Fälle schlechten Benehmens in fremden Lande sehr empfindlich war. Aber bei den Bulgaren war die gröbere Art doch sehr auffällig und die Erfahrungen vieler Deutschen in dieser Beziehung sicher nicht zufällig.

Nun spielte dabei sicher der lange Krieg eine nicht geringe Rolle; auch bei uns rekrutierte sich das Heer und speziell das Offizierkorps im Krieg mit einer weniger sorgfältigen Auslese, als es im Frieden möglich gewesen war. Viele junge Männer entbehrten der Erziehung, die ihnen früher zuteil geworden wäre. Bei den Bulgaren war es von Einfluß, daß nach den schweren Verlusten der beiden Balkankriege ein großer Teil des Offiziersersatzes notgedrungen aus dem Unteroffiziersstand genommen werden mußte. Daß dabei nur die militärische Brauchbarkeit und nicht die Bildung die Auswahl bedingte, war leicht $\mathrm{zu}$ verstehen.

Vor allem ist aber die grobe Art der Bulgaren dadurch zu erklären, daß sie in der Hauptsache ein Bauernvolk sind. Auch bei uns sind Männer aus Gebieten mit Bauernbevölkerung in ihren Gewohnheiten sehr wohl von den Städtern zu unterscheiden und bei aller Liebe, welche die Oberbayern in ganz Deutschland genießen, spricht man doch von den groben Bayern.

In Bulgarien betrug 1910 die ländliche Bevölkerung mehr als $80 \%$ des Gesamtvolks, während in Städten nicht ganz $20 \%$ lebten. Das erklärt sich zum Teil aus der geschichtlichen Entwicklung, welche vor allem in der Türkeinzeit das Wachstum der Städte hinderte und die bulgarische Bevölkerung aufs Land und in die Berge trieb. Bis kurz vor dem Krieg war in Bulgarien eine starke Volksbewegung im Gang. Nach dem Sturz der Türken- 
herrschaft strömte die Bevölkerung des Gebirges in die verödeten Städte und Dörfer der Täler und Ebenen.

Eine eigene, städtische, höhere Kultur, in der türkischen Zeit kaum möglich, konnte sich erst in den letzten Jahrzehnten entwickein; Tradition gibt es noch kaum und Nachahmung des Ausländischen herrscht noch durchaus vor. Dazu kam vor allem der starke russische Einfluß. Die Befreiung vom Türkenjoch durch die Russen führte viele Bulgaren in das russische Heer, auf russische Schulen, an russische Universitäten. Gerade in RuBland erzogene Offiziere betonten vielfach eine Abneigung gegen westliche Manieren und trugen rauhe Sitten ostentativ zur Schau.

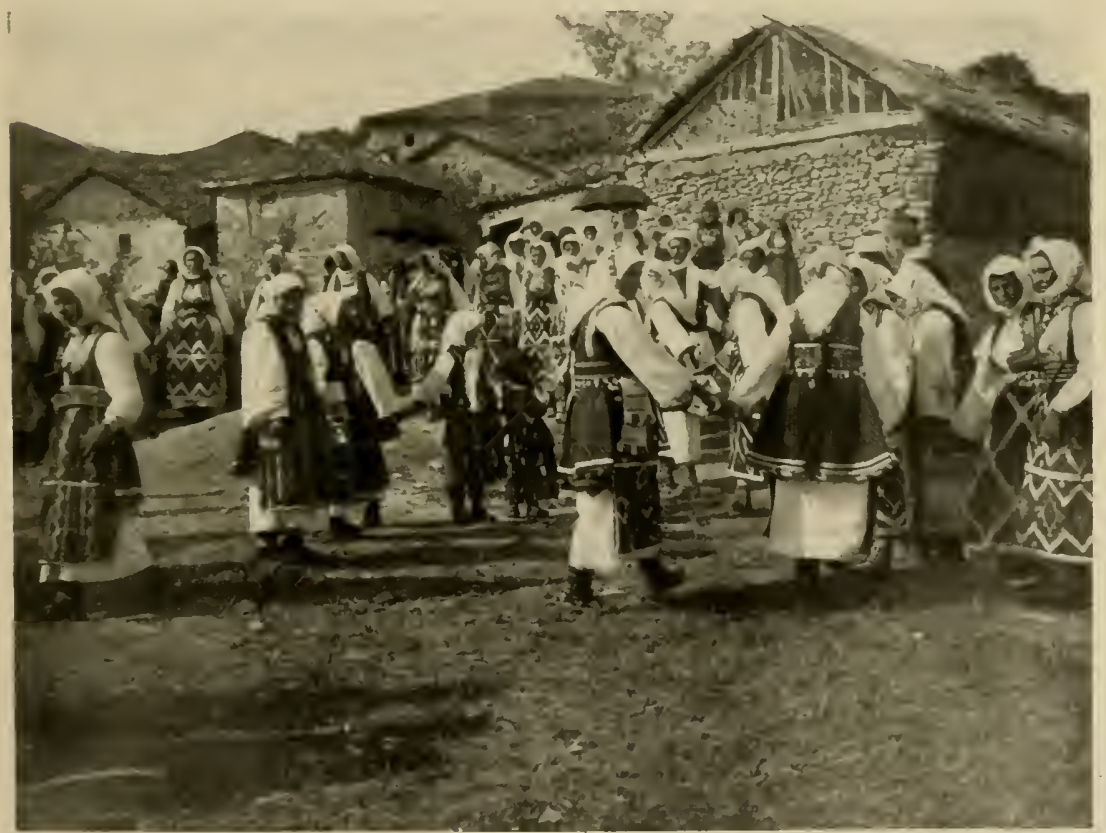

Abb. I 40. Tanz im Dorf Kopaněi, südlich vom Wodno. Juni 1918.

Mit der gröberen Art des Bauernvolks sind aber bei der Masse der Bulgaren auch viele der Vorzüge der ländlichen Bevölkerung verbunden. Ganz außerordentlich war die körperliche Leistungsfähigkeit und Anspruchslosigkeit der bulgarischen Soldaten. An der mazedonischen Front führten sie vielfach ein wahres Hungerdasein; und mit welchen Unterkünften sie sich zufrieden gaben, war unseren deutschen Soldaten unverständlich. Der Mangel 
an Sauberkeit und die Vernachlässigung der Kleidung war offenbar eine Folge des langen Kriegs. Auch bei unseren Soldaten trat in Mazedonien mit der Zeit eine starke Nachlässigkeit auf. Allerdings so verlumpt, zerrissen und verschmutzt wie manche bulgarischen Regimenter war nie eine deutsche Truppe.

Die Bauernbevölkerung bulgarischen Stammes in Mazedonien und was ich von ihr im Zartum Bulgarien sah, war im allgemeinen sehr sauber und in der Kleidung sehr sorgfältig und adrett. An Ehrlichkeit und anständiger Gesinnung geben die bulgarischen Bauern den unserigen nichts nach. Wie bei uns ist ja in dieser Beziehung während des Kriegs auch dort vieles zugrunde gegangen. Was aber die Moral in den Beziehungen der Geschlechter anlangt, so glichen die Sitten der bulgarischen Bauern denen unserer besten, saubersten Landbevölkerung.

So gewann ich denn den Eindruck eines ausgezeichneten, physisch und moralisch gesunden Kerns der bulgarischen Bevölkerung.

Geradezu rührend ist die Lernbegier der Bulgaren. Wo sie konnten, suchten Soldaten und Offiziere von uns Deutschen zu lernen. Nicht nur die Sprache, sondern in jedem Gebiet; Handwerker wie Ärzte, Beamte und Offiziere wie Studenten sahen zu unserer höheren Kultur auf, und suchten vom Zusammenleben mit den Deutschen zu profitieren, so viel sie nur konnten. Ein Fall, den ich beobachten konnte, ist geradezu typisch; ich könnte ihm viele ähnliche anschließen. In einer Gebirgsstellung lagen deutsche Spezialtruppen oben am Berg, während die unteren Stellungen von Bulgaren besetzt waren. Ein Unteroffizier hatte fast täglich die bulgarischen Stellungen zu passieren, um unten Befehle zu holen. Eine Gruppe junger bulgarischer Offiziere hielt ihn jedesmal mindestens eine Stunde auf, bewirtete ihn freundlich, um eine Konversationsstunde mit ihm abzuhalten und ihre Fehler im Deutschen sich von ihm korrigieren zu lassen.

In Bulgarien waren ja sehr gute Volksschulen überall in starker Vermehrung, überall wurde die Gründung von Mittelschulen angestrebt und während des Kriegs wurde eifrig am Ausbau der Universität in Sofia gearbeitet, welche bis dahin erst drei Fakultäten besaß, und der eine medizinische Fakultät noch fehlte. Ich sah mir gern und oft bulgarische Schulen an und hatte einen ganz guten Eindruck von Zucht, Disziplin und Lerneifer der Schüler und Schülerinnen. Auch im besetzten Mazedonien waren sofort 
bulgarische Schulen eröffnet worden. Es war dies ja seit Jahrzehnten schon das wichtigste nationale Propagandamittel der konkurrierenden Völker auf dem Balkan geworden.

Bei allen vorzüglichen Eigenschaften, welche ich bei dem bulgarischen Volk zu beobachten glaubte, zwei wichtige Fähigkeiten vermißte ich, wo ich sie bei der Arbeit beobachten konnte. Das war einmal das Talent zur Organisation und vor allem die Fähigkeit zum Durchhalten. Sicher ist die Klarheit aller Einsichten durch die besonderen Verhältnisse während der Kriegszeit getrübt gewesen. Aber gerade in dieser Zeit, in welcher Anspannung höchster Leistungsfähigkeit nationale Forderung war, hätten diese Fähigkeiten sich im rechten Lichte zeigen sollen.

Es war mir sehr auffallend, wie schwer selbst die Begabtesten der bulgarischen Ärzte, in deren Tätigkeit ich einen tieferen Einblick gewann, ihre Autorität in einem größeren Betrieb still und unauffällig durchsetzen konnten. Wie oft konnte ich sehen, daß ein Vorgesetzter sich selbst mit viel unnötiger Arbeit belastete und absolut nicht fertig brachte, seine bulgarischen Untergebenen zu planmäßiger Arbeit zu bringen, während alles aufs beste klappte, wenn ein deutscher Gehilfe ihnen zur Seite stand, oder etwa ein französischer Kriegsgefangener zur Verfügung stand, der an geordnete Arbeit gewöhnt war.

Daß Gebäude, Straßen, Eisenbahnen so ganz vernachlässigt wurden, daß alles verkam, ist ja wohl mit eine Erscheinung gewesen, welche durch die Jahrzehnte der Unruhe auf dem Balkan verursacht war. Es mag auch sein, daß die Jahrhunderte der Türkenherrschaft den Bulgaren abgewöhnt hatten, eigenen Besitz, der doch stets unsicher war, sorgfältig zu pflegen. Das gilt vor allem für Mazedonien. Da habe ich kaum ein bulgarisches Haus gesehen, wo nicht etwas baufällig war, Scheiben fehlten, der Mörtel an vielen Stellen abgefallen war, die Stühle und Tische zerbrochene Beine hatten. Die Vorhänge waren oft zerrissen, die Fenster hielten nicht dicht, Schubladen wackelten hin und her oder waren nicht zu bewegen, Schränke, Haus- und Zimmertüren schlossen nicht und die meisten Schlüssel fehlten. Sicher war das alles im Zartum Bulgarien, welches doch seit 1878 geordnetere Zustände gehabt hatte, viel besser. Aber auch dort sah man überall Spuren von Vernachlässigung und wenn auch nicht so viel wie in Mazedonien, allerorts Ruinen. 
Die Eisenbahnen sahen ja auch bei uns am Ende des Krieges nicht zum besten aus. Aber in Bulgarien und wo Bulgaren auf der Eisenbahn fuhren, da waren die Abteile bös zugerichtet. Fenster gab es überhaupt nicht mehr. Der bulgarische Soldat ist in seinen Bewegungen sehr plump; beim Ein- und Aussteigen wurden mit Gewehren und Tornistern, mit Lasten und Kisten regelmäßig Scheiben zertrümmert. Und alles, was nicht niet- und nagelfest war, verschwand allmählich in den Abteilen. Griffe und Haken, Zugbänder und Netze, Vorhänge und Lampen waren verschwunden und alle Wagen in der übelsten Weise verschmutzt. Vor allem die Aborte waren in einem schweinigen Zustand.

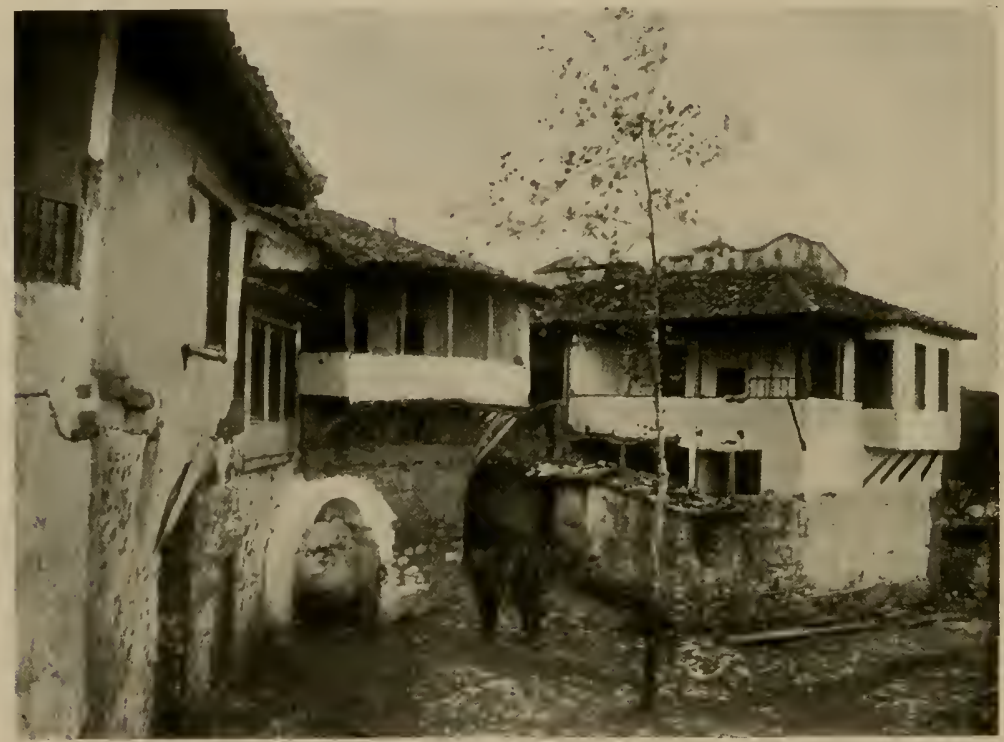

Abb. I4I. Mazedonische Stadthäuser.

Das ist der Bulgare nicht etwa so gewöhnt. In den bulgarischen Häusern besteht der Abort in der Regel aus einem dunklen gepflasterten Raum mit einem runden Loch im Boden. Diese primitiven Orte, wie sie ja in ganz Südeuropa üblich sind, werden im bulgarischen Bürgerhaus meist sehr sauber gehalten. Aber der bulgarische Bauer ist sehr gleichgültig gegen seine Umgebung; er liegt am Boden zwischen allem möglichen Unrat und so stört ihn ein verschmutztes, voll Papier, Asche und Nahrungsabfällen liegendes Eisenbahnabteil in seinem Behagen nicht sehr 
Den größten Kontrast, den man sich vorstellen kann, stellt eine bulgarische Volksmenge auf einem Bahnhof mit einer japanischen dar. In Japan war ich auch zur Kriegszeit 1904 und 1905. Da gab es auch manch eiliges Verladen von Soldaten und Verkehrsnot fürs Publikum. Wie ist aber der Japaner durch jahrhundertlange Erziehung diszipliniert; fast instinktiv ordnet er sich hinter der Sperre in Reih und Glied, geht langsam und gleichmäßig hindurch und sammelt sich in kleinen Gruppen vor den Wagen, in welche ohne Hast, Gedränge und schweigend eingestiegen wird.

Dagegen die brüllende Masse von Bulgaren, die sich boxend und tretend durch die Sperre auf den einfahrenden Zug stürzen, an ihm emporklettern, mit den Gewehren in der Luft fuchteln, einander umstoßen, in Massen in ein Abteil eindringen, wobei Scherben, Eßgeschirre, Flaschen herumfliegen! Leider ist es heutzutage in dem früher so geordneten Deutschland auch nicht viel anders.

Selten sah ich in einem solchen Getümmel einen bulgarischen Offizier den Versuch machen, Ordnung zu schaffen. Oft hat man bei den Bulgaren den Eindruck, als seien sie stark von dem türkischen Fatalismus beeinflußt.

Und ähnlich wirkte oft auf mich ihre Entschlußunfähigkeit, etwas mit letztem, starken Willensaufwand zum guten Ende durchzuführen. Lag es daran, daß sie niemals Byzanz eroberten? Sind sie so sehr vom Schicksal gedrückt worden, daß sie immer im letzten Moment verzweifeln, daß das Glück ihnen auch einmal zuteil werden könnte? Im Leben des einzelnen sah ich oft die Unfähigkeit, widerwärtige Verhältnisse in seiner Umgebung durch Willensaufschwung zu überwinden, daran schuld werden, daßo großes Talent, edle Fähigkeiten sich nicht durchrangen. Auch sonst scheinen mir die Südslaven manche nationale Fehler mit uns Deutschen $z u$ teilen. Ihre Zersplitterung in einzelne Stämme mit zäh festgehaltenen Stammeseigentümlichkeiten haben sie auch in den 1500 Jahren ihrer Geschichte verhindert, sich jemals zu einer großen Einheit zu vereinigen. Sind nicht sie und wir Völkergruppen, die wohl geeignet wären einander ein abschreckendes Beispiel zu geben und voneinander zu lernen? Sind wir nicht Schicksalsverwandte, die Sympathie für einander haben sollten und den Versuch unternehmen müßten, sich gegenseitig zu verstehen und zu helfen? 
War man in einem großen Kreis bulgarischer Offiziere und Ärzte, so konnte es einem wie in einem entsprechenden Kreis von Deutschen ergehen. Man hatte das Gefühl, als könne man aus der Vielgestaltigkeit der Gesichter und Typen Schicksal und Geschichte der Natur ablesen.

Viele der älteren Offiziere sahen, ihrer Ausbildung und Tradition entsprechend, genau aus wie Russen, dieser glich einem Türken, jener war ein ausgesprochener Südslave; bei einem sah der Semit, auch wohl einmal der Armenier oder ein Tropfen Zigeunerblut hindurch, am sympathischsten waren mir diejenigen, welche bulgarischen Bauern glichen. Wie oft mußte ich beim Anblick einer solchen Gesellschaft denken, wie gleicht dies Volk uns in Schicksalen und unerfüllten Idealen. Es wäre doch der Mühe wert, sich in das Wesen und die Art dieser Nation zu versenken, von ihren Schicksalen zu lernen und ihr Streben nachzuahmen.

Statt dessen sah man vor allem bei unseren jüngeren Offizieren manch spöttisches Lächeln und hörte viele unfreundliche Bemerkungen über schlechte Manieren und über das Knoblauchessen. Das war weder Überhebung noch schlechte Meinung, sondern es war eine leichtfertige Verkennung der Rolle, welche jeder Deutsche dort zu spielen hatte. Es fehlte die zart sich äußernde Überlegenheit des wahren Kulturträgers, welcher so viel ausrichten kann und gerade dort ausgerichtet hätte. Unsere hochgebildeten bulgarischen Freunde hatten eine ganz andere Geschicklichkeit im Umgang, z. B. mit den Albanern. Ich werde im nächsten Kapitel davon erzählen.

Uns fehlte in diesen Dingen die Erfahrung und diejenigen, welche die Erfahrung und den Takt hatten, unsere Jugend und manchen Alten über den Umgang mit fremden Völkern zu unterrichten, waren nicht am rechten Ort dazu verwendet. Wieviel ist in dieser Beziehung bei uns versäumt und verfehlt worden. Unsere Truppen, die so lange mit den Bulgaren zusammen zu arbeiten genötigt waren, hätten über das Wesen, die Besonderheiten, die Fehler und Vorzüge unserer Bundesgenossen unterrichtet werden müssen. Sie hätten von der Tragik im Schicksal der Bulgaren etwas erfahren müssen; dann wäre jenes überlegene milde Urteil und das feine Verhalten erzielt worden, welches durch das Verständnis bedingt wird. 
Daß dies Ziel in Zukunft hoffentlich mit besserem Erfolg erstrebt werden kann, dazu kann jeder beitragen, welcher einen etwas tieferen Blick in das Wesen eines Volkes getan hat, wozu manchmal Zufall und ein gewisses Ahnungsvermögen hilfreich sind. Wie manches im Wesen der Bulgaren sich durch ihre Geschichte erklären läßt, davon mögen die folgenden Schilderungen eine Vorstellung geben; sie stellen für mich ein Erlebnis dar, welches mir einen sehr tiefen Eindruck hinterließ. 


\section{ACHTZEHNTES KAPITEL}

\section{DER TSCHIFFLIK VON BARDOWCE}

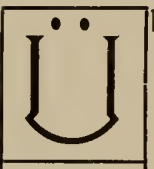

berall in der Türkei trifft man herrschaftliche Landbesitzungen, welche weite Strecken fruchtbaren Landes mit einer ganzen Anzahl von Dörfern umfassen. Meist befindet sich im Mittelpunkt des Gebietes, von Mauern eingeschlossen, das Herrenhaus, welches oft die Größe und das stattliche Aussehen eines Schlosses haben kann. In der Regel liegt nahe dabei eines der zum Gebiet gehörenden „Eingeborenendörfer"s.

Solcher Güter gibt es zahlreiche in Mazedonien und auf meinen Spazierfahrten und Ausflügen, die ich in der Umgebung von Üsküb machte, kam ich nicht selten mit meinen bulgarischen Freunden in solche Besitzungen und durch die zugehörigen Dörfer. Die Herrenhäuser warén vielfach zerstört, oft auch $z u$ bulgarischen

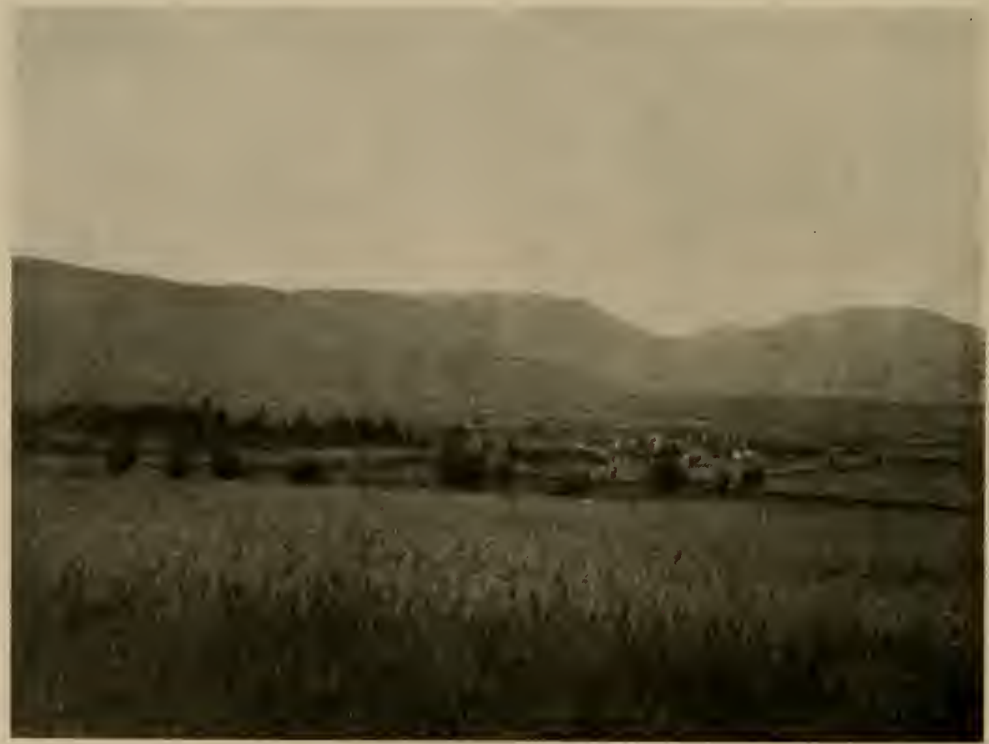

Abb. 142. Der Tschifflik von Bardowce. Daneben im Hain das Dorf Bardowce. 
Heeres- und Verwaltungszwecken in Gebrauch und dann von Militär bewacht. Die Dörfer selbst waren meist in besserem Zustande und im vollen Betrieb fleißiger Landwirtschaft.

Das Land um Üsküb ist sehr fruchtbar und bei richtiger Bewirtschaftung läßt sich aus ihm viel herausholen. Der Wardar liefert das Wasser, welches in Mazedonien das Lebenselement aller Landwirtschaft ist. So kann man in der Umgebung von Üsküb weite Strecken angebauten Landes durchwandern. Im Frühling ist das breite Wardartal eine einzige grüne Fläche. Allerdings die einzelnen Stücke sind selten von bedeutender Größe. Oft ist aber ein Gebiet ziemlich einheitlich mit Gerste, Weizen oder Roggen bepflanzt, Hafer spielte bei Üsküb eine geringere Rolle.

Später im Jahre begann die Arbeit auf den Mais- und Mohnfeldern, welche sehr sorgsame Pflege verlangen und nur dann Ertrag bringen, wenn viel Fleiß auf sie verwandt wird. Und das geschieht in der Regel; die Bauern, Männer und Frauen, machten mir in der Üsküber Gegend einen außerordentlich fleißigen Eindruck. Bei Tagesanbruch ziehen sie, mit Proviant versehen, auf ihre Felder hinaus, um erst abends nach Sonnenuntergang heimzukehren. Oft, wenn ich nach dem Abendessen mit den bulgarischen Ärzten noch einen längeren Spaziergang unternahm, von dem wir erst zwischen Io und 1 I Uhr heimkehrten, trafen wir noch arbeitende Bauern und Bäuerinnen drauken auf den Feldern. Die Mittagsruhe, welche die Leute draußen hielten, schien mir nicht sehr lange zu dauern. Abends hatten sie fast immer noch eine gute Strecke bis nach Hause zurückzulegen.

Oft sah ich den Bauer allein auf dem Acker mit seinem primitiven Pflug schaffen. Meist war dieser mit zwei Zugtieren bespannt. Selten waren dies Pferde, in der Regel Ochsen oder noch häufiger Büffel. Die prachtvollen, mächtigen schwarzen Gestalten dieser Tiere hoben sich oft malerisch vom Abendhimınel ab, wenn die schneebedeckten Hänge des Ljubotren in die glühende Luft hineinragten. Das waren unvergeßliche Bilder von groler Schönheit.

Der Pflug wurde wie bei uns an zwei gebogenen Handhaben geführt, welche der Bauer mit beiden Händen faßte. In der rechten Hand hielt er eine lange, dünne Stange mit scharfer Spitze. Mit dieser, dem landesüblichen Ersatz der Peitsche, wurden die Büffel am Nacken und an den Flanken gestochen und gestoßen, wenn sie nicht recht vorwärts wollten. Die Pflugschar war nur ein kurzer, schmaler Eisenhaken, der kaum 25-30 $\mathrm{cm}$ in den Boden 
eindrang. Trotzdem hatten die Büffel eine tüchtige Arbeit in dem harten, steinigen Boden zu leisten und mußten fest angetrieben werden.

Sie gingen zu beiden Seiten der einfachen Deichsel, welche schief zwischen ihren Köpfen vorragte. Diese stellte die einzige Verbindung mit dem Pflug dar, Stricke und Zügel gab es nicht. An Stelle eines Jochs lag ein vierkantiger langer, schwerer Balken quer über dem Nacken beider Büffel und stand seitlich noch ein Stück heraus. Mit diesem Balken war die Deichsel durch Metall-, meist Kupferspangen, fest verbunden. Räder hatte der mazedonische Pflug nicht.

Die Verbindung der Büffel mit diesem Joch wurde dadurch gesichert, daß unter dem Hals jeden Tieres ein dünnerer, kürzerer Balken dem Querjoch parallel lag; das schwere Joch war mit ihnen durch sechs senkrechte Stöcke fest verbunden. Zwei davon steckten zu beiden Seiten der Deichsel, je zwei bildeten um den Hals der Büffel einen Rahmen, aus dem er nicht herauskonnte und welcher ihre Kraft auf den Pflug übertrug. Schwer und hart lag dies Gestell auf dem Nacken der Tiere, welche meist an den Stellen, an denen das Holz auf ihrer Haut rieb, wund oder mit Schwielen bedeckt waren.

Derselbe wenig schonende, einigermaßen tierquälerische Rahmen diente auch zur Bespannung der üblichen $z$ weiräderigen Bauernwagen. Dieser Karren ruhte auf einer Achse, an der zivei hohe schwere Räder saßen. Es war kein sanftes Fahren in solchen Wagen auf holperigem Feldweg oder querfeldein. Sie wurden zum Transport von allen möglichen Feldprodukten verwandt und um viel $\mathrm{Heu}$, Stroh, Getreide zu fassen, waren sie auf beiden Seiten mit einem hohen Geländer aus spitzen Stangen und Brettern eingefaßt. Das gab diesen Karren ein höchst charakteristisches Aussehen. Selten wurden diese mit Büffeln bespannt; man sah vor ihnen fast immer kurzhörnige kleine Ochsen von gedrungenem Bau (Abb. 143).

So lange die Felder brach lagen, sah man oft Herden von Rindern und vor allem von Schafen unter Aufsicht in der Regel jugendlicher Hirten auf ihnen weiden.

Die Ernte war sehr vom Klima des Jahres abhängig. Dürre war für sie die größte Gefahr. Nur wer bewässern konnte, war von ihr weniger bedroht Getreide wurde meist noch mit der Sichel geschnitten, kaum je auf dem Feld aufgeschichtet, sondern in kleinen Bündeln nach Hause gefahren. Dort wurde es in 
quadratischen Gebäuden, primitiven Scheunen aufbewahrt, welche Wände aus Flechtwerk, manchmal auch Lehmwände besaßen. Auch in großen Haufen im Freien aufgeschichtet, sah man es manchmal.

Heu konnte in dem heißen Niederland keines gewonnen werden. Aber wo Gebirge in der Nähe waren, holte man es sich von den Matten herunter. Die verschiedenen Ackerprodukte verlangten ganz verschiedene Behandlung, stets aber viel Arbeit. Das galt besonders vom Mohn, der auch bei Üsküb viel gepflanzt wurde.

Es wurde viel und hart auf den Feldern gearbeitet. Die Arbeiter waren meist bulgarische Slaven, was man an ihrer Tracht

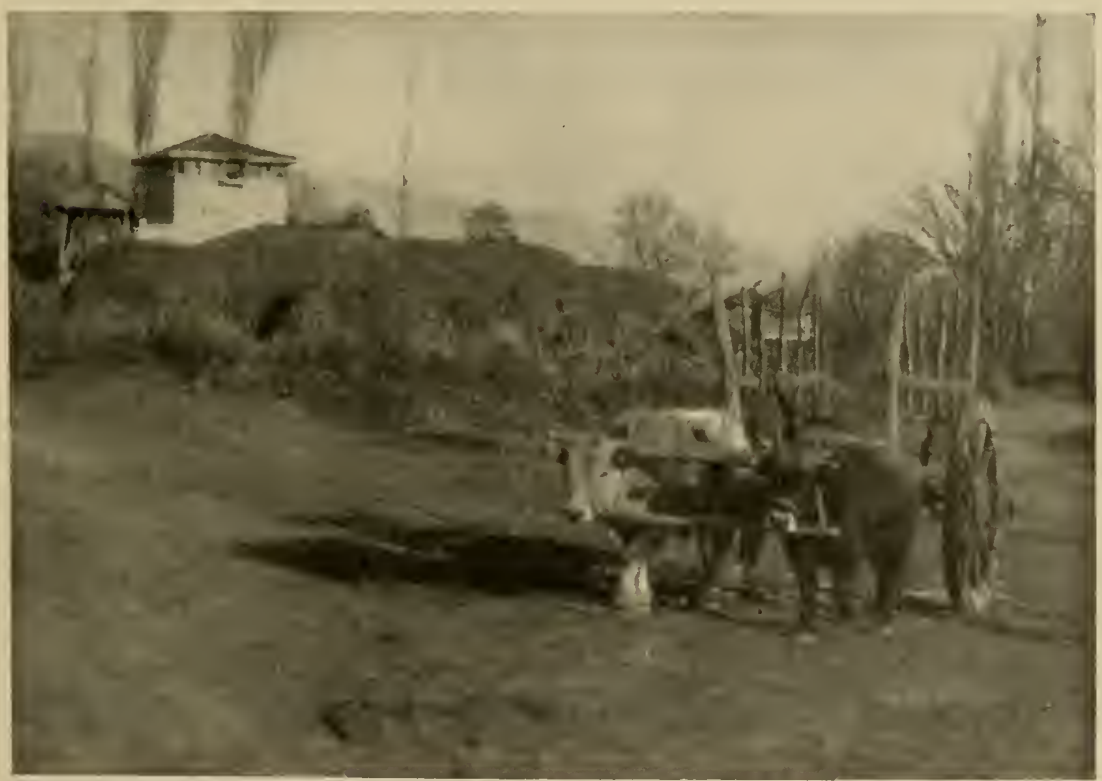

Abb. 143. Ochsenwagen vor dem Dorf Orman.

erkannte und aus den Antworten entnehmen konnte, welche sie auf Ansprache meiner bulgarischen Begleiter gaben. Hier und da sah man auch Türken auf den Feldern und besonders als Hirten Albaner.

Nicht selten besuchte ich die Dörfer, um Einblick in das Leben der mazedonischen Bulgaren zu gewinnen. Kam man im Frühling während des Tages ins Dorf, so traf man nur alte Frauen und kleine Kinder in den Höfen und Gärten an. Alle anderen waren draußen in den Feldern bei der Arbeit. Ein Dorf 
sah im Frühling von außen sehr freundlich aus. Meist steckte es tief im Grünen. Hoch ragte eine Gruppe von Pappeln über das Ganze und alle Häuser waren von Obstbäumen eingehüllt. Wenn diese blühten, trug das Dorf sein schönstes Kleid. Kirschen-, Pflaumen- und Apfelbäume spielten die Hauptrolle, dazwischen standen Birnbäume; Aprikosen und Pfirsiche fehlten nicht. Sie hüllten das Dorf in ein Blütenmeer, das es duftig umspann. Am Ende der Blütezeit konnte der Wind Wolken von Blütenblättern über die Dächer·wirbeln, die wie Schnee den Boden der Höfe und die Gassen des Dörfchens bedeckten. Hecken umschlossen die einzelnen Häusergruppen. Zwischen ihnen gackerten die Hühner. Am Bach oder Teich des Dorfes trieben sich Gänse und Enten herum, wälzten sich wohl auch Schweine im Schlamm. Es waren die kurzen, hochrückigen, meist schwarzen, mit dichtem Borstenpelz bedeckten Balkanschweine. Die Schafe, Rinder und Pferde waren mit den Menschen draußen. An den Hecken sah man hier und da eine der niemals fehlenden Ziegen knabbern. Feigen- und Granatapfelbäume, die im Süden so häufig gewesen waren, fehlten hier bei Üsküb meistens. Aber auch hier waren die Gärten, welche außen um das Dorf lagen, mit Kohl, Tomaten, Paprika, Melonen bepflanzt. $Z_{w i e b e l n}$ und Lauch spielten eine grofe Rolle. Hier und da sah man auch hier die schwarzblauen Auberginen.

Im Sommer hingen an den Häusern die grellroten Paprikaschoten, später auch Maiskolben an der Sonne zum Trocknen. Auch Tabaksblätter sah man an den Hauswänden in der Sonne dörren. Tabak spielte im Anbau eine während des Kriegs stets zunehmende Rolle. Mit der Teuerung stieg sein Wert und schließlich pflanzte jeder Bauer, jeder Soldat sich seinen Tabak selbst. Auch große Felder wurden mit ihm angelegt und damit erwuchs dem Bauern neue Arbeit, aber auch eine neue Einnahmequelle.

Ein Haus, dessen Lehmwand von den goldbraunen Tabaksblättern behängt war, an dessen Fenstern die leuchtend roten Paprikaschoten hingen, mit den dunklen Schlagschatten darüber, welche das schwere Strohdach auf die Mauern warf, bot in der Glut der mazedonischen Sonne ein malerisches Bild von exotischem Zauber.

Kam man abends zum Dorf, so hörte man in allen Gehöften Geräusche der Menschen und heimgekehrten Tiere. Die Stiere brüllten, die Pferde stampften, Kinder und Mädchen sangen, die Wagen knarrten mit ihren ungeschmierten Rädern. Auf den 
ziegelgedeckten Haupthäusern jedes Gehöftes rauchten die Schornsteine, hier und da blinkte ein Feuerschein aus einem Haus über den WVeg. Hunde kläfften und fuhren dem Fremdling an die Beine. Als die Dämmerung niedersank, konnte man ein absonderliches Schauspiel beobachten. Das Geflügel suchte sich seine Nachtquartiere auf. Die Gänse und Enten drückten sich in die Gebüsche und Winkel zwischen den Häusern hinein, begaben sich auch unter die eigenartigen Pfahlbauten, die in den Höfen standen. Am eigenartigsten war aber das Benehmen der $\mathrm{H}$ ühner. Auf den Höfen gab es kein Hühnerhaus, sie fanden ihr Nachtquartier ganz wo anders. Mit seinem letzten Kikeriki für diesen Tag schwang der Hahn sich hoch hinauf auf einen stattlichen Baum. Bald folgten ihm seine Hennen nach und wenn es dunkel wurde, kam eine nach der anderen hinauf zu dem sicheren Nachtaufenthalt. $\mathrm{Zu}$ ihnen gesellten sich die Truthähne und -hühner.

Die ganzen Bäume waren dann von den großen Vögeln bedeckt, welche ihren Kopf unter die Flügel steckten und im Dunkel der Nacht wie seltsame Früchte erschienen.

Eines Tages, als ich mit meinen bulgarischen Freunden das Dorf Orman (Abb. 143, S. 287) besuchte, ließ ich mir von ihnen die Bestandteile eines Gehöftes erklären; um einen Hofraum herum stehen immer eine Anzahl Baulichkeiten, deren Zusammengehörigkeit durch einen sie umfassenden Zaun oder eine Hecke gekennzeichnet ist.

Sie bezeichneten mir das hohe, weifgetünchte Haus im Hintergrund als das Haus der Herrschaft; im Dorf Orman sei es bei seiner einfacheren Ausstattung wohl von dem Verwalter des Herrn bewohnt. Unter ihm stehe das Dorf mit all seinen Gehöften. Das ganz wohnlich aussehende größte Haus im Hintergrunde des Hofs sei das Haus des Vaters oder Großvaters der Familie, die den Hof bewohne. Im Hof standen allerhand Gebäude herum, an deren regelloser Anordnung man erkannte, dalo sie nach und nach dem Bedürfnis entsprechend entstanden waren. Manche dienten als Scheunen, andere als Geräteschuppen, Ställe gab es keine. Manche waren aus Balken gebaut, die $\mathrm{W}$ ände bestanden aus Flechtwerk, ein mächtiges Strohdach deckte sie. Andere waren aus Lehmziegeln gebaut, selten waren sie einmal weilugetüncht. Während das Vaterhaus ein längliches Gebäude mit einer großen Eingangstüre war, welches mehrere Fenster aufwies und ein rotes Ziegeldach trug, hatten die meisten anderen Gebäude einen quadratischen Grundriß und waren mit Stroh gedeckt. Die 
Vorratshäuser für Stroh und Getreide hatten meist nur einen Eingang aber keine Fenster, höchstens an einer Seite ein kleines viereckiges Luftloch.

Besonders merkwürdig erschienen mir kleine quadratische Pfahlbauten, deren in jedem Hof eines oder mehrere standen. Sie waren meist etwas abseits von den anderen Bauten errichtet. Sie hatten einen Eingang, zu dem eine kleine Leiter hinaufführte. An der Hinterwand hatten sie in der Regel ein einziges kleines Fenster. Meist waren sie aus Flechtwerk gebaut, das mit Lehm beworfen und außen geweißt war. Der Fußboden war auf einem Rahmen aus Balken in ähnlicher Weise hergestellt, und sah einer Tenne ähnlich.

Das Häuschen stand auf vier oder mehr Pfählen, die zum Teil durch schiefe Streben gestützt waren. Das Dach, in Gestalt einer vierseitigen Pyramide war fast ebenso hoch wie die Wände des Hauses und bestand aus mehreren Lagen von Stroh. Die Spitze war, um den Regen abzuhalten, mit einem Deckel überzogen, der aus Geflecht, Reisig oder Holz bestand. Der Querschnitt der Häuschen war quadratisch mit etwa $2 \frac{1}{2}$ qm Bodenfläche. Sie waren $4-5 \mathrm{~m}$ hoch.

Schaute man in die Hütte hinein, so war sie bei Tag fast immer leer, machte aber den Eindruck eines primitiven Wohnraums. In einer Ecke lag ein Haufen von Decken, offenbar das Schlaflager der Bewohner. An einer Wand stand eine Truhe. Auf dem Boden standen einige Körbe und Schüsseln. Eine Feuerstelle fehlte, der Pfahlbau hatte auch keinen Schornstein, während das Vaterhaus meist deren mehrere besaß. Die Häuschen waren verschieden gut gebaut und in verschieden gutem Erhaltungszustand, reinlicher oder schmutziger, wohlgeordnet oder in wildem Durcheinander, offenbar je nach der Art ihrer Bewohner.

Als ich meine bulgarischen Freunde fragte, was diese Häuschen wohl zu bedeuten hätten, ob das wohl Arbeiterwohnungen seien, zögerten sie einen Augenblick mit der Antwort, dann sagte der eine von ihnen: „Ja, wenn Sie wollen, Arbeiter- oder Knechtswohnungen, aber anders als Sie meinen. Soll ich es Ihnen klar und deutlich sagen, so muß ich diese Pfahlbauten als Fortpflanzungshäuser bezeichnen."

Er sagte dies mit einem eigentümlichen Blick und in einer bitteren Art, die ich sonst nicht bei ihm gewohnt war. Und als ich zuredete, erfuhr ich von meinen Freunden Dinge, die mir 
zeigten, wie die Bulgaren jahrhundertelang unter dem Joch der Türken gelitten haben müssen und in welch raffinierter Weise die letzteren verstanden, die Kräfte der Unterjochten für ihre Zwecke auszunutzen.

Nachđem sie mir die ganzen Verhältnisse geschildert hatten, fuhren wir nach einigen Tagen nach dem Tschifflik Bardovce hinaus, wo sie mir an einem typischen, großzügigen Beispiel die Methoden der Türken und ein interessantes Stück mazedonischer Ethnographie vor Augen führten. Ich habe keine Dokumente gesehen und in keinen Büchern eine Bestätigung dieser Angaben gefunden. Ich schildere, was ich sah, und füge dazu die höchst einfache und überzeugende Erklärung, welche meine Freunde mir gaben. Ich habe keine Ursache anzunehmen, daß sie ungenau unterrichtet waren, oder daß politischer Haß sie beeinflußte. Zudem hatte ich allen Grund sie für gut orientiert zu halten, da die Bewohner dieser Dörfer zu ihnen, den Ärzten, als vertrauende Patienten vielfach gekommen waren. Und der gute Arzt pflegt ja ein Beichtvater des Volks zu sein.

Als wir uns dem Herrschaftshaus des Gutes Bardov ce näherten, fuhr unser Wagen in schlankem Trab durch eine Allee auf einer breiten Straße vor ein weißes Tor mit rotem Ziegeldach vor, welches sich mitten in einer hohen Mauer aus Ziegelsteinen erhob. Wie eine Festung war der Herrensitz von dieser $3-4 \mathrm{~m}$ hohen Mauer rings umschlossen. Sie selbst hatte eine Ziegelbekrönung und zeigte keinerlei Schmuck. Über die Mauer schauten hohe Bäume und die steilen, turmähnlichen Schornsteine stattlicher Gebäude heraus.

Wie wohl in alten Zeiten hielten wir vor dem verschlossenen Tor und pochten mit dem metallenen Klopfer an, daß es durch den Hof schallte. Es war aber nicht mehr die Dienerschaft des türkischen Paschas, des einstigen Besitzers, die uns öffnete, es waren bulgarische Soldaten, welche das in den Gebäuden aufbewahrte Armeemagazin bewachten.

Gleich neben dem Tor befand sich das Pförtnerhaus; zur anderen Seite dehnten sich lange niedrige Stallgebäude aus, denen jetzt das Dach fehlte. Das Schloß war geplündert worden und hatte auch sonst manchen Schaden gelitten. Aber wir bekamen doch einen Eindruck von der einstigen Pracht und dem Luxus, den sich der Pascha hier in seinem Landsitz hatte leisten können. 
Im vorderen Teil des hier kahlen Hofs ragte ein stattliches, aus verschiedenfarbigen Steinen gebautes zweistöckiges Haus empor. Es hatte eine dreiteilige Fassade; der Mittelteil war zwischen den Seitenflügeln etwas zurückgefaßt und hatte einen rundlichen Umriß. In diesem Teil befand sich das weitläufige Treppenhaus, groß angelegt, durch seine Mitte führte das Hauptportal ins Haus. Zu beiden Seiten schlossen sich an Treppenhaus und Gänge Räume an, die saalartig umfangreich und mit ornamentalen Malereien geschmückt waren, Nischen mit plastischem Schmuck und Wandbrunnen enthielten. Daneben befanden sich Kammern und Schlafzimmer nebst Baderäumen. Ein großer Saal wurde als Speisezimmer bezeichnet. Das Haus war so als das "S elamlik", das

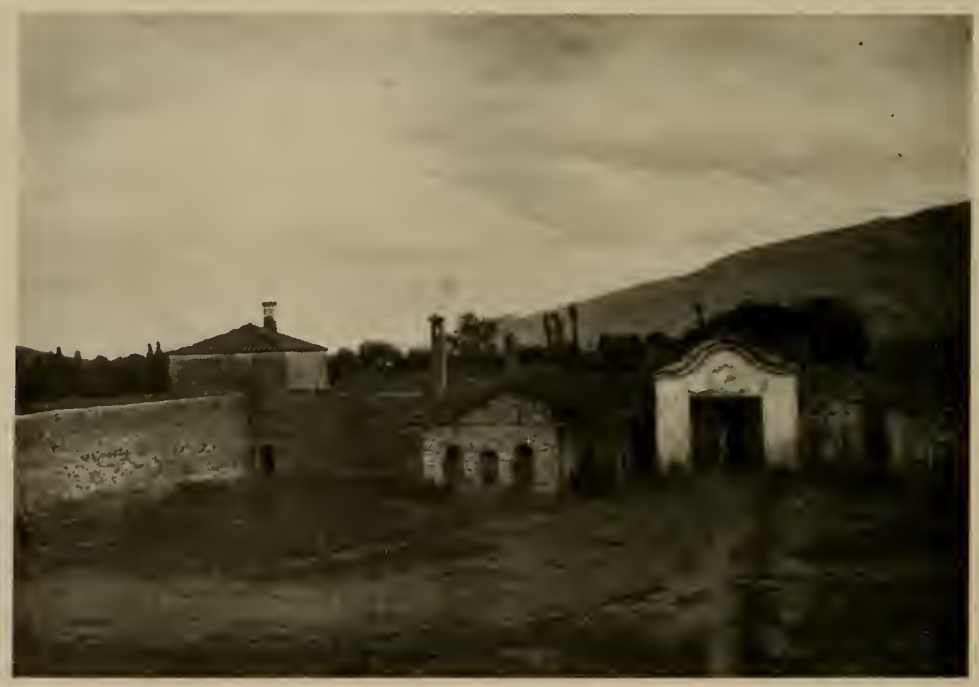

Abb. 144. Hofraum des Tschifflik.

Männerhaus, das Wohn- und Repräsentationshaus des Herrn charakteristiert. Wenn die Reste der Ausstattung auch nicht sehr feinen, erlesenen Geschmack verrieten, das Haus mußte, als die Fenster und Türen noch ganz waren, als die Wände mit Teppichen behängt, die Böden mit solchen belegt waren, Divans die Zimmer umfaßten, Tische und andere Möbel sie erfüllten, einen pompösen Eindruck gemacht haben.

Das Selamlik war früher durch eine schwebende Brücke im oberen Stockwerk mit dem nebenanliegenden etwas kleineren, aber auch recht stattlichen Nebengebäude verbunden. Es war das 
„Haremlik“, das Frauenhaus, welches den Harem des Paschas beherbergte. Es war nach allen Seiten durch Mauern von der Außenwelt getrennt, auch sein Hofraum von dem des Selamlik. Rings um das Haremlik waren hohe Bäume angepflanzt, welche den Platz vor den Haus anmutig beschatteten und jeden Blick von der Außenwelt auf die oberen Stockwerke des Hauses verhinderten. Der Bauplan des Hauses entsprach im wesentlichen dem des Selamlik mit seiner Dreiteiligkeit. Auch hier war der Mittelteil ein luftiges Treppenhaus mit weiten Gängen und großen Fensteröffnungen. Die Raumeinteilung war ähnlich wie in dem anderen Haus; auch hier war viel zerstört, immerlin manche reizvolle Holzschnitzerei

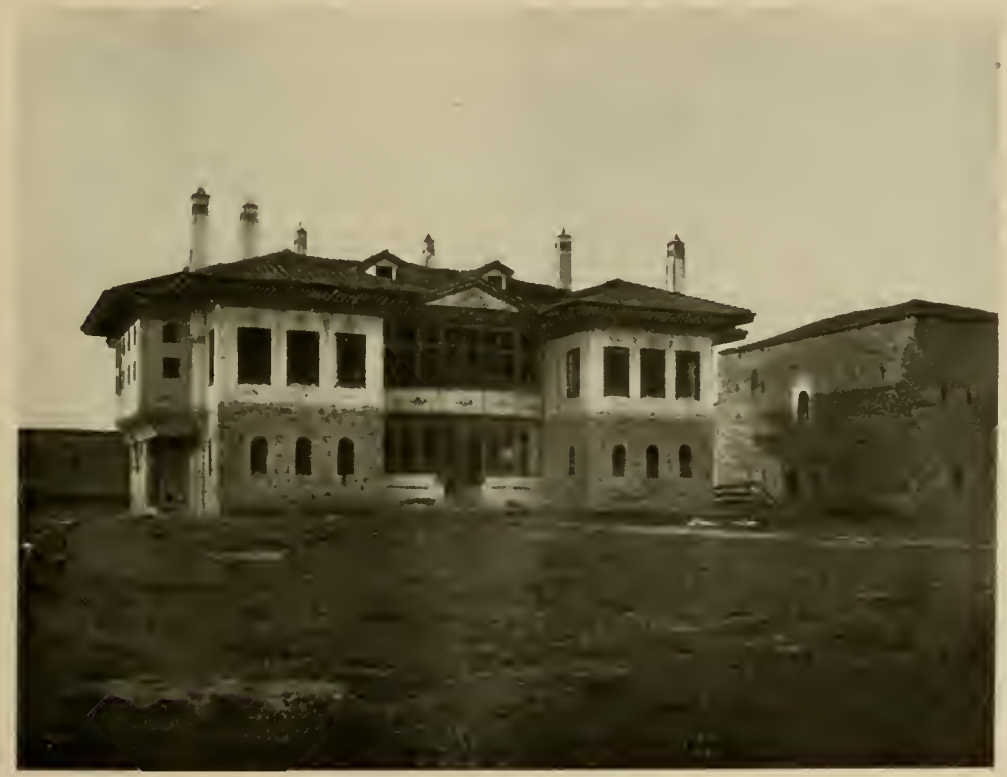

Abb. 145. Selamlik.

an Türrahmen und Fenstergittern erhalten. Die holzgeschnitzten Fenstergitter sind ja oft der Hauptreiz der Architektur von türkischen Haremsbauten.

Auch im Haremshof befanden sich dem Hauptgebäude gegenüber Wirtschaftsbauten, in denen wohl Küche und Dienerinnen untergebracht waren. Ringsum gut von der Welt abgeschlossen war so der Harem, nur zugänglich dem Pascha selbst, der von seinen Räumen aus auf luftiger Brücke direkt in die Räume seiner Frauen gelangte. 
Trotz aller Zerstörung machte das Gebäude doch immer noch einen stattlichen Eindruck und man konnte sich wohl vorstellen, wie in ihm einst der Pascha hauste, der Schrecken für alle seiner Untergebenen, der Aussauger des Vilajets Üsküb, der hier seine Reichtümer ansammelte und ein frohes Leben genoß auf Kosten der Einwohner des Landes, deren elende Wohnstätten wir nun im Anschluß an die Besichtigung des Herrenhauses noch einmal genauer uns ansehen wollten.

Das Dorf Bardowce lag dicht bei dem Schloß, beide am Fuß eines Hügels gelegen, von dem aus man beide übersehen konnte. Trutzig lag das Herrenhaus zwischen seinen hohen Mauern,

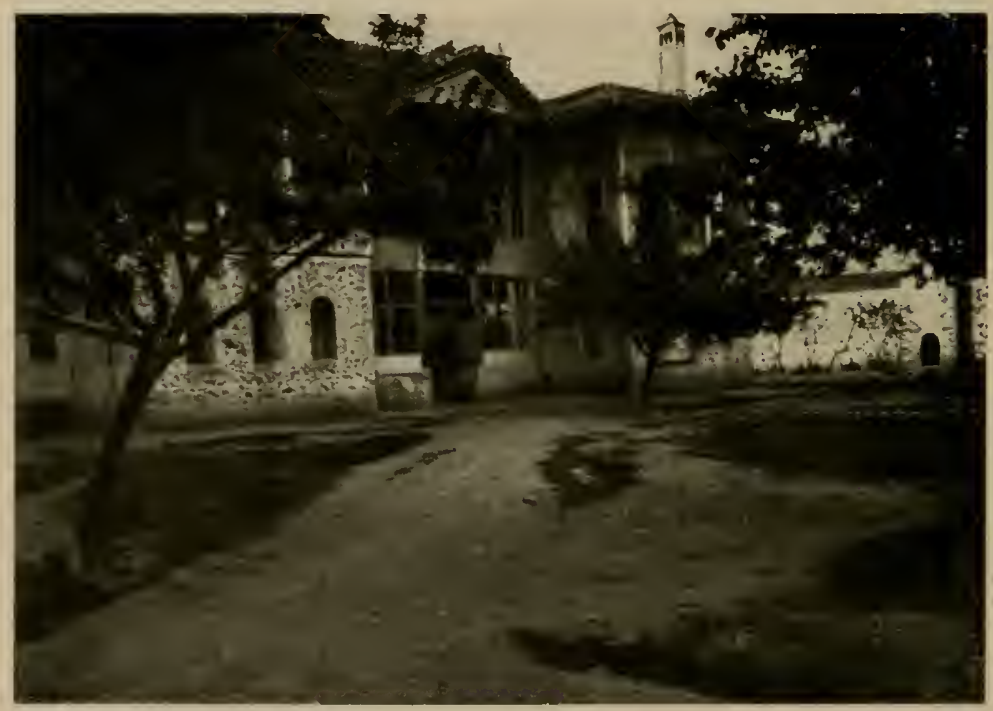

Abb. 146. Haremlik.

während die Hütten des Dorfes noch mehr als die des Dorfes Orman in einem Hain stattlicher Bäume verborgen lagen, so daß man von oben nur einzelne Dächer hervorlugen sah.

Ein wohltuender Schatten umfing uns, als wir durch die Gäßchen bummelten, welche die einzelnen Hofstätten miteinander verbanden. Wir sahen uns einen Hof nach dem anderen an; sie glichen sich sehr untereinander, nur daß die Größe des Elternhauses und die Zahl der Scheunen und Nebengebäude verschieden waren. Im Hof stand wohl ein unbespannter Wagen, Hühner und 
Enten liefen umher, aber sonst war es still. Die Bewohner waren heute wieder, am Arbeitstag, draußen bei der Arbeit.

Nur einzelne Kinder huschten durch die Zäune, während wir uns ungestört umsahen und meine Freunde mir erzählten und erklärten, was sie von den Zuständen wußten. Das Elternhaus enthielt eine Küche und mehrere Räume mit Betten und anderen Möbeln. Aus ihm schauten mehrere Kinder heraus. Meine Freunde berichteten mir, daß die Leute in den Dörfern zur Zeit der Türken Leibeigene gewesen seien, ohne Freizügigkeit. So gehörten die Bewohner eines Dorfes in der Regel zu ganz wenig Familien.

Der Vater einer Familie hatte ein bestimmtes Stück Land zur Bebauung angewiesen bekommen. Er hatte dieses mit seinen

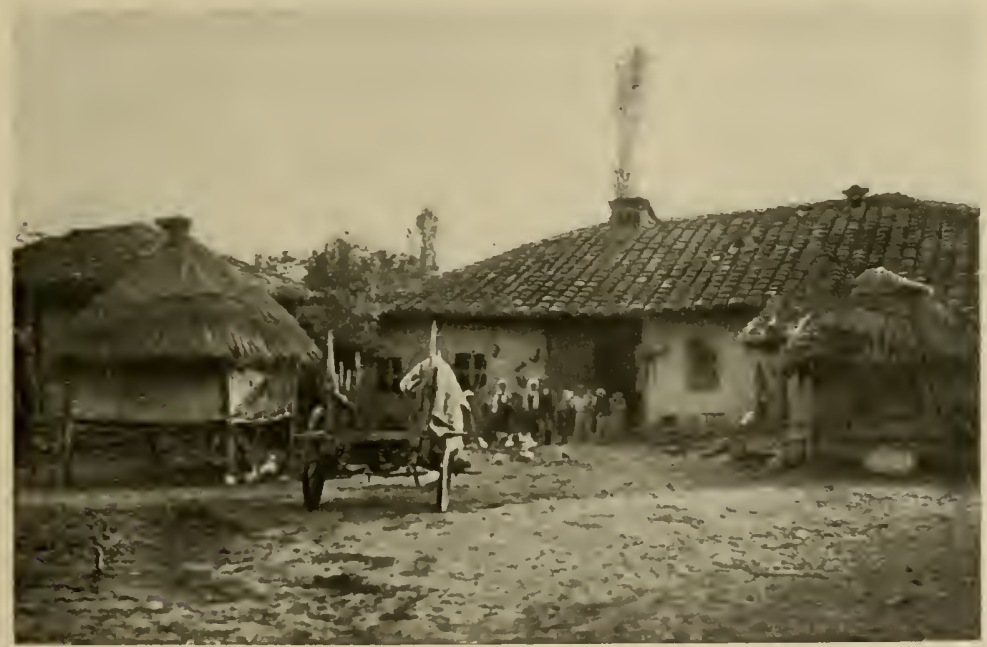

Abb. 147. Elternhaus.

Söhnen und deren Frauen ganz frei zur Verfügung. Es scheint, daß ihm nicht viel in die Art der Bebauung und in die Arbeit hineingeredet wurde. Aber vom Ertrag hatte er die Hälfte an den Herrn abzuliefern, die andere Hälfte stand zu seiner Verfügung. Das sei wenigstens das Verfahren in der letzten Zeit der Türkenherrschaft gewesen. $\mathrm{Ob}$ in früherer Zeit andere Sätze üblich waren, konnte ich nicht erfahren. Vielfach hätten sich die Leute dabei nicht schlecht gestanden, natürlich je nach der Arbeitsleistung und dem Ausfall der Ernte. Im Jahre 1918 schien sie .nicht schlecht gewesen zu sein, die Vorratshäuser waren wohl gefüllt 
Und damals waren ja die Leute unter bulgarischer Herrschaft freie Bauern. Was mag jetzt aus ihnen geworden sein?

Das seltsamste in den Höfen waren die Fortpflanzungshäuser. Nach der Zahl dieser Pfahlbauten konnte man abschätzen, wieviel verheiratete Söhne der Vater in diesem Hof hatte. Manche Höfe hatten nur eines, andere zwei oder drei, selten mehr. Als Zweck dieser Häuser wurde mir bezeichnet, die jungen Eheleute sollten in ihnen ihre Ruhe haben, um Kinder zu erzeugen. In jedem Haus lebte je nur ein junges Paar. Sie hatten nicht zu kochen und keine Haushaltssorgen. So lange die junge Frau ihr Kind stillte, behielt sie es bei sich. War es abgewöhnt, so kam

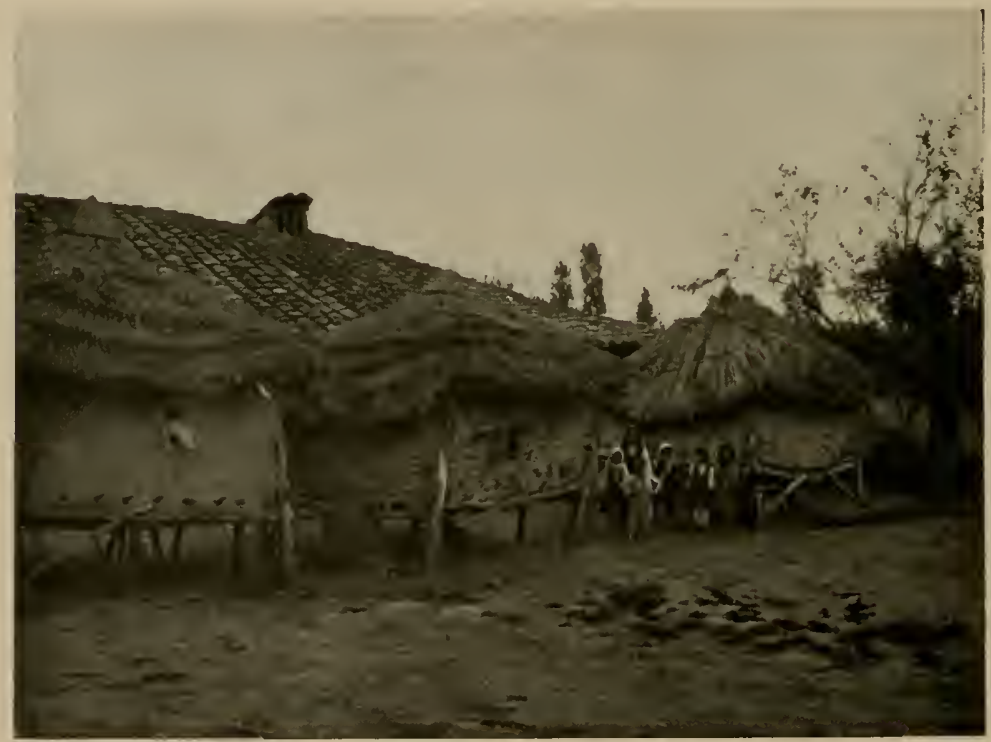

Abb. I 48 . Fortpflanzungshäuser.

es zur übrigen Kinderschar in das Haus des Großvaters, wo auch die Verpflegung der ganzen Familie besorgt wurde. Das Paar hatte nur für baldige weitere Nachkommenschaft zu sorgen und auf den Feldern mitzuarbeiten. Je mehr solche Häuser also da waren, um so mehr Aussicht auf reichlich Arbeitskräfte. Wahrlich eine raffinierte Methode, unter Ausnützung des unterjochten Volkes die Interessen des Paschas zu fördern. Es gelang mir allerdings nicht, klare Auskunft darüber zu erhalten, ob die Türken die Urheber dieses Verfahrens waren, oder ob alte slavische Sitten dahinter steckten. 
Das Resultat schien wenigstens die Methode zu loben; als am Nachmittag die ganze Kinderschar eines Hofes sich vor uns versammelte, zählten wir I+ Kinder von 6-12 Jahren als die Nachkommenschaft der hier wohnenden Paare. Auf meiner Photographie der Kindergruppe erblickt man auf einem Dach im Hintergrund ein Storchennest, wie ein Symbol der Methode (Abb. 149).

Die Höfe, die Bewohner und ihre Kinder habe ich noch manches Mal besucht und einiges von ihren Sitten beobachtet. Im Herbst wurde auf dem harten Boden des Hofes das Getreide gedroschen, indem Ochsen und Pferde im Kreis herum getrieben wurden, welche mit ihren Hufen die Körner aus den Ähren

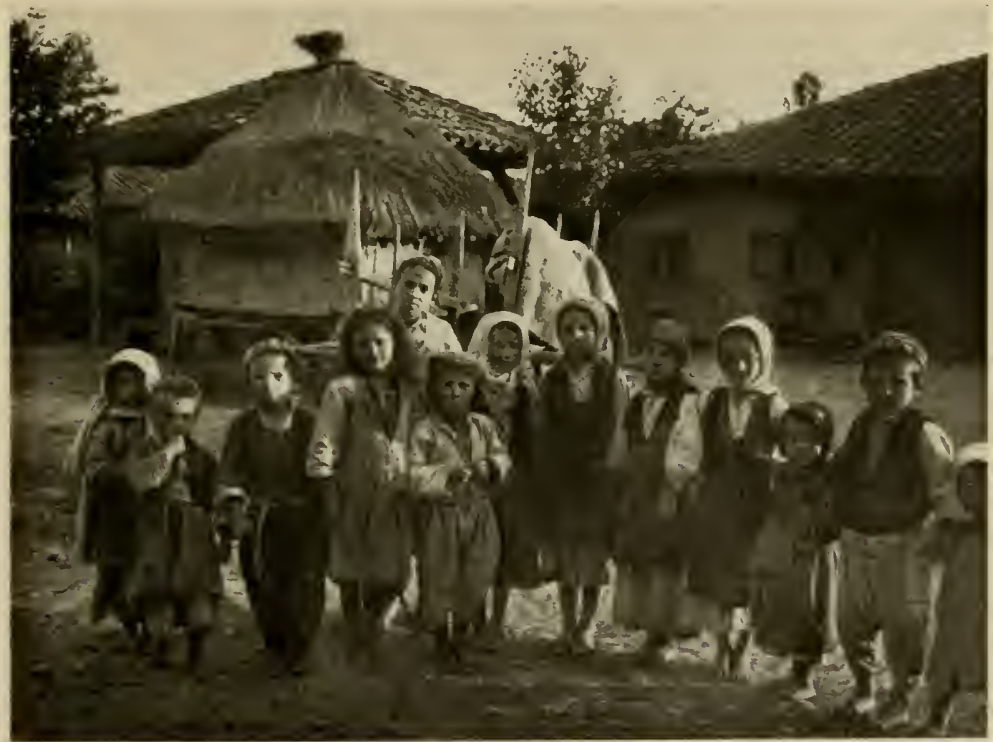

Abb. I49. Die Resultate der Methode.

trampelten. Dieser altertümliche Ersatz der Dreschflegeln war noch ganz allgemein in Mazedonien verbreitet. Nach der Ernte hörte man überall Peitschenklang, Rufen und Singen der Männer und das Trappen der pflügenden Tiere, die, heftig angetrieben, erst in sich verkleinernden Kreisen, dann nach Umkehr in immer größeren Kreisen an der Leine liefen, welche mitten in dem Getreidehaufen an einer Stange befestigt war (Abb. 130). Meist wirbelte in dieser trockenen Zeit eine mächtige Staubwolke um die Dreschszene auf. Auch bei der bulgarischen Armee wurde so gedroschen und ganz selten sah ich Dreschflegeln oder gar eine Dreschmaschine. Auch 
hier war dem Ochsen und dem Pferd, weiches drosch, in der Regel das Maul nicht verbunden.

Zum Schluß wurde das Stroh weggeschafft, und es blieb ein Haufen von Körnern, Spreu und viel Staub und Steinchen auf dem Boden liegen. Die Körner wurden dann in ebenfalls primitiver Weise von Spreu und Staub getrennt, indem die Masse an windigen Tagen auf eigenartigen Schaufeln in die Luft geworfen wurde. Dabei trennte sich das Schwere vom Leichten. Staub und Spreu flogen davon, während die Körner niederfielen und in Säcke gesammelt wurden, nachdem die Prozedur mehrmals wiederholt worden war. Daß einem beim Zerbeißen des mazedonischen Brotes oft die Zähne knirschten, wird man verstehen.

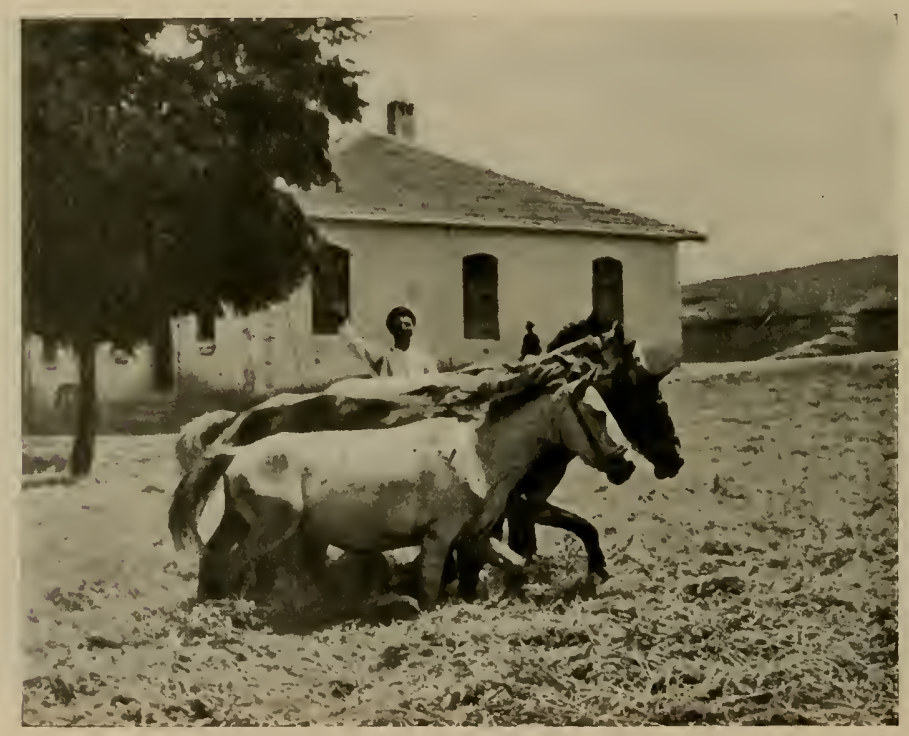

Abb. I50. Das Dreschen mit Pferden.

Nicht nur Arbeit gab es in den Dörfern zu beobachten, sondern gelegentlich auch freudige Feste. Als ich eines Sonntags in die Nähe des Dorfes kam, ertönte aus einem Hof dröhnende Musik. Ich erfuhr, daß dort Hochzeit sei und getanzt würde. Auf der gleichen Tenne, wo neulich die Pferde und Ochsen das Getreide ausgetreten hatten, war eine muntere Gesellschaft versammelt. Alle hatten sie ihre schönen, bunten Feiertagsgewänder an, eine fröhliche Stimmung herrschte. In einer Ecke saß die Musik am 
Boden, eine riesige Flöte quiekte, ein Dudelsack dudelte und als wichtigster Bestandteil der Kapelle erhob eine mächtige Pauke ihr Donnergetöse. Männer und Frauen schwenkten sich im Kreise und Kinder ahmten nebendran ihre Rhythmen nach. Es waren ähnliche Tänze, wie ich sie an anderer Stelle dieses Buches geschildert habe. Ein feierlicher Augenblick war es, als das junge Paar erschien und durch die Reihen der Tänzer hindurchwandelte, auch sie beide in der eigenartigen Tracht der Gegend.

Am Tag vorher hatte die Vorfeier der Hochzeit stattgefunden. Da wurden die Besucher von festlich gekleideten Familienmitgliedern empfangen. Sie kamen mit Eseln und Maultieren an, deren Sättel mit Geschenken beladen waren. An diesem Tag ließ sich die Braut noch nicht sehen; das Haus des Bräutigams war noch ohne Braut. Er empfing Gäste und forderte zum Tanz auf, der auch an diesem Tage bis tief in die Nacht andauerte.

Als Freund und Befreier wurde man von den Leuten meist freundlich begrüßt und mit Kaffee, Rakischnaps und Süßigkeiten bewirtet, kam man zu einer solchen Festlichkeit dazu.

Als ich abends über den Hügel nach Üsküb zurückkehrte, trat mir, nachdem ich einen Überblick über den Kreislauf des Lebens eines mazedonischen Bauern gewonnen hatte, noch eindrucksvoll das Symbol seines Abschlusses entgegen. Oben am Hügel über dem Dorf lag der Friedhof des Dorfes, in welchem die

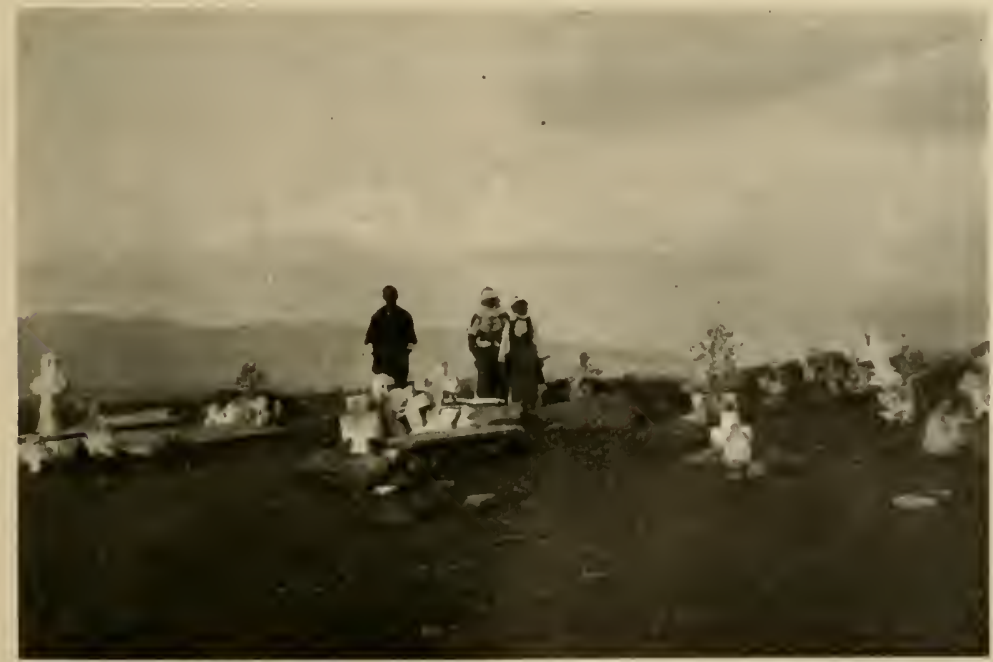

Abb. 151. Der Friedhof von Bardowce. 
früheren Bewohner des Dorfes ihre letzte Ruhe gefunden hatten. Es war ein stimmungsvoller Anblick. Auf dem rasenbewachsenen Rücken des Abhanges zog sich eine stattliche Gruppe von steinernen Kreuzen hin, zwischen denen die eigenartigen Kastengräber der Balkanslaven lagen. Alle Kreuze waren sorgfältige Steinmetzarbeit, sie erhoben sich niedrig über dem Boden, die einen nach links, die anderen nach rechts gebeugt. Man hatte den Eindruck, daß die Bauern mit Liebe und Sorgfalt die Ruhestätten ihrer Toten pflegten.

Ein feiner Abendduft lag über der Landschaft; im Westen ging die Sonne unter. Ihre Strahlen vergoldeten die hellen Kreuze und beleuchteten die mächtigen geballten Wolken, welche am Himmel standen. Ein Bild von wundersamer Farbenpracht breitete sich vor mir aus; stiller Frieden lag über der Abendlandschaft. An einem frischen Grab standen zwei Frauen und ein alter Mann, deren Umrisse sich eigenartig von der farbigen Ferne abhoben. Ich wanderte langsam heimwärts, von Gedanken erfüllt. Ob wohl diesem Volk, diesen mazedonischen Bulgaren, je eine freundliche Zukunft erblüht? 


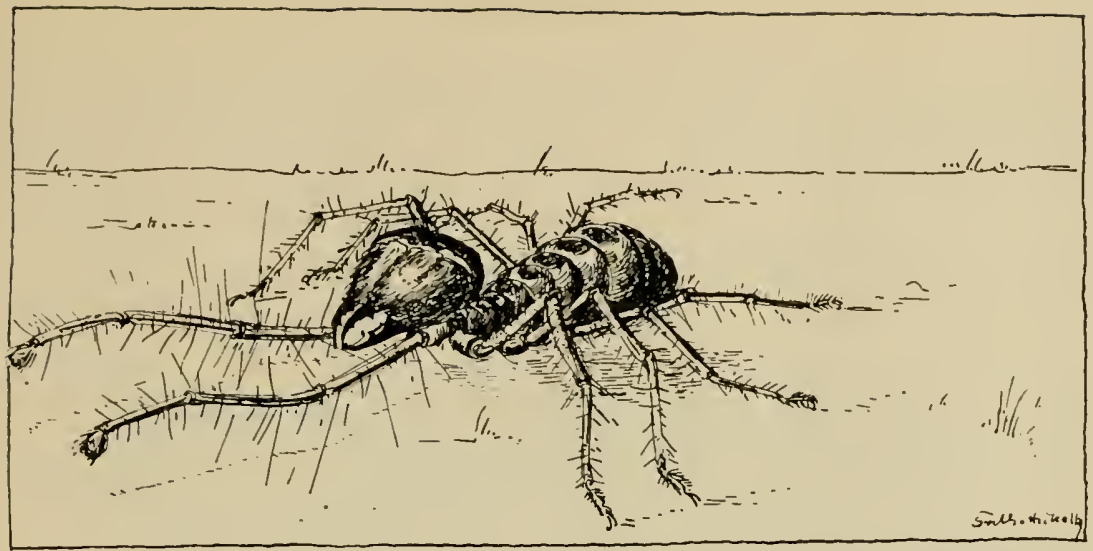

Galeodes in Greifstellung.

\section{NEUNZEHNTES KAPITEL BEOBACHTUNGEN AN MAZEDONISCHEN SPINNEN}

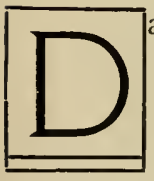

$\mathrm{a} \beta$ in einem so insektenreichen Land wie Mazedonien die Spinnen auffallende Bestandteile der Tierwelt sein mußten, durfte ich wohl von vornherein annehmen. Ich wurde nicht enttäuscht. Überall im Lande begegnete ich Spinnenarten, welche teils durch ihre Gestalt und Färbung, teils - und das in besonderem Maße - durch ihre Bauten auffielen.

Die verfallenen Häuser Mazedoniens mit ihren Lehmziegelwänden und dem hölzernen Fachwerk boten einer Unmenge von Spinnen Herberge und Jagdgefilde. An meinem eigenen Haus und an meinem Laboratorium war die Bautätigkeit einer eigenartigen Spinne an den Außenwänden vielfach zu beobachten.

Wo ein Loch in der Wand war, wo eine Spalte in einer Bretterverschalung oder zwischen Balken und Mauer sich hinzog, dat leuchteten eigenartige Sternfiguren auf, aus einer hellgrauen Substanz gebildet. In der Mitte einer weißlichen Fläche gähnte ein dunkles Loch, das offenbar tief in die Mauer hineinführte. Um die weißliche Fläche sah man einen Kranz von Strahlen mehr oder weniger weit sich über die Wand spannen. War die Wand dunkel, so leuchtete der Stern hell auf, war sie hell, so hob er sich schwach 
in feingrauer Farbe von ihr ab. Oft waren die Sternchen dick mit Staub bedeckt, vor allem an alten verlassenen Häusern (Abb. 153).

Sah man genauer hin, so bemerkte man bald, daß es sich um $\mathrm{B}$ auten von Spinnen handelte. Durch das schwarze Loch ging es in die Wohnröhre hinein, welche mehrere Zentimeter lang war. Im Hintergrund saß die kleine, dunkelgefärbte Spinne und lauerte auf Beute. Die helle Scheibe um das Loch besteht aus einem dichten Gewirr von dickeren und feineren Fäden, die nach allen Seiten durcheinander gefilzt sind. Sie bilden ein festes, federndes Gewebe und stellen den Eingang in die Wohnröhre dar. Stramm-

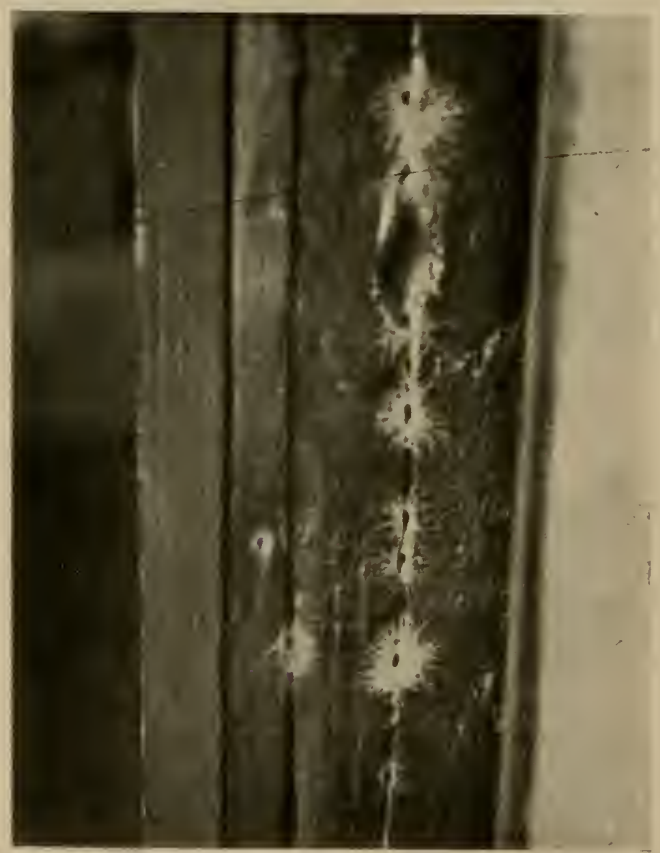

Abb. 153. Nesteingänge von Filistata insidiatrix Forsk. gespannt ist dies Gewebe, welches meist der Mauer nicht dicht anliegt, sondern über die Spalte, den Rand des Mauerloches oder zwischen Steinen sich ausdehnt, durch Spannfäden, wie sie auch sonst an Spinnennetzen nötig sind. Bei unserer „L, ochröhrenspinne" sind sie nur wenige Zentimeter lang und mit ihrem äußeren etwas verdickten Ende an der Unterlage angeklebt. Vielfach sind die Fäden verzweigt, indem an ihnen seitlich oder querverlaufende Hilfsspannfäden angebracht sind.

Klebfäden konnte ich am Netz nicht feststellen. Bei den eigenartigen Gewohnheiten der Spinne braucht sie wohl auch keine. Selten sah ich sie zum Netz herauskommen. Gelegentlich konnte ich sie abends einmal auf die helle Fläche heraustreten sehen und sie dann auch beobachten.

Das Tier war sehr schwer zu fangen; blitzschnell tauchte es in die Tiefe seiner Lochröhre hinein und war für alle Instrumente unerreichbar, die ich anwenden konnte. Sehr leicht gelang es aber, 
es unter Ausnutzung seiner Freßgier zu überlisten. In der Regel fing sie an der Mündung ihrer Röhre auf der Wand vorbeilaufende Insekten, vor allem die um die benachbarten Ställe umherschwärmenden Fliegen.

Hielt ich nun mit der Pinzette eine lebende Fliege vor ihr J.och, so kam sie langsam und vorsichtig heran, stürzte sich schließ-

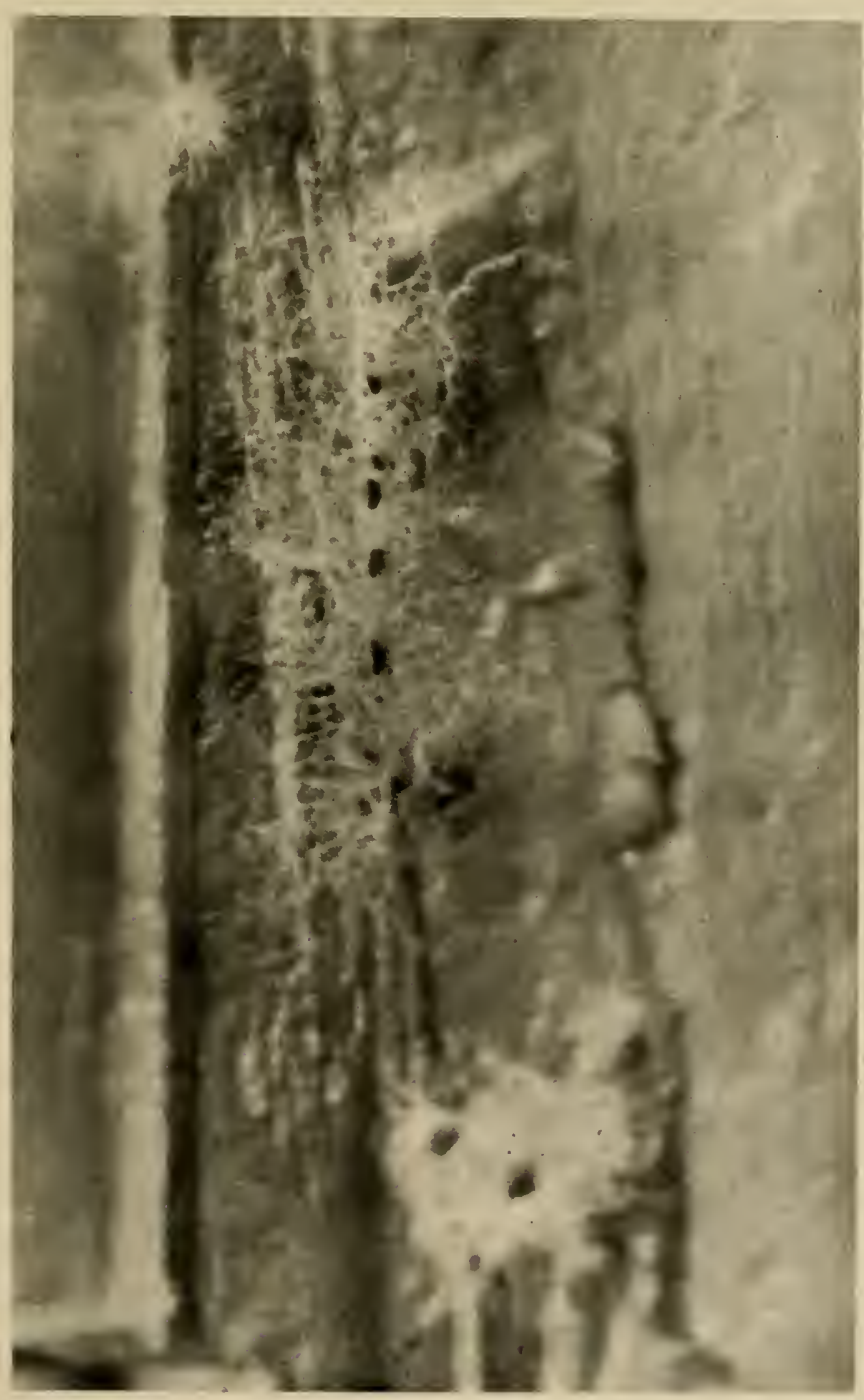

Abb. 154. Nestbauten einer Anzahl Individuen der Lochröhrenspinne (Filistata insidiatrix Forsk.). 
lich mit einem plötzlichen Sprung auf die Beute. Da sie diese nicht mehr losließ, konnte ich sie an ihr herausziehen und rasch in das Fangglas befördern.

So gelang es mir, Exemplare in die Heimat mitzuuehmen, wo sie als die Art Filistata insidiatrix Forskal bestimmt wurde, eine Form, die auch sonst in Europa verbreitet ist (Abb. I55 A).

Nicht selten waren Wände von Häusern im südlichen Wardartal von hunderten der Sternchen bedeckt, welche die Behausungen dieser Spinnen verrieten. Waren ihrer viele nebeneinander, so gingen die Umrahmungen der einzelnen Löcher in die ihrer Nachbarn über. Man vergleiche die umstehende Abbildung (Abb. 154). So entstanden manchmal ganz eigenartige Ornamente an den Hauswänden, wobei das ganze Gewebe durch zahlreiche kreuz und quer verlaufende Fäden befestigt war und die regelmäßige Sternform oft vollkommen verschwand.

Zwischen den Nestern der Filistata sah man in großer Zahl Spinnen von einer anderen Art herumsausen, es war Dendryphantes nidicolens Walck., eine Springspinne aus der Familie der Attiden (Abb. ${ }_{55}$ B). Diese lief immer auf der Wand zwischen den Nestern herum, lauerte auch einmal nahe einem der Löcher. Nie sah ich sie aber in eins der Löcher eindringen. Höchst amüsant war es aber, sie zu beobachten, wie sie oft mit raschem Sprung der Lochröhrenspinne ihre frisch gefangene Beute, welche diese unter ihrer Türe festhielt, aus den Klauen rif und abseits eiligst aussaugte. Da die Springspinne stets in den Städten der Lochröhrenspinne in größerer Anzahl vorkam, so vermute ich, daß sie die ständige Gewohnheit hat, die Filistata auszuplündern und als Straßenräuber in deren Siedlungen sich aufzuhalten.

In den Häusern selbst, in den Ställen, Gängen, Kellern, auf den Aborten gab es viele Spinnenarten mit ihren Netzbauten, vielfach die auch bei uns an ähnlichen Orten häufigen Arten. Auch in meinem Schlafzimmer hielten sich neben allerhand anderem Getier mancherlei Spinnen auf. Vor allem die Netzspinnen beseitigte ich nicht, sondern duldete sie, da es an ihnen manches zu beobachten gab und sie mir noch dazu Schnaken und Fliegen wegfingen.

Ein Exemplar der auch in Deutschland gelegentlich beobachteten Art Pholcus opilionoides Lchk., die ich die Wackelspinne nennen möchte, lebte den ganzen Sommer 1917 in meinem Zimmer, bis ich sie am Ende meines Aufenthaltes mit 
ihren sämtlichen unterdessen abgeworfenen Häuten in ein Spiritusglas steckte. Sie hatte im Frühjahr als ganz kleines Tierchen ihr erstes Nest in den Winkel zwischen Decke und Rückwand meines Zimmers gebaut, hatte im Laufe des Sommers viermal sich gehäutet und hatte jedesmal die abgeworfene Haut im Netz hängen gelassen, so daß man meinen konnte, in dem einen Netz hausten nun fünf verschieden große Spinnen der gleichen Art. Diese Spinne sieht aus wie ein Weberknecht mit ihren feinen, langen Beinen, auf denen ihr kleiner Körper, wie bei einem Weberknecht schwebt. Sie gleicht auch sonst jenen eigenartigen Spinnentieren, den Phalanginen, die man bei uns in Deutschland außer mit dem Namen Weberknecht auch als Schuster oder Schneider

Abb. 155 A.

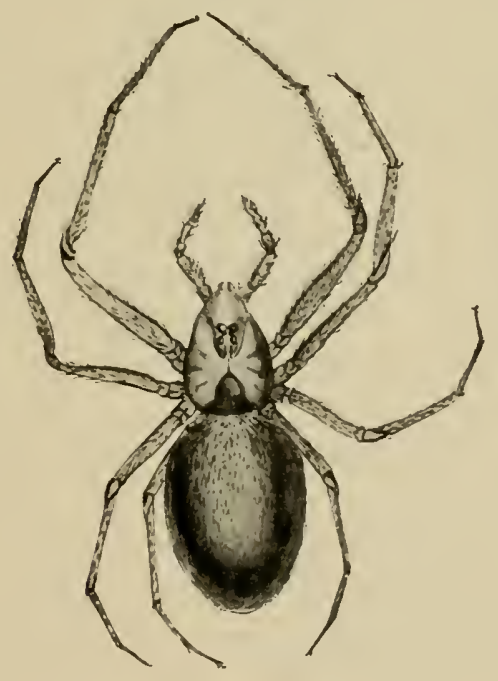

Abb. ${ }^{1} 55$ B.

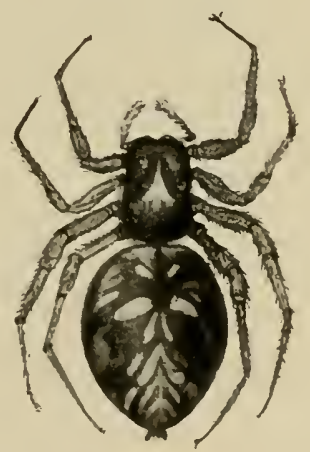

Abb. I 55 A. Lochröhrenspinne (Filistata insidiatrix Forsk.) und ihr Nesträuber Abb. I55 B. Dendryphan. tes nidicolens Kaluckova.

bezeichnet. Die Wackelspinne teilt mit diesen Tieren nicht nur die Eigentümlichkeit, leicht die Beine zu verlieren, sondern auch das eigentümliche Wackeln und Schaukeln auf ihren fadendünnen Beinen. Stößt man in der Nähe des Netzes zufällig an die Wand, so fangen die Tiere an, wie toll hin- und herzuschwingen, wobei sie abweckselnd mit sämtlichen vier linken und darauf mit den vier rechten Beinen Kniebeugen machen. Dieses emsige Wackeln macht einen ganz eigenartigen Eindruck und hat ja seit jeher die Aufmerksamkeit der Menschen erweckt. 
Bei den Beobachtungsstreifzügen in der Umgebung von Kaluckova war es unvermeidlich, gewisse Spinnenarten anzutreffen, deren Netze überall ausgespannt waren. In den Stacheleichenbüschen fand ich regelmäßig eine kleine Spinne aus der Gattung Linyphia (L. frutetorum C. L. Koch), die ein unregelmäßiges Wirrnetz baute. Das Netz war klein, bestand aus zarten Fäden und war an Spannfäden in Lücken der Stacheleichenbüsche zwischen deren Blättern und Zweigen aufgehängt. Die Spinne saß meist lauernd mitten im Netz.

Noch auffallender waren die Bauten der Segelnetzspinne, welche in den Gassen von Kaluckova, auf den Schuttplätzen, in den Hecken, an den Häusermauern überall in großer Menge vorkamen. Die Netze hatten bis $z u \quad 1 / 2 \mathrm{~m}$ Umfang und waren segelförmig an den Zäunen zwischen Disteln und anderen krautigen Pflanzen, an Gräsern und Büschen aufgehängt. An festen Spannfäden hingen die verschieden gestalteten $Z$ ipfel, die in den sackförmigen Grund des Netzes führten. Diese Zipfel waren bald länger, bald kürzer. Im Hintergrund ging der Sack in eine lange Röhre über. Diese begann mit einer kreisformigen, wohlabgegrenzten, aus dichtem Gewebe gebauten Öffnung von $3-5 \mathrm{~cm}$ Weite. Die anschließende Röhre war $20-30 \mathrm{~cm}$ lang. Sie war oft frei zwischen den Pflanzen aufgehängt, so daß man ihren Bewohner von außen wahrnehmen konnte. Nicht selten aber ragte die Wohnröhre der Spinne in Erdlöcher, Mauerspalten, zwischen Balken und Pflanzen hinein. Die Röhre war ein dichtes Geflecht aus sehr dicken Fäden. Der Sack war auch ziemlich grob und fest, oft sehr schmutzig von Staub und zahllosen Insektenresten. Auch er bestand aus einem wirren Gewebe dicker Fäden. Von seinen Rändern zogen sich starke Spannfäden nach verschiedenen Richtungen. Der ganze Beutel war vollkommen asymmetrisch angelegt, die Wohnröhre ragte nicht in der Mitte heraus, sondern lag mehr an der Seite und war oft abgebogen.

Vorn in der Wohnröhre saß die Spinne auf der Lauer mit dem Kopf nach vorn gerichtet. Es war ein stattliches Tier, zur Art Drassus lapidicola Walck. gehörig. Fiel ein Insekt ein, so rannte sie rasch in das Beutelnetz vor und bewältigte das Opfer. Wurde sie dabei erschreckt, so kehrte sie ebenso rasch in die Wohnröhre zurück und saß ganz ruhig, mit dem Kopf gegen das Ende der Röhre, das Hinterteil nach außen gerichtet und ließ sich da mit der Pinzette leicht, ohne einen Fluchtversuch zu machen, herausholen. 
Von einer Art der gleichen Gattung Drassus pubescens Thor. habe ich bei Dedeli unter einem Stein im Mai die Wohnröhre und in ihr den Eierkokon des Tieres, von der Mutter bewacht, gefunden (Abb. 156). Die auffallendste echte Spinne im südlichen Wardartal, die auch sonst im heißen Mazedonien weit verbreitet ist, war eine Form, welche ich als die Silberspinne bezeichnen möchte. Es ist ein großes Tier, mit ausgestreckten Beinen fast $15 \mathrm{~cm}$ umfassend. Der Körper ist mit eigenartigen Fortsätzen versehen und von einem auffallend harten Chitinpanzer umhüllt, nicht so weich, wie es sonst die Körper der meisten Spinnen sind. Der Hinter-

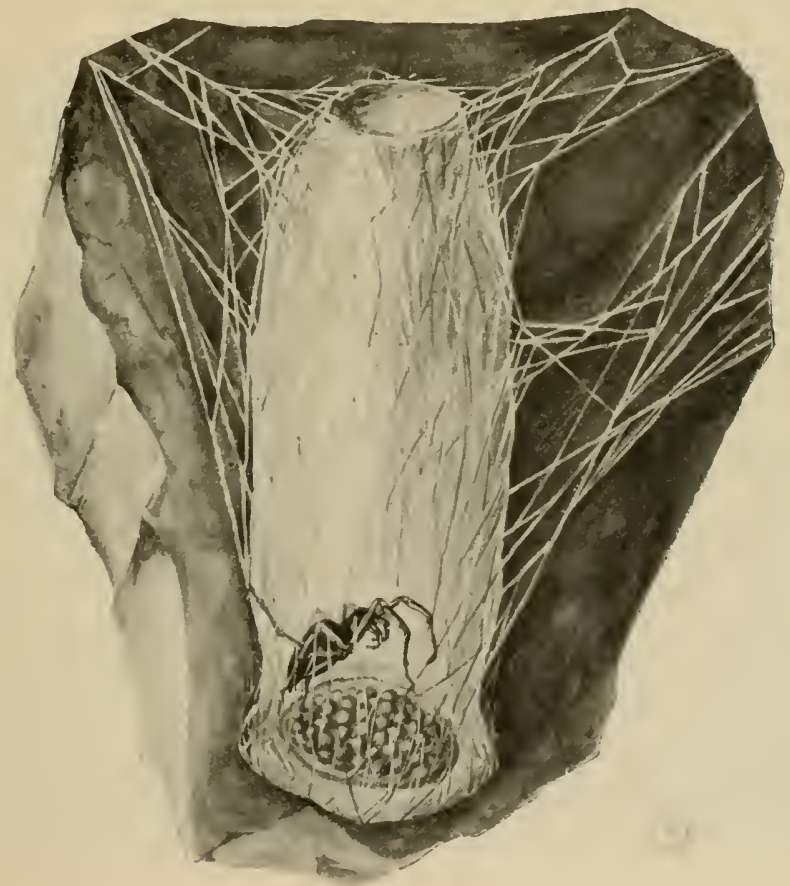

Abb. 156. Nest und Kolon von Drassus pubescens Thor. Dedeli, unter Stein.

leib hat einen eigenartigen polygonalen Umriß mit dreieckigen Vorragungen und tiefen Einsenkungen dazwischen. Der Körper zeigt bei dem lebenden Tier einen eigentümlichen Silberglanz, der das Tier sehr auffallend macht. Die Beine sind gelb und dunkelbraun geringelt. An der Unterseite des Leibes ragen starke Spinnröhren hervor. Die Spinne hat den Namen Argiope lobata Pall. (Abb. 158).

Sie baut zwischen den Büschen der Hügel bei Kaluckova ein sehr groljes Radnetz, das man weithin sehen kann. Es mißt 
bis zu einem Meter im Durchmesser (meist $60-80 \mathrm{~cm}$ ) und hängt meist frei in der Luft hoch über dem Boden. Zwischen zwei Stacheleichensträuchern ist ein oft mehrere Meter langer gelblicher, seidiger Faden von beträchtiicher Dicke straff gespannt. Er ist der Aufhängef aden für das große Radnetz. Zu seiner Versteifung dienen viele nach allen Richtungen ausgehende straffe Spannfäden. Der Haupttragfaden besteht aus etwa 30 Einzelfäden, die Spannfäden nur aus 12 solchen, von denen 10 breit bandförmig, zwei jedoch viel dünner sind. Diese letzteren sind besonders elastisch und tragen wesentlich zur Spannkraft des ganzen Gebildes bei.

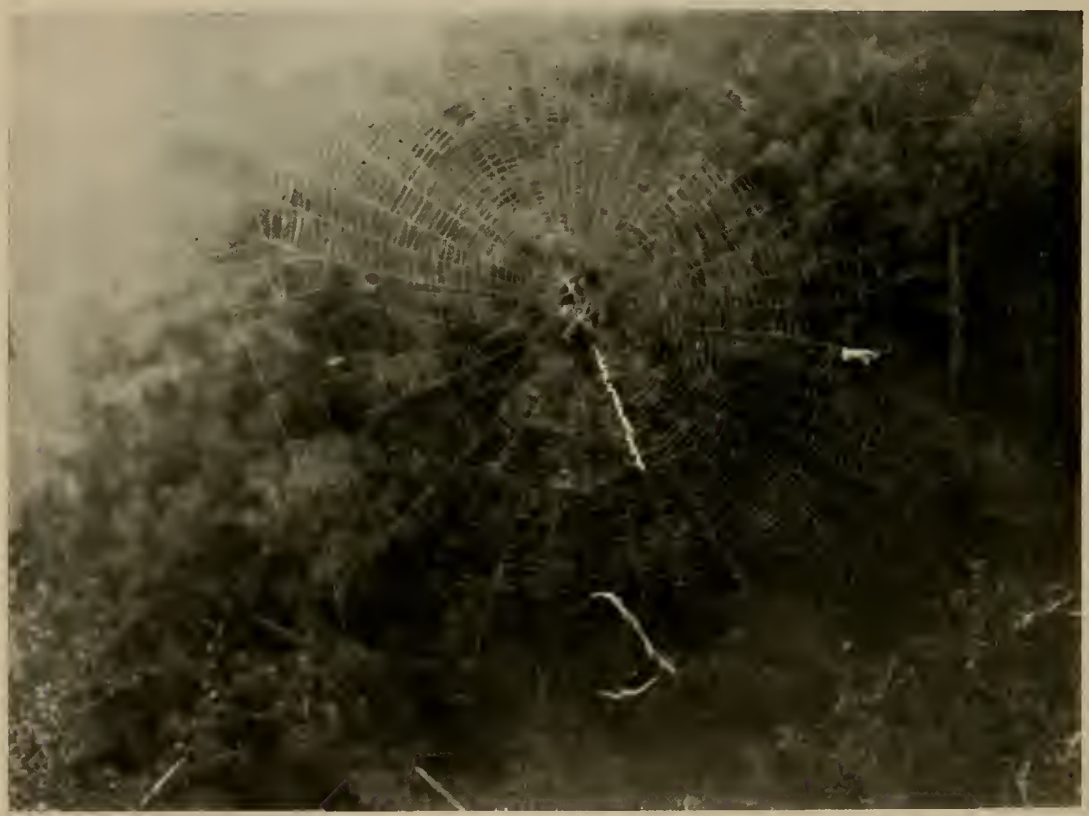

Abb. 157. Radnetz von Argiope lobata Pall., der Silberspinne.

In der Mitte unter dem Aufhängefaden befindet sich das große Radnetz. Das Zentrum des großen Rades mit seinem Durchmesser von $60-80 \mathrm{~cm}$ nimmt eine kleinere kreisförmige Scheibe von etwa io cm Durchmesser ein. Diese Scheibe besteht aus nicht klebenden Fäden. In ihrer Mitte sitzt die Spinne als groteske Erscheinung vollkommen ruhig und unbeweglich. Wie ein silberner Schild glänzt ihr Hinterleib; ihre Beinpaare hält sie in einer ganz eigenartigen Stellung, immer je zwei paarweise 
aneinandergelegt, die zwei hinteren Paare schief nach hinten, die zwei vorderen Paare schief nach vorn gestreckt. So entsteht ein schiefes Kreuz, das man von weitem schon vom Mittelpunkt des Radnetzes ausstrahlen sieht.

Um das kleine Mittelnetz mit seinem engen Bau mit zahlreichen Radien und einer ganzen Anzahl konzentrischer Kreise breitet sich das lockerer gebaute große Rad aus, nach allen Seiten $20-30 \mathrm{~cm}$ breit. Auch dessen Hauptfäden, also die radiären Fäden, sowie die inneren und äußersten Kreise bestehen aus trockenen festen Fäden. Dazwischen in der Mitte ist eine Zone von kleberigen Kreisfäden, an denen die Beuteinsekten kleben bleiben. Der äußere Rand des Netzes hat eine nicht ganz. regelmäßige polygonale Form, die zum Teil bedingt ist durch Spannfäden, welche das Net\%rad nach allen Seiten mit Zweigen und Blättern der Umgebung, mit Gräsern, Holzstückchen und Steinen in Verbindung setzen.

Das auffallendste an dem Netz, das neben seinem glänzenden Insassen weithin sichtbar ist, besteht in einem leuchtend weißen Band,

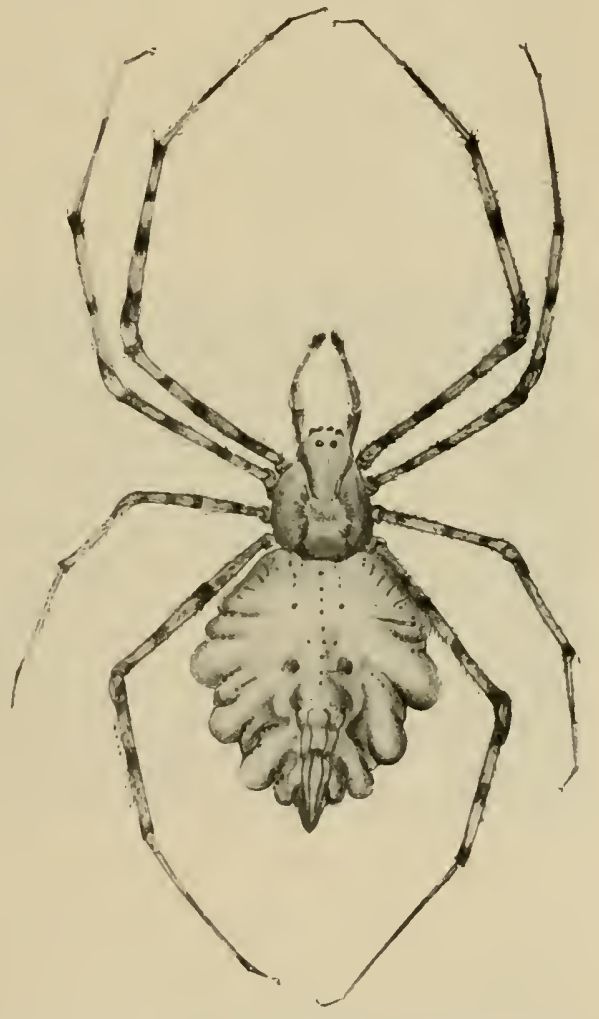

Abb. 158. Silberspinne Argiope lobata Pall. Weibchen. Nat. Größe. welches sich von dem mittleren kleinen Hofkreis der Spinne zum äußeren Rand des großen Rades hinzieht. Es besteht aus glänzend weißen, dicht verflochtenen trockenen Seidenfäden (Abb. 157).

Vor diesem wellenförmigen Band sitzt die lauernde Spinne, stets mit dem Kopf gegen dieses gerichtet. Ich hatte den Eindruck, als wirke dies Band anlockend wie eine Blume auf allerlei fliegende Insekten. Ich sah besonders häufig Schmetterlinge auf das Netz der Silberspinne zufliegen, an den Klebfäden hängenbleiben und 
sich dann durch unruhige Zappelbewegungen immer mehr im Netz verfangen. Meist blieb dem Opfer aber dazu nicht viel Zeit, denn mit erstaunlich rascher Bewegung schwang die große Spinne, die bisher so träge auf ihrem Lauerplatz gesessen hatte, sich über die Fäden des Netzes zu ihm hin. Mit raschem Bil3 war der Schmetterling getötet und nun wurde er von dem wilden Tier mit den Beinen in eine rasche Wirbelbewegung versetzt. Im Nu ist das Opfer, und wenn es ein großes, starkes Tier ist, vollkommen in eine dichte Hülle glänzend weißer Fäden eingewickelt, so daß man von ihm nichts mehr sieht.

Eine Abbildung (Abb. 157) zeigt uns eine photographische Aufnahme des eigenartigen Netzes, in welchem man auch in der Mitte die Argiope in ihrer eigenartigen Stellung sieht. Es war nicht einfach,

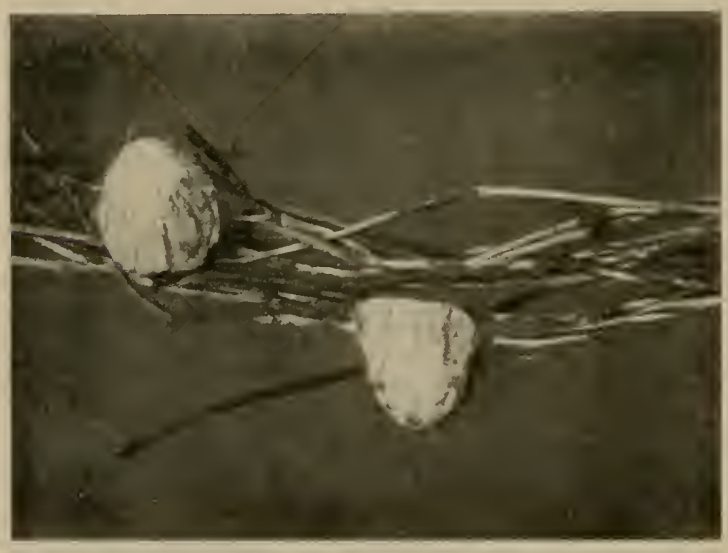

Abb. 159. Eierkokons von Argiope brunnichii Leop., einer Verwandten der Silberspinne. die feinen Fäden des Netzes auf die photographische Platte zu bannen, zumal die meisten Netze dieser Spinne zwischen den Büschen frei gegen den Himmel hingen. Es gelang mir nur dadurch, daß ich nach langem Suchen ein geeignetes Netz in günstiger Urngebung auffand, welches sehr praktisch zur Abendsonne hing. Dort wartete ich abends solange ab, bis die untergehende Sonne so tief stand, daß ihre Strahlen das Netz trafen. Als dessen Fäden nun selbstleuchtend vor dem dunkelen Hintergrund einer Stacheleiche standen, machte ich eine mehrere Minuten dauernde Zeitaufnahme, die immerhin ein brauchbares Resultat lieferte. Argiope lobata Pallas ist im südlichen Mazedonien eine häufige Form. Ähnlich wie sie, baut Argiope brunnichii Leop., welche auch am Körper lebhaft schwarzgelb gefärbt ist. Letztere Form fand ich häufig auf der Hochebene von Stip. Damals war offenbar deren Hauptfortpflanzungszeit, welche überwinternde Kokons lieferte. Denn es war Ende August, als ich jene großen zipfelförmig ausgezogenen Kokons in großer Anzahl zwischen Steinen und an Pflanzen fand. Sie sind nebenan abgebildet (Abb. 159). 
Eine seltsame Spinnenform, welche im südlichen Wardartal nicht selten ist, und welche ich in Mazedonien nur dort antraf, beschäftigte die Phantasie unserer Soldaten sehr viel. Es war ein großes rasches Tier mit unheimlich langen Beinen, das vor allem abends, über die Lagerplätze huschend, die Leute gespensterhaft anmutete. Bei Kaluckova traf ich sie besonders draußen im Wardartal beim Fliegerlager, am häufigsten in der Gegend von Mravinca, die ja überhaupt in ihrer Tierwelt manche Besonderheiten bot. Da fand ich das Tier manchmal am Tage unter Steinen. Im Fliegerlager bei Hudova sah ich aber nicht selten nachts im grellen Licht einer Bogenlampe das unheimliche Wesen wie einen Schatten pfeilschnell über den hell beleuchteten Boden huschen. Dann flog die ganze lustige Gesellschaft auf und sauste hinter der großen Spinne her, um dem Professor die Beute zu sichern.

So erhielt ich manches Exemplar des gefürchteten Tieres, welches Offiziere wie Soldaten als große Spinne die „Vogelspinne“, nannten. Die Art hat aber mit diesen südamerikanischen Riesenspinnen nichts zu tun, gehört vielmehr in die Gruppe der Gliederspinnen (Solifugen) und erwies sich in der Heimat nach Bestimmung der konservierten Exemplare als die Art Galcodes graecus C. L. Koch.

Die Solifugen sind Tiere, welche in Wüsten und Steppen aller Erdteile eine große Rolle spielen. In den südrussischen Ebenen, in den ungeheueren Wüsten und Steppen Zentralasiens, in Syrien, Ägypten, Nord- und Südafrika kommen sie in einer großen Zahl von Arten und meist in großen Mengen vor. So weist denn auch das Vorkommen auf dem Balkan auf wichtige Beziehungen seiner Tierwelt zu den Steppen des Ostens hin.

Galcodes graecus, die griechische Walzenspinne, ist ein höchst auffälliges, bizarr aussehendes Tier. Der wulstige Leib mit dem mächtigen Kopf wird von vier Paaren langer dünner Beine getragen, zu denen als fünftes Paar von Gliedmaßen die oft weit vorgestreckten Kiefertaster kommen. Die haben ein stumpfes keulenförmiges Ende und werden von dem Tier beim l.aufen auch als fünftes Beinpaar benutzt. Von allen Spinnentieren sind diese sogenannten „Walzenspinnen" durch den vom Hinterleib scharf abgesetzten Kopf unterschieden. An dem mächtigen dunkelbraunen Kopf trägt das Tier eine große, senkrecht gestellte Schere, die aus den sogenannten Kieferfühlern gebildet wird.

Dieses gewaltige Beißwerkzeug macht, vor allem wenn das Tier die Schere weit öffnet, einen erschreckenden Eindruck. Aber 
dieser Schrecken ist kaum berechtigt. Die Wunde kann wohl bluten, sie kann hinterher eitern und so gefährlich werden. Aber alle Erzählungen von Krankheit oder Tod, die der Biß des Galeodes verursacht hätte, denen ich nachging, erwiesen sich als Legenden. Es war auch sehr unwahrscheinlich, da in der Beiloschere der Walzenspinne gar keine Giftdrüse ist.

Mehrmals gelang es Exemplare von Galeodes graecus lebend zu erbeuten. Ein großes Weilochen wurde in einem Käfig aus Drahtgaze mehrere Wochen lang lebend gehalten und gab dem ganzen Personal des Lazaretts Kaluckova viel Anlaß zur Belustigung und mir zu manchen interessanten Beobachtungen.

Wie das bei anderen Walzenspinnen beobachtet worden ist, so ist auch Galeodes graecus ein vorwiegend nächtliches Tier. Im Freien habe ich sie nur nachts angetroffen; vor allem kam sie gern in den Lichtkreis der großen Bogenlampen, die einige der militärischen Lager im Wardartal sich leisten konnten. Das gefangene Tier war aber auch bei Tag sehr lebhaft.

Kam man an seinen Käfig, so nahm es sofort eine Bereitschaftsstellung ein; es wich bis an den Hinterrand des Käfigs zurück, hob den Hinterleib etwas in die Höhe und streckte die Maxillarpalpen nach vorn. Dabei vernahm man ein eigentümliches knisterndes Geräusch.

Alle Bewegungen des Galeodes sind außerordentlich rasch und intensiv. Brachte man irgend ein lebendes Tier in seinen Käfig, so dauerte es kaum einige Sekunden, bis dies verschwunden und verschluckt war. Gefangen wurden die Fliegen, mit denen das Tier meistens gefüttert wurde, oft schon im Flug mit den Maxillarpalpen, an deren Enden sie offenbar kleben blieben. Unser Galeodes war unersättlich. Er konnte in einem Tag hunderte von Stubenfliegen vertilgen.

Die Wochen, in denen wir ihn lebend hielten, waren die heifesten und fliegenreichsten des Jahres. Überall in allen Arbeitsund Wohnräumen waren Fliegenfallen aufgestellt, deren ganzes Erträgnis der Walzenspinne zugute kam. Jedermann war aber bemüht, dem Gefangenen allerhand Extras zuzuwenden, so daß dem Tier mit der Zeit wohl die gesamte erreichbare Insektenwelt der Umgebung angeboten wurde. Nichts wurde verschmäht. Heuschrecken, Käfer, Libellen, Schmetterlinge wurden mit dem gleichen Appetit verzehrt, wie gelegentlich ein Stück Fleisch. Kein Unterschied wurde gemacht zwischen toten und lebenden Tieren. 
Ebenso wie Galeodes fliegende und sonst rasch sich bewegende Tiere mit großer Schnelligkeit erhaschte, so bewiesen auch andere Beobachtungen die hohe Entwicklung seines Gesichtssinnes; es folgte mit Bewegungen des ganzen Körpers und vor allem mit den Tastern aufs genaueste irgendeinem Gegenstand, den man in seine Nähe brachte.

Wenn ein größeres und härteres Insekt zerkleinert wurde, so konnte man die Bewegungen seiner Kiefer verfolgen, welche wie ein Schnabel an der Zerkleinerung der Beute arbeiteten und sorgfältig die Muskeln aus den Skeletröhren herauspräparierten.

Bemerkenswert ist die große Erregbarkeit von Galeodes. Geringste Reize bewirkten die Annahme der Bereitschaftsstellung; näherte sich ihm ein Gegenstand, so fuhr er wie wild geworden

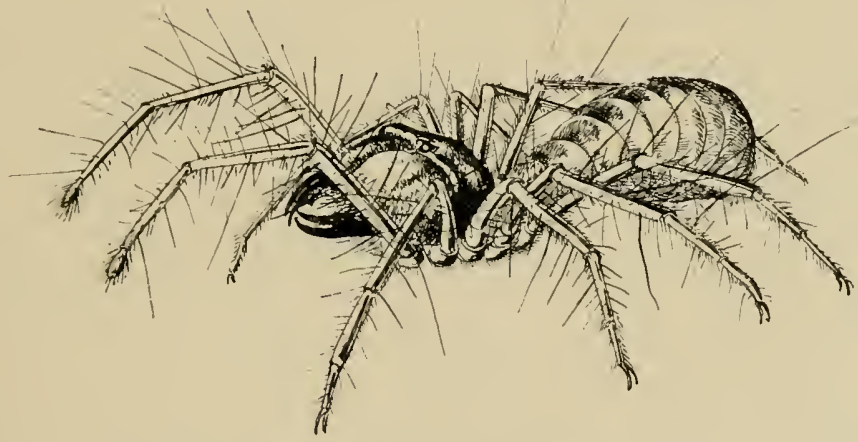

Abb. I6o. Walzenspinne Galeodes graecus in Bereitschaftsstellung. Nat. Größe.

auf ihn los und suchte ihn zu fassen. Dabei wurde der Eindruck der großen Erregung des Tieres noch dadurch vermehrt, daß in solchen Momenten die vorderen Thoraxabdomensegmente lebhaft gehoben und gesenkt wurden. Man hatte den Eindruck eines erregten Atmens; es werden wohl auch sicher Atembewegungen gewesen sein. Tatsächlich liegen ja die Atemöffnungen an den ersten Segmenten des Leibes.

Besonders bemerkenwert war die große Tastempfindlichkeit des Tieres, die wohl bei seiner nächtlichen Lebensweise eine wichtige Rolle spielt. Bei Berührung auch nur eines einzelnen Haares nahm das Tier sofort die Abwehrstellung ein. Auch fuhr es mit den Tastern gegen die berührte Stelle. Besonders die langen Beine des Tieres erwiesen sich als äußerst reizbar gegen Berührung. Die langen Haare, welche den ganzen Körper und alle Gliedmaßen 
bedecken, sind alle Sinneshaare. Sie tragen viel bei zu dem charakteristischen Aussehen des Tieres, das bereit scheint, von allen Seiten Reize aufzunehmen.

Berührung eines einzelnen Haares an den Tastern, an irgendeinem der Beine, am Hinterleib, selbst mit einem ganz zarten Gegenstand, z. B. mit einem Menschenhaar, führt prompte Reaktion herbei. Es erfolgt stets eine rasche Drehbewegung gegen die berührte Stelle. Berührung des Hinterendes veranlaßte eine blitzschnelle Umdrehung des ganzen Körpers. Dabei war die Verwendung der einzelnen Beine in unabhängiger Bewegung sehr bemerkenswert.

Ganz besonders empfindlich gegen Berührungsreize sind die schaufelförmigen Fortsätze am hintersten Beinpaar, die sogenannten Malleoli. Auf ihre Berührung reagiert das Tier blitzschnell und sehr heftig. Welche spezielle Funktion diese besonderen Sinnesorgane bei Galeodes haben mögen, ist noch nicht bekannt. Sicher sind sie geeignet, dem Tiere eine genaue Prüfung von ihnen berührter Gegenstände zu ermöglichen. So mögen sie im Geschlechtsleben eine Rolle spielen. Leider fehlte mir, angesichts der vielen Aufgaben, die in jener Zeit sich vor mir auftürmten, die Zeit, das Tier eingehend auf seine Reizreaktionen in sorgsam angestellten Experimenten zu prüfen. Es hätte dies sicher sehr interessante Ergebnisse geliefert.

Jedenfalls hatte ich den Eindruck, daß das Tier vielmehr unter dem Einfluß von Reizreaktionen steht und automatisch reagiert, als derjenige Forscher annimmt, der bisher die Tiere wohl am eingehendsten studiert hat. Heymons lehnt ihre starke Abhängigkeit von Tropismen ab. Mir dagegen scheinen solche in ihrem Leben eine grole Rolle zu spielen. Gerade seine Beobachtung, daß sie in der transkaspischen Steppe so leicht den Eisenbahngeleisen sich anschließen und an ihnen blieben, scheint mir eine Folge ihrer sehr auffälligen Thigmotaxisreaktionen zu sein, die ich beobachten konnte.

In Mazedonien scheint die Fortpflanzungszeit, ähnlich wie in der transkaspischen Steppe, im Juni und Juli zu liegen. Kleine jugendliche Exemplare fanden sich vom August an in den Herbstmonaten.

$\mathrm{Zu}$ den Spinnentieren gehören auch die Skorpione; nach den Erfahrungen, die ich sonst im südlichen Europa gemacht hatte, hätte ich erwartet, sie in Mazedonien in großer Zahl anzutreffen. 
Es wurden mir auch aus den ersten Jahren des Balkanfeldzuges sogar von Ärzten recht seltsame Geschichten von Abenteuern unserer Soldaten mit Skorpionen erzählt. So wurde von Lähmungen und langdauernden Anästhetien nach Skorpionsstichen berichtet. Da ich nach eigenen Erfahrungen Schmerz und Folgen eines Skorpionstiches bei den südeuropäischen Formen nicht schlimmer einschätzte als die eines Wespenstiches, so war ich auf Sammlung neuer Erfahrungen sehr gespannt.

Es stellte sich bald heraus, daß Skorpione in Mazedonien durchaus keine häufigen Tiere sind. Ich habe allerdings eine Sammlung von Arten dieser Gruppe zusammengebracht; aber diese war das Resultat angestrengter Sammelarbeit und des Umwälzens von vielen Tausenden von Steinen. So ist es auch verständlich, daß ich nie einem Eingeborenen oder Soldaten begegnet bin, der von einem Skorpion gestochen gewesen wäre. Folgende Arten habe ich in Mazedonien gefunden:

I. Euscorpius carpathicus I. bei Üsküb sowohl im Tiefland als am Pepelak und an der Kobeliza in $2100 \mathrm{~m}$ Höhe.

2. Buthus occitanus Amoreux, der mehr im Süden beobachtet wurde. Ich fand ihn bei Mravinca und Kaluckova sowie in der Babunaschlucht bei Veles.

Überblicke ich meine Tagebuchnotizen über Spinnen, so ist es sehr auffallend, daß vielfach für die ersten Frühlingsexkursionen große Zahlen von Spinnenfunden verzeichnet sind. Natürlich hängt dies zum Teil damit zusammen, daß ich mich an solchen Tagen in besonders spinnenreichen Gegenden befand. Aber nicht weniger sind jene reicheren Funde dadurch bedingt, daß an Tagen, an denen die sonstige Tierwelt durch Kälte und ungünstiges Wetter vertrieben oder zur Untätigkeit gezwungen war, die Kraft und Aufmerksamkeit von mir und meinen Mitarbeitern mehr der Aufgabe gewidmet werden konnte, den Spinnen in ihren Verstecken nachzugehen.

So fand ich in und bei Üsküb im Februar, März und April 1918 viele Spinnenarten und konnte an ihnen manche Beobachtungen machen. Anfang März traf ich den Weberknecht (Phalangium cormutum L.), der auch sonst in Nazedonien sehr häufig war. Eine ganze Anzahl von $W$ olfsspinnen waren schon in den ersten Märztagen, während des verfrühten Vorfrühlings (vgl. S. 166) sehr mobil. So liefen am Wardarufer zahlreiche Exemplare von Lycosa paludicola Clerck frei auf dem Sand umher, und zwar waren es Männchen, Weibchen und zahlreiche kleine Tierchen darunter. Am 
gleichen Tage fand sich dort Trochosa cinerea $\mathrm{F}$., auch frei umherlaufend auf dem sonnenbeschienenen Sand. Eine andere Art der gleichen Gattung wurde fast an der gleichen Stelle erst Mitte April gleichzeitig mit der ersteren beobachtet, es war dies Trochosa infernalis Motsch. Diese Arten bauen Röhren im Boden, welche bei $\operatorname{Tr}$. cinerea etwa $25 \mathrm{~cm}$ lang werden.

Besonders auffällig waren in der Üsküber Gegend die mächtigen Taranteln; große, dunkle, behaarte Spinnen, welche Röhren im Boden bewohnen. Eine der Arten (Tarentula praegrandis C. L. Koch), kam in der ganzen Umgebung von Üsküb sehr häufig.

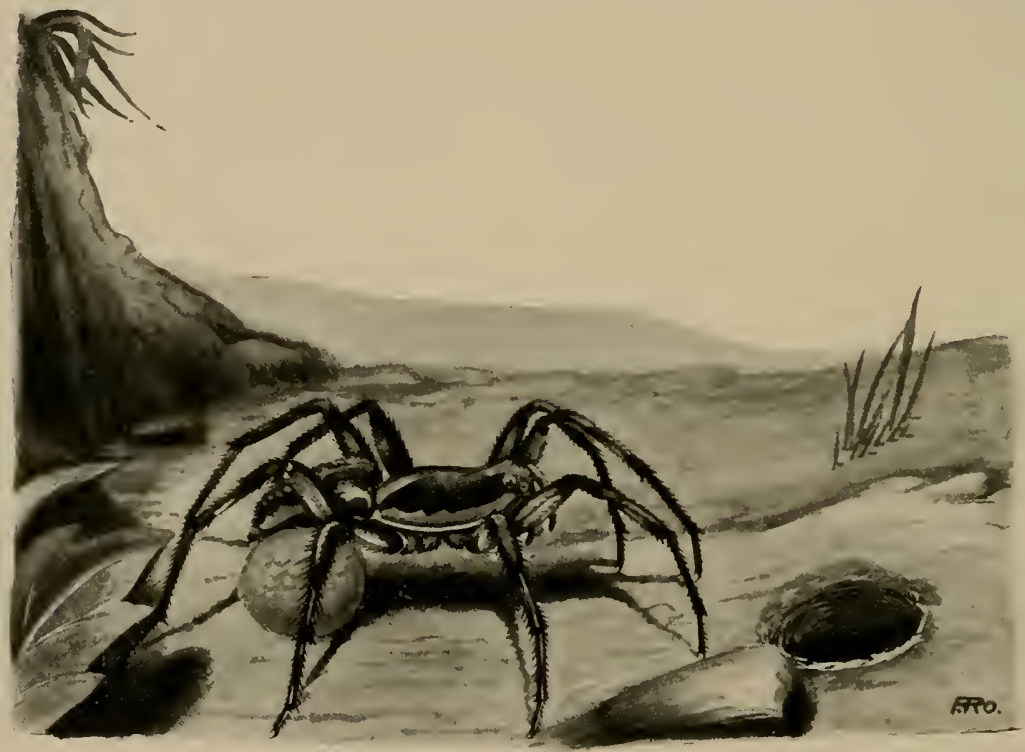

Abb. 161. Tarentula praegrandis (C. L. Koch) mit ihrem Bodenloch.

vor (Abb. 161). Ich habe sie auch bei Dedeli und im Gebirge, auf dem Wodno und später im Sommer auf dem Tomorosgebirge in $1500 \mathrm{~m}$ Höhe beobachtet. Überall baute sie schiefe Röhren in den Boden, welche $20-35 \mathrm{~cm}$ lang waren. Diese Röhren hatten einen Durchmesser von etwa $1-1 \frac{1}{2} \mathrm{~cm}$ und waren mit einem festen Spinnstoff ausgekleidet, so daß man sie ganz bis zu ihrem rundlich geschlossenen Ende aus der Erde herauspräparieren konnte.

In sie tauchten die Spinnen, wenn man sie verfolgte, blitzschnell hinein und verkrochen sich bis ans unterste Ende. Man sah sie oft nahe dem Ausgang ihrer Röhre auf der Lauer sitzen; doch waren sie nicht selten auf Streifzügen unterwegs. 
Die Deckel- oder Minierspinnen aus den Gattungen Cteniza und Nemesia, welche im westlichen Mittelmeergebiet häufig sind, und welche ich früher bei Bozen und in Italien beobachtet hatte, fand ich in Mazedonien nicht, obwohl ich sehr auf sie fahndete.

Eine zweite Art der Gattung Tarentula (T. apuliae Walck.), die ich schon im Jahre 1917 bei Kaluckova gesehen hatte, ein mächtiges Tier mit dunkelbraunem Hinterleib und gelbbraun geringelten Beinen fing ich auch Mitte April bei Üsküb. Am 10. April erbeutete ich ein stattliches Weibchen, welches einen großen, kugeligen Eikokon mit sich trug. Die Begattungszeit war also bei diesem Tier so früh im Jahr schon abgeschlossen. Eine dritte Art Tarentula cuneata Clerck fand ich bei Üsküb schon Anfang März.

Noch mehrere Arten der gleichen Gattung habe ich in Mazedonien beobachtet, so T. trabralis Clerck in einem Kiefernwald bei Strumiza, T. pulverulenta var. aculeata Clerck auch schon im März im Karadakh. Im Süden Mazedoniens war Tarentula radiata Latr. häufiger; ich fand sie dort überall im Wardartal und auf den Bergen. Bei Hudova bedeckten ihre Röhren weite Flächen in der Ebene, besondes in den Maulbeerpflanzungen.

Bei Kaluckova hatte ich als Röhrenbewohner Mygale icterica C. L. Koch (Trechona) beobachtet.

In den drei Frühlingsmonaten traf ich in und um Üsküb ferner noch Runcinza lateralis C. L. Koch im März in ganz. jungen Exemplaren. Unter Steinen fand ich Pisaura mirabilis Clerck und Drassus pubescens Thor. Xysticus luctator L. Koch lief frei herum, während Epeira ubrichii Hahn und E. redii Scop. beim Bauen ihrer Radnetze waren und Liocranum tenuissinum L. Koch am Wardar an Pappeln herumlief.

Zur gleichen Zeit fanden sich in Zimmern, Kellern und Gängen Teutana triangulosa Walck., Pholcus opilionioides Schrank, der auch hier eine besondere Vorliebe für Aborte zeigte, Cicurina cicur Menge und das einzige Mal in Mazedonien Tegenaria pagana C. L. Koch. Dazu kamen Gnaphosa mufula L. Koch und lugubris C. L. Koch. Auf dem Wodno, also am sonnigen Berghang, lieferte die gleiche Periode nicht weniger als 12 Spinnenarten.

Im April war auch am Katlanovosee, besonders im Schilf, der Reichtum an Spinnen groß. So fand sich Hyctia canestrinii Can. und Rad. direkt in Schilfhalmen wohnend. Auch sonst fand ich die Art stets in Wassernähe, so am Wodno und bei Gewgeli am Wardar. Becker gibt dasselbe für die in Algier entdeckte, 
von ihm in Belgien am Meer in den Dünen beobachtete verwandte Art $H$. nivoyi Luc. an.

Direkt als Wasserspinne kann Dolomedes lumbatus Hahn bezeichnet werden, eine Art, welche zwischen dem Schilf lebt. Ihre Lebensweise scheint ganz ähnlich zu sein, wie sie Becker für $D$. fimbriatıs Clerck geschildert hat. Sie scheint deren südliche Vertreterin zu sein, stürzt sich wie diese ins Wasser, um da ihre Beute zu fangen.

Auch von der dritten Spinnenart, die ich im Röhricht des Katlanovosees fand, ist von ihren nördlichen Fundorten bekannt, daß sie die Nähe des Wassers liebt. So beschreibt Becker, daß Epeira cornuta Clerck ihr Radnetz an, im oder über dem Wasser wachsenden Pflanzen baut. Am Katlanovosee waren die Spannfäden zwischen den Binsenrohren ausgespannt.

Ein eigenartiges, auffallendes Tier, welches auch in Deutschland nicht selten vorkommt, war dort Theridium lineatum Clerck; der Rücken dieses Tieres ist silbergrau mit dunkelbraunen Längsstreifen.

Auch sonst ließe sich von mazedonischen Spinnen mancherlei berichten. Bei der Schilderung der einzelnen Gegenden und besonderer Landschaftsformen wird Gelegenheit sein, auf sie zurückzukommen.

Meine reiche mazedonische Spinnensammlung wurde von Dr. Roewer (Bremen) bearbeitet. Sie enthält viele für den Balkan neue Formen, wenn auch keine neuen Spezies.

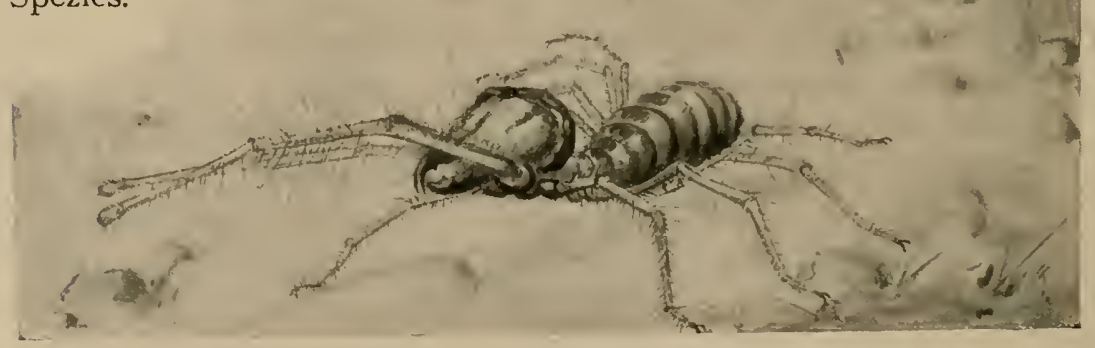

Abb. 162. Walzenspinnen in verschiedenen Stellungen. 


\section{DAS CHROMBERGWERK VON RADUSCHE}

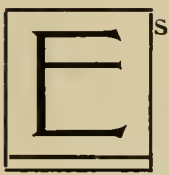

war ein interessanter Weg, der mich mit meinen Präparatoren an einem schönen Aprilmorgen (18. April 1918) das Wardartal aufwärts nach Radusche führte. Der Kleinbahnzug war uns vor der Nase weggefahren und ein Marsch von etwa $20 \mathrm{~km}$ lag vor uns. Aber es wehte ein frischer Wind, die Landschaft prangte im schönsten Frühlingsgrün, große weiße Wolken zogen am tiefblauen Himmel dahin.

Links von uns erstreckte sich ein hoher Gebirgszug, mit dem Wodno beginnend, nach Westen ziehend und so den Südrand des Wardartals bildend. Eine Schlucht von riesigen Dimensionen unterbrach die Kette; es war der Durchbruch der Treska, des mächtigen Nebenflusses des Wardar, der stärker als dieser, dem Flußlauf wohl den Namen gegeben hätte, wenn nicht der kleinere Wardar die Hauptrichtung des Flußsystems bestimmte. Blau ragte das schön umrissene, klar modellierte Gebirge hinter einem von Pappeln und Obstbäumen umhüllten Dorf auf. Es war ein Landschaftsbild von großer Schönheit und der für Mazedonien charakteristischen Farbigkeit, das Dorf mit seinen weißen Häusern und roten Dächern, seinem grünen Park und dem zarten Schleier der blühenden Bäume, in den großen Rahmen der Gebirgslandschaft gestellt.

Der Kleinbahnlinie folgend bogen wir in das Flußtal ein, dessen Windungen in die Berge führten. Eine lachende Frühlingslandschaft begleitete uns zunächst. Grüne Wiesen mit blühenden Obstbäumen, weiß überhauchten Weißdornbüschen und duftenden Blumen waren das richtige Tummelfeld vieler Vögel. Am Flußufer lauerten Eisvögel von den Büschen auf die kleinen Fische und stürzten sich, wie funkelnde Edelsteine aufblitzend, zum Wasser hinab (Alcedo atthis atthis L.).

Von den Obstbäumen sah man einen kleinen Vogel lustig tirelierend senkrecht in die blauen Lüfte steigen, um dann langsam 
zum Boden niederzuschweben. Es war der Baumpieper (Anthus trivialis trivialis L.), der genau so seinen Balzflug ausführte, wie ich ihn wenige Jahre vorher genau zur selben Jahreszeit im oberen Donautal beobachtet hatte. Über die Steine des Flußufers hüpften zwitschernd weif-schwarze Bachstelzen und die gelbgefleckten Schafstelzen. Stare (Sturnus vulgaris balcanicus Stres.) und die Balkanamsel wetteiferten mit ihrem Gesang, die Erinnerung an den Frühling der Heimat wachzurufen. Besonders schön war hier das Lied der Mönchsgrasmücke (Sylvia atricapilla atricapilla L.). Zwei andere Grasmücken, die Zaungrasmücke (Sylvia carruca carruca L.) und die Dorngrasmücke (Sylvia communis communis Lath.) huschten durch die Hecken. Auch Kohlmeisen und Blaumeisen waren beim Absuchen der Rinde der Obstbäume fleißig tätig.

So ging die Zeit unterm Beobachten schnell dahin, während wir flußaufwärts in öderes, winterlicheres Gelände kamen. Der Fluß machte mehrere große Windungen, trat an eine kahle Bergwand heran, welche in ein enges Tal umbog. Neben dem Fluß ließ die Schlucht gerade noch Raum für die schmale Straße und das Geleise der Schmalspurbahn, die hier steil emporzuklettern hatte.

Durch das Tal mit seinen rötlichen Felsenwänden erblickte man über dem steinerfüllten, brausenden Fluf ein Stück der Schardakhkette. Es war gerade der Teil um den Ljubotren, der hier als prachtvolle Pyramide sich in der Mitte des Bildes stattlich abhob. Er wie die ihn umgebenden Berge waren noch tief herab mit Schnee bedeckt. So war es wieder ein malerisches Bild von großer Schönheit, das ich längere Zeit beim Ansteigen bewundern durfte.

Nach etwa einer Stunde erweiterte sich das Tal; wir kamen an die Endstation der Kleinbahn, die von Baracken und Schuppen umgeben war. Zahlreiche kleine Güterwagen standen auf Nebengeleisen, zum großen Teil schon mit Erzen beladen, um mit dem Nachmittagszug nach Üsküb befördert zu werden.

Vor uns erhoben sich die gewaltigen Halden des Bergwerks, welche hier die Nordhänge des Tals einnahmen. Oben am Berg standen verschiedene Häuser, das Wohnhaus des Direktors, ein Beamtenkasino, in welchem wir freundlich bewirtet wurden, und Verwaltungsgebäude.

Nach einem Besuch bei dem Direktor besichtigen wir das Werk, welches als Tagbau betrieben und infolgedessen sehr leicht 
zu überblicken war. Einige der Hügel und Rücken des Berges bestanden aus Serpentin, welches von Chromeisenerz stark durchsetzt war. Dieses wurde durch oberflächliche Sprengungen in Trümmer zerlegt, welche auf kleinen Karren auf Schienen zu bestimmten Stellen gebracht und angehäuft und von da zu Tal gebracht wurden.

So machte die Landschaft einen öden Eindruck; Pflanzen wuchsen keine auf diesen Hängen, nur an den Rändern und in den Schluchten zeigte sich die übliche trockene Buschvegetation. Grünlich-grau war das Gestein, an einzelnen Stellen traten tiefschwarze Massen hervor; das war das chromreichste Erz. Dort

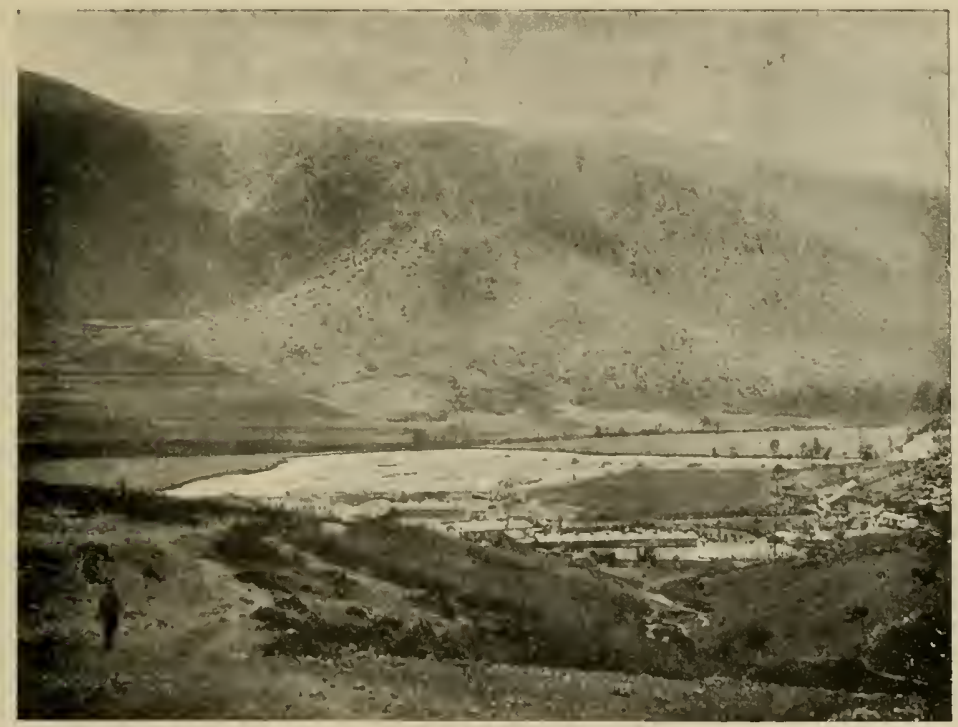

Abb. 163. Radusche. Lage am Fluß, Bahnstation und Häuser.

wurde gesprengt und gearbeitet. Hier sah man dunkle Menschenmassen zusammengedrängt: hunderte von Arbeitern, welche die Gesteinsmassen in die „Hunde“ schaufelten. Diese liefen auf schmalen Geleisen, die wagerecht den Hängen entlang verliefen. So war das ganze Gelände in Terrassen geteilt, welche parallel übereinander einige hundert Meter an der Talwand sich hinzogen.

Die erzhaltigen Steintrümmer wurden mit Klopfmaschinen zerkleinert, die Stücke sortiert, die gehaltreichsten Erze, die fast schwarz waren, von den grauen geringeren und diese von dem Grundgestein gesondert. Dieses blieb auf den Halden zurück, 
während das Erz in Körben auf einer primitiven Schwebebahn hinab zur Bahnstation gebracht und in die Güterwagen verladen wurde.

So bildeten sich an den Abhängen mächtige Schutthalden, von denen manche weiß wie Schnee von den bunten, meist grünlichen Felsen des Grundgesteins seltsam abstachen.

Dieses einfache Bergwerk war schon in Friedenszeiten abgebaut worden, aber infolge der geringen Rentabilität und der Transportschwierigkeit hatte es nie richtig floriert und lag meist

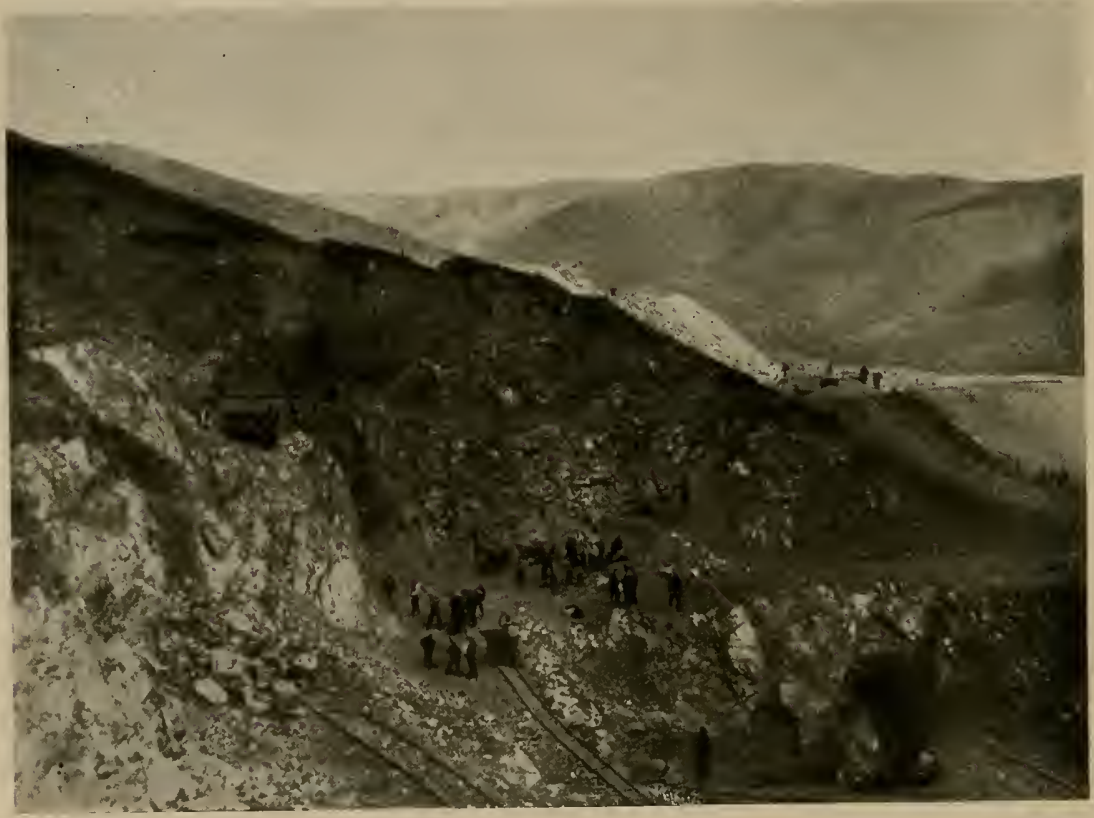

Abb. 164. Chromerz-Tagebau bei Radusche.

still. Die Arbeiterzahl, die man dort in serbischer und früher in türkischer Zeit beschäftigte, hatte wohl niemals die Zahl too erreicht. Zur Zeit meines Besuchs war dort großer Betrieb. Man beschäftigte gerade 3700 Arbeiter, meist Mazedonier und Albaner. Über ihre Leistungsfähigkeit, Arbeitsamkeit, Arbeitsdisziplin wurde sehr geklagt. Aber gearbeitet werden mußte doch mit allen Kräften. Denn Chrom war für die deutsche Heeresleitung ein wichtiger Artikel. Nachdem der Wolframimport von Übersee, vor allem von Birma, vollkommen abgeschnitten war, hatte man in Deutschland alle alten Werke, die Ersatzmetalle, wie Molybdän 
liefern konnten, wieder in Betrieb gesetzt, so kleine Bergwerke in den hohen Bergen der Alpen.

Aber deren Erträge waren ungenügend, angesichts der großen Mengen, die man zur Härtung des Stahls für Panzerplatten für Forts, Befestigungen, für die Marine brauchte. Es war ein schwerer Notstand, zu dessen Behebung alle Hebel in Bewegung gesetzt wurden. Die einzigen Bergwerke, die Chrom lieferten und in unseren Händen waren, lagen in Mazedonien und im türkischen Kleinasien. Nur Radusche war von diesen einigermaßen günstig zu einer leistungsfähigen Bahnlinie gelegen. Die anderen Werke in Mazedonien, nahe bei Dedeli, waren sehr klein und wenig ertragreich.

So liefert denn in jener Zeit Radusche all das Chrom, welches wir zur Stahlhärtung bekamen. Es herrschte daher ein fieberhafter Betrieb dort und auf der Kleinbahn. Alles Geförderte wurde sofort, abtransportiert, fuhr nach Deutschland und wurde dort gleich nach der Ankunft verarbeitet.

Man bekam hier einen Einblick in eine der vielen Nervenleitungen des Kriegsorganismus und lernte verstehen, wie außer politischen und militärischen Notwendigkeiten auch harter wirtschaftlicher Zwang die Besetzung eines Landes und das Halten einer Front unerläßlich machte.

Da noch viele andere wichtigen Elemente des wirtschaftlichen Lebens aus dem Balkan flossen, ich erinnere nur an das serbische Kupfer aus Bor, an das Opium für die Arzneifabrikation, an Reis, Getreide, Ö1 und all die Lebensmittel sowie das Petroleum aus Rumänien, so wird man verstehen, welche Folgen der Zusammenbruch dieser Front auf alle Dispositionen unserer Heeresleitung haben mußte. 


\section{EINUNDZWANZIGSTES KAPITEL}

\section{DER KATLANOVOSEE}

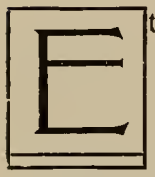

twa $20 \mathrm{~km}$ östlich von Üsküb liegt im Winkel zwischen dem Wardar und der südlich in diesen mündenden Pcinja ein eigenartiger Sumpfsee, der Katlanovosee. Er und seine Umgebung bot dem Zoologen viel Interessantes. So war er das Ziel zahlreicher Ausflüge, welche der Vogelwelt, den Insekten und Spinnen wie den Wassertieren galten. Bei diesen war häufig mein Begleiter mein früherer Assistent Dr. N a ch ts heim. Es war mir gelungen, ihn vom Postüberwachungsdienst zu befreien und ihn nach Mazedonien kommandiert zu bekommen, wo er nützlichere Tätigkeit fand.

Nördlich vom Katlanovosee zieht sich ein schmales Sumpfgebiet bis in die Gegend von Üsküb, in welchem zahlreiche Bäche versickern. Somit ist jetzt der See im wesentlichen ein Sammelbecken dieser Bäche. Es ist nicht ausgeschlossen, daß er früher einmal vom Wardar durchflossen wurde oder diesen an anderer Stelle mit der Pcinja verband, ehe diese sich ihre Schlucht zun Wardar gewühlt hatte.

Der lange Weg von Üsküb zum See war reizvoll durch die Blicke auf die Berge der Ungegend; entzückend schöne Formen hatten vor allem Osri und Kitka, welche als letzte Ausläufer der Golesniza Planina in die Wardarebene etwa $1500 \mathrm{~m}$ hoch emporragten und diese damit fast bis zur Wardarklamm zwischen Taor und Selenikovo fortsetzten. Nördlich zogen sich die Höhen des Karadak hin. Kleine Dörfer lagen in Gruppen von Pappeln und Obstbäumen malerisch vor den Bergen. Auf den Bäumen sah man viele Storchennester.

Wie diese, so hatte der Sumpfwald, der sich zwischen Üsküb und dem See hinzog, eine reiche Vogelwelt angelockt, deren Studium ich manchen Tag im April 1918 widmete. Prachtvolle alte Eichen, Weiden, Erlen und Haselgebüsch bildeten diesen lichten Wald, in welchem auch Pappeln nicht fehlten. Zwischen den Gruppen großer Bäume dehnten sich Flächen dichten Gestrüpps aus, die besten Schlupfwinkel für die mannigfaltige Vogelwelt. 
Einige alte Bäume waren die Ruheplätze großer Raubvögel. Sie standen meist einsam, so daß es außerordentlich schwer war, sich an sie heranzupürschen, um die Riesenvögel genau zu betrachten oder gar erlegen zu können. Immerhin gelang es, manche der dort sitzenden Arten mit großer Sicherheit festzustellen, zum Teil als Beute von Offizieren und eines Veterinärs, die mehr Zeit auf die Jagd verwenden konnten, als ich, den viele andere Probleme festhielten.

Wie überall in Mazedonien war hier der $\mathrm{K}$ aiseradler an häufigsten (Aquila heliacea heliacea Lad.); die meisten Adler, welche in Mazedonien jung aus den Nestern genommen und bei den Abteilungen aufgezogen wurden, gehörten zu dieser Art. Ich habe ihrer viele in allen Teilen des Landes gesehen. Mit Sicherheit glaube ich ferner beim Katlanovosee den schön braunen Schreia dle r (Aquila pomarina pomarina Pr.) und den gefleckten Schel1adler (Aquila maculata $\mathrm{Gm}$.) beobachtet zu haben. Im ganzen habe ich in Gebiet fünf Adlerarten gesehen, zu den genannten noch den $\mathrm{Z}$ wergadler in der Golesniza Planina (Hieraëtus pennatus Gm.) und bei Hudova den Schlangenadler (Ciraïtus gallicus Gm.) als ziemlich häufige Form.

Dazu kommt noch der $\mathrm{F}$ ischadler (Pandion haliaëtus haliaëtus Lad.), der auch in der Nähe des Sees nicht selten war; im Winter konnte ich mehrmals auch Seeadler (Haliaitus albicilla L.) beobachten.

Einer der alten Bäume im Sumpfwald war der Schlafplatz eines riesigen Gänsegeiers (Gyps fulvus fulvus Habl.). Wie oft suchte ich in der Dämmerung an ihn heranzukommen. Doch nie gelang es, ihn zu überraschen. Er hatte sich seinen Schlafbaum so vorsichtig ausgesucht, da $\beta$ man beim Heranschleichen von keiner Seite Deckung fand. Schließlich gelang es einem mich oft begleitenden Tierarzt ihn zu erlegen.

An den Abfallhaufen der Korpsschlächtereien konnte man oft auch Mönchsgeier (Aegyptius monachus L.) und den Aasgeier (Neophron pernopterus pernopterus L.) beobachten. Es war ein phantastischer Anblick, wenn die riesigen Vögel sich um die Reste der geschlachteten und gefallenen Tiere balgten. Ein wüstes Geschrei erhob sich um die Abdeckereien herum, wenn die Tiere sich hoch aufrichteten, den nackten Hals zurückbogen und die breiten Federn ihrer Flügel weit auseinander spreitzten. Auch diese beiden Arten kamen in den Sumpfwald zum Schlafen. 
Es ist das eine stattliche Schar großer Vogelarten, welche ich damit verzeichne. Für mich als Zoologen gehört es zu den starken Eindrücken, die ich von Mazedonien mitnahm, so viel von der Vogelwelt beobachten zu können. Überall erblickte man Adler und Geier; bei jedem Ausflug in die Berge sah man entweder die Paare der Adler in mächtigen Kreisen hoch oben nahe den Wolken streichen, oder man konnte ganze Scharen von Geiern tief herab. schweben und sich auf ein Aas stürzen sehen. Auch die Mengen von Vögeln, die oft von einer Art sich an einem Ort versammelten, waren überwältigend. Wie belebt ist die Luft noch in den Ländern Europas, in denen noch nicht die Eisenbahnschienen das ganze Land, Telegraphen- und Telephondrähte die Luft durchkreuzen und hunderte von Fabrikschornsteinen sie verpesten und den Beherrschern der Lüfte die freie Bahn sperren.

Einen nicht geringen Beitrag zu diesen Erlebnissen lieferte die Gegend des Katlanovosees. Im Sumpfwald waren Falken, Weihen, Sperber und Bussarde noch häufiger als ihre großen Vettern. Eine große Rolle spielen dort auch die Eulen. Oft streifte ich bis tief in die Dämmerung durch die Büsche. Dann flogen nicht selten allerhand Eulenarten leichten Fluges über meinen Kopf dahin.

Eine eigenartige Beobachtung konnte ich an Waldohreulen (Asio otus otus L.) machen. Als ich eines Tages durch ein dichtes Gebüsch drang, flog ein Schwarm von etwa I 2 Exemplaren dieser Art vor mir auf. Ich schoß ihrer zwei herunter, die anderen verschlüpften sich so tief in die Büsche, daß ich keine mehr von ihnen an diesem Abend auftreiben konnte. Als ich am nächsten Tag dieselbe Stelle aufsuchte, trieb ich offenbar denselben Schwarm wieder auf. Ich wiederholte meinen Besuch in den nächsten I 4 Tagen, es war Mitte April, mehrmals und fand die Tiere jedesmal in demselben Buschstück. Es war dies offenbar ihr Schlafplatz, wo sie vor der Paarungszeit in Gesellschaft schliefen. Schließlich habe ich sie doch vertrieben, da ich mehrmals eine wegschoß.

Auch die $Z$ wergohreule (Otus scops scops L.), sowie die Sumpfohreule (Asio flammeus flammeus Pontopp.) waren bei Üsküb nicht selten. Von Käuzen fanden sich der Steinkauz (Carine noctua indigena $\mathrm{Brehm}$ ) und der $\mathrm{W}$ ald k a u $\mathrm{z}$ (Strix aluco aluco L.) nicht selten in der Umgegend von Üsküb; in der Stadt selbst sah ich einmal einen gefangeren $\mathrm{R}$ auhfußkauz (Cryptoglaux funerea funerea L.). Mehr mit Käuzen hatte ich im Jahr 
vorher in Kaluckova zu tun gehabt, wo wir sie zur Untersuchung ihrer Blutparasiten lebend hielten.

Der Uhu (Bubo bubo bubo L.) ist in Mazedonien ein sehr häufiger Vogel. Nicht selten wurden von unseren Soldaten seine Nester ausgenommen und die Jungen in Käfigen aufgezogen.

Daß in Sumpfwald allerhand Kleinzeug von Vögeln vorkam, ist nicht verwunderlich. Der Wendehals (Jynx torquilla torquilla L.) trieb dort sein munteres Wesen. An den Stämmen lief der Baumläufer (Certhia brachydactyla brachydactyla. Brehm) lebhaft auf und ab. Auch der Kleiber holte sich an den Tümpeln Lehm zum Bau seines Nestes (Sitta europaea caesia Wolf). Ein reiches Leben von $M$ eise $n$ huschte durch die Baumkronen, allerhand Arten, so die Kohlmeise (Parus major major L.), die Blaumeise ( $P$. coeruleus coeruleus L.) und Sumpfmeise (Parus palustris stagnalis Br.). Sehr lebhaft waren die Schwanzmeisen, von denen hier zıvei Formen, wie fast überall, häufig waren (Aegithalus caudatus I. und Aegithalus caudatus mazedonicus). Alle waren sie beim Nestbau. Besondere Freude machten mir die Beutelmeisen, welche hier wie am See selbst zahlreich vorkamen und deren sorgfältig gebaute Nester an den Büschen und am Schilf hingen.

Manchen schönen Abend verbrachte ich hier im Wald, die Vögel beobachtend. Durch die noch kaum belaubten Bäume strahlte der gelbe Himmel hindurch, blau leuchteten die Berge und wurden immer blauer, während es im Gebüsch und in den Baumkronen immer stiller wurde und all die munteren Vögel ihre Schlafplätze aufsuchten und nur die Eulen stillen Fluges durch die Lüfte strichen.

Zum See selbst war vom Sumpfivald aus nochi ein gut Stück Landstraße zurückzulegen. Dürre Felsenhügel mit niederen Büschen begleiteten den Nordrand der Straße. Von ihnen flog gelegentlich eine Felsentaube herüber (Columba livia L.). Den Katlanovosee erkannte man als solchen erst, als man ihm ganz nahe war. Jenseits, im Süden, ragten die Randberge des WVardartales auf, welche bis dicht an den See herantraten. Von der Landstraße aus ging es flach über eine sandige Ebene zum See, dessen Wasserfläche man vor Pflanzenwachstum kaum irgendwo erblickte. Ein Meer von Schilf und Röhricht breitete sich vor meinen Augen aus, im Frühjahr dürr und gelb, später im Jahr prächtig grün.

Wenn am frühen Morgen ein frischer Wind durch das Röhricht strich, ging ein Rauschen über die ganze Fläche, das in 
der Ferne sich verlor, um irgendwo wieder anzuheben. Eine eigenartige Musik ging von diesem See aus. Allerhand Geräusche tönten aus dem Schilfmoor heraus. Fast dröhnend wie Paukenwirbel drang geheimnisvoll anschwellendes Rauschen aus den Herzen der Schilfwälder hervor. Waren es Scharen von Wildgänsen, Enten oder Wasserhühnern, welche das Röhricht durchbrachen, das Wasser aufwühlten, indem sie in wilder Flucht vor dem nahenden Menschen sich davonmachten?

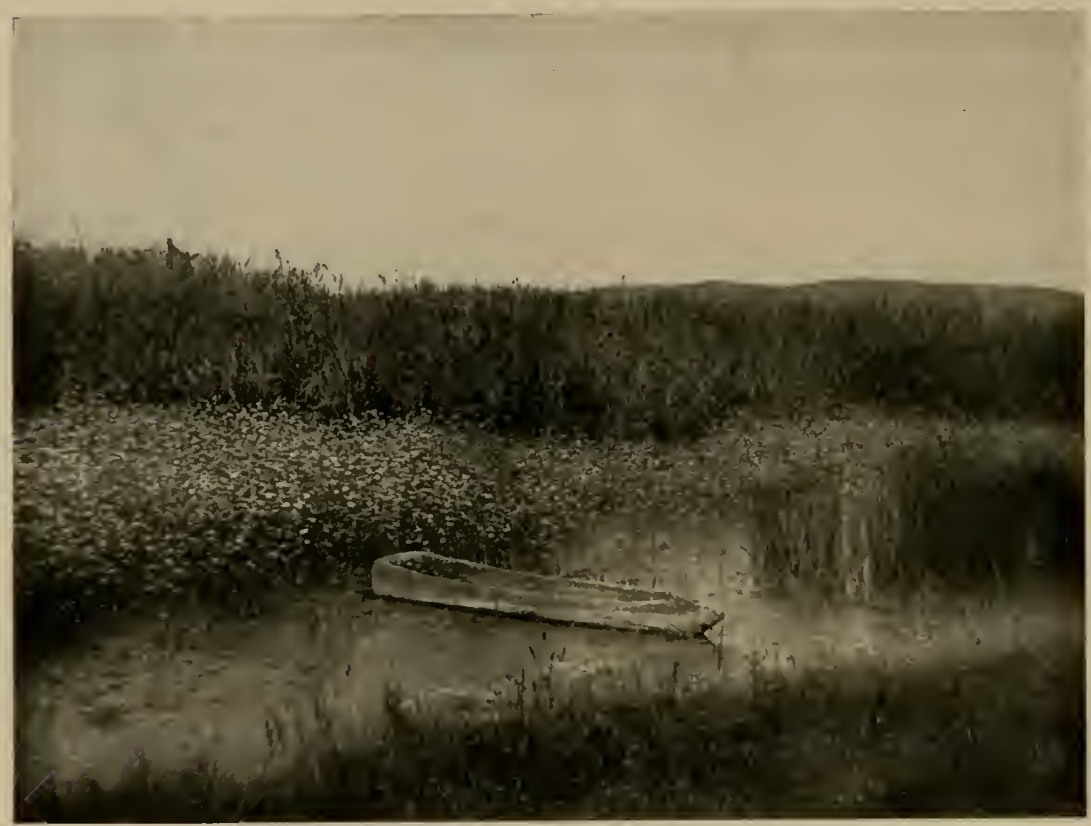

Dr. Nachtsheim phot. Abb. I65. Alter Einbaum im Katlanovosee, Dahinter Wasserschierling und Röhricht.

Es war kein leichtes Gelände, um Tiere zu beobachten und zu erjagen, dieser See, dessen seichtes Wasser fast ganz überwachsen war und nur stille einsame Lichtungen weit draußen offen gelassen hatte. Am Ufer waren einige kleinere Becken zu entdecken, in denen alte Einbäume, morsche Fischerkähne im Wasser versunken lagen. Der Krieg mußte die Fischer vom See vertrieben haben; denn auch die kleinen Schilfhütten am Ufer und auf Sandbänken im Innern des Schilfwaldes waren verfallen und vernachlässigt.

Bei unserem ersten Erkundungsausflug lagerten wir an einer sandigen Bucht, in welcher ein solcher Kahn lag. Rasch hatte 
mein Assistent sich ausgezogen und suchte das Boot zu heben und mit seiner Mütze auszuschöpfen. Dazwischen fing er mit dem Handnetz Wasserkäfer und allerhand Schwimmwanzen, die in Menge in seichten Wasser herumschwammen.

Plötzlich stürzte er erschreckt ans Ufer; Blut lief an vielen Stellen von seinen Schenkeln herab, an seinem Körper hingen fast ein Dutzend Blutegel. Noch hatten sich die Bestien nicht ganz fest angesaugt, so daß es gelang, ihn schnell davon zu befreien. Es war der echte medizinische Blutegel (Himdo medicinalis L.), welcher den See für uns außerordentlich schwer zugänglich machte. War ein Vogel geschossen, so fiel er im Schilf nieder und es kostete Zeit, ihn aufzufinden. In dieser Zeit saugten sich überall im See Blutegel an den Jäger und so mußte überlegt werden, wie man einen Kahn flott machen konnte, um ungefährdet ins Innere der Schilfwälder zu gelangen. Es gelang schließlich, und auch ein primitives Ruder wurde aus einem Brett geschnitzt. Aber oft mußte man doch aus dem Kahn heraus, um das Netz einzuholen oder den gefallenen Vogel zu suchen. So hat jeder von uns seine Portion Blut opfern müssen, um die Erforschung des Sees durchzusetzen. Es ging auch so und manche interessante Beobachtung wurde erzielt.

Mit großem Geschrei flogen zahlreiche Rohrweihen (Circus acruginosus aeruginosus L.) über dem Röhricht, mit Gebrause sich aus ihm erhebend und in die Tiefe sich stürzend. Zwei Ammern trieben sich mit grellem Geschrei im Schilf herum, die Rohrammer (Emberiza schoenichus canneti $\mathrm{Br}$.) und eine größere Gimpelammer (Emberiza schocniches reiseri Hart.). Im dürren Gras am Ufer liefen am Boden Schafstelzen (Budytus fava feldeggi Michah.) und Kalanderlerchen (Mclanocorypha calandra calandra L.) umher.

Es war ein reiches Leben um das Schilfmeer und in ihm; es gab viel zu beobachten und zu erbeuten. Im Mai tauchten viele Drosselrohrsänger (Acrocephalus arundinaceus arundinaceus L.) auf, deren Gesang die I.uft erfüllte; auch der Sumpfrohrsänger (A. palustris Bechst.) ließ sich erbeuten, ebenso der Schilfrohrsänger (A. schocnaboenus L.). Alle diese machten ein großes Wesen im Schilfwald; ihre Nester waren vielfach am Schilf zu beobachten und im Sommer gab es viel junge Brut. Die Tiere waren fast ungestört und wurden nur hier und da von einem Sperber oder einem anderen Raubvogel erbeutet. 
In großen Mengen kommen im Sumpf um den See die Lachfrösche (Rana ridibında) vor und waren eine beliebte Kost für die zahlreichen Störche und anderen Stelz- und Wasservögel, von denen viele zur Beobachtung gelangten und von uns und den jagenden Offizieren erbeutet wurden. Ein prachtvolles Tier war der Löffelreiher (Platalea leucorodia leucorodia L.) mit seinem leuchtend weißen Gefieder und seinem fleischfarbenen breiten Schnabel und Kehlsack. Offenbar waren Nester mitten im Röhricht, zu denen die Tiere immer wieder niederflogen. Es war aber unmöglich, mit den morschen Kähnen so tief in das Schilfgewirre einzudringen. Ebenso brüteten im See Fischreiher (Ardea cinerea cinerea L.) und Purpurreiher (Ardea pupurea purpurea L.), deren Nester man auch an unerreichbaren Stellen mit dem Glas feststellen konnte.

Seltener waren im Jahre 1918 die Rohrdommeln (Botaurus stellaris stellaris L.) geworden, welche im Jahr vorher noch sehr häufig gewesen sind. Immerhin gelang es, diese im Frühjahrsröhricht mit seiner gelbraunen Farbe kaum sichtbaren Vögel im Juni, als das Schilf grasgrün war, mehrfach zu erbeuten.

Wundervolle, glänzende Tiere waren die purpurbraunen Sichler, die Ibisse mit ihren schwarzen gebogenen Schnäbeln (Plegadis falcinellus falcinellus L.), welche recht zahlreich im dichten Dickicht vorkommen und unzweifelhaft dort auch brüteten, wie aus den vielen jungen Vögeln zu erschließen war.

Graziös stolzierten Kraniche (Megalornis grus grus L.) durch die Gräser, ihren grauen Federbusch behaglich wiegend. Einen gewaltigen Lärm machten auffliegend die Wildgänse und Wildenten. Außerordentlich häufig war im Winter 1917 die Wildgans (Anser anser L.), die Saatgans (Anser fabalis fabalis Lath.) und im Frühling bei Üsküb die Brandgans (Tadorna tadorna L.).

Die vielen Entenarten, welche regelmäßig oder auf dem Zug vorkommen, will ich nicht einzeln aufführen. Ich will nur die Löffelente (Spatula clypeata L.), die Moorente (Nyroca nyroca Güld.), die Spießente (Dafila acuta L.), die Tafelente (Nyroca ferina ferina L.) und die Eisente erwähnen, welche allerdings nicht von mir, einmal bei Üsküb erlegt wurde.

Verschiedene Teich hühner konnten nicht mit Sicherheit identifiziert werden, dagegen die Wasserralle (Rallus aquaticus aquaticus L.) wurde am Rand des Katlanovosees mehrfach geschossen. 
Das war eine reiche interessante Vogelwelt, die sich an den zahlreichen Tagen, welche wir dem See und seiner Ungebung widmeten, uns darbot. Dr. Nachtsheim machte außerdem zahlreiche Planktonfänge, welche Copepoden, Daphniden und Ostrakoden enthielten; sicher waren darunter interessante Formen. Leider konnten sie nicht genau bestimmt werden, da sie zu den wenigen Bestandteilen unserer Ausbeute gehören, welche auf dem Rückzuge dem Feinde in die Hände fielen.

Dagegen blieben die reichen Spinnensammlungen erhalten, welche im Schilfgebiet des Katlanovosees zusammengebracht wurden. Zwischen Schilf und Röhricht fanden sich allerhand interessante Arten. Es war vor allem im Anfang April 1918, daß ich dort sehr auf die Spinnen achtete. Auffällig war, daß angesichts der Armut an Insekten sich auffallend viele Spinnen im Röhricht herumtrieben. So flog am 2. April schon ein Theridium lineatum Clerck wie Altweibersommer an langen Seidenfäden durch die Luft. Es war ein auffallendes Tier mit drei dunkelbraunen Streifen auf dem Rücken und je fünf solchen auf silberweißem Grund am Kopf. Größere Exemplare der Art fanden sich am Boden.

Zwischen Rohrstengeln hatte eine Spinne denjenigen unserer Kreuzspinnen ähnliche Radnetze von nicht sehr großem Durchmesser ausgespannt. Es war eine Epeira cormuta Clerck., von der schon am 9. April Männchen und Weibchen auf den Netzen beieinander waren. In Schilfhalmen selbst wohnte Hyctia canestrinii Can. und Pav. An solchen kletterte Dolomedes limbatus Hahn auf und ab, während Pisaura mirabilis Clerck und Drassus pubescens Thor. sich am Rand des Sees unter Steinen fanden.

Später im Jahre kletterten vielerlei Käfer aus der Gattung Donacia auf den Schilfrohren herum; Libellen in vielen Arten, tiefblau, grau, rot, grün gefärbt, Eintagsfliegen, Köcherfliegen, flogen zwischen den Halmen hindurch und über ihnen, während ihre Larven im Wasser sich entwickelten. Kleine Fische, deren Vertreter auch verloren gingen und die somit nur als Lenciscus-Arten bezeichnet werden können, schwammen in ganzen Schulen an sonnigen, schilffreien Stellen des Sees.

Nicht immer war es möglich von Üsküb her mit dem Wagen den direkten Weg zum See zu machen. Dann war die Hin- und Rückreise etwas beschwerlicher. Man fuhr mit einem Bummelzug nach der Station Selenikovo, von wo über die Hügel ein nicht reizloser Weg durch ein insektenreiches Tälchen führte. Der Rück- 
weg wurde dann durch die Wardarschlucht, die sich zwischen Taor und Selenikovo erstreckt, zurückgelegt. Bei Selenikovo war nämlich weithin die einzige Brücke über den Wardar auf das rechte Ufer, auf welchem die Bahnstrecke lief. Dort bestieg man nachts einen Güterzug, welcher etwa um Mitternacht auf einer Zwischenstation von einem Personenzug eingeholt wurde, der einen nach Üsküb zurückbrachte.

Am südlichen Ende des $\mathrm{Katlanovosees}$ erhoben sich lehmige Hügel, im Frühjahr üppig mit blühenden Pflanzen bewachsen, die von der üblichen reichen Insektenwelt umflogen

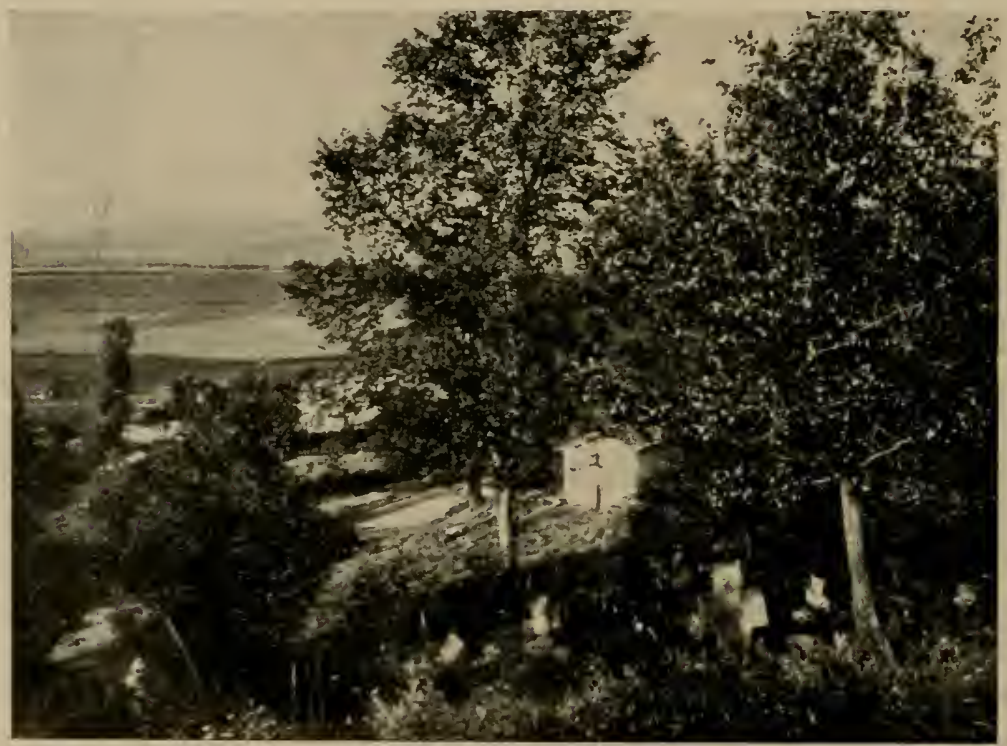

Abb. 166. Kapelle und Friedhof von Taor.

waren. An einem Hang, nicht weit vom See, entdeckten wir in einer senkrechten Lehmwand eigenartige Löcher, welche offenbar von Menschenhand gebohrt waren. Wir erfuhren, daß sie von den Bewohnern der Nachbarschaft angelegt waren, um durchgegangene Bienenschwärme einzufangen, die sich gern an dieser Lehmwand niederließen (vgl. dazu S. 372 und Abb. 186).

Wollte man durch die Wardarschlucht nach Selenikovo, so mußte man das lange nach Südosten gestreckte Ende des Sees umgehen, um an seinem Westufer den Durchbruch des Wardar bei Taor zu erreichen, wo See und Fluß nur wenig hundert 
Meter voneinander getrennt waren. Taor, am Hügel gelegen, zwischen Obstbäumen gelagert, mit einer kleinen weißen Kapelle auf grünem Rasen, war das Ziel der Sehnsucht vieler Juristen der Armee, da es der Geburtsort des oströmischen Kaisers Justinian, des Urhebers der Pandekten, ist. Wenige sind dort gewesen, da der Ort sehr unbequem zu erreichen war. So sei diesen die von mir aufgenommene Photographie der Kapelle von Ta or gewidmet (Abb. I66).

Dicht bei Taor beginnt nach der Üsküber Talweite die lange Velesenge des Wardars, welche sich bis Krivolac erstreckt. Ihre hohen Felsenufer sind aus kristallinischen Schiefern, paläozoischen

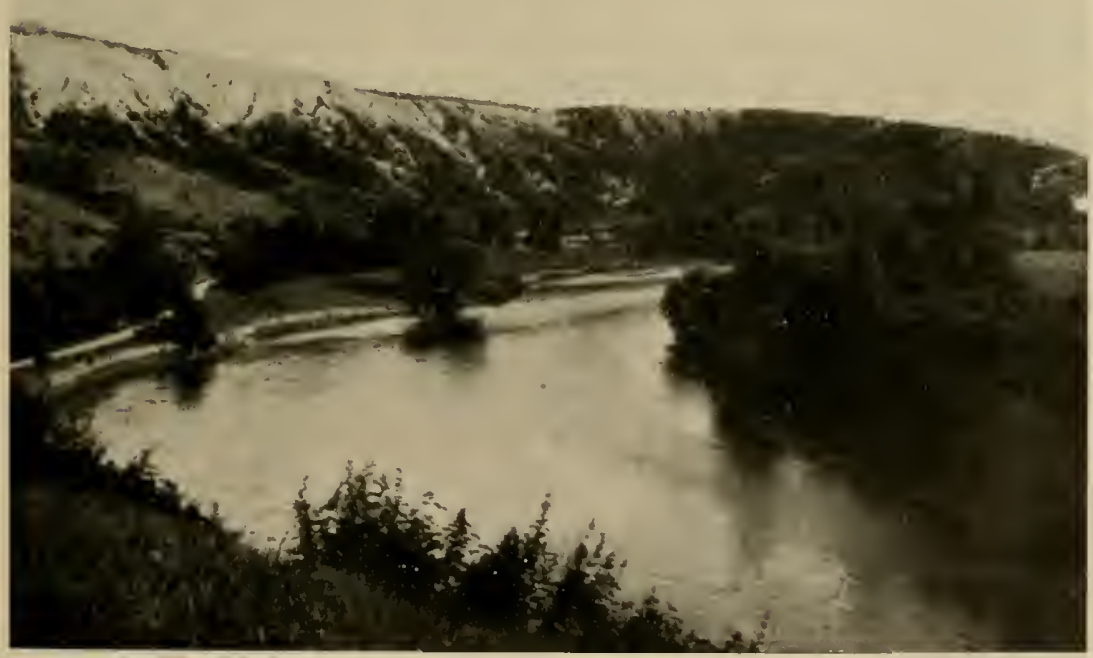

Abb. 167. Wardar bei Selenikoro.

Schiefern, mesozoischen Kalken, paläozoischen Flyschschiefern und jungtertiären Ablagerungen in buntem Wechsel aufgebaut.

So entstehen reizvolle Felsenlandschaften von wechselnder Höhe und mannigfaltiger Gestaltung und Färbung. Schön und reich ist auch die Flora der Flanken dieser Enge. Kurz hinter Ta or ziehen sich steile Abstürze von Kalkbergen bis Selenikovo hin (Abb. 167). Die weißen Hänge spiegelten sich im farbig vom Abendhimmel überstrahlten Wasser des Wardar, welches hier von üppigem 
Buschwerk und stattlichen Bäumen eingefaßt ist. Pappeln, Ulmen, Eschen, Erlen, viele Weidenbäume und -büsche warfen bunte Schatten auf den Spiegel des Flusses, über den die Büsche tief sich neigten. So ist mir die letzte Heimkehr vom Katlanovosee in schöner Erinnerung.

Nicht minder interessant waren Streifzüge in den Hängen des Wardartales zwischen Selenikovo und Veles. Kurz hinter Selenikovo begannen Schieferberge, welche im Mai mit blühenden Sträuchern wilden Flieders mit weißlichen und lila Blüten bedeckt waren. Es war die Syringa vulgaris L., deren Blüten kleiner sind und weniger stark duften, als diejenigen des persischen und chinesischen Flieders, aber auch wie jene bei uns als Ziersträucher angebaut werden. Auf den Felsen gab es viele Schlangen und Eidechsen; Hasen und Felsenhühner sprangen vor dem Kletterer auf.

Eine wundervolle Pflanze kam in den kristallinischen Schiefern kurz vor Veles an den Steilwänden der Schlucht vor. Es war die der Christrose ähnelnde, rosenrot gefärbte, von einer Rosette dunkelglänzender Laubblätter umschlossene Ramondia nataliae, benannt nach jener Königin Natalie von Serben, deren Namen einstmals so viel in den Zeitungen Europas herumspukte, ein wohl nicht ganz berechtigter Name für Ramondia serbica Pančič. 


\section{BESUCH BEI DEN ALBANERN}

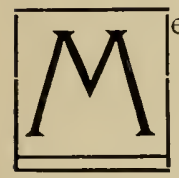

eine bulgarischen Freunde hatten den kühnen Plan, an den Abhängen des Ljubotren eine Wildschweinjagd zu veranstalten. Ein alter Albaner, ehemaliger Patient und seither treuer Anhänger des Dr. Molloff, hatte eingeladen, bei ihm Quartier zu nehmen.

Es war um die Wende von Februar und März, als wir uns frühmorgens in die Eisenbahn setzten, welche von Üsküb nach Nordwesten über Prizren nach Mitrowitza führt. Wir fuhren aber nur die $36 \mathrm{~km}$ durch das Lepenatztal bis Kazanik, einem kleinen Ort, welcher bei $425 \mathrm{~m}$ Höhe am Fuß des Ljubotren gelegen ist. Es war eine interessante Fahrt durch das tiefeingeschnittene Tal des Flüßchens, welches im flotten Lauf, über Steine plätschernd, dem Wardar zufließt.

Kazanik liegt sehr reizvoll vor dem noch tief mit Schnee bedeckten Ljubotren, der allerdings bei unserer Ankunft in Wolken steckte. Hier und da öffneten sich die Wolken, und wir konnten einen Blick auf weite Schneefelder tun, welche sich jenseits der Waldzone ausdehnten. Kazanik mit seiner weißen Moscheekuppel und seinem schlanken Minaret liegt zwischen Bäumen eingebettet $z u$ beiden Seiten des Lepenatzflusses, der kurz unterhalb des Ortes in eine Schlucht eintritt. Der Zug hatte uns vorher durch einige Tunnels geführt.

Den Ort durchfloß die Lepenatz als starker Bach mit steilen Ufern. Über den Steinen in seinem Bett flogen zahlreiche Wasserstare, Männchen und Weibchen. Es war ein anziehendes Schauspiel, wie sie von Stein zu Stein flogen, bald mit gespreizten Flügeln auf den Felsen standen, bald sich in das Wasser stürzend. Wie sich im Laufe unserer Forschungen herausstellte, ist der mazedonische Wasserstar eine besondere Form (Cinchus cinchus orientalis Stresem.), so ähnlich er auch dem heimischen Vogel sah, den ich aus dem Schwarzwald und den Voralpen so gut kannte.

Während unsere Tragtiere herangebracht wurden, durchstreifte ich das Flußufer und das malerische Tal. Wir brachen am Nach- 
mittag auf, zweigten bald von der Bahn ins Lepenatztal nach Norden ab. Es war ein weites Tal, welches wir etwa I Stunde aufwärts verfolgten, um dann steil die Berge hinaufzuklimmen, an die Hänge des Ljubotren.

Der Abend sank schon herab, als wir in der Höhe von etwa $700 \mathrm{~m}$ durch Obstgärten, an Zäunen, Hecken und Mauern vorbei an ein Holztor gelangten, welches auf Klopfen sich vor uns öffnete. Wir traten in einen nicht sehr großen Hof, dessen eine Längsseite von einem niedrigen Haus eingenommen war, sein einziges Stockwerk war von einem Strohdach bedeckt. Die anderen Seiten des Hofes waren von Schuppen und Vorratshäusern eingefaßt. Über dem Eingang hing das Dach weit vor und war von Balken gestützt.

Unser Gastfreund, ein alter Albaner von über 70 Jahren, namens Mustafa Visch, trat uns freundlich entgegen und begrüßte uns unter umständlichen Formen. Wir traten in das dunkle Haus ein, dessen an der linken Seite befindlichen Fenster tief in der Wand saßen. Eine niederige Decke war von Balken gestützt, die in zwei Reihen standen, so daß in der Mitte ein Durchgang auf einen offenen Kamin führte, in welchem ein mächtiges Holzfeuer prasselte.

Dessen Schein genügte, um uns das Zurechtfinden in Raum zu gestatten. Wir sahen, daß die beiden Abteilungen des Zimmers mit schönen dicken Teppichen belegt waren. Die Abteilung links war für uns vorbereitet, die rechts gelegene, etwas kleinere, hatte der alte Mann für sich und seine Söhne reserviert.

Das erste war, daß wir vor dem Betreten der Teppiche unsere sehr schmutzigen Stiefel ablegten und ermüdet uns auf den Boden setzten. Unser alter Gastfreund, gekleidet in enge, schwarze wollene Hosen, ein wollenes Hemd, über welches eine emaillierte Kette mit einer Taschenuhr hing, schaute aus einer pelzverbrämten, langen braunen Jacke hervor; unter dem roten Bauchgürtel ragten noch Zipfel eines weißen Wamses heraus. Den Kopf deckte das übliche halbkugeliche, weiße Filzkäppchen. Ähnlich warm und gut waren die übrigen Männer gekleidet.

Mit mir waren sechs Bulgaren mitgekommen, dazu hatte ich meinen Burschen und den Präparator Aigner, die bulgarischen Herren ihre Bedienung und noch Bedeckungsmannschaften bei sich. Dennoch kamen wir ganz gut unter, denn die Bedienung verschwand bald draußen, machte eine Küche ausfindig und begann für uns zu kochen. 
Es war ganz behaglich in dem von dem starken Feuer durchstrahlten Raum auf unseren dicken Teppichen. Anfangs hatte man etwas Angst vor Ungeziefer. Aber bei der allmählichen Gewöhnung an Schmutz fand man das Quartier recht sauber, breitete die Decken aus und bald kam unser Essen. Wir boten natürlich unseren Gastfreunden von unserem Proviant an, was sie erwiderten, als sie nach uns ihre Speisen bereiteten und es sich gemütlich machten.

Mit dem greisen Vater lebten drei unverheiratete Söhne zusammen, welche alle auch schon über 5o Jahre alt waren. Zwei davon machten einen sehr gesetzten, klugen Eindruck, während der Dritte etwas abnorm zu sein schien. Es war außerordentlich interessant $\mathrm{zu}$ beobachten, wie respektvoll sie mit ihrem alten Vater umgingen. Trotz ihres Alters, hatten sie noch keine Rechte im Haus. Der Vater hatte stets den Vortritt, sie warteten, bis er sie aufforderte, sich zu setzen.

An dem Kaminfeuer wurde dann ihr Essen zubereitet, welches aus Hammelfleisch mit Reis und Gemüse bestand. Während wir auf unseren Decken lagen, beobachteten wir ihr eigenartiges Gehaben. Zwei Öllampen, welche an der verräucherten Holzdecke aufgehängt worden waren, verbreiteten ein gelbes Licht über den Boden des Gemachs, warfen dunkle Schatten hinter den Balken, während vom Kamin von Zeit zu Zeit ein Krachen ertönte, Funken aufsprühten und ein heller Schein den ganzen Raum erfüllte.

Die vier Greise hockten sich um einen kleinen, niedrigen, dreibeinigen Tisch, auf den die große, dampfende Schüssel zwischen sie gestellt wurde, es war der rußgeschwärzte, halbrunde Topf, welcher vorher an einem langen Hacken über dem Kaminfeuer geschwebt hatte. Vor jedem von ihnen stand ein Messinggefäß mit Wasser und lag ein sauberes Wischtuch.

Nun kam der Vater zuerst mit dem Essen daran, griff mit den Fingern in den Topf und holte sich ein gutes Stück heraus, führte es zum Mund, wusch dann seine Hände $a b$, ehe er von neuem hineingriff. Dann bot er den gefischten Brocken demjenigen seiner Söhne dar, den er offenbar bevorzugte. Er steckte ihn ihm direkt in den Mund. Das war das Zeichen, daß diese auch mit ihrer Mahlzeit anfangen konnten. Sie verfuhren genau so wie der Alte. Mit ihren Fingern waren sie ebenso reinlich wie er. Und so wußte ich die Ehre zu schätzen, als der alte Mann einen möglichst schönen Happen Fleisch für mich herausfing und ihn mir in 
den Mund steckte. Als die Alten fertig waren, wurde zur größeren Feier noch ein guter, süßer, schwarzer Kaffe gebraut und in kleinen Täßchen auch uns allen angeboten.

Wir hatten uns alle schon längst zum Schlafen ausgestreckt, als die alten Männer sich auch dazu anschickten. Die Söhne bereiteten dem Vater das Lager aus Kissen und Teppichen, dann der jüngste der Fünfziger seinen beiden Brüdern das ihrige. Schließlich ordnete er umständlich das seine, löschte die letzte Lampe und kroch unter seine Decken. - Ich hatte als Letzter von uns blinzelnd das alles mit angesehen. Nun flackerte das Feuer im Herd noch einmal auf und dann begann auf allen Seiten ein mächtiges Schnarchen. Man schlief gut und fest und mit dem Gefühl voller Sicherheit unter dem Dach des neuen Gastfreundes.

Früh am nächsten Morgen wurde zur Wildschweinjagd aufgebrochen. Es war eine stattliche Schar, welche gemeinsam loszog. Albaner zogen zahlreich als Jäger und Treiber mit, alles hohe, schlanke Gestalten, mit Gewehren über der Schulter. Der große Troß, der Lärm, mit dem man in die Höhe gegen den Wald stieg, flößte mir wenig Vertrauen auf das Gelingen der Jagd ein.

Es ging zunächst über grasige Hänge, durch dichten Busch steil den Berg hinan. An zwei Dörfern kamen wir noch vorbei, welche alle dasselbe Bild boten wie unser Dorf Dubrava. Alle Häuser standen abseits des Weges, eingeschlossen durch dichte Hecken. In den Gärten standen schöne Obstbäume.

Weiter oben hatten wir an einer tiefen Schlucht entlang zu wandern, bis wir nach etwa $1 \frac{1}{2}$ Stunden an den Rand eines Eichenwaldes kamen, der zuerst aus Buschwerk bestand, allmählich, je tiefer wir in ein Tal hineinkamen, immer mehr zum Hochwald wurde. Das ganze Tal wurde inmer dichter vom Eichenwald erfüllt.

Wir Jäger wurden an das obere Ende des Tales verwiesen; die Albaner sollten an beiden Seiten am Hang durch den Hochwald treiben, und man versicherte uns, die Sauen würden schußgerecht bei uns herauskommen. Der fürchterliche Lärm, mit dem die Menschenmenge in den Wald eingezogen war und den sie drinnen ungemindert fortsetzte, die große Schießerei, die alsbald ohne jeden Grund losging, und das sinnlose Ansetzen der Schützen überzeugten mich, daß bei dieser Jagd nichts herauskommen konnte.

So beschloß ich denn, mich in der Umgebung meines Standplatzes genau umzusehen. Ich war in einer durch Holztrieb ent- 
standenen Lichtung des Eichenwaldes postiert. Auf dem laubbedeckten Boden lagen einzelne gefällte Stämme, rings umher standen noch prachtvolle alte Baumriesen. Anı Himmel zogen große Wolken und ließen dann und wann einen blauen Flecken klar werden. Damit wurden auch die roten Buchenwälder der höheren Region und über ihnen die Schneeflächen der Matten zeitweise sichtbar. In der Hauptsache blieb es aber ein trüber Tag.

Es dauerte gut zwei Stunden, bis die übrige Jagdgesellschaft und die Treiber herankamen. Trotzdem erlosch das Getöse in den Tälern nicht. Waren je Wildschweine im Gebiet, sie hatten sich sicher längst in stillere, verborgenere Gegenden zurückgezngen. Soviel ich suchte, ich fand keine Spuren, keine Losung, keine Andeutung, daß je Wildschweine hier gehaust hatten. Kein Tier irgendeiner Art brach durch den Wald. Außer dem Lärm, den die Menschen machten, herrschte tiefste Stille. Es hätten weihevolle Stunden sein können, in dieser stillen, winterlichen Einsamkeit des Bergwaldes.

Ein wenig genoß ich davon, als ich bis zum Schneerand anstieg und mich dort ruhig eine Zeitlang hinsetzte. Kein Tier regte sich im Gebiet, kaum ein Vogel flog vorbei, nur ein Specht trommelte in der Ferne. Ich wälzte Steine, löste Rinden von alten Bäumen. So fand ich Hackstellen des Spechtes; unter einem losgelösten Rindenstück fand ich etwa $5^{\circ}$ schwarzrot gefleckte Blattwanzen im Winterquartier. Ähnlich fand ich solche Wanzen auch an anderen Stellen in Mazedonien. Es sind dies Aradiden, Rindenwanzen, deren geselliges Leben und gemeinütziges Überwintern auch sonstwo beobachtet ist. Unter Steinen fand ich eine Anzahl Spinnen. Es waren junge Exemplare einer Wolfsspinne (Lycosa sp.).

Sonst war es hier oben in einer Höhe zwischen $1200-1500 \mathrm{~m}$ noch ohne jedes Tierleben. Ich genoß die schöne frische Luft und meine Einsamkeit und war froh, als die Jagdgesellschaft enttäuscht sich wieder versammelte und den Rückmarsch zu unserem Gastfreund nach Dubrava antrat.

Da unten erwartete mich Besseres; denn schon beim Aufstieg hatte ich bemerkt, daß weiter unten das Vogelleben des Frühlings schon seinen munteren Anfang genommen hatte. Am Rande des Waldes, wo dieser in die Kulturlandschaft überging, da tönten schon die Lockrufe und der Gesang von vielen Vögeln. Überall huschte es in den Kronen, kletterte es auf den Stämmen. Auf 
den hohen Eichen sah man Baumläufer sich verfolgen (Certhia familiaris familiaris L.), zahlreich waren die Kleiber (Sitta europaea caesia Wolf), auch schon Männchen und Weibchen gepaart. Sehr zahlreich waren die Trauermeisen (Parus hugubris lugubris Temm.), die auf den hohen Bäumen am Waldrand lärmten. Dort waren auch kleine Flüge der Nonnenmeise (Parus communis fruticeti Wallengr.). Und überall trieben sich in großen Mengen Schwanzmeisen (Aegithalos caudatus macedonicus Dress.) umher.

Ging man aus dem Wald heraus, so kam man auf eine Wiese, auf der sich Obstbäume, vor allem Apfelbäume mit dicken Knospen erhoben. Die Wiese war vom Schmelzwasser des Schnees sehr naß und noch dürr und braun. Trotzdem war in den Bäumen ein Lärmen und Singen im Gange, daß man den ganzen Frühling im Herzen spürte. Amseln und Drosseln freuten sich da ihres Lebens und waren zum Teil schon beim Nesterbauen. Sehr drängte sich mit ihrer schallenden Stimme die Balkanamsel vor (Turdus merula aterrima Mad.), in zahlreichen Paaren war die Miste1drossel vertreten (Turdus viscivonus viscivorus I.). Und fast ebenso zahlreich waren die Pärchen der Ringdrossel (Turdus torquatus alpestris Bg.). Auf dem Heimweg am nächsten Morgen war die Vogelwelt nicht weniger lebhaft. Zwischen den Meisen unten im Tal, in den Büschen erregte meine besondere Freude ein ganzer Flug von Gimpeln. Mit ihrem silbergrauen Rücken, ihrem roten Brüstchen, ihrem dunkelen Schnabel machten sie einen sehr feinen Eindruck. Wer hätte gedacht, daß wenige Tage darauf tiefer Schnee das Land wieder bedeckte, und all den Vögeln da oben die L.enzesfreude bös versalzen war.

Höchst feierlich war unser Abschied von den albanischen Gastfreunden. Sie begleiteten uns zu ihrem Haus hinaus, schüttelten uns die Hände und unser Oberarzt, sowie ich, offenbar für den Alten die Angesehensten der Gesellschaft, wurden von ihm mit dem albanischen Kuß, dem Aneinanderlegen der Wangen, verabschiedet. Flott liefen unsere Pferdchen den Berg hinunter. Nachmittags bestiegen wir in Kazanik den Zug, der uns abends wieder nach Üsküb ins Standquartier brachte. Ich war zufrieden, diesen Blick ins intime Leben der Albaner getan zu haben.

Während dieser Tage waren wir mit keiner Frau zusammengekommen. Zwei verschleierte Wesen waren in Kazanik vor uns geflohen. Im Haus unserer Gastfreunde hatten wir, obwohl sie im anderen Teil des Hauses wohnten, von Frauen nichts gesehen noch gehört. 


\section{DER WODNO, DIE TRESKASCHLUCHT UND DAS KLOSTER MARKOVA}

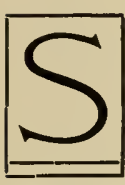

chon an einem der ersten Tage, die ich in Üsküb weilte, Mitte Mai 1917, hatte ich einen Spaziergang auf den $1000 \mathrm{~m}$ hohen Berg, der sich südlich der Stadt erhebt, auf den Wodno unternommen. Damals schon konnte ich in den wenigen Stunden eine Anzahl interessanter Beobachtungen machen.

Am Fuß des Berges liegt der slavische Friedhof. Alle diese mazedonischen Gräberstätten machen auf uns Deutsche einen ungeordneten und vernachlässigten Eindruck. Die Gräber liegen kreuz und quer durcheinander; sie bestehen aus kastenförmig z.usammengesetzten Steinplatten, sind meist ohne Inschriften, unregelmäßig gebaut, oft etwas zerfallen. Dazwischen wachsen regellos Gras und Kräuter und allerhand Büsche. Hier in Üsküb beschatteten stattliche Bäume die Gräber. Die Umgebung war nicht reinlich gehalten und gar im Sommer, wenn die Pflanzen verdorrt und Gräber und Bäume verstaubt waren, machte die Stätte einen unfreundlichen und unfriedlichen Eindruck.

Das Seltsamste sind aber die Besucher des Friedhofs. Sie machen ihren Toten regelrechte Besuche. In Feiertagsgewändern, hier am Rand der Stadt, teils städtisch, teils ländlich gekleidet, kommen sie mit Körben und Paketen voll EBwaren zum Friedhof heraus. Auf den Grabstätten lagern sie, packen ihre Sachen aus und es beginnt eine allgemeine Speisung. Für den Toten wird sein Anteil auf sein Grab gelegt. Dabei geht alles ganz behaglich zu, als mache man bei einem Lebendigen seinen Besuch. Man hat den Eindruck, als weckten die Leute alte Erinnerungen an den Toten bei solcher Gelegenheit so sehr auf, daß sie sich vorstellen, er weile in ihrer Gegenwart. Selten, wenn der Tote erst seit kurzem im Grabe liegt, ertönen Klagen. Gebete werden stets gesprochen. Bei Beerdigungen ist der Pope dabei, es wird allerlei Pomp entfaltet und Gesänge von weicher, melancholischer Art, auch laute Klagen erschallen dann. 
Hinter dem Friedhof geht es steil auf Saumpfaden und engen Steigen den Berg hinan. Wie oft bin ich auf diesem Berg herumgestreift und was gab es da alles zu beobachten und zu bewundern.

Der Wodno ist ähnlich wie die Plaguša Planina das Musterbeispiel eines mazedonischen Gebirges von etwa $1000 \mathrm{~m}$ Höhe. Charakteristische Unterschiede bringen hier die etwas nördlichere Lage und der größere Quellenreichtum mit sich. Außerdem

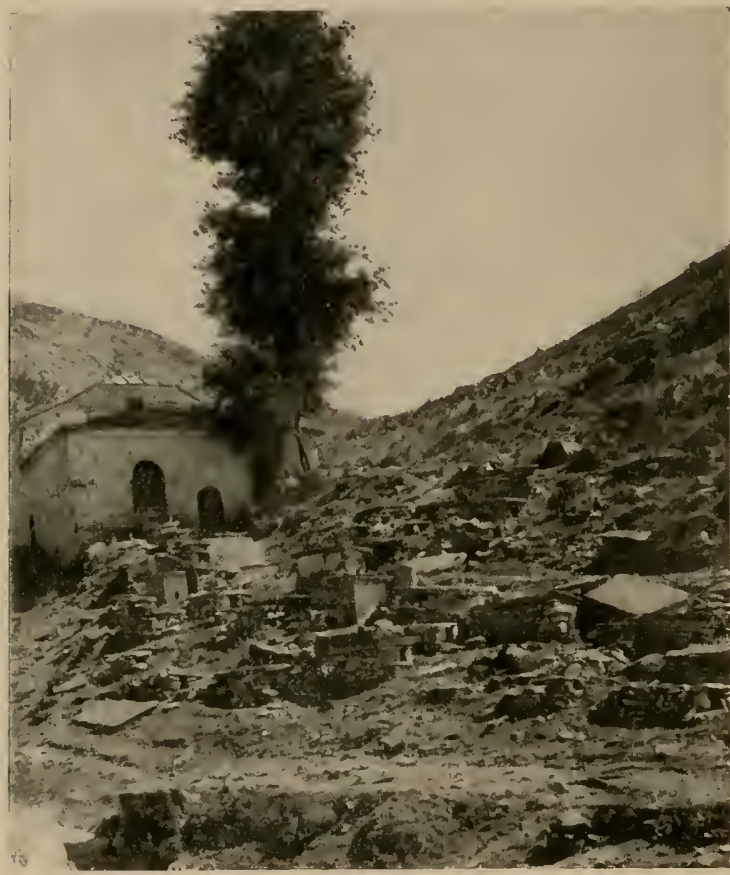

Prof. $M$ ïller phot ist der Gesteinsuntergrund ein abweichender. Im unteren Teil liegen Alluvionen des Wardar, darüber Marmor, Kalk und Schiefer. An seinen Abhängen sind drei deutliche Terrassen erkennbar.

Wald ist hier infolge der Nähe der großen Stadt noch weniger erhalten als in der Plaguša. Wo Wasser ist, an den Schluchten und in der Nähe der Ortschaften, sind größere Baumbestände vorhanden. So sind die Dörfer von stattlichen Obst- und Nußbäumen, Pappeln, Erlen und Weiden umgeben. In der Nähe des Dorfes Neresi befindet sich ein stattlicher Hain von Edelkastanien (Abb. 173, S. 355), der einzige, den ich in Mazedonien sah, außer einem bei Kalkandelen im Sarskatal. In dem westlichen Teil des Bergzuges, gegen die Treskaschlucht zu, mehren sich Bestände von Eichen und Buchen, die aber stets ziemlich licht sind, höchstens Wäldchen, keine Wälder bilden. $\mathrm{Zu}$ allen Zeiten des Jahres gab es auf dem Wodno etwas Interessantes $\mathrm{zu}$ beobachten. Im ersten Frühling waren auch hier, wie unten in Üsküb, Spinnen besonders häufig; im Kapitel über die Spinnenfauna Mazedoniens habe ich auch die Arten erwähnt, 
die auf dem Wodno vorkommen. Von Arten, welche ich unten im Tal nicht antraf, erwähne ich den Weberknecht (Metaphalangium propinquum Luc.), von dem ich hier oben schon im April ein junges Männchen fand. Von echten Spinnen stiel ich ebenfalls Anfang April auf die Springspinne (Hyctia canestrinii Canest. u. Pav.), von Wolfsspinnen auf die stattliche Lycosa amentata (Clerk), welche sonst im Süden Mazedoniens häufiger war.

Röhrenspinnen waren auch oben nicht selten, so die große Tarentula praegrandis C. L. Koch. Unter den Steinen fanden sich außer allerhand Spinnen viele Juliden und Skolopender, auch Skorpione der Art Euscorpius carpathicus I. Unter anderen Steinen gab es zu dieser Zeit zahlreiche langhörnige Käfer aus der Gattung Dorcadion, die jetzt im Frühjahr in vielen Arten auftrat, während ich im vorigen Sommer nur zerfallene Reste von ihnen gefunden hatte.

Die ersten Frühlingsschmetterlinge sahen nicht viel anders aus als bei uns; auch hier flogen zuerst Zitronenfalter, Weißlinge, kleine $F$ üchse und vor allem der unvermeidliche Distelfalter, dieser häufigste Tagschmetterling Mazedoniens.

Beim Aufstieg kam man durch blühende Hecken, in den Dörfern blühten die Obstbäume. Weiße und gelbe Krokus sproßten zwischen den Büschen, Veilchen dufteten und etwas später tauchten zahlreiche Anemonen auf. Einen wundervollen Kontrast zu den fernen schneebedeckten Bergen bildeten die sanft grünenden Weiden und Pappeln, die blütenbedeckten Pfirsich-, Pflaumen- und Aprikosenbäume, später die Apfel- und Birnbäume.

Winterlicher wurde der Eindruck, stieg man im April in die Gipfelregionen des Wodno, dort waren die Flächen noch braun und kahl; nur in windgeschützten Mulden hatten die Büsche ausgetrieben. An einer solchen Stelle konnten wir interessante Beobachtungen machen. Nahe dem Gipfel fanden sich alle Sträucher bedeckt von tausenden kleiner Käfer. Es war unser Marienkäfer, der Siebenpunkt (Coccinella septempunctata B.), der gerade aus seinem Winterquartier mobil wurde. So ließ sich hier feststellen, daß dieser Käfer in Mazedonien im Winter auf Berggipfeln Massenquartiere bezieht. Das tut er wohl auch in Deutschland; wenigstens ist im Riesengebirge entsprechendes schon gesehen worden. Aber in Mitteleuropa hat man bisher kaum auf dies Verhalten geachtet.

Mir fielen damals gleich die interessanten Beobachtungen ein, 
welche in Kalifornien an einer Coccinellide gemacht und wirtschaftlich in sehr kluger Weise ausgenutzt wurden. Die Art Hippodamia convergens überwintert dort in Mengen im Gebirge, während sie im Sommer in der Ebene als Blattlausvertilgerin in den ausgedehnten Melonenpflanzungen eine sehr nützliche Arbeit tut. Die amerikanischen Entomologen haben diese biologischen Eigentümlichkeiten ihrer einheimischen Art rationell ausgenützt. Im Winter werden von eingelernten Sammlern die Käfer in den vorher erkundeten Winterquartieren eingeheimst, in kalten Räumen bis zum Frühsommer aufgehoben und dann in bestimmt zugemessenen Portionen auf den Melonenfeldern ausgesetzt.

Das hat sich als sehr erfolgreich und gewinnbringend bewährt, ist zu einer Dauerorganisation gemacht worden und wird mit Nutzen in Kalifornien weiter betrieben. Wenn ich an die Melonenfelder unten im Wardartal dachte und an die Möglichkeiten eines zukünftigen größeren Betriebes durch die Bulgaren, so nahm ich mir sofort vor, ihnen unsere Entdeckung mitzuteilen. Leider entwickelte sich alles anders als man damals hoffte.

Vom Gipfel des Berges zieht sich der Kamm zu immer höheren und unwirtlicheren Felsenmassen hin, die schließlich in ungeheurem Absturz zum Tal der Treska abfallen. Dieses stellt eine der majestätischsten Schluchten in dem an solchen Schaustücken so reichen Mazedonien dar. Als in Februar die Sonne einen trügerischen Frühling über das Tal von Üsküb gezaubert hatte, habe ich einen Ausflug mit einigen deutschen Ärzten in die Treskaschlucht und an ihren Westhang unternommen.

Mächtig strömt die Treska aus der schattigen Klamm hervor, deren Wände $600-800 \mathrm{~m}$ hoch fast senkrecht $\mathrm{zu}$ beiden Seiten aufsteigen. Welche Arbeit hat das Wasser da wohl in Jahrtausenden geleistet, um das harte Gestein bis zu dieser Tiefe durchzubohren. Auf beiden Seiten führen steile Saumpfade hoch in die Felsen hinauf, wo zwei einsame Bergklöster sicher jahrhundertelang eine Zuflucht der mazedonischen Christen waren. Heute liegen beide in Ruinen.

Das eine von ihnen, Sveti Nedelja, war unser Ziel. Auf steilen Pfaden klommen wir die Hänge entlang. Einige junge Albaner, Hirten, welche wir unterwegs antrafen, trugen uns unseren Proviant hinauf und zeigten uns den Weg, der allmählich bis zu einer Höhe von $800-900 \mathrm{~m}$ uns führte. Hier waren die Hänge unten von einer eigenartigen Buschvegetation bedeckt, die aus 
Buchsbaum (Buxus sempervirens L.) bestand. Auf dem vergilbten Rasen erhoben sich Gruppen dieser dunklen Büsche; in den oberen Teilen zeigten ihre Blätter noch ihr glänzendes Dunkelgrün, während sie unten durch den Winter dunkelrotbraun gefärbt waren, so daß sie fast aussahen, als wären sie aus Bronze gegossen. Zwischen dem Buchs standen Wacholdersträucher, die zum Teil baumartig gewachsen waren und in ihren Umrissen fast an Kiefern erinnerten (Juniperus communis L.).

Später im Jahr, im Juni, blühte in der Treskaschlucht aufer anderen eigenartigen Pflanzen die schöne, eigenartige Ramondia serbica Pančič. mit ihren großen rosaweißen Blüten in einem Kranz dunkler Blätter zwischen dem grauen Gestein, ein schönes Bild darbietend.

Jede Wendung des Steigs brachte neue wilde Gebirgslandschaften. Stellenweise konnte man weit in die gewaltige Klamm hineinschauen, die nach Süden eng und hoch sich hinzog. Ihre Wände stiegen in Absätzen fast senkrecht in die Höhe; auf den Vorsprüngen standen Bäume und Büsche und von ganz oben sahen wir tief hinunter auf die Ruinen von Kirche und Kloster von Sveti Nikola. Wie auf einer aus den Felsen hervorragenden Plattform lagen die Gemäuer auf einer kleinen Fläche höchst malerisch in der Felsenwildnis am rechten Ufer der Treska, während wir am linken emporkletterten.

Da lag nicht weniger romantisch das Kloster Nedelja an den Felsen angeklammert vor uns. Die Vorliebe der slavischen Mönche für bizarre Felsenlandschaften hatte hier sich ausleben können. Heute war es noch schwerer, von einem Mauerrest zum anderen zu gelangen als einstmals, als noch hölzerne Treppen und Galerien sie verbanden. Die Trümmer hingen ziemlich isoliert, zum Teil über tiefem Abgrund, umwuchert von Brombeersträuchern, Rosenhecken und Buchsbaum. Reste von Türmen und Arkadengalerien waren noch $z u$ erkennen.s Auch hier in der Höhe waren die Mauern zum Teil aus Felsgestein mit wagrechten $Z$ wischenlagen aus roten Ziegeln gebaut.

Die Mönche hatten auch hier die Lage für schöne Aussichten gut gewählt. Auf kleinen Balustraden, über dem Abgrund hängend, hatte man großartige Blicke die Schlucht aufwärts, in ihre Tiefe, aus der der Fluß nur leise zu uns herauf brauste und vor allem zur Schlucht hinaus in das Tal von Üsküb. Man sah drunten den Zusammenfluß des Wardar mit Treska und Lepinatz, die 
Felder und Baumgruppen der Talfläche, jenseits die Hänge des Karadakh, ein schönes, farbiges Bild. Während wir oben verweilten, kreisten fünf mächtige Mönchsgeier über uns und tauchten oft tief in die Schlucht hinein, so dalo wir von oben auf ihre Rücken und ihre schimmernden Flügelfedern blicken konnten.

Im Mai wurde es immer reizvoller auf dem Wodno. Eine Menge interessanter blühender Pflanzen entzückten den Botaniker, so Astragalus fugioniferus Fisch. und Genista nyssana Petr. Im Dörfchen Oberw odno bildeten Erlen, Weiden und andere Büsche einen dichten Hain um einen kleinen Bach, in welchem die Frauen des Ortes ihre Wäsche wuschen. An den Obstbäumen hingen schon reifende Früchte.

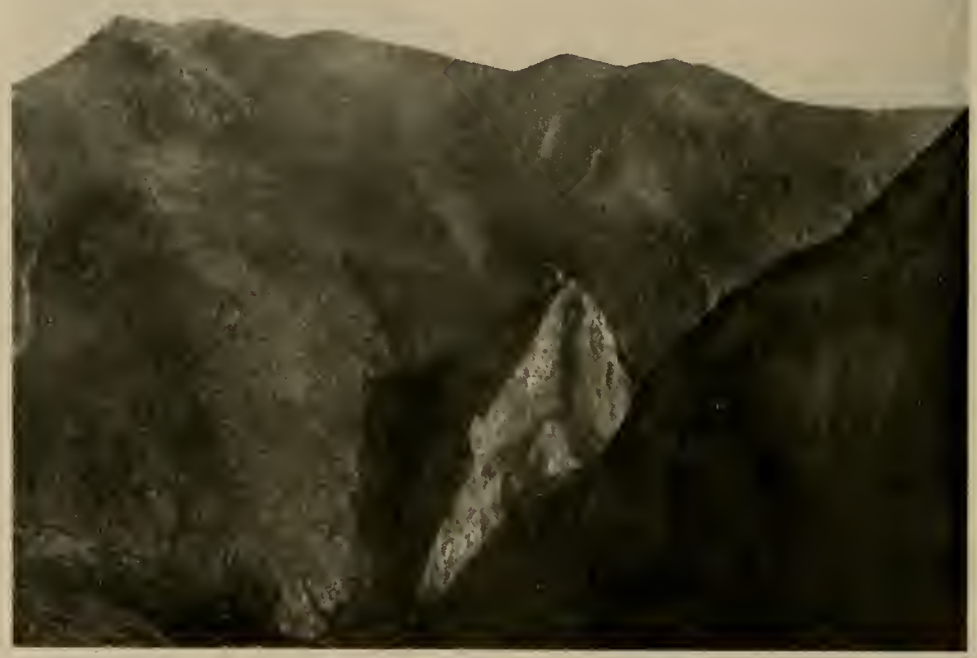

Abb. 169. Treskaschlucht von Sv. Nedelja gesehen.

Auf den Wegen wälzten die heiligen Skarabäen ihre Mistkugeln und eine Fülle von Bienen beflogen die Blüten. Vor allem auffallend waren solitäre Bienen mit langen Fühlern, Vertreter der Gattung Eucera, und Arten von Andrena und Halictus sah man in ihren Löchern im Boden ein- und ausfliegen.

Um einen Begriff von der Mannigfaltigkeit, die mir manchmal an einem Ort entgegentrat, zu geben, führe ich die Bienenarten einzeln an, die nach den Bestimmungen von Dr. Friese damals am Wodno von mir gefangen wurden: von Eucera die 
Arten E. seminuda Bz. und E. caspica var. peregi Moos., von Halictus die charakteristischen Vertreter H. quadrinotatus $\mathrm{K}$., malachurus $\mathrm{K}$. und rufocinctus $\mathrm{K}$. Noch reicher war die Gattung Andrena vertreten, und zwar mit sieben Arten (A. thoracica $\mathrm{F}$., A. pectoralis Perez, A. bimaculata var. apiformis Kriechb., $A$. groynana K., A. ephippizm var. macedonica Friese n. var., $A$. flavipes K., A. taraxica Gir.). Gerade dort war es auch möglich, das Vorkommen von zwei Generationen im Jahre bei einigen Arten, so Andrena thoracica F. und pectoralis Perez, von denen je eine Generation im April und eine im Juli flog.

Dieselbe Feststellung gelang bei Anthophora crinipes Sm., von der auch beide Generationen auf dem Wodno gefunden wurden; und die gleiche Beobachtung wurde auch bei A. acervorum L. gemacht.

Damit war die Menge der Wodnobienen noch nicht erschöpft. Im Frühjahr flogen noch Ceratina cyanea K., Osmia comuta L. und im Hoch- und Spätsommer kam noch eine ganze Anzahl dazu, so Osmia notata F., O. dimidiata Mor. Vier Arten von Megachile (M. lagopoda L., M. leucomalla Gerst., M. apicalis Spin., M. argentata L.), ferner noch Anthidium cingulatum Latr.

Auf die Gefahr hin, manchen Leser etwas zu langweilen, habe ich diese lange Liste hier eingefügt, um zu zeigen, wie vielseitige Aufgaben dem Naturforscher dort im Lande überall sich boten.

Im Mai und Juni besuchte ich auch die Südseite des Wodno und kam öfter bei den Vorbereitungsexpeditionen für die große Forschungsfahrt in die Golesniza Planina ins Kloster Markovo. Man erreichte es am besten auf einem Weg, der über den östlichen Sattel des Wodno in das Tal der Markova Reka führte. Am Abhang lag das Dorf $\mathrm{K}$ isela-Voda, bei welchem Dr. Gripp interessante Pflanzenversteinerungen entdeckte. Entweder durch das Tal des Markovabachs oder über die Hänge des Wodno gelangte man in ein engeres Stück des Tals, in welchem an einem lößartigen Hang inmitten von Pappeln und Weiden, von grünen Wiesen umgeben, das malerische gastliche Kloster lag.

Es ist dem heiligen Dimitri geweiht, so auch die malerische Kirche in ihm, welche aus der Serbenzeit Mittelmazedoniens stammt. Daher ist sie in Bau und Stil erheblich verschieden von der älteren Kirche in Neresi (S. 365). Auch diese Kirche ist reich ausgemalt; die Malereien sind zwar zum Teil überschmiert, aber besser erhalten als in Neresi. In der Apsis finden sich Darstellungen von Heiligen und Engeln. 
Am Bach lag ein großer Lehmschuppen, dessen Wand für den Zoologen außerordentlich interessant war. Ich besuchte ihn zweimal, um dort $\mathrm{zu}$ beobachten und $\mathrm{zu}$ sammeln. Oft hatte ich in Mazedonien Wände voll der Nester von einsam lebenden Bienen gesehen. Beim Anstieg zur Klosterruine Sv. Nedelja in der Treskaschlucht waren die sandigen Wände neben dem Weg zum Teil ganz porös gewesen von den Nestern von Anthophora und ähnlichen Bienen. Damals schon, in den ersten Tagen des Februar, waren die ersten dieser Bienen ausgeflogen, und zwar waren es damals nur Männchen gewesen, welche wohl ver-

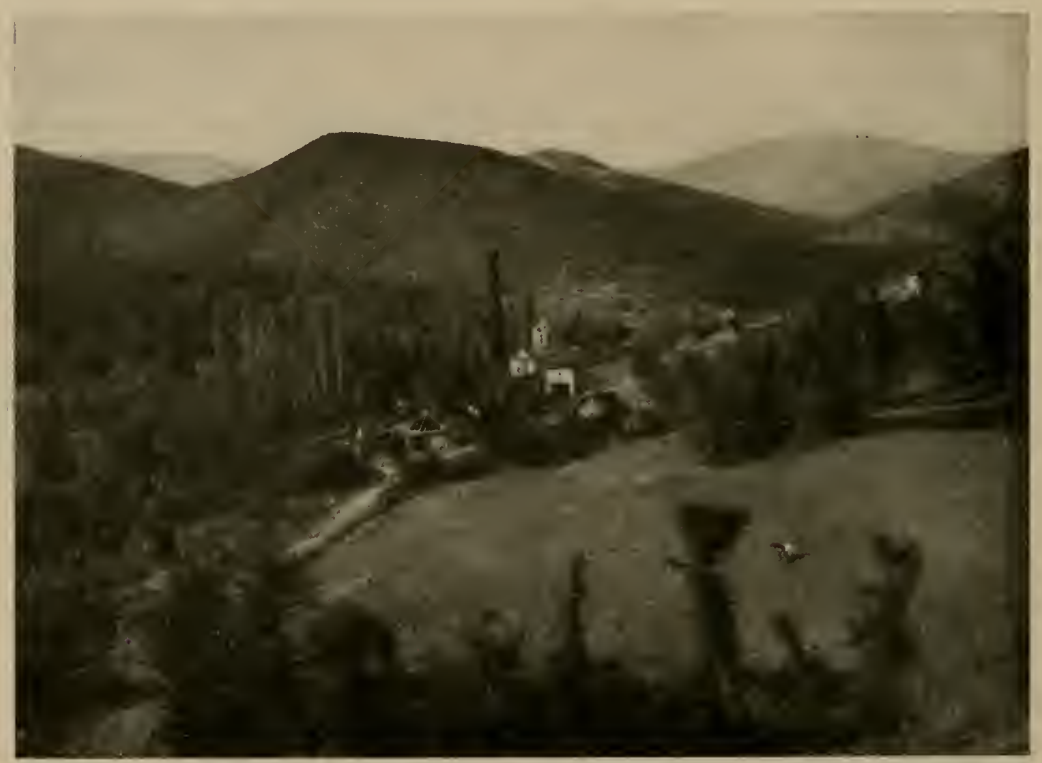

Abb. 17o. Kloster Markovo (Sveti Dimitri).

Dr. Gripp phot.

geblich auf das Ausfliegen der Weibehen gewartet hatten. Denn in jenen Tagen hatte der harte Winterrückschlag eingesetzt. Im Juni an der Lehmmauer bei Markovo sah es anders aus; da flogen nur Weibchen. Die hier wohl rechtzeitig ausgeflogenen Männchen waren längst gestorben und hatten die Weibchen bei der Arbeit des Bauens und Pflegens der Brut allein gelassen. Diesmal waren die Bienenweibchen in eifrigster Tätigkeit.

Viele hundert Bauten senkten sich in die Lehmwand hinein, von deren Aussehen die umstehende Photographie eine Vorstellung gibt (Abb. 172, S. 351). Nicht alle diese Bauten waren von der gleichen 
Bienenart gebaut. Manche Öffnungen hatten einen kleinen Durchmesser, in diese sah man kleine Bienchen hineinkriechen, andere waren größer und waren das Werk größerer Tiere. Vor allem waren aber auffallend die Bauten der offenbar häufigsten Art, welche einen zierlichen Vorbau trugen, der das Loch umfaßte und in Gestalt einer nach unten gekrümmten Röhre über die Oberfläche der Lehmwand vorragte. Die war nicht ringsum geschlossen, sondern bestand aus einem zierlichen Gitterwerk, welches in Gestalt von Stäbchen und Strängen ein luftiges Gebilde darstellte. Offenbar hatte die Biene beim Bau kleine Lehmklümpchen heran-

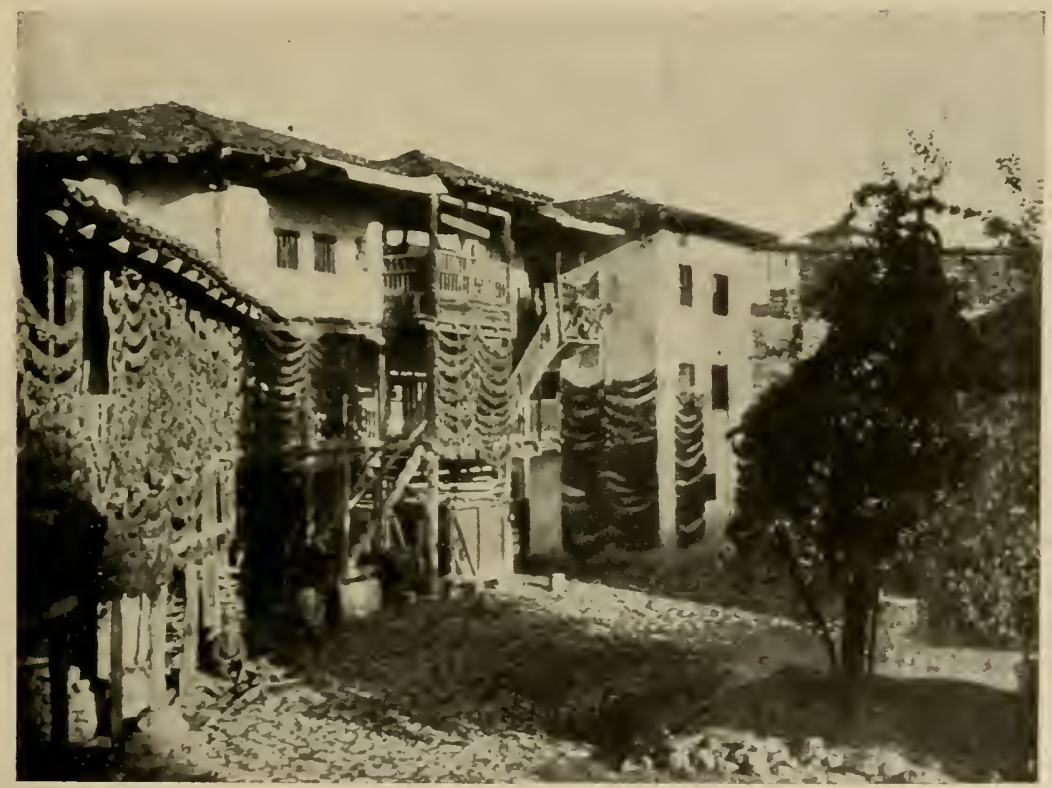

Abb. 1 7 I. Klosterhof von Markoro. Tabak zum Trocknen und Gähren aufgehängt.

getragen und eins an das andere angeklebt. Da der Anbau genau die gleiche Farbe hatte, wie die Lehmwand selbst, so war es nicht unwahrscheinlich, daß die Baumeisterin beim Aushöhlen der inneren Röhre des Baues das ausgegrabene Material der Lehmwand gleich beim Anbau verwandte. Dabei war sie ganz eigenartig vorgegangen; sie hatte nicht etwa gleichmäßig am Umkreis des Ausgangsloches angebaut, sondern oben und unten kleine Lehmwürstchen gebildet, die da und dort untereinander verklebten und so das Gitterwerk erzeugten. Die ganze große Kolonie war noch im vollen Ausbau. Manches Weibchen, welches einen oder 
mehrere Bauten schon gefüllt hatte, fing gerade mit einem neuen an. So konnte man alle Stadien des Baues an der Wand nebeneinander sehen. Hier bohrte eine Biene gerade an einem neuen Loch, dort schloß eine einen fertigen Bau; hier war eine an der Ausgangsröhre tätig, dort war eine andere eifrig beim Aus- und Einfliegen und beim Eintragen von Blütenstaub und Honig als Nahrung für ihre Brut.

Denn in der Lehmwand hatte die Bienenmutter im inneren röhrenförmigen Bau eine Reihe von Zellen geglättet, jede durch eine Zwischenwand von der vorigen getrennt, in die sie Blütenstaub eingetan, etwas Honig hinzugefügt und dann vor dem Zuschließen ein Ei auf diesen Nahrungsvorrat gelegt hatte. War sie mit einem Bau fertig, so begann sie mit einem neuen und so fort, bis ihre Kräfte erschöpft waren und sie sich zum Sterben hinlegte. Ihre Brut ließ sie wohlversorgt mit genügender Nahrung zurück. Die konnte ohne die Mutter auskommen; und wenn sie im nächsten Frühling ausschlüpfte, Männchen und Weibchen, die sich begatteten, dann starben die Männchen wieder nach kurzem, fröhlichem Leben im Sonnenschein und ließen die Weibchen allein bei der großen Sommerarbeit, die sie ungelernt, ohne Leitung und ohne die Gesellschaft von Eltern, durchzuführen hatten. Und das konnten sie auch sehr gut; denn sie hatten alle Fähigkeiten dazu als Erbgut von ihren Vorfahren mitbekommen, wie schon ihre Eltern.

Wir sahen auf dem Bild neben den Nestern mit den Ausgangsröhren auch allerhand Nester von verschiedenen Bienenarten ohne solche.

Es war reizvoll $\mathrm{zu}$ beobachten, wie an all den Hunderten von Bienennestern ein ständiges Aus- und Einfliegen stattfand. Die Erbauerin der Anflugsröhren war eine große, dunkle Biene (Anthophora parietina F.), von der diese Bauweise schon lange bekannt ist. Achtete man nun auf den Anflug der verschiedenen Bienen, so konnte man große Unterschiede in der Art bemerken, wie die einzelnen Tiere ihr eigenes Nest fanden. Bei den Formen mit den einfachen Löchern, so z. B. Andrena hattorfiana Spm. (vgl. Abb. 189, S. 377), sah man vielfach die Bienen, wenn sie anflogen, zunächst vor der Lehmwand hin und herfliegen, als suchten sie ihr eigenes Nest. Nach einiger Zeit flogen sie direkt auf ein Nest zu und krochen in dieses hinein. Nicht immer aber hatten sie das richtige getroffen. Manchmal kamen sie sofort wieder heraus und suchten von neuem. Ja es kam vor, daß sie 
schleunigst wieder zurückkamen, vertrieben von der rechtmäßigen Eigentümerin.

Ganz anders verhielt sich aber Anthophora parietina, die Erbauerin der Anflugsröhren; denn als solche erwiesen sich bei diesen Beobachtungen jene Vorbauten. Ohne Zögern flog jede ankommende Biene auf ihr eigenes Nest los und bewies die Richtigkeit der Wahl dadurch, daß sie drinnen blieb, solange die Arbeit dauerte, die sie dort $z u$ erfüllen hatte. Stracks schlüpfte sie mit dem Kopf voraus in den Bau und kam ebenso mit dem Kopf zuerst wieder heraus; die anderen Bienen, welche in fremde Bauten geraten waren, kamen meist rücklings aus diesem zurück.

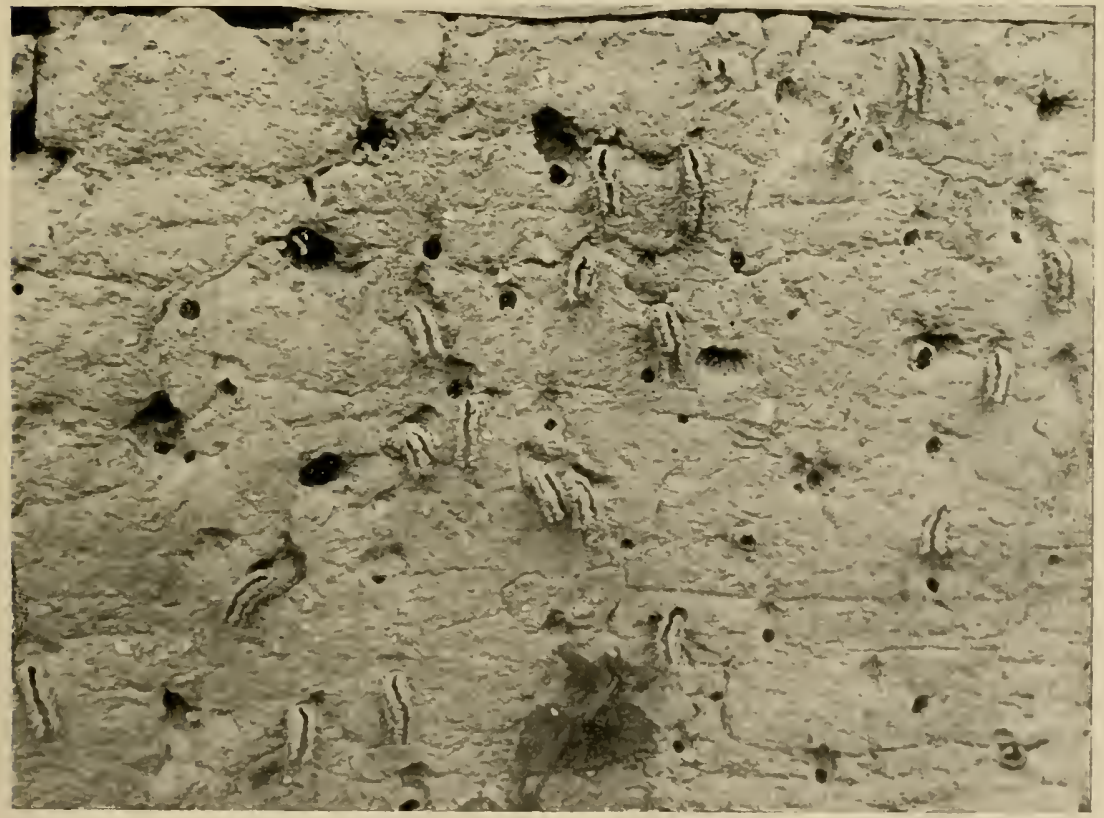

Abb. 172. Ausschnitt aus der großen Bienenkolonie von Anthophora parietina F von Markovo 1918.

Es war ersichtlich, daß in den Einzelheiten des Baues, in der A nordnung cler Lehmspangen, in der Größe der Durchbrechungen, in der Biegung der Röhre, in den Einzelheiten des Ausgangs die einzelnen Anflugsröhren untereinander verschieden waren. So kam ich zu dem Schluß, daß der Vorteil dieser Bauten in einer solchen großen Kolonie darin bestand, daß jede Biene ihren eigenen Bau an seiner Form rasch erkennen konnte. 
Ich prüfte diese meine Theorie, indem ich kleine Veränderungen an den Ausgängen vornahm, Stückchen vom Rand oder das ganze gekrümmte Ende abbrach. Es war auffallend, wie die heimkehrende Biene, die zunächst geradewegs auf ihre Röhre losgeflogen war, nun zögerte, ähnlich wie ihre weniger künstlich bauenden Nachbarn der anderen Arten hin und herflog und sich oft erst nach langer Zeit entschloß, den Versuch des Einfliegens zu machen.

Wie interessant wäre es gewesen, längere Zeit vor diesen Bauten $\mathrm{zu}$ verweilen, $\mathrm{zu}$ beobachten und $\mathrm{zu}$ experimentieren. Leider war dies zunächst unmöglich und die Absicht, noch einmal die Stelle aufzusuchen, wurde durch allerlei Ereignisse verhindert.

Damals konnte ich noch beobachten, daß um die Nester zahlreiche andere Hymenopteren herumflogen, welche als Nestparasiten in die Löcher eindrangen, um ihre Eier bei der fremden Brut unterzubringen. Es waren mancherlei Formen, unter ihnen am auffälligsten die wie Edelsteine schimmernden Goldwespen (Chrysiden), deren Schönheit sie nicht hindert, solche für die Bienenbrut verderbliche Absichten zu verfolgen. Dazu kamen andere Arten von Nestparasiten, welche im 25. Kapitel erwähnt sind.

Überall in Mazedonien, wo ich solche Siedelungen solitärer Bienen an Lehm- und Lößwänden antraf, in Kaluckova an den Lehmmauern der Häuser und Gärten, bei Valandova, Dedeli und Üsküb fing ich solche Goldwespen mit ihren prachtvollen, wie in glänzende Metallpanzer gehüllten Körpern, Tiere von verschiedenster Größe bis herab zu winzig kleinen Wespchen, welche wie Goldstaub schimmerten.

Am Wodno fand ich auch zahlreiche Ameisenarten, darunter einige, die ich sonst in Mazedonien nicht beobachtet hatte. Daß die Körnerameisen aus der Gattung Messor hier bis hoch hinauf zahlreich vorkommen, überall ihre Bauten und Straßen sichtbar waren, ist nicht verwunderlich. Ebensowenig, daß in den Obstund sonstigen Bäumen Camponotus-Arten häufig bauten. Interessanter war mir das Auffinden eines eigenen Baues der kleinen Diebesameise Solenopsis fugax West., welche also hier ihrem deutschen Namen keine Ehre machte. Auch eine noch winzigere dunkelbraune kleine Ameise (Plagiolepis pygmaea Latr.), eine südliche Form, die ich schon aus dem Kaiserstuhl bei Freiburg i. Br. kannte, fand ich nur auf diesem Berg.

Nicht minder interessant was das Vogelleben. Hier erlegte ich schon Mitte April einen Kuckuck (Cuculus canorus canorus L.), 
der also hier, wie an der Riviera früher angekommen war, als bei uns in Deutschland. Auch der Grünling war schon da (Chloris chloris mïhlei Parrot.). Der Weidenlaubsänger (Phylloscopus collybita collybita Viell.), und der Vitislaubsänger (Ph. trochilus trochilus L.) waren etwas später häufig in den grünen Büschen. Dort ließen sich auch verschiedene Grasmücken hören und an den unteren Hängen war auch hier die Nachtigall ein häufiger Vogel. Am Eingang der. Treskaschlucht trieb sich in den hohen Bäumen am Fluß die Sumpfmeise herum (Parus palustris stagnalis Br.). Dort und weiter oben am Berg wimmelte es manchmal von Zaunkönigen (Troglodytes troglodytes L.).

Ebenfalls in der Treskaschlucht begegnete mir die Ringdrossel (Turdus torquatus alpestris Br.) und an den Hängen gab es zahlreiche Balka namseln (Turdus merula aterrima Mad.).

Damit ist der Reichtum bei weitem nicht erschöpft; denn in den Hainen oben bei Neresi flogen der NuBhäher (Garrulus glandarius L.) und Spechtarten (Picus viridis Dofleini Stres.). Die Würge $r$ waren häufig, in den kahlen oberen Zonen gab es Heidelerchen (Lullula arborea flavescens Elenka), auch Feldlerchen (Alauda ariensis cantarella Bp.) und selbst $\mathrm{H}$ a ube $\mathrm{n}$ lerchen kamen ganz oben vor.

Daß Raubvögel, Adler, Geier, Bussarde, Falken und all die Krähenvögel auch auf dem Berg nicht fehlten, braucht kaum erwähnt zu werden.

So ist es verständlich, daß mir als Naturforscher und Zoologen der Wodno in guter Erinnerung geblieben ist. Aber wie auch sonst die Gegend von Üsküb, so bot er auch in seinen Dörfern manche Gelegenheit zu Studien über Kultur und Lebensweise der Mazedonier. Davon soll das nächste Kapitel einiges berichten. 


\section{NERESI \\ (ÜBER DIE KIRCHEN, KLÖSTER UND FESTE DER MAZEDQNIER)}

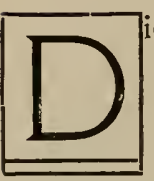

ie Erinnerung an einen heißen, bunten Tag steht klar vor meinem Gedächtnis und mit ihm verknüpft sind manche andere Erfahrungen, die ich bei den slavischen Mazedoniern über ihr Volkstum und ihren Zusammenhang mit der Geschichte des Landes machen durfte. Den Tag, der in mir zuerst ein starkes Interesse für die Menschen, welche Mazedonien bewohnen, weckte, den durfte ich im Klosterhof von Neresi, angesichts seiner altehrwürdigen malerischen Kirche verleben, wenige Wochen nach meiner Ankunft in Mazedonien.

Hoch oben am Wodno, in etwa $800 \mathrm{~m}$ Höhe, liegt, einer Schlucht angeschmiegt, das Dorf Neresi. Seine Häuser sind von Obstbäumen umgeben, Weinlauben überdachen die Höfe. Die Schlucht ist mit Pappeln, Ulmen, Erlen und allerhand Gesträuch bestanden. Oberhalb des Dorfs steigen steile Hänge zur Gipfelregion des Wodno hinan. Auf ihnen breiten sich grasbedeckte Weiden aus, unterbrochen von stattlichen Baumgruppen. Letztere bestehen meist aus mächtigen Edelkastanien. Die braunen Stämme, die gerundeten, tiefschattenden Kronen der prachtvollen Bäume rahmen in reizvollster Weise das liebliche Dorf mit seiner malerischen Kirche ein, über welche hinaus ein weiter Blick ins Wardartal und auf den jenseits gelegenen blau schimmernden Karadakh sich öffnet.

Nur einmal außer hier bei Neresi habe ich in Mazedonien Edelkastanien angetroffen, worauf ich früher schon einmal hinwies. Es war dies bei Kalkandelen, hoch im Tal der Sarska, etwa in der gleichen Meereshöhe von etwa $800 \mathrm{~m}$, in der auch der Hain bei Neresi liegt. Es war windstill, als ich in den kühlen Schatten des Hains von Neresi eintrat; hier war gut ausruhen vom heißen Anstieg. Das Schweigen im Walde wurde nur von einem tiefen, dröhnenden Ton unterbrochen, der aus der Krone einer uralten Kastanie zu mir 
herabdrang. Wie Orgelklang brauste es da oben und als ich genauer hinsah, bemerkte ich Hunderte von Bienen, welche ein Astloch um. schwärmten. Ein großes Bienenvolk hauste in einer Höhle in dem mächtigẻn Baum; irgendein Ereignis mochte es erschreckt haben und das erregte Summen der Tausende von Insassen des Nestes fand an den dünnen Wänden des alten Stammes eine gute Resonanz.

Bei der primitiven Bienenzucht, die in Mazedonien betrieben wird, kommt es nicht selten zum Verwildern von Schwärmen der Honigbienen, welche in Höhlen oder Baumlöchern sich ansiedeln und da das freie Dasein führen, welches das ursprüngliche Bienenleben darstellte.

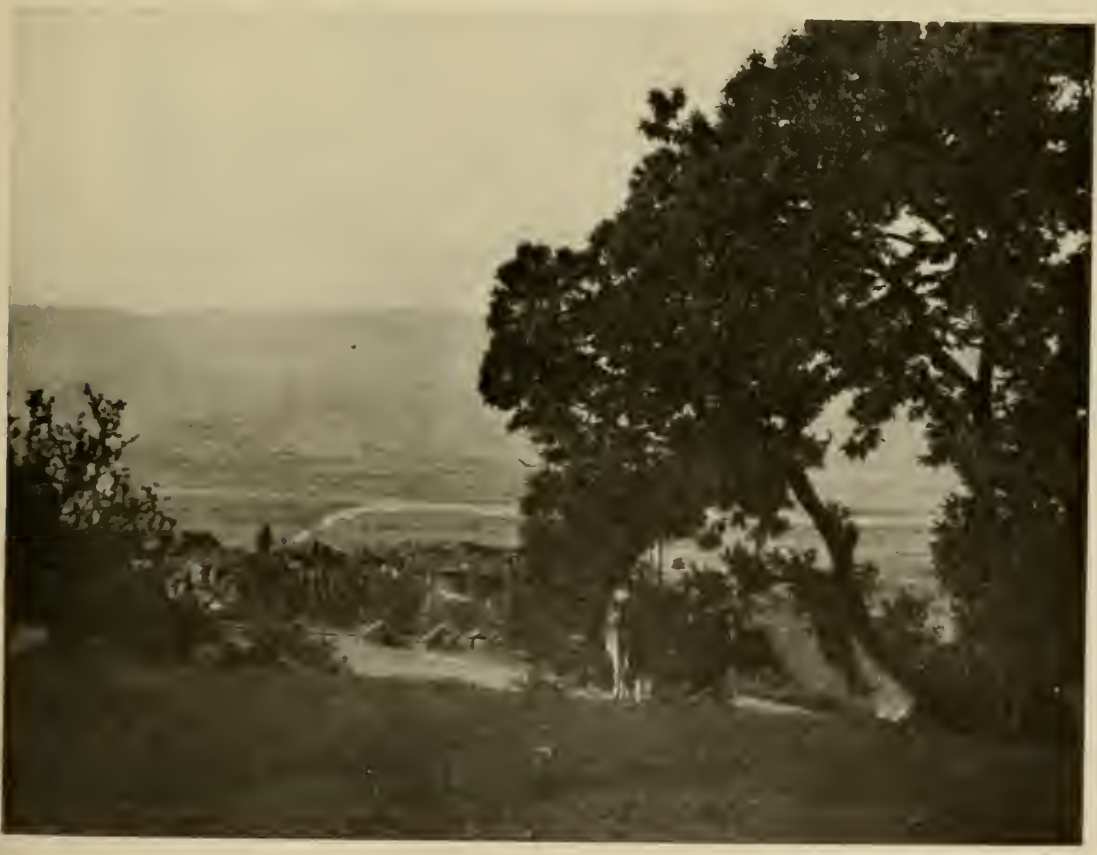

Abb. 173. Blick auf Kloster und Dorf Neresi aus dem Edelkastanienhain.

Bei meinen Wodnowanderungen kam ich fast stets nach Neresi oder doch in die Nachbarschaft des Dorfs. So entstand im Frühling, als die Apfelbäume blühten, das Bild, welches die Titeltafel dieses Buches darstellt. Der Tag, dessen Eindrücke ich heute schildern will, war ein heißer Augustag im Jahre 1917. Während der Vorbereitungen zur Schardakhexpedition unternahm ich die Wanderung in Begleitung des deutschen Verbindungs- 
offiziers, Hauptmann Lessing, da ich gehört hatte, daß oben in Neresi an diesem Tag ein Heiligenfest gefeiert werde.

Es war mittags um 2 Uhr, als wir aufbrachen und der schattenlose Anstieg von etwa 2 Stunden Dauer war an dem heißen Sommertag sehr ermüdend. Die Hänge des Wodno unten und in den mittleren Höhen waren dürr und vegetationslos, die Büsche am Rand des Pfades verstaubt und doch war der Landschaft nicht jeder Reiz genommen. Noch sah man zahlreiche Ameisen an der Arbeit, Schmetterlinge schwebten in der heißen Luft, Eidechsen safoen still auf den Felsen.

Das Interessanteste waren aber die Menschen, welche die Straße herabkamen. Sie kehrten schon vom Fest zurück, alle in

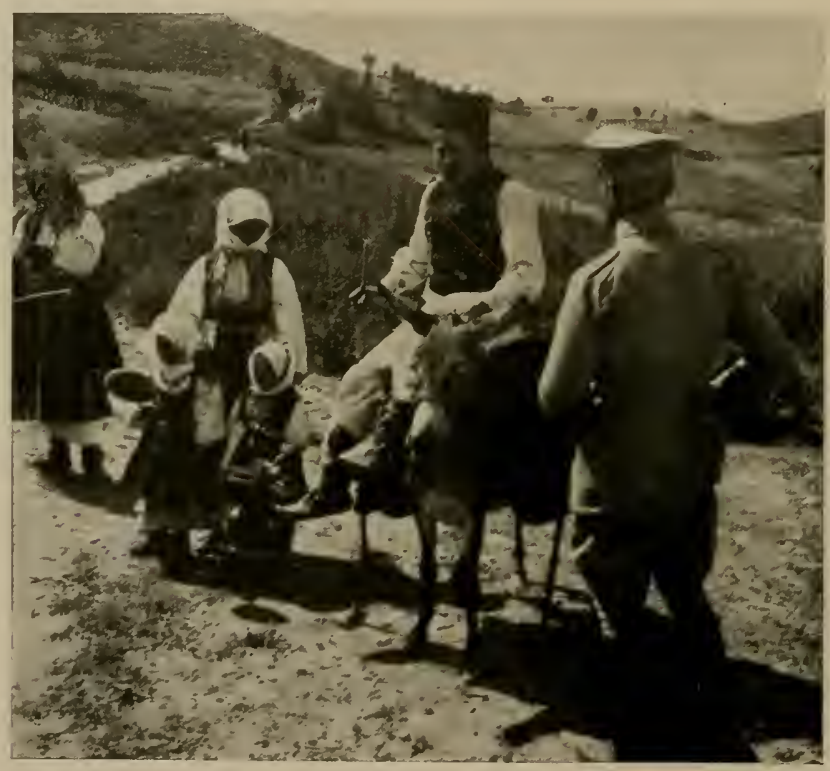

Abb. 174. Mazedonische Bauernfamilie auf der Rückkehr vom Klosterfest in Neresi.

ihren schönen bunten Feiertagskleidern, Männer, Frauen, junge Mädchen und Kinder in größeren und kleineren Gruppen. Wir fürchteten schon, wir könnten zum Fest zu spät kommen. Das verriet aber unsere Unerfahrenheit mit den Gewohnheiten der mazedonischen Bauern; wir unterschätzten ihre Ausdauer bei den Tanzfesten.

Als wir in Neresi ankamen, waren die Gassen noch von geputzten Menschen erfüllt, die sich zum Teil zur Heimkehr bereit 
machten. Meist sah man je eine Familie eine Gruppe bilden, Mann und Frau, dabei die Kinder verschiedenen Alters und Wachstums, dazu manchmal Schwestern und Brüder von Mann und Frau. Oft wurden Trag- und Reittiere mitgeführt. Da zeigte sich stets das charakteristische Bild, daß, wenn nur ein Esel oder Pferdchen dabei war, der Mann, mochte er auch jung und kräftig sein, auf dem Tier saß, während Frauen und Kinder nebenher trotteten.

$\mathrm{Ab}$ und auf durch eine Schlucht gelangten wir in den weiten Klosterhof; heute stand das Tor weit offen und der eingehegte Raum war noch von einer großen Schar Menschen erfüllt. In

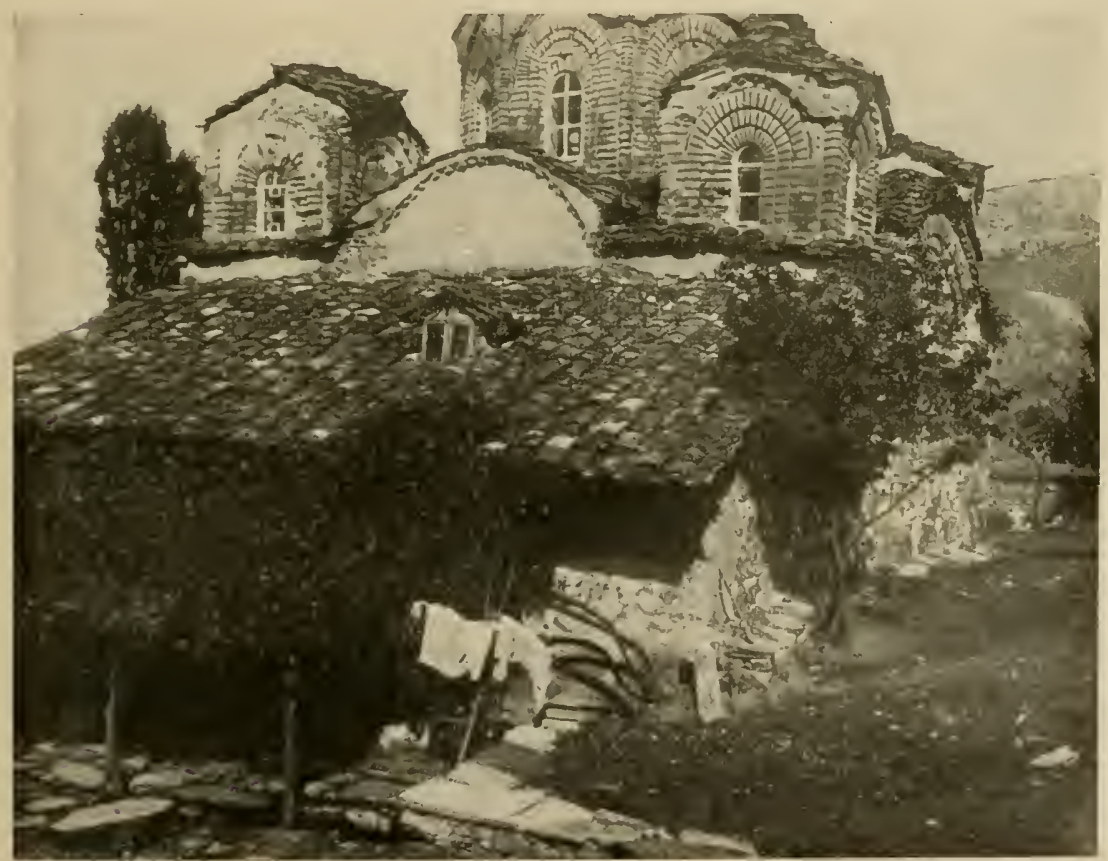

Abb. 175. Die Laube vor der Kirche von Neresi.

einer Ecke bei der Kirche ertönte die Tanzmusik. Wir kamen also nicht zu spät.

Das Kloster Neresi ist ein ziemlich kleines Anwesen. Wie gewöhnlich steht an der einen Seite des Klosterhofs die Kirche und wendet ihm ihren Haupteingang zu. Eine Anzahl schattenspendende Bäume stehen um die Kirche herum. Letztere ist eine typische Anlage, ein Mittelturm von vier Ecktürmen umgeben, das Ganze aus Hausteinen mit eingeschaltenen schmalen Bändern roter 
Ziegel gebaut. Die Dächer der kuppelartigen Türme bestehen aus schweren Hohlziegeln und bilden flache achtseitige Pyramiden.

Um den Hof stehen aus Holz und Steinen gebaute Häuser mit großen, luftigen Holzgalerien. Solche geräumigen Häuser sind ein wesentlicher Bestandteil der mazedonischen, überhaupt der Balkanklöster und haben eine von deren wichtigsten Aufgaben zu erfüllen. Sie dienen als Massenquartiere für die Besucher der Klöster, welche dort in großer Menge zusammen kommen. Sie sind oft weit hergekommen und bleiben nicht selten tagelang im Kloster, um dort die Heiligenfeste zu feiern. Wie es in anderen christlichen Ländern nicht anders ist, sind die kirchlichen Feiern mit Volksfesten verknüpft.

$\mathrm{Zu}$ diesen strömt die Bevölkerung der ganzen Umgegend zusammen und oft haben die Wallfahrer tagelange Reisen zurückgelegt, um rechtzeitig das meist hochgelegene Kloster zu erreichen. Dort finden sie ein Dach, das sie deckt, einen meist hölzernen Boden, auf dem sie ihre mitgebrachten Decken ausbreiten und schlafen können. Kochstellen sind vorhanden, wo sie die auch mitgebrachte Nahrung zubereiten dürfen. Doch werden alle Gäste meist freigiebig von den Mönchen bewirtet. Dazu dient das auf Stiftungen beruhende Vermögen der Klöster; denn die wenigen jeweils in einem Kloster hausenden Mönche verbrauchen selbst nicht viel.

So sind die Häuser bei den Festen von zahlreichen Quartiergästen angefüllt, meist hat jede Familie ihr Plätzchen für sich und es entwickelt sich ein munteres Leben in den Hallen und Galerien, die sonst oft wochen- und monatelang leer stehen mögen. In gefeierten Klöstern versammeln sich oft solche Massen von Besuchern, Familien mit Weibern und Kindern, dal3 die Behausungen nicht ausreichen für die Fülle, und oft Hunderte oder gar Tausende im Freien, innerhalb der Klostermauern oder in der Umgebung lagern müssen.

So sind die mazedonischen Klöster stets gastliche Stätten, wo auch der Fremdling beherbergt wird und ich habe manche freundliche Erinnerung an solche mitgenommen. Von den Mönchen wurde man oft sehr gut bewirtet und manch guten Tropfen Wein habe ich bei ihnen genossen.

In der grellen Sonne bewegte sich im Klosterhof von Neresi eine bunte Menge von Männern, Frauen und Kindern. Alle hatten ihre Köpfe in irgendeiner Weise vor den Strahlen der Sonne ge- 
schützt. Auch wenn sie die dort üblichen flachen runden, oft schön gestickten Mützen trugen, hatten selbst die Männer neist weiße, auch farbige und bunt gewebte Tücher um den Kopf geschlungen. Nur wenige hatten Strohhüte oder Militärmützen aufgesetzt. Alle Frauen hatten große weiße Tücher um Kopf und Nacken gelegt, welche durch ein über Scheitel und Ohr gelegtes, um den Hals geschlungenes buntes, meist gesticktes breites Band festgehalten wurde. Unter dies hatten sie Blumen gesteckt.

Alle hatten sie weiße Hemden mit weit offenen Ärmeln und schön gesticktem, über die Handgelenke fallenden Saum an. Bei manchen waren die Ärmel eng geschlossen durch ein breites Band

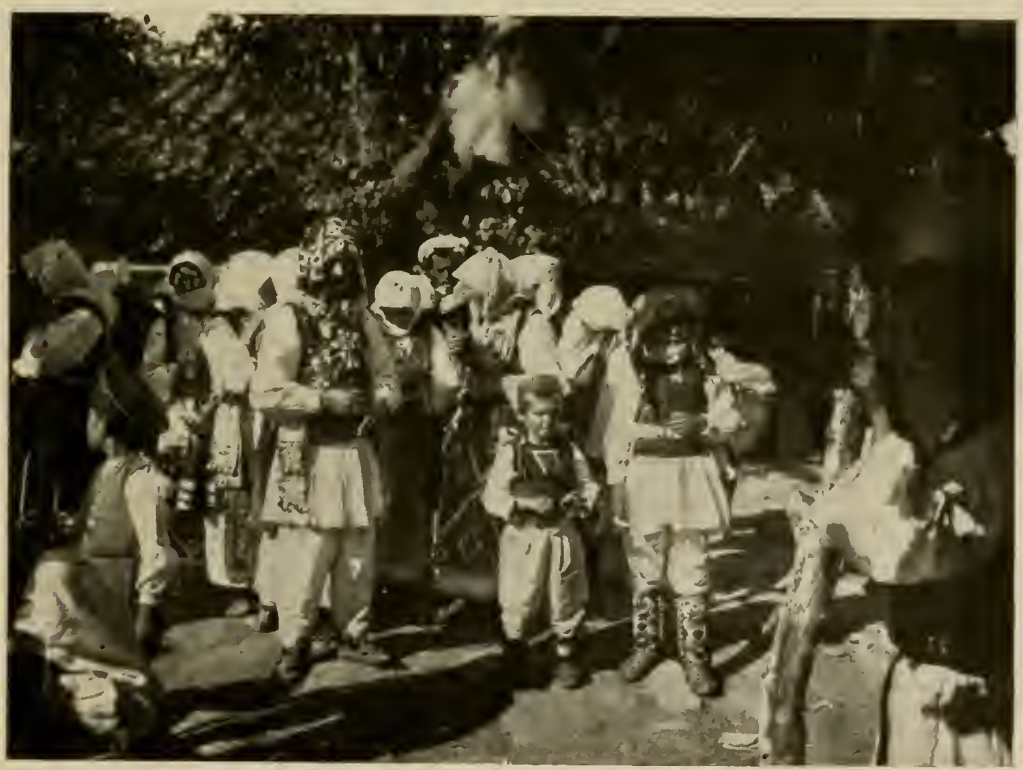

Abb. I76. Gruppe nach dem Tanz in Neresi.

mit feiner Stickerei. Der Hals war frei, doch durch das Kopftuch mit bedeckt. An der Brust schaute das blütenweiße Hemd aus einem tiefen, viereckigen Ausschnitt der kurzen, ärmellosen Weste heraus. Über die Brust schlangen sich Halsketten aus Silber, bunten Steinen, emaillierten Plättchen hergestellt mit allerlei Anhängseln. Allen Mädchen und jungen Frauen hingen unter dem Kopftuch zwei oder mehr lange, eng geflochtene Zöpfe den Rücken herab und reichten meist über das Knie hinaus. Oft waren bunte Seidenschnüre oder Bänder hineingeflochten, um vor allem das 
Hinterende zu verstärken (Abb. I77). Das Handgelenk trug silberne oder sonstwie kostbare Armringe.

Die Hüften umspannte ein breiter Gürtel aus farbigem, festem Wollgewebe. Von ihm hing ein langer, enger weißer Rock bis kurz über die Knöchel herab. Ihn überdeckte bis zu den Knien ein kurzer Rock mit einem breiten unteren Saum, der oft ebenso schön gewirkt war wie der Gürtel. Darüber hing vorn die breite, steife Schürze bis zu den

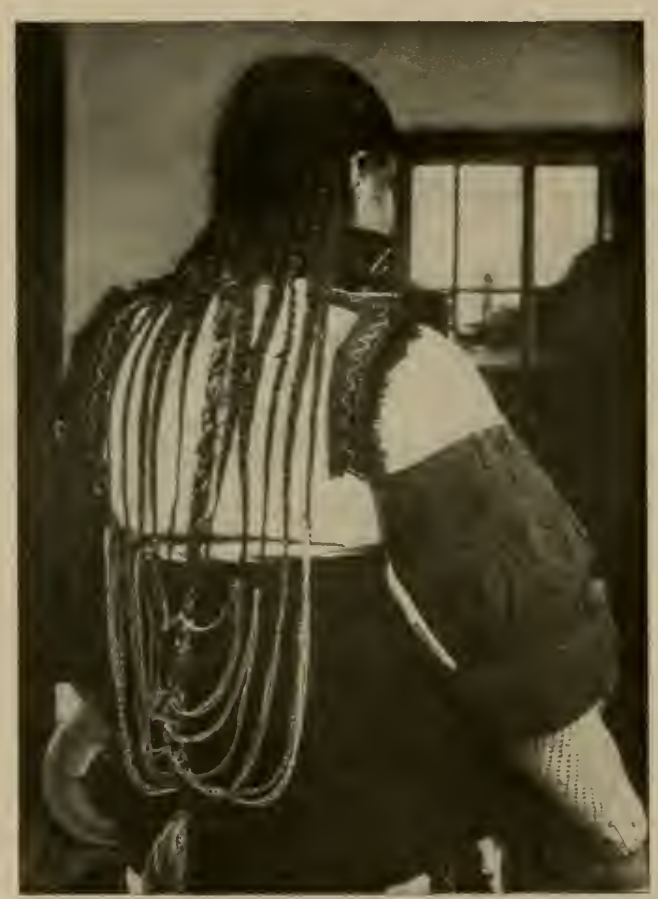

Abb. 177. Zopfschmuck einer mazedonischen Bauersfrau. Südmazedonien bei Negorci. Füßen in gleicher Länge wie der weiße Rock.

Die Schürze ist der besondere Stolz der Mazedonierin: sie ist in reiz. vollen, meist polyedrischen Mustern aus schwerer Wolle gewebt. Weiß und rot waren hier in Neresi an Kleid wie Schürze die vorherrschenden Farben. Die Füße waren meist mit schwarzen Strümpfen bedeckt und steckten in aus Leder eigenartig gebogenen Schuhen, an denen Schuhkörper und Sohle aus einem Stück gefertigt waren, den sogenannten Opanken.

Ähnlich waren die Anzüge der Männer gefertigt. Auch hier weiße Ärmel, kurze ärmellose, wollene Westen, die meist schwarz waren. Die Männer trugen wie die Frauen Gürtel, von denen an der rechten Seite zwei breite Streifen herabhingen, die man auch bei den Weibern nicht selten beobachten konnte. Unter dem Gürtel schaute ein kurzer weißer Rock heraus, den aber nicht alle Männer, sondern vorwiegend die jüngeren trugen. Unter ihm folgten enge weiße Hosen, die entweder bis auf die Schuhe herabhingen oder von diesen durch schön gewirkte Gamaschen getrennt waren.

Von dieser bunten, bewegten Menge wurden wir nicht 
unfreundlich begrüßt und aufgefordert, in einer Laube Platz \%u nehmen, die von Reben umrankt, an der Seite der Kirche hinzog und eine einfache Holzbank mit einem Tisch davor enthielt (A bb. ${ }_{75}$, S. 357). Da Hauptmann Lessing den Dolmetscher machen konnte, entspann sich bald eine lebhafte Unterhaltung.

Als einer der Kirchenvorstände von meinem Begleiter hörte, ich sei Naturforscher, meinte er, das treffe ja sehr gut, denn heute sei das Fest des heiligen $\mathrm{Panteleimon}$ und der sei der Heilige der Ärzte und Naturforscher. Er führte uns in die Kirche, wo es von Weihrauch duftete und vor dem Ikonostas, der Schranke

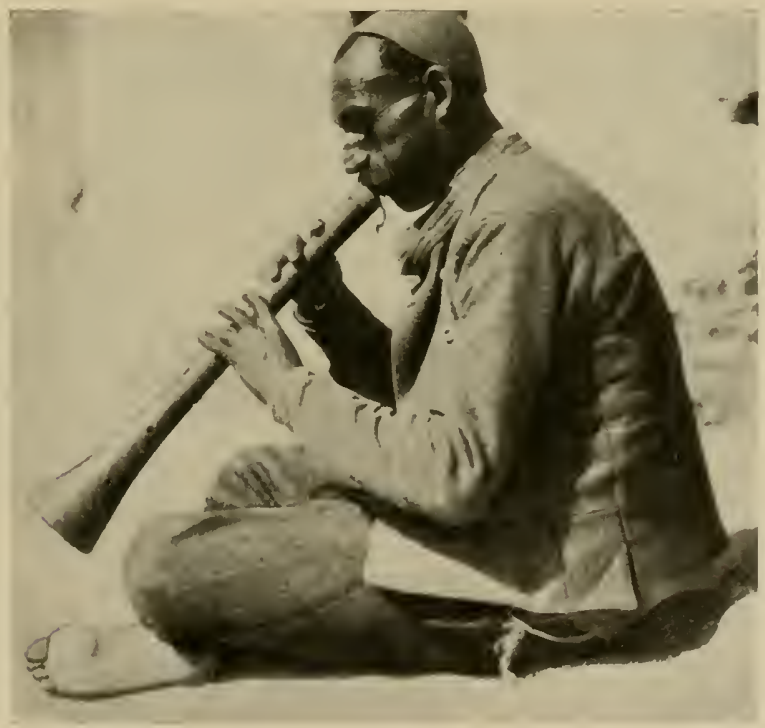

Abb. 178. Zigeuner als Flötenbläser.

zwischen dem Kirchenraum und dem Allerheiligsten, brannten zahlreiche Kerzen. Unter den Heiligen, welche in alten Bildern in dem reichen Schnitzwerk der Schranke eingerahmt waren, zeigte er mir Sveti Panteleimon mit den Geräten und Abzeichen des Arztes. Als ich mich darauf entschloß, dem Heiligen eine stattliche Kerze anzuzünden, war die Freundschaft geschlossen. Man veranlaßte uns, wieder unseren Platz auf der Bank in der Laube einzunehmen, bewirtete uns mit Kaffee und mit Raki, dem trefflichen Zwetschenschnaps der Bulgaren.

Unterdessen hatten die Tänze wieder begonnen und die Tanzmusik dröhnte durch den Hof. Es waren Zigeuner, welche musizierten; drei Instrumente gab es, einen Dudelsack, eine lange 
schwarze Holzflöte und eine dröhnende Pauke. Es war eine grelle, schrille Musik mit eigenartigem Rhythmus, welcher den Tänzen entsprach. Alle Tänze der Balkanvölker sind Reigentänze; Serben, Bulgaren, Rumänen, Griechen ủnd Mazedonier tanzen in ähnlicher Weise. Doch gibt es eine Menge von Varianten dieser Tänze, nicht nur nach den verschiedenen Nationen, sondern auch vielfach nach den verschiedenen Landschaften. Überall haben sie einen ähnlichen Namen: Choros, Horo u. dgl.

Die Rhythmen erscheinen unserem Ohr etwas absonderlich, aber sie schmeicheln sich ein, vor allem, wenn man mit den Augen

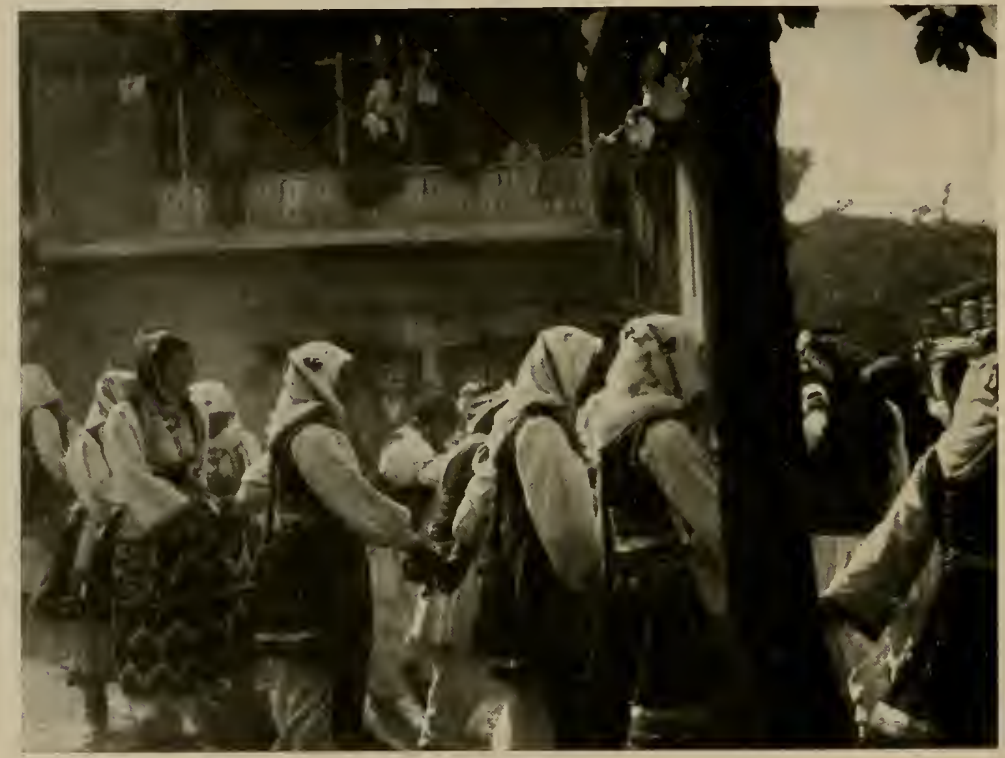

Abb. 179. Frauenkreis beim Tanz in Neresi.

den Bewegungen der Tänzer folgt. Bei vielen Tänzen bedingt der Tanzrhythmus ein Fortschreiten der Tänzer in einer Richtung; denn bei solchen werden mehr Schritte in einer Richtung als in der anderen ausgeführt.

So werden bei einem Tanz drei Schritte nach rechts gemacht, worauf zwei Schritte nach links folgen; bei einem anderen Tanz folgen sich 5 und 3 Schritte. Die Verschiedenheiten der Rhythmen sind sehr zahlreich.

Jeder Tänzer reicht seinem Nachbarn die Hand; so werden Ketten gebildet, welche sich aber nicht zu Kreisen schließen, wenn auch meist die Tänzer einer Kette sich im Kreis anordnen. Meist 
wird je eine Kette von Männern und eine von Mädchen und Frauen gebildet. Das war bei den Tänzen, welchen ich damals in Neresi zusah, stets der Fall. Bald bildeten die Frauen den inneren und die Männer den äußeren Kreis, bald kam es zur umgekehrten Reihenfolge. An anderen Orten sah ich auch gelegentlich Ketten aus Männern und Frauen gleichzeitig gebildet.

Ein Vortänzer leitet den ganzen Tanz. Oft findet sich in der Männerkette ein männlicher Vortänzer, in der Frauenkette eine Vortänzerin. Meist ist der Vortänzer der vorderste in der Kette, er führt beim Tanz und gibt das Tempo an. Er kann dabei auch an der zweiten oder dritten Stelle eingereiht sein, läßt auch einmal los und greift an irgendeiner Stelle ein, wo es mit Tempo und Rhythmus hapert.

In der Kette pflegen die besten Tänzer vorn dem Vortänzer sich anzuschließen und die geringsten und ungeschicktesten den Abschluß zu bilden. Das ist oft auch eine Reihenfolge des Alters; denn am Schluß findet sich meist die Jugend. Auch Kinder pflegen bei nicht ganz feierlichen Gelegenheiten am Reigen teilzunehmen und wenn es genug sind, eine besondere Kette zu bilden.

Das Tempo des Tanzes pflegt anfangs mäßig, sogar langsam zu sein. Das hängt natürlich vom besonderen Tanz ab. Während des Tanzes wird durch den Vortänzer das Tempo allmählich beschleunigt, bis es allmählich zu rasender Bewegung der Füße und Drehung des ganzen Kreises führt: Es bietet ein eigenartiges Bild, wenn der Kreis der Männer und derjenige der Frauen sich in gleichem Tempo ineinander bewegen, wobei der Rhythmus jeden einzelnen Körper bewegt und über die ganze Kette sich fortpflanzt.

Manchmal wird die Schnelligkeit zur Raserei, wobei die Menschen sich erschöpfen; der Vortänzer gibt ein schnelleres und immer schnelleres Tempo an, dem die Musik genau folgt. Sind die Tänzer ermüdet, d. h. gibt der Vortänzer dies zu, so wird eine Pause gemacht. Die Kette löst sich auf, die einzelnen stehen schwitzend und stark atmend umher und ruhen sich aus. Sie setzen sich auch nieder und nehmen Erfrischungen zu sich.

Damals in Neresi setzte sich der Tanz stundenlang fort; die Leute waren unermüdlich und zeigten, Frauen wie Männer, dabei eine erstaunliche körperliche Leistungsfähigkeit. Man hatte durchaus den Eindruck, daß sie allmählich in einen gewissen Rausch gerieten. Dabei überschritt die Leidenschaft in keinem Fall, dem 
ich beiwohnte, einen mäßigen Grad; der Tanz blieb stets dezent und in der Ausführung gemessen.

Solche Tänze werden nicht nur in den Klöstern bei religiösen Feiern ausgeführt, sie spielen im Leben der Bauern überhaupt eine große Rolle, man kann sie in den Dörfern an Sonn- und Feiertagen unter dem großen Schattenbaum des Dorfes oder auf dem Gemeindeplatz beobachten; bei Hochzeiten und anderen Familienfesten dürfen sie nicht fehlen.

Hier im Kloster ging es geordneter her als bei den Tänzen, welche in den Dörfern etwa zur Feier einer Hochzeit stattfanden. Dort nahmen neben den Festgebern auch allerhand andere Leute an

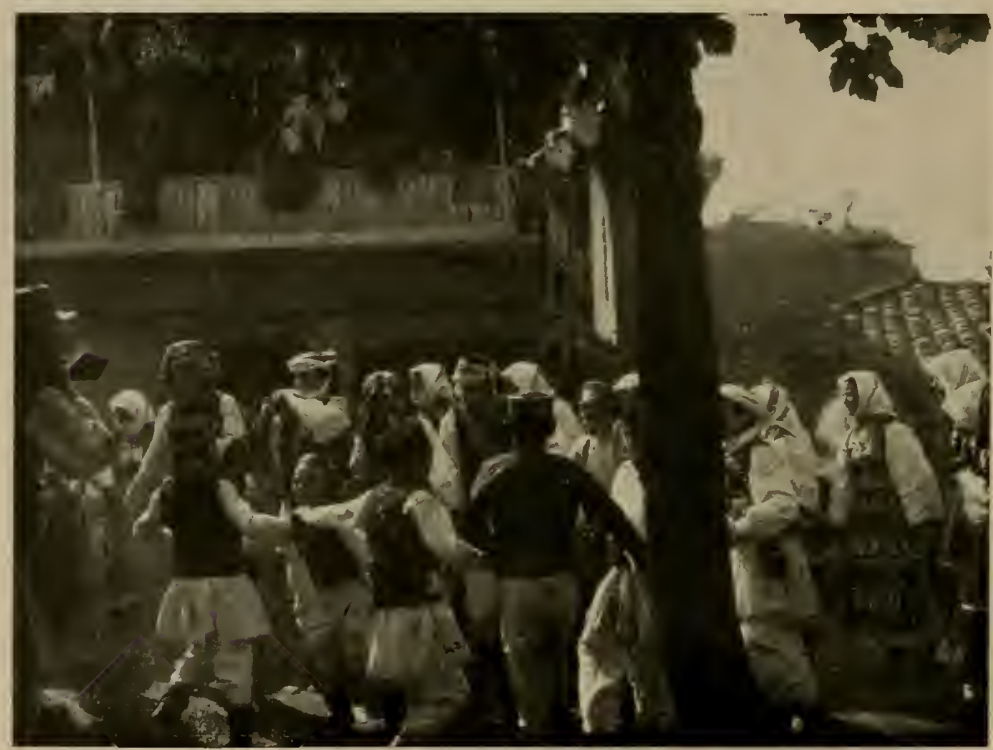

Abb. 180. Junger Männerkreis beim Tanz in Neresi.

den Tänzen teil, vor allem die Kinder der Nachbarschaft, die viel weniger gut gekleidet, oft direkt verlumpt waren. Dann unterschied sich der Anfang der Kette mit dem geregelten Tanz, den stattlichen, schön geschmückten Frauen sehr von dem Hinterende, wo Mädchen von 8-12 Jahren, ungeschickt und ungraziös mittanzten, die Hände oft loslassend und so die Kette sprengend, daß der Vortänzer immer wieder eingreifen mußte.

Noch schlimmer war das im Männerkreis, dem sich oft ganz kleine Knaben angliederten, von denen einige die Hanswürste 
machten, schrien, lachten, den Tanz störten und jubelnd Purzelbäume schlugen.

In den Klöstern waren immer die Kirchen besonders interessant, soweit sie alt waren und früheren Jahrhunderten entstammten. Dann war die Bauweise von besonderem Interesse und weckte Gedanken an die Geschichte des Landes. Und zwar waren es meist bulgarische Traditionen, welche aus den alten Bauten zu einem sprachen. Die Kapitel über Prilep und Ochrida werden Gelegenheit geben, auf sie zurückzukommen.

Während des Feldzugs waren auch deutsche und bulgarische Archäologen und Kunsthistoriker an der Erforschung und Katalo. gisierung der historisch, kulturell oder künstlerisch wertvollen Bauwerke und Kunstdenkmäler tätig. Ihnen will ich nicht ins Handwerk pfuschen, wenn ich der Bauten und ihrer Ausschmückung gedenke, welche auf meinen Pfaden mir begegneten. Vielmehr will ich der Anregungen gedenken, die von ihnen ausgingen und mich veranlaliten, mit offenen Augen auch diese Zeugnisse der Entwicklung der Balkanvölker anzuschauen.

Während Kirchen späteren Ursprungs vielfach als Basiliken gebaut sind, sind alte Kirchen, wie die von Neresi, meist als Kuppelkirchen mit einer großen zentralen Kuppel und vier Randkuppeln angelegt. Diese Grundform wird meist als byzantinische Bauweise bezeichnet, wenn sie auch offenbar älter ist als die byzantinische Kunst und, wie Strzygowski gezeigt hat, auf armenische Ursprünge zurückzuführen ist. Dem altarmenischen Konchenquadrat entspricht der Grundriß der Kirche von Neresi, wenn auch hier durch Anbauten an der Portalseite und am Chor eine Längsachse geschaffen ist. Sehr reizvoll sind in Neresi die Einfassungen der Fenster, ganz typisch der Gegensatz des achteckigen Zentralkuppelturmes zu den quadratischen Ecktürmen.

Das Innere mit dem freien Raum für die Gemeinde, anschließend an das Hauptportal, zeigt die übliche Trennung des Allerheiligsten durch den Ikonostas, die Bilderwand mit reicher Schnitzerei und Vergoldung und Heiligenbildern von nicht sehr hervorragender alter Malerei. Einige Steine und Säulenteile inı Innern deuten auf hohes Alter der Kirche hin. Sie stammt aus dem I2. Jahrhundert. Alte freskenähnliche Temperamalereien sind in den Ecktürmen und in der Apsis erhalten; weniger wertvolle Malereien aus neuerer Zeit finden sich im Hauptraum. In der Hauptsache gehen die gottesdienstlichen Handlungen hinter 
der bildgeschmückten Schranke vor sich. Deren drei Türen spielen im Ritus eine große Rolle. Der meist schöne Gesang der Priester im Wechsel mit den in der Kirche antwortenden Chören geben dem Gottesdienst eine feierliche Weihe. Sehr groß ist der Prunk im slavischen Ritus. Ein Aufgebot von zahlreichen Priestern mit oft sehr prunkvollen bunt- und goldgestickten Gewändern macht auf das Volk einen starken Eindruck.

Tradition spielt in der griechischen Kirche eine sehr große Rolle. Das ist ja in Religionen die Regel; aber gerade in der

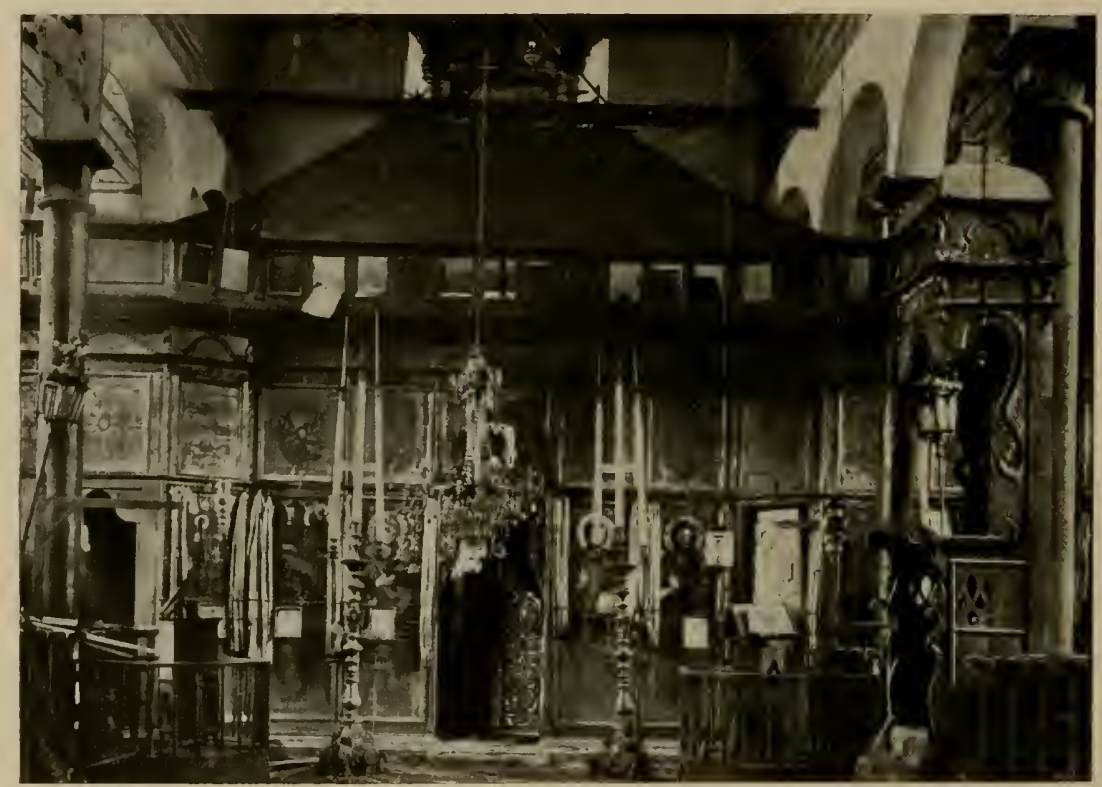

Abb. 18r. Inneres der Kirche in Doiran mit Kanzel (rechts) und bedachtem Allerheiligsten.

Balkankirche ist sie wohl ganz besonders streng. So ähneln sich die Balkankirchen in Bauweise, Einrichtung, Schmuck außerordentlich untereinander. Damit ist natürlich infolge der Nachahmung guter alter Vorbilder auch ein gewisses Niveau gewahrt. So kann es einen oft erstaunen, in einer Dorfkirche eine ganz merkwürdig gute Ausschmückung anzutreffen.

Als Beispiel möchte ich die kleine Dorfkirche von Gradeč im Wardartal etwas oberhalb Hudowa anführen. Sie liegt als einfacher Bau mit viereckigem Glockenturm und niederem Ziegeldach in einem Hain von grünen Bäumen. Die Kirche ist von einem 
gedeckten Umgang mit einfachen Holzsäulen umgeben. Wie denn sonst die Innenwände von bulgarischen Kirchen gänzlich von Temperamalereien auf Kalkflächen bedeckt zu sein pflegen, die

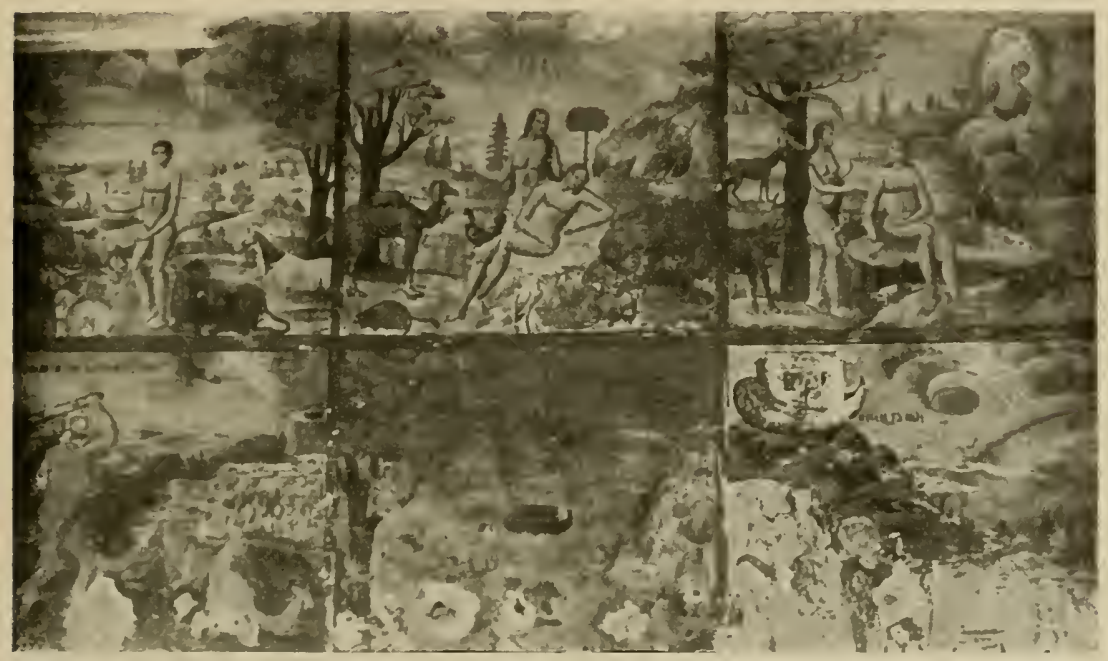

Abb. 182. Adam und Eva im Paradies. Sündenfall.

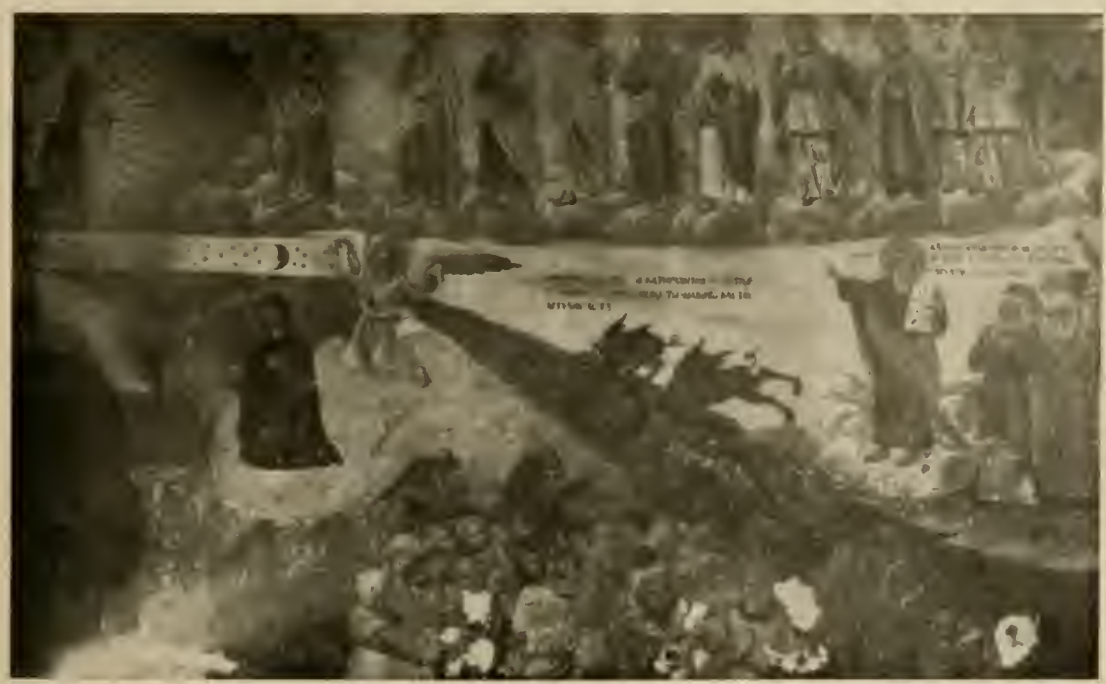

Abb. 183. Heilige und Teufel.

wie Fresken aussehen, so ist hier die durch das Dach des Umgangs geschützte Außenwand der Kirche vollkommen mit teilweise 
gut erhaltenen Malereien überzogen. Sie stellen Szenen aus der heiligen Geschichte, Adam und Eva im Paradies, den Sündenfall, das jüngste Gericht, die heilige Dreifaltigkeit und Scharen von Heiligen dar.

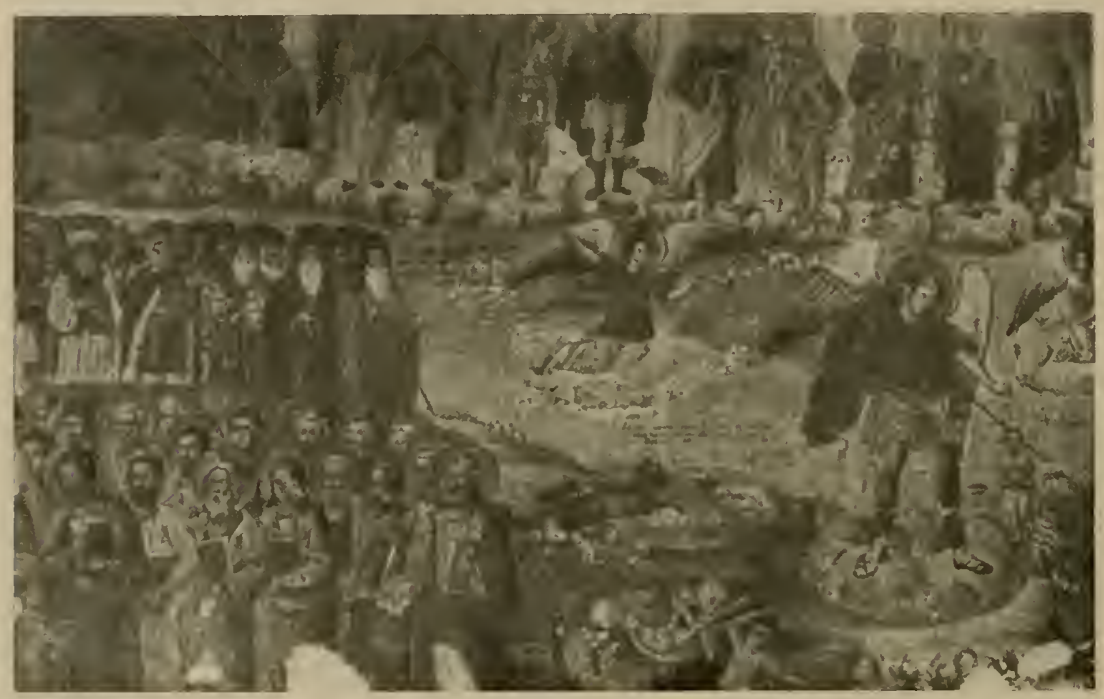

Abb. I 84. Jüngstes Gericht und Heilige.

Es scheint, dalb die Bilder auf alten Grundlagen immer wieder neu übermalt sind. Die Grundlage scheint aber höchst anständig gewesen zu sein und so finden wir in dieser kleinen Kapelle in dem Dorf von höchstens 20-30 Häusern eine schön und reich geschmückte Kirche. Was mag der Balkan an solchen Dingen beherbergt haben, die jetzt durch die unablässigen Kämpfe der Nationen, der Religionen und Konfessionen zerstört sind! 


\section{BIENEN MAZEDONIENS}

A

Is ich nach Nazedonien zog, wußte ich schon, daß von den wilden Bienen der Balkanhalbinsel noch sehr wenig bekannt war. Und noch dazu wußte ich, daß unser bester Bienenkenner, Dr. H. Friese in Schwerin, meine Ausbeute bearbeiten würde. So wurde denn um alle Standquartiere und auf allen Wanderungen sorgsam auf Bienen geachtet und soviel beobachtet und gesammelt, als Zeit und Kräfte mir und meinen Helfern erlaubte. So kam eine Sammlung von etwa 1800 Bienen zusammen, von denen bisher 205 Arten und Varietäten bestimmt sind; dabei fanden sich eine ganze Anzahl neuer Arten und Formen und für viele Arten stellte sich ein neues Verbreitungsgebiet heraus. Auch für die Ökologie der Arten wurden manche neue Beobachtungen gemacht.

Bisher waren Hymenopteren in Istrien, Dalmatien, Bosnien, der Herzegowina, von den griechischen Inseln und aus Griechenland selbst bekannt geworden, aber noch kaum etwas aus den zentralen Teilen des Balkan und vor allem wenig aus den Hochgebirgen. Daß meine Sammlung trotz aller Arbeit und Aufmerksamkeit noch viele Lücken in unserer Kenntnis der mazedonischen Bienen übrig läßt, hat wohl seinen Hauptgrund darin, daß ich mich oft zur besten Zeit nicht in den für Bienenbeobachtung günstigsten Gebieten aufhalten konnte. Wie schade, daß nicht ein guter Bienenspezialist mich auf den Reisen begleiten konnte; es wären dann ganz andere Resultate erzielt worden.

Bei meiner Darstellung will ich mich zunächst an meine eigenen Beobachtungen halten. Als alter Bienenfreund habe ich die Honigbienen nicht vernachlässigt und versucht, festzustellen, welche Rassen dieses Haustieres in Mazedonien vorkommen und in welcher Weise sie dort gezüchtet werden. Beachtenswert ist, daß vier verschiedene Formen der Honigbiene von mir beobachtet wurden, nämlich außer den überall vertretenen, der gewöhnlichen dunkeln Biene (Apis mellifica L..) und der hellen, gelblichen Italiener Biene (Apis mellifica var. ligustica Spin.) fanden sich 
zwei weitere Bienenformen. Relativ häufig begegnete mir die $\mathrm{krainer}$ Biene (Apis mellifica var. carnica Poelm), seltener die griechische oder Hymettusbiene (Apis mellifica var. cecropia Kiesew.).

Davon kamen die dunkle deutsche Biene bei Üsküb und Kaluckova, die italiener Biene an der Mala Rupa und bei Prilep vor. Die krainer Biene fing ich am häufigsten und in den weitest auseinander liegenden Orten. Ich stellte sie fest von Koinsko, Kaluckova, Üsküb bis Bucin und zum Prespasee. An diesem letzteren Fundort kamen drei der Bienenformen vor, die deutsche, die griechische und die krainische; die griechische war vor allem längs des Wardar weit verbreitet.

Das zeigt, daß die Bienenzucht mit einer gewissen Intensität in Mazedonien betrieben wird. Um so überraschter war ich über den ursprünglichen Stand, auf dem die Zuchtmethoden geblieben sind. Ich habe nur eine dunkle Erinnerung, ein oder zweimal moderne Bienenstöcke mit Wechselrähmchen, wie sie in Deutschland wohl jetzt seit 5o Jahren fast jeder Bienenzüchter besitzt, gesehen zu haben. Da das aber in größeren Ortschaften an der großen Verkehrsstraße war, so kann ich nicht sagen, ob die Bauten Eingeborenen oder etwa deutschen oder anderen Soldaten gehörten.

Jedenfalls kann die neuere Bienenzuchtmethode in Mazedonien keinen breiteren Boden gewonnen haben; denn wo ich mir Bienenstöcke genauer ansah, handelte es sich stets um die alten primitiven Bauten. Bei uns werden solche seit Einführung der Wechselrahmen nur mehr in den Heidegegenden verwendet, da der Heidehonig sich meist nicht zentrifugieren läßt. So gibt es bei uns in Hannover, Friesland und in Holland den alten strohgeflochtenen Stülpkorb. In Mazedonien wird aber der Wabenbau der Bienen beim Ernten des Honigs immer noch zerstört und den Bienen wird nicht die große Arbeitsersparnis gegönnt, welche die nach dem Zentrifugieren immer wieder verwendbaren Waben der Wechselrahmen ermöglichen. Hier findet man meist als Bienenhäuser verschieden gestaltete Lehmgefäße verwendet. Man sieht diese auf Brettern unter dem Dachrand an der Außenwand des Hauses aufgestellt, gelegentlich auch auf Brettgestellen im Hof. Eine ganz große Bienenzucht bekam ich auf meinen Wanderungen in Mazedonien nicht $z u$ sehen. $O b$ alle Völker Mazedoniens Bienen züchten, konnte ich nicht feststellen. Vielleicht ist es nur ein Zufall, daß ich Bienenstöcke vorwiegend bei Griechen und Aromunen, auch bei Bulgaren fand. 
Eigenartige, glockenförmige Bienenstöcke, aus IVeiden geflochten, außen mit Lehm und Mist überschmiert, stellt das Bild aus einem Bauernhofe in Koinsko dar (Abb. 185). Ähnliche Stöcke sah ich in Krusevo bei einer Aromunenfamilie.

Bei der primitiven Bienenpflege in Mazedonien kann es nicht verwundern, daß man nicht selten auf wilde Bienenvölker stößt, welche in hohlen Stämmen alter Bäume sich niedergelassen haben. Ein solches in einer Edelkastanie angesiedeltes sehr starkes Volk habe ich im vorigen Kapitel erwähnt (s. S. 354).

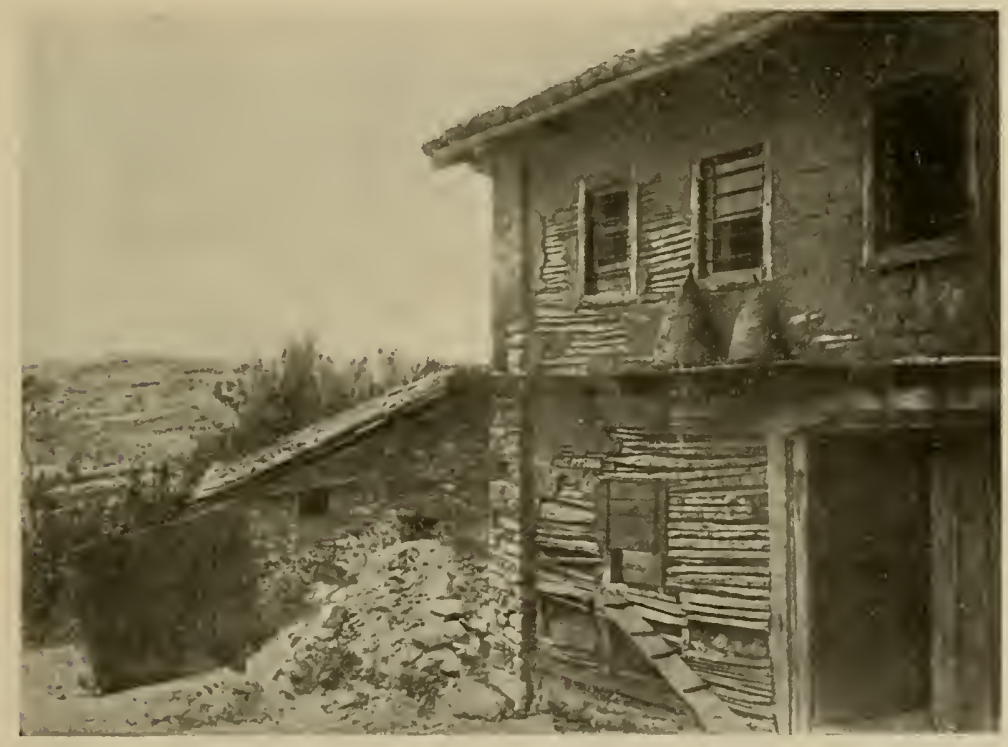

Abb. 185. Bauernhaus in Koinsko mit Bienenstöcken.

Eine eigenartige Methode, Bienenschwärme einzufangen, beobachteten wir an einem lehmigen Hang nicht weit vom Dorfe Taor, südlich vom Katlanovosee. An dem Steilhang eines Hügels waren in der glatten, senkrechten, uncl daher vegetationslosen l.ehmwand einige tiefe Gruben mit kreisrunder Öffnung eingebohrt, die mit Kuhmist ausgeschmiert waren. Die fast $1 / 2 \mathrm{~m}$ im Durchmesser erreichenden löcher waren zum Teil außen mit Brettern zugenagelt; eines der Bretter enthielt ein kleines Flugloch. Die Einwohner der Umgebung bezeichneten sie als Lockmittel für durchgegangene Schwärme, die häufieg hierher fliegen sollen und von dort heimgebracht würden. Es scheint dies vielfach der Brauch 
zu sein. Speziell in der Gegend des Katlanovosees sahen wir öfter solche „Bienenschwarmfallen“ (Abb. 186).

Die Balkanvölker scheinen alle den Honig sehr zu lieben; alle haben Gerichte und Konfekte, die aus ihm bereitet sind. Ich erinnere nur an die verschiedenen Formen des türkischen Honigs, der auch bei uns früher auf Jahrmärkten feilgeboten wurde. Bei Begrüßungen wurde von Bulgaren nicht selten auf Tellerchen Honig gereicht, den man mit kleinen Löffeln aß.

Wie häufig Bienenstöcke und wilde Bienenvölker in Mazedonien sein müssen, sah man an den Massen von sammelnden

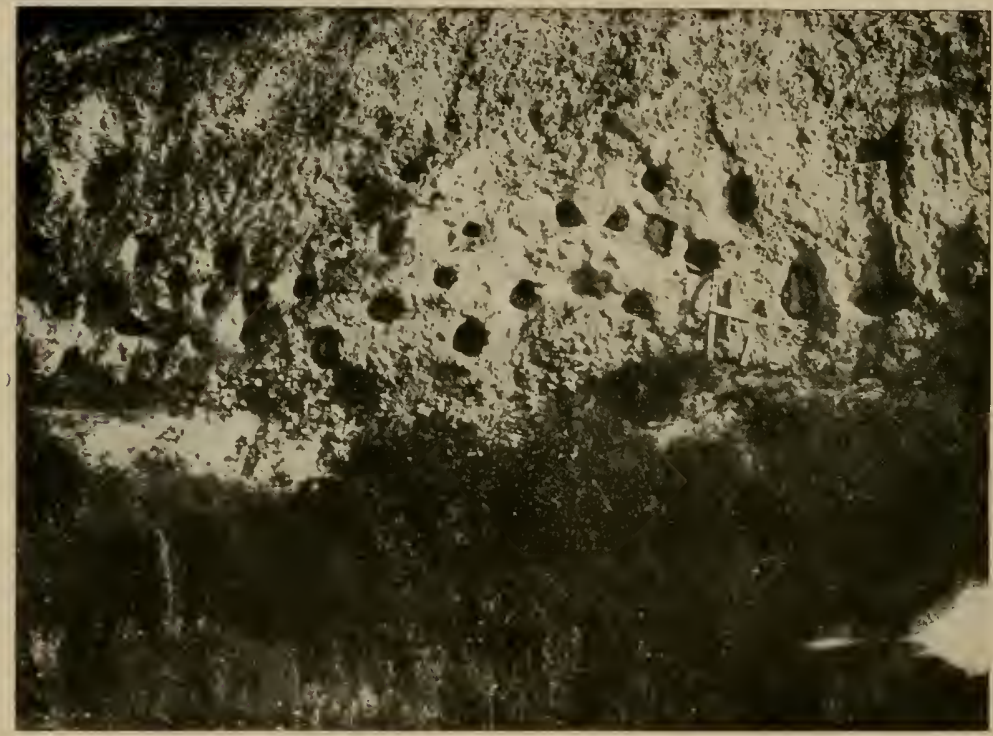

Abb. I 86. Bienenschwarmfallen bei Taor.

Honigbienen, die man auf jeder blühenden Wiese, an jedem blumenbedeckten Baum oder Strauch antraf. Nur im Hochgebirge fehlten die Bienen vollkommen.

Nicht ganz so zahlreich wie die Honigbienen, aber immerhin in stattlichen Mengen waren die $\mathrm{Hummeln}$ vertreten. 40 Arten und Varietäten von Hummeln und Schmarotzerhummeln brachte ich mit. Ich denke gern an die Geschäftigkeit der bunten, wolligen Tiere zurück, wie sie brummend die Blumen umflogen oder in Löcher im Boden, zwischen Baumwurzeln, in Spalten der Gartenmauern einschlüpften. Die durch meine Funde festgestellte reiche 
Hummelfauna Mazedoniens macht nach Frieses Angabe einen alpinen Eindruck, erinnert an diejenige unserer Alpen. Dabei ist wieder, wie bei fast allen Tiergruppen, hervorzuheben, der Einschlag von typischen Steppenhummeln. Eine solche ist z. B. Bombus eversmanmi var. steveni Rad., die ausschlieblich in dem südlichen Flachland zwischen Hudova und dem Doiransee gefunden wurde, jener Gegend, die auch sonst an Steppentieren reich ist. Eine weitere typische Steppenhummel ist Bombus haematurus Kriechb., die im Nikolatal, also auch noch im südlichen Flachland, allerdings auch einmal im Gebirge bei Gopes gefunden wurde. Eine dritte Steppenform ist B. nivcatus var. vorticosus Gerst., die von Kaluckova und der Plaguša Planina bis nach Prilep und Kalkandelen verbreitet ist, selbst im Schardakh an der Kobeliza in über $1200 \mathrm{~m}$ Höhe vorkam.

Während viele der Hummelarten von der Ebene bis zu Höhen von etwa $1500 \mathrm{~m}$ in den Hügeln und Bergen verbreitet waren, habe ich schon früher im I4. Kapitel das Vorkommen typisch nordisch-alpiner Formen in Höhen von $2000-2400 \mathrm{~m}$ an der Kobeliza im Schardakh erwähnt. Dort fing ich in der Übergangszone von $1400-1800 \mathrm{~m}$ Bombus lapponicus var. pratincola Nyl., auf den Alpenmatten über $2000 \mathrm{~m}$ die var. alpestris Friese, var. helieticus Friese und var. balcanicus Friese. Die var. helzeticus kam auch in der Gipfelregion des Peristeri vor.

Soweit ich Hummelnester beobachten konnte, befanden sie sich stets im Boden, zwischen Baumwurzeln oder unter Steinen.

Am 28. Juli 1917 konnte ich in Plauš einen eigenartigen Vorgang bei einer Hummelart beobachten; es war ein Hochzeitsflug, vergleichbar demjenigen der Bienenkönigin. An der Wand eines Hauses flog ein Schwarm von I $_{5-20}$ Hummeln stürmisch unter lautem Summen umher. Voraus flog stets das große starke Weibchen, umgeben, umschivirrt von der Schar ihrer Drohnen. Sie flog immer an der Wand des Hauses entlang, schlüpfte in Löcher hinein, kam wieder hervor, immer verfolgt von den Männchen. Diese folgten ihr zum Teil in das Loch linein, während die anderen, die ihre Spur verloren hatten, planlos vor der Wand herumbrummten, bis sie wieder auftauchte; dann schlossen sie sich von neuem ihrem Gefolge an. Schließlich gelangte ein Männchen zur Begattung. Es war nicht ganz klar, ob nicht mehrere Männchen die Begattung noch versuchten. Ich fing einige der Männchen; schließlich kam die Königin aus einem Loch nicht mehr hervor. Die Männchen 
zerstreuten sich und es trat Ruhe ein. Die Art war Bombus eversmanni var. apicalis Mor.

Leider konnte ich die Hummelkönigin nicht aus ihrem Loch herausbringen um festzustellen, ob das zur Begattung gelangte Männchen wie die Bienendrohne nach dem Akt sofort abstirbt.

Wo Hummeln flogen, da fanden sich auch fast immer solitäre Bienen. Die vielgestaltigen, so interessanten einsam lebenden Bienen waren, wenn auch an Artenzahl nicht so überwältigend, wie man vom Balkan vielleicht erwartet hätte, doch in ganz großen Individuenzahlen vertreten. Überall im Lande traf ich sie an, von den Seen und den Flußtälern bis in die höchsten Bergesregionen. Auf fast jeder Seite meines Tagebuches findet sich die Notiz „Bienen“. In der Nähe von Kaluckova, im Wardartal, auf der Plaguša Planina, bei Üsküb, am Wodno, ist mir die Erinnerung an manchen Pfad und Wegrand mit den Bildern fliegender Bienen verknüpft, welche da ihre Nestlöcher aufsuchten. Und diese Löcher mit den feingearbeiteten kreisrunden Eingangsöffnungen habe ich ja an manchen Stellen dieses Buches erwähnt. Schon in den ersten Tagen meines Aufenthaltes in Mazedonien freute ich mich an den Eucera-Arten, mit ihren langen, leise zitternden Fühlern, wenn sie die Blüteneingänge abtasteten oder eine fleißige Anthophora verdrängten, die vor ihnen in die Blume eindringen wollte. Beim Absuchen der Ameisennester sah ich auf den Hügeln bei Kaluckova, an den lehmigen und tonigen IVänden der Schluchten und Hohlwege hunderte ihrer Bauten und sah die unermüdlichen Tiere an ihnen arbeiten und in sie eintragen.

Da kamen die Osmien und andere Bauchsammler und hatten ihre Unterseite dick eingepudert mit dem weißen, gelben oder roten Blütenstaub, den die reichen Fluren ihnen darboten. Viel häufiger als solche waren aber überall in Mazedonien die Beinsammler, welche bei der Heimkehr ihre Hinterbeine weit vom Leib abspreizen mußten, so dick waren sie von den Pollenhöschen, die sie sich unterwegs beim Besuch der Blumen angezogen hatten.

Gut vertreten waren in allen Gegenden von Mazedonien, die ich aufsuchte, die Anthophorinen, von denen ich 3 I Arten in etwa 200 Exemplaren mitbrachte. Bei der Gattung Anthophora konnte durch meine Sammlungen zum ersten Male das Vorkommen von zwei Generationen im Jahr festgestellt werden. Die erste fand sich bei Anthophora acervorum L. im Februar, März und April 
bei Kaluckova und auf dem Wodno bei Üsküb, die zweite an denselben und anderen Orten, so Gopes im Juli und August. Ebenso wurde von Anthophora crinipes Sm. die erste Generation im April bei Üsküb und Kaluckova, die zweite an denselben Orten im Juli nachgewiesen.

Selbst in den Dörfern und ihren Straßen konnte man viele solitäre Apiden beobachten. Da bauten sie vielfach in den Lehmwänden der Häuser und Gärten. Eine Art sah ich da z. B. als Baustelle immer den Mörtel der Steinhäuser benutzen. Andere liebten die Stengel der Brombeerbüsche der Schluchten, manche bauten in den dürren Stengeln von Disteln und Königskerzen.

Auch die Obstbäume der Gärten und die Maulbeerpflanzungen boten vielen Bienen, besonders den Holzbewohnern, Wohnung. Ende April traten im Wardartal viele der schönen stahlblauen und violetten Holzbienen aus der Gattung Xylocopa auf; ganze Schwärme von ihnen belebten die blütenreiche Ebene. Unter ihnen war besonders auffallend $\mathrm{Xylocopa}$ olivieri I.ej. durch ihren wundervollen rotbraunen Pelz. Ebenso schön waren Xylocopa valga Gerst. (Abb. 187) und andere Formen der Gattung. Etwas später im Juni und Juli traten die Arten der Gattung Ceratina auf. Auf Steinen und Felsen fanden sich in

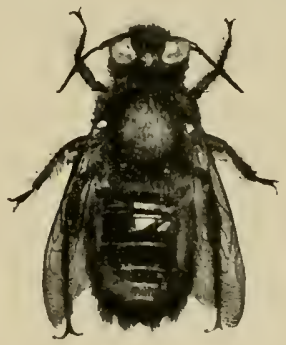

Abb. 187. Xylocopa valga Gerst. Vergr. $1 \frac{1}{2}$. der Plaguśa Planina nicht selten die aus Lehm aufgebauten Nester der Mörtelbiene (Chalicodoma muraria var. nigerrima Perez), welche aussahen wie eine an den Felsen geworfene Handvoll Lehm, der dort getrocknet war.

$\mathrm{Zu}$ gleicher Zeit mit den Xylocopa-Arten traten in der Nähe von Kaluckova große Mengen von WVespen auf, von welchen ähnlich wie jene, die großen schwarz-gelben Scolia-Arten sich sehr bemerkbar machten und wegen ihres Stiches sehr gefürchtet wurden. Polistes- und Vespa-Arten waren häufig und ihre Papiernester sah man viel an den Hausdächern und in Bäumen. Wir segneten sie als Fliegenfänger. In einem anderen Kapitel habe ich die Fliegenplage in Mazedonien geschildert und erwähnt, daß diese vielfach Essen im Freien unmöglich machte. Das wurde oft noch dazu kompliziert, daß um unseren EBtisch sich hunderte von Wespen versammelten und uns oft noch von der Gabel vor 
dem Mund die Fliegen wegfingen, um sie zur Ernährung ihrer Larven ins heimische Nest zu tragen.

Im 23. Kapitel habe ich bei Schilderung meiner Streifzüge am und auf dem Wodno bei Üsküb die wundervolle Bienenwand im Markovatal beim Kloster Markova beschrieben (S. 348). Dort befindet sich auch ein Bild dieser großen Kolonie von Anthophora parietina F. (Abb. 172, S. 351). Ich füge hier noch ein weiteres Bild bei, welches einen Überblick über diese große Stadt von Bienennestern bietet.

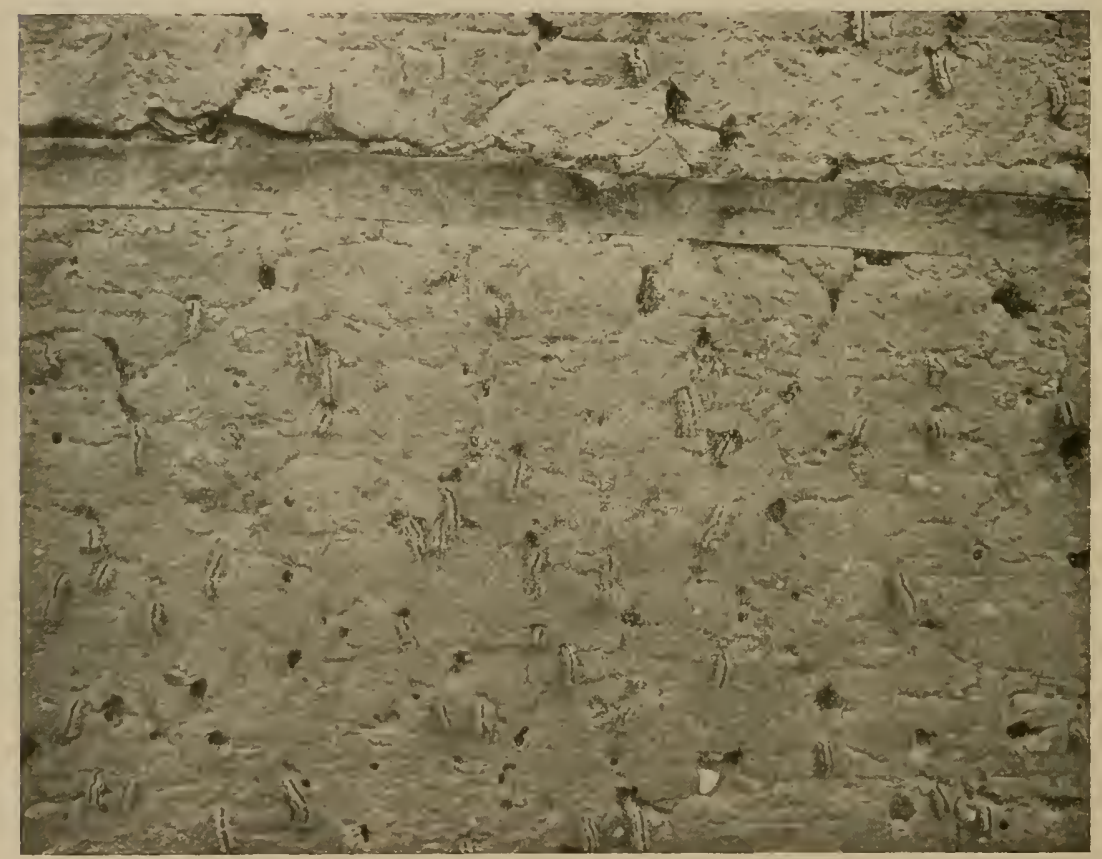

Abb. 188. Überblick über einen Teil der Lehmwand mit der Nesterkolonie von Anthophora parietina F. beim Kloster Markova.

Meinen dortigen Angaben möchte ich hier noch einiges zusetzen. Als ich mich mit meinen Begleitern länger an der Bienenwand aufhielt und mir dort $\mathrm{zu}$ schaffen machte, mit dem Netz Bienen fing, konnte ich eine Beobachtung machen, welche zeigt, daß auch bei diesen vollkommen einsam lebenden Bienen gelegentlich Ansätze von sozialem Handeln vorkommen. Plötzlich umschwärmte uns mit lautem Summen ein großer Schwarm der Bienen; sie flogen hastig auf uns los und prallten gegen uns, so daß 
wir aus Angst vor ihren Stichen instinktiv zurückfuhren. Ähnliche Beispiele gemeinsamer Verteidigungsaktionen sind von Friese und Alfken bei Andrena ovina Klug und gerade bei Anthophora parictina F. beobachtet worden. Meine Beobachtung schließt sich also rollkommen den Angaben dieser Forscher an und bestätigt, daß während diese solitären Bienen sich sonst gegenseitig gar nicht beachten und sie sich gegenseitig niemals helfen, ein sie gemeinsam bedrohender übermächtiger Angriff eine Vereinigung vieler Individuen zur Abwehr veranlaßt. Wenn es sich damit auch nicht um echtes soziales Zusammenwirken handelt, so müssen doch Instinkte durch Warnungslaute oder sonstwie geweckt werden, welche bei den sozialen Insekten bestimmt sind, eine große Rolle zu spielen.

Außer den solitären Bienen flogen emsig vor der Lehmwand bei Markova andere Hymenopteren umher. Das waren die Schmarotzerbienen, welche in die Nester der Anthophora

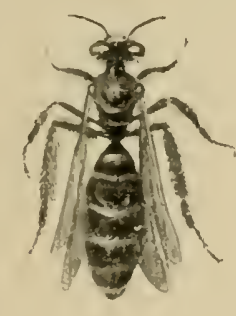

$a$

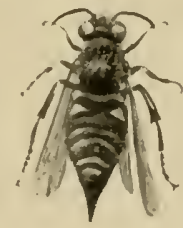

b

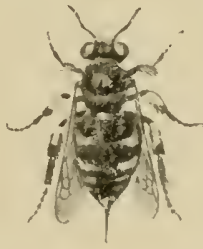

$c$

Abb. 189. Mitbewohner der Nestkolonie von Anthophora pametina. a Andrena hattorfiana Spm. $b$ Crocisa scutellaris Lep. $c$ Coelioxys rufescens Gef. Markova. Vergr. 2 : I.

einzudringen suchten, um da ihre eigenen Eier an dem aufgespeicherten Futter und bei dem Ei der rechtmäßigen Eigentümerin des Nestes abzulegen. Es waren dies schwarz-weiß gefärbte Bienen der Arten Crocisa scutcllaris Lep. und Coclioxy's rufescens Gef. Das sind die typischen Nestparasiten der Anthophora parietina F.

Die verhielten sich ganz anders zu den Nestern; trieben sich unruhig vor den Eingängen herum, ängstlich vor den Besitzern ausweichend und machten den Eindruck von richtigem Diebsgesindel. Derartige Brutschmarotzer waren in Mazedonien den großen Mengen der solitären Bienen entsprechend auch sehr viel und oft zu beobachten. Ich habe in früheren Kapiteln schon die Schwebfliegen der Gattungen Anthrax und Bombylius erwähnt, welche am Boden an den Eingängen der Bienennester hinflogen. Auch 
die Goldwespen, die ähnliche Instinkte haben, habe ich oft an den Lehmwänden vor Erfüllung ihrer bösen Absichten weggefangen.

An vielen Orten habe ich Schmarotzerhummeln aus der Gattung Psithyrus beobachtet und auch die Nomada-Arten, jene Bienen, die besonders bei den Osmia-Arten parasitieren. So gelang auf der Mala Rupa ein interessanter Fund. Da fing ich Panurgus banksiunus am selben Tag und am selben Ort, wie die schon als ihr Nestschmarotzer verdächtigte Nomada similis Mor., so daß dadurch eine neue Bestätigung dieses Abhängigkeitsverhältnisses erbracht wurde.

Gebirgsbienen gehörten überhaupt zu den interessantesten Bestandteilen unserer Ausbeute an Bienen. Die Balkanfauna an Bienen zeigte wie die anderen Tiergruppen außer eigenen Formen eine Zusammensetzung aus nördlichen und südlichen (mediterrane) Elementen, zu denen sich nicht wenig östliche Steppenformen gesellen. Dazu kommen die wohl als Eiszeitrelikte zu deutenden Hochgebirgstiere. Von Interesse ist von den letzteren die neu von uns entdeckte Osmia bulgarica Friese, welche ich am Pepelak und Liseč in der Golesniza Planina bei etwa $1800-2000 \mathrm{~m}$ Höhe fing. Sie lehnt sich an Osmia inermis Zett. an, welche außer in den Alpen in Finnland, Lappland und Schottland lebt. Solche Alpentiere, aber ohne eiszeitliche Beziehungen, stellen z. B. Megachile analis Nyl. von der Mala Rupa und Andrena ephippium var. macedonica Friese dar und wohl manche anderen Bienen meiner Sammlung. 


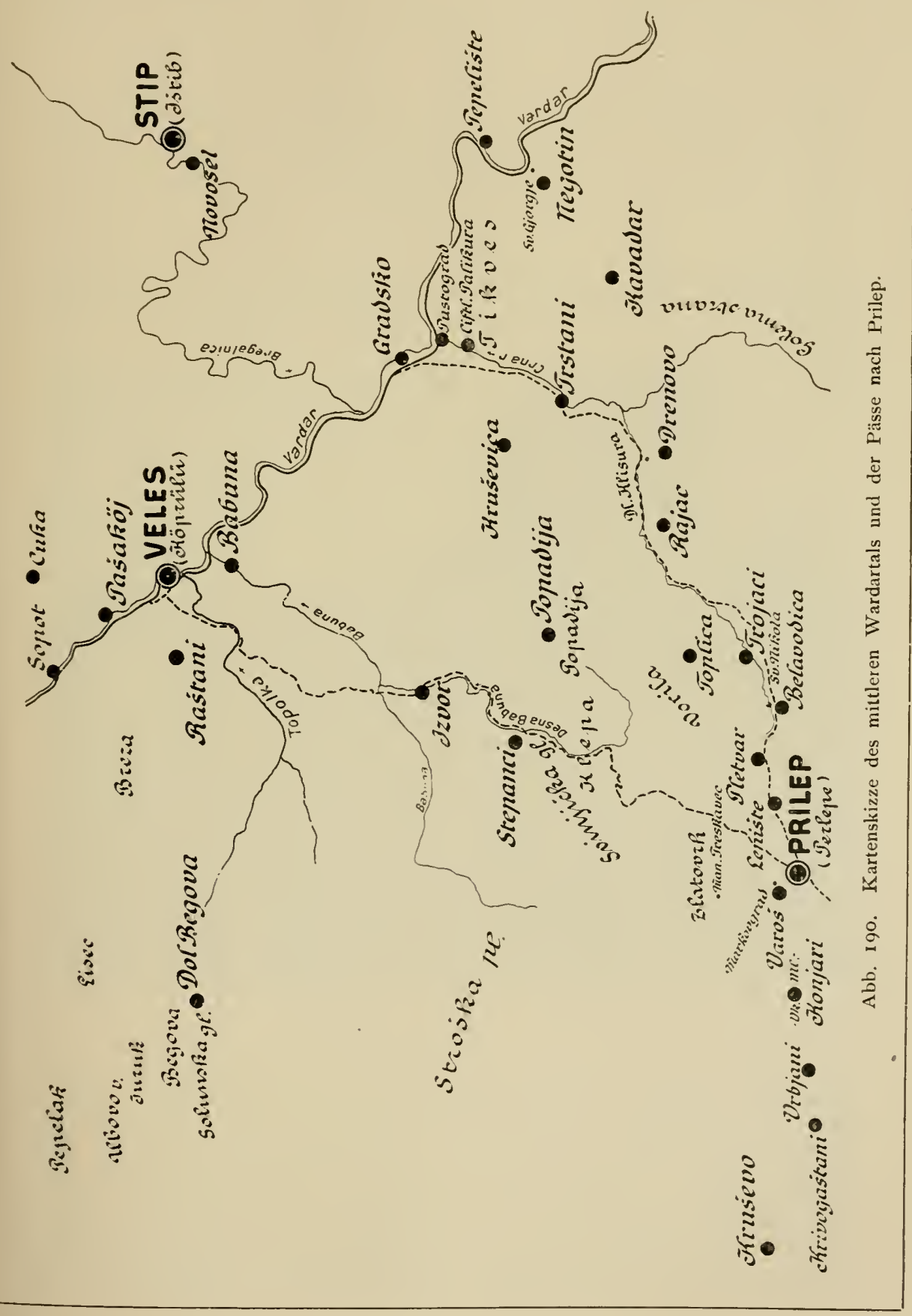




\section{DIE ERFORSCHUNG DER GOLESNIZA PLANINA}

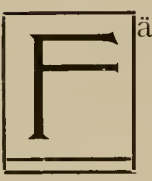

ährt man von Üsküb mit der Orientbahn südwärts gegen Veles, so fällt einem im Westen ein Gebirge von reichen Formen auf. Im Frühling und Frühsommer glänzen von seinen Gipfeln breite Schneefelder herüber. Je öfter ich vorüberfuhr, um so lebhafter wurde mein Wunsch, dies Gebirge kennen zu lernen. Bisher war nur einmal ein deutscher Geograph, K. Östreich, ein guter Kenner Mazedoniens, an seinem Rand gewesen und hatte eine Skizze von ihm entworfen, welche manches Interessante versprach.

Als ich im Sommer 1918 mein Standquartier in Üsküb hatte, konnte ich dem Plan näher treten. Es mußten gewiß Schwierigkeiten vorhanden sein, die es verhindert hatten, daß die so wanderlustigen Offiziere und Ärzte der verbündeten Truppen in Üsküb das reizvolle Gebirge in den Jahren der Besetzung nicht aufgesucht hatten. Es war bisher ein unbekanntes Gebiet geblieben.

Im April 1918 traf ich die ersten Vorbereitungen zu einer Expedition in das südlich von Üsküb gelegene Gebirge. Zunächst suchte ich nach dem Studium der Karten aus der Ferne einen Überblick ïber die Lage des Gebirges und günstige Anmarschwege zu gewinnen. Einen guten Einblick in seine Lage und seinen Aufbau gewann ich vom Gipfel des $1100 \mathrm{~m}$ hohen, südlich im Weichbild von Üsküb ansteigenden Wodno, den wir ja schon im 23. Kapitel kennen lernten. Im April sah ich von dessen Gipfel das wundervolle Bild der schneebedeckten Berge, welches die nebenstehende Abbildung wiedergibt (Abb. I91). Mächtige steile Gipfel schimmerten rosig im Glanz der Abendsonne und winkten vielversprechend zu mir herüber, als ich den festen Entschluß faßte, sie zu besteigen. Vom Gipfel des Wodno übersah man das weite Tal, durch welches man an das Gebirge herankam; ein Bachtal führte tief ins Gebirge hinein, das mußte man verfolgen, um in 
die Schluchten und an die steilen Abstürze heranzukommen, die jetzt von tiefblauen Schatten scharf hervorgehoben wurden.

Einige Vorexpeditionen bereiteten die Unternehmung vor, die planmäßig ausgedacht, die Unterstützung unserer obersten Heeresleitung fand. Ich wurde in meinem Vorhaben in großzügigster Weise gefördert. Zunächst war das Einverständnis der bulgarischen Behörden, die zuerst alle möglichen Bedenken wegen angeblich im Gebiet hausender serbischer Banden vorbrachten. Schließlich siegte aber doch der Wunsch, durch uns genaueres über das auch den Bulgaren wenig bekannte Gebiet zu erfahren.

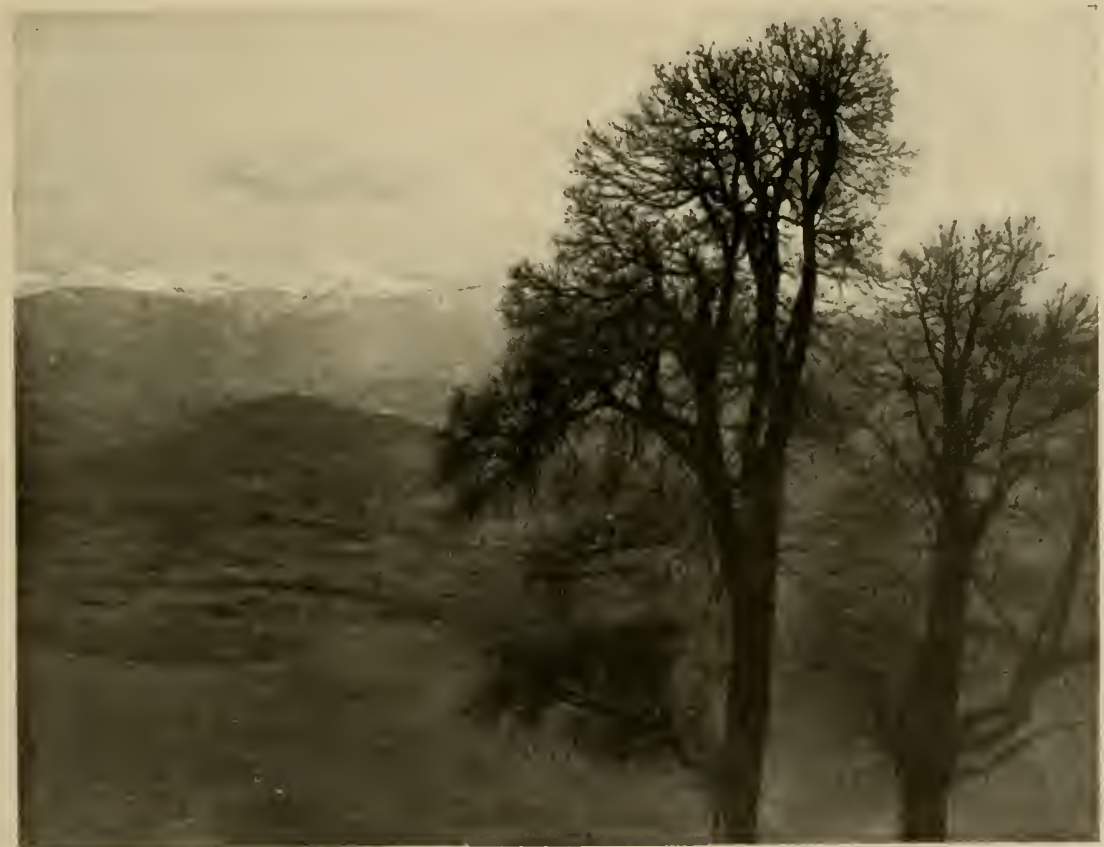

Abb. 191. Golesniza Planina im April, gesehen vom Wodno (Gipfelregion).

Wir bekamen Führer, Tragtiere, Bedeckungsmannschaften zugesagt; ein Dolmetscher, der serbisch, albanisch, türkisch, kutzowallachisch, bulgarisch, deutsch, französisch und allerhand andere Sprachen beherrschte, wurde uns zugewiesen. Die deutsche Heeresleitung stellte mir Reit- und Tragpferde, dazu die nötigen Mannschaften und gab mir die Möglichkeit, den sehr wichtigen Reiseproviant aus dem Magazin in Üsküb zu erwerben. 
So war es denn eine stattliche Karawane, die sich zum Abmarsch auf einem kleinen Platz in Üsküb ansammelte, wo sie feierlich von General von Scholtz und den Herren seines Stabes verabschiedet wurde. Etwa 30 Pferde und Lasttiere wirbelten den Staub der Straße auf, als wir stolz abrückten.

An der Expedition nahmen von deutschen Gelehrten außer mir zwei der Mitglieder der mazedonischen landeskundlichen Kommission teil: der Botaniker Prof. Born müller aus Weimar und der Geologe Dr. Gripp aus Hamburg. Mich begleitete ein ganzer Stab von Zoologen und technischen Hilfskräften, Prof. M üller, Dr. Nachtsheim, die Präparatoren Aigner und Rangnow und mein getreuer Johann Maier. Auch die anderen Forscher hatten ihre Geliilfen bei sich.

Der Marsch ging nun um den östlichen Sattel des Wodno herum auf dessen Südseite. Ein mehrstündiger Ritt führte uns gegen Abend zum Kloster Markovo, das ich bei den Vorexpeditionen als geeigneten Ausgangspunkt für die Gebirgsexpedition gewählt hatte. Über das Kloster und seine Ungebung finden sich Angaben im 23. Kapitel (S. 347). (Vgl. dort auch Abb. 170 u. 17 1.)

Bei dämmerndem Morgen brachen wir am 17. Juni 1918 auf, durchritten das obere Markovatal und erreichten um Mittag das kleine türkische Dörfchen Crnvrj, das mir von einer Vorexpedition her schon bekannt war. Unterwegs hatten wir schon gewisse Schwierigkeiten mit unserer Lasttierkarawane, deren Lasten zum Teil schlecht gepackt waren und in dem steilen Gelände abrutschten. Wir sammelten dabei Erfahrungen mit unseren Leuten, die sich für später als sehr wichtig erwiesen.

In Crnvrj rasteten wir im Garten des mir schon bekannten Hodscha vor dem schweren steilen Anstieg und bereiteten unser erstes Mittagsmahl. Bald brachen wir aber auf, denn wir hatten keine Zeit zu verlieren, wenn wir am Abend einen geeigneten Lagerplatz in anständiger Meereshöhe erreichen wollten.

Es ging zunächst das Bachtal hinauf, in der Hauptrichtung südwärts, bald aber begann das Klettern am östlichen Talrand empor zu dem uns winkenden hochstämmigen Tannenwald. Der Weg, ein offenbar von Hirten benützter Pfad, war so steil, daß wir oft von unseren Pferden absteigen mußten, um sie zu führen. Es wollte viel heißen, daß sogar unsere Bulgaren stellenweise den Sattel verließen. 
Während wir beim Anmarsch meist durch Buschwerk und niederen Buchenwald gekommen waren, brachte uns der Anstieg bald in stattliche Bestände von Tannen (Abies alba Will.). Es waren schöne Edeltannen, welche an der gegenüberliegenden Talseite einen geschlossenen, dichten Wald bildeten. An unserer Seite wechselten dichte Bestände mit lichten Hainen und größeren Waldwiesen. Man hatte vollkommen den Eindruck eines deutschen Waldes, eines Gebirgswaldes mit seinen stattlichen Edeltannen und ihren weiflich schimmernden Stämmen. Zwischen den Tannen wuchsen, besonders an den Waldwiesenrändern, allerhand Laubbäume. Es war eigenartig, hier im fremden Land Buchen, Birken, Zitterpappeln und Eichen neben den Tannen emporragen zu sehen, alle noch im frischen Grün des Frühsommers.

Ein wundervoller Anblick bot sich aber dar, als wir in etwa I $200 \mathrm{~m}$ Höhe an große Waldwiesen kamen, welche von hohen lilienartigen Gewächsen bestanden waren. Vor einer solchen Wiese stand ich lange Zeit, ergriffen von der Schönheit; mein Pferd legte mir seinen Kopf über die Schulter und stand leise schnaubend ebenso still wie ich.

Jenseits der Wiese erhob sich ein Wald von stolzen Tannen, in tiefem Schatten wie eine hohe dunkle Wand den offenen Raum abgrenzend. Zwischen den Tannenwipfeln sichtbar und hoch über ihnen hinaufragend lagen die Berghänge der anderen Talseite; graue Felsen mit Waldflecken und Matten dazwischen waren von goldenem Sonnenschein übergossen. Nur das ferne Rauschen des Talbaches verriet die Tiefe der Sichlucht, die hinter den Tannen lag und deren Wände wir heraufgeklettert waren. Vor der dunklen Wand des Waldes breitete sich leuchtend vom Sonnenglanz die hellgrüne Wiese aus, bedeckt von hunderten von Lilien, den Asphodelos mit ihren schlanken Blütenständen. Sie weckten klassische Erinnerungen an alte Griechen, die auf der Asphodelos-W'icse die Schatten ihrer Freunde erwarteten. Man mulste sich daran erinnern, daß man nicht weit vom Land der Griechen war, dem der Deutsche so viel von seiner Seele geschenkt hat. Es war Asphodehus albus Willd. (Abb. 192, S. 384).

Ein leiser Wind wehte über die goldglänzende WViese; die Lilien schwankten zart und weil über dem wogenden Gras. Kühlung umwehte mich und gab Mut für den steilen weiteren Anstieg. Der Bach, der in der Tiefe rauschte, war der gleiche, dessen Tal wir vom Kloster Markova an verfolgt hatten. Seine Quellen ent- 
flossen einem weiten Bergzirkus, der vor uns manchmal offen lag, während wir an seiner Ostwand emporklommen. Dieser Quellbezirk enthält keine Seen, wie Östreich und der serbische Forscher Cvijić annahmen, welche die Markova Reka, den Talbach, als Ausfluß der Seen betrachteten. Wir konnten uns überzeugen, daß im Quellgebiet der Markova Reka keine Seen lagen, was uns auch die Aussagen der Bevölkerung vorausgesagt hatten·

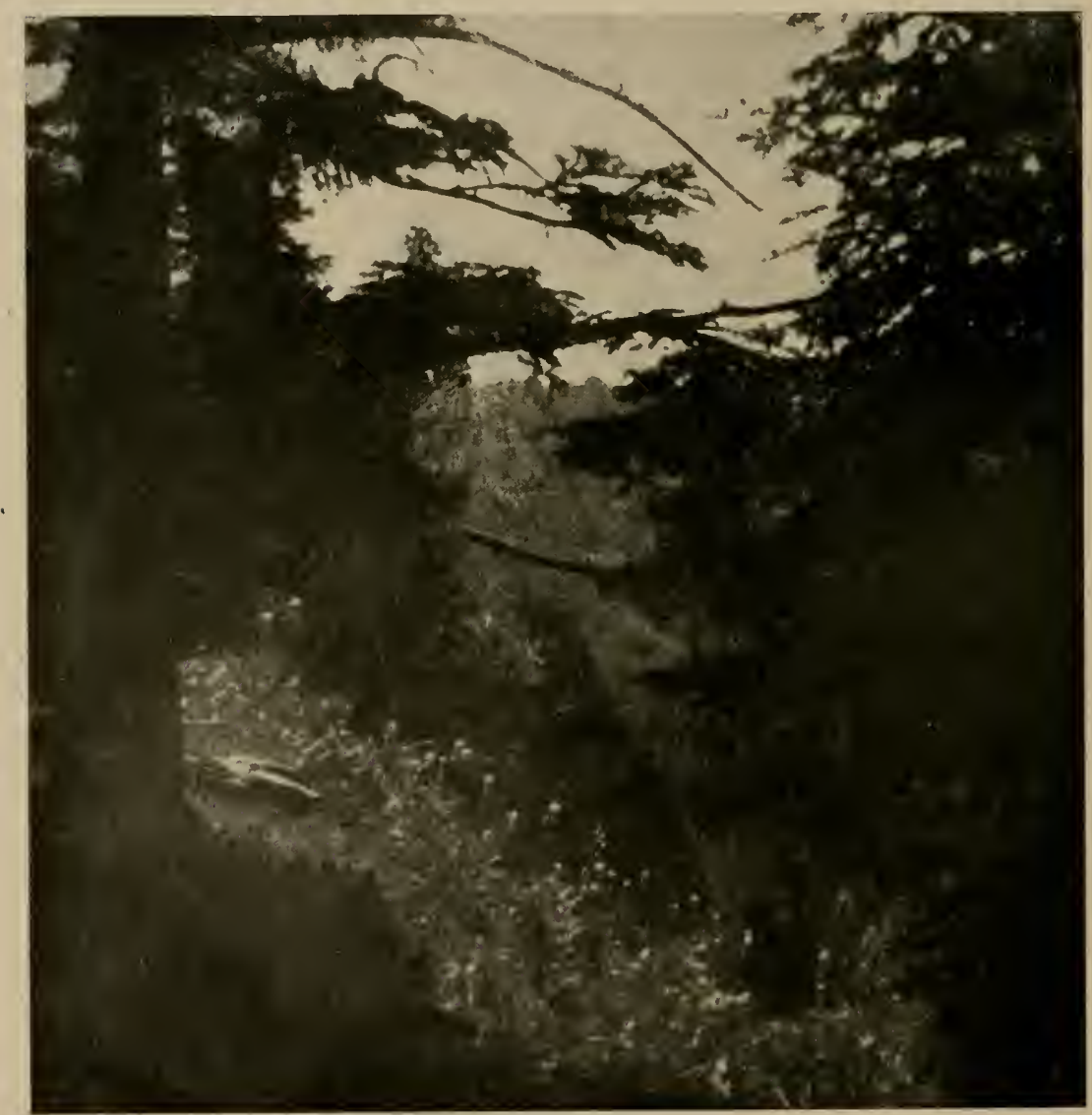

Abb. 192. Lilien im Tannenwald (Asphodelos albus Willd. Abies alba Will.). Anstieg zum Pepelakkar.

Nach etwa einer Stunde Rittes durch den Tannenwald gegelangte unsere Karawane auf eine ausgedehnte Berghalde, in welcher der Wald immer mehr von hochgrasigen Wiesen unterbrochen wurde. Nun tauchte vor uns, noch hoch über dem Wald, 
das Schneefeld des Pepelak auf, das uns schon den ganzen Tag die Marschrichtung angab. Denn unterhalb dieses auffallenden Schneebandes dachte ich unser erstes Lager zu schlagen.

Als wir den Bergsattel erreicht hatten, kamen wir durch eine offenere Landschaft, in der Matten mit Gebüschen und kleineren Baumgruppen abwechselten. Mächtige Felsblöcke, vielfach von phantastischen Formen, lagen auf den Halden umher, oft von einem kleinen Hain überschattet.

Das Gestein bestand aus Gneis. Wir waren auf dem Sattel zwischen dem Tal der Markova Reka und dem eines südlichen Bachlaufes. So steil und hoch der von uns erstiegene Talrand gewesen war, so sanft war der Übergang von diesem Palo zu dem weit weniger tiefen Tal des südlich fließenden Baches. Wir hatten mit dem $\mathrm{PaB}$ eine Höhe von $1600 \mathrm{~m}$ erreicht.

Vor uns sahen wir noch einen letzten Waldstreifen, einen stattlichen Buchenwald, darüber tauchte eine Mattenregion auf, die über Hügel und Buckel bergan zog, in das Felsengebiet hinein, das sich daran anschloß. Unter dem Wald floß ein munterer Bach talwärts, der viel Geröll mit sich führte. Der Wald mußte noch durchstiegen werden, ehe ich meinen von dem scharfen Marsch in der glühenden Hitze ermatteten Leuten eine Ruhepause gönnen durfte. Die meisten waren sehr erschöpft und lagerten sich alsbald am oberen Rand des WValdes, um auszuruhen. Die Pferde wurden abgesattelt, nur die Lasttiere mußten mit ihrem Gepäck weiden; denn lange sollte die Rast nicht dauern.

Unterdessen war ein interessanter Fund gemacht worden. Bisher hatten wir ja in der Hauptsache schon bekanntes Gelände durchwandert und in der für mich neuen Zone des Tannenwaldes war die Sorge um unsere Tragtiere mit ihren kostbaren Lasten, die Arbeit des Steigens und die große Hitze naturwissenschaftlichen Beobachtungen hinderlich gewesen.

Zwei unserer Nachzügler hatten eine Giftschlange erbeutet, die sehr unserer Kreuzotter ähnlich war und tatsächlich stellte sie sich als eine solche heraus. Damals wurde sie zunächst für lïpcra macrops Mih. gehalten, jene Form, welche wir auf der Kobeliza gefunclen hatten. Bei genauer Untersuchung in der Heimat wurde nachgewiesen, daß es sich doch um eine echte, wenn auch etwas abweichende Kreuzotter (Vipera berus L.) handelt, die auch sonst in den Gebirgen des Balkan gefunden wurde. 
Während meine Leute am Waldrand rasteten, ritt ich am Bach entlang bergauf, um einen Lagerplatz zu suchen. Er sollte möglichst hoch liegen, um die Bergbesteigungen abzukürzen, sollte aber nahe am Bach sein, Weide darbieten und womöglich Brennholz liefern. Obwohl ich und mein Pferd schon recht müde waren, suchte ich das Ziel bald zu erreichen, da wir doch vor Sonnenuntergang unsere Zelte aufschlagen sollten. Es war ein merkwürdig ivelliges Gebiet, das sich zu beiden Seiten des Baches hinzog; ich mußte beständig auf Hügel hinauf und in Falten hinunter reiten, um allmählich in die Höhe $\mathrm{zu}$ gelangen. Überall waren üppige Wiesenmatten, vielfach sumpfiger Boden; nirgends fand sich ein trockener Lagerplatz nahe dem Bach. Holzige Gewächse fehlten vollkommen. So kam ich schließlich in die Felsenlandschaft hinein; das Tal verengerte sich und fand seinen Abschlulb in einem grandiosen Felsenzirkus, dessen obere Randeinfassung jenes Schneeband darstellte, dem ich zustrebte. Vor ihm vermutete ich die zwei kleinen Seen, welche auf den Karten ohne Namen angegeben waren. Ich hatte vor, zunächst diese zu erforschen und wollte daher mit dem ersten Lager möglichst nahe an sie heran.

Zwei Stunden war ich vom Rastplatz am Waldrand geritten, als ich endlich an einen Platz kam, der zum Lagerplatz geeignet erschien. Er lag unter den ersten Felsenwänden, war von großen Blöcken bestreut, dazwischen mit Rasen bewachsen. Weide war also da, Wasser auch, nur Holz fehlte, da er weit über der Baumgrenze lag. Die notwendige Winddeckung war durch einen mächtigen Felsen mit steilem Abfall gegeben. Wir bestimmten später die Meereshöhe des Lagerplatzes auf $1950 \mathrm{~m}$.

Es dauerte lange, bis meine Truppe nachkam; am letzten Rastplatz hatte sich ein Unfall ereignet. Die erschöpften Mannschaften hatten nicht genügend auf die Pferde geachtet und so hatte mein Wachtmeister einen Huftritt an den Kopf erwischt, als er schlafend am Boden lag. Zum Glück hatten wir gerade an diesem Tag einen Arzt bei uns, der uns bis ins erste Lager begleiten wollte. Der hatte den Verletzten verbunden und nahm ihn am nächsten Tag wieder mit nach Üsküb zurück.

Wir aber schlugen vor Abend noch unsere Zelte auf; wir schmiegten sie möglichst tief in die Mulden vor den Felsen hinein, um vor dem vom Berg herunterfegenden Wind geschützt zu sein. Direkt über uns dehnten sich Grashalden in einen Halbkreis von Felsen hinein, deren oberer Rand von einem langen, schmalen 
Schneefeld eingefaßt wurde. Eine prachtvolle Mondnacht folgte dem anstrengenden Tag. Wir waren alle zu sehr ermüdet, als daß wir sie genießen konnten. Zudem trieb ein kalter Wind uns in die Zelte und unter die warmen Decken.

Am nächsten Morgen machte ich mich zeitig auf, um womöglich die so viel angezweifelten Seen aufzufinden. Steil die Talmulde hinauf ging es durch sumpfiges Gelände zwischen Felsen in der Richtung auf das Schneeband. Ein noch kälterer Wind als gestern abend wehte von oben herunter uns entgegen und ver-

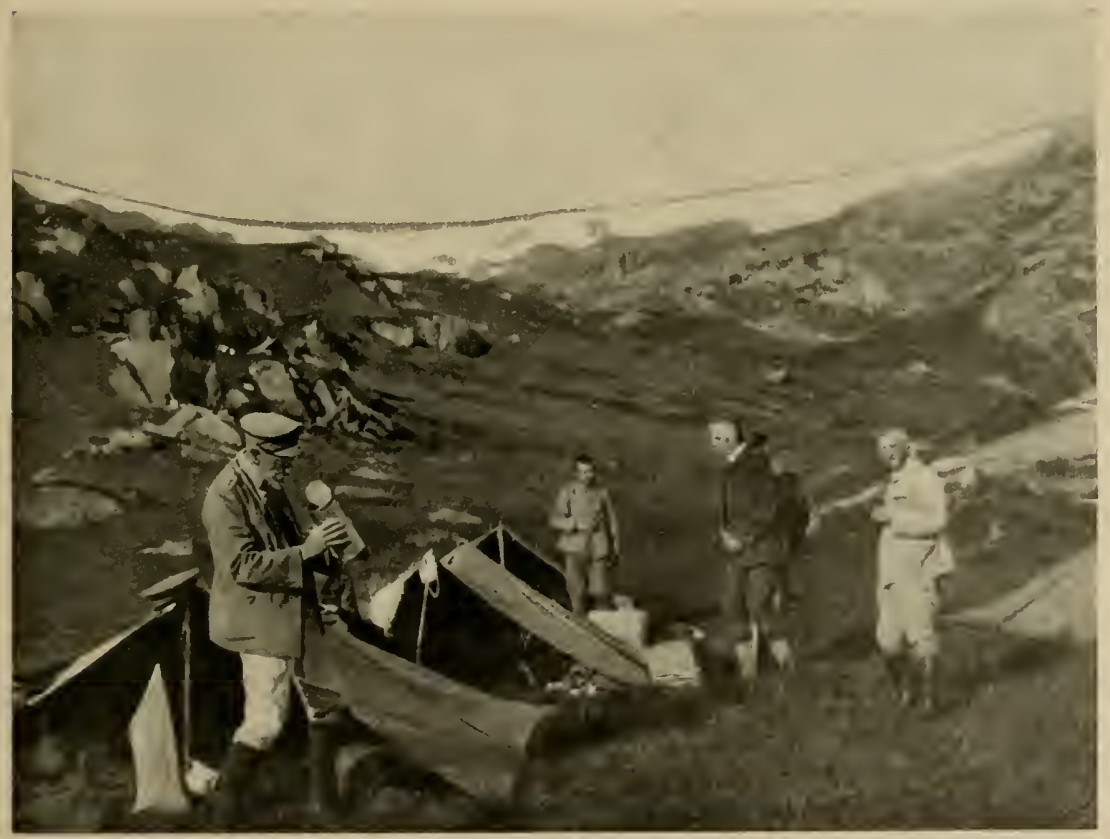

Abb. 193. Lager am Pepelakkar.

sprach wenig Gutes für die nächsten Tage.

Kaum dreiviertel Stunden hatte ich anzusteigen, da stand ich vor den Seen. Es waren zwei kleine Wasseransammlungen, kaum 1-2 $\mathrm{m}$ tief, mit klarem Wasser; der Boden war von Steinen bedeckt. Grün schimmerten sie aus dem weißgrauen Gestein heraus, wenn man aus der Höhe auf sie hinabblickte. Ein Damm aus Felsentrümmern und Geröll trennte sie von dem Abhang der Talmulde.

Das klare, kalte Wasser enthielt eine spärliche Tierwelt: Larven der Chirocephalus-Art, welche wir einige Tage später 
weiter unten im Begovatal im erwachsenen Zustand fanden, Wasserkäfer, oligochäte Würmer und sonst sehr wenig Getier. Es waren diese kleinen Wasseransammlungen eine rechte Enttäuschung. Wir hatten nach den Karten etwas Gröleres und Interessanteres erwartet. Die Wasserkäfer waren Dytisciden, unserm Gelbrand verwandt, aber kleinere Arten. Zwei Arten fanden sich in dem kalten Wasser, Gaurodytes solieri Aubé, eine alpine Art, und Gaurodytes nitidus F. Auch eine Wasserwanze (Corixa Sahlbergi (?) wurde dort gefangen.

Hinter den Seen stieg der Berg schroff zum Schneeband hinan; eine mächtige Schutthalde füllte den Raum zwischen scharfen Felsenrippen aus. Das Schneeband war kaum $50 \mathrm{~m}$ breit; an den Schnee schloß sich noch eine steile Halde an, die bis zum Bergkamm reichte, der über die drei Gipfel des Pepelak hinstrich. Das Gestein des Berges, wie der Ufer der Seen war Gneis. Das herabfließende Schmelzwasser füllte die Seen. Von ihnen floß es in einigen Rinnsalen ab, welche in kleinen Wasserfällen talab strebten. Die Seen lagen auf einer Meereshöhe von $2100 \mathrm{~m}$.

Die Pepelakseen sind typische Karseen. Hinter ihnen steigen die Berge steil an; vor ihnen liegt eine Moräne von 6-7 m Höhe. Unser Geologe Dr. Gripp stellte fest, daß in der Moräne seitlich des Abflusses Kuppen aus Granatglimmerschiefer aufragen, welche zu Rundhöckern abgeschliffen sind und deutliche Gletscherschrammen aufweisen. Er fand etwa $25 \mathrm{~m}$ höher die Reste eines zweiten Kars mit einer etwa $150 \mathrm{~m}$ langen Moräne von durchschnittlich $7 \mathrm{~m}$ Höhe. Diese kleinen zwei Kare liegen in der Rückwand eines viel größeren Kars, das den ganzen Bogen zwischen den Gipfeln Pepelak-Nord und Pepelak-Süd umfaßt. Als Reste des einstigen Karsees finden sich in $2020 \mathrm{~m}$ Höhe zivei durch einige Felskuppen getrennte Moorbecken. Am Gestein am Rande dieses Karbodens sind ebenfalls Rundhöcker nachzuweisen.

So waren denn die Annahmen Östreichs, der schon vor 20 Jahren Spuren einer einstmaligen stärkeren Vereisung erwälınt hatte, bestätigt. In den nächsten Tagen sollten wir viel gro!3artigere Eiszeitspuren auffinden.

Beide Seen sind miteinander durch einige Rinnsale verbunden, der nördliche liegt ein klein wenig höher als der südliche, so daß das Wasser von ersterem zu letzterem abfließt. Aus dem südlichen See flielst der Bach $a b$, an dem wir unser Lager aufgeschlagen 
hatten, und an welchem ich am Abend des vorigen Tages entlang geritten war. Er hatte also nichts mit dem Markovabach zu tun.

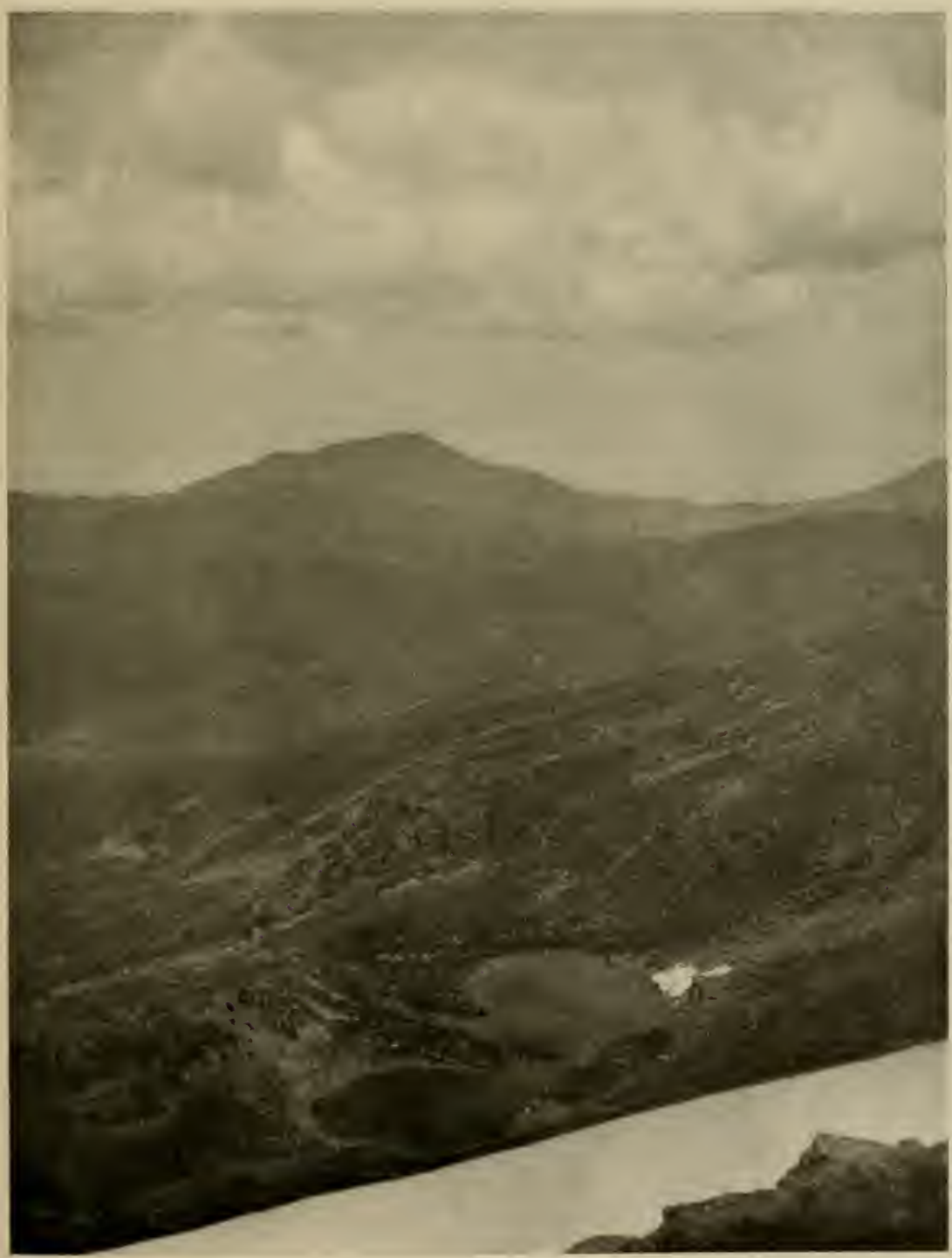

Abb. 194. Pepelakseen, vom Schneeband aus gesehen.

Er heißt bei den Bewohnern des Gebirges Jezero Reka, also Seebach und mündet bei Aldince in die Kadina Reka, welche selbst ein Nebenflüßchen des Wardar ist. 
Als ich von den Seen zum Lager wieder abstieg, kam ich zwischen den Wasserfällen in ein Gebiet, welches von einer wundervollen Fülle von Alpenpflanzen überwachsen war. Zwischen den Steinen drängten sich üppige Büsche der Alpenrose, deren rote Blüten sich von den Steinen und dem dunklen Laub reizvoll abhoben (Rhododendron myrtifolium Schott und Kotchy). Die schönen Sterne der Anemone narcissiflora und nemoralis L. wetteiferten mit dem Ranunculus nivalis und den grellen Geum-Arten (montanum L., molle V. B. und coccineum F.). Veilchen (Viola Griesebachiana Vis) standen neben Pedicularis limnogena, dazu kamen Primeln (Primula intricata), ein roter Steinbrech neben weißen und prachtvollen großen Enzianen (Gentiana cruciata L.). Kleine Büsche von Salix polaris, einer Zwergweide, wuchsen dicht am Wasser. An den moosigen Stellen sah man die feinen Glöckchen einer Soldanelle ( $S$. pindicola Hauskn). Wo der Boden etwas moorig wurde, sproßte ein charakteristisches Sumpfmoos, eine Sphagnum-Art, welche Gattung damit zum erstenmal auf dem Balkan nachgewiesen wurde. Etwas weiter bergab, vor allem an den Waldrändern, stand in voller Farbenpracht in großen Mengen eine schöne, leuchtend gelbe Akelei (Aquilegia aurea Janka). Neben den Alpenrosen wuchs der Türkenbund in großen, blühenden Büschen (Lilium martagon L.).

Am selben Tag wurde noch ein Erkundungsmarsch auf den Kamm des Pepelak unternommen, über dessen drei Gipfel und auf die Hochfläche fortgesetzt, die sich südlich des Kammes hinzog, um einen Plan für die Fortsetzung der Expedition gleich ins Auge fassen zu können. Schon beim Anmarsch waren die drei dunklen Spitzen über dem weilo leuchtenden Schneefeld als charakteristisches Merkmal des Pepelak erschienen. Beim Anstieg sah man nun, daß ein südlicher Gipfel näher am mittleren lag, während der nördliche in größerer Entfernung einsam aufragte. Ich kletterte die Felsen hinauf und umging das Schneeband im Süden. So kam ich zuerst auf den südlichen Pepelakgipfel. An seinem steinigen Abhang fand sich wieder eine artenreiche alpine Flora. Wenn der Wind ruhte, so summten um die farbenprächtigen Blumen allerhand Insekten, darunter zahlreiche Hummeln. Zwischen ihnen schwirrten Exemplare eines dem Taubenschwanz ähnlichen Schmetterlings (Hemaris scabiosae). Kleine dunkle Motten flogen vor unseren Tritten auf, um sich schnell wieder zu setzen. Unter den Steinen waren zahlreiche Käfer zu finden. 


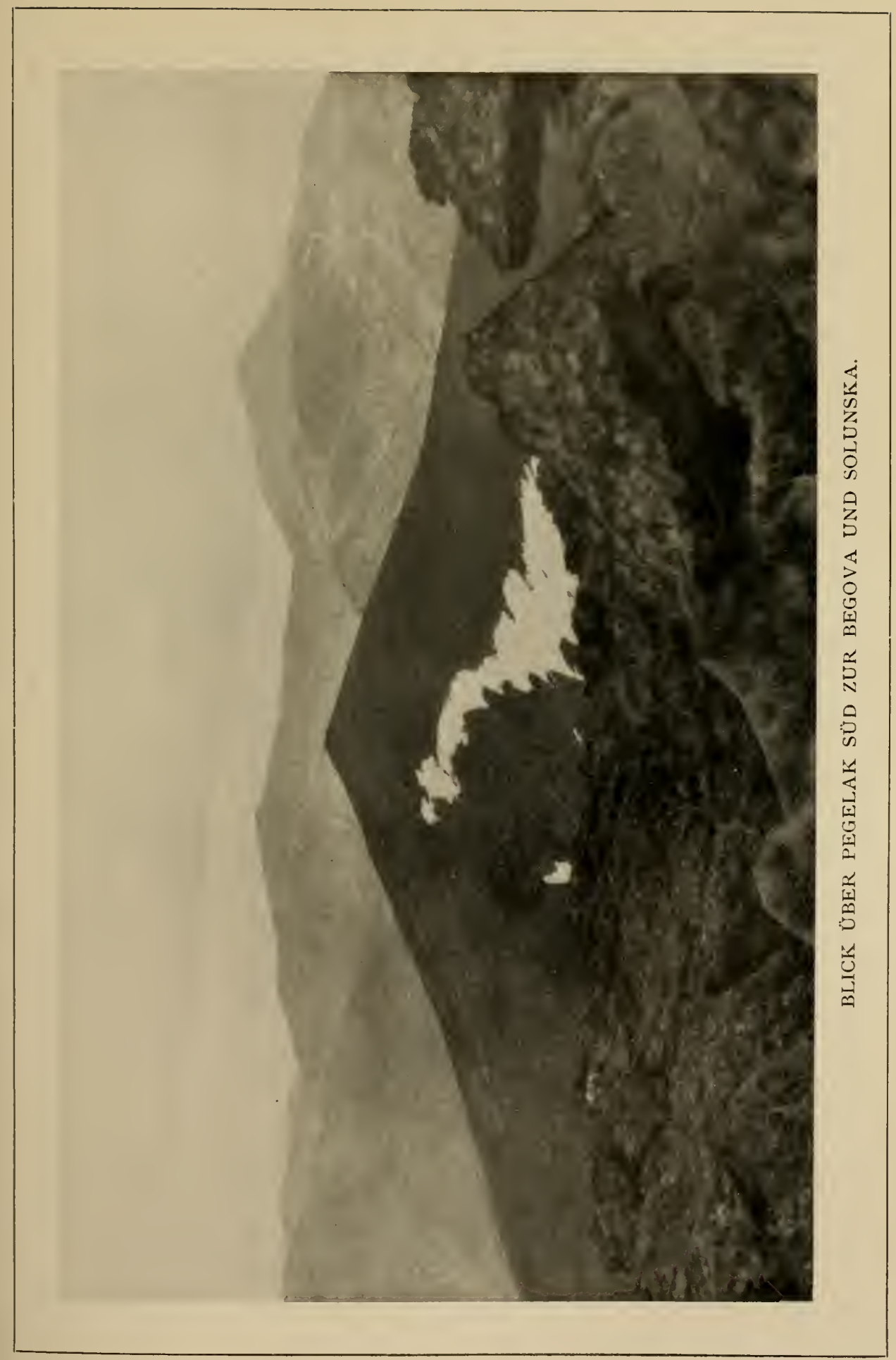



Als wir am Gipfel in warmer Sonne saßen, umschwärmten uns zahlreiche Tagschmetterlinge; vorwiegend die gewöhnlichen Vanessa-Arten, die bei dem starken Wind sehr schwer zu fangen waren. Es war die übliche Gipfelversammlung, die wir schon öfter erwähnt haben.

Während wir die Fernblicke genossen und uns in der Gegend orientierten, wurden die Instrumente abgelesen und die notwendigen Aufnahmen gemacht. Wir bestimmten die Höhe des südlichen Pepelakgipfels auf $2290 \mathrm{~m}$.

Vor uns lag ein wundervolles Gebirgsbild. Zu unseren Füßen fielen die Felsen steil ab zu den Matten, kleine Schneefelder waren überall noch $z u$ sehen. Direkt nach Süden zog ein flaches Hochtal, das abgegrenzt wurde durch eine Kette hoher Marmorberge mit weißblinkenden Flanken. Kahle, wilde Felsengebiete taten sich da vor uns auf; nur hier und da sah man kleine Rasenflächen, sonst war die Pflanzenwelt sehr spärlich. Ganz im Süden erhob sich in zarter Bläue ein Berg von schönen Umrissen, eine mächtige Pyramide, die ein gut Stück höher sein mußte als unser Standpunkt. Es war die Solunska, die eines unserer nächsten Ziele werden sollte.

Wir wanderten in den Nachmittagsstunden noch über den Kamm, am Hang des mittleren Gipfels entlang zum Nordgipfel. der etwas höher ist als der Südgipfel; er mißt $2300 \mathrm{~m}$. Das weißgraue Gestein um uns herum war Glimmerschiefer, meist Granatglimmerschiefer.

Auch hier um uns nur Steine und kleinere und größere Grasflächen! Westlich des Pepelakkammes zieht sich ein welliges Hochgebiet hin, welches von den nachher zu beschreibenden Kalkbergen abgegrenzt wird. Ich bestieg einen der westlich vom PepelakNordgipfel gelegenen Kalkberge, der noch etwas höher war als jener, nämlich $2315 \mathrm{~m}$.

Ungefähr an dessen Flanke zog sich die Grenze der Urgesteinszone gegen das Kalkgebiet hin; an der Nordseite der Kalkhöhe zog sich eine tiefe Schlucht hinab, deren Anfang von einer mächtigen Schutthalde gebildet wurde. Die linke Seite war eine steile Wand, an deren unterem Ende mehrere große Schneefelder lagen. An deren Rändern flogen eigenartige dunkle Schmetterlinge, eine Noctuide, die uns ein Eiszeitrelikt zu sein schien.

Tatsächlich stellte sich das Tier als die Eule Anarta melanopa Thnbg. var. rupestralis $\mathrm{Hb}$. heraus, welche aus den Alpen und 
vom Gran Sasso in Süditalien bisher in besonderen Formen bekannt ist, während die Stammform in Lappland, Labrador und auf den Shetlandinseln vorkommt. So stimmt das Vorkommen dieses Schmetterlinges gut zu den sonstigen Eiszeitspuren, welche wir im Gebiet fanden.

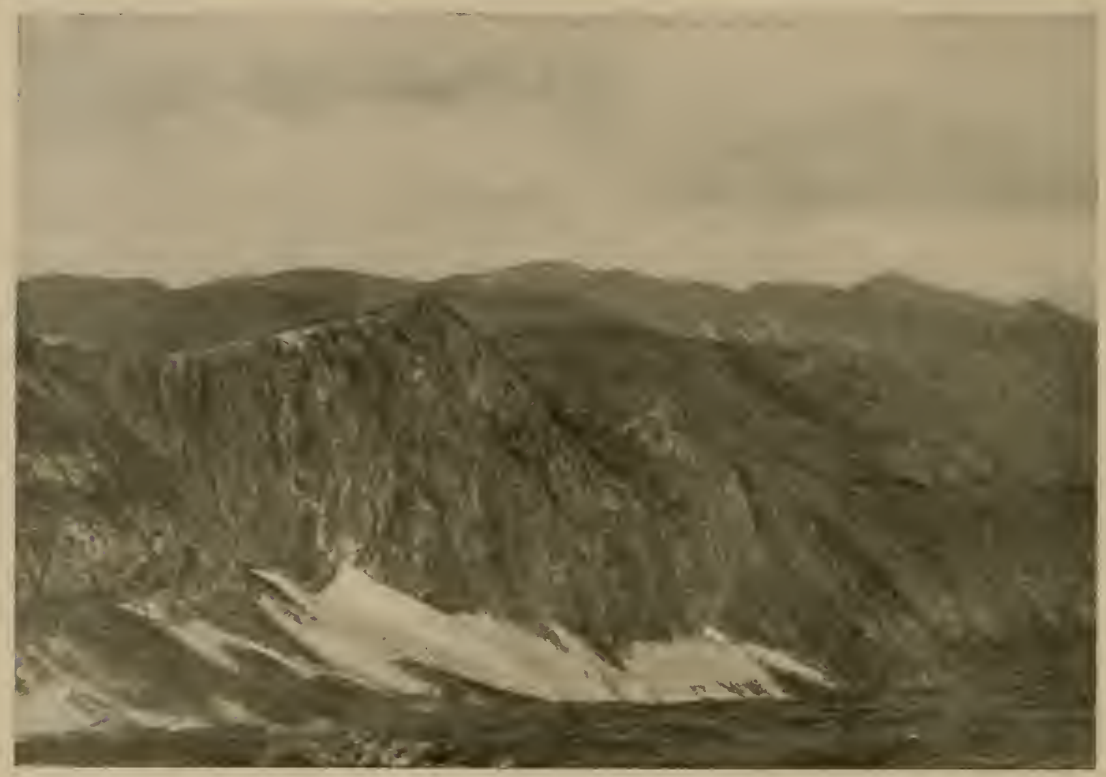

Abb. 195. Rand des Kalkgebirges der Karaschiza westlich vom Pepelak. Flugstelle von Anarta.

Nach den Feststellungen unseres Geologen Dr. Gripp stellt der Pepelak mit seinen drei Gipfeln das Nordende eines schmalen

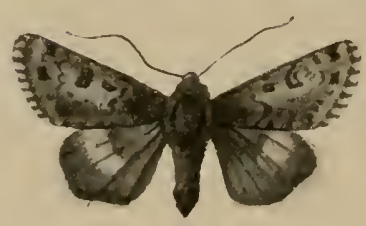

Abb. 196 .

Anarta melanopa Thnbg. var. rupestralis $\mathrm{Hb}$. Als Eiszeitrelikt im mazedonischen Gebirge erhalten. Bergzuges dar, der von Nordivesten nach Südosten verläuft. Er erstreckt sich bis nahe an das Dorf Jabolcista hin und zeigt nur eine Unterbrechung, welche von Östreich als Salakova-Senke bezeichnet wurde. In seinem Verlauf bildet der Höhenzug eine bemerkenswerte Grenze zwischen zwei ganz verschiedenartigen Landschaftstypen. Östlich von dem Bergzug streichen fünf einander parallele Bergrücken von Südwesten nach Nordosten; sie enden alle an ihrem nordöstlichen Ende in Gestalt rundlicher Bergkuppen, deren Höhe jewveils von Norden nach Süden geringer wird. 
Als Namen dieser Bergzüge wurden Herrn Dr. Gripp von den Einwohnern des Dorfes Jabolcista angegeben: Salakova, Schachkaviza, Eilagiza und Jurudschiza. Etwas höher als diese ist die quer vor ihnen liegende Mumjitza, auf der zahlreiche Felsklippen aufragen. Sie fällt steil nach Westen zur oberen Kadina Reka ab, während sie auf der Ostseite in einen sanften Abhang übergeht. Alle diese Berge zeigen mattenberleckte breite Rücken, während steilere Hänge dichten, grünen Buchenwald tragen. Zwischen dem Südende der Mumjitza und dem südöstlich von ihr gelegenen Berg Liseč, den wir von unserem dritten Iager mehr

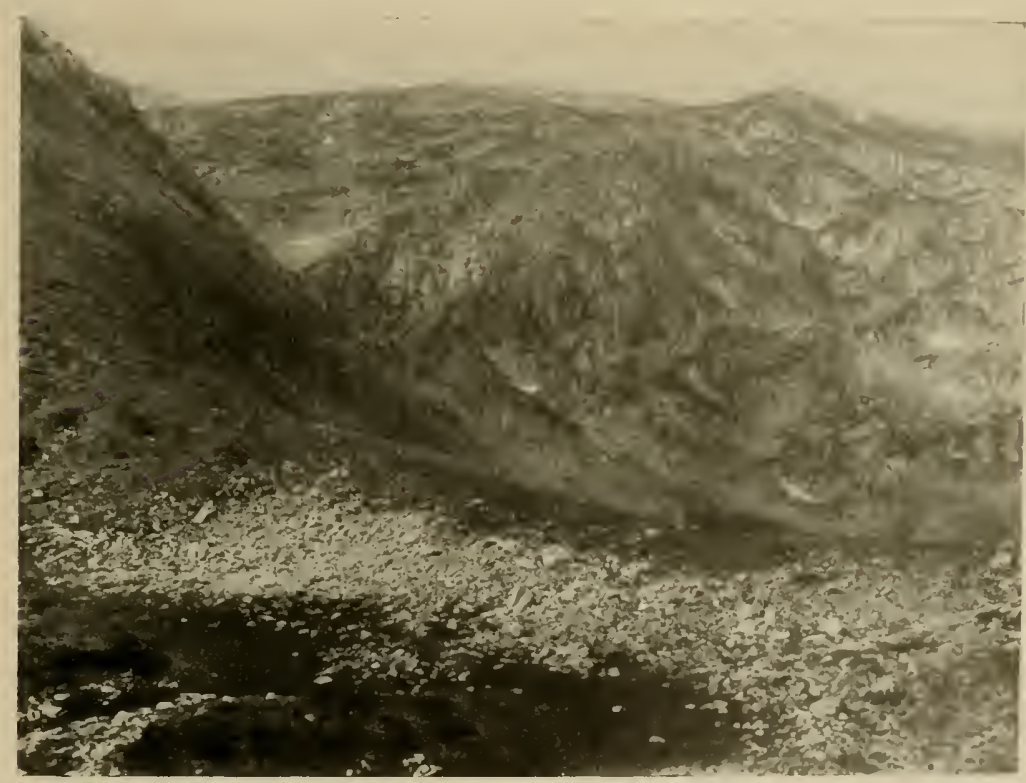

Abb. 197. Endmoräne des Gletschers im Wannental. Golesniza Planina.

aus der Nähe sehen konnten, ragten zwei schmale, parallele Höhenzüge empor; der näher gelegene, genannt Szriba(i)tschan erreicht die Höhe von $1805 \mathrm{~m}$, während dịe zwischen ihm und dem Liseč hinziehende zweite Kette, deren Namen wir in dem öden menschenarmen Gebiet nicht erfahren konnten, noch höher ist.

Dr. Gripp beobachtete in diesem Gebiet nur Gneise. Dieser einheitlichen Gesteinszusammensetzung schreibt er die gleichmäßige Oberflächengestaltung des Gebietes zu. Angelagert an diese Gneise fand er eine Hülle von Glimmerschiefer, zum Teil Granatglimmerschiefer, aus der auch der größte Teil des Pepelak und des Höhen- 
zuges zusammengesetzt ist, der sich vom Pepelak bis Jabolcista erstreckt.

Ganz anders als diese milden, gleichartigen Berge sehen die Gebirgszüge aus, welche westlich von diesem Glimmerschiefergebirge liegen. Es ist das weiße, kahle, baumlose und überhaupt vegetationsarme Gebiet, welches ich oben schon erwähnte. Wir alle, welche die Gebirge der Gegend von Triest, von Istrien oder der Herzegowina kannten, wurden durch seinen Anblick an den Karst erinnert. Unser Geologe bestätigte uns die Richtigkeit dieser Annahme. Es war ein typisches Kalkgebirge; die Gesteine, die es zusammensetzten, waren nur Marmor und Dolomit. Und

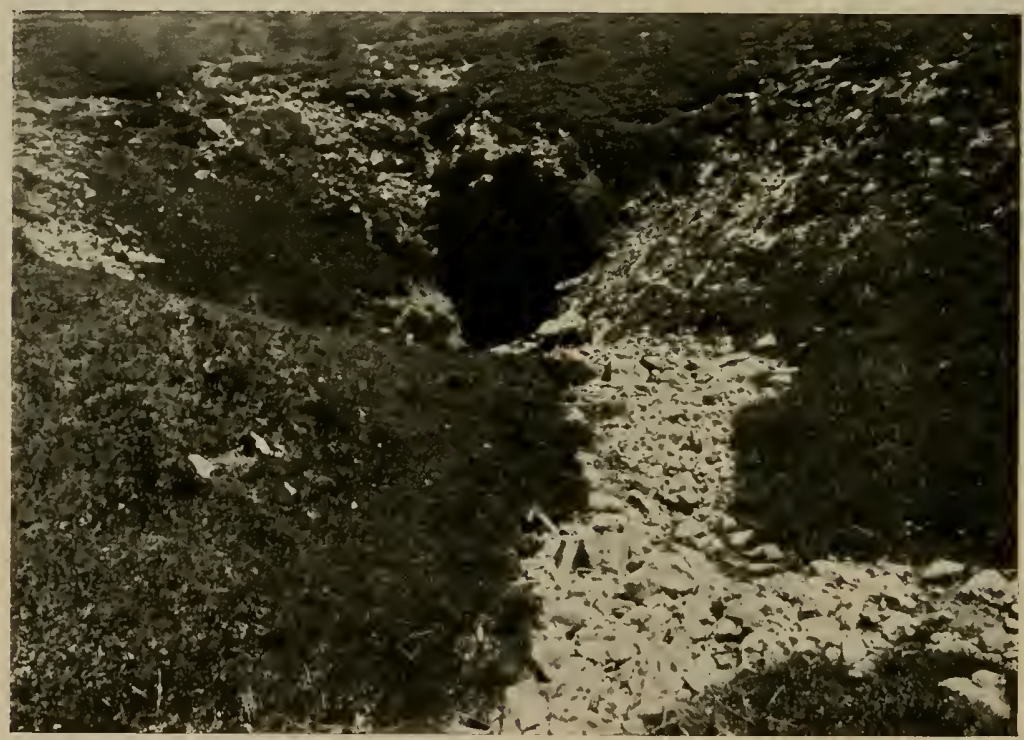

Dr. Gripp phot.

Abb. 198. Doline bei Lager 2 im Golesnizagebirge.

überall traten uns die typischen Karstphänomene entgegen, welche für Gebirge vom Bau des Karstes in aller Welt charakteristisch sind und den Namen dieses südkrainischen und küstenländischen Gebirges zu einem geologischen Fachausdruck gemacht haben.

Vor allem war die Wasserarmut dieser Berge auffällig. Streifte man durch diese weißen, plattigen Gesteine, dann mußte man seine Feldflasche wohlgefüllt mitnehmen. Denn auf Quellen konnte man nicht rechnen. Die Täler und Schluchten waren trocken und keine munteren Bäche durchströmten sie. Wo Schmelz- 
wasser von den Schneefeldern herabflol, versickerte es bald im Boden oder verschwand in unterirdischen Spalten. Die Täler waren sämtlich abflußlos. Die für den Karst so bezeichnenden Dolinen waren überall in großen und kleinen Ausmaßen anzutreffen. Es sind das Einsturztrichter, welche dadurch entstanden sind, daß unterirdische Höhlen durch Auslaugung der Felsen sich bildeten, in welche später die Felsendecke einstürzte. Solche riesigen Dolinen wie im adriatischen Gebiet, in denen große Felder und Gärten, ja ganze Dörfer liegen können, fanden wir allerdings hier im Hochgebirge nicht. Karstphänomene werden wir weitere zu erwähnen haben, wenn uns die Beschreibung der weiteren, von uns durchforschten Strecken der Golesniza Planina dazu führt.

Besonders interessant für den Geologen waren die Beobachtungen einer Auflagerung von mehreren hundert Metern mächtigen Marmormassen auf dem kristallinen Schiefer. An zwei Stellen konnten solche Überlagerungen beobachtet werden; in beiden Fällen lagerten helle Kalke und Kalke mit Glimmer, die unter $50-70^{\circ}$ nach Südwesten einfielen, über den kristallinen Schiefern, und zwar ohne jede Transgressionsmerkmale zu zeigen. Die Kalke gingen nach oben bald in graue Dolomite und hellen Marmor über. Im Patiskatale fand Dr. Gripp eine linsenförmige Scholle von Gneis von einer Länge von $8-10 \mathrm{~m}$ in den untersten Lagen der Kalke.

Interessanter und auffälliger waren uns anderen Naturforschern die Spuren einer einstigen starken Vereisung der Gebirge, welche Dr. Gripp eifrig untersuchte und abends im Lager, wenn wir schmausend vor unseren Zelten saßen, hörten alle gern $z u$, wenn er von seinen Beobachtungen erzählte.

Die Resultate im Gebiet der Karseen des Pepelak haben wir oben schon zusammengefaßt. Vor dem Karstgebiet zeigten sich im Gebiet des Gneisgebirges viele Spuren der Gletschertätigkeit, die sehr auffällig waren. Südlich vom Pepelakkar fand sich am Osthang des Glimmerschieferzuges in rg9o $\mathrm{m}$ Mcereshöhe ein weiteres Kar. Etwas südlich von diesem lagen auf dem Glimmerschiefer 80 Marmorblöcke von verschiedener Größe, den Grestein nach vollkommen den anstehenden Gesteinen im westlich liegenden Karstgebirge entsprechend. Daran anschließend am Westhang der Höhe sind Rundhöcker zu finden, auf denen verstreut gerundete Marmorblöcke umherliegen. Wir können daraus schließen, daß in das Tal zwischen dem Glimmerschiefergebirge und dem Karst ein 
Gletscher sich ausdehnte, der bei 2040 m Höhe das Tal ausfüllte. Es muß ein prachtvoller großer Gletscher gewesen sein, dessen Eis hier hinabfloß. Kein anderes Transportmittel wäre fähig gewesen, die mächtigen Marmorblöcke und Kalkfelsen aus dem Karstgebiet weit in das Gneisgebiet hinein zu verschleppen. Im Tal selbst lagen in 1945 und $1990 \mathrm{~m}$ Höhe noch zwei mächtige Moränen aus Marmorgeschieben, von denen die obere $3 \mathrm{~m}$ hoch und $50 \mathrm{~m}$ lang, die untere $15 \mathrm{~m}$ hoch und $120 \mathrm{~m}$ lang ist. Im Grunde des Zungenbeckens der oberen Moräne gibt es mehrere Dolinen. Unterhalb der tieferen Moräne liegt eine steile Marmorwand, an deren Fuß eine Quelle entspringt (Östreichs SalakovaQuelle). Ihr Abfluß, dem zwei kleine Bäche seitlich zufließen, durchbricht in der Salakova-Senke die Glimmerschieferkette und fließt steil bergab zur Kadina Reka.

Nach Süden schließt sich westlich vom Glimmerschieferzug das von Östreich so benannte Wannental an; in Wahrheit handelt es sich um zwei größere, abflußlose Täler. Sie führen Bäche, deren Wasser von Glimmerschiefergebirge kommt und welche jetzt verstärkt durch die Schneeschmelzwasser des Frühlings noch im Tal in Dolinen verschwanden.

Am Abend unseres ersten Tages im Pepelaklager erlebten wir einen starken Barometersturz, ein kalter Regen trieb uns in unsere Zelte, die Temperatur sank auf $6^{\circ} \mathrm{C}$. Nebelschwaden zogen das Tal herauf und hüllten unser Lager vollständig ein. Eine kurze Aufklarung ermöglichte uns wenigstens abzukochen. Nachts aber kam wieder Regen, dem ein schweres Gewitter und schlimme Kälte folgten. Das schlechte Wetter hielt den ganzen nächsten Tag an, gegen Abend schneite es sogar; das dauerte die Nacht hindurch an. Gegen Morgen trat sogar Frost ein, wir hatten $-4^{\circ} \mathrm{C}$, morgens im Zelt noch $-1,5^{\circ} \mathrm{C}$; die Erde war stark gefroren, der Schnee war nicht liegengeblieben, aber Wiesen und Felsen waren stark bereift. Und das widerfuhr uns während des subtropischen Sommers Mazedoniens in der Nacht zum längsten Tag des Jahres.

Der Tag wurde trotzdem gut ausgenützt, obwohl es unmöglich war, in dem immer wieder aufziehenden dichten Nebel sich weit vom Lager zu entfernen. Der Botaniker kam immerhin zu seinem Rechte. An den zahlreichen Wasserläufen, welche den Berg herabliefen, standen neben farbenprächtigen Polstern von Läusekraut (Pedicularis limnogena Gris.), die goldenen Sträule der Sumpf- 
dotterblume; dazwischen bogen sich im Wind die Stengel der roten Bachnelke (Geum coccineum S. S.). Die Bachnelken waren hier im Kar sehr häufig, und zwar kamen vier Arten vor (Geum montanum I., G. mollc V. B., G. urbanum 1. und das rotblühende Geum coccineum L. L.) Prof. Bornmüller benützte die Zeit, um nach Bastarten zwischen diesen nahe verwandten Arten zu suchen und er fand tatsächlich solche auffallend häufig. So waren zahlreich Bastarte von coccincum und montanum, ebenso von urbanum und coccincum, dagegen sehr selten solche von molle und coccineum.

Selbst für den Zoologen gab es trotz Regen, Nebel und Kälte manches zu beobachten. Um die Zelte trieben sich zahlreiche Wasserpieper (Anthus spinoletta L.) herum, Braunkehlchen (Saxicola rubetra L.) schwirten in den Felsen oberhalb des Lagers, Feldlerchen und Ohrenlerchen gab es auch. Das schlechte Wetter zwang einen Steinadler und einen Lämmergeier nebst einem Schwarm Alpendohlen zu einem flüchtigen Besuch in unseren Tiefen.

Ja ich konnte hier sogar zwischen den Bächen eine ganze Anzahl von Ameisenhaufen entdecken. Es war eine Formica-Art (Serviformica fusca L.), welche in dieser Bergeshöhe zwischen den Polstern einer hier häufigen Wachholderart (Jumiperus nana Will.) regelrechte Haufen hauptsächlich aus Wachholdernadeln gebaut liatte. An dem kalten Tag waren die Tiere alle tief im Bau verkrochen. Am nächsten Morgen überraschte uns klarer Himmel in unserer Höhe, während die Täler, so auch das IVardartal, tief unten im Nebel steckten. Wasser und Schwämme waren selbst im Zelt gefroren, die Zeltbahnen hart und steif. Die kurze Stunde Sonnenschein half uns unsere Sachen annähernd trocknen, unsere Waschung im Bachwasser vollbringen. Wir brachten diesen Tag noch in der Umgebung des Lagers zu, die verschiedenen begonnenen Untersuchungen fortsetzend. Nachmittags stieg ich einige Kilometer bergab, um die Buchenwaldregion am Sattel, welche wir beim Aufstieg rasch durchschritten hatten, noch einmal zu durchstreifen. In dem schönen, lichten Buchenbestand war ein reiches Vogelleben. Vor allem wimmelte es von kleinen Singvögeln, von denen Kleiber, die beim Nestbau waren, Baumläufer, Zaunkönige, Drosseln und WValdlaubsänger beobachtet wurden.

Vor uns lag, blau hinter dem Buchenvald sich erhebend, der schön umrissene Berg Liseč, hinter welchem die Berge des Wardartals um Veles und die jenseitigen Gebirge auftaucliten. 
Am nächsten Morgen, am 24. Juni, hatte schöner Sonnenschein uns begrülot, nachdem wir noch beim Sternenschein begonnen hatten, die Zelte abzuschlagen und die Tragtiere zu bepacken. Aber noch ehe wir losritten, erhob sich ein starker, kalter Wind, schwere Wolken zogen von Westen heran. Trotzdem setzten wir uns in Bewegung und erklommen die Hänge des Pepelakkargebiets. Südlich des Südgipfels wollten wir den Sattel überschreiten, um in das längs der Karstberge hinziehende Tal zu gelangen.

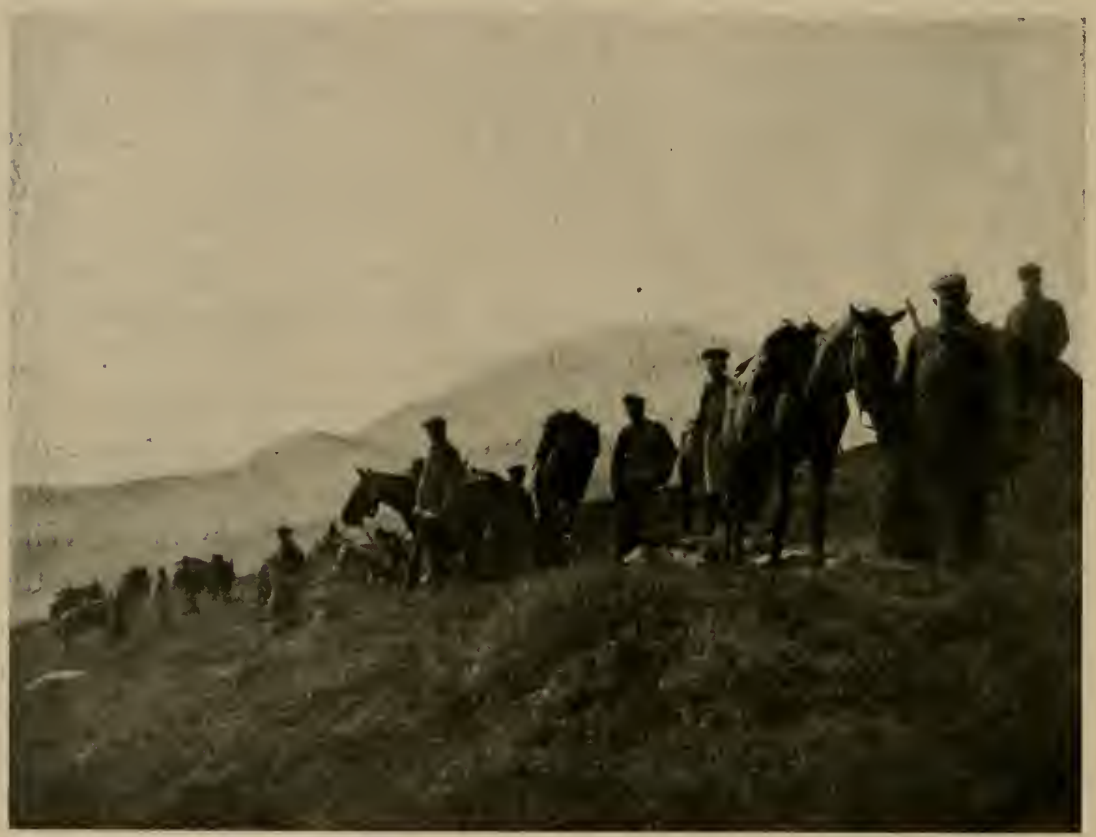

Abb. 199. Meine Karawane am Pepelaksattel.

Oben auf dem Sattel überfiel meine Karawane ein gewaltiger Sturm; die Stöße des Westwindes brachten Menschen und Pferde aus dem Gleichgewicht. Es war kaum möglich, sich aufrecht zu erhalten. Dabei war es bitter kalt, daß die Hände einem am Zügel erstarrten. Plötzlich entriß mir, der ich auf alle Menschen und Tiere aufpassen mußte und darum auch auf mich selber am wenigsten achten konnte, ein Windstoß meine Militärmütze und trug sie über das Schneefeld im Nu kilometerweit zu den Seen und über sie hinweg. Sie war dahin und die Reise mußte ohne Mütze fortgesetzt werden. 
Zum Glück kamen wir bald über den Sattel und ritten abwärts in das Tal, welches sich am Fulb der Marmorberge hinzog. Trotzdem kamen wir noch nicht in Winddeckung und alle Mitglieder der Expedition litten an diesem Tage sehr durch den eiskalten Wind.

Ganz einsam und menschenleer war hier das Gebirge auf beiden Seiten des Tales. In den letzten Tagen latten wir keine Hütte und keine menschliche Siedelung angetroffen. Nordwärts vom Pepelak hatten wir einige Hirten mit ihren Herden in der Ferne gesehen. In der Tiefe hatten wir Dörfer bemerkt und mit einem von ihnen waren wir auch in Beziehungen getreten. Und so sollte es noch für einige Tage weiter gehen.

Es war ein wasserloses Tal, welches wir nun zu durchreiten hatten. Schroff und kahl stiegen zu unserer Rechten die Karstberge auf, eine lange Kette von Gipfeln, an deren Südostecke ein Doppelkegelberg mit schönen Umrissen emporragte, der höchste Gipfel des ganzen Gebirges, der für die nächsten Tage unser wichtigstes Ziel war. Diesen Berg hat Östreich wohl als erster Forscher 1899 bestiegen und nannte ihn Begova. Cvijić gibt ihm den Namen Jakupiza; den kannte aber keiner der Einwohner, die wir in diesen Tagen befragten. Die österreichische Karte I: 200000 bezeichnet die beiden Gipfel als Solunska und Begova. Diese beiden Namen wurden uns bestätigt, wobei allerdings der Name Begova auch auf das weitere Gelände ringsum bezogen wurde und ja weiter nichts bedeutet als der Besitz des Beg.

Die Rast bei der von Dr. Gripp untersuchten Moräne war wenig erfreulich; denn keiner von uns fand Deckung vor dem kalten Winde, der durch das Tal fegte. So ritt ich bald mit Dr. Gripp voraus, um zu versuchen, rechtzeitig einen geeigneten Lagerplatz zu finden. Der Ritt führte über die zweite Moräne, dann links über einen Hang hinauf durch den letzten Teil des Wannentals. Hier sahen wir an vielen Stellen die Zeugen der Arbeit des Gletschereises in den gewaltigen Marmorblöcken, die oft über $40 \mathrm{~m}$ über der Talsohle auf den Gneis lagen.

Nun ging es hinab und auf eine weite Fläche hinaus, an deren gegenüberliegendem Rand Nadelgehölz uns eine geeignete Lagerstätte zu versprechen schien. Seit Tagen schien zum ersten Male wieder ein Waldbestand uns zu winken. Die hohen Gipfel, vor allem die Solunska, waren hier durch vorragende Berge der Kalkkette verdeckt; aber weit die Vorberge hinauf sah man den 
Nadelholzbestand reichen, der der Landschaft einen ganz anderen Charakter gab, als ihn die öden Wiesen- und Steinregionen besaßen, die wir zu verlassen im Begriff waren.

Unsere Pferde griffen auf dem weichen Wiesenboden flott aus. Es war eine noch magere Wiese, über welche wir ritten, man sah ihr an, daß der Schnee noch nicht lange von ihr abgeschmolzen war. In munterem Ritt ging es über eine weite, flache, von Bächen durchzogene Talebene, an derem jenseitigen Rand neue Berge aufragten, an die im Sürostwinkel die hohen Berge sich anschlossen, die allmählich frei wurden und in einem kühlen Nachmittagslicht vom trüben Himmel sich abhoben.

Wieder packte uns der Wind an und wir suchten wieder Winddeckung für unser Lager, die wir schließlich am Südrand des Tales auf einem Felsen fanden, hinter welchem dicht anschließend das Nadelholz anfing, zu unserem Erstaunen Legföhren, Latschen, die mich höchst heimatlich anmuteten.

Vor dem Felsen stand eine zeltförmige kleine Hütte aus Reisigholz; sie wurde von unseren bulgarischen Soldaten und den Tragtierführern freudig begrüßt. So winkte ihnen doch die Aussicht, einige Nächte unter Dach zuzubringen, wenn dies Dach auch nicht übermäßig fest und dicht war. Wir schlugen unsere Zelte etwas oberhalb der Hütte auf der Felsplatte auf und bald rauchten die Lagerfeuer, so daß man hoffen durfte, vor der Nacht durch warme Nahrung die durchfrorenen Körper etwas zu erholen.

Holz gab es genug in der Nähe, denn die ganzen Hänge waren von dem Krummholz bedeckt, dessen dunkelgrüne Nadeln einen neuen erfreulichen Farbton in die Landschaft brachten. Dicht bei unseren Zelten begannen die Latschenbestände und zogen sich auf allen Hängen weit hinauf. Es waren stattliche Büsche, oft fast baumartig emporragend. Mit ihren liegenden Ästen und oft hervorragenden Wurzeln erschwerten sie das Steigen sehr. Die Latschen hatten lange, weiche Nadeln von dunkelblaugrüner Farbe. Die Bestände waren durch diese blaugrüne Färbung außerordentlich charakteristisch und beherrschten durch diesen Farbton vielfach die Stimmung der vorherrschend düsteren Landschaften im Solunskagebiet. Es war Pinus montana Mill., Sbsp. mughus Scop.

In unserer Nähe war der Legföhrenbestand immerhin etwas gelichtet; verbrannte Stellen zeigten uns, wie unvorsichtig und nachlässig die Bevölkerung auch hier mit dem kostbaren Holz umgegangen war. Die kleine Hütte war von Köhlern errichtet 
worden, welche offenbar regelmäßig im Hochsommer einige Monate zum Kohlenbrennen hier verbringen. Im Krummholzwald zeigten auf zahlreichen Lichtungen die Reste von Kohlenmeilern, daß3 hier eifrig gearbeitet worden war. Aus manchen Meilern konnten wir uns noch erhebliche Mengen Holzkohlen herausholen, die unsere Feuer nachhaltig machten, und uns erlaubten, um sie herum hockend, uns ordentlich anzuwärmen.

Während die Zelte aufgeschlagen und gekocht wurde, hatten wir Naturforscher Zeit, uns an unserer neuen Arbeitsstätte umzusehen. Es war eine großartige Landschaft, die sich um uns ausbreitete. Vor uns lag eine weite, grasbewachsene Ebene, durch welche mehrere Bachläufe sich verzweigten. Direkt unseren Zelten gegenüber, also nördlich von ihnen, zog sich von West nach Ost eine Hügelkette hin, welche dem Gneisgebiet angehörte und dies durch ihre graue Färbung erkennen ließ. Sie setzte die Begrenzung des Wannentals fort, das gleichsam durch eine Pforte sich in das weite Tal öffnete. Westlich zogen die hellen Karstberge heran und grenzten mit ihren weißen Wänden das Tal ab, sich fortsetzend in die stattlichen Gipfel der Begova und Solunska. Diese prachtvollen Berge erhoben sich steil etwas rechts hinter unserem Lager; wir brauchten nur einige hundert Meter in die Ebene hinauszuwandern, um einen grandiosen Anblick zu genießen. Von der Abendsonne rosig überhaucht hoben sich die mächtigen Kalkhalden aus dem dunklen Polster der Latschen, welche auf dieser Talseite überall hoch die Hänge hinaufstiegen. Tiefe, blaue Schatten hoben die zerrissenen Wände der beiden Kegel scharf hervor.

Der Blick nach Norden und Osten war weniger großartig; ziehende Wolkenschwaden verhüllten meist die Aussicht. Immerhin war diese sehr interessant. Der Grund des weiten Tals war wellig und 7.um Teil mit Rasen bedeckt. Zahlreiche Rinnen durchzogen ihn, von Bächen und den von allen Höhen niederrauschenden Schneeschmelzwässern gebildet. Auf den ersten Blick mußte man an einen ausgetrockneten Seeboden denken, eine Meinung, die tatsächlich von Östreich ausgesprochen wurde. Das ganze Tal gehörte dem Karstgebiet an und als interessante Karsterscheinung konnten wir zwei von West und Nord zuströmende Bäche feststellen, welche in der Mitte der Talebene beide gemeinsam plötzlich im Boden verschwanden. Beide Bäche strömten hier in eine tiefe Doline; ihr Wasser wurde vom Boden verschluckt, um irgendwo weit bergab aus einer Felsspalte wieder zum Vorschein zu kommen.

D o f l e in, Mazedonien. 
Das Tal wies auch die Spuren einer einstigen Vergletscherung auf. Am Ostrande war es eng geschlossen und setzte sich in eine trockene Schlucht fort, welche durch Moränen gesperrt war und an ihren Rändern Marmorblöcke auf dem Gneis trug, die Verlauf und Mächtigkeit des einstigen Gletschers anzeigten.

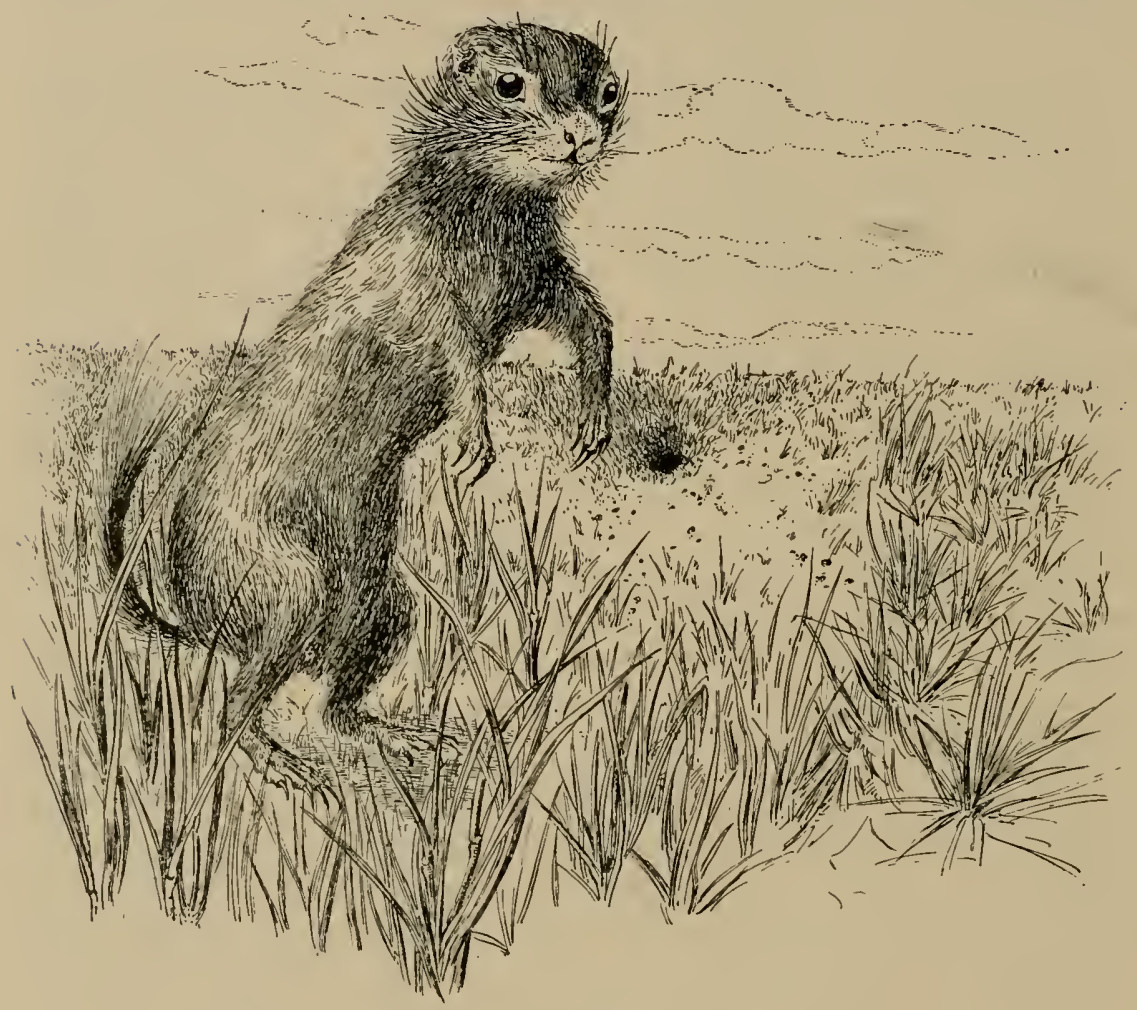

Abb. 200. Ziesel nahe seinem Loch (Citillas citillus L.).

Das Tal selbst gab zu allerhand Beobachtungen Anlaß. Die Präparatoren waren eifrig auf der Vogeljagd, wobei interessante Arten, wie die Ohrenlerche (Chionophilos alpestris balcanicus Rchw.), erbeutet wurden (Abb. 20I). Im Talgrunde waren zwischen dem kurzen Rasen viele Erdlöcher mit ausgeworfenem Sand zu beobachten, von denen viele von $\mathrm{Zi}$ ieseln bewohnt waren. Dieses fast hamstergroße Nagetier hatte ich in Mazedonien schon oft beobachtet. Er ist ein reizvolles, putziges Tierchen; oft sieht man es, wie ein Murmeltier aufgerichtet vor seinem Erdloch sitzend und Männchen machen, um schnell wie der Wind sich in die Tiefe zu stürzen, sobald es den Menschen bemerkt (Abb. 200). 
Einige Belegstücke wurden geschossen, um diesen eigenartigen Fundort festzulegen. Es war auffallend, dies Steppentier in so großer Meereshöhe $(2000-2200 \mathrm{~m})$ so zahlreich zu finden. In den Ebenen des Wardar bei Hudova und Üsküb hatte ich immer nur einzelne gesehen, hier waren hunderte von Löchern im

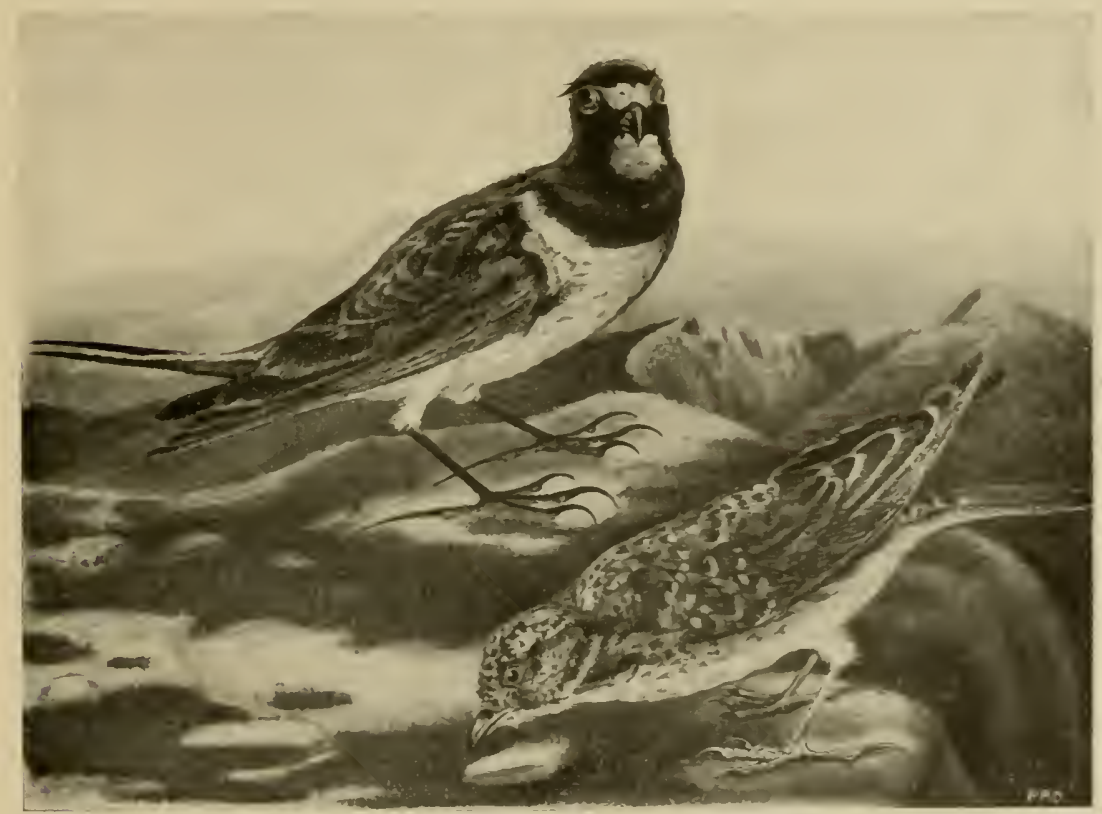

Abb. 20I. Ohrenlerche im mazedoniscben Hochgebirge, oben Männchen, unten Weibchen. (Chionophilos alpestris balcanicues (Rchw.).

Talboden und die Tiere ließen sich leicht beobachten, da sie in dieser einsamen Gegend viel weniger scheu waren, als im Tiefland. Die Weibchen waren hier gerade trächtig, also fast 6 Wochen später als im warmen Tiefland. Hier oben müssen sie auch einen viel längeren Winterschlaf halten als unten. Auch die Nahrung mußte bisher sehr mager gewesen sein, denn vor kurzem hatte der Schnee noch das Tal gedeckt. So hatte das Tier hier auch wohl sicher noch keine Vorräte eingetragen, bei welcher Tätigkeit ich es im Wardartal schon viel früher im Jahre beobachtet hatte. Dort hatte ich den Ziesel große Gras- und Heubüschel, größer als er selbst, im Mund im raschesten Lauf einschleppen sehen. Hier auf dem Balkan scheint also der Ziesel seine Vorräte nicht nur in den Backentaschen einzutragen, wie er 
das in Rußland tun soll. Die bisherigen Untersuchungen ließen keine Abweichungen von der typischen Form (Citillus citillus L.) erkennen.

Ein Iltis, der rasch in einem der Bauten verschwand, konnte leider nicht erbeutet werden.

Im Tal war eine Senke stark versumpft, zahlreiche größere und kleinere Tümpel von geringer Tiefe waren da durch das Schmelzwasser des Schnees entstanden; von ihnen waren einige im Austrocknen begriffen, einige wenige schon ganz ausgetrocknet. In diesen Tümpeln und in ihrer Umgebung fand sich eine reiche Tierwelt. Ich beobachtete dort Laubfrösche, Unken, den großen Bachfrosch (Rana ridibunda L.), im Wasser tummelten sich verschiedene Arten von Wasserkäfern (Gautrodytes-Arten), Wasserwanzen und Käferfliegenlarven. Vor allem aber wimmelten einzelne der Tümpel von ungeheueren Massen einer Euphyllopoden-Art (Chirocephalus diaphanus stagnalis); zu vielen Tausenden schwammen die rotgelben Krebschen in langsamer Bewegung in dem kalten Wasser umher. Sie waren in allen Entwicklungsstadien vertreten, auch erwachsene Männchen und Weibchen, welch letztere auch schon reichlich Eier entwickelt zeigten. Die Dauereier dieser Tiere sinken in den Schlamm, der den Boden der Tümpel bedeckt. Ist das Wasser der Tümpel verdunstet, so trocknen die Krebseier mit dem Schlamm aus und können Trockenheit und schwersten Frost überstehen. Füllt neues Schmelzwasser die Tümpel von neuem, so schlüpfen junge Krebschen aus den Eiern aus und erfüllen die entstehenden Gewässer mit neuem Leben. Aus den frisch ausgetrockneten Tümpeln nahm ich Schlammproben mit, um später in der Heimat im Laboratorium die Chirocephalus zu neuem Leben zu erwecken. Es war dieselbe Branchiopoden-Art, welche in den Pepelakseen erst den Larvenzustand erreicht hatte.

Von Chirocephalus diaphanus sind bisher zwei Rassen beschrieben worden, eine größere und eine kleinere. Unser Fund gehört zur kleineren Rasse, die bisher in Mazedonien noch nicht beobachtet war, während die größere schon einmal im Wardartal gefunden wurde. Sie gilt als eine Art subtropischen Ursprungs, eine Warmwasserform, welche ihr Hauptverbreitungsgebiet im Norden Afrikas hat. Daß sie trotzdem starke Temperaturschwankungen aushält, beweist unsere Beobachtung, daß das Wasser der Tümpel im Begovatal nachmittags bis $22,4^{\circ} \mathrm{C}$ erreichte, während morgens in der Frühe eine Eisdecke ihre Oberfläche überzog. In den 


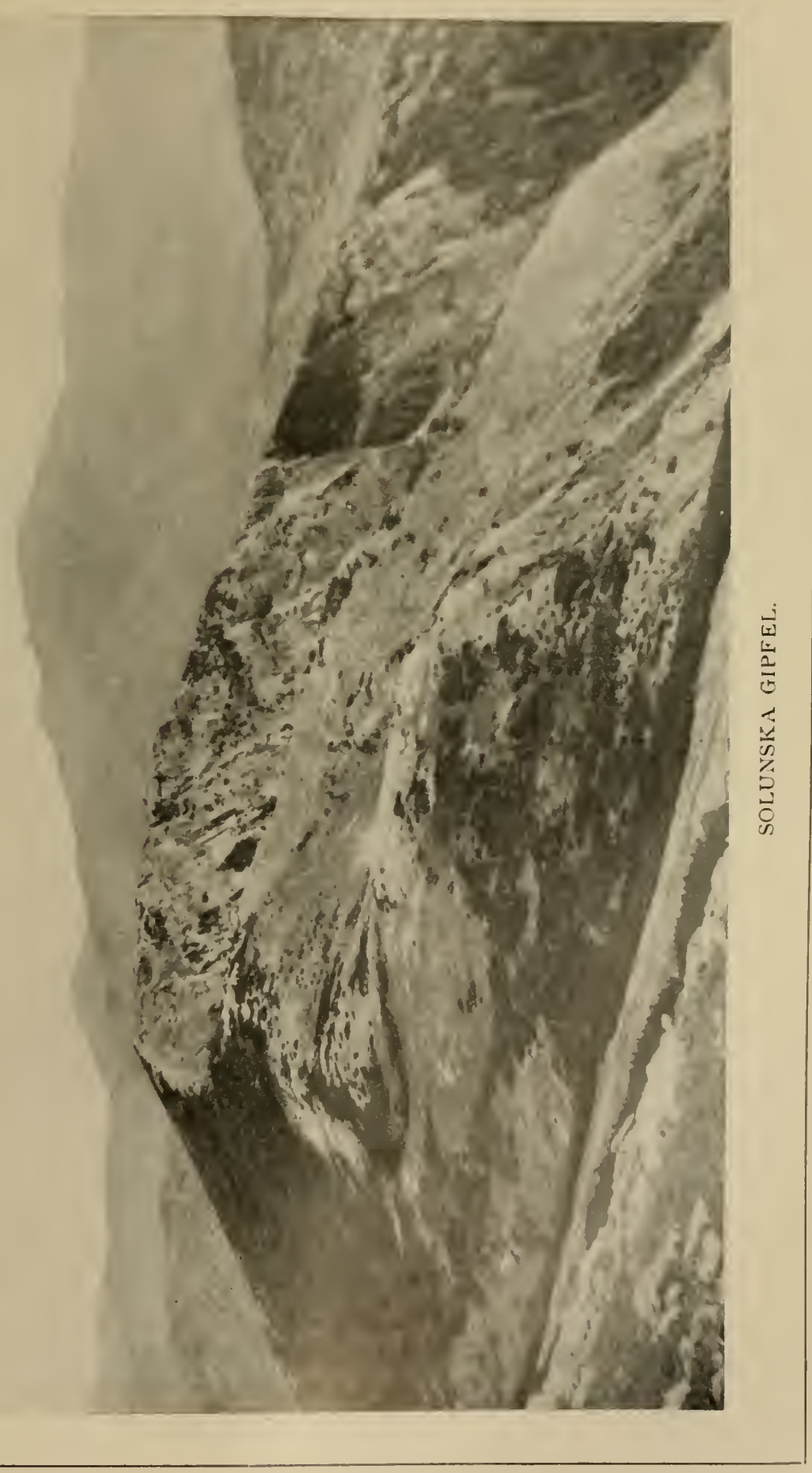



Tümpeln lebte außerdem ein Kopepode Diaptomus tatricus IVierz., bei welchen die Männchen prachtvoll von Carotin rot gefärbt, die Weibchen aber mit Ausnahme der roten Eier farblos waren. Auch diese Art war neu für Mazedonien.

Dem ereignisreichen Tag folgte eine bitterkalte Nacht. Morgens um 5 Uhr maß das Thermometer noch $2^{\circ}$ unter Null. Die Zeltbahnen waren dick bereift. Aber uns Bergwanderer grüßte ein wolkenloser Himmel und machte uns den Entschluß leicht, an diesem Tag die Besteigung der beiden Hochgipfel zu unternehmen. Wir stiegen die tiefe Mulde hinan, welche sich vor Begova und Solunska, wie die beiden Gipfel nach den Aussagen der Einwohner hießen, ausbreitete. Wir hatten Felsblöcke zu überklettern und - wer Latschenwälder der Alpen kennt, wird würdigen, wie schwer es war über die Wurzeln und Äste der sehr stattlichen Legföhren hinwegzuklettern, um durch das Moränenfeld des großen Kars zu gelangen, das sich hier vom Sattel $z$ wischen beiden Gipfeln zu uns erstreckte. Die oberen Mulden des Karhanges waren noch mit ausgedehnten Schneefeldern erfüllt, von denen murmelnde Bäche sich zu kurzem Lauf zwischen den Kalk- und Marmorblöcken des Hanges entwickelten. Beim Aufstieg an die jenseitigen Hänge des Kars verließen wir bald die Latschenzone und kamen in ein fast vegetationsloses felsiges Gebiet. Der Anstieg war an dem kühlen Morgen nicht allzu anstrengend. Die Höhendifferenz von unserem hocligelegenen Lagerplatz bis zu den Gipfeln war ja nicht sehr beträchtlich. Dazu kam, wie in allen von mir besuchten mazedonischen Gebirgen, mochten sie noch so entlegen und einsam sein, das Vorhandensein von Pfaden, die allerdings oft undeutlich waren, selbst verschwanden, um nach einigen hundert Metern wieder erkennbar zu werden. Jetzt war die Gegend ja vollkommen menschenleer; aber im Sommer wurde sie von zahlreichen Hirten mit ihren Herden durchzogen, die alle Pässe überwandern. Auch inögen Schmuggler und Flüchtlinge diese Pfade ausgetreten haben und noch vor kurzer Zeit mochte manche Bande in diesem wüsten Gebirge Zuflucht gesucht und gefunden haben.

Wir stiegen einen Berg hinan, der mit der Begova durch einen offenbar leicht zu überschreitenden Sattel verbunden war. Als wir höher kamen, wurde der Pfad unerkennbar, wir hatten fest zu klettern über steile Hänge und plattige Gesteine. Rückwärts hatten wir einen schönen Blick in das weite Kar mit seinen 
Kalkfelsen und Marmortrümmern, zwischen denen nach unten immer größere Inseln von Vegetation sichtbar wurden, bis an den unteren Hängen der dunkle breite Gürtel des Latschenwaldes sich ausbreitete. Über das Kar hinaus sahen wir die schwarzen Felsengipfel des Pepelak mit ihren Schneebändern und östlich von ihm den grünen Liseč.

An den A bhängen der Solunska gab es mancherlei typisch alpine Pflanzen. So wuchsen an den Felsen polsterbildende Steinbrecharten mit Blattrosetten, welche eine einheitliche wie ein Mosaik aussehende Fläche bildeten. Die Arten sind noch nicht bestimmt(A bb. 202).

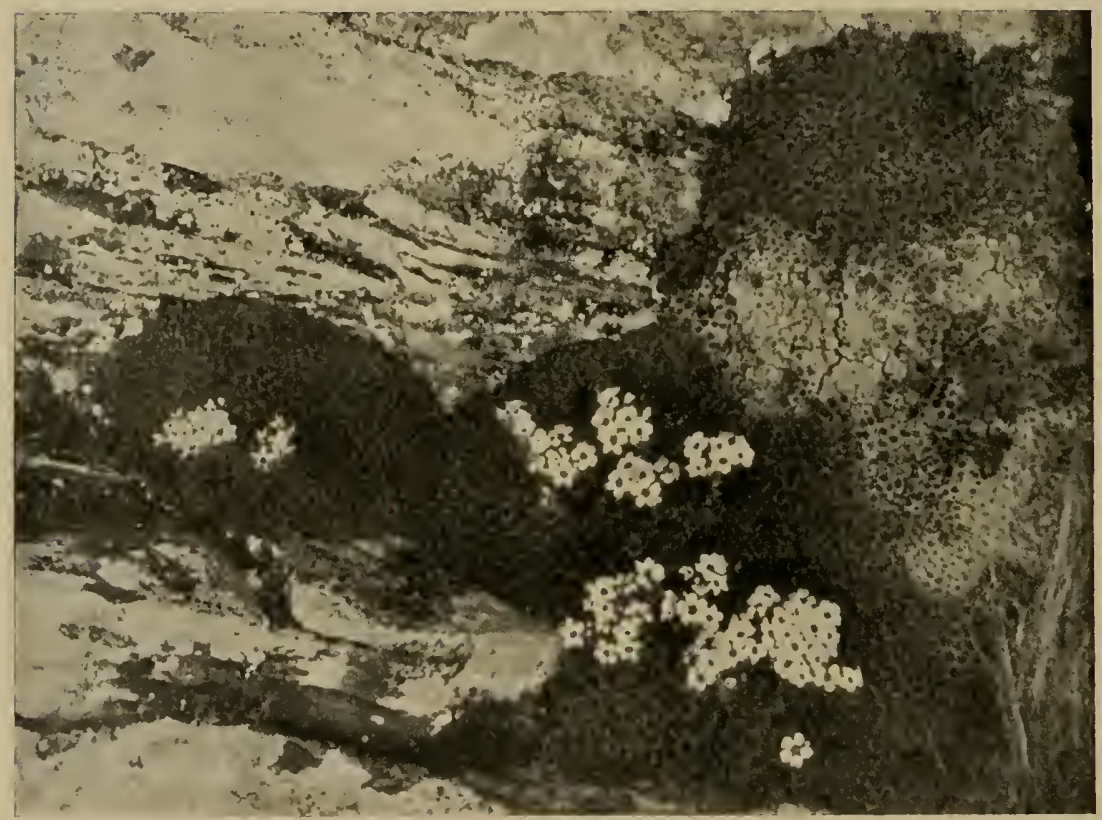

Abb. 202. Saxifraga sp. Polsterbildender Steinbrech.

Auch Gentiana cruciata L. und die gelbe Akelei Aquilegia aurea Janka wuchsen dort.

Am Rande eines Schneefelds wurden einige Schmetterlinge der Gattung Mnemosy'ne aus der Gruppe der Parnassier gefangen. Sie waren offenbar auf dem Flug in die Hochregion begriffen, wie andere Schmetterlinge aus den Gattungen Vanessa und Colias, die mit uns im warmen Sonnenschein gipfelwärts strebten, und die wir dann oben in großen Flügen antrafen. 
Überall mußten wir auf dem Weg kleine und große Dolinen umgehen. Wir stiegen zuletzt auf den Westhang der Gipfelregion über kahle Kalkfelsen hinan an einem tiefen Gesteinsspalt, der in eine von Schnee erfüllte Höhle überging. Hier mußten Alpendohlen ihre Brutstätte haben; denn ein großer Schwarm dieser blauschwarzen Vögel mit ihren roten Schnäbeln und gelben Beinen flog lärmend aus der Felsspalte vor uns auf, vergeblich beschossen von unseren ermüdeten Präparatoren (Pyrrhocorax graculus L.).

Wir erstiegen nacheinander die beiden Gipfel der durch einen steilen Grat getrennten Schwesterberge, der Begova und Solunska. Auf jeder der Spitzen des Doppelkegels weilten wir längere Zeit und bestimmten die Höhe des nördlichen Gipfels (Begova) mit $2420 \mathrm{~m}$, den der südlichen Solunska mit $2530 \mathrm{~m}$.

Auf dem Gipfel der Solunska blieben wir über Mittag im schönen Sonnenschein; und während gemessen und photographiert wurde, konnte ich einen Fernblick von wunderbarer Größe genießen. Von der Solunskaspitze hat man einen Rundblick über das gesamte Mazedonien. Den Horizont im Westen begrenzten der Schardakh mit dem Ljubotren und der Kobeliza, südlich davon der mächtige Kegel des Korab und die blauen Ketten der albanischen Berge. Im Südwesten erkannte man die Kessel, in denen der Ochrida- und Prespasee liegen mußten, daneben den Peristeri. Darüber hinaus lag Dunst auf der Ebene von Saloniki, aus dem noch einzelne Gipfel aufragten.

In der Mitte des Bildes dehnten sich, Kette hinter Kette, die mazedonischen Mittelgebirge wie ein von Wellen bewegtes Meer. Direkt südlich das Berg- und Talgewirre des Babunagebietes, die von Bergen umsäumte Ebene von Prilep; ja an deren Grenzen, die man so ferne wähnte, wenn man der umständlichen Reise dorthin gedachte, erkannte man deutlich die Kette der Granitberge, an deren Hang das Kloster Treskowač und die absteigende Kette bis zum Varosberg, jenseits der Ebene die Berghalde, an der die Stadt Kruse wo liegt.

Mehr gegen Osten verfolgte man, ohne den Fluß selbst zu sehen, den Verlauf des Wardar, das Felsenland von Demirkapu und fern dahinter die Gebirge der Belasiza, der Dudica und Mala Rupa. Seltsam deutlich tauchte im Osten die Ebene um Stip, in ihr diese Stadt selbst auf, die sie umgebenden Felsenberge und die von Veles zu ihr führende Straße. 
Ich genol mit tiefem Empfinden des Glücksgefühls, welches über mich kommt, wenn ich einer schönen, großzügigen Landschaft gegenüberstehe. Wie ein wundervolles Kunstwerk liegt sie vor mir, erfüllt mich und es kann wie ein Rausch über mich kommen. Nun sauge ich sie mit ihrer ganzen Schönheit in mich hinein; sie tritt in mich ein, wird ein Teil meiner Seele.

Dann beginnt es in mir zu schaffen; ich stehe all dieser Schönheit der Welt nicht mehr passiv gegenüber. Ich bemächtige mich ihrer. Ich rahme sie ein, sie wird zum Kunstwerk in mir, mit ihren Schatten und Lichtern, ihren Massen, ihrem Duft, ihren

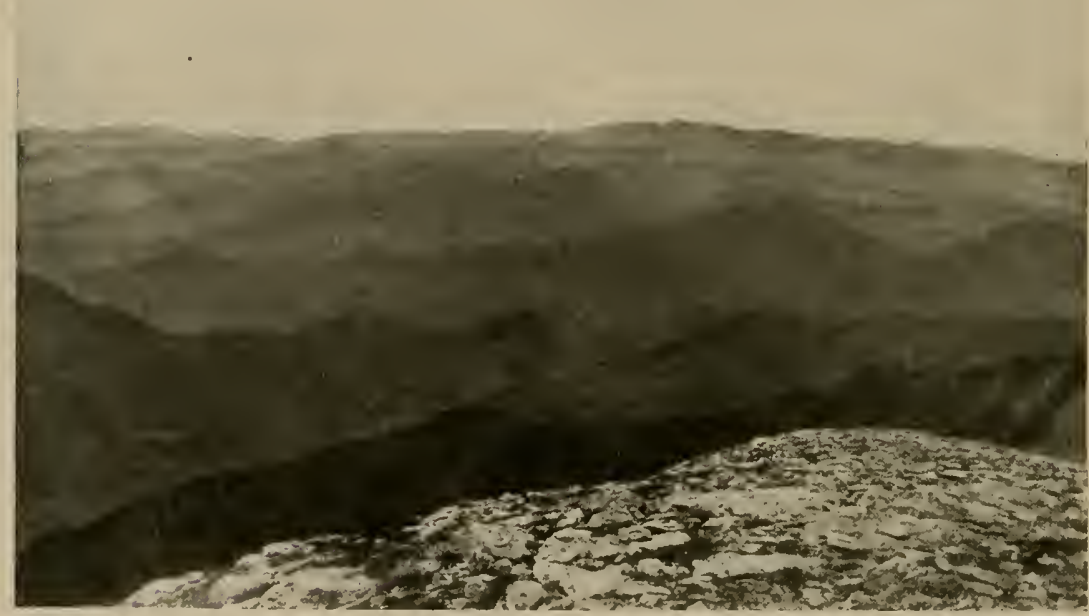

Abb. 203. Gebirgsketten gesehen südwärts vom Solunskagipfel.

Formen und Farben. So nehme ich sie für alle Zeiten in mich auf, sie kann jeden Augenblick in ihren großen Zügen und mit all ihren Einzelheiten vor mein inneres Auge treten, so, wie ich sie in dem Augenblick des starken Eindrucks erschuf. Und so zwingt sie mich, sie wieder neu zu erzeugen, in der in mir geborenen Form, in Worten oder mit dem Pinsel.

Das ganze mir bekannte Mazedonien lag im Glanze des Mittags vor mir, mit seinen Bergen und Tälern, Flußläufen und Ebenen in allen Einzelheiten deutlich durch die Klarheit des 
ersten schönen Tages nach dem Regenwetter. Alle Erinnerungen an die Erlebnisse und an die großen Natureindrücke, die ich in diesem weiten Gebiete genossen hatte, lebten in meiner Seele auf. So wurde ich nicht satt, stundenlang in die Ferne zu schauen und mit wohligen Gefühlen im warmen Sonnenschein zu schwelgen.

Nicht minder reizvoll war die nähere Ungebung, die grellen Steinhalden mit ihren blauen Schlagschatten, die Umrahmung durch die ausgedehnten Latschenbestände und jenseits gegen Veles und das Wardartal die grünen, bewaldeten, schöngeformten Berge, auf denen blaue IVolkenschatten wanderten.

Nach der anderen Seite sah man in eine breite U-förmige Talung, welche im Südwesten von sehr stattlichen Karstbergen begrenzt wurde; diese stellen eine Fortsetzung der vom Pepelak aus beobachteten Karstkette dar.

Bereichert, in froher Stimmung trat ich den Abmarsch durch die Latschenregion an, nachdem am Gipfel noch eine ganze Anzahl von Schmetterlingen und Dipteren erbeutet worden waren, die sich hier ein Stelldichein gegeben hatten, unter anderen Hesperia malvac L. Von Vögeln wurden in der Gipfelregion außer der Alpendohle die Steindrossel (Saxicola mbetra L.) und der Mauerläufer (Tichodroma muraria L.) beobachtet.

Auch in der Latschenregion war das Insektenleben an dem warmen Sonnentag erwacht, so daß der Marsch talwärts zum Lager bis zum Abend sich hinzog. Auf dem Grasboden zwischen den Latschen bildeten Gruppen eines schönen Enzians (Gentiana verna var. aestivalis R.u.Sch.) leuchtend blaue Flecken. Auch sonst war eine reiche Alpenflora hier in der Entwicklung begriffen. An den Felsen klebten die Polster mehrerer Steinbrecharten, von denen eine von dekorativer Schönheit in der Photographie der umstehenden Abbildung festgehalten ist (Abb. 202, S. 406). Es ist eine der typischen polsterbildenden alpinen Arten. Große Begeisterung erregte bei unserm Botaniker der erstmalige Fund der A 1 penbärentraube Arctostaphylos wva ursi Sprg. im mazedonischen Gebirge.

Im Sumpftal und im Latschengebiet wurden interessante Käfer gefangen, darunter ein zierlicher Dorcaclion, silbergrau gefärbt mit schwarzen Flecken, wohl eine neue Art und der Rüsselkäfer Cleonus albicans Schm. Am Sumpf flog der Bläuling Callophry's rubi L., während weiter oben in den Felsen der Spanner Larentia turbata $\mathrm{Hb}$. gefangen wurde. 
Am Nachmittag des nächsten Tages (26. Juni) brachen wir unser Lager in dem schönen, latschenumrahmten Begovatal ab, um noch in einer tieferen Region vor dem Rückmarsch eine Station zu machen. Es ging steil das Abflußtal hinab, in welches früher der Gletscher noch ein Stück hineingereicht hatte. Wir traten nun wieder in das Gneißgebiet ein. Hier bildete sich im Talgrund ein plätschernder Bach, der uns beim steilen Abritt begleitete, dabei sich immer mehr vergrößernd und verstärkend.

Im Anfang des Gneißtales war eine Talmulde reich mit Brennesseln und Disteln bewachsen. Nach den Erfahrungen in den Alpen war dies ein sicheres Anzeichen, daß hier früher einmal eine menschliche Siedelung gewesen sein mußte. Von einer solchen war aber keine Spur mehr zu entdecken, was bei der primitiven Bauart der Sommerwohnungen, welche die Bewohner des Gebirges hierzulande nur für die gute Jahreszeit zu errichten pflegen, nicht verwunderlich war.

In dem steilen Tal mit seinem reichen Pflanzenwuchs flogen viele Insekten. Wir fanden eine schöne große Art des Parnassiers Mnemosyne, von dem wir ja Ausflüglern am Solunskahang begegnet waren. Arten von Argynnis, Erebia (E. medusa F.), Geometriden und Arctien nebst Bienen und Wespen gab es in zahlreichen Formen.

Allmählich verschwanden die Latschen; an ihre Stelle trat Buchengestrüpp, das allmählich höher wurde. Gegen Abend langten wir in flottem Trab auf einem grünen Wiesenhügel an, der an seinem unteren Rand von einem prachtvollen Buchenhochwald abgegrenzt wurde. Unsere Pferde wieherten fröhlich, als sie das frische grüne Gras der Matte sahen; ihnen war es ja oben in den Bergen in der Vorfrühlingszone nicht allzu gut ergangen. Hier war in einer Meereshöhe von $1620 \mathrm{~m}$ ein sehr geeigneter Lagerplatz für uns gefunden. Ein Bach plätscherte in der Nähe und noch dazu wurde eine Almhütte entdeckt mit großen Hürden für Schafherde11, die schon bewohnt war. Das erschien eine gute Gelegenheit unsere Verpflegung zu verbessern. So wurden denn rasch die Pferde abgesattelt, die Zelte aufgeschlagen und die Lagerfeuer angezündet. Man freute sich allgemein auf etwas mehr Behagen und wärmere Nächte, als wir sie in der Hochregion gehabt hatten.

Die Almhütte, eine Mandra, wie man sie hier wie überall, wo Türken regiert haben, benennt, war eine primitive, aber ziemlich 
große Reisighütte, in der eine ganze Anzahl Hirten hausten mit einer großen Schafherde von mehreren hundert Köpfen. Es waren nur Männer und einige Knaben hier oben, Albaner, Türken und Aromunen friedlich beieinander, ein Bild des Völkergemisches Mazedoniens. Der Obersenn, ein Aromune, begrüßte mich sehr freundlich, als ich ihn mit meinem Dolmetscher aufsuchte. Er versprach uns Milch und Käse zu liefern und erzählte manches Interessante. $\mathrm{Er}$ berichtete, daß Rehe und Hirsche im Gebiet vollkommen fehlten, während in den Wäldern Wildschweine nicht seiten seien. In der Hochregion kämen aber Gemsen vor. Ganz sicher scheint mir letzteres nicht, wenn es auch sehr wohl möglich ist. Es ist jedenfalls sehr auffallend, daß wir keine Gemsen bei unseren einsamen Streifzügen in der Hochregion beobachtet haben. Immerhin ist ja möglich, daß sie sehr selten sind, da ihnen jedenfalls von den Albanern, die geschickte Jäger sind, viel nachgestellt wird.

Vor allem sprach er von den Wölfen, die seinen Herden nachstellten, was ich ihm gern glaubte, nachdem ich am Pepelak schon einen prachtvollen alten Wolf erbeutet hatte. Ich ging denn auch nachts auf den Anstand, aber ohne Erfolg. Es war eine helle Mondnacht, in der der Obersenn mich zum angeblichen Wechsel der Wölfe oberhalb des Waldes ins Latschendickicht führte. Ich saß lauernd in den Latschen am Rand einer kleinen Wiese, in deren Mitte er ein Böckchen als Lockmittel angepflockt hatte, während der fast volle Mond rot über dem Berg aufging.

Es war wundervoll am mondüberglänzten Berghang zu sitzen, auf den die dunklen Latschen schwarze Schatten warfen; zwischen ihnen ragten phantastisch geformte riesige Felsblöcke in die Höhe. Ein leichter Wind bewegte die Büsche und trug das Rauschen des Waldes herauf. Ich hörte Grillen zirpen, hier und da die leise Stimme eines Vogels. Aber die Wölfe kamen nicht, ich hörte sie tief unten im Tale heulen, wo die Hunde der Hirten ihnen wütend antworteten. Und als das Böckchen sich auf die Viese zum Schlafen gelegt hatte und keine Lust mehr zeigte, die Wölfe durch sein Blöken anzulocken und auch mein Führer in seinem Busch ein mörderisches Schnarchen anhob, nahm ich an, daß auch er kein großes Zutrauen auf das Erscheinen der Wölfe habe. Ich entschloß mich, lieber nach dem ermüdenden Tag zu meinem Zelt zurückzukehren. Es war ein wundervoller Weg bergab durch den Buchenwald, durch dessen mächtige Stämme 
das Licht des Vollmondes fiel. Ich war aber doch froh, als ich auf der silbern überglänzten Matte zu meinem Zelte gelangte und zwischen 1 und 2 Uhr nachts in einen erquickenden Schlummer fiel.

Die nächsten Tage dienten der Erforschung der Waldregion, welche manches schöne Ergebnis brachte. Von der Mandra führte ein ganz kurzer Pfad durch den Wald aufwärts bis zur W'aldgrenze, die hier hochstämmig an die Matten, die von Latschengruppen bestanden waren, stieß. Den Weg kreuzten viele Waldbäche, von üppiger Pflanzenwelt, vor allem Doldenpflanzen, umrahmt. Der Wald bestand aus hochstämmigen, schönen blanken Buchen. Man hätte glauben können, in einem deutschen Walde zu wandern, hätte er nicht so viele Spuren einer barbarischen Behandlung gezeigt. Es war ein trauriger Eindruck, zu bemerken, wie die Bevölkerung hier so gar kein Verständnis dafür hat, den Wald zu hegen und zu pflegen, der für seine Wohlfahrt so wichtig wäre. Wo hier Wald ist, wird ein planloser Raubbau getrieben, niemals planmäßige Ausnützung. Hier verdankte der alte stattliche Wald sein Leben nur dem Umstand, daßß der Abtransport des Holzes zu beschwerlich und kostspielig ist, sonst wäre er längst verschwunden.

In der Nähe des Pfades war grausam in ihm gehaust worden. Zahlreiche gefällte Stämme faulten unbenutzt am Boden. Ihnen waren nur die Äste abgeschnitten, die zum Feuermachen geeignet waren. Die meisten stattlichen Stämme waren in der Mitte abgehauen, was einen traurigen Eindruck machte.

Für mich war es reizvoller, tief in den unverletzten Wald einzudringen und die Vogelwelt zu beobachten, die sehr reich war und vollkommen an die unseres Buchenwaldes erinnerte. Spechte, vor allem der Mittelspecht und der Liljefordspecht, viele Meisen, am zahlreichsten die Nonnenmeise, Amsel, Misteldrossel, Singdrossel, Rotkehlchen, Baumläufer, Kleiber und Häher belebten die hohen Hallen des schattigen Waldes.

Vor allem reizvoll war die Grenzregion gegen das Latschengebiet, wo zahlreiche rasenbedeckte Blößen sich am Waldrand einfügten. Hier war in etwa $1700 \mathrm{~m}$ Meereshöhe ein außerordentlich reiches Insektenleben.

Auf den Blößen ragten große, seltsam gestaltete Felsblöcke empor, deren einen wir wegen seines pompösen, denkmalähnlichen Aussehens in unseren Gesprächen den Hindenburgfelsen nannten. Vor dem dunklen Hintergrund der Latschen wuchsen auf den Wiesen schneeweise Blattrosetten einer für das Hochgebirge typi- 
schen Königskerze. Es war Verbascum longifolium Ten. Wie zarter weißer Samt sahen die Blätter aus, die sich auch wie solcher anfaßten. Etwas abwärts am Waldrand flogen große Schwärme von Schmetterlingen über den Blumen der Walchwiese. Da war die eigentliche Flugstätte der schönen Mncmosync, die wir in den höheren Regionen nur spärlich angetroffen hatten. Hier gab es schöne Argymmus-Arten, dunkle Geometriden, bunte Bärenspinner, viele Hummeln; solitäre Bienen in großen Massen umschwärmten die Blumen, dazu summten mit ihnen um die Wette Bombyliden und andere große bunte Fliegen. Unter den Steinen fanden sich

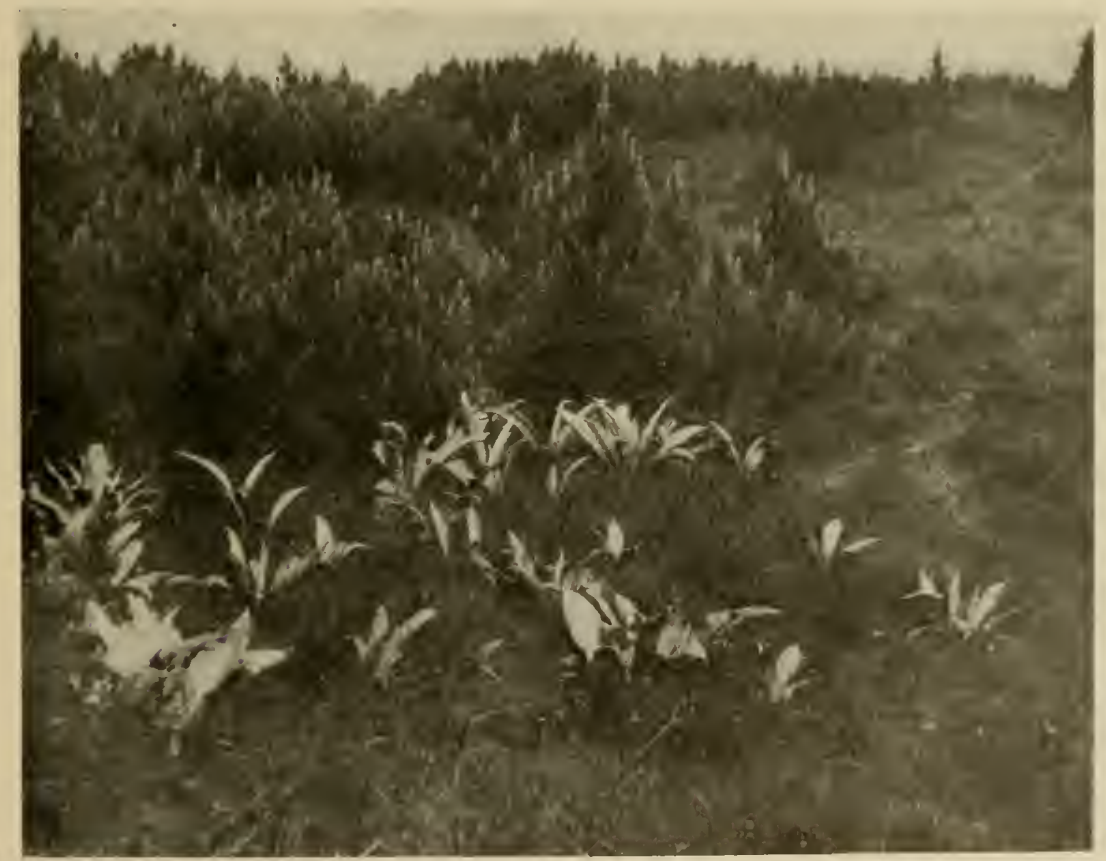

Abb. 204. Wollige Königskerze zwischen Latschen. (Verbascum longifolium Ten. zwischen Pinus montana Mill. subsp. mughus Scop.) Golesniza Planina 1800 m. 2:- Juni 1918.

interessante Käferarten, auf den Felsen liefen Sandlaufkäfer herum. Von den Bienen möchte ich Andrena dubitata Schenck und die neuentdeckte Osmia bulgarica Friese erwähnen. Sehr reichlich waren die Hummeln vertreten, von denen wir allein in dieser Region neun Arten fingen, vor allem Gebirgsformen (vgl. Anmerkungen zu diesem Kapitel). 
Durch die Luft zogen Raubvögel, Sperber, Bussarde, Weihen, Habichte ihre Kreise. Adler fehlten nicht. Ein schöner Kaiseradler ließ sich auf einem dürren Baume nieder, ließ aber leider keinen zum Schuß nahe genug heran.

Durch die verschiedenen Streifzüge der Mitglieder der Expedition wurde die Eigenart der Bergregion in der Meereshöhe von I $500-1800 \mathrm{~m}$ ziemlich eingehend erforscht. Unterhalb der Latschenzone zogen sich hier am Abhang von Begova und Pepelak hochstämmige. Buchenwälder, zum Teil abwechselnd mit Weißtannen hin. Zwischen diesen breiteten sich weite Grasmatten aus. An

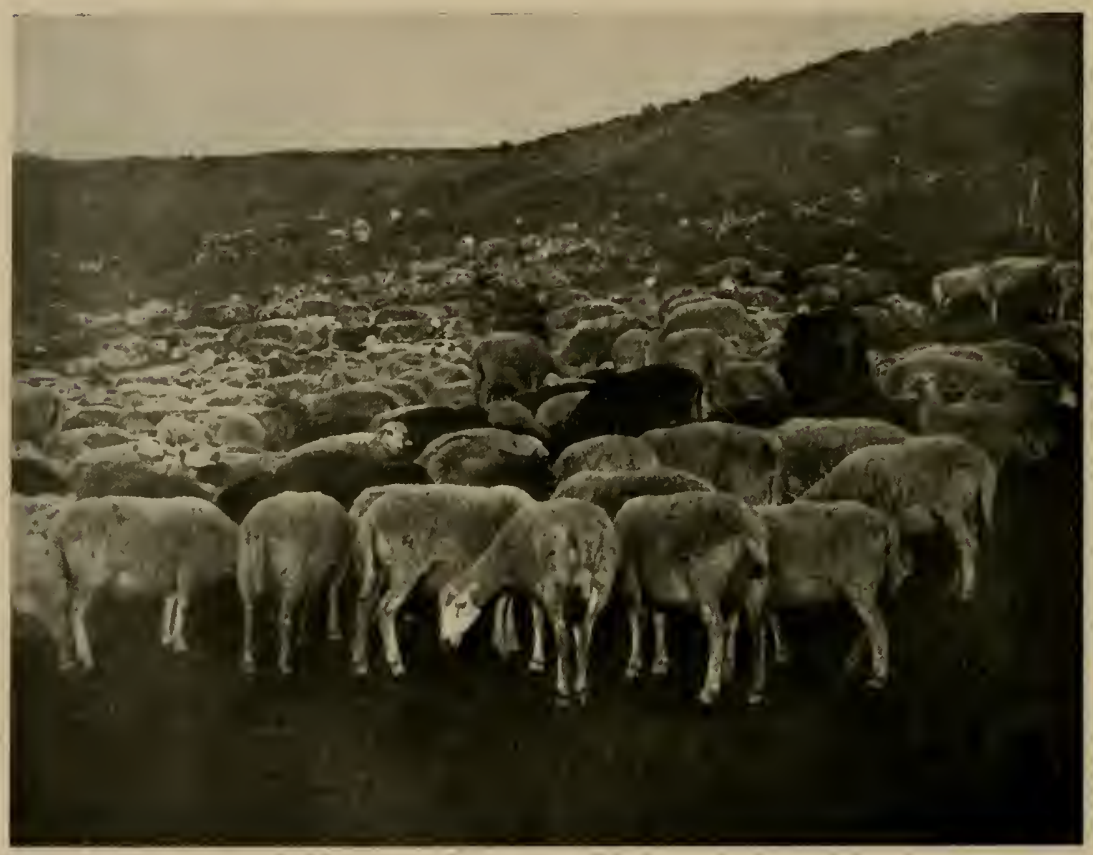

Abb. 205. Schafherde auf Matte unterhalb der Latschenzone.

steilen Talhängen traten oft nackte Gneißfelsen in weiter Ausdehnung auf. Den gleichen Charakter besaßen die anschließenden Berge von gleicher Höhe, so der Liseč und die Bergketten, welche sich zwischen dem Gesamtstock der Golesniza und dem Wardartal in der Gegend von Veles hinzogen.

Die großen Grasflächen dienten als Viehweiden, in dieser Höhe vorwiegend für Schafe, von denen Herden von vielen Hunderten bis Tausenden beobachtet wurden. Die Hirten ver- 
sorgten uns auch reichlich mit Butter, Käse und Milch, was alles von den Schafen stammte. Abends wurden die Schafe zum Melken in die Sennhütten getrieben. Sie wurden in Hürden gejagt, von denen sie einzeln durch einen schmalen Durchgang zu den fünf Melkern gelangten, deren jeder ein Schaf mit grober Hand erfaßte und schief über ein Gestell von Brettern und Latten stellte, dalb es nicht davonlaufen konnte. Dann wurde die wenige Milch, die ein Schaf liefert, mit drei bis sechs energischen Melkzügen am Euter in Holzeimer gespritzt, worauf sofort ein neues Schaf an die Reihe kam. Der ganze Betrieb war auffallend gut organisiert.

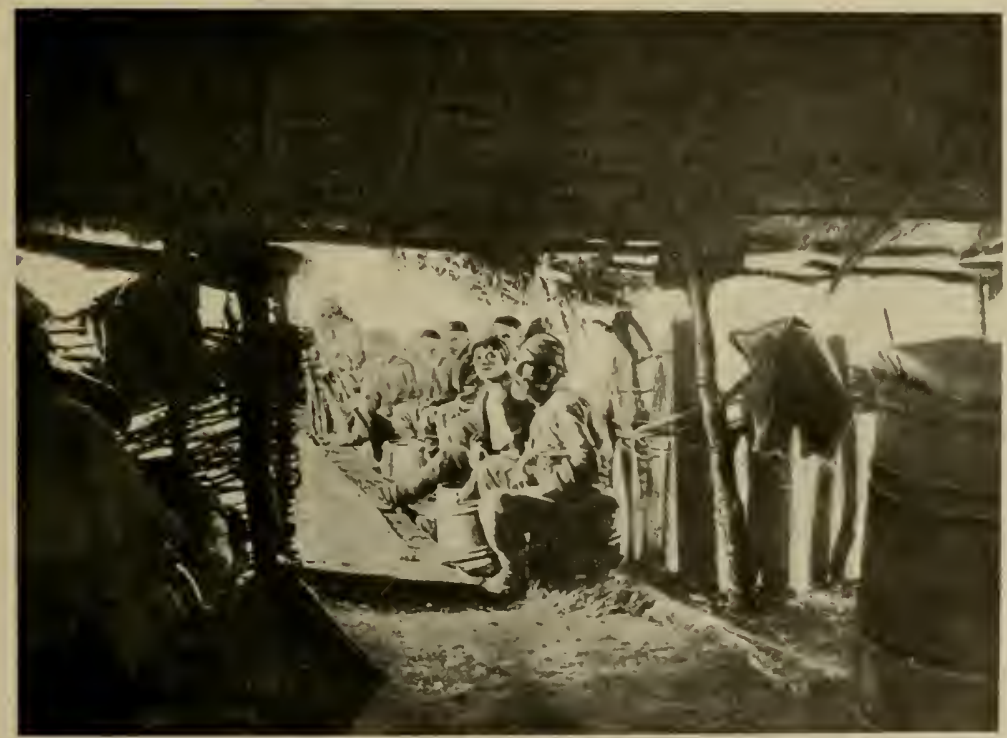

Abb. 206. Die Hirten in der Mandra Sribatschan.

Dr. Grip phot.

Jugendliche Albanerknaben brachten immer rasch frische Schafe heran und nahmen die gemolkenen Tiere weg, die dann stumpf und ruhig, mit gesenkten Köpfen in der Hürde standen, ehe sie wieder auf die Weide gelassen wurden. So vollzog sich die Arbeit auffallend rasch und planmäßig, nicht ohne Geschrei der I.eute und ein wildes Gebelle der vielen großen Hunde, welche zum Hüten der Herden dienten. Es waren schöne große Hunde, vom Typus der Schäferhunde mit zottigem Fell, die hier benutzt wurden. Meist werden sie von ihrem Herrn sehr schlecht behandelt, sind daher bissig, feig und für den einsamen Wanderer nicht 
ungefährlich. An ihren Herrn sollen sie sehr anhänglich sein, sie machen überhaupt den Eindruck einer vorzüglichen Rasse.

In der Mandra dampfte die Milch in großen Töpfen, in denen sie zu dem vorzüglichen Kiselo Mleko, der Sauermilch, dem Yogurth zubereitet wurde. Es wurde auch gebuttert und Käse hergestellt. Die Produkte wurden von hier mit Lasttieren in etwa einem Tagesmarsch nach Veles gebracht.

Der Rückmarsch, nach Abbruch des Lagers, führte uns am Nachmittag des 28. Juni durch Buchenwälder und malerische Schluchten über den Kamm, welcher das Begovamassiv mit

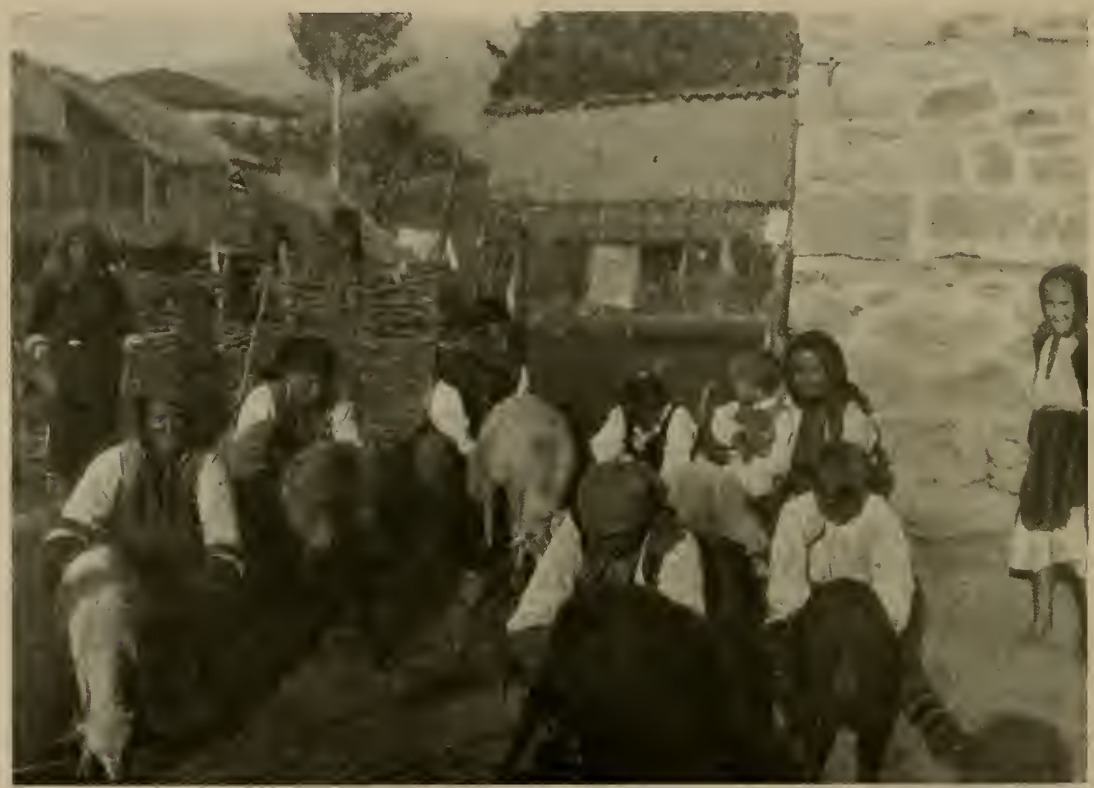

Abb. 207. Bauern in Kiselawoda beim Schafmelken.

dem Lise č verbindet. Unsere Absicht, letzteren noch zu besteigen, mußten wir aufgeben, da wir die Entfernungen unterschätzt hatten. Der Proviant für die Mannschaften ging auf die Neige, ebenso der Hafer für die Pferde. Auch waren am letzten Abend Abgesandte der bulgarischen Opcinabehörden in der Mandra angelangt, welche Einspruch erhoben, daß den Bundesgenossen in der Sennerei deren Produkte verkauft wurden. Da wir unsere wesentlichen Ziele erreicht hatten, beschloß ich auf dem $\mathrm{Pa} \beta$ nach Südosten den $\mathrm{Ab}$ stieg anzutreten und am nächsten Tage Üsküb wieder zu erreichen. 
Im Walde wurden noch zahlreiche Schnecken gesammelt, Nacktschnecken und Clausilien. Die Waldbäche beherbergten auch eine reiche Fauna, vor allem Larven von Trichopteren und Perliden, deren Imagines auch vielfach herumflogen, viel gejagt von der häufigen Lacerta muralis, der Mauereidechse. Im Wasser der Bäche fanden sich zahlreiche Larven des gefleckten Salamanders (Salamandra maculosa), der sich also hier in einer Höhe von $1800 \mathrm{~m}$ fast genau zur selben Zeit fortpflanzt wie in Deutschland. Von den zahlreichen Wasserwanzen seien Velia rivulorum, Limnotrechus lateralis var. costae, Notonecta glauca var. furcata und eine CorixaArt erwähnt. Auch die Alpenplanarie (Planaria alpina) fehlte diesen Bergbächen nicht, wie denn dies Eiszeitrelikt in den mazedonischen Bächen eine regelmäßige Erscheinung ist.

Während wir jenseits des Lisečkammes abstiegen, kamen wir durch malerische Waldgruppen und weite Wiesenflächen. Auf letzteren weideten grolje Viehherden, als wir etwa auf $1000 \mathrm{~m}$ Höhe herabgekommen waren, mehrten sich die Herden von Rindern und Pferden. Trotzdem begegneten wir wenig Menschen und diese waren ausschließlich Türken und Albaner.

Der Charakter der Landschaft änderte sich, je tiefer wir herabritten. Es war ein Gebiet von grolßer eigenartiger Schönheit. Gruppen mächtiger Bäume, zum Teil von riesigen Ausmaßen, wechselten mit Buschwerk und grünen Wiesen. Auf weiten Flächen standen wieder die schlanken Asphodelos (Asphodelus albus Willd. und Asphodelina lutea Reichenb.), die hier jetzt schon am Verblühen waren. Große Bestände von Farnen bedeckten den Waldboden.

Es war geradezu eine Parklandschaft, in der meist alte Buchen, dazwischen Eichen, Eschen und Ulmen in schönen Gruppen dic Ausblicke umrahmten, die wir zunächst auf das verlassene Gebirge genossen. Bald aber öfnete sich vor uns der Blick in das Tal der $\mathrm{K}$ adina R eka. Dies Flülbchen strömte raschen Laufes durch ein enges, auf den Hängen bewaldetes Tal. Der Talgrund war grün von Wiesen und Feldern, zwischen denen vereinzelte, sehr sauber aussehende türkische Bauernhäuser standen. Ein Dorf konnten wir aber in der ganzen Gegend nicht wahrnehmen. Über dem Kadinatal erhoben sich jetzt im Glanz der Nachmittagssonne die vom Wardartal so wohlbekannten stattlichen Gipfel von Kitka und Ostri.

Rasch ritt jetzt die Karawane den Hang hinab zum Ufer der Kadina Reka; am Einfluß eines stattlichen Nebenbaches schlugen wir auf einer üppigen Wiese unser letztes Lager auf. Der Nachmittag

Doflein, Mazedonien. 
wurde noch zu Beobachtungen und Sammlungen ausgiebig ausgenutzt. Das Kadinatal ist eine üppige Gegend, voll interessanter Pflanzen und Tiere, so daß Zoologen und Botaniker noch reichlich Beute machten, während für den Geologen hier weniger zu suchen war.

Wasserstare flogen über das rauschende Wasser der Kadina; die Wiesen am Ufer waren von einer bunten Blütenpracht bedeckt; die Ochsenzunge (Anchusa hybrida Tem.) spielte da eine große Rolle. Die Berghänge waren von Buchenbüschen dicht bestanden, zwischen denen Weißdorn und andere Dornbüsche vorkamen. Am Fluß erhoben sich stattliche Ulmen, Weiden und andere Bäume. Im Grase hüpften zahllose Heuschrecken und über den Wiesenblumen schwangen sich im stolzen Flug Perlmutterfalter, während dunkle Erebien und Bläulinge in Menge auf den Blüten saßen. Als die Zeltbahnen ausgelegt und die Zelte aufgestellt wurden, sammelten sich unter ihnen viele Laufkäfer einer großen, schönen Art. Um die Zelte flogen "Landlibellen“, Vertreter einer buntgefärbten Ameisenlöwenart aus der Gattung Ascalaphus.

Hier brauchten wir nachts im Zelt nicht mehr zu frieren; wir waren bis auf $870 \mathrm{~m}$ herabgestiegen und näherten uns wieder dem Gebiet des Sommers. Unsere Pferde genossen die üppige Weide und meine Mannschaften waren sichtlich froh, daß mit dem Proviant nicht mehr gespart $\mathrm{zu}$ werden brauchte. Mit leichter bepackten Pferden erfolgte am Morgen des 29. Juni der Abmarsch, zunächst die Kadina abwärts, auf dicht umbuschten, etwas halsbrecherischen Pfaden über dem Flul, der wieder durch einen Engpal brach. Ehe die Kadina in scharfem Winkel nach Osten zum Wardar abbog, verließen wir ihr Tal und erklommen auf steilem Pfad einen Paß, der in der bisherigen Richtung des Flußlaufes fast gerade nach Süden über einen Kamm führte, der vom Ostri bis hier herüber reichte.

Es war eine anständige Leistung nicht nur unserer mazedonischen Tragtiere, sondern vor allem unserer deutschen und rumänischen Reitpferde, uns diese steile Paßstraße hinaufzutragen. Im eigentlichen Europa hätte man sein Pferd am Zügel hinaufgeführt. Hier hatten sich unsere deutschen Pferde so an die Erfordernisse der mazedonischen Gebirge gewöhnt, daß sie freiwillig ein flottes Tempo anschlugen und mit sicherem Schritt alle Schwierigkeiten des Pfades, der oft wie eine steile Treppe den Berg hinaufführte, überwanden.

Oben auf dem ganz schmalen $\mathrm{Pa}$ empfing uns eine bulgarische, aus Albanern gebildete Wache, welche den Übergang beaufsichtigte. Wir wurden von der bunten, verlumpten Gesellschaft, 
die einer irregulären Bande angehörte, freundlich aufgenommen und rasteten da oben eine kurze Weile neben den Reisighütten und Lagerfeuern der wilden Kerle.

Dann ritten wir sehr steil einen Hang hinab, der durch ein ziemlich breites Tal an den Hängen des Ostri entlang, unterhalb des Dorfes Paligrad nach Crvenavoda führt. Die Wand des Bergs, an dem wir entlang ritten, fiel steil in ein schon recht trockenes, felsiges Tal ab. Die Pflanzenwelt des Gebirges hatten wir schon verlassen; die Vegetation wurde allmählich wieder mazedonisch; zwischen trockenem, rotgelbem Boden erhoben sich niedrige Büsche. Es eröffneten sich vor uns schöne Ausblicke in die Hügel- und Bergketten der Brazda und Rudina Planina. Vor dem Dorf Crvenavoda (Rotwasser) kamen wir an zwei kreisrunden, flachen Becken vorbei, welche wie Pfannen im lehmigen Boden eingesenkt waren. In der Mitte jeder Pfanne strudelte ein Strom perlenden Wassers hervor. Es waren Mineralquellen, welche offenbar, nach den roten Niederschlägen zu schließen, Eisen und unzweifelhaft Schwefel enthielten. Die Luft ringsumher war von starkem Schwefelduft erfüllt.

Ohne uns lange aufzuhalten, setzten wir unseren Ritt steil bergab fort und stiegen nun bald in das Gebiet des altbekannten Markovatales ab. Nun wurde es allmählich wieder gehörig warm der Himmel war wolkenlos und die mazedonische Sonne brannte unbarmherzig auf uns herab. Die warmen Hüllen, Decken und Mäntel, die oben in den Bergen so notwendig gewesen waren, hatten wir längst auf den Tragtieren verladen.

Vor uns dehnte sich die breite Mulde des unteren Markovatales aus, das wir jetzt von seiner Nordseite ganz im Unterlauf des Baches, nahe seiner Mündung in den Wardar durchqueren wollten. Wieder hatten wir die vom Wasser zerrissene und modellierte Landschaft eines mazedonischen Flußtales vor uns. Von allen Seiten sah man tiefe, steile Schluchten die Berge und Hügel hinab dem Bach zustreben, dem durch sie alle Gewässer des Gebietes zugeführt wurden. Mehr und mehr machte sich die Trockenheit des Gebietes auf den Hügelpfaden und auf den Halden, die wir hinabritten, geltend. Die Pflanzenwelt wurde immer geringer; die Kulturpflanzen der Äcker, die Hecken überwogen. Menschen und Pferde wurden durstig und begannen sich nach Wasser und Schatten zu sehnen.

So strebten wir an dem türkischen Ort Kolicane rorbei einem in einem Ulmenhain gelegenen malerischen türkischen Fried- 
hof $z u$, in welchem der Schatten der Bäume uns anlockte. Aber leider gab es dort in der ganzen Gegend kein Wasser.

So ritten wir denn lieber nach Kolicane zurück, einem am Bergabhang malerisch gelegenen Städtchen, an dessen Rand sich auch ein Ulmenhain mit Resten eines alten Friedhofes befand. Dort fanden wir, wie vorauszusehen, Wasser für die Pferde und schönen Schatten. Hier hielten wir Mittagsrast und kochten ab, umringt von den türkischen Einwohnern des Ortes, deren Knaben uns bereitwilligst Wasser heranschleppten.

Trotz aller Müdigkeit wurde auch hier noch beobachtet und gesammelt. Im Hain standen zahlreiche fast meterhohe Büsche von zwei gelbblühenden Korbblütlern, Alantarten, nämlich Inula hirta L. und I. salicina L. Unser Botaniker, Prof. Bornmüller, prophezeite, daß da auch der Bastart zwischen beiden wachsen müsse; und richtig, kaum 5 Minuten suchte er, so hatte er ihn in zahlreichen Exemplaren gefunden.

Nachmittags ritten wir über einen Höhenrücken in die weite Mündungsebene des Markovabaches, dann am Wardar entlang auf guter Landstraße auf Üsküb zu. Wieder ragte vor uns der Wodno mit seinen im Abendschein scharf hervorstechenden Rinnen und Kanten auf. Wir überblickten den Weg, den wir vor Io Tagen bergwärts zurückgelegt hatten.

Auf der Straße mußten wir einen schlanken Trab anschlagen, denn ein nahendes Gewitter zog am Berg entlang. Der Wind wirbelte bereits ungeheure Staub- und Sandwolken auf. Kurz vor der Stadt Üsküb faßte uns noch das Gewitter und so ritten wir in strömendem Regen in guter Ordnung in die Stadt ein. Am Abmarschplatz löste sich die Karawane auf. Ich führte noch die Pferde und Mannschaften über die Wardarbrücke durch die ganze Stadt zum Zitadellenberg, wo Pferde und Leute im Heerespferdedepot vollzählig und wohlbehalten wieder abgeliefert wurden.

Dann rückte ich persönlich mit meinem braven Burschen in mein nahegelegenes Quartier bei den bulgarischen Freunden wieder ein, müde und hungrig nach den anstrengenden Tagen.

Nach einem erfrischenden heißen Bad saß ich abends behaglich bei meinen Freunden und erzählte befriedigt von den wundervollen Natureindrücken und den interessanten wissenschaftlichen Beobachtungen, welche dieses schöne Stück Mazedoniens mir beschert hatte. 


\section{STIP UND DAS OVČE POLJE}

I

Mazedonien gibt es auch echte Steppe, und zwar Grassteppe. Nie allerdings erreicht sie eine sehr große Ausdehnung und immer wieder schwanken ihre Grenzen, indem das Kulturland bald in ihr Gebiet vordringt, bald vor ihr zurückweicht. Glich im heißen Spätsommer 1917 schon ein großer Teil Südmazedoniens einer Steppe, so war das mit der Hochebene bei $\mathrm{Stip}$ in noch viel höherem Grade der Fall. Ich habe sie nur flüchtig kennen gelernt, doch will ich ihrer Eigenart eine kurze Darstellung widmen.

Von Veles steigt eine prächtige Landstraße am linken Wardarufer in einigen eleganten Kurven auf die Hochebene hinauf, um auf ihr fast eben zu verlaufen. Sie führt in einem flachen Bogen direkt ostwärts nach der Stadt Stip und von da über Radovista und Strumiza weiter. Sie wurde noch in türkischer Zeit von französischen Ingenieuren ganz vorzüglich gebaut.

Ist man den Talhang des Wardar hinauf gelangt, so dehnt sich weit nach Osten vor einem die Hochebene und verschwimmt in der Ferne in blauem Dunst. Sie ist in der Hauptsache flach und am 30. August war sie von graugelbem dürrem Gras bedeckt. In der Ferne erhoben sich einzelne steilumrissene Bergblöcke, Granitlakkolithe $\mathrm{zu}$ einer Höhe von etwa $450 \mathrm{~m}$ und damit etwa $250 \mathrm{~m}$ über der Hochfläche. Ein solcher Felsenberg oder vielmehr eine Gruppe von solchen bildet das Skelett der Stadt Stip.

Stip, auch Istib genannt, eine malerische Stadt, an der Bregalniza gelegen, ist die Hauptstadt des Gebietes, welches Ovče Polje, das Schafsfeld, genannt wird. Die Bregalniza kommt von Nordosten und strömt noch etwa 6 Kilometer über Stip in dieser Richtung weiter; dann biegt sie nach Einmündung der Lakaviza in rechtem Winkel nach Nordwesten ab, um nach I 2 Kilometern eine ebenso energische, rechtwinkelige Umbiegung in ihrer früheren Richtung zu machen, um ihrer Mündung in den Wardar, kaum 6 Kilometer oberhalb Gradsko, zuzustreben. Im Oberlauf durchströmt die Bregalniza ein weites Sumpfgebiet bei Koschana, welches durch seine Reisfelder berühmt ist. 
Es war Steppe mit ihrer ganzen Öde und ihrem ganzen Reiz, die ich hier durchfuhr. Im Anfang kamen wir noch durch abgeerntete Getreidefelder, Weinberge, Melonenfelder und weite Grasflächen, zwischen denen wesentlich von Türken bewohnte, ärmliche, halbzerstörte Dörfer lagen. Hier hatten die Balkankriege gehaust. An der Straße lag ein großes bulgarisches Militärmagazin, in dem ein gut Teil der Ernte des Gebietes zusammengeschleppt war. Wichtig war dies Stück Steppe offenbar den verbündeten Heeren für die Beschaffung von Heu. Wie Kirchen oder Paläste groß und hoch erhoben sich Haufen von Stroh und Heu in der Ebene, die oft $100 \mathrm{~m}$ lang und $20-30 \mathrm{~m}$ breit sein mochten. Lange Züge von heu- und strohbeladenen Wagen, bespannt mit Ochsen oder Büffeln, begegneten uns auf der Straße auf ihrer Fahrt nach dem Wardartal.

Auf der Fahrt fielen mir Anzeichen des Aufschwunges, des Unternehmungsgeistes im Land auf. Einige türkische Landbesitzer hatten, was hier in der weiten Ebene sicher rationell war, Dampfpflüge und andere landwirtschaftliche Maschinen genossenschaftlich angeschafft und einen Großbetrieb eröffnet, der offenbar schon seine Früchte getragen hatte.

Hier war alles auf grolue Maßstäbe angelegt. Das galt auch von der sehr charakteristischen Tierwelt, die hier $z u$ beobachten war. Sie war hauptsächlich durch Heuschrecken vertreten, welche zu vielen Tausenden im Gras hüpften und fraßen und deren Zirpen die Luft mit einem mächtigen Gebrause erfüllte. Es waren viele Arten von allen möglichen Färbungen und Größen. Die einen gelb, die anderen grün; hellbraune, rotbraune, dunkelbraune bis schwarze gab es, andere waren grau, wieder andere zeigten Flecken verschiedener Farben. Manche schwirrten mit geräuschvollem Flug in die Höhe und entfalteten dabei rote, blaue, gelbe, schwarzgefleckte Hinterflügel. Andere krochen still und geräuschlos am Boden zwischen den Gräsern dahin.

Unter ihnen spielte eine kleine, gelbe Form von Gespensterheuschrecken (Ameles decolor Charp.) eine große Rolle; sie fingen Bläulinge und andere kleine Schmetterlinge. Die großen Arten der Heuschrecken hielten sich vorwiegend an die Pflanzen. Da gab es bis zu $10 \mathrm{~cm}$ lange, den Wanderheuschrecken ähnliche Formen. Ganz seltsam in der Gestalt waren die Saga-Arten, welche bald grün, bald gelbbraun gefärbt waren.

Daß Käfer, Tausendfüßler, Skorpione nicht fehlten, braucht kaum hervorgehoben zu werden. Dazu kamen eigenartige Spinnen, 
von denen, der Insektenmenge entsprechend, einzelne Arten in sehr viel Individuen auftraten.

So war die Silberspinne (Argiope lobata Pallas) und ihre schwarzgelb gefärbte nahe Verwandte (A. brunichii Scop.) hier sehr häufig. Hier war schon das Nahen des Herbstes zu bemerken; denn die Weibchen waren eifrig beim Verfertigen von Eikokons, die schneeweiße Gewölbe darstellten, die mit Zipfeln am Gras und an Steinen angeklebt wurden. Auch andere Spinnen waren bei dieser Tätigkeit, so die eigenartige Lathrodectus tredecimguttatus (Rossi), welche ihre kugeligen, fein gebauten Kokons meist unter Steinen unterbringt; hier hatten eine ganze Anzahl Weibchen sich einen gebleichten Pferdeschädel als geeigneten Schlupfwinkel ausgesucht, dessen Hirnhöhle 20-3o der zarten Kugeln enthielt.

Aufregung brachte den beiden mich begleitenden Jägern, dem unverwüstlichen Hauptmann Jungmann und seinem treuen Begleiter Leutnant Slevogt ein großer Flug Zwerg-

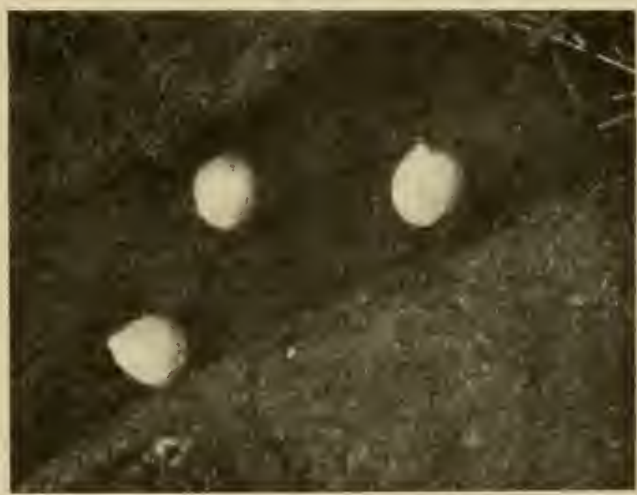

Abb. 208. Kokons der Spinne Lathrodectus tredecinguttatus (Rossi). Verkl. $2 / 3$ trappen, der einige hundert Meter von uns einfiel. Das ist ein Charaktervogel dieses steppenähnlichen Gebietes. Ich fand die Zwergtrappe (Otis tetrax oricntalis Hartl.) in Mazedonien stets, wenn ich auf weite Ebenen kam, so in den Gerstenfeldern bei Krivolac, im Ackerland oberhalb Üsküb.

Es war ein reizvoller Anblick, die großen Vögel auffliegen zu sehen, wobei jedesmal die helle Unterseite und die weißen Armschwingen aufblitzten. Wenn sie sich niederließen und gravitätisch durch das Gras wateten, erkannte man beim Männchen den schwarzen Hals mit der Krause, die zwei dunkeln Querbinden auf dem Schwanz. Es war jedesmal eine aufregende Jagd, an die vorsichtigen, schnellen Vögel heranzukommen, die geduckt am Boden liefen, um plötzlich auffliegend einen halben Kilometer weiter sich niederzusetzen, um den Jäger von neuem zu foppen und zu ermüden. Wir konnten ihre Verfolgung unseren trefflichen 
Jägern überlassen und uns den kleineren Tieren widmen, die uns genug Arbeit gaben.

Da gab es, auch typisch für die Steppenlandschaft, eine ganze Anzahl von Lerchenarten. Am Boden liefen zahlreich die Kalanderlerchen (Melanocorypha calandra calandra L.), die auffallend großen, aufrechten Tiere mit der lauten Stimme. Haubenlerchen belebten den Steppenboden (Galerida cristata meridionalis Brehm). Für alle diese Lerchen war hier in der Steppe Ende August der Tisch reich gedeckt. Nicht nur trugen die meisten Pflanzen Samen, kaum irgendwo sah man noch eine Blüte, auch der Insektenreichtum kam ihnen zugute.

Viele von ihnen gleichen auch dem Steppenboden in Farbe und Zeichnung so ausgezeichnet, daß sie durch Ducken dem scharfen Blick der sie verfolgenden Raubvögel entgehen. Das gilt vor allem von der Kurzzehenlerche, die auch auf der Hochebene sich fand (Calandrella brachydactyla moreatica Mühlb.), eine charakteristische südliche Form. Eine vierte Lerchenart schließlich war besonders häufig, die südöstliche, in Asien weitverbreitete Form der Feldlerche (Alauda arvensis cantarella Bp.).

Daß der Wiedehopf (Upupa epops epops L.) hier nicht fehlte, braucht kaum erwähnt zu werden. Wie possierlich sah er aus, als er auf dem Pferdeschädel saß, seinen Schopf sträubte und sich nach allen Seiten umschaute. Ähnlich reizvoll war die besonders in der Nähe der Stadt Stip häufige türkische Turteltaube (Streptopelia decaocto decaocto Friv.), die überall, wo Türken leben oder einmal lebten, sich festgesetzt hat und mit ihrem Ruf, ihrer schönen Färbung und ihren zierlichen Bewegungen die Landschaft anmutig belebt.

Die häufigsten und auffälligsten Vögel auf der Hochebene von Stip waren aber die Falken. Sie waren in dieser letzten Augustwoche zu Tausenden hier versammelt. Und es war nicht etwa die Vorbereitung zum Herbstzug ins Winterquartier, die sie hier zusammengeführt hatte, es war die reiche Weide, die sie auf die Steppe gelockt hatte.

Schon während der Fahrt im Auto die Landstraße entlang, war die Menge der Falken äußerst auffallend gewesen, die auf den Telegraphendrähten, je 6 bis 10 zwischen zwei Stangen saßen. Ungestört durch Lärm und Staubwolke bespähten sie von ihrem erhöhten Sitze aus den Steppenboden und tauchten alle paar Minuten auf ihn herab. Es waren vor allem zwei Arten, die sich hier ver- 
sammelt hatten, der Turmfalke (Falco timunculus timunculus I.) und der Rötelfalke ( $F$. naumanmi naumanni Fleisch.). Beide sind Insektenfresser und nähren sich mit Vorliebe von Heuschrecken. Jetzt im Herbst gab es für sie unerschöpflich viel zu fressen. Sie sammelten sich, wo es viele Heuschrecken gab; und diese waren ja jetzt alle ausgewachsen, große stattliche Ticre, eine fette Nahrung.

Alle Falken, welche in Kaluckova zu Blutuntersuchungen auf ihre den Malariaparasiten verwandten Blutschmarotzer geschossen worden waren, hatten den Magen voll Heuschrecken. Und gar hier auf der Steppe, da brauchten sie nicht zu hungern. Sie konnten dick und feist in den grimmen Winter hineingehen.

In dieser Spätsommer- und Herbstzeit konnte ich bei diesen Falken und anderen Vögeln wiederholt eine interessante Beobachtung machen. In der Zeit der Dürre kam es durch Unvorsichtigkeit oder Absicht nicht selten zu Bränden auf der Steppe und in den Buschwäldern der dürren Hügel. Dann fraß die Flamme knisternd von Busch zu Busch, eilte schnell über die begrasten Zwischenräume und weilte länger bei den Buschgruppen. So zog sie über einen Abhang, eine Fläche, eine Hügelreihe hin.

Und vor der Flammenzone, vor dem Rauchschwaden, sah man dichte Flüge von Vögeln, vor allem aus unsern zwei Falkenarten zusammengesetzt, sich versammeln. Sie flohen nicht etwa vor dem Feuer, sie hielten sich eher in seinem Bereich, oder es war vielmehr ein Gürtel in etwa $10 \mathrm{~m}$ Abstand und immer vor diesem, in dem sie sich zusammendrängten. Da saßen sie auf den höheren Büschen, flatterten und schwebten in geringer Höhe in der Luft und tauchten immer wieder zum Boden nieder.

Mehrfach eilte ich auf einen solchen Rand eines Brandes los, um mich zu überzeugen, was denn die Falken dort hinzog. Und was ich vermutete, bestätigte sich. Vor dem Brand rissen die Insekten aus, vor allem die flinken Heuschrecken, aber auch die anderen, welche sich auf dem Boden bewegten. Ein breites Band von Käfern, Wanzen, Tausendfüßlern wanderte vor dem Feuer her. Was leicht beschwingt war, die Schmetterlinge, die Bienen, die Fliegen hatten sich lange vorher davongemacht. Aber die laufenden und hüpfenden Insekten und mit ihnen Mäuse, Eidechsen, Frösche, Schildkröten und alles derartige Getier lief vor dem Feuer davon und damit in den gierigen Rachen von allerhand Räubern, die sich die Gelegenheit zu Nutze machten. Allerdings 
habe ich nur bei den beiden Falkenarten direkt beobachtet, daß sie zum Teil von weither auf die Rauchsäulen losflogen, offenbar weil die Erfahrung sie gelehrt hatte, daß in dieser Jahreszeit im Zusammenhang mit solchen reiche Beute auf sie wartete.

Stundenlang hatte die Beobachtung und Jagd mich und meine Begleiter auf der Hochebene aufgehalten, so daß es schon Nachmittag war, als wir abwärts zur Bregalniza, in die Stadt Stip fuhren, um dort eine Mittagspause zu machen. Die Stadt liegt ziemlich ausgedehnt auf einer Anzahl von Hügeln, über denen dunkle Granitfelsen sich erheben. So gewährt sie einen malerischen

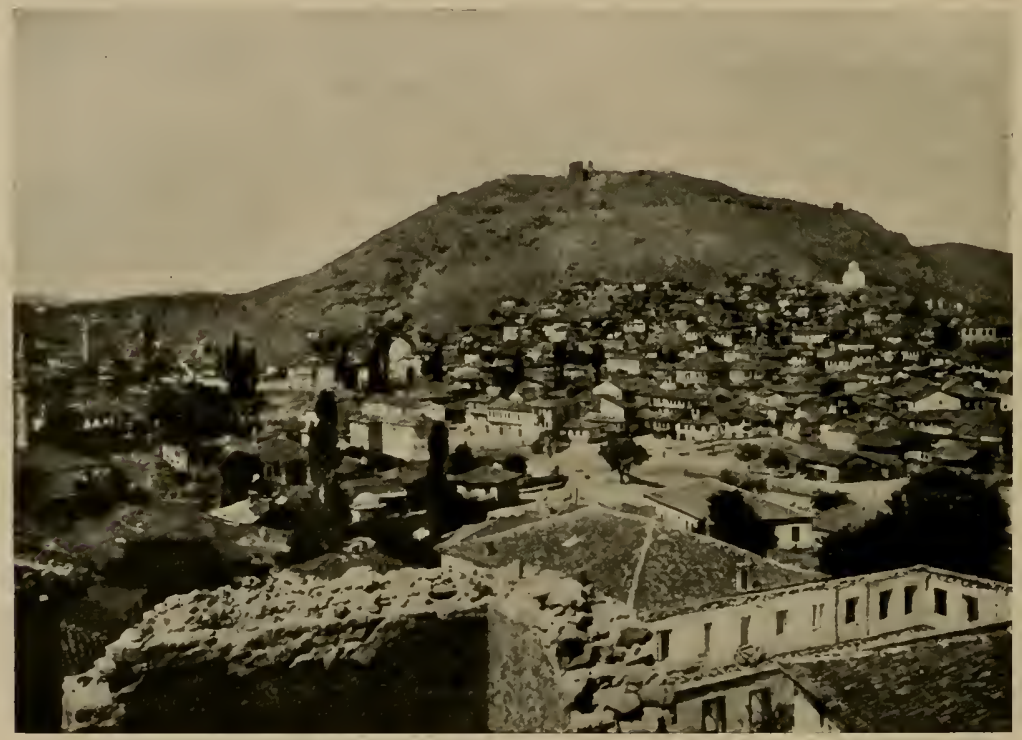

Abb. 209. Ansicht von Stadt und Burg Stip vom Moscheehügel.

Anblick. Zudem ragen auf dem einen der Granitfelsen Ruinen einer alten Türkenburg in die Höhe.

Es ist wie Veles eine richtige Türkenstadt mit Moscheekuppeln und Minarets; die Häuser klettern wie dort die steilen Hügel hinauf, sind aus Steinen gebaut und mit roten Hohlziegeln gedeckt. So entsteht das gleiche bunte, malerische Bild wie in Veles, nur daß hier der dunkle Felsen einen andersartigen, weniger harmonischen Hintergrund bildet als das graue Gestein von Veles. Wir fahren durch enge Gassen über einen Marktplatz; Läden und Werkstätten verraten lebhafte Tätigkeit in der Hauptstadt einer wohlhabenden Provinz. Wir gelangen an eine stattliche, breite Brücke, welche 
über die Bregalniza führt, deren Bett, breit durch die Häuser der Stadt führend, ausgemauert ist. Aber welch eigentümlicher Anblick; das breite Flußbett, dessen steile Mauern, von denen Treppen hinabführen, verraten, daß der Fluß im Winter und Frühling viel Wasser führen muß, lag jetzt ganz trocken, so daß ich trocknen Fußes, durch Sand watend, hindurch gehen konnte.

Im Schatten einiger Bäume jenseits der Brücke ließen wir unseren Wagen unter Aufsicht des Fahrers stehen und stiegen selbst einen steilen Weg bergan zu einer Moschee mit leuchtend grüner kupfergedeckter Kuppel, deren säulengetragene Vorhalle uns als Rastplatz lockte. Und es lohnte wohl dort eine Nachmittagsstunde zu verbringen. Ringsum lagen zwar Ruinen und selbst das Minaret war zur Hälfte zerstört. Hier hatte sich im Balkankrieg der Türkenhaß Luft gemacht.

Die Moschee war aber immerhin noch erhalten; sie war aus Steinen massiv erbaut, außen mit Platten bedeckt. Solche, abwechselna

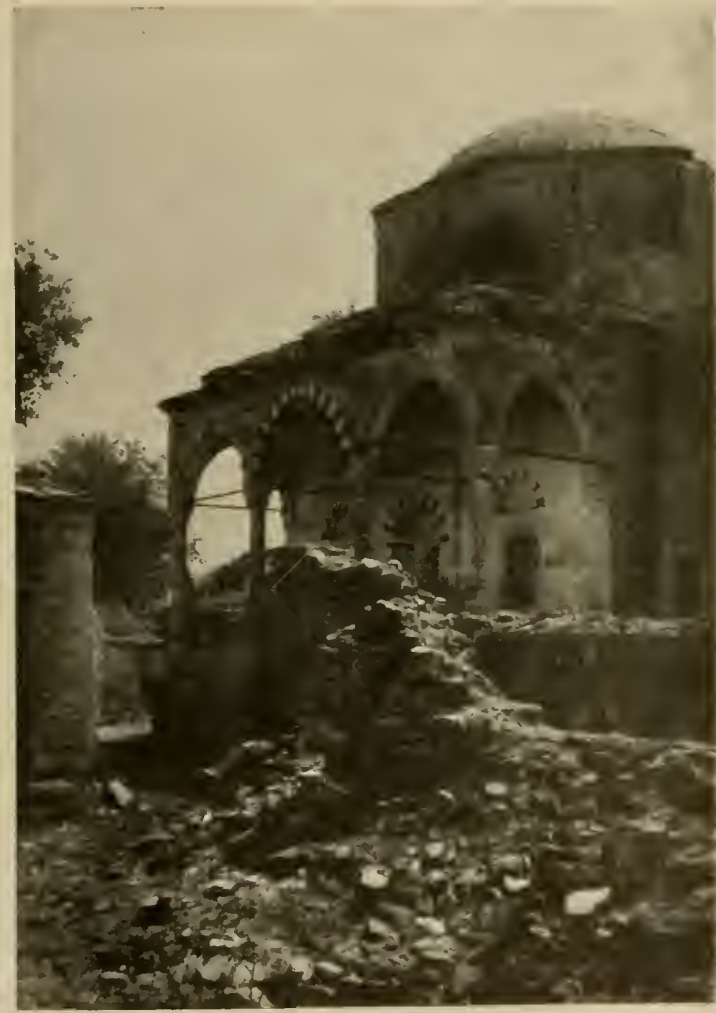

Abb. 210. Moschee in Stip. schwarz und weiß, umgeben die Bogen der Vorhalle und die drei Türen, welche ins Innere führten. Der hochgewölbte Raum war mit Ziegeln gepflastert. Verwüstung herrschte auch hier und Trümmer lagen umher. So war es anziehender in der Vorhalle sich niederzulassen, die von schlanken Marmorsäulen mit schön ausgearbeiteten Kapitellen getragen war. Die Säulen machten den Eindruck, als stammten sie 
von einem antiken Bau. Ihre Basen waren mit Kupfer beschlagen. Hier wie an der Kuppel hatte sich zum Glück noch kein beschlagnahmender Beamter betätigt.

Von der Ecke der Vorhalle hatten wir einen sehr schönen interessanten Überblick über die Stadt, deren weiße Häuser teils in der Fläche zwischen den Hügeln sich ausdehnten, teils an den Felsen emporkletterten. Zwischen den dunkelroten Dächern erhoben sich zahlreiche weiße Minarets und mit ihnen an Schlankheit wetteifernd dunkle Pappeln; aus Gärten ragten viele Obstbäume hervor, die zum Teil voll Äpfel hingen. Zwischen den Felshügeln eröffnete sich ein weiter Blick über die dunstige Ebene und auf ferne Berge. Kapellen leuchteten weiß von den Hügeln und eine große stattliche Kirche ragte aus den gleichmäßigen Straßen der unteren Stadt empor.

Gerade vor uns begrenzte eine ziegelgedeckte Mauer einen schattigen Garten. Während wir, behaglich auf den Treppen der Moschee sitzend, unser mitgebrachtes Mittagsmahl verzehrten, öffnete sich das Pförtchen und eine Anzahl von Kindern trat hervor und begann vertraulich sich uns zu nähern. Es waren Mädchen und Knaben von 3-I 2 Jahren. Da einer von uns einige türkische Worte konnte, entspann sich eine Unterhaltung, die sich im wesentlichen darauf beschränkte, daß sie uns ihre Namen nannten; Fatme, Hassan, Achmed, Osman und die kleine Bülü vertrieben uns unter Plaudern und Scherzen die Zeit. Als wir uns aber nach dem Essen die Zigaretten anzündeten, fing ein heftiges Betteln an, dem der Hauptmann schließlich nachgab.

Alle diese Kinder, auch der fünfjährige Hassan, zündeten sich ihre Zigaretten regelrecht an und rauchten mit Behagen. Traurig saß zunächst die kleine dreijährige Bülü daneben und verzog die Augen zum Weinen. Als der Hauptmann ihr auch eine Zigarette von fern hinhielt, patschte sie bittend in die Hände und strahlte mit dem ganzen Gesicht, als sie sie wirklich bekam. Dann zündete sie sie an Achmeds Zigarette kunstgerecht an, zog den Rauch tief ein, schluckte ihn hinunter und blies ihn durch die Nase wieder heraus. All das geschah so gewandt, mit so graziösen, fast koketten Handbewegungen, ohne Husten und Verschlucken. Als wir uns freundschaftlich von unserer netten Tischgesellschaft verabschiedeten, zweifelten wir nicht daran, daß die gewandte Raucherin, die graziöse Bülü, trotz ihres Rotznäschens einmal der Stern eines Harems werden würde. 
Ein Rundgang zeigte uns dann noch die wesentlichen Teile der Stadt. Trotz der Hitze war es nicht unangenehm in den engen Straßen zu bummeln, in welche die weit vorgebauten Häuser tiefen Schatten warfen. Es waren malerische Durchblicke, an den vorragenden Dächern und Balkonen mit Schnitzerei und Fachwerk vorbei, auf die steilen Felshänge der Granithügel, über denen ein wolkenloser Himmel blaute.

Es gab viele Obstläden, in denen es Äpfel, Birnen, Zwetschen und frische Nüsse und Haselnüsse zu kaufen gab. Auch Trauben

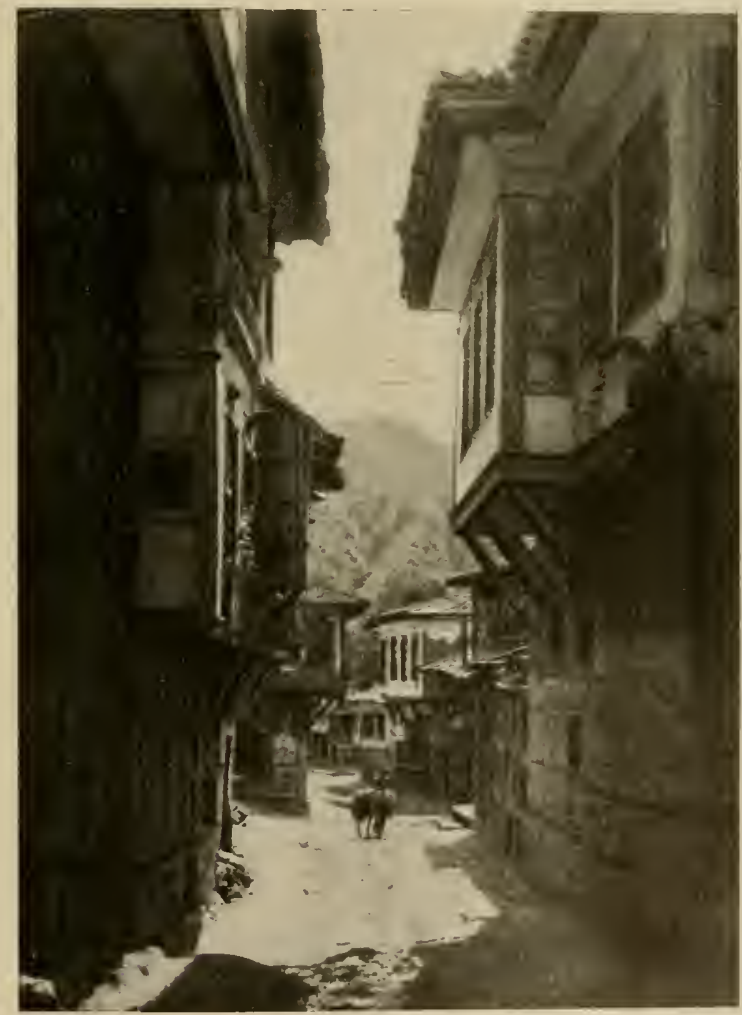

Abb, 21 I. Stadtstraße in Stip.

und köstliche süße Melonen bildeten mit Tomaten und Paprikaschoten einen farbigen Vordergrund für das schöne Straßenbild. Nerkwürdig gut und reich beschickt waren die Läden; in den Stoffhandlungen sah man noch viele englische und deutsche Stoffe und in der Apotheke bekamen wir eine Flasche Gielßhübler, die 
wir zu dem vortrefflichen Kaffee tranken, den wir in einem kleinen Kaffeehaus an der Bregalniza in Messingkannen auf glühenden Holzkohlen in gut türkischer Weise zubereitet bekamen.

Dann besuchten wir noch die griechische Kirche, eine stattliche, dreikupplige Basilika mit seitlicher Säulenhalle. Sehr reizvoll war die Schnitzerei am Ikonostas im Innern, während die Malerei nicht sehr bedeutend war. Eigenartig war eine verschlossene Gittergalerie für Frauen oben im Kirchengewölbe, in der die Frauen abgesondert von den Männern dem Gottesdienst beiwohnten.

Schöne Blicke auf den Hügel mit der Moschee und ihrer herrlich grün patinierten Kuppel boten sich im Rahmen der stattlichen weißen Säulen des Umgangs der Kirche, um welche prachtvolle Bäume und allerhand blühende Pflanzen standen. An den Säulen saßen massenhaft schlafende Stechfliegen (Stomoxys calcitrans L.) bereit, sich auf die Beter zu stürzen.

Von der Kirche wanderten wir noch durch das trockene Bett der Bregalniza zu dem Vorort Novo Sielo, der als Schwefelbad berühmt ist. Wir kamen an einer graziösen kleinen Moschee mit einem säulenreichen Vorraum und schlankem Minaret vorbei zu dem malerisch zwischen uralten Pappeln und Weiden gelegenen Dorf. Ein niedriges Haus enthielt ein viereckiges Badebecken aus Zement, in welchem ein $50^{\circ} \mathrm{C}$ messendes, gelbliches Wasser brodelte, welches auf Kilometer im Umkreis die Luft mit Schwefelgeruch erfüllte.

Unter einer alten Pappel lagerten wir uns und waren damit beschäftigt, Schmetterlinge, Käfer und Ameisen an den alten Stämmen zu beobachten, als ein glühend heißer Staubsturm uns in die Stadt zurücktrieb. Dieser machte uns auch die Rückfahrt nach Veles nicht sehr erfreulich und füllte auch diese Stadt, als wir ankamen, mit Staub und afrikanischer Glut, welche die Steppe bis zum Wardartal wirken machte. 


\section{KLIMA UND SEUCHEN IN MAZEDONIEN}

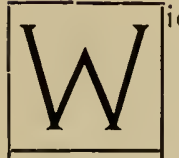

ie auf die Tier- und Pflanzenwelt, so hat das Klima eines Landes auch auf den Menschen einen starken Einfluß. Und vor allem macht sich die Wirkung eines ungewohnten Klimas sehr bemerkbar, wenn größere Bestandteile eines Volkes plötzlich in ein Klima versetzt werden, das stark von dem ihres Heimatlandes abweicht. So hatten denn deutsche Soldaten an den verschiedenen Fronten sehr unter Klimaeinflüssen zu leiden. Und gerade in Mazedonien galt das Klima bei unsern Truppen als besonders ungesund.

Das ist nun in dieser Verallgemeinerung unrichtig. Allerdings brachte es für unsere Soldaten manche Überraschungen. Ganz anders als in Italien oder Südfrankreich war der Gegensatz zwischen Sommer und Winter in Mazedonien auferordentlich groß. Während im Hochsommer Temperaturen bis $42^{\circ} \mathrm{C}$ im Schatten auftraten, in Kaluckova z. B. im Juli und August regelmäßig solche von $35-40^{\circ} \mathrm{C}$ gemessen wurden, sank das Thermometer im Dezember und Januar nicht selten auf $-10^{\circ} \mathrm{C}$, ja es wurden gelegentlich selbst im Flachland Temperaturen von -23 bis $-28^{\circ} \mathrm{C}$ gemessen. Das sind ungeheuere Gegensätze.

Wie kommt es nun, daß dieses Land ein so ganz anderes Klima besitzt als Süditalien und Sizilien, mit dem es unter gleicher Breite liegt. Das ist durch den Einfluß der Nachbarländer bedingt. Das heitere Wetter, der andauernd blaue Himmel des Sommers sind bewirkt durch den Einfluß des subtropischen Hochdruckgebietes, welches über das Mittelmeer bis zum Balkan sich ausdehnt. Dazu kommt aber die Einwirkung der stark erhitzten Landflächen Vorder- und Südasiens. Diese erzeugt vor allem die Regenarmut und Dürre. Sie hat auf den Hauptteil Mazedoniens einen stärkeren Einflulo als das ferner gelegene Meer.

Das macht sich auch im IVinter bemerkbar. In dieser Zeit ist das ganze Mittelmeergebiet dem subtropischen Einfluß 
entzogen. So herrscht wie in jenem auch in Mazedonien regnerisches Wetter und Wolkenbedeckung vor. Sehr oft macht sich aber dann die innerasiatische Kälte bemerkbar, dann fallen eiskalte Nordwinde in das Land ein, dann tritt Schneefall ein und sinkt die Temperatur oft sehr tief.

So entstehen jene Kontraste, welche die Tier- und Pflanzenwelt beeinflussen und unter denen unsere Soldaten so sehr zu leiden hatten, weil sie sich gegen sie zunächst nicht zu schützen wußten.

Im allgemeinen kann man die Jahreszeiten in Mazedonien folgendermaßen charakterisieren. Der Sommer ist sehr heiß und trocken; sonniges Wetter herrscht von Mai bis Oktober unter Luftströmungen, die in der Hauptsache von NW nach SO gerichtet sind. Gewitter kommen nicht selten vor, sind aber meist durch geringe Regenmengen ausgezeichnet. Ende September bis Anfang Oktober beginnt der Herbst, der durch kalte Regen, und zwar mit großen Regenmengen auffällt. In dieser Zeit strömen große Wassermassen die Berge herunter, die Hauptarbeit an den Schluchten wird geleistet, Überschwemmungen treten ein. Im Dezember tritt gewöhnlich der Winter ein, der in der Hauptsache vom Januar bis März dauert. Starke Schneefälle und tiefe Temperaturen sind für ihn charakteristisch.

Der Frühling, der meist erst Anfang April beginnt, nicht selten aber früher schon Vorstöße macht, ist eine schöne Jahreszeit auch in Mazedonien. Der April kann noch recht kalt sein. Er ist die Zeit der prachtvollen Wolkenbildungen, die auch im Mai und Juni die Landschaft wunderbar verschönen. Auch im Lenz bringen starke Regengüsse nicht selten Überschwemmungen. So haben wir also zwei Regenperioden im Jahre; der Frühling ist aber keine eigentliche Regenzeit, diese ist vielmehr der Herbst.

Das ist das Klima, wie es sich hauptsächlich in den Ebenen und im Hügelland darstellt; in den Gebirgen herrscht dagegen ein Klima, welches vollkommen demjenigen Mitteleuropas gleicht, also für unsere Truppen sicher gesund war. Aber dennoch gab es in Mazedonien, unabhängig von Klima und Temperaturen, Regionen, die man gesundheitlich als gut und als schlecht bezeichnen konnte. Berüchtigt als ungesund waren die größeren Städte, wie Üsküb, Veles, Prilep u. a. und eben'so die Sumpfgebiete an der Front. Als Regionen mit besonders viel Krankheitsfällen wurden viel genannt der Doiransee, die Gegend bei Bogdanci und Negorci 
am Wardar, der Prespasee. Dazu kamen die Übernachtungsquartiere der Urlauber, was ich im nächsten Kapitel für Drenovo erklären werde (S. 470).

Quartiere in Höhenregionen von 800-1200 m waren gesundheitlich günstiger als solche in der Ebene. Das hing insofern indirekt mit dem Klima zusammen, als in den kühleren Gebieten die Landeseinwohnerschaft von Seuchen weniger verfolgt war. Vor allem war aber für gewisse Krankheiten von größter Bedeutung, daß in der Höhe die sie übertragenden Insekten nicht vorkommen. Wir werden das unten bei den Malariamücken und den Pappatacci $\mathrm{zu}$ besprechen haben.

Sicher spielten für die Gesundheitsverhältnisse bei unseren Truppen die Quartierverhältnisse eine große Rolle. Wir Deutsche sind gewöhnt, unser Klima in guten, dicht gebauten, im Winter heizbaren, im Sommer kühl zu erhaltenden Häusern zu ertragen. Das fanden wir in Mazedonien nicht vor. Die vielfach baufälligen primitiven Häuser waren im Winter sehr kalt; wie oft mußten unsere Soldaten in ganz primitiven Hütten, in Baracken und Unterständen hausen, in denen man nicht warm bekommen konnte.

Das war besonders in den ersten Jahren der Besatzung schlimm. Da gab es in den Häusern keine Heizöfen, Heizmaterial war kaum zu beschaffen. Der Nachschub für diese Dinge war ganz besonders schlecht. Nicht besser war es im Sommer, wo ein Schutz gegen die Hitze ebenso notwendig gewesen wäre. In den letzten Jahren des mazedonischen Feldzuges hatte man wenigstens in den Lazaretten im Winter für Heizung, im Sommer für berieselte Zelte und für kühle Steingebäude gesorgt. Ich habe in verschiedenen Kapiteln darauf hingewiesen.

Aber in den Quartieren konnte durchaus nicht überall für erträgliche Verhältnisse gesorgt werden. Jeder suchte sich zu helfen so gut es ging, und so wetteiferten unsere Soldaten mit den Bulgaren im Raubbau am Holz. Wie viele verlassene Dörfer wurden nur wegen des Holzmangels zerstört, wie viel hunderttausend Bäume, die sich Mazedonien noch erhalten hatte, fielen der Holznot zum Opfer. Auch in ganz Mitteleuropa hat ja die Kohlennot die Ausbreitung von Krankheiten ganz enorm befördert. Wie mußte das erst in einem Lande wie Mazedonien der Fall sein, wo so viel Einflüsse die Widerstandsfähigkeit der Körper herabsetzten.

Was aber für die Ausbreitung von Seuchen besonders gefährlich war, war die Zusammendrängung vieler Menschen in geDoflein, Mazedonien. 
wissen Gebieten des Landes. Nicht nur die Menge der einquartierten Soldaten, auch die Zivilpersonen, welche von den Fronten sich geflüchtet hatten, die vielen Menschen, deren Gewerbe und Handel sie an die Soldaten ketteten, sammelten sich in den größeren Städten und Lagern an. Wo die Menschen dicht beieinander sitzen ist die Übertragung und Ausbreitung von Seuchen besonders begünstigt. Das wurde in Mazedonien, ähnlich wie in Polen, in Rußland, in der Türkei besonders schlimm durch die Vernachlässigung der Wohnungen, den Schmutz in den Häusern, in den Dörfern und Städten, durch die Primitivität in hygienischen Verhältnissen, den Mangel an reinlichen Aborten, an Wasserleitungen, an Kanalisierung usw.

Dazu kam auf dem Balkan als besonders erschwerendes Moment die Masse des Ungeziefers in den Wohnstätten der Menschen und an ihrem eigenen Körper. Jeder Balkankrieger wird mit Grausen an die Flöhe und Wanzen denken, die dort in jedem Bauern- und Bürgerquartier in Massen über ihn herfielen. Ganz besonders schlimm war die Wanzenplage. Ein wirklich wanzenfreies Quartier gab es in Mazedonien überhaupt nicht. Dem General ging es da nicht besser als dem Landsturmmann und dem Burschen.

Ein Erlebnis wird mir unvergeßlich bleiben und ich möchte es als besonders charakteristisch schildern. Eines abends saß ich beim Oberbefehlshaber der i I. Armee, General von Steuben, mit den Herren seines engeren Kreises in seinem Salon bei behaglichem Gespräch. Es war ein einfaches Zimmer, die Wände mit Teppichen behängt. Plötzlich trat eine Stockung im Gespräch ein, aller Blicke waren krampfhaft auf mich gerichtet. Auch ich schwieg und überlegte mir, ob ich wohl eine taktlose oder törichte Äußerung getan hätte oder was sonst passiert wäre. Da bat mich der General, mich einmal umzusehen und als ich das tat, sah ich an der Wand hinter mir eine Karawane von 20-30 Wanzen in langer Reihe auf mich losmarschieren.

„Das passiert alle Abende“, sagte der General, „drum sitzen wir alle mit Abstand von der Wand, was ich Ihnen auch empfehlen möchte". Und dann begannen die allgemeinen Klagen über die Wanzenplage, die man überall hören mußte. Überall gab es dieses Ungeziefer und selbst in jedes neugebaute Quartier, in jede Baracke wurden sie verschleppt. Ich werde nie den Jammer der jungen Flieger in ihren ganz verwanzten Baracken vergessen, 
die früh morgens nach schlafloser Nacht zum Flug nach Saloniki oder sonstwie zur Front aufsteigen mußten, unerfrischt vom Schlaf, mutlos und an der Hoffnung der Wiederkehr verzweifelnd, da sie körperlich und geistig nicht über ihre vollen Kräfte verfügten.

Mit aller Energie wurde an vielen Orten, besonders in den Städten, gegen das Ungeziefer gearbeitet; es gelang aber nur an einzelnen Stellen, in Quartieren, Offiziersheimen und Kasernen oder Lazaretten einen vorübergehenden Erfolg mit Schwefeldämpfen zu erzielen. In den undicht gebauten Häusern der Mazedonier waren alle solche Versuche vergeblich. Die Mittel fehlten, ebenso die Arbeitskräfte, um solche Arbeiten durchzuführen. Hindernd trat da auch die Bürokratie der Militärverwaltung und vor allem unseres Sanitätswesens entgegen. IVas habe ich gekämpft, um einmal die Erlaubnis vom Armeearzt zu erhalten, in den freistehenden Baracken meiner Fliegerfreunde einen Versuch mit der damals neu erprobten Cyankalimethode zu machen. Da keine Vorschriften und Paragraphen darüber existierten, durfte so etwas nicht gemacht werden.

Etwas mehr Erfolg hatte in Mazedonien der Kampf gegen die Kleiderläuse, weil hier die Natur mithalf. In manchen Gegenden, so in Serbien und Albanien, waren Läuse sehr verbreitet, Kopfläuse, Kleiderläuse wie Filzläuse. Die Kleiderläuse hielten sich vor allem leicht in den Wollgewändern der Menschen. Während Wanzen und Flöhe offenbar nur gelegentlich Bakterien und andere Krankheitserreger beim Blutsaugen von einem Menschen auf den anderen übertragen, scheinen die Kleiderläuse gesetzmäßig mit der Übertragung der Spirochaete recurrentis, dem Erreger des Rückfallfiebers und mit dem noch unbekannten Erreger des gefährlichen Flecktyphus verknüpft zu sein. So war das Vorkommen der Kleiderläuse eine Vorbedingung für das epidemische Auftreten der genannten gefährlichen Seuchen.

Wie an allen anderen Fronten waren diese Krankheiten auch in Mazedonien anfangs in sehr beängstigenden Prozentzahlen beim Heer aufgetreten: auch hier wurde bald die Entlausung eingeführt und streng auf sie gehalten. Und da der Urlaubsschein vom Entlausungsschein und jede Grenzüberschreitung von vollzogener Entlausung abhing, so gelang es in ziemlich kurzer Zeit diese Plage erheblich einzudämnen. Zumal war der heiße mazedonische Sommer der Entwicklung der Läuse sehr ungünstig, so daß nur im Winter eine Zunahme der Verlausung und damit im Zusammenhang ein Aufflackern von Rückfallfieber und Flecktyphus 
in den Jahren 1917 und I9I8 sich noch zeigte. Herde von Flecktyphus gibt es auf dem Balkan seit jeher und so ging von diesen immer wieder einmal eine Epidemie aus. Da für die Bekämpfung aber alles sehr gut organisiert war, so gelangte eine solche nicht mehr zu größerer Ausdehnung. Auch von unseren Soldaten haben diese Seuchen manches Leben vernichtet, aber so furchtbare Epidemien, wie sie in Polen, unter den Serben und Rumänen wüteten, haben unser mazedonisches Heer nicht betroffen.

Um so schlimmer war aber auf dem Balkan das Wechselfieber, die Malaria. Die hat uns manchen Soldaten gekostet und noch mehr für viele Jahre ihres Lebens in Arbeitsfähigkeit und Lebensfreude beeinträchtigt.

Bekanntlich stellt die Malaria in doppelter Weise ein zoologisches Problem dar. Der Parasit, der in den roten Blutkörperchen des Menschen lebt, diese zerstört und ihn dadurch blutarm und durch seine Giftwirkung fieberkrank macht, ist ein einzelliges Tier aus der Gruppe der Protozoen. Und damit dieser Parasit durch bie Haut des Menschen in dessen Blutgefäße und so in die Blutkörperchen gelangen kann, bedarf er eines Transportmittels und einer Hilfe beim Einspritzen ins Blut des Menschen. Beides leistet ihm wiederum ein Tier; und zwar ist es ein blutsaugendes Tier aus der Gruppe der Stechmücken.

Alle blutsaugenden Insekten ernähren sich in der Hauptsache vom Blut der Wirbeltiere. Dabei saugen sie mit einem Stechrüssel das Blut in ihren Darm als Nahrung; damit das Blut genügend durch die feine Wunde nachfließt, spucken die meisten Blutsauger beim Saugen ihren Speichel hinein, der in manchen Fällen die Blutgerinnung hindert, stets aber eine Entzündung hervorruft. Diese hat ihre Bedeutung für den Sauger und den Gesaugten. Bei letzterem bringt sie das Zusammenströmen von reichlich Blut zur Wunde zustande. So kommt es zur Schwellung und zu dem bekannten unangenehmen Jucken beim Insektenstich. Für den Blutsauger bedingt das einen reichen Blutzufluß zu dem saugenden Rüssel und sichert ihm eine richtige Portion zum Sattwerden nach einem oder einigen Stichen.

So ist das Stechen der Wanzen und Flöhe zwar sehr unangenehm, aber in der Regel nicht gefährlich, keine Seuche übertragend. Das ist auch bei der großen Mehrzahl der Stechmücken der Fall. Auch solche spielten in Mazedonien an vielen Orten eine höchst unangenehme Rolle. So waren Veles, Teile 
von Üsküb, der Prespasee, der Doiransee und andere Abschnitte der mazedonischen Front berüchtigte Stechmückennester, wo die Menschen ganz bös von diesen Plagegeistern gequält wurden. Das war ganz besonders schlimm, wenn sie zu den Wanzen und Flöhen und allerhand anderem Gesindel noch dazu kamen. Zum Glück hatten wir es in Mazedonien nicht so schlecht, wie unsere Feinde. Die Franzosen in der Wardarebene bei Saloniki und besonders die Engländer an der Strumafront müssen in reinen Stechnückenhöllen gesessen haben. Wir hörten das aus ihren Berichten und konnten es daran merken, daß in der Frontgegend oft mächtige Rauchsäulen aufstiegen, wenn sie sich durch Abbrennen des Schilfs in den Sümpfen zu retten suchten. Sie zogen sogar manchmal wegen der Schnakenplage ihre Front etwas auf höher liegendes Gelände zurück und konnten sicher sein, daß wir ihnen in diese Hölle in der Schnakenzeit nicht nachfolgten.

Die Schnaken, die am meisten plagten, zum Teil auch am Tage bei heißer Sonne stachen, gehörten zu den Gattungen Culex, Culicada, Acdes u. a., von denen man jetzt seit etwa 20 Jahren weiß, daß sie sich an der Übertragung des menschlichen Malariaparasiten niemals beteiligen. Seither weiß man nämlich, daß es nur die Stechmücken der Gattung Anopheles sind, welche in allen Teilen der Erde die menschliche Malaria übertragen. So wie also der Mensch der einzige Organismus ist, welcher die echte Malaria bekommt, so ist es auch nur die gleiche Parasitenform, die in ihm gedeiht und nur durch Arten der Gattung Anopheles vermittelt werden kann, also nur in solchen lebensfähig bleibt. So sehen wir denn in dieser gesetzmäßigen Verkettung dreier Organismen von verschiedener Art, von denen das eine nicht leben kann, ohne daß beide anderen vorhanden sind, ein interessantes zoologisches Problem vor uns.

Da ich nun selbst Protozoenforscher bin und mich mit dem Malariaproblem und seinen biologischen Grundlagen früher viel beschäftigt hatte, so war es naheliegend, daß ich meine Kenntnisse in diesem Gebiet sogleich in den Dienst der Heeresleitung und meiner leidenden Kameraden stellte und untersuchte, was über die Zoologie der Malaria in Mazedonien festzustellen war und was man etwa durch neue Beobachtungen zu ihrer Bekämpfung beitragen könne.

Vorläufig war noch nicht bekannt, welche Malariamücken in Mazedonien vorkommen. Man weiß jetzt längst, daß auf der 
ganzen Welt mehrere Dutzend Anophelesarten leben, welche alle die Menschenmalaria zu übertragen vermögen. In Europa sind bisher vier Arten nachgewiesen worden, von denen nur zwei in Deutschland vorkommen. Diese heißen Anopheles maculipennis Meig. und Anopheles bifurcatus L. ... Zu diesen kam noch eine für Mazedonien besonders interessante Art Anopheles superpictus Grass u. Fel., während die vierte europäische Art bisher auf dem Balkan nur in Rumänien und im Donaugebiet gefunden wurde; es ist dies Anopheles pseudopictus Grass u. Fel. Wahrscheinlich fehlt sie in Mazedonien. Jedenfalls konnte ich sie trotz eifrigen Nachforschens in den zwei Jahren IgI7 und IgI 8 nicht finden.

Anopheles maculipennis und bifurcatus leben auch hier in der altbekannten Weise im Larvenzustand in stehenden Tümpeln. So konnte man sie in der auch sonst in der Welt üblichen Methode bekämpfen, indem man entweder die Brutstätten zuschüttete, Abläufe anlegte und ihr Entstehen und Bestehen in der Nähe menschlicher Siedelungen verhinderte. War eine Beseitigung der Wasseransammlungen nicht möglich - und das war in Mazedonien oft der Fall, wo das Wasser zur Bewässerung von Feldern und Gärten vielfach angestaut werden mußte, so konnte man durch Aufgießen einer dünnen Schicht von Petroleum oder Saprol die Puppen und Larven der Stechmücken am Atmen verhindern und so ersticken. Denn die Entwicklungsstadien der Stechmücken sind Luftatmer und müssen in kurzen Abständen sich an der Wasseroberfläche immer wieder Luft zum Atmen holen. Sperrt man ihnen diese durch eine dünne Ölschicht $a b$, so müssen sie ersticken und sterben.

Diese Methoden waren in Mazedonien von den Armeehygienikern, unter denen besonders der erfahrene Professor Fülleborn aus Hamburg sich hervorgetan hatte, in den ersten Jahren schon an vielen Stellen mit Erfolg angewandt worden. Es hatte sich aber herausgestellt, daß in vielen Gegenden die Maßregeln nicht eingeschlagen hatten. So hatten sie besonders an verschiedenen Lazaretten versagt, welche man am Ende von Schluchten aufgeschlagen hatte, um sie mit fließendem Wasser leicht versorgen zu können.

Gerade in meinem Standquartier Kaluckova war dies der Fall gewesen und hier speziell hatte man die betrübende Beobachtung machen müssen, daß die Ruhrkranken, die an diesem Ort konzentriert wurden, fast regelmäßig noch dazu im Lazarett an Malaria erkrankten und damit viel schwerer behandelt und dem 
drohenden Tod entrissen werden konnten. Das mufte besondere Ursachen haben, und diese zu untersuchen, nahm ich mir vor.

Schon im Jahre 1917 gelang es mir festzustellen, daß gerade in der Gegend von Kaluckova die kleinste der europäischen A nophelesarten (Anopheles superpictus) auffallend häufig vorkam. Außer durch ihre Kleinheit ist sie besonders von der auch häufigen Art A. maculipennis durch die Anordnung der dunkeln Flecken auf den Flügeln leicht zu unterscheiden. Die vier Flecken liegen nämlich am Vorderrand der Flügel in einer Reihe hintereinander (vgl. die untenstehende Abb. 212). Auch sonst zeigt sie einige leicht nachweisbare Unterschiede von den anderen Arten.
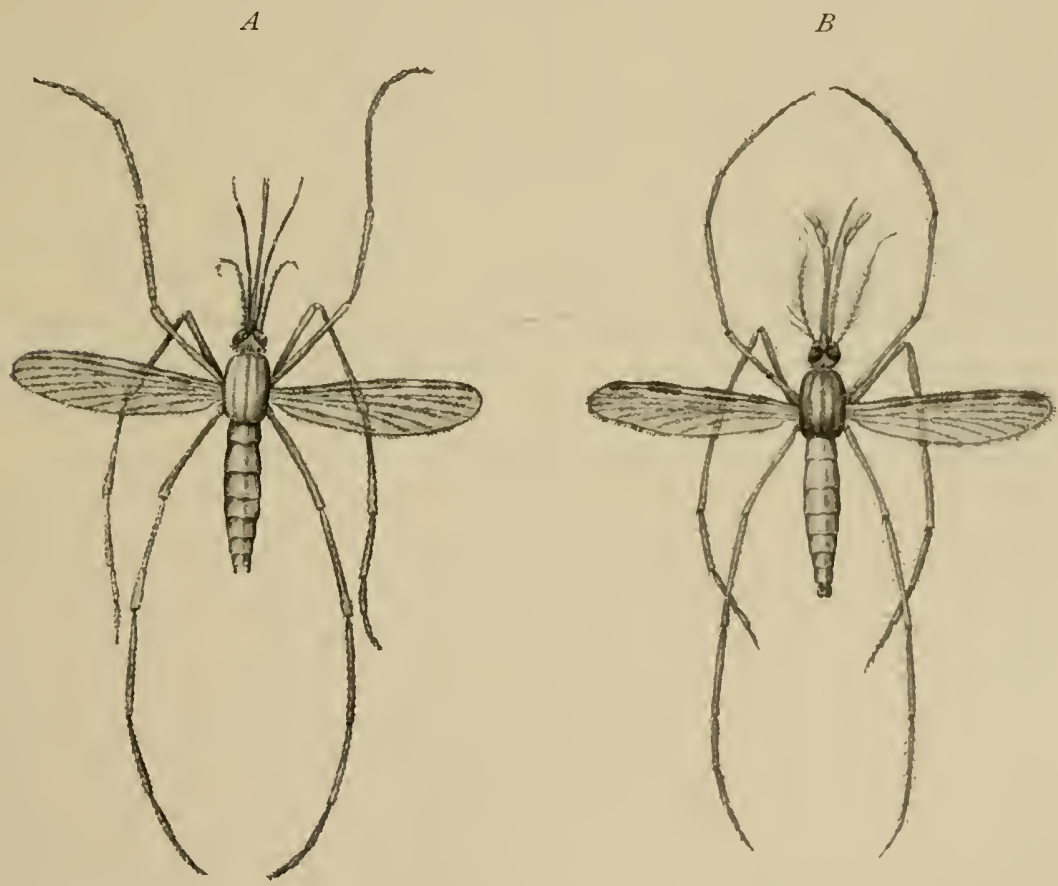

Abb. 21 2. Anopheles superpictus Gr. u. Fel, Schluchtenfiebermücke. $A$ Weibchen. $B$ Männchen. Vergr. 5 .

Wie war es wohl zu erklären, daß gerade diese Form bei Kaluckova die häufigste war? Die Untersuchungen der Schluchten klärten diese Frage auf. Es stellte sich dabei heraus, daß gerade Anopheles superpictus in den Schluchtbächen brütet. Und zwar findet man die Larven nicht, wie man das bisher für alle Anopheles-Arten annahm, nur im ruhenden Wasser stehender 
Tümpel, sondern auch im strömenden Schluchtbach. Da lagen sie vor allem in charakteristischer Lage mit dem Hinterende an den Steinrändern des Bachufers angelehnt. So wurden sie von der leisen Strömung nicht mitgerissen.

Auch in den Sammelgläsern und Glasschalen, in denen ich die Larven aufhob, zeigten sie eine ganz besondere Neigung sich mit dem Hinterende an die Glaswand anzulegen, was für eine mit ihrer Lebensweise zusammenhängende Besonderheit spricht.

Die Larven von Anopheles superpictus konnte ich dann in vielen Gegenden Mazedoniens als bevorzugte Bewohner der Schluchtbäche feststellen, in denen gelegentlich auch diejenigen von $A$. maculipennis vorkommen. So waren denn die Schluchten nicht mehr als harmlose Nachbarschaft von Lazaretten und Truppenquartieren anzusehen und unter anderen erwies sich die Verlegung bzw. Aufhebung des Lazaretts $\mathrm{Kaluckova}$ vor dem nächsten Sommer als notwendig.

Immerhin war die Bekämpfung der Malariamücken auch in den Schluchten nicht unmöglich. Ich gab dafür ein Mittel an, welches die Natur mich gelehrt hatte und welches mir in diesem Lande selbst für die Einwohner ausnützbar und mit wirtschaftlichen Zwecken verknüpfbar erscheint. Nachdem ich nämlich beobachtet hatte, daß nach starken Regengüssen die Tümpel der Schluchtbäche von dem angeschwollenen Wasser glatt von Schnakenlarven ausgespült werden, welche dann auf den Geröll- und Sandbetten des im Sommer austrocknenden Unterlaufs absterben, empfahl ich dafür eine Nachahmung des natürlichen Vorganges durch einfache Handgriffe.

Bei geeigneter Auswahl der richtigen Stelle kann man in jeder Schlucht mit einer Arbeitskraft in einem Tage aus dem vorhandenen Geröll eine labile Sperre herstellen, welche eine Wassermasse staut, genügend für eine einmalige radikale Durchspülung der Schlucht. Gleichzeitig könnte in dieser Weise angestautes Wasser zur Bewässerung von Anbauland ausgenützt werden und nur periodisch alle paar Wochen zur Schnakenbekämpfung Dienste tun.

Auch andere Malariabeobachtungen konnten auf dem Balkan gemacht werden, die nicht ohne Interesse waren. So zeigte sich die Verschleppung der Malaria stets an das Vorhandensein der Anopheles geknüpft, wobei die Menschen als Dauerträger der Parasiten eine große Rolle spielten. So wurde die Malaria be- 
sonders in der schlimmen Form der Tropica in vielen Gegenden des Balkan erst während des Krieges eingeschleppt, in denen sie früher gefehlt hatte. Es zeigte sich, daß das neue Auftreten von Tropikafällen fast immer mit dem Erscheinen von meist asiatischen, türkischen Truppen und an der feindlichen Front von farbigen Abteilungen in Zusammenhang stand; diese hatten als Malariaträger in ihrem Blut die Infektionsformen des für das Land neuen Parasiten mitgebracht.

Auch wurde zum ersten Male auf dem Balkan von unseren Militärärzten auf die Wichtıgkeit der Kindermalaria geachtet. An manchen Orten, so am Prespasee, in Struga an Ochridasee, war es sehr auffallend, wie die meisten Kinder bleich und hohläugig, vielfach abgemagert und mit vorstehendem Bauch herumliefen. Sie wurden untersucht und erwiesen sich als sogenannte Milzbäuche, d. h. als Malariaträger, bei denen durch den Einfluß des Parasiten die Milz stark geschwollen war.

Solche Kinder, welche ihre Jugend in einem ständigen Kampfe mit dem Malariatod verbrachten, waren dauernd Infektionsquellen für die Anopheles, welche in einem so belasteten Ort während des ganzen Sommers mit Malariakeimen beladen, auf gesunde Ankömmlinge lauerten, um sie beim Stechen zu infizieren. Kam Einquartierung in einen solchen Ort, so war mit Sicherheit anzunehmen, daß dort in kürzester Frist ein hoher Prozentsatz der Leute mit Malaria infiziert wurden.

Anopheles superpictus scheint mir gegenüber den auch bei uns verbreiteten Arten $A$. maculipennis und bifurcatus eine südliche Form zu sein. Darauf weist zunächst einmal hin, daß ich sie im südlichen Teile Mazedoniens viel häufiger fand als im nördlichen. Während ich in Üsküb unter zahlreichen A. maculipennis nur ganz selten einen vereinzelten $A$. superpictus fand, waren es in Kaluckova zehnmal mehr von dieser letzteren kleinen Form. An allen südlichen Fundorten, so in Veles und Dedeli war sie die häufigere. Das mag ja zum Teil aus ihrer Vorliebe für Schluchten zu erklären sein.

Aber andererseits ist bemerkenswert, daß $A$. superpictus später im Frühling aus dem Winterquartier kommt und später seine Eier legt als $A$.maculipennis. Das Winterquartier ist eine ausgezeichnete Gelegenheit, um die Häufigkeit einer Art in einer Gegend festzustellen. Auch in Mazedonien überwintern nur die Weibchen in Kellern, Häusern, Ställen, Schuppen, aber auch in Erdspalten und 
Höhlen im Freien. A. superpictus hat eine besondere Tendenz in solchen natürlichen Verstecken zu überwintern.

Die Weibchen von 4. maculipennis haben oft schon kurz nach dem Verlassen des Winterquartiers legereife Eier besessen, das Legen beginnt bei dieser Art schon im April. Bei superpictus habe ich es vor Ende April bis Anfang Mai nicht beobachtet.

Bei Anopheles gibt es scheinbar als Norm im Sommer drei Generationen; bei günstiger Witterung und guten Ernährungsverhältnissen kann es wohl auch zu mehr Sommergenerationen kommen. Normal dürfte wohl folgende Reihenfolge sein: Die überwinternden Weibchen legen im Frühling Eier, aus diesen entsteht im Mai die Frühlingsgeneration, die im Mai und Anfang Juni fliegt, sich begattet und zur neuen Eiablage gelangt. Aus diesen Eiern entsteht die Sommergeneration, die meist Anfang August sich zeigt. Sie legt im Herbst ihre Eier, aus diesen entstehen wieder erwachsene Männchen und Weibchen. Erstere sterben schnell ab, die begatteten Weibchen gelangen meist nicht mehr zur Eiablage, sondern überwintern im Winterquartier, um die nächste Generation erst im Frühling hervorzubringen. Die hier eingefügte Tabelle zeigt, daß die Generationen von $A$. superpictus immer ein wenig denen von $A$. maculipennis nachfolgen.

\begin{tabular}{|c|c|c|}
\hline & $\begin{array}{l}\text { Anopheles } \\
\text { maculipennis }\end{array}$ & $\begin{array}{l}\text { Anopheles } \\
\text { superpictus }\end{array}$ \\
\hline $\begin{array}{l}\text { I. Gen. } \\
\text { II. Gen. } \\
\text { III. Gen. }\end{array}$ & $\begin{array}{c}\text { April-Mai } \\
\text { Anfang August } \\
\text { September-Oktober } \\
\text { Überwinterung }\end{array}$ & $\begin{array}{c}\text { Maı } \\
\text { August-September } \\
\text { Oktober } \\
\text { Überwinterung }\end{array}$ \\
\hline
\end{tabular}

Mit den Generationen der Malariamücken hingen auch die Höhepunkte der Malariaepidemien in Mazedonien zusammen. Kurze Zeit nach der Entwicklung zahlreicher Mücken stieg die Zahl der Erkrankungen an Malaria stark an.

Die schlimmsten, unangenehmsten Quälgeister in Mazedonien waren winzig kleine Mücken, welche in gewissen Zeiten den Schlaf fast unmöglich machten. Es waren dies die Pappataccifliegen, kleine $2 \frac{1}{2} \mathrm{~mm}$ lange Tierchen, welche einem einen brennend schmerzhaften Stich beibrachten, der auf die verschiedenen Menschen ganz verschieden ein- und nachwirkte. Wer mit ihnen ernsthaft zu

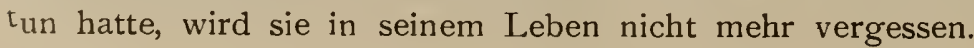


Zunächst ist man gar nicht geneigt, so kleinen Wesen, die kaum größer sind als Blattläuse, Beachtung zu schenken. Sie zwingen sich aber bald Beachtung auf. Sie sind im ganzen Orient verbreitet, kommen auch im übrigen Südeuropa, in Italien, in Malta und Nordafrika vor und sind überall sehr gefürchtet. Überall treten sie lokal auf, sind auf besondere Orte beschränkt und fehlen oft dicht daneben.

Im Winter sind die geflügelten Tiere vollkommen verschwunden; eine Überwinterung der Weibchen, wie bei den Stechmücken, kommt bei ihnen offenbar nicht vor. Sie treten Anfang bis Mitte Mai auf und erreichen ein Maximum der Häufigkeit in Mazedonien im Juni, dem ein zweites Maximum im September folgt. Im Oktober bis November verschwinden sie vollkommen, was nicht mit einem Überwintern zusammenhängen kann. Nach vollendeter Eiablage sterben nämlich die Weibchen.

Die Fappatacci haben ein eigenartiges Aussehen; sie haben dünne nicht allzu lange Beine, lange, zart behaarte Fühler, vorstehende Augen und einen ziemlich langen Stechrüssel am Kopf. Der Leib ist beim Männchen schmäler als beim Weibchen und trägt am Hinterende einen eigenartigen Klammerapparat. Die Flügel sind lang und schmal, fein geädert und behaart und werden in der Ruhe in - einer eigenartigen Stellung gehalten, welche als Engelsflügelhaltung be-

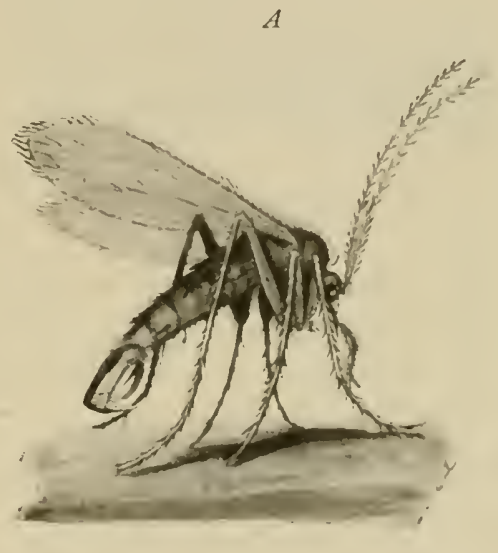

$B$

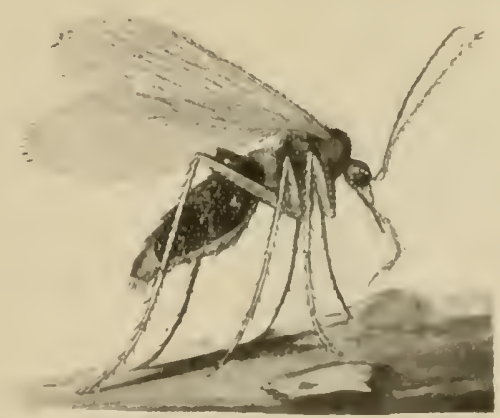

Abb. $21_{3}$. Phlebotomus papatassii L. Pappataccifliegen. $A$ Männchen. $B$ Weibchen mit blutgefülltem Darm. Vergr. 20. zeichnet wird (vgl. die obenund umstehenden Abbildungen 213, 214 und 215).

An der Wand sitzen sie mit stark nach unten abgebeugtem Kopf, aufrechten Fühlern und abstehenden Beinen. Rührt sich etwas in ihrer Umgebung, so nehmen sie eine Bercitschaftsstellung 
ein, aus der sie durch einen seitlichen Sprung sich einige Meter an der Wand entfernen, um meist bald sich wieder zu setzen. Sie sind auf Tastreize, Bewegungen

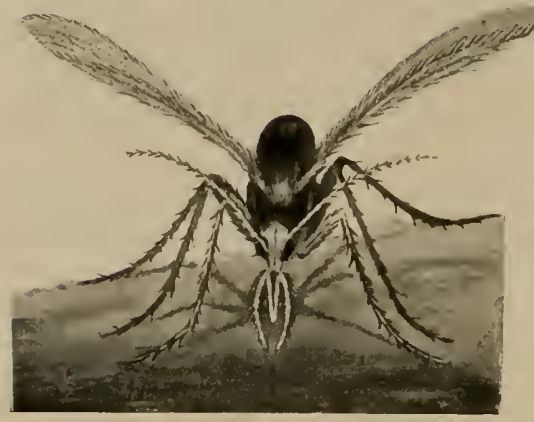

Abb. 214. Pappatacciweibchen in Engelstellung von vorn.

und Lichtreize außerordentlich empfindlich. Licht zieht sie an. Sie haben eine ausgesprochene Tendenz sich auf rauhe Unterlagen zu setzen.

Hat man abends sein Moskitonetz auf Pappatacci sorgfältig geprüft und vollkommen frei von ihnen gefunden, so findet man dennoch morgens oft deren $50-$ 60 unter dem Netz. Sie sind offenbar durch den Geruch des Menschen angezogen worden und mit großer Geschicklichkeit durch die Maschen des Netzes gekrochen. Weibchen wie Männchen werden gleicherweise durch den Menschen angezogen, obwohl nur die Weibchen Blut saugen. Es werden also auch die Männchen durch den Menschengeruch angelockt, obwohl sie sich nicht an ihm ernähren. So sehen wir bei ihnen den Geruchssinn in ähnlicher Weise in den Dienst der Fortpflanzung gestellt, wie bei manchen Schwärmern unter den Schmetterlingen, wo die Geschlechter auf

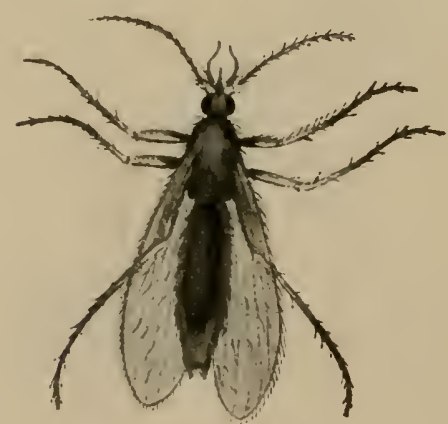

Abb. 215. Pappataccimücke. Weibchen von oben: voll Blut gesaugt. den Geruch gewisser Blüten sich an diesen versammeln, ohne dab sie an diesen saugen, was ihnen gar nicht möglich ist, da sie einen verkümmerten Saugrüssel haben und im Imagozustand überhaupt keine Nahrung zu sich nehmen.

Morgens fand ich die Weibchen stets voll Blut gesaugt auf der Innenseite meines Moskitonetzes ruhig sitzend und fing sie regelmäßig alle $\mathrm{zu}$ wissenschaftlichen Zwecken weg. Dabei fand ich viele Pärchen in Begattung vereinigt; dann war das Weibchen stets voll Blut gesaugt; das Männchen hing entgegen manchen Angaben stets nach unten.

In der Regel stachen die Pappatacci nur nachts, doch konnte ich in manchen Fällen ebenso wie bei den Anopheles auch ein 
Stechen bei Tag beobachten. Nachts war ihr Stechen vielfach qualvoll, manche Menschen reagierten auf sie sehr stark und waren am ganzen Körper nach den Stichen von Quaddeln bedeckt; die Stiche hatten oft ein Ekzem zur Folge. Die Ärzte, Schwestern, Kranken konnten in den kritischen Monaten in Kaluckova überhaupt kaum mehr schlafen und kamen auf diese IVeise körperlich und seelisch sehr herunter. Kaluckova, Hudova, Veles und andere Orte waren von diesen Tieren stark geplagt, während sie in Üsküb weniger hervortraten, in Prilep fast ganz und in hochgelegenen Orten wie Gopes vollkommen fehlten. Vor allem im südlichen Wardargebiet litten unsere Truppen ganz außerordentlich unter diesen Quälgeistern.

Besonders schlimm war aber, daß auf die Stiche der Pappatacci eine Krankheit auftrat, welche mehrere Tage hohes Fieber, Kopfschmerzen, Gliederschmerzen und ein lang anhaltendes Schwächegefühl mit sich brachte. Die Krankheit, als Pappataccifieber bezeichnet, befiel fast jeden, der in das verseuchte Gebiet kam. Auch in der Türkei, in Kleinasien, Syrien und Palästina hatten unsere Soldaten schlimm unter diesen Bestien zu leiden. Zuerst hielt man die Krankheit für harmlos und glaubte nicht an Nachwirkungen. In den späteren Jahren des Feldzugs zeigten sich aber immer schlimmere Folgeerscheinungen, so daß sie sehr gefürchtet wurde.

So tat man denn alles, um sie zu bekämpfen. Es scheint, daß die Larven vor allem in Lehmmauern, Steinspalten, Bodenritzen leben. Ich suchte in angestrengter Weise nach ihren Brutstätten in Kaluckova, Rabrovo, in Veles, in Üsküb, kurz an allen Stätten, an denen man jede Nacht Massen der Imagines sammeln konnte. Die Schwierigkeit sie zu finden, lag vor allem an der Kleinheit der Eier, Larven und Puppen. Ich kam zur Überzeugung, daß die Hauptbrutstätten in den Lehmbauten und Hausruinen des Landes sein müßten.

Ebenso intensiv wurde natürlich nach dem durch die Pappataccimücken übertragenen Krankheitserreger gesucht. Nan suchte ihn im Darm der Weibchen, im Blut der Kranken, suchte dort vor allem in den ersten Krankheitstagen. Schließlich kam man zur Überzeugung, es müsse ein invisibler Virus sein. Merkwürdig ist die Tatsache, daß die überwinterten Larven Tiere aus sich hervorgehen lassen, die bald die Krankheit verbreiten können. Das muß 
natürlich für alle Überlegungen über die Herkunft des Krankheitskeimes von Bedeutung sein. Man dachte an eine Vererbung durch das Ei, die ja bei anderen Parasiten festgestellt ist.

Ich habe mir nach meinen persönlichen Erfahrungen Gedanken über einen besonderen Zusammenhang gemacht, den ich hier zur Diskussion stellen möchte. Ich halte es für möglich, daß gewisse, normalerweise im Darm der Pappatacciweibchen lebende Parasiten, Bakterien oder andere Organismen, sich jedes Jahr neu an Menschenblut gewöhnen. So wären nur solche Tiere infektiös, welche mehr als einmal an Menschen gesaugt haben. In ihrem Darm wäre die Vorbereitung an das Leben im Menschenblut erfolgt. Ich versuchte, den Beweis für diese Annahme bei mir selbst zu führen, indem ich keiner Pappataccimücke gestattete, ein zweitesmal an mir zu saugen. Das führte ich durch, indem ich jeden Morgen alle Mücken unter meinem Moskitonetz wegfing und alle in meinem Zimmer vorhandenen tötete.

Obwohl ich sehr oft gestochen wurde, habe ich die Krankheit in den beiden Jahren meines Aufenthaltes in Mazedonien nicht bekommen, obwohl ich an den verseuchten Stellen lebte und meine ganze Umgebung wiederholt erkrankte. Doch gebe ich $\mathrm{zu}$, daß es sich mit meiner Annahme um eine noch unbewiesene Hypothese handelt.

Von anderen Plagegeistern in Mazedonien möchte jich noch die Bremsen erwähnen, welche Menschen, Pferde. Maultiere, Rinder und andere Tiere sehr quälten. Die Pferde waren oft von Dutzenden dieser Blutsauger bedeckt. Es waren eine ganze Anzahl Arten, welche in Frage kamen. Ich nenne hier Tabanus graecus Fb., T. ater Rossi, T. tergestinus Ers., T. umbrinus Mg., die zum Teil durch ihren Namen schon ihre südliche Zugehörigkeit zeigen. In den Anmerkungen zu diesem Kapitel gebe ich eine längere Liste der von mir beobachteten Bremsenarten. Ein unangenehmer Blutsauger war auch Haematopota pluvialis $\mathbf{L}$.

Für unsere Pferde und Rinder waren auch die Lausfliegen (Hippobosca equina L.) eine schwere Plage, zumal manchmal 50- Ioo dieser schwer abzulösenden Blutsauger sich unter dem Schwanz an After und Vulva der armen Tiere anhefteten. Gefährlich waren die Zecken, die Ixodiden, welche bei Pferden und Rindern das Blutharnen, eine schwere, oft tödliche Krankheit übertrugen. Auch Dasselfliegen kamen häufig vor, und man sah bei den 
Rindern nicht selten die von ihnen er\%eugten Beulen. Auch die Pferde litten unter solchen, wie daraus hervorgeht, daß zwei Pferdeverfolger Oestrus (Rhinoestrus) purpureus Brauer und Gastrophilus equi L. nicht selten waren.

Als Krankheitsüberträger mögen auch die Stubenfliegen und Schmeißfliegen eine Rolle gespielt haben, welche jeden Knt in ungeheuren Mengen bedeckten und von ihm auf alle Speisen flogen. Sie mögen bei der Übertragung der Ruhr und des Typhus mitgewirkt haben. Diese beiden Krankheiten spielten auch in Mazedonien ihre verderbliche Rolle; bemerkenswert ist dabei, daß es sich fast ausschließlich um Bakterienruhr handelte, während die in der Türkei häufige Amoebenruhr nur ganz selten vorkam. 


\section{PRILEP UND SEINE PÄSSE (BABUNA- UND PLETWARPASS)}

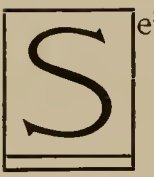

eitdem Monastir in die Hände der Feinde gefallen war, spielte Prilep eine wichtige Rolle als Hauptstadt im Westteil der mazedonischen Front. Seit jeher war sie als Durchgangspunkt auf dem Wege nach Südmazedonien und Südalbanien bedeutend gewesen. So waren hauptsächlich zwei Pässe seit altersher als Zugangsstraßen nach dieser Stadt üblich. Beide waren jetzt für die Versorgung der Front ausgebaut worden, der Babuna- und der Pletwarpaß, die vom Wardartal nach Südwesten nach Prilep führten. Beide hatten ein Gebirge auf diesem Weg zu überqueren, so daß für die Versorgung der Front die Strecke von $70-80 \mathrm{~km}$ große Schwierigkeiten bedeutete.

$\mathrm{Zu}$ meinem ersten Besuch in Prilep wählte ich im Juni 1917 den Weg über den Babunapaß, wobei Veles den Ausgangspunkt darstellte. Dort fand ich bei Hauptmann Jungmann gastliche Aufnahme und das für die Fahrt so wichtige Beförderungsmittel. Über die Paßstraße ging ein regelmäßiger starker Verkehr von Lastfuhrwerken und Kraftwagen. Um diesen zu bewältigen, war im Laufe der Zeit die Straße immer besser ausgebaut worden; außerdem war eine Kleinbahn über den Babunapaß im Bau, die jedes Vierteljahr ein Stück weiter vorgeschoben wurde, während der Rest der Strecke für den Proviant- und Munitionstransport an die Front durch eine Schwebebahn überwunden wurde.

Die Straße von Veles nach dem Babunapaß ging zuerst geradeaus südlich an der Topolka entlang, um dann über eine Höhe hinweg die Babuna zu erreichen, welche bei Izvor direkt aus Süden in einem breiten Tal dem Gebirge entströmt. Es ist eine eigenartige, abwechslungsreiche Landschaft, welche man durchfährt, während allmählich die Ketten des Gebirges immer höher vor einem aufsteigen. Diese Gegend hatte ich auf Kreuz- und Querfahrten mit Hauptmann Jungmann ziemlich genau kennen gelernt, da er mich oft bei den Inspektionen seiner Lager mitgenommen hatte. 
An der ganzen Straße hatte er Lager von Kriegsgefangenen, hauptsächlich Rumänen, welche am Straßen- und Bahnbau arbeiteten. In der Umgebung dieser Lager habe ich mit ihm manche Exkursion gemacht, welche besonders viel interessante Insekten brachte.

Nicht weit von Veles war eine Stelle, wo bei Anlage einer Sandgrube für die Straßenarbeiten der Hauptmann Zühne und Kieferstücke eines Mastodon ausgegraben hatte. Ich sah mir die Örtlichkeit sehr genau an; denn dort sollten später weitere Ausgrabungen vorgenommen werden. Es fand sich in der Grube eine eigenartige Schichtung von feinem Sand, Geröll und Lehm, dazwvischen dünne schwarze Schichten. Spätere Grabungen förderten hier prachtvolle Fossilien zutage. Es fanden sich hier außer weiteren Resten des Mastodon eine große Menge versteinerter Säugetierskelette von Antilopen, Pferden und dergleichen, vergleichbar der berühmten Fundstätte von Pikermi in Attika. Die Ausbeutung hatte im Herbst 1918 kaum begonnen, als der Rückzug uns vertrieb und leider eine planmäßige Durcharbeitung unmöglich machte, die hoffentlich in nicht $z u$ ferner Zukunft wieder aufgenommen werden kann.

So bot jedes der Lager irgendeine Besonderheit für den Naturforscher. Bei einem waren ausgedehnte sumpfige Reisfelder, deren Wasser interessante Tiere beherbergte, bei Izvor enthielt ein Teich Wasserschildkröten. Dort war im Frühsommer 1917 der Kopf der Feldbahn angelangt, fest wurde an dem Schienenstrang gearbeitet; das Lager war von hunderten von Arbeitern erfüllt, hier meist von den Bulgaren gepreßte Arnauten. Daneben dehnte sich ein malerisches Türkendorf aus.

Die Gegend vor dem Gebirge war reich angebaut; anfangs Juni waren die Getreidefelder gerade schnittreif. Die Dörfer, sich als türkische Siedlungen meist durch ihr Minaret verratend, lagen hoch in den Hügeln und Bergen und boten mit ihren schwarzroten Ziegeldächern, welche aus reichen Obstbaumbeständen hervorlugten, reizvolle Bilder.

Bei Izvor verläßt die Straße das Tal und beginnt an der Babuna entlang ins Gebirge aufzusteigen. In immer kühner werdenden Serpentinen führt sie allmählich die Hänge hinauf; zunächst überschreitet sie auf zahlreichen Brücken den windungsreichen Bach. Nach Stepanci, dem späteren Endpunkt der Kleinbahn, beginnt die stärkste Steigung, die schließlich steil zur Paßhöhe von $1060 \mathrm{~m}$ hinaufsteigt. Hier verläßt die Straße den Babuna- 
fluß und folgt zunächst einem seiner Zuflußbäche, der den Namen Desna führt. Weiter oben fährt man an einer starken Mineralquelle mit erfrischendem Wasser vorbei, wo meist eine kurze Rast gemacht wurde. Je weiter man hinauf kommt, desto grüner werden die Berge, welche schließlich eine Höhe von etwa $1600 \mathrm{~m}$ erreichen. Die höheren von ihneı sind oben dicht bewaldet. Die Kuppen haben schöne, mannigfaltige Formen, sie zeigen steile Hänge, sind von tiefen Schluchten durchzogen, einige der ferneren Höhen sind kahle Felsengipfel.

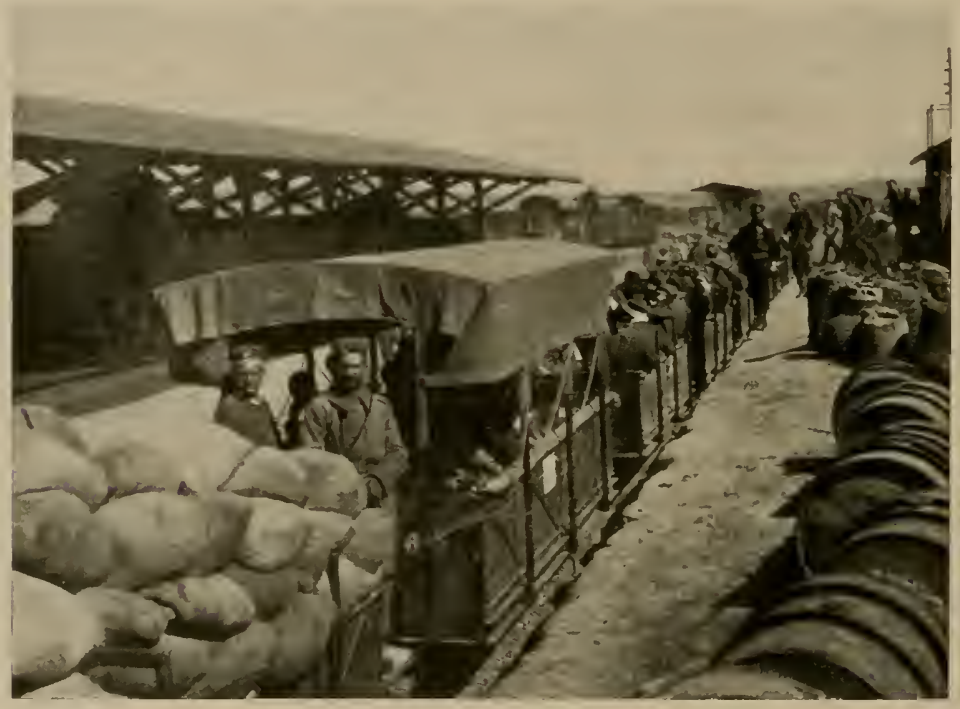

Abb. 2I6. Am Feldbahnhof in Drenovo.

Ein mit Silberlinden bewachsener Berg, besonders ein tiefer, von Vegetation erfüllter Einschnitt an seinem Hang verlockte mich zu einer Exkursion. Es war in einer Höhe von etwa $700 \mathrm{~m}$. Ein frischer Bach strömte durch das rote Gestein, welches in mächtigen Platten ausgebildet war, auf denen man leicht die Schlucht aufwärts klettern konnte. Hier war dichtes Buschwerk; Kräuter und Wiesenpflanzen, welche vor 3 Wochen bei Kaluckova geblüht hatten, waren jetzt im Juni hier in schönstem Flor, so Salbei, viele Doldenpflanzen, Malven, Klee- und Wickenarten. Dem entsprach auch die reiche Insektenwelt, die auch aus annähernd denselben Formen sich zusammensetzte, welche vor einigen Wochen die Fluren bei Kaluckova und Hudova belebten. Von Schmetterlingen flogen 
auch hier die Frühlingsgeneration von Distelfalter, Ochsenaugen, Weißlingen, vor allem des Baumweißßlings, dazu zwei Satyriden, die offenbar Bergformen waren, da ich sie in der Ebene nicht beobachtet hatte. Ähnlich verhält es sich mit den Käfern, unter den Cetonien (Rosenkäfer) besonders häufig waren, den Bienen, den Fliegen. Von Libellen herrschten hier die schönen, metallisch blauen Wasserjungfern (Caloptery'x) vor. Der Reichtum der Pflanzenund Tierwelt war offenbar durch den Wasserreichtum, das spätere Auftreten der Formen durch die Höhenlage bedingt.

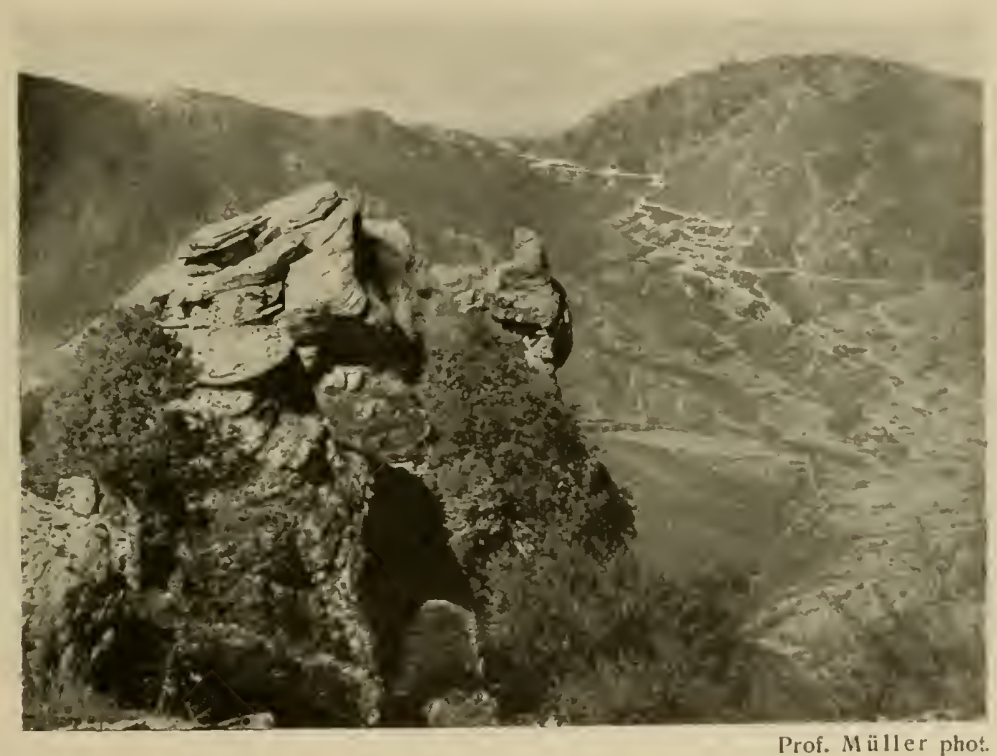

Abb. 217. Paßende der Babunastraße, von dem Felsen über Han Abdipasa.

Bei der Weiterfahrt nahm die Paßstraße immer mehr den Charakter einer Hochgebirgsstraße an. Immer enger wurden die Windungen, immer verwegener die Kurven, steiler die Steigungen, welche das Auto keuchend und fauchend emporklomm. Prachtvolle Rückblicke eröffneten sich auf die Talwindungen mit ihren vielgestaltigen Abschlüssen. Jedes Bild wurde verschönert durch die dunklen Wolkenschatten, welche auf die Hänge fielen.

Kühle Luft wehte mich an, als der Wagen die alte Pal\}karawanserei, den Han Abdipasa, erreichte. Diese lag in einem tiefen Taleinschnitt, dessen Hintergrund die Paßhöhe abgrenzte. Über ihm waren alle Berge bewaldet; Eichenwälder dehnten sich aus und zwischen ihnen verriet der Silberglanz, der mit dem Wind 
über die Waldoberfläche in Wellen dahinzog, große Bestände von Silberlinden. Beim Han Abdipasa befand sich ein kleines Lazarett, in welchem mein Mitarbeiter, Professor Müller, im Sommer I 918 mehrere Wochen als Gast verbrachte. Viele seiner Aufzeichnungen zeugen von der reichen Vogelwelt in diesen Bergen und Wäldern.

Jenseits des Han stieg die Straße immer steiler in immer engeren Serpentinen zur Paßhöhe hinan. Hier war sie noch nicht vollkommen ausgebaut, so daf mein Auto ab und $\mathrm{zu}$ in kritische Situationen kam. Auf ihr staute sich manchmal der ungeheure

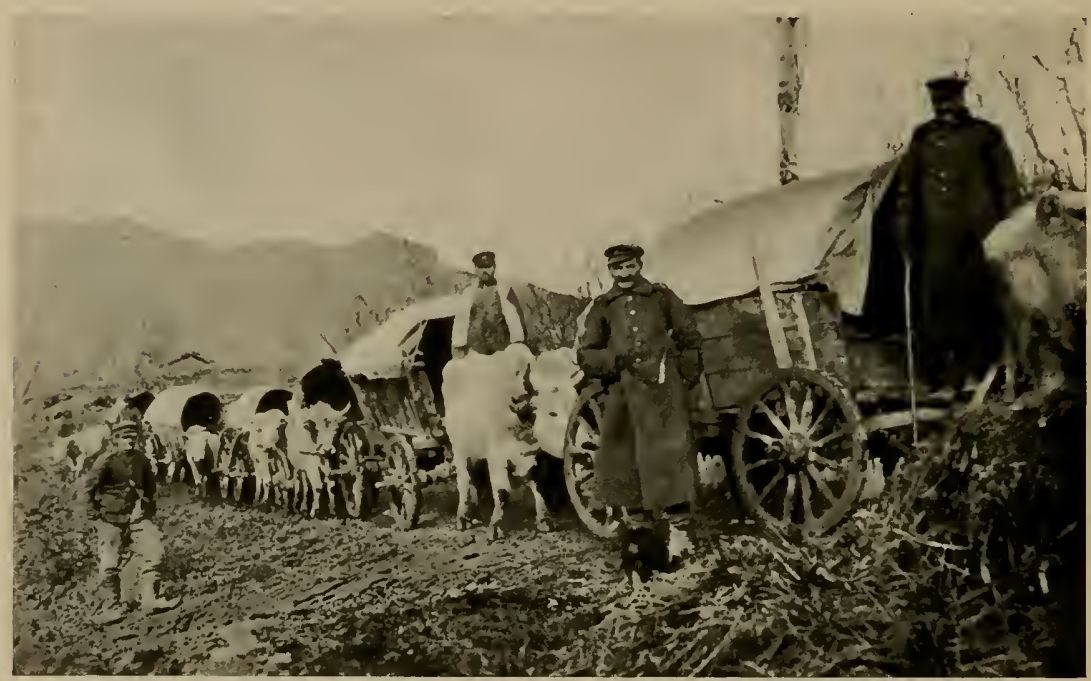

Abb. 218. Bulgarische Ochsenkolonne auf dem Marsch.

Verkehr, der sich zwischen Front und Etappe vollzog. Es war nicht langweilig, auf dieser Straße zu fahren. Außer der schönen Landschaft brachte die Straße selbst genug Abwechslung. Jetzt marschierte eine bulgarische Infanteriekolonne frontwärts verstaubt und müde an uns vorbei, dort hielt an einer Kurve eine Batterie deutscher Feldartillerie mit ihren sorgfältig eingewickelten Geschützen. Dann fuhr eine Sanitätskolonne mit Kranken bergab vorbei. In langen Reihen tobten Lastautos vor uns her. Unendliche Züge von bulgarischen Ochsenwagen hatten Mühe durch das Gewühl sich durchzuschlängeln. Hilflos erschien dazwischen ein mazedonischer Bauernwagen, auf dem eine ganze Familie mit Hausrat untergebracht war. Pferde von reitenden Truppen scheuten vor den Autos und waren schwer an den Abgründen vorbei zu bringen. 
Daß es nicht immer glatt abging, zeigten Skelette und Leichen von Pferden und Büffeln, die in der Tiefe lagen, zeigten die auf der Straße zusammengebrochenen Wagen, die an Kurven zertrümmert liegenden Kraftwagen. Da war oft das Ausweichen nicht leicht und gab zu mancher Verzögerung Anlaß. Aber der Eindruck des ungeheuren, fieberhaften Betriebes eines Heeresnachschubes war ganz außerordentlich. Wie trieb das alles nach vorn zur Front! Daneben spielte der Rücktransport der leeren Wagen, der Kranken und Verwundeten eine viel geringere Rolle.

Wie trefflich war der ganze Betrieb organisiert. Überall waren Stationen, Übernachtungs- und Verpflegungsplätze, Reparaturwerkstätten, Lazarette eingerichtet, welche halfen, den großen Betrieb aufrecht zu erhalten. Ohne diese Arbeit des deutschen Heeres wäre es nicht möglich gewesen, die mazedonische Front 3 Jahre lang zu halten.

Der Verlust von Monastir und das Zurückweichen der mazedonischen Front vor dem Heer Sarrails war die Schuld des mangelhaften Nachschubdienstes der Bulgaren. Wir haben zwar im Laufe der Zeit ihre kleinen von Ochsen und Büffeln gezogenen Karren sehr schätzen gelernt. Die zähen, anspruchslosen Zugtiere und deren Treiber können etwas gehöriges leisten, wenn es auf Zeit nicht ankommt. Aber, wenn es sich darum handelte, in kurzer Zeit viel Munition, Heeresgerät, Proviant an einem Ort beisammen zu haben, dann versagte dieses Transportmittel, so viel tausende von Ochsenkarren auch in Bewegung gesetzt wurden.

$\mathrm{Da}$ mußte deutsche Organisationstüchtigkeit eingreifen. Und was diese geleistet hat, davon bekam man an den Stralben nach Prilep einen Eindruck, der Bewunderung herausforderte. $\mathrm{Zu}$ dem starken Verkehr mit Lastautos, zu den Feldbahnen kam als wesentliche Ergänzung ein System von Seilbahnen, welche als Schwebebahnen mit geschickter Ausnützung des Geländes über die Gebirge führten. Nach Prilep waren vier solche geleitet, zwei über den Babuna- und zwei über den Pletwarpaß. Außerdem waren noch eine ganze Anzahl von solchen an den verschiedenen Gebirgsfronten in Betrieb.

Bei der Fahrt sah man an den Drahtseilen schwebend, von Mast zu Mast wandernd, die kleinen Tragwagen dahingleiten, welche Munitions- oder Proviantkisten, Eisenstangen, Wellblech, Pfähle, große Bündel Heu oder Stroh trugen. Hier und da salı man auch einen waghalsigen Soldaten in einem solchen sitzen. 
Das bedeutete ein großes Wagnis. Nicht selten rissen die Drahtseile und die Lasten stürzten herab. Es war nicht leicht, in diesem Gelände den Betrieb ständig aufrecht zu erhalten. Dem kühnen Passagier, der am Drahtseil oft in einer Höhe von hunderten von Metern ein Tal überquerte, in dessen Tiefe ein Fluß brauste, konnte es widerfahren, daß mitten in dieser luftigen Reise der Betrieb stockte; dann konnte er verurteilt sein, die grandiose Aussicht, die sich ihm da oben bot, für mehrere Stunden zu genießen, ja es konnte ihm blühen, in der Höhe zu übernachten. Jedenfalls war es ratsam, sich für eine solche Unternehmung reichlich mit Proviant zu versorgen.

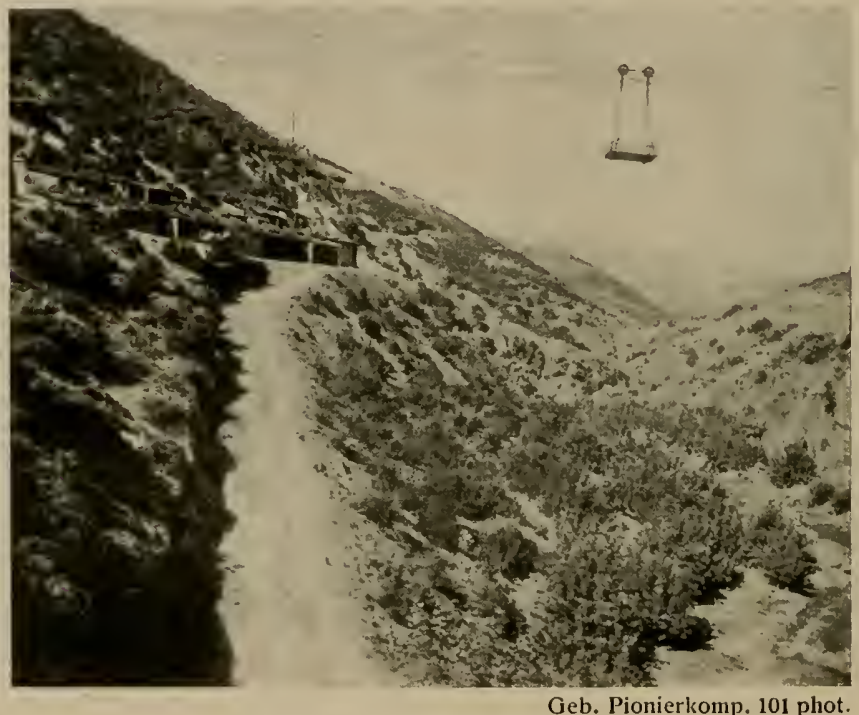

Abb. 219. Schwebebahn.

Die Seilbahnen wurden schließlich auf eine große Leistungsfähigkeit gebracht und beförderten im Tag mehrere hundert Tonnen (bis 30o), so daß vor allem immer der genügende Vorrat an Granaten und anderer Munition für eine mehrtägige Schlacht an der Front bereit lag und kontinuierlich ergänzt werden konnte. Jetzt darf man ja ruhig erzählen, daß schließlich immer an der Front Munition für 4 "Verdunschußtage“ bereit lag; auf der Strecke lag der Vorrat für weitere 2 Tage und am Ende der Feldbahn noch einmal so viel. Das waren ganz große Leistungen; man konnte sie erst ganz einschätzen, wenn man erfuhr, daß um 100 Tonnen ${ }_{15} \mathrm{~km}$ weit in einem Tag zu transportieren 3000 Ochsenwagen mit 6000 Ochsen nötig waren. 
An den End- und Anfangsbahnhöfen der Feld- und Seilbahnen, auf den Umschaltstellen der letzteren war immer ein großer Betrieb, der einen Eindruck von den gewaltigen L.eistungen gab, welche das Heer an dieser schwierigen liront zu erfüllen hatte.

Vom $\mathrm{Pa} \beta$ aus, der in der Höhe von $1060 \mathrm{~m}$ lag, ging es steil in das Tal hinunter, an dessen Ende die Stadt Prilep liegt. Ein seltsamer Anblick bot sich bei der Abfahrt dem Auge dar. Das Tal war ziemlich eng, von zwei steilen Bergketten eingefaßt und erweiterte sich erst kurz vor Prilep, um da in die weite Ebene der Pelagonia auszumünden. Die schroffen Berge, teils aus

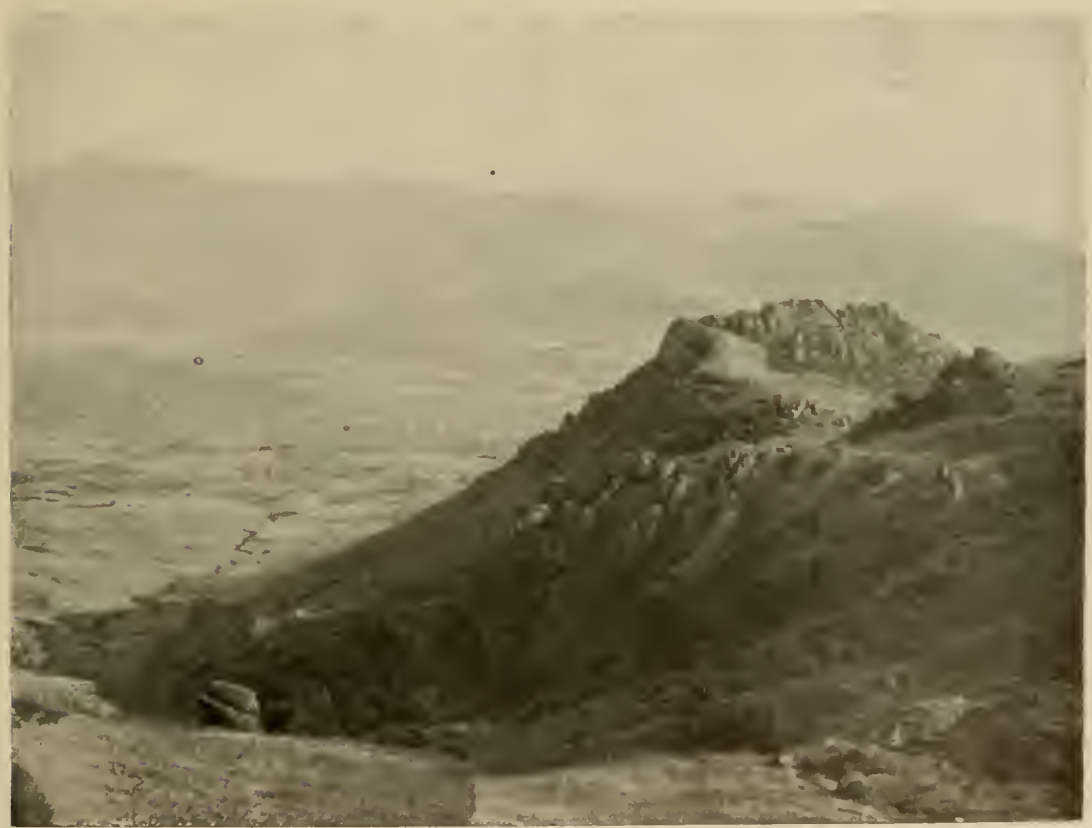

Abb. 220. Granitberg bei Prilep und Blick in das Tal oberbalb der Stadt.

Kalk, teils aus Granit aufgebaut, erschienen fast vegetationslos. Weithin konnte man die weiße Straße in vielen Serpentinen durch das dunkle Gestein bergab verlaufen sehen, überall von Staubwolken begleitet, die der starke Verkehr aufwirbelte.

Durch eine bizarre Felsenlandschaft geht es in sausender Fahrt das Tal hinab, zur Stadt, die allmählich, breit in der Ebene sich ausdehnend, vor den Blicken auftaucht. An halb ruinierten mohammedanischen Grabdenkmälern, einer weißen Kaserne, einem 
öden türkischen Friedhof vorbei, rasselt das Auto über holperiges Pflaster in die Gassen der Stadt binein.

Pappeln, Minarets, Kirchtürme ragen über den dunklen Dächern und grauen Mauern der Stadt auf, die infolge ihres Reichtums an Gärten wie eine Vegetationsinsel aus der dürren Öde des Felsentals sich abhebt. Doch bei der Einfahrt bemerkt man von den Gärten zunächst nichts; denn als echt türkische Stadt zeigte Prilep nach außen nichts von der Schönheit seiner Häuser und Gärten. Lehmmauern begrenzen meist die Straßen, welche die Besitztümer einschließen. Anders wird das Bild erst, wenn man in das Ge-

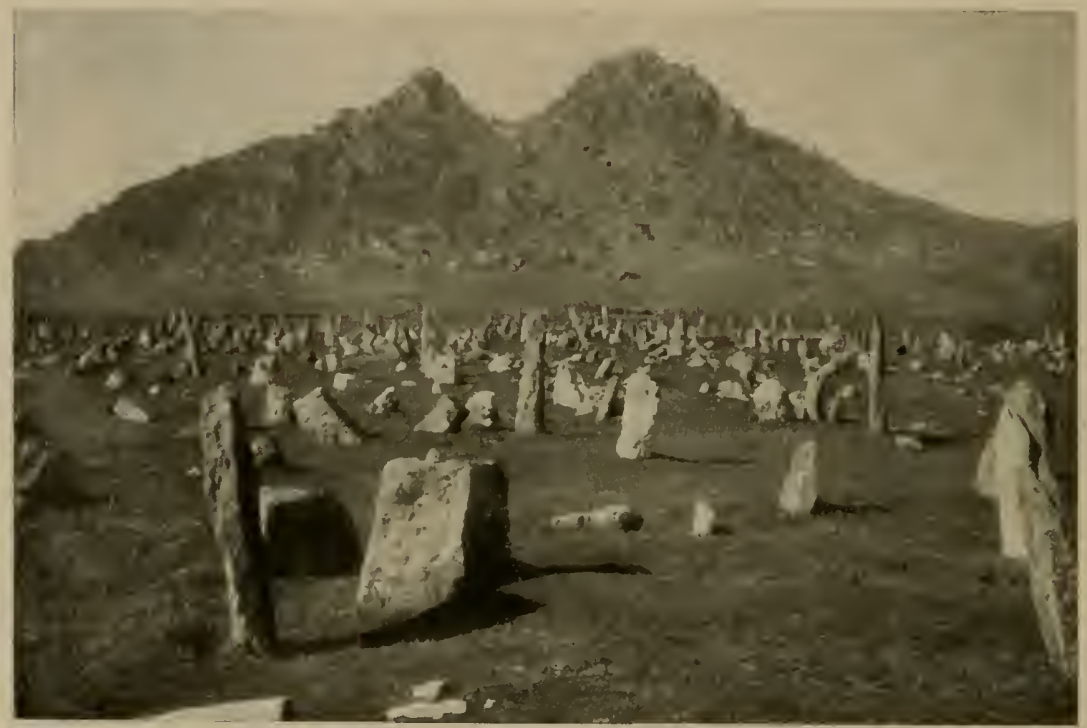

Abb, 221. Türkischer Friedhof von Prilep, dahinter Markograd.

schäftsviertel, den Bazar gelangt, wo das übliche Leben einer orientalischen Stadt vor den offenen Werkstätten und Läden sich abspielt.

In Prilep lag das Oberkommando der XI. Armee. Ihr Befehlshaber war gerade in jenen Tagen Exzellenz von Steuben geworden, eine liebenswürdige, feingebildete Persönlichkeit, in dessen Gesellschaft ich manche behagliche Stunde verbrachte und von dem ich manche Hilfe erfuhr. Das war vor allem bei späteren Besuchen in Prilep der Fall; hier nahm ich im September 1917 an einem Front-Hochschulkursus teil und im Juni 1918 besuchte ich Prilep nochmals. So hatte ich Gelegenheit, auch die nähere Umgebung der Stadt kennen zu lernen. 
Prilep ist von anderen mazedonischen Städten nicht erheblich verschieden; sie hat weniger individuellen Charakter als andere. Weder Kirchen noch Moscheen haben besondere Art und Geschichte. So ist sie eine gleichgültige Stadt, wenn auch das Leben ebenso bunt ist, wie in anderen Städten.

Eigenartig und interessant ist aber die Umgebung von Prilep. Das Tal, an dessen Ende die Stadt liegt, ist von zwei Bergketten eingefaßt, die einander parallel verlaufen und die in mancher Beziehung sich voneinander unterscheiden. Sie streichen in der Hauptsache von Norden nach Süden. Die westliche Kette besteht in

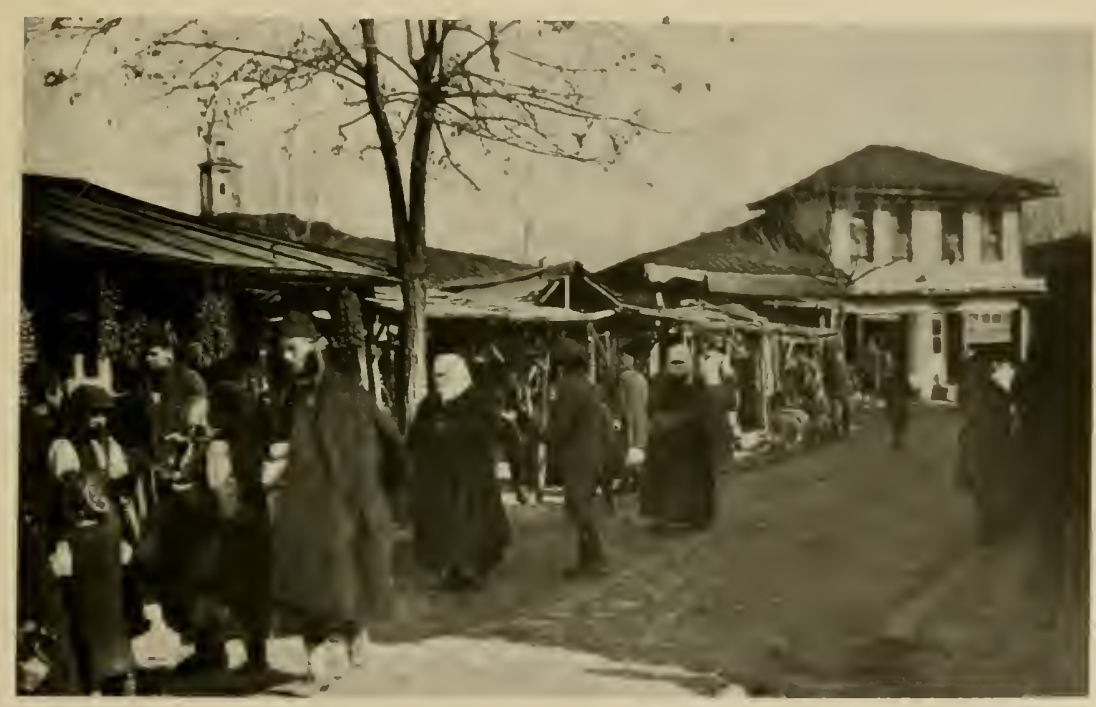

Abb. 222. Geschäftsviertel (Bazar) in Prilep.

ihrem südlichen Teil aus Granit, der an den Bergen in gerade»u bizarren Formen zutage tritt. Weiter im Norden, gegen den Paß $z u$, sind die Berge aus Kalk aufgebaut, aus welchem auch die ganze östliche Kette besteht. Mächtige Marmormassen kommen im Kalkgebiet vor.

Ganz besonders charakteristisch für die Gegend von Prilep ist die Granitlandschaft, die am Varosberg und nördlich von ihm am Zlatovrh, an welchem das Kloster Treskaveč liegt, vorherrscht. Das dunkle, oft rote Gestein mit den gewaltigen Steilwänden, den Hängen voll riesiger Blöcke, der mageren Pflanzenwelt bringt eine Landschaft hervor, welche ganz einzigartig ist. Die Berge sehen aus wie steil aufgetürmte Steinhaufen; tiefe 
Schatten lassen die Spalten scharf von den glatten Flächen des Granits sich abheben.

Besonders gut konnte man die seltsamen Granitformen am Varosberg studieren, welcher als Abschluß der westlichen Kette mit seinen eigenartigen Umrissen in die Ebene südlich Prilep hineinragt. Weithin über die Ebene und von fernen Bergen erkannte man die beiden pyramidenförmigen Gipfel des Varosberges als Wahrzeichen Prileps. Zwei mächtige Granitmassive stiegen steil einige hundert Meter über der Talsohle auf. Die Konturen sind stark zerrissen, feine Zacken und breite Buckel überragen

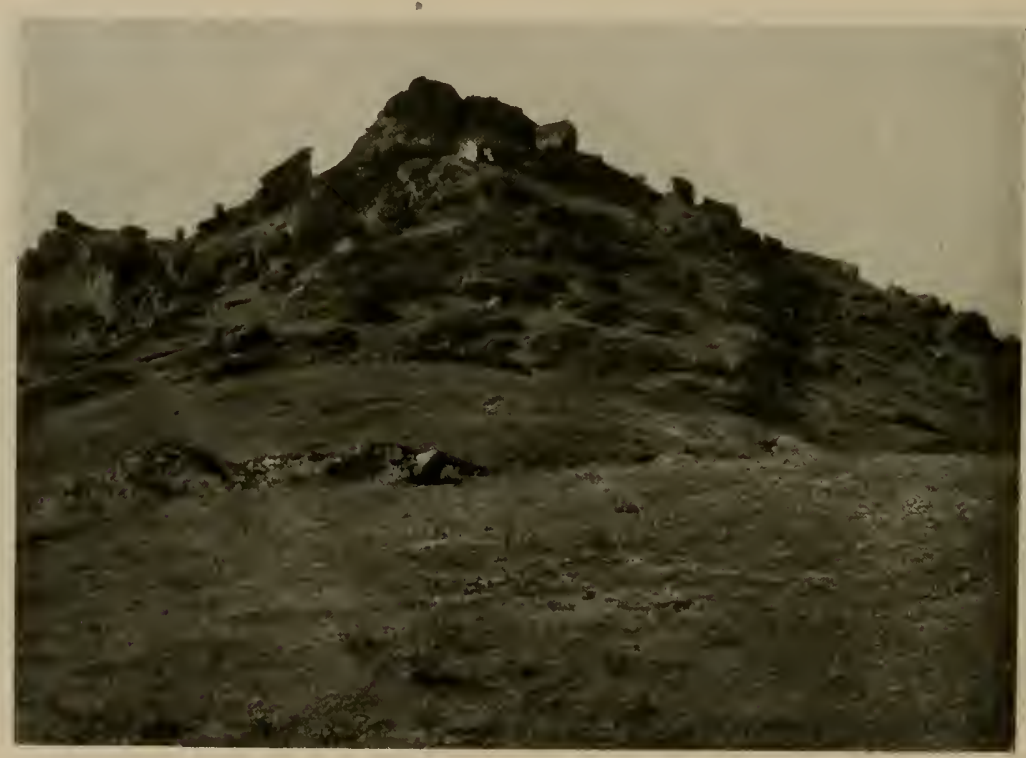

Abb. 223. Granitberg nördlich von Prilep.

allenthalben den Umrilo und geben seinen schönen Linien etwas eigenartig unruhiges. So sind auch die Abhänge, welche nur in der Gipfelregion einzelne größere Flächen zeigen; sonst sind sie von kleinen und großen -Gesteinsbrocken bedeckt, die übereinander geschichtet eine oft unübersehbare Wirrnis bilden, ein starkes Hindernis für die Ersteigung des Berges, da es sich um mächtige Blöcke mit Durchmessern von Io-50 Metern und mit glatten schlüpfrigen Wänden handelt. Viele von ihnen haben die sogenannte Wollsackform mit abgeschliffenen, gerundeten Kanten. Eigenartig malerisch sehen sie vor allem dann aus, wenn 
sie mit dunkelbraunen Moospolstern und grauen Flechten bedeckt sind. Dann heben sie sich farbig vom kurzen Rasen ab, der zwischen ihnen die Hänge bedeckt, welche die Möglichkeit zum Besteigen der steilen Berge geben.

Neben den einjährigen Pflanzen und allerhand Kräutern und kleinen Büschen, welche diesen Rasen bilden, außer den in den Spalten der Felsen wachsenden Pflanzen, spielen Sträucher und Bäume im Granitgebiet bei Prilep eine geringe Rolle. Wa ch holder ist hier der häufigste Strauch und die Form, die hier vorkommt (Juniperus excelsa L.), wächst manchmal zu stattlichen Bäumen heran und bietet damit einen überraschenden Anblick.

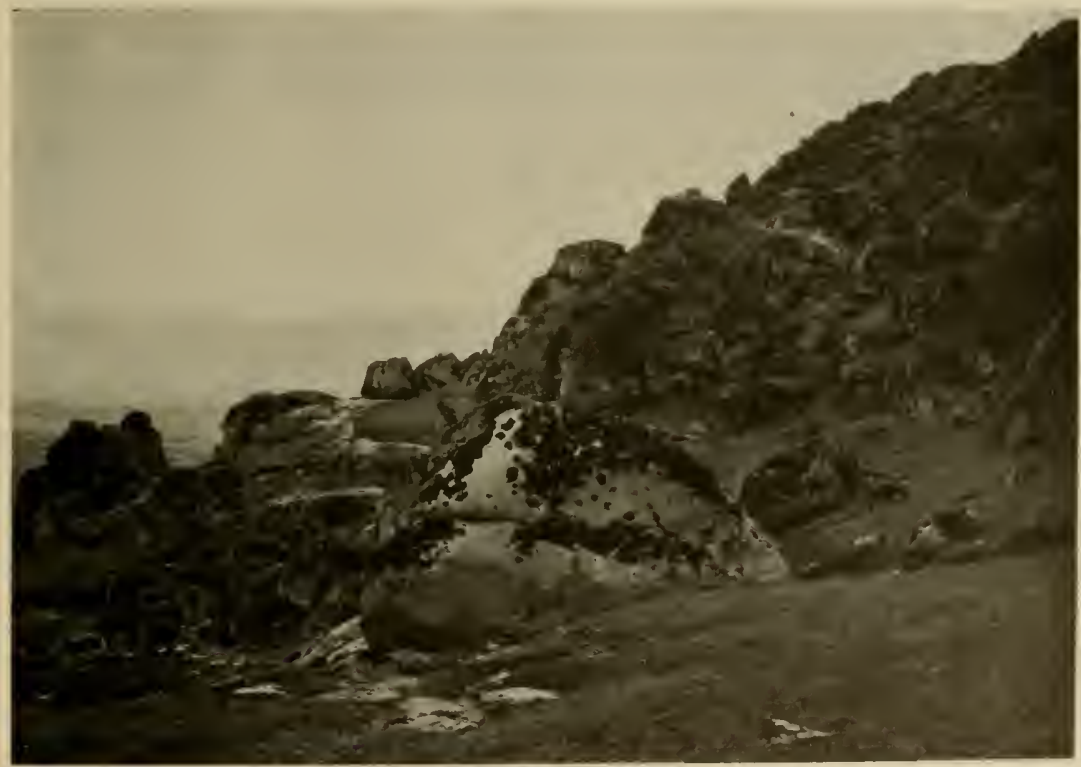

Abb. 224. Granitfelsen mit Moos und Flechten bewachsen.

Auch die Tierwelt war an diesen Hängcn nicht übermäßig reich. Immerhin flogen zahlreiche Schmetterlinge, unter denen ein Bläuling (Lycacna admetus Esp.) besonders auffiel. Da, wo Ticre geweidet hatten, gab es viele Mistkäfer, vor allem Pillendreher, von denen hier Scarabaeus sacer L. und S. pius Illig eifrig beim Pillendrehen waren. Auch ein stattliches Exemplar des glänzend schwarzen Baumschröters (Sinodendron cylindricum I..) fand sich hier und wies darauf hin, daß die weitere Umgebung nicht ganz baumlos sein konnte. Eine große Raubfliege Schizopogon sculiger Lw. machte sich in größeren Mengen bemerkbar. 
Auch Heuschrecken gab es an den heißen Hängen in großer Zahl. Nicht weiter erstaunlich war es, hier Felsenvögel zu beobachten, unter denen waren bemerkenswert der muntere Felsenkleiber (Sitta neumayeri Michah.) und das Steinhuhn (Alectornis graeca graeca Meissn.), das mit knatterndem Flug mehrmals vor mir aufstieg; dabei stieß ich in Juni 1917 auf ein Gelege von Io Eiern, welches in einer Mulde zwischen Steinen lag.

Bei weiterem Aufsteigen wurde immer deutlicher, daß die eigenartigen Umrisse des Berges nicht nur das Werk von Naturkräften waren, sondern daß auch Menschenhand dabei mitgewirkt hatte. Auf beiden Gipfeln waren Mauerreste erkennbar, welche von einer sehr ausgedehnten Burg herrühren mußten. Wie aus dem Felsen gewachsen, erhoben sich Türme, Durchgänge waren von Rundbogen überwölbt, Häuser waren noch deutlich als einstmals mehrstöckige Gebäude zu erkennen; hohe, steile Mauern zeigten noch Reste von Zinnen und waren von mächtigen Walltürmen eingefaßt.

Es waren die Reste der Burg Markograd, von der noch manche sagenhaften Erinnerungen bei den slavischen Mazedoniern berichten. Nach der Bauart handelt es sich wohl um einen Bau aus dem späten Mittelalter. Den beiden Gipfeln entsprechend handelt es sich um zwei Burganlagen, welche durch einen großen Mauerring umfaßt waren. Bemerkenswert ist der Mangel an Schießscharten und überhaupt die Seltenheit nach außen gerichteter Fensteröffnungen. An den Türmen wiesen Balkenlöcher darauf hin, daß einstmals bedachte Holzgallerien diese außen umgaben. Am Abhang sind die Reste einer Außenbefestigung zu erkennen, welche offenbar die ganze große Anlage vor Angriff schützte. An einer Seite, in der Richtung gegen die Stadt Prilep, glaubt man die Reste einer Zufahrt zu bemerken; sie führt zu einem Eingang mit auffallend engem Torbogen.

Es war schwer, sich eine bestimmte Vorstellung von Alter und Entstehung der Burg zu machen. Der Tradition nach war es die Burg des serbischen Helden Marko Kraljevič, von dem phantastische Sagen im Umlauf sind, in denen er als Riese und fast als Gespenst auftritt. Aimé Boué scheint vor roo Jahren die Bauten etwas besser erhalten gesehen zu haben. Er schreibt von einer Kapelle und einer Quelle in einem Turm an der Ostseite, die ich nicht auffand. Bei letzterer mag es sich doch wohl um eine Zisterne gehandelt haben. 
Beim Herumklettern auf den Felsen und in den Ruinen gab es viel zum Schauen und zu beobachten. Wie malerisch bauten sich Türme und Wälle auf den Felsblöcken auf. Man überlegte sich, ob wohl der eine zweistöckige Bau das Frauenhaus, ein anderer größerer das Männerhaus gewesen sei.

An den Felsen in der Gipfelregion zeigten tiefe glatte Rinnen, Furchen, blanke Rundungen, untergreifende Rillen, daß gewaltige Naturkräfte an der Ausgestaltung dieser Formen gearbeitet haben mußten. Man konnte sich kaum vorstellen, daß all das schon beim Übergang aus dem feuerflüssigen Lustand des Granits entstanden

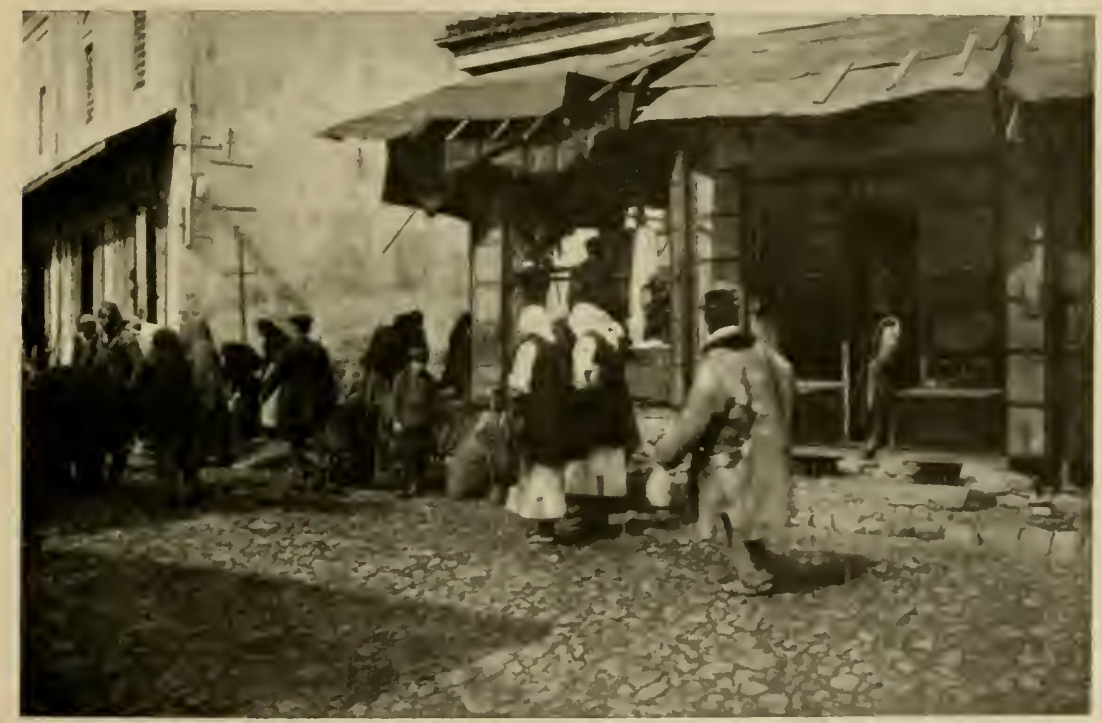

Abb. 225. Im Geschäftsviertel von Prilep.

war. Unwillkürlich multe man an Wasserkräfte denken und in der Phantasie trat beim Blick auf die weite Ebene in Süden des Berges das Bild eines großen Sees auf, der einst sich bis Monastir ausgedehnt haben mag. Die geologische Beschaffenheit des Bodens der Ebene, der Verlauf der Cerna läßt tatsächlich eine solche Annahme zu. Als der See verschwand, mochte auch der Berg hier sich gehoben und in seine Höhen die Spuren der Wirkungen eines kräftigen Flusses mitgenommen haben.

Jetzt schweift der Blick weit über die dunstige Ebene, welche in der Ferne von einem Kranz von Bergen eingefaßt ist. Direkt nach Westen sieht man in der Babaplanina an klaren Tagen 
die weiße Häusermasse von Krusevo aufschimmern. In weitem Bogen fassen die Berge nach Süden; schneebedeckt erhebt sich aus dieser Kette die schöne Pyramide des Peristeri. Kahle Berge ziehen am Ostrand der Ebene als Selecka Planina südwärts zum Cernabogen. Von diesem erstreckte sich zur Zeit meines Besuches die Front über Monastir westwärts zum Peristeri, von da zum Prespa- und Ochridasee; man ahnte die Lücken in den Gebirgen, in denen die Seen lagen und sah jenseits von ihnen Bergketten, die schon zu Albanien gehörten.

Wie von einem Turm konnte man zwischen den Felsen, durch ein Mauerloch oder eines der alten Fenster nach Osten zu steil auf die Stadt Prilep hinunterblicken. In der Vogelperspektive lag das Häusergewirre mit seinen Gärten und Pappelgruppen, mit seinen Kirchen und Minarets weit auf dem Talboden ausgebreitet. Von hier aus sah die Stadt ganz anders malerisch und reizvoll aus, als innerhalb ihrer Gassen.

Jenseits im Osten stiegen wieder Bergketten mit klar umrissenen Konturen empor, die Kalkberge der Ostkette des Tales von Prilep, während nach Norden die wilden Formen der Granitberge den weiteren Ausblick verhinderten.

Es war nicht einfach, vom Gipfel und der Burg nach Westen über die glatten Granitplatten zu Dorf und Kloster Varos herabzuklettern. Einer meiner Begleiter glitt an gefährlicher Stelle aus, rutschte über eine Felsenfläche weit hinab und entging nur durch einen Glückszufall einem bösen Schicksal.

Aus dem Bild des in einer Nische des Granitfelsens eingeschmiegten Klosters kann man entnehmen, welche tolle Kletterei wir hinter uns hatten, als wir vom Gipfel an der Hinterseite des Klosters ankamen. Hätte es nicht einen so eigenartigen Hintergrund in den Granitmassen des Berges, welche fast wie erstarrte Lavaströme aussehen, so würde es sich kaum von vielen der Balkanklöster unterscheiden. Immerhin ist die Anordnung der im rechten Winkel zueinander stehenden Gebäude, von denen das eine zwischen zwei im oberen Stockwerk vorragenden Flügeln eine graziöse Säulengallerie einfaßt, das andere zwei Säulenhallen in Holzbau übereinander zeigt, recht eigenartig. Die Kirche mit allerlei alten Architekturbestandteilen füllt die Ecke zwischen beiden Gebäuden aus. Hohe Grundmauern tragen die Fundamente der Bauten, so daß man vom Dorf aus eine hohe Treppe zu ersteigen hat. 
Im letzteren steht eine interessante Kirche, von einem Friedhof mit den üblichen Kistengräbern umgeben. Die Nord- und Ustseite ist mit einer langweiligen weißen Bogengallerie verbaut. Von der Süd- und Westseite zeigt aber das Kirchlein den malerischen altmazedonischen Typus bulgarischen Ursprungs. Sie scheint allerhand Schicksale durchgemacht zu haben, so daß die ursprüngliche Anlage kaum mehr zu erkennen ist. Jedenfalls ist sie von einem graziösen zehnsäuligen Kuppelturm überragt; an der Westseite sieht man noch die Anlage von Konchen, die verschiedene Art und Behandlung der Bausteine weist auf viele Reparaturen hin.

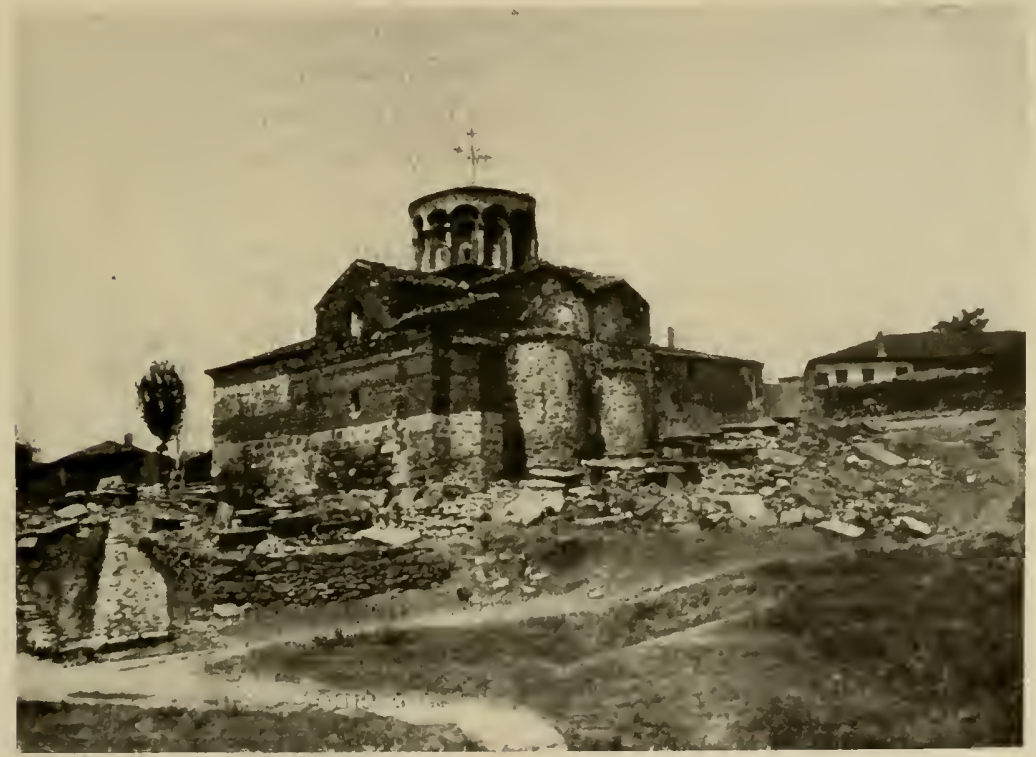

Abb. 226. Kirche im Dorf Varos.

In vieler Beziehung interessanter ist das hochgelegene Kloster Treskawetz, welches auch in der Granitkette, und zwar auf einer Höhe von $1226 \mathrm{~m}$ gelegen ist. Als im September 1917 in Prilep ein Hochschulkursus stattfand, den das Oberkommando für die Studenten der XI. Armee veranstaltete, und bei welchem wir Professoren unsere Vorlesungen in einer Moschee abhielten, gehörte zu den besonderen Veranstaltungen uns zu Ehren auch eine Bewirtung durch die Stadt Prilep in diesem altheiligen Kloster.

An einem Nachmittag ritten wir die 2 Stunden durch die grandiose Granitlandschaft auf den Berg hinauf. Das Kloster, 
eigenartig in seltsame Felsen eingebaut, war eine weitläufige Anlage, von hohen Mauern umgeben. Zwischen den Türmen und Schornsteinen ragten Granitklötze empor, welche in ihren bizarren Gestalten fast wie Menschenarbeit aussahen.

Das Kloster erfüllte seine Aufgabe als Festquartier sehr gut, denn es war in mächtigen dreigeschossigen Galleriebauten mit einer großen Anzahl sauberer Zimmer ausgestattet, welche viele hundert Pilger aufnehmen konnten. Schon am Eingang zum Kloster waren wir von dem Bürgermeister von Prilep, angesehenen Bürgern dieser Stadt, bulgarischen Beamten und Offizieren feierlich empfangen worden.

In einer rebenumrankten Veranda fand ein Festessen statt, bei welchem wir mit den Bulgaren vereinigt saßen und bei welchem politische Reden gehalten wurden. Der Bürgermeister, ein blasser, schlanker Mann, der als bulgarischer Verschwörer lange Jahre in türkischen Gefängnissen gelegen hatte, hielt eine feurige deutschfreundliche Rede, auf welche der Kenner der griechischen Literatur und der antiken Geschichte Mazedoniens v. Willamowitz, der Berliner Professor in formvollendeter, feiner Rede antwortete.

In angeregten Gesprächen durchwanderte man dann zusammen die Räume des Klosters und besichtigte vor allem die ehrwürdige Kirche, deren Ursprung die Bulgaren auf das 9. Jahrhundert zurückführen wollen. Es war sehr interessant, mit den gebildeten Männern durch die für sie traditionsreichen Räume $z u$ wandern und den Erzählungen zu lauschen, welche von dem alten Zusammenhang ihres Volkes mit Mazedonien berichteten.

Es war bemerkenswert, wie sie mit einer wahren Zärtlichkeit sich in die alten Erinnerungen versenkten, als wir alte heilige Bücher anschauten und uns ein Gewölbe gezeigt wurde, das erst vor nicht langer Zeit aufgedeckt wurde, und in welchem ein russischer Gelehrter wichtige alte Urkunden aufgefunden habe. Alte halbzerstörte Fresken an der Wand lösten die Erinnerung an den großen Zaren Simeon aus, der einst ein großes Bulgarenreich über fast der ganzen Balkanhalbinsel beherrscht und das Kloster Treskaveč unterstützt hatte.

Wehmütig wurden ihre Erzählungen, als sie auf den Zaren Samuel zu sprechen kamen, der während seiner 4ojährigen Regierung (976-1014) eine Unmenge von Wechselfällen in den unaufhörlichen Kriegen mit Byzanz erlebte, in Ochrida glänzend residierte, dem aber schließlich in dem Konstantinopeler Kaiser 
Basileus Bulgaroktonos ein furchtbarer, blutdürstiger Gegner erstand. Der machte schließlich durch die Schlacht an der Belasiza Planina bei Strumiza all dem, was Samuel in seinem Leben erreicht hatte, ein Ende. Ja, er bringt ihm indirekt den Tod, indem er ihm 15000 bei Strumiza gefangene Bulgaren geblendet, unter der Führung je eines von hundert, der nur einäugig gemacht wurde, nach Ochrida zurückschickte. Bei deren Anblick ist er so erschüttert, daß ein Schlaganfall den greisen Mann trifft und tötet.

Es ist eine tragische Geschichte, welche durch die 700 Jahre bis zur Unterjochung durch die Türken auf den Balkanvölkern

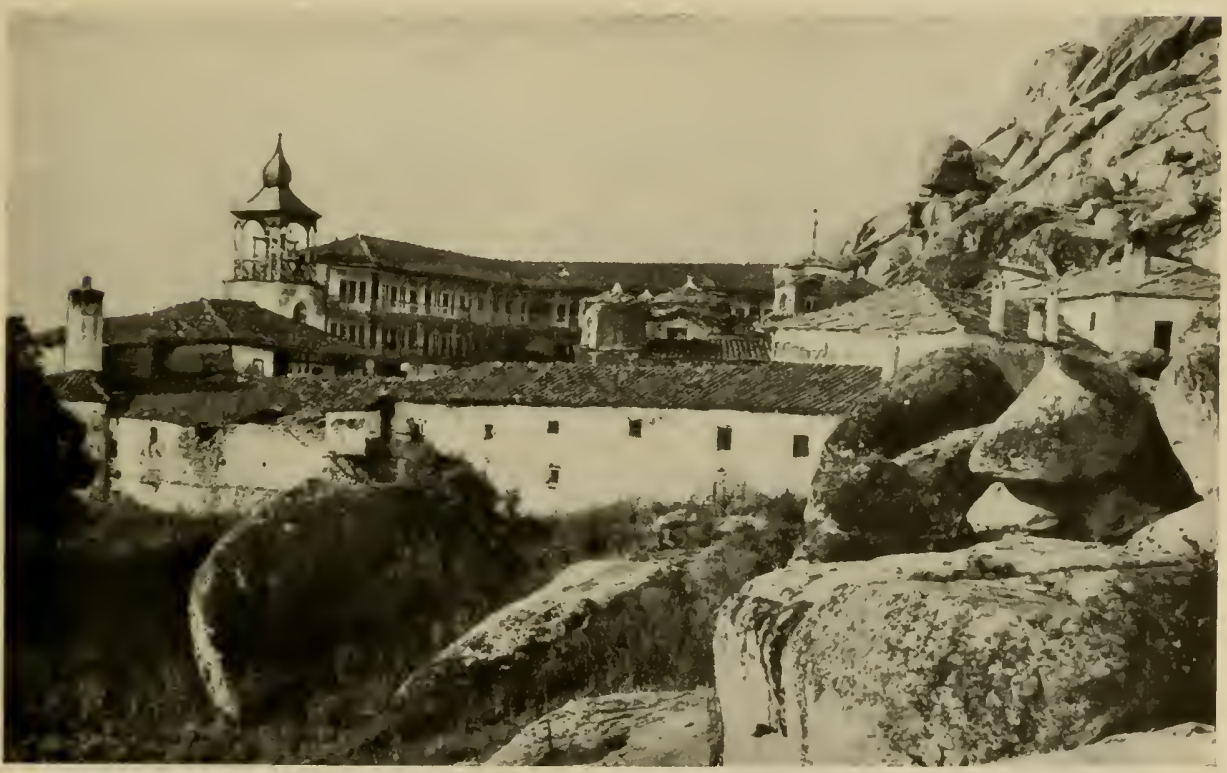

Abb. 227. Gesamtansicht des Klosters Treskaveč.

lastet und heute noch nicht zum Abschluß gebracht ist. Immer wieder wird die Ruhe auf der Halbinsel durch Völkerwanderungen erschüttert, die stets zunächst auf die Slaven stoßen. Deren unversöhnliche Gegensätze zu den Griechen treiben sie von einem Krieg in den andern durch all die Jahrhunderte hindurch. Immer wieder kommen sie wieder in die Höhe, gründen neue und größere Reiche, die bald wieder zusammenstürzen. Einmal über das andere Mal stehen bulgarische Heere vor Konstantinopel, ohne daß es ihnen jemals gelingt, die Weltstadt einzunehmen. Immer wieder werden sie in den Abgrund gestürzt und unterjocht, um nach neuer 
Freiheit und neuem Glanz zu streben. $\mathrm{Zu}$ allem Unglück kommt noch die Feindschaft zu dem Brudervolk der Serben, die im Laufe der Jahrhunderte immer bitterer geworden ist und beide Völker verhinderte zu Größe und Selbständigkeit zu gelangen. Dann kamen die Jahrhunderte türkischer Knechtschaft, die jedes Streben nach Unabhängigkeit unterdrückte, bis mit der Zerrüttung des Türkenreiches sich neue Hoffnung regte.

Nun waren sie endlich so weit, auf bessere Zeiten blicken zu dürfen und nun liegen sich die Balkanvölker wieder als bitterste Feinde in den Haaren. Seufzend gestehen sie das zu, aber mit

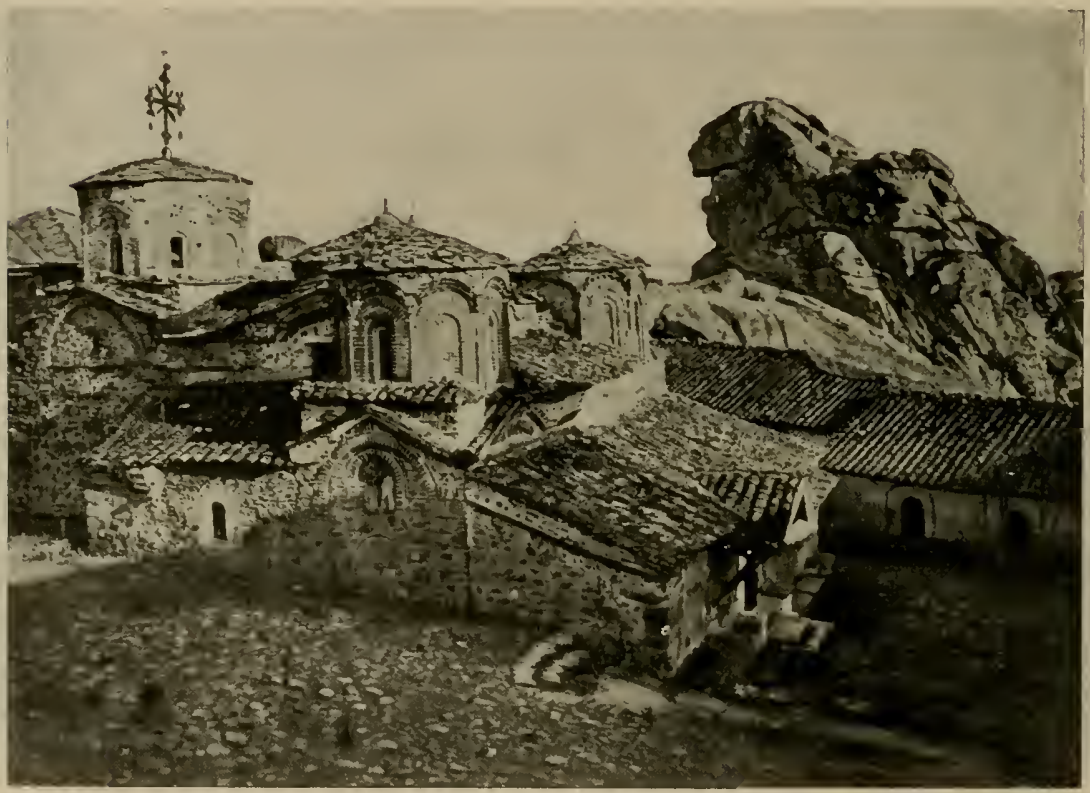

Abb. 228. Kirche im Kloster Treskaveč im Granitgebirge.

glänzenden Augen sprechen die Bulgaren die Hoffnung aus, mit Hilfe der Deutschen endlich das Ziel zu erreichen, die ersten auf dem Balkan zu werden.

Nun schweifen ihre Gedanken ab und tauchen in das Gebiet der Sagen und Märchen. Sie erzählen von der Zarin Maria, welche den Sultan heiratet und mohammedanisch wird, um ihr Volk zu retten. Sie kommen auf die Geschichte von der Schlange und dem Blitz und von den zwei Hirten. Darüber ist die Zeit vergangen und nach freundschaftlicher Verabschiedung trenne ich mich von den 
bulgarischen Herren und steige in der Abenddämmerung die steilen Hänge zum Tal, zur Stadt hinab.

Die Strahlen der sinkenden Sonne dringen tief in das Tal hinein und gönnen tiefen Einblick in die phantastische Landschaft, in der ich plötzlich nach den starken Eindrücken des Nachmittags ganz eiusam wandere. Öde und baumlos liegt eine schroffe Granitpyramide vor mir; scharf und klar treten die einzelnen Felsblöcke, die Rinnen und Schluchten infolge der langen Schatten hervor. Immer schöner und malerischer werden die Bilder. Vor einem kahlen Felsenberg tut sich ein kleines Tälchen auf, in seiner Tiefe

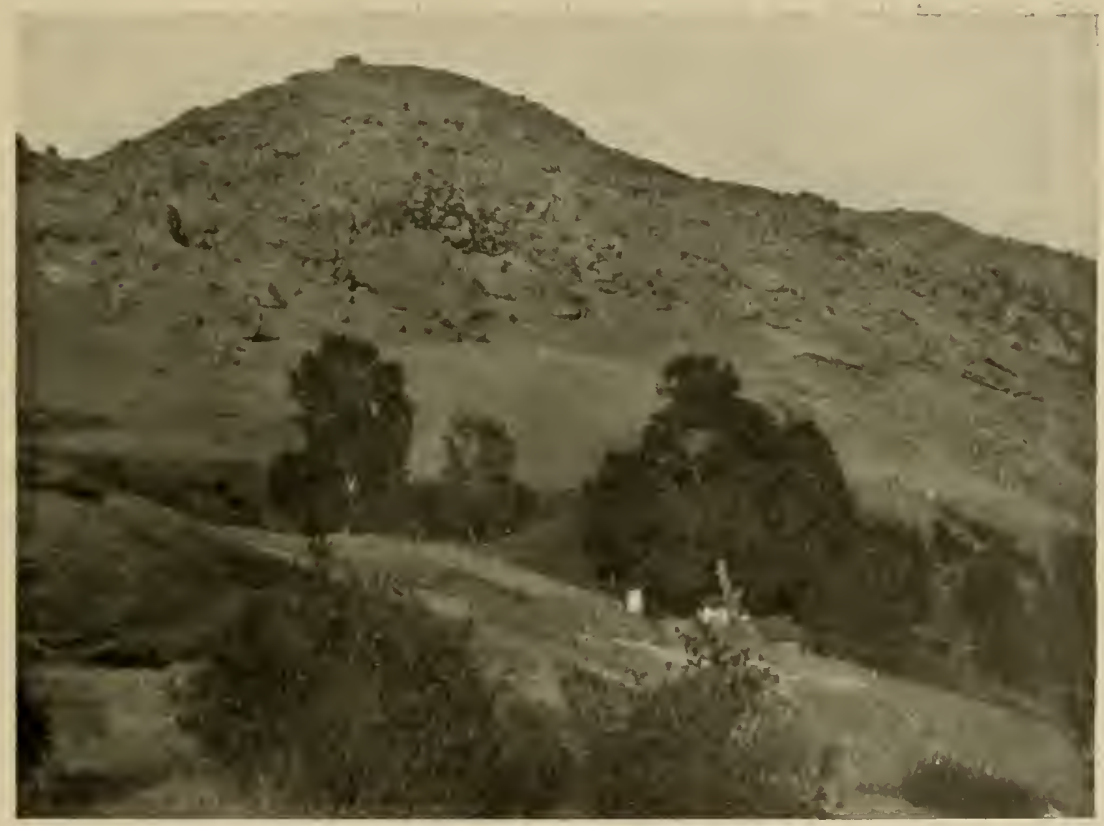

Abb. 229. Türkenbrunnen in der Granitlandschaft beim Kloster Treskaveč.

leuchtet üppiges Gras empor, Bäume und Büsche umgeben einen weiß blinkenden türkischen Brunnen. Er verrät uns die Ursache des starken Pflanzenwachstumes. Wie stets sind Schattenbäume um diesen erquickenden Brunnen gepflanzt, welche die Stätte zum geeigneten Ruheplatz im letzten Drittel des heißen Anstieges zum Kloster machen.

Von der Quelle aus schweift mein Blick zu den Bergketten des Kalkgebirges auf der jenseitigen Seite des Tales. Drüben sehe ich eine weiße Straße aufblinken., und sich den Bergen drüben 
aufwärts der Talwand anschmiegen und in das Massiv vordringen. Staubwolken liegen über der Straße und verraten, daß auch hier abends ebenso starker Verkehr ist, wie auf der Babunastraße. Es ist die Straße, welche zum Pletw ar pa 8 führt, die zweite Verbindung von Prilep mit dem Wardartal.

Auch die Pletwarstraße habe ich einmal auf der Fahrt von Prilep zur Haupteisenbahn Mazedoniens benützt. Es war im Sommer 1917; nach den Qualen durch Hitze und Staub, denen ich damals ausgesetzt war, spürte ich keine Verführung, die Fahrt öfter zu machen, zumal ich die interessanten. Gebiete am Ende der Strecke öfter zu besuchen Gelegenheit hatte.

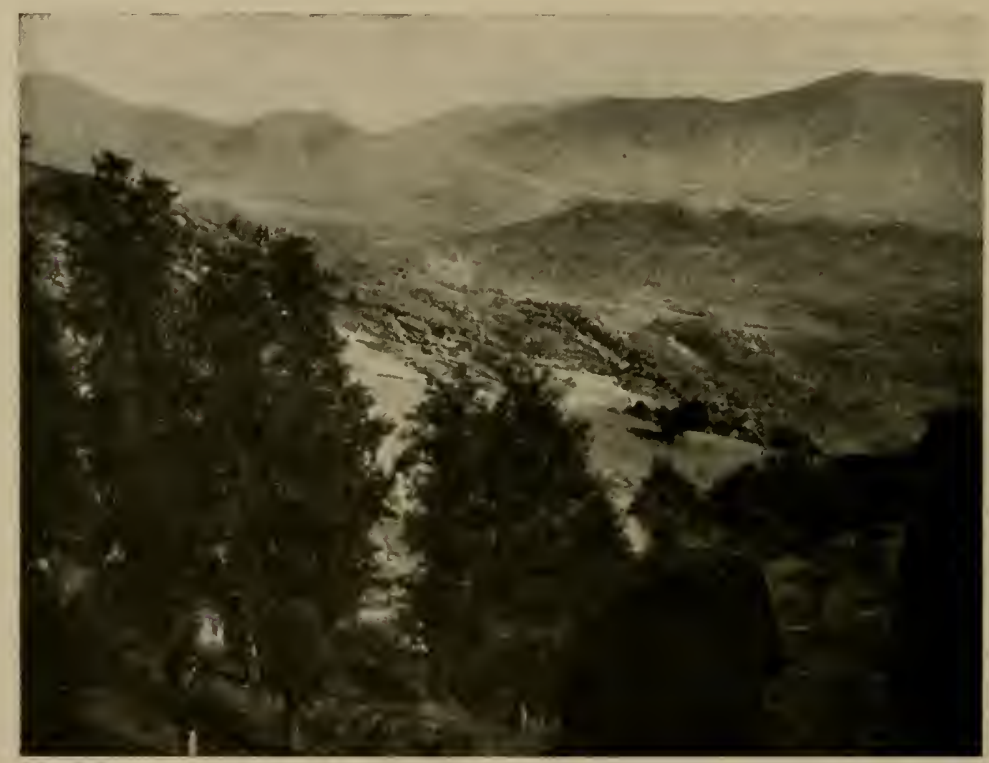

Abb. 230. Hain im Granitgebirge bei Treskaveě. Blick ins Tal von Prilep und auf den Beginn der Pletwarstraße.

An sich war dieser $P a ß$ nicht weniger interessant als die Babunastraße, manche Strecken sogar besonders romantisch. Von Prilep kommend, bog man bald rechts von der Babunastraße ab und fuhr steil an der östlichen Talseite aufwärts. Im Juni 1917 war die Straße sehr zerfahren und der Verkehr sehr gesteigert. Es wurde fieberhaft an der Kleinbahn gebaut, welche damals bis Trojazi reichte, in einigen Monaten aber bis Prilep durchgeführt wurde und von da Anschluß erhielt einerseits gegen Monastir und den Cernabogen, andererseits die Cerna aufwärts über 
Pribilci bis Lera unterhalb Gopes, und damit die Verbindung mit den Fronten am Prespa- und Ochridasee und Albanien herstellte.

Bei der Fahrt war mein Auto stets in eine dichte Staubwolke gehüllt, denn es herrschte regster Verkehr. Er war eher stärker als am Babunapaß; denn hier wurden die Truppentransporte hauptsächlich weitergeleitet. So sah man in den offenen Kleinbahnwagen deutsche, österreichische, ungarische, bulgarische Truppen auf dem Transport, wobei sie auf jeder Station den heimwärts reisenden Urlaubern begegneten. Landstraße und Schienenstrang der Kleinbahn waren zu beiden Seiten auch hier auf diesem Paß von den Leitungen der Seilbahn begleitet, an denen unablässig leere und gefüllte Tragen, die sogenannten Hunde, nach oben und unten wanderten.

Bei der Fahrt den $\mathrm{Pa}$ aufwärts kam ich durch die Dörfer Pletwar, Belawodiza nach Trojazi. Von der eigenartigen Landschaft konnte man zunächst nicht viel beachten, denn unendliche Züge von Lastkraftwagen waren gerade in diesen Tagen in Bewegung. Überall wurde gearbeitet und gebaut; die Straße erforderte unablässig Reparaturen, überall wurden Abkürzungen angelegt, neue Brücken, Quartiere, Verpflegungsstationen, Unterkünfte gebaut. Eine Menge Steinbrüche lieferten das Material für Straßen- und Bahnbau, Stationen wurden eingerichtet für Feldbahn und Seilbahn, Gefangenenlager beherbergten die Arbeitskräfte für die enorme Arbeit, welche auch hier die Etappe zu bewältigen hatte.

So ging es stundenlang weiter durch heibe Sonne und Staub. Trotzdem wurde die Aufmerksamkeit immer wieder erregt durch die Landschaftsbilder, die Felsen und Schluchten, die hohen Berge, an denen ich vorbeikam. Der Paß führte nun abwärts an dem Rajetzbach entlang, welcher sein Wasser der Cerna zuführt. Er hatte mächtige Schluchten gegraben in der großen und kleinen Klisura, floß am schimmernden Marmorberg vorbei um schließlich durch die mächtige Adlerschlucht (die große Klisura) in die Cerna zu münden. Etwas oberhalb der Mündung lag der Bahnhof und das Barackenlager von Drenovo.

Wir, ich hatte zwei in Urlaub in die Heimat fahrende junge Dragoneroffiziere in mein Auto aufgenommen, atmeten auf, als wir in dem behaglichen kleinen Offiziersheim in Lager von Drenovo eine Stunde Rast machen konnten. Es war eine Erlösung, sich die 
Kleider reinigen, die zentimeterhohe Staubschicht von den Gesichtern abwaschen und einen kühlen Trunk genießen zu dürfen.

Drenovo hat einen bösen Namen in der Hygiene des Kriegsschauplatzes gewonnen; auf der Heimreise, wie bei der Rückkehr an die Front hat hier mancher Soldat sich eine schwere Malaria geholt. Lange Zeit war dies bei beiden Reisen die Übernachtungsstelle der Urlauber. In der sumpfigen Gegend des Barackenlagers wimmelte es von Malariamücken und die kurzen Stunden der Nachtruhe in den schlecht verwahrten Baracken haben vielen die schlimme Infektion durch deren Stich gebracht, die sie in

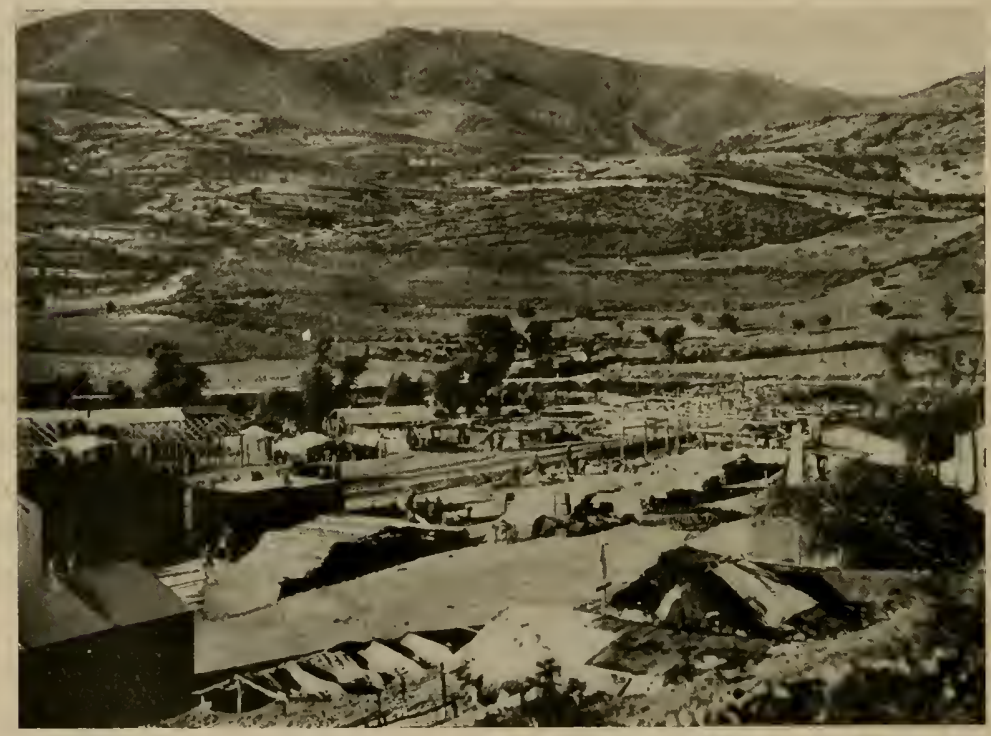

Abb. 23I. Lager und Bahnhof von Drenovo. Im Hintergrund das Dorf.

den Jahren an der Front im gesunden Hochgebirgsklima Mazedoniens nicht bekommen hatten.

Damals auf der Durchreise hatte ich nicht Zeit und Kraft, den hoch am Berghang gelegenen Ort Drenovo zu besuchen. Das holte ich im April 1918 nach, als ich mit meinem Freund Popoff eine genußreiche Fahrt durch diese Gegend machte. Da wanderte ich durch das malerische Örtchen zu der alten Kirche, die an dessen obersten Rand ganz außerhalb des Verkehrs lag. Deshalb wurde sie von Deutschen selten besucht, wenn sie das auch durchaus verdient hätte. 
Die Kirche sah allerdings von außen aus wie eine Scheune. Trat man dagegen in den hohen Innenraum ein, so wurde man überrascht durch eine Anzahl gewaltiger Säulen, welche das Dach stützten und fast zu mächtig für den engen Raum waren. Es waren offenbar antike Säulen oder doch solche aus byzantinischer Zeit, die hier verwandt waren und dem erfahrenen Archäologen wichtige Aufschlüsse über die Geschichte des Landes versprachen. In dieser Kirche fanden sich auch Fragmente eines Tierfrieses mit merkwürdigen Formen, welche auf orientalische Beziehungen hinweisen.

Nach erfrischender Rast wurde die Fahrt nach dem Endpunkt der Feldbahn, dem großen Etappenlager Grazko fortgesetzt, wo ich auf die Hauptbahnlinie und den Wardar zurückkam, kurz vor der Einmündung der Cerna in den letzteren. Grazko war kein erfreulicher Aufenthalt, diese riesige Stadt von Zelten und Baracken, in kahler dürrer Gegend; ungeheure Mengen von Geräten, Munition, Waffen lagerten hier sowohl für die Cerna-, Monastir- und Seenfront, wie für jene am Doiransee und unteren Wardar.

Immerhin gab es hier zwei Anziehungspunkte, die Ruinen der antiken Stadt Stobi und das deutsche Gut Palikura. Stobi war eine römische Stadt, günstig an der Mündung der Cerna in den Wardar gelegen, aus der Hauptstadt der Päonier entwickelt. Sie war von jeher ein befestigter Brückenkopf. Noch erkannte man dicht am Fluß Reste einer Stadtbefestigung. Während der Besetzung wurden von Deutschen verschiedentlich Ausgrabungen dort gemacht. Zum Teil wurden sie dilettantisch betrieben, schließlich aber von Fachmännern geleitet und haben manches Interessante geliefert. Ich habe die Ruinen in verschiedenen Phasen der Ausgrabung besucht. Soweit ich Einblick gewann, ist das wesentliche Resultat der Forschungen die Feststellung der Grenzen und Befestigungen der alten Stadt, in der auf die altmazedonische Periode eine römische und eine byzantinische Periode folgten. Die römischen Reste sind spärlich, während aus byzantinischer Zeit viel mehr zum Vorschein kam. Der Verlauf der Befestigungen an der Cerna ließ sich ziemlich klar stellen, Grundrisse von Häusern, zwei Kirchen, Kloaken wurden aufgedeckt. Auch wurden römische und byzantinische Grabsteine gefunden. Von einer der byzantinischen Kirchen ließ sich ein gut Stück der Baugeschichte durch verschiedene Perioden hindurch verfolgen. In den Basiliken sind in byzantinischer Zeit römische Bauteile verwandt worden. Die byzantinischen 
Bauten sollen meist im 5. Jahrhundert entstanden sein. Gräber in der einen Kirche, ein Kuppelgrab, ein Friedhof wurden aufgedeckt, dazu ein Mosaikfußboden, dessen Arbeit auf römischen Ursprung hinweist. In der anderen stammen Säulen und Stufen von einem größeren römischen Tempel. Sie wurden offenbar nach dessen Zerstörung in die Kirche eingebaut.

Besonders stattlich muß die dreischiffige Basilika bei Palikura gewesen sein, die wohl auf eine gröluere Ausdehnung der Stadt Stobi hinweist. Hier sind eine große Anzahl von Säulen, Friesen, Marmorplatten und Inschriften gefunden worden. In dieser Kirche ist aber alle Arbeit von weit geringerem Typus und weist auf Entstehung in späterer Zeit hin. Auch sonst wurden in Mazedonien von unseren und den bulgarischen Truppen viele interessante Reste aus prähistorischen Zeiten, aus Altertum und Mittelalter gefunden. Im Jahre 1918 wurde an ihrer planmäßigen Erfassung gearbeitet und es sind wohl Veröffentlichungen darüber zu erwarten.

Palikura selbst ist während des Krieges als Versuchslandgut vom preußischen Landwirtschaftsministerium bewirtschaftet worden. Es war schon 33 Jahre vor dem Kriege in Händen eines deutschen Besitzers gewesen. Sowohl dieser als die preußische Verwaltung hatten, soweit ich erfuhr, manche Mißerfolge. Doch hatte ich bei einem Besuch in dem Gut den Eindruck grober Fortschritte, die wohl leider seither nicht mehr fortschreiten konnten.

Von dem ersten Ausflug nach Prilep brachte ich mehr als naturwissenschaftliche Ergebnisse, starke Eindrücke von der Kultur und Geschichte des Landes und noch stärkere von der Arbeit und Leistung unseres Heeres in diesem fernen fremden Gebiet mit. Ich habe ihnen absichtlich Raum gegeben; denn jetzt nach dem Zusammenbruch unserer Unternehmungen ist es wichtig, in Deutschland unter dem Einfluß des Mißerfolges, nicht die Größe und Tüchtigkeit unseres Volksheeres zu vergessen. Das, was Mannschaften und Offiziere mit Treue, Ausdauer, körperlicher und geistiger Energie in diesem Lande leisteten, das kann nicht ganz verloren gehen und wird wieder ein Zeugnis von dem guten Kern des Volkes werden, wenn die Deutschen eine neue Zukunft gewinnen.

$\mathrm{Zu}$ zoologischen Forschungen war die erste Fahrt nach Prilep nur eine Erkundung gewesen, die zu späteren Reisen den Anstoß gab, wovon weitere Kapitel Auskunft geben sollen. 


\section{DREISSIGSTES KAPITEL}

\section{AMEISENLÖWEN}

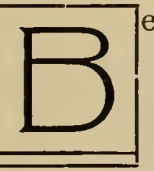

ei den klimatischen, botanischen und zoologischen Beziehungen Mazedoniens zu den asiatischen Steppen war ein großer Reichtum an jenen Neuropteren zu erwarten, die man gewöhnlich unter dem Namen der Ameisenlöwen zusammenfaßt und welche Rösel von Rosenhof sehr passend als Landlibellen bezeichnet. Da ich infolge einer eingehenden biologischen und tierpsychologischen Untersuchung des einen der deutschen Ameisenlöwen mich für diese Tiergruppe sehr interessierte, achtete ich von vornherein auf ihr Vorkommen in Mazedonien.

Schon in den ersten Tagen in Kaluckova, im Mai I9 7 , entdeckte ich auf den Hügeln der Umgebung in Mengen jene charakteristischen Sandtrich ter, deren Bau und Verwendung zum Ameisenfang ich bei der deutschen Art so genau studiert hatte. Überall gab es diese Trichter, hier aber nicht so sehr an Abhänge und Stellen mit Regenschutz gebunden; vielmehr lagen sie überall frei im Gelände. In Rabrovo, dessen Zelt- und Barackenlager im schattenlosen Tal angelegt war, fanden sich zahllose Trichter in dem feinen Staub der Straßen und Plätze. Hier in dem Lande mit seinem trockenen Sommer brauchen die Ameisenlöwen sich nicht vor dem Regen zurückzuziehen, wie die Larve von Myrmeleon formicarius L. in Deutschland. Obwohl die Trichter genau so aussahen wie jene, die ich in Deutschland studiert hatte, merkte ich bald, daß die in Südmazedonien häufigste Larve $z u$ einer anderen Ameisenlöwenart gehören müsse.

Bei Kaluckova war am häufigsten die Larve von Macronemurus appendiculatus Latr, einem zarten Tier mit durchsichtigen Flügeln, deren Oberfläche fein irisierte, wenn das Licht von der Seite auf sie fiel. Gegen die Flügelspitze hin war ein gelbliches Randmal sichtbar. Der Kopf trug zwei an der Spitze verdickte Fühler, vorstehende kugelige Augen, der Körper war dunkelbraun mit gelben Längsstreifen an den Seiten des Hinterleibes und gelben 
Flecken in der Brustregion. Das Männchen trug am Hinterende zwei behaarte Fortsätze und war kleiner als das Weibchen (Abb. $234 A$ u. $B$ ).

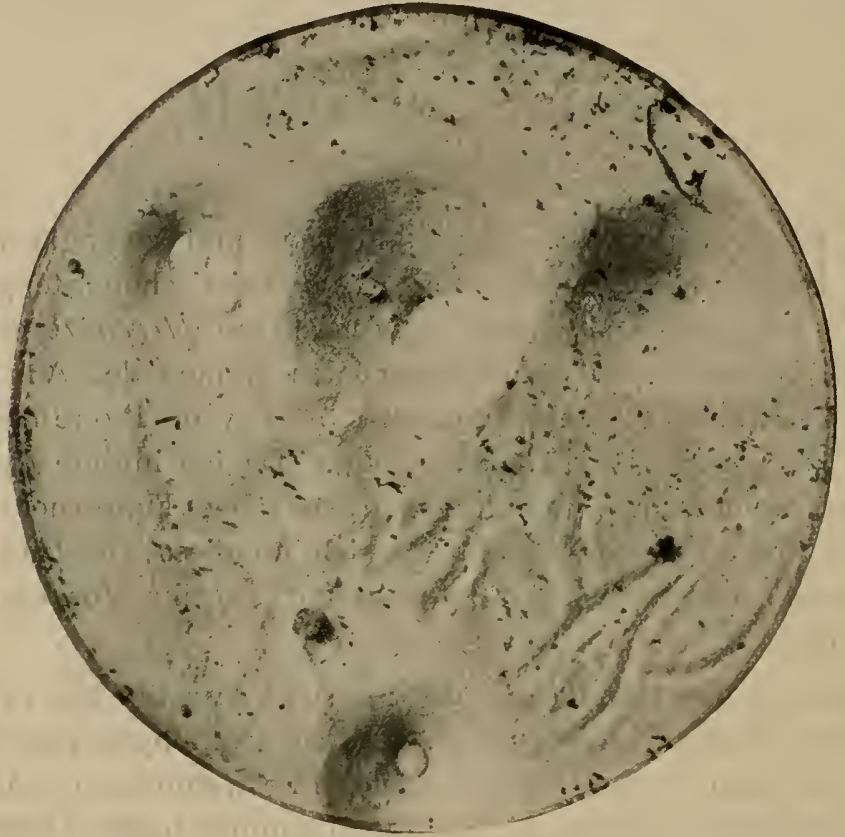

Abb. 232. Trichter und Kriechspuren der Larven mazedonischer Ameisenlöwen (Myrmecaelurus trigrammus Pall.) Üsküb.

Davon, daß das Tier so aussah, hatte ich aber damals, als ich mir die Larven aus ihren Sandtrichtern holte, noch keine

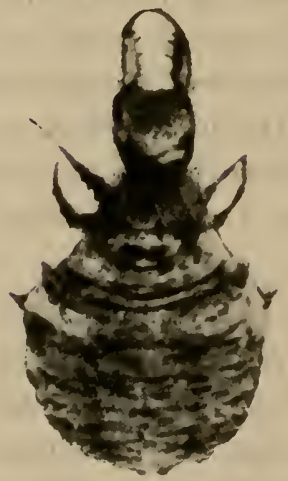

Abb. 233. Ameisenlöwe. Larve von Macronemurus appendiculatus Latr. Kaluckova. Vergr. 5 . Ahnung; daß ähnlich aussehende Tiere aus ihnen werden müßten, wußte ich wohl. Aber $\mathrm{zu}$ welcher Art sie gehörten, war mir noch unbekannt. Erst gegen den Juni traten die Imagines auf und deren Zusammengehörigkeit mit den Larven ergaben mir Züchtungen aus Larven, die ich lebend hielt und durch fleißiges Füttern mit Ameisen zur Verpuppung brachte.

Um so interessanter war die Untersuchung der Larven; ich hatte in Deutschland die im Westen häufige Larve von Myrmeleon formicarius genau auf Bau, Lebensweise und Reaktionen durchforscht und eine Monographie 
über sie geschrieben ${ }^{1}$ ). So merkte ich sogleich, daß die hier vorliegenden Larven ganz anders reagierten und somit sicher zu einer anderen Art gehörten. Während die Larven der deutschen Art nur rückwärts kriechen können, sah ich die hier vor mir sitzenden gerade so flott sich vorwärts bewegen. Allerdings, wenn sie sich zum Trichterbau in den Sand einwühlten, ging auch hier das Hinterende voran, wobei merk würdige, wie Schaufeln aussehende Gebilde an diesem eine wichtige Rolle spielten (Abb. 233).

Beim Bau des Trichters liefen sie zuerst oberflächlich in einer Spirale auf dem Sand herum, dabei eine Furche ziehend. Versetzte man ihnen einen leichten Tastreiz am Hinterende, so setzten sie sich vorwärts in Bewegung; beim Laufen benutzten sie das erste und zweite Fußpaar, wobei zuerst das erste, dann das zweite, abwechselnd links und rechts vorgesetzt wurden. Die Bewegungen waren sehr lebhaft, die Reaktionen dieselben wie bei dem von mir studierten deutschen Ameisenlöwen.

Er stellte sich tot wie jener; nahm eine ähnliche Bereitschafts-

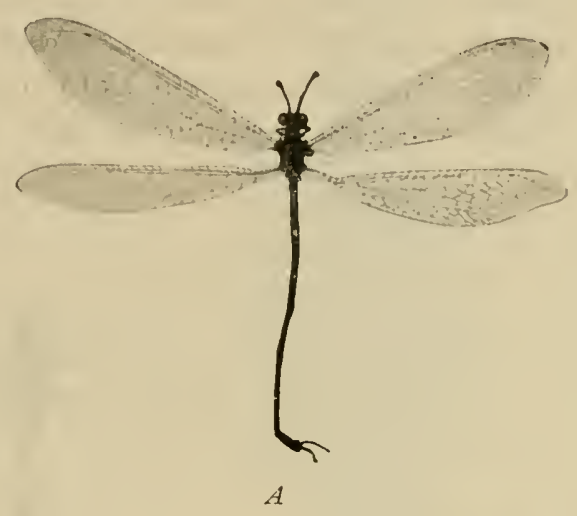

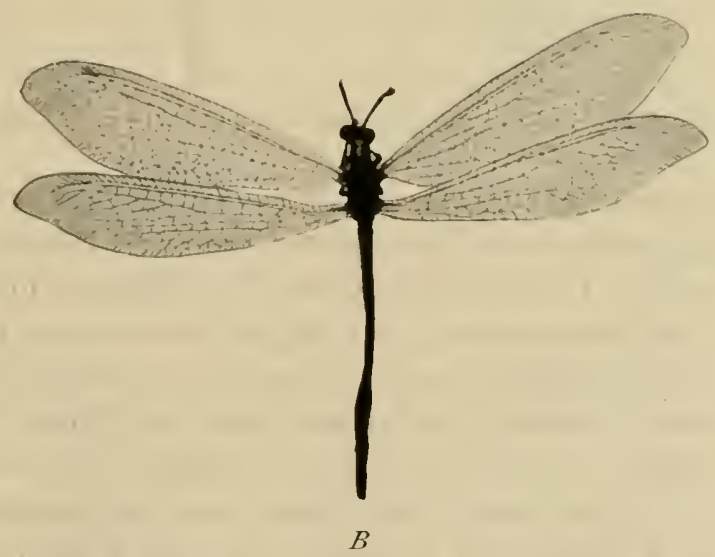

Abb. 234. Macronemurus appendiculatus Latr. $A$ Männchen. $B$ Weibchen. Nat. Gr.

stellung an, führte denselben Schnappreflex aus, drehte sich, auf den Rücken geworfen, schnell durch einseitiges Anstemmen des Kopfes um. Er zeigte Reizbarkeit durch Licht, stellte sich im Trichter nach dem Lichteinfall ein.

1) F. Doflein. Der Ameisenlöwe. Eine biologische, tierpsychologische und reflexbiologische Untersuchung. Jena. Gustav Fischer 1916. 
Schon im Mai und Anfang Juni traten Imagines dieser Art bei Kaluckova, im Wardar- und Nikolatal zahlreich auf. Die von mir gefütterten Larven kamen nur zum Teil zur Verpuppung in kugeligen Kokons, welche von Sandkörnern umhüllt waren.

Eine zweite Form des Ameisenlöwen, der bei Kaluckova Trichter baute, war Myrmeleon formicalynx $\mathrm{F}$. Auch von dieser Form hielt ich die Larven in Gefangenschaft, züchtete sie und erzielte aus ihnen Imagines. Auch sie liefen sowohl vorwärts als rückwärts, bauten große tiefe Trichter und entsprachen in den Reaktionen im wesentlichen den anderen von mir untersuchten

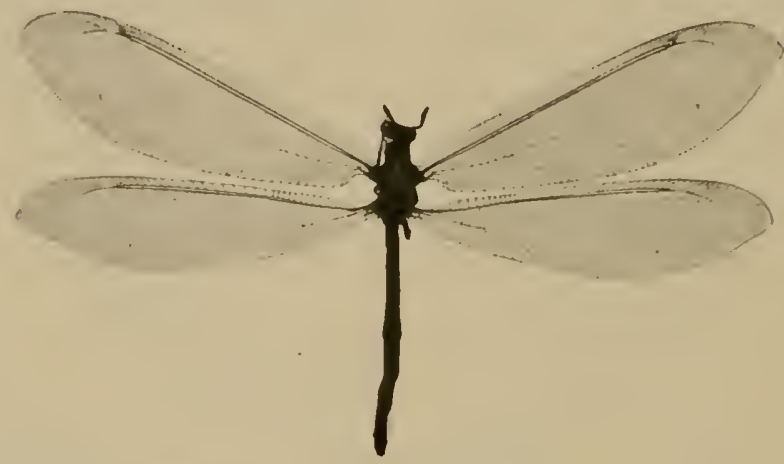

Abb. 235. Myrmeleon formicalynx F. Nikolatal. Nat. Gr.

Larven. Die Imagines waren größer als die von Macronemunus appendiculatus Latr., hatten breitere Flügel mit sehr deutlichem, weißem Randmal an beiden Flügelpaaren, hinter welchen eine deutliche Verdunkelung des Flügels sichtbar war (Abb. 235). Der Körper war im allgemeinen schwarz, mit gelben Flecken am Prothorax. Gelbe Streifen fanden sich auch am Kopf. Femur und Tibia der Beine waren auch gelb, mit schwarzbraunen Gelenken.

Noch eine dritte Form von Ameisenlöwen baute im Wardartal Trichter. Sie war allerdings bei Üsküb häufiger als im Süden. Ich fand sie aber auch bei Mravinca und Veles.

Es war dies eine sehr stattliche, lange Larve, die besonders schlank gebaut war (Abb. 236). Sie erreichte eine Länge von fast $2 \mathrm{~cm}$. Die Fühler sind 14 gliederig. Kopf und Rücken sind auffallend gezeichnet. Auch sie baute tiefe Trichter, konnte vorwärts und rückwärts laufen; sehr eigenartig ist der schroffe Übergang vom Vorwärtslaufen zum Rückwärtsgehen und umgekehrt. Die Tiere wechseln oft rasch hintereinander damit ab. 
Auffallend ist die größere Reizbarkeit dieser Larven, verglichen mit den anderen von mir studierten Arten. Das Totstellen dauert hier immer nur sehr kurz, die Reizreaktionen, vor allem der Schnappreflex, sind sehr intensiv. Der Phototropismus ist sehr ausgesprochen; das Tier läuft auch vorwärts auf die Lichtquelle los. Merkwürdig ist das starke Aufbäumen des Vorderendes. Die Larve kann selbst an senkrechten Wänden mit dem Vorderende voran hinaufklettern.

Die Larve dieses Ameisenlöwen unterscheidet sich überhaupt in ihrem Verhalten sehr von den anderen von mir studierten Formen.

Im April und Mai gab es viele kleine und mittelgroße Larven, im Juni herrschten die großen Larven vor, die Trichter waren dann auch auffallend groß. Im Juli scheint die Zeit der Verpuppung zu sein, welche nicht lange dauert. Ein Exemplar, welches sich in Gefangenschaft anfangs August verpuppt hatte, schlüpfte am 23. August

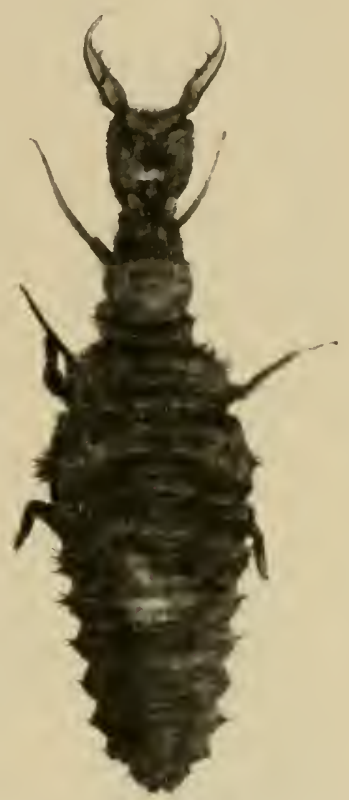

Abb. 236. Ameisenlöwe. Larve von Myrmecuelurus trigrammus Pall. Üsküb. Vergr. 5. aus. Bei meinen in Gefangenschaft gehaltenen Individuen, die alle schöne kugelrunde, sandkörnerumkleidete Kokons bauten, war wohl die Larvenzeit stets

etwas über die Norm ausgedehnt.

In Mazedonien flogen die Imagines dieser Form vor allem im Juli. Es war Myrmecaelurus trigrammus Pall. (Abb. 237). An Flügeln und

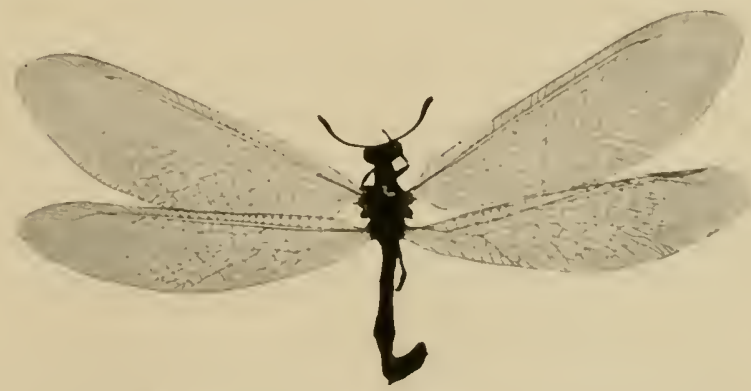

Abb. 237. Myrmecaelurus trigrammus Pall. Üsküb. Nat. Gr.

Körpern der Individuen dieser Art herrschte die gelbe Farbe vor. Die Fläche der Flügel mit ihren braunen Adern zeigte einen zarten gelbgrünen Glanz. Der Hinterleib war im wesentlichen gelb, mit dunkelbraunen Längsstreifen, ähnlich sahen Kopf und Brustabschnitte aus. 
Dieses Tier trat Ende Juni und im Juli in großen Mengen auf. Männchen und Weibchen waren zu gleicher Zeit da.

Um diese Zeit gab es nur mehr wenig Trichter und vom September an wurden es ihrer wieder mehr; diese waren dann aber noch sehr klein und beherbergten entsprechend kleine Larven. Offenbar war im Juii und anfangs August Begattung und Eiablage erfolgt, so daß im Herbst die neue Generation erschien. Die jungen Larven überwintern hier und es scheint mir unzweifelhaft, daß sie in diesem heißen Lande sich schon in einem. Jahre zum geschlechtsreifen Tier entwickeln.

Schon vom Mai an waren die Imagines von zahlreichen anderen Arten von Ameisenlöwen oder sagen wir lieber von

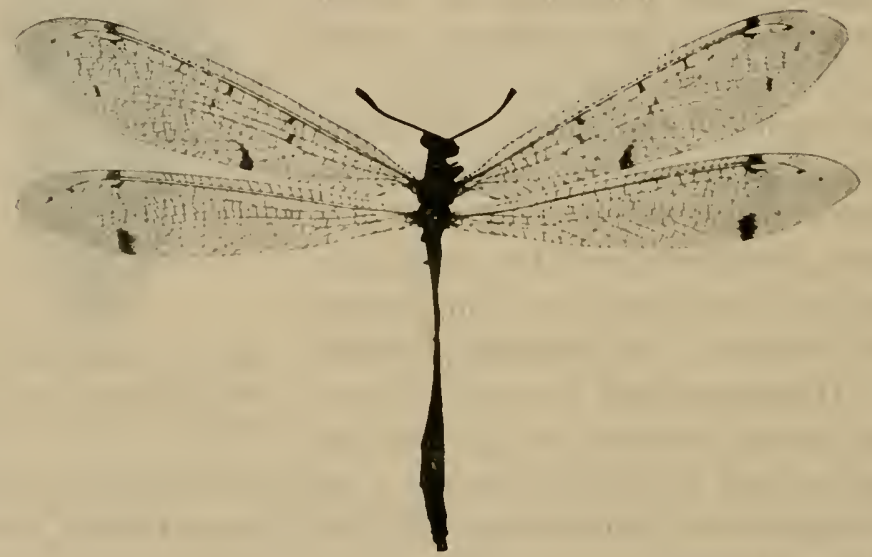

Abb. 238. Formicalynx tetragrammus Pallas. ․ Kaluckova. Nat. Gr.

Landlibellen in Mazedonien aufgetreten. Bis in den Hochsommer nahm Arten- und Individuenfülle immer mehr zu, so daß in dieser Zeit im Landschaftsbild mit den Heuschrecken die Landlibellen eine größere Rolle spielten als die Schmetterlinge. Manche von ihnen glichen aber auch im Flug, in der Farbigkeit, in der Eigenart der Formen Schmetterlingen.

Mehrere Formen traten in dieser Zeit im Wardartal auf, welche durch die zarte Durchsichtigkeit der Flügel den bisher beschriebenen drei Arten sehr ähnlich waren. Es war vor allem Formicalynx tetragrammus Pall., ein stattliches Tier mit dunklem Körper und dunkler Aderung der Flügel, welche auch mehrere dunkle Flecken trugen (Abb. 238). Von dieser Art sowie von Creagris plumbeus Oliv., einer zartflügeligen Landlibelle, ohne Flecken auf 
den Flügelı, mit schwarzem, ungestreiftem Körper habe ich die Larven nicht mit Sicherheit gefunden.

Umgekehrt fand ich von Megistopus flavicornis |Rossi nur die Larven, wenn ich sie nach der Bearbeitung von Redtenbacher richtig bestimmt habe.

Von Ende Mai an traten zwei eigenartige Formen im südlichen Wardartal, am Doiransee, bei Demirkapu und Veles auf, die weiter nördlich jedenfalls viel seltener waren. Zuerst kam von ihnen Nemoptera sinuata Oliv., ein graziöses, seltsam anmutendes Insekt. Anfang Juni kam dieses schöne Tier in Hunderten von Exemplaren auf den grasigen Hängen des Nikolatals vor, I4 Tage später wimmelte es von ihm einige hundert Meter höher auf der Plaguša Planina. Das Tier ist durch eine grol3e Verschiedenheit der Vorderund Hinterflügel ausgezeichnet; die Vorderflügel sind breitoval, die Hinterflügel sind lange, schmale Bänder, die nach hinten sich spatelförmig verbreitern. Beide Flügel haben eine blaßgelbe Grundfarbe mit dunkelbraunen Flecken; letztere sind zum Teil so eigenartig verteilt, als hätte ein Maler sie willkürlich auf die Flügel gepinselt (Abb. 240, S. 480).

Nur die Vorderflügel leisten Flugarbeit, indem sie rasch schlagen; die bandförmigen Hinterflügel flattern unbewegt hinter dem Tier her und wirken offenbar als Stabilisatoren. In der Regel fliegen die Nemopteren ganz lang-

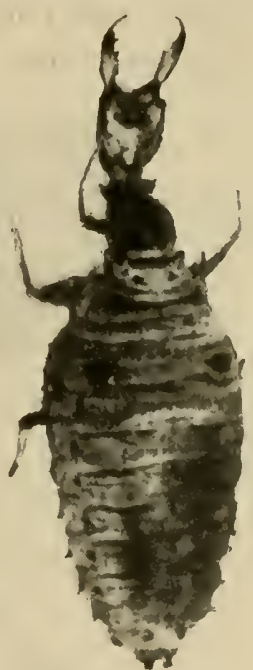

Fig. 239. Ameisenlöwe. Larve von Megistopus favicornis Rossi. Üsküb. Vergr. 5. sam, taumelnd von Blüte zu Blüte, während ihre Hinterflügel wie Wimpel hinter ihnen im Wind sich wiegen. Eine Wiese voll von diesen Tieren, die im hellen Sonnenschein sich behaglich über den Blüten schaukeln, von Zeit zu Zeit auf einer duftigen Dolde wie in einem Flughafen landen, bietet einen höchst reizvollen Anblick dar. Wollte man sie fangen, oder verfolgte sie ein Vogel, so erfolgte die Flucht in ziemlich raschem Flug.

Sie traten, Männchen und Weibchen gleichzeitig, in großen Mengen auf und verschwanden ebenso allmählich Ende Juni. In den höheren Regionen, in denen sie etwas später aufgetreten waren, dauerten sie auch etwas länger aus. 
Fast noch phantastischer sah die andere Art aus, deren große braungefleckte Flügel eine Spannweite von $10-12 \mathrm{~cm}$, gelegentlich sogar noch mehr erreichten. Es sind dies die sogenannten „R Riesenhafte", die Art, die im gleichen Gebiete wie Nemoptera flog und womöglich in noch größeren Mengen auftrat, war Palpares libelluloides Dalm (Abb. 241 u. 242). Auch bei dieser größten unter den europäischen Landlibellen war der Flug meist etwas schwerfällig und taumelnd. Bei starkem Wind konnten sie sich nicht in der Luft halten, wurden zu Boden geschleudert und zogen sich zwischen Gras und Büsche zurück. Wie die Nemopteren, sah man sie viel bei Tage fliegen, wie denn die meisten der mazedonischen Ameisenlöwen Tagtiere sind.

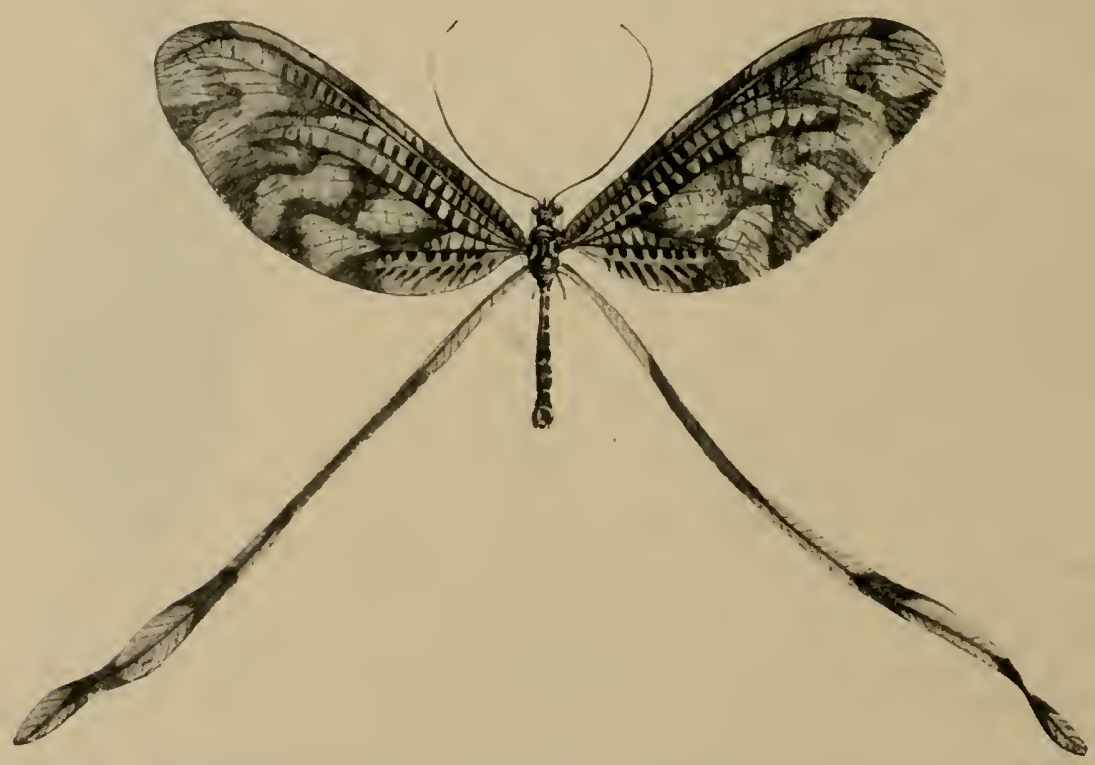

Abb, 240. Landlibelle mit verschiedenen Flügeln. (Nemoptera sinuata Oliv.) Nat. Gr.

Bei windstillem Wetter im heißen Sonnenschein gaukelten sie in lebhafterem Flug über offene Flächen, über Wiesen und die bebuschten Hügel. $\mathrm{Zu}$ den grünen und grauen Flächen des Untergrundes, zu den blühenden Pflanzen an Tümpeln, Băchen und in den Schluchten bildeten sie mit den braunen Tönen ihrer Flügel einen malerischen Gegensatz. Ihre Flügel haben einen länglichen Umriß, sind im Grundton leicht bräunlich gefärbt, dunkler sind die Adern und den starken Randadern entlang zieht sich ein gelblicher Streifen. Eigenartig unregelmäßig verteilt sind 
die dunkelbraunen gegitterten großen Flecken über die Fläche des Flügels, während regelmäßige kleine Farbtupfen sich den Rändern entlang ordnen. Der ganze Körper, Kopf, Brust und Hinterleib ist der Länge nach schwarzbraun und gelb gestreift, wobei ein dunkler Streifen die Mittellinie des Rückens darstellt.

Auch bei dieser Art traten Männchen und Weibchen gleichzeitig auf; die Männchen sind leicht an den griffelförmigen Fortsätzen des Hinterendes zu erkennen. Auffallend ist gerade bei dieser Art die Versammlung von vielen Männchen um ein Weibchen gewesen; ich beobachtete oft 5-7, ja 8 Männchen, welche sich um ein Weibchen drängten.

Wie die Schmetterlinge, denen sie vielfach so ähnlich sehen, sind auch die Imagines der Ameisenlöwen gegen Temperatur-

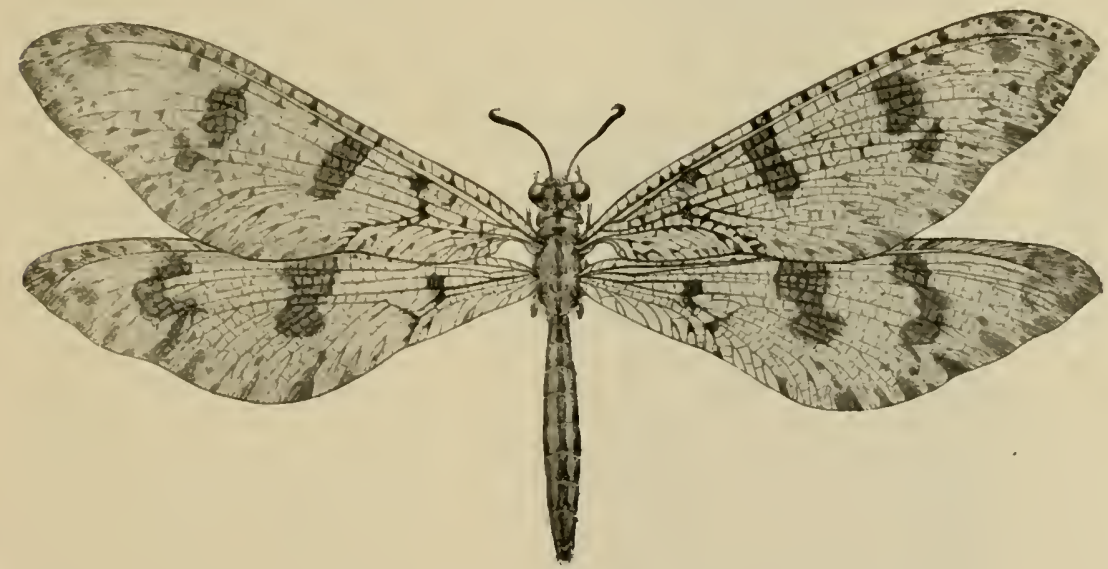

Abb. 241. Palpares libelluloides Dalm. Großer braungefleckter Ameiseniöwe. Nat. Gr.

schwankungen sehr empfindlich. Morgens in der Frühe und abends bei sinkender Temperatur waren sie auffallend schwerfällig, so daß man sie ohne weiteres an den Flügeln fassen konnte, ohne daß sie davonflogen. Nemoptera und Palpares waren in der Mittagssonne beweglicher, aber auch dann gehörten sie zu den am leichtesten zu fangenden Insekten.

Nemoptera und Palpares gehören sicher zu den Ameisenlöwen, welche keine Trichter bauen. So waren ihre Larven nicht so leicht $\mathrm{zu}$ finden und $\mathrm{zu}$ beobachten, als diejenigen der oben erwähnten Formen, die man ohne weiteres in ihren Trichtern aufsuchen konnte. Über die Lebensweise der Palpares-I.arven gelang es mir nicht, irgendwie Beobachtungen zu machen. Sie müssen 
sehr verborgen leben, möglicherweise sind sie nächtliche Tiere. Wie viel habe ich nach ihnen gesucht; wie viel Steine haben wir umgewälzt, wie viel in der Erde gegraben, bis es gelang, eine einzige Larve $z u$ fangen. Diese grub im Winter (Januar 19i8)

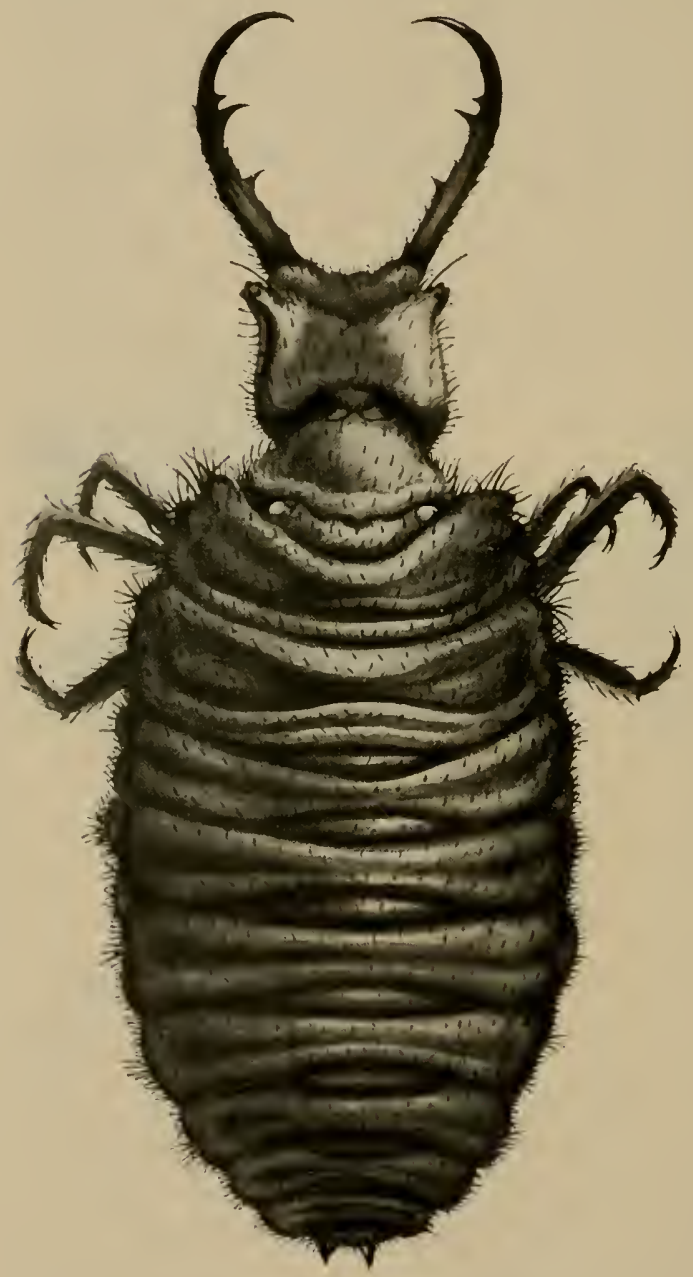
der Entomologe Rangnow aus der Erde am Grünberg bei $\mathrm{Ka}$ $1 \mathrm{u} \mathrm{ckova}$ heraus. Grob und stattlich ist diese Larve, über $3 \mathrm{~cm}$ lang, fast so breit wie die anderen Ameisenlöwenlarven lang sind. Wie zahireich müssen bei der Menge, in der die Imagines auftraten, auch ihre Larven im gleichen Gebiet sein. Ich halte es für ganz ausgeschlossen, daß sie Trichter bauen, die hätten uns bei der genauen Durchforschung, die ich mit meinen Mitarbeitern vornahm, nicht entgehen können. Immerhin weist der Bau der Larve auf ein Wühlen in lockerem Substrat hin.

Ebenso merkwürdig ist es, daß ich die Larven von Nemoptera an den Fundorten, an denen Abb. 242. Larve von Palpares libelluloides Dalm. Vergr.6. die Imagines in großen Mengen auftraten, nicht gefunden habe, obwohl ich intensiv nach ihnen suchte. Eine Larvenform, die sicher nicht zu den Trichterbauern gehört und in mancher Beziehung, so durch die Gröle, zu Nemoptera gehören könnte, konnte ich aber bisher nicht mit Sicherheit bestimmen. 
Gegen Ende Juli verschwanden Nemopteren und Riesenhafte allmählich vollkommen; selten sah ich ein totes Tier oder Reste von einem solchen im Freien.

Statt ihrer traten andere Formen auf, unter denen die auffallend gefärbten Ascalaphiden eine große Rolle spielten (Abb. 243). So fand ich bei Selenikovo eine unserem Ascalaphus macaronizes Scop. durch gelb und braun gefleckte Flügel ähnliche Form.

Durch massenhaftes Auftreten an wenigen Tagen Mitte Juni I917 war in der Umgebung von Kaluckova eine Art mit den typischen langen Fühlern, mit dem Endknopf und einem braunen Fleck auf jedem Flügel

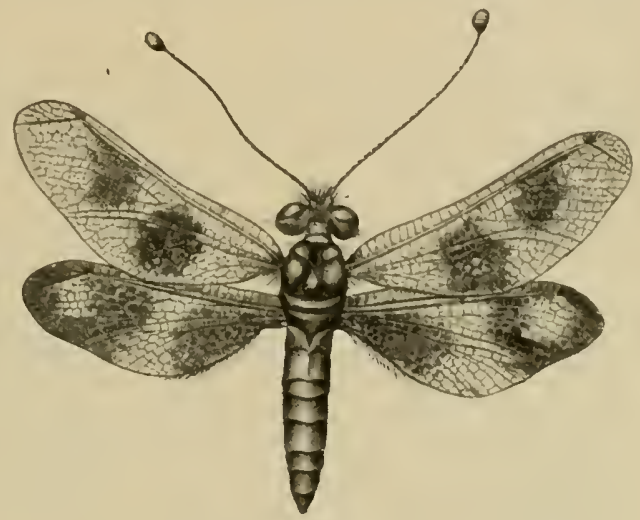

Abb. 243. Blattlausameisenlöwe. Ascalaphus sp. gekennzeichnete Art bemerkenswert. Es war Delyoproctophylle australis Fabr. Hunderte von Individuen flogen einige Tage lang auf den Hügeln von Kaluckova herum, um nach Verlauf dieser Tage ebenso spurlos zu verschwinden wie die anderen Arten. Eigenartig war bei dieser Form, daß ihr Körper, auf Papier gelegt, dort einen starken Fettflecken hinterließ.

Die Sammlung von Ameisenlöwen und ihren Larven, welche ich aus Mazedonien mitbrachte, ist wie viele andere Gruppen des Tierreichs bisher noch recht flüchtig durchgearbeitet. Ihre definitive Bearbeitung, welche ich selbst in die Hand genommen habe, soll in einer wissenschaftlichen Zeitschrift erscheinen. 


\section{KRUSEVO ALS AROMUNENSTADT}

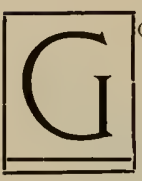

opes und Krusevo, diese beiden Städte fasse ich zur Betrachtung in diesem und dem nächsten Kapitel zusammen, weil sie viel Gemeinsames haben. Sie sind beide Bergstädte und ihre Bewohner sind vorwiegend Aromunen oder Kutzowallachen. Die eine an den Hängen der Baba Planina in fast $1200 \mathrm{~m}$ Höhe gelegen, Krusevo, habe ich nur einmal besucht, in Gopes war ich mehrmals z.u verschiedenen Jahreszeiten.

Um nach Krusevo zu gelangen, muß man von Prilep quer durch die flache Ebene direkt nach Westen $22 \mathrm{~km}$ weit wandern oder fahren, ehe man das Gebirge erreicht, auf welchem die Stadt liegt. Weiß sieht man ihre Häuser beim Anmarsch über die Ebene blinken. Als ich das erste Mal nach Mitte Juni 1917 über die Ebene von Prilep fuhr, erschien sie wie ein üppiger Garten. Weithin war sie von grünen Ährenfeldern bedeckt, auf denen Weizen und Roggen fast $2 \mathrm{~m}$ hoch standen; selbst die Gerste, die im Wardartal schon geerntet war, war hier noch nicht ganz gelb, bei einer Meereshöhe von etwas über $600 \mathrm{~m}$. Im westlichen Teil der Ebene gab es ausgedehnte Pflanzungen von Hanf. In den Gräben stand reichlich Wasser, das zur Bewässerung der Felder diente und verschiedenen Bächen entstammte, die von Norden, Osten und Westen der Cerna zuströmten. Als niedere Hügelkette sah man im Süden die alte Barriere, durch welche die Cerna bei Topolčani in die Ebene von Monastir, in die eigentliche Pelagonia durchbricht. Man verstand wohl, daß früher ein See die Ebene, die man jetzt durchfuhr, erfüllt haben mochte.

Das Wasser, welches überall in den Gräben stand, mußte die Entwicklung der Malariamücken sehr begünstigen. Damit brachte ich unwillkürlich die Bauart der Häuser in Verbindung, welche in den Gütern und Dörfern der Ebene einen auffallenden Typus darstellten. Sie ragen turmartig hoch empor und der obere, etwas vorragende Stock ist der von Menschen bewohnte und mit Fenstern versehene. So sehen die Herrenhäuser in all den Orten 
der Ebene aus, die man durchfährt, in Konjari, Urbjani und Krivogastani. Man denkt unwillkürlich an eine Flucht vor den niemals hoch fliegenden Malariamücken, wenn man diese Turmhäuser sieht und sich daran erinnert, daß auch in der Campagna von Rom in Sommer die Bauern aus Furcht vor dem Fieber auf dem Dach schlafen. Hier allerdings werden auch andere Beweggründe vorliegen, etwa Schutz vor nächtlichen Überfällen. Und das geht auch aus den Schilderungen früherer Reisenden hervor, sowie aus den Schießscharten des unteren Stockwerkes.

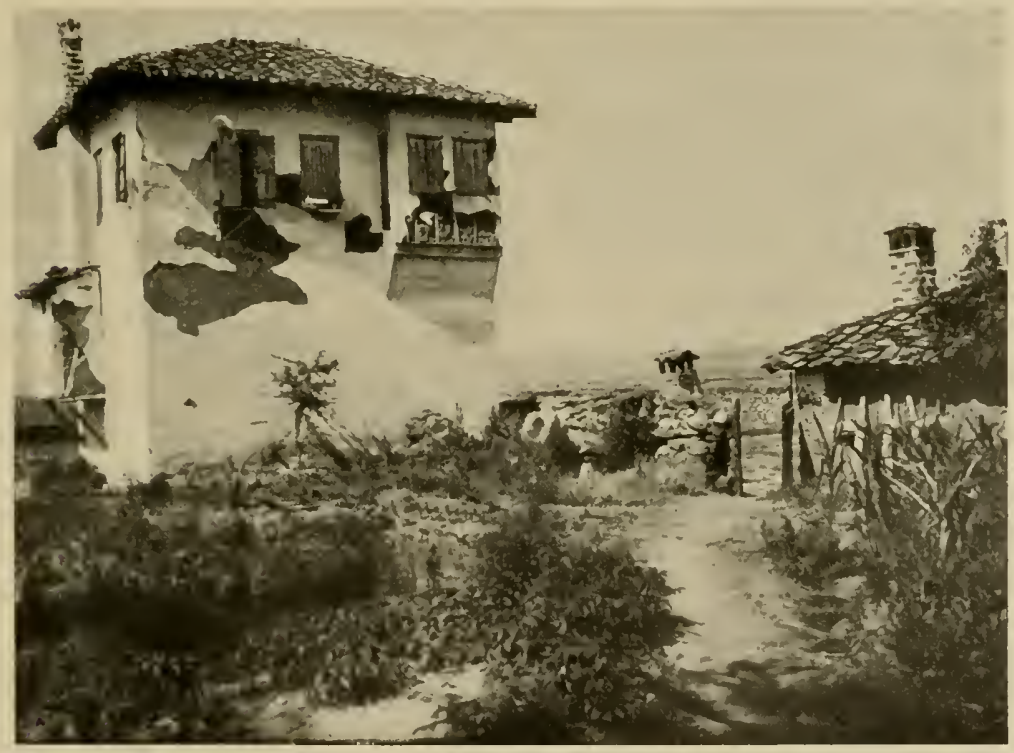

Abb. 244. Hochgebautes Haus bei Prilep.

Als ich Anfang September 1917 mit Hauptmann Pfeiffer von Prilep über die Ebene fuhr, war sie dürr und staubig. Die Felder waren abgeerntet. Heuschrecken waren die vorherrschenden Tiere und auf den Telegraphendrähten saßen viele Falken, auf sie lauernd. Lerchen und Elstern waren neben ihnen die auffallendsten Vögel.

Wir ließen unsern Wagen unten am Berg stehen und stiegen in $1 \frac{1}{2}$ Stunden die Landstraße hinauf, welche in vielen Windungen einer tiefen Schlucht entlang angelegt ist, die $600 \mathrm{~m}$ nach Krusevo hinanführt. $Z u$ ihren Seiten war die Pflanzenwelt sehr dürftig, wenige Bläulinge flogen, auch Wespen gab es, aber vor 
allem Heuschrecken und unter ihnen waren die Gespensterheuschrecken besonders häufig. Links von der Schlucht sah man am Hang die weißen Gebäude des Klosters Sveti Spas.

Nach einer Straßenbiegung liegt plötzlich die weit ausgebreitete, ziemlich große Stadt an den Berghängen vor unsern Blicken. Es war ein überraschender, höchst reizvoller Anblick, der sich uns darbot. Flimmernd lag die weiße Stadt an der Bergwand und in die Schluchten eingeschmiegt; hinter ihr breitete sich als dunkle Fläche ein großer Buchenwald aus, welcher den Gipfeln eine in Mazedonien ganz ungewohnte Einheitlichkeit und Ruhe gab. Die meisten Häuser waren weiß oder doch sehr hell getüncht, die Dächer mit großen Schieferplatten gedeckt, welche über das Bild ein gedämpftes Grau breiteten, eine ganz andere Farbenwirkung als bei den Türkenstädten mit ihren grellroten Ziegeldächern. Die Form des Daches ist meist eine vierseitige Pyramide, kein zweiseitiges Giebeldach, wie bei den bulgarischen Häusern. Die Häuser sind offenbar im Zusammenhang mit dem Raummangel an den Steillehnen der Hänge hoch gebaut, haben keine äußeren Galerien und Vorhallen. Zuerst wurde ich an italienische Gebirgsstädte erinnert; aber gegenüber diesen stach die große Einförmigkeit in der Bauweise der Häuser erheblich ab, es gab weniger Individualität als in jenem Land.

Immerhin waren die Straßenbilder, als wir durch die steilen Gassen kletterten, sehr malerisch und eigenartig. Während im Gesamtanblick bei dem starken Sonnenschein die grelle Helle der Häusermassen mit den vielen gleichmäßigen Fenstern zunächst einen verwirrenden, fremdartig abweisenden Eindruck hinterlassen hatte, bauten sich jetzt an den Einzelschluchten zwischen den Gruppen von Bäumen individuellere Bilder auf, welchen die ungewohnte Waldfläche des Hintergrundes etwas für die an die Grellheit mazedonischer Städtebilder gewöhnten Augen harmonisches und sympathisches gab.

Die Hauptmasse der Häuser war groß und städtisch, eines davon war zu einem Soldatenerholungsheim ausgebaut, welches ein Rittmeister Fries leitete. Es war ein guter Gedanke gewesen, hier in der frischen Bergluft, nahe dem Waldesschatten eine Art von Kurort für den mazedonischen Kriegsschauplatz einzurichten, in welchem Soldaten sich von akuten Erkrankungen und Erschöpfungszuständen erholen konnten, ohne den Strapazen der Heimreise ausgesetzt $z u$ sein. 
Hier wohnten die Rekonvaleszenten sauber und angenehm, hatten von ihren Fenstern einen schönen und freundlichen Ausblick und alles war darauf abgesehen, ihnen durch Abwechslung und Unterhaltung die Erholung zu fördern.

Mich interessierte natürlich zunächst besonders der Buchenwald, der die Gipfel der südlichen nicht sehr steilen Berge in merkwürdig geradlinigen, abgeschnittenen Beständen bedeckte. Es war ein eigenartiger Eindruck, einmal wieder einen richtigen schattigen Wald zu betreten, dessen hohe graue Stämme und hellgrüne Blätter das fremdartige Bild der weißen Stadt umfaßten (Abb. 245). Der Boden des Waldes war von einer glatten Fläche brauner Blätter bedeckt; auf ihm wuchs nicht viel von Gräsern und Kräutern, was wohl zum Teil mit der Jahreszeit zusammenhing.

Trat man jenseits aus dem Wald heraus, so fand man statt der erwarteten grünen Wiese ein kahles Geröllfeld, über welches der Wind pfiff. Vielleicht waren solche regelmäßigen Winde die Ursache des plötzlichen Aufhörens, des geradlinigen Abschlusses der Wälder.

Ein Gang durch die Stadt zeigte die städtische Wohnweise der hier wohnenden Menschen; es waren alles Stadtleute, die hier lebten, Handwerker, Kaufleute, Gewerbetreibende, Viehzüchter, keine Ackerbauer. Dem entsprach auch der mangelnde Anbau in der Umgebung der Stadt, der ja wohl auch durch die Höhenlage bedingt ist.

Nicht zum wenigsten war aber der Charakter der Stadt durch seine Einwohner bestimmt. Es war schon eigenartig, eine mazedonische Stadt ohne ein einziges Minaret vor sich zu sehen. Zwei Kirchen mit niederen Türmen, welche sich nicht übermäßig in der Größe von den anderen Gebäuden der Stadt unterschieden, bewiesen ihren rein christlichen Charakter.

Ist es nicht seltsam, daß eine solch stattliche Ansiedelung im Jahre $185^{8}$ der Geographie noch unbekannt war? Das gibt der Konsul von Hahn in seinem Buch an, welches er über seine Studienreise im Interesse der Anlage der Orientbahn geschrieben hat. Wie die übrigen aromunischen Städte ist auch Krusevo vor nicht allzulanger Zeit gegründet worden, von Angehörigen dieses Stammes, welche durch Räubereien oder Bedrückung aus anderen Teilen des türkischen Balkan verdrängt wurden.

Aromunen nennen sich die Angehörigen dieses Volkes selbst in ihrer romanischen, dem Rumänischen ähnlichen Sprache, 
die vom Lateinischen aus der Zeit, in welcher der Balkan einen Teil des römischen Reiches darstellte, abzuleiten ist. Kutzowallachen (lahme Wallachen) werden sie spöttisch von Türken und Slaven genannt, ebenso wie der hauptsächlich von den Serben gebrauchte Name Zinzaren ein Spitzname ist, der auf ihre Aussprache gemünzt ist. Gustav Weigand, wohl der beste Kenner der romanisch sprechenden Völker des Balkan, ist der Meinung, daß diese jetzt so weit zerstreuten Volksbestandteile einst ein einheitliches Volk gebildet haben mit einheitlichem Wohnsitz. Aber auch er hält sie für der Rasse nach so wenig einheitlich, wie

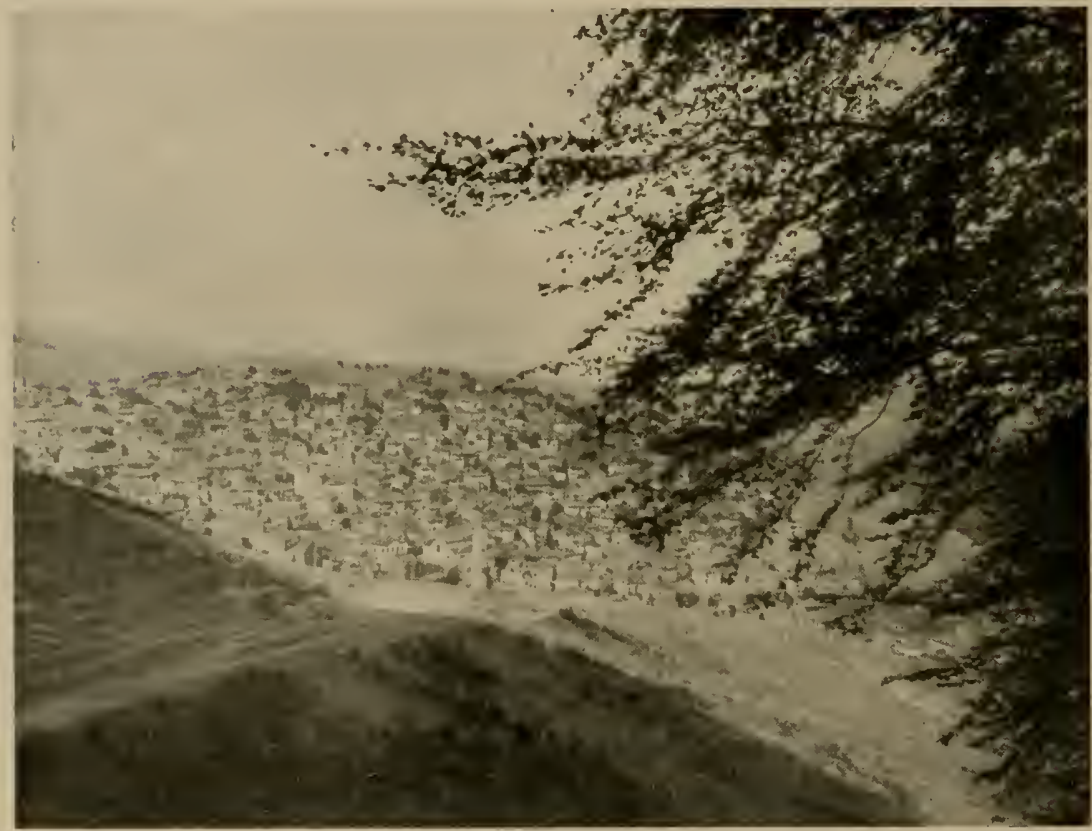

Abb, 245. Die Aromunenstadt Krusevo vom Buchenwald aus gesehen.

es einst die römischen Kolonisten waren, aus denen sie entstanden sein müssen. In alle den Jahrhunderten der Slavenwanderungen, der byzantinischen und türkischen Herrschaft, mögen manche Vermischungen vorgekommen sein. Aber die Sprache hält. Die auf dem Balkan zerstreuten A romunen, denen als romanisch sprechende Balkanvölker die Rumänen (bezeichnet als DacoRumänen), die Mogleniten und Istrier zur Seite stehen, erreichen nur die Zahl von höchstens 160000 . Dazu sind sie ganz außerordentlich zersplittert und zerstreut angesiedelt. 
Weigand hält für ihre ursprüngliche Heimat das westliche Nord-Thessalien, um das Gramosgebirge herum, von da sind sie hauptsächlich nach Nordosten ausgewandert, und man findet Bestandteile von ihnen in Griechenland, in Albanien, in Bulgarien, in Serbien, kurz über die ganze Balkanhalbinsel zerstreut. Sie erscheinen hauptsächlich in zwei Stämme geteilt, die sich gegenseitig als Karaguni, die Schwarzröcke, und die Farserioten, die fast immer weiße Kleidung tragen, bezeichnen. Während die ersteren seßhafte Stadtbewohner sind, leben letztere als Nomaden, schlagen ihre Hütten im Gebirge auf, wo es ihnen paßt und wo sie Weiden pachten; sie sind Hirten, welche keinen eigenen Grundbesitz haben. Trotzdem beide Stämme in enger Berührung sind, die Farserioten nicht selten zum seßhaften Leben übergehen, heiraten sie in der Regel nicht untereinander.

Daß die Aromunen bis in die neueste Zeit auf dem Balkan so viel wanderten, war meist nicht freiwillig. Religiöse Verfolgungen, Bedrückung, Plünderung durch die Türken und vor allem durch die Albaner veranlaßten sie aus der alten Heimat auszuwandern und sich an Orten niederzulassen, wo Volksgenossen es gut gefunden hatten. So stammen z. B. die Aromunen in Krusevo vorwiegend aus Platsa, Mekoro, Linotopi und Nikolitsa in Albanien. Aber die Neigung zum Wandern scheint auch ohnehin im Volk zu stecken. Nicht nur haben sie eine große Neigung besondere Sommerdörfer im Gebirge und W'interquartiere in tieferen Regionen zu bewohnen, sondern die Farserioten als Hirten sind, wie wir oben sahen, typische Nomaden. Auch findet man aromunische Kaufleute und Handwerker im ganzen Orient, in Österreich, in Rußland.

So kommt es, daß sie mehr als irgend ein anderes Balkanvolk zersplittert sind und nur in kleinen Gruppen zusammen wohnen. Sie sind zwischen den großen zusammenhängenden Nationalitäten des Balkan: den Albanern, den Serben, den Bulgaren und Griechen wohl kaum erhaltungsfähig und werden wohl allmählich in jenen aufgehen. Im Süden sind sie vielfach schon gräzisiert, in Albanien albanisiert: gerade die Albaner haben z. B. sogar in den aromunischen Siedelungen in Mazedonien Fortschritte gemacht, so von mir bekannten Orten in Lera und Kazani am Peristeri, in der Gegend von Resna und dem Prespasee sowie bei Ochrida.

Dabei spielen kirchliche Streitigkeiten keine geringe Rolle, indem die einen dem griechischen Patriarchen sich unterwerfen, 
andere der nationalen Kirche anhängen und damit jahrhunderte alte Gegensätze auf dem Balkan weiterführen. Auch die Agitation und Schulengründung von Rumänien aus konnte schon vor dem Kriege nicht übermäßig viel erzielen. Wie das jetzt nach den fürchterlichen Kriegsjahren sein wird, ist noch nicht zu übersehen.

Eines haben allerdings die Schulen erreicht. Man findet unter ihnen sehr wenig Analphabeten, ganz im Gcgensatz zum Königreich Rumänien, wo 1904 noch unter 5406209 Bewohnern sich noch 4719363 Analphabeten zählen ließen.

In einer Stadt dieses Volkes fand ich mich also in Krusevo; sicher unterschied sich hier die Mehrzahl der Bewohner von den Mazedoniertypen, denen ich bisher begegnet war. Die Einwohner der Stadt bestanden nach Zählungen, die allerdings vor der Kriegszeit zurücklagen, aus 7000 Aromunen, 4000 Bulgaren und 800 Albanern, insgesamt waren es 12000 Menschen. Die Leute waren größer als die meisten Türken und Bulgaren, die ich gesehen hatte, nicht ganz so grolb als Albaner. Auffallend viel Blonde fanden sich unter ihnen; die Gestalten waren vielfach elegant, schlank, die Bewegungen harmonischer als bei den mazedonischen Bauern. Nun war es allerdings hier Stadtbevölkerung. Unter den Hirten im Gebirge hatte ich nicht selten dunkle, vierschrötige Erscheinungen getroffen, die wohl zu den Farserioten gehörten. Hier in Krusevo, in Gopes und in Ochrida habe ich in Mazedonien die reizvollsten Erscheinungen von jungen Frauen gesehen, während die schönsten Männer Albaner waren.

Ich machte auf den Wunsch des Ortskommandanten einen Besuch bei dem Bürgermeister, der mich sehr freundlich aufnahm und mir nachmittags als Geschenk ein photographiertes Panorama der Stadt, Stickereien und Blumen schickte. Bei diesem Gang hatte ich Gelegenheit auch in Häuser hereinzuschauen, die wie die Straßen der Stadt für mazedonische Verhältnisse sehr sauber waren. In Zimmern mit sauber geputzten Fußböden fand man zum Teil ganz gute Möbel, Teppiche, gepolsterte Bänke an den Wänden, gelegentlich auch Betten, welche als besondere Kulturerwerbung der reichen Krusevaner gerühmt wurden. Auch Ungeziefer soll bei ihnen selten sein.

Auch hier in der Stadt schienen die alten Sitten durch den Krieg wieder aufgewacht; denn man sah viele Frauen mit Spindel und Rocken Wolle und Hanf spinnend in den Höfen, was sonst bei den Hirten stets üblich ist. Viele Leute trugen hier städtische 
Kleider; wenn auch Viehzüchter in der Stadt wohnten. Eine einheitliche Nationaltracht haben überhaupt die Aromunen nicht, sie gleicht jeweils derjenigen ihrer Nachbarn.

Spuren eigener alter Kultur findet man überhaupt wenig bei ihnen und vor allem nicht in einer Stadt von so jungem Bestand. So sind auch ihre Kirchen ziemlich neue Bauten. Das hindert nicht, daß die eine von ihnen sehr schöne Holzschnitzereien enthält. Die Handwerker der Aromunen sind überhaupt sehr tüchtig, besonders ihre Silberarbeiter und Goldschmiede.

Eine Aromunenstadt unterscheidet sich wesentlich von einem der schmutzigen Dörfer mazedonischer Bulgaren. Das gilt nicht in gleichem Maße von den Dörfern und vor allem nicht von den Hütten der Hirten, in denen allerdings immer eine besondere zum Wohnen und eine besondere zur Käsebereitung dient.

Was aber die Städte und Dörfer der Aromunen auszeichnet, ist ihre Lage, welche fast stets derjenigen von Krusevo ähnelt. Sie liegen immer in größeren Bergeshöhen. Darin spricht sich sicher schon wie in den Winter- und Sommerdörfern eine Neigung zu frischer Höhenluft, zu gutem Wasser, das Bedürfnis nach hochgelegenen Weideplätzen aus. Aber die Lage der Ansiedelungen in langen Seitentälern, abseits von den Hauptverkehrsstraßen zeigt, daß die Bewohner gleichzeitig damit Schutz vor Räubern und marodierenden Soldaten suchen. Sie sind ein wenig aus der großen Welt herausgetreten, sie wohnen nicht an der Straße, sie reizen nicht das Auge des Begierigen.

Sie stellen allerdings in ihren Städten nur wirtschaftliche Vereinigungen dar, nicht solche zu Schutz und Vereinigung gegen Feinde, wenn sie eine solche auch ohne weiteres durch ihre Einwohnerzahlen sind. Doch ist es sehr bezeichnend, daß Aromunenstädte nie Mauern und Befestigungen aufweisen. 


\section{GOPES}

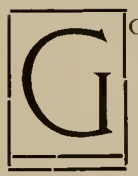

opes ist auch eine Aromunenstadt oder richtiger ein großes Dorf mit städtischen Häusern, hochgelegen, wie die meisten Ansiedlungen dieses Volkes. Viermal bin ich in das Gebirge gereist, in welchem dieser Ort $1200 \mathrm{~m}$ hoch liegt. Jedesmal erfolgte die Reise mit anderen Hilfsmitteln und zu anderer Jahreszeit und brachte so verschiedene Eindrücke, daß es sich lohnt, die verschiedenen Reisen nach Gopes kurz zu schildern.

Mein erster Besuch, eine Rekognoszierung, führte mich in gutem Auto des A.O.K XI in einem Tag von Prilep nach Gopes und wieder zurück. Es war in den 18 Stunden, die er für mich dauerte, ein reicher Tag, der frühe Morgen hatte mich über die Ebene wieder nach Krivogastani gebracht, dann am Gebirge entlang über Bucin längs der Cerna nach Murgas. Kurz hinter diesem Ort geht es an einen Nebenbach, die Mramoriča (auch Smileva Reka genannt) und diese aufwärts zum Dorf Smilevo, von wo es in sehr steilen Kurven nach Gopes hinauf führte. Es war ein köstlicher Genuß, an dem schönen, klaren 20. Juni 1917 durch die grüne Landschaft am rauschenden Bach entlang zu fahren. Ein kühler Morgenwind beugte die Pappeln, Weiden und Obstbäume. Grüne Wiesen breiteten sich neben gutgepflegten Feldern aus. Der Weg und der Bach treten bald auf die eine, bald auf die andere Seite des Tales. Schhließlich führte eine Flußbrücke zu dem kurvenreichen Bergweg, der mich schnell nach Gopes brachte.

Ein malerischer Blick öfnete sich vor mir durch den sommergrünen Buchenwald auf das Städtchen Gopes.

Es war der erste größere Buchenwald, den ich nach kurzem Aufenthalt in Mazedonien kennen lernte; die silberglänzenden, grauen Stämme, zum Teil alt und knorrig, das flirrende Laub, das sich vom wolkenlos blauen Himmel abhob, der Gesang der Vögel aus den Kronen der Buchen stimmten mich von vornherein empfänglich für all die Naturschönheit, die mich da oben erwartete. Jede Kurve gab einen neuen Ausblick auf die für mich ganz neuartige 
Stadt mit ihren großen Häusern, ihren steilen Gassen, den Gruppen von Obstbäumen, Erlen, Pappeln, welche keine solche Wirkung von Mauern und Steinen aufkommen ließen, wie sonst in mazedonischen Städten. Als anmutiges Landstädtchen erschien mir Gopes, umgeben von einer großzügigen Gebirgslandschaft. Schroff stürzten die Hänge hunderte von Metern in die Täler hinab; aber es waren nicht kahle Felsen, sondern grüne Wiesen, umrahmt von Hecken und Buschwerk, abwechselnd mit Gruppen schön gewachsener Bäume und kleinen und größeren Wäldern. Frische Gebirgsluft wehte durch die Gassen, deren Häuser in der Bauart reiche

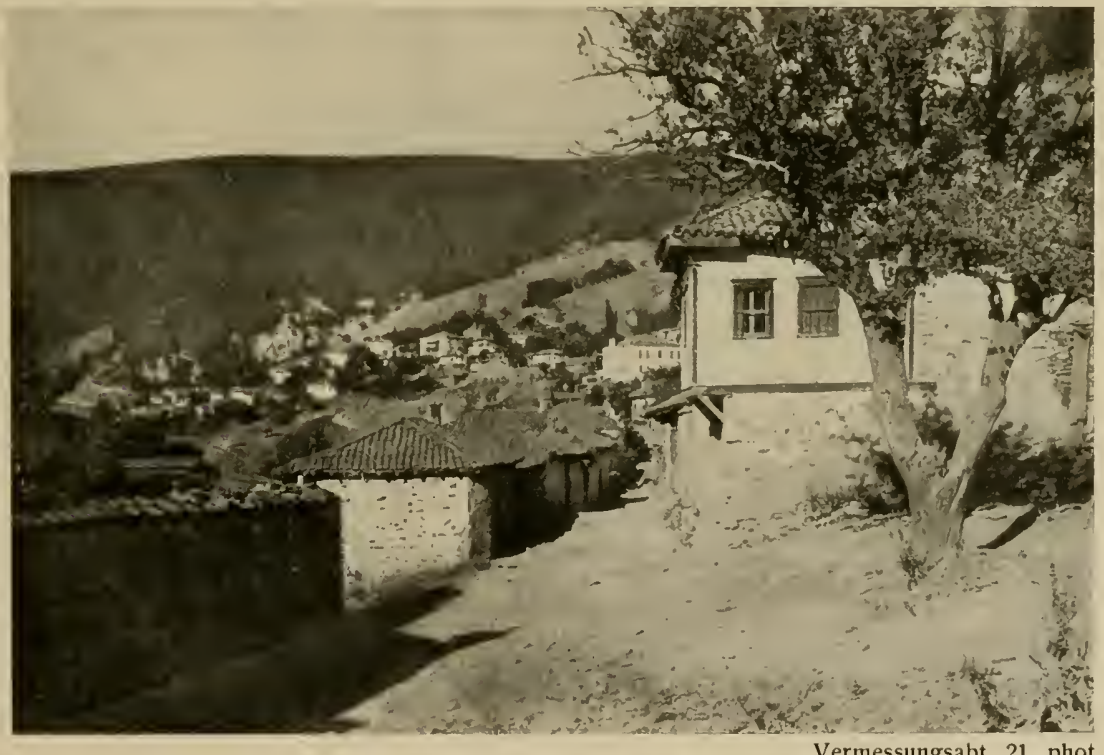

Ahb. 246. Gopes im Sommer.

Abwechslung zeigten; manche waren mit Holzveranden und Vorbauten geziert; überhaupt Holzwerk und Hausteine an den unteren Stockwerken brachten eine bunte Mannigfaltigkeit ins Straßenbild, die noch gesteigert wurde durch die Verschiedenfarbigkeit der Dächer, die mit roten Ziegeln, häufiger aber mit grauen Schieferplatten gedeckt waren. Ein warmes, heiteres Bild, ohne die Grellheit der türkischen Städte, gehoben durch die Durchblicke auf die Wälder und die grandiosen Bergformen, welche nach allen Seiten sich über die Ortschaft erhoben.

Den Eindruck, den Gopes auf mich gemacht hatte, entsprach 
die Aufnahme, die ich dort fand; ebenso war die wissenschaftliche Ausbeute, welche der kurze Besuch mir dort brachte, sehr erfreulich. Ohne lang zu zögern, hatte ich eine Exkursion auf einen Berg über dem Ort unternommen, über den ein Paß zur Stadt Resna führt. Beim Aufstieg weitete die Landschaft um mich sich mehr und mehr, tiefe Einblicke in die Täler öffneten sich und das ganze Bild war von dem stolzen Kegel des Peristeri gekrönt. Noch lag reichlich Schnee auf seinen Hängen; in kühler Bläue überragte er die warme, farbige Landschaft.

Der Berg, den ich hinanstieg, war von einem stattlichen Buchenwald bedeckt; lauschige, schattige Pfade führten durch ihn hindurch. Bei diesem meinem ersten Besuch konnte ich noch die waldreiche Umgebung von Gopes in ihrer vollen Schönheit bewundern. Jeder spätere zeigte mir den Waldbestand ausgeraubt und kläglich gemindert. Bei meiner letzten Durchreise durch Gopes waren in der nächsten Umgebung des Ortes nur noch kümmerliche Baumgruppen übrig geblieben.

An den Schluchten standen aber im Juni 1917 noch prachtvolle Stämme weichblätteriger Eichen, Weiden, Pappeln, Haselnuß, an denen Efeu kletterte. Oben breiteten sich zwischen ihnen auf Lichtungen üppig grüne Waldwiesen aus; am Waldrand waren große Flächen von Adlerfarn bedeckt. Den Rand der Wiesen faßten duftende Wildrosen, Brombeersträucher, Weißdorn ein. Und welche Blütenpracht bedeckte den Boden der Wiesen; hier in etwa $1500 \mathrm{~m}$ Höhe war noch voller Bergfrühling. Dem entsprach auch der Reichtum der Insektenwelt, besonders der Schmetterlinge, die hier meine Aufmerksamkeit fesselten.

Unter den letzteren waren es charakteristische Gebirgsformen, die hier sich zeigten; so unter den Scheckenfaltern, wie Melitaea didyma, von der bei Kaluckova die südliche Form geflogen war, gab es hier den nördlichen Vertreter; Melitaea attalia mehadiensis Gelh. ist ein typischer Gebirgsschmetterling. Von der Gattung Pararge fand ich einen Vertreter unseres Mauerfuchses (P. maera L.), in einer interessanten Form (Übergänge zu adrasta Hübn.), und die eigenartige $P$. roxellena $\mathrm{Kr}$. Scharen leuchtender Bläulinge umschwebten die Wiesenblumen, so Cephyrus quercus L. und Lycaena scmiargus Rott., L. amandus Schn. Dazwischen zog der altbekannte goldbraune Silberstrich (Argynnis paphia L.) seine stolzen Kreise. Mit ihm flog ein zweiter Perlmutterfalter (Argynnis daphne Schiff.). 
Die schönste Überraschung war aber ein echter Alpenfalter, eine mit dem Apollo verwandte Form, eine auffallend kleine Mnemosyne, die hier in zahlreichen Exemplaren flog. Es war eine anstrengende Jagd in der strahlenden Sonne, bei der mir ein junger Soldat, der mir als Begleiter mitgegeben war, eifrig half. Es gelang, eine ganze Anzahl dieses schönen weißen Schmetterlinges $\mathrm{zu}$ erbeuten.

Auf den blühenden Sträuchern taten sich wohl die metallisch glänzenden Rosenkäfer (Cetonia aurata var. tunicta Reit.). Am schattigen Boden lief der grünglänzende Puppenräuber (Calosoma sycophanta L.) auf der Suche nach Raub herum.
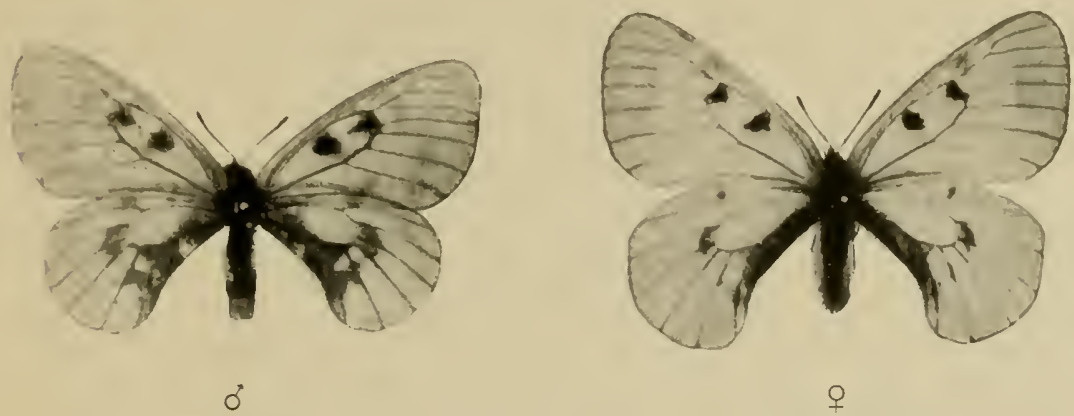

Abb. 24i. Mnemosyne sp. Form von Gopes.

Von Fliegen erinnere ich mich an eine lebhafte Hummelfliege (Hemipenthes morio L.) und die auffallende Raubfliege Laphria Aava L. Von Bienen flogen Andrena greynana var. acstiva K., Anthophora Kessleri Mor. und die schöne Xylocopu valga Gersh. (vgl. auch Abb. I87, S. 375) umher; eine Schmarotzerbiene (Mlelecta lactuosa Scop.) und eine stattliche Hummel (Bombus haematurus Kriechb.) schwirrten am Boden entlang.

Noch manches interessante Tier konnte ich in den wenigen Stunden, die mir an diesem Tag gewährt waren, beobachten. Um so dankbarer empfand ich dies, als ich im nächsten Jahr kaum einen Monat später bei einer neuen Exkursion nach Gopes eine ganz veränderte Fauna, keine einzige der diesmal beoachteten Arten, mehr vorfand.

Der Aufenthalt hier oben weckte in mir zwei Pläne, die im nächsten Jahr zur Ausführung gelangten. Ich beschloß beim Anblick des Peristeri, diesen eigenartigen Berg zu besteigen und seine Natur kenneı zu lernen. Noch stärker zog es mich in die 
Tiefe, als ich von der Paßhöhe nach Westen und Südwesten blickte. Frei lag vor mir eine weite Ebene, in deren Mitte die Stadt Resna mit ihren weißen Häusern aufblinkte. Die Ebene war eingefaßt von einer Kette hoher Berge, hinter denen die albanischen Gebirge auftauchten.

Zwischen dem Berg, auf dem ich stand, und jenen fernen Ketten aber blinkte im Süden im zarten Duft der Spiegel des Prespasees auf. Also so nahe $z u$ meinen Füßen lag dieser schöne blaue See und ähnlich mußte jenseits jener Bergkette der Ochridasee liegen, von dessen Schönheit viele Berichte mir geworden waren.

Ganz anders sah die Landschaft um Gopes aus, als ich einige Monate später auf der Fahrt zum Ochridasee sie durchreiste. Da war auch hier viel verdorrt und verbrannt. Pflanzenwelt und Tierwelt vollkommen verändert.

Und noch mehr umgewandelt erschien sie mir, als ich am 18. Dezember 1917 eine Winterfahrt nach Gopes unternahm. Als ich im Auto durch die Ebene von Prilep fuhr, da strahlten alle Gebirge, welche sie umgeben, in einem schimmernden Schneegewand. Nicht nur der hohe Peristeri mit seinen Nachbarbergen, die ganzen Mittelgebirge lagen in tiefem Schnee. Da genoß ich auf der Fahrt in der Ebene ein wundervolles Schauspiel. Erstaunlich war schon die Menge von Elstern, Dohlen, Raben, Krähen, die sich bei der winterlichen Kälte in der Nähe der Dörfer angesammelt hatten. Auffälliger waren die großen Zahlen von Kiebitzen, die an den Gräben herumflogen und vor allem der Falken, die trotz der Kälte hier ausgehalten hatten.

Das Seltsamste wareı aber die Massen von Wildgänsen, die sich in der Ebene von Prilep in diesen Tagen angesammelt hatten. Schon bei der Fahrt durch Serbien und Nordmazedonien hatte ich große Mengen dieser Vögel an den Flüssen gesehen. Vor allem im Wardar schwammen an jeder Windung, in jeder Bucht eine Anzahl Paare dieser stattlichen Vögel, meist gleichzeitig mit Stockenten und anderen Wildenten. Hier aber auf der Ebene von Prilep waren ihrer gewaltige Massen versammelt.

Woher mochten sie alle kommen? Alle paar Minuten flogen 100 bis 200 Stück vor meinem Wagen auf, ganze Wolken von ihnen zogen am Himmel dahin. Schließlich durfte ich die Zahl, die vor mir aufgetaucht und an mir vorbeigeflogen war, auf 20000 schätzen. Sie waren auf dem Zug aus dem Norden hier angelangt 


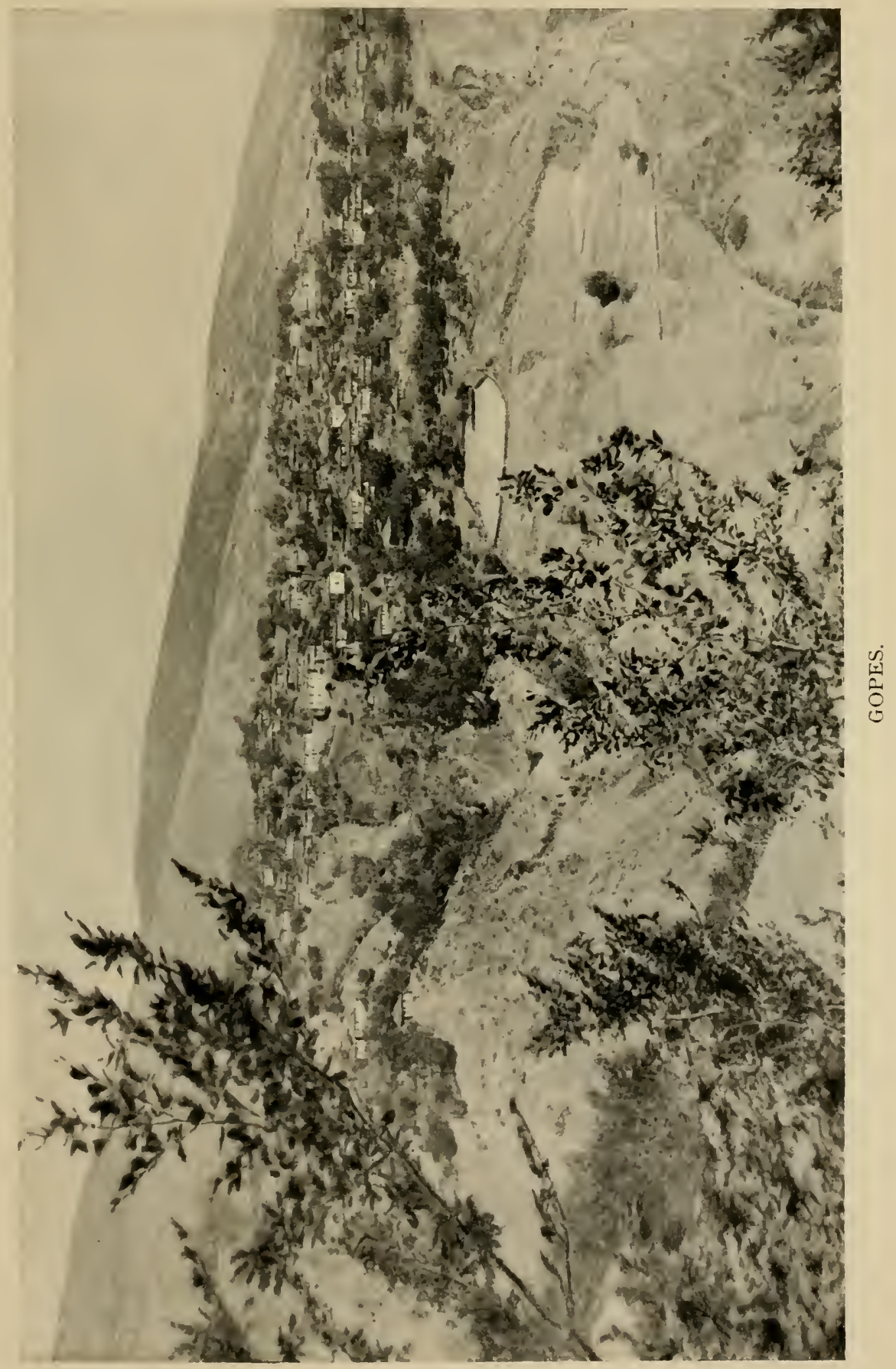



und hatten im Lande Station gemacht. Weitere Zuzüge kamen ständig an und offenbar war der Zug weiter nach Süden gerade in dieser reichen Ebene der Pelagonia zum Stocken gekommen. So war eine Stauung entstanden, welche zu den Massenansammlungen führte.

In Lera erwartete mich ein Pferdewagen, der mich den Berg hinauf durch tauenden Schnee und Schmutz nach Gopes brachte. Zum Schluß der Fahrt kam ich in Nebel; dessen Schwaden zogen zwischen den alten Buchen und Eichen dahin, öffneten gelegentlich den Ausblick auf schneebedeckte Halden und in die tiefen Schluchten

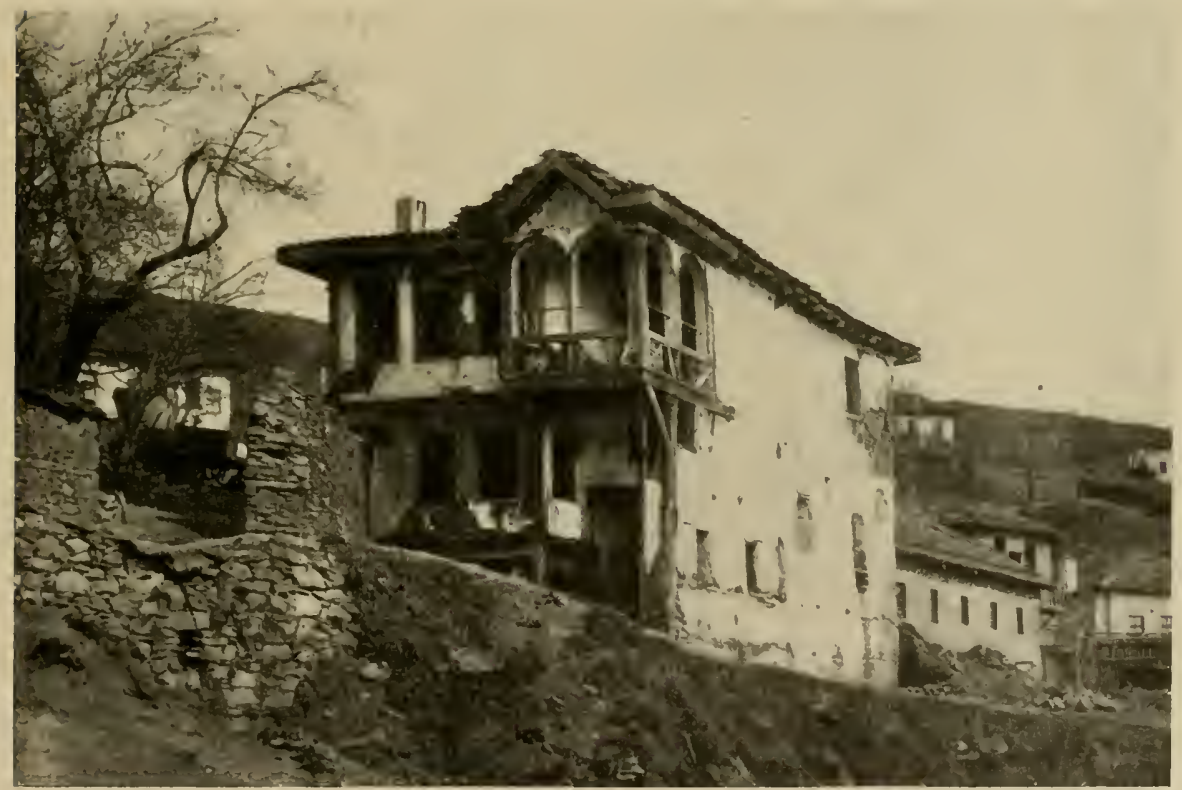

Abb. 248. Haus mit Veranden in Gopes.

und Täler; Krähen und Dohlen flogen krächzend von Baum zu Baum. Es war ein reizvoller Anblick, den der verschneite Ort mit den schwer beladenen Dächern darbot, so ganz anders als im Sommer und doch fast schöner in den malerischen Einzelbildern, welche Bäume und Häuser darboten.

Es war eine eigenartige Aufgabe, welche ich diesmal mitten im Winter in Gopes zu erfüllen hatte. Ich brachte dem Etappeninspekteur der XI. Armee, Exzellenz von Krane, das Ehrendoktordiplom der naturwissenschaftlichen Fakultät der Universität 
Freiburg im Breisgau, meiner damaligen Fakultät. Es war dies eine Ehrung des Generals, welcher durch sein Eintreten für unsere Kommission der Wissenschaft wertvolle Dienste geleistet hatte. Das wurde in einem eigenartigen Fest kurz vor Weihnachten in der entlegenen Gebirgslandschaft gefeiert. Der General hatte zu der Festlichkeit alle Doktores aller Fakultäten, die bei den in der Umgebung verteilten Truppen an der Front standen, eingeladen.

Es war ein feierlicher Augenblick, als ich im Kreis dieser stolzen Schar, angetan mit dem Amtstalar meiner Fakultät, das Ehrendiplom entrollte, verlas und mit einer Ansprache überreichte, in der ich die Verdienste des Heeres um die Erforschung des Landes, die enge Verknüpfung, welche der Krieg zwischen Armee und Gelehrten gebracht hatte, hervorhob und das Verdienst des Generals dabei betonte. Bei seinem Dank war der General so gerührt, daß ihm die Tränen in die Augen traten. Dabei wirkte auf ihn, wie auf uns alle, die ganz eigenartige Situation, unter der der feierliche Akt sich vollzog. In dem kleinen Zimmer des Aromunenhauses, dessen Beleuchtung für den Abend nach Möglichkeit gesteigert war, hatte sich um uns eine glänzende Gesellschaft geschart. Sie kamen aus den Stellungen und Unterständen, die sich an der Grenze Griechenlands im Hochgebirge hinzogen, waren oft manchen Kilometer weit auf Gebirgssteigen geklettert und geritten, um diese friedliche Feier mitzumachen.

Den nächsten Tag, den ich noch in Gopes verweilen mußte, verwandte ich zu einer Besteigung einer beschneiten Höhe, die sich über Gopes erhebt. Es war die Kuppe 1680 , über jenem $\mathrm{Pa} 0$ nach Resna, an welchem ich im Juni so gute Insektenausbeute gemacht hatte. Es ging wieder durch den beschneiten Buchenwald, anfangs auf schlammigen Pfaden, die weiter oben gefroren und von Glatteis überzogen waren. Später bedeckte Weg und Waldboden tiefer Schnee, so daß kein Pfad mehr zu erkennen war.

Durch den Schnee führten zahlreiche Tierspuren, welche auf Füchse und eine Spur, welche auf einen Wolf deuteten. Letzteres war durchaus nicht unmöglich, denn man hatte mir abends die Photographie eines dicht bei Gopes erlegten Wolfes gezeigt und auch Bären kamen im Gebiet vor.

Um in dem pfadlosen Schnee in der grenzenlosen Bergeinsamkeit eine Orientierung $z u$ haben, bewegte ich mich gegen eine Kuppe, die ein trigonometrisches Signal trug. Noch schien starke Nachmittagssonne, ein dunkelblauer Himmel stach scharf 


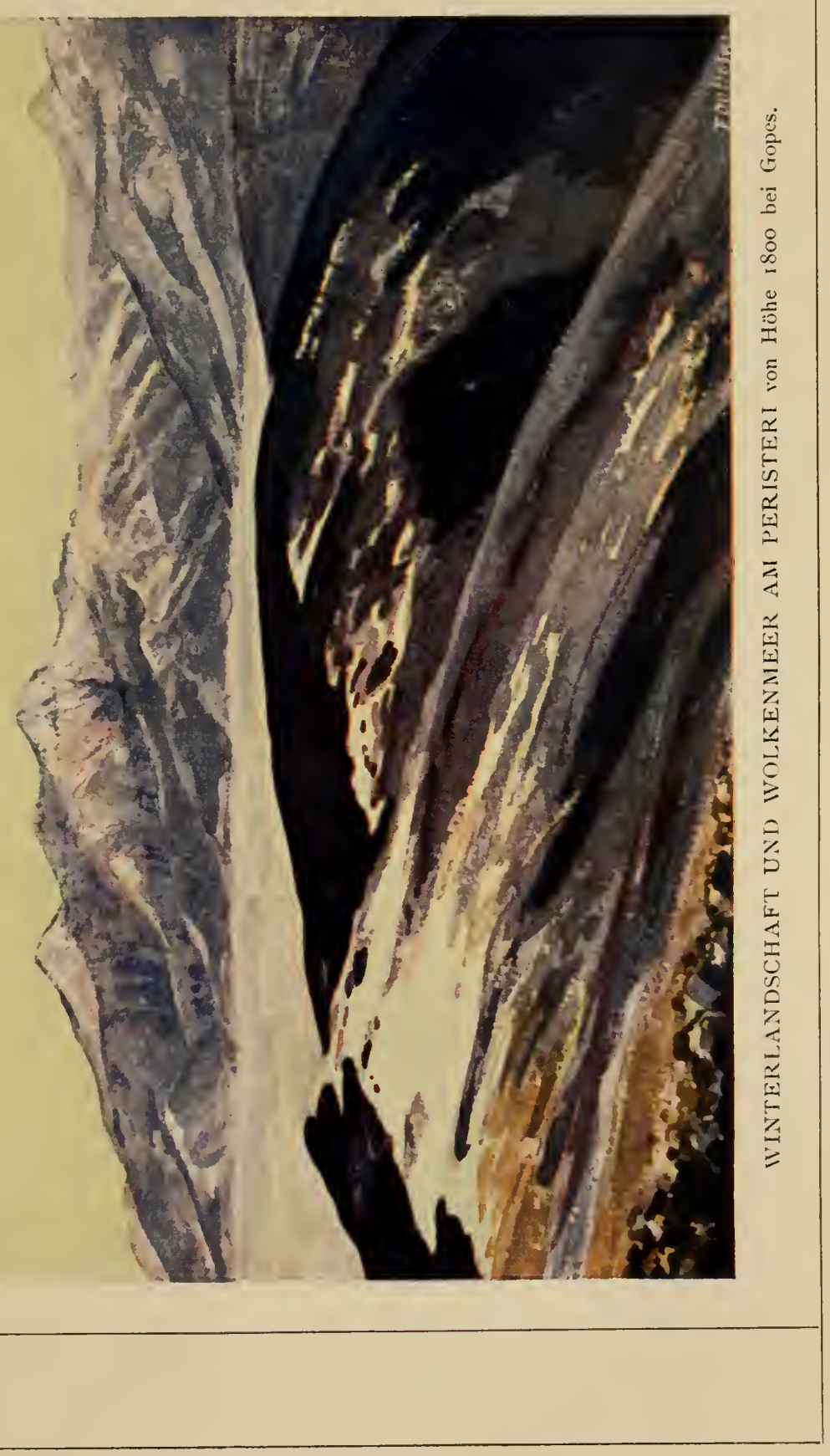



von den weißen Schneeflächen ab, auf welchen tiefblaue Schatten lagen. Immer prachtvollere Blicke taten sich vor mir auf, hinunter auf die Ebene bei Resna und nördlich des Prespasees und vor allem nach Süden auf den edelumrissenen Block des Peristeri. Als ich auf der Kuppe angelangt war, begann der Tag sich zu neigen, gelber begann das Sonnenlicht die Schneeflächen zu färben. Aus der Tiefe stiegen Nebelschwaden auf, welche in die Täler eindrangen und diese allmählich erfüllten. Immer weiter breiteten sie sich aus und bedeckten schließlich wie ein weites Meer die Ebene, während gleichsam Buchten und Häfen sich in die Täler und zwischen die Berge erstreckten. Es war die Zeit, in der an der Front der „Abendsegen“ ertönte, die regelmäßige Beschießung, die auch hier in den Gebirgsstellungen nicht unterblieb. Als die letzten Schüsse verhallt waren, breitete sich tiefste Stille um mich aus, nur hier und da knisterte es im frierenden Schnee. Im Westen, unter der sinkenden Sonne, schimmerte durch den Nebel der blinkende Spiegel des Prespasees durch, vor allem das Sumpfgebiet im Norden blitzte auf. Die Insel im See ist deutlich sichtbar.

Westwärts werden der Tomoros und Malisat, die Berge am Ochridasee, albanische schneebedeckte Gebirge, mit leuchtenden weißen Flächen und starken blauen Schatten sichtbar. Der Schein der Sonne wird röter und röter; in ihm leuchtet die Pyramide des Peristeri in Glut, die von tiefblauen Schatten sich abhebt. Die fernen Ketten schimmern wie Alpenglühen.

Wie düstere Inseln ragen die näheren Berge aus dem silberig erglänzenden Wolkenmeer heraus; dunkelviolette Schatten lassen sie als schwere Massen von der duftigen, flockigen Oberfläche des Nebelmeeres sich abheben. In dieser regt und bewegt es sich, sie erscheint stürmisch bewegt, zu gewaltigen Wellenungetümen aufgetürmt. Und wie Gischt an der Brandung bäumen sich die Wolkenränder an den Felsen auf.

Nun wird um mich das Licht fahler; nur die Spitze des Peristeri und weit drüben bei den Feinden der Kaimaktschalam erstrahlen noch in rosigem Licht. Die Schatten werden immer blauer und durchsichtiger. Schließlich verschwindet alle Röte von den Bergen. Ein zartes Gelb legt sich auf ihre Schneefelder, während die Schluchten in tiefe Tinten von Indigo getaucht werden. In der Ferne erscheinen aber die Kettengebirge zauberhafter noch als zuvor. Das Nebelmeer dehnt sich weit dahin wie eine un- 
endliche schneebedeckte Ebene, aus der wie Inseln, wie ferne antarktische Gebirge die Ketten hervorragen, deren Gipfel die Wolken noch überragen. Kalt und einsam, menschenleer und verlassen, wie aus Kristall gebaut, schweben sie am Horizont. In einer hier eingefügten Farbenskizze habe ich versucht, den großen Eindruck festzuhalten.

Während ich hinabzusteigen beginne, dehnen sich die Nebelmassen immer mehr zu langen Wülsten aus; sie dringen mir auf meinem Weg entgegen. Aus der Tiefe drängen sie herauf. Sie bilden stürmende, wühlende Massen und erscheinen mit ihren grün-

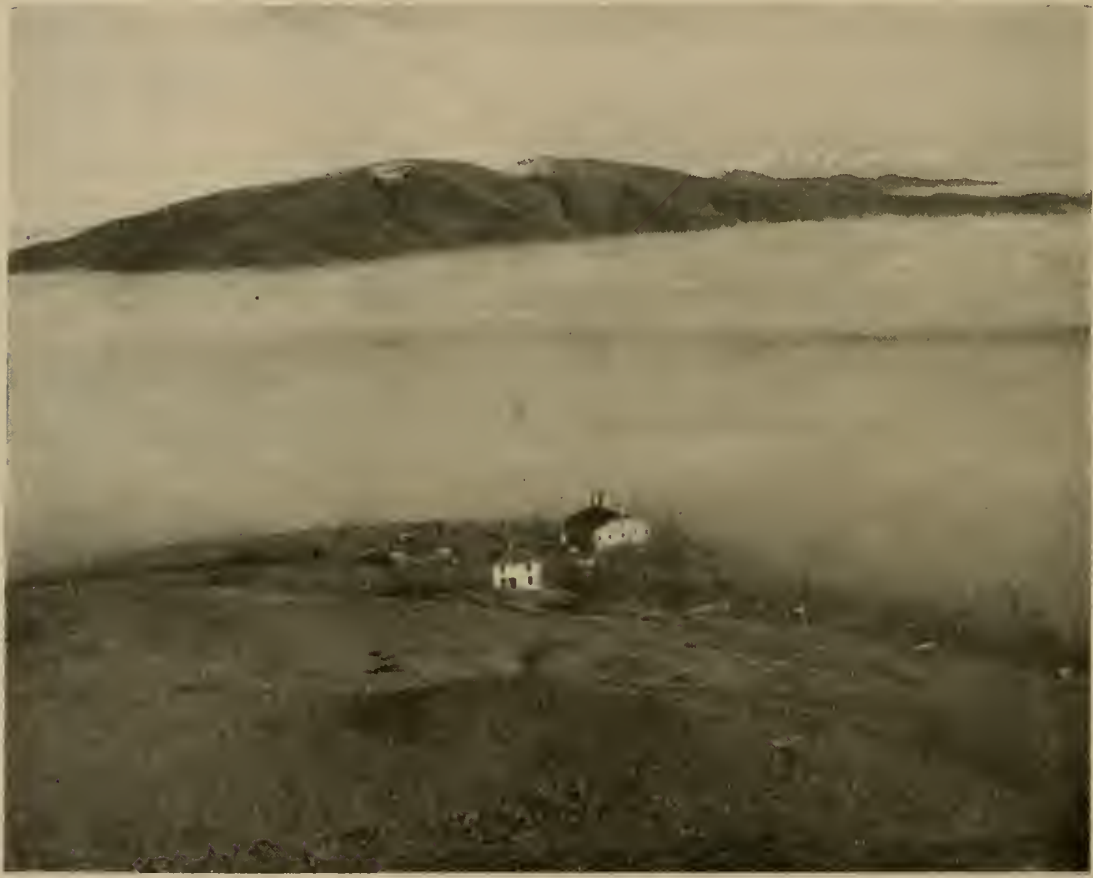

Abb. 249. Gopes im Winternebel.

lichen Schatten heller, leuchtender als die dunkler und dunkler werdenden Berginseln.

Ich steige ihnen entgegen, in sie hinein, durch sie hindurch; tiefe Dämmerung umgibt mich; da tauchen die Häuser von Gopes vor mir auf, durch irgendeinen Reflex rosig angehaucht. Zwischen Nebelschwaden klettern sie aus dem Abgrund hervor, die Kirche mit ihren Türmchen, die Dächer und blau beschatteten Wände. 
Wolken wälzen sich durch die engen Gassen aus dem Tal herauf. Hier und da blinkt ein mattes Licht in den Fenstern eines alten Hauses auf.

An diesen Winterabend mußte ich denken, als ich an einem heißen Julitag 1918 die letzte Reise nach Gopes machte, schwer mit vielerlei Gepäck belastet, um das dortige Hauptquartier als Ausgangspunkt $z u$ einer Besteigung des Peristeri, des Tomoros und zu Untersuchungen auf dem Prespa- und Ochridasee zu verwenden. Es waren glühend heiße Tage, an denen ich die Reise von Üsküb über Veles nach Prilep, von dort mit der Kleinbahn über Bucin und Lopatiče nach Sviniste machte, um von diesem Ort nach Gopes hinaufzureiten.

Oben fand ich alle erwartete Unterstützung und bestieg noch einmal den Berg, der mir im Winter einen so unvergeßlichen Eindruck hinterlassen hatte. Auch an diesem Tag bot er Interessantes. Allerdings die Waldverwüstung hatte noch weitere Fortschritte gemacht. Aber der Insektenreichtum war noch ähnlich groß wie im vorigen Jahr. Doch waren jetzt andere Arten beim Flug; so unter den Schmetterlingen interessante Blutströpfchen, Zygaeniden-Arten. Aber die Mnemosynen, welche im Jahre vorher so zahlreich hier flogen, waren jetzt entsprechend der um einen Monat vorgeschrittenen Jahreszeit verschwunden. 


\section{DREIUNDDREISSIGSTES KAPITEL}

\section{SOMMER IN MAZEDONIEN}

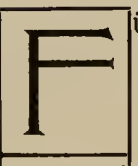

ür den Naturforscher war der Sommer wohl die eindrucksreichste Jahreszeit in Mazedonien. Von ihm war in manchen Kapiteln dieses Buches die Rede; ich erwähnte oft seinen Einfluß auf Tier- und Pflanzenwelt, auf den Charakter der Landschaft. Hier möchte ich zusammenfassend ein einheitliches Bild vom Sommer Mazedoniens geben, da ich ihn für das Verständnis dieses eigenartigen Stückes von Europa für besonders wichtig halte.

Bis in den Juni hinein erstreckt sich der Frühling mit seinem Reichtum an Blüten, mit seinem fröhlichen Vogelleben, mit der stürmischen Entwicklung der Insektenwelt. Überwältigend ist in dieser Zeit die Energieproduktion des Lebens im ganzen Land. Nur im Hochgebirge fängt der Frühling später an und hält länger aus. Wenn im Flachland und in den Tälern schon die Sommerdürre herrscht, kann man ins Gebirge in den Frühling hineinsteigen.

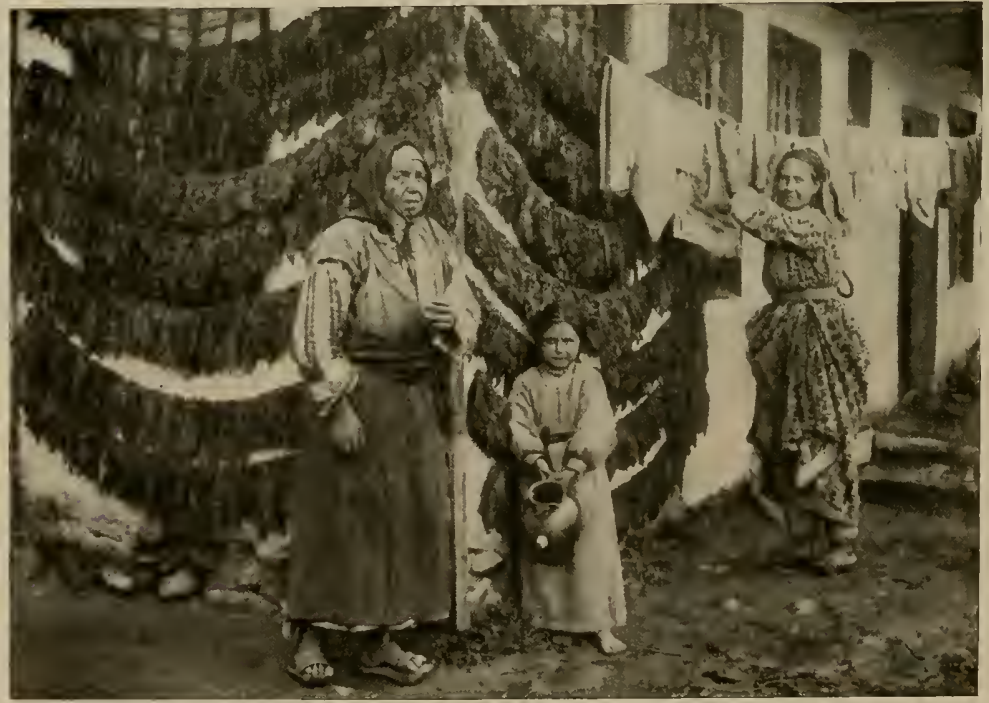

Abb. 250. Mazedonisches Bauernhaus mit trocknenden Tabaksblättern. 
Ende Juni, Anfang Juli beginnt unten das große Sterben. Die einjährigen Pflanzen, deren Blütenpracht den Frühling so reizvoll machte, haben ihre Samen gereift und können nun verdorren. Die Sonne beginnt, von Wolken unverhüllt, in ihrem Tageslauf unerbittlich auf das Land herabzustrahlen. Durch den Juli, August und September dehnen sich fast hundert wolkenlose Tage. Es ist die Zeit der hohen Tagestemperaturen. Mitte Juli steigt der exakt gemessene Thermometer regelmäßig am Nachmittag über $35^{\circ} \mathrm{C}$, nicht selten auf $40^{\circ}$ und darüber; und das dauert den August hindurch und vielfach ein gut Stück in den September hinein. Dabei sind die Morgentemperaturen schon um und über $30^{\circ}$ und auch nachts sinkt das Thermometer selten tiefer. Und noch höher, oft ganz erheblich höher, waren die Strahlungstemperaturen, welche von den sonnendurchglühten Wänden der Häuser, den Felsen, den Lehmhalden ausgingen. Das war die Zeit, in der die deutschen Soldaten unter dem Land Mazedonien litten, in der sie ihm fluchten. Es wurde zum schattenlosen, staubigen Land, das sie mit der Wüste verglichen.

Tatsächlich nahm das Tiefland immer mehr den Charakter der verbrannten Steppe an. Die Blüten waren verschwunden, selbst die Büsche und Bäume hatten ihre Samen und Früchte angesetzt. Die Wiesen und Rasen verwelkten. Staub begann überall im Winde aufzuwirbeln und dämpfte das Grün, das in der Landschaft noch lebte.

Wenige Pflanzen blühten noch, wenige vor allem in voller Pracht, viele zeigten welke Blüten und Fruchtstände neben spärlichen Blüten, so der Rittersporn, die Glockenblumen, die Königskerzen und vor allem die Disteln, die sich jetzt vordrängten. Aber auch diese begannen gelb und braun zu werden. Viele der Pflanzen hatten dornige, stachelige Samen.

Auffallend still war es im Frühsommer in der gelbgrauen Landschaft geworden. Die Gesänge der Vögel waren verstummt, nachdem für die meisten von ihnen die Paarungs- und Brutzeit vorbei war. Vor allem zur heißen Mittagszeit war nichts von ihnen $\mathrm{zu}$ bemerken; sie hatten sich in den Büschen versteckt. Viele waren in die Schluchten und Haine der Berghänge verzogen, ja manche Arten waren vollkommen verschwunden und waren in die Berge gewandert.

Selbst die sonnenliebenden Eidechsen sah man jetzt nicht mehr so viel auf den glühend heißen Steinen umherhuschen. Auch 
bei ihnen waren die Weibchen beim Eierlegen und ihre Beute war kärglicher geworden. Die Insekten waren viel weniger geworden; bei vielen Tagschmetterlingen war die erste Generation verschwunden und von der zweiten fraßen die Raupen an den Futterpflanzen. Auch für viele solitäre Bienen galt ähnliches. Vor allem fehlte die Masse der Blütenkäfer, die mit den anderen Blüteninsekten, den Wanzen, den Blattwespen, den Fliegenarten so sehr zum Reichtum der Frühlingstierwelt beigetragen hatten.

Eigenartig war die Ruhe, die in der Natur in den heißen Mittagsstunden herrschte. Zwar lagen die Mauereidechsen und die schönen großen Smaragdeidechsen träg in der Sonne. Aber auch sie hatten wenig Neigung sich zu bewegen. Schon Theokrit wußte, daß die Eidechsen um diese Zeit hier im Lande mittags schlafen. Nur die Mistkäfer wälzten unbekümmert ihre Kotkugeln. Die Vögel waren ganz still, selbst die Ameisen wanderten kaum auf ihren Straßen und hielten Mittagsruhe.

Auffallend war die Flucht vieler Tiere in den Schatten. In Hainen und vor allem in kleinen Bergwäldern, so in dem Buchenivald der Plaguša Planina, waren ganze Versammlungen von Vögeln in das grüne Düster unter den Bäumen geflüchtet. Selbst Tagschmetterlinge waren aus der grellen Sonne gewichen und saßen in Scharen auf den Buchenstämmen, so verschiedene Satyrus-Arten. Verständlicher war es, daß die tagfliegenden Eulen (Arctiiden) den Waldschatten aufgesucht hatten.

In den Schluchten versammeiten sich in der Wassernähe vor allem viele Amphibien, welche dem Wasser dorthin nachgezogen waren. Nicht nur Frösche, sondern auch Kröten fand man dort in dieser Zeit in ungewohnten Mengen. Hier fanden sie wenigstens einen Hauch von Feuchtigkeit unter Steinen und in Felsspalten. Dorthin zogen sie sich zurück, als die steigende Dürre die Bäche mehr und mehr austrocknete. Dann hielten die Amphibien, Molche und Frösche, ihre Sommerruhe in diesen Verstecken. Dort gesellten sich $\mathrm{zu}$ ihnen die Krebse und Taschenkrebse, die auch eine Ruhezeit durchmachen mußten. Besonders auffällig war dies bei den Bachfischen, z. B. den Barben, die, im Schlamm vergraben, in einen Sommerschlaf versanken. Fische, Krebse und andere Wassertiere fand ich auch öfters tot in den ausgetrockneten Bachbetten liegen, wo die Verdunstung des Wassers sie liegen gelassen hatte. So fand ich z. B. am 30. Juli in verschiedenen trockenen Schluchten Süßwasserkrabben 
tot umherliegend. Eine Sommerruhe war ganz allgemein bei den Landschnecken. Diese hatten alle, besonders die Helix-Arten, in dieser Zeit sich in ihre Häuser zurückgezogen und diese mit einem dicken Kalkdeckel verschlossen. Vielfach hingen sie, mit Schleim angeklebt, an den verdorrten Stengeln der Pflanzen, mit denen gleichzeitig die Dürre sie überrascht hatte. Und das konnte auch schon im Mai passieren, wenn plötzlich trockene Hitze einsetzte.

Nacktschnecken gab es in Mazedonien ja nur sehr wenig. Die Exemplare weniger Arten, die ich im Lande auffand, waren stets unter Steinen, in Erdlöchern, in der Nähe von Brunnen oder Quellen in feuchtem Boden entdeckt worden.

Alle diese Tiere, wie auch die vielen kleinen Geschöpfe der Tümpel, welche in Zysten oder anderen Dauerzuständen zu übersommern vermochten, erwarteten so, ihres Lebens wenigstens sicher, die ersten ergiebigen Herbstregen. Die waren nicht vor Ende September zu erwarten. Im Jahre 1917 erlebte ich den ersten Herbstregen an ro. September; aber er und seine Nachfolger in den nächsten Wochen waren noch nicht fähig die Erde zu nässen. Obwohl sie aus schwarzen Wolken kamen, erreichten ihre Tropfen die dürstende Erde nicht, sondern waren verdunstet, lange ehe sie den Boden erreichen konnten.

Trotzdem war die Sommerlandschaft Mazedoniens nicht ganz frei von Tieren. Im Gegenteil, im Juli schon mehrten sich die Vertreter einer neuen Sommertierwelt. Schon im Juni waren manche $\mathrm{Heuschrecken-Arten} \mathrm{in} \mathrm{geflügeltem} \mathrm{Zustande} \mathrm{auf-}$ getreten. Ich vergesse natürlich nicht, dafo einzelne überwinterte Formen schon vorher da waren. Unendlich war vorher die Masse der kleinen und kleinsten Larvenstadien gewesen. Für die heranwachsenden Heuschrecken war die Pflanzennahrung, die ihnen die Sommerdürre zurückgelassen hatte, nicht zu hart. Sie begannen allmählich die Landschaft zu beherrschen.

Und mit ihnen und ihrer Zunahme begann die Steppe zu herrschen mit ihrer eigenartigen Tierwelt. Noch hatten manche Heuschrecken nur halblange Flügel, andere waren erwachsen. Gerade die südlichen Formen kamen in der Entwicklung nachgehinkt. Unendliche Mengen von langfühlerigen $\mathrm{L}$ a u bheuschrecken (Locustiden) mit ihren schönen grünen, gelben und rötlichen Flügeldecken begannen im Gesang mit den Grillen zu wetteifern. An Zahl bei weitem überwiegend waren aber die Feldheuschrecken, die Acridïden, die häufig durch die Fär- 
bung ihrer Flügeldecken so vollkommen ihrer Umgebung ähnelten, daß man sie erst entdeckte, als sie vor dem Schritt des Wanderers aufflogen, um ebenso $z u$ verschwinden, sobald sie an geeignetem Ort sich niederließen.

Es ist hier die Gelegenheit auf die formenmannigfaltige Heuschreckenfauna von Mazedonien einen Blick zu werfen. Heusckrecken gehören zu Mazedonien, wie die Dornsträucher und Disteln, wie die Ameisenlöwen, wie die Turmfalken und Ziesel, wie Dohlen, Elstern, Würger und Geier. Und sie herrschten geradezu im Spätsommer in einer Steppengegend vor.

Unter ihnen spielten Gespensterheuschrecken (Mantodeen) keine geringe Rolle der Zahl nach. Die häufigste Art war jetzt gegen den Herbst die kleinste Form von den drei Arten von Mantodeen, welche in dem von mir besuchten Teile von Mazedonien vorkamen. Es war Ameles decolor Charp., welche in Hunderten von gelben und braunen Individuen auftrat; bei ihr gibt es nie grüne Exemplare, wie bei den anderen Mantodeen des Landes. Nur das Männchen hat bei dieser Art die langen, gelbbraunen, papierdünnen Flügel, während das Weibchen stummelflügelig ist. Im Verlauf des Frühsommers hatte man sie allmählich von ganz kleinen Stadien heranwachsen sehen, jetzt im Spätsommer waren sie geschlechtsreif, allerdings zum Teil sehr spät. Ich fand noch zwischen dem 20. und 25. August Exemplare mit unentwickelten Geschlechtsorganen. Man sah sie vielfach Bläulinge und andere kleine Schmetterlinge fangen.

Die zweite Gespensterheuschrecke in Mazedonien, fast ebenso häufig wie der kleine Ameles, war die richtige Gottesanbeterin Mantis religiosa $\mathrm{L}$. Dieses große stattliche Tier $\mathrm{kam}$ in grünen und gelben Individuen vor. Hier sind beide Geschlechter langflügelig. Auch diese Art entwickelt sich während des Sommers und wird gegen den Herbst geschlechtsreif. Anfang Juli traten im südlichen Wardartal Massen von Larven auf, Ende Juli, Anfang August waren sie erwachsen, aber die Geschlechtsorgane noch nicht fertig entwickelt. Im September und Oktober findet die Fortpflanzung statt. Dann sieht man vielfach an Steinen angeklebt ihre Eierkokons, einige Zentimeter lange, gewölbte Gebilde aus einer zarten Substanz, in denen 80-Ioo der länglichen Eier parallel nebeneinander liegen.

Die dritte hierher gehörige Form ist Empusa fasciata Brull. Das ist ein Tier, welches eine merkwürdige Tendenz hat, an allen 
möglichen Stellen des Körpers Zipfel und Lappen zu entwickeln. An den Beinen, am Hinterleib, ja selbst an seinem Eikokon kommen solche vor. Es ist ein stattliches Tier, welches als Larve den Hinterleib stets aufwärts zurückgebogen trägt. Das Männchen hat lange gefiederte Fühler. Ein merkwürdiger Augenfleck auf der Innenseite der Vorderbeine fiel mir bei manchen Exemplaren auf und zeigte sich variabel.

Von ihr fand ich bei Üsküb im Winter gar nicht selten unter Steinen relativ große, aber noch ungeflügelte Larven. Auch

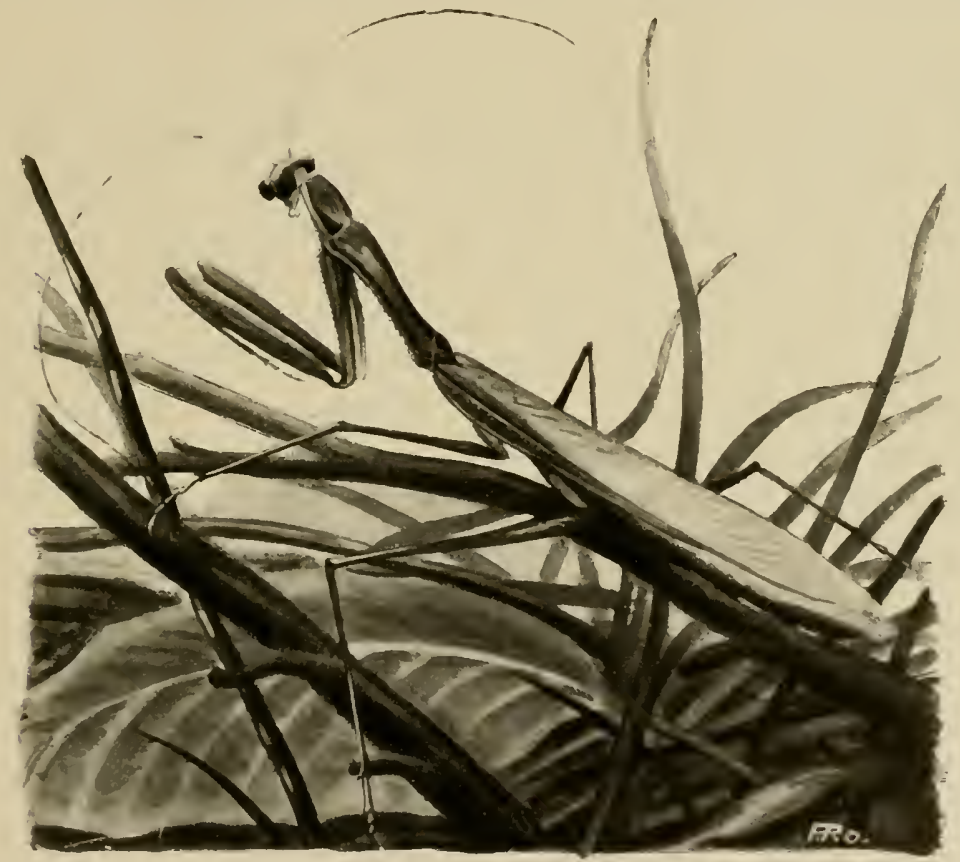

Abb. 251. Gespensterheuschrecke. Mantis religiosa L.

im Süden bei Kaluckova und Dedeli kommt die Art vor. Nirgends fand ich sie aber so häufig wie bei Üsküb. Im Frühjahr kriechen sie aus dem Winterquartier und bei eifriger Insektenjagd wachsen sie bald heran und bekommen Flügel. In der zweiten Hälfte des Mai sind sie geschlechtsreif und beginnen mit der Fortpflanzung. Ich habe sie öfter im Käfig gehalten, wo sie leicht mit allerhand Insekten $z u$ füttern sind.

Im Juli sind schon kleine, kaum i cm lange, flügellose Larven da, welche den Hinterleib aufrecht zurückgeschlagen tragen und 
in ihrer Hagerkeit einen bizarren Eindruck machen. Diese kleinen Larven wachsen bis zum Eintritt des Winters bis zur halben Größe heran, um dann zu überwintern. Ende August kamen sie in Veles oft in großen Massen in die Zimmer hinein.

Ameles decolor Charp. ist die einzige Mantide, welche nachts ans Licht flog, diese aber oft in großen Mengen.

Von Lokustodeen, den Heuschrecken mit den langen dünnen Fühlern, erwähne ich Decticus albifrons $\mathrm{F}$., einen nahen Verwandten unseres Warzenbeißers; er ist etwas größer als dieser und niemals grün gefärbt wie er.

Ganz abenteuerliche Erscheinungen sind die Saga-Arten, deren ich zwei in Mazedonien antraf, die grüne Saga serrata Fabr. und die olivbraune, schwarzgefleckte Saga natoliae Serv. Mit ihren langen, ungeschlachten Beinen, ihren kurzen, wie verkrüppelt aussehenden Flügeldecken und ihren plumpen Bewegungen scheinen sie gar nicht recht in das Geschlecht der Heuschrecken hineinzupassen. Von ihnen ist Saga natoliae die südliche Form, die im Balkan und Kleinasien weit verbreitet ist; sie wird nördlich von S. serrata abgelöst. Letztere pflanzt sich fast ausschließlich parthenogenetisch fort, man findet von ihr fast nur Weibchen, während erstere Männchen und Weibchen im normalen Prozentverhältnis hervorbringt.

Oft in ungeheueren Mengen trat Tryxalis nasuta Fab. auf, die Schnabelheuschrecke, mit ihrem schief aufgerichteten Kopf, den breiten, oft parallel nach vorn gerichteten Fühlern, den dünnen Vorderbeinen und sehr langen Hinterbeinen. Solange sie flügellose Larven waren, konnte man sie für junge Stabheuschrecken der Gattung Bacillus halten. Diese in Istrien, Dalmatien und Italien so häufige Form habe ich in Mazedonien nicht gefunden. Sind die Flügel herangewachsen mit ihrem dunkelbraunen, weifogefleckten Längsstreifen, dann ist eine Verwechslung mit einer Stabheuschrecke nicht mehr möglich.

Von den anderen Feldheuschrecken wäre Caloptenus italicus L. hervorzuheben; dies graubraune, schwarzgestreifte Tier mit den roten Hinterschienen und roten Hinterflügeln war überall häufig. Auch die Wanderheuschrecken waren nicht selten. Sie waren in erwachsenem Zustande auffallend große Tiere, sie erreichten 8-io $\mathrm{cm}$ Länge und machten nicht nur mit ihren eigenen Tönen einen gewaltigen Lärm, sondern auch wenn man sie fing und sie sich durch die Büsche zu Boden fallen ließen, so 
gab es ein mächtiges Gerumpel. Die verschiedenen Individuen dieses Acridium aegyptium L. waren sehr verschieden gefärbt, bald gelblich, bald braun, bald auffallend rot.

Eine verwandte, halb so große Form, grün, schwarz gefleckt, mit rötlichen Hinterbeinen, Pachytilus nigrofasciatus de Geer tritt im Gegensatz $z u$ den verwandten Arten nicht als Wanderheuschrecke auf.

Ich habe oft die Oedipoda-Arten, die Schnarrheuschrecken, erwähnt, welche beim Auffliegen ihre roten und blauen Unterflügel aufblinken ließen, während sie durch betäubendes Schnarren ihre Verfolger erschreckten. Setzten sie sich auf den Boden nieder, so waren sie wegen ihrer Ähnlichkeit mit dem Untergrund, welche mit diesem variierte, wie von ihrer Umgebung verschluckt, wenn sie sich still am Boden hielten. Erschreckt fuhr man zurück, wenn sie an ganz unerwarteter Stelle wieder aufschnarrten. Neben Oedipoda coerulescens L. kam O. miniata Pall. nicht selten vor, jene mit blauen, diese mit grellroten, am Ende schwarzgebänderten Hinterflügeln.

Durch kohlschwarze Färbung des ganzen Körpers, von dem sich die roten Hinterflügel scharf abhoben, wenn das Tier sich vom Boden im Flug erhob, ist Psophus stridulus L. ausgezeichnet. Das Tier war in der Steppe bei Gradzko und Krivolak, aber auch bei Stip eine Charakterform, kam aber auch in den Bergen vor.

Formen von mediterranem Typus sind Paracinema tricolor Thunb. und die Arten von Glyphanus, so G. obtusus Fieb. und G. heldreichi Br.

Eine eigenartige kleine Heuschrecke (Tettix subulatus L.), im erwachsenen Zustande kaum etwas über einen Zentimeter lang, ein graubraunes, lebhaft springendes Tierchen, hielt man kaum für etwas anderes als eine Larve, wenn es vor einem aufsprang. Daß man es leicht für eine Iarve hielt, lag auch an dem frühen Auftreten der Form, welche ich am Katlanovosee schon Ende März und Anfang April in erwachsenen Individuen fand; die Art überwintert als Larve.

Auch andere Tiergruppen nahmen während des Sommers an Individuenzahl und an Einfluß auf das Landschaftsbild zu. Das galt vor allem für die $\mathrm{Zikaden}$ und die Ameisenlöwen. Erstere begannen in den Mittagsstunden durch ihren Gesang die Heuschrecken und Grillen vollkommen aus dem Feld zu schlagen. Von der großen Wirkung des Konzerts der Zikaden habe ich 
schon im Kapitel über den Doiransee erzählt. Die Zikaden als echte Sonnentiere paßten so recht in die Steppenlandschaft des mazedonischen Sommers. In der stärksten Sonne saßen die großen Arten an den Stämmen der Eschen, an den höchsten Büschen und erhoben ihren betäubenden Gesang, wenn sonst alles in der Natur ruhte. Die gröBte Zikade Mazedoniens ist Cicada plebeja Scop., ein silbergraues Tier; als wichtiges Instrument im Zikadenorchester ist Tettigia orni $\mathrm{L}$. zu verzeichnen, denen sich Cicadatra atra Ol. und Tibicina haematodes Scop. anschließen.

So schwebten auch die Scharen der Landlibellen, der A meisenlöwen in der heißen Sommerluft. Auffallend war es, wie eine Art nach der anderen in großen Individuenzahlen auftrat; jedesmal die Landschaft so sehr belebend, daß man jeweils glaubte, jetzt in der Myrmeleon-, jetzt in der Nemoptera- oder PalparesLandschaft $\mathrm{zu}$ verweilen.

Das war die Zeit, in welcher die Steppe im Flachland von Mazedonien regierte. Jetzt drängte sich alles hervor, was der Steppe entsprach, was mit ihr $\mathrm{zu}$ tun hatte. In der Mittagssonne hörte man den $\mathrm{Ziesel}$ im dürren Gras rascheln und hastig sein Bündel Heu in seinen Bau schleppen. Von einem Stein schaute einen der Wiedehopf neugierig an, spreizte seinen Schwanz und die bunten Federn seines Schopfes, die ihn einem Indianerhäuptling gleichen machten. Wenn die Nacht herabgesunken war und der Boden noch glühte, huschte über ihn die gespensterhafte Gliederspinne Galeodes graecus mit ihren langen Beinen dahin und stürzte sich wie ein Vampyr über ihre Beute.

Nun war die böse Zeit für die Herden. Der verdorrte Boden mit seinen harten Büschen gab nur mehr den Ziegen dürftige Nahrung. Die Schafherden hatte man, wo es ging, in die Berge gebracht. Aber die Pferde und Rinder litten in dieser Zeit bitter an Hunger und Durst. Es war ein trauriger Anblick, die abgemagerten Ochsen und Pferde in Herden über dem trockenen Boden die spärliche Nahrung suchen zu sehen. Es mochte einen erbarmen, wenn die hageren Tiere, denen die Rippen weit herausstanden, mit den Vorderbeinen in die Krone eines kümmerlichen Maulbeerbaumes kletterten, um da die wenigen übrig gebliebenen Blätter abzuknabbern. Sie, die Ärmsten, konnte man nicht entbehren; sie brauchte man jetzt im Kriege überall für Transporte, zum Nachschub, als Trag- und Reittiere und zum Schlachten. 
Wie mancher Ochse, wie manches Pferd erlag den Strapazen und dem Hunger, stürzte an der Straße nieder, starb und konnte nicht fortgeschafft werden. Da sammelte sich bald um das Aas eine Schar gieriger Tiere an. Lange stank es nicht in die Gegend hinein; denn durch den Geruch angelockt, kamen die Dohlen, die Krähen, die Kolkraben, zu denen sich hier im Lande stets die Elstern gesellten. Kaum hatten sie begonnen sich gütlich zu tun, so scheuchte ein gewaltiger Schatten sie auf. Ein riesiger Geier senkte sich auf das Aas herab; bald kamen seine Genossen dazu und ehe sie gesättigt waren, wurde das kleinere Gesindel zum

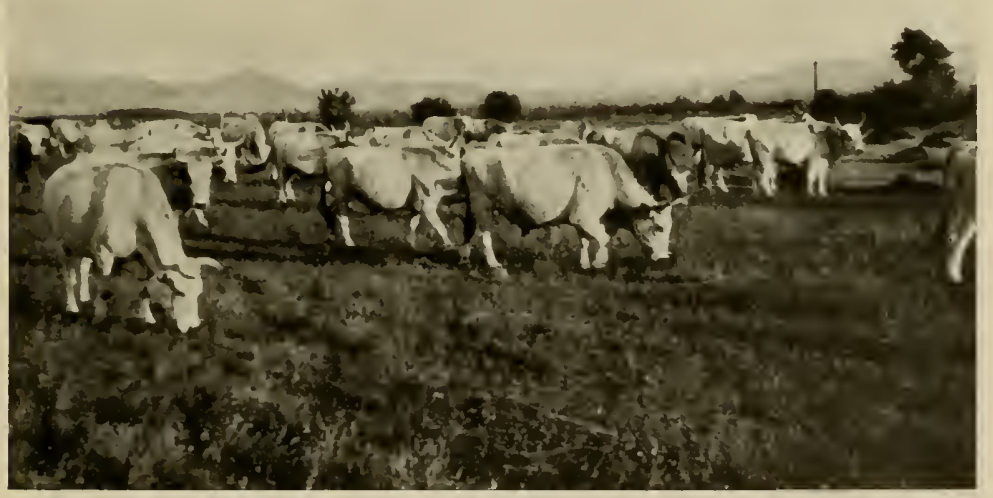

Abb. 252. Hungernde Rinderherde im Hochsommer.

Mahle nicht zugelassen. Kaum wiederum hatten die Geier das Aas mit vollen Kröpfen verlassen, so stürzte sich die schwarze Bande der Kleinen zu Hunderten auf den Rest und bald ragte das Sklelet rein genagt in den dörrenden Sonnenschein.

Nicht immer warteten die Aasvögel den Tod ihres Opfers ab; ich habe die Erinnerung an ein grausiges Erlebnis nördlich des Katlanovosees. Gegen Abend, auf staubiger Landstraße heimkehrend, bemerkte ich in einem Dornbusch eine große Schar von Krähen, Dohlen und Elstern, die sich da mit mächtigem Geschrei zu schaffen machten. Einen großen Kolkraben, der sich auf die Gruppe herabsenkte, schoß ich und als ich ihn holen wollte, sah 
ch im Busch ein seltsames Bild vor mir. Ein starkes Schaf war hier von der Herde zurückgelassen worden, nachdem es sich mit seiner Wolle in den Stacheln des Judendornes so verfangen hatte, daß es nicht mehr loskam. Das war gefundene Beute für die Aasvögel. In Scharen hatten sie sich auf das unglückliche Tier niedergelassen, hatten ihm lebend die Augen ausgehackt und hatten vom Kopf aus begonnen, ihm Fleischstücke abzureißen. So hatten sie angefangen das Tier bei lebendem Leib aufzufressen, als ich seinem Leben durch einen Schub ein Ende machte.

Wo es Wasser gab, wurde es von Menschen und Tieren zum Baden aufgesucht. Auch die Haustiere machten da keine

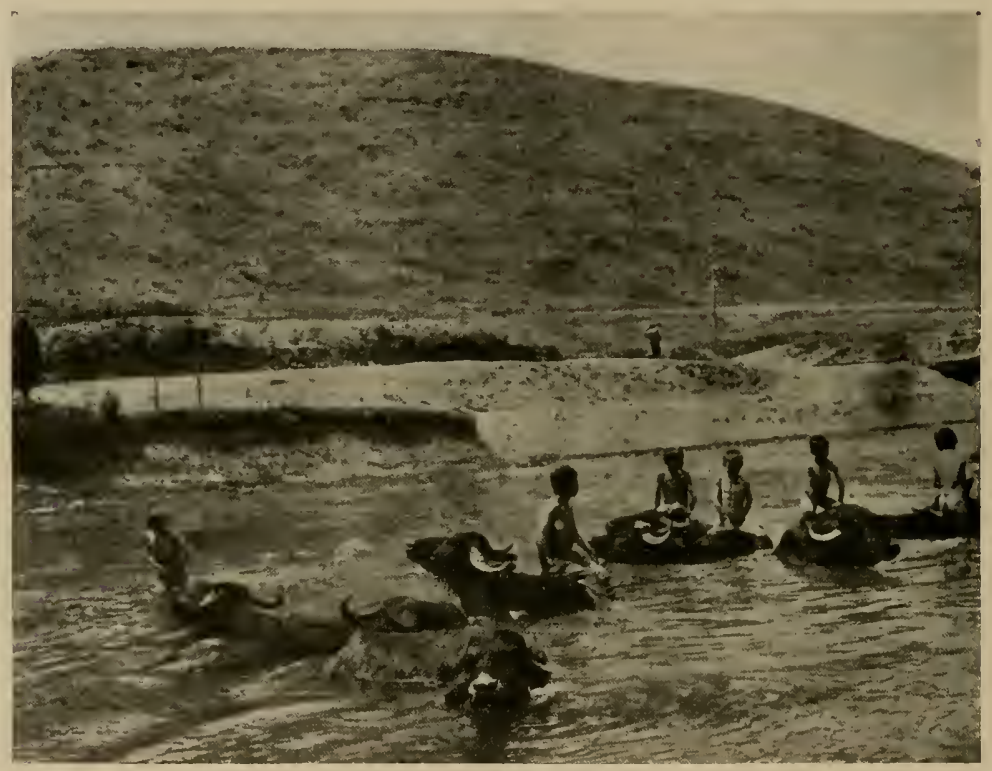

Abb. 253. Badende Büffel.

Ausnahme. Reizvolle Bilder boten die im Wasser liegenden Büffel, bei denen oft nur mehr die Nase und die Ohren aus dem Wasser schauten. Ganze Rinderherden stiegen an den seichten Seeufern, z. B. des Prespasees, ins Wasser, Pferde tummelten sich da. Schafe und Ziegen dagegen scheuen das Wasser.

Glücklich waren Menschen und Tiere zu preisen, welche in der heißen Zeit in die Berge durften. Ich habe oft in früheren Kapiteln die schönen, fetten Herden von Rindern und Schafen erwähnt, die ich im Sommer im Hochgebirge auf den Matten 
über 1500 man traf. Aber nicht nur diese Haustiere des Menschen waren der Hitze der Ebene entflohen, auch manche andere Tiere fand man in Sommer im Hochgebirge, die im Frühling in der Ebene gewesen waren. So waren manche der mitteleuropäischen Vögel, Finken, Amseln, Drosseln, zur Sommerfrische in die Berge gezogen.

Auch unter den Insekten sah ich später im Sommer Arten, die ich im Frühling in der Ebene beobachtet hatte, immer höher in den Bergen sich zeigen, je höher hier der Frühling hinaufstieg.

Eine Folge der hohen Sommertemperaturen zeigte sich deutlich bei den Pflanzen und Tieren. Wie bei den einjährigen Pflanzen oft die ganze Vegetationsperiode in wenig Tagen ablief, so daß Gewächse, die weite Gebiete mit ihren farbenprächtigen Blüten bedeckt hatten, wie mit einem Schlage verschwunden waren, so war auch bei Tierarten das plötzliche Auftreten und Verschwinden außerordentlich auffallend.

Oft fand ich an einem Berge, in einem Tale eine Käferart, einen Schmetterling, eine Zikade, in vielen Tausenden von Exemplaren. Jede Blüte, jeder Busch war von ihnen bedeckt. Kam ich nach wenig Tagen wieder dorthin, so war die Art oft spurlos verschwunden, manchmal noch durch wenige Exemplare vertreten. Für uns Bewohner gemäßigter Zonen war dieser rasche Ablauf des Lebens in dieser heißen Sonne sehr eindrucksvoll.

Manche Beispiele von Satyriden und den Thekla-Arten, auch den Bläulingen habe ich in früheren Kapiteln schon erwähnt; so auch die Zikaden und die Ameisenlöwen. Ähnliches beobachtete ich bei Käfern, so z. B. kam der schwarzgelbe Käfer Mylabris variabilis Pall. Mitte Juli 1917 auf der Plaguśa Planina in vielen Tausenden von Exemplaren auf jeder Doldenpflanze vor; nach 14 Tagen war die Art aus dem Gebiete verschwunden. Ähnliches galt für Conitis bifarciata Sivark. am Katlanovosee Mitte Juni 1918. So trat im Nikolatal im April 1918 Lychus (Halosinus) collaris Fabr. in ebenso großen Mengen auf, wie Lychus (Halosimus) syriacus L. im Mai bei Dedeli. Sehr auffallend war das Massenvorkommen des mächtigen Bockkäfers Cerambyxx (vgl. Abb. 29 auf S. 53), der in Mengen hoch durch die Luft flog und dabei mit seinen langen Fühlern einen phantastisch großen Eindruck machte. Er war auch dadurch interessant, daß bei ihm die Fühlerlänge der einzelnen Individuen sehr stark variierte. 
Während das Massenauftreten der Arten sicher von dem Vorkommen der Futterpflanze und besonderen Verhältnissen abhängt, ist das kurze Leben der Individuen wohl auf den raschen Verbrauch der Imagines in der Sommerhitze des Landes zurückzuführen.

Wie verschieden die Gesetzmäßigkeiten sein mögen, welche das Massenauftreten einer Art in einer bestimmten Gegend bedingen, das fiel mir sehr auf, als am 15. Juli 1917 plötzlich an einem schönen Morgen das ganze Tal bei Hudova von einem viele Tausende von Individuen umfassenden Libellenschwarm erfüllt war. Sie kamen in großen Schwärmen von Süden und flogen nach Norden, und zwar gegen den stark wehenden Nordwind, gegen den sie sehr gut ankamen. Um alle Bäume und Häuser von Kaluckova brandeten die Massen an; ich durchstreifte an diesem Tag die ganze Gegend; überall sah ich die Iibellenschwärme, sowohl in Kalkova, in Hudova, Gradec, im ganzen Gebiet. Aus den verschiedensten Lagern des Tales wurde das seltsame Phänomen gemeldet. Am Tag herrschte nicht mehr als $24^{\circ} \mathrm{C}$ im Schatten, das Wetter war auffallend kühl. Den Tag über flogen immer neue Scharen heran. Abends nahmen sie ab und an den nächsten Tagen waren fast alle, bis auf einige Nachzügler, verschwunden.

Den Namen der Art, den ich Dr. F. $R$ is verdanke, ist Aeschna mixta; alle an jenem Tag gefangene Individuen sind unausgefärbte Stücke, die erst nach $2-3$ Tagen ihre volle Ausfärbung erreicht hätten. Die gleiche Beobachtung wurde auch sonst bei Massenflügen von Libellen gemacht, wie nach Mitteilung von Dr. Ris nicht selten bei Hemianax ephippiger, einer mediterranen Form.

Diese Tatsache weist offenbar darauf hin, daß es sich um Tiere von gleichem Alter und annähernd gleicher Herkunft handeln muf. Ihre Versammlung an einem Ort scheint wohl durch Windrichtung und barometerische Bedingungen verursacht $\mathrm{zu}$ sein. Der englische Naturforscher W. H. Hudson gibt in seinem so reizvollen Buch über La Plata eine Schilderung von den aus Millionen von Individuen bestehenden Schwärmen der Libelle Aeschna bonariensis Raml., welche in Argentinien vor dem Südwestwind, dem Pampero, vorausfliegen. Also auch dort vor einem kalten Wind erscheinend. Daß die von mir beobachteten Tiere gegen Norden flogen, war wohl durch den Schutz bedingt, den ihnen die 
nördlich gelegenen Talwände, Bäume und Häuser vor dem Wind gewährten.

Meine Beobachtung schließt sich jedenfalls meinen anderen Feststellungen über das massenhafte Auftreten einer Tierart an wenigen Tagen im sommerlichen Mazedonien an. Das plötzliche Verschwinden der Libellen ist allerdings wohl nicht durch deren raschen Tod, sondern durch Verteilung auf Bäche und Flußufer einer weiteren Umgebung nach dem Nachlassen des kalten Winds zu erklären.

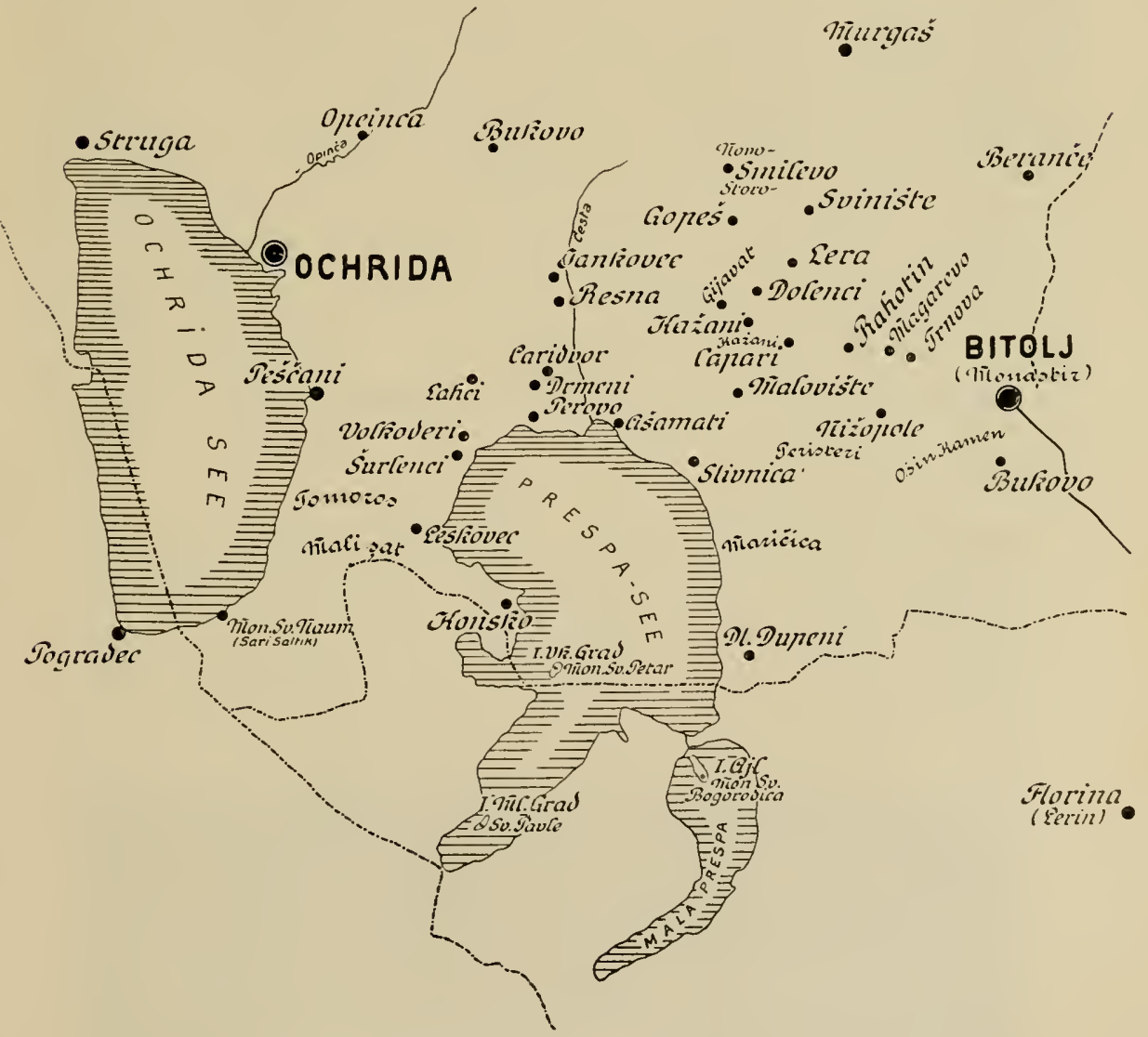

Abb. 254. Kartenskizze von Westmazedonien. Gebiet der großen Seen. 


\section{DER PERISTERI. Die MAZEDONISCHEN ALPEN.}

ieder ragte ein hohes mazedonisches Gebirge vor mir auf, der Peristeri, auf dessen Gipfel jetzt noch Mitte Juli ein kleines Schneefeld sichtbar war. Von diesem, den weißen Flügeln der Taube, hat er seinen griechischen Namen. Mächtig erhob der Berg sich vor mir mit seinen drei Gipfeln, als ich am 17. Juli an einem sehr heißen Morgen von Gopes nach Dolenci ins Tal der Semniča abstieg, welche vom Peristeri kommt. An ihren Quellbächen liegen Kazani und das Aromunendorf Maloviste, von dem sonst gewöhnlich der Aufstieg auf den Peristeri von den Deutschen unternommen wurde. Ich plante ihn aber von Čapari aus, wo als Leutnant ein junger Königsberger Zoologe, Dr. H.C. Müller, in Quartier lag. Dieser

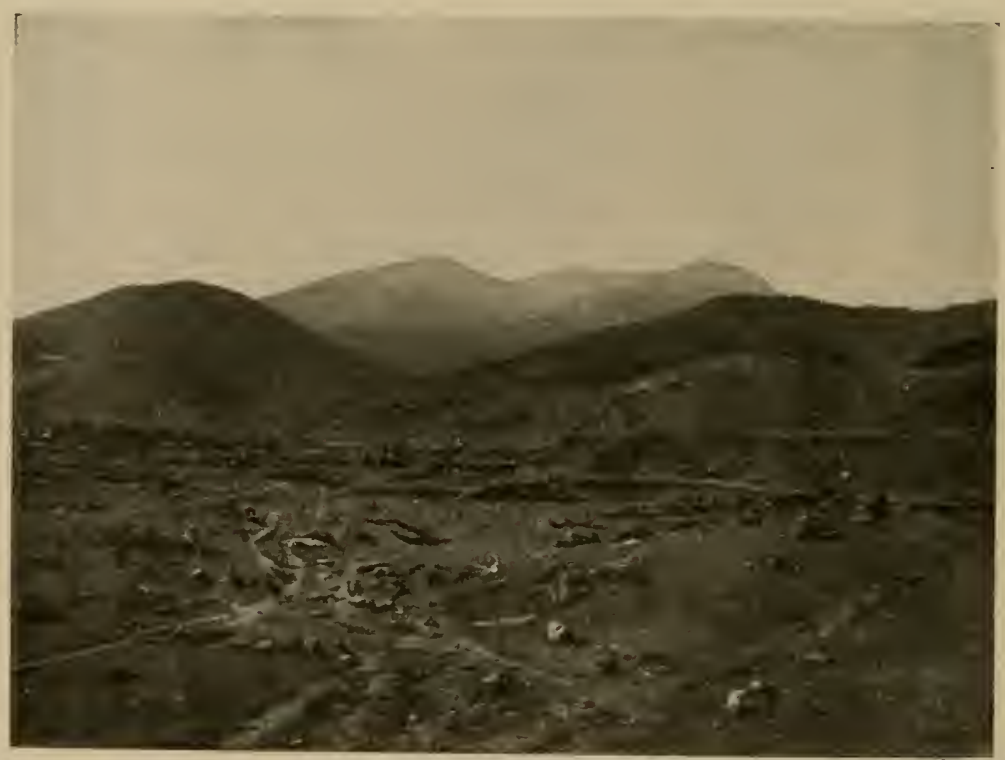

Abb. 256. Blick über Čapari auf den Peristeri. 
hatte mir angeboten, mich und meine Mitarbeiter als Führer auf den Peristerigipfel zu begleiten.

Schon in Dolenci holte uns Dr. Müller mit seinem Wagen ab, der uns den Širokabach entlang nach dem malerischen Dörfchen Čapari führte, wo wir freundschaftlich aufgenornmen wurden. Der Bach durchbrauste das reich von Bäumen beschattete Dorf, in welches er vom Hang des Peristeri durch eine tief eingerissene Schlucht hineinstürzte. In alle Gassen des Dorfs blickte groß und würdevoll die gewaltige Gestalt des Peristeri hinein.

Es war ersichtlich, daß wir einen geeigneten Ausgangspunkt für den Aufstieg auf den Hauptgipfel des Peristeri gewählt hatten. Offenbar war die Schlucht ein viel von den bulgarischen Truppen begangener Weg, der, ohne durch Wald zu führen, sehr steil, aber geradewegs uns in die Gipfelregion brachte.

Am I 8. Juli, $3 \frac{1}{2}$ Uhr morgens, begann der Anmarsch steil durch die Schlucht hinauf; es stieg sich gut in der Nacht, auch als wir die Schlucht verließen und uns ostwärts auf einen Sattel wandten, der von üppigem Mattengras bewachsen war, aus dem kahle Felsen hervorragten. Während bisher im Dunkeln nichts zu beobachten gewesen war, änderte sich das sogleich, als auf dem Sattel bei $1700 \mathrm{~m}$ Höhe un $5 \frac{1}{2}$ Uhr die Sonne über einen Felsgrat empor kam. Ein schöner Sonnenaufgang fand uns auf einem üppigen Wiesenboden, wo uns die ersten zwerghaften Exemplare der für den Peristeri charakteristischen Zirbelkiefer (Pinus peuce) begegneten. Vorher war der Boden von Adlerfarn weithin bedeckt gewesen, zwischen dem Wolfsmilch, Thymian, hier und da Erdbeerpflanzen standen. Die großen Farnflächen waren manchmal durch Wiesen unterbrochen, in denen mitteleuropäische Grasarten und ein weißer Klee die Charakterpflanzen waren.

Hier oben war aber die Pflanzenwelt reicher; zwischen den vereinzelten Sträuchern der Zirbelkiefer wuchsen Gruppen eines niedrigen Wachholders (Juniperus nana Willd.). Von blühenden Pflanzen fielen Königskerzen, Schafsgarben, Nelken auf. Ich habe auf dem Peristeri keine Pflanzen gesammelt, da der deutsche Botaniker Grisebach schon im Jahre 1839 hier Beobachtungen gemacht hatte und Professor Bornmüller, mein botanischer Mitarbeiter in Mazedonien, im Jahre 1917 schon dort gewesen war. Immerhin werde ich noch manche Pflanzen aus der alpinen Region erwähnen.

Um so mehr nahm ich mit meinen Begleitern die Zeit wahr, 
um auf Tiere $z u$ achten. Eine Menge von kleinen grauen Schmetterlingen aus der Gruppe der Spanner (Geometriden) flogen vor unseren Schritten aus den Büschen vor uns auf (Anaites simpliciata Tr.). Parnassier fanden wir hier nicht. Wahrscheinlich war es für die Mnemosynen zu spät und für die Apollos zu früh. Zwei für die Höhenzone charakteristische Heuschreckenarten waren aber häufig. Eine schwarze Form mit roten Unterflügeln glich sehr der Art, welche ich in der gleichen Höhenzone auf der Mala Rupa gefunden hatte. Sie führte einen ähnlichen Balzflug aus wie jene, aber stieg dabei nicht so ausgesprochen senkrecht in die Höhe wie sie (Stcnobothrus morio Fab.). Eine zweite kleine Heuschrecke, die in großen Mengen vorkam, zeichnete sich im

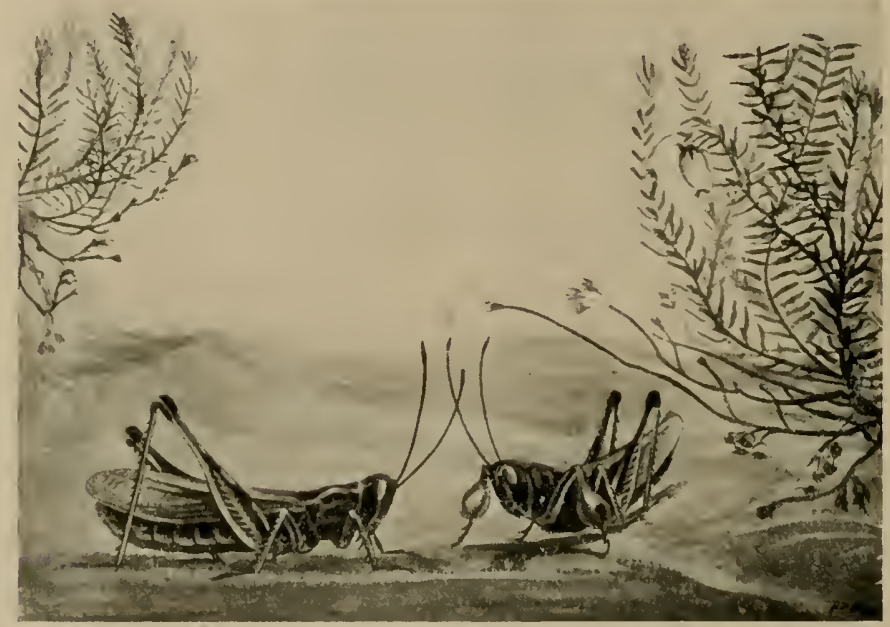

Abb. 257. Gomphocerus sibiricus L. Heuschrecke, deren Männchen verdickte Vorderbeine besitzt. Männchen und Weibchen einander gegenübersitzend.

männlichen Geschlecht durch eigentümlich verdickte Vorderschienen aus, welche offenbar im Geschlechtsleben eine Rolle spielen. Diese Form, die hier abgebildet ist, ist durch diesen geschlechtlichen Dimorphismus besonders gekennzeichnet, welcher sonst bei Heuschrecken selten vorkommt.

Aus den grünen Matten ragten Gruppen schroffer, heller Felsen empor, welche in den Spalten von rötlichem Detritus erfüllt waren. Ein schöner, gleichmäßiger, dunkelgrüner Rasen überzog die Hänge dazwischen. Es war selbst hier in einer Höhe von $1800-2000 \mathrm{~m}$ sehr heiß, die Sonne brannte auf uns herab, als wir 
an einem solchen Felsen rasteten. Da erschienen plötzlich feindliche Flieger über uns. Sie wurden von einer Flakbatterie bei Rasotin beschossen, wobei ein Blindgänger nahe bei uns niederfiel. So wurde man grausam daran erinnert, daß wir Naturforscher nicht einmal in dieser weihevollen Einsamkeit der Natur ungestört unseren Forschungen nachgehen durften.

Wir ließen uns aber nicht bei unserer Tätigkeit behindern, welche uns reizvolle Funde in Aussicht stellte; denn über den Matten flogen interessante Gebirgsschmetterlinge dahin. Es waren dunkle Erebien (Erebia cpiphron oricntalis Elw., E. euryale Esp., E. tyndarus balcanica Reb.).

Nach fast 5 Stunden Steigens langten wir in einem karartigen Kessel der Gipfelregion an. Mächtige Granitblöcke bedeckten seine Hänge, wirr übereinander gestürzt und durcheinander geworfen. Eine tiefe Mulde zog sich zu einem etwas eingebogenen Gipfelkamm. Der ganze Hang war von ungeheuren Massen von Geröll bedeckt. Wir waren in etwa $2100 \mathrm{~m}$ Höhe angelangt. Die Mulde streckte sich nach Süden und kehrte uns ihren Nordhang entgegen. Auf diesem lag das einzige kleine Schneefeld, welches der Sommer oben bei etwa $2400 \mathrm{~m}$ zurückgelassen hatte. Zwischen den Steinen rann Schmelzwasser des Schnees herab, welches im Grunde schwarze, sumpfige Erde angesammelt hatte, zwischen der allerhand Pflanzen von ausgesprochen alpinem Typus wuchsen. Auch von diesen hat $\mathrm{Grisebach}$ eine ausführliche Liste gegeben. Mir fiel damals besonders eine entzückende rosenrote Nelke auf, die große blütenreiche Polster zwischen den Steinen bildete (Dianthus myrtinervis Gris.). Ich habe von einem solchen Polster eine photographische Aufnahme gemacht, welche hier eingefügt ist (Abb. 258, S. 520). Die Abbildung gibt einen Eindruck von der charakteristischen Hochgebirgsumgebung, in welcher die Pflanze wächst. Die Augen auf sich zog auch ein stattlicher Enzian (Gentiana punctata L.) mit gelben, braungefleckten Blüten, der große Büsche bildete. Unten am Sumpf stand ein stattliches Fettkraut mit großen violetten Blüten (Pinguicula grandiflora Lam.), ein alpiner Vertreter dieser insektenfressenden Pflanzengattung. Dazu kam ein mächtiges Läusekraut (Pedicularis comosa L.) und ein leuchtend blaues Vergißmeinnicht.

In diesem steinernen Kessel, in der Hochgebirgseinöde, lag eine bulgarische Kompanie. Sie hatte im Schutz von Felsen in möglichster Winddeckung eine Anzahl Hütten und Baracken gebaut 
und führte da ein entbehrungsvolles Dasein. Wir waren in nächster Nähe der Front, welche über den Gipfel des Peristeri hinzog. In Sommer war der Aufenthalt hier oben nicht weiter schlimm und jedenfalls der Gesundheit zuträglich. Aber im Winter hatten die Soldaten kein leichtes Leben. Hier lag zuzeiten der Schnee $15 \mathrm{~m}$ hoch. Die Hütten waren dann vollkommen vergraben; so mußten sie Proviant und Munition aufgespeichert haben, da sie auf Wochen von der Welt abgesperrt sein konnten.. Auch das Holz mußte aus der Baumregion heraufgeschleppt werden.

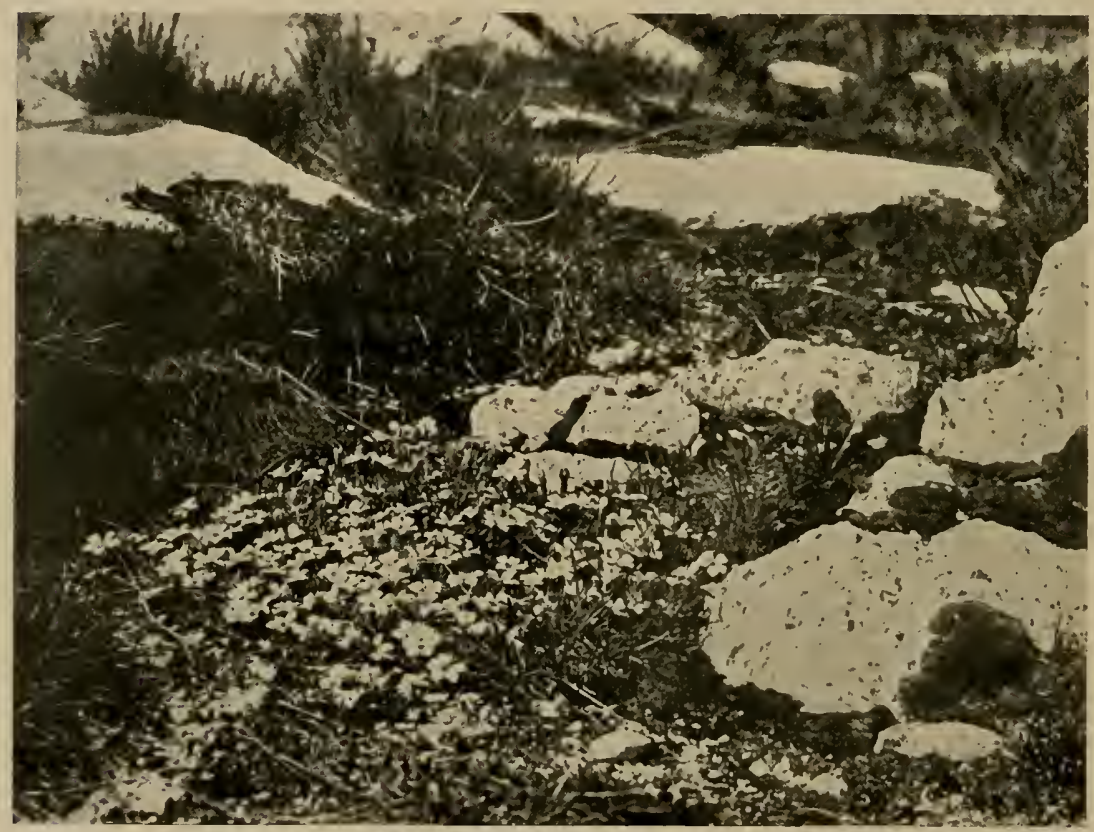

Abb. 258. Alpennelke (Dianthus myrtinervis Gris.).

Wir waren von der Kompanie freundlich aufgenommen worden, vor allem von ihrem Hauptmann, der ein umgänglicher, sympathischer Mann war und bald sein starkes Interesse für naturwissenschaftliche Fragen und vor allem für Botanik verriet. Er bot uns seine Begleitung auf den Gipfel an, die uns sehr willkommen war.

Es war ein anstrengender Anstieg, ein schwieriges Klettern über die glatten, bunt durcheinander gewürfelten Granitblöcke, welche den ganzen Hang bedeckten. Wir hatten noch einige hundert Meter bis zum Gipfel emporzuklimmen; Pfad gab es keinen, 
kein Wiesenstück, keinen Streifen Erdkrume. Alles nur Steine, glatte, mächtige Felsen oder durcheinander geworfene kantige Blöcke. So gab es auch auf dem Anstieg immer weniger Vegetation und die äußerste Gipfelregion trug gar keine höheren Pflanzen; da wuchs nur hier und da etwas Moos oder eine Flechte als Kruste auf dem Gestein. Die einzigen Tiere, die hier oben zu beobachten waren, Ohrenlerchen (Chionophilos alpestris balcanicus Rchn.) schwirten durch die Felsspalten (vgl. Abb. 201, S. 403).

Der im Hochgebirge eingelebte Hauptmann brachte uns mit seinen langen Schritten bald auber Atem. Doch in kaum einer

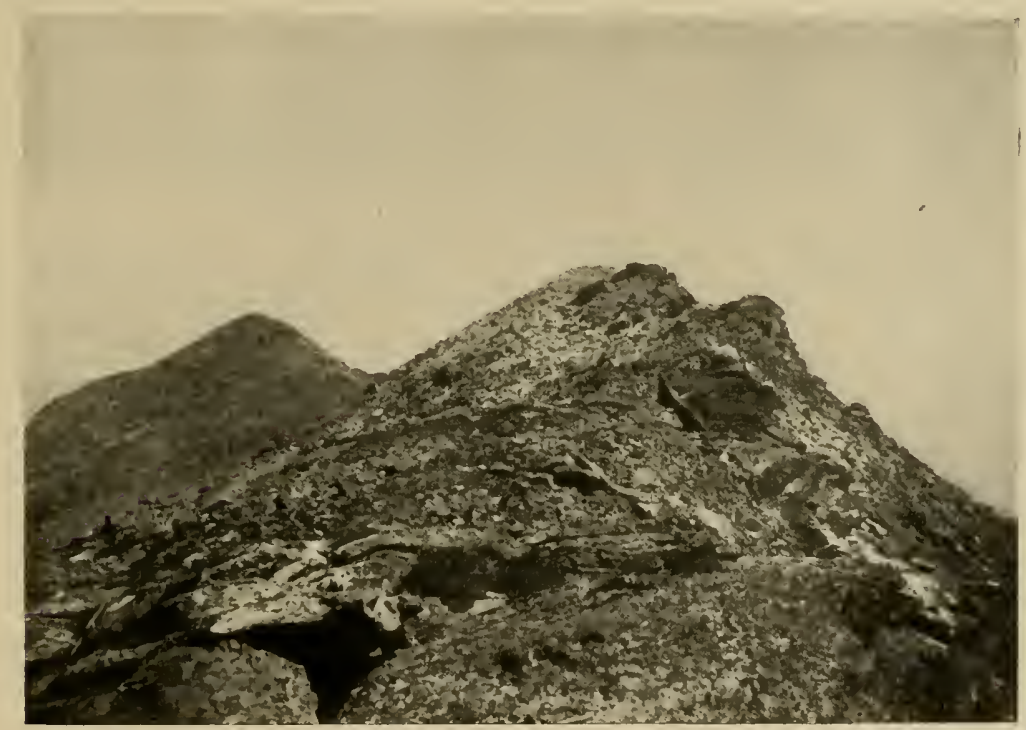

Abb. 259. Gipfel des Peristeri.

Stunde erreichten wir das Schneeband, durchwateten dieses und klommen über die letzten Felsenplatten zu dem kahlen Gipfel empor, dessen Höhe mir mein Anerö̈dbarometer mit $2460 \mathrm{~m}$ angab, während die Karte $2535 \mathrm{~m}$ als Gipfelzahl verzeichnet.

Ich trat hinaus auf den kleinen Gipfelraum, atmete tief auf, reckte meine Arme in die Höhe, und begann mit einem frohen Jodler mein Entzücken, welches das Bild in mir erweckte, das vor mir lag, auszuposaunen. Da faßte mich still der bulgarische Hauptmann an der Schulter und zog mich hinunter in Deckung. „Wir sind nicht auf dem Rigi hier, gleich wirds schielen." Und er deutete mit dem Finger auf die französischen Gräben, die sich 
kaum $200 \mathrm{~m}$ vor uns hinzogen, in denen ich aber niemand sich regen sah.

Man konnte auch aus der Deckung genug sehen und beobachten; und auch aus einem anderen Grund war Deckung erwünscht, nämlich als Schutz vor dem kalten Wind, der in der Gipfelregion blies. Meine von dem Anstieg erschöpften Kameraden zogen vor, in einer Felsmulde, welche die Sonne erwärmte, zu schlafen. Ich durfte mir aber keine Ruhe gönnen. Ich mußte die I oder 2 Stunden, die ich auf dem Gipfel des Peristeri verbringen durfte, richtig ausnutzen. Ein starkes Glücksgefühl erfüllte mich, daß es mir gelungen war, auch diesen Gipfel zu ersteigen und Beobachtungen zu machen. So hatte ich zu photographieren, Skizzen zu machen, Notizen aufzuzeichnen und aufzufassen, was nur möglich war. Zuerst wollte ich aber die Schönheit der Landschaft in mir aufnehmen und dann mich orientieren.

Die nächste Umgebung war nicht allzu reizvoll. Drei kahle Felsengipfel ordneten sich als Gipfelmassiv in einem Bogen an, grobes, plattiges Gestein, ohne grolen Reiz in Farbe und Form. Und viele Einzelheiten des Mittelgrunds wurden durch die menschlichen Bauten gestört. Da waren zuerst hinter den Gipfelfelsen Gräben und Unterstände der Bulgaren. Und jenseits zogen sich über eine Mulde, welche zu dem anstoßenden südlich verlaufenden Gebirgskamm führte, auf dieser Seite eigene, drüben feindliche Gräben. Auf den Rückseiten der vorliegenden Berge sah man überall gerade Linien, Zickzackstreifen durch Gräben, Serpentinen von neugebauten Zufahrtsstraßen und all den Spuren des grausamen Kriegs gezogen.

Naturforscher und Künstler in mir aber wirkten zusammen, um all dies häßliche Menschenwerk in dem Bild auszulöschen, das innerlich in meiner Seele die Lichtstrahlen, die aus allen Weiten zu mir flogen, aufbauten. Und es blieb Schönes und Ergreifendes genug an der Landschaft, die sich, während ich in den Felsen herumkletterte, nach einander nach allen Himmelsrichtungen unter mir ausbreitete.

Zunächst blickte ich über die Mulde und den Sattel im Süden, der den Peristerigipfel mit einem breiten, bewaldeten Bergrücken verband; da unten lagen, wie die Augen des Gebirges, zwei kleine dunkelgrün schimmernde Seen; sie erinnerten in Gestalt und Größe an die Karseen, die wir auf dem Pepelak im Monat vorher ent- 
deckt hatten. Von der Karte konnte ich ablesen, daß sie Lakul Mik und Lakul Mare hießen, was auf aromunische Benennung hinwies.

Was war das für eine seltsame Empfindung, kaum $1 / 2$ Stunde von diesen interessanten Gewässern entfernt und als Naturforscher verhindert $z u$ sein, sie $z u$ untersuchen, weil sie zwischen feindlichen Stellungen lagen. Hier war die Lage so, daß es auch nachts nicht möglich gewesen wäre, dorthin zu dringen, ohne festgenommen zu werden.

So mußte ich den Blick sehnsuchtsvoll in die Ferne schweifen lassen, über die Gebirge Griechenlands und vor allem nach Westen und Südwesten in die Gegend des Prespasees. Von einem Ausblick auf einem vorragenden Felsen aus konnte ich den ganzen Prespasee und Mala Prespa, den kleinen, durch eine schmale Landbrücke von ihm getrennten südlichen See überschauen. Versumpftes Schilfufer zog sich als breites Band um das Nordende des Prespasees. Auf seinen blinkenden Spiegel senkten sich im Westen steile Felswände herab, eine Halbinsel ragte aus ihnen hervor und ein zartes Inselbild schwamm wie ein Phantom im Blau des Sees. Nördlich von ihm zog der Tomoros hin, anschließend die Berge, welche ihn vom Ochridasee trennen und die Verbindung mit dem Schardakh und den albanischen Bergen herstellen.

Nördlich des Prespasees und seines grünen Schilfgürtels dehnte sich die weite, baumreiche Ebene mit der Stadt Resna aus. Noch eigenartiger war aber der Blick nach Westen. Da sah ich steil die Felswände entlang wie aus dem Flugzeug hinab in die Straßen von Monastir. Es ist ein eigenartiger Eindruck, eine Großstadt von über 100000 Einwohnern, und noch dazu eine orientalische Stadt mit den Kuppeln von Moscheen und ihren Minarets, mit baumreichen Gärten, mit großen hellen Gebäuden und tausenden von Dächern von einem hohen Berg zu überblicken.

Um die Stadt herum zogen die feindlichen Stellungen; während ich herunterblickte, begann eine heftige Artilleriebeschießung.

Nach $1 \frac{1}{2}$ Stunden traten wir den Abstieg an. Doch ließ uns der bulgarische Hauptmann nicht ohne weiteres durch sein Lager durchmarschieren. Er hatte ein treffliches Mittagsmahl mit guten bulgarischen Gerichten zubereiten lassen. Gut gestärkt, nach anregenden Gesprächen, traten wir um $2 \frac{1}{2}$ Uhr nachmittags den Rückmarsch in die Tiefe an. Vorher hatte ich mich nicht nur von den freundlichen Offizieren und Mannschaften, sondern auch 
von einer Meute prachtvoller Hunde zu verabschieden. Zwölf gewaltige Tiere, drei junge, neun alte waren die Freunde der Truppe in der Bergeinsamkeit. Sie gehörten zu der prachtvollen, langhaarigen Schäferhunderasse, welche ich immer bei den Hirten im Gebirge antraf. Während aber sonst meist die Tiere verprügelt, schlecht behandelt und tückisch waren, konnte in diesem Fall festgestellt werden, welch treue, kluge Kameraden man aus dieser Rasse erziehen kann.

Der Marsch nach Čapari hinunter führte auf einem Umweg auf die Schlucht zurück, durch welche wir morgens angestiegen

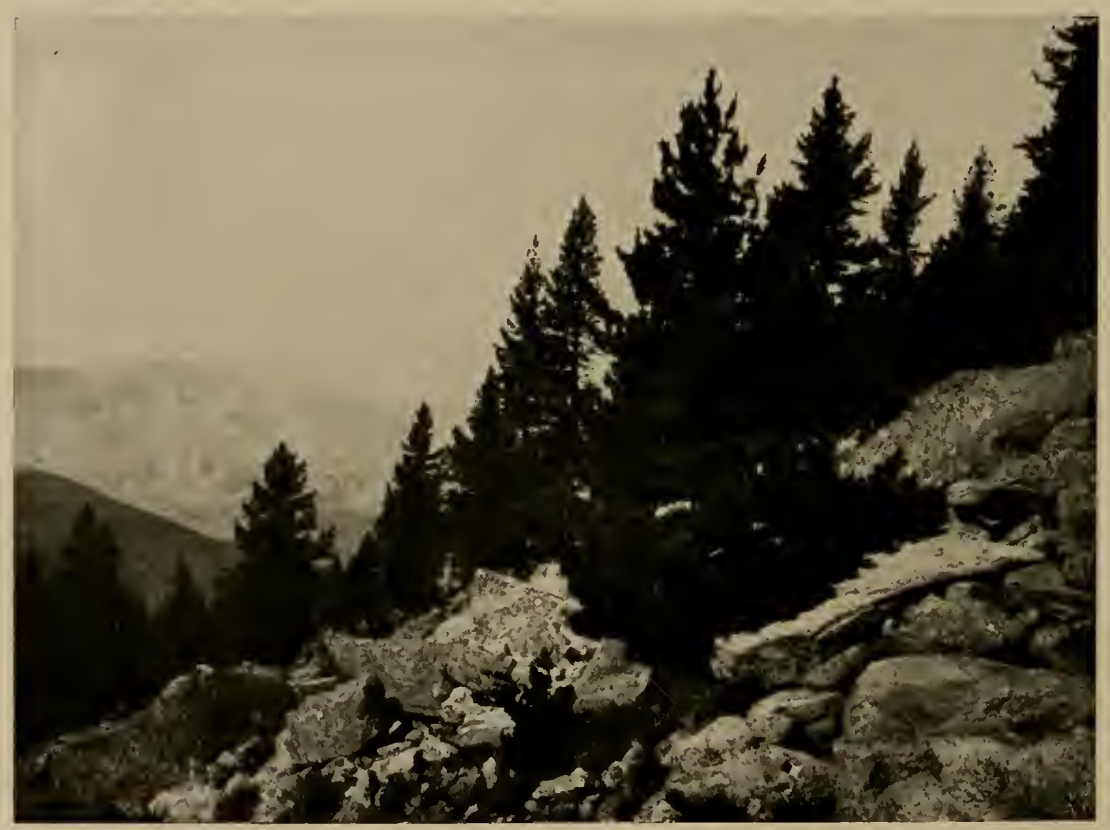

Abb. 260. Pinus peuce am Peristeri $1800 \mathrm{~m}$.

waren. Dieser Umweg war außerordentlich lohnend. Ich ließ mich $z u$ ihm durch einen prachtvollen Wald von hochstämmigen Kiefern verlocken, der die Wände eines tief eingeschnittenen Tales bedeckte, das sich gegen Monastir in die Ebene erstreckte. Es war eine obere Abzweigung des Dragortals und offenbar der Aufstieg, den im Jahre 1839 Grisebach von Monastir über Margarevo gemacht hat.

Die Halde, auf welcher der Wald sich weithin ausdehnte, war mit einem Geröll gewaltiger Granitblöcke bedeckt. Es war 
nicht einfach, den Abhang hinabzuklettern; in Sprüngen ging es von Fels zu Felsen, über glatten Rasen und über morsche Stämme gestürzter Kiefern. Der Wald bestand aus schönen, schlanken Vertretern einer Zirbelkiefer (Pinus peuce). Die tannenähnlich gewachsenen Bäume mit ihren langen, dunkeln Nadeln und braunen Stämmen hoben sich malerisch von den grauen Felsen des Granits ab. Große grüne Grasbüschel und die Blätter des jetzt verblühten Asphodelus albus L. mit den Samenkapseln wuchsen zwischen den Steinen.

Am Boden der Schlucht bildeten die Kiefern einen dichten Wald, der sich zu einer Waldwiese öffnete, auf cler viele rote

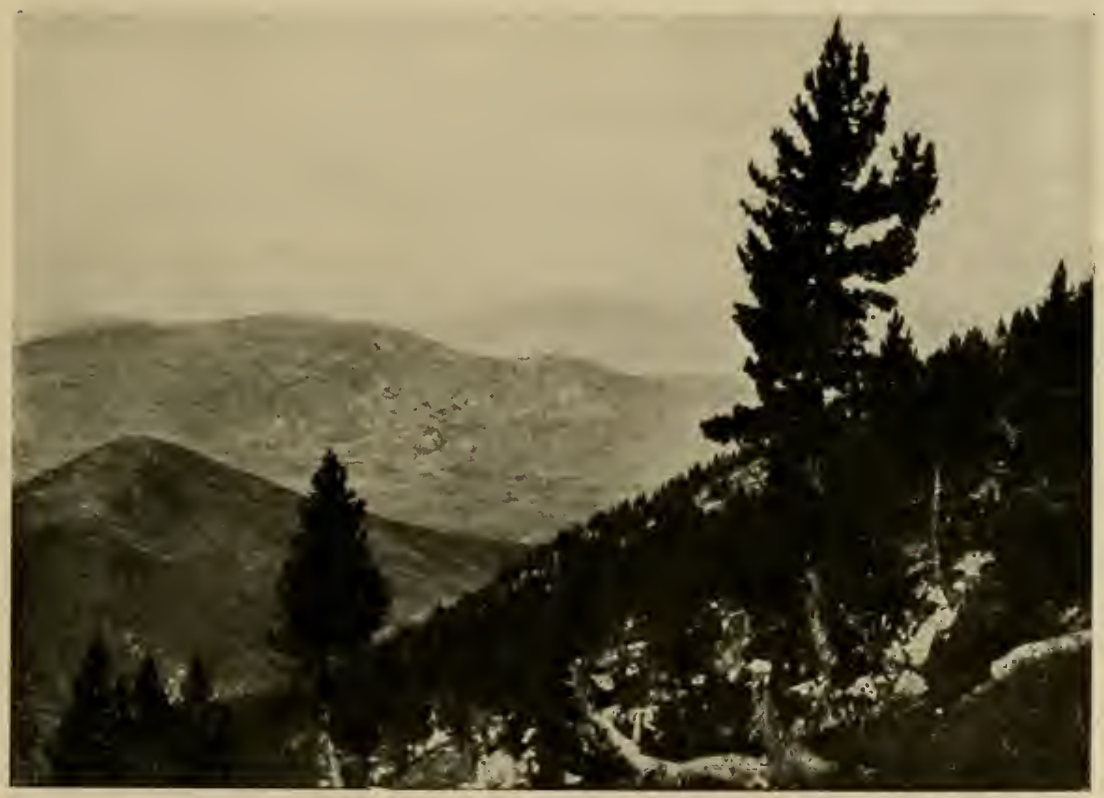

Abb. 26r. Pinus peuce und Blick ins Tal vom Peristerihang in $1800 \mathrm{~m}$.

Disteln und Doldenpflanzen blühten und Himbeeren reiften. Hier gab es noch einmal reiche zoologische Ausbeute. Viele schön gefärbte Hummeln brummten von Blüte zu Blüte. Außer den morgens erbeuteten Erebien flogen hier zahllose Schmetterlinge, von denen ich Actaea cordula Fabr. und den schönen Perlmutterfalter Argymnis pales balcanicus Rbl. erwähnen möchte. Auch Heuschrecken, Bienen, Fliegen wurden in vielen Arten erbeutet.

Eine bescheidene kleine Zauneidechse, die wir nicht weit von dem Bach an den Felsen der Schlucht fingen, erwies sich als ein 
besonders interessanter Fund. Es war der südlichste Fundort von Lacerta agilis L., der mitteleuropäischen Form der Zauneidechse. Es war nicht die östliche Form L. agilis exiqua, sondern die typisch mitteleuropäische, wie sie bisher mit Sicherheit auf dem Balkan nur in der Herzegowina beobachtet worden war.

Über all diesen Naturforscherinteressen wurde aber auch die Schönheit der Landschaft nicht vergessen. Die warme Nachmittagssonne vergoldete die Felsenhalden und die Stämme der Kiefern. Schon begannen die Schatten über die Hänge und Talwände sich auszubreiten. In vollem Sonnenglanz lagen noch die Hänge der Berge nördlich von Monastir und der Kette bei Gopes. Klar umrissen ragten die Kronen der Kiefern in den glühenden Himmel hinein.

Mit Bedauern blickte ich auch hier in die sinn- und zwecklose Verwüstung, welche die bulgarischen Truppen in dem wundervollen Bestand der Kiefern angerichtet hatten. Wie wird sich in den nächsten Jahrzehnten schon der Raubbau rächen, der im Krieg an den geringen Waldbeständen Mazedoniens ohne jede Voraussicht geübt wurde.

Schon lag von neuem abendlicher Schatten in der Schlucht, als wir müde und befriedigt dem Eingang des Dorfs Capari zu marschierten. Froh dachte ich nachts daran, daß ich das Wasser, das mich in den Schlaf rauschte, oben am Rande des Schnees hatte entspringen sehen.

Ich halte es für richtig, hier einen knappen Überblick über unsere gesamten Beobachtungen in den mazedonischen Alpen zu geben. Es waren Hochgebirge von mittlerer Höhe, welche ich im Schardakh, in der Mala Rupa, in der Golesniza Planina, in der Belasiza Planina, im Peristeri und im Tomoros kennen lernte. Daneben habe ich noch eine ganze Anzahl stattlicher Mittelgebirge besucht. Ich nenne von ihnen die Plaguša Planina, die Berge bei Demir Kapu und am Doiransee, das Babunagebirge, den Karadakh bei Üsküb, die Wodnokette, das Gebirge bei Gopes und Krusevo.

Mazedonien in seiner Gesamtheit betrachtet ist ein gebirgiges Land, erfüllt von Kettengebirgen, welche den malerischen 
Charakter des Gebietes bedingen. Während die Mittelgebirge $1000-1400 \mathrm{~m}$ Höhe erreichen, sind in den Alpen Mazedoniens die höchsten Gipfel etwa $2400-2700 \mathrm{~m}$ hoch. An Wildheit der Formen und Größe der Dimensionen kann sich diese Gebirgswelt mit unseren Alpen nicht messen. Touristische Schwierigkeiten für die Erreichung der Gipfel kommen nicht in Frage. Kletterpartien kommen kaum in Betracht. Viele der von mir bestiegenen Gipfel waren auf Saumpfaden zu erreichen.

In anbetracht der relativ geringen Höhen und der südlichen Breite der Lage zeigen die Gebirge einen auffallenden Reichtum in ihrer alpinen Flora und Fauna. Wir lernten sie als die Zufluchtsorte der Wälder kennen. Die Baumgrenze liegt entsprechend der südlichen Lage erheblich höher als in unseren Gebirgen. Im Schardakh lag sie über $1800 \mathrm{~m}$, in der Mala Rupa sogar in etwa $1900 \mathrm{~m}$, am Peristeri etwa ebenso hoch, in der Golesniza Planina mit ihrer Latschenregion sogar bei $2000 \mathrm{~m}$.

Sehr charakterisch für alle mazedonischen Gebirge war die Gliederung in Vegetationszonen, wie sie stets in den südlichen Gebirgen so auffällig sind. Je nach dem Charakter des Flachlandes war der Fuß des Gebirges entweder von typischer Kulturvegetation umfaßt oder von der in den ersten Kapiteln dieses Buches beschriebenen Steppenflora. Verließ man in den südlichen Gebirgen, also in der Belasiza Planina oder in der Mala $\mathrm{Rupa}$ und am Peristeri die Hügellandschaft, kam man über $200-300 \mathrm{~m}$ Höhe hinauf, so ließ man die Stacheleiche und den Judendorn bald hinter sich, mit ihnen die sie begleitenden Kräuter. Auf diese Zone folgte die der weichblättrigen Eichen, der Wachholderbüsche, unter welche sich Eschen, Hainbuchen und andere Bäume mischten. Diese Region ging direkt über in die des Eichenbuschwaldes, die in den verschiedenen Gebirgen bis in die Höhe von 700-900 $\mathrm{m}$ reichte. Zwischen diesen Eichenwaldungen waren Wiesen ausgestreut mit einer sehr reichen Flora blühender Kräuter.

Von 750 bis etwa $1500 \mathrm{~m}$ erstreckte sich die Buchenwaldregion. Sie war allen Gebirgen charakteristisch. Es war die Zone des Hochwaldes, in welcher auch, besonders aber an der oberen Grenze, sich $\mathrm{N}$ adelwald anschloß. Dieser bestand meist aus Weißtannen, so auf der Mala Rupa und auf der Kobeliza. am Peristeri war sie durch die Pimus peuce vertreten, nur im Gebiet der Golesniza Planina fanden wir in $1900-2200 \mathrm{~m}$ 
die Bergfö hre, die Latsche. Auch in dieser zweiten Gebirgszone spielten die reizvollen Waldwiesen mit ihrem Blüten- und Insektenreichtum eine große Rolle. Auf diesen Wiesen und an den Rändern des Waldes fanden sich die mazedonischen Sennereien. Im Waldesschatten wuchsen als Schattenblumen Anemonen und Sauerklee. Überhaupt hatte diese ganze Zone einen ausgesprochen mitteleuropäischen Charakter in Pflanzen und Tierwelt. Hier flogen im Wald der Liljefordspecht, Mittelspecht, Amsel und Misteldrossel, Kleiber, Nonnenmeise, Waldbaumläufer, Rotkehlchen; hier brütet der Buchfink. Hier ist die Zone, in welche sich im Sommer viele der mitteleuropäischen Vögel verziehen.

In der Latschenregion der Begova wurden Tannenmeise, Heckenbraunelle, Hausrotschwanz und Hänfling angetroffen.

Typische alpine Flora beginnt in der Regel erst in den mazedonischen Alpen von $1400-I_{500} \mathrm{~m}$ ab. Natürlich ziehen sich auch hier mit den Bächen Alpentiere und -pflanzen weit abwärts. An Nordhängen fand man nicht selten schon alpine Vertreter in $1100-1200 \mathrm{~m}$ Höhe in größeren Beständen, so die für die erste alpine Zone der mazedonischen Gebirge sehr charakteristischen Pflanzen, den Germer, Veratrum album, und das zarte Heidekraut Bruckenthalia spiculifolia Salisb. Mit dieser zusammen fand ich auf fast allen Alpenbergen Mazedoniens in der gleichen Region die balzende Heuschrecke Stenobothrus miniatus Charp.

In dieser Zone flogen die Parnassier, früh im Sommer die Mnemosynen, später die Apollos; da gab es die charakteristischen alpinen Erebien, die Bläulinge, die Perlmutterfalter und Spanner, welche für diese Zone charakteristisch waren.

Hier begannen nun allmählich die Matten zu herrschen, die typischen alpinen Felsenpflanzen vorzuwiegen. Wie bei den Tieren, so ist bei den Pfianzen der Felsen ein charkteristischer Wohnort der alpinen Formen. Alpine Felsentiere und -pflanzen folgen den Felsen in die Tiefe; Felsentiere und -pflanzen der Tiefe steigen mit den Felsen zu den Alpengipfeln empor.

So herrschten denn in den mazedonischen Alpen von Pflanzen neben den Enzianen, den Alpenrosen bald immer mehr die Steinbrech-, Nelken- und andere Pflanzenarten vor, welche Polster und Rosetten bildend, wie Moos sich an die Felsen heften.

Auf den Matten der Regionen über $2200 \mathrm{~m}$ war eine wundervolle alpine Flora von großem Formenreichtum vorhanden und mit 
ihr eine charakteristische Alpentierwelt. Und das, obwohl hier unter der Breite des $40-42^{\circ} \mathrm{N}$, sich kein ewiger Schnee, keine Gletscherbildung von größerer Ausdehnung gehalten hat. So war denn hier nicht wie in den Hochalpen eine sehr reiche, formenreiche Nivalfauna wie sie neuerdings vor allem in den schweizer Alpen durch $\mathrm{Zschokke}$ und seine Schüler eine eingehende Untersuchung erfahren hat, entwickelt. Wir haben in den mazedonischen Alpen in der Golesniza und am Peristeri nur geringe Massen von Dauerschnee angetroffen. Aber wir fanden die Spuren einstiger Vergletscherung auch in den mazedonischen Alpen und damit auch Relikten der einstigen Eiszeit, wie sie zu erwarten waren.

In den höchsten Felsenregionen und Grasflächen über $2000 \mathrm{~m}$ fanden wir die Brutstätten der Ohrenlerche, der Feldlerche und des Braunkehlchens; in den zerklüfteten Felsgebieten der Begovagipfelregion mit ihren Schneefeldern und Schneelöchern gab es Scharen von Alpendohlen, auch Alpenbraunellen ließen sich hier nachweisen. Den Felsen nachgefolgt waren ebenso hier hinauf der Alpenmauerläufer und der Felsenkleiber.

Auch unter den Insekten und niederen Tieren ließen sich typisch alpine Formen und Eiszeitrelikte nachweisen. Ich habe in früheren Kapiteln auf den Schmetterling Anarta, auf die Alpenplanarie, auf die nordischen $\mathrm{Hummelformen} \mathrm{hin-}$ gewiesen. Die weitere Verarbeitung des Materials verspricht noch manchen interessanten Aufschluf. Unsere Untersuchungen der Biologie der mazedonischen Alpen sind erste Vorstöße gewesen, denen die Forschungen der Botaniker und der vielen, besonders österreichischen Entomologen vorausgingen. Noch viel Interessantes ist von zukünftigen, vertiefteren Untersuchungen zu erwarten. 


\section{AM PRESPASEE.}

Im September I9i7 hatte ich vergebens versucht, auf den Prespasee zu gelangen. Ich hatte die Parklandschaft am Nordende des Sees durchwandert und war bis an sein sumpfiges Ufer gelangt. Aber persönliche Unfreundlichkeiten der deutschen Offiziere hatten mich vergebens zurückkehren lassen, und auch im Jahre 1918 drohten ähnliche Widerwärtigkeiten den Plan zu stören. Auf Quartier und Verpflegung sollte es schließlich nicht ankommen. Die Motorboote und die zugehörigen Marinemannschaften hatten den Befehl, sich mir zur Verfügung zu stellen und das war das Wesentliche.

Die Boote erwiesen sich als sehr gut und leistungsfähig, die Mannschaften waren gefällig, voll Interesse für unsere Zwecke; und so kam ich mit ihnen sehr gut zurecht. Ich konnte meine Absichten am Prespasee vollkommen erreichen, zumal mein Mitarbeiter Dr. Nachtsheim mir die Hauptarbeit bei der Seenuntersuchung abgenommen hatte.

Inmitten einer weiten Sumpffläche lag nahe dem Nordende des Prespasees eine kleine Hütte, in welcher die Seeleute hausten. Wir selbst übernachteten im Dorf Podmočani im Freien neben einem Heuhaufen, da man uns dort kein Quartier anwies. In der schönen warmen Nacht war dies nicht unangenehm und in gewissem Sinn vorteilhaft; denn die Hütte der Marinemannschaften dicht am See wimmelte von Anopheles, so daß wir dort, wenn auch nicht unter allen Umständen Malaria bekommen, doch sicher eine durch die Stechmücken gestörte Nacht gehabt hätten.

Das Nordende des Prespasees ist sehr versumpft. Man kann vielfach infolge des unsicheren Strandgeländes gar nicht bis an das freie Wasser heran. Ähnlich wie am Doiransee umgibt ein breiter Schilfgürtel das Ufer. Das Niveau des Sees ist häufigen Schwankungen unterworfen, was wohl hauptsächlich dem Umstand zuzuschreiben ist, daß er keinen Abfluß hat; denn die im Volk verbreitete Annahme, daß er einen unterirdischen Abfluß zum tiefer gelegenen Ochridasee habe, ist wohl kaum ernsthaft zu diskutieren. 
Wie beträchtlich die Wasserstandsschwankungen sind, beweist die Tatsache, daß der Ort Perovo, der auf der Karte etwa I $\mathrm{km}$ nördlich des Nordufers eingezeichnet ist, zur Zeit meines Aufenthalts auf einer Insel lag. Er konnte nur im Boot über einen Kanal von etiva $200 \mathrm{~m}$ Breite erreicht werden.

Der Prespasee liegt in einer Meereshöhe von $857 \mathrm{~m}$. Er umfaßt ein Areal von $288 \mathrm{qkm}$, ist also etwas kleiner als der Ochridasee, welcher der größte der mazedonischen Seen ist. Er ist ein relativ seichter See, denn seine grölite Tiefe erreicht nur $5+, 2 \mathrm{~m}$.

War er mir schon vom Peristeri und von der Höhe über Gopes aus sehr reizvoll erschienen, so bestätigte sich dieser Ein-

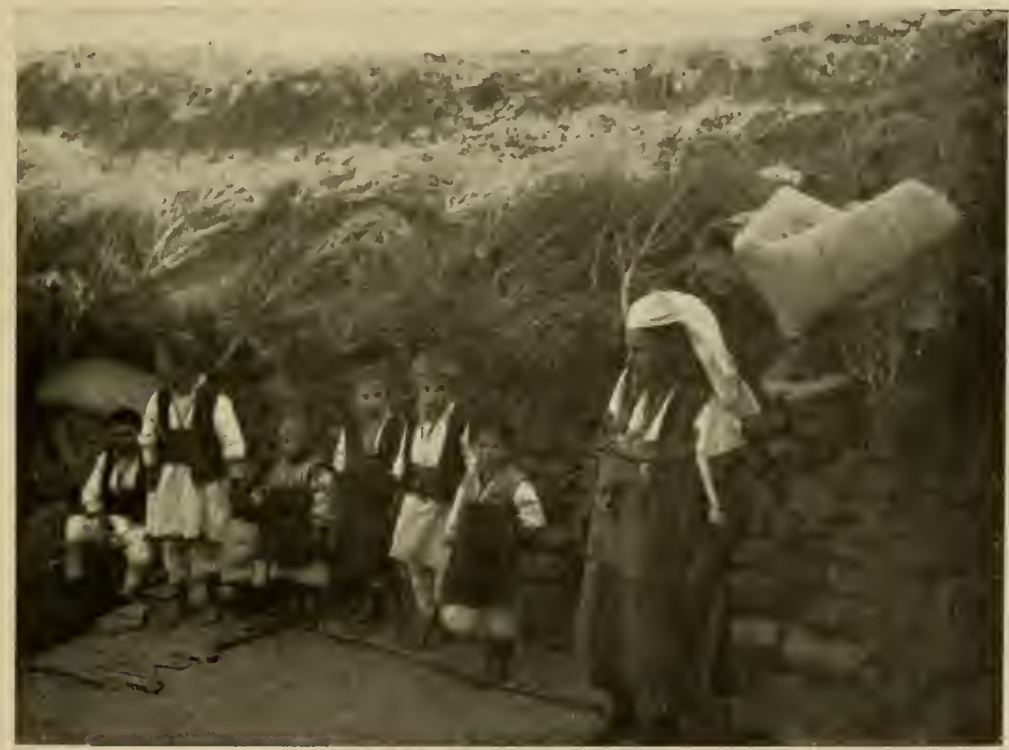

Abb. 26I a. Arbeiterfamilie in Lera.

druck, als ich an seinem Nordufer stand. An beiden Längsufern war der See von stattlichen Gebirgen eingefaßt. Im Osten traten die Ausläufer des Peristeri an ihn heran. Ihre schönen Formen bildeten einen sehr malerischen Hintergrund zu der blauen Fläche des Sees. Auch das Westufer war von hohen Bergen eingefaßt, Tomoros und Malisat gehörten zu ihnen. Fern im Süden sah man auch stattliche Berge über dem See aufrageı. Vor allem am Westufer traten die Berge steil an den See heran. Hier waren 
es zum Teil mächtige Steilabstürze zum See, unter denen wir bei Motorbootfahrten herankamen. Auch die beiden bergigen Inseln traten bei diesen Fahrten deutlich hervor. Ich bedauerte sehr, daß ich diese Inseln und den im Süden an den großen anschließenden kleinen Prespasee mit seiner Insel infolge der feindlichen Besetzung nicht besuchen konnte. Gerade die eine Insel im Prespasee machte nicht nur einen sehr malerischen Eindruck, sondern sie enthält in der dem heiligen Achil gewidmeten Basilika ein Bauwerk altbulgarischer Kunst, das sehr interessant sein muß.

Das Sumpfgelände am Nordende des Prespasees macht einen sehr eigenartigen Eindruck. Vielfach sind es sumpfige Wiesen

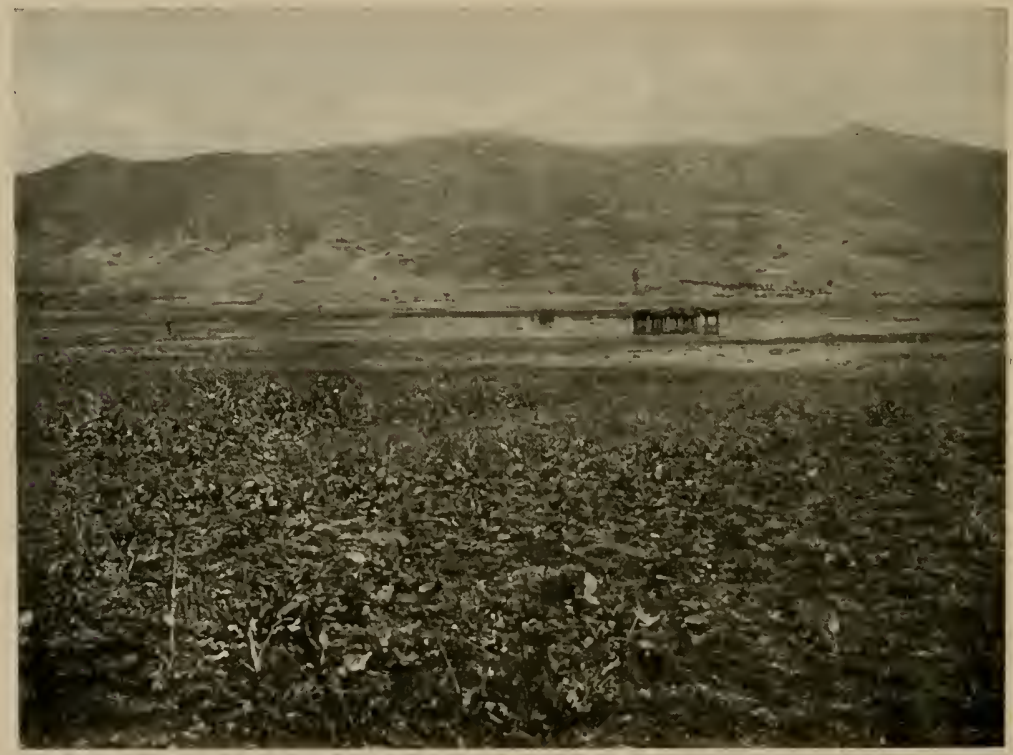

Abb. 262. Am Nordrande des Prespasees. Blick gegen die Ausläufer des Peristeri n. O.S.O.

welche an den See grenzen, zum Teil ist das Ufer in zahlreiche kleine Inseln und Sandbänke geteilt. Schöne Baumgruppen treten an vielen Stellen an den See heran; ja Wälder von Ulmen, Erlen, Weiden und Eichen sind oft als Sumpfwälder für den Menschen kaum erreichbar und infolgedessen sichere und günstige Brutstätten für zahlreiche Reiher, Adler, Geier und andere Vögel.

Die weiten Wiesen bilden eine gute Weide für Pferde und Rinder und so waren sie damals von großen Herden von Rindern, 
Eseln, Maultieren, Pferden und Büffeln belebt, was nicht wenig zum Reiz des Landschaftsbildes beitrug. Gruppen von Pferden oder Stieren sah man oft in seichten Wasser des Strandes stehen und da saufen, Büffel in den tieferen Tümpeln sich suhlen und der Kühlung im Wasser erfreuen.

Dazwischen stolzierten Reiher; Uferläufer, Sichelschnäbel, Brachvögel, Enten und Gänse suchten sich zwischen Gras und Schilf ihre Nahrung. Kraniche und Störche fanden sich zahlreich ein, dazu Purpurreiher, Fischreiher, Löffelreiher und auch hier die schönen Edelreiher. Unendliche Mengen von Fröschen erhoben ihre Stimmen vor allem in den Abendstunden. Ringelnattern von verschiedenen Formen schwammen im Wasser oder huschten durch das Schilf.

Nicht selten hörte man die dröhnende Stimme der Rohrdommeln ertönen, Rallen, Schnepfen, Brachvögel und Bekassinen liefen am Strand entlang. Daß auch hier Rohrsänger und Rohrweihen häufig waren, wie am Katlanovosee, braucht kaum erwähnt zu werden. Auch Nachtreiher wurden beobachtet.

$\mathrm{Da}$ es in dem sumpfigen Gelände nicht leicht war, an die Vögel heranzukommen und die erlegte Beute auch zu sichern, ist verständlich. So wurden dort mehr Tiere beobachtet als erbeutet. Leichter war es auf den Motorbootfahrten an die Tiere heranzukommen. Durch Schilf, Buschwerk und tote Bäume, die als Zeugen des Wachstums des Sees aus dem Wasser hervorragten, fanden die flotten Seeleute als Führer der Motorboote geschickt ihren Weg. Unsere Motorboote auf dem Prespasee waren besonders gut und rasch und da sich die feindlichen in diesen Tagen selten auf dem See zeigten, konnten wir es wagen, uns weit nach Süden in den schönen, bergumgebenen Teil des Sees zu begeben und dahin unsere Untersuchungen auszudehnen.

Daß wir dabei von den Feinden nicht unbemerkt blieben, erfuhr ich erst später auf der Rückreise in Prilep, wo unser Nachrichtenoffizier mir belauschte Gespräche des Feindes über die seltsamen Manipulationen auf dem Prespasee erzählte. Sie hatten sich allerlei Gedanken über Minenlegen u. dgl. gemacht, während wir harmlos loteten und die Planktonnetze ins Wasser senkten.

Vor allem war es schön in der Abendstimmung an die Felsenhänge oder gegen die Insel heranzufahren und bei aufglühendem Himmel über den milchblauen See zu steuern, auf dem tausend Reflexe von den vielfarbigen Wolken wiedergestrahlt wurden. 
Reizvoll war die Rückfahrt durch die Schilfinseln. Dort sammelten sich hunderte ron Kormoranen [Phalacrocorax carbo subcormoranus (Brehm)] und der Zwergscharbe ( $P$. pygmaeus Pall.) auf den toten Bäumen an, die ihnen als Schlafbäume dienten (Abb. 263). Aus dem Schilf trieb das Geräusch unseres Bootes die verschiedensten Entenarten, Wasserhühner, Taucher auf. Ja stolze Peli$\mathrm{k}$ ane sahen wir einige Male in der Ferne wie duftige Wölkchen über dem Wasser schweben. Auch Adler, Fischadler und Seeadler zogen in großen Kreisen ihren Schlafbäumen in den Sumpf-

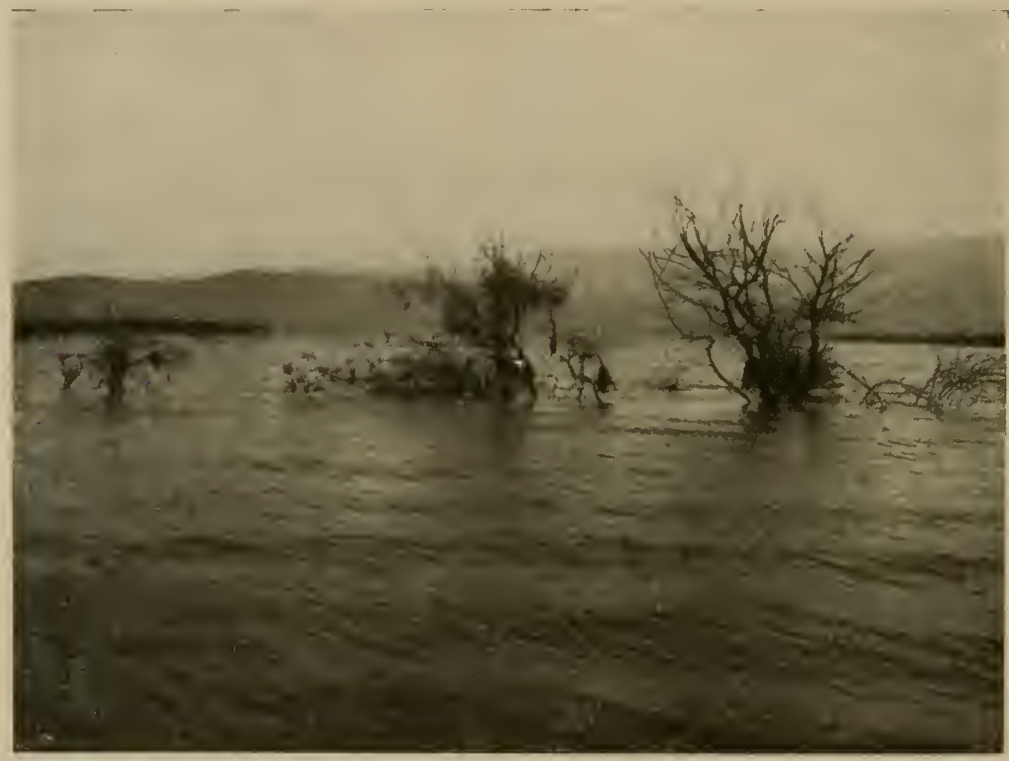

Abb. 263. Schlafbäume der Kormorane im Prespasee.

wäldern zu, aus denen Fledermäuse sich erhoben und über dem See Insekten jagten.

Daß mein Sammler tagsüber an Ufer manches von Insekten und Spinnen erbeutete, ist selbstverständlich. Schmetterlinge und Käfer, Wanzen und Heuschrecken, Ameisenlöwen und vor allem zahlreiche Libellen wurden erbeutet.

Bemerkenswert, weil bezeichnend dafür, wie abhängig man beim zoologischen Beobachten vom Zufall ist, oder vielmehr von der Zeit und der Örtlichkeit, an die man gerade gerät, ist die Tatsache, daß ich damals im Juli 1918 am Prespasee kaum solitäre Bienen beobachtete, während ich bei meinem ersten Besuch, am 
22. Aug. 1917, in den Niederungen nördlich vom See, deren eine Menge fing. So erbeutete ich damals allein neun echte Halictus-Arten, darunter H. morbillosis Kriechb., eine typisch östliche Art, welche von Ungarn bis weit nach Kleinasien vorkommt. Vielfach waren es zweite Generationen, die gerade jetzt zur Stelle waren, so z. B. von Andrena carbonaria Scop. Außer den solitären gab es damals auch zahlreiche Honigbienen, und zivar die gewölnnliche deutsche Biene und die griechische (Apis mellifica var. cecropia L.).

Wir anderen, vor allem Dr. Nachtsheim, waren unterdessen mit Untersuchungen auf dem See beschäftigt. Hier zeigte sich, wie im Doiransee, ein großer Reichtum an Algen im Wasser. Auch Peridineen in großer Zahl traten auf. Das tierische Plankton war reich vor allem an Krebsen. Unter ihnen waren Daphniden und Copepoden etwa gleich stark vertreten. Unter letzteren traten Diaptomiden besonders hervor. Diaptomus Steindachneri kam in verschieden großen Rassen vor. Ähnlich wie im Doiransee gab es hier auch eine schöne, durchsichtige Form von Leptodora. Sie war aber nicht sehr reichlich vorhanden; trat hauptsächlich in Fängen aus Tiefen von 5- I $2 \mathrm{~m}$ auf, weniger an der Oberfläche. Auch hier waren Muschellarven in Mengen im Plankton vertreten.

$\mathrm{Da}$ in diesem See bei der geringen Tiefe, die er erreicht, keine solche Variation in den Fängen durchgeführt werden konnte, wie im Ochridasee, ist zu verstehen. So nahmen wir uns vor, nach diesen ersten Feststellungen zu anderen Jahreszeiten wiederzukehren. Das hätte interessante Resultate versprochen. Leider kam der Rückzug dazwischen und verhinderte die beabsichtigte Vertiefung unserer Seenforschungen auf allen vier Seen Nordmazedoniens. 


\section{RITT ÜBER DEN TOMOROS.}

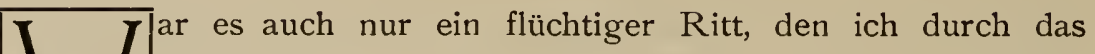
Tomorosgebirge machen konnte, ich werde nie bereuen, die Anstrengungen auf mich genommen zu haben, um einen Blick in das ganz eigenartige Gebirge zu tun. Schon die Aussichten, welche mir beim Anstieg auf den Prespasee, beim Abstieg auf den Ochridasee zuteil wurden, gehören zu den schönsten landschaftlichen Eindrücken, welche ich von diesen malerischen Seen Mazedoniens mitgenommen habe.

Vor Tagesanbruch stand mein Wagen vor meinem Quartier in Podmocani an der Nordostecke des Prespasees bereit; ich hatte eine lange Fahrt um das ganze Nordende des Sees vor mir, ehe ich in Volkoderi an seiner Nordostecke anlangte, wo mich früh 6 Uhr Reitpferde erwarten sollten, welche mir der Stab der oben auf dem Tomoros liegenden bulgarischen Division versprochen hatte.

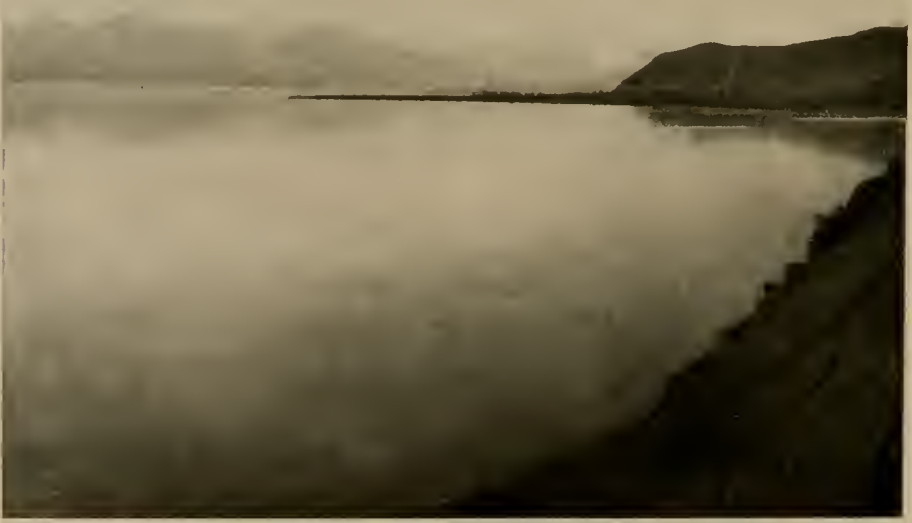

Abb. 264. Nordostende des Prespasees. 
Ich hatte einen großen Bogen um das Sumpfland durch die Parklandschaft zu machen, ehe ich an den Fuß der Berge gelangte. Im Morgendunst bot der silbrig glänzende See manchen reizvollen Blick. Während die Berge im Osten im Nebel .verschwanden, stiegen die Gebirge und die Halbinsel Vakufče im Westen dunkelblau aus dem See empor. Ganz köstlich hoben sich die Silhouetten von langen Pappelreihen und mächtigen Ulmengruppen vom Silberspiegel des Sees ab, wenn wir um sie und sein Wasser nordwärts ausbiegen mußten.

Als nun im Osten die Sonne heraufstieg, vergoldete sie die kahlen Flanken des Tomoros, der immer höher vor uns sich erhob. Immer weiter streckte sich das Vorgebirge in den See hinaus, in der Ferne erkannte man bloß die Umrisse der Insel mit dem Kloster Sv. Peter. Schluchten wurden an den Abhängen des Berges vor uns sichtbar und zeigten uns einen schwierigen Weg zu den Wäldern in der Höhe an. Indem wir jetzt die Hügel hinanfuhren, tauchten auch im Süden schön geformte Berge auf, welche die Nordwestecke des Sees als Bucht vor uns abschlossen.

Wundervolle Blicke auf den blauenden See wechselten in reicher Fülle ab, als ich und mein Kamerad, Leutnant Müller, der Weggenosse bei der Peristeribesteigung, nun zu Pferde die Vorberge hinanritten. Wir hatten zunächst kahles, menschenleeres Gelände zu durchreiten; ehe wir bei Pescani den Ochridasee erreichten, trafen wir auf keine menschliche Siedelung mehr.

Nach ${ }_{1} 1 / 2$ stündigem Ritt gelangten wir durch niederes Eichengebüsch in ein schön bewaldetes Tal. Sehr bemerkenswert war schon hier der Mangel an Wasser. Alle Schluchten lagen trocken, keinen Quell trafen wir an. Der Wald, obwohl er stattliche Bäume enthielt, blieb licht und enthielt reichlich Unterholz. Er war hauptsächlich aus Buchen zusammengesetzt. Schöne grüne Waldwiesen waren reichlich in ihn eingefügt.

Auf ihnen tummelte sich eine formenreiche Insektenwelt. An den heißen Hängen des. Tomoros fiel die Farbenpracht vieler Insekten besonders auf. Groß war der Reichtum an Bläulingen; unter ihnen gab es nicht nur leuchtend blaue Arten, sondern auch die rotgolden blinkenden Formen und jene mit den eigenartigen Fortsätzen an den Flügeln. Ich nenne von ihnen Thekla spini Schiff., Th. ilicis Esp., Chry'sophanus virga aurea L., Lycacna argus L., L. astrarche Bgstr., L. admetus Esp. Diese Reihe von Namen 
soll einen Begriff von dem Formenreichtum geben, der unter diesen farbenprächtigen Faltern hier vertreten war.

Von Käfern waren besonders auffallend die grüngolden schimmernden. Rosenkäfer (Cetonia aurata var. tumiicta Reit. und var. viridiventris Reit.). In dem gemischten Bestand von Buchen, Eichen, Ahorn und Linden fanden sich manche von den Bäumen abhängige Käfer, wie der schöne gefleckte Alpenbock (Rosalia alpina I..).

Um beobachten und sammeln zu können, banden wir unsere Pferde zeitweise an Sträucher oder Bäume an, in deren Umgebung

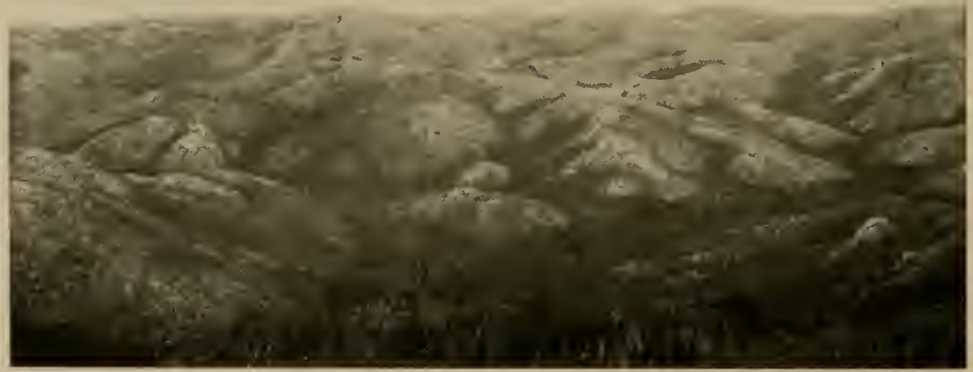

Abb. 265. Karstlandschaft im Tomoros.

sie reiche Weide fanden. So kamen wir langsam unter manchen interessanten Beobachtungen in die Höhenzone, in der der Wald allmählich abnahm. Buschwerk löste ihn ab, zwischen welchem sich hier und da ein höherer Baum erhob.

Nun gelangten wir allmählich in eine ganz eigenartige Landschaft, in welcher wir jetzt für anderthalb Tage blieben. Das Gebirge des Tomoros ist zum großen Teil aus Kalk aufgebaut. Und zwar trägt es einen ausgesprochenen Karstcharakter. Dem entspricht die Trockenheit und Wasserarmut. Vor allem aber ist die Oberfläche des Gebirges von einer ganz seltsamen Struktur. 
Kahl dehnen sich weite Flächen vor den Augen aus, grell von der Sonne bestrahlt. Aber die Eintönigkeit der Oberfläche ist von einer Unmenge von Schattenflecken unterbrochen, welche eine eigenartige Modellierung verraten. Löcher und Trichter sind oft seichter, oft tiefer in den Boden eingesenkt und verraten die eigenartigen Kräfte, welche hier an der Bodengestaltung tätig sind. Es ist eine echte Karstlandschaft mit ihren Dolinen, den Einsturztrichtern, die, mit Vegetation erfüllt, dunkel von der dürren, weißblinkenden Kalksteinfläche sich abheben.

Karst traf ich hier während meinen mazedonischen Wanderungen zum ersten Male in größerer Ausdehnung an. Diese Gebirgsform ist im Inneren der Balkanhalbinsel nicht allzu häufig, während sie im Westen eine große Rolle spielt. In Istrien, Dalmatien, Bosnien und der Herzegowina ist sie vorherrschend. Speziell in Südkrain, dessen Gebirge sie den Namen verdankt, ist diese Formation verbreitet. Ihre Dolinen, Höhlen, im Boden versinkenden und plötzlich als mächtige Flüsse hervortretenden Bäche haben sie berühmt gemacht. In kleinerem Maßstab hatte ich früher Karstlandschaft in der Golesniza Planina angetroffen und im 26. Kapitel beschrieben.

Eine solche Karstlandschaft füllt nun den zentralen Teil des Tomorosgebirges aus. Ringsum dehnt sich steiniges Gebiet, hier und da durch die dunkeln Laubmassen von Gehölzen und Tebüschen unterbrochen. Es waren zum Teil Bilder von großer malerischer Schönheit, welche ich durchritt, um die Gipfelregion zu erreichen.

Hell flimmerte die Sonne auf den weißen Kalktrümmern der Oberfläche, zwischen denen saftig grüne Rasenflächen und dichte Polster einer mehr und mehr alpin erscheinenden Pflanzenwelt sich ausbreiteten.

So war der Charakter der Landschaft, in welcher sich die Stellungen der bulgarischen Division hinzogen, in deren Stab ich mit meinen Begleitern gastliche Aufnahme fand. Ein kleines Tälchen, in der Höhe von etwa $1900 \mathrm{~m}$ gelegen, überragt von den Gipfelspitzen des Gebirgs, beherbergt die Hütten, die auch hier praktisch im Windschutz angelegt, mit Heizungseinrichtungen für den Winter versehen, uns aufnahmen.

Obwohl es 22. Juli war, herrschte in der Höhe eine erfrischende Kühle, die bulgarischen Offiziere, welche uns sehr freundlich begrüßten, zeigten auch hier starkes Interesse für meine 
Forschungen. Ja, einer von ihnen sammelte sogar Insekten. Mit ihm machte ich noch am Nachmittag Streifzüge in der außerordentlich interessanten und reizvollen Umgebung.

Es gab viel auf- und abzuklettern; denn Hügel, Felsen, Schluchten und Tälchen wechselten beständig miteinander ab. Die Quartiere lagen noch etwas unterhalb der Waldyrenze, so daß Hügel und Schluchten noch stattliche Buchen trugen. Eine reiche Pflanzenwelt wuchs zwischen dem Geröll, Doldenpflanzen, Disteln, Glockenblumen, Königskerzen waren in mannigfachen Arten vertreten. Leider hatte ich diesmal keinen Botaniker bei mir, so daß

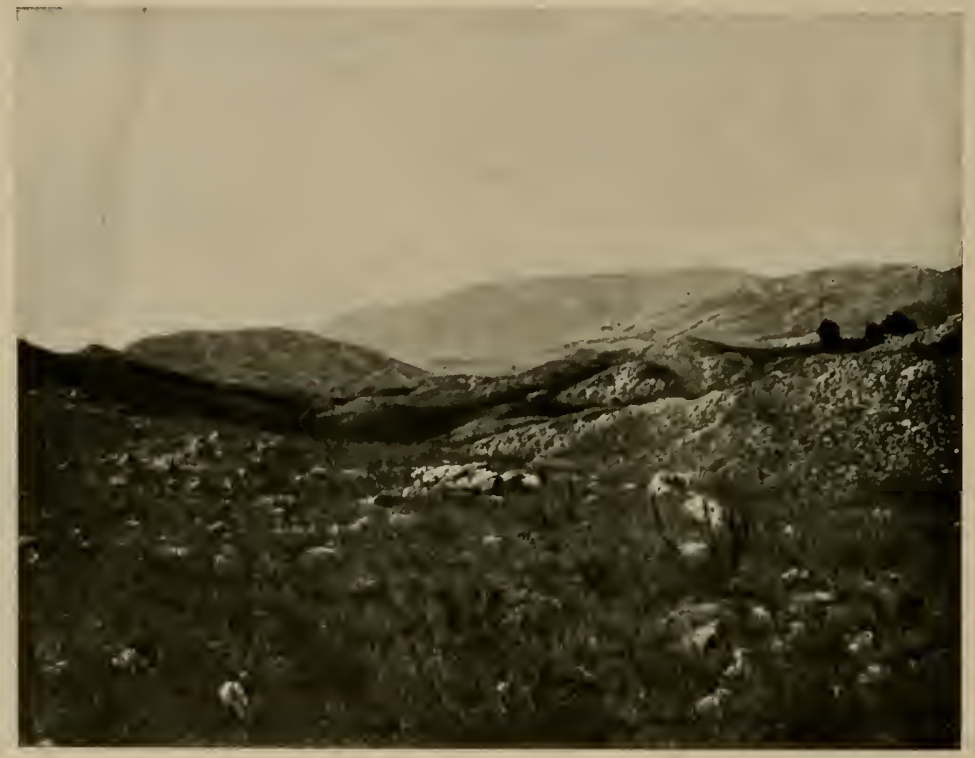

Abb. 266. Hochmatten im Tomorosgebirge.

ich keine genauen Angaben über die sicher sehr interessante Pflanzenwelt der Gipfelregion des Tomoros machen kann.

Südwärts von den Stellungen der Bulgaren erhoben sich noch höhere Gipfel, die teils noch zum Tomoros, teils zum anschließenden Gebiet des Malisat gehörten. Dort drüben lagen französische Truppen. So war es nicht möglich, viel weiter südlich vorzudringen. Zwar reizten die schönen klaren Formen der Berge, verklärt vom abendlichen Licht, die Sehnsucht des Naturforschers. Aber die Zeit war mir knapp zugemessen; ich mußte am nächsten Abend in Ochrida ankommen. 
Es war ein langer, ermüdender $\mathrm{Weg}$, der am nächsten Morgen uns im Fußmarsch in westlicher Richtung das Gebirge hinab zu dem schönsten See Mazedoniens führte. Auch abwärts führte der Weg zunächst durch typisches Karstgebiet. Hier trafen wir eine Anzahl typischer Dolinen an, tiefe trichterförmige Einsenkungen in den Boden, welche im Grund von üppiger Vegetation erfüllt waren. Kahle Kalkbuckel in unendlicher Folge, mit einer gewissen Regelmäßigkeit angeordnet, erzeugten Landschaftsbilder von einer so phantastischen Eigenart, daß man sich auf einen fremden Weltkörper versetzt glauben konnte.

Vertrauter wurde das Landschaftsbild in der Region hochstämmigen Buchenwalds, dessen Waldwiesen wiederum reich an Insekten waren. Auf alten Eichen kam hier der Eichenbock (Cerambyx cerdo L..) vor; dort fand sich auch der mächtige Proceros gigas L. Von Schmetterlingen gab es hier und weiter oben eine Anzahl Gebirgsformen und typisch südliche Arten. Ich erwähne den Scheckenfalter (Melanargia larissa), eine gelb und weiße Form ähnlich der taurica. Zwei schöne Augenfalter flogen hier (Satyrus hermione L. und S. briseis minor Oberth.), ein südliches Tier. Wie am Peristeri kam Actaca cordula Fabr. vor und als charakteristische Hochgebirgsform Epinephele lycaon Rott, ein Verwandter unseres Sandauges.

Auch hier flatterten ähnliche Bläulinge, wie ich sie beim Aufstieg angetroffen hatte, und zwischen ihnen dickköpfige Hesperiden, so Hesperia cinare Rbr. und Carcharodes altheae $\mathrm{Hb}$. Als wir den Wald verließen, strahlte tief unter uns zum ersten Male der blaue Spiegel des Ochridasees auf. Steinige, schwach bebuschte Buckel bildeten den Vordergrund, hinter welchem still und klar der See sich breitete, den im Westen die Ketten der albanischen Berge abschlossen. Wie eine italienische Landschaft lag das Uferland vor uns; große weiße Wolken schwebten am westlichen Himmel.

Das Städtchen Pescani am Ostufer des Ochridasees war unser Ziel; dort sollte uns ein Motorboot aus Ochrida erwarten. So mußten wir aus der Gipfelregion des Tomoros ein gut Stück nordwärts wandern, um nicht in das Gebiet der feindlichen Front zu geraten. In diesem einsamen, menschenleeren Gebiet wäre ein Abirren gefährlich gewesen. Doch bald erkannte ich bekannte Gegenden und konnte die Führung übernehmen.

Ein steiler Weg führte uns über einen gut ang ebauten Hüge 
mit meist abgeernteten Feldern, schönen Gruppen von Ulmen und Obstbäumen zu dem malerischen Ort Pescani hinunter. Am Strand hatten wir eine Zeitlang auf unsere Lasttiere $\mathrm{zu}$ warten, welche unsere Ausrüstung zu tratgen hatten.

Wir hatten uns dabei nicht zu langweilen; denn die Landschaft, die vor uns lag, konnte sich mit den schönsten der Welt messen. Schon beim Abstieg hatte das Südende des Sees, die Gegend von Pogradec und Sv. Naum als prachtvolles Bild vor uns gelegen. Welch wundervollen Umriß boten einander überschneidend die stolzen Pyramiden des Tomoros und Malisat, von denen wir etwas Abstand gewonnen hatten. Vorgebirge in Hügeln endend, ragten eines vor dem anderen in den dunkelblauen See hinaus, jedes in sanften violetten Tönen das andere überbietend. Ein leichter Wind warf blinkende Streifen über den See, in dessen Flut die weilen Wolkenballen gespiegelt auftauchten. Und je mehr wir uns dem Strand näherten, um so reizvollere Rahmen bildeten die Baumgruppen, die Häuser von Pescani, die Schiffe im Hafen um die sonnendurchglühte Landschaft.

In einstündiger Fahrt brachte das Boot uns nach Ochrida. Allmählich hob sich die weißblinkende Stadt aus dem blauen Wasser vor uns empor mit den Ruinen der alten Festung als Bekrönung des Stadtbergs über sich. Die schön geformten albanischen Berge längs des Drintals gaben dem farbigen Bild eine harmonische Abgrenzung.

Immer bunter wurde das Bild, je mehr Einzelheiten im Stadtbild sichtbar wurden; Kirchen, Kuppeln, Türme tauchten auf; die weißen Mauern der Häuser, die roten und grauen Dächer, die gelblichen Felsen stimmten eigenartig zusammen mit der Fülle von Pappeln, Obstbäumen, Erlen und Weiden, die hier selbst im Hochsommer die Seenähe in frischem Grün erhalten hatte.

Seltsam stach von dieser Fülle von Farben das indigoblaue Wasser des Sees ab, das gegen das Land hin heller und heller wurde und schließlich mit einem leuchtend grünen Streifen an das von weißen Steinen besäte Ufer grenzte. Von schönen Eindrücken erfüllt, warm von Sonne und Schönheit, stiegen wir im Hafen von Ochrida ans Land. 


\section{DIE WIRBELTIERE MAZEDONIENS}

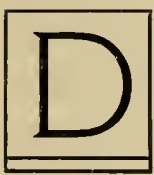

ie einzige größere Tiergruppe, bei welcher schon ein allgemeiner Überblick über unsere wesentlichen Forschungsresultate gegeben werden kann, sind die Wirbeltiere. Unter ihnen treten die Säugetiere und Fische an Zahl der Sammlungsexemplare und auch an Bedeutung der wissenschaftlichen neuen an ihnen geförderten Ergebnisse zurück. Dagegen haben die Sammlungen der Amphibien, Reptilien und Vögel mancherlei interessante Funde und Tatsachen ergeben, die in diesem Buch schon gebracht werden können. So lohnt es sich, sie hier in diesem Kapitel knapp zur zusammenfassenden Darstellung zu bringen.

Aus ihr wird hervorgehen, daß wie stets ein solcher erster Vorstoß in ein unbekanntes Land und eine im wesentlichen unbekannte Fauna nur vorläufige Ergebnisse und viele neue Fragestellungen bringt. Vor allem die Säugetierfauna bedarf noch sehr genauer Durchforschung, die viel zum Verständnis der Verbreitung der Säugetierwelt Europas beitragen dürfte. Zu einer rationellen Durchforschung der Säugetiere Mazedoniens bedürfte es des Zusammenwirkens von Sportsleuten mit Wissenschaftlern, um vor allem die Zugehörigkeit der Rehe, Hirsche, Gemsen, der Bären, Wölfe, Schakale, der Wildschweine und all der Kleinsäugetiere zu erweisen.

Nicht allzu reich waren die Erfahrungen, welche ich mit meinen Helfern über die mazedonischen Säugetiere sammeln konnte. Bei der vielseitigen Tätigkeit, die sich auf wenig Mitarbeiter verteilte, kamen die Säugetiere, deren Jagd und Beobachtung so zeitraubend ist, schlecht weg. Immerhin gewann ich einen gewissen Einblick in die Säugetierwelt Mazedoniens. Auch Prof. Müller beschäftigte sich so viel wie möglich mit diesen Tieren; seine Aufzeichnungen habe ich hier mit benützt.

Fledermäuse flogen nicht selten in der Luft; ihre Schlafstellen in den vielen Ruinen, in alten Bäumen, so in den hohlen Platanen des Nikolatales und an anderen Orten, habe ich öfter 
abgesucht. Leider fing ich im Bergwerk bei Rabrovo im Mai 1918 nur mehr einige Exemplare von zwei Arten. Im Winter war nach Aussage der Soldaten der verlassene Schacht von hunderten dieser Tiere erfüllt gewesen, die aber, als ich in der Gegend ankam, ihn schon verlassen hatten.

Unter den Nagetieren war die Hausmaus häufig; ich habe auch die Waldmaus gesehen. Die Ratten waren teils Hausratten, teils wohl sicher Mus rattus alexandrinus. Prof. Müller hält die von ihm gesammelten Tiere für von beiden abweichend. Eine weißgelbe Ratte mit dunkeln Augen kam in Veles vor.

Eichhörnchen sind auch in den ausgedehnteren Wäldern offenbar selten. Ein schwarzbraun gefärbtes Exemplar im Sommerkleid wurde von Prof. Müller im Buchenwald oberhalb des Han Abdipasa im Babunagebirge bei $1300 \mathrm{~m}$ Höhe erlegt. Vom Ziesel (Citillus citillus L.) war im Kapitel 26 die Rede; auch in der Golesniza Planina, unserem dort beschriebenen Fundort, handelt es sich offenbar um die typische Form. Aber das Vorkommen in etwa $2000 \mathrm{~m}$ Höhe ist sicher bemerkenswert.

Hasen gab es reichlich in den Ebenen und Hügeln Mazedoniens. Unsere Offiziere und Soldaten haben ihrer viele erlegt; allein die Flieger in Wardartal bei Dedeli haben in einem Winter ihrer über 100 zur Strecke gebracht. In ganz Mazedonien kam ein großer, stattlicher Hase vor. Über seine Zugehörigkeit kann ich noch keine näheren Angaben machen. Der Lepus europaeus mediterraneus kann es nicht sein, da dieser offenbar, von Sardinien beschrieben, eine kleine Inselform ist. Die Balkanhasen müssen erst noch genauer untersucht werden.

Igel, Maulwurf und Spitzmäuse wurden von uns beobachtet und auch erbeutet. Sie scheinen sich von den unseren nicht wesentlich $\mathrm{zu}$ unterscheiden, wenigstens die Formen, die uns zu Gesicht kamen.

Von kleinen Raubtieren wurden Marder, Fuchs, Dachs, Wiesel, Hermelin, der Tigeriltis und die Fischotter festgestellt. Bälge bei Händlern in Kalkandelen beweisen ziemlich sicher das Vorkommen von Luchs und Wildkatze im Schardakh. Wölfe gibt es überall in Mazedonien im Gebirge; sie wurden von unseren Soldaten am Peristeri, bei Gopes und in anderen Gebirgen erlegt. Von dem von mir mitgebrachten Wolf aus der Golesniza Planina ist im 26. Kapitel berichtet. Auch der Bär wurde während meines Aufenthalts am Peristeri einmal von Truppen dort erlegt. Schakale 
scheinen besonders im Süden nicht selten zu sein; von ihnen sah man auch schlecht erhaltene Felle gelegentlich bei Händlern.

Gar nicht so sehr selten scheint das Wildschwein in den Bergen zu sein. Von vergeblichen Jagden und aufgefundenen Spuren ist ja in verschiedenen Kapiteln einiges erwähnt worden. $\mathrm{Reh}$ und Hirsch scheinen aber sehr selten und verscheucht zu sein. Sie leben wohl nur noch in den Wäldern der hohen Gebirge. Mehrfach wurden im Babunagebirge, in der Marianska Planina, und in anderen Bergen Rehe zur Strecke gebracht. Von Hirschen erfuhr ich seltener: doch erwarben wir in Koinsko einmal eine schöne Decke, und ein stattliches Achtergeweih, das in der Treskaschlucht im Freien gefunden wurde, hatte ich zu sehen Gelegenheit. Es ist hier abgebildet (Abb. 267).

Mit den Wäldern sind natürlich alle diese jagdbaren Tiere immer mehr vertrieben und in die unwegsamsten Gebirgsgegenden verscheucht worden. Das gilt selbst für die Gemsen, welche weit

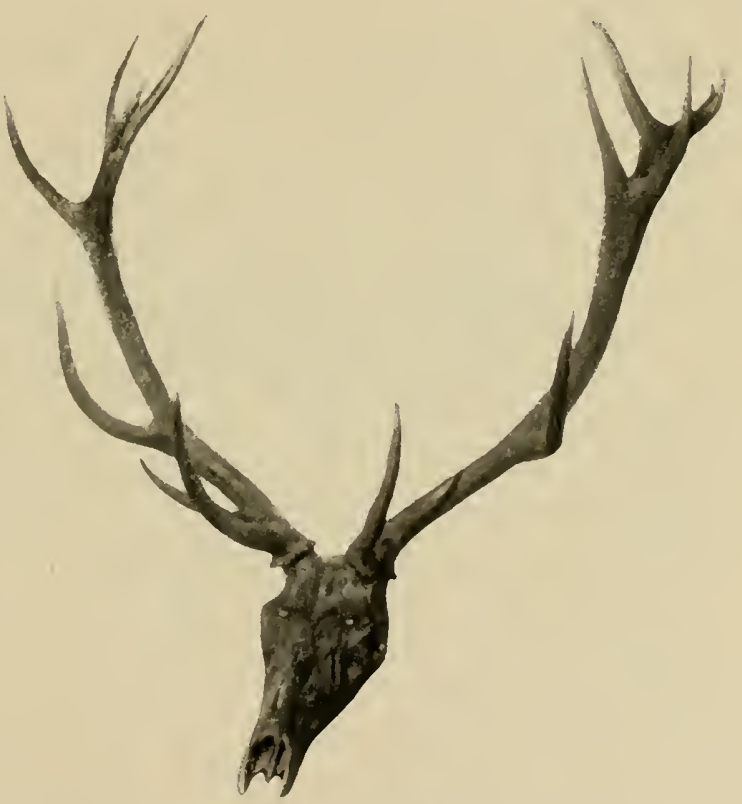

Abb. 267. Geweih und Schädeldecke eines mazedonischen Hirsches.

außerhalb der bewohnten Gegenden leben, aber im albanischen Grenzgebiet von den Gebirgsvölkern eifrig gejagt werden. Ihr Vorkommen im Schardakh und den umliegenden Bergen konnte ich durch Erwerbung eines Gehörns und durch Besichtigung einer schönen Winterdecke beim Bürgermeister des Dorfs Veseca an der Kobeliza feststellen. Auch im Korab kommen Gemsen wohl sicher vor.

Damit sind nicht allzu eingehende Kenntnisse über die Säugetiere Mazedoniens gewonnen. An ihnen ist noch viel $z u$ tun. Im großen und ganzen zeigt sich die Säugetierfauna aus typisch europäischen Formen zusammengesetzt, doch werden unter den 
Kleinsäugetieren sich wohl auch zahlreiche südliche und östliche Formen nachweisen lassen.

Viel tiefer konnten wir in die Vogelwelt Mazedoniens eindringen. Außer vielen Beobachtungen brachten wir eine Sammlung von 3200 gut präparierten, genau bezeichneten Vogelbälgen heim. Diese liegt, von Dr. Erwin Stresemann bearbeitet, auch schon publiziert vor. Über das Vorkommen der Tiere ist in den Kapiteln dieses Buches manches mitgeteilt worden, wobei die Benennungen der Vögel sich stets auf die Arbeit Dr. Stresemanns stützten.

Hier sei noch einiges Zusammenfassende über die Ornis Mazedoniens mitgeteilt. Nach der Durcharbeitung unserer Ausbeute stellt sich Mazedonien, wie für andere Tiergruppen, auch für die Vögel als Mischgebiet dar. Dabei erscheinen mitteleuropäische und mediterrane Formen fast im gleichen Verhältnis beteiligt. Allerdings im südlichen Wardartal stechen die südlichen Formen besonders hervor.

Dabei ist ein Vordringen südlicher Formen nordwärts und umgekehrt nördlicher Formen südwärts zu erkennen, wobei die Verbreitungsgrenzen Schwankungen zu unterliegen scheinen. Besonders bemerkenswert ist, daß nördliche Formen, wenn sie weiter südlich vordringen, dort höher in die Gebirge aufsteigen und dort ihnen zusagende Klimazonen aufsuchen.

$\mathrm{Zu}$ diesen Elementen gesellen sich östliche Formen, die teils auf den Nordosten, also auf die Steppen Südrußlands und den Nordrand des schwarzen Meers, teils auf den Südosten und damit auf das Kaukasusgebiet und Kleinasien hinweisen. Mehr noch als unter den Vögeln zeigen sich solche Beziehungen in der Pflanzenwelt und unter den Insekten.

Schon in den bisher angeführten Tatsachen zeigen sich Abhängigkeiten von klimatischen Einflüssen. Solche haben wir in vielen der früheren Kapitel dieses Buches in ihrem Einfluß auf die Tier- und Pflanzenwelt, selbst auf die Oberflächengestaltung des Landes kennen gelernt. So fanden wir auch in den verschiedenen Formationen mit einer bestimmten Pflanzenwelt immer charakteristische Vögel beieinander. Eine knappe Zusammenstellung in der Reihenfolge vom Tal ins Hochgebirge wird interessante Gesichtspunkte vor Augen führen.

Im Tal, z. B. bei Hudova, in den Maulbeerpflanzungen fanden wir Zaun- und Kappenammer, Rotkopfwürger, Maskenwürger 
(Lanus mubicus) (Abb. 201, S. 403) Blaurake, Bienenfresser. An den Felswänden der Schluchten, die vom Tal abzweigten, gab es die Aasgeier, Turm- und Rötelfalken, Felsentauben, Blaumerle und Steindrossel, Felsenkleiber, Steinsperling, Felsenschwalbe und Mehlschwalbe.

Stiegen wir auf die Hügel vor den Gebirgen, wo Palinurus und Quercus coccifera wuchsen, so saßen auf diesen der Rotrückenwürger, Feld- und Haussperling, schlüpften durch die Sträucher der Hänfling, der Heckensänger (Agrobates). Hier gab es alle Grasmücken.

Darüber in den Geröllfalten an den Berglehnen hausten der graue Steinschmätzer und der Mittelmeersteinschmätzer. Die Ge-

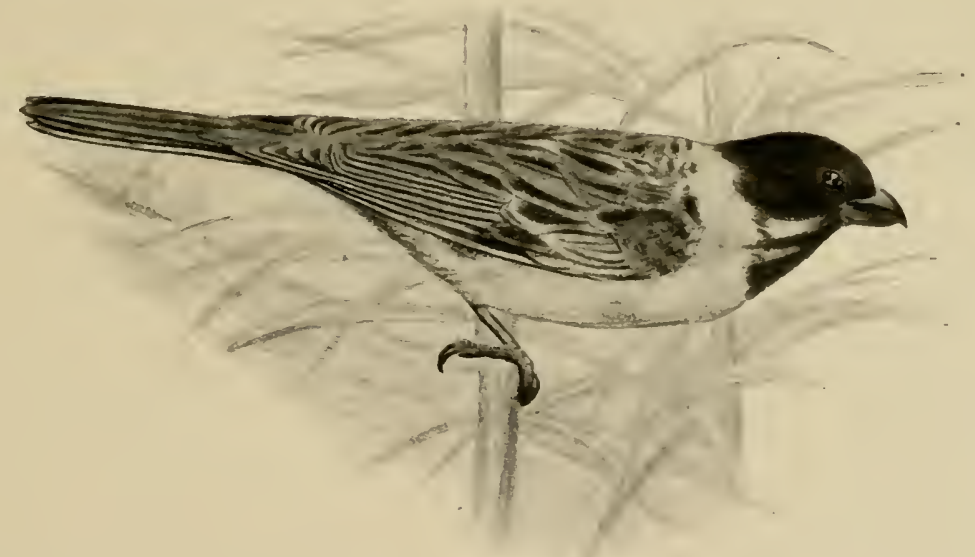

Abb. 267 a. Die Balkan-Gimpelammer Emberiza pyrrhuloides reiseri Hart.

hölze und Kulturlichtungen dieser submontanen Region bewohnten der Buntspecht (Dryobates major balcanicus), der Grünspecht, die Blau- und Kohlmeise, Turteltaube, Eichelhäher, Elster, Nachtigall, Seidenrohrsänger, Kuckuck usw.

Die montane Zone, wie sie etwa von der Plaguša Planina in dem Buschwald aus weichblätterigen Eichen dargestellt war, beherbergte den Pirol, die Trauermeise, den Wendehals.

Der Buchentvald, wie wir ihn in der Mala Rupa, am Liseč in der Golesniza Planina und in anderen Gebirgen fanden, war das Wohngebiet von Amsel, Misteldrossel, Singdrossel, Rotkehlchen, Nonnenmeise, Kleiber, Waldbaumläufer, Liljefordspecht, Mittelspecht und Waldlaubsänger. 
Die Latschenregion, wie wir sie in der Golesniza entdeckten, war der Zufluchtsort von Heckenbraunelle, der Tannenmeise und des Hausrotschwanzes. Darüber in der alpinen Grasflur der Mattenregion des gleichen Gebirges gab es den Wasserpieper, die Ohrenlerche, die Feldlerche und das Braunkehlchen. Darüber schließlich grenzte die Gipfelregion der Solunska mit ihren Felsengraten, mit ihren Schneefeldern und Spalten, in der nun die Hochalpenvögel anzutreffen waren: Die Alpenbraunelle, Alpendohle, Steindrossel und Mauerläufer.

Dazu kommen als besonders interessante Zonen, in denen die Wasser-, Strand- und Rohrvögel hausten, die Schilfwälder der Seen, des Doiran-, Prespa- und Ochridasees, die wir aber am kleinen Katlanovosee am besten studieren konnten. Da war besonders interessant Emberiza pyrrhuloides reiseri Hart. (Abb. 267 a S. 547) und die anderen Rohrammern, die Rohrweihen, die Rohrdommeln, die ganze große Gruppe der Reiher, der Enten und Gänse, der Teichhühner, Strandläufer und was da alles zusammen kam, vom Cormoran bis zum Pelikan.

Nicht weniger bemerkenswert war das Steppengebiet mit dem Wiedehopf, den Trappen, den Wachteln, den vielen Falken.

Hervorheben möchte ich schließlich noch einmal in diesem Zusammmenhang, daß das südliche Wardartal bis in die Gegend von $\mathrm{Hudova}$ sowie die mit ihm zusammenhängende Region des Doiransees sich als reich an südlichen Vogel-, Reptilienund Insektenformen herausgestellt hat. Es ist offenbar eine der Pforten, durch welche südliche Formen nordwärts vordringen. Ähnliche Verhältnisse dürften bei genauerer Erforschung auch südlich des Prespasees und des Peristeri zu finden sein.

Gerade die Tatsachen über die Verbreitung der Vögel geben einen interessanten Einblick in die Art und Weise, wie Tiere überhaupt in Mazedonien sich verbreitet haben können. Ich zitiere hier direkt die Ergebnisse, welche Dr. Stresemann aus der Bearbeitung unserer mazedonischen Ausbeute gezogen hat. „Als Ausgangspunkt der gegen Mitteleuropa vorgedrungenen ostmediterranen Vögel wollen wir die kleinasiatische Küste bei Smyrna betrachten; sie war noch gegen Ausgang der Pliozänzeit durch eine Landbrücke, die „Ägäis“, mit Griechenland breit verbunden. Uns interessiert hier die Wanderstraße, welche von Griechenland weiter zur Mündung des Wardar und von da den Wardar hinauf bis Üsküb führt, um dann ins Tal der „Bulgarischen“ Morawa 
einzuschwenken und ihr ins nordserbische Flachland zu folgen. Der Strom der Wanderer wird auf diesem Wege allmählich dünner. Es drangen vor:

\section{Nur bis Smyrna:}

Emberiza cineracea Halcyon smyrnensis smyrnensis

Garmulus glandarius Krynickı

Bis zu den Kykladen (Kythnos usw.):

Ceryle mis mis

\section{Bis Griechenland:}

Emberiza caesia

Sylvua melanocephala

Sylvia mupeli

Coccy'stes glandarius

\section{Bis zur Wardarmündung:}

Cisticola cisticola cisticola

Hirindo daurica rufula

Hippolais olivetorum

\section{Bis zum Fuß der Plaguša-Planina:}

Lanius mubicus

Agrobates galactodes syriacus

\section{Bis Veles:}

Sitta neumayeri

Sylivia cantillans albistriata

Sylvia hortensis carassirostris

Monticola solitarius solitarius

\section{Bis Üsküb:}

Hippolais pallida claeica

Oenanthe hispanica melanoleuca Phylloscopus bonelli orientalis

\section{Bis Vranje:}

Cettia cetti

\section{Bis Nisch:}

Emberiza melanocephala

Lanius senator

\section{Bis Palanka:}

Budytes flavus feldeggi
Calandrella brachydactyla moreatica

Falco naumanmi naumanni.

Ebenso allmählich sehen wir den faunistischen Übergang in umgekehrter Richtung sich vollziehen, wenn wir von den mitteleuropäischen Formen ausgehen und deren südliche Verbreitungs- 
grenzen feststellen. Hierbei fällt auf, daß Arten, welche bei uns auch oder ausschließlich in den Niederungen brüten, mit zunehmender Annäherung an die mediterrane Klimaprovinz das Flachland mehr und mehr räumen, um sich dafür im kühleren Gebirge anzusiedeln. Im mittleren Mazedonien sind diese Verhältnisse schon scharf betont. Dort brüten nicht im Tiefland und der submontanen Region, sondern

a) ausschließlich in den Wäldern der montanen, ja oft sogar in denen der subalpinen Region:

Serinus canaria scrinus, Fringilla coelebs, Emberiza citrinella, Emberiza cia, Anthus trivialis, Certhia familiaris, Certhia brachydactyla, Ficedula albicollis, Phylloscopus collybita, Turdus philomelos, Turdus viscivorus, Turdus merula, Erithacus rubecula;

b) nur in der alpinen Region:

Alauda arvensis, Saxicola rubetra, Prunella modularis, Phoenicurus ochruos gibraltariensis.

Die Nordgrenze Serbiens bildet annähernd die südliche Verbreitungsgrenze für:

Budytes flavus flavus Hippolais icterina

Phylloscopus trochilus trochilus Sylvia hippolais hippolais.

Bis zur Südgrenze geschlossener Fichtenwaldungen (KopaonikPlanina, vielleicht sogar Schardakh) reicht das Brutgebiet vieler echter Nadel waldbegleiter:

Spinus spinus

Parus cristatus

Parus atricapillus assimilis

Tetrao urogallus
Nucifraga caryocatactes

Picoides tridactylus

Cryptoglaux funerea

Pyrrhula pyrrhula.

Es sind ferner nach unserer Kenntnis verbreitet:

\section{Bis zum Fuße des Schardakh:}

Picus canus canus

Dryobates major pinetorum.

\section{Bis zur Golesniza bzw. Babuna Planina:}

Emberiza citrinella

Certhia familiaris

Prunella modularis

Ficedula albicollis

Jynx torquilla
Turdus philomelos

Phylloscopus collybita

Phyllosiopus sibilatrix

Phoenicurus phoenicurus phoenicurus

Columba oenas oenas. 
Bis zur Linie Belasiča Planina - Mala Rupa - Baba Planina: Parus communis

Saxicola metra

Alauda arvensis.

Bis zur Wardarmündung:

Passer montanus.

\section{Bis Nordgriechenland:}

Sturmus vulgaris.

Neben einer südöstlichen Einwanderung (von Kleinasien her) und einer nördlichen (von Mitteleuropa her) hat auf der Balkanhalbinsel nach aller Wahrscheinlichkeit auch eine solche von Nordosten, d. h. von den Tiefländern am Nordrand des Pontus her bestanden. Die Mehrzahl der Arten, die wir hierzu rechnen, hat die doppelte Schranke, welche ihnen Balkan-Gebirge und Thrakische Masse auf ihrem nach dem Adriatischen und Ägäischen Meer gerichteten Vordringen entgegenstellten, nicht zu überwinden vermocht. $\mathrm{Zu}$ den wenigen, die bis nach Mazedonien gelangten, gehören vielleicht Melanocorypha calandra, Lanius minor, Falco vespertinus, Asio flammeus, Otis tetrax."

Auch über den Vogelzug konnte manche Beobachtung gemacht werden. Es ist wohl keine Frage, daß eine wichtige Zugstraße durch Mazedonien führt. Manche Vögel, die hier vorkommen, müssen aus den verschiedenen Gebieten des Nordens stammen. Bei manchen ist wohl mit Sicherheit anzunehmen, daß sie nordrussischer Herkunft sind. So erscheinen mit großer Regelmäßigkeit als Wintergäste in Mazedonien der Bergfink, die Singdrossel sowie Falco columbarius aesalon und Anser albifrons.

Bemerkenswert ist die Tatsache, daß im Frühjahr die Vögel kaum früher ankommen als in Mitteleuropa. Die Mehrzahl der Zugvögel kommt bei Monastir, Veles und Üsküb kaum I 4 Tage früher als bei Wien oder München an, oft ist der Unterschied noch geringer.

Beim Herbstzug zeigt sich dagegen ein gewisser Unterschied, indem in Mazedonien die Vögel länger zögern. Manche Art, wie z. B. Sylvia hippolais, Sylvia atricapilla, Sylvia curruca, Saxicola rubetra findet man noch im Lande, nachdem sie aus Mitteleuropa schon wochenlang vollkommen verschwunden sind. Regelmäßig überwintern, von den spezifisch südosteuropäischen Arten und Phylloscopus collybita abgesehen, in Mazedonien ungefähr dieselben Arten wie am Niederrhein. Das ist ein Unterschied gegenüber 
Griechenland mit seinem maritim beeinflußten Klima, wo z. B. die Mönchsgrasmücke und Phylloscopus trochilus den Winter in großen Scharen zubringen. Manche Arten scheinen auch auf Frühjahrs- und Herbstzug länger Station in Mazedonien zu machen. Ich erwähnte in einem früheren Kapitel die ungeheuere Menge von Wildgänsen und Enten, die einige Wochen vor Weihnachten im Wardartal und an den Seen verweilten, ehe sie definitiv verschwanden.

Von den Beobachtungen, welche Professor Müller über die Reptilien und Amphibien in Mazedonien gemacht hat, habe ich in den früheren Kapiteln schon manches angeführt. Ganz interessant waren seine Feststellungen, daß manche Arten, die früher für Varietäten gehalten wurden, hier so konstant gemeinsam miteinander vorkommen, ohne daß man je eine Kreuzung antrifft, daß seine Befunde wohl sicher als Beweise dafür dienen können, daß es sich um gute Arten handelt, Das gilt z. B. für die große Smaragdeidechse (Lacerta major Blgr.), welche sehr häufig mit Lacerta viridis Laur, gemeinsam lebt. Auch für die gestreifte mazedonische Eidechse gilt dies, die mit der eigentlichen Mauereidechse in großer Anzahl auf demselben Gelände vorkommt, sobald man über $500 \mathrm{~m}$ in die Höhe steigt. Prof. Müller hat das besonders am Babunapaß schön beobachtet, wo beide Arten auf den Steinen des Izvorsticabaches durcheinander wimmelten, ohne daß man auch nur eine einzige Zwischenform finden konnte. Es handelt sich in dieser Eidechse um eine Lokalform einer hauptsächlich auf den Cykladen lebenden Eidechsenart. Jene Art hat den Namen Lacerta milensis de Bedr.; der mazedonischen Form wird Prof. Müller einen neuen Namen geben.

Sehr interessant waren folgende Eidechsenfunde von uns: Lacerta agilis auf dem Peristeri, was den südlichsten bisher bekannten Fundort darstellt. Ebenso die Entdeckung von Lacerta vivipara und der Schlange Vipera macrops im Schardakh. Dort haben wir ja auch Rana temporaria gefunden.

Im Babunagebiet fand sich Ablepharus pannonicus. Sonst sind die interessanten Funde meist in früheren Kapiteln besprochen worden.

Im allgemeinen besteht die Reptilien- und Amphibienfauna aus Formen, die auch in Mitteleuropa vorkommen. Südliche Elemente unter den charakterisitschen Bewohnern Mazedoniens sind Rana graeca, Molge vulgaris graeca, Clemmys caspia rivulata, 
Testudo graeca und ibera, Gymnodactylus kotschyi, Ophisaurus apus, Lacerta major, Lacerta milensis, Typhlops vermicularis, Eryx jaculus, Zamenis dahli, Coluber leopardinus, Coluber quatuorlineatus, Tarbophis fallax, Coclopeltis monspessulana, Vipera ammodytes (Abb. 268).

Soweit wir feststellen konnten, gehen von diesen Formen im Wardartal nur folgende nordwärts über Demir Kapu hinaus: Molge vulgaris graeca, Testudo graeca und Testudo ibera, Lacerta major und milensis, Coluber quatuorlineatus und Vipera ammodytes.

Von östlichen Formen sind hervorzuheben: Lacerta taurica, Ablepharus pannonicus und Zamenis caspius. Auch der große Lachfrosch kann als östliche Form angesprochen werden.

Eine vollständige Liste der von uns beobachteten Amphibien und Reptilien ist im Anhang zu diesem Kapitel verzeichnet.

Auch den Süßwasserfischen konnten wir aus mancherlei Gründen kein allzu vertieftes Studium widmen. Immerhin wurden eine ganze Anzahl Fische erbeutet, die

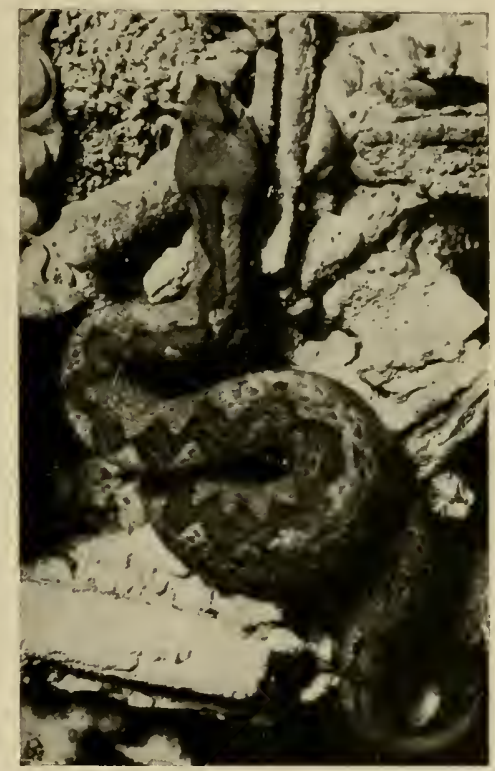

Dr. Opitz phot. Abb. 268. Sandviper (Vipera ammodytes L.) n. d. Leben.

sich auf 5 Familien, 14 Gattungen verteilten und 20 Arten angehörten. Sie wurden bei Schilderung des Fanges in den einzelnen Kapiteln schon erwähnt und zum Teil in Lebensgewohnheiten geschildert. Eine Liste ist in den Anmerkungen zu diesem Kapitel angeführt. Aus ihr geht hervor, daß es sich wesentlich um Formen mitteleuropäischer und Mittelmeerflußgebiete handelt. 


\section{ACHTUNDDREIZIGSTES KAPITEL}

\section{Ochrida}

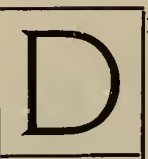

ie Stadt Ochrida und der blaue See, an dem sie liegt, galt in der Armee als der Glanzpunkt von Mazedonien. Jeder, der ihn dienstlich hatte sehen dürfen, wurde beneidet, und als im Sommer des Jahres 1918 den Offizieren Erholungsausflüge im Bereich des Kriegsschauplatzes gewährt wurden, war Ochrida das beliebteste Ziel. Das verdiente es auch, denn mit der reizvollen Lage der Stadt verband sich die Schönheit des Sees und ein angenehmes Klima. Dazu kam der Reichtum an historischen Erinnerungen, welcher die Stadt zu einem Nationalheiligtum der Bulgaren machte.

Der Weg nach Ochrida, welcher gewöhnlich eingeschlagen wurde, führte vom Endpunkt der Feldbahn in Lera, am Nordende des Prespasees vorbei über die Stadt Resna. Diese flach in der Ebene nördlich des Prespasees gelegene Stadt war von reichtragenden, gut bewässerten Feldern und Gärten umgeben. Sie wurde als Geburtsstadt Enver Paschas bezeichnet. Doch war auch sie von vielen Bulgaren bewohnt und oft ein Zentrum nationaler Bewegungen gewesen. Von ihr aus führte eine ganz ordentliche Straße über das Petrinagebirge, welches in einer Paßhöhe von etwa $900 \mathrm{~m}$ überschritten wurde. Dort war ein stattlicher Buchenwald, der in der Höhe von Tannen abgelöst wurde. Auch dies Gebirge machte einen interessanten Eindruck und es wäre eine lockende Aufgabe gewesen, seinen Übergang ins Gebiet des Tomoros zu verfolgen. Doch hiel3 es diesmal eilen; denn von Ochrida hatten in Resna aufregende Nachrichten uns ereilt.

Die Feinde hatten wieder einmal am schwächsten, westlichen Flügel unserer Stellungen, an der albanischen Grenze, eine Offensive eingeleitet. Diese hatte bei den schwachen österreichischen Truppen, welche diesen Flügel hielten, kaum Widerstand gefunden. Zwei französische Divisionen sollten im Vorrücken sein und hätten schon Pogradeč. und damit das Südende des Sees in Händen. So sollte auch dieser See mir nur teilweise zugänglich sein. Da galt es zu eilen, um überhaupt noch Forschungen auf dem See durchführen zu können; denn die Feinde sollten heftig weiter vorstoßen. 


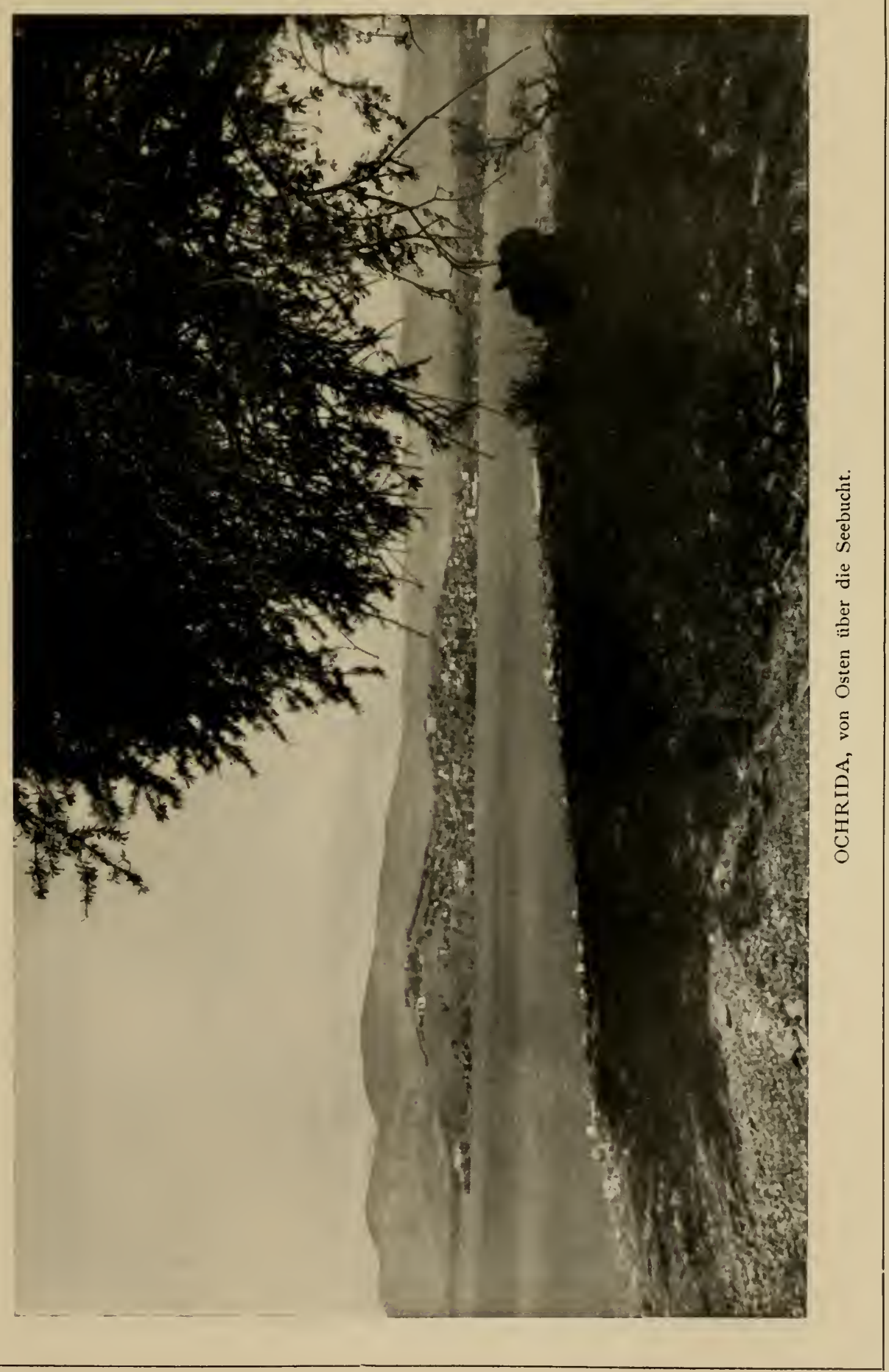



Einen sehr deprimierenden Eindruck hatte mir der österreichische Kommandant gemacht, den ich im Offiziersheim in Resna auf der Flucht angetroffen hatte. Er hatte offenbar nach seiner Niederlage vollkommen Nerven und Besinnung verloren und war abgesetzt und zurückbefohlen worden.

Sehr gespannt auf die Zustände, die ich in Ochrida antreffen sollte, setzte ich meine Fahrt mit möglichster Beschleunigung fort. Die Straße hatte an den Abhängen des Gebirges einen großen Bogen nach Norden gemacht. Bei der Fahrt das Gebirge abwärts verfolgten wir das schöne Tal der Opinča eine längere Strecke. Dieser starke, klare Bach fließt rauschend zwischen Steinblöcken dem Ochridasee zu; seine malerischen Ufer sind von stattlichen Pappeln und Weiden bestanden. Zahlreiche Wasseramseln flogen über sein Wasser von Stein zu Stein, von unserem Wagen aufgeschreckt. Wir hatten auf unserer Fahrt ein gut Stück der römischen Via Egnatia befahren.

Trotz allen Staubes und der herbstlichen Trockenheit machte die Umgebung von Ochrida einen freundlichen Eindruck, als die Stadt sich vor uns erhob; ein großer Teil von ihr bedeckte die Hänge eines steil ansteigenden Hügels, die von den Mauermassen einer großen türkischen Festung gekrönt sind. Wie schön leuchtete uns die blaue Fläche des Sees zwischen den weißen Mauern entgegen, als er endlich vor uns auftauchte. Das war nun wirklich ein blauer See. Er war blauer als der Gardasee, so blau wie die Adria oder der indische Ozean. Er versprach mir Wunder von Schönheit, als ich etwas erregt in die belebten, von Truppen wimmelnden Straßen der Stadt einfuhr.

Es war für Mazedonien eine große Stadt, auch zur Zeit meines Besuchs muß sie über 10 ooo Einwohner beherbergt haben. Das Auto fuhr mich durch die holprigen Straßen bis an den Hafen herunter, wo sich ein prachtvoller Blick auf die weite Fläche des Sees und die blauen Berge eröffnete, die ihn umrahmen.

Ochrida spielt in der Geschichte Mazedoniens eine nicht geringe Rolle. Fast 900 Jahre lang war es der Sitz des bulgarischen Patriarchen. Im 10. Jahrhundert war es die Hauptstadt des damals einen großen Teil der Balkanhalbinsel umfassenden bulgarischen Reiches. Auch der letzte bulgarische Zar Samuel residierte hier; nach der Vernichtung des bulgarischen Reiches durch den byzantinischen Kaiser Basileios II Bulgaroktonos verlor Ochrida jede politische Bedeutung. Aber es behielt für 
den Balkan ein großes kirchliches Ansehen, denn sein Erzbischof blieb das unabhängige Oberhaupt der bulgarischen Kirche und nannte sich als solches Patriarch ,von ganz Bulgarien, Serbien, Albanien und dem westlichen Meere". Das hatte allerdings oft nur bildliche Geltung.

Die historische Bedeutung der Stadt spricht sich in dem Bestand von altbulgarischen kirchlichen Gebäuden aus, an denen Ochrida und seine Umgebung reich ist. Schon gleich bei meiner Ankunft bekam ich den Eindruck des Überwiegens bulgarischer Bevölkerung. Die Namen der Listen des Quartieramtes waren zu-

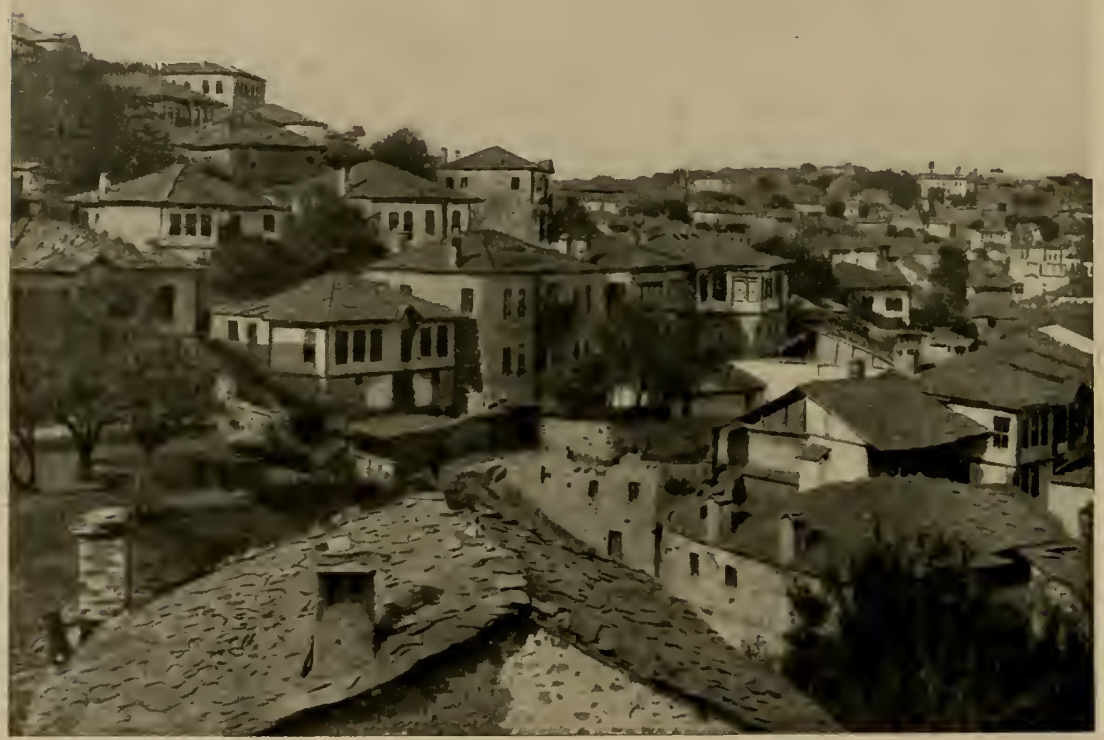

Abb. 269. Oberstadt von Ochrida.

meist bulgarisch. Auch mein Quartierwirt war Bulgare mit Namen Kazareff, doch stellten die Frauen des Hauses sich als Aromunen heraus. Die Männer aus ihren Familien waren wegen der Bedrückungen vor Jahren nach Rumänien ausgewandert. Auch die Nachbarn waren Aromunen und in ihrem Haus sah ich die schönste Frau, die ich auf dem Balkan angetroffen habe; es war eine stolze, schlanke Erscheinung mit schönen Gesichtszügen, großen dunklen Augen, braunem Haar und so eigenartig geschmackvoll gekleidet, 
daß sie auffallen mußte. Ich hatte den Eindruck, daß griechisches oder römisches Blut in ihren Adern flieluen müsse.

Außer Aromunen spielen Albaner in der Bevölkerung von Ochrida eine große Rolle; nächst den Bulgaren sind sie an Zahl vorherrschend. Jetzt nach der Besetzung durch die verbündeten Truppen wagten sie sich nicht mehr hervor, früher hatten sie die Christen in Ochrida sehr schlecht behandelt, gequält und geknechtet, wie noch aus Berichten aus den Jahren 1889 und 1904 hervorgeht.

Mein Quartier war besonders schön und günstig gelegen; es war ein großer Saal in einem stattlichen Haus am Hang des Vor-

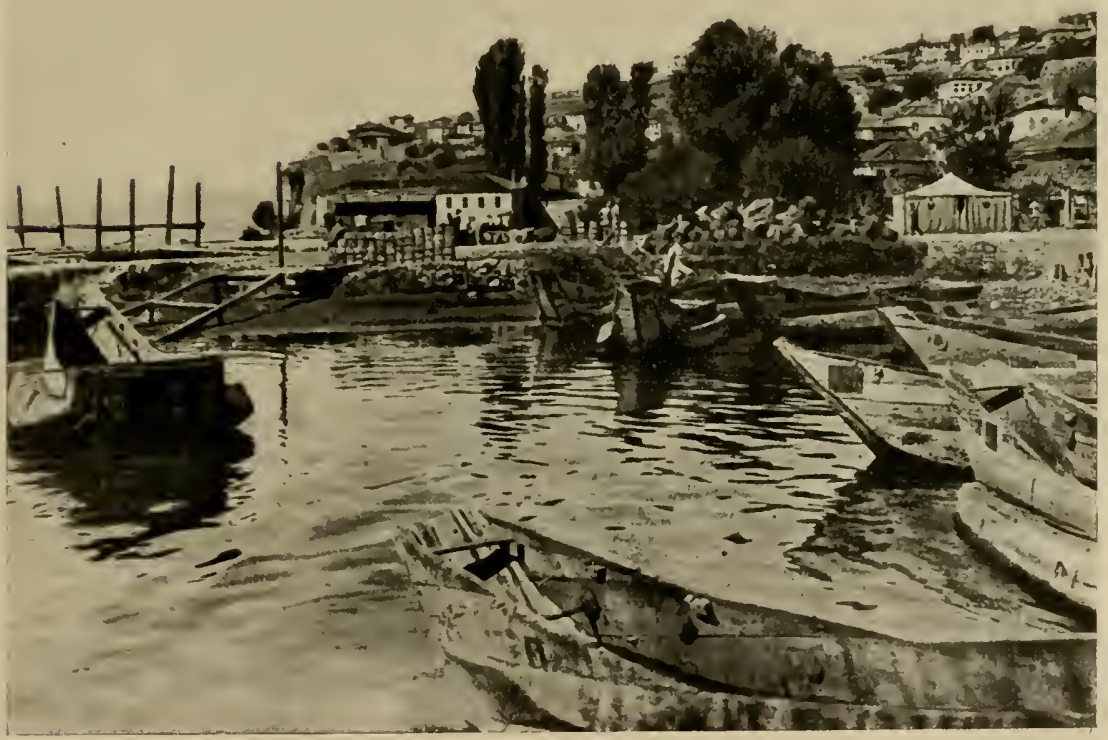

Abb. 270. Hafen von Ochrida mit "Auslegerbooten".

gebirges, an welchem die Stadt am weitesten in den See hineinreichte. Aus den großen Fenstern hatte ich einen prachtvollen Blick über einen Teil der Stadt, auf den Hafen und weithin über den See hinaus. Die Einrichtung war die übliche, doch auffallend gut erhalten und reinlich, die Wirte ganz besonders freundlich. Verpflegung fand ich in der österreichischen Offiziersmesse, Hilfe für wissenschaftliche Untersuchungen in dem kleinen Laboratorium des österreichischen Lazaretts. Von den Zuständen, die ich dort vorfand, muß ich einiges erzählen, da sie so außerordent- 
lich charakteristisch sind und deutlich zeigen, warum Österreich im Krieg nicht durchhalten konnte.

Die Offiziersmesse der Österreicher lag dicht am Hafen; sie war nett und sauber eingerichtet; man merkte die Frauenhand, die in ihr waltete. Bei der ersten Mahlzeit lernte ich in der Leiterin eine Grazerin, Tochter eines mir wissenschaftlich bekannten Zoologen kennen, die mit großer Energie nicht nur diese Verpflegungsanstalt in Ordnung hielt, sondern auch mit einer anderen österreichischen Frau tapfer in dem Lazarett mitarbeitete. Abends hatte man Gelegenheit mit den österreichischen Offizieren zu sprechen, welche alle mutloser und zielloser waren als diese Frauen; weniger bereit auszuharren als diese. Offenbar war die Leitung an dieser Front energielos und unfähig gewesen. Malaria und andere Seuchen hatten die Truppen sehr geschwächt; bei vielen Abteilungen waren $60-80 \%$ der Mannschaften krank. Die sanitären Maßregeln wurden bei weitem nicht so streng und konsequent durchgeführt als bei den deutschen Truppen.

Zudem bestanden die Truppen aus Kroaten, Dalmatinern und Bosniern, die alle nicht wußten, wofür sie hier kämpfen sollten Auch die Offiziere waren nur zum Teil gut und tüchtig; es waren schneidige, begabte, tüchtige Männer unter ihnen, aber durchweg spielte die Neigung zu gutem und behaglichem Leben eine allzugroße Rolle. Die Gespräche am Abendtisch zeigten, wie planlos und schwächlich diese Männer meist dachten. Merkwürdig stach von ihnen die Tatkraft und das energische Denken der beiden Frauen ab.

Daß die Front solange sich noch gehalten hatte, war den kleinen deutschen Abteilungen $z u$ verdanken, welche mit Aufopferung trotz großer zahlenmäßiger Unterlegenheit die Feinde aufgehalten hatten, bis deutsche und bulgarische Hilfe herankam. Ein blutjunger Leutnant, der den Ruinenhügel bei Pogradeč gegen eine große feindliche Abteilung mit seinen Maschinengewehren so lange gehalten hatte, bis der Rückzug über den See gedeckt war, saß an dem zweiten Abend bei mir und erzählte in bescheidenster Weise von seinen Erlebnissen. Er war blaß und erregt, bis er den letzten seiner Mannschaft glücklich in Ochrida gelandet wußte.

Unterdessen kamen immer mehr deutsche Truppen an. Auch für ihre Offiziere sorgten die österreichischen Damen; der Stab der neugebildeten Ochridadivision unter ihrem General Posseldt, den wir schon aus dem Hain Mamre kennen, wurde in den ersten 
Tagen in der österreichischen Offiziersmesse mit den österreichischen Offizieren verpflegt. Und alles klappte vorzüglich.

Bald brachte die Division die Feinde am Seeufer im Westen, bei Lin zum Stehen und damit war Ochrida gerettet. Für mich war also die Möglichkeit gegeben, meine Arbeiten fortzusetzen. Der Stab verließ bald die Offiziersmesse und siedelte sich in einem kleinen weißen Haus unterhalb meines Quartiers an. Es stand auf einer Terrasse, welche hoch über den See aufgebaut war, zu dem steile Treppen hinunter führten. Das Haus wurde Schlol genannt war, während das Land serbisch war, für den König von Serbien gebaut worden und jetzt im Besitz des Zaren von Bulgarien. Ich werde nie die höfische Komödie vergessen, welche sich um die Verwendung des Schlößchens als Stabsquartier telephonisch und telegraphisch abspielte, bis das Haus schließlich doch vom Stab geräumt werden mußte.

Während all dieser Ereignisse hatte ich Zeit genug gehabt, mich in der Stadt Ochrida umzusehen und ihre Umgebung zu durchstreifen. Die Stadt verdient eine knappe Beschreibung; denn sie ist in mancher Beziehung recht eigenartig.

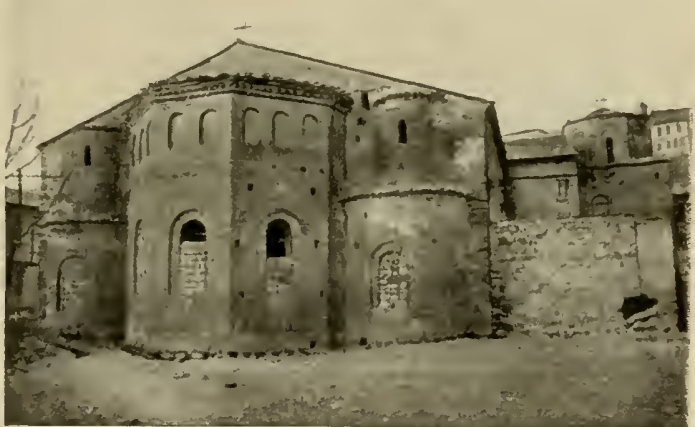

Aus Filow.

Abb. 270a. Ostseite der Sophienkirche in Ochrida.

Sie ist in der

Hauptsache auf zwei Hügeln aufgebaut, welche beide von Ruinen türkischer burgartiger Befestigungen gekrönt sind. Ein großer Teil der Stadt erstreckt sich im Tal bis an den Seestrand und hinter den Hügeln weithin in die Talebene. Steile Gassen mit steinigem holperigem Pflaster führen den Hügel hinan; bis zur Zitadellenruine hinauf ist es eine gehörige Kletterei. Die Häuser in den Straßen sind die üblichen mazedonischen Bauwerke mit den vorragenden oberen Stockwerken, die Gassen meist eng und schattig. Am See wohnen Fischer und Schiffer; am Hafen zieht sich eine lange Reihe großer weißer Gebäude hin, welche damals meist als Büros und Lazarette verwandt waren.

Als muhamedanische Stadt würde man Ochrida nicht ohne 
weiteres erkennen; Moscheen und Minarets spielen im Stadtbild keine wesentliche Rolle. Vom See aus z. B. sieht man kein einziges Minaret, sie liegen alle im Teil der Stadt hinter dem Kastellhügel. Aber auch die interessanten, alten christlichen Kirchen ragen nicht stark hervor; sie sind relativ klein und bescheiden. Am meisten treten hervor eine neuere viertürmige Kirche ohne besonderen Charakter und ein sehr geschmackloses grelles Schulgebäude, welches ein wertvolles altes Tabernakel verdrängt hat.

Wie bei den meisten mazedonischen Städten bringt auch in Ochrida mehr die Landschaft mit der Fülle der gleichartigen Häuser

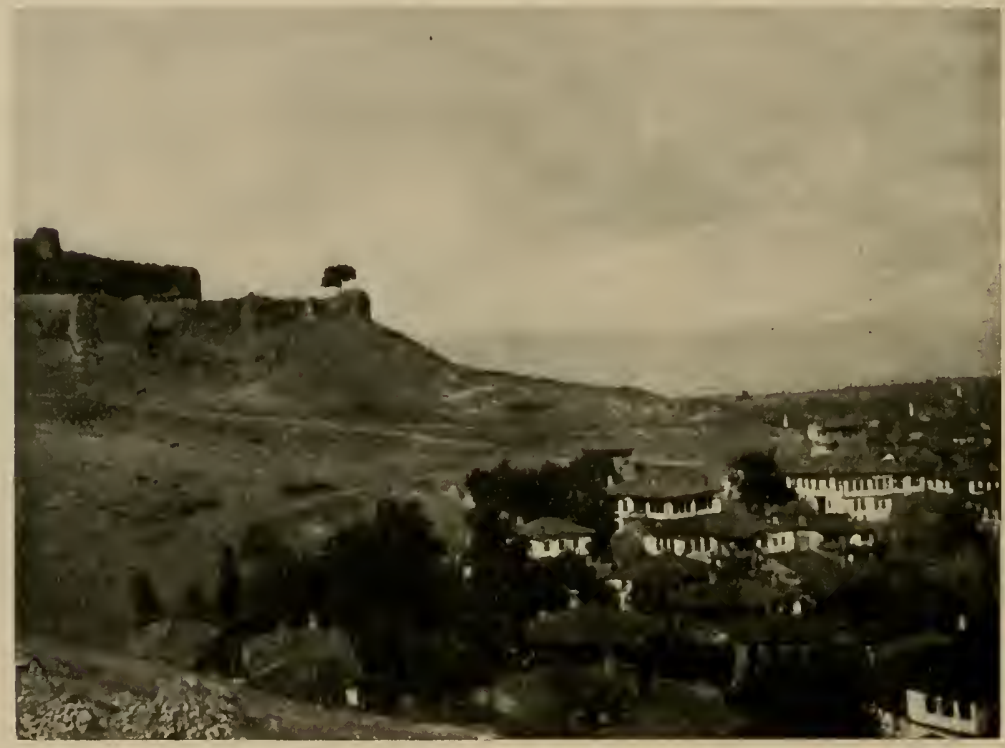

Abb. 27 I. Unterstadt von Ochrida mit Burgberg.

die malerische Wirkung hervor, als irgend welche Bauprinzipien oder architektonisch hervorragende Gebäude. Bei Ochrida wird die farbige Wirkung des Bildes dadurch erhöht, daß zu den roten Ziegeldächern viele nit gelbgrauen Steinplatten gedeckt hinzukommen. Dabei wirkt natürlich sehr stark der blaue See mit, der immer wieder durch die Gassen emporleuchtet. Sehr eigenartig sind im mazerlonischen Städtebild die vielen gleichmäßigen Fenster der Häuser, welche vielfach zu zweien oder dreien gruppiert die Häuserflächen charakteristisch modellieren.

Wie von unten die gewaltigen Mauermassen des Kastells 
über die kleinen Häuser der Stadt dominieren, so boten sie auch mit ihren Ruinen, Türmen, Mauerlöchern und Torbögen reizvolle Umrahmungen für die Blicke hinab auf den dunkelblauen See oder die reiche Landschaft. Wie weit die Reste dieser, wie der anderen dieser mazedonischen Burgen, auf die Trutzbauten der bulgarischen Zaren gegen die Byzantiner zurückgehen, und wie weit sie türkischen Ursprungs sind, dürfte schwer zu entscheiden sein. Das Haupttor der Burg soll aus dem Ende des 10. Jahrhunderts, also aus der Zeit des Zaren Samuel stammen.

Von bulgarischer Kunst in Mazedonien haben wir schon im 24. Kapitel bei der Besprechung des Klosters Neresi gehört. Ochrida als jahrhundertelanger Sitz des bulgarischen Patriarchats beherbergt manche Reste altbulgarischer kirchlicher Kunst. Besonders interessant sind die Kirchen Hagia Sofia und Sveti Climent. Erstere liegt nahe dem See, in dem Stadtteil unterhalb des Schlößchens an einem freien Platz. Es ist ein stattlicher Bau, der hauptsächlich aus einer dreischiffigen, gewölbten Pfeilerbasilika besteht, dem ein Querbau mit zwei Seitentürmen westlich vorgelagert ist. Das Innere war recht vernachlässigt. An der Nordwand des Hauptbaues waren weiße Säulen als Rest einer offenen Halle zu erkennen. Immerhin waren Schritte zu einer Restaurierung dieses

Nationalheiligtums schon während des

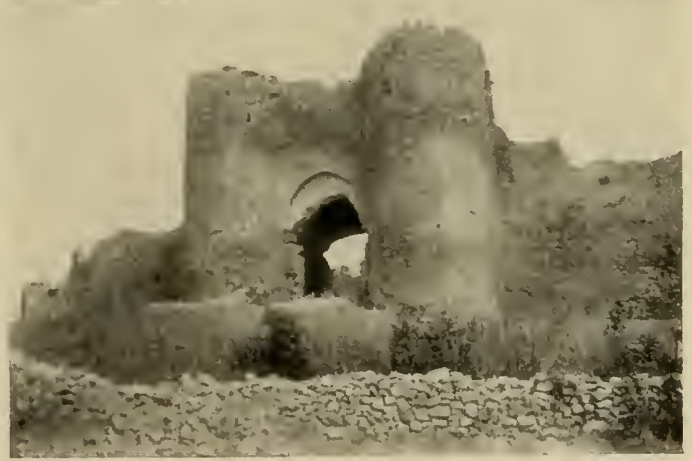

Aus Filow.

Abb, 272. Haupttor der Burg von Ochrida. Ende des Io. Jahrhunderts.

Krieges geschehen; so vor allem war ein Teil der Fresken, die in alter Zeit alle Wände der Kirche bedeckten, wieder freigelegt. Die Kirche hatte nämlich während der Türkenzeit als Moschee gedient. In dieser Zeit waren die Fresken übertüncht gewesen. Was man von ihnen vor allem in dem oberen Raum des Querbaues sehen konnte, machte einen sehr interessanten Eindruck.

Die Kirche scheint prachtvoll ausgestattet gewesen zu sein: darauf weisen in ihr aufgefundene Reste der Marmorumrahmung der Ikonostasis und andere mit Reliefs versehene Marmorplatten 
hin. Solche sind auch in den türkischen Mimbar eingebaut, dessen außerordentlich reich verzierte Bekrönung ein marmorner Baldachin mit zarten Säulchen und feiner auf den Orient hinweisenden Ornamentik bildet, offenbar die einstige Kanzel der Kirche (Abb. 273).

Einer späteren Periode gehören die anderen altbulgarischen Gotteshäuser in Ochrida an. Sie entsprechen als Kreuzkuppelkirchen dem Typus, den wir in Neresi kennen lernten, von

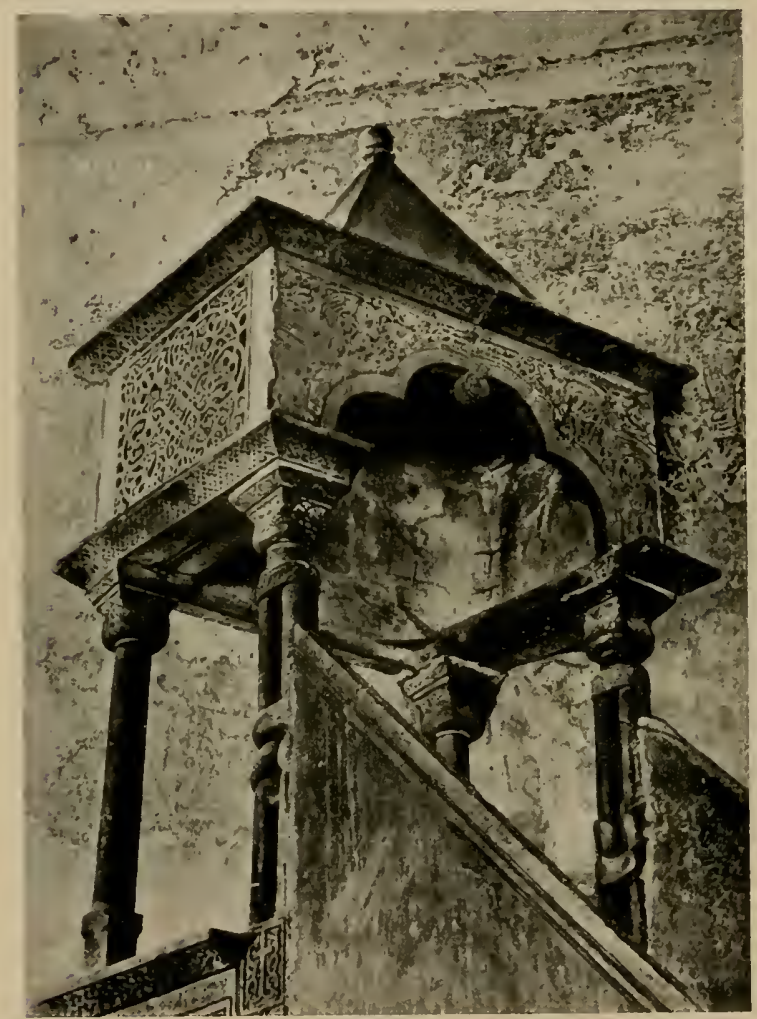

Aus Filow.

Abb. 273. Marmorner Oberteil der Kanzel in der Sophienkirche von Ochrida. 14. Jahrh. dem uns Varos bei Prilep ein Beispiel gab, und der auch sonst in Mazedonien wie in Altbulgarien häufig vertreten ist. So sah ich in Tirnowo eine ganze Anzahl von Repräsentanten dieses Typus. In dem zweiten Reich der Bulgaren baute man keine großen Basiliken mehr wie die Sofienkirchen in Sofia und Ochrida. Man baute viel mehr, dafür aber viel kleinere Kirchen, die fast alle Kreuzkuppelkirchen waren und viel reicher ornamental geschmückt waren als die Monumentalbauten des ehrgeizigeren alten Reichs.

Von den Kirchen aus dieser Zeit ist in Ochrida besonders die dem heiligen Climent geweihte zu erwähnen, Sie liegt oben am Berg und sie ist eine Kreuzkuppelkirche, deren Kuppel auf schweren Pfeilern ruht (Abb. 274). Gerade in der Gegend von Ochrida fanden die beiden Apostel des Christentums Climent und $\mathrm{Naum}$ eine große Verehrung. Sie hatten im Auftrag des Zaren Boris unter den 
Bulgaren Mazedoniens das Christentum verbreitet, nachdem sie im Jahre 885 nach dem Tode Methodis aus Mähren, wo sie als Schüler Cyrills und Methodis sich entwickelt hatten, an dessen Hof gekommen waren. Leider konnte ich infolge des Vordringens der Feinde das Kloster Sv. N a u m bei Pogradeč nicht besuchen, dessen Kirche besonders durch seine Malereien berühmt war, und welche das Grab dieses Heiligen beherbergt. Doch auch in Sv. Climent fanden sich sehr schöne Malereien vor allem am Ikonostas. Ein segnender Christus aus dem 13.-I4. Jahrhundert fiel besonders auf (Abb. 275). Im Kloster Sveti Climent hat seinerzeit der Jenenser

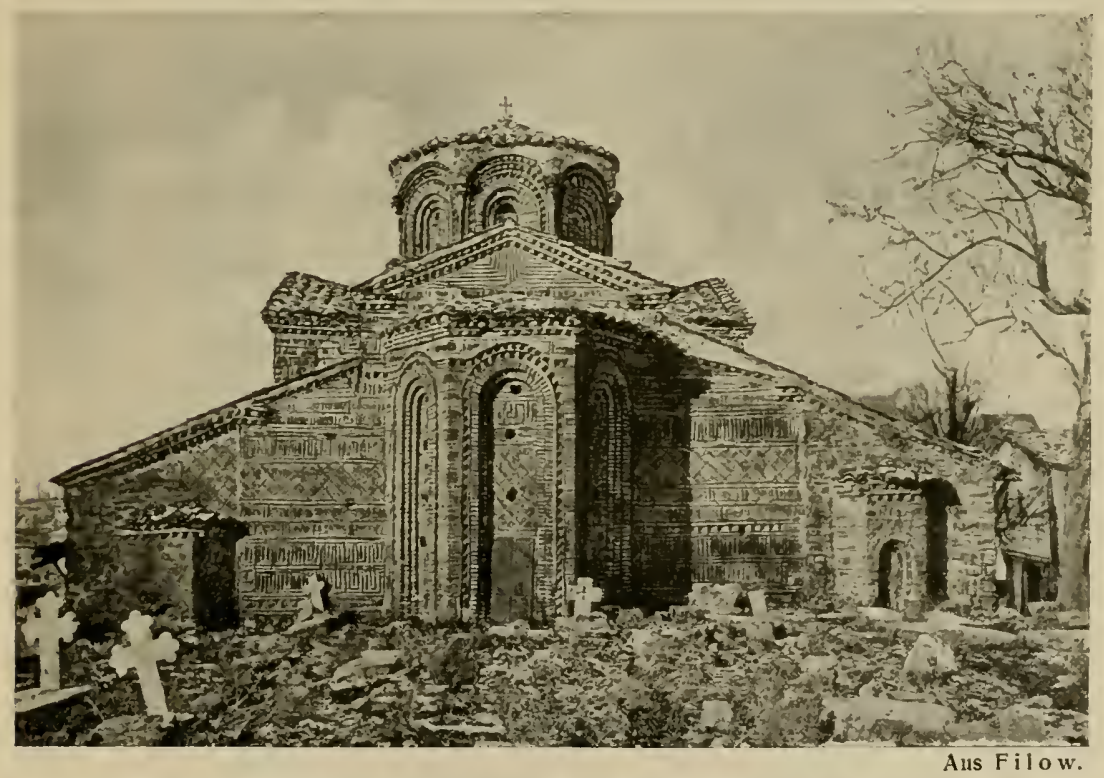

Abb. 274. Ostseite der Kirche Sveti Climent in Ochrida. Gebaut I 295.

Professor Gelzer für die Kirchengeschichte des Balkans wichtige Dokumente entdeckt. Wo mögen diese mittlerweile hingeraten sein?

Sehr schön und interessant sind in Sv. Climent auch die Holzschnitzereien und Metallarbeiten, welche überhaupt in den bulgarischen Kirchen eine große Rolle spielen und auch durch die Türkenzeit hindurch eine gute Tradition bewahrt haben.

Von den zahlreichen anderen Kirchen Ochridas möchte ich noch eine erwähnen, welche infolge ihrer malerischen Lage manchem Besucher wie mir in unvergeßlicher Erinnerung geblieben sein wird. Es ist die am westlichen Ende auf einem in den vorragenden Felsen- 
vorsprung erbaute kleine Kirche Sveti Jon, dem heiligen Johannes geweiht. In der Armee wurde sie meist als die Fischerkapelle bezeichnet, wohl wegen ihrer Lage bei den Fischerhäusern am See.

Sv. Jon ist eine kleine Kreuzkuppelkirche aus Haustein mit roten Zwischenlagen von Ziegeln gebaut. Hohe Strandmauern sind auf den schroffen Felsen zu ihr emporgebaut, um die Plattform herzustellen, auf der sie steht. Treppen führen durch diese

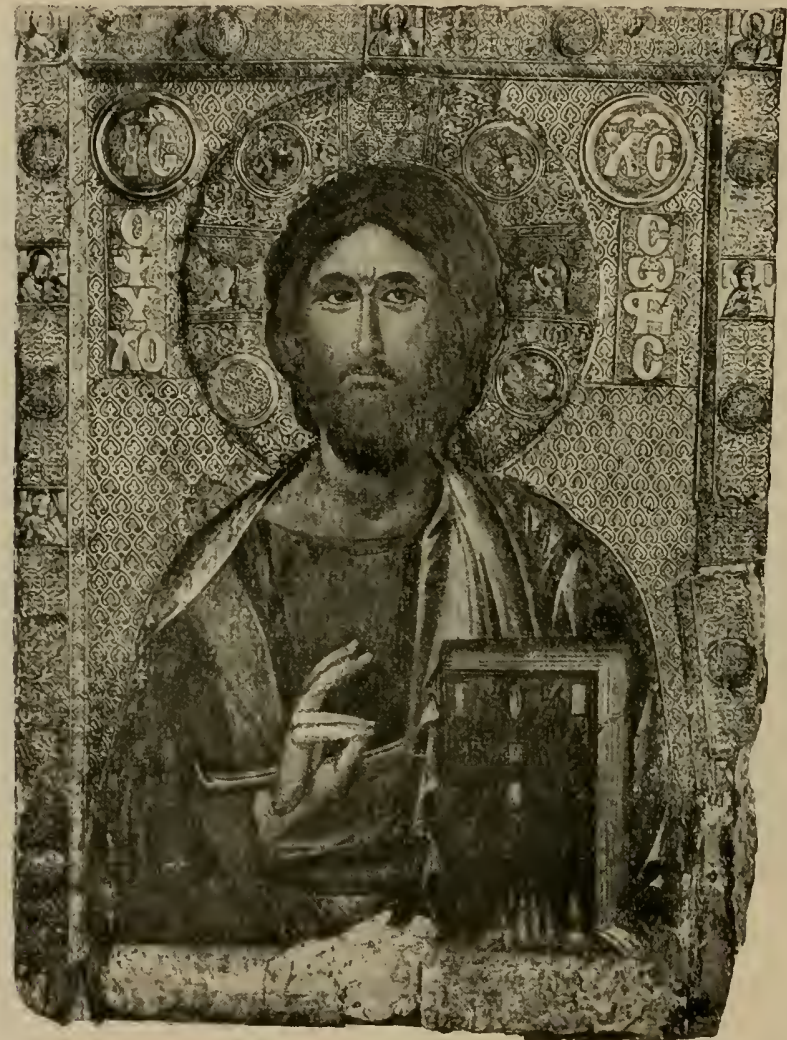

Aus Filow.

Abb. 275. Segnender Christus. Ikone aus der Climentkirche in Ochrida. 13.-I4. Jahrh.

zu einem felsigen Strand hinab, an welchem ich manches köstliche Bad in dem klaren Wasser des Sees genossen habe. Mächtige alte Bäume ragen vor den Felsen auf und erhöhen die malerische Schönheit des Bildes, welches die Kirche darstellt, die sich wundervoll vom Himmel und dem dunkelblauen Wasser des Sees abhebt, wenn man im Kahn von der Stadt her sich ihr nähert.

Nicht weniger schön stellt sie sich dar, kommt man über die Felsen den Pfad von der Stadt her zu ihr herabgestiegen. Wie 


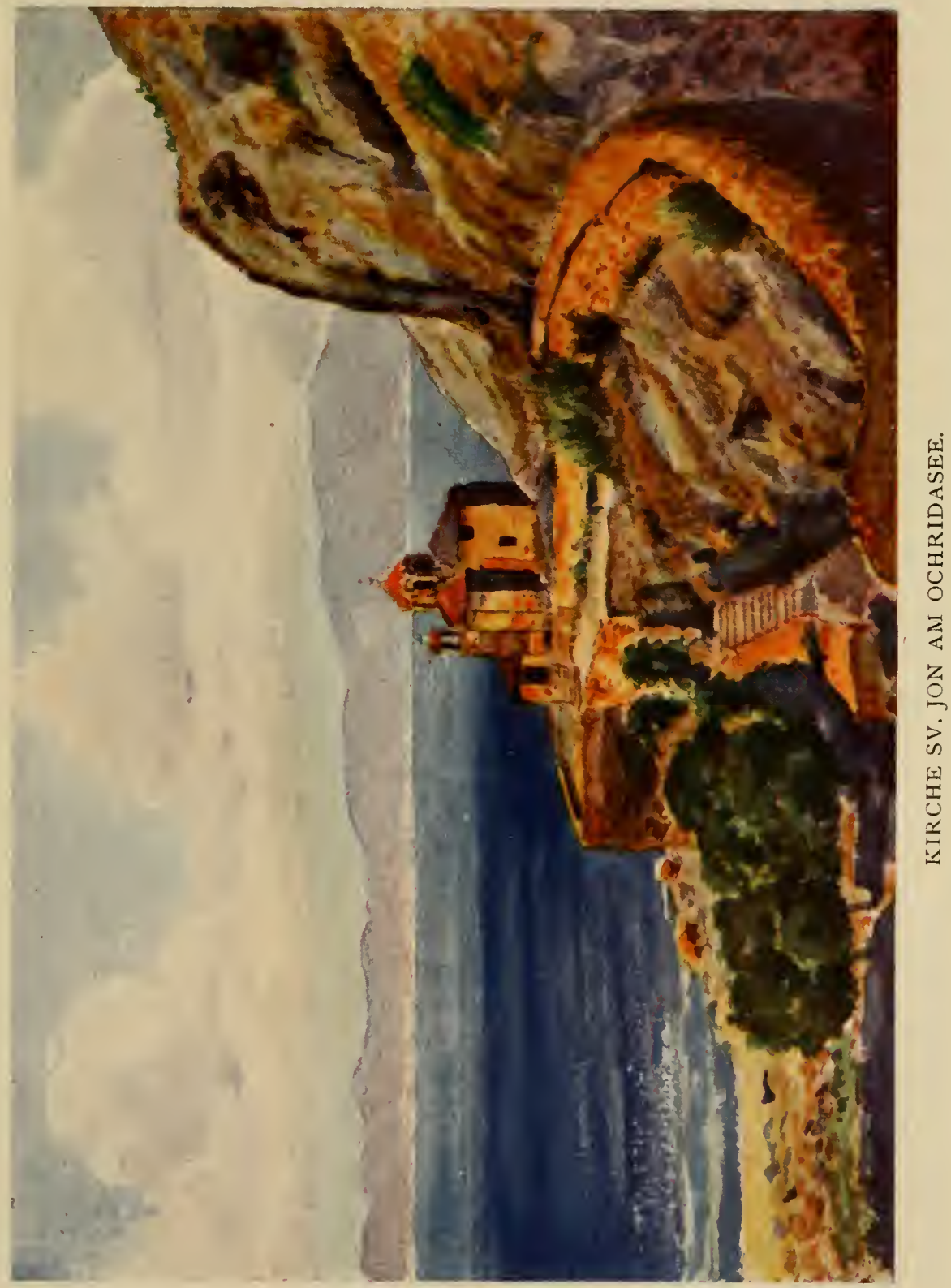



wunderbar hob sich ihr Umriß vom goldglühenden Abendhimmel $a b$, wenn drüben jenseits der nördlichen Seebucht die albanischen Berge in tiefen blauen und violetten Tönen verdämmerten. Aus der Tiefe rauschte die Brandung des an die Felsen anschlagenden Sees herauf. Weit erstreckte sich der Blick von den Treppen, die zur Kirche führten, oder von dem kleinen über den See hinausgebauten Balkon aus über die weite Fläche des Sees. Wie seltsam flimmerte der Wiederschein des Abendhimmels von den dunkelblauen Wellen, wie zart verschwammen seine Grenzen im fernen

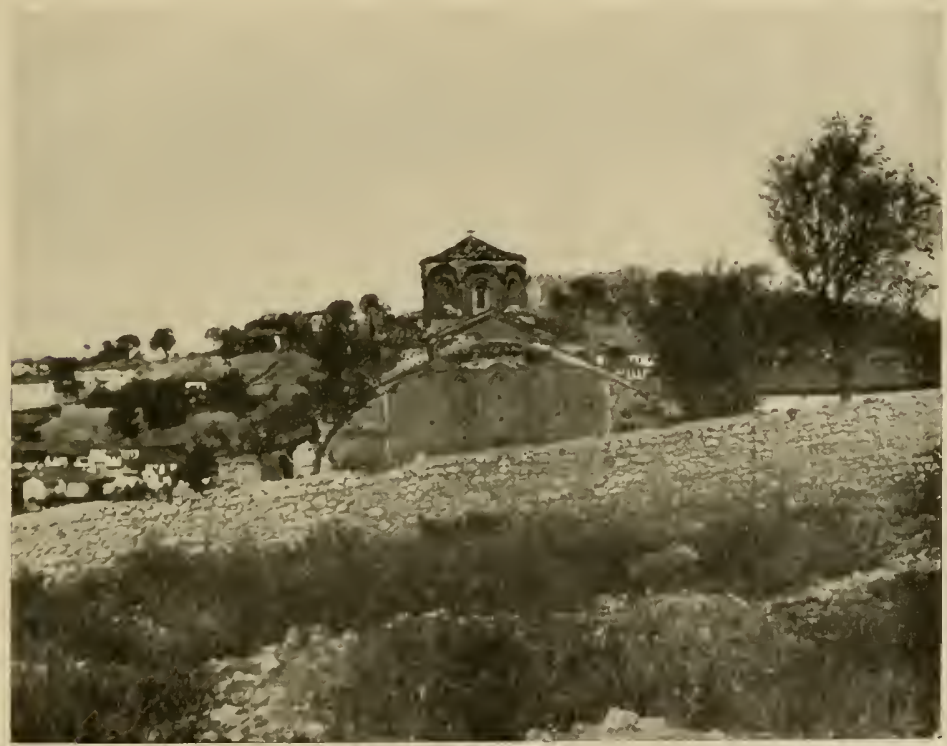

Dr. Nachts heim phot.

Abb. 276. Sveti Climent, St. Clemenskirche in Ochrida auf der Varoshöhe.

Süden; welch schönen Abschluß des Bildes gaben die harmonischen Umrisse des Tomoros und Malisat!

Auch die Einwohner von Ochrida besaßen Verständnis für die poetische Schönheit der Örtlichkeit. Abends wandelten junge Leute, Liebespaare hier heraus, genossen die Abendstimmung, saßen auf den Felsenklippen und sangen ihre schwermütigen Lieder.

Es war fast der einzige Ort in Mazedonien, wo ich die alten Lieder singen hörte. Hier konnte man auch an Frieden und geruhsame Zeiten denken, wenn die Dämmerung niedersank, der Spiegel des Sees dunkel wurde und nur die Berggipfel und die wandernden Wolken am Himmel noch die letzten roten Gluten der Sonne wiederstrahlten. 


\section{DER OCHRIDASEE}

er schöne See mit seinen malerischen Ufern bot auch
dem Naturforscher manche Probleme und so setzte ich
denn alle meine Kräfte daran, von seiner Natur, seiner
Tier- und Pflanzenwelt möglichst viel zu erkunden. So streifte ich seine Ufer ab, suchte durch Fischer möglichst viel von seiner Tierwelt zu erwerben und auf eigenen Fahrten sie zu erforschen. Im Jahre $1918 \mathrm{kam}$ mir Dr. Nachtsheim zuhilfe, der einen großen Teil seiner Zeit und Arbeitskraft speziell der Durchforschung der Wasserbiologie Mazedoniens widmete.

Meine Ziele wurden sehr gefördert durch die österreichische Flottille, die den Wachdienst auf dem See unter sich hatte. Ihre Motorboote, Kähne und Fischerboote wurden mir zur Verfügung gestellt, und ich kann die Tüchtigkeit und Schneid ihrer Offiziere und Mannschaften aufs höchste anerkennen. Nicht nur bei der Verteidigung dieser gefährdeten Front, beim Transport unserer Division und ihres Materials haben sie Treffliches vollbracht, auch mir haben sie sehr wesentliche Dienste geleistet.

Der Ochridasee liegt in Meereshöhe von $687 \mathrm{~m}$, also fast $200 \mathrm{~m}$ tiefer als der $857 \mathrm{~m}$ hoch gelegene Prespasee. Seine Oberfläche erreicht 270 Quadratkilometer gegenüber den 288 des etwas größeren Prespasees. Wie der Prespasee liegt er zwischen hohen Bergen, die sich hier weiter nördlich erstrecken als bei jenem. Seine größte Tiefe, etwa in der Mitte seiner Längenausdehnung, erreicht $285 \mathrm{~m}$, er ist also beträchtlich tiefer als der Prespasee, der nur $54 \mathrm{~m}$ als größte Tiefe besitzt.

Der Seeboden fällt an vielen Stellen steil zu größeren Tiefen ab, was an der dunklen Farbe des Wassers erkennbar ist. Nur am Nordende, vor der Stadt Ochrida und ganz im Süden lassen grüne Streifen des Wassers auf seichte Stellen schließen. Vor allem der sandige Nordstrand gegen Struga hin senkt sich langsam ab. Hier, wie in der Bucht südlich von Ochrida wird der See von schmalen Schilfstreifen eingefaßt, die nirgends die Mächtigkeit erreichen, wie am Prespa- und Doiransee. 
Vielfach fallen die Felsenufer steil zum See ab, was den malerischen Reiz der Strandlandschaften bedingt. Das ist vor allem direkt nördlich der Stadt Ochrida der Fall sowie auf langen Strecken des Ost- und Westufers.

Von allen Seiten strömen kurze Bäche aus den Bergen dem See zu; ganz kurz ist der Hauptzufluß, der Drin, welcher als richtiger Karstfluß in der Nähe des Klosters Sv. Naum als starker Bach entspringt, um sich nach ganz kurzem Lauf in den See zu ergießen. Das entspricht dem im 33. Kapitel geschilderten Charakter des Tomorosgebirges als Karstgebiet. Es ist wohl die Ursache zu der in der Bevölkerung verbreiteten Sage von einer unterirdischen Verbindung des Ochridasees mit dem Prespasee, durch welche man die Niveauschwankungen des letzteren erklären will. $\mathrm{Zu}$ einer solchen Annahme liegen aber keine wirklichen Grundlagen vor.

Bei Struga entströmt der Drin, als relativ mächtiger Fluß, dem See, fließt eine lange Strecke nach Norden, um sich dann nach Westen und teilweise nach Süden $z u$ wenden und südlich des Skutarisees im Dringolf ins Adriatische Meer zu münden.

Die Ufer des Sees lernte ich auf verschiedenen Exkursionen kennen. Ein Ritt in Begleitung von zwei mir mitgegebenen Blücherhusaren führte mich nach Struga an das Nordende des Sees zum Ausfluß des Drin. An einem Kloster und einigen Dörfern vorbei ging der Ritt in flottem Trab zum kiesigen und sandigen Flachstrand des Sees; nördlich von ihm dehnte sich eine fruchtbare Ebene aus, im Anfang begrenzt von einem seltsamen purpurroten Felsenberg, vor welchem Ruinen eines Dorfes lagen.

An dem Binsenufer flogen vor unsern Pferden, die flott durch das seichte Wasser galoppierten, Kormorane, Bleßhühner und Enten auf. In den Büschen waren, trotz der Herbstzeit, noch zahlreiche Grasmücken in Bewegung. Vor mir lag bald das große Dorf Struga, vollkommen eingehüllt in Weiden und Pappeln. Unterhalb des Ortes am Drin liegen ausgedehnte Sümpfe. Diese sind von Weiden, Röhricht und mancherlei Sumpfpflanzen dicht bewachsen; auch Schilf mit seinen braunen Kolben bedeckt große Flächen. Struga war ein in der Armee berüchtigtes Fiebernest.

Im Schatten von Weiden liegen im hier recht breiten Drin die so wohlbekannten breiten Boote mit ihren unförmlichen Seitenwülsten; unterhalb des Dorfes ist die ganze Breite des Flusses durch Zäune und Gatter aus Schilf und Reisig abgesperrt. Zivischen 
ihnen sind Reusen aufgestellt, um die Fische, welche zwischen Fluß und See wechseln, abzufangen. Schon vor vielen Jahren wurden diese Weidengeflechte und die bei ihnen aufgestellten Hütten mit ihren Dächern aus Röhricht von Besuchern erwähnt. So hat sie z. B. der Aromunenforscher Weigand im Jahre i 889 gesehen. Dieser erwähnt, daß damals schon die Fischerei in Struga um 100000 M. auf 2 Jahre verpachtet war.

Das muß sie wohl getragen haben; denn während meines Aufenthaltes in Ochrida sah ich oft die Ausbeute enormer Fänge.

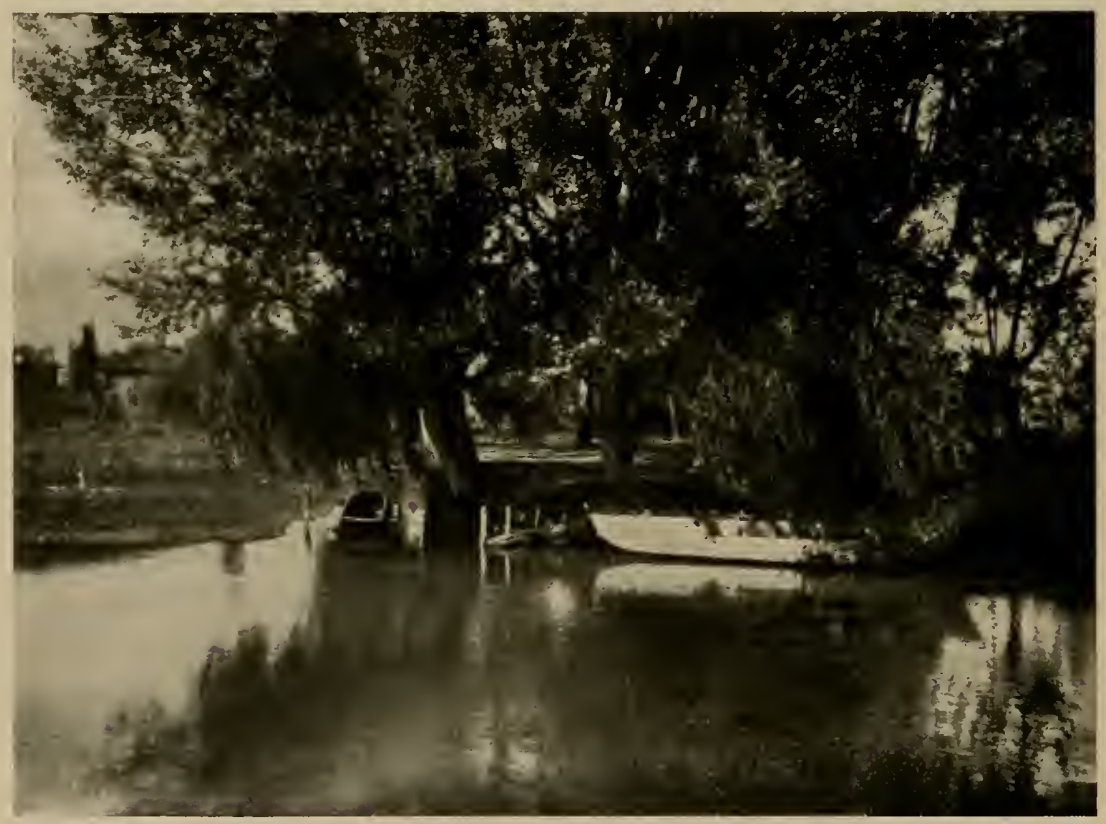

Abb. 277. Bootshafen am Drinaausfluß aus dem Ochridasee.

Nicht selten werden an einem Tag Hunderte von Zentnern von Aalen in Struga erbeutet. Es ist ein imposanter Eindruck, wenn man Haufen von vielen Hundert der armsdicken, mehr als einen Meter langen Fische sich durcheinander winden sieht, wenn ihre weißen Bäuche aufblinken, während sie ihre blauschwarzen Rücken nach unten kehren.

Vielerlei kleine und größere Fische sah ich im Wasser umherhuschen, als ich mit meinen Husaren ins Sumpfgelände hineinritt, um mit einem von ihnen, der ein gelernter Fischer war, Krebse 
zu fangen. Während unsere Pferde an einer trockenen Stelle grasten, zog der Mann sich aus, sprang ins Wasser und holte unter den Pflanzenpolstern an der Uferwand einen ganzen Sack von Flußkrebsen heraus. Während sie anfangs frei herumschwammen und, auf dem Schlamm sitzend, erspäht werden konnten, zogen sie sich bald in ihre Löcher zurück. Auf diese mußte das ganze Ufer und alle Rohrinseln abgesucht werden, was mein Husar sehr geschickt und sachverständig ausführte.

Unterdessen umschwammen ihn Wasserkäfer, Schwimm-

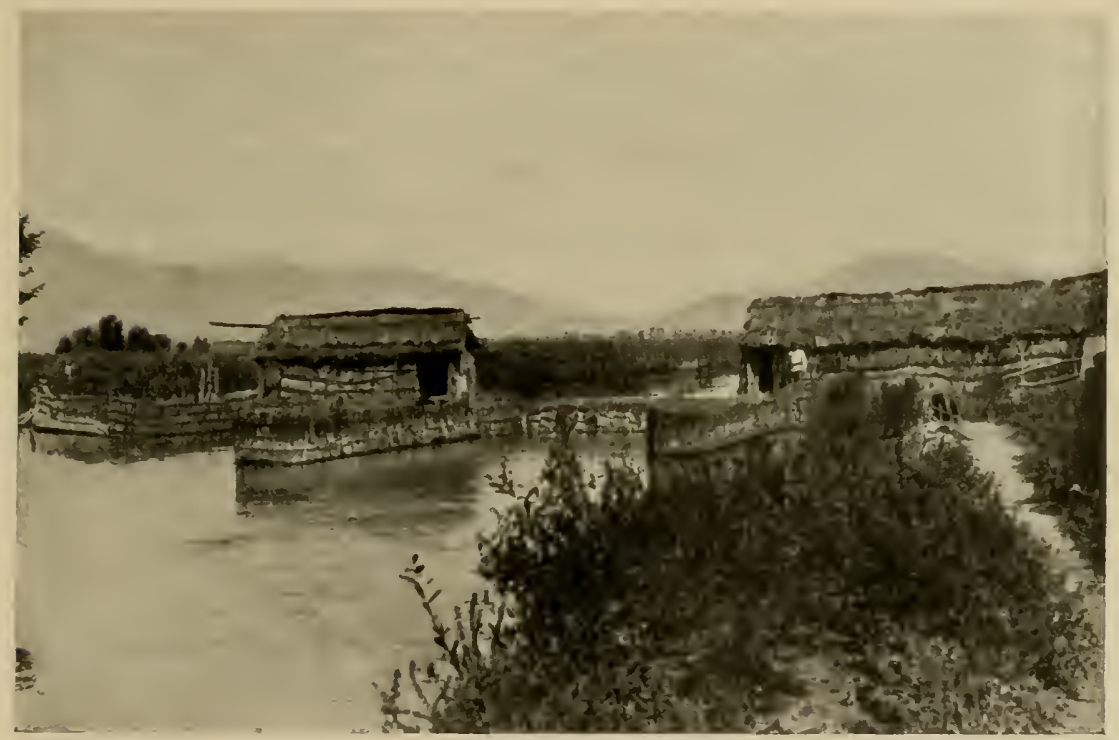

Abb. 278. Fischsperre in der Drinmündung bei Struga am Ochridasee.

wanzen und allerhand Getier, zum Glück fehlten aber hier die Blutegel. Libellen vieler Arten umschwirrten uns während unserer Fischerei. Der Krebs stellte sich als eine auch bei uns verbreitete Art des Flubkrebses heraus (Astacus fuviatilis L.). In der Umgebung herrschte ein reiches Vogelleben. Allerhand Arten von Rohrsängern und anderen rohrbewohnenden Kleinvögeln huschten durch das Schilf.

In der nächsten Umgebung flogen auf oder ließen sich nieder Fischreiher und Purpurreiher. Besonders schön zu beobachten war ein ganzer Flug von weißblinkenden Edelreihern. Uferläufer und andere Stelzvögel, Enten, Teichhühner und 
viel anderes Wassergeflügel war in Mengen vorhanden. Ich bedauerte sehr, damals keinen Präparator bei mir zu haben; denn ich scheute mich, die Tiere zu schießen, ohne Belegstücke für wissenschaftliche Zwecke mitnehmen zu können.

Eine ähnlich reiche Vogelwelt fand sich auch südlich von Ochrida am Strand des Sees, den ich mit meinen Begleitern nach Wassertieren absuchte. Dabei erwies sich als besonders ergiebig das Ufer und seitlich liegende Tümpel bei Goriza und gegen Sv. Stefan. Dort wurden viele Muscheln aus den Gattungen Unio und Anodonta gefangen. Auffallend war im See das Massenvorkommen der Muschel Dreissensia, welche bekanntlich vor einigen Jahrzehnten eine Wanderung durch ganz Westeuropa vom Osten her gemacht hat und jetzt auch bei uns in Deutschland im Süßwasser heimisch geworden ist. Bemerkenswert war später beim Fang des Planktons, in welch ungeheuren Massen Muschellarven, wahrscheinlich meist solche von Dreissensia, das Wasser des Sees in allen Schichten belebten.

Auch Schnecken aus den Gattungen Lymnaers und Paludina waren in großen Mengen zu finden: dabei allerlei Wasserinsekten, Käfer, Schwimmwanzen und Larven vieler Arten. An den Felsen und Steinen, besonders unterhalb der Kirche Sv. Jon, fanden sich massige Krusten eines Süßwasserschwammes.

Um die Fische des Sees zu bekommen, mußte ich mich mit den am See ansässigen Fischern in Verbindung setzen; denn ich selbst hatte keine Fischereigeräte zur Verfügung. Dazu sollte mir eine Empfehlung eines bulgarischen Politikers dienen, welche dieser mir an den Erzbischof mitgegeben hatte. In dessen Haus wurde ich sehr liebenswürdig empfangen und die Erfüllung meiner Wünsche mir versprochen, Das war aber offenbar in jenen Tagen nicht ganz leicht. Die Stadt war infolge der kriegerischen Ereignisse von Militär überflutet, welches alles Eßbbare und damit auch die Fische für sich beanspruchte.

So war es denn wichtig, daß mir ein Polizist zugewiesen war, der die Fischer gut kannte und vor allem in ihrer Sprache sich gut mit ihnen verständigen konnte. Dabei sprach er ganz gut deutsch, mit sehr ausgesprochen österreichischem Akzent. Als ich ihn frug, wo er denn sein Deutsch gelernt habe, erzählte er mir, er sei Jahre lang in Karlsbald und Franzensbad gewesen. Auf meine weitere Frage, was er dort gemacht habe, antwortete er mit spitzbübischem Lächeln: „Ich war dort Honigtürke!“ Wieso? „Ja, 
ich stand mit einem Fez oder Turban an der Promenade und verkaufte türkischen Honig. Die meisten Honigtürken in Deutschland und Österreich sind mazedonische Bulgaren. Aber dort ist vorteilhaft Türke zu sein, man setzt einen $\mathrm{Fez}$ auf, auch wenn man slavischer Christ ist und die Leute dort können doch türkische und bulgarische Sprache nicht unterscheiden. Wenn man Chef des Geschäfts ist, verdient man viel Geld, weniger als Straßenverkäufer!"

Dieser Helfer sorgte dafür, daß die Fischer mir Fische aus dem Ochridasee heranbrachten.

Außer den Aalen gab es auch reichlich Karpfen im See; allerdings so stattliche Exemplare fanden sich hier nicht, wie ich sie seinerzeit im Wardar erbeutet hatte. Von Weiffischen wurden eine ganze Anzahl gebracht, so die mit unserem A itel verwandten Squalius illyricus $\mathrm{H}$. u. K, und $S q$. dobula $\mathrm{H}$. Auch die gleiche Art von $\mathrm{Barben}$, welche ich im Wardar und seinen Nebenflüssen gefunden hatte, kam hier reichlich vor (Barbus plebejus Val.). Bei Struga hatte ich selbst einen unserer $\mathrm{N}$ ase verwandten Fisch, in Italien Stric genannt (Chondrostoma genei Bon.) erbeutet. Dort fingen wir auch den $\mathrm{Gründling} \mathrm{(Gobio} \mathrm{vulgaris} \mathrm{Cw}$.). In Ochrida selbst wurden die Arten Chondrostoma phoximus Heck. u. Ch. soetta H. u. K. von den Fischern gebracht.

Eine heimische Erscheinung ist der Schiet (Aspius rapax Ag.), während die la u be nähn li chen, silbrig blinkenden Alburmus alborella $\mathrm{H}$. u. K. und $A$. scoranzoides $\mathrm{H}$. u. K. echt südliche Formen sind. Dasselbe gilt von Leuciscus adspersus Heck.

Der beliebteste Fisch auf dem Fischmarkt von Ochrida, gerühmt von allen Besuchern der Stadt und in normalen Zeiten weithin versandt, ist die Ochridaseeforelle. Es ist das ein prachtvoller Vertreter der Lachsfische mit allen Vorzügen dieser Gattung, der prachtvollen Färbung wie dem guten Geschmack des Fleisches. In stattlichen $50-70 \mathrm{~cm}$ langen Exemplaren sah man das Tier in jenen Tagen manchmal bei den Österreichern und bei den Blücherhusaren auf dem Kasinotisch. Die Seeforelle, von den Eingeborenen Latzniza genannt, wird wissenschaftlich als Salmo dentex Heck. bezeichnet; doch hat Ste indachner die Form aus dem Ochridasee als Salmo ochridanus Steind. abgetrennt.

Daß mit diesen I I Fischarten, von den I 4 Arten aus dem Ochridasee, welche frühere Reisende auf dem Fischmarkt von Ochrida konstatiert haben wollen, drei fehlen und dazu vielleicht 
noch manche andere, die $\mathrm{zu}$ entdecken gewesen wäre, hat seine Ursache in einem seltsamen Mißgeschick. Die große Auswahl von Seefischen, welche durch die Sorge des Erzbischofs für meine wissenschaftliche Sammlung bestimmt war, fiel leider durch Dummheit des Fischers und durch die Energie des Kasinovorstandes des Offizierkasinos der deutschen Division diesem in die Hände und wurde dort verzehrt.

Vor allem von den Seeforellen Ersatz zu schaffen, war in jenen Tagen, also Mitte September, sehr schwer, da sie nur mit komplizierten Apparaten einer Fischerflottille in der Tiefe des Sees gefangen werden konnten, wo sie sich in dieser Jahreszeit aufhielten. Stürmisches Wetter hinderte in den Tagen, die ich damals noch in Ochrida weilte, das Ausfahren dieser Boote.

Andere Forschungen gaben die Möglichkeit, eine Erklärung des Tiefenvorkommens der Seeforelle in diesem Teil des Jahres

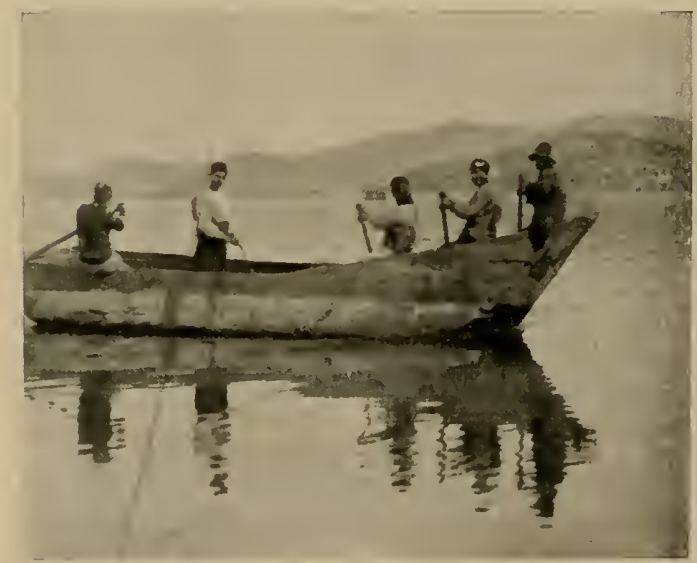

Abb. 279. Auslegerboot auf dem Ochridasee. zu finden. Ich hatte mich mit Apparaten ausgerüstet, um auch in diesem See Plankton zu fangen. Um das auch in größeren Tiefen ausführen $z u$ können, hatte ich mir von der Telegraphenabteilung in Prilep Kabel und dünne, feste Stahldrähte in der Länge von mehreren 100 Metern verschaff, mit denen Lotungen und Fänge in größeren Tiefen durchgeführt werden konnten.

Fahrten auf dem See zum Zwecke solcher Forschungen wurden mehrere noch in diesem Herbst von mir unternommen; im Jahre I 918 übernahm Dr. Nachtsheim diesen Teil der Untersuchungen. Ich will nur kurz über meine Fahrten berichten, um dann die wesentlichen Resultate unserer Forschungen darzustellen.

Im Hafen von Ochrida, wie in allen Orten am See, lagen jene eigenartigen, schweren Ruderboote, welche für diesen See ganz besonders charakteristisch sind. Es sind breite, plumpe Schiffe mit erheblichen Rauminhalt, welche an beiden Seiten in aus- 


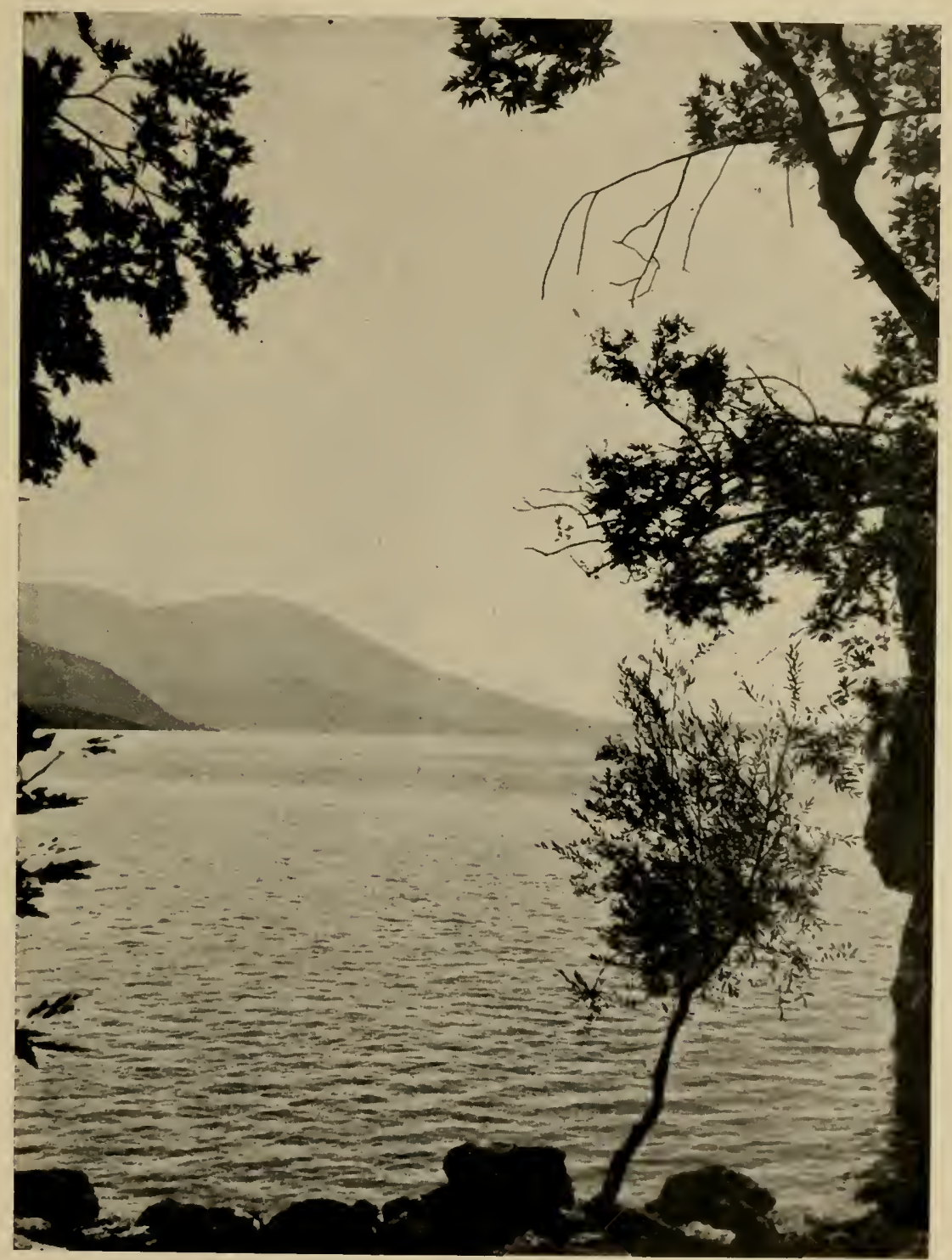

BLICK ÜBER DEN OCHRIDASEE. - Im Hintergrund Tomoros und Malisat. 

gehöhlten Baumstämmen eine Art von Auslegern besitzen. Sie machen die Boote ziemlich stabil, aber schwer beweglich. Auch sind sie bei hohem Seegang für das Boot durch ihre dünnen Wandungen nicht ungefährlich, da starke Wellen, Anstoß an harte Gegenstände, diese leicht durchschlagen und clamit das Boot zum Sinken bringen. Das Rudern ist in ihnen sehr beschwerlich und kommt gegen starken Wind und Wellengang nicht an. Gesegelt wird in diesen Booten nicht, wie denn überhaupt das verschönende Motiv des Segelschiffs auf diesem malerischen See vollkommen fehlte.

Mit einem solchen Boot machte ich verschiedene kürzere Fahrten, bei denen vor allem das Plankton der Oberfläche in Landnähe, also über geringeren Tiefen studiert wurde. Das Oberflächenplankton war im Ochridasee meist bräunlich oder braun, Fänge in der Bucht von Struga waren durch Algen grünlich gefärbt. Sehr viel reicher als in den Oberflächenschichten war das Plankton aus Tiefenfängen von $30 \mathrm{~m}$ Tiefe ab.

Um solche auszuführen, mußte man weiter auf den See hinaus. Sollte das nicht allzuviel Zeit rauben, so brauchte man dazu die Hilfe eines Motorbootes. In jenen bewegten Tagen standen diese aber nicht zur Verfügung, und da ich im September 1917 noch solche Fänge durchsetzen wollte, mußte ich mich in einem der großen Eingeborenenboote mit einem kleinen Motorkahn hinausschleppen lassen; in letzterem wäre nicht Platz genug für meine Apparate und meine Hilfskräfte gewesen. Dies Motorboot hatte sofort eine Panne und mußte liegen bleiben, während wir uns durch Rudern langsam südwärts arbeiteten. Wir langten schließlich gegenüber Lin vor einem roten Vorgebirge an. Dort ergab eine Lotung eine Tiefe von über $100 \mathrm{~m}$. Darauf wurde ein Fang mit dem Planktonnetz in etwa $80 \mathrm{~m}$ Tiefe ausgeführt. Dieser ergab eine ganz riesige Ausbeute; das Glas war mit einem Brei von vielen Tausenden von kleinen Tieren gefüllt, unter denen Krebse vorherrschten, deren Färbung den ganzen Tierbrei paprikarot erscheinen ließ.

Dies Resultat war nicht ohne große Not erreicht. Während wir arbeiteten, erhob sich ein starker Wind von Norden. Er fegte über die Oberfläche des Sees und erregte hohe Wellen. Es war ein prachtvoller Anblick, wie der See sich immer dunkler färbte und die mächtigen Wellen, mit weißen Schaumkämmen gekrönt, sich zu uns heranwälzten.

Vergebens suchten wir durch Rudern gegen diesen gewaltigen Seegang anzukämpfen. Die meterhohen Wellen warfen unser 
plumpes Boot hilflos umher; es war unheimlich, sie krachend gegen die dünnen Seitenwände anprallen zu hören. Es kostete die größte Mühe, das Boot wenigstens gegen die Wellen zu stellen; ein Rückwärtsrudern nach Ochrida zu war ganz unmöglich. Wir sahen beim Blick gegen das Land, daß wir, statt nordwärts voranzukommen, immer weiter nach Süden abgetrieben wurden. Wir kamen schließlich über Pescani und immer weiter über die feindliche Front hinaus. Das Boot schwankte hin und her, stieg hoch auf die Wogenkämme hinauf, um mit Krachen und Gepolter in die Wellentäler hinabzustürzen.

Die See wurde immer schwerer, die Wellen erreichten eine Höhe von fast zwei Metern. Selbst auf dem Meer hatte ich in kleinem gebrechlichen Boot selten etwas Derartiges erlebt. Schließlich wurde ich sogar seekrank, was mir selbst auf dem Meer unter ähnlichen Umständen nicht passiert war. Zu unserer Freude nahte jetzt unser Motorboot, das repariert worden war. Kaum hatte es, wie toll von den Wellen herumgeworfen, das Tau zu uns herüber geworfen und gerade angefangen uns norwärts $z u$ fahren, als neue Havarie eintrat. Der Motor versagte, die Leine verfing sich in die Schraube des Bootes, beide Boote taumelten hilflos auf den Wellen umher und stießen wiederholt heftig aneinander.

Die Situation wurde immer kritischer und trotzdem genoß ich den prachtvollen Anblick, als der Matrose des Motorbootes sich auszog und nackt sich ins Wasser stürzte, um zu tauchen und unter Wasser mit einem Messer die Leine aus der Schraube herauszuschneiden. Rot wie ein Krebs tauchte er aus dem indigoblauen Wasser empor. Ich zitterte für sein Leben; aber mit bew underungswerter Gewandheit brachte er, was er wollte, fertig und stieg heftig atmend ins Boot zurück. Aber bei dem schweren Wogengang kam er nicht mit dem Motor zurecht.

Woge auf Woge brauste gegen uns heran, der Nordwind wurde immer stärker. Der Abend sank hernieder. Leuchtend hoben sich die Wogenkämme von dem schwarzblauen Wasser ab. Rot lag der Abendschein auf den Hängen des Tomoros und seinen Kalkfelsen. So weit waren wir nach Süden getrieben und schon weit hinter den feindlichen Linien. Schon berieten wir, der mich begleitende Husarenleutnant und meine Matrosen, wie wir wohl ans Land kommen und uns durch die feindlichen Linien in der Nacht hindurchschleichen könnten.

Da nahte ein kritischer Augenblick; wir hörten einen Motor 
arbeiten; aus dem Dunst tauchte ein Patrouillenboot auf. War es feindlich? Sie hielten uns jedenfalls für Feinde; denn sie machten ilıre Maschinengewehre klar. Da im letzten Moment erkannte der österreichische Oberleutnant, der das Patrouillenboot führte, mich und sein Boot, das er mir am Morgen geliehen hatte. Wir waren gerettet. Das starke Motorboot nahm uns ins Schlepptau und nun ging es in sausender Fahrt nordwärts gegen den Wind und die Wellen auf Ochrida los. Der Nordwind brauste uns um die Ohren, der Gischt spritzte über uns und unser ganzes Boot. Als wir in Ochrida anlangten und unsere Ausbeute nebst den Instrumenten heil an Land brachten, wartete eine vielhundertköpfige Menge am Kai auf das „erbeutete feindliche Boot“. Soldaten und Zivilisten waren sehr enttäuscht, daß es nur Gelehrte waren, die da eingebracht wurden. Unsere Fahrt hinter die feindliche Front bildete eine Zeitlang das Armeegespräch an der westlichen Front in Mazedonien.

Eine Reihe harmloserer Fahrten brachten mir und im nächsten Jahr Dr. Nachtsheim die erwünschten Aufschlüsse über das Plankton des Ochridasees. Es erwies sich als viel ärmer an pflanzlichen Bestandteilen als dasjenige des Doiran- und Prespasees. Das hing wohl mit der größeren Tiefe des Sees zusammen. Das tierische Plankton war dagegen außerordentlich reich. Vor allem in größeren Tiefen enthielt es ein Gewimmel von kleinen Krebsen aus den Gruppen der Copepoden und Daphniden Dazu kamen große Massen von Muschellarven, wohl Glochidien der im See so häufigen Dreissensia. Die Copepoden gehörten zu den Arten Cyclops strenuzs und Diaptomus Steindachneri und D. vulgaris. Von Daphniden sind es Bosminen, Arten von Scapholeberis u. dgl. Leptodora, welche im Doiran- und Prespasee häufig vorkam, vermißten wir im Ochridasee.

Von Interesse ist die Tatsache, daß zu der Zeit, in der die Seeforellen in der Tiefe sich aufhielten und dort von den Fischern gefangen wurden, in diesen Tiefen die großen Massen von Planktontieren lebten. So fanden denn die Fische dort ihren gedeckten Tisch, ihre reichen Weidegründe. Die Magenuntersuchung bewies, daß tatsächlich das Plankton zu dieser Zeit ihre Hauptnahrung ist. So zeigt also ihre Verbreitung in den verschiedenen Tiefen des Sees ähnliche Gesetzmäßigkeiten wie sie z. B. für die Fische des Bodensees, besonders für die Felchen nachgewiesen worden sind. 


\section{ENDE DES FELDZUGES UND DER FORSCHUNGSARBEITEN IN MAZEDONIEN}

1

m August 1918 hatte ich, durch persönliche Verhältnisse gezwungen und ermüdet durch 7 Monate intensiver und strapazenreicher Arbeit, für einige Wochen nach Deutschland zurückkehren müssen. Im September war ich, gut ausgerüstet für neue große Unternehmungen, auf der Rückreise zu meinem Standquartier in Üsküb. Unglücksschwangere Nachrichten hatten mich schon unterwegs erreicht. Der Sommer war ja schon von bösen Ahnungen erfüllt gewesen. Aber noch hoffte ich, daß es gelingen würde zu meiner Arbeitsstätte zu gelangen und weiter arbeiten zu können.

Noch während der Reise aber mußte ich alle Hoffnung aufgeben; General von Krane, den ich als Mitpassagier im Balkanzug in Ungarn traf, riet mir sogar sofort umzukehren. Ich beschloß aber, soweit wie möglich weiter zu fahren und meine Mitarbeiter, meine Ausrüstung, und das, was von Sammlungen noch in Mazedonien war, nicht im Stich zu lassen.

Glücklich gelangte ich noch nach Serbien, aber nicht über Nisch hinaus. Schon war Üsküb unerreichbar. Die Front war durchbrochen und in voller Aufrollung begriffen. Dort, wo schon im Frühjahr die Bulgaren eine schwere Schlappe erlitten hatten, an der Front südlich der Mala Rupa, war dem Feind der Durchbruch gelungen. In diesem Gebiet hatten schon im Sommer bulgarische Regimenter gemeutert. Die Bulgaren haben zuerst versagt. Hier an der Front begann der Zusammenbruch, der alle Fronten erfassen sollte.

Die Ursachen sind durchsichtig. Daß die Bulgaren zusammenbrechen mußten, war vorauszusehen. Wer unter ihnen lebte, mußte es voraussagen. Das Volk war zermürbt durch fast ein Jahrzehnt Kriegszustand. Drei Kriege hatte es hintereinander bestehen müssen, 
die ihm Viele seiner Besten gekostet hatten. Das ganze bulgarische Heer war kriegsmüde. Kaum klammerte es sich noch an die alten mazedonischen Traditionen und Hoffnungen. Die Kraft versagte, die Organisation versagte, Nachschub und Verpflegung versagten. Als der Hunger an der Front nagte, versagten auch die Verbündeten; auf die Türken und Österreicher war schon längst kein Verlaß mehr.

Nun hatten noch wir, diejenigen ihrer Verbündeten, die bis jetzt sie gestützt und versorgt hatten, sie im Stich gelassen. Die ungeheueren Kämpfe an der Westfront hatten die oberste Heeresleitung gezwungen ein Regiment nach dem anderen, eine Batterie nach der anderen von der mazedonischen Front wegzunehmen. Schließlich waren nur noch die Spezialwaffen übrig geblieben.

Da hatten die Feinde gegen die zermürbte Front einen energischen Stoß gerichtet, waren durch einsame Wälder und Gebirge von dem Gebiet der Dudica durch die Marianska Planina und die Ketten südlich Drenovo unbemerkt bis Demirkapu vorgestoßen und hatten damit mit einem Schlag die ganze Front aufgerollt. Die Wardarfront war abgeschnitten, die einzige normale Rückzugslinie bedroht.

Als ich in Nisch anlangte erfuhr ich, daß schon Veles genommen und Üsküb bedroht sei. Nun galt es auch für mich, zu retten, was zu retten war. Schon hatte ich telephonisch und telegraphisch Verbindung mit meinen Mitarbeitern erzielt. Mein Eigentum, Sammlungen, Laboratoriumsausrüstung war gerettet, meine Leute alle in Sicherheit. Allmählich sammelten sie sich um mich; Kisten und Koffer langten mit den verschiedensten Transportmethoden in Nisch an. Das Heerespferdedepot, meine freundlichen Nachbarn auf dem Zitadellenberg in Üsküb, hatten mit all dem ihrigen auch mein Laboratorium gerettet.

Nun galt es selbst mit all diesen Dingen aus dem Wirrwar, das sich nun entwickelte, nordwärts zu entrinnen. Die Stäbe rückten an, brauchten alle Quartiere und allen Raum. Für uns und unsere Schätze war kein Platz mehr. So war man froh, uns mit einem leeren Güterwaggon zufrieden zu stellen; den ließ ich in der Folge an alle möglichen Güter- und Personenzüge anhängen und fuhr so langsam durch Serbien nordwärts und sammelte unterwegs allmählich Menschen und Besitztümer der mazedonischen Forschungskommission auf. 
Es waren noch qualvolle Tage, die ich in Paracin und schließlich in Semendria verbrachte, immer wartend auf Menschen, eintreffende Sammlungen, Instrumente und vor allem auf die mit Spannung erwarteten Nachrichten von Freund und Feind. Immer weiter verschob sich die Front, die gehalten werden sollte, nach Norden. An einem Ort nach dem anderen sausten die Autos der hohen Stäbe weiter nordwärts an uns vorbei.

Mein Bursche, meine Präparatoren, Prof. Müller, Dr. Nachtsheim, langten bei mir an, oder kamen für kurze oder längere Zeit mit mir zusammen. So erhielt ich nach und nach Nachrichten von den befreundeten Abteilungen. Ich hörte vom Hain Mamre und den Truppen der dortigen Front, daß sie nach Osten ausgebogen seien und nach Zerstörung wichtiger Vorräte durch Bulgarien nordwärts strebten. Hauptmann Jungmann kam kurz vor der Besetzung noch aus Veles heraus; ich war in Semendria mit ihm beisammen, wo er eine Kiste mit Säugetierfossilien noch unter dem Arm trug, die er gerettet hatte.

Ein Rest unserer Armee bei Prilep und am Ochridasee hatte sich westwärts wenden müssen und schlug sich durch Albanien ans Adriatische Meer durch und kam über Fiume nach Ungarn. Mein Bursche war noch im verlassenen Üsküb gewesen, der Pionierpark in Fudova, die großen Magazine in Gradzko waren in die Hände der Feinde gefallen.

Ach, was war da zerstört und vernichtet; wie lag man am Boden nach all den Träumen, mit denen man einst südwärts gezogen. Da galt es den Kopf aufrecht zu halten. Und ich mit meinen Leuten hatte alles Recht dazu. Alles wirklich Wesentliche von unseren Resultaten, ja sogar der größte Teil der Ausrüstung war gerettet. Fast alle Sammlungen waren schon in der Heimat, vieles rollte auf dem Wege dorthin oder war unter meiner Obhut. So galt es jetzt mit Energie diese Schätze noch über die Donau zu bringen. Dann hatte man seine Pflicht erfüllt, hatte sich in die Heimat zu begeben und dort neuer Aufgaben zu harren.

Als alles gerettet war, alle Sammlungen in der Heimat angelangt, gesichert und geordnet waren, da galt es für jeden einzelnen der Mitglieder der Forschungskommission in seine Stellung und Pflichten als Staatsbürger wieder einzutreten. Jeder hatte zu arbeiten, um im Land nach der Niederlage und den Wirren der Revolution wieder Ordnung schaffen zu helfen. 
Trotz der gehäuften beruflichen Arbeit, trotz der schwierigen Lebensverhältnisse, trotz der Last, die vor allem auf der Seele all der beteiligten Männer lastete, gelang es doch in den zwei seit der Niederlage verflossenen Jahren einen guten Teil unserer Resultate zu verarbeiten. Manches davon ist in den Kapiteln dieses Buchs niedergelegt.

Niemals ist es natürlich in einer so kurzen Zeit möglich, die wissenschaftlichen Ergebnisse reicher Sammlungen und vieler Tagebücher, vieler Beobachtungen und Gedankenarbeit in abgeschlossenem Zustand zu überliefern. Noch manches Jahr mag darüber hingehen, bis alle Resultate der verschiedenen Forscher, die teils in dem fernen Lande mitgearbeitet haben, teils an unseren Sammlungen als Bearbeiter einzelner Gruppen und Probleme mitwirken, fertig vorliegen.

Ein Buch, wie das vorliegende, soll mit seinem vorläufigen Ergebnis ein Zeugnis davon ablegen, wie in dem zerstörenden Krieg aufbauende Arbeit mit Hilfe der Armee geleistet wurde. Es soll ein bisher unbekanntes Land, einen weißen Fleck auf der Karte Europas dem Verständnis unseres Volkes näher führen und zeigen, was dort für alle Zweige unseres Wissens und unserer Kultur noch zu suchen ist.

Und so schlielie ich dies Buch in dankbarer Gesinnung gegen alle, welche mir zur Erreichung meiner Ziele in Mazedonien Hilfe geleistet haben. Wie viele Namen durfte ich in diesem Band nennen von Heerführern, Offizieren, Mannschaften, von Kollegen und Mitarbeitern, von Deutschen, Österreichern, Bulgaren, die mithalfen, all das auszuführen, was in diesem Buch beschrieben ist. Ihnen allen sei mein Dank ausgesprochen und die Hoffnung, daß der Inhalt des Bandes ihnen schöne, wertvolle Erinnerungen an das farbige, eigenartige Land Mazedonien erwecke. 


\title{
ANMERKUNGEN ZU DEN KAPITELN.
}

\author{
Anmerkungen zum 1. und 2. Kapitel. \\ Frühling in Mazedonien und Kaluckova und das \\ Forscherhaus.
}

Pflanzen bei Kaluckova.

Thymian Thymus lanuginosus Mill.

Kamille Anthemis austriaca Jacq.

Rosa Cistrose Cistus villosus L.

Strohblume Xeranthemum annun L.

Labkraut Galium verum L.

Lichtnelken $\left\{\begin{array}{l}\text { Silene racemosa Otte. } \\ \text { Lychnis coronaria Lam. }\end{array}\right.$

Goldklee Trifolium campestre Schreb.

Rote Wicke Vicia tenuifolia Roth.

Gelbe Schafgarbe Achillea coarctata Schreb.

Großes Zittergras Briza maxima L.

Diptam Dictamnus albus L. var. macedonicus Borb.

Aronsstab Dracunculus vulgaris Schott.

Stacheleiche Quercus coccifera $\mathrm{L}$.

Weichblätterige Eichen $\left\{\begin{array}{l}\text { Quercus macedonica L. } \\ \text { Quercus pubescens L. } \\ \text { Quercus lanuginosa Lam. } \\ \text { Quercus conferta WK. }\end{array}\right.$

Esche Ornus fraxinus $\mathrm{L}$.

Judendorn Paliurues spina cristi Miller.

Flockenblume, rot Centanrea scabiosa St. Jurinea $s p$.

Rittersporn Delphinizen consolida var, micranthum Boas.

\section{Anmerkungen zum 3. Kapitel. \\ Pflanzen der Ebene von Hudova.}

Große, gelbe Wolfsmilchart Euphorbia virgata WK.

Rote Wicke Vicia temuifolia Roth.

Heckenrose Rosa canina L.

Dort Urform der Gartenhyazinthe Hyaciuthus orientalis L.

Kornblume Centaurea cyanus $\mathrm{L}$.

Roter Mohn Papaver rhoeas L. 


\section{Bockkäfer.}

Clytus ornatus Herbst.

Cl. rhamni Germ.

Argalia punctata L.

Stromatium unicolor Oliv.

Agapanthia cynarae Germ.

Cerambys miles Bon.
C. cerdo L.

C. coronatus Kust.

Morimues funereus Mals.

Aromia moschata I.

Clytus floralis Pall.

Purpurica badensis Götze.

Ich erwähnte in den Kapiteln 2 und 3 den großen Reichtum an Asiliden (Kaubfliegen) im Frühling.

Ich füge hier eine Liste der auffälligsten Formen bei, deren Bestimmung ich Herrn Engel, München verdanke.

Dymachus fuscipennis Mg., Üsküb, Kaluckova.

Stichopogon scaliger Lw., Prilep.

Protophanes punctatus Mg., Woduo.

Heligmon munda Lw., Mrawinca.

Entolmus setibarbus Lw., Kaluckova.

Andrenosoma maroccanum Stip., Kaluckova, Plagusa Planina.

Laphria flava L., Gopes.

Stenopogon sabandris, Üsküb.

St. elongatus Mg., Kaluckova.

St. coracinus Lw., Üsküb, Kaluckova, Piravo.

Asilus crabroniformis $\mathrm{L}$., Lisec.

Promachus leoninus Lw., Doiransee.

Dysmachus bimzeronatus Lw., Mala Rupa, Üsküb.

\section{Anmerkungen zum 4. Kapitel. Mravinca und sein Feldlazarett.}

Die große Libellensammlung ist noch nicht durchgearbeitet und daher sind von den meisten Libellenarten noch keine genauen Namen angegeben. Die Bearbeitung liegt in den Händen von $\mathrm{Dr}$. R is, Rheinau (Schweiz).

Die Rhynchoten werden ron Dr. Schumacher, Berlin bearbeitet. Ein Teil ist schon bestimmt. Auch sonst liegen von Schumacher Publikationen über Balkanrhynchoten vor.

Die Fische sind von Prof. Dr. Zugmayer, München bestimmt.

Die reiche Sammlung von Mollusken ist noch unbearbeitet; sie befindct sich in den Händen von K. Hesse, Venedig.

\section{Anmerkungen zum 5. Kapitel. Plaguša Planina.}

\section{Vögel.}

Kuckuck Cuculus canorus canorus L.

Nachtigall Aëdon megarhynchos megarhynchos Brehm.

Haubenlerche, Balkanhaubenlerche Galerida cristata meridionalis Brehm.

Feldlerche, südeuropäische Alauda arvensis cantarella Bp. 
Feldsperling Passer montanus montanus L.

Turteltaube Streptoptila turtur turtur L.

Zaungrasmücke Sylvia curruca curruca L.

Vgl. E. Stresemann, Avifauna macedonica. München 1920.

\section{Pflanzen.}

Häufige Büsche.

Helianthemum r'ulgare L., bei uns in Gärten.

Blasenstrauch Colutea arborescens L.

Salbei mit violetten Hochblättern Salvia sclarea L.

Pfingstrose Paeonia decora Anders.

Natternkopf Echizem italicum L.

Weißdorn Crataegus oxyacantha L.

Buschbildender Ehrenpreis Veronica austriaca L.

Königskerze Verbascum pulverulentum M. B.

Fravenmantel Alchemilla acutiloba Stev.

Bäume.

Platane Platanus orientalis L.

Feldahorn Acer campestre L.

Hainbuche Carpinus duinensis Scop.

Silberlinde Tilia tomentosa Monsch.

Türkischer Haselbaum Corylus colurna L.

Birke Betula pubescens Ehrh.

\section{Anmerkungen zum 6. Kapitel. Nikolatal.}

\section{Pflanzen.}

Platane Platanus orientalis $\mathrm{L}$.

Feldahorn Acer campestre L.

Hainbuche Carpinus duinensis Scop.

Sanddorn Hippophaë rhamnoides L.

Silberlinde Tilia tomentosa Monsch.

Türkischer Haselbaum Corylus colurna L.

Eichenarten $\left\{\begin{array}{l}\text { Quercus macedonica L. } \\ \text { Quercus pubescens L. }\end{array}\right.$

Wachbolder Juniperus communis L.

IVeißdorn Crataegus oxyacantha L.

Salbei Salvia sclarea L.

Heckenrose Rosa canina L.

Johanniskraut Hypericum olympicum L.

Rote Skabiose Knautia macedonica Grieseb.

Weiße Lilie Lilium candidum L.

Esche Ornus fraximus $\mathrm{L}$.

Orchidee Himantoglossum caprinum M. B. 


\section{Anmerkungen zum 7. Kapitel. \\ Fahrt in die Mala Rupa.}

\section{Pflanzen aus der unteren Region.}

Tausendguldenkraut Erythraea centaureum Pers.

Hornkraut Stellaria holostea L.

Walderdbeeren Fragraria resca L.

Friechender Wachholder Juniperus nana Willd.

\section{Pflanzen aus der alpinen Region.}

Weißtanne Abies alba Mill.

Birke Betula pubescens Ehrh.

Irola orphanites Boas.

Sempervizum batens Grieseb.

Nelke Dianthus silzestris Wulf.

Erika Bruckenthalia spiculifolia Salisb.

Taubenkopf Silene venosa Asch.

Kriechender Günsel Ajuga genevensis L.

Gundermann Giechoma hirsuta W. K.

Weißes Galium Galium molhugo L.

Achillea millefolium.

Weiße Kornblume Centaurea orbelica Wel.

Lamizu striatum S. S.

Habichtskraut mit wolligen Blättern Hieracizım pannosum.

Kleine dunkelrote Rose Rosa orientalis.

\section{Schmetterlinge.}

Die Parnassius-Art und die Mnemosyne konnten noch nicht sicher als Unterarten benannt werden.

Erebia tyndarus balcanica Reb.

E. euryale Erp.

E. medusa $\mathrm{F}$.

E. melas herzegontinensis Schar.

Coenonympha arcania, welche bei uns in der Ebene fliegt, in der Mala Rupa Gebirgsschmetterling.

Lycaena argus L.

L. semiargus Rott.

L. meleager Gip. in Koinsko.

L. arion obscura Frey. in $2600 \mathrm{~m}$.

4. Vögel.

Buchfink Fringilla coelebs coelebs L.

Kleiber Sitla europaea caesia Wolf.

Kohlmeise Parus major major L

Ansel Turdus merula aterrimus Med.

Singdrossel Turdus musicus L.

Pirol Oriolus oriolus oriolus L.

Häber Garrulus glandarizıs giandarizs L. 


\section{Anmerkungen zum 8. Kapitel. Regenwürmer und Ackererde in Mazedonien.}

Die in diesem Kapitel crwähnten Regenwürmer wurden von Prof. Dr. H. Udc, Hannover bestimmt.

Zitierte Werke:

Ch. Darwin, Die Bildung der Ackererde durch die Tätigkeit der Würmer. Stuttgart 1899. Hensen.

Michaelsen, Oligochaeta, I0. Lief. des Tierreichs. Berlin 1900.

\section{Anmerkungen zum 9. Kapitel. \\ Das geliebte Veles.}

Bei Veles und in den Schluchten kommen von Käfern folgende Formen in großen Mengen vor:

Anomala bicolor var. dichroa Reit.

Amphicoma vulpes Fabr. in orangegelber Form.

Dorcadion lineatocolle Kraatz.

Von Dipteren die Bombyliden

Bombylius fuliginosus Wd.

$B$. discolor M. $\mathrm{Km}$.

$B$. analis $\mathrm{Pb}$, auf S. 138 abgebildet.

Von Schmetterlingen sind herrorzuheben

Papilio alexanor Esp.

Euchlö̈ groni H. S.

E. cardamines $\mathrm{L}$.

Argynnis latonia $\mathrm{L}$.

A. aglaia $\mathrm{L}$.

A. niobe $f$. eris $\mathrm{Mg}$.

A. pandora Schiff.

Satyrus anthelea amalthea Fried.

Lycaena cyllarus.

Allopea thaumas Hufn.

A. lineola Ochs.

\section{Anmerkungen zum 10. Kapitel.}

Am Doiransee.

Von Dipteren sind die Stratiomyiden

Lasiopa tenuirostris Loew.,

Stratiomyza erythrocera Egger,

von Käfern die Bostrychide

Capnosa tenebriosa Sal.

Dic Chironomiden sind noch nicht bearbeitet. 


\section{Anmerkungen zum 11. Kapitel.}

\section{Die mazedonischen Ameisen und ihre Bauten.}

Eine ausführlichere Arbeit über die mazedonischen Ameisen ist vom Verfasser veröffentlicht unter dem Titel:

F. Doflein: Mazedonische Ameisen. Beobachtungen über ihre Lebensweise. Jena 1920, Gustav Fischer.

\section{Anmerkungen zum 12. Kapitel. Schluchten des Balkan.}

\section{Deutsche Schmetterlinge.}

Großer und kleiner Fuchs Vanessa urticae L. und $V$. polychloros L.

Tagpfauenauge Vanessa Jo. L., das weiße C $V$. C. album L.

Distelfalter Vanessa cardui L.

Weißlinge: Pieris brassicae $\mathrm{L}$. der große Koblweißling, $P$. rapae $\mathrm{L}$. der Rübenweißling, $P$. rapi L. Grünader, $P$. daplidice L. der Resedafalter

\section{Wasserwanzen aus den Schluchten.}

Hydrometra stagnorum.

Velia rivulorum.

Limnotrechus lateralis.

Limnotrechus lateralis var. costac.

Nepa cinerea.

Notonecta glauca var. furcata.

Corixa striata.

Die gleichen Arten kommen in den meisten Schluchten vor.

\section{Anmerkungen zum 13. Kapitel.}

\section{Im Hain Mamre.}

Von $\mathrm{Käfern}$ sind hervorzubeben

Cerambyx cerdo L.

Leptura moesiaca Dan.

Trichizes gallicus Herr.

Dorcadion lugubris Kraatz.

Chlorophanus axinus Fabr.

Rhynchita hungarica Neb.

Von Schmetterlingen war sehr häufig

Lycaena icarus L.

Im Hain nicht selten

Catocala nymphagogra H.S.

Über die europäischen Termiten findet sich Näheres in:

Escherich, K., Die Termiten oder weißen Ameisen. Eine biologische Studie. I.eiprig 1909.

Am ausführlichsten in

Grassi, B. e Sandias, A., Costituzione e sviloppo della società dei Termitidi. Catania 1893. Topografia Galatola. 


\section{Anmerkungen zum 14. Kapitel. Die Expedition in den Schardakh.}

Über die Flora des Schardakh finden sich ausführliche Darstellungen in: A. Griesebach, Reise durch Rumelien nnd nach Brussa im Jahre i839. Göttingen I84 I, Vandenhoek und Ruprecht.

\section{Anmerkungen zum 15. Kapitel. Die Bevölkerung Mazedoniens.}

Es gibt wenig wirklich zuverlässige Literatur ïber die Verteilung der Bevölkerung Mazedoniens. Die serbischen und bulgarischen Schriften sind fast stets national gefärbt und daher parteiisch.

\section{Anmerkungen zum 16. Kapitel. Üsküb als Standquartier.}

Von historischen Daten, welche Üsküb und Mazedonien angehen, wurden im Führer für den Hochschulkurs in Üsküb (25. März bis 6. April 1916) folgendes angegeben:

359-336 v. Chr. Philipp II. König von Mazedonien. $336-323$ Alexander der Große.

I 46 Mazedonien römische Provinz. Skupi Mittelpunkt der dardanischen Provinz.

323-337 n. Chr. Konstantin der Große (geb, in Nisch).

395 Gründung des oströmischen (byzantinischen) Reiches.

$527-565$ Justinian I. (geb. in Taor bei Selenikovo).

7. Jahrhundert Einfall der Slaven in Mazedonien.

679 Gründung des bulgarischen Reiches unter Isperich (auch Asparuch genannt). Allmähliche Ausdehnung auf Mazedonien.

907-929 größte Ausdehnung des bulgarischen Reiches unter Zar Simeon.

Ior9 Mazedonien kommt unter die Herrschaft von Byzanz.

Seit 1026 Verfall des byzantinischen Reiches.

I 205 Mazedonien kommt zu dem neuen Bnlgarenreich; dessen höchste Blüte unter Zar Asen II. (I 2 I $8-4$ I).

133 I Mazedonien unter Serbien; dessen höchste Blüte unter Zar Stefan Duschan (133 I - 55), Üsküb dessen Hauptstadt.

1 371 Einfall der Türken in Mazedonien.

1389 Sieg der Türken unter Murad I. über die Serben auf dem Amselfelde.

1375-1912 türkische Herrschaft über die Slavenstaaten des Zentralbaikan und damit über Mazedonien.

1912 I. Balkankrieg. Sieg der Serben über die Tüıken bei Kumanovo. Besetzung von Üsküb durch die Serben 24. Okt. 19 I 2.

1913 II. Balkankrieg. Vertreibung der Bulgaren aus Mazedonien nach der Schlacht an der Bregalnitza 8. Juli 1913.

25. Okt. I9I5 die Bulgaren rücken in Üsküb ein.

1915-1918 Mazedonien unter bulgarischer Verwaltung.

Sept. 19 I8 Üsküb von Ententetruppen besetzt und seither wieder serbisch. 
Anmerkungen zum 17. Kapitel.

\section{Die Bulgaren in Mazedonien} und zum 18. Kapitel.

Der Tschifflik von Bardowce.

Wichtigste allgemeine Literatur über Mazedonien.

Ami Boué, La Turquie d'Europe. Paris 1840 . Herausgegeben von der Boné-Stiftungskommission. Wien 1889 .

v. d. Golt\%, C., Ein Ausflug nach Mazedonien. Berlin 1894. R. v. Deckers Verlag,

O. Schenck (enthält eine Liste älterer Literatur).

Mazedonien. Ein Erinnerungswerk für die Mitkämpfer auf dem mazedonischen

Kriegsschauplatz. Herausgegeben vom Armee-Oberkommando der XI. Armee.

Berlin 1918, Dietrich Reimer.

Kaßner, K., Bulgarien, Land und Lente. Bibliothek des Ostens, Bd. II. Leipzig 1916, Werner Klinkhardt.

Ischirkoff, Bulgarien, Land und Leute. Bulgarische Bibliothek I. Leipzig 1916. Iwan Parlapanoff.

\section{Anmerkungen zum 19. Kapite1. \\ Beobachtungen an mazedonischen Spinnen.}

Die Bestimmungen der mazedonischen Spimen wurden durch Dr. Roewer, Bremen durchgeführt.

Anmerkungen zum 23. Kapitel.

Der Wodno.

Pflanzen vom Wodno.

Fettkraut Sedum acre L. var. sartorianum L.

\section{Anmerkungen zum 24. Kapitel.}

Neresi.

$\mathrm{Zu}$ dem archäologischen und kunstgeschich(lichen Inhalt dieses Kapitels sowie des 29. Kapitels über Prilep und des 38. über Ochrida lieferten Material:

I. Strzygowski, J., Die bildende Kunst des Ostens in: Bibliothek des Ostens, Bd. III.

Leipzig 1916, Werner Klinkhardt.

2. Filow, B. D., Die altbulgatische Kunst. Bern 1919, Paul Haupt, Akademische

Buchbandlung vorm. Max Drechsel.

\section{Anmerkungen zum 25. Kapite1. Bienen Mazedoniens.}

Die Bearbeitung der von mir gesammelten Bienen Mazedoniens durch Dr. Friese, Schwerin erscheint in den Zoologischen Jahrbüchern, Abteilung für Systematik. 


\section{Anmerkungen zum 26. Kapitel. Die Erforschung der Golesniza Planina.}

Hummelarten der Hochregion oberhalb des Waldes.

Bombus terrestris var. lucorum L., Lisec, Pepelak, Begova.

B. machrocatus Gerst.

B. pratorum L., Lisec.

$B$. soroensis $\mathrm{F}$., Lisec.

B. derhamellus $\mathrm{K}$.

$B$. lapidarizs $\mathrm{L}$.

B. muscorum $\mathrm{F}$.

B. hypnorum L.

B. agrorum $\mathrm{F}$.

Eine monographische Darstellung der Expedition in die Golesniza Planina durch Geologen, Botaniker und Zoologen ist ron Dr. Gripp, Prof. Bornmüller, Prof. Doflein und Dr. Nachtsheim geplant.

\section{Anmerkungen zum 28. Kapitel.}

\section{Klima und Seuchen in Mazedonien.}

Die wichtigsten von mir in Mazedonien beobachteten Bremsen (Tabaniden) sind folgende:

Tabanus graecus Fb., Nikolatal, Plaguša Planina, Lisec.

T. gigas Hbst,, Markova.

T. ater Rossi, Topolkaschlucht.

T. bifarius Lw., Prespasee.

T. tergestinus Ess., Mala Rupa.

T. auripilus v. aterrimus $\mathrm{Mg}$., Lisec.

T. umbrinus Mg., Demir Kapu, Doiransee.

T. spadopterus Mg., Nikolatal.

T. autumnalis L. Kaluckova.

Haematopota pluvialis L., Kaluckova.

\section{Anmerkungen zum 29. Kapitel. Prilep und seine Pässe.}

Mazedonische Wachholderarten.
I. Juniperus communis L.
2. J. excelsa M. B.
3. J. nana Willd.

\section{Anmerkungen zum 30. Kapitel. Ameisenlöwen.}

Die Arbeit des Verfassers über den deutsclıen Ameisenlöwen ist:

Der Ameisenlöwe. Eine biologische, tierpsychologische und reflexbiologische Unter. suchung, Jena 1916, Gustav Fischer. 
Anmerkungen zum 31. und 32. Kapitel. Krusevo als Aromunenstadt und Gopes.

Außerordentlich wichtig zur Kenntnis der romanisch sprechenden Völker des Balkans ist das Werk

Weigand, Die Aromunen.

\section{Anmerkungen zum 32. Kapitel.}

\section{Gopes.}

Von Melitaca didy'ma kommt bei Gopes die nöıdliche Form vor, wälırend hei Kaluckova die südliche flog. Melitaea athalia mehadiensis Gah., welche bei Gopes und am Lisec gefangen wurde, ist eine Gebirgsform. Dort flog auch Pararge roxellana Kr. und Cephyrus mbi L., die unten fehlten. Von Lycaenen L. meleager Erp. und L. amandus Schn.

Sommerpflanzen.

\section{Anmerkungen zum 33. Kapitel. \\ Mazedonischer Sommer.}

Flockenblumen Centaurea scabiosa L.

Jurinea Sp.

Rittersporn Delphinizum consolida var. macranthum Boas.

Disteln Carduus leiophyllus Petr.

Silybum marianum L.

Königskerzen lerbascum pulverulentum M. B.

Natternkopf Echium italicum L.

\section{Anmerkungen zum 34. Kapitel. \\ Der Peristeri.}

Pflanzen aus der Matten- und Alpenregion des Peristeri sind von Griesebach 1839 in seinem Buch über Rumelien bescìrieben. Vgl. Anmerkung zum 14. Kapitel.

Neue Veröffentlichungen über die Flora Mazedoniens sind von Prof. Bornmüller, Weimar zn erwarten.

\section{Anmerkungen zum 35. Kapitel. Am Prespasee.}

Bienen am Prespasee.

Halictus sexcinctus $\mathrm{F}$.

H. tetragonicus.

H. morbillosus, Kriechbiene, rein östl. Art. Ungarn bis weit nach Kleinasien.

H. lencozonizes $\mathrm{K}$.

H. albipes $\mathrm{Sn}$.

H. malachurus $\mathrm{K}$.

II. maculatus Sin.

H. minutus $\mathrm{K}$. 
Andrena carbonaria Scop., 2. Gen.

Melitta melanura var. nigrohirta Alfk.

Alle am 22. August 1917 gefangen.

\section{Anmerkungen zum 36. Kapitel. Ritt über den Tomoros.}

Da auf dem Tomoros noch kaum gesammelt wurde, will ich eine etwas reichere Liste von Insektenvorkommen hier einfügen.

Käfer.

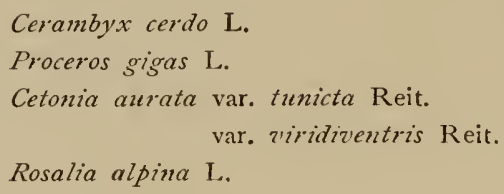

\section{Dipteren.}

Phthiria paedii Mg.

\section{Sch metterlinge.}

Melanargia larissa vic. tantica.

Satyrus hermione L.

S. briseis maior Obthr. (stidliches Tier)

$S$. actaea cordula Fabr.

Epinephele lycaon Rot.

Thecla spini Schiff.

T\%. ilicis Esp.

Cephyrus quercus L.

Lycaena argues L.

L. astrarche Bgrtr.

L. admeta Erp.

Hesperia cinare Rbr.

Carcharodus altheae $\mathrm{Hb}$.

\section{Bienen.}

Chalicodoma lefeburei var. tristis Friese.

Bombus soroensis $\mathrm{F}$.

$B$. agromum J. var. obscuriventris

Friese.

B. pomorum L.

$B$. hortensis L.

Dasypoda pyrotricha var. nigra noz. var. Friese.

\section{Anmerkungen zum 37. Kapitel. Wirbeltiere Mazedoniens.}

Liste der mazedonischen Amphibien und Reptilien, welche von den Mitgliedern der mazedonischen landeskundlichen Kommission und ihren Helfern 1917 und 1918 beobachtet wurden.

\section{Batrachia salientia.}

Rana ridibunda Pall., Seefrosch, Lachfrosch.

$R$. temporaria L., Taufrosch.

R. graeca Blgr., griechischer Braunfrosch.

$R$. agilis Thom., Springfrosch.

Bufo viridis Laur., Wechselkröte.

B. vulgaris Laur., Erdkröte. 
Hy.la arborca $\mathrm{L}$.., Laubfrosch.

Bombinator pachypus Bonap., gelbbäuchige Unke.

\section{Batrachia gradientia.}

Salamandra maculosa Laur., Erdsalimander.

Molge cristata cristata Laur., Kammolch.

M. z'ulgaris graca Wolterstorff, griechischer Teichmolch.

(M. anlgaris gracia wurde von Prof. Mïller bei Veles in einer Zwergfon gefangen. $\mathrm{Ob} \cdot \mathrm{er}$ überhaupt nur in dieser Form in Mazedonien vorkommt, konnte er nicht ermitteln, da er ihn nur bei Veles fand. Auffallend ist, daß von dem Kammolch eine mitteleuropäische und von dem Teichmolch eine südöstliche Form in Mazedonien vorkommt.)

\section{Chelonia.}

Clemmy's caspiu riz'ulata Vol., kaspische Sumpfschildkröte (nur bei Mravinca gefunden, kommt auch im Doiransee vor, geht aber offenbar nicht nördlicher als Mravinca).

Emy's orbicularis L, europäische Sumpfschildliröte.

Testudo gracca L. und Testudo ibera Pall.

\section{Lacertilia.}

Gymnodactylus kotschy'i Std., europäischer Nacktfinger (geht nicht über den Kessel von Hudova nach Norden hinaus).

Ophisaumes apus Pall., am Doiransee uicht selten, auch bei Hudova gefunden (Dr. Fehringer leg.).

Anguis fragilis L., im Nukolatal, sonst nur in höberen Lagen.

Lacerta viridis Laur., kleine Smaragdeidechse.

L. major Blgr., große Smaragdeidechse.

L. agilis agilhs L., Zauneidechse.

L. tanrica Pall., taurische Eidechse.

L. muralis muralis Laur., Mauereidechse.

L. muralis sowie $L$. riridis leben erst von etwa $600 \mathrm{~m}$ an. L. riridis geht ausnahmsweise in kïhlen feuchten Tälern (Nikolatal) bis zum Wardar.

L. vivipara Jacqu., Bergeidechse.

L. milensis maz. var. Überall in tiefen wie in höheren Lagen. Lebt in einzelnen Stïcken, z. B. auf dem Malarupa-Gipfel.

Ablepharus pannonicus. In einem Exemplar bei Han Abdipasa gefangen. Angeblich auch bei Gopes beobachtet.

\section{Ophidia.}

Typhlops rermicularis Merr, ein Exemplar vom Doiransee (Burgeff leg.).

Eryx jaculus L., zwei Exemplate vom Doiransee (Burgeff leg.).

Tropidonotus natrix persa Pall., Streifenringelnatter.

Tr. tessellatus Laur., Würfelnatter.

Zamenis caspius Iwan., Balkennatter.

Coluber leopardinus leopardinus Bonap., Leopardnatter.

C. quatuorlineatus quatuorlineatus Lacep., Vierstreifennatter.

C. longissinus Laur., Äskulapnatter (Dr. Sternfeld leg.).

Coronella austriaca Laur., Glattnatter. Nur im Gebirge (Malarupa, Golesniza). 
Tarbophis fallax Fleischn., Katzenschlange.

Coelopeltis monspessulana Herm., Eidechsenuatter.

Vipera macrops Méhely, Großangenviper.

$V$. berus L., Kreuzotter. Nur auf der Golesniza gefangen.

$V$. ammodytes L., Sandotter.

Fische, welche von der mazedonisch-landeskundlichen Kommission im Jahre 1917 und 1918 beobachtet wurden (5 Familien, 14 Gattungen, 20 Arten).

Anguillidae Anguilla fuviatilis Ag., Ochridasee.

Cottidae Cottus ferrugineus H. \& K., Wardar.

Salmonidae Salmo dentex Heck., Wardar.

", obtusirostris Heck., Ocliridasee.

Cobitidinae Cobitis elongata H. \& K., Miletkovo.

" taenia L., Miletkovo.

Cyprininae Clyprinus carpio L, Ochrida und Wardar.

Squalius illyricus H. \& K., Oclırida.

" dobula H., Ochrida.

Barbus plebejus Val., Wardar, Nikola, Ochrida.

Chondrostoma genei Bon., Wardar und Struga.

" phoxinus Heck., Ocbrida.

" soettá $H$. \& K., Ochrida.

Phoxinus laeris Ag., Wardar.

Aspius rapax Ag., Ochrida.

Alburnus alborella $\mathrm{H}$. \& $\mathrm{K}$., Struga und Wardar.

" scoranzoides H. \& K., Struga und Wardar.

Abramis melanops Heck., Wardar.

Gobio vulgaris Cuv., Struga.

Lenciscus adspersus Heck., Oclirida.

Ochridasee: Anguilla fuziatilis, Salmo obtusirostris, Cyprinus carpio, Squalius illyricus, Squ. dobula, Barbus plebejus, Chondrostoma phoximus, Ch. soetta, Aspius rapax, Leuciscus adspersus.

Wardar: Cottus fermgineus, Salmo dentex, Cyprinus carpio, Barbus plebejus, Chondrostoma genei, Phoxinus laevis, Albumes alborella, A. scoranzoides, Abramis melanops, Silurus glanis L.

Andere Fundorte: Cobitis elongata, C. taenia, Gobio vulgaris (det. Zugmayer 1919). 


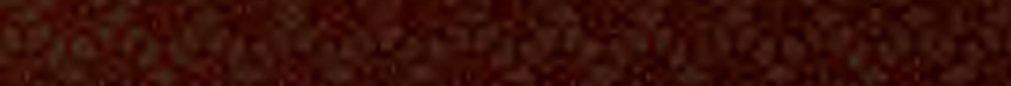

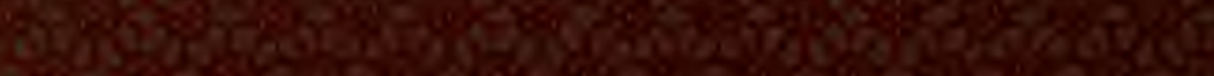

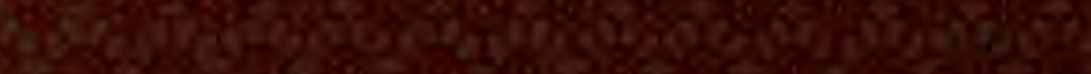

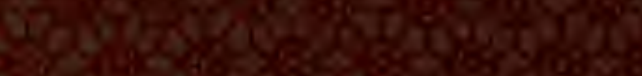

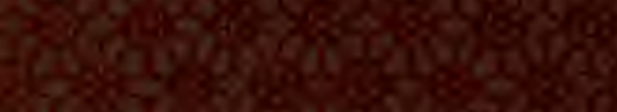

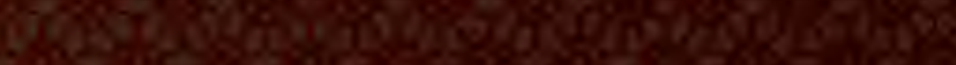

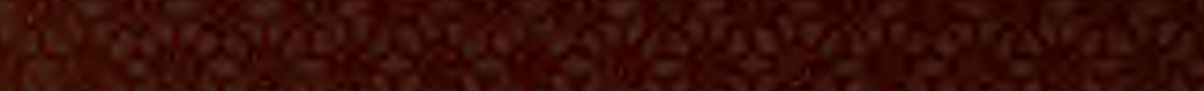

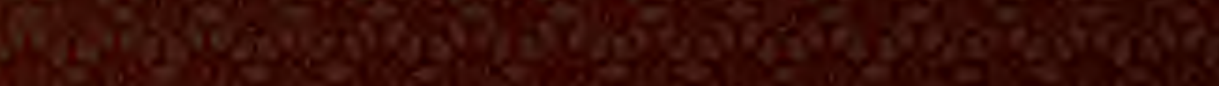

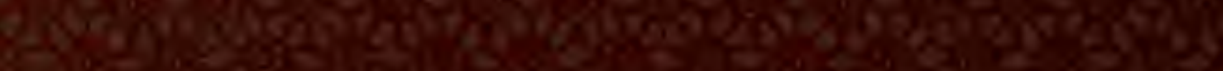

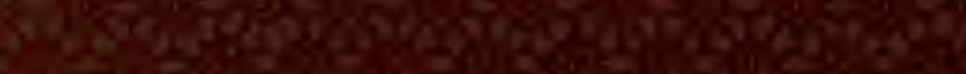

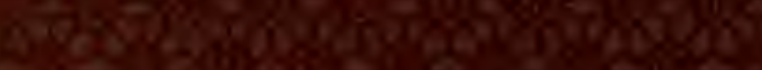

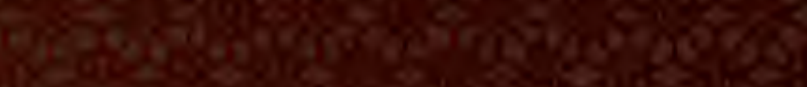

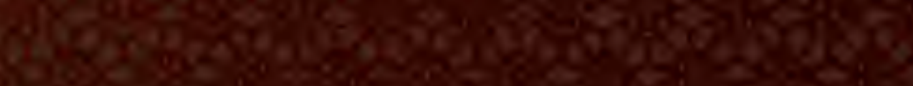

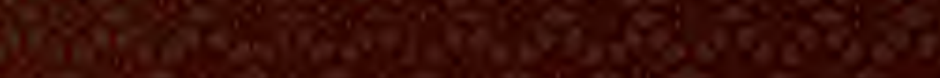

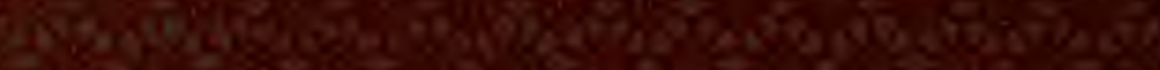

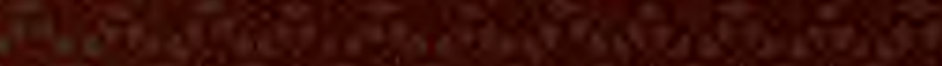
37.

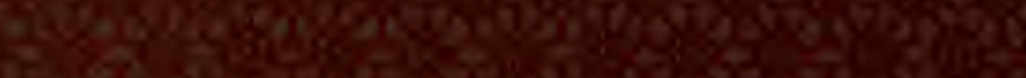

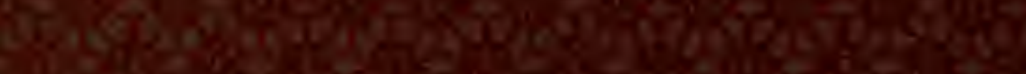
7w.

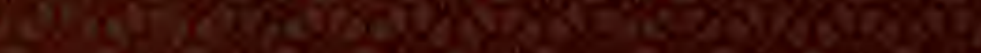
Ty

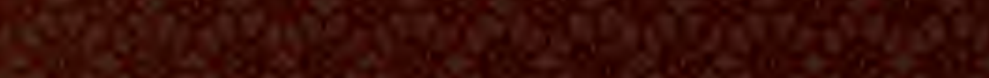

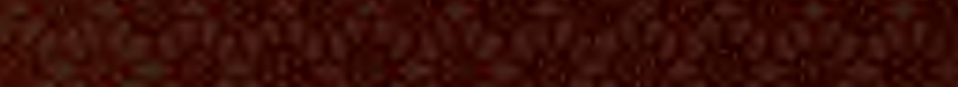

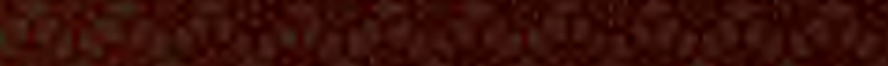

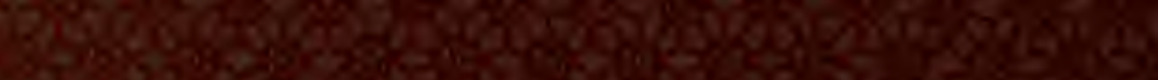

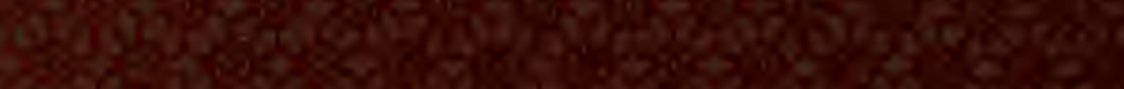

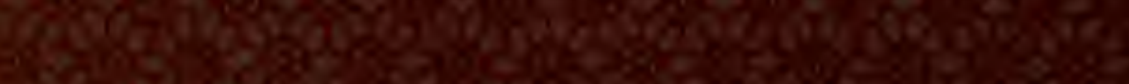

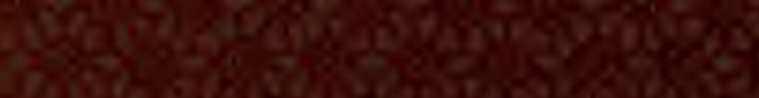




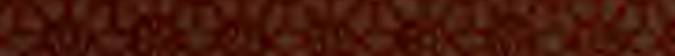

anas.

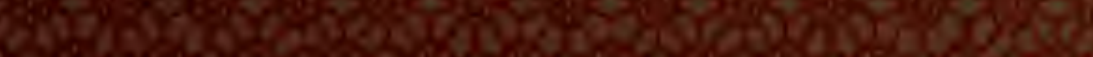
Wh

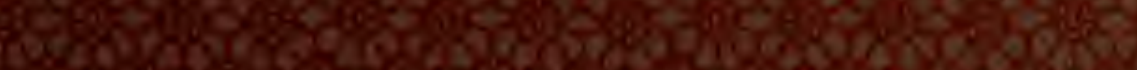

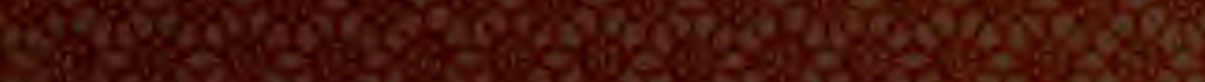

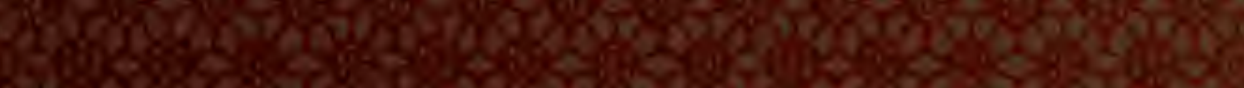

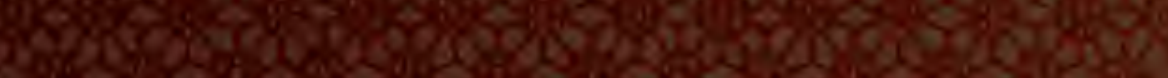

mors X

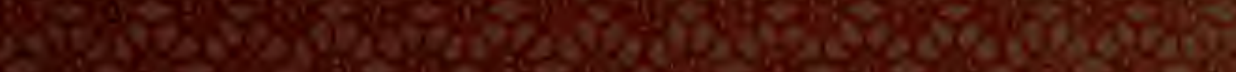

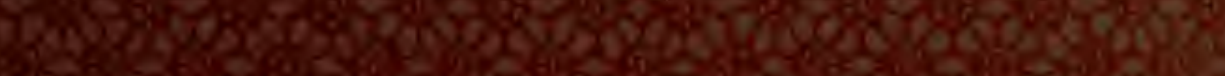

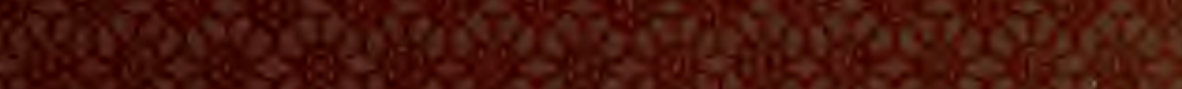

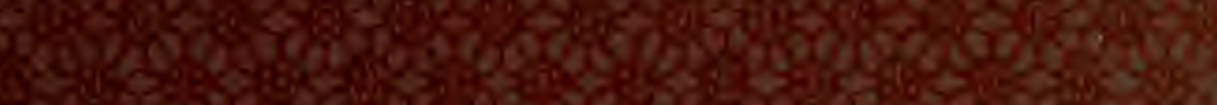

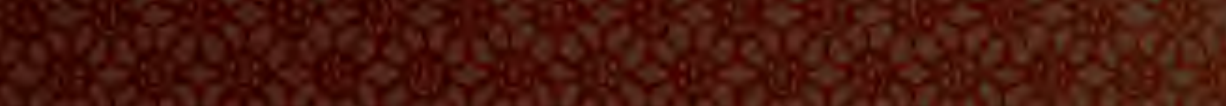

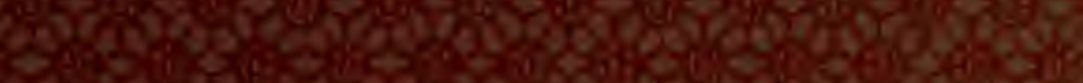
Q Wor.

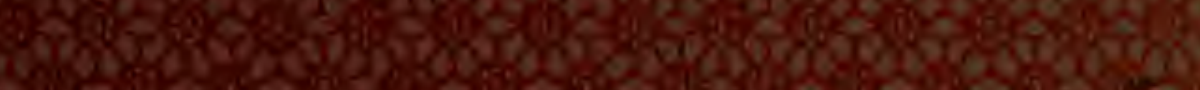
W

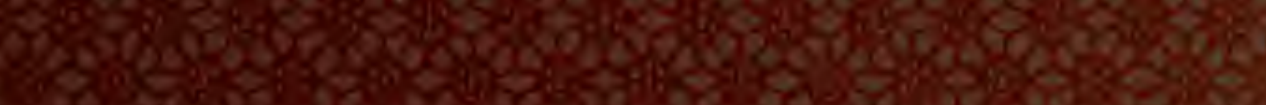

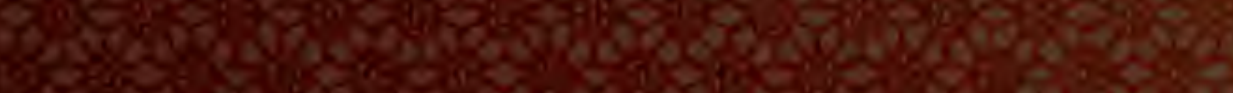
Cor.

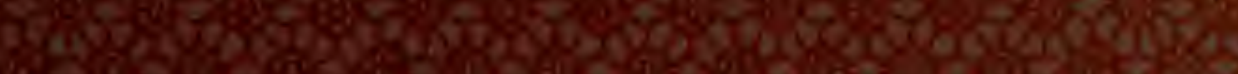

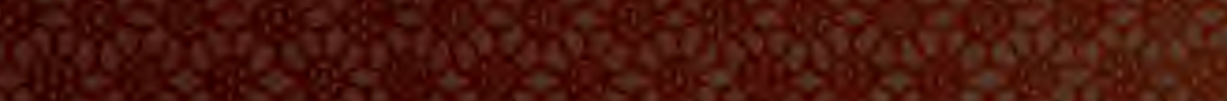

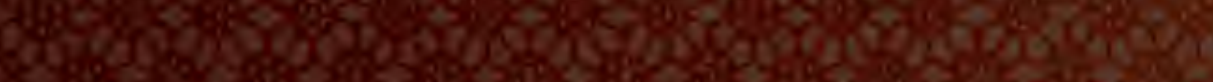

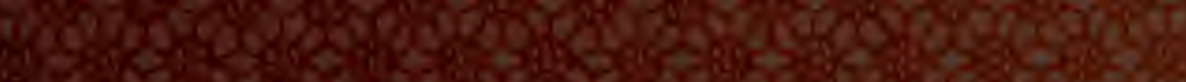
(5as) 0 (19)

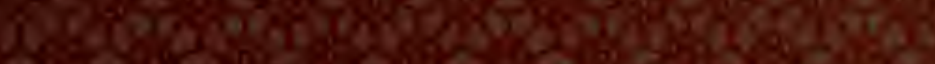

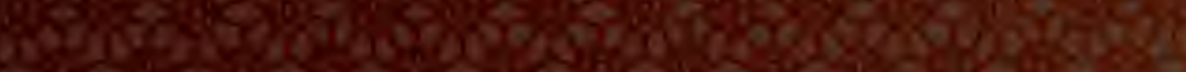

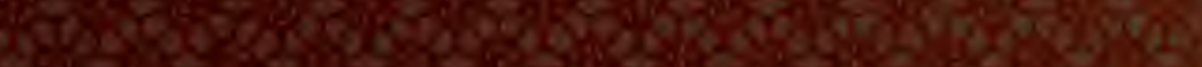


